MARTIN STESKAL

DAS PRYTANEION IN EPHESOS 


\title{
FORSCHUNGEN IN EPHESOS
}

Herausgegeben vom

\section{ÖSTERREICHISCHEN ARCHÄOLOGISCHEN INSTITUT IN WIEN}

\author{
BAND IX/4
}

Gemeinsam veröffentlicht vom

\section{ÖSTERREICHISCHEN ARCHÄOLOGISCHEN INSTITUT IN WIEN \\ und der}

\section{ÖSTERREICHISCHEN AKADEMIE DER WISSENSCHAFTEN IN WIEN}

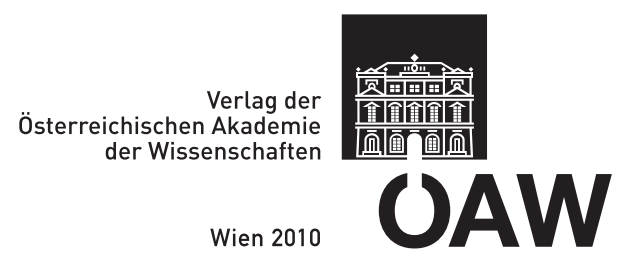




\title{
FORSCHUNGEN IN EPHESOS IX/4
}

\author{
Martin Steskal
}

\section{Das Prytaneion in Ephesos}

\author{
Mit Beiträgen von \\ Nicole M. High, Sabine Ladstätter, Matthias Pfisterer \\ und Georg A. Plattner
}

\author{
Redaktion
}

Barbara Beck-Brandt und Andrea M. Pülz

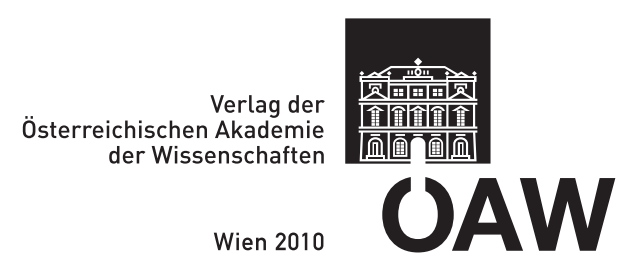


Gedruckt mit Unterstützung des

Fonds zur Förderung der wissenschaftlichen Forschung एUE Der Wissenschaftsfonds.

Umschlagbild:

Prytaneion. Geöffnetes 3-D-Modell von Südosten

Copyright (C) ÖAI Wien, Bild: M. La Torre, J. Jost

Die verwendete Papiersorte ist aus chlorfrei gebleichtem Zellstoff hergestellt, frei von säurebildenden Bestandteilen und alterungsbeständig.

$$
\begin{aligned}
& \text { Alle Rechte vorbehalten } \\
& \text { ISBN 978-3-7001-6842-3 } \\
& \text { Copyright (C) 2010 by }
\end{aligned}
$$

Österreichische Akademie der Wissenschaften Wien

Redaktion: Barbara Beck-Brandt, Andrea M. Pülz

Satz und Tafelerstellung: Andrea Sulzgruber

Druck und Bindung: Ferdinand Berger \& Söhne Ges.m.b.H., A-3580 Horn

$$
\begin{gathered}
\text { http://hw.oeaw.ac.at/6842-3 } \\
\text { http:/verlag.oeaw.ac.at }
\end{gathered}
$$




\section{INHALTSVERZEICHNIS}

VORWORT DER GRABUNGSLEITUNG EPHESOS .................................................................... IX

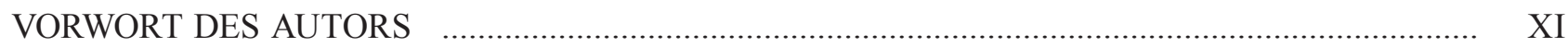

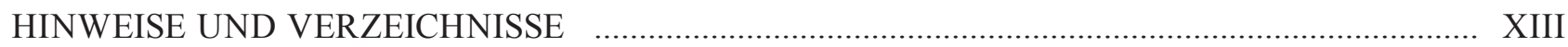

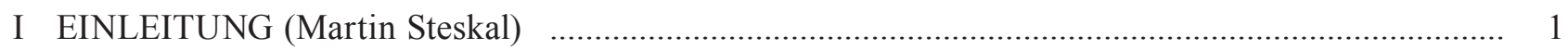

I.1 Vorbemerkung zum Stand der Prytaneion-Forschung ............................................................. 1

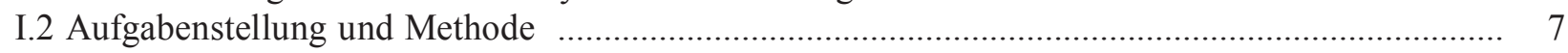

II AUSGRABUNGS- UND FORSCHUNGSGESCHICHTE (Martin Steskal) f..................................... 9

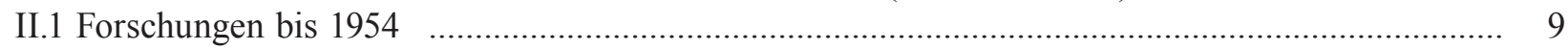

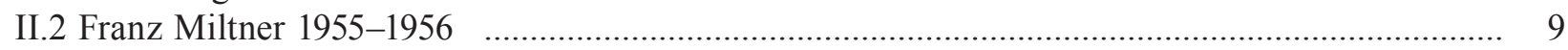

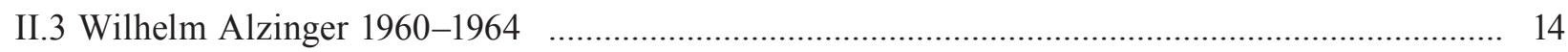

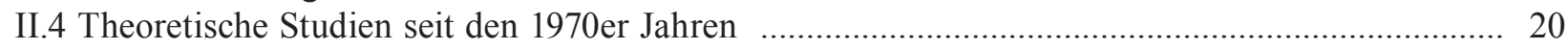

III BAUBEFUND UND BAUBESCHREIBUNG (Martin Steskal) ….......................................... 29

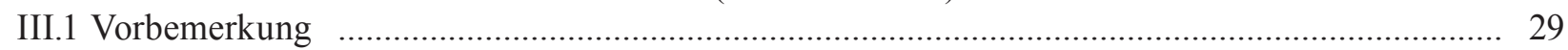

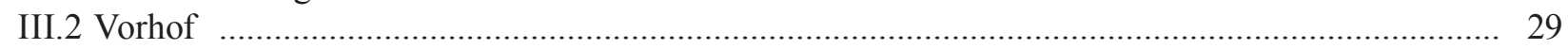

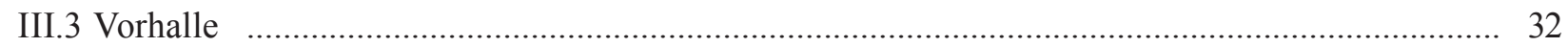

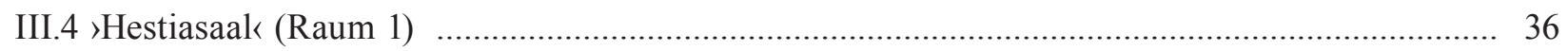

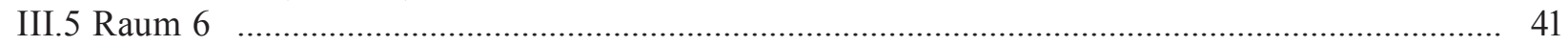

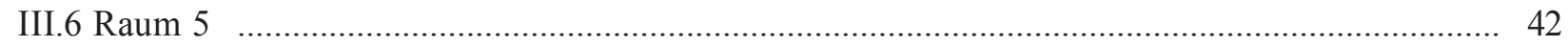

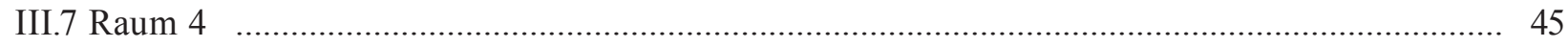

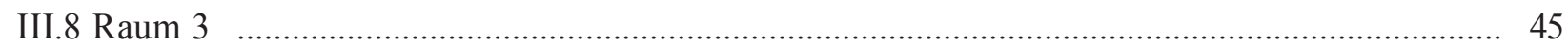

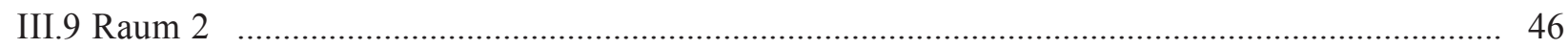

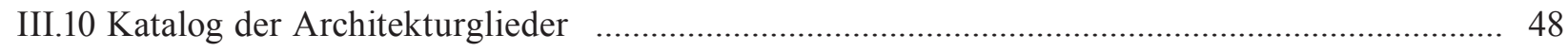

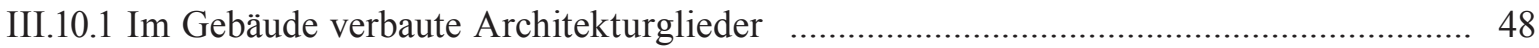

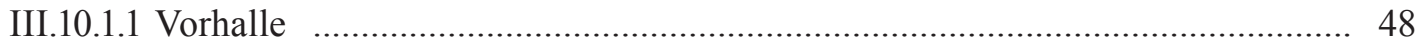

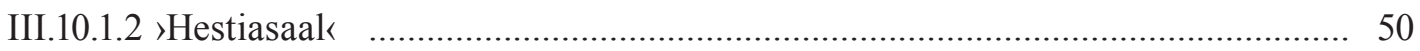

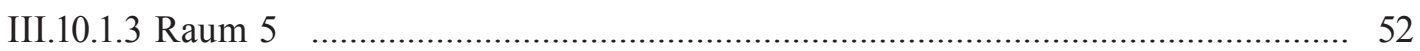

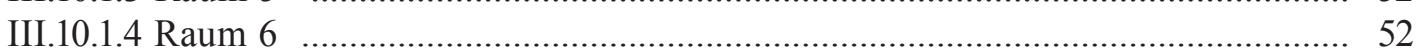

III.10.2 Als Spolien verbaute Architekturglieder ............................................................. 52

III.10.3 Im Zerstörungsschutt des Gebäudes gefundene Architekturglieder ……................... 52

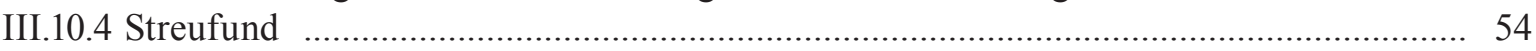

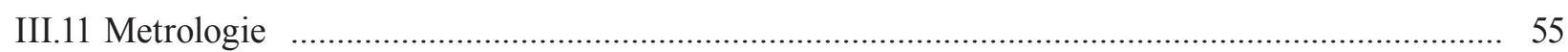

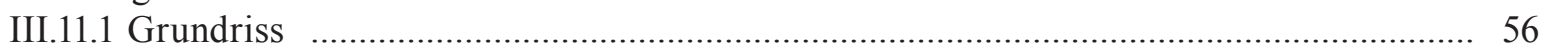

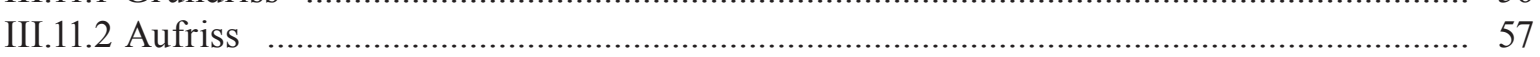

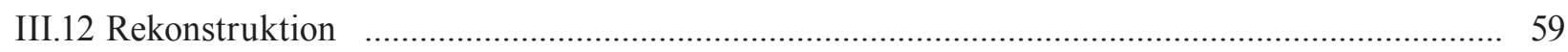

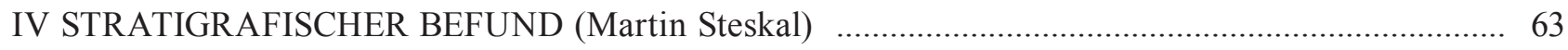

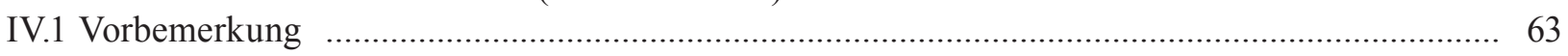

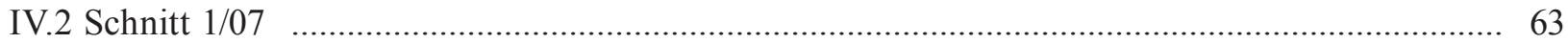




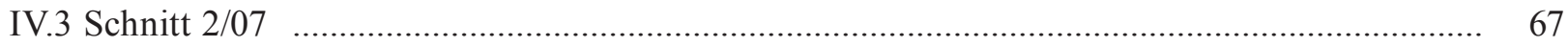

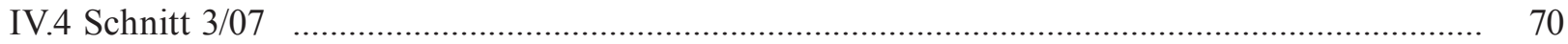

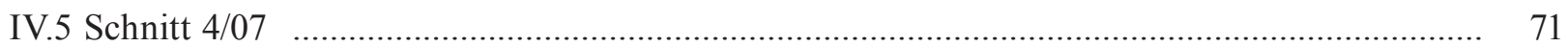

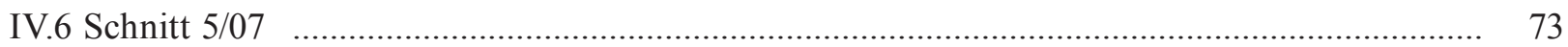

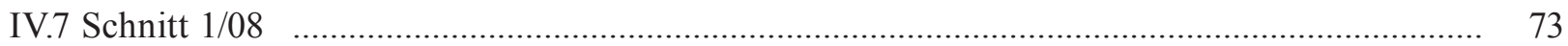

V BAUPHASEN UND CHRONOLOGIE (Martin Steskal) …...................................................

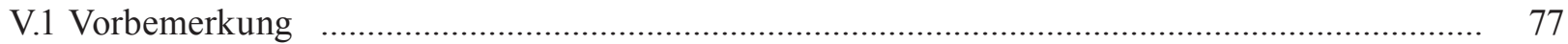

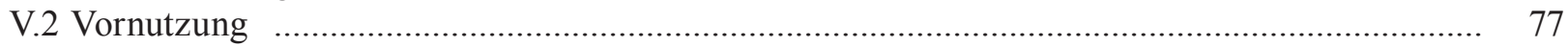

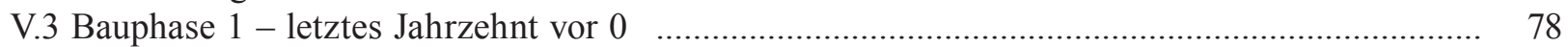

V.3.1 Bauphase 1a - 1./2. Jahrhundert n. Chr. ....................................................................... 79

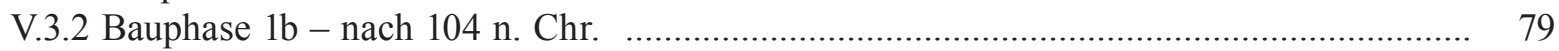

V.4 Bauphase 2 - zweites Viertel 3. Jahrhundert n. Chr. …........................................................ 80

V.5 Aufgabe des Gebäudes - Mitte 4. Jahrhundert n. Chr. . ...................................................... 81

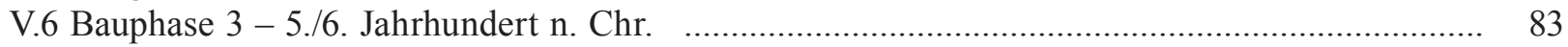

V.6.1 Bauphase 3a - Mitte 7. Jahrhundert n. Chr. ………….................................................. 83

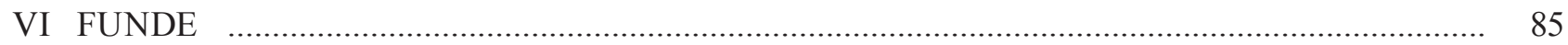

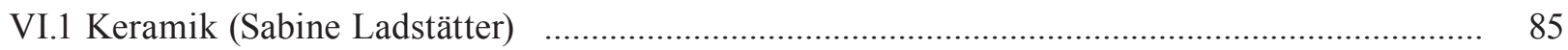

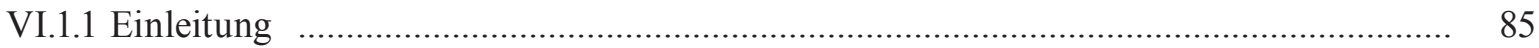

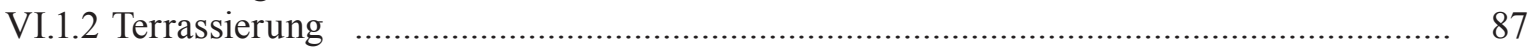

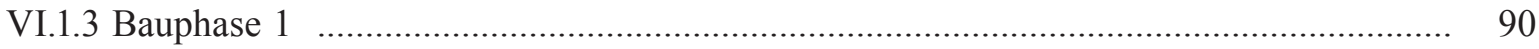

VI.1.3.1 Bauphase 1 - Vorhof ................................................................................... 92

VI.1.3.2 Bauphase 1 - >Hestiasaak ................................................................................ 99

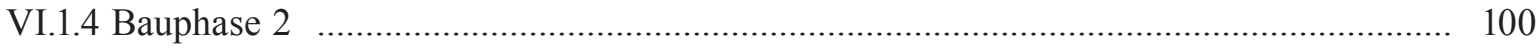

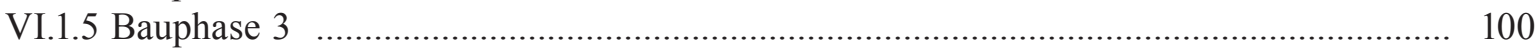

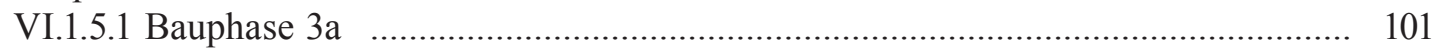

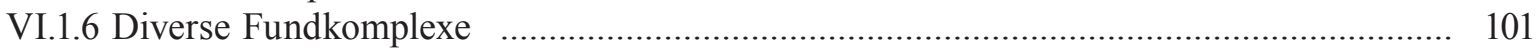

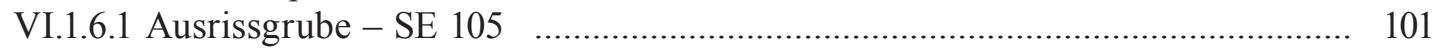

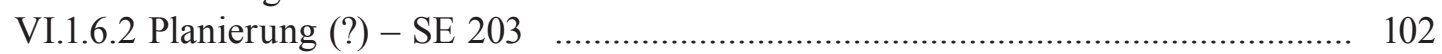

VI.1.6.3 Kanalverfüllung - SE 205 _.............................................................. 102

VI.1.6.4 Grubenverfüllung - SE 214 .............................................................. 102

VI.1.7 Katalog (Sabine Ladstätter - Nicole M. High) ....................................................... 103

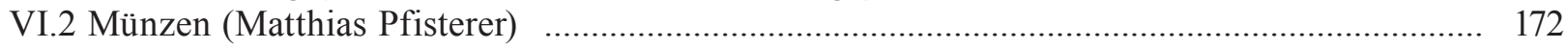

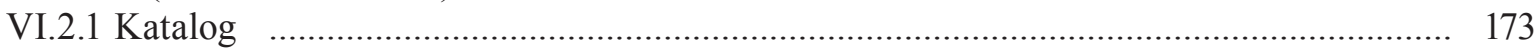

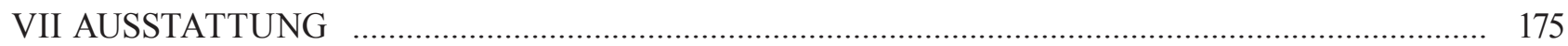

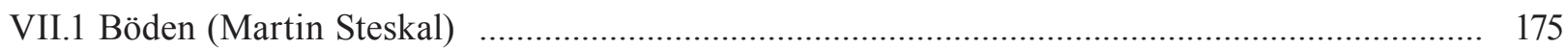

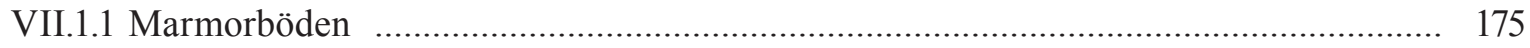

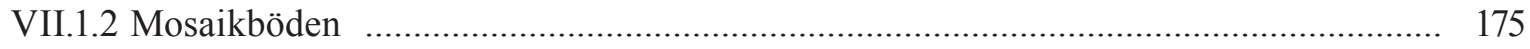

VII.2 Wanddekoration (Martin Steskal)

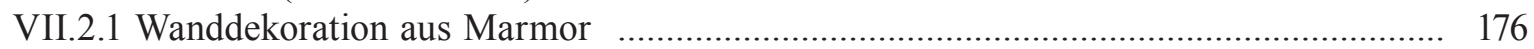

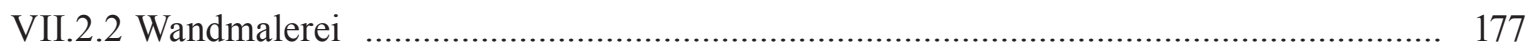

VII.3 Türen und Fenster (Martin Steskal)

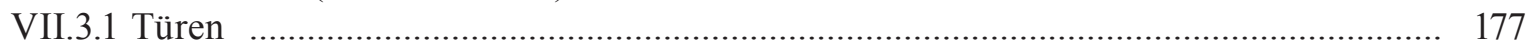

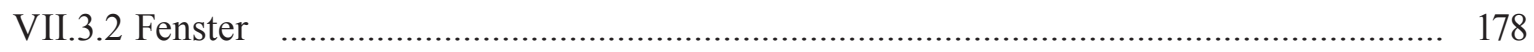

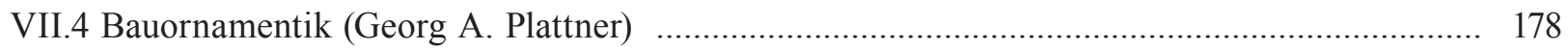

VII.4.1 Im Gebäude verbaute Architekturglieder ……..................................................... 179

VII.4.1.1 Die dorische Vorhalle (KatNr. A 1-11) .................................................... 179

VII.4.1.2 Der 〉Hestiasaak (KatNr. A 12-26) ........................................................ 181

VII.4.1.3 Raum 5 (KatNr. A 27. 28) …………....................................................... 186 
VII.4.2 Im Zerstörungsschutt des Gebäudes gefundene Architekturglieder

(KatNr. A 32-46)

VII.4.2.1 Basen

VII.4.2.2 Kapitelle

VII.4.2.3 Diverse Bauteile

VII.4.3 Exkurs zu den dorischen Architekturen in Ephesos .......................................... 190

VII.4.3.1 Die `Neronische Halle` ............................................................................ 191

VII.4.3.2 Kleinere dorische Ordnungen in Ephesos .............................................. 195

VII.5 Skulpturenausstattung (Nicole M. High - Martin Steskal) ............................................... 197

VII.5.1 Im Gebäude aufgestellte Skulpturen _................................................................ 197

VII.5.2 Sekundär verbaute oder im Zerstörungsschutt gefundene Skulpturen ................... 203

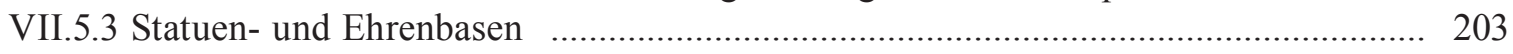

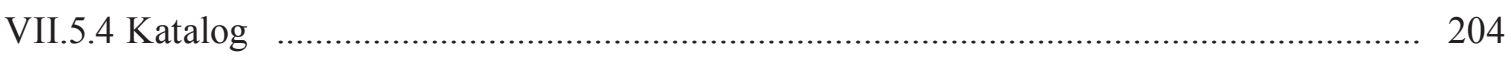

VIII FUNKTION DER RÄUME (Martin Steskal) ................................................................. 211

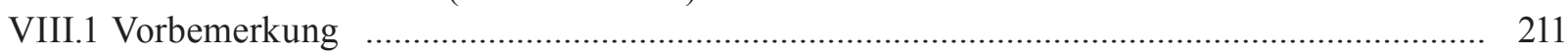

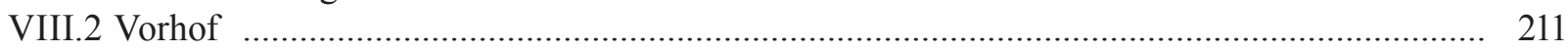

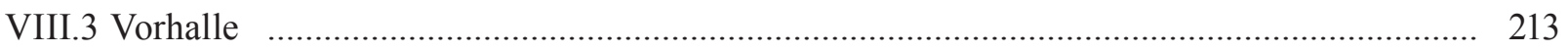

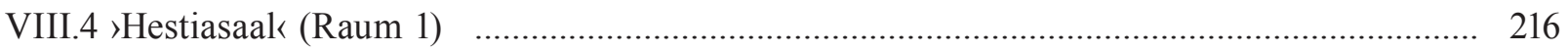

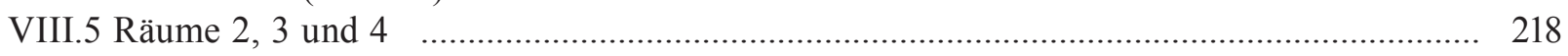

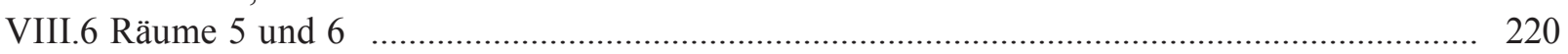

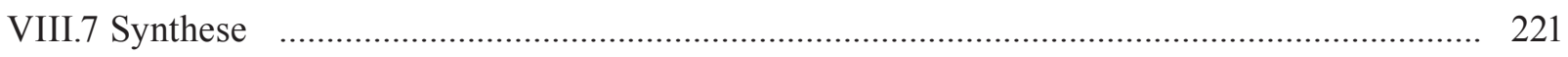

IX EXKURS ZU DEN PRYTANEIA IN KLEINASIEN - EINE VERGLEICHSSTUDIE

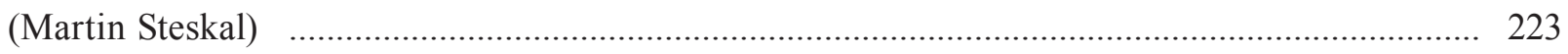

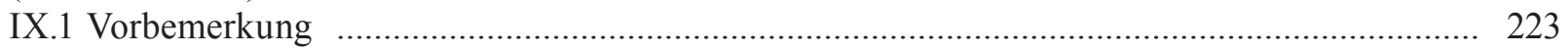

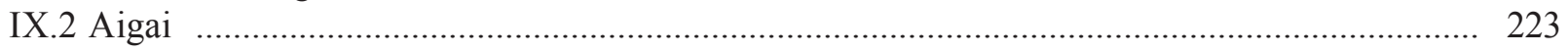

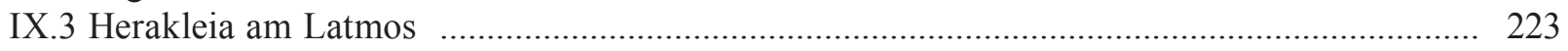

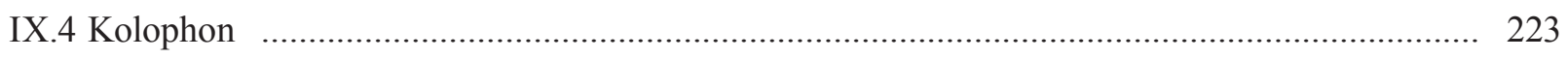

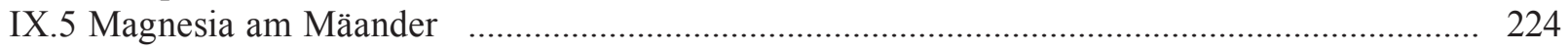

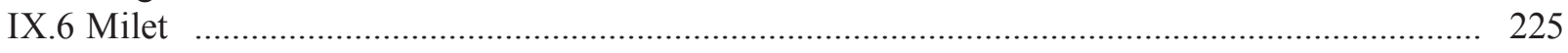

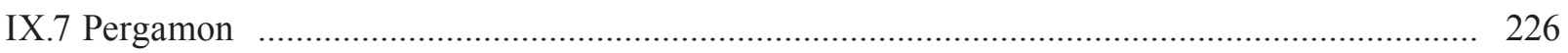

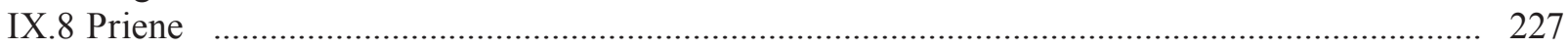

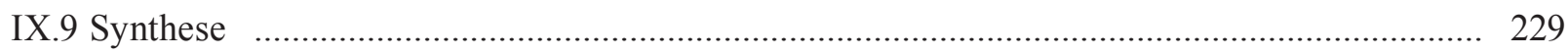

ZUSAMMENFASSUNG, SUMMARY, ÖZET (Martin Steskal) ................................................... 233

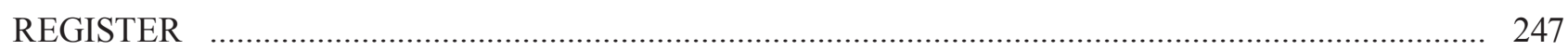





\section{VORWORT DER GRABUNGSLEITUNG EPHESOS}

Als im Jahr 1955 Franz Miltner im Zuge einer Begehung des Antikengeländes auf einen »aus dem Erdreich ragenden Stumpf einer Säule mit herzförmigem Querschnitt« stieß, war der Grundstein für die Entdeckung des politischen Zentrums von Ephesos gelegt. Bald erbrachten die hier gefundenen epigrafischen Zeugnisse den Nachweis dafür, in dem freigelegten Objekt den Kultkomplex für Hestia Boulaia zu erkennen und diesen mit dem Prytaneion der Stadt zu verbinden. Der Höhepunkt der Grabungsarbeiten war zweifelsohne mit der Entdeckung der Artemisstatuen erreicht, deren ursprüngliche Aufstellung die Bedeutung des Prytaneions im Rahmen offiziell-städtischer Kulthandlungen bekräftigt.

Es ist Wilhelm Alzinger zu verdanken, die einzelnen Gebäude am Südfuß des Panayırdağ in einen größeren Kontext gestellt und übergreifend interpretiert zu haben. Seinen überzeugenden Argumenten zufolge lag hier das Regierungsviertel - der sog. Staatsmarkt oder die obere Agora - von Ephesos, während die in der Hafenebene gelegene untere Agora primär Handelsaktivitäten vorbehalten war. Zudem konnte Alzinger für den sog. Staatsmarkt ein frühkaiserzeitliches Bauprogramm erschließen, dem allerdings ältere, in den Hellenismus zu datierende Bauaktivitäten vorausgegangen waren.

Wie zahlreiche andere von Franz Miltner zügig ausgegrabene Gebäude blieb auch das Prytaneion im Detail unpubliziert. Dieses Desiderat wird durch die nun vorliegende Publikation geschlossen. Im Rahmen eines vom FWF geförderten Projektes erfolgte eine kontextuelle Neubearbeitung des Gebäudes, im Zuge derer auch gezielte Grabungen durchgeführt wurden. Dadurch war es einerseits möglich, die Bauzeit des Gebäudes exakt zu definieren, andererseits eine etwaige Vorgängerbebauung auszuschließen. Die Masse an Fundkeramik des 3.-1. Jahrhunderts v. Chr. in den augusteischen Planierschichten lässt aber zweifelsohne die Schlussfolgerung zu, dass das Areal in hellenistischer Zeit intensiv genutzt wurde. Eine genaue Analyse des Baubefundes führte zu einem neuen, überzeugenden Rekonstruktionsvorschlag, der speziell in der Frage der Dachlösung deutlich von älteren Entwürfen abweicht. Mit einer Einbettung des ephesischen Monuments in den bekannten, vergleichbaren Denkmälerbestand und einer Diskussion der in der Forschung postulierten Prytaneia geht die Publikation weit über eine Materialvorlage hinaus. Die minutiöse Aufarbeitung der Grabungsdokumentation erlaubte wiederum Neuinterpretationen zu den Fundumständen der Artemisstatuen und den daraus resultierenden Diskussionen über den Umgang mit kaiserzeitlicher Skulptur in der Spätantike. Die Publikation zeigt aber auch ganz deutlich die Grenzen der Bearbeitung eines bereits vor Jahrzehnten mit anderen Fragestellungen und Methoden freigelegten Monuments auf. Gerade für die späteren Phasen sowie die häufig mit einem Funktionswandel verbundenen Nachnutzungen ließen sich nur wenige gesicherte und zudem aussagekräftige Befunde fassen. Umso bedeutender ist allerdings der Nachweis einer Nutzung des Areals in den Dark Ages (7.-9. Jahrhundert), die bislang in Ephesos kaum belegt sind.

Martin Steskal hat mit bewundernswert zielorientierter Energie nicht nur die wissenschaftliche Bearbeitung des Prytaneions, sondern auch die Projektkoordination übernommen und diese zu einem zeitgerechten Abschluss gebracht. Für die Bearbeitung von Einzelaspekten bzw. Materialgruppen konnten neben der Keramikanalyse die Kolleginnen und Kollegen Nicole M. High, Matthias Pfisterer und Georg A. Plattner gewonnen werden. Die am Österreichischen Archäologischen Institut durchgeführte Redaktion lag in den Händen von Barbara Beck-Brandt und Andrea M. Pülz, die Tafelvorlagen und die Bildbearbeitung erfolgten durch Nicolas Gail und Nicola Math. Ihnen allen sei ganz herzlich gedankt. Die Österreichische Akademie der Wissenschaften hat das Manuskript dankenswerterweise in ihr Publikationsprogramm aufgenommen, den Gutachtern der ÖAW sowie des Scientific Board der Reihe »Forschungen in Ephesos« verdanken die Autorinnen und Autoren wichtige Anmerkungen und Hinweise. Letztendlich ist aber dem FWF sowie dem BMWF für maßgebliche Druckkostenzuschüsse Dank auszusprechen, wodurch die Publikation des Manuskripts erst ermöglicht wurde. 



\section{VORWORT DES AUTORS}

Das im Jahr 1955 entdeckte Prytaneion von Ephesos ist als zentraler Bau des Regierungsviertels seit über einem halben Jahrhundert Gegenstand der wissenschaftlichen Auseinandersetzung. Obwohl oft in Vorberichten und kurzen Abhandlungen besprochen, blieb eine umfassende und vollständige Vorlage dieses Gebäudes aber bis dato ein Desiderat in der ephesischen Forschungsgeschichte. Da grundlegende Fragen zu den einzelnen Bauphasen, zum architektonischen Aufbau sowie zur Nachnutzung des Areals nicht endgültig geklärt waren, wurden im Jahr 2007 neue Forschungen zum ephesischen Prytaneion begonnen. Die Leitung des Projektes wurde dem Autor vom damaligen Grabungsleiter von Ephesos, F. Krinzinger, überantwortet. Die Arbeiten wurden in den Jahren 2008 und 2009 unter der Grabungsleitung von J. Koder weitergeführt. Den Leitern der Ausgrabung sei für ihre Unterstützung bei der Umsetzung dieses Projektes herzlich gedankt.

Ziele der neu konzipierten Forschungen am Prytaneion waren eine grundlegende Analyse des archäologischen und architektonischen Befundes mitsamt seiner Ausstattung unter Berücksichtigung der Resultate der Altgrabungen. Die Ergebnisse dieser Arbeiten liegen nunmehr vor und können als Band der Reihe »Forschungen in Ephesos« einem interessierten Publikum vorgestellt werden.

Finanziert wurden diese am Österreichischen Archäologischen Institut in Wien durchgeführten Arbeiten durch den Fonds zur Förderung der wissenschaftlichen Forschung (FWF-Projekt P19257-G02), der das Projekt nicht nur auf eine solide finanzielle Basis gestellt, sondern auch in schwierigen Zeiten gefördert und voll inhaltlich unterstützt hat. Explizit möchte ich mich in diesem Zusammenhang bei B. Asamer für zahlreiche Hilfestellungen herzlich bedanken. Das ÖAI stellte seine Infrastruktur in Wien und Ephesos zur Verfügung. Der Dank des Autors gilt daher der aktuellen und ehemaligen Leitung des ÖAI und der Grabungen in Ephesos, S. Ladstätter, J. Koder sowie F. Krinzinger, die das Projekt zu allen Zeiten vorbehaltlos unterstützt haben. Für die Möglichkeit, die Einrichtungen des ÖAI in Athen nutzen zu können, und für zahlreiche fruchtbare Diskussionen danke ich dem Leiter der Zweigstelle, G. Ladstätter.

Besonderer Dank gilt V. Mitsopoulos-Leon, die mir großzügig ihre Unterlagen und Dokumentationen zu den Funden der Prytaneion-Grabungen der 1960er Jahre zur Verfügung gestellt hat und sich für einen wissenschaftlichen Austausch jederzeit anbot.

Das vorliegende Manuskript hätte nicht ohne den Beitrag der Mitautoren N. M. High, M. Pfisterer, S. Ladstätter und G. A. Plattner entstehen können, denen für ihr großes Engagement und zahlreiche Diskussionen herzlich gedankt sei.

Im Feld, bei der Aufarbeitung der Funde und bei unterschiedlichen Arbeiten in Wien wurde der Autor von J. Eitler, N. M. High, A. Hochleitner, D. Katzjäger, P. Mayrhofer, G. A. Plattner, J. Reuckl, H. Schwaiger, B. Stark, F. Stoldt und L. Zabrana tatkräftig unterstützt; Ch. Kurtze übernahm Vermessungsaufgaben. Ihnen allen sei aufrichtig gedankt. Die mühsamen Grabungsarbeiten vor Ort wurden von den einheimischen Arbeitskräften souverän und mit viel Einsatz bewältigt. Stellvertretend für alle Beteiligten gebührt den beiden Vorarbeitern, Sefer Baba und İbrahim Kınac1, sowie Berat Bulut bester Dank. Für die Digitalisierungen der Architekturzeichnungen, die grafische Aufarbeitung und zahlreiche Diskussionen fühle ich mich L. Zabrana verpflichtet. Mein Dank gilt auch M. La Torre für seinen substanziellen Beitrag in der Frage um die Rekonstruktion des Gebäudes und die Anfertigung des 3-D-Modells, bei der ihm J. Jost behilflich war. Die Digitalisierung der Fundzeichnungen und Teile der Tafelmontage wurden von N. Math übernommen. Ihr und N. Gail, der für die Anfertigung zahlreicher Fotos, die Bildbearbeitung und die Herstellung der Vorlagen für die Tafelmontage verantwortlich zeichnet, gilt der Dank des Autors. Bei der Aufbereitung der Archivalien zum Prytaneion waren mir I. Benda-Weber, F. Jaksche und G. Wlach behilflich. Wichtige inhaltliche Hinweise, kritische Kommentare und Publikationsgenehmigungen erhielt ich von 
M. Aurenhammer, W. Aylward, P. Brun, E. Doğer, V. von Graeve, W. Hoepfner, A. von Kienlin, M. Lawall, F. Pirson, A. Pülz, W. Raeck, H. Taeuber, V. Scheibelreiter, A. Sokolicek und A. Waldner.

Für die kollegiale Zusammenarbeit und wichtige Hinweise zur Altgrabung dankt der Autor dem Efes Müzesi Selçuk, allen voran P. Büyükkolancı, F. Kat sowie seinem Leiter C. Topal und dem ehemaligen Museumsbeamten M. Büyükkolancı.

Die Redaktion des Manuskriptes übernahmen A. M. Pülz und B. Beck-Brandt; die Übersetzungen in die türkische und englische Sprache erfolgten durch N. Kul-Berndt und N. M. High. Auch ihnen sei herzlich gedankt.

Der Österreichischen Akademie der Wissenschaften sei abschließend für die Aufnahme in das Publikationsprogramm sowie für viele fruchtbare interdisziplinäre Kontakte gedankt. Ohne einen vom FWF gewährten Druckkostenzuschuss hätte der vorliegende Band in dieser Form nicht erscheinen können. 


\section{HINWEISE UND VERZEICHNISSE}

\section{Abgekürzt zitierte Literatur (Bibliografie)}

Die Abkürzungen und Siglen folgen den Richtlinien des Österreichischen Archäologischen Instituts $<\mathrm{http} / /$ www.oeai.at/publik/autoren.html>.

Alzinger 1962

Alzinger 1970

Alzinger 1972-1975

Alzinger 1974

Atlante I

Atlante II
W. Alzinger, Die Stadt des siebenten Weltwunders. Die Wiederentdeckung von Ephesos (Wien 1962).

RE Suppl. XII (1970) 1588-1704 s. v. Ephesos: B. Archäologischer Teil (W. Alzinger).

W. Alzinger, Das Regierungsviertel, ÖJh 50, 1972-1975, Beibl. 229-300.

W. Alzinger, Augusteische Architektur in Ephesos, SoSchrÖAI 16 (Wien 1974).

Enciclopedia dell'Arte Antica. Classica e Orientale. Atlante delle Forme Ceramiche I. Ceramica fine Romana nel Bacino Mediterraneo (Roma 1981).

Enciclopedia dell'Arte Antica. Classica e Orientale. Atlante delle Forme Ceramiche II. Ceramica fine Romana nel Bacino Mediterraneo (Roma 1985).

Aurenhammer (in Druckvorbereitung) M. Aurenhammer (Hrsg.), Die Skulpturen von Ephesos. Die Porträts, FiE 10, 3 (in Druckvorbereitung)

Aurenhammer - Sokolicek (in Druck) M. Aurenhammer - A. Sokolicek, The Remains of the Centuries. Sculptures and StatueBases in Late Antique Ephesus. The Evidence of the Upper Agora, in: Ch. Ratté - O. Dally (Hrsg.), Archaeology and the Cities of Asia Minor in Late Antiquity. An International Symposium at the University of Michigan, 8.-10. Jänner 2008, JRA Suppl. (in Druck).

Aydin 2007 B. Aydın, The Hellenistic Pottery and Small Finds of Kordon Tumulus at Kordon Köyü/Salihli (Manisa) 2001, ÖJh 76, 2007, 7-63.

Bammer 1976/1977

Bammer 2008

A. Bammer, Zu ÖJh 50, 1972-1975 Beibl. 242 ff. 249 ff., ÖJh 51, 1976/1977, $57-58$.

A. Bammer, Zur Dekonstruktion römischer Architektur. Studien zur Architektur im Nordbereich der sog. Oberen Agora von Ephesos, Anatolia Antiqua 16, 2008, 165-180.

Bammer - Fleischer - Knibbe 1974 A. Bammer - R. Fleischer - D. Knibbe, Führer durch das Archäologische Museum in Selçuk-Ephesos (Wien 1974).

Bauer 1996

F. A. Bauer, Stadt, Platz und Denkmal in der Spätantike. Untersuchungen zur Ausstattung des öffentlichen Raums in den spätantiken Städten Rom, Konstantinopel und Ephesos (Mainz 1996).

Berns - Hesberg - Vandeput - Waelkens 2002 Ch. Berns - H. v. Hesberg - L. Vandeput - M. Waelkens (Hrsg.), Patris und Imperium. Kulturelle und politische Identität in den Städten der römischen Provinzen Kleinasiens in der frühen Kaiserzeit. Kolloquium Köln, November 1998, BABesch Suppl. 8 (Leiden 2002).

Bier (in Druck)

Brands - Severin 2003

L. Bier, The Bouleuterion at Ephesus, FiE 9, 5 (in Druck).

G. Brands - H.-G. Severin (Hrsg.), Die spätantike Stadt und ihre Christianisierung. Symposium vom 14. bis 16. Februar 2000 in Halle/Saale (Wiesbaden 2003).

Brandt - Gassner - Ladstätter 2005 B. Brandt - V. Gassner - S. Ladstätter (Hrsg.), Synergia. Festschrift Friedrich Krinzinger I (Wien 2005).

Consp.

E. Ettlinger - B. Hedinger - B. Hoffmann - Ph. M. Kenrick - G. Pucci - K. Roth-Rubi G. Schneider - S. von Schnurbein - C. M. Wells - S. Zabehlicky-Scheffenegger, Conspectus formarum terrae sigillatae italico modo confectae, Materialien zur römisch-germanischen Keramik 10 (Bonn 1990).

Cook 1959/1960

J. M. Cook, Greek Archaeology in Western Asia Minor, ARepLond 1959/60, 27-57.

Eichler 1961

F. Eichler, Die österreichischen Ausgrabungen in Ephesos im Jahre 1960, AnzWien 98, 1961, 65-75.

Eichler 1962

F. Eichler, Die österreichischen Ausgrabungen in Ephesos im Jahre 1961, AnzWien 99, 1962, 37-54.

Eichler 1963

Eichler 1964
F. Eichler, Die österreichischen Ausgrabungen in Ephesos im Jahre 1962, AnzWien 100, 1963, 45-60.

F. Eichler, Die österreichischen Ausgrabungen in Ephesos im Jahre 1963, AnzWien 101, 1964, 39-44. 
Eichler 1965

Engelmann 1985

Fenn 2008

Fittschen 1973

Fleischer 1973

Fleischer 1978

Fleischer 1983

Fleischer 1999

Fleischer 2002

Fleischer 2008

Foss 1979

Frazer 1885

Friesinger - Krinzinger 1999

Gassner 1997

Graf 1999

Grierson

Groh 2006

Hagemann 1880

Halfmann 2001

Hansen - Fischer-Hansen 1994

Hayes 1972

Herda 2005

Hoepfner - Lehmann 2006

Hoepfner - Schwandner 1994

Holland 1944

Humann 1904

İnan - Rosenbaum 1966

Iro - Schwaiger - Waldner 2009

Jobst 1977

Karwiese 1995

Karwiese 1999
F. Eichler, Die österreichischen Ausgrabungen in Ephesos im Jahre 1964, AnzWien 102, 1965, 93-110.

H. Engelmann, Die Bauinschriften des Prytaneions von Ephesos, in: Lebendige Altertumswissenschaft. Festschrift Herrmann Vetters (Wien 1985) 155-157.

N. Fenn, Thin-Walled Pottery from an Early Imperial Complex at Priene/Ionia, ReiCretActa 40, 2008, 249-254.

K. Fittschen, Rez. zu: »J. İnan - E. Rosenbaum, Roman and Early Byzantine Portrait Sculpture in Asia Minor«, GGA 225, 1973, 46-67.

R. Fleischer, Artemis von Ephesos und verwandte Kultstatuen aus Anatolien und Syrien, EPRO 35 (Leiden 1973).

R. Fleischer, Artemis von Ephesos und verwandte Kultstatuen aus Anatolien und Syrien, in: S. Şahin - E. Schwertheim - J. Wagner (Hrsg.), Studien zur Religion und Kultur Kleinasiens. Festschrift Friedrich Karl Dörner, EPRO 66, 1 (Leiden 1978) 324-358.

R. Fleischer, Neues zu kleinasiatischen Kultstatuen, AA 1983, 81-93.

R. Fleischer, Neues zum Kultbild der Artemis von Ephesos, in: Friesinger - Krinzinger 1999, 605-609.

R. Fleischer, Die Amazonen und das Asyl des Artemisions von Ephesos, JdI 117, 2002, 185-216.

R. Fleischer, Die Kultstatue der Artemis von Ephesos und verwandte Götterbilder, in: Seipel 2008, 25-41.

C. Foss, Ephesus after Antiquity: A Late Antique, Byzantine and Turkish City (Cambridge 1979).

J. G. Frazer, The Prytaneum, the Temple of Vesta, the Vestals, Perpetual Fires, The Journal of Philology 14, 1885, 145-172.

H. Friesinger - F. Krinzinger (Hrsg.), 100 Jahre Österreichische Forschungen in Ephesos. Akten des Symposions Wien 1995, AForsch 1 = DenkschrWien 260 (Wien 1999).

V. Gassner, Das Südtor der Tetragonos-Agora. Keramik und Kleinfunde, FiE 13, 1, 1 (Wien 1997).

F. Graf, Ephesische und andere Kureten, in: Friesinger - Krinzinger 1999, 255-262.

$\mathrm{Ph}$. Grierson, Catalogue of the Byzantine Coins in the Dumbarton Oaks Collection and in the Whittemore Collection, III: Leo III. to Nicephorus III. 717-1081, Part 1: Leo III. to Michael III. (717-867) (Washington 1973).

St. Groh unter Mitarbeit von V. Lindinger - K. Löcker - W. Neubauer - S. S. Seren, Neue Forschungen zur Stadtplanung in Ephesos, ÖJh 75, 2006, 47-116.

G. Hagemann, De Prytaneo (Breslau 1880).

H. Halfmann, Städtebau und Bauherren im römischen Kleinasien. Ein Vergleich zwischen Pergamon und Ephesos, IstMitt Beih. 43 (Tübingen 2001).

M. H. Hansen - T. Fischer-Hansen, Monumental Political Architecture in Archaic and Classical Greek Poleis. Evidence and Historical Significance, in: D. Whitehead (Hrsg.), From Political Architecture to Stephanus Byzantius. Sources for the Ancient Greek Polis, Historia Einzelschriften 87 (Stuttgart 1994) 23-90.

J. W. Hayes, Late Roman Pottery (London 1972).

A. Herda, Apollon Delphinios, das Prytaneion und die Agora von Milet. Neue Forschungen, AA 2005, 243-294.

W. Hoepfner - L. Lehmann (Hrsg.), Die griechische Agora. Bericht über ein Kolloquium am 16. März 2003 in Berlin (Mainz 2006).

W. Hoepfner - E.-L. Schwandner, Haus und Stadt im klassischen Griechenland, Wohnen in der klassischen Polis I ${ }^{2}$ (München 1994).

L. B. Holland, Colophon, Hesperia 13, 1944, 91-171.

C. Humann, Magnesia am Maeander. Bericht über die Ergebnisse der Ausgrabungen der Jahre 1891-1893 (Berlin 1904).

J. İnan - E. Rosenbaum, Roman and Early Byzantine Portrait Sculpture in Asia Minor (London 1966).

D. Iro - H. Schwaiger - A. Waldner, Die Grabungen des Jahres 2005 in der Süd- und Nordhalle der Kuretenstraße, in: Ladstätter 2009, 53-87.

W. Jobst, Römische Mosaiken aus Ephesos I. Die Hanghäuser des Embolos, FiE 8, 2 (Wien 1977).

St. Karwiese, Groß ist die Artemis von Ephesos. Die Geschichte einer der großen Städte der Antike (Wien 1995).

St. Karwiese, Gedanken zur Entstehung des römischen Ephesos, in: Friesinger - Krinzinger 1999, 393-398. 
Keil 1939

\section{Kenzler 1999}

Kleiner 1968

Knell 1991

Knibbe 1981

Knibbe 1995

Knibbe 1998

Knibbe 1999

Knibbe - Langmann 1993

Knibbe - Thür 1995

Koester 1995

Krinzinger 2001

Krinzinger 2002

Ladstätter 2003

Ladstätter 2005

Ladstätter 2007

Ladstätter 2008

Ladstätter 2009

Ladstätter 2010

Ladstätter - Pülz 2007

Ladstätter - Sauer 2005

Ladstätter - Scheibelreiter 2010

Lätzer (in Druck)

Lang 1985

Lawall 2007

LiDonnici 1992

Liebeschuetz 2001

Martin 2003

Martin 2006
J. Keil, Kulte im Prytaneion von Ephesos, in: W. M. Calder - J. Keil (Hrsg.), Anatolian Studies Presented to William Hepburn Buckler (Manchester 1939) 119-128.

U. Kenzler, Studien zur Entwicklung und Struktur der griechischen Agora in archaischer und klassischer Zeit, Europäische Hochschulschriften 72 (Frankfurt 1999).

G. Kleiner, Die Ruinen von Milet (Berlin 1968).

H. Knell, Vitruvs Architekturtheorie. Versuch einer Interpretation ${ }^{2}$ (Darmstadt 1991).

D. Knibbe, Der Staatsmarkt. Die Inschriften des Prytaneions, FiE 9, 1, 1 (Wien 1981).

D. Knibbe, Via Sacra Ephesiaca: New Aspects of the Cult of Artemis Ephesia, in: Koester 1995, 141-155.

D. Knibbe, Ephesus. ЕФЕ $\Sigma \mathrm{O} \Sigma$. Geschichte einer bedeutenden antiken Stadt und Portrait einer modernen Großgrabung im 102. Jahr der Wiederkehr des Beginnes österreichischer Forschungen (1895-1997) (Frankfurt 1998).

D. Knibbe, Via Sacra Ephesiaca, in: Friesinger - Krinzinger 1999, 449-454.

D. Knibbe - G. Langmann, Via Sacra Ephesiaca I, BerMatÖAI 3 (Wien 1993).

D. Knibbe - H. Thür, Via Sacra Ephesiaca II. Grabungen und Forschungen 1992 und 1993 , BerMatÖAI 6 (Wien 1995).

H. Koester (Hrsg.), Ephesos. Metropolis of Asia. An Interdisciplinary Approach to its Archaeology, Religion, and Culture, Harvard Theological Studies 41 (Valley Forge 1995).

F. Krinzinger (Hrsg.), Studien zur hellenistischen Keramik in Ephesos, ÖJh Ergh. 2 (Wien 2001).

F. Krinzinger (Hrsg.), Das Hanghaus 2 von Ephesos. Studien zu Baugeschichte und Chronologie, AForsch 7 = DenkschrWien 302 (Wien 2002).

S. Ladstätter, Keramik, in: C. Lang-Auinger (Hrsg.), Hanghaus 1 in Ephesos. Funde und Ausstattung, FiE 8, 4 (Wien 2003) 22-85.

S. Ladstätter, Keramik, in: Thür 2005, 230-358.

S. Ladstätter, Mode oder politisches Manifest? Überlegungen zur Übernahme römischen Formenguts in der frühkaiserzeitlichen Keramik von Ephesos, in: Meyer 2007, 203-219.

S. Ladstätter, Römische, spätantike und byzantinische Keramik, in: Steskal - La Torre 2008, 97-189.

S. Ladstätter (Hrsg.), Neue Forschungen zur Kuretenstraße von Ephesos. Akten des Symposiums für Hilke Thür vom 13. Dezember 2006 an der Österreichischen Akademie der Wissenschaften in Wien, AForsch 15 = DenkschrWien 382 (Wien 2009).

S. Ladstätter, Wohneinheiten 1 und 2. Keramik, in: F. Krinzinger (Hrsg.), Hanghaus 2 in Ephesos. Die Wohneinheiten 1 und 2. Baubefund, Ausstattung, Funde, FiE 8, 8 (Wien 2010) 172-279. 530-587.

S. Ladstätter - A. Pülz, Ephesus in the Late Roman and Early Byzantine Period: Changes in its Urban Character from the Third to the Seventh Century AD, in: A. G. Poulter (Hrsg.), The Transition to Late Antiquity on the Danube and Beyond, Proceedings of the British Academy 141 (Oxford 2007) 391-433.

S. Ladstätter - R. Sauer, Late Roman C Ware und lokale spätantike Feinware aus Ephesos, in: F. Krinzinger (Hrsg.), Spätantike und mittelalterliche Keramik aus Ephesos, AForsch $13=$ DenkschrWien 332 (Wien 2005) 143-210.

S. Ladstätter - V. Scheibelreiter (Hrsg.), Städtisches Wohnen im östlichen Mittelmeerraum. 4. Jh. v. Chr. - 1. Jh. n. Chr. Akten des internationalen Kolloquiums vom 24.-27. Oktober 2007 an der Österreichischen Akademie der Wissenschaften, AForsch $18=$ DenkschrWien 397 (Wien 2010).

A. Lätzer, Studien zu einem späthellenistisch-frührömischen Fundkomplex aus dem Hanghaus 2, ÖJh 78, 2009 (in Druck).

G. J. Lang, Zur oberen Osthalle der Agora, der »Neronischen Halle« in Ephesos, in: Lebendige Altertumswissenschaft. Festschrift Hermann Vetters (Wien 1985) 176-180.

M. Lawall, Hellenistic Stamped Amphora Handles, in: Mitsopoulos-Leon - Lang-Auinger 2007, 28-60.

L. R. LiDonnici, The Images of Artemis Ephesia and Greco-Roman Worship. A Reconsideration, HarvTheoIR 85, 1992, 389-415.

J. H. W. G. Liebeschuetz, The Decline and Fall of the Roman City (Oxford 2001).

A. Martin, Western Sigillata in the Hanghäuser at Ephesos, ReiCretActa 38, 2003, 247-249.

A. Martin, Italian Sigillata in the East: Two Different Models of Supply (Ephesos and Ostia), in: D. Malfitana - J. Poblome - J. Lund (Hrsg.), Old Pottery in a New Century. Innovating Perspectives on Roman Pottery Studies. Atti del Convegno Internazionale di Studi Catania, 22-24 Aprile 2004 (Catania 2006) 175-188. 
McDonald 1943

McDonald 1948

Meriç 2002

Merkelbach 1980

Meyer 2007

Meyer-Schlichtmann 1988

Miller 1978

Miltner 1956-1958

Miltner 1957

Miltner 1958a

Miltner 1958b

Miltner 1959

Mitsopoulos-Leon 1972-1975

Mitsopoulos-Leon 1991

Mitsopoulos-Leon 2007

Mitsopoulos-Leon - Lang-Auinger 200

Morris 2001

Murray 1990

OCK

Peacock - Williams

Plattner 2003

Plattner 2008

Plattner 2010

Portefaix 1999

Preuner 1864

Quatember - Waldner - Pfisterer - Aurenhammer 2008 U. Quatember - A. Waldner - M. Pfisterer - M. Aurenhammer, Die

Rogers 1991

Rogers 1999a

Rogers 1999b

Rogers 2007

Rotroff 1997

Rotroff 2006

W. A. McDonald, The Political Meeting Places of the Greeks (Baltimore 1943).

W. A. McDonald, Types of Greek Civic Architecture - The Prytaneion, AJA 52, 1948, $374 \mathrm{f}$.

R. Meriç, Späthellenistisch-römische Keramik und Kleinfunde aus einem Schachtbrunnen am Staatsmarkt in Ephesos, FiE 9, 3 (Wien 2002).

R. Merkelbach, Der Kult der Hestia im Prytaneion der griechischen Städte, ZPE 37, 1980, 77-92.

M. Meyer (Hrsg.), Neue Zeiten - Neue Sitten. Zu Rezeption und Integration römischen und italischen Kulturguts in Kleinasien. Akten des Internationalen Kolloquiums in Wien 2005, WForsch 12 (Wien 2007).

C. Meyer-Schlichtmann, Die pergamenische Sigillata aus der Stadtgrabung von Pergamon. Mitte 2. Jh. v. Chr. - Mitte 2. Jh. n. Chr., PF 6 (Berlin 1988).

St. G. Miller, The Prytaneion. Its Function and Architectural Form (Berkeley 1978).

F. Miltner, XXI. Vorläufiger Bericht über die Ausgrabungen in Ephesos, ÖJh 43, 1956-1958, Beibl. 27-36.

F. Miltner, Ergebnisse der österreichischen Ausgrabungen in Ephesos im Jahre 1956, AnzWien 94, 1957, 13-25.

F. Miltner, Ephesos. Stadt der Artemis und des Johannes (Wien 1958).

F. Miltner, Die neuen Artemisstatuen aus Ephesos, Anatolia 3, 1958, 21-34.

F. Miltner, XXII. Vorläufiger Bericht über die Ausgrabungen in Ephesos, ÖJh 44, 1959, Beibl. 289-312.

V. Mitsopoulos-Leon, Keramik aus Basilika und Prytaneion - Ein Überblick, ÖJh 50, 1972-1975, Beibl. 495-524.

V. Mitsopoulos-Leon, Die Basilika am Staatsmarkt in Ephesos. Kleinfunde. 1. Teil: Keramik hellenistischer und römischer Zeit, FiE 9, 2, 2 (Wien 1991).

V. Mitsopoulos, Die Lampen, in: Mitsopoulos-Leon - Lang-Auinger 2007, 64-113.

V. Mitsopoulos-Leon - C. Lang-Auinger (Hrsg.), Die Basilika am Staatsmarkt in Ephesos. 2. Teil: Funde klassischer bis römischer Zeit, FiE 9, 2, 3 (Wien 2007).

S. P. Morris, The Prehistoric Background of Artemis Ephesia: A Solution to the Enigma of her >Breasts`?, in: U. Muss (Hrsg.), Der Kosmos der Artemis von Ephesos, SoSchrÖAI 37 (Wien 2001) 135-151.

O. Murray (Hrsg.), Sympotica. A Symposium on the Symposion (Oxford 1990).

A. Oxé - H. Comfort - Ph. Kenrick, Corpus Vasorum Arretinorum: A Catalogue of the Signatures, Shapes and Chronology of Italian Sigillata, Antiquitas 41 (Bonn 2000).

D. Peacock - D. Williams, Amphorae and the Roman Economy: An Introductory Guide (London 1986).

G. A. Plattner, Ephesische Kapitelle des 1. und 2. Jhs. n. Chr. (ungedr. Diss. Universität Wien 2003).

G. A. Plattner, Bauornamentik, in: Steskal - La Torre 2008, 275-282.

G. A. Plattner, Architekturdekoration, in: F. Krinzinger (Hrsg.), Hanghaus 2 in Ephesos. Die Wohneinheiten 1 und 2. Baubefund, Ausstattung, Funde, FiE 8, 8 (Wien 2010) 149-155. 510-524.

L. Portefaix, The Image of Artemis Ephesia - A Symbolic Configuration Related to Her Mysteries?, in: Friesinger - Krinzinger 1999, 611-617.

A. Preuner, Hestia-Vesta. Ein Cyclus religionsgeschichtlicher Forschungen (Tübingen 1864).

Grabung des Jahres 2005 beim Nymphaeum Traiani in Ephesos, ÖJh 77, 2008, 265-334.

G. M. Rogers, The Sacred Identity of Ephesos. Foundation Myths of a Roman City (London 1991).

G. M. Rogers, The Mysteries of Artemis at Ephesos, in: Friesinger - Krinzinger 1999, 241-250.

G. M. Rogers, The Philosebastoi Kuretes of Ephesos, in: Scherrer - Taeuber - Thür 1999, $125-130$.

G. M. Rogers, From the Greek Polis to the Graeco-Roman Polis. Augustus and the Artemision of Ephesos, in: H. Elton - G. Reger (Hrsg.), Regionalism in Hellenistic and Roman Asia Minor. Acts of the Conference Hartford, Connecticut (USA), August 22-24 1997 (Bordeaux 2007) 137-145.

S. Rotroff, Hellenistic Pottery. Athenian and Imported Wheelmade Table Ware and Related Material, Agora 29 (Athen 1997).

S. Rotroff, Hellenistic Pottery: The Plain Wares, Agora 33 (Athen 2006). 
Rumscheid 1998

Scherrer 1990

Scherrer 1995a

Scherrer 1995b

Scherrer 1997

Scherrer 2007

Scherrer - Taeuber - Thür 1999

Schmitt Pantel 1992

Schwarzer 2004

Schwarzer 2008

Seipel 2008

Seiterle 1979

SNG Tüb.

Soldan 1999

Steskal 2007

Steskal 2008

Steskal - La Torre 2008

Thür 1995

Thür 1996

Thür 1999

Thür 2003

Thür 2005

Thür 2007

Tosi 1966

Turnovsky 2005a

Turnovsky 2005b

Vaag - Nørskov - Lund 2002
F. Rumscheid, Priene. Führer durch das »Pompeji Kleinasiens« (Istanbul 1998).

P. Scherrer, Augustus, die Mission des Vedius Pollio und die Artemis Ephesia, ÖJh 60, 1990, 87-101.

P. Scherrer (Hrsg.), Ephesos. Der neue Führer. 100 Jahre österreichische Ausgrabungen 1895-1995 (Wien 1995).

P. Scherrer, The City of Ephesos from the Roman Period to Late Antiquity, in: Koester 1995, 1-25.

P. Scherrer, Anmerkungen zum städtischen und provinzialen Kaiserkult: Paradigma Ephesos - Entwicklungslinien von Augustus bis Hadrian, in: H. Thür (Hrsg.), »... und verschönerte die Stadt ...«. ... KAI KO $\Sigma$ MH $\Sigma$ ANTA THN ПO $\Lambda$ IN ... Ein ephesischer Priester des Kaiserkultes in seinem Umfeld, SoSchrÖAI 27 (Wien 1997) 93-112.

P. Scherrer, Der conventus civium Romanorum und kaiserliche Freigelassene als Bauherren in Ephesos in augusteischer Zeit, in: Meyer 2007, 63-75.

P. Scherrer - H. Taeuber - H. Thür (Hrsg.), Steine und Wege. Festschrift Dieter Knibbe, SoSchrÖAI 32 (Wien 1999).

P. Schmitt Pantel, La cité au banquet. Histoire des repas publics dans les cités grecques, CEFR 157 (Rom 1992).

H. Schwarzer, Der sogenannte Bau H. Zum mutmaßlichen Prytaneion von Pergamon, IstMitt 54, 2004, 173-182.

H. Schwarzer, Die Stadtgrabung. Das Gebäude mit dem Podiensaal in der Stadtgrabung von Pergamon, AvP 15, 4 (Berlin 2008).

W. Seipel (Hrsg.), Das Artemision von Ephesos. Heiliger Platz einer Göttin. Eine Ausstellung des Kunsthistorischen Museums Wien in Zusammenarbeit mit dem Archäologischen Museum Istanbul und dem Ephesos-Museum, Selçuk. Archäologisches Museum Istanbul, 22. Mai bis 22. September 2008 (Wien 2008).

G. Seiterle, Artemis, die große Göttin von Ephesos. Eine neue Deutung der Vielbrüstigkeit eröffnet einen Zugang zum bisher unbekannten Kult der Göttin, AW 10, 3, 1979, 3-16.

Sylloge Nummorum Graecorum. Deutschland. Münzsammlung der Universität Tübingen, 4. Heft: Mysien - Ionien (München 1989).

U. Soldan, Frauen als Funktionsträgerinnen im kaiserzeitlichen Ephesos: Die weiblichen Prytaneis, in: Friesinger - Krinzinger 1999, 115-119.

M. Steskal, Konstruktionszeichnungen zweier Voluten aus dem Prytaneion in Ephesos, ÖJh 76, 2007, 371-392.

M. Steskal, Rituelle Bestattungen im Prytaneion von Ephesos? Zu den Fundumständen der Artemis Ephesia-Statuen, ÖJh 77, 2008, 363-373.

M. Steskal - M. La Torre, Das Vediusgymnasium in Ephesos. Achäologie und Baubefund, FiE 14, 1 (Wien 2008).

H. Thür, Der ephesische Ktistes Androklos und (s)ein Heroon am Embolos, ÖJh 64, 1995, 63-103.

H. Thür, Ein dorischer Torbau auf dem Staatsmarkt in Ephesos, in: F. Blakolmer K. R. Krierer - F. Krinzinger - A. Landskron-Dinstl - H. D. Szemethy - K. Zhuber-Okrog (Hrsg.), Fremde Zeiten. Festschrift Jürgen Borchhardt I (Wien 1996) 345-361.

H. Thür, Die spätantike Bauphase der Kuretenstraße, in: R. Pillinger - O. Kresten - F. Krinzinger - E. Russo (Hrsg.), Efeso paleocristiana e bizantina - Frühchristliches und byzantinisches Ephesos, AForsch 3 = DenkschrWien 282 (Wien 1999) 104-120.

H. Thür, Das spätantike Ephesos. Aspekte zur Frage der Christianisierung des Stadtbildes, in: Brands - Severin 2003, 259-273.

H. Thür (Hrsg.), Hanghaus 2 in Ephesos. Die Wohneinheit 4. Baubefund, Ausstattung, Funde, FiE 8, 6 (Wien 2005).

H. Thür, Wie römisch ist der sog. Staatsmarkt in Ephesos?, in: Meyer 2007, 77-90.

G. Tosi, Contributo allo studio dei pritanei, ArtAntMod 33, 1966, 10-21. 151-172.

P. Turnovsky, Late Antique and Byzantine Pottery of the Church of St. Mary in Ephesos. An Introduction, ReiCretActa 39, 2005, 217-224.

P. Turnovsky, The Morphological Repertory of Late Roman / Early Byzyantine Coarse Wares in Ephesos, in: J. M. Gurt I Esparraguera - J. Buxeda I Garrigós - M. A. Cau Ontiveros, LRCW I. Late Roman Coarse Wares, Cooking Wares and Amphorae in the Mediterranean, BARIntSer 1340 (Oxford 2005) 635-645.

L. E. Vaag - V. Nørskov - J. Lund, The Pottery. Ceramic Material and Other Finds from Selected Contexts, The Maussolleion at Halikarnassos, Reports of the Danish Archaeological Expedition to Bodrum 7 (Aarhus 2002). 
Waldner 2009a

Waldner 2009b

Warner Slane 1997

Wilberg 1923

Witetschek 2008
A. Waldner, Keramische Evidenzen zur Baugeschichte des unteren Embolos von Ephesos (ungedr. Diss. Universität Wien 2009).

A. Waldner, Heroon und Oktogon. Zur Datierung zweier Ehrenbauten am unteren Embolos von Ephesos anhand des keramischen Fundmaterials aus den Grabungen von 1989 und 1999, in: Ladstätter 2009, 283-315.

K. Warner Slane, The Fine Wares, in: S. Herbert (Hrsg.), Tel Anafa II, I, JRA Suppl. 10 (Ann Arbor 1997) 249-406.

W. Wilberg, Die Agora, in: FiE 3 (Wien 1923) 1-90.

St. Witetschek, Ephesische Enthüllungen 1. Frühe Christen in einer antiken Großstadt zugleich ein Beitrag zur Frage nach den Kontexten der Johannesapokalypse, Biblical Tools and Studies 6 (Leiden 2008).

Zabehlicky-Scheffenegger - Schneider 2005 S. Zabehlicky-Scheffenegger - G. Schneider, Ephesian Cooking Vessels of the Augustan Period, in: M. Berg Briese - L. E. Vaag (Hrsg.), Trade Relations in the Eastern Mediterranean from the Late Hellenistic Period to Late Antiquity: The Ceramic Evidence, Halicarnassian Studies 3 (Odense 2005) 63-67.

\section{Antike Autoren}

Die Abkürzungen der antiken Autoren und Werktitel folgen H. Cancik - H. Schneider (Hrsg.), Der Neue Pauly. Enzyklopädie der Antike (1996) I, A-Ari S. XXXIX-XLVII.

\section{Verzeichnis der im Text und Katalog verwendeten Abkürzungen}

Neben den vom Deutschen Archäologischen Institut vorgeschlagenen Abkürzungen und Kurzformen $<$ http:// www.dainst.org> werden folgende verwendet:

$\begin{array}{llll}\text { A. } & \text { Anfang } & \text { H. } & \text { Hälfte } \\ \text { AO } & \text { Aufbewahrungsort } & \text { hell. } & \text { Hellenistisch } \\ \text { ARS } & \text { African Red Slip Ware } & \text { inkl. } & \text { inklusive } \\ \text { B } & \text { Breite } & \text { InvNr. } & \text { Inventar-Nummer } \\ \text { Bdfrgt. } & \text { Bodenfragment(e) } & \text { ITS } & \text { Italische Sigillata } \\ \text { Bearb. } & \text { Bearbeitung } & \text { KatNr. } & \text { Katalog-Nummer } \\ \text { cf. } & \text { confer } & \text { L } & \text { Länge } \\ \text { D. } & \text { Drittel } & \text { Lit. } & \text { Literatur } \\ \text { Dm } & \text { Durchmesser } & \text { LRC } & \text { Late Roman C-Ware } \\ \text { DmBd } & \text { Durchmesser Boden } & \text { M. } & \text { Mitte } \\ \text { D } & \text { Dicke } & \text { Mat. } & \text { Material } \\ \text { DmRd } & \text { Durchmesser Rand } & \text { o. } & \text { oben } \\ \text { DmWd } & \text { Durchmesser Wand } & \text { o. Nr. } & \text { ohne Nummer } \\ \text { E. } & \text { Ende } & \text { Rd } & \text { Rand } \\ \text { EM } & \text { Efes Müzesi Selçuk } & \text { Rdfrgt. } & \text { Randfragment(e) } \\ \text { erh. } & \text { erhalten } & \text { rek. } & \text { rekonstruierte(r) } \\ \text { Erh. } & \text { Erhaltung } & \text { RL } & \text { Rüstloch } \\ \text { ERSW } & \text { Ephesian Red Slip Ware } & \text { ROW-Lampe } & \text { Red-on-White-Lampe } \\ \text { ESA } & \text { Eastern Sigillata A } & \text { s. } & \text { siehe } \\ \text { ESB } & \text { Eastern Sigillata B } & \text { SE } & \text { Stratigrafische Einheit } \\ \text { ESC } & \text { Eastern Sigillata C } & \text { T } & \text { Tiefe } \\ \text { FJ } & \text { Fundjahr } & \text { TR } & \text { Tonrohr } \\ \text { FO } & \text { Fundort } & \text { u. } & \text { unten } \\ \text { Frgt. } & \text { Fragment(e) } & \text { ungedr. } & \text { ungedruckte } \\ \text { Gew. } & \text { Gewicht } & \text { V. } & \text { Viertel } \\ \text { GHD } & \text { Grabungshaus-Depot Selçuk } & \text { Verf. } & \text { Verfasser } \\ \text { H } & \text { Höhe } & \text { Wdfrgt. } & \text { Wandfragment(e) }\end{array}$

Spezifische numismatische Abkürzungen sind am Beginn des relevanten Kapitels angeführt. 


\section{Abkürzungen der Katalogobjekte}

$\begin{array}{ll}\text { A } & \text { Architekturteile } \\ \text { M } & \text { Münzen } \\ \text { K } & \text { Hellenistische, römische und spätantike Keramik } \\ \text { SK } & \text { Skulptur }\end{array}$

\section{Alphabetisches Autorenverzeichnis}

Nicole M. High

Kelsey Museum of Archaeology, University of Michigan, 434 South State Street, Ann Arbor, MI 481091390, USA

Sabine Ladstätter

Österreichisches Archäologisches Institut

A-1190 Wien, Franz Klein-Gasse 1

Matthias Pfisterer

Kunsthistorisches Museum Wien, Münzkabinett

A-1010 Wien, Burgring 5

Georg A. Plattner

Kunsthistorisches Museum Wien, Antikensammlung

A-1010 Wien, Burgring 5

Martin Steskal

Österreichisches Archäologisches Institut

A-1190 Wien, Franz Klein-Gasse 1

\section{Planzeichner und -umzeichner, Fotografen}

Alzinger, W.

Durgut, F. und O.

Eitler, J.

Fleischer, R.

Gail, N.

High, N. M.

Hochleitner, A.

John, W.

Jost, J.

Knibbe, D.

Kurtze, Ch

Ladstätter, S.

La Torre, M.

Math, N.

Mayrhofer, P.

Plattner, G. A.

Stark, B.

Steskal, M.

Zabrana, L.
W. A.

F. O. D.

J. E.

R. F.

N. G.

N. H.

A. $\mathrm{H}$.

W. J.

J. J.

D. K.

C. K.

S. L.

M. L.

N. M.

P. M.

G. P.

B. S.

M. S.

L. Z. 


\section{Abbildungen (mit inkludiertem Abbildungsnachweis)}

TAFELABBILDUNGEN

Tafelabb.

Kapitel I

Taf. 1, 1:

Taf. 2, 1:

Taf. 3, 1:

Taf. 4, 1:

Taf. 4, 2:

Taf. 5,1 :

Taf. 5, 2:

Taf. 5, 3:

Kapitel II

Taf. 6, 1:

Taf. 6, 2:

Taf. 6, 3:

Taf. 7, 1:

Taf. 7, 2:

Taf. 8, 1:

Taf. 8, 2:

Taf. 8, 3:

Taf. 9, 1:

Taf. 9, 2:

Taf. 9, 3:

Taf. 10, 1:

Taf. 10, 2:

Taf. 10, 3:

Taf. 11, 1:

Taf. 11, 2:

Taf. 12, 1:

Taf. 12, 2:

Taf. 13, 1:

Taf. 13, 2:

Taf. 14, 1:

Taf. 14, 2:

Taf. 15, 1:

Taf. 15, 2:

Taf. 16, 1:

Taf. 17, 1:

Taf. 17, 2:

Taf. 18, 1:

Taf. 18, 2:

Taf. 19, 1:

Taf. 19, 2:

Taf. 19, 3:

Taf. 20, 1:

Taf. 20, 2:
Inhalt

Ephesos. Stadtplan

Oberer `Staatsmarkt` von Ephesos. Übersichtsplan

Prytaneion. Generalisierter Grundriss mit Raumnummern (1:250) geschnittene Bauteile dunkel, aufsichtige Bauteile hell

Oberer >Staatsmarkt< von Ephesos. Luftbild

Prytaneion. Aufnahme vom Bülbüldağ

Prytaneion von Süden

Prytaneion von Norden

Prytaneion von Osten

Prytaneion 1955. Freilegung des $>$ Hestiasaales $<$ entlang der Westwand Prytaneion 1955. Freilegung des >Hestiasaales`entlang der Westwand Prytaneion 1955. Grundriss

Prytaneion 1955. Freilegung des Stereobats der Vorhalle

Anastylose des südöstlichen Säulenschaftes (A 16) des >Hestiasaales`

Freilegung von Raum 6

Freilegung des westlichen Stylobats des Vorhofes

Freilegung der Südostecke des Stylobats des Vorhofes

>Schöne Artemis $\measuredangle$ in Fundlage (Raum 5)

$>$ Schöne Artemis` (EM InvNr. 718)

২Kleine Artemis` (EM InvNr. 717)

Kopie der >Kleinen Artemis` (EM 231/56)

$>$ Große Artemis` in Fundlage (Vorhof)

$>$ Große Artemis` (EM InvNr. 712)

Prytaneion 1956. Grundriss

Spätantik/byzantinisches Mauerwerk in Raum 5 vor Abtragung

Freilegung der $>$ Kuretenhalle $<$ am unteren Embolos

>Kuretenhalle< am unteren Embolos

Scholastikiatherme. Eingemauerte Säule und Kapitell aus dem Prytaneion

Oberer >Staatsmarkt< 1957

Nordwand des $>$ Hestiasaales $\prec$ vor Entfernung des Statuentorsos

Nordwand des >Hestiasaales` nach Entfernung des Statuentorsos

Zeichnerische Aufnahme der Nordwand des >Hestiasaales` 1960

Zeichnerische Aufnahme der Nordwand der Vorhalle 1960

Prytaneion. Generalisierter Grundriss mit Sondagenplan 1960-1963 (1:250) Prytaneion. Sondage I (1960). Ost- und Südprofil

Prytaneion. Sondage I und II (1960). Planum

Prytaneion. Sondage II (1960). Südprofil

Prytaneion - Bereich `Akademiegasse «. Schrankenplatte $(\mathrm{P} / 60 / 55)$ aus Sondage II

Prytaneion - Bereich `Akademiegasse «. Sondage II (1960)

Prytaneion - Bereich >Akademiegasse . Sondage II (1960).

Schrankenplatte in Fundlage

Prytaneion. Sondage IV (1960). Planum, Nord- und Ostprofil

Prytaneion. Sondage IV (1960)

Prytaneion. Sondage IV und V (1960). Planum und Ostprofil
Nachweis

C. K., (C) ÖAI

C. K., (C) ÖAI

L. Z., P. M., M. S., (C) ÖAI

F. O. D., (C) ÖAI

N. G., (C) ÖAI

M. S., (C) ÖAI

M. S., (C) ÖAI

M. S., (C) ÖAI

Pl. 407, (C) ÖAI

Pl. 405, C ÖAI

Miltner 1956-1958, Abb. 18.

Pl. 406, (C) ÖAI

Pl. 656, (C) ÖAI

Pl. 634, (C) ÖAI

1956 9a, 4, (C) ÖAI

1956 9a, 7, (C) ÖAI

(C) ÖAI

N. G., (C) ÖAI

N. G., (C) ÖAI

(C) ÖAI

(C) ÖAI

N. G., (C) ÖAI

Miltner 1959, Abb. 139.

Pl. 606, (C) ÖAI

A-W-OAI-N III 0225, (C) ÖAI

Pl. 353, C ÖAI

1957 333, 12, (C) ÖAI

1957 5, 12, C ÖAI

19563,13 , (C) ÖAI

1961 224, 6, (C) ÖAI

Ephesos 1960, Prytaneion,

Blatt 1 (W. A., D. K.), (C) ÖAI

Ephesos 1960, Prytaneion,

Blatt 52 (W. J.), (C) ÖAI

L. Z., M. S., P. M., C ÖAI

Ephesos 1960, Prytaneion, Blatt 23 (W. A.), C ÖAI

Ephesos 1960, Prytaneion, Blatt 27 und 27A (W. A.), (C) ÖAI

Ephesos 1960, Prytaneion, Blatt 32 (W. A.), C ÖAI

Ephesos 1960, Prytaneion, Blatt 55 (W. J., W. A.), (C ÖAI Ephesos 1960, Prytaneion, Blatt 55 (W. J., W. A.), (C) ÖAI Ephesos 1960, Prytaneion, Blatt 55 (W. J., W. A.), (C) ÖAI Ephesos 1960, Prytaneion, Blatt 49 (W. A.), (C) ÖAI 1960 236, 10, C ÖAI Ephesos 1960, Prytaneion, Blatt 57 (W. A.), (C ÖAI 
Taf. 20, 3:

Taf. 21, 1:

Taf. 21, 2:

Taf. 21, 3:

Taf. 22, 1:

Taf. 22, 2:

Taf. 22, 3:

Taf. 23, 1:

Taf. 23, 2:

Taf. 23, 3:

Taf. 23, 4:

Taf. 24, 1:

Taf. 24, 2:

Taf. 24, 3:

Taf. 24, 4:

Taf. 25, 1:

Taf. 25, 2:

Taf. 25, 3:

Taf. 26, 1:

Taf. 26, 2:

Taf. 26, 3:

Taf. 26, 4:

Taf. 27, 1:

Taf. 28, 1:

Taf. 28, 2:

Taf. 29, 1:

Taf. 29, 2:

Taf. 29, 3:

Kapitel III

Taf. 30, 1:

Taf. 31, 1:

Taf. 32, 1:

Taf. 32, 2:

Taf. 33, 1:

Taf. 34, 1:

Taf. 35, 1:

Taf. 35, 2:

Taf. 36, 1:

Taf. 37, 1:

Taf. 37, 2:

Taf. 37, 3:

Taf. 37, 4:
Prytaneion. Sondage VIII (1961). Planum

Prytaneion. Sondage VIII (1961). Südprofil

Prytaneion. Sondage VIII (1961). Nordwand der Vorhalle

Prytaneion. Sondage X (1961). Planum

Prytaneion. Sondage XI (1961). Planum

Zeichnerische Aufnahme der Südwand des `Hestiasaales` 1961 - Westteil

Zeichnerische Aufnahme der Südwand des `Hestiasaales` 1961 - Ostteil

Prytaneion. Sondage XVI (1961). Ostprofil

Prytaneion. Sondage XVI (1961). Osthälfte Raum 4

Prytaneion. Sondage XVIII (1961). Eingang in `Hestiasaak (Tür 3)

Prytaneion. Lesbisches Kymation aus Sondage XVIII (?)

Prytaneion. Sondage XIX (1961). Zentrales Fundament im `Hestiasaal Prytaneion. Sondagen XXI und XXVI (1961). Planum

Prytaneion. Sondage XXI (1961). Westprofil

Prytaneion. Sondage XXIII (1961). Planum

Prytaneion. Sondage XXII (1961). Planum

Prytaneion. Sondage XXII (1961). Ostprofile

Prytaneion. Sondage XXII (1961). Südhälfte Raum 6

Prytaneion. Sondage XXV (1961). Planum

Prytaneion von Norden (1961) mit Sondagen XVIII, XIX, XXV, XXVI und XXXI

Prytaneion. Sondage XXIX (1961). Planum und Südprofil

Prytaneion. Architekturprobe des dorischen Gebälks der Vorhalle (1961) Prytaneion 1961. Grundriss

Prytaneion. Sondage XXXI Nordhälfte (1962). Planum und Ostprofil

Prytaneion. Sondage XXXI Südhälfte (1962). Planum und Ostprofil

Prytaneion. Rekonstruktion der dorischen Ordnung der Vorhalle (1964) Prytaneion. Rekonstruierte dorische Ordnung der Vorhalle (1968)

Prytaneion. Rekonstruktion der Vorhalle (W. J.)

Prytaneion. Grundriss Bauaufnahme (1:150)

Prytaneion. Generalisierter Grundriss mit Hauptmaßen (1:250)

Vorhof von Süden

Vorhof. Südwand (1:100)

Prytaneion. Südfront $(1: 100)$

Vorhof. Ostwand (1:100)

Stylobatblöcke der Westseite

Stylobatblöcke der Südostecke

Stylobatblöcke der Westseite und der Südostecke (1:50)

Vorhof. Östliche Regenrinne von Norden

Vorhof. Südliche Regenrinne von Osten

Vorhof. Westliche Regenrinne von Süden

Nord-Süd verlaufender Kanal unter östlichem Umgang
Ephesos 1961, Prytaneion, Blatt 15 (W. A.), (C) ÖAI Ephesos 1961, Prytaneion, Blatt 10 (W. A.), (C) ÖAI 1961 246, 5, C ÖAI Ephesos 1961, Prytaneion, Blatt 19 (W. A.), (C) ÖAI Ephesos 1961, Prytaneion, Blatt 18 (W. A.), (C) ÖAI Ephesos 1961, Prytaneion, Blatt 28 (W. J.), (C) ÖAI Ephesos 1961, Prytaneion, Blatt 28A (W. A.), C ÖAI Ephesos 1961, Prytaneion, Blatt 56 (W. A.), C ÖAI 1961256,9 , C ÖAI 1961 256, 7, (C) ÖAI Ephesos 1961, Prytaneion, Blatt 62 (W. J.), C ÖAI 1961 256, 3, (C ÖAI Ephesos 1961, Prytaneion, Blatt 50 (W. A.), (C) ÖAI Ephesos 1961, Prytaneion, Blatt 49 (W. A.), (C) ÖAI Ephesos 1961, Prytaneion, Blatt 54 (W. A.), (C) ÖAI Ephesos 1961, Prytaneion, Blatt 36 (W. J.), (C) ÖAI Ephesos 1961, Prytaneion, Blatt 36A (W. J.), (C) ÖAI 1961 255, 3, C ÖAI Ephesos 1961, Prytaneion, Blatt 48 (W. A.), (C) ÖAI 1961 252, 6, C ÖAI

Ephesos 1961, Prytaneion, Blatt 59 (W. A.), (C) ÖAI 1961 268b, 3, C ÖAI Eichler 1962, Abb. 1. Ephesos 1962, Prytaneion, Blatt 37 (W. A.), C ÖAI Ephesos 1962, Prytaneion, Blatt 37A (W. A.), (C ÖAI 1964 413, 1, (C) ÖAI 1968 627, 2, (C) ÖAI Alzinger 1974, Taf. 34, 65a.

P. M., M. S., J. E., L. Z., (C) ÖAI

L. Z., P. M., M. S., C ÖAI

M. S., (C) ÖAI

P. M., L. Z., (C) ÖAI

P. M., L. Z., (C) ÖAI

P. M., L. Z., (C) ÖAI

M. S., (C) ÖAI

M. S., (C) ÖAI

J. E., L. Z., (C) ÖAI

M. S., (C) ÖAI

M. S., (C) ÖAI

M. S., (C) ÖAI

M. S., C ÖAI 
Taf. 38,1 : Taf. 39, 1-3: Taf. 40, 1-3: Taf. 41, 1. 2: Taf. 42, 1:

Taf. 42, 2-4: Taf. 43,1 :

Taf. 43, 2:

Taf. 44, 1:

Taf. 44, 2:

Taf. 45,1 :

Taf. 45, 2:

Taf. 45, 3:

Taf. 46, 1:

Taf. 46, 2 :

Taf. 46, 3:

Taf. 46, 4:

Taf. 47, 1:

Taf. 47, 2:

Taf. 47, 3 :

Taf. 48, 1:

Taf. 49, 1:

Taf. 50, 1:

Taf. 50, 2:

Taf. 51, 1:

Taf. 52, 1:

Taf. 53, 1:

Taf. 53, 2:

Taf. 53, 3:

Taf. 54, 1:

Taf. 54, 2:

Taf. 54, 3:

Taf. 55, 1:

Taf. 55, 2:

Taf. 56, 1:

Taf. 56, 2:

Taf. 57, 1:

Taf. 57, 2:

Taf. 57, 3:

Taf. 58, 1:

Taf. 58, 2:

Taf. 58, 3:

Taf. 58, 4:

Taf. 59, 1:

Taf. 59, 2:

Taf. 59, 3:

Taf. 60, 1:

Taf. 60, 2:

Taf. 60, 3:

Taf. 60, 4:

Taf. 61, 1:

Taf. 61, 2:

Taf. 61, 3:

Taf. 62, 1:

Taf. 62, 2:

Taf. 62, 3:

Taf. 62, 4:

Taf. 63, 1:

Taf. 63, 2:
Sockel und Aufsatz Ehrenbasis SK 12. 13 (1:25)

Sockel Ehrenbasis SK 12

Aufsatz Ehrenbasis SK 13

Aufsatz Ehrenbasis SK 13

Aufsatz Ehrenbasis SK 14 (1:25)

Aufsatz Ehrenbasis SK 14

Fundament und Bothros im Zentrum des Vorhofes (1:50)

Fundament und Bothros von Süden

Fundament und Bothros von Osten

Detail Bothros

Vorhalle von Westen

Vorhalle von Osten

Vorhalle von Süden

Vorhalle. Stereobat der dorischen Ordnung

Vorhalle. Euthynterieschicht von Westen

Stylobatblock vor der westlichen Antenmauer (1:50)

Stylobatblock vor der westlichen Antenmauer

Vorhalle. Westliche Antenmauer von Osten

Vorhalle. Westliche Antenmauer von Süden

Vorhalle. Westliche Antenmauer von Westen

Vorhalle und Raum 6. Westwände (1:100)

Prytaneion. Westfront (1:125)

Vorhalle. Östliche Antenmauer von Westen

Vorhalle. Östliche Antenmauer von Süden

Vorhalle und >Hestiasaak . Ostwände (1:100)

Vorhalle. Nordwand (1:100)

Vorhalle. Nordwand im Bereich von Tür 1

Vorhalle. Nordwand im Bereich von Tür 2

Vorhalle. Nordwand im Bereich von Tür 3

Vorhalle. Nordwand im Bereich von Tür 4

Vorhalle. Abgemauerte Türen 1 und 2

Vorhalle. Sekundäre Türschwelle in Tür 4

Vorhalle. Kureteninschrift auf Nordwand (IvE 1023)

Vorhalle. Kureteninschrift auf Nordwand (IvE 1024)

Vorhalle. Dorische Ordnung von Süden (1:100)

Vorhalle. Dorische Ordnung von Norden (1:100)

Vorhalle. Dorische Ordnung. Draufsicht (1:50)

Vorhalle. Dorische Ordnung. Schnitt durch Gebälk nach Westen (1:50)

Vorhalle. Dorische Ordnung. Säulen A 3. A 4 (1:100)

Vorhalle. Dorische Ordnung. Säulen A 1. A 2 (1:100)

Vorhalle. Oberlager der Säule A 2 (1:50)

Vorhalle. Dorisches Gebälk von Süden

Vorhalle. Dorisches Gebälk von Norden

Vorhalle. Dorisches Gebälk von Osten

Vorhalle. Dorisches Gebälk von Westen

Vorhalle. Dorisches Gebälk. Draufsicht

Vorhalle. Horizontalgeison A 10 (1:50)

Vorhalle. Horizontalgeison A 10

Im Prytaneion deponiertes Horizontalgeison A 11 (1:50)

Im Prytaneion deponiertes Horizontalgeison A 11

Vorhalle. Kapitell A 6

Vorhalle. Kapitell A 5

Vorhalle. Dorische Ordnung mit Lage der Inschriften (1:100)

Vorhalle. Detail Inschriften auf Säule A 3 (IvE 1012. 1020. 1021.

1036. 1040. 1042)

Vorhalle. Säule A 3 Trommel C. Einarbeitung für profilierte Brüstung (1:10) P. M., L. Z., C ÖAI

Vorhalle. Säule A 3 Trommel C. Einarbeitung für profilierte Brüstung

Vorhalle. Säule A 4 Trommel C. Einarbeitung für profilierte Brüstung

Vorhalle. Marmorblock/-platte sowie Sockel der Ehrenbasis SK 15

westlich von Tür 3

Vorhalle. Sockel Ehrenbasis SK 15
B. S., L. Z., (C) ÖAI

M. S., (C) ÖAI

M. S., (C) ÖAI

M. S., (C) ÖAI

N. H., L. Z., C ÖAI

M. S., (C) ÖAI

J. E., L. Z., (C) ÖAI

M. S., (C) ÖAI

M. S., (C) ÖAI

M. S., (C) ÖAI

M. S., (C) ÖAI

M. S., (C) ÖAI

M. S., (C) ÖAI

M. S., (C) ÖAI

M. S., (C) ÖAI

J. E., L. Z., (C) ÖAI

M. S., (C) ÖAI

M. S., (C) ÖAI

M. S., (C) ÖAI

M. S., (C) ÖAI

P. M., L. Z., (C) ÖAI

P. M., L. Z., (C) ÖAI

M. S., (C) ÖAI

M. S., (C) ÖAI

P. M., L. Z., (C) ÖAI

M. S., (C) ÖAI

M. S., (C) ÖAI

M. S., (C) ÖAI

M. S., (C) ÖAI

Pl. 494, (C) ÖAI

19563,18 , (C) ÖAI

M. S., (C) ÖAI

M. S., C ÖAI

P. M., L. Z., (C) ÖAI

P. M., L. Z., (C) ÖAI

P. M., L. Z., (C) ÖAI

P. M., L. Z., (C) ÖAI

P. M., L. Z., (C) ÖAI

N. H., L. Z., (C) ÖAI

M. S., (C) ÖAI

M. S., (C) ÖAI

M. S., (C) ÖAI

N. H., L. Z., (C) ÖAI

M. S., (C) ÖAI

N. H., L. Z., (C) ÖAI

M. S., (C) ÖAI

M. S., (C) ÖAI

M. S., (C) ÖAI

P. M., L. Z., (C) ÖAI

M. S., (C) ÖAI

M. S., (C) ÖAI

M. S., (C) ÖAI

M. S., (C) ÖAI

M. S., (C) ÖAI
P. M., L. Z., (C) ÖAI

P. M., L. Z., (C) ÖAI

M. S., (C) ÖAI

M. S., (C) ÖAI 
Taf. 63, 3:

Taf. 63, 4:

Taf. 63, 5:

Taf. 64, 1:

Taf. 64,2 :

Taf. 65, 1:

Taf. 65, 2:

Taf. 66, 1:

Taf. 66, 2:

Taf. 67, 1:

Taf. 67, 2:

Taf. 68, 1:

Taf. 68, 2:

Taf. 69,1 :

Taf. 69, 2:

Taf. 69, 3:

Taf. 69, 4:

Taf. 69, 5:

Taf. 69, 6:

Taf. 70, 1:

Taf. 70, 2:

Taf. 70, 3:

Taf. 70, 4:

Taf. 71, 1:

Taf. 71, 2:

Taf. 72,1 :

Taf. 72, 2:

Taf. 72, 3:

Taf. 73,1 :

Taf. 73, 2:

Taf. 74,1 :

Taf. 74,2 :

Taf. 75, 1:

Taf. 76,1 :

Taf. 76, 2:

Taf. 77, 1:

Taf. 78, 1:

Taf. 79, 1:

Taf. 80, 1:

Taf. 81, 1:

Taf. 82, 1:

Taf. 83, 1:

Taf. 84, 1:

Taf. 85,1 :

Taf. 86, 1:

Taf. 86, 2:

Taf. 87, 1:

Taf. 87, 2:

Taf. 88, 1:

Taf. 88, 2:

Taf. 89,1 :

Taf. 90,1 :

Taf. 90, 2:

Taf. 91, 1:

Taf. 91, 2:

Taf. 91, 3:
Vorhalle. Sockel Ehrenbasis SK 15 (1:25)

Vorhalle. Marmorplatten östlich von Tür 3

Vorhalle. Marmorspolie mit rinnenförmiger Vertiefung

Vorhalle. Mosaik. Westseite

Vorhalle. Mosaik. Detail Westseite

Vorhalle. Mosaik. Ostseite

>Hestiasaal< von Norden

$>$ Hestiasaal<. Westwand

$>$ Hestiasaak. Nord-Süd-Schnitt nach Westen (1:100)

>Hestiasaal<. Fotogrammetrische Aufnahme der Westwand

>Hestiasaal . Westwand (1:100)

>Hestiasaal<. Südwand

>Hestiasaal<. Südwand (1:100)

>Hestiasaal<. Marmornes Türgewände von Tür 2

>Hestiasaal<. Türsturz A 30 in Laibung von Tür 2 verbaut

>Hestiasaalく. Türsturz A 30 in Laibung von Tür 2 verbaut (1:50)

>Hestiasaal<. Türsturz A 30 (1:25)

>Hestiasaal<. Türsturz A 31 (1:25)

>Hestiasaak. Türsturz A 31 nach Bergung

>Hestiasaal<. Westliche Türlaibung von Tür 4

>Hestiasaak. Westliche Türlaibung von Tür 4 (1:50)

>Hestiasaal<. Westliche und östliche Türlaibung von Tür 3

>Hestiasaal<. Westliche und östliche Türlaibung von Tür 3 (1:50)

>Hestiasaak. Ostwand

>Hestiasaalk. Nord-Süd-Schnitt nach Osten (1:100)

$>$ Hestiasaal . Nordostecke. Detail Gesims sowie Rest der Marmorverkleidung

`Hestiasaal<. Fragmente des Gesimses A 26 (1:25)

>Hestiasaalk. Fragmente des Gesimses A 26

$>$ Hestiasaal<. Nordwand

>Hestiasaal<. Nordwand $(1: 100)$

`Hestiasaak. Nordwand. Keilsteinbogen Innenansicht

>Hestiasaak. Nordwand. Keilsteinbogen Draufsicht

>Hestiasaak. Südwestlicher Säulenstuhl mit Basis A 12. 13

>Hestiasaalく. Südwestlicher Säulenstuhl mit Basis A 12. 13

>Hestiasaal . Südwestlicher Säulenstuhl mit Basis A 12.13 (1:50)

`Hestiasaak. Südöstlicher Säulenstuhl mit Eck-Doppelhalbsäulen A 14-16

>Hestiasaal`. Südöstlicher Säulenstuhl mit Eck-Doppelhalbsäulen

A $14-16(1: 50)$

>Hestiasaak. Nordöstlicher Säulenstuhl mit Eck-Doppelhalbsäulen A 17-20 M. S., (C ÖAI

>Hestiasaalく. Nordöstlicher Säulenstuhl mit Eck-Doppelhalbsäulen A 17-20 J. E., P. M., L. Z., C ÖAI $(1: 50)$

>Hestiasaak. Detail Kompositkapitell A 20

>Hestiasaal<. Nordwestlicher Säulenstuhl mit Eck-Doppelhalbsäulen

A 21-24

>Hestiasaak. Nordwestlicher Säulenstuhl mit Eck-Doppelhalbsäulen A $21-24(1: 50)$

>Hestiasaal<. Detail Kompositkapitell A 24

>Hestiasaak. Detail Kompositkapitell A 24

>Hestiasaal«. Originale attische Basis A 47

>Hestiasaal<. Originale attische Basis A 47 (1:25)

>Hestiasaal<. Kompositkapitell A 25

>Hestiasaal<. Kompositkapitell A 25 (1:25)

>Hestiasaal<. Werkriss auf südwestlichem Säulenstuhl A 12 (Volute 1)

>Hestiasaalく. Werkriss auf südwestlichem Säulenstuhl A 12 (Volute 2)

>Hestiasaal . Werkriss auf südwestlichem Säulenstuhl A 12 (1:4)

`Hestiasaal<. Zentrales Fundament für Anrichte

`Hestiasaal . Zentrales Fundament für Anrichte. Freigelegte Westseite mit Versatzmarken zur Verlegung der Blöcke

>Hestiasaal . Unterkonstruktion für Sitzbänke an der Ostseite von Norden

>Hestiasaal<. Unterkonstruktion für Sitzbänke an der Westseite von Süden

>Hestiasaal Unterkonstruktion für Sitzbänke an der Westseite von Norden
B. S., L. Z., (C) ÖAI

M. S., C ÖAI

M. S., (C) ÖAI

M. S., (C) ÖAI

M. S., C ÖAI

M. S., (C) ÖAI

M. S., (C) ÖAI

M. S., (C) ÖAI

P. M., J. E., L. Z., (C) ÖAI

C. K.

P. M., L. Z., (C) ÖAI

M. S., C ÖAI

P. M., L. Z., (C) ÖAI

M. S., (C) ÖAI

M. S., C ÖAI

J. E., L. Z., C ÖAI

B. S., L. Z., (C) ÖAI

B. S., L. Z., (C) ÖAI

M. S., (C) ÖAI

M. S., (C) ÖAI

J. E., L. Z., (C) ÖAI

M. S., (C) ÖAI

J. E., L. Z., (C) ÖAI

M. S., (C) ÖAI

P. M., J. E., L. Z., (C) ÖAI

M. S., ( ) ÖAI

M. S., (C) ÖAI

P. M., L. Z., (C) ÖAI

M. S., (C) ÖAI

M. S., (C) ÖAI

M. S., (C) ÖAI

M. S., (C) ÖAI

J. E., L. Z., (C) ÖAI

M. S., (C) ÖAI

J. E., L. Z., (C) ÖAI

M. S., (C) ÖAI

M. S., (C) ÖAI

J. E., P. M., L. Z., (C) ÖAI

M. S., (C) ÖAI

M. S., C ÖAI

M. S., (C) ÖAI

P. M., L. Z., (C) ÖAI

M. S., (C) ÖAI

N. H., L. Z., (C) ÖAI

N. G., (C) ÖAI

N. G., (C) ÖAI

N. H., M. S., L. Z., (C) ÖAI

M. S., (C) ÖAI

M. S., (C) ÖAI

M. S., (C) ÖAI

M. S., (C) ÖAI

M. S., (C) ÖAI 
Taf. 92, 1:

Taf. 92, 2:

Taf. 93, 1:

Taf. 93, 2:

Taf. 94, 1:

Taf. 94, 2:

Taf. 95, 1:

Taf. 96, 1:

Taf. 97, 1:

Taf. 97, 2 :

Taf. 98, 1:

Taf. 98, 2:

Taf. 99, 1:

Taf. 99, 2:

Taf. 100,1 :

Taf. 100, 2:

Taf. 101, 1:

Taf. 101, 2:

Taf. 102, 1:

Taf. 102, 2:

Taf. 103, 1:

Taf. 103, 2:

Taf. 104, 1:

Taf. 104, 2:

Taf. 105, 1:

Taf. 106, 1:

Taf. 106, 2:

Taf. 107, 1:

Taf. 107, 2:

Taf. 108, 1:

Taf. 109, 1:

Taf. 110, 1:

Taf. 110, 2:

Taf. 111, 1:

Taf. 112, 1:

Taf. 112, 2:

Taf. 113, 1:

Taf. 113, 2:

Taf. 114, 1:

Taf. 114, 2:

Taf. 114, 3:

Taf. 115,1 :

Taf. 115, 2:

Taf. 115, 3:

Taf. 116, 1:

Taf. 116, 2:

Taf. 117, 1:

Taf. 117, 2:

Taf. 118, 1:

Taf. 119,1 :

Taf. 120, 1:

Taf. 120, 2:

Taf. 120, 3:

Taf. 121, 1:

Taf. 121, 2:

Taf. 122, 1:

Taf. 122, 2:

Taf. 123, 1:

Taf. 124, 1:

Taf. 124, 2:

Taf. 125, 1:
Raum 6 von Norden

Raum 6. Südwand (1:50)

M. S., (C) ÖAI

Raum 6/Vorhalle. Tür 1. Westliche Türlaibung und östliche Zusetzung (1:50) J. E., L. Z., (C) ÖAI

Raum 6. Nordwand. Detail Wandmalerei

Raum 6. Ostwand

Raum 6. Westwand

Raum 6. Ostwand (1:50)

Raum 6. Westwand (1:50)

Raum 6. Nordwand

Raum 6. Nordwand (1:50)

Raum 6/Raum 5. Tür von Norden

Raum 6/Raum 5. Westliche und östliche Türlaibung (1:50)

Raum 6. Säulentrommel A 29

Raum 6. Säulentrommel A 29 (1:25)

Raum 6. Rampenartige Treppe an der Südwand

Raum 6. Marmorbasis vor der Ostwand

Raum 6. An die Nordwand angesetzte sekundäre Mauer

Raum 6. Detail der an die Nordwand angesetzten sekundären Mauer

Raum 5 von Süden

Raum 5 von Norden

Raum 5. Südwand

Raum 5. Südwand (1:50)

Raum 5. Westwand

Raum 5/>Akademiegasseく. Marmorschwelle der sekundären Tür

Raum 5. Westwand (1:50)

Raum 5. An die Nordwand angesetzte sekundäre Mauer

Raum 5. Detail der an die Nordwand angesetzten sekundären Mauer

Raum 5. Ostwand

Raum 5. Nordwand

Raum 5. Ostwand (1:50)

Raum 5. Nordwand (1:50)

Raum 5. Sekundäre Nord-Süd-Mauer von Westen

Raum 5. Sekundäre Nord-Süd-Mauer von Osten

Raum 5. Sekundäre Nord-Süd-Mauer (1:50)

Raum 5. Sekundäre Nord-Süd-Mauer vor Sicherung

Raum 5. Gewölbe vor Absturz der Ostwand

Raum 5. Sekundäre Mauer zwischen Säule und Westwand

Raum 5. Säule A 27. 28 (1:50)

Kanal nördlich der Räume 5, 4, 3, 2

Bauwich nördlich der Räume 5, 4, 3, 2

Kanal nördlich der Räume 5, 4, 3, 2. Schnitt nach Osten (1:50)

Raum 4 von Norden

Raum 4. Nordwand

Raum 4. Nordwand (1:50)

Raum 4. Südwand

Raum 4. Südwand (1:50)

Raum 4. Westwand

Raum 4. Westwand (1:50)

Raum 4. Pfeiler der Ostwand

Raum 4. Pfeiler der Ostwand (1:50)

Raum 3 von Osten

Raum 3. Südwand

Raum 3. Südwand (1:50)

Raum 3. Pfeiler der Westwand

Raum 3. Pfeiler der Westwand (1:50)

Raum 3. Nordwand oberer Teil

Raum 3. Nordwand unterer Teil

Raum 3. Nordwand (1:50)

Raum 3. Ostwand

Raum 3. Ostwand (1:50)

Raum 3. Ausfluss des Wasserreservoirs
M. S., (C) ÖAI

M. S., (C) ÖAI

M. S., (C) ÖAI

P. M., L. Z., (C) ÖAI

P. M., L. Z., (C) ÖAI

M. S., C ÖAI

P. M., L. Z., (C) ÖAI

M. S., (C) ÖAI

J. E., L. Z., (C) ÖAI

M. S., (C) ÖAI

N. H., L. Z., (C) ÖAI

1961 252, 8, (C) ÖAI

1961251,11 , C ÖAI

1961 251, 5, (C) ÖAI

1961 254, 1, C ÖAI

M. S., (C) ÖAI

M. S., (C) ÖAI

M. S., C ÖAI

P. M., L. Z., (C) ÖAI

M. S., (C) ÖAI

M. S., (C) ÖAI

P. M., L. Z., (C) ÖAI

Pl. 561, (C) ÖAI

Pl. 576, (C) ÖAI

M. S., (C) ÖAI

M. S., (C) ÖAI

P. M., L. Z., (C) ÖAI

P. M., L. Z., (C) ÖAI

M. S., (C) ÖAI

M. S., (C) ÖAI

P. M., L. Z., (C) ÖAI

1961 252, 12, (C) ÖAI

Pl. 533, (C) ÖAI

Pl. 602, (C) ÖAI

N. H., L. Z., (C) ÖAI

M. S., (C) ÖAI

M. S., (C) ÖAI

N. H., L. Z., (C) ÖAI

M. S., (C) ÖAI

M. S., (C) ÖAI

P. M., L. Z., (C) ÖAI

M. S., (C) ÖAI

P. M., L. Z., (C) ÖAI

M. S., (C) ÖAI

P. M., L. Z., (C) ÖAI

M. S., (C) ÖAI

P. M., L. Z., (C) ÖAI

M. S., (C) ÖAI

M. S., (C) ÖAI

P. M., L. Z., (C) ÖAI

M. S., (C) ÖAI

P. M., L. Z., (C) ÖAI

M. S., (C) ÖAI

M. S., (C) ÖAI

P. M., L. Z., (C) ÖAI

M. S., (C) ÖAI

P. M., L. Z., (C) ÖAI

M. S., (C) ÖAI 
Taf. 125, 2: Taf. 125, 3: Taf. 126, 1: Taf. 126, 2: Taf. 127, 1: Taf. 127, 2: Taf. 128,1 : Taf. 128, 2: Taf. 129, 1: Taf. 129, 2: Taf. 130, 1: Taf. 130, 2: Taf. 131, 1: Taf. 131, 2: Taf. 131, 3: Taf. 131, 4: Taf. 131, 5: Taf. 131, 6: Taf. 132, 1: Taf. 132, 2: Taf. 132, 3: Taf. 132, 4: Taf. 132, 5: Taf. 132, 6: Taf. 133, 1: Taf. 133, 2: Taf. 133, 3: Taf. 133, 4: Taf. 133, 5: Taf. 133, 6: Taf. 134, 1: Taf. 134, 2: Taf. 134, 3: Taf. 134, 4: Taf. 134, 5: Taf. 134, 6: Taf. 135, 1: Taf. 135, 2: Taf. 135, 3: Taf. 135, 4: Taf. 136, 1: Taf. 136, 2: Taf. 136, 3: Taf. 136, 4:

Kapitel IV Taf. 137, 1: Taf. 138, 1: Taf. 138, 2: Taf. 139, 1: Taf. 139, 2: Taf. 139, 3: Taf. 140, 1: Taf. 140, 2: Taf. 141, 1: Taf. 141, 2: Taf. 141, 3: Taf. 142, 1: Taf. 142, 2: Taf. 142, 3: Taf. 143, 1:
>Hestiasaal<. Sekundäre Öffnung in Nordwand zur Wasserentnahme

Raum 2 von Westen

Raum 2. Südwand

Raum 2. Südwand (1:50)

Raum 2. Westwand

Raum 2. Westwand (1:50)

Raum 2. Nordwand oberer Teil

Raum 2. Nordwand (1:50)

Raum 2. Ostwand

Raum 2. Ostwand (1:50)

Raum 2. Ziegelbogen in Sturzlage

Raum 2. Ende der 1960er Jahre bereits weitgehend zerstörter Ziegelbogen Attische Basis A 32

Attische Basis A 32 (1:25)

Attische Basis A 33

Attische Basis A 33 (1:25)

Attische Basis A 34

Attische Basis A 34 (1:25)

Attische Basis A 35

Attische Basis A 35 (1:25)

Attische Basis einer Dreiviertelsäule A 36

Attische Basis einer Dreiviertelsäule A 36 (1:25)

Rundbasis A 37

Rundbasis A 37 (1:25)

Pfeiler-/Pilasterbasis A 38

Pfeiler-/Pilasterbasis A 38 (1:25)

Pfeiler-/Pilasterbasis A 39

Pfeiler-/Pilasterbasis A 39 (1:25)

Pfeiler A 40

Pfeiler A 40 (1:25)

Zahnschnittgeison mit Sima A 41

Zahnschnittgeison mit Sima A 41 (1:25)

Dorisches Kapitell A 42

Dorisches Kapitell A 42 (1:25)

Tuskanisches Kapitell A 43

Tuskanisches Kapitell A 43 (1:25)

Korinthisches Kapitell A 44

Korinthisches Kapitell A 44 (1:25)

Pilasterkapitell A 45

Pilasterkapitell A 45 (1:25)

Kämpfer A 46

Kämpfer A 46 (1:25)

Sockel Ehrenbasis? SK 16

Sockel Ehrenbasis? SK 16 (1:25)
M. S., (C) ÖAI

M. S., (C) ÖAI

M. S., (C) ÖAI

P. M., L. Z., (C) ÖAI

M. S., (C) ÖAI

P. M., L. Z., (C) ÖAI

M. S., (C) ÖAI

P. M., L. Z., C ÖAI

M. S., (C) ÖAI

P. M., L. Z., (C) ÖAI

Pl. 529, (C) ÖAI

1967 573, 27, C ÖAI

M. S., (C) ÖAI

B. S., L. Z., (C) ÖAI

M. S., (C) ÖAI

B. S., L. Z., (C) ÖAI

M. S., (C) ÖAI

B. S., L. Z., (C) ÖAI

M. S., (C) ÖAI

B. S., L. Z., (C) ÖAI

M. S., C ÖAI

B. S., L. Z., (C) ÖAI

M. S., (C) ÖAI

B. S., L. Z., (C) ÖAI

M. S., (C) ÖAI

N. H., L. Z., (C) ÖAI

M. S., (C) ÖAI

B. S., L. Z., (C) ÖAI

M. S., (C) ÖAI

B. S., L. Z., (C) ÖAI

M. S., (C) ÖAI

B. S., L. Z., (C) ÖAI

M. S., (C) ÖAI

N. H., L. Z., C ÖAI

M. S., (C) ÖAI

B. S., L. Z., ( $\bigcirc$ ÖAI

M. S., (C) ÖAI

N. H., L. Z., (C) ÖAI

M. S., (C) ÖAI

B. S., L. Z., (C) ÖAI

M. S., (C) ÖAI

B. S., L. Z., (C) ÖAI

M. S., (C) ÖAI

B. S., L. Z., (C) ÖAI

Prytaneion. Generalisierter Grundriss mit Sondagenplan 2007-2008 (1:250)

Schnitt 1/07. Ausgangssituation von Süden

Schnitt 1/07. Endsituation von Süden

Schnitt 1/07. Endsituation von Westen

Schnitt 1/07. Westprofil

Schnitt 1/07. Nordprofil

Schnitt 1/07. Westprofil (1:50)

Schnitt 1/07. Nordprofil (1:50)

Schnitt 2/07. Ausgangssituation von Süden

Schnitt 2/07. Kanal SE 204

Schnitt 2/07. Endsituation von Süden

Schnitt 2/07. Südprofil

Schnitt 2/07. Ostprofil

Schnitt 2/07. Nordprofil

Schnitt 2/07. Südprofil (1:50) 
Taf. 143, 2: Taf. 144, 1: Taf. 144, 2:

Taf. 145,1 : Taf. 145, 2: Taf. 146, 1: Taf. 146, 2: Taf. 147, 1: Taf. 147, 2:

Taf. 147, 3: Taf. 148, 1: Taf. 148, 2: Taf. 148, 3: Taf. 149, 1: Taf. 149, 2: Taf. 149, 3: Taf. 150, 1: Taf. 150, 2: Taf. 151, 1: Taf. 151, 2: Taf. 152, 1: Taf. 153, 1: Taf. 153, 2: Taf. 154, 1: Taf. 155, 1: Taf. 155, 2: Taf. 156, 1: Taf. 156, 2: Taf. 157, 1: Taf. 157, 2: Taf. 158, 1: Taf. 158, 2:

Kapitel V Taf. 159, 1:

Taf. 160, 1:

Taf. 161, 1:

Kapitel VI

Taf. 162:

Taf. 163:

Taf. 164:

Taf. 165:

Taf. 166:

Taf. 167:

Taf. 168:

Taf. 169:

Taf. 170:

Taf. 171:

Taf. 172:

Taf. 173:

Taf. 174:

Taf. 175:

Taf. 176:

Taf. 177:

Taf. 178:
Schnitt 2/07. Nordprofil (1:50)

Schnitt 3/07. Ausgangssituation von Süden

A. H., L. Z., C ÖAI

$\begin{array}{ll}\text { Schnitt 3/07. Ausgangssituation von Süden } & \text { M. S., (C) ÖAI } \\ \text { Schnitt 3/07. Fundament und Estrich (SE 303, SE 304) des Marmorplatten- } & \text { M. S., (C) ÖAI }\end{array}$ bodens

Schnitt 3/07. Endsituation von Süden

Schnitt 3/07. Planum Endzustand (1:50)

Schnitt 3/07. Ostprofil

Schnitt 3/07. Ostprofil (1:50)

Schnitt 4/07. Ausgangssituation von Osten

Schnitt 4/07. Fundament und Estrich (SE 402 bodens

Schnitt 4/07. Kalkgrube SE 407

Schnitt 4/07. Endsituation von Osten

Schnitt 4/07. Ostprofil

Schnitt 4/07. Südprofil

Schnitt 4/07. Nordprofil (1:20)

Schnitt 4/07. Ostprofil $(1: 20)$

Schnitt 4/07. Südprofil (1:20)

Schnitt 5/07. Ausgangssituation von Westen

Schnitt 5/07. Endsituation von Westen

Schnitt 5/07. Endsituation von Süden

Schnitt 5/07. Nordprofil

Schnitt 5/07. Süd- und Nordprofil (1:20)

Schnitt 1/08. Ausgangssituation von Westen

Schnitt 1/08. Endsituation von Westen

Schnitt 1/08. Planum Endzustand (1:50)

Schnitt 1/08. Nordprofil

Schnitt 1/08. Nordprofil (1:20)

Schnitt 1/08. Ostprofil

Schnitt 1/08. Ostprofil (1:20)

Schnitt 1/08. Westprofil

Schnitt 1/08. Westprofil $(1: 20)$

Sekundäres Wasserreservoir in Raum 7 östlich des Prytaneions

Sekundäre Wasserentnahmestelle östlich von Raum 7

M. S., (C) ÖAI

B. S., L. Z., (C) ÖAI

M. S., (C) ÖAI

B. S., L. Z., C ÖAI

M. S., C ÖAI

M. S., (C) ÖAI

M. S., (C) ÖAI

M. S., (C) ÖAI

M. S., (C) ÖAI

M. S., (C) ÖAI

B. S., L. Z., (C) ÖAI

B. S., L. Z., (C) ÖAI

B. S., L. Z., (C) ÖAI

M. S., (C) ÖAI

M. S., (C) ÖAI

M. S., (C) ÖAI

M. S., (C) ÖAI

B. S., L. Z., (C) ÖAI

M. S., (C) ÖAI

M. S., (C) ÖAI

B. S., L. Z., (C) ÖAI

M. S., (C) ÖAI

B. S., L. Z., (C) ÖAI

M. S., (C) ÖAI

B. S., L. Z., (C) ÖAI

M. S., (C) ÖAI

B. S., L. Z., (C) ÖAI

M. S., (C) ÖAI

M. S., (C) ÖAI

L. Z., M. S., P. M., (C) ÖAI

L. Z., M. S., P. M., C ÖAI

L. Z., M. S., P. M., (C ÖAI

N. H., N. M., (C) ÖAI

N. H., N. M., (C) ÖAI

N. H., N. M., (C) ÖAI

N. H., N. M., (C) ÖAI

N. H., N. M., (C) ÖAI

N. H., N. M., (C) ÖAI

N. H., N. M., () ÖAI

N. H., N. M., C ÖAI

N. H., N. M., (C) ÖAI

N. H., N. M., (C) ÖAI

N. H., N. M., C ÖAI

N. H., N. M., (C) ÖAI

N. H., N. M., (C) ÖAI

N. H., N. M., (C) ÖAI

N. H., N. M., (C) ÖAI

N. H., N. M., (C) ÖAI

N. H., N. M., (C) ÖAI 
Taf. 179:

Taf. 180:

Taf. 181:

Taf. 182:

Taf. 183:

Taf. 184:

Taf. 185:

Taf. 186:

Taf. 187:

Taf. 188:

Taf. 189:

Taf. 190:

Taf. 191:

Taf. 192:

Taf. 193:

Taf. 194:

Taf. 195:

Taf. 196:

Taf. 197:

Taf. 198:

Taf. 199:

Taf. 200:

Taf. 201:

Taf. 202:

Taf. 203:

Taf. 204:

Taf. 205:

Taf. 206:

Taf. 207:

Taf. 208:

Taf. 209:

Taf. 210:

Taf. 211:

Taf. 212:

Taf. 213:

Taf. 214:

Taf. 215:

Taf. 216:

Taf. 217:

Taf. 218:

Taf. 219:

Taf. 220:

Taf. 221:

Taf. 222:

Taf. 223:

Taf. 224:

Taf. 225:

Kapitel VII

Taf. 226, 1:

Taf. 226, 2:

Taf. 227, 1:

Taf. 227, 2:

Taf. 228, 1-3:

Taf. 229, 1:

Taf. 229, 2:

Taf. 229, 3:

Taf. 230, 1. 2:

Taf. 231, 1:

Taf. 231, 2:

Taf. 231, 3:
K 261-275

K 276-282. 285-294

K 295-301. 304-310. 313-318

K 319-335

K 336-356

K 357-372

K 373-390

K 391-402

K 403-414

K 415-428

K 429-438

K 439-448

K 449-458

K 459-466. 468-472

K 473-483

K 484-497

K 498-510

K 511-520

K 521-528

K 529-536

K 537-545

K 546-557

K 558-571

K $572-589$

K 590-603

K 604-617

K 618-622. 624-626

K 627-637

K 638. 640-658

K 659-673

K 674-686

K 687-697

K 698-704. 706-708. 712-714

K 715-730

K 731-740

K 741-752

K 753-766

K 767-779

K 781-786. 788-794

K 4. 36. 37. 60. 89. 116. 120.121. 132. 134. 139-143

K 144-150. 158. 162. 164-166. 173

K 214. 226. 279-286

K 287. 288. 291. 302. 303. 311. 312

K 321. 355. 428. 462. 467. 488. 529

K 616-622

K 638.639.641. 647.649.652.674.705.708-711

K 751. 787-789. 792

$>$ Neronische Halle $<$. Blick von Norden

$>$ Neronische Halle . Sockelzone an der >Marmorstraße

`Neronische Halleく. Polsterquader der Sockelzone: Saum an den Stoßflächen >Neronische Halleく. Stylobat mit Risslinien zur Markierung der Säulenachse `Neronische Halle‘. Dorische Kapitelle

$>$ Neronische Halle $<$. Eckarchitrav

$>$ Neronische Halleく. Architrav: Soffitte

$>$ Neronische Halle`. Architrav: Rückseite

N. H., N. M., (C) ÖAI

N. H., N. M., (C) ÖAI

N. H., N. M., (C) ÖAI

N. H., N. M., (C) ÖAI

N. H., N. M., (C) ÖAI

N. H., N. M., (C) ÖAI

N. H., N. M., (C) ÖAI

N. H., N. M., (C) ÖAI

N. H., N. M., (C) ÖAI

N. H., N. M., (C) ÖAI

N. H., N. M., (C) ÖAI

N. H., N. M., (C) ÖAI

N. H., N. M., (C) ÖAI

N. H., N. M., (C) ÖAI

N. H., N. M., (C) ÖAI

N. H., N. M., (C) ÖAI

N. H., N. M., (C) ÖAI

N. H., N. M., (C) ÖAI

N. H., N. M., (C) ÖAI

N. H., N. M., (C) ÖAI

N. H., N. M., C ÖAI

N. H., N. M., (C) ÖAI

N. H., N. M., (C) ÖAI

N. H., N. M., (C) ÖAI

N. H., N. M., (C) ÖAI

N. H., N. M., (c) ÖAI

N. H., N. M., (C) ÖAI

N. H., N. M., (C) ÖAI

N. H., N. M., (C) ÖAI

N. H., N. M., (C) ÖAI

N. H., N. M., (C) ÖAI

N. H., N. M., (C) ÖAI

N. H., N. M., (C) ÖAI

N. H., N. M., (C) ÖAI

N. H., N. M., (C) ÖAI

N. H., N. M., (C) ÖAI

N. H., N. M., (C) ÖAI

N. H., N. M., (C) ÖAI

N. H., N. M., (C) ÖAI

N. G., (C) ÖAI

N. G., (C) ÖAI

N. G., (C) ÖAI

N. G., (C) ÖAI

N. G., (C) ÖAI

N. G., (C) ÖAI

N. G., (C) ÖAI

N. G., (C) ÖAI

G. P.

G. P.

G. P.

G. P.

G. P.

G. P.

G. P.

G. P.

G. P.

G. P.

G. P.

G. P.
>Neronische Halle<. Geison

`Neronische Halle`. Geison: Wasserrinne an der Oberseite

>Neronische Halleく. Geison: vertikaler Gusskanal an der Stoßfuge
G. P. 
Taf. 232, 1: Taf. 232, 2:

Taf. 233, 1:

Taf. 233, 2:

Taf. 234, 1:

Taf. 235, 1 :

Taf. 235, 2:

Taf. 235, 3:

Taf. 236, 1 :

Taf. 236, 2:

Taf. 237, 1. 2:

Taf. 238, 1:

Taf. 238, 2:

Taf. 238, 3:

Taf. 239, 1:

Taf. 239, 2:

Taf. 239, 3:

Taf. 240, 1:

Taf. 240, 2:

Taf. 240, 3:

Taf. 240, 4:

Kapitel IX

Taf. 241, 1:

Taf. 241, 2:

Taf. 242, 1:

Taf. 242, 2:

Taf. 243, 1:

Taf. 243, 2:

Taf. 243, 3:

Taf. 244, 1:

Taf. 244, 2:

Taf. 244, 3:

Taf. 245, 1:

Taf. 245, 2:

Taf. 246, 1:

Taf. 246, 2:

Taf. 247, 1:

Taf. 247, 2:

Taf. 247, 3:

Taf. 248, 1:

Taf. 248, 2:

Taf. 248, 3:

Schnitte

Taf. 249, 1:
`Neronische Halleく. Geison: Südostecke mit Ansatz des Schräggeisons

$>$ Neronische Halleく. Eckgeison von der Nordseite

$>$ Neronische Halle<. Zugang an der östlichen Langseite

>Neronische Halle<. Dorisches >Antenkapitell am Zugang in der

östlichen Langseite

Domitiansterrasse. Architekturprobe der Fassade

Domitiansterrasse. Dorisierende Kapitelle vom Untergeschoss der Fassade

Domitiansterrasse. Dorisches Gebälk des Untergeschosses der Fassade

Domitiansterrasse. Sockelzone des mittleren Fassadengeschosses

Vediusgymnasium. Pfeilerkapitell aus dem $>$ Marmorsaak

Ostgymnasium. Pfeilerkapitell aus dem >Marmorsaal

〉Südliches Hafentor<. Pfeilerkapitell

Tetragonos Agora. Architrav

Basilike Stoa auf dem >Staatsmarkt $<$. Halbsäulen-Pfeilerkapitell

vom Obergeschoss

Domitiansplatz. Kapitell

Männlicher Porträtkopf SK 5

Porträt einer jungen Frau SK 6

Porträt einer Frau SK 7

Männliche Porträtbüste SK 8

Männliche, hermenförmige Büste SK 9

Linker Unterarm einer männlichen Kolossalstatue SK 11

Torso einer männlichen Ehrenstatue SK 10

Bouleuterion von Aigai

Übersichtsplan der Agora von Herakleia am Latmos

Nördliche Stoa der Agora von Kolophon

Übersichtsplan der Agora von Magnesia am Mäander

Stadtplan von Milet

Sog. Prytaneion von Milet in der Südwestecke des Nordmarktes von Süden Delphinion von Milet

Bau H von Pergamon

Bau $\mathrm{H}$ von Pergamon von Westen

Bau $\mathrm{H}$ von Pergamon von Nordosten

Grundriss des Prytaneions von Priene

Prytaneion von Priene von Nordwesten

Prytaneion von Priene von Osten

Prytaneion von Priene. Ehreninschrift für M. Aurelius Tatianus

Prytaneion von Delos von Süden

Prytaneion von Lato auf Kreta von Südwesten

Aufgang zum Prytaneion von Lato von Süden

Prytaneion von Dodona von Nordwesten

Grundriss des Prytaneions von Kassope

Tholos der Athener Agora von Südosten

Prytaneion. Übersicht Schnitte durch Bauaufnahme (1:250)
G. P.

G. P.

G. P.

G. P.

G. P.

G. P.

G. P.

G. P.

G. P.

G. P.

G. P.

G. P.

G. P.

G. P.

N. G., (C) ÖAI

N. G., (C) ÖAI

N. G., (C) ÖAI

N. G., (C) ÖAI

N. G., (C) ÖAI

(c) ÖAI

N. G., (C) ÖAI

M. S.

K. Wulzinger, Das Rathaus von Herakleia am Latmos, in: F. Krischen, Antike Rathäuser (Berlin 1941) Taf. 26.

Holland 1944, Abb. 10.

Humann 1904, Blatt 3.

Herda 2005, Abb. 1 (nach

B. F. Weber, Ausschnitt).

M. S.

M. S.

W. Dörpfeld, Die Arbeiten zu Pergamon 1908-1909, AM 35, 1910, Taf. 15 (Ausschnitt).

M. S.

M. S.

Th. Wiegand - H. Schrader, Priene. Ergebnisse der Ausgra bungen und Untersuchungen in den Jahren 1895-1898 (Berlin 1904) Abb. 225.

M. S.

M. S.

M. S.

R. Étienne, Le Prytanée de Délos, REA 99, 1997, Abb. 2.

M. S.

M. S.

M. S.

Hoepfner - Schwandner 1986, Abb. 68.

M. S.

L. Z., P. M., M. S., J. E., (C) ÖAI 
Taf. 250, 1:

Taf. 251, 1:

Taf. 252, 1:

Taf. 253, 1:

Taf. 254, 1:

Taf. 254, 2:

Taf. 255, 1:

Taf. 256, 1:

Taf. 256, 2:

Taf. 257, 1:

Taf. 258, 1:

3-D-Modelle

Taf. 259, 1:

Taf. 260, 1:

Taf. 261, 1:

Taf. 262, 1:

Taf. 263, 1:
Prytaneion. Schnitt A-A' (1:100)

Prytaneion. Schnitt B-B' $(1: 125)$

Prytaneion. Schnitt C-C' $(1: 100)$

Prytaneion. Schnitt D-D' $(1: 100)$

Prytaneion. Schnitt E-E' $(1: 150)$

Prytaneion. Schnitt F-F' (1:150)

Prytaneion. Übersicht Rekonstruktionsschnitte (1:250)

Prytaneion. Schnitt a-a' (1:150)

Prytaneion. Schnitt b-b' (1:150)

Prytaneion. Schnitt c-c' (1:100)

Prytaneion. Schnitt d-d' (1:100)

Prytaneion. Geschlossenes Modell von Südosten

Prytaneion. Geöffnetes Modell von Südosten

Prytaneion. Vogelperspektive des Modells von Südwesten

Prytaneion. Modellperspektive vom Vorhof in die Vorhalle

Prytaneion. Modellperspektive des \Hestiasaales` Richtung Norden
L. Z., P. M., (C) ÖAI

L. Z., P. M., N. H., (C) ÖAI

L. Z., P. M., (C) ÖAI

L. Z., P. M., A. H., (C) ÖAI

L. Z., P. M., N. H., J. E., (C)

ÖAI

L. Z., P. M., N. H., J. E., (C)

ÖAI

L. Z., P. M., M. S., C ÖAI

M. L., (C) ÖAI

M. L., (C) ÖAI

M. L., (C) ÖAI

M. L., (C) ÖAI

M. L., J. J., (C) ÖAI

M. L., J. J., (C) ÖAI

M. L., J. J., (C) ÖAI

M. L., J. J., (C) ÖAI

M. L., J. J., (C) ÖAI

\section{TextabBildungen}

\begin{tabular}{|c|c|c|c|}
\hline Textabb. & Seite & Inhalt & Nachweis \\
\hline Abb. 1: & 66 & Harris Matrix. Schnitt 1/07 & M. S., (C) ÖAI \\
\hline Abb. 2: & 68 & Harris Matrix. Schnitt 2/07 & M. S., (C) ÖAI \\
\hline Abb. 3: & 71 & Harris Matrix. Schnitt 3/07 & M. S., (C) ÖAI \\
\hline Abb. 4: & 72 & Harris Matrix. Schnitt 4/07 & M. S., (C) ÖAI \\
\hline Abb. 5: & 73 & Harris Matrix. Schnitt 5/07 & M. S., (C) ÖAI \\
\hline Abb. 6: & 75 & Harris Matrix. Schnitt 1/08 & M. S., (C) ÖAI \\
\hline Abb. 7: & 86 & Scherbenzahl pro stratigrafische Einheit & S. L., C ÖAI \\
\hline Abb. 8: & 86 & Scherbenzahl pro Bauphase & S. L., (C) ÖAI \\
\hline Abb. 9: & 87 & $\begin{array}{l}\text { Sigillataspektrum aus den Grabungen im Prytaneion 2007/2008 } \\
\text { (blau: Randstücke, rot: Bodenstücke, gelb: Wandstücke) }\end{array}$ & S. L., C ÖAI \\
\hline Abb. 10: & 88 & $\begin{array}{l}\text { Zusammensetzung des Fundspektrums des hellenistischen } \\
\text { Terrassierungsstratums }\end{array}$ & S. L., C ÖAI \\
\hline Abb. 11: & 89 & $\begin{array}{l}\text { Zusammensetzung der Feinware des hellenistischen } \\
\text { Terrassierungsstratums }\end{array}$ & S. L., (C) ÖAI \\
\hline Abb. 12: & 91 & Zusammensetzung des Fundspektrums von Bauphase 1 & S. L., C ÖAI \\
\hline Abb. 13: & 91 & Zusammensetzung der Sigillaten von Bauphase 1 & S. L., C ÖAI \\
\hline Abb. 14: & 91 & Zusammensetzung der hellenistischen Feinware von Bauphase 1 & S. L., C ÖAI \\
\hline
\end{tabular}





\title{
I EINLEITUNG
}

\author{
(Martin Steskal)
}

\section{I.1 Vorbemerkung zum Stand der Prytaneion-Forschung}

Systematische Forschungen zum Gebäudetypus `Prytaneion` und Reflexionen über die Funktion solcher Bauten erfolgten bis dato nur spärlich. So verwundert es nicht, dass St. G. Miller die wohl übergreifendste Studie über Prytaneia mit den Worten beginnt ${ }^{1}: »$ Within the realm of Greek civic architecture, the prytaneion is pre-eminent both for its ubiquity and for its obscurity. One cannot read far in the literature of antiquity without encountering mention of this building, but a vision of the architectural form of the prytaneion rarely, if ever, springs to mind when one reads or hears the word.« Der Umstand, dass Prytaneia über keinen kanonischen Grundriss verfügten, hat dazu geführt, dass heute nur wenige Gebäude tatsächlich als Prytaneia zu identifizieren sind. Wann immer somit epigrafische Quellen fehlen, die das Gebäude explizit als Prytaneion ausweisen, ist es nur anhand von Analogieschlüssen möglich, eine solche Identifizierung vorzunehmen. Wesentliche Parameter sind dabei die Lage der Gebäude innerhalb der Stadt - insbesondere die Nähe zur Agora und zu anderen Regierungsgebäuden ${ }^{2}$-, ihr Raumangebot oder das Vorhandensein eines Herdes (einer $\dot{\varepsilon} \sigma \tau i ́ \alpha)$.

Trotz des spärlichen Publikationsstandes und der geringen Anzahl sicher identifizierter Bauten wurden schon früh allgemein gehaltene Studien zu Aussehen und Funktion dieser Gebäude vorgelegt ${ }^{3}$. So begann die wissenschaftliche Auseinandersetzung mit Prytaneia - angeführt von A. Preuner ${ }^{4}$, G. Hagemann ${ }^{5}$ und J. G. Frazer ${ }^{6}$ - bereits im ausgehenden 19. Jahrhundert. A. Preuner analysiert als Erster die Funktion von Prytaneia und ihre Verbindung zum Hestiakult, wobei er den Zeitpunkt des Aufkommens dieses Gebäudetypus wie folgt skizziert ${ }^{7}$ : $»$ Es ist klar, dass, solange Könige in Attika herrschten, Prytaneen im späteren Sinne nicht bestanden haben werden, dass es dagegen ein Prytaneon kurz nach oder unmittelbar seit ihrer Vertreibung gegeben haben wird.« Als wesentliches Merkmal dieser Bauten nennt er die ehrenvollen Speisungen, die er als allgemein üblichen Brauch beschreibt ${ }^{8}$. Die Verbindung von Prytaneion und Herd scheint ihm in diesem Kontext evident, wobei er in der Frage, inwieweit solche Bauten in allen griechischen Städten zu finden wären, unentschieden bleibt ${ }^{9}$ : »Die Allgemeinheit von Prytaneen ist zwar wahrscheinlich, wird aber nicht schlechthin behauptet werden können. Es entsprach ihrer Idee, dass eine Hestia darin war. Diese fehlte nie, wo ein Prytaneon war. Auch kann daran nicht gezweifelt werden, dass die Speisung und Bewirthung im Prytaneon da, wo sie stattfand, mit dieser Hestia in Verbindung gedacht wurde.« Die Verbindung von Prytaneia mit dem Hestiakult erklärt er stringent ${ }^{10}$ : »Das republicanische Gebäude, das nunmehr an die Stelle der alten Königswohnung trat, war, es ist keine Frage, das Prytaneon: die Hestia

1 Miller 1978, 1.

2 Dass eine solche räumliche Verbindung erst ab hellenistischer Zeit bestand, vermutet Kenzler 1999, 294. 296.

$3 \mathrm{Zu}$ den ebenfalls bereits früh einsetzenden Detailanalysen zu einzelnen Prytaneia, vor allem zum Prytaneion von Athen, s. Miller 1978, 38-127. 225-239 mit älterer Lit.

4 Preuner 1864, bes. $95-121$.

5 Hagemann 1880 und G. Hagemann, De Graecorum Prytaneis capita tria (Breslau 1881).

6 Frazer 1885, 145-172.

7 Preuner 1864, 97. 115: »Es war der politische Staat, der sich die Prytaneen baute: der Staat, in dem republicanische Verfassungen an Stelle des patriarchalen Königthums getreten waren.«

8 Preuner 1864, 95-102.

9 Preuner 1864, 106.

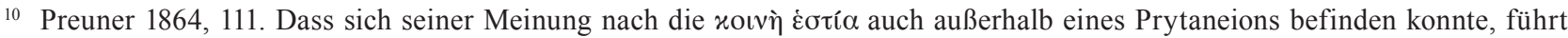
Preuner 1864, 121-125 aus. 


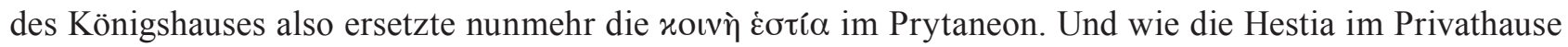
heilig war, so war es noch mehr die gemeinsame im Staatshause. Die ewigen Feuer darauf mögen auf eine Sitte zurückweisen, wo man sich auch in Privathäusern scheute, die Herdfeuer zu löschen.« Das Opfer an

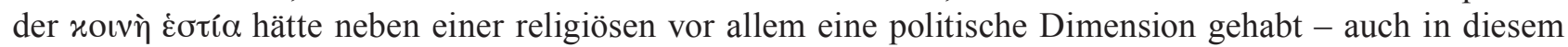
Zusammenhang stellt er eine unmittelbare Verbindung zwischen Privatem und Öffentlichem her, »weil der Staat der Familie nachgebildet ist $\ll^{11}$. Das Prytaneion wiederum würde den Staat als Haus symbolisieren ${ }^{12}$. Die Bedeutung der Göttin Hestia betrachtet er differenziert ${ }^{13}$ : »Hestia ist nicht Göttin des Feuers überhaupt, sondern ist wesentlich Göttin des bestimmten Zwecken dienenden Feuers. Sie waltet im heiligen Feuer auf Altar und Herd.« Ihre Rolle als Göttin der Familie und Häuslichkeit sieht er als zweitrangig ${ }^{14}$.

J. G. Frazer führt die allgemeinen Studien zu diesem Gebäudetypus fort und liefert in einem Aufsatz von 1885 eine prägnante Analyse zu Aussehen und Funktion von Prytaneia ${ }^{15}$. Er versucht dabei die gemeinsamen Wurzeln des griechischen Prytaneions und des italischen Vestatempels herauszustreichen ${ }^{16}$. Die wesentlichen Charakteristika dieses Gebäudetypus beschreibt er bereits in weiten Zügen richtig ${ }^{17}$ : »Every Greek state had its prytaneum which may be described as the town-hall of the capital. ... The essential feature of the prytaneum was its hearth $(\dot{\varepsilon} \sigma \tau i \alpha)$ which differed from other hearths only in this that it was preeminently the hearth of the city, the common hearth. On this hearth there burned a perpetual fire. The prytaneum was sacred to Hestia, the personified goddess of the hearth. In the prytaneum ambassadors were entertained and distinguished citizens maintained at the public expense, and it was the head-quarters of the officials known as prytanes. « Er versucht aber auch die Funktion des Prytanen zu konkretisieren ${ }^{18}$. $» \ldots$ the prytanis was anciently the king or perhaps rather the chief or headman of a petty independent town and ... the prytaneum was his house.« Da zum Zeitpunkt seiner Studie nur wenige Prytaneia bekannt sind, nimmt Frazer, ausgehend von der Tholos in Athen und runden italischen Vestatempeln, eine generell runde Gebäudeform an - fälschlich wie sich später herausstellen sollte ${ }^{19}$. Er fasst zusammen ${ }^{20}$ : »The prytaneum, a round building with a pointed, umbrella-shaped roof, was originally the house of the king, chief, or headman (prytanis) of an independent village or town and it contained a fire which was kept constantly burning. It is only necessary to add that when a colony was sent out, the fire for the chief's house (prytaneum) in the new village was taken from that in the chief's house of the old village."

Mehr als ein halbes Jahrhundert später ist es W. A. McDonald, der in seiner Studie zu politischen Versammlungsräumen bei den Griechen im Jahr 1943 u. a. die Unterschiede und Gemeinsamkeiten von Bouleuterion und Prytaneion herausarbeitet ${ }^{21}$ : »Hence, the prytaneum emerged in the historical period as the building in which the sacred city hearth was located and where the councillors, along with distinguished citizens and foreigners, took their meals. But never in later times, as far as is known, did it retain its old

11 Preuner 1864, 113. 115; vgl auch später Merkelbach 1980, 79: »Dieser Kult der Hestia war also für den Griechen ein deutliches Zeichen dafür, dass die ganze Stadt eigentlich eine einzige grosse Familie war, die sich beim Fest zum Mahl um ihren Herd versammelte."

12 Preuner $1864,215$.

13 Preuner 1864, 203.

14 Preuner 1864, 207-216.

15 Frazer $1885,145-172$.

16 Frazer 1885, 145-158; cf. bereits Preuner 1864.

17 Frazer 1885, $145 \mathrm{f}$.

18 Frazer $1885,146 \mathrm{f}$.

19 Frazer 1885, 150. Der Vorstellung von einer obligatorisch runden Gebäudeform, die schon zuvor etwa von K. Th. Pyl, Die griechischen Rundbauten im Zusammenhange mit dem Götter- und Heroencultus (Greifswald 1861) 88 und Hagemann 1880, 37 sowie später von G. Leroux, Les origines de l'edifice hypostyle en Grèce, en Orient et chez les Romains (Paris 1913) 183 formuliert wurde, widerspricht J. Charbonneaux, Tholos et Prytanée, BCH 49, 1925, 158-178 bes. 168 in Kenntnis eines besseren Denkmälerbestandes: »Le plan rectangulaire, complexe, des Prytanées s'est done adapté comme la maison aux nécessités des fonctions, des temps et des lieux. La Tholos au contraire représente le type architectural le plus simple et le plus rebelle à l'évolution.« Kreisrunde Prytaneia werden danach nochmals von F. Robert, Thymélè. Recherches sur la signification et la destination des monuments circulaires dans l'architecture religieuse de la Grèce (Paris 1939) 394 postuliert.

20 Frazer 1885, 152.

21 McDonald 1943, 127; s. zuvor noch die Lexikaeinträge: Smith's Dictionary of Greek and Roman Antiquities II (1891) 514 f. s. v. Prytaneion (G. Marindin) und Ch. Michel, Prytaneum, in: Ch. Daremberg - E. Saglio, Dictionnaire des antiquités grecques at romaines IV 1 (Paris 1907) $742 \mathrm{f}$. 
function as the regular meeting place of the council. This purpose was served by a new building, called sbouleuterion another at the very center of the civic life of each town. Hence, for small towns to have their prytaneum and bouleuterion transferred and merged into a single prytaneum and bouleuterion in a larger town meant their complete disappearance as political entities.« Aufgrund gemeinsamer Wurzeln der beiden Regierungsgebäude bringt er Hestia auch mit dem Bouleuterion in Verbindung ${ }^{22}$ : »Hestia was the patron goddess of the sacred fire which was kept burning in the prytaneum of every Greek city, and this substantiates the theory that the prytaneum originally included among its functions that of being the meeting place of the council. Thus, when the bouleuterion became differentiated as a separate building, the patron goddess of the prytaneum naturally took her place in it.« Ab der Mitte des 4. Jahrhunderts v. Chr. sei daher auch immer wieder von der »Hestia Boulaia« die Rede ${ }^{23}$. Generell vermutet er zu Recht eine kontinuierliche Übertragung von Aufgaben des Prytaneions auf das Bouleuterion; neben der Verlagerung der Ratsversammlung in den neuen Gebäudetypus seien auch die ursprünglich im Prytaneion untergebrachten Archive in das Bouleuterion verlagert worden ${ }^{24}: »$ This transfer is a logic one, for, when the meeting place of the council was shifted, the archives would logically be changed in order to be accessible as possible for constant reference.« Die Frage, warum nur so wenige Prytaneia tatsächlich bekannt sind, beantwortet er wenige Jahre später wie folgt ${ }^{25}$ : Das Prytaneion sei ein »vital building in every Greek city, and it is mentioned in literary or epigrafical sources in connection with over seventy of them. ... A review of the pertinent literary and epigrafical information suggests that the prytaneion was regularly located among other public buildings and constructed on a moderately monumental scale«.

Einer grundsätzlichen Problematik in der Prytaneion-Forschung widmet sich G. Tosi 1966, die sich insbesondere zu der Frage, ob es grundrisstypologische Gemeinsamkeiten unter den wenigen bekannten Prytaneia geben würde, sehr kritisch äußert ${ }^{26}: »$ La funzionalità e la >essenzialità< della planimetria, insieme con l'importenza della ubicazione, rappresentano le caratteristiche comuni ai pritanei greci. ... La diversa realizzazione del tipo nelle singole poleis, pur rimanendo costante, nelle sue linee fondamentali, la funzione dei pritanei fino alla decadenza delle poleis, si giustifica sia nel diverso momento storico e nel diverso ambiente artistico in cui sorsero, sia con il fatto che i caratteri tipologici dell'edificio non appaiono cosi spiccati da creare una classe di edifici del tutto originale, quale i Greci seppero realizzare per i templi o per $\mathrm{i}$ teatri.« Sie schließt daher aus der Analyse bekannter und fraglicher Prytaneia wie in Olympia, Lato, Dreros, Delos, Magnesia am Mäander, Priene, Agrigent oder Athen, dass beim aktuellen Wissens- und Denkmälerbestand grundsätzliche Fragen offenbleiben müssen ${ }^{27}$ : $\gg$ Tuttavia riteniamo che, per quanto riguarda la tipologia, esso trovi la sua soluzione nel riconoscimento di caratteristiche planimetriche, topografiche e funzionali, che si diversificano da quelle dell'abitazione privata, anche se, come abbiamo già osservato, la tipologia dell'edificio è ricostruibile attualmente solo a grandi linee.«

Auch R. E. Wycherley bezweifelt in seiner kurzen Darstellung des Gebäudetypus >Prytaneion` die Existenz eines kanonischen Grundrisskonzeptes solcher Bauten ${ }^{28}$. Anhand mehrerer konkreter Beispiele belegt E. Fossel im selben Jahr die städtebauliche und funktionale Verbindung von Agora, Bouleuterion und Prytaneion sowie die topografische Nähe dieser Bauten zueinander ${ }^{29}$.

Die jüngste übergreifende Studie zum Prytaneion stammt von St. G. Miller aus dem Jahr 1978, der in dieser Arbeit auch spezifische Analysen einzelner Bauten vornimmt ${ }^{30}$. Derartige Einzelanalysen werden bis zum heutigen Tag sporadisch weitergeführt ${ }^{31}$. Ehe Miller sich den - zum Zeitpunkt seiner Studie bekannten

22 McDonald 1943, $137 \mathrm{f}$.

23 McDonald 1943, $281 \mathrm{f}$.

24 McDonald 1943, 156.

25 McDonald 1948, 374.

26 Tosi 1966, $163 \mathrm{f}$.

27 Tosi 1966, 164.

28 R. E. Wycherley, How the Greeks Built Cities ${ }^{2}$ (London 1967) 134-138.

29 E. Fossel, Zum sogenannten Odeion in Ephesos, in: Festschrift Fritz Eichler (Wien 1967) 72-81 bes. 79-81.

30 Miller 1978.

31 Jüngere Detailanalysen spezifischer Prytaneia erschienen seit Miller 1978 zu (in Auswahl): Athen: A. S. Henry, Invitations to the Prytaneion at Athens, Antichthon 15, 1981, 100-110; M. J. Osborne, Entertainment in the Prytaneion at Athens, ZPE 41, 1981, 153-170; S. Angiolillo, Hestia, l'edificio F e l'altare dei 12 dei ad Atene, Ostraka 1, 2, 1992, 171-176; W. Hoepfner, 
und fraglichen - Prytaneia widmet, unternimmt er eine eingehende Funktionsanalyse, wobei sein Hauptaugenmerk auf einer möglichst umfassenden Einbeziehung der antiken literarischen und epigrafischen Quellen liegt ${ }^{32}$. Generell geht er davon aus, dass das Amt der Prytanie schon vor der Errichtung von Prytaneia existierte ${ }^{33}$ : $\gg$ And if ... the name of the building prytaneion derives from the name of the office prytanis, then an interesting conclusion is forthcoming: the prytaneion was imported to those cities later than the establishment of terminology for their officials corresponding to the prytaneis at Athens and elsewhere. If, on the other hand, a city did not have prytaneis and did not import the prytaneion, then one might hear of buildings which appear to be fulfilling the function of the prytaneion, but which are called by other names. ... These buildings must have been prytaneia in all but name."

Als erste Funktion des Prytaneions beschreibt Miller die Ehrenspeisung, wobei er zwischen $\xi \varepsilon ́ v ı \alpha$,

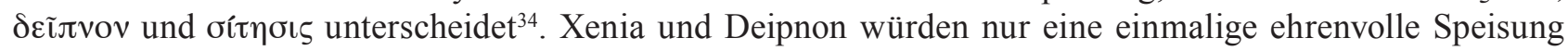
auf Staatskosten bedeuten; trotz einiger Ausnahmen wäre die Xenia prinzipiell Fremden gewährt worden, während das Deipnon den Bürgern der Stadt vorbehalten gewesen wäre. Die Sitesis wäre ebenfalls zunächst auf Bürger beschränkt gewesen, später seien aber auch fremde Wohltäter und Stifter mit einer solchen Speisung ausgezeichnet worden ${ }^{35}$. Die Sitesis wäre entweder auf Lebenszeit oder, wenn es sich um einen öffentlichen Beamten der Stadt - in erster Linie einen Prytanen - handelte, bis zum Ende der jeweiligen Dienstzeit gewährt worden. Eine weitere Kategorie von Speisungen, nämlich die ỏeíoı Speisungen politischer Funktionäre im Prytaneion betroffen. All diese ehrenvollen Speisungen seien in erster Linie Männern vorbehalten gewesen; überliefert sei lediglich eine Ausnahme: In der ersten Hälfte des 1. Jahrhunderts v. Chr. wäre eine gewisse Polygnota aus Theben in das Prytaneion von Delphi geladen worden $^{36}$. Die Gewährung von Speisungen auf Staatskosten wäre im Laufe der Jahrhunderte immer gän-

Bauten der Demokratie, in: W. Hoepfner - G. Zimmer (Hrsg.), Die griechische Polis - Architektur und Politik (Tübingen 1993) 86-91; G. C. R. Schmalz, The Athenian Prytaneion Discovered?, Hesperia 75, 2006, 33-81. - Delos: D. Williams, Captain Donnelly's Altar and the Delian Prytaneion, RA 2004, 51-68. - Kassope: Hansen - Fischer-Hansen 1994, 35 f.; Hoepfner

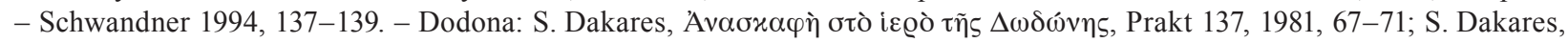

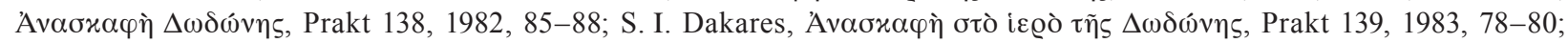

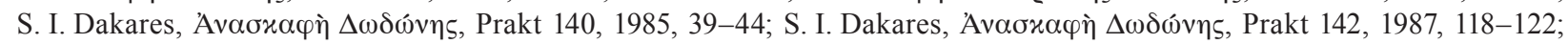

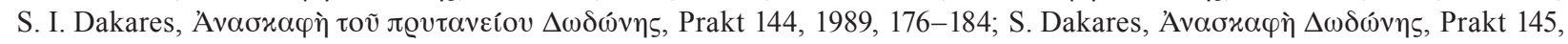

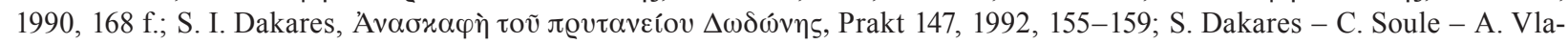

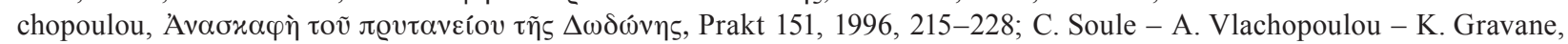

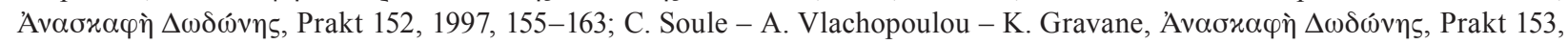
1998, 143-151; S. Dakaris - C. Tzouvara-Souli - A. Vlachopoulou-Oikonomou - K. Gravani-Katsiki, The Prytaneion of Dodona, in: P. Cabanes (Hrsg.), L'Illyrie méridionale et l'Epire dans l'antiquité, 3. Actes du IIIe Colloque international de Chantilly.

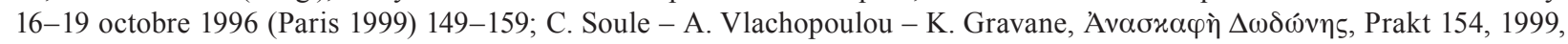

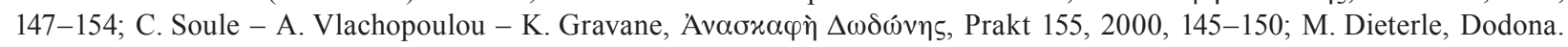
Religionsgeschichtliche und historische Untersuchungen zur Entstehung und Entwicklung des Zeus-Heiligtums, Spudasmata 116 (Hildesheim 2007) 139-141. 162-164. - Olympia: H. Kyrieleis, Die Untersuchungen zur Frühzeit Olympias im Bereich des Prytaneion. 1986-87 und 1990-91, in: H. Kyrieleis, 1982 bis 1999, OlBer 12 (Berlin 2003) 66-154; Ch. Schauer, Fundgruppen archaischer und klassischer Zeit aus dem Bereich des Prytaneion, in: Kyrieleis a. O. 155-205; J. Heiden, Die Agorai von Elis und Olympia, in: Hoepfner - Lehmann 2006, 58. - Pergamon: Schwarzer 2004, 173-183; Schwarzer 2008, 116-118. - Sparta: N. M. Kennell, Where was Sparta's Prytaneion?, AJA 91, 1987, 421-422. - In Priene wurde eine noch nicht abschließend veröffentlichte bauhistorische Untersuchung von A. von Kienlin durchgeführt, s. vorab: W. Raeck, 2006 Yılı Çalışmaları, KST 29, 2008, 342; Abb. 9-10 sowie A. von Kienlin, Zur baulichen Entwicklung der Agora von Priene, Boreas 21/22, 1998/1999, 241-259 bes. $253 \mathrm{f}$.

32 Miller 1978, 4-37. Die antiken Stellen (466 Katalogeinträge) gibt er in einem Anhang in Original und Übersetzung wieder: Miller 1978, 132-218.

33 Miller 1978, 10.

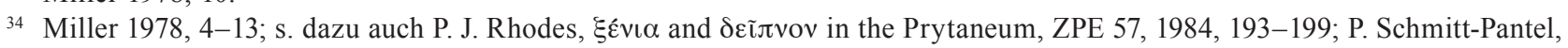
Les repas au prytanée et à la tholos dans l'Athènes classique. Sitesis, trophè, misthos. Réflexions sur le mode de nourriture démocratique, AnnAStorAnt 2, 1980, 55-68; P. Spitzer, Hospitalité et invitation au prytanée, Cahiers du Centre G. Glotz 5, 1994, 27-49.

35 Cf. dazu später auch M. Rausch, Isonomia in Athen. Veränderungen des öffentlichen Lebens vom Sturz der Tyrannis bis zur zweiten Perserabwehr, Europäische Hochschulschriften III 821 (Frankfurt 1999) 326 f.; Schmitt Pantel 1992, $225-227$.

36 G. Colin, Epigraphie. Les inscriptions de la terrasse du temple et de la région nord du sanctuaire, FdD 3, 4 (Paris 1930$) 57$ Z. 26-28. Da in der Kaiserzeit auch Frauen das Amt der Prytanie bekleiden konnten, ist davon auszugehen, dass diese Ausnahme viel öfter zur Anwendung kam, als von Miller vermutet; s. dazu Merkelbach 1980, 80 und Soldan 1999, 115-119. - Zur mög- 
giger geworden, wodurch diese ihren exklusiven Charakter zusehends verloren hätten; diese Entwicklung geht laut Miller Hand in Hand mit einem kontinuierlichen Bedeutungsverlust der Prytaneia als wichtige politische Einrichtungen ${ }^{37}$ : $\gg$ On this political plane, the prytaneion was a flourishing institution throughout the Classical period, but already in the fourth century B.C., its significance had begun to wane. During the Roman period it became necessary to explain to one's readers just what a prytaneion had been. ... It is quite understandable that the importance of an institution bound so intimately with the concept of Greek interpolis relations would, along with the polis, decline as an international force during the Hellenistic era."

Die zweite wichtige Funktion der Prytaneia läge in der Beheimatung des Herdes der Hestia ${ }^{38}:$ »In the prytaneion was the eternal flame, burning on the common hearth, which signified the life of the polis. ... It is quite understandable then if colonists took with them a spark of fire from the hearth in the prytaneion of their mother city as a symbol both of the life of their new foundation and of the source of that life.« Diese religiöse Funktion hätte die politische deutlich länger überdauert ${ }^{39}$ : $\gg T h e$ prytaneion, however, continued to play a religious role, and it remained an important establishment for activities within the city. This shift of emphasis back to the religious was evolutionary and cannot precisely be dated, but is most obvious in the Roman period when it became more complete and formal.«

Des Weiteren hätten Prytaneia als städtisches Archiv, als Ort, an dem Recht gesprochen wurde, aber auch als soziale Einrichtungen fungiert, in denen sozial Schwache auf Staatskosten verköstigt wurden ${ }^{40}$.

Einen wesentlichen Punkt in Millers Arbeit stellt das Aussehen von Prytaneia dar ${ }^{41}$. Er stellt sich dabei sowohl gegen eine obligatorische Rundform dieser Bauten als auch gegen eine Identifizierung mit dem Megaron oder dem Privathaus. Seinen Zugang beschreibt er wie folgt ${ }^{42}$ : $\gg$ Rather than relying upon misleading analogies of function ... to other architectural types, such as the megaron/oikos or the Hestia/Vesta/tholos parallels to prytaneia, our approach will be to utilize the sources for specific parts of the prytaneion, as well as for more general descriptions of the building, in order to see what sort of structure is to be expected in the remains. « Er versucht somit zu klären, inwieweit grundrisstypologische, strukturelle oder topografische Parallelen zwischen den sicher bestimmten Prytaneia bestünden, die in der Folge zu einer leichteren Identifizierung neu entdeckter Bauten führen könnten. Die Lage innerhalb der Stadt sei in diesem Kontext vorgegeben: Prytaneia hätten sich prinzipiell in der Nähe der Agora befunden; dennoch wären Ausnahmen möglich ${ }^{43}$ : $\gg I n$ cities of great age or of singular religious importance the prytaneion might not be close to the agora, but in a city where the planning had been unencumbered by pre-existing structures, as in a colony or a city rebuilt after widespread destruction, one can expect to find the prytaneion in or near the agora.« Das nötige Raumangebot fasst er wie folgt zusammen ${ }^{44}$ : 》One should expect with some probability a prytaneion to have two rooms (the dining room and the room of the hearth), a courtyard (perhaps with anterooms connecting it with the two large rooms), and some indeterminable number of subsidiary rooms. These buildings will be well constructed, located on or near the agora, and will contain certain typical movable objects.« Die genannten Parameter sucht er an den bekannten Prytaneia in Athen, Delos, Lato, Olympia, Dreros, Ephesos, Kolophon, Magnesia am Mäander, Morgantina und Priene zu verifizieren ${ }^{45}$.

lichen Lokalisierung des delphischen Prytaneions an der Peribolosmauer des Heiligtums s. A. Jacquemin, Wohnen in Delphi im 4. und 3. Jh. v. Chr., in: Ladstätter - Scheibelreiter 2010, 27-32; J. Bousquet, Les comptes du quatrième et du troisième siècle, Corpus des inscriptions de Delphes 2 (Paris 1989) Nr. 81, 15-18.

37 Miller 1978, 23. Dieser Bedeutungsverlust, der sich sowohl in architektonischen als auch urbanistischen Belangen manifestiert, könnte sich seiner Meinung nach an den Prytaneia von Kolophon, Morgantina und Priene widerspiegeln; cf. Miller 1978, $126 \mathrm{f}$.

38 Miller 1978, $13 \mathrm{f}$.

39 Miller 1978, 24.

40 Miller 1978, 16-20; zur Funktion eines Gerichtes, konkret in Athen, s. später auch K.-W. Welwei, Athen. Vom neolithischen Siedlungsplatz zur archaischen Großpolis (Darmstadt 1992) 142 f.; K.-W. Welwei, Das klassische Athen. Demokratie und Machtpolitik im 5. und 4. Jahrhundert (Darmstadt 1999) 360 Anm. 246.

${ }_{41}$ Miller 1978, 25-37.

42 Miller 1978, 26.

43 Miller 1978, 30.

44 Miller 1978, $36 \mathrm{f}$.

45 Miller 1978, 38-127. In einem Anhang behandelt Miller 1978, 225-234 weitere Gebäude, deren Identifizierung als Prytaneion postuliert wurde, aber nicht gesichert ist: Aigai, Argos, Kyrene, Delphi, Eleusis, Kassope, Kourion, Megara Hyblaea, Messene, 
Er kommt schließlich zu folgenden Ergebnissen ${ }^{46}$ : Das Prytaneion hätte seine Ursprünge in geometrischer Zeit; in archaischer Zeit wäre es bereits fest in den griechischen Städten etabliert gewesen. Sein Name sei von der Amtsbezeichnung >Prytanis $<$ hergeleitet. Obwohl ein kontinuierlicher politischer Bedeutungsverlust im Laufe der Jahrhunderte zu konstatieren sei, hätte vor allem die Präsenz der Hestia mit ihrem Herd, in dessen unmittelbarer Nähe die ehrenvollen Speisungen stattfanden, das Überleben dieses Gebäudetypus bis in die römische Zeit gesichert. Die wichtigsten Funktionen des Prytaneions, das grundsätzlich in der Nähe der Agora gelegen wäre, hätten zudem folgendes Raumangebot nötig gemacht: ein Raum für den Herd der Hestia, ein Speisesaal sowie Nebenräume zu Lagerzwecken. Mittels dieser Parameter wären auch bis dato unbekannte Prytaneia zu identifizieren.

Die wesentlichen Charakteristika eines Prytaneions werden kurz danach nochmals von R. Merkelbach zusammengefass ${ }^{47}$ : $»$ Jede griechische Stadt hatte ein Prytaneion, in welchem sich die gemeinsame Feuerstelle - Hestia - der Polis befand. Die Fürsorge für das heilige Feuer war einem Beamten übertragen, der häufig den Titel Prytanis trug; es kommen auch andere Bezeichnungen vor. Der Prytanis war der oberste religiöse Beamte der Stadt; ... Wer das Amt des Prytanis übernahm, der gewann grosses Ansehen unter seinen Mitbürgern und bestritt während des folgenden Jahres die Repräsentationskosten seiner Heimatstadt. Der Prytanis unterhielt das ewige Feuer im Herd der Stadt; er vollzog die üblichen Opfer und bewirtete bei den Opfermahlzeiten einen Teil der Bürger; im Prytaneion wurden auch die Gesandten anderer Städte empfangen und verpflegt, ebenso jene `Ehrenbürger`, welchen man das Recht auf lebenslängliche Speisung im Prytaneion verliehen hatte.« Diese Prytanie sei in der Kaiserzeit auch von jungen Frauen aus begüterten Haushalten übernommen worden ${ }^{48}$. Aufgrund der hervorragenden Quellenlage in Bezug auf Ephesos kann St. J. Friesen sogar konkretisieren ${ }^{49}$ : »In the case of the Ephesian prytaneia, our statistical sample is excellent. During the first two and a half centuries CE, there would have been 250 prytaneis and we know whether a man or a woman served in about 129 of those cases. ... The relative frequency with which men and women served as prytaneis ... suggests that women served as prytaneis about $23 \%$ of the time in the first 250 years of the Common Era, with the highest percentage of attestations in the first half of the first century and the first half of the third century.« Er folgert daher weiter: »Since this comes very close to the figures obtained for provincial highpriestesses, I conclude that a significant development has been identified regarding gender expectations and public offices in western Asia Minor. In the first half of the first century CE, elite women in Asia began to fill religious offices that had previously been the domain of men." Der Besitz des römischen Bürgerrechtes scheint in diesem Kontext von sekundärer Bedeutung gewesen zu sein, wie etwa M. Dräger ausführt ${ }^{50}$ : »Dennoch besaßen in Ephesos, der bedeutendsten Stadt der Provinz, vor der constitutio Antoniniana nicht einmal alle Angehörigen der Führungsschicht die civitas - selbst die angesehenste Magistratur in Ephesos, die eponyme Prytanie, war noch Ende des zweiten Jahrhunderts $n$. Chr. Ephesiern ohne römisches Bürgerrecht zugänglich.«

Eine aktualisierte Liste an epigrafisch oder literarisch überlieferten Prytaneia wird 1994 von M. H. Hansen und T. Fischer-Hansen vorgelegt ${ }^{51}$. Auch sie verweisen auf die ursprünglich große Zahl an Prytaneia ${ }^{52}$ : »Every polis must have had a prytaneion, and since there were more than a thousand poleis, including colonies, there must have been over a thousand prytaneia.« Die beiden Autoren gehen davon aus, dass - entgegen dem archäologischen Befund - Prytaneia auch immer mit einer Küche ausgestattet waren ${ }^{53}$ : We doubt that the eternal flame was used to heat the soup served to the guests entertained by the state in the

Milet, Olynth, Palatitza, Pergamon und Thasos.

46 Miller 1978, 128-131.

47 Merkelbach 1980, 81 f.; s. danach auch St. J. Friesen, Ephesian Women and Men in Public Office During the Roman Imperial Period, in: Friesinger - Krinzinger 1999, 109 f.; DNP X (2001) 493 f. s. v. Prytaneion (W. Eder).

48 Cf. Merkelbach 1980, 80; D. Knibbe - B. İplikçioğlu, Ephesos im Spiegel seiner Inschriften (Wien 1984) 22 f.; Soldan 1999 , 115-119; Witetschek 2008, 46.

49 St. J. Friesen, Ephesian Women and Men in Public Office During the Roman Imperial Period, in: Friesinger - Krinzinger 1999, 110.

50 M. Dräger, Die Städte der Provinz Asia in der Flavierzeit. Studien zur kleinasiatischen Stadt- und Regionalgeschichte, Europäische Hochschulschriften III 576 (Frankfurt 1993) 91.

51 Hansen - Fischer-Hansen 1994, 31-34.

52 Hansen - Fischer-Hansen 1994, 31.

53 Hansen - Fischer-Hansen 1994, 34. 
prytaneion. Therefore, a complete prytaneion must have been equipped with two fireplaces, one for Hestia and one for the kitchen, but as far as we know two fireplaces have never been found in any building identified as a prytaneion.« Neben kurzen Zusammenfassungen von bereits bei St. Miller behandelten Prytaneia stellen sie das erst später entdeckte Prytaneion von Kassope vor ${ }^{54}$.

Obwohl spezifische Arbeiten zum Themenkreis >Prytaneion<, die insbesondere auch Studien zum Amt der Prytanie ${ }^{55}$ und zum Hestiakult ${ }^{56}$ beinhalten, bis zum heutigen Tag fortgeführt werden, ist die Anzahl publizierter Einzelmonumente nach wie vor gering. Mit der Vorlage eines der sicher identifizierten Gebäude, nämlich des Prytaneions von Ephesos, soll dieser Forschungsstand nun erweitert und bereichert werden.

\section{I.2 Aufgabenstellung und Methode}

Seit seiner Entdeckung im Jahr 1955 stehen das Prytaneion von Ephesos (Taf. 1-5), sein Aussehen, seine Funktion und seine Beziehung zum benachbarten Regierungsviertel im Mittelpunkt der wissenschaftlichen Auseinandersetzung ${ }^{57}$. Da das Gebäude und sein stratigrafischer Befund nach der Ausgrabung nicht vollständig ausgewertet wurden, blieben die einzelnen Bauphasen, der architektonische Aufbau sowie die Nachnutzung des Areals in weiten Bereichen ungeklärt ${ }^{58}$. Auf Anregung des damaligen Grabungsleiters von Ephesos, F. Krinzinger, wurden daher im Jahr 2007 neue Forschungen zum ephesischen Prytaneion begonnen, die dem Verfasser überantwortet wurden. Die Arbeiten wurden in den Jahren 2008 und 2009 unter der Grabungsleitung von J. Koder weitergeführt. Die neu konzipierten Forschungen am Prytaneion sollten eine grundlegende Analyse des architektonischen Befundes mitsamt seiner Ausstattung unter Berücksichtigung der Resultate der Altgrabungen beinhalten. Die Bauforschung sollte dabei durch eine tiefgreifende archäologische Nachuntersuchung der Anlage, die die einzelnen Bau- und Nachnutzungsphasen definieren und einen möglichen Vorgängerbau bestimmen sollte, unterstützt werden. Neben diesen Arbeiten galt es, das Gebäude einer kulturhistorischen Analyse zu unterziehen, die seine architektonische und funktionale Verbindung zum angrenzenden Regierungsviertel beleuchten sollte.

Bei der Neuuntersuchung des Prytaneions griffen archäologische und bauhistorische Methoden eng ineinander. Die punktuellen Grabungen und Reinigungen dienten demnach nicht nur der Klärung der Chronologie der Nutzungsgeschichte des Gebäudes, sondern auch der Lösung grundrisstypologischer Fragestel-

54 Hansen - Fischer-Hansen 1994, 35 f.; dazu auch: Hoepfner - Schwandner 1994, 137-139. Die neu entdeckte Anlage war Mil-

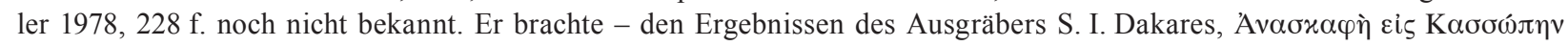

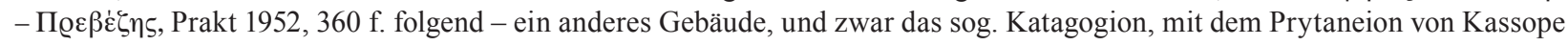
in Verbindung, lehnte letztlich aber eine Identifizierung als Hauptkultgebäude der Stadt ab; s. dazu Hoepfner - Schwandner 1994, 127-132.

55 Zum Prytanenamt s. etwa J. Bleicken, Die athenische Demokratie ${ }^{4}$ (Paderborn 1995) 193-209. 231-234; Soldan 1999, 115-119; F. Gschnitzer, Prytanen. Ein Beitrag zum geschichtlichen Verständnis griechischer »Staatsaltertümer«, in: F. Hampl - I. Weiler (Hrsg.), Kritische und vergleichende Studien zur Alten Geschichte und Universalgeschichte, Innsbrucker Beiträge zur Kulturwissenschaft 18 (Innsbruck 1974) 75-88; RE Suppl. XIII (1973) 730-816 s. v. Prytanis (F. Gschnitzer); St. Dow, Prytaneis. A Study of the Inscriptions Honoring the Athenian Councillors, Hesperia Suppl. 1 (Athen 1937).

56 Zum Hestiakult in Auswahl: Preuner 1864, bes. 95-121; H. Martin, Mémoire sur la signification cosmographique du mythe d'Hestia dans la croyance antique des Grecs, MemAcInscr 28, 1, 1874, 335-353; Frazer 1885, bes. 145-158; Roscher, ML I (1890) 2605-2653 s. v. Hestia (A. Preuner); RE VIII 1 (1913) 1257-1304 s. v. Hestia (W. Süß); EAA IV (1961) 18-22 s. v. Hestia (W. Fuchs); St. G. Miller, Hestia und Symmachos, OpRom 9, 1973, 167-172; Merkelbach 1980, 77-92; I. Marazov, Aspects of the Royal Hestia. 1. Hestia and the Idea of Autochthonicity, Orpheus 1990, 73-89; I. Marazov, Aspects of the Royal Hestia. 2. Hestia, Wealth, Fire and the Sun, Orpheus 1, 1991, 73-86; Schmitt Pantel 1992, 93-100; DNP V (1998) 512-514 s. v. Hestia (F. Graf); H. F. North, Hestia and Vesta. Non-Identical Twins, in: N. W. Goldman (Hrsg.), New Light from Ancient Cosa. Classical Mediterranean Studies in Honor of Cleo Rickman Fitch (New York 2001) 179-188.

57 Zur Forschungsgeschichte s. M. Steskal, Kapitel II. Cf. auch allgemeine Darstellungen zur Baugeschichte und Architektur des Prytaneions: J. Keil, Führer durch Ephesos 4(Wien 1957) 113 f.; Miltner 1958a, 27 f. 41-43; Alzinger 1962, 221-229; Alzinger 1970, 1646-1648; Alzinger 1974, 51-57; Alzinger 1972-1975, 229-249; Miller 1978, 98-109; E. Lessing - W. Oberleitner, Ephesos. Weltstadt der Antike (Wien 1978) 148; Foss 1979, 80; W. Elliger, Ephesos. Geschichte einer antiken Weltstadt ${ }^{2}$ (Stuttgart 1992) 62 f.; M. Büyükkolanc1 - Ü. Yüğrük, Prytaneion, in: Scherrer 1995a, 86-89; Karwiese 1995, 82. 129; G. Wiplinger - G. Wlach, Ephesos. 100 Jahre österreichische Forschungen ${ }^{2}$ (Wien 1996) 70 f.; Knibbe 1998, 28 f.; İ. A. Atila - Ö. Atalay, Ephesos und das Haus der Mutter Maria (Antalya 2009) 12.

58 Auf die Bedeutung einer »Neuaufrollung der Grabungen bzw. der Aufarbeitung des vorhandenen Fundmateriales« des Prytaneions verwies zuletzt Scherrer 2007, 68. 
lungen. Die stratigrafischen Grabungen wurden nach dem $>$ Single-Layer-Prinzip ${ }^{59}$ durchgeführt, wobei die einzelnen Schichten dreidimensional als Schichtkörper digital dokumentiert wurden. Die grafische Darstellung der Harris-Matrices erfolgte unter Zuhilfenahme des Programms ArchEd in der Version 1.4.1. Zur Dokumentation des flächigen archäologischen Befundes sowie des Grundrisses kam im Feld eine Totalstation zum Einsatz, wobei als Software das Programm TachyCAD (Version 6) der Firma kubit GmbH verwendet wurde. Der tachymetrisch erstellte Grundriss (absolute Höhe des Meterrisses: 47,90 m) wurde im Detail in Handaufmaß ergänzt. Die Dokumentation der Sondagenprofile wurde zunächst von Hand gefertigt (Aufnahmemaßstab 1:20); später wurden die Zeichnungen mithilfe von CAD-Programmen digitalisiert ${ }^{60}$. Die zeichnerische Aufnahme der einzelnen Architekturglieder erfolgte grundsätzlich in Handaufmaß (Aufnahmemaßstab 1:10 bzw. 1:20), während die Wandansichten mittels fotogrammetrischer Hilfsmittel dokumentiert wurden. Dazu wurde das Programm PhoToPlan (Version 4) der Firma kubit GmbH für die maßstabsgerechte Entzerrung der Digitalfotos eingesetzt. Die Digitalfotos wurden nach ihrer Entzerrung im Maßstab von 1:20 auf einem Farbplotter ausgedruckt und vor Ort auf verzugsfreier Folie durchgezeichnet. Durch das Zeichnen unmittelbar vor dem Befund konnten auch kleinste Details nachgetragen oder Korrekturen vorgenommen werden, was bei einer völligen Auslagerung der Arbeiten ins Büro kaum noch möglich gewesen wäre. Das gesamte Planwerk der Bauaufnahme wurde anschließend mittels CAD-Programmen weiterbearbeitet.

Durch die Auswertung der archäologischen und architektonischen Befunde, die Analyse des Fundmaterials und der Ausstattung des Gebäudes sowie durch die Einbeziehung der älteren Forschungen sollte ein ganzheitliches Bild von den Arbeiten und erzielten Ergebnissen gewonnen werden:

Nach dem einleitenden Kapitel (I) zum Stand der Prytaneion-Forschung und der Aufgabenstellung und Methode wird in Kapitel II ausführlich die Ausgrabungs- und Forschungsgeschichte des Prytaneions von Ephesos dargestellt. Die Ausführlichkeit dieser Darstellung ist insofern von Bedeutung, als in diesem Zusammenhang zahlreiche unpublizierte Archivmaterialien der Altgrabung vorgestellt werden, die für die weiteren Interpretationen unerlässlich sind. In den Kapiteln III und IV werden der architektonische und stratigrafische Befund eingehend diskutiert, um dann als Resultat einen Überblick über die Bauphasen und die Chronologie des Gebäudes liefern zu können (Kapitel V). Im Rahmen einer interdisziplinären Zusammenarbeit werden schließlich das Fundmaterial und die Ausstattung des Gebäudes unter Beiziehung spezialisierter Fachkolleginnen und -kollegen vorgestellt (Kapitel VI und VII). Das Hauptaugenmerk bei der Bearbeitung der Keramik liegt dabei auf einer zeitlichen Einordnung der einzelnen Fundkomplexe, wogegen keramologische Fragestellungen weitgehend unberücksichtigt bleiben. Diese Vorgangsweise erklärt sich aus dem sehr heterogenen Fundbestand, der meist aus Planierschichten geborgen wurde. Das Fundmaterial der Altgrabung muss dabei, da eine genaue stratigrafische Zuordnung nur in Ausnahmefällen möglich ist, über weite Strecken ausgeblendet werden ${ }^{61}$. Mit Kapitel VIII soll die Funktion der einzelnen Räume beleuchtet werden. Eine allgemeine Vergleichsstudie zu Prytaneia in Kleinasien (Kapitel IX) sowie eine anschließende Zusammenfassung (Kapitel X) in deutscher, englischer und türkischer Sprache beschließen den Band.

\footnotetext{
59 s. dazu: E. C. Harris, Principles of Archaeological Stratigraphy ${ }^{2}$ (London 1989).

${ }^{60}$ AutoCAD ${ }^{\circledR}$ in den Versionen 2008 und 2009 der Firma autodesk ${ }^{\circledR}$.

${ }^{61}$ Das Fundmaterial der Altgrabung ist nur noch zu einem Bruchteil im Depot des Grabungshauses in Selçuk vorhanden.
} 


\title{
II AUSGRABUNGS- UND FORSCHUNGSGESCHICHTE
}

\author{
(Martin Steskal)
}

\section{II.1 Forschungen bis 1954}

Während bereits früh Spekulationen über die Lokalisierung des ephesischen Prytaneions angestellt wurden, sollte die tatsächliche Identifizierung des Gebäudes erst ein gutes halbes Jahrhundert nach Beginn der österreichischen Forschungen in Ephesos erfolgen ${ }^{62}$. So vermutete J. T. Wood in seiner Publikation von 1877 das Prytaneion noch im Badblock des Theatergymnasiums ${ }^{63}$; J. Keil wiederum identifizierte das Prytaneion 1923 zunächst mit dem sog. Macellum westlich des Stadions ${ }^{64}$ und schließlich 1939 mit dem Peristylhaus oberhalb des Theaters ${ }^{65}$. Es blieb somit F. Miltner vorbehalten, diese zentrale topografische Frage in den Grabungsjahren 1955/1956 endgültig zu klären ${ }^{66}$.

\section{II.2 Franz Miltner 1955-1956}

Der Beginn der von F. Miltner geleiteten Grabungsarbeiten im Bereich des Prytaneions, die zur späteren Identifizierung des Gebäudes führen sollten, ist mit dem 21. 9. 1955 bestimmt ${ }^{67}$. Von der noch völlig unausgegrabenen Ruine zeigt sich zunächst nur ein einzelner Säulenschaft (KatNr. A 23). Der Ausgräber fasst in

62 Zur Forschungsgeschichte von Ephesos: G. Wiplinger - G. Wlach, Ephesos. 100 Jahre österreichische Forschungen ${ }^{2}$ (Wien 1996); Knibbe 1998; T. Wohlers-Scharf, Die Forschungsgeschichte von Ephesos. Entdeckungen, Grabungen und Persönlichkeiten, Europäische Hochschulschriften 38, 54 2(Frankfurt 1996); Alzinger 1962; cf. auch U. Quatember, Zur Grabungstätigkeit Franz Miltners an der Kuretenstraße, in: Brandt - Gassner - Ladstätter 2005, 271-278.

63 J. T. Wood, Discoveries at Ephesus Including the Site and Remains of the Great Temple of Diana (London 1877) 102: »On the east side of the Forum (gemeint ist das Areal der Verulanushallen, Anm. d. Verf.) and near the great Theatre there are the remains of a very fine stone building which I believe was either the Prytaneum or the Curia. It is about 250 feet square, which is, singularly enough, the size of many of the public buildings in the city. The solid piers of masonry, of which many remain, are particularly well built of large blocks of marble. It was probably erected about the same time as the great Gymnasium, which I assign to the first century of the Christian era." Dem widerspricht J. Keil, Ephesos. Ein Führer durch die Ruinenstätte und ihre Geschichte (Wien 1915) $52 \mathrm{f}$.

${ }^{64}$ J. Keil, Die Agora. Inschriften, in: FiE 3 (Wien 1923) 155 Bezug nehmend auf IvE 3071: »Den Angaben unserer Inschrift und der allgemeinen Erwägung, daß das Prytaneion nicht allzu weit von der Stadtebene zu suchen sein dürfte, würde z. B. ein Ansatz auf dem Hügel westlich von Stadion, der von Westen her durch einen teilweise in den Fels gehauenen Weg zugänglich war und auf seiner Höhe einen von Säulenhallen umgebenen Rundraum trug, gut entsprechen.«

65 Keil 1939, 119-128 bes. 123: »Völlig ausgeschlossen wäre es nicht, dass wir in dem nur teilweise ausgegrabenen Gebäudekomplex oberhalb des Theaters das Prytaneion zu erkennen hätten.«

66 Zur Forschungsgeschichte des Prytaneions s. Miltner 1958a, 27 f. 41-43; Alzinger 1962, 221-229; Alzinger 1972-1975, 232-235; Bammer 2008, 165-170. - Grundlage der folgenden Forschungsgeschichte bilden neben den vorläufigen Grabungsberichten die handschriftlichen Tagebücher und brieflichen Korrespondenzen, die Fotodokumentation, Zeichnungen und Skizzen von Architekturgliedern sowie Grundrisspläne. Die angeführten Quellen werden heute im Dokumentationsarchiv des ÖAI in Wien verwahrt und können dort eingesehen werden. Mit der ausführlichen Vorlage der unpublizierten Archivalien soll der Fachwelt ermöglicht werden, Einblick in die jeweiligen Erkenntnisprozesse zu erhalten. Die Schlüsse und Ergebnisse dieser Forschungen decken sich selbstverständlich nicht immer mit den Resultaten, die seit 2007 erzielt werden konnten.

67 F. Miltner, Tagebucheintrag vom 21. 9. 1955: »Etwas westlich des Hochpflasters und 25 m nordwärts von diesem wird eine Ecksäule (mit üblichem herzförmigen Querschnitt) im Hang gefunden. Da manches dafür spricht, dass sie noch in situ steht, wird aufgegraben.« - An den Arbeiten vor Ort beteiligt sich neben dem Leiter F. Miltner (1955): F. Gschnitzer (Epigrafik). Gschnitzer publiziert später maßgeblich zum Amt der Prytanie: RE Suppl. XIII (1973) 730-816 s. v. Prytanis (F. Gschnitzer); F. Gschnitzer, Prytanen. Ein Beitrag zum geschichtlichen Verständnis griechischer »Staatsaltertümer«, in: F. Hampl - I. Weiler (Hrsg.), Kritische und vergleichende Studien zur Alten Geschichte und Universalgeschichte (Innsbruck 1974) 75-88. 
seinem Bericht zusammen ${ }^{68}$ : Wenige Meter östlich dieses Baues, dem bloß durch eine kaum 2 m breite Ostwestgasse getrennt, ein mehr oblonges Gebäude ostwestlicher Orientierung vorgelagert zu sein scheint, ragte eine Säule von herzförmigem Umriß ca. 0,4 m hoch aus dem Boden. Eine an ihr durchgeführte Tiefgrabung ergab, daß sie noch auf ihrem Sockelpostament in situ ... steht." Obwohl man die Nord-Süd-Ausdehnung des $>$ Hestiasaales ${ }^{69}$ durch die Anlegung eines ca. 1,50 m breiten Schnittes entlang der Westwand bis auf das Bodenniveau (Taf. 6, 1.2) bereits früh fassen kann und auch erkennt, dass das Gebäude offenbar weiter nach Westen ausgreift, bleibt die Funktion der Anlage zunächst noch unklar ${ }^{70}$. Der unmittelbar anschließende Fund von Inschriften an der Außenseite der Südwand des `Hestiasaales` ermöglicht Miltner jedoch einen ersten Interpretationsversuch ${ }^{71}: » A n$ der Aussenwand sind architravartige Blöcke eingemauert, welche zum Teil Inschriften tragen, die sicherlich auf den Bau unmittelbar Bezug haben. Danach muss es sich entweder um das Vereinslokal der Kureten oder um das Bouleuterion handeln.« Im Zuge der weiteren Freilegung des >Hestiasaales` und der Vorhalle kann Miltner die Funktion des Gebäudes konkretisieren ${ }^{72}$ : $\gg$ Da eine der auf der Südwand des Herzsäulenbaues neben der Inschrift auf dem Türsturz die Hestia Boulaia erwähnt (IvE 1065, Anm. d. Verf.), womit sich zeigt, dass die Kureten mit dem Rat als eigenes Synhedrion aufs engste verbunden sind, wird der Herzsäulenbau mit grösster Wahrscheinlichkeit als der Kern des Prytaneions anzusehen sein.« Ohne den »Hestiasaak, die Vorhalle oder andere Bereiche des Gebäudes vollständig freigelegt zu haben, werden die Arbeiten mit dem Ende der Ephesos-Kampagne 1955 am 10. 11. 1955 vorläufig beendet (Taf. 6, 3). Als Ergebnis des ersten Grabungsjahres fasst Miltner zusammen ${ }^{73}$ : »Danach ist klar, daß es sich um den für den Kult der Hestia Boulaia bestimmten Saal handelt, in dessen Mitte der Herd für das heilige Feuer der Stadt gestanden haben muß und der einen Teil des Bouleuterions bildete; wie weit in den Räumen dieser Anlage, deren Ostausdehnung noch fraglich ist, auch das Prytaneion untergebracht war bzw. beide Anlagen vielleicht identisch waren, wird die nächste Grabung zu klären haben. Mit diesem Bau muß aber aufs engste das Kollegium der Kureten zusammengehangen haben.« Aufgrund paläografischer Überlegungen zu im Gebäude verbauten Inschriften mit rein griechischer Namensgebung wie etwa Aлć $\lambda \lambda \eta \varsigma$ A $v \delta \varrho o \mu \alpha ́ \chi 0 v$ und

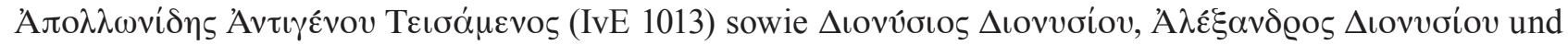

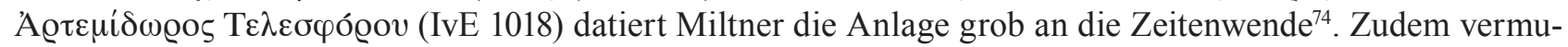
tet er nach stilistischer Analyse des - zu diesem Zeitpunkt einzigen - >herzförmigen< Kompositkapitells eine umfassende Restaurierung der Anlage im zweiten Viertel des 3. Jahrhunderts n. Chr. ${ }^{75}$. Den oberflächlich bereits freigelegten Stereobat der Vorhalle (Taf. 7, 1) bringt Miltner richtig mit den damals vor der Südfas-

68 Miltner 1956-1958, 27 f.; cf. auch F. Miltner, Ergebnisse der österreichischen Ausgrabungen in Ephesos im Jahre 1955, AnzWien 93, 1956, 48 f.; F. Miltner, Bericht über die Ausgrabungen in Ephesos 1955, TAD 7, 1957, 16 f.

69 Die vom Ausgräber F. Miltner eingeführte Bezeichnung `Hestiasaal für Raum 1 wird im Folgenden beibehalten, da sie in der gesamten Sekundärliteratur rezipiert wird. Dass vielmehr der ursprüngliche Querraum 2-4 als >Hestiasaal zu bezeichnen wäre, ergibt sich aus der Beurteilung der Funktion der Räume; s. dazu M. Steskal, Kapitel VIII.4 und 5.

70 Cf. F. Miltner, Tagebucheintrag vom 25. 10. und 27. 10. 1955.

71 F. Miltner, Tagebucheintrag vom 28. 10. 1955.

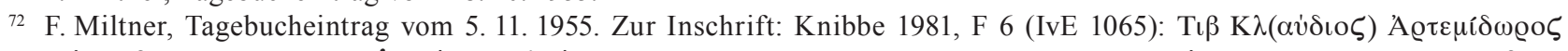

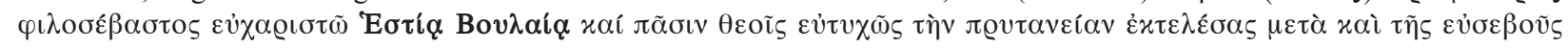

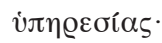

73 Miltner 1956-1958, 29 f.

74 Miltner 1956-1958, 33. Knibbe 1981, B 13 (IvE 1013) und B 18 (IvE 1018) datiert diese Inschriften allerdings an das Ende des 1. bzw. den Anfang des 2. Jhs. n. Chr. Als älteste im Gebäude verbauten Inschriften, die in das frühe 1. Jh. n. Chr. datieren, nennt er (jeweils auf Säulentrommeln der dorischen Ordnung): Knibbe 1981, B 1 (IvE 1001). B 2 (IvE 1002) und B 3 (IvE 1003).

75 Nach Miltner 1956-1958, 33 f. Abb. 20 korrespondiert dieses Kapitell zeitlich mit einem im Schutt des >Hestiasaales` gefundenen männlichen Porträtkopf (KatNr. SK 5), der von Fittschen 1973, 52 severisch datiert wird. Inwieweit diese Porträtplastik tatsächlich einmal im Prytaneion aufgestellt war, ist genauso unbekannt wie der Aufstellungsort weiterer im Zerstörungsschutt des Gebäudes gefundener Stücke: İnan - Rosenbaum 1966, 138 Nr. 172 (Porträt einer jungen Frau, Mitte 3. Jh. n. Chr., gefunden in Raum 6, 1956; KatNr. SK 6); 128 f. Nr. 153 (Porträt einer Frau, severisch, gefunden im Vorhof, 1956; KatNr. SK 7) sowie der linke Unterarm einer männlichen Kolossalstatue (KatNr. SK 11). Beim Absturz der byzantinischen Ostwand von Raum 5A wird 1961 zudem die hintere Hälfte einer bärtigen Porträtbüste (unpubliziert) gefunden (KatNr. SK 8); cf. W. Alzinger, Tagebucheintrag vom 7. 8. 1961. In der Ostmauer des Vorhofes verbaut, findet sich außerdem 1963 eine hellenistische hermenförmige Büste (KatNr. SK 9); cf. Eichler 1964, Taf. 1; KatNr. SK 10 (Torso einer männlichen Ehrenstatue, späthellenistisch). - Zu den Skulpturenfunden s. N. M. High - M. Steskal, Kapitel VII.5. 
sade der Scholastikiatherme befindlichen Säulen in Verbindung und folgert daraus ${ }^{76}: » \ldots$ da sie größtenteils Kuretenlisten tragen, und zwar im allgemeinen spätere als jene an der Südfassade des Herdsaales, so liegt der Schluß nahe, daß sie von der Vorhalle des Hestiakultsaales stammen. Trifft das zu, so würde sich für die Zerstörung des Kultgebäudes der Hestia und damit auch die Auflösung des Kuretenkollegiums und die Aufhebung des Prytaneions und seiner Funktionen die theodosianische Zeit ergeben, ... «

Im August 1956 werden die Arbeiten unter der Leitung von Miltner wieder aufgenommen ${ }^{77}$. Ziel der Kampagne ist es, den gesamten Bezirk des >Hestiasaales` freizulegen. Im Prytaneion selbst werden zunächst Restaurierungsarbeiten vorgenommen, im Zuge derer das im Schutt gefundene Kompositkapitell (KatNr. A 24) auf den in situ angetroffenen nordwestlichen Säulenschaft (KatNr. A 23) gesetzt wird ${ }^{78}$. In unmittelbarem Anschluss wird mit der »Schuttabfuhr im Raum der Vorhalle« begonnen, um auf diese Weise in die westlichen Nebenräume der Anlage gelangen zu können; gleichzeitig wird aber auch die Freilegung des $>$ Hestiasaales` selbst fortgeführt ${ }^{79}$. Die Arbeiten werden mit großem Tempo vorangetrieben; schichtenspezifische Beobachtungen werden während der gesamten Grabungskampagne allerdings kaum getätigt ${ }^{80}$. Die Grabungstätigkeit wird schließlich auf das ganze Gebäude ausgedehnt, um auch in den westlichen Nebenräumen des >Hestiasaales $<$ (Taf. 8, 1) und am Vorplatz das Bodenniveau zu erreichen (Taf. 8, 2. 3) ${ }^{81}$. Auch die kleinen Räume nördlich des >Hestiasaales` werden nun unter großen technischen Schwierigkeiten freigelegt, wobei bald erkannt wird, dass sie einer sekundären Bauphase zuzuordnen sind und als Wasserspeicher - gemäß Miltners Meinung als Zisternen - fungierten ${ }^{82}$. Während die Grabungen ohne wesentliche Rücksichtnahme auf Stratigrafie und genauere Dokumentation von Funden fortgeführt werden, gilt es am 18. 9. 1956 innezuhalten, als man im nördlicheren der beiden westlichen Nebenräume des $>$ Hestiasaales (Raum 5) einen exzeptionellen Fund tätigt (KatNr. SK 1; Taf. 9, 1. 2) ${ }^{83}$ : »In dem Raum ... wird auf dem Boden in Rückenlage eine aus durchschimmernden glänzend poliertem Marmor gefertigte Kultstatue der

76 Miltner 1956-1958, $35 \mathrm{f}$.

77 Cf. die Berichte von Miltner 1959, 289-312; Miltner 1957, 23-25; F. Miltner, Bericht über die Ausgrabungen in Ephesos 1956, TAD 7, 1957, 23 f. An den Arbeiten dieses Jahres beteiligen sich neben dem Leiter F. Miltner (1956): W. Alzinger (Archäologie), K. H. Göschl (Bauforschung) und W. Mach (Restaurierung).

78 Inwieweit sich eben dieses Kapitell ursprünglich auf dem nordwestlichen Säulenschaft des >Hestiasaales` befunden hat, kann aus den Fundumständen nicht rekonstruiert werden. Cf. F. Miltner, Tagebucheintrag vom 6. 8. 1956: »Architekt Göschl mit Kunstakademiker Mach beginnt mit der Aufnahme im Hestiasaal, damit hier das Kapitell, das der Fundlage nach wohl aus dem Südosteck stammt, auf der Säule im Nordwesteck aufgesetzt werden kann.« Der im Schutt gefundene südöstliche Säulenschaft (KatNr. A 16) wird bis zum 5. 10. 1956 wiederaufgestellt (Taf. 7, 2).

79 F. Miltner, Tagebucheintrag vom 19. 8. 1956.

80 Die »Schuttabfuhr« bzw. die »Ausräumungsarbeiten« werden im Grabungstagebuch gerne mit Adjektiven wie »zügig« oder »flott« beschrieben. Cf. beispielsweise F. Miltner, Tagebucheinträge vom 22. 8.-24. 8. 1956. Etwas genauere Angaben finden sich in einem 1956 parallel zum offiziellen Grabungstagebuch geführten Tagebuch W. Alzingers. Dort wird das Gebäude als >Bouleuterion< bezeichnet.

81 F. Miltner, Tagebucheintrag vom 23. 8. 1956.

82 F. Miltner, Tagebucheinträge vom 2. 9. und 7. 9. 1956.

83 F. Miltner, Tagebucheintrag vom 18. 9. 1956. Durch die Besonderheit des Fundes verpflichtet, notiert Miltner als eine der wenigen Ausnahmen folgende schichtenspezifische Beobachtung: F. Miltner, Tagebucheintrag vom 28. 9. 1956: »Im Westraum (Raum 5, Anm. d. Verf.) lässt Keramik annehmen, dass das Artemisniveau etwa im 3. Jh. entstanden ist; beim Tiefergraben unter dieses Niveau treten Lampen des 1. Jhs. auf.« Da er die Fundstücke in der Folge weder inventarisiert noch dokumentiert, sind diese Datierungsansätze heute nicht mehr zu überprüfen. Der von Miltner im Grabungstagebuch als »Artemisniveau« bezeichnete Nutzungshorizont, den er ca. $30 \mathrm{~cm}$ über dem ursprünglichen Laufniveau lokalisiert, führt allerdings zu erheblichen Ungereimtheiten hinsichtlich der Deponierungssituation der \Schönen Artemis $\measuredangle$. So werden weitere Fragmente der Statue in Schichten unter diesem Stratum gefunden. Cf. F. Miltner, Tagebucheintrag vom 26. 10. 1956: »Am Hestiasaal wird im Raum 6 die ursprüngliche Südwand freigemacht, in der annähernd axial eine breite Tür nach Süden sich öffnet; die ursprüngliche Mauer biegt im Westen nach Norden um; im Schutt werden, und zwar in den untersten Schichten, weitere Fragmente der ersten Artemis gefunden.« Ein weiteres Fragment der \Schönen Artemis〈 findet W. Alzinger 1961 in Raum 6 beim »Abgraben auf das Niveau des Hestiasaales« und somit wiederum unter dem »Artemisniveau«; cf. W. Alzinger, Tagebucheintrag vom 9. 8. 1961. Teile der Statue wären folglich vergraben gewesen, während der Großteil der Statue auf (sic!) dem Nutzungshorizont gelegen wäre. Andere Teile, wie etwa der Kopfaufsatz, fehlen überhaupt. Der Großteil der Statue war also nicht vergraben oder gar bestattet, sondern kam - aus Gründen, die uns nicht bekannt sind - auf dem »Artemisniveau« zu liegen. Von einer »Bestattung« der Statue, wie sie Miltner 1958a, 97-104; Miltner 1959, 308 f. und Alzinger 1962, 224 postulieren, kann aufgrund der Fundlage somit keine Rede sein; s. dazu ausführlich Steskal 2008, 363-373; cf. auch N. M. High - M. Steskal, Kapitel VII.5. 
Artemis gefunden. Auf dem Gesicht und der Brust noch beträchtliche Spuren der einstigen Vergoldung. ... Die Statue ist bis auf eine geringfügige Beschädigung der Nase und, von den abgebrochenen Händen abgesehen, vollständig. Knapp über dem niederen Standsockel ist sie in zwei Teile gebrochen.« Abgesehen von dieser als \Schöne Artemis` bezeichneten Statue werden in kurzem Abstand weitere Skulpturen der Göttin gefunden: am 28. 9. 1956 die `Kleine Artemis` in der Ostecke der Vorhalle (KatNr. SK 2; Taf. 9, 3) ${ }^{84}$, am 2./3. 10. 1956 südlich des zentralen Fundaments des Vorhofes die >Große Artemis` (KatNr. SK 4; Taf. 10, 2. $3)^{85}$ sowie am 13. 10. 1956 südlich der $>$ Kleinen Artemis` im Norden des östlichen Umgangs des Vorhofes ein Fußteil einer identischen - offenbar in Serie produzierten - Statue (KatNr. SK 3; Taf. 10, 1) ${ }^{86}$.

Mit dem Ende der Grabungskampagne 1956 gelingt es, das Gebäude vollständig bis auf das jeweils jüngste Bodenniveau freizulegen (Taf. 11, 1). Um dies zu erreichen, werden spätantik/byzantinische Mauern, insbesondere in den Räumen 5 und 6, teilweise abgetragen (Taf. 11, 2) ${ }^{87}$. Neben den Artemisstatuen sind unter den Funden des Jahres 1956 vor allem Architekturglieder der dorischen Ordnung der Vorhalle hervorzuheben ${ }^{88}$, von denen der Architravblock und der Teil des Metopen-Triglyphen-Frieses Kureteninschriften tragen (IvE 1010 bzw. 1030). Der Fund dieser Architekturglieder ermöglicht es Miltner, auch andere Bauteile, die am unteren Embolos gefunden wurden, dem Prytaneion zuzuweisen ${ }^{89}: » Z u$ der dorischen Architektur der Vorhalle des Hestiasaales gehört allem Anschein nach ein gut gearbeitetes dorisches Kapitell auf der Kuretenstrasse vor dem Brunnenhaus (westl. Oktogon), welches von den seinerzeitigen Grabungen herrührt. Vermutlich stammt es in letzter Linie aus der Kuretenhalle, so dass damit der endgültige Beweis für die Vermutung erbracht wäre, dass die Kuretensäulen von Scholastikia aus dem Hestiasaal herunter verbracht wurden.« (Taf. 12). Dies würde dadurch bekräftigt, dass »hinter dem Westende der Halle XII der Scholastikiatherme eine Säule mit einer Kuretenliste, wie solche in der straßenseitigen Arkadenhalle verwendet waren, und auf ihr ein dorisches Kapitell, gleichfalls mit einer Kuretenliste, eingemauert gefunden wurden, welch letzteres in seinen Abmessungen in gleicher Weise zu den Säulen wie zu dem Architrav und zu dem Metopenfries paßt. $\aleph^{90}$ (Taf. 13, 1). Er geht daher von einer systematischen Beraubung des Gebäudes aus, das zur Gewinnung des Baumaterials zerstört worden wäre ${ }^{91}$. Neben dieser profanen Erklärung des Zerstörungsbefundes des Prytaneions offeriert Miltner aber auch einen religiös motivierten Grund, indem er äußert, dass »der Bau von den Christen im heiligen Eifer niedergerissen« worden wäre ${ }^{92}$.

${ }^{84}$ F. Miltner, Tagebucheintrag vom 28. 9. 1956: »Im Osteck der Vorhalle, wo an einer Stelle der Mosaikboden erreicht wird, wird abermals eine Kultstatue der Artemis gefunden, jedoch kopflos und ohne Basis: etwa halbe Lebensgrösse, Marmor der auch schon in Ephesos üblich.« - Zum Fund der Artemisstatuen s. auch Miltner 1959, 305-309; Miltner 1958b, 21-34; Miltner 1957, 23-25; Steskal 2008, 363-373; N. M. High - M. Steskal, Kapitel VII.5.

85 F. Miltner, Tagebucheinträge vom 2./3. 10. 1956: »In der Vorhalle wird nach Süden gegraben und von der Strassenrückwand nach Norden. Dabei wird im Südteil der Torso einer dritten Artemisstatue gefunden.« Den Bothros nördlich des Fundaments lässt Miltner vollständig ausräumen, ohne das Fundmaterial genauer zu beschreiben; s. Steskal 2008, 363-373; N. M. High - M. Steskal, Kapitel VII.5.

86 F. Miltner, Tagebucheintrag vom 13. 10. 1956: »... im Nordosteck der Halle Fussteil einer weiteren Artemis Ephesiastatue und zwar eines zweiten Exemplares der zweiten.«; s. Steskal 2008, 363-373; N. M. High - M. Steskal, Kapitel VII.5.

87 Cf. F. Miltner, Tagebucheintrag vom 26. 9. 1956: »Die Ausräumung der Westräume geht, durch die späteren Einbauten behindert, welche abgetragen werden müssen, nur langsam vonstatten.«

88 Es handelt sich dabei um einen Architravblock (KatNr. A 7), einen Teil des Metopen-Triglyphen-Frieses (KatNr. A 8) und zwei Blöcke des Horizontalgeisons (KatNr. A 9. 10).

89 F. Miltner, Tagebucheintrag vom 7./8. 10. 1956. Zu den Baugliedern dieser als $>$ Kuretenhalle $<$ bezeichneten Stoa s. R. Heberdey, VII. Vorläufiger Bericht über die Grabungen in Ephesus 1904, ÖJh 8, 1905, 76 f.; F. Miltner, XX. Vorläufiger Bericht über die Ausgrabungen in Ephesos, ÖJh 42, 1955, Beibl. 34 f.; Thür 1999, 112-116; Thür 2003, 271 f.; H. Thür, Zur Kuretenstraße von Ephesos. Eine Bestandsaufnahme der Ergebnisse aus der Bauforschung, in: Ladstätter 2009, 9 f. Die Funde von Architekturgliedern mit Kureteninschriften am unteren Embolos führen letztlich zur modernen Namensgebung >Kuretenstraßeく. Aus demselben Grund werden die Scholastikiathermen am Beginn ihrer Ausgrabungen noch als `Kuretenthermen< bezeichnet. - Fragmente einer marmornen Stele mit Kureteninschrift, die wohl aus dem Prytaneion stammt, findet man im Pflaster des Theaterplatzes verbaut: F. Miltner, XXIV. Vorläufiger Bericht über die Ausgrabungen in Ephesos, ÖJh 45, 1960, Beibl. 50 f. Abb. 31; s. auch Knibbe 1981, B 54 (IvE 47). Im Bereich des Westtores der Tetragonos Agora ist eine weitere fragmentierte Kuretenliste auf einer Säule erhalten (IvE 1055), cf. Scherrer 1995b, 19.

90 Miltner 1959, 301 f.; cf. Miltner 1957, 23 f.

${ }_{91}$ Die von Miltner 1959, 299 f. geäußerte Vermutung, dass die Reliefs mit den Gründungslegenden vom sog. Hadrianstempel ursprünglich im >Hestiasaak aufgestellt gewesen waren, ist indes nicht zu belegen.

${ }_{92}$ Miltner 1959, 309; Miltner 1958a, 100 vermutet namentlich die Christin Scholastikia, für die Zerstörung des Gebäudes verant- 
Als vorläufiges Ergebnis konstatiert Miltner ${ }^{93}$ : »Der schon 1955 ausgegrabene Saal mit den vier Säulen von herzförmigem Querschnitt in den Ecken erwies sich, wie vermutet, als ein Hypäthralsaal, in dessen Mitte sich das Fundament des Herdes für das heilige Feuer von dem übrigen, aus besonders großen Marmorplatten gefügten Boden abhebt. ... Die nördliche Rückwand weist nur in der Mitte einen, von kleinen Antenpfeilern flankierten, später zugemauerten Durchlaß ... auf, durch den eine mindestens zweistufige Treppe aus Marmorquadern in den dahinterliegenden Raum führte, der wohl die Cella des Heiligtums der Hestia Bulaia darstellte. Unmittelbar westlich von Herdsaal und Cella lagen ursprünglich zwei ... Räume unbekannter Bestimmung. Herdsaal und westliche Nebenräume sind durch die ... seitlichen Antenmauern der Vorhalle zu einer Einheit zusammengefaßt. Auf dem die Halle nach Süden abgrenzenden ... Fundament waren, wie sich jetzt ergab, Säulen ... aufgerichtet, die eine dorische Architektur trugen. Mit allem gegenwärtig gebotenen Vorbehalt darf man in der Vorhalle mit sechs Interkolumnien rechnen. « Auch die Bauphasen des Prytaneions, zu denen er sich schon zuvor geäußert hat ${ }^{94}$, versucht Miltner nun zu präzisieren. Vor allem die Restaurierung der Anlage in der ersten Hälfte des 3. Jahrhunderts n. Chr. erweitert er um folgenden Befund ${ }^{95}$ : »Im Herdsaal sind zwischen den Postamentsockeln Ziegelmauern von nur geringer Höhe in späterer Zeit eingezogen worden, welche einfach auf das Marmorpflaster aufgelegt wurden: sie sind allem Anscheine nach als der Unterbau von Sitztribünen zu verstehen, auf denen in vier Reihen hintereinander nach überschlägiger Berechnung etwa 200 Leute Platz fanden.« Abgesehen vom Kernbau des Prytaneions vermutet Miltner weiters, dass »dieser ganze an der Westfront des Sockelfundamentes (Chalkidikum, Anm. d. Verf.) beginnende und bis zum Odeion (Bouleuterion, Anm. d. Verf.) reichende Bezirk seit der hellenistischen Zeit das Prytaneion von Ephesos ist. ${ }^{96}$

Während in den darauffolgenden Jahren die Freilegungsarbeiten im Areal nördlich des `Staatsmarktes` teilweise fortgeführt werden, unternimmt Miltner im Prytaneion nur Reinigungsarbeiten (Taf. 13, 2) ${ }^{97}$. Der Schwerpunkt der Kampagnen 1957/1958 liegt aber längst in anderen Bereichen: Es sind dies insbesondere die weitere Ausgrabung der Scholastikiatherme und die durchgehende Freilegung der \Kuretenstraßeく. Trotzdem werden aber die Forschungen am Prytaneion nicht völlig eingestellt. So wird bei der Aufnahme der Inschriften im Gebäude 1957 in der nördlichen Zumauerung des >Hestiasaales〈 ein Torso einer männlichen Ehrenstatue erkannt und aus der Vermauerung herausgelöst (KatNr. SK 10; Taf. 14; 240, 4) ${ }^{98}$. Der noch 1958 geäußerte Plan einer Wiederaufstellung der >Großen Artemis` auf dem zentralen Fundament des Vorhofes wird hingegen nicht ausgeführt ${ }^{99}$.

Durch den überraschenden Tod des Ausgräbers des Prytaneions, F. Miltner, am 23. 7. 1959 kommen die Arbeiten am Gebäude kurzfristig zum Erliegen. Doch bereits 1960 werden die Forschungen unter der Grabungsleitung von F. Eichler, der die »vollständige Klärung des Prytaneionsbezirkes als vordringliche Aufgabe $\ll$ betrachtet $^{100}$, und unter der örtlichen Leitung von W. Alzinger wieder aufgenommen ${ }^{101}$.

wortlich zu sein: »Es ist aber auch zu erwägen, ob nicht Scholastikia dieses Heiligtum in ihrem heiligen Eifer für die Lehre des Evangeliums alles, was heidnisch war, zu verdammen, selbst zerstört hat.« Dem nicht genug, macht Miltner $1958 \mathrm{a}, 101$ Scholastikia auch für das Umstürzen der im Vorhof aufgestellten >Großen Artemis` persönlich verantwortlich: »Die Christin ließ die Statue wohl stürzen, doch die Trümmer blieben unberührt am alten Platze liegen, denn das Geheimnis mystischen Glaubens umwehte auch noch das gestürzte Bild der Gottheit.« Man hätte es aus diesen Gründen auch nicht gewagt, die Statue nach ihrem Sturz völlig zu zerschlagen oder zu Kalk zu verbrennen.

93 Miltner 1959, 290-293.

94 Miltner 1956-1958, $35 \mathrm{f}$.

95 Miltner 1959, $297 \mathrm{f}$.

96 Miltner 1957, 24.

97 Cf. F. Miltner, XXIII. Vorläufiger Bericht über die Ausgrabungen in Ephesos, ÖJh 44, 1959, Beibl. 366.

98 Cf. F. Miltner, Tagebucheintrag vom 13. 8. 1957.

99 Cf. F. Miltner, Tagebucheintrag vom 27. 7. 1958.

100 Eichler 1962, 37.

101 Cf. Eichler 1961, 66 f. 


\section{II.3 Wilhelm Alzinger 1960-1964}

H. Vetters notiert am 6. 9. 1960 zum Beginn der Kampagne 1960 in das Grabungstagebuch ${ }^{102}$ : »Prytaneion: Vom verstorbenen Grabungsleiter wurden lediglich diverse Grundrißskizzen und div. Detailaufnahmen von Architekturbruchstücken übernommen. Um das vorhandene Zeichnungsmaterial zu vervollständigen, wurde mit der Aufnahme der Nordwand des Hestiasaales begonnen.« W. Alzinger, dem die örtliche Leitung der Forschungen am Prytaneion übertragen wird, beginnt daher mit der zeichnerischen Dokumentation des aufgehenden Mauerwerks. Unterstützt wird er dabei von D. Knibbe, der parallel dazu die zahlreichen Inschriften des Gebäudes aufnimmt. Mit großem Aufwand dokumentieren beide zunächst die Nordwand des $>$ Hestiasaales` (Taf. 15, 1) ${ }^{103}$. Gemeinsam mit W. John, der auch für die zeichnerische Aufnahme der Nordwand der Vorhalle verantwortlich ist (Taf. 15, 2), vervollständigt W. Alzinger den Grundriss und fertigt Detailzeichnungen von Architekturgliedern an.

Am 26. 9. 1960 beginnt W. Alzinger schließlich mit einer Reihe von Sondagen unter Bodenniveau, die die Baugeschichte des Prytaneions klären sollen (Taf. 16):

Um einen etwaigen Vorgängerbau zu bestimmen, legt er zunächst in der Nordwestecke des Vorhofes einen 1,50 $\times 2,50 \mathrm{~m}$ großen Schnitt an (Sondage I). Die Sondage führt er bis auf den gewachsenen Boden (»in ca. 4,00 m Tiefe «), wobei er schon zuvor in $» 2,30 \mathrm{~m}$ Tiefe« nach fünf Steinlagen die Unterkante des Stereobats erreicht (Taf. 17, 1) ${ }^{104}$. An der Unterkante des Stereobats konstatiert er eine Kleinschlagschicht aus Kalksteinsplittern (Schicht 7 in Sondage I), die von der Bearbeitung der Quaderblöcke des Stereobats herrührt. Ein kongruentes Stratum konnte weiter östlich in Sondage XXXI (1962) sowie im 2007 durchgeführten Schnitt 1/07 (SE 119) nachgewiesen werden ${ }^{105}$. Um weitere Klarheit zur Stratigrafie in diesem Bereich zu erhalten, erweitert er die Sondage in zwei Schritten bis zur westlichen Begrenzung der >Akademiegasse $\left(\right.$ Sondage II; Taf. 17, 2) ${ }^{106}$. Während er sowohl im offenen Hof (Sondage I) als auch im westlichen

102 H. Vetters, Tagebucheintrag vom 6. 9. 1960. - Das offizielle Tagebuch wird in diesem Jahr von H. Vetters geführt, der auf die schriftlichen Dokumentationen der jeweiligen Projektleiter zurückgreift. - An den Arbeiten vor Ort beteiligen sich neben dem Projektleiter W. Alzinger (1960): F. Eichler (Fundjournal), W. John (Bauforschung) und D. Knibbe (Epigrafik).

103 Cf. H. Vetters, Tagebucheinträge vom 6. 9.-15. 9. 1960. Die zeichnerische Dokumentation wird von sehr präzisen Kommentaren W. Alzingers zur Struktur des Gebäudes begleitet. Mit der Fertigstellung der steingerechten Zeichnung der Nordwand des >Hestiasaales` versucht er bereits eine vorläufige Definition der Bauphasen dieses Raumes. H. Vetters, Tagebucheintrag vom 15. 9. 1960: »Vorläufige Scheidung der Bauperioden: 1.) Marmorsockel (1. Jhd. n. Chr.). 2.) Umbau mit Säulen, Marmorpflaster, regelmäßiges polygonales Mauerwerk aus dunklen Kalksteinen, erste Zumauerung der Nische der Nordwand (cf. Mauerwerk unter dem östlichen Bogenteil), Freilassen einer Türöffnung statt der Nische (3. Jhd.). 3.) Einbau der Sitzbänke mit Ziegelunterbau und Marmorverkleidung, regelmäßiges Ziegelmauerwerk der Nord-, West- und Südwand, 2. Zumauerung der Nische unter Beibehaltung der Türöffnung (vielleicht unmittelbar nach Periode 2). 4.) Zumauerung der Türöffnung in der Nordwand (spät). 5.) Erhöhung des Niveaus (Schwelle in der Südostecke) und Zumauerung der Nebeneingänge in der Südwand. 6.) Abermalige Aufhöhung bis zur Leiste aus Mörtel an der Zumauerung der Nordwand.«

104 Cf. H. Vetters, Tagebucheinträge vom 26. 9.-1. 10. 1960. - Die Beschreibung des Grabungsverlaufes wird von knappen Informationen zum Fundmaterial ergänzt, wobei die Angaben meist nur sehr summarisch ausfallen (»hellenistische Keramik«, »Gebrauchskeramik«, »einfache Keramik«, »atypische Scherben«, »Terra Sigillata«, »Kleinfunde«, etc.). Genauere Angaben finden sich dann, wenn es sich um Fragmente von Skulpturen oder gestempelte bzw. mit Inschriften versehene, aber auch reliefierte Keramik handelt. Neben diesen knappen Angaben werden vom Grabungsleiter F. Eichler sowie von V. MitsopoulosLeon Fundjournale geführt, in denen Fundkisten den jeweiligen Sondagen zugewiesen sowie die einzelnen Funde beschrieben und ausführlich dokumentiert werden (Fundjournal Eichler heute im ÖAW-Archiv, Fundjournal Mitsopoulos-Leon heute im ÖAI-Archiv Wien). Vor allem die akribische Funddokumentation von Mitsopoulos-Leon, die mir großzügigerweise zur Verfügung gestellt wurde, war in diesem Zusammenhang überaus wertvoll. Cf. auch den Vorbericht: Mitsopoulos-Leon 1972-1975, 495-524. Im Laufe der Arbeiten erwies sich jedoch der Umstand als problematisch, dass der Ausgräber zwar detaillierte Profilzeichnungen anlegte, die die Komplexität der Straten sehr gut wiedergeben, er die Grabung aber in Halbmeter-Abhüben durchführte und so die meisten der im Profil erkannten Schichten durchschlagen wurden. Der größte Teil des dokumentierten Fundmaterials ist daher durchmischt und trotz seiner hervorragenden Bearbeitung chronologisch von nur geringer Aussagekraft. Ein Großteil der ehemals im Depot des österreichischen Grabungshauses in Selçuk aufbewahrten Fundkisten und Funde der Jahre 1960-1963 ist zudem heute nicht mehr vorhanden oder nicht mehr zuzuordnen. Klein- und Keramikfunde der Grabungen von F. Miltner zwischen 1955 und 1956 sind überhaupt keine mehr erhalten.

105 Bei der von ihm beschriebenen Brandschicht (Schicht 5 in Sondage I) dürfte es sich um ein lokales Phänomen handeln, da sie weder in der angrenzenden Sondage II noch in den benachbarten Schnitten XXXI, 1/07 und 2/07 nachgewiesen werden konnte.

106 H. Vetters, Tagebucheinträge vom 1. 10.-10. 10. 1960. 
Umgang des Peristyls (Ostteil Sondage II) das jüngste Stratum jeweils in das 1. Jahrhundert n. Chr. datiert, ist das jüngste Laufniveau der >Akademiegasse< seiner Meinung nach erst im 4./5. Jahrhundert $n$. Chr. entstanden (Taf. 18, 1). Im Umgang des Peristyls lokalisiert er noch Reste eines Kalkmörtelestrichs, auf dem seiner Meinung nach ursprünglich ein Marmorplattenpaviment verlegt war ${ }^{107}$. Die ältesten Schichten beider Sondagen datiert er in hellenistische Zeit. Unter der >Akademiegasse< tätigt er als herausragenden Fund in $» 1,50 \mathrm{~m}$ Tiefe« in einer »spätantiken Aufschüttungsschicht« eine Schrankenplatte mit christlichen Symbolen (Taf. 18, 2; 19, 1. 2) ${ }^{108}$. Sondage II führt er wie Sondage I bis auf den gewachsenen Boden.

Über die kleine Sondage III in der Südostecke des Peristyls des Vorhofes verliert Alzinger nur wenige Worte (Taf. 16) ${ }^{109}$ : Nach Abtragen eines Kalkmörtelestrichs, der als Bettung eines Marmorplattenpaviments diente, und diverser Aufschüttungsschichten stößt er bis auf die Unterkante des Fundaments der Ost- und Südmauer des Vorhofes vor, um auf diesem Niveau die Grabung zu beenden.

In der Südwestecke des Peristyls des Vorhofes legt Alzinger zunächst Sondage IV an, die er dann um Sondage V nach Osten vergrößert (Taf. 16) ${ }^{110}$. In Sondage IV stößt er bereits »1,50 m unter der Krone der Südmauer« des Vorhofes auf einen Steinplattenbelag, auf dem zwei Tonrohrleitungen liegen (Taf. 19, 3; 20, 1). Da der Plattenbelag nach Norden nicht weiterläuft, kann Alzinger in diesem Bereich tiefer graben. Er legt dabei »0,73 m östlich der Westmauer« des Vorhofes einen parallel verlaufenden Mauerzug (»Mauer A«) frei (»Krone 0,60 m tief«, »Fundamente enden in 1,70 m Tiefe«). Um den weiteren Verlauf der »Mauer A« zu verifizieren, erweitert er den Schnitt nach Osten (Sondage V; Taf. 20, 2). Er stößt dabei »in einer Tiefe von 1,50 m« auf die Krone der 0,65 m starken, nun parallel zur Südmauer des Vorhofes verlaufenden »Mauer A«. Auf demselben Niveau findet er weitere Platten des bereits in Sondage IV festgestellten Pflasters, das sich aber im Ostteil der Sondage nicht mehr nachweisen lässt ${ }^{111}$. Die Grabung beendet er mit Erreichen des sterilen gewachsenen Bodens in $» 5 \mathrm{~m}$ Tiefe«. Den jüngsten Nutzungshorizont, den er in den Sondagen I und II in das 1. Jahrhundert n. Chr. datiert, setzt er hier in »augusteisch/tiberianische Zeit«, wobei er diesen Datierungsansätzen jeweils ein »?« anhängt. Gemäß seinen stratigrafischen Kommentaren auf der Profilzeichnung (Taf. 20,2) datiert er »Mauer A« in späthellenistische Zeit. Die ältesten Straten gehen seiner Meinung nach nicht über die hellenistische Zeit hinaus.

Neben den Untersuchungen zur Baugeschichte des Prytaneions werden aber auch Überlegungen zur Zerstörung und Nachnutzung des Gebäudes angestellt1 ${ }^{112}$. F. Eichler fasst zusammen ${ }^{113}$ : »Nach der Zerstörung der frühkaiserzeitlichen Anlage, die wohl im 4. Jh. n. Chr. erfolgte, wurden viele ihrer Werkstücke nach anderen Stellen verschleppt und dort wiederverwendet, so an der Therme der Christin Scholastikia. Was im Bereiche des Prytaneions liegen geblieben war, wurde zu einer mächtigen Schuttschicht zusammengeschaufelt, über der späte Wohnbauten errichtet wurden.«

Mit einer Reihe weiterer Sondagen unter Bodenniveau versucht Alzinger 1961 die Baugeschichte des Gebäudes genauer zu klären ${ }^{114}$.

107 Dieser Estrich wird von Alzinger auch in der Südostecke des Umgangs (Sondage III und XXI) sowie vom Verf. in der Nordostecke des Umgangs (Schnitt 2/07, SE 206) festgestellt.

108 Cf. H. Vetters, Tagebucheinträge vom 6. 10.-8. 10. 1960. Es handelt sich dabei um eine Schrankenplatte mit drei lateinischen Kreuzen auf der Vorderseite, wobei sich das zentrale Kreuz auf einer Kreisscheibe befindet. Dieses zentrale Kreuz ist durch ein Wellenband, das jeweils in einem herzförmigen Blatt endet, mit den flankierenden Kreuzen verbunden. Auf der Rückseite befindet sich ein weiteres lateinisches Kreuz. Der heutige Aufbewahrungsort ist unbekannt. Cf. dazu allgemein: Th. Ulbert, Studien zur dekorativen Reliefplastik des östlichen Mittelmeerraumes (Schrankenplatten des 4.-10. Jahrhunderts), Miscellanea Byzantina Monacensia 10 (München 1969); RBK I (1966) 900-931 s. v. Cancelli (Ch. Delvoye). Für den freundlichen Hinweis sei A. Pülz gedankt.

109 Cf. H. Vetters, Tagebucheinträge vom 11. 10.-13. 10. 1960. Von Sondage III haben sich keine Zeichnungen oder Fotografien erhalten.

110 Cf. H. Vetters, Tagebucheinträge vom 14. 10.-5. 11. 1960.

111 Bei diesem Pflaster könnte es sich um den Belag des `Clivus sacer handeln, der dann an dieser Stelle ursprünglich eine Breite von ca. 6,70 m besessen hätte (heute: ca. 3,80 m).

112 Darüber hinaus beginnt Alzinger am Ende der Kampagne mit der Anfertigung einer Baubeschreibung. Cf. H. Vetters, Tagebucheinträge vom 6. 11.-8. 11. 1960.

113 Eichler 1961, 68.

114 Neben dem Projektleiter W. Alzinger beteiligen sich an den Arbeiten vor Ort (1961): W. John (Bauforschung), D. Knibbe (Epigrafik) und W. Mach (Restaurierung). 
Zunächst legt er einen $5 \times 2 \mathrm{~m}$ großen Schnitt an der Nordseite der Vorhalle, unmittelbar vor Tür 2, an (Sondage VIII; Taf. 16) ${ }^{115}$, den er bis auf die Unterkante des Kalksteinfundaments der Vorhallen-Rückwand »in 2 m Tiefe« führt (Taf. 20, 3; 21, 1. 2). In einer Erdaufschüttung über einem postulierten ursprünglichen Marmorboden findet er eine Münze eines der Söhne des Septimius Severus, die er als terminus post quem für den - an dieser Stelle fehlenden - Mosaikboden heranzieht ${ }^{116}$. Von diesem hypothetischen Marmorboden findet er allerdings auch in den weiteren Schnitten in der Vorhalle keine Spuren, da auch das bauzeitliche - und später vollständig entfernte - Paviment auf demselben Niveau wie der Mosaikboden gelegen haben muss ${ }^{117}$. Sondage X legt er an der Westwand des $>$ Hestiasaales` an (Taf. 16) ${ }^{118}$. Er erkennt dabei, dass das Gelände, auf dem das Prytaneion errichtet ist, stark nach Süden abfällt: So erweist sich das Fundament des Marmorsockels der Westwand im Norden als nur mit einer Lage Kalksteinquadern gebildet (bis 0,25 m Tiefe), während es nach Süden zunächst zweilagig (bis 0,60 m Tiefe) und schließlich dreilagig konstruiert ist (bis 0,90 m Tiefe; Taf. 21, 3) ${ }^{119}$. Es wurde zudem in eine seichte Baugrube gesetzt, die unmittelbar in den sterilen gewachsenen Boden gegraben worden war. Sondage XI in der Südostecke des `Hestiasaales` (Taf. 16) muss er nach dem Abgraben von lediglich 0,20 m beenden, da er auf das Kalksteinquaderfundament des Säulenstuhls der dort befindlichen >Herzsäule< stößt (Taf. 22, 1) ${ }^{120}$.

Nach mehrmonatiger Unterbrechung führt Alzinger seine Grabungen am 7. 8. 1961 weiter, wobei er zunächst die Räume 5 und 6 bis auf das Niveau des $>$ Hestiasaales` freilegt ${ }^{121}$. Parallel dazu setzt er gemeinsam mit W. John die Bauaufnahme fort (Taf. 22, 2. 3). Zur Klärung des Grundrisses der Räume nördlich des $>$ Hestiasaales legt er entlang der Ostmauer von Raum 4 Sondage XVI an (Taf. 16; 23, 1. 2) ) $^{122}$. Er konstatiert dabei unter dem Nutzungshorizont aus Ziegelplatten eine in den Fels gearbeitete Baugrube zur Nordwand des Raumes sowie den stark nach Süden abfallenden anstehenden Felsboden. Im Eingangsbereich zwischen Vorhalle und `Hestiasaak (Tür 3) stößt er in Sondage XVIII auf das Fundament der Vorhallen-Rückwand (Taf. 16; 23, 3) $)^{123}$. Es erweist sich als Mauerwerk aus ca. $1 \mathrm{~m}$ langen Kalksteinblöcken. An der Oberfläche des Fundaments stellt er noch Reste von Estrich fest, den er mit der Fixierung der nicht mehr vorhandenen Türschwelle oder von Marmorplatten in Verbindung bringt. In »etwa $1 \mathrm{~m}$ Tiefe« gelangt er auf den sterilen gewachsenen Boden, wo er den Schnitt beendet. Knapp zwei Wochen nach Beendigung des Schnittes findet er nachträglich im Aushub ein Fragment eines hellenistischen lesbischen Kymations (Taf. 23, 4) und äußert folgende vage und freilich nicht zu belegende Vermutung ${ }^{124}$ : »Aus der anhaftenden Erde kann geschlossen werden, daß das Fragment in der roten Erdschichte gefunden wurde. Vielleicht stammt es vom ältesten Bau an dieser Stelle, dessen Architektur jedoch auf kleinste Stücke zerschlagen worden sein muß.« Im >Hestiasaak legt er mit Sondage XIX die Nordseite des zentralen Fundaments frei (Taf. 16; 24, 1) ${ }^{125}$. Unter dem um 0,20 m zurückspringenden Sockel besteht das Fundament aus einer 0,30 m starken Lage »aus schönen großen Kalksteinquadern«. Die Außenflächen des Sockels, der im oberen Teil über das Marmorplattenpaviment des >Hestiasaales` ragt, erweisen sich als »geglättet und zeigen guten Fugenschluß«. Südlich von Sondage III (1960) untersucht Alzinger in Sondage XXI (Taf. 16; 24, 2. 3) die Ostmauer des Vorhofes ${ }^{126}$. Er

115 Cf. W. Alzinger, Tagebucheinträge vom 16. 4.-2. 5. 1961.

116 Cf. Eichler 1962, 39 f.

117 Cf. Sondage XVIII (1961), XXXI (1962) und XXXVI (1963).

118 Cf. W. Alzinger, Tagebucheintrag vom 22. 4. 1961. - Ausgelassene Sondagennummern benennen Schnitte im Bereich zwischen Prytaneion und Bouleuterion, die im Zuge dieser Arbeit nicht behandelt werden.

119 Die zahlreichen Sondagen in allen Bereichen des Gebäudes belegen den generellen Abfall des Geländes von Nord nach Süd.

120 Cf. W. Alzinger, Tagebucheintrag vom 23. 4. 1961.

121 Cf. W. Alzinger, Tagebucheinträge vom 8. 8.-10. 8. 1961.

122 Cf. W. Alzinger, Tagebucheinträge vom 12. 8.-16. 8. 1961.

123 Cf. W. Alzinger, Tagebucheinträge vom 15. 8.-16. 8. 1961.

124 W. Alzinger, Tagebucheintrag vom 28. 8. 1961. Dieses Fragment wird in der Folge in den publizierten Vorberichten als Beleg für einen hellenistischen Vorgängerbau bemüht - ohne jedoch darauf zu verweisen, dass es nicht während der Grabung, sondern erst im Aushub gefunden wurde. Cf. Eichler 1962, 39: »Ein Bruchstück eines sehr feinen lesbischen Kymations mit Spuren der Bemalung, das sich in einer Sondage fand, dürfte der Bauornamentik dieser frühen Periode (bald nach der lysimachischen Stadtgründung, Anm. d. Verf.) angehören.«

125 Cf. W. Alzinger, Tagebucheintrag vom 16. 8. 1961. Cf. auch den analogen Befund an der Westseite des Fundaments (Schnitt 4/07).

126 Cf. W. Alzinger, Tagebucheinträge vom 19. 8.-27. 8. 1961. 
legt dabei unter einem jüngeren Nutzungsniveau aus »Ziegelmehlestrich« analog zur früheren Sondage II (1960) den Kalkmörtelestrich des verlorenen Marmorplattenpaviments frei. Die Unterkante der Ostmauer findet er in $» 1,50 \mathrm{~m}$ Tiefe«, wo er die Grabung beendet, ohne auf den sterilen gewachsenen Boden gelangt zu sein. Innerhalb der Aufschüttungsschichten lokalisiert er »in $1 \mathrm{~m}$ Tiefe« eine »nahezu durchgehende Brandschicht « sowie »in 0,55 m Tiefe« einen weiteren - allerdings nicht durchgehend erhaltenen - »Ziegelmehlestrich « ${ }^{127}$. Während sich in Sondage XX im östlich benachbarten Raum 13 zeigt, dass die Westmauer dieses Raumes »auf einem Gußmauerfundament « aufsitzt ${ }^{128}$, kann dieses opus caementicium-Fundament in Sondage XXI an der Ostmauer des Vorhofes nicht nachgewiesen werden. In einer »Tiefe von 1,34 m« stößt er auf das Fundament der 1960 in den Sondagen IV und V angetroffenen, West-Ost verlaufenden »Mauer A«, die jedoch $» 0,80 \mathrm{~m}$ westlich der Hallenrückwand« abbricht. Mit Sondage XXIII legt er das opus caementicium-Fundament des >Doppelmonuments〈 im Temenos östlich der Ostmauer des Vorhofes frei ${ }^{129}$ (Taf. 16; 24, 4). Es reicht bis unmittelbar an die Ostmauer des Prytaneions heran. In Sondage XXII an der Südwand von Raum 6 (Taf. 16. 25) ergräbt er wiederum das Fundament der Vorhallen-Rückwand ${ }^{130}$. Es besteht, wie auch schon zuvor in den Sondagen VIII und XVIII festgestellt, aus Kalksteinquadern, wobei sich die oberste Lage als nur grob, die unteren Lagen als sehr sorgfältig bearbeitet erweisen. In etwa $\gg 2 \mathrm{~m}$ Tiefe« beendet Alzinger den Schnitt. Um den Verlauf der bereits 1960 in den Sondagen IV und V und zuvor in Sondage XXI festgestellten »Mauer A« zu bestimmen, legt er anschließend im südlichen Umgang des Vorhofes mit Sondage XXV eine ca. 4,30 $\times 1,50 \mathrm{~m}$ große Fläche frei (Taf. 16; 26, 1) ${ }^{131}$. In $\gg 0,55 \mathrm{~m}$ Tiefe« stößt er auf die parallel zur Südmauer des Vorhofes verlaufende Mauer. Bis etwa »1,50 m Tiefe« notiert er noch Keramikfunde, ohne jedoch auf die Stratigrafie an sich einzugehen. Diese Dokumentationsmethode ist über die gesamte Grabungsperiode von 1960-1963 zu verfolgen. Eine Überblicksaufnahme zeugt von den Grabungsaktivitäten des Jahres 1961 im Bereich des >Hestiasaales`, der Vorhalle und des Vorhofes (Taf. 26, 2). Zur Verifizierung des Verlaufs der »Mauer A« legt er etwa $5 \mathrm{~m}$ östlich der Sondage XXV, im südöstlichen Bereich der Stoa des Vorhofes, die L-förmige Sondage XXVI an (Taf. 16; 24, 2) ${ }^{132}$. Unmittelbar unter dem Niveau der Stoa deckt er einen 0,20 m breiten und ca. 0,25 m tiefen Kanal auf, der das Wasser der Regenrinne des Vorhofes und des Nord-Süd verlaufenden Kanals unter dem östlichen Umgang des Vorhofes ableitete. In »1 m Tiefe« stößt er schließlich auf das Fundament von »Mauer A«. Die letzte Grabungsaktivität des Jahres befindet sich mit Sondage XXIX in der Nordwestecke von Raum 7A, also östlich der Ostmauer des $\gg$ Hestiasaales〈 (Taf. 16; 26, 3) ${ }^{133}$. In $\gg 2,85 \mathrm{~m}$ Tiefe« erreicht er den anstehenden Fels. Es zeigt sich, dass das »um ca. 0,18-0,20 m verbreiterte Fundament« der Ostwand des `Hestiasaales« in einer in den Fels geschlagenen Baugrube sitzt.

In dieses Grabungsjahr fällt schließlich auch die Aufstellung einer Architekturprobe des dorischen Gebälks der Vorhalle, bestehend aus einem Kapitell (KatNr. A 6), einem Architravblock (KatNr. A 7), einem Fragment des Metopen-Triglyphen-Frieses (KatNr. A 8) und einem Block des Horizontalgeisons (KatNr. A 9; Taf. 26, 4).

Das Ergebnis der Kampagne 1961 lässt sich wie folgt zusammenfassen ${ }^{134}$ : W. Alzinger geht von einem frühhellenistischen Vorgängerbau aus, der bald nach der lysimachischen Stadtgründung errichtet hätte werden sollen. Die zweite Bauperiode, der er vor allem die dorische Architektur der Vorhalle zurechnet, datiert er in augusteische Zeit. In diese Periode setzt er auch den Sockel aus Marmorquadern, das darüber aufgehende Bruchsteinmauerwerk sowie den Keilsteinbogen der Nordwand des 〉Hestiasaales $<$. Die Errichtung des Peristyls des Vorhofes datiert er in eine dritte Bauperiode um $100 \mathrm{n}$. Chr. In der ersten Hälfte des 3. Jahrhunderts wären schließlich die >Herzsäulen` im 〉Hestiasaak errichtet sowie der Mosaikboden in der Vorhalle verlegt worden. Als noch später bezeichnet er die Ziegelmauern im Inneren des `Hestiasaales`,

127 Vergleichbare Straten konnten im weiter nördlich angelegten Schnitt 2/07 nicht festgestellt werden.

128 Es handelt sich bei Sondage XX in Raum 13 weniger um eine Grabung als um eine größer angelegte Reinigung; W. Alzinger, Tagebucheintrag vom 20. 8. 1961 spricht wörtlich vom »Auskehren« des Raumes.

129 Cf. W. Alzinger, Tagebucheintrag vom 21. 8. 1961.

130 Cf. W. Alzinger, Tagebucheintrag vom 19. 8. 1961.

131 Cf. W. Alzinger, Tagebucheinträge vom 21. 8.-22. 8. 1961.

132 Cf. W. Alzinger, Tagebucheinträge vom 23. 8.-27. 8. 1961.

133 Cf. W. Alzinger, Tagebucheinträge vom 28. 8.-30. 8. 1961.

134 Eichler 1962, 38-41. 
wobei er sich nicht festlegt, ob es sich um den Unterbau von Sitzstufen oder um Klinen gehandelt haben könnte. Ebenfalls lässt er zu diesem Zeitpunkt offen, inwieweit nicht das bis dato unidentifizierte ephesische Bouleuterion im Prytaneion untergebracht gewesen wäre ${ }^{135}$. Mit Ende der Kampagne kann er einen neuen, detailgenaueren Grundriss der Anlage vorlegen (Taf. 27).

Die Grabungen der Kampagne 1962 reduziert Alzinger auf den Bereich nördlich des Prytaneions und auf einen Nord-Süd-Schnitt durch die Vorhalle und den Vorhof (Sondage XXXI) ${ }^{136}$. Nördlich der Rückwand des Prytaneions deckt er einen an seiner West- und Ostseite abgemauerten Schacht auf, der der Trockenhaltung der Nordwand des Gebäudes diente ${ }^{137}$. Die Kanalwangen erweisen sich in ihrem unteren Teil als in den anstehenden Fels geschnitten. Die Mauerstrukturen nördlich der Nordwand des Gebäudes bezeichnet er als byzantinisch und nicht mehr mit dem Prytaneion in Verbindung stehend. Zur weiteren Klärung der Baugeschichte legt er die 1,50 m breite, die Vorhalle und den Vorhof schneidende Sondage XXXI (Taf. 16. 28) $\mathrm{an}^{138}$. Er stößt dabei auf teils vertraute Straten und Befunde, wie etwa die Ost-West verlaufende »Mauer A« im südlichen Umgang des Vorhofes, die er bereits in den Jahren zuvor in den Sondagen IV, V, XXI, XXV und XXVI angetroffen hat. Südlich des Stereobats gelangt er an dessen Unterkante unter Aufschüttungsschichten auf die Kleinschlagschicht aus Kalksteinsplittern, die von der Bearbeitung der Quaderblöcke des Stereobats herrührt. Ein kongruentes Stratum konnte weiter westlich in Sondage I (1960) sowie im 2007 durchgeführten Schnitt 1/07 (SE 119) nachgewiesen werden. Innerhalb der Vorhalle tieft er die Sondage bis auf die Unterkante des Stereobats »in 2,50 m Tiefe« ab. Dieser erweist sich als in den sterilen gewachsenen Boden gesetzt. Von der Bearbeitung der Oberflächen der Fundamentblöcke rühren Schichten durchsetzt mit zahlreichen Kalksteinsplittern her. Ein bauzeitliches Niveau unter dem im Bereich der Sondage fehlenden Mosaikboden kann Alzinger allerdings nicht ausmachen. Großes Interesse widmet er der Stratigrafie des Vorhofes im Bereich des Bothros und des Fundaments der >Großen Artemis $\measuredangle$. Für das Fundament konstatiert er zwei Bauperioden, wobei er die ältere in hellenistische Zeit datiert. 2,13 m südlich des Fundaments stößt er in etwa $\gg 2,50 \mathrm{~m}$ Tiefe«, wo er die Grabung auch beendet, auf ein in West-Ost-Richtung verlaufendes »altes Fundament«, bestehend aus einer unvermörtelten Steinschar. An der Rückwand des südlichen Umgangs stellt er fest, dass sich die Struktur des bis in $» 2,50 \mathrm{~m}$ Tiefe« hinabreichenden Fundaments in $» 1 \mathrm{~m}$ Tiefe« ändert; er vermutet daher an dieser Stelle eine ältere Mauer. Eine solche Beobachtung kann er jedoch in den zuvor an der Rückwand des südlichen Umgangs durchgeführten Sondagen III, IV, V, XXV und XXVI nicht tätigen.

Neben den beschriebenen Ausgrabungen des Jahres 1962 beginnt Alzinger die im Jahr zuvor aufgerichtete Architekturprobe des dorischen Gebälks der Vorhalle auf die zugehörigen obersten Säulentrommeln zu setzen. Diese lässt er dafür an der unteren \Kuretenstraßeく abbauen.

1963 werden die Grabungen im Prytaneion fortgesetzt ${ }^{139}$. Zunächst legt Alzinger auf Höhe der westlichen Antenmauer einen Schnitt quer über die `Akademiegasse` zur Untersuchung der Fundamente des Gebäudes an (Sondage XXXII; Taf. 16) ${ }^{140}$. Das Fundament der Antenmauer aus nicht vermörtelten Quadermauern

135 Bestärkt fühlt sich Alzinger durch den Fund einer Inschrift auf einem Marmorquader unmittelbar vor der Nordwand des `Hestiasaales`, westlich der zwei nach Norden führenden Stufen (IvE 740B). Auf der Inschrift, die in das 1. Jh. v. Chr. datiert,

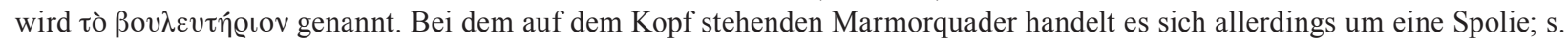
L. Bier, The Bouleuterion at Ephesos: Some Observations for a New Survey, in: Scherrer - Taeuber - Thür 1999, 16; Eichler 1962, 41. Bier (in Druck) deutet diese Inschrift, wenn nicht als Beweis, so doch als Hinweis für die Existenz eines hellenistischen Bouleuterions im Areal des oberen \Staatsmarktes«. Das Gebäude selbst sei aber nicht zu identifizieren; s. schon zuvor W. Alzinger, Die Lokalisierung des hellenistischen Rathauses von Ephesos, in: Bathron. Beiträge zur Architektur und verwandten Künsten. Festschrift Heinrich Drerup, Saarbrücker Studien zur Archäologie und Alten Geschichte 3 (Saarbrücken 1988) 21-29, der ein hellenistisches Bouleuterion unter der Westhälfte des späteren römischen Baues als gesichert annimmt. Kritisch dazu: Thür 2007, 80.

136 Cf. den Grabungsbericht bei Eichler 1963, 46. Neben dem Projektleiter W. Alzinger beteiligen sich vor Ort (1962): W. John (Bauforschung), D. Knibbe (Epigrafik), W. Mach (Restaurierung) und V. Mitsopoulos-Leon (Fundbearbeitung).

137 Cf. W. Alzinger, Tagebucheinträge vom 17. 5.-4. 6. 1962.

138 Cf. W. Alzinger, Tagebucheinträge vom 2. 5.-28. 5. 1962.

139 Cf. Eichler 1964, 40 f. An den Arbeiten vor Ort sind neben dem Leiter W. Alzinger des Weiteren beteiligt (1963): A. Bammer (Bauforschung), R. Fleischer (Archäologie), D. Knibbe (Epigrafik), V. Mitsopoulos-Leon (Funbearbeitung), F. Ölzant (Restaurierung) und G. Seiterle (Archäologie).

140 Cf. W. Alzinger, Tagebucheinträge vom 17. 8.-1. 9. 1963. 
sitzt, wie sich zeigt, unmittelbar auf dem sterilen gewachsenen Boden. Es reicht 3,05 m unter das Niveau des Stylobats der Vorhalle (absolut: 42,99 m) ${ }^{141}$. Eine Baugrube kann er nicht ausmachen. Gleichzeitig wird mit der Abnahme der Mosaikreste der Vorhalle begonnen, um den Westteil der Vorhalle archäologisch untersuchen und den Boden später mittels einer Bettung aus Beton sichern zu können. Im Vorhof legt Alzinger daraufhin auf Höhe des Fundaments die sich über die Umgänge des Hofes und den Bereich östlich des Fundaments erstreckende, $2 \mathrm{~m}$ breite, Ost-West orientierte Sondage XXXV an (Taf. 16) ${ }^{142}$. In dieser Sondage, die er bis auf den sterilen gewachsenen Boden führt, werden ältere Konstruktionen angeschnitten, die nach Alzinger in hellenistische Zeit datieren und mit den 1961 in der Orchestra des Bouleuterions aufgedeckten Fundamenten in Zusammenhang stehen könnten ${ }^{143}$. In der Nordwestecke der Vorhalle legt er unter dem abgehobenen Mosaikboden Sondage XXXVI an (Taf. 16) ${ }^{144}$. Wie Alzinger darstellen kann, liegt der Mosaikboden »auf einer 0,10 $\mathrm{m}$ starken Zementschicht« und diese wiederum auf wiederverwendeten Marmorplatten (darunter auch Fragmente von Kuretenlisten). Unmittelbar auf dem gewachsenen Boden stößt er auf eine dünne Brandschicht, von der er vermutet, dass sie beim »Abbrennen des Unkrautes bei der Rodung des Platzes« entstanden sein könnte. Er beendet die Sondage, ohne ein bauzeitliches Niveau entdeckt zu haben. Die zweigeteilte Sondage XXXVII in Raum 5 legt er an, um Fundamentgruben am Kalksteinquadermauerwerk der West- und Ostwand feststellen zu können (Taf. 16) ${ }^{145}$. Ferner kann er an der Ostmauer die bauzeitliche Tür nach Raum 4 nachweisen. Ost- und Westmauern des Raumes weisen in den anstehenden Fels eingeschnittene Fundamentgruben auf. Die ebenfalls West-Ost ausgerichtete Sondage XXXVIII vor der Ostwand von Raum 6 erreicht bereits »0,70 m unter der Höhe der Türschwelle« nach Raum 5 den gewachsenen Boden (Taf. 16) ${ }^{146}$. Die sekundäre Rampe an der Westwand des Raumes wird im Zuge dieser Grabungen teilweise abgetragen.

Wie sich bei Anlage des Schnittes 1/07 im Sommer 2007 zeigte, wurde im Bereich des Vorhofes auch entlang des Stereobats eine $1 \mathrm{~m}$ breite Sondage angelegt, die bis auf dessen Unterkante geführt worden war. Von dieser Sondage gibt es keine Aufzeichnungen, womit auch ihr Zeitpunkt und etwaige stratigrafische Beobachtungen unbekannt bleiben.

Die Ergebnisse der zahlreichen Sondagen W. Alzingers im Bereich des Prytaneions referiert F. Eichler in seinem Jahresbericht ${ }^{147}$ : $»$ Die Existenz eines voraugusteischen Baues im Bereich des Hestia-Saales und seiner Nebenräume ist nicht nachweisbar; die erste Anlage entstand um Christi Geburt. In hellenistischer Zeit war der Platz unverbaut, jedoch künstlich angeschüttet worden, woraus sich die bei früheren Tiefgrabungen gefundenen hellenistischen Keramikscherben erklären." In diese Aufschüttungsschichten seien in augusteischer Zeit die Fundamente des Prytaneions verlegt worden, wobei man die einzelnen Baugruben bis zum gewachsenen Boden ausgeschachtet hätte. Alzinger wendet sich daher gegen einen früher von ihm selbst postulierten hellenistischen Vorgängerbau ${ }^{148}$. Der ersten, augusteischen Bauperiode rechnet er nunmehr die dorische Vorhallenfront zu, die er mit sechs 7,42 m hohen Säulen zwischen den Anten und einem verbreiterten Mitteljoch rekonstruiert ${ }^{149}$. Als Überdachung der Anlage nimmt er ein Satteldach an, das sämtliche Räume des Gebäudes einheitlich überdeckt hätte ${ }^{150}$. Er wendet sich daher gegen die von F. Miltner vermutete Hypäthral-Lösung des $>$ Hestiasaales ${ }^{151}$.

Während der Grabungskampagne 1963 wird auch an der Erweiterung der Architekturprobe der dorischen Ordnung der Vorhalle gearbeitet ${ }^{152}$. Dabei ersetzt man zunächst den fehlenden Stylobat durch ein-

${ }^{141}$ Cf. die Schnittzeichnung »Prytaneion - Odeion« nach Norden (ÖAI InvNr. 2360/8).

142 Cf. W. Alzinger, Tagebucheinträge vom 31. 8.-15. 9. 1963 sowie die Zeichnungen Ephesos 1963, Blätter 4. 6. 8. 9 (R. F.).

143 Cf. dazu die Sondagen XII und XIII in der Orchestra des Bouleuterions. Ephesos 1961, Prytaneion, Blatt 17 (W. A.).

144 Cf. W. Alzinger, Tagebucheinträge vom 31. 8.-14. 9.1963 sowie die Zeichnung Ephesos 1963, Blatt 5 (R. F.).

145 Cf. W. Alzinger, Tagebucheinträge vom 9. 9.-16. 9. 1963.

146 Cf. W. Alzinger, Tagebucheinträge vom 9. 9.-14. 9.1963 sowie die Zeichnung Ephesos 1963, Blatt 7 (R. F.).

147 Eichler 1964, 40.

148 Wie er ihn beispielsweise noch am Beginn der Grabungskampagne 1963 formulierte; cf. W. Alzinger, Tagebucheintrag vom 14. 8. 1963; cf. auch Eichler 1962, 38-41.

149 Cf. Bammer 1976/1977, 57; Bammer 2008, 170.

150 Cf. W. Alzinger, Tagebucheintrag vom 18. 8. 1963.

151 Miltner 1959, 290.

152 Cf. W. Alzinger, Tagebucheinträge vom 1. 9.-17. 9. 1963. 
zelne Betonsockel ${ }^{153}$. Die zum Gebäude gehörenden Trommeln werden von der \Kuretenhalle zum Prytaneion transportiert und entsprechend ihrer Entasis zusammengefügt. Da nur noch ein begrenzter Bestand an Säulentrommeln der Vorhalle vorgefunden wird, werden die Trommeln entgegen ihrer ursprünglichen Anordnung zusammengesetzt, was durch das abrupte Abbrechen oder den unvermittelten Beginn von $\mathrm{Ku}-$ reteninschriften auf den Trommeln eindrucksvoll belegt wird. Säule KatNr. A 3 wird im Zuge der Anastylose auf diese Weise samt Kapitell wieder vollständig aufgerichtet; die Wiederaufstellung der westlichen Säulen KatNr. A 1 und A 2 sowie der östlichen Säule KatNr. A 4 erfolgt zunächst nur partiell ${ }^{154}$. Auf eine zeichnerische oder fotografische Dokumentation der Unter- und Oberlager der Trommeln verzichtet man unglücklicherweise.

Während Alzinger in den darauffolgenden Jahren seine Grabungen auf den Bereich zwischen Prytaneion und Bouleuterion, die Basilike Stoa und den >Staatsmarkt< konzentriert, beendet er seine Ausgrabungsaktivitäten im Prytaneion mit diesem Jahr ${ }^{155}$.

1964 wird schließlich versucht, die von Alzinger angefertigte Architekturprobe des dorischen Gebälks der Vorhalle durch vollständiges Zusammensetzen einer zweiten Säule auf ihr ursprüngliches Niveau zu heben (Taf. 29, 1. 2) ${ }^{156}$. Fehlende Trommeln werden dabei durch zurückgesetzte Betontrommeln ergänzt. Die östliche Säule KatNr. A 4 wird im Zuge dieser Anastylose wieder vollständig aufgerichtet. Das von Alzinger zusammengesetzte Gebälk wird allerdings entgegen seiner ursprünglichen Anbringung über dem erweiterten Mitteljoch auf die östlichen Säulen KatNr. A 3 und A 4 gesetzt.

Neben der Anastylose der Architekturprobe werden 1964 die Inschriften des Prytaneions von D. Knibbe aufgenommen ${ }^{157}$.

Ende der 1980er und am Beginn der 1990er Jahre wird schließlich das sog. Banketthaus westlich des Prytaneions vom Efes Müzesi Selçuk unter der Leitung von M. Büyükkolancı und Ü. Yüğrük freigelegt ${ }^{158}$. Darüber hinaus werden fortlaufend Konsolidierungsmaßnahmen am Gebäude getätigt, die besonders in Raum 5 augenscheinlich werden, wo die byzantinische Trennwand zwischen den nördlichen Raumabteilen sowie die nördliche Schildwand von Raum 5A gesichert werden. In diesem Zusammenhang werden seitens des Efes Müzesi Selçuk auch kleinere Grabungen in den Räumen 5 und 6 durchgeführt. Der Keilsteinbogen der Nordwand des >Hestiasaales`, dessen östliche Keilsteine seit der vollständigen Freilegung des Raumes 1956 stets absturzgefährdet waren und teilweise auch abgestürzt sind, wird noch in den 1960er Jahren mittels eines Betonpfeilers gesichert.

\section{II.4 Theoretische Studien seit den 1970er Jahren}

In einer Reihe theoretischer Studien, die auf den feldarchäologischen Untersuchungen der 1950er und 1960er Jahre basieren, versucht insbesondere W. Alzinger ab den 1970er Jahren, die Baugeschichte des Prytanei-

153 Die Sockel werden später im Bereich der Säulen zu einem durchgehenden Stylobat erweitert.

154 Cf. M. Steskal, Kapitel III.3.

155 In der westlich angrenzenden >Akademiegasseく unternimmt er 1964 noch weitere Tiefgrabungen (Sondage XLI, XLII und XLIII), die aber zu keinen verwertbaren Ergebnissen in Bezug auf das Prytaneion führen. Cf. W. Alzinger, Tagebucheinträge vom 5. 8.-4. 9. 1964.

156 Cf. W. Alzinger, Tagebucheinträge vom 22. 8.-30. 8. 1964. Mitarbeiter: F. Ölzant und A. Bammer. Zu der von W. Alzinger geleiteten Anastylose s. D. Knibbe, Wiederbeginn und Aufstieg, in: 100 Jahre Österreichisches Archäologisches Institut 1898-1998, SoSchrÖAI 31 (Wien 1998) 71 f.: »Eher Architekturproben als Anastylosen waren auch die Arbeiten, die Alzinger an der dorischen Vorhalle des Prytaneions durchführte. Er stellte mit den als Spolien an der Südfront der Scholastikiatherme bereits 1904 von Rudolf Heberdey angetroffenen mächtigen unkannelierten und über und über mit Inschriften bedeckten Säulentrommeln zwei Säulen auf und verband diese durch einen Architravblock zu einem Joch, auf dem er eine Platte des Metopenfrieses und darüber einen Geisonblock montieren ließ.«; Knibbe 1998, 251; A. Bammer, Nachruf auf Univ.-Prof. Wilhelm Alzinger, ÖJh 67, 1998, 201: »In Ephesos führte Alzinger Grabungen an jener Stelle fort, wo Miltner zuletzt weltbekannte Funde gemacht hat, nämlich im Prytaneion. ... Ebenso wie zuvor Miltner zeigte er großes Interesse für Wiederaufbauten und Rekonstruktionen, so daß das sog. Regierungsviertel sich heute architektonisch verständlich präsentiert.«; Eichler 1965, 106; T. Wohlers-Scharf, Die Forschungsgeschichte von Ephesos. Entdeckungen, Grabungen und Persönlichkeiten, Europäische Hochschulschriften 38, $54{ }^{2}$ (Frankfurt 1996) 263. - In einer jüngst vorgelegten Studie betont A. Bammer seine Verdienste um die Aufstellung der Architekturprobe: Bammer 2008, 167.

157 Cf. W. Alzinger, Tagebucheinträge vom 1. 10.-5. 11. 1964.

158 s. M. Büyükkolanc1 - Ü. Yüğrük, Banketthaus, in: Scherrer 1995a, 88. 
ons zu klären. Eine erste Analyse legt er 1970 vor $^{159}$. Demnach sei die Anlage aufgrund stilistischer und epigrafischer Indizien in augusteischer Zeit - »vermutlich unmittelbar nach Christi Geburt« - im Zuge der "großzügigen Neuplanung des Stadtzentrums« errichtet worden. Ein Vorgänger-Prytaneion an dieser Stelle sei laut Alzinger entgegen früheren Meinungen nicht nachzuweisen. Die inschriftlich überlieferte Weihung $(\text { IvE } 437)^{160}$ von $» 14$ Säulen samt Basen, Fries, Statuen und einem Tor« bringt er mit der Errichtung des Peristyls des Vorhofes des Prytaneions in Verbindung. Er räumt zwar ein, dass die Ausgestaltung des Vorhofes »schon zu einem früheren Zeitpunkt ähnlich gewesen sein« müsste, wie die Grabungen gezeigt hätten; dennoch datiert er die Stiftung anhand der epigrafischen Evidenz in flavische Zeit ${ }^{161}$. Das Fundament in der Mitte des Vorhofes interpretiert er anders als F. Miltner, der von einem Sockel für die `Große Artemis〈Statue ausging ${ }^{162}$, als einen Altar. Ebenfalls im Gegensatz zu Miltner wiederholt er seine Theorie von einem überdachten $>$ Hestiasaak ${ }^{163}$, in dessen Mitte sich ein Anrichtetisch befunden hätte. Als Kultraum dürfte seiner Meinung nach der Querraum hinter der Nordwand des $\gg$ Hestiasaales` gedient haben (Räume 2, 3 und 4). Die Aufstellung der `Herzsäulen` im ১Hestiasaak datiert er in das 3. bzw. 4. Jahrhundert n. Chr. Noch später seien die doppelten Ziegelmauern, die als Bankfundamente gedient haben könnten, zwischen den Säulen eingezogen worden. Das Prytaneion hätte sodann als Ersatz für das inzwischen zerstörte Bouleuterion fungiert. Die Zerstörung der Anlage sei schließlich in theodosianischer Zeit erfolgt ${ }^{164}$. Die Verschleppung der Architekturglieder der Vorhalle vermutet Alzinger aber erst später, »etwa gleichzeitig mit der Zerstörung der Basilika (Basilike Stoa, Anm. d. Verf.) um 500 n. Chr. «165. Nach der Zerstörung seien schließlich Zisternen zur Speicherung von Wasser im Prytaneion eingerichtet worden.

Die Ergebnisse zur Baugeschichte wiederholt Alzinger im Wesentlichen in seiner Studie zur augusteischen Architektur in Ephesos 1974 ${ }^{166}$. Auch in der Funktionsanalyse folgt er seinen Angaben von 1970, indem er den Querraum hinter der Nordwand (Räume 2, 3 und 4) als Ort für den Kult der Hestia und den >Hestiasaal als Raum für die Versammlungen und öffentlichen Ausspeisungen anspricht. Das zentrale Fundament im >Hestiasaak sei in Analogie zum Prytaneion von Lato auf Kreta als Platz für eine Anrichte zu deuten. Die beiden westlichen Räume 5 und 6 könnten seiner Meinung nach »dem Kollegium der Kureten vorbehalten gewesen sein«. Die asymmetrische Form des Grundrisses deutet er als funktionsbedingt, da hinter der dorischen Fassade »einerseits ein großer Hauptsaal und anderseits auch notwendige Nebenräume untergebracht « werden mussten ${ }^{167}$. Er vergleicht das Gebäude in diesem Zusammenhang mit dem Heiligtum der Demeter und Kore in Priene. Die Ornamentik und Proportionen der Bauglieder interpretiert Alzinger als kanonisch und den »autochthonen Traditionen « verpflichtet ${ }^{168}$ : »Rein funktionsmäßig war auch für den Architekten keinerlei Anlaß gegeben, Gewohntes zugunsten einer Neuerung fallen zu lassen. Für eine rein griechische Einrichtung gab es auch keine Möglichkeit, das in gewissen Grenzen bleibende Repertoire durch Import eines fremden Architekturkonzeptes zu bereichern. Die Asymmetrie war somit von vornhe-

\footnotetext{
159 Alzinger 1970, 1646-1648.

160 s. J. Keil, Die Agora. Inschriften, in: FiE 3 (Wien 1923) 155; Keil 1939, 123; Miltner 1956-1958, 39 f. Anm. 41; Miltner 1959 , 295 f.; Eichler 1965, 106; Miller 1978, 107 f.; Engelmann 1985, 155-157. - IvE 437 (zwei Fragmente eines Bogens, gefunden im Schutt der ২Kuretenstraßeく und des Südeingangs der Scholastikiatherme; die von der Bogenöffnung unterbrochenen Zeilen sind zusammengezogen wiedergegeben):

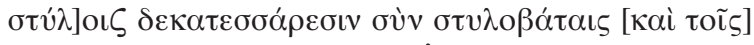

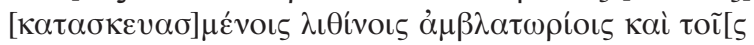

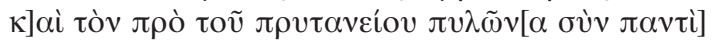

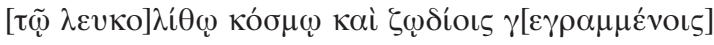

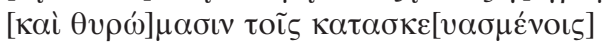

161 Nach freundlicher Auskunft von H. Taeuber datiert diese Inschrift aus paläografischen Überlegungen grob in das 1./2. Jh. n. Chr.

162 Cf. Miltner 1959, 305-309.

163 So Miltner 1959, 290, der von einer hypäthralen Lösung ausgeht. Dem hält Alzinger das Fehlen der nötigen Drainagierungen im >Hestiasaak entgegen.

164 Hier folgt Alzinger Miltner 1956-1958, 35 f.

165 Zur Zerstörung der Basilike Stoa um 500 n. Chr. s. Alzinger 1972-1975, 299; Bauer 1996, 291; Ladstätter - Pülz $2007,406$.

166 Alzinger 1974, 51-57.

167 Alzinger 1974, 54: »In Ephesos wird der Ankömmling zuerst irritiert, es wird eine Axialität vorgetäuscht, die gar nicht vorhanden ist."

168 Alzinger 1974, 54.
} 
rein gegeben. Allerdings versuchte der Architekt durch die Vorhalle mit betontem Mittelintercolumnium diesen scheinbaren Fehler auszugleichen. ... Die Detailformen sind hellenistisch, wenn auch überall gewisse Abstrahierungen im Sinn puristischer Tendenzen festzustellen sind, welche die Architektur deutlich von manchen verspielten Beispielen älterer Zeit abheben."

In besonderer Ausführlichkeit behandelt Alzinger das Prytaneion in seiner bahnbrechenden Studie zum Regierungsviertel von Ephesos ${ }^{169}$. Seinen Beitrag beginnt er wie folgt ${ }^{170}$ : „Wenn man in der Geschichte der Grabungen von Ephesos nach Höhepunkten sucht, so muß wohl die Entdeckung des Prytaneions im Jahre 1955 als ein solcher bezeichnet werden. Allerdings wurden die Folgen dieses Fundes in ihrer ganzen Tragweite erst viel später richtig erfaßt.« War die Funktion der Sattelhöhe zwischen den beiden Stadtbergen Bülbüldağ und Panayırdağ bis zu diesem Zeitpunkt unklar, so schließt Alzinger nun aus der Identifizierung des ephesischen Prytaneions ${ }^{171}$ : $\gg$ Der Platz beim Odeion war also nichts anderes als der Staatsmarkt von Ephesos, das eigentliche Zentrum der Stadt, die Agora beim Hafen hingegen der Verkaufsmarkt.« Dieser Schlussfolgerung geht folgende Überlegung voraus ${ }^{172}$ : »Soweit Prytaneia annähernd zu identifizieren sind, liegen diese stets in unmittelbarer Nähe der Agora ... « Durch die wenige Jahre zuvor erfolgte Identifizierung des Bouleuterions im ehemaligen Odeion durch E. Fossel seien die wichtigsten Regierungsbauten nunmehr bekannt und die Lokalisierung des >Staatsmarktes`gesichert ${ }^{173}$. Die bereits 1970 und 1974 veröffentlichten Ansichten zur Baugeschichte des Prytaneions führt er nochmals deutlich aus ${ }^{174}$. In einigen Punkten konkretisiert er: Die inschriftlich belegte Stiftung der Hallen des Vorhofes (IvE 437) datiert er nach der Buchstabenform nun in das 3. Jahrhundert n. Chr. Das Fundament in der Mitte des Vorhofes deutet er wiederum als Altar und nicht als Basis für die davor gefundene >Große Artemis<-Statue. Bei der Rekonstruktion der dorischen Vorhalle folgt er dem Vorschlag von W. John (Taf. 29, 3), der sechs Säulen in antis mit einem erweiterten Mitteljoch sowie eine Giebelkonstruktion vorschlägt ${ }^{175}$. Im überdachten $>$ Hestiasaal sieht er den Ort »für die im Prytaneion obligaten Gastmähler und Ausspeisungen«. Die Kultstätte der Hestia Boulaia des ephesischen Prytaneions vermutet Alzinger in dem im Norden anschließenden Querraum (Räume 2, 3 und 4). Die westlichen Räume 5 und 6 seien dem »Priesterkollegium« vorbehalten gewesen. Das Gebäude wäre - wie schon zuvor formuliert - um Christi Geburt errichtet worden; ein Vorgänger-Prytaneion hätten die zahlreichen Grabungen nicht bestätigt. Eine grundlegende Veränderung hätte das Gebäude mit dem Einbau der `Herzsäulen ২ im 〉Hestiasaak erfahren; diese Modifikationen seien am Ende des 3. oder erst im 4. Jahrhundert $n$. Chr. erfolgt. Noch später seien schließlich die Ziegelaufmauerungen zwischen den >Herzsäulen` entstanden. In seiner letzten Phase wäre der Bau als Zisterne genutzt worden.

St. G. Miller widmet 1978 in seiner Arbeit zu Funktion und Bauform von Prytaneia ein ganzes Kapitel der ephesischen Anlage ${ }^{176}$. In einigen Bereichen widersprechen seine Interpretationen aber dem tatsächlichen Befund ${ }^{177}$. Für das Prytaneion unterscheidet er vier große Bauphasen: eine hellenistische, eine augusteische, eine severische und eine byzantinische. Er postuliert somit eine hellenistische Bauphase, ob-

169 Alzinger 1972-1975, 229-300. Parallel dazu wird von Mitsopoulos-Leon 1972-1975, 495-524 ein Vorbericht zur Keramik aus dem Prytaneion vorgelegt. s. auch den posthum erschienen Beitrag von W. Alzinger, Das Zentrum der lysimachischen Stadt, in: Friesinger - Krinzinger 1999, 389-392.

170 Alzinger 1972-1975, 229.

171 Alzinger 1972-1975, 241.

172 Alzinger 1972-1975, 238.

173 E. Fossel, Zum sogenannten Odeion in Ephesos, in: Festschrift Fritz Eichler (Wien 1967) 72-81; Alzinger 1972-1975, 253 f.

174 Alzinger 1972-1975, 241-249; s. auch Alzinger 1970, 1646-1648; Alzinger 1974, 51-57.

175 Über das Urheberrecht dieser theoretischen Rekonstruktion herrscht Unklarheit. Es wird auch von A. Bammer beansprucht. Cf. A. Bammer, Architektur, ÖJh 50, 1972-1975, Beibl. 405 sowie Bammer 1976/1977, 57. - Wenige Jahre später wiederholt Alzinger seine Theorie von der Rekonstruktion der Vorhalle und vergleicht dabei das ephesische Prytaneion grundrisstypologisch mit den sog. Oikoi (Räume VII-IX) des Heiligtums des Zeus in Labraunda, cf. W. Alzinger, Ephesos vom Beginn der römischen Herrschaft in Kleinasien bis zum Ende der Principatszeit: Archäologischer Teil, in: ANRW II 7, 2 (Berlin 1980) 817 f.; zu den sog. Oikoi: A. Westholm, Labraunda. Swedish Excavations and Researches. The Architecture of the Hieron, ActaAth 5, 1, 2 (Lund 1963) 69 Abb. 59; P. Hellström, Dessin d'architecture hécatomnide à Labraunda, in: Le dessin d'architecture dans les sociétés antiques. Actes du colloque de Strasbourg 26-28 janvier 1984 (Strasbourg 1985) 153-165. Auch in Labraunda verbindet eine im Grundriss langrechteckige Halle zwei dahinter liegende, asymmetrisch angeordnete Räume.

176 Miller 1978, 98-109.

177 Generell unterscheiden sich seine Angaben zu den Raummaßen von den tatsächlichen Dimensionen wesentlich. Zu den tatsächlichen Raummaßen s. M. Steskal, Kapitel III.3. 
wohl der Ausgräber W. Alzinger in den Publikationen wenige Jahre zuvor mehrfach einen hellenistischen Vorgänger ausschloss ${ }^{178}$. Miller hält entgegen ${ }^{179}$ : $» A g a i n$, neither pottery nor its stratigraphic context was presented, and I do not feel compelled to accept this undocumented statement.« Von einem hellenistischen Vorgänger geht er vor allem deswegen aus, um ein zentrales Theorem seiner Arbeit zu stützen: »the general principle of the immovability of the hearth of Hestia ${ }^{180}$. Die dorische Ordnung der Vorhalle rekonstruiert er entgegen dem Baubefund als »pentastyle in-antis $\aleph^{181}$; die Vorhalle sei seiner Meinung nach erst in severischer Zeit errichtet worden. In Raum 6 nimmt er zehn 0,85 × 1,88 m große Klinen an, geht allerdings von der heutigen lichten Weite der Tür in Raum 6 aus $(1,68 \mathrm{~m})$, die sich aber durch die Zumauerung in byzantinischer Zeit von der tatsächlichen lichten Weite von 2,72 m wesentlich unterscheidet; während er im Text von zehn Klinen spricht, stellt er in seiner Abb. 9 darüber hinaus zwölf Klinen dar ${ }^{182}$. Die zentralen Stützen in den Räumen 5 und 6, die Miller postuliert, sind tatsächlich erst sekundär an diese Stelle gelangt. Das Marmorplattenpaviment des >Hestiasaales` betrachtet er als sekundär - in Wirklichkeit aber ist es original. Bei der Funktion des zentralen Fundaments bleibt er unentschieden. Den Marmorsockel des `Hestiasaales` spricht er der augusteischen Phase zu. Den Einbau der \Herzsäulen ‘ datiert er severisch; die Ziegelmauern zwischen den Säulenstühlen, die er als Sitzbänke interpretiert, seien noch später entstanden. Das Gebäude sei schließlich am Ende des 4. Jahrhunderts n. Chr. zerstört worden, was aus der Verbauung von Architekturgliedern der dorischen Vorhalle in der Scholastikiatherme hervorgehen würde, deren Renovierung er an das Ende des 4. Jahrhunderts n. Chr. datiert. Die Identifizierung des Gebäudes als Prytaneion betrachtet er als gesichert ${ }^{183}$.

Einen Meilenstein in der Erforschung des Prytaneions bildet schließlich die Vorlage der Kureten- und Prytaneioninschriften im Jahr 1981 durch D. Knibbe ${ }^{184}$. Seine Arbeit fokussiert primär auf den Ursprung, die Funktion und die Organisation des Kultvereins der Kureten. Mittels prosopografischer Analysen geht Knibbe zudem - sich des fragmentarischen Erhaltungszustandes des Inschriftenbestandes bewusst - auf das System der ephesischen Bürgereinteilung ein. Die Rolle der Kureten sieht er in erster Linie in der Realisierung der bei Strabon (Strab. 14, 1, 20) beschriebenen mythologischen Begebenheit der Niederkunft Letos »unter dem hilfreichen Lärmen der Kureten « in Form eines alljährlichen Mysterienspiels ${ }^{185}$. Dieses Mysterienspiel sei neben der Artemisprozession um den Panayırdağ das wichtigste Ereignis im kultischen Jahresablauf von Ephesos gewesen. Obwohl der Ablauf des Mysterienspiels im Detail nicht bekannt sei, betont Knibbe ${ }^{186}$, »daß wir es mit einem das ganze Volk von Ephesos vereinenden Frühlingsfest zu tun haben, ein altes Vegetationsmysterium, in dessen Mittelpunkt ein heiliger Baum stand, der im Kult der archaischen Ephesia, die ja auch eine Vegetationsgöttin ist, eine große Rolle gespielt hat«. Der Sitz des

178 So etwa Alzinger 1970, 1646-1648; Alzinger 1974, 51-57; Alzinger 1972-1975, 229-300. - Mehrfach weist Miller aber daraufhin, dass das Fehlen einer Vorlage des stratigrafischen Befundes und der Funde aus dem Prytaneion chronologische Überlegungen erschweren. Miller 1978, 104: »No detailed discussion of the date of the building at Ephesos has been made, nor is any possible here without knowledge of the artifacts and the stratigraphy of the area."

179 Miller 1978, 106 Anm. 20.

180 Miller 1978, 107.

181 Rogers 1991, 88 nimmt später sogar acht - korrekt wären sechs - dorische Säulen an; zudem vermutet er, dass sich die Herdstelle auf dem zentralen Fundament des >Hestiasaales` befunden hätte.

182 s. dazu B. Bergquist, Sympotic Space: A Functional Aspect of Greek Dining-Rooms, in: Murray 1990, 58, die neben Raum 6 auch Raum 5 als Speisesaal in Betracht zieht.

183 Miller 1978, 108 f. Neben der epigrafischen Evidenz (Nennungen der Hestia Boulaia und der Kureten) führt Miller 1978, 109 auch die Bauform ins Treffen: »Architectural criteria also suggest that the building was the prytaneion of Ephesos. The courtyard, the principal rooms for Hestia and dining (...), and the subsidiary rooms are all present in the building. Its quality of construction is quite good - indeed monumental - and there are no difficulties in recognizing the building as a major civic structure. Given the location, the building may, in all probability, be identified as the prytaneion of Ephesos."

184 Knibbe 1981. Cf. auch die bereits 1970 von D. Knibbe veröffentlichte, kurze Darstellung der Kultvereinigung der Kureten: RE Suppl. XII (1970) 286 f. s. v. Ephesos: A. Historisch-epigrafischer Teil (D. Knibbe); s. auch J. Poerner, De Curetibus et Corybantibus (Halle 1913); Ch. Picard, Ephèse et Claros. Recherches sur les sanctuaires et les cultes de l'Ionie du nord, BEFAR 123 (Paris 1922) 277 f.; Keil 1939, 119-128; Graf 1999, 255-262; Rogers 1999a, 241-250; Rogers 1999b, 125-130; Rogers 2007, 137-145. - Eine Zusammenstellung der inschriftlichen Zeugnisse von Ephesos mit Nennung der Hestia bietet C. R. Dethloff, Corpus of Inscriptions of the Goddess Hestia (ungedr. Diss. The Johns Hopkins University of Baltimore 2003) Nr. 132-151.

185 Knibbe 1981, 70-73; Portefaix 1999, 613; Rogers 2007, 139 f.

186 Knibbe 1981, 73. 
Kuretenkollegiums sei in hellenistischer Zeit das Artemision gewesen, wo es neben seinen kultischen Auf-

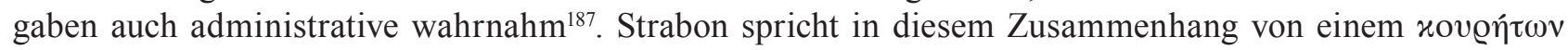

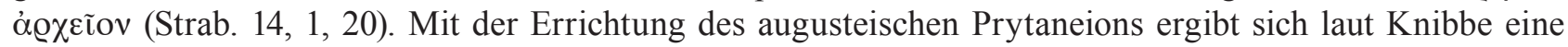
Zäsur für die ephesischen Kureten ${ }^{188}$. Sie wären nunmehr als Körperschaft des neu errichteten Prytaneions aufgetreten; zur selben Zeit sei auch mit der jährlichen, öffentlichen Aufzeichnung der Kuretenlisten auf Steindenkmälern begonnen worden ${ }^{189}$. Mit ihrer Übersiedlung vom Artemision in das Regierungsviertel von Ephesos und ihrer Neukonstitution als Kultverein des Prytaneions hätten die Kureten zwar ihre administrative Funktion im Artemisheiligtum verloren, nach wie vor seien sie aber an den ortygischen Mysterien und der jährlichen Wiederholung des Geburtsdramas aktiv beteiligt gewesen ${ }^{190}$. Im Prytaneion hätten sie als »Opferassistenten« des Prytanen bei der Durchführung der zahlreichen kultischen Handlungen, die in diesem Gebäude beheimatet waren, fungiert ${ }^{191}$. Die Bedeutung der Kureten wäre in diesem Kontext vor allem im 1. und 2. Jahrhundert n. Chr. maßgeblich gewesen. Mit dem Beginn des 3. Jahrhunderts hätte sich diese Rolle grundlegend geändert, nämlich »als die Kureten vor dem Hintergrund tiefgreifender und vielfältig miteinander verflochtener geistiger und materieller Umwälzungen von der Bühne des Prytaneions abgetreten sind ${ }^{192}$. Die Gründe dafür seien in der sinkenden wirtschaftlichen Prosperität und dem Bedeutungsverlust der ortygischen Mysterien gegenüber anderen Kulten seit dieser Zeit zu suchen ${ }^{193}$. Die Kureten, deren aktive Funktionsperiode sich auf ein Jahr erstreckte, wurden - wie Knibbe ausführt ${ }^{194}$ - vom Prytanen ernannt, der auch für die Finanzierung des Kuretensynedrions verantwortlich zeichnete. Allerdings dürften auch »Altmitglieder« existiert haben, die dem Verein offenbar auf Lebenszeit angehörten. Innerhalb des Kuretensynedrions sei »das ganze reichhaltige Spektrum des bunten Demos« von Ephesos vertreten gewe$\operatorname{sen}^{195}$.

Besonders verdienstvoll ist der Versuch D. Knibbes, die Kureteninschriften hinsichtlich ihrer Relevanz für die Baugeschichte des Prytaneions zu analysieren ${ }^{196}$. Generell hält er fest, dass die Kureteninschriften dort auf den Architekturgliedern des Prytaneions platziert worden wären, wo sich ein geeigneter Platz ge-

187 Knibbe 1981, 74. Inwieweit sie auch in vorhellenistischer Zeit ihren Sitz im Artemision hatten, ist aufgrund fehlender schriftlicher Belege spekulativ.

188 Knibbe 1981, 75-92.

189 Zu möglichen früheren Kuretenverzeichnissen folgert Knibbe 1981, 74 richtig: »Daß sich bisher nirgendwo der geringste Hinweis auf eine Kuretenliste aus hellenistischer oder womöglich noch älterer Zeit gefunden hat, muß nicht unbedingt bedeuten, daß man keine Kuretenverzeichnisse geführt hat; man hat vielleicht nur unterlassen, sie auf Stein öffentlich zu verzeichnen.«

190 Knibbe 1981, 78 zum kaiserzeitlichen Kuretensynedrion: »Ortygia und Prytaneion waren eins geworden, Artemis und Hestia wurden von ein und demselben Kultverein betreut.« Knibbe 1999, 451: »Das Prytaneion wurde gleichsam zur 〉Botschaft der Artemis in der Stadt, ...«.

191 Knibbe 1981, 76; s. dazu kritisch Rogers 1999a, 242 Anm. 10. Nach Rogers 1991, 88 haben die Kureten in erster Linie als Hüter des Feuers fungiert. - Zu den im Prytaneion angesiedelten Kulten s. Knibbe 1981, 101-105. Neben Hestia Boulaia und Artemis nennt er: Demeter Karpophoros und ihre Tochter Kore, Sosipolis, Apollon Klarios, Apollon Manteios, Theos Kinnaios, Tyche und das personifizierte Heilige Feuer. - Dem Prytanen musste aufgrund der Fülle und Komplexität der Kulthandlungen zudem ein sog. Hierophant zur Seite gestellt werden, der verhindern sollte, dass rituelle Fehler begangen werden; cf. Graf 1999, 257.

192 Knibbe 1981, 76. 91 f. Zur Entwicklung des kaiserzeitlichen Kuretensynedrions: Knibbe 1981, 76-92. Zur absoluten Chronologie der Inschriften: Knibbe 1981, 93-95.

193 Knibbe 1981, 92: »Was wirklich ausschlaggebend war, war vielmehr, daß die ortygischen Mysterien angesichts der seit dem Beginn des 2. Jh.s langsam aber stetig gestiegenen Bedeutung Hestias und der übrigen Prytaneiongottheiten, die sich parallel mit dem Schlechterwerden der Zeiten als Heilsgötter zunehmend an Beliebtheit erfreuten, zu einem inhaltsleeren Spektakel geworden waren, für das man, als die wirtschaftliche Kraft zu sinken begann, auch nichts mehr zu zahlen bereit war. ... Eine keineswegs unbedeutende Größe in diesem Umschichtungsprozeß ist das Christentum, gegen das sich die sterbende Welt der griechischen Polis zur Wehr gesetzt hat.«

194 Knibbe 1981, 96-100.

195 Graf 1999, 255 f. siedelt die Kureten eher in der städtischen Oberschicht an und bezeichnet das Synedrion als »Honoratio-

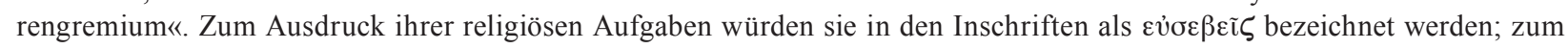

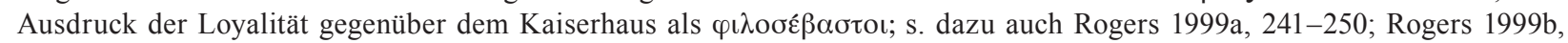
125-130.

196 Knibbe 1981, $165 \mathrm{f}$. 
boten hätte. Eine zeitliche Abfolge sei anhand ihrer Position im Gebäude folglich nicht rekonstruierbar ${ }^{197}$. Für die Baugeschichte sei vor allem eine Inschrift von Bedeutung, die den Prytanen Dionysodoros als Stifter von Reparaturmaßnahmen am Gebäude bald nach $104 \mathrm{n}$. Chr. nennt (IvE 1024) ${ }^{198}$. Dionysodoros hätte auch die baulichen Voraussetzungen für die in seinem Amtsjahr vorgenommene Installierung des Kultes für Apollon Manteios geliefert. Die endgültige Zerstörung des Baues sei laut Knibbe »erst das Werk von fanatischen Christen gewesen und kann daher nicht vor 381 erfolgt sein ${ }^{199}$. Eine erst in die Mitte des 5. Jahrhunderts zu datierende Inschrift (IvE 1352) auf der untersten dorischen Säulentrommel KatNr. A 4 sei demnach erst nach der sekundären Verbauung am unteren Embolos auf das Architekturglied gelangt ${ }^{200}$.

In dasselbe Horn stößt wenige Jahre später H. Engelmann, der durch eine Zusammenstellung der Bauinschriften des Prytaneions die Baugeschichte der Anlage konkretisieren will ${ }^{201}$. Er führt zunächst die bereits erwähnte Stiftung von 14 Säulen samt Ausstattung für den Vorhof ins Treffen (IvE 437), die er nach J. Keil in das 1. Jahrhundert $\mathrm{n}$. Chr. datiert. Die Umgänge der Hallen bezeichnet er als »Porticus ambulatoria $\aleph^{202}$. Auf den 〉Hestiasaak mit seinen angrenzenden Räumen bezieht er eine Inschrift traianischer Zeit (IvE 462), die von umfangreichen Baumaßnahmen durch einen Prytanen berichtet. Dieser benutzte insgesamt 9000 Drachmen, um mehrere Bauvorhaben wie die Verlegung eines neuen Marmorbodens, die Erneuerung des Daches, die Renovierung angrenzender Räume, die Errichtung eines Solariums und die Aufstellung von Säulen zu realisieren ${ }^{203}$. Als drittes epigrafisches Zeugnis nennt Engelmann die ebenfalls bereits thematisierten Renovierungen des Prytanen Dionysodoros (IvE 1024), die er um 105 n. Chr. datiert. Dionysodoros hätte zudem den Apollon Manteios-Kult im Prytaneion eingeführt ${ }^{204}$. Eine weitere, nicht näher einordenbare, fragmentarische Inschrift (IvE 528), die im Pflaster südlich der Therme am >Staatsmarkt gefunden wurde, würde schließlich nicht quantifizierbare Reparaturen im Prytaneion aufzählen; genannt wären lediglich Maßnahmen in Bezug auf Basen, Säulen und Architrave ${ }^{205}$.

Die Bedeutung des Prytaneions als Kultstätte der Artemis im Rahmen der jährlichen Prozession, aber auch als Dependance des Artemisions innerhalb der Stadt führt wiederum D. Knibbe aus ${ }^{206}$. Demnach wäre der Machtanspruch der Artemis innerhalb der Stadt durch die bewusste Platzierung von Altären an strategisch wichtigen Punkten manifestiert worden. Einer dieser wichtigen Punkte sei im Areal des späteren Prytaneions gelegen, das »nicht zufällig« an dieser Stelle errichtet worden wäre ${ }^{207}$ : »Das Prytaneion war, was sich auch in Inschriften spiegelt, in denen Artemis nahezu gleichberechtigt mit Hestia erscheint, zugleich ein Artemisheiligtum und rein optisch sogar vornehmlich ein solches durch die große Artemisstatue, die vor dem Prytaneion auf einem Sockel stehend den ganzen dahintergelegenen Bau dominierte.« Die Etablierung eines Hestiaheiligtums in der Stadt sei zudem erst im Zuge der Neukonstituierung von Ephesos unter Augustus erfolgt. Hestia sei dabei aus »Alt-Ephesos« beim Artemision in die Neustadt übersiedelt, ohne sich jedoch von der dominierenden Stellung der Artemis emanzipieren zu können ${ }^{208}$ : »Der schlaue Gegenschachzug des Artemisions, für die neue Residenz einen Ort durchzusetzen, an dem Hestia von vorneherein im Schatten der großen Göttin bleiben mußte, war offenbar römischerseits nicht zu unterlaufen

197 Knibbe 1981, 106 f.

198 Entspricht Knibbe 1981, B 24; cf. auch Halfmann 2001, 63.

199 Für eine Zerstörung kurz nach 400 n. Chr. plädiert später nochmals Liebeschuetz 2001, 34.

200 Knibbe 1981, 166 Anm. 377; cf. auch Ch. Roueché, Enter Your City! A New Acclamation from Ephesos, in: Scherrer - Taeuber - Thür 1999, 134-136.

201 Engelmann 1985, 155-157.

202 Engelmann 1985, 155.

${ }^{203}$ Die Inschrift, die in zwei Fragmenten im Süden des Vorhofes - allerdings nicht in situ - gefunden wird, erwähnt allerdings nicht explizit das Prytaneion als Ziel dieser Maßnahmen. Dass diese Arbeiten tatsächlich im Prytaneion durchgeführt wurden, ist $\mathrm{m}$. E. nicht zu belegen.

204 Engelmann 1985, 156 f. In diesem Zusammenhang nennt er auch die Belege für den Demeter Karpophoros-Kult im Prytaneion (IvE 10. 1060. 1067).

205 Engelmann 1985, 157.

206 Knibbe - Langmann 1993, 11. 21; cf. auch Knibbe 1995, 143 f. 146 Anm. 8; Knibbe 1998, 113; Knibbe 1999, 451.

207 Knibbe - Langmann 1993, 21; cf. auch Knibbe 1998, 113, der nicht nur ein hellenistisches Vorgänger-Prytaneion an dieser Stelle ablehnt, sondern auch vermutet, dass das Prytaneion am >Staatsmarkt esos gewesen sei.

208 Knibbe - Langmann 1993, 21. 
gewesen.« Dieser Sicht schließen sich später St. Karwiese, P. Scherrer, St. Groh und St. Witetschek an ${ }^{209}$. C. Schulte interpretiert dieses Phänomen jedoch als eine Form der Unterordnung der Artemis unter die im ephesischen Prytaneion beheimateten Gottheiten ${ }^{210}$. Obwohl der Einfluss der Artemis innerhalb der Stadt durch die Einrichtung des augusteischen Prytaneions zurückgedrängt worden wäre, hätte sich die religiöse, wirtschaftliche und finanzielle Bedeutung des Heiligtums in keiner Weise als geschmälert erwiesen.

Besondere Resonanz in der Fachwelt finden schließlich die im Prytaneion gefundenen Statuen vom Typ der Artemis Ephesia. Sie werden seit ihrer Auffindung im Jahr 1956 bis zum heutigen Tag einer kaum noch zu überblickenden Zahl von kulturhistorischen und stilkritischen Studien unterzogen ${ }^{211}$.

Eine von A. Bammer durchgeführte Untersuchung des architektonischen Befundes des Gebäudes basierend auf den Arbeiten der 1960er Jahre wird 2008 vorgelegt ${ }^{212}$. Die von ihm vorgelegten idealisierten und schematisierten Zeichnungen werden allerdings einer modernen, steingerechten Bauaufnahme nicht gerecht. So stellt er Ziegel- und Bruchsteinmauerwerk nur im Umriss dar; Quadermauerwerk wird unter Vernachlässigung seiner natürlichen Konturen überhaupt nur in horizontalen und vertikalen Linien wiedergegeben $^{213}$. Abgesehen von mehreren formalen Fehlern ${ }^{214}$ erweisen sich vor allem eklatant falsche Angaben in der Bemaßung von über einem Meter als problematisch. So bemisst er die Innenmaße der Vorhalle mit $7,62 \times 20,09 \mathrm{~m}$, während der tachymetrisch vom Verf. ermittelte Wert 7,20 $\times 21,38 \mathrm{~m}_{\text {beträgt }}{ }^{215}$. Einem folgenschweren Rechenfehler unterliegt er, indem Bammer die von ihm vermutete Länge der Vorhalle mit der Stärke der beiden seitlichen Wände von jeweils 1,17 m addiert; sein Ergebnis lautet nämlich 23,43 m anstelle von 22,43 m, was einen Fehler von exakt 1,00 m ergibt ${ }^{216}$ : »Die Vorhalle ist 7,62 m tief und innen 20,09 m lang, mit den beiden seitlichen Wänden bzw. Anten 1,17 m Stärke 23,43 m breit.« Aber auch inklusive des Rechenfehlers von 1,00 m weicht der Wert von 23,43 m noch immer vom korrekten Maß von 23,67 m ab. Die erheblichen Diskrepanzen zu den tatsächlichen Werten setzen sich fort ${ }^{217}$ : So betrüge die Höhe des Fundaments der Vorhalle inklusive der Euthynterie 2,70 m, tatsächlich sind es 2,24 m; der untere Durchmesser der dorischen Säulentrommeln sei 1,10-1,15 m entgegen den korrekten 1,20 m, usw. Einen logischen Fehler begeht Bammer weiters, indem er konstatiert, dass es unsicher sei, »ob die dorische Vorhalle zur Zeit der

209 Karwiese 1995, 82; Karwiese 1999, 397; Scherrer 1990, 91 f.; Groh 2006, 66; Witetschek 2008, 26. - Anders: Bammer 2008, 178 f., der den Charakter des Prytaneions, des Hauptkultgebäudes der Stadt, als »pseudoreligiös« bezeichnet. Dies steht freilich in diametralem Widerspruch zur großen Zahl der im Prytaneion beheimateten Kulte.

210 C. Schulte, Die Grammateis von Ephesos. Schreiberamt und Sozialstruktur in einer Provinzhauptstadt des römischen Kaiserreiches, Heidelberger althistorische Beiträge und epigrafische Studien 15 (Stuttgart 1994) 130.

211 Auswahl: Miltner 1959, 305-309; RE Suppl. XII (1970) 323-328 s. v. Ephesos: C. Numismatischer Teil (St. Karwiese); Fleischer 1973, 46-137; E. Heinzel, Zum Kult der Artemis von Ephesos, ÖJh 50, 1972-1975, 243-251; Fleischer 1978, 324-358; Seiterle 1979, 3-16; Fleischer 1983, 81-93; LIMC II 1 (1984) 755-763 s. v. Artemis Ephesia (R. Fleischer); A. Bammer - U. Muss, Das Artemision von Ephesos. Das Weltwunder Ioniens in archaischer und klassischer Zeit (Mainz 1996) 71-78; B. Brenk, Artemis of Ephesos. An Avant Garde Goddess, in: Actes du VIe Colloque international du C.I.E.R.G.A. Les panthéons des cités. Origines et développements ( $1^{\text {re }}$ partie), Kernos. Revue internationale et pluridisciplinaire de religion grecque antique 11, 1998, 157-171; W. Burkert, Die Artemis der Epheser: Wirkungsmacht und Gestalt einer Großen Göttin, in: Friesinger - Krinzinger 1999, 59-70; Fleischer 1999, 605-609; U. Muss, Zur Dialektik von Kultstatue und Statuetten im Artemision von Ephesos, in: Friesinger - Krinzinger 1999, 597-603; Portefaix 1999, 611-617; St. Karwiese, Artemis Ephesia »Sebasteia«: Ein Entzifferungsbeitrag, in: Scherrer - Taeuber - Thür 1999, 61-75; Morris 2001, 135-151; K. Radner, Kompositstatuen vom Typus der Ephesia aus dem vorkroisoszeitlichen Heiligtum. Zur Herstellung und Pflege von Götterstatuen im östlichen Mittelmeerraum und im Vorderen Orient im frühen ersten Jahrtausend, in: U. Muss (Hrsg.), Der Kosmos der Artemis von Ephesos, SoSchrÖAI 37 (Wien 2001) 233-263; Fleischer 2002, 185-216 bes. 208-215; S. Szidat, Die »Buckel« der Artemis Ephesia. Zur Bedeutung des Motivs und seinen ikonographischen Vorläufern, JdI 119, 2004, 83-129. - Bereits zuvor: H. Thiersch, Artemis Ephesia. Eine archäologische Untersuchung, AbhGöttingen 3, 12 (Berlin 1935). - Zusammenfassend: N. M. High - M. Steskal, Kapitel VII.5.1.

212 Bammer 2008, 165-180. - Eine kurze Beschreibung des Prytaneions jüngerer Zeit bietet Thür 2007, 81.

213 Cf. etwa Bammer 2008, Abb. 4 mit falscher Bildunterschrift: Dargestellt ist die Ostwand der Räume 5 und 6.

214 So hätten laut Bammer 2008, 165 etwa »1991 im Bereich der östlichen Kammern des Hestiasaales im Prytaneion Grabungen« stattgefunden. Tatsächlich besitzt der >Hestiasaak aber östlich keine zum Prytaneion gehörenden Kammern. Auf den >Herzsäulen` hätten sich nach Bammer 2008, 171 korinthische Kapitelle befunden, während noch heute zwei der Kompositkapitelle in situ auf den Eck-Doppelhalbsäulen für jedermann sichtbar sind.

215 s. dazu M. Steskal, Kapitel III.3.

216 Bammer 2008, 170.

217 Bammer 2008, 168. 170. 
Erneuerung des Prytaneions in der späten Kaiserzeit noch aufrecht stand«, wo er doch kurz zuvor festhält, dass Architekturglieder der dorischen Ordnung der Vorhalle »in Sturzlage« gefunden wurden ${ }^{218}$. Grundsätzlich problematisch ist es, eine Stilrichtung wie den Dekonstruktivismus ${ }^{219}$, der erst in den 1980er Jahren seinen Anfang fand, künstlich auf antike Gebäude umzulegen. Ein »Hintansetzen der Gesetze der Schwerkraft und Belastbarkeit architektonischer Formen ${ }^{220}$ ist am Prytaneion von Ephesos nicht erkennbar.

Schließlich nimmt H. Schwarzer das ephesische Prytaneion in seine Studie über sakrale Banketträume mit Liegepodien auf und interpretiert die Unterkonstruktionen der Sitzbänke im >Hestiasaak als Speiselager $^{221}$. Die quadratische Struktur in der Raummitte sieht er als den Rest des heiligen Herdes, den nördlich anschließenden Querraum 2-4 als »die mutmaßliche Cella der Herdgöttin Hestia Boulaia«. Obwohl er auf den vorläufigen Charakter der Datierung der einzelnen Bauphasen verweist, unterscheidet er vier Phasen, welche in hellenistische, augusteische, severische und byzantinische Zeit datieren würden. Die dorische Ordnung der Vorhalle datiert er severisch und rekonstruiert sie - offenbar nach St. G. Miller ${ }^{222}$ - mit fünf Säulen, ohne dies belegen zu können.

Die teils stark divergierenden Beurteilungen des ephesischen Prytaneions sowie das Fehlen einer Auswertung der Stratigrafie, einer vollständigen steingerechten Bauaufnahme und einer gesicherten Rekonstruktion ermunterten im Jahr 2007 zu einer abschließenden Neuuntersuchung des Gebäudes, deren Ergebnisse im Folgenden präsentiert werden sollen.

218 Bammer 2008, 168-171.

219 s. M. Wigley, Architektur und Dekonstruktion. Derridas Phantom (Basel 1994); A. C. Papadakis, Dekonstruktivismus - eine Anthologie (Stuttgart 1989).

220 Bammer 2008, 165.

221 Schwarzer 2008, 124. Konkret ordnet Schwarzer 2008, 155-163 dieses von ihm postulierte Liegepodium seiner Kategorie II $\mathrm{zu}$.

222 Miller 1978, $100 \mathrm{f}$. 



\title{
III BAUBEFUND UND BAUBESCHREIBUNG
}

\author{
(Martin Steskal)
}

\section{III.1 Vorbemerkung}

Das $1170 \mathrm{~m}^{2}$ große Prytaneion in Ephesos besaß einen klar akzentuierten Grundriss, der erst in späterer Zeit komplex überformt wurde (Taf. 30. 31. 249-254). Die sich im Norden des Gebäudes befindlichen Raumeinheiten konnten über einen Vorhof im Süden und eine nördlich anschließende Vorhalle erschlossen werden ${ }^{223}$. Über die Vorhalle gelangte man in den im Osten befindlichen ২Hestiasaak (Raum 1) sowie in den später abgemauerten Querraum nördlich davon (Räume 2, 3 und 4). Westlich des $>$ Hestiasaales $\$ befanden sich ursprünglich zwei Räume (Raum 5 und 6), wobei der nördliche Teil des nördlichen Raumes 5 in späterer Zeit in zwei kleinere Raumkompartimente unterteilt wurde (Raum 5A und 5B). Das stark von Süd nach Nord ansteigende Gelände bedingte auch unterschiedliche Nutzungsniveaus: So lag das Nutzungsniveau der nördlichen Räume 2, 3 und 4 um bis zu 1,30 m höher als in den benachbarten Räumen 5 und 6 sowie im `Hestiasaak und war nur über Treppen zu erreichen. Die Ausrichtung der Räume an der durch das Peristyl des Vorhofes und vor allem die dorische Fassade der Vorhalle vorgegebenen zentralen Mittelachse wurde in den nördlich anschließenden Räumen aufgelöst. Der Aufriss des Gebäudes war hybrid gestaltet und verband den dorischen mit dem ionischen Architekturkanon.

Die folgende Baubeschreibung behandelt die einzelnen Räume in der Reihenfolge: Vorhof, Vorhalle, >Hestiasaak, Raum 6, Raum 5, Raum 4, Raum 3, Raum 2.

\section{III.2 Vorhof}

Der Vorhof des Prytaneions ist als rechteckige Triporticus mit Innenmaßen von 18,40 $\times 21,65 \mathrm{~m}$ konfiguriert (Taf. 5, 1; 32, 1); im Westen, Süden und Osten ist der Platz von Bruchsteinmauern gerahmt, die Mauerstärken von 0,70-0,76 m (Westmauer), 0,63-0,76 m (Südmauer) und 0,65-0,72 m (Ostmauer) aufweisen. Im Norden ist der Vorhof durch den Stereobat der Vorhalle begrenzt. Der Erhaltungszustand der begrenzenden Bruchsteinmauern, die zugleich die Rückwände der Triporticus bilden, ist durchweg unterschiedlich ${ }^{224}$ :

Die Westmauer, die durch die >Akademiegasse` im Westen begrenzt ist, kann nur im südlichen Teil auf eine Länge von 4,70 m von der Südwestecke des Vorhofes verfolgt werden. An der Südwestecke misst die erhaltene Höhe ca. 0,70 m über dem Niveau der >Akademiegasseく. An der Innenseite reicht die Mauer an keiner Stelle über das Niveau des Stylobats des Vorhofes (45,96 m); sie ist daher nur noch im Fundament ablesbar. Das Ende der Westmauer sowie ihr Anschluss an den Stereobat der Vorhalle konnten in Sondage II (1960) festgestellt werden (Taf. 18, 1): Die Bruchsteinmauer der Westmauer trifft an dieser Stelle auf das Quadermauerwerk des Fundaments der Vorhalle, ohne in sie einzubinden. Im Gegensatz zur Ostmauer des Vorhofes fluchtet sie aber nicht mit der Innenseite der Antenmauer der Vorhalle, sondern läuft das Antenhaupt mittig an. Das Fundament der Westmauer reicht, wie in Sondage IV (1960) gezeigt werden konnte, bis auf eine absolute Höhe von 44,55 m hinab (Taf. 20, 2). Das Mauerwerk besteht aus kaum behauenen Bruchsteinen in grauem Kalkmörtelverband; der Kalkmörtel weist als Hydraulefaktor einen sehr geringen

\footnotetext{
223 Die Nummerierung und Benennung der einzelnen Räume wurde von den Ausgräbern der 1950er (F. Miltner) und 1960er Jahre (W. Alzinger) übernommen; cf. Eichler 1962, 38 Abb. 1; Alzinger 1972-1975, 243 f. Abb. 5; Alzinger 1974, Taf. 24, 42. In die Baubeschreibung fließen auch Erkenntnisse ein, die W. Alzinger in Tagebüchern und auf Zeichnungen notierte; diese werden heute im Archiv des ÖAI in Wien verwahrt.

224 Zum Vorhof cf. auch den Grabungsbefund: M. Steskal, Kapitel IV.2 und 3.
} 
Anteil an Ziegelsplitt auf. Ohne System sind Ausgleichsschichten aus kleinformatigen Feldsteinen im Mauerwerk angeordnet.

Anders als die Westmauer ist die Südmauer großteils im Aufgehenden erhalten (Taf. 32, 2); im Bereich der Südwestecke erreicht sie allerdings nicht das Niveau des Stylobats des Vorhofes (45,96 m). Die erhaltene Mauerkrone steigt entsprechend dem Plattenbelag des >Clivus sacer im Süden von West nach Ost gleichmäßig an. Die Höhe der Mauer beträgt an der Außenseite ca. 0,30-1,30 m. Ost- und Westmauer sind im Verband an die Südmauer angesetzt, deren Fortsetzung nach Osten jedoch durch eine deutliche Fuge getrennt wird. Wie in Sondage IV (1960) festgestellt, befindet sich die Unterkante des Fundaments an der Westecke auf einem Niveau von ca. 43,55 m (Taf. 20, 2). Das Mauerwerk entspricht dem der Westmauer; vereinzelt finden sich auch Ausgleichsschichten aus Ziegeln. An der Südseite sind zudem an einigen Stellen Reste von Putz erkennbar. An der Seite des Vorhofes besitzt die Mauer einen 0,15 m großen Fundamentvorsprung. In der Südmauer sind 7,20, 9,79 und 12,27 m von der Südwestecke drei Vertikalfugen erkennbar. Zwischen der zweiten und dritten Vertikalfuge befindet sich eine sekundär zugemauerte, im Rohbau 2,48 m breite Türöffnung, die als Haupteingang in das Gebäude fungierte (Taf. 33, 1). Die Südmauer ist im Aufgehenden im Bereich der abgemauerten Tür um 0,15 m stärker ausgeführt, entspricht also der Stärke des Fundaments. Gegen den Vorhof ergibt sich dadurch ein Mauervorsprung. Inwieweit das Gebäude westlich der ersten Vertikalfuge der Südmauer bzw. auch in der Westmauer des Vorhofes - also von der Seite der >Akademiegasse $<$ - einen Zugang besaß, ist heute nicht mehr zu klären, da die Mauern hier nur noch im Fundament erhalten sind.

Das Aufgehende der Ostmauer ist durchgehend erhalten (Taf. 34, 1): Im nördlichen Teil ist sie bis zu 0,95 m, im südlichen Teil bis zu 1,25 m hoch. Die Unterkante der Mauer liegt, wie in Schnitt 2/07 gezeigt werden konnte, bei Niveau 44,45 m. Der Anschluss an den Stereobat der Vorhalle entspricht dem der Westmauer. 8,83 m von der Südostecke des Vorhofes ist ein deutlicher Absatz im Mauerwerk erkennbar. Das Mauerwerk südlich dieses Absatzes ist unterschiedlich strukturiert: Das sorgfältig gesetzte untere Bruchsteinmauerwerk ist mit einem gut erhaltenen Fugenverstrich ausgestattet; das darüberliegende Bruchsteinmauerwerk erweist sich hingegen als unregelmäßig gefertigt und nicht korrekt gefluchtet. 10,80, 12,05, 13,88 und 14,84 m von der Südostecke des Vorhofes entfernt befinden sich Vertikalfugen. Zwischen den beiden letzten Vertikalfugen kann eine im Rohbau $0,96 \mathrm{~m}$ breite Tür 0,36 m über dem Niveau des Stylobats des Vorhofes postuliert werden (Niveau: 46,32 m). 17,11 m von der Südostecke des Vorhofes befindet sich $20 \mathrm{~cm}$ über dem Niveau des Stylobats des Vorhofes eine zur Hälfte erhaltene Türschwelle (Niveau: 46,16 m); die südliche Türlaibung zeichnet sich klar im Mauerwerk ab. In dieser Türlaibung ist eine kreisrunde, im Durchmesser 0,125 m große Öffnung ausgespart, in der sich eine vertikal nach oben verlaufende Tonrohrleitung befand. Im gesamten Bereich der Ostmauer sind Marmorspolien verbaut.

Von der Triporticus sind heute nur noch wenige Stylobatblöcke im Bereich der Nordwestecke (drei Blöcke; Taf. 35, 1; 36) und an der Südostecke (zwei Blöcke; Taf. 35, 2; 36), eine umlaufende, kanalförmige Regenrinne (Taf. 37), die das Wasser von den Dachflächen sammelte, und ein Nord-Süd verlaufender Kanal unter dem östlichen Umgang in situ erhalten (Taf. 37, 4), während sich die Säulenstellung nur noch anhand von Versatzspuren auf dem Stylobat rekonstruieren lässt. Die marmornen Stylobatblöcke, die auf vermörtelten Bruchsteinfundamenten ruhen (Stärke des Fundaments im Osten: 1,00 m; im Süden: 0,68 m; im Westen: $0,80 \mathrm{~m}$ ), sind sehr sorgfältig gearbeitet und weisen an den Stoßflächen Anathyrosis auf. Die Größe der einzelnen erhaltenen Blöcke variiert durchweg: So beträgt ihre Länge zwischen 0,90-1,72 m, ihre Tiefe 0,63-0,70 m und ihre Höhe 0,21-0,22 m. Die Tiefe der westlichen Halle ist inklusive Stylobat mit 4,41 m zu rekonstruieren; die Tiefe der östlichen Halle misst 4,22 m, die der südlichen Halle 4,35 m (jeweils inkl. Stylobat). Während die abweichende Tiefe der Südhalle aus den begrenzten räumlichen Gegebenheiten resultiert, ist die Ursache für die leicht divergierenden Tiefen der Ost- und Westhalle durch den Umstand zu erklären, dass die Ostmauer des Vorhofes mit der Innenseite der Antenmauer der Vorhalle fluchtet, während die Westmauer mittig auf die Antenmauer anläuft. Grund dafür könnte der benötigte Bauplatz für die Errichtung des opus caementicium-Fundaments des östlich an das Prytaneion angrenzenden Temenos mit seinem >Doppelmonument sein, das bis knapp an die Ostmauer des Vorhofes heranreichte, wie auf einer Planumszeichnung der Sondage XXIII (1961) deutlich wird (Taf. 24, 4).

Dem Stylobat ist eine 0,48 $\mathrm{m}$ breite und im Schnitt 0,32-0,39 $\mathrm{m}$ tiefe Regenrinne vorgelagert (Niveau Sohle: 45,42-44,93 m), deren Wände und Sohle mit etwa $17 \mathrm{~mm}$ starken Marmorplatten ausgekleidet wa- 
ren $^{225}$. Sie leitete das Regenwasser der zu rekonstruierenden Pultdächer, die Walme oder abschließende Ortgänge besaßen, ab. Die Regenrinne ist durch das Fundament des Stylobats, eine Lage aus Bruchsteinen am Boden und durch ein 0,33 m starkes Mäuerchen aus Ziegeln vor dem Stylobat definiert. Die Marmorplatten wurden in ein Mörtelbett gesetzt (opus signinum) und sind vor allem im Westteil auch heute noch erhalten; die Abdeckplatten der Rinne haben sich indes nicht erhalten. Die westliche Regenrinne endet 0,65 m, die östliche Regenrinne ca. 0,60 m vor der Euthynterie der Vorhalle. Bei den Anläufen der Regenrinnen fanden sich Elemente von Ost-West orientierten Tonrohrleitungen, deren Oberkanten in der Höhe der Euthynterie liegen $(45,70 \mathrm{~m})^{226}$. Der tiefste Punkt der Regenrinne befindet sich in ihrer Südostecke $(44,93 \mathrm{~m})$. Von hier entwässerte der Kanal in einen sekundären, Nord-Süd verlaufenden Kanal unter dem östlichen Umgang der Triporticus. Wie aus der Planumszeichnung der Sondage XXVI (1961) hervorgeht (Taf. 24, 2), biegt der Kanal an der Südostecke des Stylobats in Richtung Südostecke des Vorhofes ab. Der 0,34-0,37 m breite, 0,47-0,50 m tiefe, Nord-Süd verlaufende Kanal (Niveau Sohle: 45,24-45,31 m), der ursprünglich etwa 0,34 m vor der Euthynterie endete, wird im Westen durch das Bruchsteinfundament des Stylobats und im Osten durch eine 0,37 m starke Bruchsteinmauer begrenzt. Besonders im südlichen Abschnitt haben sich noch Teile der Kanalabdeckung aus Kalkstein- und Marmorplatten erhalten. Die Sohle aus Bruchsteinen und Ziegeln sowie die Kanalwangen waren mit einem sehr groben hydraulischen Estrich (opus signinum) verputzt. Zu einem späteren Zeitpunkt wird der Kanal 1,91 m vor der Euthynterie abgemauert und erhält eine Abzweigung nach Nordosten. Nördlich der südlichen Regenrinne sowie westlich der östlichen Regenrinne konnte im Bereich der Südostecke des offenen Hofes ein weiterer, 0,16-0,21 m breiter und 0,15-0,22 m tiefer Kanal nachgewiesen werden (Niveau Sohle: 45,15-45,25 m). Begrenzt wurde der Kanal von der hofseitigen Kanalwange der Regenrinne sowie von einem 0,31-0,40 m starken Mäuerchen aus Bruchsteinen und Ziegeln. An der Südostecke, an der die Kanalwangen etwas verstärkt waren, mündete der Kanal in die Regenrinne und folglich weiter in den Nord-Süd verlaufenden Kanal unter dem östlichen Umgang. Die Sohle dieses Kanals besteht aus Bruchsteinen und Ziegelfragmenten, über denen ein grauer Kalkmörtel aufgetragen wurde. Über der östlichen Regenrinne befand sich der untere Teil einer Ehrenbasis mit dreiseitig gekehltem Sockelprofil (KatNr. SK 12; Taf. 38. 39), den die Ausgräber noch in situ angetroffen haben. In unmittelbarer Nähe fanden sich der obere Teil dieser Ehrenbasis (KatNr. SK 13227; Taf. 38. 40. 41) sowie ein weiterer Teil einer Ehrenbasis (KatNr. SK 14228; Taf. 42), deren ursprünglicher Aufstellungsort jedoch nicht mehr festzustellen ist.

Von der Säulenstellung des Peristyls ist nichts mehr erhalten; sie kann jedoch aufgrund von Versatzspuren auf den Stylobatblöcken rekonstruiert werden: Da an der Westseite zwei Auflagerspuren für Basen mit quadratischen Plinthen erkennbar sind $(\approx 0,62 \times \approx 0,62 \mathrm{~m})$, kann die Jochweite mit 2,98 $\mathrm{m}$ bestimmt werden, wobei die Kante der nördlichsten Basis exakt 2,00 m von der Euthynterie des Stereobats der Vorhalle entfernt lag. Auch am Stylobatblock der Südostecke findet sich eine Versatzspur für eine Basis. Der Stylobat der Triporticus reichte nicht bis an die Euthynterie heran. Während die Jochweiten der West- und Ostseite identisch und folglich je fünf Säulen ionischer Ordnung zu rekonstruieren sind, ergibt sich für die mit sechs Säulen ionischer Ordnung zu rekonstruierende Südseite aufgrund der geringeren Länge des Stylobats ein engeres Joch von rekonstruierten 2,77 m (Gesamtzahl der Säulen: 14) 229.

Im Zentrum des Vorhofes - leicht nach Nordosten versetzt - liegt ein 0,80 m tiefer Bothros mit glockenförmigem Querschnitt, dessen oberer, kreisrunder Durchmesser 0,70 m misst (Taf. 43. 44); der Durchmesser des Bodens beträgt 1,13 m (Niveau Boden: 44,23 m). Die Wände des Bothros sind aus Bruchstein- und

\footnotetext{
225 Die teilweise umgestürzten und gebrochenen marmornen Kanalwangen wurden 2007 geklebt und wieder versetzt.

226 L der Tonrohrelemente: 0,49 m; die Dm außen und innen sind nicht mehr feststellbar, da nur die Oberkanten der Tonrohrelemente sichtbar sind.

227 Dreiseitig profilierter Block mit Einarbeitungsspuren für Statuen der inschriftlich genannten Kureten Alexandros und Dieos (auf Schmalseiten). Die Ehreninschrift war an der Längsseite angebracht; Knibbe 1981, D 7 (IvE 613a).

228 Cf. IvE 985.

229 Da dorische und ionische Ordnungen bei öffentlichen Bauvorhaben bei Weitem vorherrschen, ist durch die Versatzspuren für Basen mit hoher Wahrscheinlichkeit von einer ionischen Ordnung auszugehen. Theoretisch wäre freilich auch eine korinthische Ordnung möglich; cf. dazu H. v. Hesberg, Formen privater Repräsentation in der Baukunst des 2. und 1. Jahrhunderts v. Chr. (Köln 1994) 92. - Die Anlage der Triporticus dürfte mit einer inschriftlich überlieferten Stiftung von 14 Säulen samt Basen, Fries, Statuen und einem Tor in Verbindung zu bringen sein (IvE 437); cf. M. Steskal, Kapitel II.4.
} 
Ziegelringscharen in Mörtelverband gefertigt; der Boden bestand aus einem heute kaum noch vorhandenen Kalkmörtelestrich. Südlich dieses Bothros befindet sich ein nahezu quadratisches, 2,51 × 2,54 m großes Fundament aus vermörtelten Bruchsteinen mit vier großen Kalksteinblöcken und einer Kalkmörtelbettung an der Oberseite (OK Kalkmörtelbettung: 45,74 m), dessen Seiten leicht aus der Flucht des Gebäudes gedreht sind (Taf. 43. 44). Die Flucht des Fundaments orientiert sich an der Lage des Eingangs in der Südmauer ${ }^{230}$. Auf der Oberfläche des Fundaments sind mehrere Vertiefungen für Kantendübel erkennbar. Die im Vorhof gefundene >Große Artemis<-Statue (KatNr. SK 4), der dieses Fundament wohl als Basis diente, wurde von F. Miltner 1956 unmittelbar südlich vor diesem Fundament in Sturzlage angetroffen (Taf. 10, 2). Welches Objekt sich in der ersten, augusteischen Bauphase 1 - also vor der Aufstellung der >Großen Artemis $<$ - auf dem Fundament befand, ist unbekannt.

\section{III.3 Vorhalle}

An den Vorhof schließt nördlich eine quergelagerte, rechteckige Stoa $(7,20 \times 21,38 \mathrm{~m})$ an, über die der >Hestiasaak und die Nebenräume 5 und 6 erschlossen werden konnten (Taf. 45, 1. 2). Die Front bildete eine heute teilweise wieder aufgestellte dorische Ordnung auf einem Stereobat und einem darüber befindlichen Stylobat zwischen zwei Antenmauern (Taf. 45, 3). Die Kalksteinblöcke der Euthynterie sind durchgehend erhalten (Niveau: 45,73 m). Der darunterliegende Stereobat ist aus Kalksteinquadern (opus rusticum) gebildet (Taf. 46, 1), die an den Sichtflächen großteils grob belassen wurden (UK Stereobat: 43,44 m; max. H ink1. Euthynterie: $2,24 \mathrm{~m}^{231}$. Die Trittfläche der Euthynterie ist $0,38 \mathrm{~m}$ tief; im westlichen Bereich sind zudem Versatzmarken (A, $\Gamma$ und E) feststellbar (Taf. 46, 2). Die Euthynterieschicht ist 1,80-2,05 m tief. Vom Stylobat ist nur noch der Block vor der westlichen Antenmauer erhalten (Niveau: 46,04 m). Auf ihm ist die Aufschnürung für den 1,18 m breiten Antenkopf zu erkennen (Taf. 46, 3. 4). Die Vorderkante des Stylobats ist aber aufgrund der Auflagerspuren auf der Euthynterie über die gesamte Länge nachweisbar. Aufgrund eines Dübellochs auf der Euthynterie in der Flucht der Ostante ist gesichert, dass die Antenmauer bis zur vorderen Stylobatkante verlaufen sein muss. Der Stylobat dürfte nur aus einer Quaderreihe gebildet worden sein. Die Blöcke des Stylobats waren mit den Euthynterieblöcken durch Dübel verbunden. Eine Kurvatur im Bereich der dorischen Fassade ist wegen des Fehlens des Großteils der Stylobatblöcke und der aufgehenden Architektur nicht nachzuweisen. An den Stylobat schloss ein heute in Beton gegossener Mosaikboden an, von dem an der West- und Ostante noch zwei größere Flächen erhalten sind (Taf. 45, 1. 2; 64; 65, 1). Das heutige Niveau des restaurierten Bodens (Westteil: 46,32-46,19 m; Ostteil: 46,18 m) entspricht wegen der künstlichen Aufschüttung darunter und zugleich moderner Setzungen nicht mehr seiner ursprünglichen Höhe.

Die 1,15 m starke westliche Antenmauer ist 1,48 m über dem Stylobat erhalten (Taf. 47-49). Das Südende fehlt, ist aber aufgrund von Versatzspuren auf dem Stylobat nachweisbar. Die Mauer ist an der Westseite durch zwei Schichten charakterisiert: Bis 1,19 m über dem Stylobat besteht sie aus zwei Lagen pseudoisodom verlegter Kalksteinquader in Kalkmörtelverband und darüber einer Schar von durch U-Eisenklammern verbundenen Quadern aus graugeädertem Marmor mit Anathyrosis. Die Marmorquader sind paarweise mit je zwei Versatzmarken versehen, wovon vier dieser Paare heute noch lesbar sind: A-A, B-B, $\Gamma-\Gamma, \Delta-\Delta$ (Zählung von Süden). An der Ostseite dieser Ante befindet sich eine 0,29 $\mathrm{m}$ hohe Fundamentschicht aus Marmor mit darüber versetzten, 0,75 m hohen Orthostaten und einer 0,44 $\mathrm{m}$ hohen Quaderschicht mit Gesims, jeweils aus graugeädertem Marmor. Die Orthostaten springen gegenüber den oberen Quadern und der Fundamentschicht um etwa $18 \mathrm{~mm}$ zurück. Die einzelnen Werksteine sind mittels U-Eisenklammern miteinander verbunden. Der Raum zwischen der Ost- und Westseite der Antenmauer wurde mit kleinformatigen Bruchsteinen ausgefüllt. In der Nordwestecke ist über dem Sockel ein bis zu 0,53 m hoher Rest des darüber errichteten, vermörtelten Bruchstein- und Ziegelmauerwerks erhalten. Das Fundament der Antenmauer aus

\footnotetext{
230 Ursprünglich könnte es sich um eine Doppeltür gehandelt haben, die W. Alzinger noch im aufgehenden Mauerwerk erkennen wollte. Die von ihm westlich der heute noch sichtbaren - jedoch sekundär vermauerten - Türöffnung beschriebene Öffnung ist heute allerdings nicht mehr nachweisbar.

231 Cf. Schnitt $1 / 07$ und 2/07.
} 
an den Sichtflächen unbearbeiteten Kalksteinquadern reicht, wie in Sondage XXXII (1963) gezeigt werden konnte, 3,05 m unter das Niveau des Stylobats der Vorhalle (absolut: 42,99 m) ${ }^{232}$.

Die östliche Antenmauer entspricht im Wesentlichen der westlichen (Stärke: 1,14 m; Taf. 50. 51). Die obere Quaderschicht mit Gesims ist allerdings nicht mehr vorhanden. 2,25 m von der Nordostecke der Vorhalle gemessen, beginnt ein bis zu 1,17 m hoch erhaltenes, vermörteltes Bruchsteinmauerwerk mit Ziegelausgleichsscharen, das sich bis in den $>$ Hestiasaak fortsetzt. Das auf den Orthostaten ruhende, spolierte Mauerwerk - so ist etwa eine im Durchmesser 0,37 m große Granitsäule verbaut - ist $0,24-0,35 \mathrm{~m}$ gegenüber der Orthostatenflucht zurückgesetzt. $0,10 \mathrm{~m}$ von der Nordostecke der Vorhalle läuft eine Tonrohrleitung durch das spolierte Mauerwerk nach Osten durch (Niveau: 47,24 m; innerer Dm: 0,135 m, äußerer Dm: 0,195 m). Zwischen 3,15 und 4,15 m von der Nordostecke der Vorhalle entfernt wurden sekundär eine $1,00 \mathrm{~m}$ breite Tür ausgebrochen und eine Türschwelle versetzt. In die Türschwelle war eine $0,19 \times 0,19 \mathrm{~m}$ große Führung für eine Tonrohrleitung geschlagen worden, die später entfernt und mit Ziegeln und Kalkbruchsteinen aufgefüllt wurde. 1,35 m vor der Nordostecke enden die Orthostatenblöcke; der freibleibende Zwischenraum ist durch vermörteltes, spoliertes Bruchsteinmauerwerk mit Ziegelausgleichsscharen vermauert. Westlich der Mauern befinden sich zwei, in der letzten Bauphase funktionslose, nach Osten führende Stufen aus Marmor bzw. Kalkstein ${ }^{233}$. Das nicht erhaltene Südende der östlichen Antenmauer ist analog zur westlichen zu ergänzen.

Der Sockel der Rückwand der Halle entspricht im Wesentlichen der Konstruktion der Antenmauern; sie ist durch vier Türöffnungen charakterisiert (Tür 1 zwischen 2,42 und 5,14 m von der Nordwestecke der Vorhalle; Tür 2 zwischen 7,80 und 9,08 m; Tür 3 zwischen 12,20 und 16,09 m; Tür 4 zwischen 20,15 und 21,40 m), wobei die Türen 2 und 4 erst sekundär errichtet wurden (Taf. 52; 53; 54, 1). Tür 1 und 2 wurden später mit spoliertem Bruchsteinmauerwerk und Ziegelausgleichsschichten vollständig verschlossen (Taf. 54, $2)^{234}$. In Tür 4 fand sich 1,42 m über der ursprünglichen Schwelle eine sekundäre, aus zwei Marmorspolien gefertigte Türschwelle (Niveau: 47,79 m; Taf. 22, 3; 54, 3). Durch eine Reparatur sind grundlegende Veränderungen an der Rückwand zu konstatieren: So sind die Orthostaten westlich der Tür 4 durch zwei Kalksteinquader und östlich an Tür 2 anschließend mittels zweier Marmorblöcke unterbrochen. Fehlende Elemente der oberen Quaderschicht zwischen den Türen 2 und 3 wurden entweder durch Marmorblöcke oder durch Ziegelausmauerungen ergänzt; westlich von Tür 4 wurden zudem zwei Marmorspolien verbaut. Bis zur Tür 1 sowie zwischen den Türen 1 und 2 bzw. 3 und 4 ist das Mauerwerk über dem Marmorsockel aus Ziegeln gefertigt $(0,29 \times 0,29 \times 0,045 \mathrm{~m})$. Das restliche Aufgehende besteht aus spoliertem Bruchsteinmauerwerk mit Ziegelausgleichsscharen; der gekehlte Fugenverstrich ist teilweise noch erkennbar. Die Orthostaten und Quader sind mit zahlreichen Kureteninschriften versehen (IvE 1013. 1018. 1022. 1023. 1024. 1051. 1062 ${ }^{235}$; Taf. 55). Der gesamte Marmorsockel wurde wie die dorische Architektur mit dem Zahneisen bearbeitet und anschließend geglättet.

Von der dorischen Ordnung (Taf. 45, 3; 56-59; 60, 1. 2; 61; 62), die mit sechs unkannelierten Säulen in antis zu rekonstruieren ist ${ }^{236}$, wurden im Areal des Prytaneions nur wenige Elemente gefunden: ein Architravblock (KatNr. A 7: erh. L 3,54 m, H 0,75 m, T 0,66-0,75 m, B Regula 0,60 m), ein Teil des Metopen-Triglyphen-Frieses (KatNr. A 8: L 1,31 m, H 0,88 m, T 0,445 m, B Metopen 0,91 m, B Triglyphen 0,60 m) und zwei Blöcke des Horizontalgeisons (KatNr. A 9: L 1,06 m, H 0,35 m, T 1,62 m; KatNr. A 10: L $1,06 \mathrm{~m}, \mathrm{H}$ 0,34 m, T 1,56 m) $)^{237}$. Aufgrund der Übereinstimmung der Breiten der Mutuli $(0,60 \mathrm{~m}) \mathrm{mit}$ der der Triglyphen können die Geisonblöcke KatNr. A 9 (in der Architekturprobe verbaut) sowie A 10 (Taf. 60, 1. 2) eindeutig der dorischen Ordnung zugewiesen werden. Farbreste an den Geisa, welche die Ausgräber der 1950er und 1960er Jahre noch zu erkennen glaubten - so seien das Kymation in dunkler Farbe als Eierstab

${ }_{232}$ Cf. Schnittzeichnung »Prytaneion - Odeion« nach Norden (ÖAI InvNr. 2360/8).

233 Untere Stufe: H 0,27 m, T 0,34-0,48 m (Niveau: 46,49 m); obere Stufe: H 0,24 m, T 0,18 m (Niveau: 46,73 m).

${ }^{234}$ Tür 1 ist auf Aufnahmen des Jahres 1968 noch verschlossen (Taf. 29, 2), wurde aber später teilweise wieder geöffnet und besitzt heute eine lichte Weite von 1,68 m (zwischen 2,42 und 4,10 m von der Nordwestecke der Vorhalle).

235 Entspricht Knibbe 1981, B 13. B 18. B 22. B 23. B 24. B 51. F 1. - Ein Konzept in der Abfolge der Inschriften lässt sich - wie auch bei den Kureteninschriften auf den Säulen und dem Gebälk der dorischen Ordnung der Vorhalle - nicht erkennen.

236 H. v. Hesberg, Formen privater Repräsentation in der Baukunst des 2. und 1. Jahrhunderts v. Chr. (Köln 1994) 92 spricht in diesem Zusammenhang von einer »unglücklichen Gesamtgestalt«.

237 Zur dorischen Ordnung s. G. A. Plattner, Kapitel VII.4.3. 
aufgemalt und auch auf der darunterliegenden Leiste rote Farbspuren erkennbar gewesen -, sind heute nicht mehr nachzuweisen. Die Geisa, die ohne Sima ausgeführt sind, an ihren Oberlagern aber Einlassungen für die Führung von Holzbalken besitzen, waren ursprünglich horizontal mittels U-Eisenklammern sowie Kantendübeln miteinander verbunden; die vertikale Verbindung zum Metopen-Triglyphen-Fries erfolgte ebenfalls mittels U-Eisenklammern und teilweise mit Dübeln. Die vertikale Verbindung zwischen Metopen-Triglyphen-Fries und Architrav erfolgte mittels Dübeln; zu ihrer horizontalen Verbindung verwendete man U-Eisenklammern. Die Architrave wiederum waren horizontal mittels U-Eisenklammern verbunden; die vertikale Verbindung mit den Kapitellen erfolgte mittels Dübeln. Auf Basis der bekannten Breite von Mutulus, Triglyphe, Metope und Regula ist eine Jochweite von 3,02 m zu berechnen ${ }^{238}$. Da die Breite der Vorhalle durch die beiden Antenmauern definiert ist (23,67 m inkl. Antenmauern), kann der Metopen-Triglyphen-Fries folglich zunächst - vorbehaltlich der Klärung des dorischen Eckkonfliktes - mit 15 Metopen à $0,91 \mathrm{~m}$ und 16 Triglyphen à $0,60 \mathrm{~m}$ rekonstruiert werden. Der überlange Architravblock KatNr. A 7, der an seiner Vorder- und Rückseite eine antike Reparatur mittels je einer 5,5 cm breiten U-Klammer aufweist, ist somit - entgegen seiner heutigen Anbringung - über ein um eine Metope und eine Triglyphe erweitertes Mitteljoch $(4,53 \mathrm{~m}) \mathrm{zu}$ setzen ${ }^{239}$. Der sich daraus ergebende dorische Eckkonflikt wird durch Verbreiterung der jeweils äußersten Metopen um jeweils $0,21 \mathrm{~m}$ gelöst, wodurch sich für die östlichste und westlichste Metope ein Breitenmaß von 1,12 m ergibt ${ }^{240}$. Ausgehend von der tatsächlichen Breite der Vorhalle von 23,67 m ergibt sich eine Differenz von $0,16 \mathrm{~m}$ auf die rekonstruierte Breite von $23,83 \mathrm{~m}(6 \times$ Normaljoch à $3,02 \mathrm{~m}+1 \times$ Mitteljoch à $4,53 \mathrm{~m}+2 \times$ B eines halben Antenkopfes à $0,59 \mathrm{~m})$.

Die von W. John vorgeschlagene zeichnerische Rekonstruktion der dorischen Fassade löst den Eckkonflikt durch Kontraktion der jeweils äußersten Joche (Taf. 29, 3) ${ }^{241}$. Den Metopen-Triglyphen-Fries lässt er regelmäßig durchlaufen. Johns Rekonstruktionsversuch basiert allerdings auf falschen Maßen: Er bemisst die Breite der Vorhalle (inkl. Antenmauern) mit 23,17 m. Dies bedeutet einen Differenz von 0,50 m zum exakten, tachymetrisch bestimmten Wert von 23,67 m. Auch A. Bammer löst den Eckkonflikt in seiner schematischen Rekonstruktion der Vorhalle durch Kontraktion der äußersten Joche und geht wie John von einer falschen Breite aus: Er nimmt 23,43 m an, was einen Fehler von 0,24 m bedeutet ${ }^{242}$.

Die Breite des Mutulus eines weiteren in der Vorhalle des Prytaneions aufgelegten Horizontalgeisons (KatNr. A 11: L 0,91 m, H 0,31 m, T 1,39 m) beträgt nur 0,51 m (Taf. 60, 3. 4). Dieses Geison ist mit seinen abweichenden Dimensionen und seiner differierenden Rhythmik jedoch an keiner Stelle des Gebäudes im Gebälk unterzubringen ${ }^{243}$. Es kann lediglich als Spolie verbaut gewesen oder nach den Ausgrabungen der 1960er Jahre in das Areal des Prytaneions verbracht worden sein ${ }^{244}$. Kapitelle, die dem Gebälk des Pryta-

${ }_{238}$ Die Jochweite von 3,02 m errechnet sich aus der Summe der Breiten zweier halber und einer ganzen Triglyphe (1,20 m) sowie zweier ganzer Metopen (1,82 m).

239 Hypothetisch wäre die Fassade auf Basis dieser Jochweite von 4,53 m auch mit vier Säulen in antis ohne erweitertes Mitteljoch zu rekonstruieren - eine optisch unbefriedigende und statisch ungünstige Lösung. Eine Erweiterung des Mitteljochs wäre bei einer Normaljochweite von 4,53 m aufgrund der vorgegebenen Dimension und Anzahl der Triglyphen und Metopen unmöglich.

240 Theoretisch wäre der Konflikt auch durch ein Stehenlassen von jeweils 0,21 m breiten Restmetopen jenseits der äußersten Triglyphen zu lösen gewesen. Diese Lösung kommt aber nur in Ausnahmefällen zum Tragen; s. dazu B. Wesenberg, Beiträge zur Rekonstruktion griechischer Architektur nach literarischen Quellen, AM Beih. 9 (Berlin 1983) 143-152; Knell 1991, 84-95; Vitr. 4, 3.

${ }^{241}$ Cf. Alzinger 1972-1975, 245 f. Abb. 7; Alzinger 1974, Taf. 34 Abb. 65a.

242 Bammer 1976/1977, 57; Bammer 2008, 170; s. dazu Eichler 1964, 40. Ebenso abgebildet bei Knibbe 1981, 189 Beil. I.

243 Versuchte man diesen Geisonblock in der dorischen Ordnung der Vorhalle zu verbauen, würden sich folgende Schwierigkeiten ergeben: Der Fries wäre dann mit 19 Metopen zu 0,67 m und 20 Triglyphen zu 0,51 m zu rekonstruieren. Mit einer Länge von 22,93 m wäre der Fries somit um 0,74 m zu kurz (B der Vorhalle 23,67 m!). Somit wären zur Lösung des dorischen Eckkonfliktes die äußersten Metopen um jeweils $0,37 \mathrm{~m}$ zu verbreitern. Rekonstruierte man auch hier die Fassade mit sechs Säulen in antis - vier Säulen in antis lassen sich weder mit noch ohne erweitertes Mitteljoch lege artis in einer solchen Fassade verbauen -, wäre das Normaljoch, bestehend aus zwei halben und zwei ganzen Triglyphen sowie drei Metopen, mit 3,54 m und das um eine Metope und eine Triglyphe erweiterte Mitteljoch mit 4,72 m zu rekonstruieren. Ausgehend von der tatsächlichen Breite der Vorhalle von 23,67 m ergäbe sich eine Differenz von 3,47 m auf die rekonstruierte Breite von $27,14 \mathrm{~m}(6 \times$ Normaljoch à $3,54 \mathrm{~m}+1 \times$ Mitteljoch à 4,72 $\mathrm{m}+2 \times \mathrm{B}$ eines halben Antenkopfes à $0,59 \mathrm{~m})$. Eine solche Lösung ist daher auszuschließen. Verkleinerte man das Normaljoch auf zwei halbe und eine ganze Triglyphe sowie zwei Metopen mit 2,36 m und das um eine Metope und eine Triglyphe erweiterte Mitteljoch mit 3,54 m, dann wären acht Säulen in antis zu rekonstruieren. Auch eine solche Lösung ist aufgrund der Enge des Interkolumniums (1,16 m!) auszuschließen.

244 Auf einer Abbildung des Jahres 1968 (Taf. 29, 2) ist der Geisonblock bereits im Prytaneion zu sehen. 
neions eindeutig zuzuordnen sind (Taf. 61, 1. 2), fanden sich im Bereich der Scholastikiatherme und der `Kuretenhalle< am unteren Ende des Embolos (KatNr. A 5. 6: L Abakus 1,26 m, Dm 0,98 m, H 0,46 m inkl. Säulenhals, H Abakus 0,168 m, H Echinus 0,137 m, H Anuli 0,05 m). Weiters konnten zwölf Säulentrommeln aus der Scholastikiatherme sowie der `Kuretenhalle ২ der dorischen Ordnung der Vorhalle zugewiesen werden. Die auf den offenbar zur späteren Aufzeichnung der Kuretenlisten unkanneliert belassenen Säulentrommeln und dem Gebälk befindlichen Kureteninschriften veranlassten F. Miltner dazu, den in der Antike als Embolos bezeichneten Straßenzug als `Kuretenstraßeく anzusprechen (Taf. 61, 3; 62, 1). Säulentrommeln und Teile des Gebälks sind heute in der Architekturprobe am Prytaneion verbaut. Die Höhe der Säulen beträgt samt der Kapitelle 7,405 $\mathrm{m}^{245}$. Entsprechend ihrer Entasis verjüngen sich die Säulendurchmesser um jeweils 0,229 m oder $19 \%$.

In Architekturprobe verbaute dorische Säulentrommeln ${ }^{246}$

\begin{tabular}{|l|c|c|c|c|}
\hline \multicolumn{1}{|c|}{ Säule } & Trommel & unterer Dm & oberer Dm & H Trommel \\
\hline KatNr. A 1 & A & $1,145 \mathrm{~m}$ & - & erh. H max. 0,88 m \\
\hline KatNr. A 2 & A & $1,143 \mathrm{~m}$ & $1,142 \mathrm{~m}$ & $1,55 \mathrm{~m}$ \\
\hline & B & - & $1,06 \mathrm{~m}$ & $\begin{array}{c}\text { erh. H max. } \\
0,69 \mathrm{~m}^{247}\end{array}$ \\
\hline KatNr. A 3 & A & $1,209 \mathrm{~m}$ & $1,156 \mathrm{~m}$ & $1,785 \mathrm{~m}$ \\
\hline & B & $1,156 \mathrm{~m}$ & $1,129 \mathrm{~m}$ & $1,43 \mathrm{~m}$ \\
\hline & C & $1,129 \mathrm{~m}$ & $1,101 \mathrm{~m}$ & $1,47 \mathrm{~m}$ \\
\hline & D & $1,101 \mathrm{~m}$ & $1,038 \mathrm{~m}$ & $0,86 \mathrm{~m}$ \\
\hline & E & $1,038 \mathrm{~m}$ & $1,025 \mathrm{~m}$ & $1,40 \mathrm{~m}$ \\
\hline KatNr. A 4 & A & $1,199 \mathrm{~m}$ & $1,175 \mathrm{~m}$ & $1,755 \mathrm{~m}$ \\
\hline & B & $1,175 \mathrm{~m}$ & $1,142 \mathrm{~m}$ & $1,39 \mathrm{~m}$ \\
\hline & C & $1,142 \mathrm{~m}$ & $1,112 \mathrm{~m}$ & $1,425 \mathrm{~m}^{248}$ \\
\hline & D & $1,057 \mathrm{~m}$ & $1,008 \mathrm{~m}$ & $1,05 \mathrm{~m}^{249}$ \\
\hline
\end{tabular}

Inschriften auf Architekturprobe

\begin{tabular}{|c|c|c|c|c|}
\hline Säulentrommel & Kapitell & Architrav & $\begin{array}{l}\text { Metopen-Tri- } \\
\text { glyphen-Fries }\end{array}$ & Inschrift \\
\hline A (KatNr. A 1) & & & & IvE 1038. 1047. $1059^{250}$ \\
\hline A (KatNr. A 2) & & & & $\begin{array}{l}\text { IvE 1003. 1028. 1031. } 1032 . \\
\text { 1061. } 1080 \mathrm{a}\end{array}$ \\
\hline B (KatNr. A 2) & & & & IvE 1014 \\
\hline A (KatNr. A 3) & & & & IvE 1012. 1020. 1040 \\
\hline B (KatNr. A 3) & & & & IvE 1021. 1036. 1042 \\
\hline C (KatNr. A 3) & & & & IvE 1001. 1002. 1002a \\
\hline D (KatNr. A 3) & & & & IvE 1005.1015 \\
\hline E (KatNr. A 3) & & & & IvE 1009. 1016 \\
\hline A (KatNr. A 4) & & & & IvE 1034. 1035. 1070. 1352 \\
\hline B (KatNr. A 4) & & & & $\begin{array}{l}\text { IvE 1004. 1006. 1029. } 1060 . \\
1066\end{array}$ \\
\hline C (KatNr. A 4) & & & & IvE 1011. 1033 \\
\hline \multirow[t]{4}{*}{ D (KatNr. A 4) } & & & & IvE 1008.1037 \\
\hline & KatNr. A 5 & & & IvE 1037 \\
\hline & & KatNr. A 7 & & IvE 1010 \\
\hline & & & KatNr. A 8 & IvE 1030 \\
\hline
\end{tabular}

245 Cf. die berechnete Säulenhöhe von 7,42 m bei Eichler 1964, 40 sowie Bammer 1976/1977, 57; Bammer $2008,170$.

246 Zählung der Säulen von West nach Ost; Zählung der Säulentrommeln von unten nach oben (A, B, C, ...).

247 Trommel B in Beton gegossen ( $\mathrm{H}$ inkl. Beton 1,63 m).

248 Zwischen Trommel C und D eine Betontrommel (H 0,70 m).

249 Über Trommel D eine Betontrommel (H 0,735 m).

${ }^{250}$ IvE 1005 durch rezente Abarbeitung heute nicht mehr vorhanden; s. Knibbe 1981, B 5. 
Die vertikale Verbindung zwischen den Säulentrommeln erfolgte mittels eines zentralen Dübels im Spiegel sowie vier weiterer Dübel in den seitlichen Lagerflächen (Taf. 58, 2). Auf der Trommel B der Säulen KatNr. A 2 sowie den Trommeln C der Säulen KatNr. A 3.4 befinden sich je zwei $35 \times 29 \mathrm{~cm}$ große, sekundäre Einarbeitungen für profilierte Brüstungen (Taf. 62, 2-4).

Westlich der Tür 3 befindet sich in situ ein in den Boden vertiefter Marmorblock bzw. eine Marmorplatte mit zwei Dübellöchern und Gusskanälen (Niveau: 46,20 m; L 2,088 m, B 0,54 m; Taf. 63, 1). Vor der Südwestecke dieses Blockes bzw. dieser Platte liegt, in den Boden versenkt, der Sockel einer Ehrenbasis (L 0,85 m, B 0,85 m; KatNr. SK 15), der ca. 0,30 m aus dem Boden herausragt (Taf. 63, 1-3). Östlich der Tür 3 in den >Hestiasaak befinden sich zwei weitere Marmorplatten oder -blöcke (1: Niveau: 46,22 m; L 1,01 m, B 0,59 m; 2: Niveau: 46,25 m; L 0,78 m, B 0,61 m, mit zwei Dübellöchern und keilförmiger Einarbeitung), die in den Boden der Vorhalle eingelassen waren (Taf. 63, 4). Vor der östlichen Antenmauer liegt eine $0,75 \times 0,63 \mathrm{~m}$ große Marmorspolie (Niveau: 46,28 m) mit einer $6 \mathrm{~cm}$ tiefen, rinnenförmigen Vertiefung in situ (Taf. 63, 5).

Der ursprüngliche Boden der Vorhalle ist nicht mehr erhalten, jedoch haben sich sowohl im westlichen als auch im östlichen Teil der Halle größere, mit mehreren Lücken durchsetzte Reste eines sekundären Mosaiks erhalten, die heute in Beton gegossen sind (Taf. 45, 1. 2; 64; 65, 1). Das polychrome Tessellat aus schwarzen, weißen, gelben und violetten Tesserae (Kantenlänge 1-1,5 cm) war ursprünglich in einen grauen Kalkmörtelestrich gebettet ${ }^{251}$. Die 1-1,85 m breite, weiße Außenzone ist durch jeweils zwei Reihen weißer Tesserae von den Hallenwänden abgesetzt und durch je zwei Reihen schwarzer Quadrate $(\mathrm{L} 5-6 \mathrm{~cm})$ verziert. Das Musterfeld ist von einer Bordüre aus zwei schwarzen und einer dazwischenliegenden weißen Leiste gerahmt (B der schwarzen Leisten 7,10 bzw. 5,50 cm). Auf dem weißen Grund des Musterfeldes befinden sich fünf Reihen gegengleich ausgerichteter Peltenwirbel von 52-54 cm Durchmesser; in der Mitte jedes Wirbels ist ein Salomonsknoten platziert. Das Musterfeld reicht im Süden knapp an die Säulenfront der Halle heran ${ }^{252}$.

\section{III.4 >Hestiasaak (Raum 1)}

Der $>$ Hestiasaak (Raum 1) besitzt einen nahezu quadratischen Grundriss $(13,47 \times 13,41 \mathrm{~m})$ und ist an allen vier Seiten von Mauern umschlossen ${ }^{253}$ (Taf. 65, 2). Über die Türen 2, 3 und 4 in der Südwand und die Öffnung in der Nordwand konnte er betreten bzw. verlassen werden. Alle vier Mauern sind durch einen sauber geschnittenen Sockel aus marmornen Werksteinen charakterisiert.

Der Marmorsockel der Westmauer war mit dem Sockel der Südmauer ursprünglich im Verband errichtet (Taf. 66. 67). An der Südwestecke zeigt sich anhand von Abarbeitungsspuren für den Durchbruch der Tür 2, dass vom originalen Bestand nur noch der innere Eckverband erhalten ist. Die gesamte Südmauer präsentiert sich heute als eine spätere Reparatur unter Verwendung alter, dem Bau zuzuordnender Werkstücke (Taf. 68). Der Raum zwischen den Marmorquadern, die die Sichtflächen bildeten, ist mit Ziegelmauerwerk in Mörtelverband (opus signinum) ausgefüllt. Westlich der Tür 3 (Taf. 70, 3. 4) ist eine Länge von 1,81 m des wiederverwendeten Marmorsockelmauerwerks erhalten; östlich dieses Eingangs in den >Hestiasaak können 2,86 m nachgewiesen werden ( $\mathrm{H}$ der unteren Quaderschicht 0,61 m, H der Orthostaten 0,725 m, $\mathrm{H}$ der oberen Quaderschicht 0,285 m). Beim Sockel östlich von Tür 3 fehlt die obere Quaderschicht. Der Raum zwischen den Marmorquadern der Sichtflächen ist hier mit Bruchsteinmauerwerk in Mörtelverband (opus signinum) ausgefüllt. Die Struktur der über dem Sockel liegenden Mauerteile entspricht der späterer Modifikationen im Bereich der Rückwand der Vorhalle: Auch hier wurden fehlende Elemente der oberen Quaderschicht entweder durch spoliertes Bruchsteinmauerwerk mit Ziegelausgleichsscharen oder Ziegelausmauerungen unter Verwendung von Marmorspolien ergänzt (Ziegel: 0,29 × 0,29 × 0,045 m).

\footnotetext{
251 Für ausführliche Informationen zum Mosaik sei W. Jobst und V. Scheibelreiter gedankt.

252 Cf. auch Miltner 1959, 290-314; Eichler 1962, 38-41; Alzinger 1970, 1646-1648; Alzinger 1974, 51-55; Alzinger 1972-1975, 235-249; Jobst 1977, 49 Abb. 86; Knibbe 1981, 75-78; W. Jobst, Antike Tessellatpavimente in Ephesos, in: Friesinger - Krinzinger 1999, $573 \mathrm{f}$.

${ }^{253}$ Zum >Hestiasaal cf. auch den Grabungsbefund: M. Steskal, Kapitel IV.4-6.
} 
Wie Abarbeitungsspuren in der Südwestecke des >Hestiasaales` zeigen, wurde die Tür 2 zu einem späteren Zeitpunkt durchgebrochen. Sie erhielt dabei eine in der Höhe des unteren Quaders der Vorhallenrückwand angesetzte Schwelle aus einer 0,11 m hohen Marmorspolie (Niveau: 46,37 m). Die Schwelle besitzt mehrere Ein- und Abarbeitungen, deren Funktion aber nicht näher zu bestimmen ist. An der Ostseite befindet sich - allerdings nicht mehr in situ - das marmorne Türgewände dieser Öffnung (L 2,80 m, B 0,79 m, Stärke 0,105 m; Taf. 69, 1). Die sekundäre Tür 2 wurde in späterer Zeit wieder verschlossen, wovon eine ungefähr 0,40 m starke Abmauerung aus spoliertem Bruchsteinmauerwerk mit Ziegelausgleichsscharen zeugt, deren Innenseite jedoch ohne einheitliche Flucht hergestellt ist. Unter den Spolien befindet sich auch heute noch ein profilierter Türsturz aus grauem Marmor, der eine Kureteninschrift trägt (IvE 1065; KatNr. A 31254; Taf. 69, 1. 5. 6). In die östliche Türlaibung von Tür 2 ist eine weitere Marmorspolie mit Inschrift verbaut (IvE 643; KatNr. A 30; Taf. 69, 1-4).

Während Tür 2 in späterer Zeit vermauert wurde, sind bei Tür 4 keine Spuren einer Zumauerung nachzuweisen (Taf. 70, 1. 2); es wurde lediglich sekundär das Niveau der Schwelle erhöht (Taf. 54, 3). Die östliche Laibung dieser Tür entspricht mit ihren Abarbeitungsspuren exakt der westlichen Laibung von Tür 2. Auch hier ist vom Originalverband nur noch der innere Eckverband erhalten. Die westliche Türlaibung ist als gerades Mauerhaupt gestaltet. Die bei den anderen Mauerhäuptern festgestellten Füllschichten sind hier jedoch nur sporadisch vorhanden. Die Türschwelle (Niveau: 46,37 m) misst 1,21 × 2,36 m; die Länge der Türschwelle sowie die Struktur des darüberliegenden Mauerwerks implizieren eine frühere Türbreite von $2,40 \mathrm{~m}$.

Der Sockel der Westmauer (Taf. 66. 67) ist sowohl mit der Nord- als auch mit der Südmauer im Verband errichtet und entspricht daher in seinen Maßen dem Sockel der Südmauer (H der unteren Quaderschicht 0,61 m, H der Orthostaten 0,725 m, H der oberen Quaderschicht 0,285 m). Das darüberliegende Mauerwerk aus opus vittatum ist bis 1,80 m von der Nordwestecke bis zu einer max. Höhe von 2,70 m über der oberen Quaderschicht erhalten (absolut: 50,55 m). Daran schließt südlich, durch eine unregelmäßige Baunaht getrennt, sekundäres opus testaceum an (Ziegelgröße: $0,32 \times 0,33 \times 0,055 \mathrm{~m}$ ), das nach Süden abfallend $2,08 \mathrm{~m}$ vor der Südwestecke endet, ursprünglich jedoch bis zur Südwestecke reichte. Bei der Baunaht ist das Ziegelmauerwerk bis zu einer Höhe von 2,25 m über der oberen Quaderschicht erhalten (OK: 50,10 m). Das Mauerwerk aus opus vittatum ist im Verband mit dem Bruchsteinmauerwerk der Nordmauer errichtet. Sowohl im Bereich des opus testaceum als auch des opus vittatum findet sich unmittelbar über der oberen Quaderschicht des Sockels ein 0,05-0,06 m tiefer Rücksprung, der in Zusammenhang mit den Versetzarbeiten des Gesimses, das an der Westwand allerdings nicht mehr erhalten ist, hergestellt wurde. Die restliche Oberseite der Quaderschicht ist in Bosse belassen. In den Lagerfugen der Ziegelmauer befinden sich bis zu 0,035 m weit vorspringende, unregelmäßig angeordnete Kalksteinsplitter, die zur Verkeilung der Eisenklammern für die Marmorwandverkleidung dienten. Unter dem Sockel der Westmauer ist ein bis zu 0,20 m breiter Fundamentvorsprung konstatierbar, der entsprechend der Sondage X (1961) dem Terrainverlauf folgend nach Süden hin kontinuierlich abtreppt und dann in mehreren Lagen angelegt ist (Taf. 21, 3).

Der Sockel der Ostmauer (Taf. 51. 71) ist analog zu dem der Westwand konfiguriert, doch hat sich in der Nordostecke ein 2,72 m langes, durchgehend erhaltenes Stück des Gesimses mit glatt polierter Oberfläche erhalten $^{255}$ (Taf. 72, 1). An der Bruchstelle des Gesimses befindet sich der Rest eines Eisendübels zur Befestigung der darüberliegenden Wandverkleidungsplatten. In die Sichtfläche des nördlichsten oberen Quaders ist ein zentrales Wolfsloch gearbeitet, das der endgültigen Positionierung des Blockes durch Herausziehen diente $^{256}$. Über dem Sockel befindet sich Mauerwerk aus Kalkbruchsteinen (opus vittatum), das in der Nordostecke ca. 3,30 m hoch über dem Sockel erhalten ist (absolut: 51,15 m) und dann abgetreppt nach Süden

\footnotetext{
254 Entspricht Knibbe 1981, F 6. Das von D. Knibbe als »heute nicht mehr auffindbar« bezeichnete linke Drittel des Türsturzes konnte 2007 unter den im >Hestiasaak aufgelegten Architekturgliedern gefunden werden.

255 Weitere Fragmente des Gesimses fanden sich im Zerstörungsschutt: KatNr. A 26 (Taf. 72, 2. 3).

256 Für zahlreiche Hinweise in Bezug auf die Funktion von Hebelöchern, insbesondere von Wolfslöchern, sei W. Aylward gedankt.
} 
abfällt. In der Ostwand sind noch sieben Rüstlöcher nachweisbar ${ }^{257}$. Im südlichen Teil der Mauer finden sich vereinzelt Spolien (Marmorplatten) ${ }^{258}$ und in geringem Ausmaß auch Ziegelmauerwerk.

Der Sockel der Nordmauer, der im Aufbau wiederum der Ost- und Westmauer entspricht, ist mit Ausnahme einer 3,25 m messenden Unterbrechung in der Mitte des $>$ Hestiasaales $\measuredangle$, die die ursprüngliche Türöffnung zum Querraum 2, 3 und 4 angibt, bis einschließlich der oberen Quaderschicht zur Gänze erhalten (Taf. 73). Vom Gesims ist ein 0,86 m langes Stück ab der Nordostecke erhalten. 4,49 m von der Nordwestecke zeigt die westliche Begrenzung der Sockelunterbrechung sowohl an der unteren als auch an der oberen Quaderschicht eine deutliche Abarbeitung, die sich auch am dazwischenliegenden Orthostaten in Form unterschiedlicher Oberflächenbehandlung nachweisen lässt. An der Ostseite, 4,62 m von der Nordostecke entfernt, ist ebenfalls eine deutliche Abarbeitung zu erkennen, die dem westlichen Sockelende entspricht. Der Orthostat ist an dieser Stelle durch eine Marmorspolie ersetzt (B 0,52-0,58 m, H 0,72 m), die drei Dübel-, zwei Klammerlöcher sowie zwei Gusskanäle besitzt, wobei zu den beiden Klammerlöchern am Anschlussblock das jeweilige Gegenstück fehlt. In der Sichtfläche des westlichsten oberen Quaders befindet sich ein zentrales Wolfsloch, das ebenso der endgültigen Ausrichtung des Blockes diente ${ }^{259}$. Unter dem Sockel der Nordmauer ist ein ca. $0,11 \mathrm{~m}$ breiter Fundamentvorsprung festzustellen ${ }^{260}$.

An der Stelle des östlichen Ansatzes des marmornen Keilsteinbogens ist der Quader des Marmorsockels sowie der darüberliegende Keilstein bis max. 0,10 m tief ausgebrochen. Die Bruchflächen sind teilweise mit opus signinum verschmiert, dessen Oberfläche glatt ist und vermutlich als Unterlage für eine Marmorplatte diente. Es handelt sich folglich um eine Reparatur, als Teile der Oberfläche des Bogens zerstört waren, da an der verbrochenen Stelle des Keilsteins ebenfalls opus signinum gleicher Konsistenz haftete. Über dem Sockel ist ein halbkreisförmiger Keilsteinbogen aus grauweißem, mittelkörnigem Marmor mit einer lichten Weite von 8,54 m errichtet (Taf. 73, 1), dessen Scheitelstück heute auf einer Länge von 4,94 m fehlt (rekonstruierte Scheitelhöhe bei 52,21 m, d. h. 4,27 m über dem Marmorsockel). Die Stärke des Bogens beträgt 0,44-0,50 m; seine Tiefe misst 1,14-1,20 m. Die einzelnen Keilsteine sind an den Sichtflächen teilweise mit kleinen Dübellöchern und vereinzelt mit Versatzmarken versehen (Westseite: 8. Keilstein: $\Delta$; Ostseite: 3. Keilstein: O; 4. Keilstein: $\Lambda$; 5. Keilstein: $\Delta$; jeweils vom Sockel gezählt). Das Profil der Sichtflächen des Bogens ist sekundär abgearbeitet. In der Mitte der Innenseite befindet sich eine $0,15 \mathrm{~m}$ breite Soffitte, die belegt, dass der Bogen ursprünglich innen ansichtig und offen war (Taf. 74). An mehreren Keilsteinen des Bogens ist der Marmor ausgebrochen. Das über dem Sockel liegende Mauerwerk ist in der Nordwestecke 2,74 m (absolut: 50,64 m), im Bereich der westlichen Bogenhälfte 3,60 m (absolut: 51,50 m), im Mittelteil 2,50 m (absolut: 50,40 m) und in der Nordostecke 3,20 m (absolut: 51,10 m) hoch über der oberen Quaderschicht des Sockels erhalten. Zwischen der Nordwestecke und dem westlichen Bogenansatz besteht das Mauerwerk bis zu einer Höhe von 1,95 m über dem Sockel aus Kalkbruchsteinen mit wenigen Marmorspolien (absolut: 49,85 m). Unmittelbar westlich des Bogenansatzes ist ein 0,92 $\times 0,90 \mathrm{~m}$ messender Marmorblock verbaut, der unregelmäßige Abarbeitungen an der Oberfläche sowie fünf Dübellöcher und ein Klammerloch aufweist. Auf dem Block befindet sich weiters eine 0,095 m lange Ausarbeitung mit fünf Bohrlöchern. Das darüberliegende Mauerwerk ist bis $1,57 \mathrm{~m}$ ab der Nordwestecke wie das anschließende Mauerwerk der Westwand als opus vittatum ausgeführt. Der restliche Mauerteil bis zum Anschluss an den

257 Rüstloch 1: 1,94 m von Nordostecke des `Hestiasaales`, 0,20 × 0,10 m, Niveau: 49,52 m; Rüstloch 2: 3,38 m von Nordostecke, $0,14 \times 0,10 \mathrm{~m}$, Niveau: 49,47 m; Rüstloch 3: 4,60 m von Nordostecke, $0,12 \times 0,12 \mathrm{~m}$, Niveau: 49,47 m; Rüstloch 4: 5,68 m von Nordostecke, $0,12 \times 0,10 \mathrm{~m}$, Niveau: 49,47 m; Rüstloch 5: 3,74 m von Nordostecke, $0,12 \times 0,16 \mathrm{~m}$, Niveau: 48,91 m; Rüstloch 6: $5,30 \mathrm{~m}$ von Nordostecke, $0,12 \times 0,08 \mathrm{~m}$, Niveau: 48,94 m; Rüstloch 7: 6,52 m von Nordostecke, $0,12 \times 0,12 \mathrm{~m}$, Niveau: $48,90 \mathrm{~m}$.

258 Unter den Spolien befand sich auch eine Marmorplatte mit einer Inschrift, die die in Ephesos bis dato unbekannten Personen Iulia Kimberis und L. Licinius Pollio nennt. Die Platte wurde geborgen und wird von H. Taeuber, dem ich für die Transkription des Inschriftentextes herzlich danke, separat vorgelegt.

259 Ähnliche Wolfslöcher sind in den obersten Scharen des Marmorsockels im Bereich der sekundär geöffneten Türen 2 und 4 zu erwarten, aber heute nicht mehr nachweisbar. Das in der Sichtfläche des östlichsten oberen Quaders der Nordmauer vorgeritzte Wolfsloch wurde wohl irrtümlich angelegt und niemals fertig ausgearbeitet. Typologisch entsprechen die Wolfslöcher des Marmorsockels denen an der Rückseite des Architravs KatNr. A 7. Allesamt dienten sie zum Ausrichten der Blöcke, nicht zum Hochheben.

260 Cf. Schnitt 3/07. Ein ähnlich dimensionierter Fundamentvorsprung an der Ost- und Südwand konnte in Sondage XI (1961) nachgewiesen werden. Cf. Taf. 22, 1. 
Bogen besteht aus Ziegeln unterschiedlicher Dimension. Innerhalb des Bogens, an den westlichen Anlauf anschließend, befindet sich ein 2,15 × 1,62 m großer Mauerteil aus Ziegeln (Maße: 0,35 ×0,35 ×0,05 m). Über dem Mauerteil aus Ziegeln liegt ein ca. 0,80 m hoher Streifen aus Bruchsteinmauerwerk mit durchgehenden ein- bis dreilagigen Ziegelausgleichsscharen mit ausgekehltem Fugenverstrich, wobei eine Schar etwa $0,35 \mathrm{~m}$ misst; sie entspricht der Struktur der Zumauerung der Mittelöffnung. Im darüberliegenden Mauerwerk ist die Stirnfläche der Westmauer von Raum 3 durch eine Baunaht, 4,50 m von der Nordwestecke, abgesetzt. Es ist ebenfalls als Bruchsteinmauer mit Ziegelausgleichsscharen gestaltet. 5,31 m von der Nordwestecke entfernt befindet sich 1,09 m über dem Bodenniveau des 〉Hestiasaales` (absolut: 47,45 m) eine $18 \times 8 \mathrm{~cm}$ große und 1,08 m tiefe Öffnung, die als Auslass des späteren Wasserreservoirs in den Räumen 3 und 4 diente. Der verbleibende Zwickel bis zum Bogenanschluss ist ohne System mit Bruchsteinen und Spolien in Mörtelverband ausgefüllt. Zwischen 4,62 und 8,35 m von der Nordwestecke ist die Mittelöffnung in Ziegel-Bruchsteintechnik mit ausgekehltem Fugenverstrich abgemauert. Etwa 0,53 m über dem Marmorsockel (absolut: 48,43 m) ist eine über die gesamte Breite der Zumauerung laufende Verputzkante erhalten, die wohl ein spätes Nutzungsniveau dieses Raumes angibt.

Unmittelbar vor der Nordwand des \Hestiasaales befinden sich zwei nach Norden führende Stufen (untere: L 3,59 m, H 0,14 m, T 0,34-0,35 m, Niveau: 46,61 m; obere: L 3,25 m, H 0,235 m, T 0,52 m, Niveau: 46,84 m; Taf. 73, 1). Die untere Stufe liegt unmittelbar auf dem Marmorplattenpaviment, wurde aber in einem Arbeitsvorgang mit diesem versetzt. Zu beiden Seiten der unteren Stufe befindet sich in der Flucht der beschriebenen Abarbeitungen an den Sockelsteinen je ein Marmorquader; die westliche dieser beiden Spolien trägt Teile einer auf dem Kopf stehenden Inschrift (IvE 740B). Auf der oberen Stufe liegen drei Marmorspolien; die östlichste Spolie ist mit einer Inschrift versehen (IvE 1201. 1201a) ${ }^{261}$. Östlich der Zumauerung ist in einer Breite von $0,74 \mathrm{~m}$ der Höhe nach durchgehend die stark verbrochene Ostwand von Raum 3 erkennbar. Sie ist als Bruchsteinmauer mit Ziegelsplittern ausgeführt. Östlich davon liegt bis 1,65 m über der oberen Quaderschicht des Sockels (absolut: 49,55 m) opus vittatum in gleicher Struktur wie in der West- und Ostwand; teilweise sind auch Marmorspolien verbaut. Der darüber verbliebene Zwickel im Anschluss an die innere östliche Bogenlaibung ist ohne System mit Bruchsteinen und Ziegelbruchstücken in lockerem Mörtelverband ausgefüllt und daher großteils ausgebrochen. Östlich des Bogens befindet sich ein durch eine Vertikalfuge über dem äußeren Bogenansatz begrenzter Pfeiler aus Kalkbruchsteinen (opus vittatum), der mit der Ostwand im Verband errichtet ist. Der verbliebene Mauerzwickel ist in derselben Technik ausgeführt. In der Nordostecke haben sich noch Reste von Verputz (opus signinum) mit glatter Oberfläche erhalten. 1,00 m über der oberen Quaderschicht des Sockels (absolut: 48,90 m) ist noch ein kleines Bruchstück einer Marmorverkleidung aus rötlich geädertem, feinkörnigem Marmor (Stärke $9 \mathrm{~mm}$ ) zu erkennen. Wie an der Westwand ist an der Nordwand eine Leiste zur Aufnahme des Gesimses ausgestemmt.

Jeweils $0,90 \mathrm{~m}$ von den vier Wänden des >Hestiasaales` entfernt stehen vier Säulenstühle aus stark gemasertem, graublauem Marmor auf sekundären, grob bearbeiteten Sockelplinthen, die über das Niveau des Marmorplattenbodens hinausreichten ${ }^{262}$ (Taf. 75-85). Als Fundament für die Sockelplinthen (H 0,46 m; Ausnahme: Nordwestsäule: H 0,38 m) dient jeweils der anstehende Fels. Die Säulenstühle selbst bestehen aus einem 0,89-0,90 m hohen, mit Deck- und Fußprofil versehenen Sockel (KatNr. A 12. 14. 17. 21). An der Sockelplinthe der Südwestsäule (KatNr. A 12) ist am oberen Rand eine Werkbosse stehen geblieben. Die einzelnen Säulenstühle und Sockelplinthen sind analog zu den Säulen an der Innenseite verkröpft. Darüber befindet sich je eine sekundäre attische Basis (KatNr. A 13. 15. 18. 22). Von den ursprünglichen Basen hat sich ein in der Domitiansterrasse gelagerter Streufund erhalten (KatNr. A 47; Taf. 86) ${ }^{263}$. Der nordwestliche Säulenschaft (KatNr. A 23) wurde von F. Miltner 1955 noch in situ angetroffen. Der südöstliche (KatNr. A 16) und der nordöstliche (KatNr. A 19) wurden in Sturzlage aufgefunden und 1956 wieder aufgestellt264.

${ }_{261}$ Die Inschrift, die einen terminus post quem für die endgültige Zumauerung der Nordwand gibt, wird von Knibbe 1981, F 14 an den Beginn des 3. Jhs. n. Chr. datiert und ist für eine exakte Datierung daher wenig hilfreich.

262 s. auch G. A. Plattner, Kapitel VII.4.1.2.

263 Die Identifizierung dieses Stückes ist G. A. Plattner zu verdanken. Aufgrund der individuellen Abmessungen der originalen Säulenstühle im ১Hestiasaak wird diese Basis mit hoher Wahrscheinlichkeit auf dem nordwestlichen Säulenstuhl gestanden haben.

264 Cf. Alzinger 1972-1975, 248. 
Der südwestliche Schaft ist verloren. Die Säulenschäfte und sekundären attischen Basen waren mittels dreier Dübel vertikal miteinander verbunden. Die originalen Basen besaßen lediglich zwei Dübellöcher und ein zentrales Wolfsloch; mit den Säulenstühlen waren sie durch einen Eisendübel verbunden. Die Höhe der Säulenschäfte, bei denen es sich um Eck-Doppelhalbsäulen handelt, ist durchweg unterschiedlich: $\mathrm{H}$ Südostsäule: 4,115 m; H Nordwestsäule: 4,145-4,175 m; H Nordostsäule: 4,23 m. Während die beiden nördlichen Säulen aus grauem Granit bestehen, ist die südliche aus graublauem Marmor mit grober weißer Zeichnung gefertigt. In Sturzlage - allerdings im Bereich der Südostsäule - fand sich ein gut erhaltenes, 0,74 m hohes, >herzförmigesく Kompositkapitell aus weißem Marmor (KatNr. A 24), das 1956 auf die nordwestliche Säule gesetzt wurde. Fragmente eines weiteren formgleichen Kapitells wurden von F. Miltner aus dem Versturzmaterial geborgen; sie wurden zusammengesetzt und das restaurierte Kapitell 1961 auf der Nordostsäule positioniert (KatNr. A 20). Das Fragment eines dritten formgleichen Kapitells konnte unter den von den Ausgräbern im >Hestiasaalk aufgelegten Baugliedern festgestellt werden (KatNr. A 25; Taf. 87). Auf den Oberlagern der Kapitelle befanden sich je zwei Dübellöcher mit Gusskanälen, die auf kurze, auf Gehrung geschnittene Architrave aus Stein hindeuten, die in die Wände einbanden. Die marmornen Säulenschäfte waren mit den Kapitellen durch drei Dübel verbunden; die Säulenschäfte aus Granit besaßen zudem ein zentrales Dübelloch ohne Gusskanal. Während die Marmorsäule KatNr. A 16 zwei Wolfslöcher auf dem Oberlager besitzt, fehlen diese bei den Granitsäulen KatNr. A 19. $23^{265}$. An der Südseite des südwestlichen Säulenstuhls (KatNr. A 12) konnte zudem ein Werkriss nachgewiesen werden, der zwei S-förmig angeordnete Voluten wiedergibt ${ }^{266}$ (Taf. 88. 89). Es handelt sich dabei offensichtlich um die Konstruktionszeichnung einer Doppelvolute eines Volutenakroters, des seitlichen Schmucks eines Geisons mit Volutenkonsole oder einer Türkonsole, genauer gesagt, um die Volutenglieder eines ionischen Türrahmens, die an beiden Seiten den Türsturz und das Hyperthyron begrenzten. Lediglich die Türkonsole könnte tatsächlich im Prytaneion baulich umgesetzt gewesen sein, da Volutenakrotere und Konsolengeisa im Prytaneion zu keiner Zeit verbaut waren. Ein materieller Beleg dafür ist aber aufgrund des Erhaltungszustandes des Monuments nicht gegeben.

Im Zentrum des >Hestiasaales $<$ befindet sich ein quadratisches Fundament von 2,37 m Seitenlänge (Niveau: 46,40 m), dessen Rand eine etwa 0,05 m breite Glättung aufweist (Taf. 90, 1). Die mit mehreren Dübel- und Klammerlöchern versehenen Randblöcke bestehen aus blaugrauem Kalkstein, die inneren Blöcke hingegen aus hellgrauem Kalkstein. Auf den inneren Blöcken sind insgesamt zwei Dübellöcher festzustellen. Das 0,175 m hohe Fundament ragt 0,03-0,04 m über das Marmorplattenpaviment; die an den Seitenflächen geglätteten Randblöcke weisen Versatzmarken auf (Taf. 90, 2). Die darunterliegende, 0,31 m tiefe Kalksteinfundamentierung springt um 0,14 m vor. Das Marmorplattenpaviment aus rechteckigen Platten fast weißen Marmors (Niveau: 46,36 m) bedeckt knapp die Hälfte der Raumfläche und ist im südlichen Bereich vor Tür 3 heute stark modern restauriert. Es wurde über einer Mörtelbettung aus opus signinum und einem darunter befindlichen Kalkmörtelestrich verlegt. Der sehr hoch anstehende Fels wurde dazu zunächst mit einer Planierschicht ausgeglichen ${ }^{267}$. Im südöstlichen Teil des Bodens sind zu Platten zersägte Blöcke mit je zwei Faszien als Belag versetzt.

Zwischen den beiden Säulen der Westseite sind - vor allem an den Anschlussteilen bei den Säulen - Reste einer max. 0,70 m hohen Unterkonstruktion in Form einer doppelten Mauer aus Kalkbruchsteinen mit darüberliegendem unregelmäßigen Ziegelmauerwerk ${ }^{268}$ auf das Marmorpaviment aufgesetzt (Taf. 91, 1). Zwischen den Säulen der Ostseite ist eine baugleiche Unterkonstruktion in durchweg besserem Erhaltungszustand vorhanden (Taf. 91, 2. 3). In der Flucht der östlichen Laibung der Tür 3 zeigt diese Unterkonstruktion einen deutlichen Abschluss. Die Sichtflächen sind zudem mit einem Putz aus opus signinum versehen. Hinter diesem Unterbau ist in der Nordwestecke des ১Hestiasaales`, im Ostteil der Nordwand und entlang der Ostwand ein etwa 0,20 m über dem Marmorplattenpaviment befindlicher Boden (Niveau: 46,55 m) aus

${ }^{265}$ Bei Architekturgliedern aus Granit scheinen Wolfslöcher nicht üblich zu sein, freundliche Auskunft W. Aylward. Bei den grauschwarz gesprenkelten Granitsäulen handelt es sich laut W. Prochaska wahrscheinlich um einen ägyptischen Import, unter Umständen vom Mons Claudianus. Die exakte Provenienz ist aber aufgrund fehlender Referenzwerte aus den dortigen Steinbrüchen nicht genauer zu bestimmen.

266 s. dazu ausführlich Steskal 2007, 371-392.

267 Cf. Schnitt 3/07 und 4/07.

268 Die Formate der Ziegel divergieren durchweg. 
Fragmenten von Ziegeln erhalten. Ob dieses sekundär erhöhte Bodenniveau für den gesamten 〉Hestiasaak angedacht war, ist heute nicht mehr zu entscheiden; entsprechende Reste haben sich nicht erhalten. Ein allgemein erhöhtes Bodenniveau hätte günstigerweise aber zu einer vollständigen Verblendung der sehr grob bearbeiteten Sockelplinthen unter den `Herzsäulen` geführt.

\section{III.5 Raum 6}

Raum 6 (Taf. 92, 1) besaß ursprünglich einen rechteckigen Innengrundriss $(7,98 \times 6,52 \mathrm{~m})$ mit je einer Türöffnung in der Süd- bzw. Nordwand. In der Spätantike wurde der Raum maßgeblich verändert: So wurden die beiden Durchgänge abgemauert und der Raum durch den Einbau von Mauern grundrisslich stark überformt.

Die Südmauer (Taf. 92) besteht heute bis in eine Höhe von 1,21 m über dem Niveau des Mosaiks der Vorhalle aus regelmäßig versetzten, behauenen Kalksteinquadern in Kalkmörtelverband (absolut: 47,59 m). Zwischen 2,42 und 5,14 m von der Westecke befindet sich Tür 1 (Taf. 93, 1). Sie wurde später durch eine Bruchstein-Ziegelmauer mit Spolien zur Gänze verschlossen. Von dieser in den letzten Jahrzehnten teilweise wieder geöffneten Abmauerung zeugt heute noch ein der Mauerstärke entsprechender Pfeiler (ca. 1,40 m) aus unregelmäßigem Bruchsteinmauerwerk mit Ziegelausgleichsscharen an der östlichen Türlaibung, der die Breite der Tür von ursprünglich 2,72 $\mathrm{m}$ auf 1,67 $\mathrm{m}$ im Rohbau verringert. Im Bereich der Schwelle ist ein Element einer Tonrohrleitung erhalten (lichte Öffnung: 0,11 m). Von der ursprünglichen Schwelle hat sich ein Teil des westlichen Gewändesteins erhalten. Die ursprüngliche Türschwelle, die sekundär von einer Nord-Süd verlaufenden Tonrohrleitung durchbrochen wurde, ist auf einer Planumszeichnung der Sondage XXII (1961) dokumentiert (Niveau: 46,31 m; Taf. 25, 1). Das ursprüngliche Quadermauerwerk ist sowohl mit dem der West- als auch mit dem der Ostmauer im Verband errichtet. Die Sichtflächen weisen vor allem im Bereich der Ost- und Nordwand Reste von Kalkmörtelverputz auf. An der Nordwand ist östlich der Tür zu Raum 5 unter dieser Putzschicht eine ältere Schicht Wandverputz mit teilweise noch erhaltener roter Wandmalerei erhalten (Taf. 93, 2). Über dem Quadermauerwerk lag opus testaceum, das nur noch in der Südostecke fragmentarisch erhalten ist (Ziegel: 0,41 ×0,36 ×0,055 m). Vor dem Fundament des Quadermauerwerks sind im Boden hochkant aufgestellte, $0,17 \mathrm{~m}$ starke Marmorplatten eingelassen; sie weisen an der der Wand zugewandten Seite einen Falz von 0,55 $\times 0,55 \mathrm{~m}$ auf. Diese Platten bildeten vielleicht den Sockel einer Wandverkleidung.

Der Aufbau der 1,22 m starken Ostmauer entspricht dem der Südmauer (Taf. 94, 1; 95); das Quadermauerwerk ist aber 0,24 m höher aufgezogen (absolut: 47,62 m). 2,50 und 5,40 m von der Südostecke ist je eine $0,17 \times 0,052 \mathrm{~m}$ bzw. eine $0,12 \times 0,055 \mathrm{~m}$ messende vertikale Rinne aus der Mauer ausgestemmt. Darüber befindet sich sekundäres opus testaceum bis zu einer Höhe von 1,50 m (absolut: 48,88 m), das Richtung Süden kontinuierlich abfällt ${ }^{269}$.

Die 1,18 m starke Westmauer des Raumes zeigt bis 1,22 m über dem Niveau des Mosaiks der Vorhalle (absolut: 47,60 m) dasselbe Quadermauerwerk wie die unteren Scharen der Süd- und Ostmauer (Taf. 48; 94, 2; 96). Analog zur Ostwand wurde auch hier 2,45 bzw. 5,39 m von der Südwestecke je eine 0,245 × 0,035 m bzw. eine $0,12 \times 0,045 \mathrm{~m}$ messende Rinne festgestellt. Ebenso wie die Vertikalrinnen der Ostmauer setzen sich die der Westmauer nicht im darüberliegenden Mauerwerk fort. Sie dürften entweder als Führungen für Rohrleitungen, oder aber - de facto spiegelsymmetrisch angelegt - als Einlassung eines Raumteilers fungiert haben. Darüber liegt ein 0,83 m hoher, 0,15 m zurückspringender Streifen opus vittatum aus behauenen Kalksteinen in Mörtelverband mit Fugenverstrich (absolut: 48,43 m). Um weitere 0,10 m zurückversetzt ist darauf max. 0,52 m hohes Bruchsteinmauerwerk erhalten (absolut: 48,95 m). Die darüber befindliche, 0,70 m starke und max. 0,92 m hohe Mauer (absolut: 49,93 m) ist sowohl außen $(0,10-0,15 \mathrm{~m})$ als auch innen $(0,25-0,30 \mathrm{~m})$ zurückgesetzt. Sie besteht aus unregelmäßigen Bruchsteinen, über denen im Norden noch zwei Ziegelscharen erhalten sind (Ziegelmaße: $0,32 \times 0,32 \times 0,055 \mathrm{~m}$ bzw. 0,155 $\times 0,32 \times 0,055 \mathrm{~m}$ ). $2,17 \mathrm{~m}$ südlich der Nordwestecke zeichnet sich eine $1,28 \mathrm{~m}$ breite, als Tür zu interpretierende Öffnung 1,34 m über dem Kalksteinsockel ab. Auf Niveau der Türöffnung ist der Ansatz eines Kalksteinbodens erkennbar

269 Mit der Errichtung der sekundären Mauer aus opus testaceum wurden die darunter befindlichen Vertikalrinnen funktionslos. 
(Niveau: 48,89 m), unter dem sich eine Nordwest-Südost verlaufende Tonrohrleitung (lichte Öffnung: $0,115 \mathrm{~m}$ ) befindet. Nach Süden anschließend sind zwei Spolien versetzt, von denen eine als Türschwelle anzusprechen ist.

An der 1,20 m starken Nordmauer sind drei in ihrer Struktur verschiedene, übereinanderliegende Teile zu unterscheiden (Taf. 97): Das Quadermauerwerk ist im westlichen Teil so hoch wie in der Westmauer (absolut: 47,60 m), in seinem östlichen Teil in der Höhe der Ostmauer (absolut: 47,62 m) erhalten. Mit beiden Mauern besteht ein konstruktiver Verband. Die Verbindung zu Raum 5 bildete eine im Rohbau 2,50 m breite, leicht aus der Raumachse verschobene Tür. Die im Ausbau 2,00 m breite Tür, von der noch die aus drei Marmorplatten bestehende Schwelle (Niveau: 46,53 m) mit Anschlagleiste, Pfannen-, Klammer- und Riegellöchern sowie die beiden marmornen Gewändesteine in situ erhalten sind, war ursprünglich nach Norden zu öffnen (Taf. 97, 1; 98). Schwelle und unterer Gewändeansatz sind in einem Stück gearbeitet, um Fugen an den Ecken zu vermeiden. Das darüberliegende Mauerwerk besteht aus unregelmäßigen Kalkbruchsteinen mit Ziegelausgleichsschichten (Ziegel: $0,47 \times 0,47 \times 0,04 \mathrm{~m}$ ) und gut erhaltenem Fugenverstrich. Es ist mit dem in gleicher Höhe liegenden Mauerwerk der Westmauer im Verband errichtet und reicht bis in eine Höhe von 3,20 m über dem Türschwellenniveau (OK: 49,73 m). Zum opus testaceum der Ostmauer besteht hingegen eine deutliche Baufuge. Die Türöffnung wurde bei der Errichtung dieser Mauer nicht mehr berücksichtigt; die Fundamentsohle liegt in der Höhe der erhaltenen Oberkante des älteren Quadermauerwerks. 1,35, 2,63, 4,53 und 6,28 $\mathrm{m}$ von der Nordwestecke entfernt, befindet sich $0,45 \mathrm{~m}$ unter der oberen Mauerkante in einer Linie je ein Tonrohrelement (lichte Weite: 0,10-0,13 m). Der oberste, 0,54 m starke und $0,47 \mathrm{~m}$ hohe Mauerwerksabschnitt aus Bruchsteinen in Mörtelverband und Ziegelausgleichsschichten (OK: $50,20 \mathrm{~m}$ ) ist beiderseits um ca. 0,12 m zurückgesetzt. Wie das tiefer liegende Mauerwerk enthält der obere Mauerabschnitt jeweils $0,18 \mathrm{~m}$ über der Mauerwerksunterkante Einlassungen für fünf Tonrohre mit einer lichten Weite von $0,13 \mathrm{~m}$. Nur in der zweiten und vierten Einlassung von Westen sind die Tonrohrelemente noch vorhanden.

In der Mitte des Raumes befindet sich als Spolie verbaut ein Stylobatblock (Niveau: 46,95 m; L 0,96 m, T 0,495 m, H 0,225 m), der eine - mittlerweile umgestürzte - Säulentrommel aus Sandstein mit abgearbeiteter Kannelur trug (H 1,015 m, Dm 0,40 m; KatNr. A 29; Taf. 99). Auf gleichem Niveau befanden sich in der Nordwestecke des Raumes die Reste eines Pithos, die im Sommer 2007 geborgen wurden. An der Ostseite liegt auf eben diesem Niveau ein schüsselförmig ausgehöhlter Kalksteinblock, der an seiner Bruchstelle eine antike Verkittung aufweist (L 0,75 m, B 0,595 m, T 0,40 m; T der Höhlung 0,345 m). Unmittelbar westlich des Stylobatblockes führt eine Nord-Süd verlaufende Tonrohrleitung vorbei, die ihre Fortsetzung im Tonrohrelement von Tür 1 der Südmauer findet (lichte Weite: 0,11 m, L 0,45 m). Diesem Niveau entspricht auch eine sekundäre, 0,31 m höher positionierte Türschwelle in Tür 1 (absolut: 46,62 m), die teilweise noch erhalten ist.

Im Zuge der Ausgrabungen des Jahres 1956 konnten entlang der Westmauer und im westlichen Teil der Südmauer die Reste einer rampenartigen Treppe nachgewiesen werden (Taf. 25, 1; 100, 1). Sie führte zur Türöffnung in der Westmauer, von der aus man in die >Akademiegasse gelangte. Ursprünglich war der Ostmauer ferner auf einem spolierten Bruchsteinfundament eine Marmorbasis vorgelegt (Taf. 100, 2), die heute - ebenso wie die Treppe an der Westwand - nicht mehr erhalten ist.

An die Nordmauer von Raum 6 war in der Höhe der Fundamentsohle der Türvermauerung eine späte, ca. 1,30 m starke Mauer angesetzt, die während der Ausgrabungen der 1960er Jahre entfernt wurde 270 (Taf. 101).

\section{III.6 Raum 5}

Raum 5 besaß in seinem ursprünglichen Zustand einen rechteckigen Grundriss mit Innenmaßen von $8,83 \times 6,52 \mathrm{~m}$ (Taf. 102). Die Struktur seiner Mauern, aber auch der Innengrundriss wurden im Laufe der Jahrhunderte grundlegend verändert. Vom ursprünglichen Kalksteinquadermauerwerk der Südmauer östlich der Tür zu Raum 6 sind ein 1,34 m hoher Sockel (OK: 47,86 m) sowie westlich der Tür zu Raum 6 ein 1,13 m hoher Sockel (OK: 47,65 m) erhalten (Taf. 102, 2; 103). Über dem westlichen Teil liegt 0,73 m hohes,

270 Ephesos 1962, Prytaneion, Blatt 40 (W. A.). 
unregelmäßiges Bruchsteinmauerwerk (OK: 48,38 m), über dem östlichen Teil eine einzelne 0,29 m hohe Schar unregelmäßiger Bruchsteine (OK: 48,67 m). Die Sichtfläche der Letzteren ist teilweise mit grauem Kalkmörtelbewurf überzogen. Die westliche Bruchsteinmauer wiederum ist mit den Nord-Süd verlaufenden Anschlussmauern im Verband errichtet. Die darüberliegende Mauer ist um 0,43 m zurückgesetzt. Sie besteht wie die Nordmauer von Raum 6 aus unregelmäßigen Kalkbruchsteinen mit Ziegelausgleichsschichten (Ziegel: $0,47 \times 0,47 \times 0,04 \mathrm{~m}$ ) sowie gut erhaltenem Fugenverstrich und fungierte als Trennwand zwischen den beiden Räumen (OK: 49,73 m). Entsprechend der Nordmauer von Raum 6 können in ihr vier quadratische Ausnehmungen $(0,18 \times 0,18 \mathrm{~m})$ für einzelne Tonrohrelemente nachgewiesen werden. Das darüberliegende Mauerwerk aus Bruchsteinen in Mörtelverband und Ziegelausgleichsschichten (OK: 50,20 m) springt um weitere $0,12 \mathrm{~m}$ zurück und beinhaltet auf gleicher Höhe wie in der Nordwand von Raum 6 fünf quadratische Ausnehmungen $(0,18 \times 0,18 \mathrm{~m})$ für Tonrohrelemente.

Die Kalksteinquader der Westmauer (Taf. 104, 1; 105) sind bis 5,06 m von der Südwestecke bis zu einer Höhe von 1,10 m über der Türschwelle zwischen Raum 5 und 6 erhalten (OK: 47,62 m). 5,05 m von der Südwestecke ist ein $1,32 \times 0,99 \mathrm{~m}$ großer Kalksteinquader eingesetzt, der 0,70 m über die Sockeloberkante ragt (OK: 48,35 m). Im nördlich anschließenden Mauerwerk liegt die Sockeloberkante 0,57 m höher als in der Südwestecke (OK: 48,22 m). Südlich des eingesetzten Quaders schließt über dem Sockel - wie an der Südmauer - 0,79 m hohes Bruchsteinmauerwerk an (OK: 48,38 m). 3,80 m von der Südwestecke ist in 1,42 m Höhe (absolut: 47,94 m) ein 0,26 × 0,26 m großes Rüstloch ausgespart. Die Oberkante des Bruchsteinmauerwerks ist durch eine Schar flacher Kalksteine und Ziegel abgeschlossen. Darüber liegt ein um 0,10 m zurückspringendes und 0,56 m hohes Bruchsteinmauerwerk (OK: 48,94 m) mit einer horizontal abgeglichenen Oberkante. Über dieser Mauer springt um 0,14 m ein 0,23 m hoher Mauerabschnitt aus Ziegeln mit vereinzelt eingefügten, kleinen Bruchsteinen zurück (OK: 49,17 m). Über dieser Mauer befindet sich wiederum um 0,23 m zurückspringend - eine Bruchsteinmauer, die nach Norden treppenförmig bis auf eine Höhe von 3,80 m über der Türschwelle ansteigt (OK: 50,32 m). Das oberste, 0,75 m starke Mauerwerk aus abwechselnd versetzten Stein- und Ziegelscharen (Ziegelmaße: 0,33 $\times 0,33 \times 0,04 \mathrm{~m}$ ) springt wiederum um 0,07 m zurück. In die Steinscharen sind vereinzelt hochkant aufgestellte Ziegel eingesetzt. An der höchsten Stelle in der Nordwestecke misst die Mauerkrone 4,67 m über der Türschwelle (absolut: 51,19 m); in der Südwestecke entspricht die Höhe der der Südmauer (OK: 50,20 m). Auf der Höhe der Unterkante des obersten Mauerwerks befindet sich zwischen 2,23 und 4,04 m von der Südwestecke eine im Rohbau 1,81 m breite Tür, von der noch eine 0,20 m hohe Marmorschwelle zeugt (Niveau Schwelle: 49,97 m). Sie vermittelte in später Zeit zwischen der >Akademiegasse und dem erhöhten Nutzungsniveau in Raum 5 (Taf. 49; 104, 2). In der Nordwestecke des Raumes ist schließlich der Ansatz einer 0,70 m starken Bruchsteinmauer zu erkennen, die etwa im Bereich der Sockeloberkante fundamentiert war und bis auf eine Höhe von 2,95 m über der Schwelle reichte (OK: 49,47 m; Taf. 106).

Der Kalksteinsockel der Ostmauer (Taf. 107, 1; 108) ist bis $5,28 \mathrm{~m}$ von der Südostecke in gleicher Höhe wie im östlichen Teil der Südmauer erhalten (OK: 47,86 m). Zwischen 5,28 und 6,58 m von der Südostecke befindet sich eine später zugesetzte, im Rohbau $1,30 \mathrm{~m}$ breite Türöffnung zu Raum 4 . Die Türschwelle ist nicht mehr erhalten; ihr Auflager liegt auf einer Höhe von 46,56 m. Die spätere Zusetzung, die heute an der Sichtfläche großteils ausgebrochen ist, besteht aus unregelmäßigen Kalksteinen in grobem Mörtelverband, die den gesamten nördlichen Bereich der Ostmauer einnehmen. Das Mauerwerk ist bis zu einer Höhe von 3,92 m über dem Türschwellenniveau zu Raum 6 erhalten (OK: 50,52 m). 6,58 m von der Südostecke beginnt abermals das Sockelmauerwerk, das 1,67 m hoch erhalten ist (OK: 48,19 m). Über dem Quadersockel der Ostwand besteht das Mauerwerk bis 2,37 $\mathrm{m}$ von der Südostecke aus max. 2,24 m hohem opus testaceum (Ziegelgröße: $0,32 \times 0,33 \times 0,055 \mathrm{~m}$; OK: 50,10 m) und anschließend bis zur Türöffnung aus max. 2,84 m hohem Mauerwerk aus Kalkbruchsteinen in Mörtelverband (opus vittatum; OK: 50,70 m). Analog zur Öffnung in der Westwand befindet sich 3,63 m von der Südostecke ein $0,11 \times 0,16 \mathrm{~m}$ großes Rüstloch über der Quadermauer (absolut: 47,94 m).

Der Kalksteinquadersockel der Nordwand (Taf. 107, 2; 109) ist bis auf eine Höhe von 2,06 m über der Türschwelle zu Raum 6 erhalten (OK: 48,58 m). Darüber befindet sich bis auf eine Höhe von 3,76 m über der Schwelle eine unregelmäßig errichtete Bruchsteinmauer (OK: 50,28 m). 1,98 m von der Nordostecke von Raum 5B ist ein Tonrohrelement in der Mauer verbaut (Niveau: 48,66 m; innerer Dm: 0,115 m, äußerer Dm: 0,18 m). 1,48 und 2,41 m westlich der Nordostecke von Raum 5B sind ab einer Höhe von 2,44 m (abso- 
lut: 48,96 m) zwei Vertikalfugen erkennbar. Entsprechende Pendants der ehemals 0,93 m breiten, nischenartigen Öffnung, die später mit Bruchsteinen wieder zugesetzt wurde, sind an der Außenseite der Mauer nicht zu erkennen. Es kann sich daher weder um eine Revisionsöffnung, die in den dahinterliegenden, Ost-West verlaufenden Entlüftungskanal geführt hätte, noch um ein Fenster handeln. Der oberste Abschluss wird von einem bis zu $0,10 \mathrm{~m}$ zurückspringenden, $0,665 \mathrm{~m}$ starken und ca. $0,50 \mathrm{~m}$ hohen Bruchsteinmauerwerk mit Ziegelausgleichsscharen gebildet (OK: 50,89 m).

Der nördliche Bereich von Raum 5 wird durch eine sekundäre, Nord-Süd orientierte, $0,83 \mathrm{~m}$ starke und 3,36 $\mathrm{m}$ lange Mauer aus Bruchsteinen mit unterschiedlich starken Ziegelausgleichsscharen und zahlreichen Marmorspolien in die Räume 5A (Nordost) und 5B (Nordwest) unterteilt (Taf. 110. 111). Aufgrund einer 2,04 m hohen, modernen Restaurierung und Sicherung kann die exakte Höhe der Mauer nicht mehr eruiert werden (OK Restaurierung: 48,58 m). Die Oberkante der Mauer, die, wie auf einem historischen Grabungsfoto klar wird (Taf. 112, 1), unmittelbar in den Schutt gesetzt ist, befindet sich auf 51,60 m. An der Nordseite der Ostwand von Raum 5B befinden sich anstelle des beschriebenen Mauerwerks zwei 0,78 $\mathrm{m}$ breite und 2,64 m hohe Ziegelpfeiler (OK: 51,46 m) aus Ziegeln unterschiedlicher Formate, die durch eine Vertikalfuge voneinander getrennt sind. In Raum 5A setzt an der Trennwand (Kämpferhöhe: 50,58 m) eine 2,22 m breite und ca. 3,20 m hohe Nord-Süd-Tonne an (Scheitelhöhe: 51,81 m), die nur noch in den Gewölbeansätzen und an der Schildwand nachzuweisen ist. Über dem Kämpfer der Westwand von Raum 5A sind 0,06 bzw. $1,29 \mathrm{~m}$ von der Nordwestecke des Raumes 5A zwei Rüstlöcher $(0,18 \times 0,22 \mathrm{~m})$ in das Gewölbe eingelassen (Niveau: 50,66 bzw. 50,60 m). Zwischen der Nordwand, die gleich wie die Trennwand strukturiert ist, und dem Ziegelgewölbe (unterschiedliche Ziegelformate) sind als Spolien dünne Marmorplatten eingelassen. In die Schildwand selbst ist $1,06 \mathrm{~m}$ von der Nordwestecke von Raum 5A unter dem Gewölbescheitel ein 0,11 $\times 0,16 \mathrm{~m}$ großes Rüstloch ausgespart (Niveau: 51,59 m). Das östliche Auflager der Tonne befindet sich unmittelbar über einer ca. 0,50 m tiefen und ca. 1,60 m hohen Bogennische, die 0,40 m hinter die Schildwand des Gewölbes zurückspringt (Kämpferhöhe: 49,54 m; Scheitelhöhe: ca. 50,40 m). Der südliche Teil der Nische ist ebenso nicht mehr vorhanden wie die restliche Ostwand von Raum 5A, die 1961 nach Regenfällen abstürzte (Taf. 112, 2).

Wie im Zuge der Ausgrabungen des Jahres 1956 gezeigt werden konnte, führte eine weitere aus Bruchsteinen, Ziegeln und Spolien gefertigte Mauer von der Türöffnung zur >Akademiegasse $<$ zu einer heute noch etwa in der Mitte des Raumes stehenden Säule (Taf. 113, 1) ${ }^{271}$. Die Säule ruht auf einem 0,28 m hohen Basisblock (absolut: 47,01 m) aus weißlichem, mittelkörnigem Marmor ${ }^{272}$ (Taf. 107, 2; 113, 2). Die aus zwei Trommeln bestehende Säule steht auf einer 0,72 $\times 0,72 \times 0,10 \mathrm{~m}$ großen Basis mit angearbeiteter Plinthe (KatNr. A 27). Die Säulentrommeln (KatNr. A 28) sind abgekantet, wodurch sich ein polygonaler Querschnitt mit 20 Ecken ergibt. Die Gesamthöhe der Säule inklusive der Basis misst 4,19 m. Neben zweier weiterer, heute nicht mehr erhaltener, kannelierter Säulen, zwischen denen 1956 die >Schöne Artemis` gefunden wurde (Taf. 9, 1), befand sich in Raum 5B eine - ebenfalls verlorene - schmale Treppe, die wahrscheinlich zur erhöhten Türschwelle in der Westmauer des Raumes führte ${ }^{273}$.

Nördlich der Räume 5, 4, 3 und 2 befindet sich hinter der 1,10 m starken Nordmauer ein 1,26 m breiter, Ost-West verlaufender, überwölbter Kanal, der kein Wasser führte, sondern lediglich dazu diente, die Nordmauer des Gebäudes trocken zu halten (Taf. 114, 1. 3); die nördliche Kanalwange dieses Entlüftungsstollens misst 0,74 $\mathrm{m}$. Über dem Ziegelgewölbe (Ziegelmaße: $0,30 \times 0,30 \times 0,05 \mathrm{~m}$ ) und dem Bruchsteinmauerwerk in Mörtelverband befindet sich 1,22 m über dem Gewölbescheitel (absolut: 50,50 m) ein begehbarer Bauwich mit einem Boden aus Kalksteinplatten, der die gesamte Nordwand des Prytaneions entlangführt (Taf. 114, 2). Die Kanalsohle, die teilweise aus dem Fels geschlagen ist, liegt bei 46,72 m. Vom Gehniveau des Bauwichs bis zur Kanalsohle wird folglich ein Niveauunterschied von 3,78 m überwunden.

\footnotetext{
271 Cf. den Grundriss bei Miltner 1959, 297 f. Abb. 139.

272 s. auch G. A. Plattner, Kapitel VII.4.1.3.

273 Cf. F. Miltner, Tagebucheintrag vom 21. 9. 1956.
} 


\section{III.7 Raum 4}

Hinter dem westlichen Bogenteil der Rückwand des >Hestiasaales` befindet sich Raum 4 (Innengrundriss: 3,30 × 3,62 m), der ursprünglich mit den Räumen 2, 3 und 5 verbunden war, in späterer Zeit aber als Wasserreservoir genutzt wurde (Taf. 115, 1). Vom ursprünglichen Querraum, bestehend aus den Räumen 2, 3 und 4, konnte auch der >Hestiasaak durch den offenen Keilsteinbogen erschlossen werden.

Das Niveau des Raumes liegt, bedingt durch den ansteigenden Fels, 1,28 m über dem Marmorplattenpaviment des >Hestiasaales` (absolut: 47,75 m). Vom originalen Mauerwerk sind nur noch die Fundamente an der Nordwand (Taf. 115, 2. 3) sowie einige Kalksteinblöcke an einem Mauerausbruch der Südwand zu sehen (Taf. 116). Um die Fundamente versetzen zu können, wurden Baugruben in den anstehenden Fels eingetieft. Der Südwand ist eine 2,56 m hohe und 0,35 m starke Bruchsteinmauer mit Ziegelausgleichsscharen vorgelegt (OK: 50,31 m). Sie ist auf unregelmäßigen Kalkbruchsteinen in Mörtelverband fundamentiert (UK: 46,85 m). Über dieser Mauer ist der obere Teil der Nordmauer des $>$ Hestiasaales` sichtbar. Von gleicher Höhe und Struktur wie die Südmauer ist auch die Westmauer (Taf. 117), die sowohl mit der Süd- als auch mit der Nordmauer im Verband errichtet ist. Auf dieser Mauer sitzt 0,25 m zurückspringend eine 0,20-0,39 m starke und bis zu 0,58 m hohe Bruchsteinmauer mit Ziegelausgleichsschichten (OK: 51,01 m), die als Schildmauer des West-Ost-Tonnengewölbes des Raumes diente. Der Ansatz dieser Ziegeltonne ist in der Nordwand in 3,70 m Höhe (absolut: 51,45 m) erhalten. Unmittelbar über dem Kämpfer ist 3,14 m von der Nordwestecke ein 0,39 $\times 0,28 \mathrm{~m}$ großes Rüstloch (Niveau: $51,50 \mathrm{~m}$ ) in die Ziegeltonne gesetzt. Unterhalb des Kämpfers ist 2,36 m von der Nordwestecke ein weiteres, $0,12 \times 0,12 \mathrm{~m}$ großes Rüstloch (Niveau: $51,23 \mathrm{~m}$ ) ausgespart. Das Aufgehende der Nordmauer, das ebenfalls aus Bruchsteinen mit Ziegelausgleichsscharen besteht, liegt exakt in der Flucht der ursprünglichen Anlage. Wie hoch das ursprüngliche Mauerwerk hochgezogen war, ist aufgrund der späteren Modifikationen nicht mehr festzustellen.

Gegen Osten ist Raum 4 durch zwei aus der Nord- und Südmauer vorspringende, max. 3,88 m hohe Pfeiler aus Bruchsteinmauerwerk mit Ziegelausgleichsscharen in seinen Ausmaßen definiert (Taf. 118. 119). Die lichte Öffnung zu Raum 3 beträgt 2,25 m und war oben durch einen Halbkreisbogen aus Ziegeln abgeschlossen, von dem noch die beiden Anläufe erhalten sind (Kämpferhöhe: 2,50 m über Raumniveau; absolut: 50,25 m). Der Durchgang zwischen Raum 4 und 3 ist sekundär durch eine 0,55 m hohe Anschüttung, auf der sich noch Reste eines Ziegelbodens erhalten haben, in seinem Niveau erhöht worden (absolut: 48,53 m). Dieses Bodenniveau, das die Aufgabe des Wasserreservoirs in den Räumen 3 und 4 bereits voraussetzt, ist auch in Raum 3 nachweisbar. Die Wände des Raumes sind sekundär bis zu einem maximalen Niveau von 50,40 m mit einer 0,03 m starken Schicht opus signinum mit geglätteter Oberfläche versehen, die aufgrund des Fehlens eines Zugangs von einer Nutzung des Raumes zur Speicherung von Wasser zeugt. Der Boden des Raumes bestand aus Ziegelplatten (Formate im Süden und Westen: 0,49 × 0,49 × 0,05 m; im Osten und Norden: $0,50 \times 0,13 \times 0,05 \mathrm{~m}$; absolut: 47,75 m) über einem Kalkmörtelestrich, der sowohl auf einer Bruchsteinlage als auch auf dem anstehenden Fels aufgebracht ist. Der Wandverputz ist in Form einer Mörtelhohlkehle an den Ziegelplattenboden angeschlossen. Es handelt sich dabei um sog. Vouten, also Abschrägungen in der Kehle zwischen Wand und Sohle, die einerseits die Dichtigkeit verbessern, andererseits aber auch die Ansiedlung unerwünschter Organismen an dieser strömungsschwachen Stelle verhindern sollten $^{274}$.

\section{III.8 Raum 3}

Der in der Flucht der Mittelachse des $>$ Hestiasaales gelegene Raum 3 besitzt einen rechteckigen Grundriss mit Innenmaßen von 3,94 × 3,25 $\mathrm{m}^{275}$ (Taf. 120, 1); wie Raum 4 wurde er in späterer Zeit als Wasserreservoir genutzt. Die 0,84 m starke Südwand (Taf. 120, 2. 3) entspricht in ihrer Struktur der Mauer in der Mittelöffnung der Nordwand des >Hestiasaales`. Das Ziegel-Bruchsteinmauerwerk ist bis zu einer absoluten Höhe von 50,46 m erhalten. Der westliche Abschluss (Taf. 121) entspricht dem östlichen Abschluss von Raum 4 und war folglich durch zwei max. 3,88 m hohe Pfeiler aus Bruchsteinmauerwerk mit Ziegelausgleichsscharen

\footnotetext{
274 s. dazu M. Döring, Römische Aquädukte und Großzisternen der Phlegräischen Felder, in: Ch. Ohlig (Hrsg.), Antike Zisternen, Schriften der Deutschen Wasserhistorischen Gesellschaft 9 (Siegburg 2007) 13.

275 Zu Raum 3 cf. auch den Grabungsbefund: M. Steskal, Kapitel IV.7.
} 
definiert (OK Nordpfeiler: 51,64 m; OK Südpfeiler: 51,70 m). Das Südende der Pfeilermauer läuft jedoch bis an die Südflucht der Südmauer durch. Die Nordmauer des Raumes (Taf. 122. 123) ist bis etwa 0,85 m über dem Bodenniveau aus Kalksteinquadern gefertigt (Niveau Boden: 47,68-47,74 m; OK Kalksteinquader: 48,59 m). Das darüberliegende Mauerwerk entspricht der Struktur der Nordmauer von Raum 4, bestand also bis zu einer Höhe von max. 4,80 m aus Bruchsteinen mit Ziegelausgleichsscharen (OK: 52,54 m). Darüber schließt um 0,10-0,20 m zurückversetzt unregelmäßiges Bruchsteinmauerwerk an, das in eine aus Bruchsteinen hergestellte Ost-West-Tonne übergeht (OK: 53,44 m), deren Innenverputz teilweise noch erhalten ist. Die Ostmauer (Taf. 124) entspricht in Aufbau und Struktur der Nordmauer, war also aus Bruchsteinen mit Ziegelausgleichsscharen hergestellt (OK: 53,30 m). In einigen Bereichen des Mauerwerks sind einfache Reparaturen und Ausbesserungen mittels qualitativ minderwertigem Kalkmörtel erkennbar. Im Süden existiert ein Verband mit der Südmauer des Raumes, im Norden läuft sie stumpf an die Nordmauer an. Der Verputz des Gewölbes der Nordmauer läuft hinter der Ostmauer durch. Insgesamt können fünf Rüstlöcher in der Nordwand nachgewiesen werden ${ }^{276}$.

Der Wandverputz aus opus signinum ist an allen vier Seiten nachweisbar; teilweise ist er bis zu seiner ursprünglichen Höhe von 2,55 m (absolut: 50,29 m) erhalten. Der Fußboden von Raum 3 ist - ähnlich wie Raum 4 - sekundär mit Ziegeln $(0,49 \times 0,49 \times 0,05 \mathrm{~m})$ gepflastert. Von diesem Boden hat sich an drei Seiten ein Steg erhalten (B an Südseite: 1,40 m; B an Ostseite: 1,50 m; B an Nordseite: 0,80 m; Niveau: 47,68-47,74 m). In der Südwestecke des Raumes befindet sich eine $35 \mathrm{~cm}$ hohe und $35 \times 68 \mathrm{~cm}$ große Einfassung einer senkrechten Tonrohrleitung (OK: 47,91 m; innerer Dm: 9,5 cm, äußerer Dm: $12 \mathrm{~cm})$, die außen mit opus signinum verstrichen ist und als Ausfluss des Wasserreservoirs diente (Taf. 125, 1). Der ehemals mit einem Stöpsel verschließbare Ausfluss leitete das gespeicherte Wasser in den >Hestiasaak ab, wo es über eine sekundäre Öffnung in der Nordwand entnommen werden konnte (Taf. 125, 2). Die verbleibende Fläche ist um 0,32-0,36 m abgesenkt (Niveau: 47,32-47,36 m) und bildet ein ehemals mit Ziegeln ausgekleidetes Becken (Taf. 120, 1). Das Becken wurde über einem 0,74 m hohen Fundament aus opus caementicium in Verbindung mit großen Kalksteinen errichtet, das bis auf den anstehenden Fels hinabreichte (absolut: 46,58 m). Es bedeckte auch 0,22 $\mathrm{m}$ hohe Marmorquader (OK 46,93 m) der bauzeitlichen Phase. Raum 4 konnte von Raum 3 aus ursprünglich nur über eine $0,89 \mathrm{~m}$ hohe, dreistufige Treppe erreicht werden. Der Wandverputz ist wie in Raum 4 mittels einer Mörtelhohlkehle (sog. Vouten) an den Fußboden angeschlossen. Im Zuge der Freilegung des Raumes konnten 1956 über dem Becken zwei weitere Nutzungsniveaus festgestellt werden, wobei das ältere mit dem erhöhten Ziegelboden im Durchgang zwischen den Räumen 4 und 3 (absolut: 48,53 m) gleichzusetzen ist $\mathrm{t}^{277}$.

In der Südwestecke des Raumes hat sich ein 1,18 $\times 1,80 \mathrm{~m}$ großes und 0,40 $\mathrm{m}$ hohes, rezentes Podest aus Bruchsteinen, Spolien und Ziegelbruchstücken erhalten (OK: 48,94 m), das den Ausgräbern der 1950er Jahre als Einstiegshilfe in diesen Raum diente (Taf. 121, 1). In der Südwand des Raumes sind die Reste einer einfachen Treppe nachweisbar, die auf das Niveau des Wasserreservoirs hinabführte (Taf. 120, 2): Die einzelnen Stufen ragen noch bis zu $31 \mathrm{~cm}$ aus der Mauer heraus und überwinden pro Stufe zwischen 40 und $54 \mathrm{~cm}$ Höhe $^{278}$. Die erste und zugleich unterste Stufe besteht aus einer Marmorspolie, bei den Stufen zwei bis vier und sechs handelt es sich um Kalksteine. Die fünfte Stufe ist verloren, doch im Mauerwerk noch gut zu erkennen ${ }^{279}$.

\section{III.9 Raum 2}

Der nördlich der Nordostecke des >Hestiasaales〈 gelegene Raum 2 misst 3,61 × 4,26 m (Taf. 125, 3). Er besitzt in seiner letzten Phase keine Verbindung zu den benachbarten Räumen.

276 Rüstloch 1: 0,38 m von Nordostecke von Raum 3, 0,12 $\times 0,11 \mathrm{~m}$, Niveau: $52,57 \mathrm{~m}$; Rüstloch 2: 0,28 m von Nordostecke, $0,15 \times 0,18 \mathrm{~m}$, Niveau: 51,55 m; Rüstloch 3: 0,53 m von Nordostecke, $0,14 \times 0,20 \mathrm{~m}$, Niveau: 50,61 m; Rüstloch 4: 3,07 m von Nordostecke, $0,12 \times 0,16 \mathrm{~m}$, Niveau: 51,51 m; Rüstloch 5: 3,29 m von Nordostecke, $0,14 \times 0,14 \mathrm{~m}$, Niveau: $50,60 \mathrm{~m}$.

277 Cf. W. Alzinger, Tagebucheintrag vom 20. 9. 1956.

278 OK 1. Stufe: 48,08 m, 2. Stufe: 48,53 m, 3. Stufe: 48,94 m, 4. Stufe: 49,41 m, 5. Stufe: 49,92 m, 6. Stufe: 50,46 m.

279 1. Stufe: 2,53 m von Südostecke des Raumes, 2. Stufe: 1,97 m, 3. Stufe: 1,58 m, 4. Stufe: 1,14 m, 5. Stufe: 0,57 m, 6. Stufe: $0,28 \mathrm{~m}$. 
Die 1,20 m starke und inklusive Fundament 4,10 m hohe Südmauer des Raumes (Taf. 126) entspricht dem östlichen Teil der Nordmauer des >Hestiasaales` (OK: 51,58 m). Sie ist lediglich mit der Ostmauer im Verband errichtet. Die insgesamt 4,93 m hoch erhaltene Westmauer (OK: 53,17 m) ist bis zu einer Höhe von 4,50 m (absolut: 52,58 m) in ihrer Struktur wie die Ostmauer von Raum 3 aufgebaut und bestand folglich aus Bruchsteinen mit Ziegelausgleichsscharen mit Fugenverstrich (Taf. 127). Sie bildete zugleich die Schildmauer für eine Ost-West verlaufende Korbbogentonne. Das 0,59 m hohe, darüberliegende Mauerwerk besteht aus kleinen Bruchsteinen und Ziegelsplittern in lockerem Mörtelverband. Fünf Rüstlöcher sind in der Westwand nachzuweisen ${ }^{280}$.

Die Nordmauer setzt sich bis ca. 0,35 m über dem Bodenniveau (absolut: 48,59 m) aus Kalksteinquadern ohne einheitlichen horizontalen Abschluss zusammen (Taf. 128). Um die Fundamente versetzen zu können, wurden - wie in Raum 4 - Baugruben in den anstehenden Fels eingetieft. In der Nordostecke steigt das Quadermauerwerk abgetreppt bis zu einer relativen Höhe von 2,50 m an (absolut: 50,74 m) und ist im Verband mit der Ostmauer errichtet. Darüber liegt bis zu einer Höhe von 3,35 m über dem Bodenniveau (absolut: 51,59 m) Mauerwerk aus kleinformatigen Kalkbruchsteinen in Mörtelverband. Auf diesem Niveau setzt schließlich eine Ost-West orientierte Korbbogentonne an. Über dieser zeichnet sich ein Bodenniveau $\mathrm{ab}(53,15 \mathrm{~m})$, das von einem Obergeschoss über Raum 2 zeugt. Das mit diesem Bodenniveau korrespondierende, 0,62 m starke Mauerwerk der Nordwand dieses Obergeschosses (OK: 54,63 m) besteht aus flüchtig versetzten Ziegeln und Bruchsteinen in lockerem Mörtelverband. Auf dem Boden befindet sich 1,73 m von der Nordwestecke ein in diese Nordwand einbindender $1,00 \times 1,03 \times 0,59 \mathrm{~m}$ großer Pfeiler gleicher Struktur. Das Mauerwerk östlich und westlich des Pfeilers besteht bis zu einer max. Höhe von 0,55 m (OK: $53,70 \mathrm{~m}$ ) aus opus testaceum. Im Mauerwerk der Nordwand des Untergeschosses sind drei Rüstlöcher nachweisbar ${ }^{281}$.

Die Ostmauer (Taf. 129) besteht in ihren unteren Lagen aus grauen Kalksteinquadern in Mörtelverband, die in der Nordostecke bis ca. 3,20 m über dem Fußboden erhalten sind (absolut: 51,44 m). Dem Mauerwerk, in dem zwischen den Quadern kleinformatige Zwickelsteine und Steinplatten eingefügt sind, fehlt ein einheitlicher horizontaler Abschluss. Darüber ist es bis ca. 4,40 m über dem Boden (absolut: 52,64 m) als Bruchsteinmauerwerk in Kalkmörtelverband ausgebildet. Noch weiter oben ist es weniger sorgfältig in lockerem Kalkmörtelverband ausgeführt (OK: 53,10 m).

Vom Wandverputz haben sich nur noch an der Nord- und Ostwand wenige Reste von Kalkmörtelestrich erhalten. Der nur noch in der Nordostecke des Raumes erhaltene Fußboden (Niveau: 48,24 m) bestand aus opus signinum, das über dem anstehenden Felsboden aufgetragen wurde.

Entlang der Südmauer liegt 0,40 m über dem Fußboden (absolut: 48,64 m) ein 0,90 m hoher und 0,85 m tiefer, flacher Ziegelbogen (Ziegelformate: $0,30 \times 0,30 \times 0,045 \mathrm{~m}$ ) in Sturzlage auf einem höher liegenden Estrich. Der Bogen, der heute nur noch in der Südwestecke erhalten ist, nahm ursprünglich die ganze Südseite des Raumes ein (Taf. 130). Mit dem erhöhten Niveau in den Räumen 3 und 4 kann auch hier eine jüngere Nutzung der Räumlichkeiten postuliert werden. Dass Raum 2 selbst als Wasserreservoir in Verwendung stand, ist indes nicht zu belegen. Er diente vielmehr als Keller oder fensterloses Untergeschoss des darüber befindlichen Stockwerkes.

\footnotetext{
${ }^{280}$ Rüstloch 1: 0,31 m von Südwestecke von Raum 2, $0,14 \times 0,14 \mathrm{~m}$, Niveau: $51,57 \mathrm{~m}$; Rüstloch 2: 0,15 m von Südwestecke, $0,12 \times 0,20 \mathrm{~m}$, Niveau: 50,59 m; Rüstloch 3: 2,84 m von Südwestecke, $0,18 \times 0,18 \mathrm{~m}$, Niveau: 49,71 m; Rüstloch 4: $3,14 \mathrm{~m}$ von Südwestecke, 0,18 × 0,18 m, Niveau: 50,68 m; Rüstloch 5: 3,12 m von Südwestecke, 0,14 × 0,15 m, Niveau: 51,56 m.

281 Rüstloch 1: 1,22 m von Nordwestecke von Raum 2, $0,30 \times 0,18 \mathrm{~m}$, Niveau: 50,74 m; Rüstloch 2: 1,75 m von Nordwestecke, $0,34 \times 0,24$ m, Niveau: 49,88 m; Rüstloch 3: 3,56 m von Nordwestecke, 0,16 × 0,12 m, Niveau: 49,85 m.
} 


\section{III.10 Katalog der Architekturglieder}

In den Katalog wurden nur jene Architekturglieder aufgenommen, die im Gebäude tatsächlich verbaut waren oder im Zerstörungsschutt des Prytaneions gefunden wurden. Architekturglieder unbekannter Provenienz bzw. Stücke, die seit Beginn der Ausgrabungen im Areal nördlich des `Staatsmarktes〈 im Jahr 1955 in das Prytaneion zur Deponierung verbracht wurden und keine Verbindung zum Gebäude aufweisen, werden nicht berücksichtigt ${ }^{282}$.

\section{III.10.1 Im GebäUde Verbaute ArchitektURgLIEDER}

\section{III.10.1.1 Vorhalle}

KatNr. A 1

Taf. 45,$3 ; 56 ; 58,1$

InvNr. PR 54/07

Dorische Säule

AO: in Architekturprobe der dorischen Ordnung verbaut (erste Säule von Westen)

FO: `Kuretenhalle $\triangleleft$ am unteren Embolos

Mat.: grauweißer Marmor

Maße: erh. H 0,88 m, unterer Dm 1,145 m

Erh.: eine Trommel (A), nur unterer Teil erhalten, ursprünglich als zweite Trommel der Säule verbaut

Bearb.: mit dem Zahneisen bearbeitet und anschließend geglättet, Inschriften auf Trommel A: IvE 1047. 1059

KatNr. A 2

Taf. 45,$3 ; 56 ; 58,1.2$

InvNr. PR 55/07

Dorische Säule

AO: in Architekturprobe der dorischen Ordnung verbaut (zweite Säule von Westen)

FO: ২Kuretenhalle $\triangleleft$ am unteren Embolos

Mat.: grauweißer Marmor

Maße: Trommel A: H 1,55 m, unterer Dm 1,143 m, oberer Dm 1,142 m; Trommel B: erh. H 0,69 m (inkl. Beton 1,63 m), oberer Dm 1,06 m

Erh.: zwei Trommeln (A + B), obere Trommel B in Beton gegossen (nur oberer Teil im Original erhalten), ursprünglich als zweite und dritte Trommeln der Säule verbaut, zahlreiche sekundäre Klammer- und Dübellöcher auf den Trommeln, auf Trommel B zwei $35 \times 29 \mathrm{~cm}$ große, sekundäre Einarbeitungen für profilierte Brüstung

Bearb.: mit dem Zahneisen bearbeitet und anschließend geglättet, auf Oberlager von Trommel B Anathyrosis sowie ein zentrales, quadratisches Dübelloch im Spiegel und ursprünglich vier Dübellöcher mit Gusskanälen in den seitlichen Lagerflächen (drei erhalten), Inschriften auf Trommel A: IvE 1003. 1028. 1031. 1032. 1061. 1080a; Trommel B: IvE 1014

\section{KatNr. A 3}

Taf. 45,$3 ; 56 ; 57,3$

InvNr. PR 56/07

Dorische Säule

AO: in Architekturprobe der dorischen Ordnung verbaut (dritte Säule von Westen)

FO: Scholastikiatherme

Mat.: grauweißer Marmor

Maße: H ges. 7,405 m (inkl. Kapitell KatNr. A 5); Trommel A: H 1,785 m, unterer Dm 1,209 m, oberer Dm 1,156 m;
Trommel B: H 1,43 m, unterer Dm 1,156 m, oberer Dm 1,129 m; Trommel C: H 1,47 m, unterer Dm 1,129 m, oberer Dm 1,101 m; Trommel D: H 0,86 m, unterer Dm 1,101 m, oberer Dm 1,038 m; Trommel E: H 1,40 m, unterer Dm $1,038 \mathrm{~m}$, oberer Dm 1,025 m

Erh.: fünf Trommeln $(\mathrm{A}+\mathrm{B}+\mathrm{C}+\mathrm{D}+\mathrm{E})$, zahlreiche sekundäre Klammer- und Dübellöcher auf den Trommeln, auf Trommel C zwei $35 \times 29 \mathrm{~cm}$ große, sekundäre Einarbeitungen für profilierte Brüstung

Bearb.: mit dem Zahneisen bearbeitet und anschließend geglättet, zur Vorhalle hin orientierte Seiten der Säulentrommeln jedoch weniger sorgfältig geglättet, Inschriften auf Trommel A: IvE 1012. 1020. 1040; Trommel B: IvE 1021. 1036. 1042; Trommel C: IvE 1001. 1002. 1002a; Trommel D: IvE 1005. 1015; Trommel E: IvE 1009. 1016

\section{KatNr. A 4}

Taf. 45,$3 ; 56 ; 57,3$

InvNr. PR 57/07

Dorische Säule

AO: in Architekturprobe der dorischen Ordnung verbaut (vierte Säule von Westen)

FO: `Kuretenhalle am unteren Embolos

Mat.: grauweißer Marmor

Maße: H ges. 7,405 m (inkl. Kapitell KatNr. A 6); Trommel A: H 1,755 m, unterer Dm 1,199 m, oberer Dm 1,175 m; Trommel B: H 1,39 m, unterer Dm 1,175 m, oberer Dm 1,142 m; Trommel C: H 1,425 m, unterer Dm 1,142 m, oberer Dm 1,112 m; Trommel D: H 1,05 m, unterer Dm 1,057 m, oberer Dm 1,008 m

Erh.: vier Trommeln (A + B + C + D), zwischen Trommel $\mathrm{C}$ und D eine ergänzte Trommel aus Beton (H 0,70 m), über Trommel D eine ergänzte Trommel aus Beton (H 0,735 m), zahlreiche sekundäre Klammer- und Dübellöcher auf den Trommeln, auf Trommel C zwei $35 \times 29 \mathrm{~cm}$ große, sekundäre Einarbeitungen für profilierte Brüstung

Bearb.: mit dem Zahneisen bearbeitet und anschließend geglättet, zur Vorhalle hin orientierte Seiten der Säulentrommeln jedoch weniger sorgfältig geglättet, Inschriften auf Trommel A: IvE 1034. 1035. 1070. 1352; Trommel B: IvE 1004. 1006. 1029. 1060. 1066; Trommel C: IvE 1011; Trommel D: IvE 1008. 1037

\section{KatNr. A 5}

InvNr. PR 09/07

Dorisches Kapitell

AO: in Architekturprobe der dorischen Ordnung auf Säule KatNr. A 3 verbaut

FO: Scholastikiatherme

Mat.: grauweißer Marmor

${ }_{282}$ Cf. in diesem Kontext den Beitrag von G. A. Plattner, Kapitel VII.4 zur Bauornamentik. 
Maße: H 0,355 m (inkl. angearbeitetem Säulenhals 0,46 m), H Abakus 0,168 m, L Abakus 1,26 m, B Abakus 1,26 m, H Echinus 0,137 m, H Anuli 0,05 m, Dm Säulenhals 0,98 m Erh.: Ansatz der Kannelur am Säulenhals vorhanden, zwei Dübellöcher und ein Wolfsloch sowie zwei Stemmlöcher auf Oberlager, Steinmetzzeichen am Oberlager: AI $\Xi$, Ecken des Abakus bestoßen, moderne Klebung an Abakus und Echinus, die 2008 erneuert wurde

Bearb.: mit dem Zahneisen bearbeitet und anschließend geglättet, auf Oberlager Anathyrosis, Inschrift auf Kapitell: IvE 1037

\section{KatNr. A 6}

InvNr. PR 10/07

Dorisches Kapitell

AO: in Architekturprobe der dorischen Ordnung auf Säule KatNr. A 4 verbaut

FO: Scholastikiatherme

Mat:: grauweißer Marmor

Maße: H 0,355 m, H Abakus 0,168 m, L Abakus 1,26 m, B

Abakus 1,26 m, H Echinus 0,137 m, H Anuli 0,05 m, Dm Säulenhals $0,98 \mathrm{~m}$

Erh.: Säulenhals nicht mehr vorhanden, ein Dübelloch und drei Stemmlöcher auf Oberlager, Steinmetzzeichen auf Oberlager: YI, Ecken des Abakus und Echinus teilweise bestoßen, an Westseite Reste zweier Eisenklammern sichtbar, die Abakus und Echinus verbanden; aufgrund der Lage der Stemmlöcher war das Kapitell ursprünglich $90^{\circ}$ gegen den Uhrzeigersinn gedreht

Bearb.: mit dem Zahneisen bearbeitet und anschließend geglättet, auf Oberlager Anathyrosis

\section{KatNr. A 7}

Taf. 45,$3 ; 56 ; 58,3.4 ; 59,1.2$

InvNr. PR 04/07

Architrav

AO: in Architekturprobe der dorischen Ordnung zwischen den Säulen KatNr. A 3 und A 4 verbaut, ursprünglich über dem erweiterten Mitteljoch angebracht

FO: im Zerstörungsschutt des Prytaneions (Vorhof)

Mat.: grauweißer Marmor

Maße: H 0,75 m, erh. L 3,54 m (ursprüngliche L 4,53 m), T 0,66-0,75 m, B Regula $0,60 \mathrm{~m}$

Erh.: antike Reparatur mittels je einer U-Eisenklammer auf Vorder- und Rückseite, auf Oberlager zwei Wolfslöcher, wobei das westliche Loch zum Hochheben des Blockes während des Bauprozesses und das östliche Loch zum Anheben während der Reparatur dienten; auf dem Oberlager finden sich auch ein Kantendübelloch sowie zwei Dübellöcher zur Verbindung mit Metopen-Triglyphen-Fries, U-Eisenklammern an Westseite zur horizontalen Verbindung der Architravblöcke, drei Wolfslöcher auf Rückseite zum Ziehen und Ausrichten des Blockes, zwei moderne U-Eisenklammern an Rückseite sowie eine moderne U-Eisenklammer zwischen westlicher Seite des Metopen-Triglyphen-Frieses KatNr. A 8 und Architrav

Bearb.: mit dem Zahneisen bearbeitet und anschließend geglättet, Inschrift auf Architrav: IvE 1010

\section{KatNr. A 8}

Taf. 45,$3 ; 56 ; 58,3.4 ; 59,1.2$
AO: in Architekturprobe der dorischen Ordnung zwischen den Säulen KatNr. A 3 und A 4 verbaut

FO: im Zerstörungsschutt des Prytaneions (Vorhof)

Mat.: grauweißer Marmor

Maße: H 0,88 m, L 1,31 m, T 0,445 m, B Metopen 0,91 m, B Triglyphen $0,60 \mathrm{~m}$

Erh.: Rückseite verbrochen und durch Beton ergänzt, westliche Seite und Teil der Triglyphe verbrochen, moderne UEisenklammer zwischen Architrav KatNr. A 7 und westlicher Seite des Metopen-Triglyphen-Frieses, auf Oberlager Wolfsloch, Dübelloch sowie drei Kantendübellöcher zur Verbindung mit Horizontalgeison und U-Eisenklammern an Ostseite zur horizontalen Verbindung der Friesblöcke, antike U-Eisenklammer an der östlichen Seite zur Verbindung mit Horizontalgeison

Bearb.: Vorderseite mit dem Zahneisen bearbeitet und anschließend geglättet, an erhaltener östlicher Seitenfläche Anathyrosis, Inschrift auf Metopen-Triglyphen-Fries: IvE 1030

\section{KatNr. A 9}

Taf. 45,$3 ; 56 ; 57,1 ; 58,3.4 ; 59$

InvNr. PR 08/07

Horizontalgeison der Vorderfront

AO: in Architekturprobe der dorischen Ordnung zwischen den Säulen KatNr. A 3 und A 4 verbaut

FO: im Zerstörungsschutt des Prytaneions (Vorhof)

Mat.: grauweißer Marmor

Maße: H 0,35 m, L 1,06 m, T 1,62 m, B Mutulus 0,60 m, B Via $0,16 \mathrm{~m}$

Erh.: auf Rückseite Einarbeitung für Balken sowie Wolfsloch, eine moderne U-Eisenklammer sowie ein antikes Kantendübelloch und drei U-Eisenklammern an östlicher Seitenfläche, moderne Bohrungen sowie ein antikes Kantendübelloch an westlicher Seitenfläche, Versatzmarke (E) auf Rückseite, das ursprünglich angeblich als Eierstab aufgemalte Kymation ist heute nicht mehr nachweisbar

Bearb.: mit dem Zahneisen bearbeitet und anschließend geglättet, an den Seiten Anathyrosis

KatNr. A 10

Taf. $60,1.2$

InvNr. PR 06/07

Horizontalgeison der Vorderfront

AO: vor der Rückwand der Vorhalle aufgelegt

FO: im Zerstörungsschutt des Prytaneions (Vorhof)

Mat.: grauweißer Marmor

Maße: H 0,34 m, L 1,06 m, T 1,56 m, B Mutulus 0,60 m, B Via $0,16 \mathrm{~m}$

Erh.: auf Rückseite Einarbeitung für Balken sowie Wolfsloch, zwei Klammerlöcher an Westseite für U-Eisenklammern zur horizontalen Verbindung, im Bereich der Einarbeitung im östlichen Teil verbrochen (hier Klammerloch einer antiken Reparatur?), Versatzmarke (B) auf Rückseite, zahlreiche Kantendübellöcher an Seitenflächen, das ursprünglich angeblich als Eierstab aufgemalte Kymation ist heute nicht mehr nachweisbar

Bearb.: Vorderseite mit dem Zahneisen bearbeitet und anschließend geglättet, Rückseite teils roh belassen bzw. mit Zahneisen bearbeitet, an den Seiten Anathyrosis

InvNr. PR 05/07

Metopen-Triglyphen-Fries 
KatNr. A $11^{283}$

InvNr. PR 07/07

Horizontalgeison

AO: vor der Rückwand der Vorhalle aufgelegt

FO: unbekannt

Mat.: grauweißer Marmor

Maße: H 0,31 m, L 0,91 m, T 1,39 m, B Mutulus 0,51 m, B Via $0,08 \mathrm{~m}$

Erh.: drei moderne U-Eisenklammern auf der Rückseite sowie ein Wolfsloch, das ursprünglich angeblich als Eierstab aufgemalte Kymation ist heute nicht mehr nachweisbar, eine abgebrochene Ecke wurde 2008 wieder angeklebt

Bearb.: Vorderseite mit dem Zahneisen bearbeitet und anschließend geglättet, Rückseite grob belassen, an den Seiten Anathyrosis

\section{III.10.1.2 >Hestiasaak}

KatNr. A 12

Taf. 75.76

InvNr. PR 11/07

Säulenstuhl auf Sockelplinthe der südwestlichen Eck-Doppelhalbsäule

AO: in situ

FO: in situ

Mat.: graublauer Marmor mit starker weißer Maserung

Maße: H Sockelplinthe 0,46 m, L Sockelplinthe $1,30 \mathrm{~m}, \mathrm{~B}$

Sockelplinthe 1,30 m, H Säulenstuhl 0,89 m, L Säulenstuhl 1,195 m, B Säulenstuhl 1,16 m, H Fußprofil 0,20 m, H Deckprofil $0,215 \mathrm{~m}$

Erh.: Sockelplinthe und Säulenstuhl an der Innenseite verkröpft, an der Sockelplinthe am oberen Rand Werkbosse erhalten, an der Ost- und an der Westseite Stemmlöcher zum Versetzen der Basis

Bearb.: Sockelplinthe lediglich mit dem Zahneisen bearbeitet, Säulenstuhl mit dem Zahneisen bearbeitet und anschließend geglättet, auf Südseite des Säulenstuhls Werkriss einer Doppelvolute

KatNr. A 13

Taf. 75.76

InvNr. PR 12/07

Attische Basis der südwestlichen Eck-Doppelhalbsäule

AO: in situ

FO: in situ

Mat.: grauweißer Marmor

Maße: H 0,455 m, L 1,045 m, B 1,045 m, H Plinthe 0,145 m, $\mathrm{H}$ Basis $0,31 \mathrm{~m}$

Erh.: an der Innenseite verkröpft, am Oberlager ein zentrales Wolfsloch sowie drei Dübellöcher mit Gusskanälen an den Rändern, Ränder der Basis teilweise bestoßen

283 Wie sich im Zuge der Rekonstruktion zeigte, kann der Geisonblock KatNr. A 11 aufgrund seiner abweichenden Dimensionen und der im Vergleich zu den Geisa KatNr. A 9 und A 10 unterschiedlichen Bearbeitung in keinem Gebälk des Prytaneions verbaut werden. Um die Diskussion über diesen Block und seine Zugehörigkeit durch ein nahes $\mathrm{Zu}$ sammenrücken zu den tatsächlich verbauten Blöcken des Horizontalgeisons (KatNr. A 9. 10) zu erleichtern, wurde er in diesem Katalog dennoch gleich im Anschluss an die Architekturglieder der dorischen Ordnung angeführt.
Bearb.: mit dem Zahneisen bearbeitet und anschließend grob geglättet

KatNr. A 14

Taf. 77.78

InvNr. PR 13/07

Säulenstuhl auf Sockelplinthe der südöstlichen Eck-Doppelhalbsäule

AO: in situ

FO: in situ

Mat:: graublauer Marmor mit starker weißer Maserung

Maße: H Sockelplinthe 0,46 m, L Sockelplinthe 1,30 m, B

Sockelplinthe 1,30 m, H Säulenstuhl 0,895 m, L Säulenstuhl

1,20 m, B Säulenstuhl 1,21 m, H Fußprofil 0,20 m, H Deckprofil $0,21 \mathrm{~m}$

Erh.: Sockelplinthe und Säulenstuhl an der Innenseite verkröpft, an der Ost- und Westseite Stemmlöcher zum Versetzen der Basis

Bearb.: Sockelplinthe lediglich mit dem Zahneisen bearbeitet, Säulenstuhl mit dem Zahneisen bearbeitet und anschließend geglättet

KatNr. A 15

Taf. 77.78

InvNr. PR 14/07

Attische Basis der südöstlichen Eck-Doppelhalbsäule

AO: in situ

FO: in situ

Mat.: grauweißer Marmor

Maße: H 0,45 m, L 1,06 m, B 1,06 m, H Plinthe 0,15 m, H

Basis $0,30 \mathrm{~m}$

Erh.: an der Innenseite verkröpft

Bearb.: mit dem Zahneisen bearbeitet und anschließend grob geglättet

KatNr. A 16

Taf. 77.78

InvNr. PR 15/07

Eck-Doppelhalbsäule (Säulenschaft der Südostsäule)

AO: in situ

FO: im Zerstörungsschutt des Prytaneions (〉Hestiasaal $)$

Mat.: graublauer Marmor mit weißer Maserung

Maße: H 4,115 m, L unten 0,85 m, B unten 0,83 m, L oben $0,80 \mathrm{~m}, \mathrm{~B}$ oben $0,80 \mathrm{~m}$

Erh.: am Oberlager zwei Wolfslöcher im Zentrum sowie drei Dübellöcher mit Gusskanälen an den Rändern, Südostecke der Säule teilweise mittels Beton ergänzt

Bearb.: mit dem Zahneisen bearbeitet und anschließend geglättet

KatNr. A 17

Taf. 79. 80

InvNr. PR 16/07

Säulenstuhl auf Sockelplinthe der nordöstlichen Eck-Doppelhalbsäule

AO: in situ

FO: in situ

Mat:: graublauer Marmor mit starker weißer Maserung

Maße: H Sockelplinthe 0,46 m, L Sockelplinthe 1,28 m, B

Sockelplinthe 1,28 m, H Säulenstuhl 0,90 m, L Säulenstuhl 1,19 m, B Säulenstuhl 1,20 m, H Fußprofil 0,23 m, H Deckprofil $0,20 \mathrm{~m}$

Erh.: Sockelplinthe und Säulenstuhl an der Innenseite verkröpft, Deckprofil des Säulenstuhls teilweise bestoßen, an der Nord- und Südseite Stemmlöcher zum Versetzen der Basis 
Bearb.: Sockelplinthe lediglich mit dem Zahneisen bearbeitet, Säulenstuhl mit dem Zahneisen bearbeitet und anschließend geglättet

KatNr. A 18

Taf. 79. 80

InvNr. PR 17/07

Attische Basis der nordöstlichen Eck-Doppelhalbsäule

AO: in situ

FO: in situ

Mat.: grauweißer Marmor

Maße: H 0,46 m, L 1,075 m, B 1,075 m, H Plinthe 0,15 m, H

Basis $0,31 \mathrm{~m}$

Erh.: an der Innenseite verkröpft, mehrere Risse durch den Marmor

Bearb.: mit dem Zahneisen bearbeitet und anschließend grob geglättet

\section{KatNr. A 19}

Taf. 79.80

InvNr. PR 18/07

Eck-Doppelhalbsäule (Säulenschaft der Nordostsäule)

AO: in situ

FO: im Zerstörungsschutt des Prytaneions (’Hestiasaalく)

Mat.: grauer Granit

Maße: H 4,23 m, L unten $0,85 \mathrm{~m}$, B unten $0,86 \mathrm{~m}$, erh. L oben $0,70 \mathrm{~m}$, erh. B oben $0,73 \mathrm{~m}$

Erh.: am Oberlager drei Dübellöcher mit Gusskanälen an den Rändern sowie ein zentrales Dübelloch, Oberfläche teilweise verwittert und abgeplatzt

Bearb.: mit dem Zahneisen bearbeitet und anschließend grob geglättet

\section{KatNr. A 20}

Taf. $79-81$

InvNr. PR 19/07 und 42/07

Kompositkapitell einer Eck-Doppelhalbsäule

AO: auf der Nordostsäule

FO: im Zerstörungsschutt des Prytaneions (১Hestiasaalく)

Mat.: weißer Marmor

Maße: H 0,74 m, L Kapitellbasis 0,80 m, B Kapitellbasis $0,80 \mathrm{~m}, \mathrm{H}$ Abakus $0,13 \mathrm{~m}$, L Abakus $1,05 \mathrm{~m}$, B Abakus 1,04 m, H Echinus 0,115 m, B Kalathoslippe 0,025 m, H Kalathos ges. 0,495 m, H Blattstab 0,13 m, H Hochblatt 0,29 m, H Lanzettblatt 0,29 m, H Volute $0,17 \mathrm{~m}$, B Volute $0,16 \mathrm{~m}$ Erh.: am Oberlager zwei Dübellöcher mit Gusskanälen teilweise erhalten, hinterer Teil des Kapitells abgebrochen, mehrere moderne Klebungen, die 2008 erneuert wurden Bearb.: mit dem Flachmeißel bearbeitet und anschließend geglättet, am Oberlager Anathyrosis

\section{KatNr. A 21}

Taf. 82.83

InvNr. PR 20/07

Säulenstuhl auf Sockelplinthe der nordwestlichen Eck-Doppelhalbsäule

AO: in situ

FO: in situ

Mat.: graublauer Marmor mit starker weißer Maserung

Maße: H Sockelplinthe 0,38 m, L Sockelplinthe 1,29 m, B

Sockelplinthe 1,29 m, H Säulenstuhl 0,895 m, L Säulenstuhl 1,175 m, B Säulenstuhl 1,175 m, H Fußprofil 0,21 m, H Deckprofil $0,19 \mathrm{~m}$

Erh.: Sockelplinthe und Säulenstuhl an der Innenseite verkröpft, an der Ost- und Westseite Stemmlöcher zum Versetzen der Basis
Bearb.: Sockelplinthe lediglich mit dem Zahneisen bearbeitet, Säulenstuhl mit dem Zahneisen bearbeitet und anschließend geglättet

KatNr. A 22

Taf. 82.83

InvNr. PR 21/07

Attische Basis der nordwestlichen Eck-Doppelhalbsäule

AO: in situ

FO: in situ

Mat.: grauweißer Marmor

Maße: H 0,38 m, L 1,045 m, B 1,045 m, H Plinthe 0,13 m, H Basis $0,25 \mathrm{~m}$

Erh.: an der Innenseite verkröpft, Oberseite der Basis teilweise abgebrochen

Bearb.: mit dem Zahneisen bearbeitet und anschließend grob geglättet

KatNr. A 23

Taf. 82.83

InvNr. PR 22/07

Eck-Doppelhalbsäule (Säulenschaft der Nordwestsäule)

AO: in situ

FO: in situ

Mat.: grauer Granit

Maße: H 4,145-4,175 m, L unten 0,87 m, B unten 0,87 m, L oben $0,80 \mathrm{~m}$, B oben $0,80 \mathrm{~m}$

Erh.: am Oberlager drei Dübellöcher mit Gusskanälen an den Rändern sowie ein zentrales Dübelloch, Oberfläche teilweise verwittert und abgeplatzt

Bearb.: mit dem Zahneisen bearbeitet und anschließend grob geglättet

KatNr. A 24

Taf. $82-85$

InvNr. PR 23/07

Kompositkapitell einer Eck-Doppelhalbsäule

AO: auf der Nordwestsäule

FO: im Zerstörungsschutt des Prytaneions (〉Hestiasaal $)$

Mat.: weißer Marmor

Maße: H 0,74 m, L Kapitellbasis 0,80 m, B Kapitellbasis $0,80 \mathrm{~m}, \mathrm{H}$ Abakus $0,13 \mathrm{~m}$, L Abakus $1,05 \mathrm{~m}$, B Abakus $1,04 \mathrm{~m}, \mathrm{H}$ Echinus $0,115 \mathrm{~m}$, B Kalathoslippe $0,025 \mathrm{~m}, \mathrm{H} \mathrm{Ka}-$ lathos ges. $0,495 \mathrm{~m}, \mathrm{H}$ Blattstab $0,13 \mathrm{~m}$, H Hochblatt $0,29 \mathrm{~m}$, H Lanzettblatt $0,29 \mathrm{~m}, \mathrm{H}$ Volute $0,17 \mathrm{~m}$, B Volute $0,16 \mathrm{~m}$ Erh.: am Oberlager zwei Dübellöcher mit Gusskanälen, Blattstab und Abakus teilweise abgebrochen

Bearb.: mit dem Flachmeißel bearbeitet und anschließend geglättet, am Oberlager Anathyrosis

\section{KatNr. A 25}

Taf. 87

InvNr. PR 28/07

Kompositkapitell einer Eck-Doppelhalbsäule

AO: in Raum 6 aufgelegt

FO: im Zerstörungsschutt des Prytaneions (〉Hestiasaalk)

Mat.: weißer Marmor

Maße: erh. H 0,32 m, H Abakus 0,13 m, erh. L Abakus $0,51 \mathrm{~m}$, erh. B Abakus $0,44 \mathrm{~m}, \mathrm{H}$ Echinus $0,115 \mathrm{~m}$, B Kalathoslippe $0,025 \mathrm{~m}, \mathrm{H}$ Volute $0,17 \mathrm{~m}$, B Volute $0,16 \mathrm{~m}$

Erh.: kleines Fragment mit Teil des Abakus, Echinus, Kalathos und einer Volute

Bearb.: mit dem Flachmeißel bearbeitet und anschließend geglättet 


\section{KatNr. A 26}

InvNr. PR 33/07a-h

Gesims des Marmorsockels

AO: in Raum 6 aufgelegt sowie in situ

FO: im Zerstörungsschutt des Prytaneions (〉Hestiasaal $)$ sowie in situ

Mat.: weißer Marmor

Maße: H 0,11 m, T 0,14 m

Erh.: über Sockel der Ostmauer ein 2,72 m langes Stück erhalten (an Bruchfläche Rest eines Eisendübels), über Sockel der Nordmauer ein $0,86 \mathrm{~m}$ langes Stück erhalten, acht weitere Fragmente in Raum 6 aufgelegt, Oberlager des Gesimses ursprünglich etwa zur Hälfte verbaut

Bearb.: Oberfläche glatt poliert, an Rückseite Sägespuren

\section{III.10.1.3 Raum 5}

KatNr. A 27

InvNr. PR 24/07

Basis

AO: in situ

FO: in situ

Mat.: weißer Marmor

Maße: H Plinthe 0,10 m, L Plinthe 0,72 m, B Plinthe 0,72 m, $\mathrm{H}$ Basis $0,22 \mathrm{~m}$, Dm unten 0,62 m, Dm oben 0,52 m

Erh.: Basis auf 0,28 m hohem Basisblock, quadratische Plinthe angearbeitet, Basis geht in Säulenfuß über

Bearb.: mit dem Zahneisen bearbeitet und anschließend geglättet

\section{KatNr. A 28}

Taf. 107,$2 ; 113,2$

InvNr. PR 25/07 und 26/07

Dorische Säule

AO: in situ

FO: in situ

Mat.: weißer Marmor

Maße: H 3,87 m, Dm unten 0,51 m, Dm oben 0,42 m

Erh.: zwei Trommeln, 20 sehr flache Kanneluren, am Oberlager ein zentrales Dübelloch mit Gusskanal, auf Ost- und Nordseite der unteren Säulentrommel Werkbosse erhalten Bearb.: mit dem Zahneisen bearbeitet und anschließend geglättet

\section{III.10.1.4 Raum 6}

\section{KatNr. A 29}

Taf. 99. 100

InvNr. PR 27/07

Dorische Säule

AO: in Raum 6 aufgelegt

FO: in situ auf dem zentralen Stylobatblock

Mat.: Sandstein

Maße: H 1,01 m, Dm unten 0,41 m, Dm oben 0,39 m

Erh.: eine Trommel, Kanneluren abgearbeitet, keine Dübellöcher

Bearb.: mit dem Zahneisen bearbeitet und anschließend grob geglättet

\section{III.10.2 Als Spolien verbaute Architektur-} GLIEDER

KatNr. A 30

Taf. $69,1-4$

InvNr. PR 58/07

Türsturz

AO: in die östliche Laibung von Tür 2 zwischen `Hestiasaal und Vorhalle verbaut

FO: in situ

Mat.: grauweißer Marmor

Maße: H 0,205 m, erh. L 1,135 m, erh. T 0,69 m

Erh.: rechter Teil des Türsturzes bestehend aus profilierter

Deckleiste und zwei Faszien, linker Teil abgeschlagen

Bearb.: mit dem Zahneisen bearbeitet und anschließend geglättet, Inschrift auf Türsturz: IvE 643

KatNr. A 31

Taf. $69,1.5 .6$

InvNr. PR 59/07 und 60/07

Türsturz

AO: in der Zumauerung von Tür 2 verbaut (PR 59/07) sowie im >Hestiasaak aufgelegt (PR 60/07)

FO: in situ

Mat.: blaugrauweißer Marmor

Maße: H 0,23 m, erh. L 1,58 m, erh. T 0,40 m

Erh.: zwei Fragmente, linker Teil des Türsturzes bestehend aus profilierter Deckleiste und zwei Faszien, rechter Teil abgebrochen

Bearb.: mit dem Zahneisen bearbeitet und anschließend geglättet, Inschrift auf Türsturz: IvE 1065

\section{III.10.3 Im Zerstörungsschutt des Gebäudes Ge- FUNDENE ARCHITEKTURGLIEDER}

KatNr. A 32

Taf. 131, 1. 2

InvNr. PR 52/07

Attische Basis

AO: aufgelegt in Raum 6

FO: im Zerstörungsschutt des Prytaneions

Mat.: grauweißer Marmor

Maße: H 0,20 m, H Plinthe 0,07 m, erh. L Plinthe 0,41 m, erh. B Plinthe 0,32 m, H Basis 0,13 m, Dm unten ca. 0,495 m, Dm oben ca. $0,375 \mathrm{~m}$

Erh.: etwa $1 / 4$ erhalten, am Unterlager ein Dübelloch sowie Risslinie, aufgrund der anhaftenden Kalkmörtelreste wohl als Spolie in einer Mauer verbaut gewesen

Bearb.: mit dem Zahneisen bearbeitet und anschließend geglättet

KatNr. A 33

Taf. 131, 3. 4

InvNr. PR 53/07

Attische Basis

AO: aufgelegt in Raum 6

FO: im Zerstörungsschutt des Prytaneions

Mat.: grauweißer Marmor

Maße: H 0,17 m, H Plinthe 0,07 m, L Plinthe 0,35 m, B Plinthe $0,35 \mathrm{~m}$, erh. H Basis $0,10 \mathrm{~m}$, Dm unten $0,35 \mathrm{~m}$

Erh.: Teile der Plinthe und Basis abgebrochen, oberer Teil fehlt vollständig, sekundär am Rand durchbohrt, Unterseite ausgehöhlt

Bearb.: mit dem Zahneisen bearbeitet und anschließend geglättet 


\section{KatNr. A 34}

InvNr. PR 31/07

Attische Basis

AO: in Raum 6 aufgelegt

FO: im Zerstörungsschutt des Prytaneions

Mat.: grauweißer Marmor

Maße: erh. H 0,17 m, H Plinthe 0,09 m, L Plinthe 0,72 m, erh. B Plinthe 0,50 m, erh. H Basis 0,08 m, Dm unten 0,62 m, erh. Dm oben $0,52 \mathrm{~m}$

Erh.: etwa $2 / 3$ erhalten, oberer Teil der Basis abgearbeitet, um als Basis wiederverwendet werden zu können, am Oberlager ein zentrales Dübelloch mit Gusskanal

Bearb.: mit dem Zahneisen bearbeitet und anschließend grob geglättet

\section{KatNr. A 35}

Taf. 132, 1.2

InvNr. PR 50/07

Attische Basis

AO: aufgelegt in Raum 6

FO: im Zerstörungsschutt des Prytaneions

Mat.: grauweißer Marmor

Maße: H 0,17 m, H Plinthe 0,04 m, L Plinthe 0,40 m, B Plinthe $0,40 \mathrm{~m}, \mathrm{H}$ Basis $0,13 \mathrm{~m}$, Dm unten $0,365 \mathrm{~m}$, Dm oben $0,32 \mathrm{~m}$

Erh.: Plinthe an drei Seiten verbrochen, aufgrund der anhaftenden Kalkmörtelreste wohl als Spolie in einer Mauer verbaut gewesen

Bearb.: mit dem Zahneisen bearbeitet und anschließend geglättet

\section{KatNr. A 36}

Taf. $132,3.4$

InvNr. PR 44/07

Attische Basis einer Dreiviertelsäule

AO: im >Hestiasaal aufgelegt

FO: im Zerstörungsschutt des Prytaneions

Mat.: grauweißer Marmor

Maße: H 0,24 m, H Plinthe 0,095 m, L Plinthe 0,56 m, B Plinthe 0,51 m, H Basis 0,145 m, Dm unten 0,56 m, Dm oben $0,50 \mathrm{~m}$

Erh.: Oberfläche teilweise abgeplatzt, sekundäre Abarbeitungen an Plinthe und Basis, am Oberlager zentrales Dübelloch, am Unterlager ein zentrales und ein seitliches Dübelloch sowie eine Vertiefung für Kantendübel, im zentralen Dübelloch Eisendübel teilweise noch vorhanden

Bearb.: mit dem Zahneisen bearbeitet und anschließend geglättet

\section{KatNr. A 37}

Taf. $132,5.6$

InvNr. PR 49/07

Rundbasis

AO: aufgelegt in Raum 6

FO: im Zerstörungsschutt des Prytaneions

Mat.: weiß geäderter, grauer Marmor

Maße: H 0,71 m, Dm unten 0,46 m, Dm oben 0,50 m, H Profil unten $0,065 \mathrm{~m}, \mathrm{H}$ Profil oben $0,065 \mathrm{~m}$

Erh.: am Oberlager zwei seitliche und ein zentrales Dübelloch mit Gusskanal sowie Versatzmarke (N), am Unterlager ein zentrales Dübelloch, Profile teilweise bestoßen

Bearb.: Seitenflächen mit dem Zahneisen bearbeitet und anschließend geglättet, Ober- und Unterlager mit dem Zahneisen bearbeitet
KatNr. A 38

Taf. 133, 1. 2 InvNr. PR 32/07

Pfeiler-/Pilasterbasis

AO: im >Hestiasaak aufgelegt

FO: im Zerstörungsschutt des Prytaneions

Mat.: grauweißer Marmor

Maße: H 0,21 m, H Plinthe 0,07 m, L Plinthe 0,60 m, erh. B Plinthe $0,37 \mathrm{~m}, \mathrm{H}$ Basis $0,14 \mathrm{~m}$

Erh.: am Oberlager ein Dübelloch mit Gusskanal, am Unterlager drei Dübellöcher mit teilweise noch erhaltenen Eisendübeln und Randschlag, Rückseite abgebrochen

Bearb.: mit dem Zahneisen bearbeitet und anschließend teilweise grob geglättet

KatNr. A 39

Taf. $133,3.4$

InvNr. PR 43/07

Pfeiler-/Pilasterbasis

AO: im >Hestiasaak aufgelegt

FO: im Zerstörungsschutt des Prytaneions

Mat.: grauweißer Marmor

Maße: H 0,20 m, H Plinthe 0,06 m, erh. L Plinthe 0,48 m, erh. B Plinthe $0,36 \mathrm{~m}, \mathrm{H}$ Basis $0,14 \mathrm{~m}$

Erh.: am Oberlager zwei Dübellöcher mit Gusskanälen, ein drittes ist im Bruch erkennbar, am Unterlager ein Dübelloch sowie Randschlag, rechte Seite abgebrochen

Bearb.: mit dem Zahneisen bearbeitet und anschließend teilweise grob geglättet

KatNr. A 40

Taf. 133, 5. 6

InvNr. PR 45/07

Pfeiler

AO: im >Hestiasaak aufgelegt

FO: im Zerstörungsschutt des Prytaneions

Mat.: grauweißer Marmor

Maße: erh. H 0,57 m, B 0,65 m, erh. T 0,44 m

Erh.: Ober- und Rückseite abgebrochen

Bearb.: mit dem Zahneisen bearbeitet und anschließend grob geglättet, an rechter Nebenseite Fragment einer Inschrift in zwei Zeilen: 1) MA... 2) $\Theta E$...

KatNr. A 41

Taf. $134,1.2$

InvNr. PR 41/07

Zahnschnittgeison mit Sima

AO: im >Hestiasaak aufgelegt

FO: im Zerstörungsschutt des Prytaneions

Mat.: grauweißer Marmor

Maße: H 0,38 m, erh. B 0,82 m, erh. T 0,68 m

Erh.: am Unterlager Teil eines eingearbeiteten Kassettenfeldes mit liegendem Vierblatt, Rückseite und rechte Seite abgebrochen, Marmor teilweise abgeplatzt

Bearb.: mit dem Zahneisen bearbeitet und anschließend geglättet, teilweise Raspelspuren, Unterlager grob gepickt

KatNr. A 42

Taf. 134, 3.4

InvNr. PR 48/07

Dorisches Kapitell

AO: aufgelegt in Raum 6

FO: im Zerstörungsschutt des Prytaneions (Raum 3)

Mat.: grauweißer Marmor

Maße: H 0,23 m, H Abakus 0,08 m, L Abakus 0,515 m, B Abakus 0,515 m, H Echinus 0,07 m, H Säulenhals 0,08 m, Dm Säulenhals $0,375 \mathrm{~m}$ 
Erh.: Teile des Abakus und Echinus abgebrochen, Werkbosse teilweise erhalten, am Unterlager Randschlag und Zentrierungspunkt, keine Dübellöcher

Bearb.: roh belassen, mit dem Zahneisen bearbeitet

\section{KatNr. A 43}

Taf. $134,5.6$

InvNr. PR 51/07

Tuskanisches Kapitell

AO: aufgelegt in Raum 6

FO: im Zerstörungsschutt des Prytaneions

Mat.: grauweißer Marmor

Maße: H 0,23 m, H Abakus 0,06 m, L Abakus 0,44 m, erh. B Abakus 0,43 m, H Echinus 0,07 m, H Säulenhals 0,10 m, Dm Säulenhals $0,30 \mathrm{~m}$

Erh.: Teile von Abakus und Echinus abgebrochen, keine Dübellöcher

Bearb.: roh belassen, mit dem Zahneisen bearbeitet

\section{KatNr. A 44}

Taf. $135,1.2$

\section{III.10.4 STREUFUND}

KatNr. A 47

Taf. 86

InvNr. PR 01/08

Attische Basis der nordwestlichen (?) Eck-Doppelhalbsäule

AO: Domitiansterrasse

FO: Domitiansterrasse

Mat.: grauweißer Marmor

Maße: H 0,30 m, L 1,04 m, B 1,04 m, H Plinthe 0,10 m, H Basis $0,20 \mathrm{~m}$

Erh.: an der Innenseite verkröpft, Ecken der Plinthe teilweise abgebrochen, an drei Seiten hat sich an der Plinthe eine Werkbosse erhalten, zwei Dübellöcher mit Gusskanal sowie ein zentrales Wolfsloch am Oberlager, ein Dübelloch am Unterlager

Bearb.: mit dem Zahneisen bearbeitet und anschließend grob geglättet

InvNr. PR 29/07

Korinthisches Kapitell

AO: in Raum 6 aufgelegt

FO: im Zerstörungsschutt des Prytaneions (Vorhof)

Mat.: grauweißer Marmor

Maße: erh. H 0,34 m, H Abakus 0,045 m, H Kalathos 0,295 m, L Abakus 0,48 m, B Abakus 0,475 m, erh. H Kranzblatt 0,235 m, Dm Kapitellbasis 0,325 m

Erh.: am Oberlager zentrales Dübelloch mit Gusskanal, Abakus und Abakusblüten teilweise bestoßen, Unterlager abgebrochen, zentrales Dübelloch

Bearb.: mit dem Flachmeißel bearbeitet und anschließend geglättet, Oberlager grob gepickt

\section{KatNr. A 45}

Taf. $135,3.4$

InvNr. PR 30/07

Pilasterkapitell

AO: in Raum 6 aufgelegt

FO: im Zerstörungsschutt des Prytaneions

Mat.: weißgelblicher Marmor

Maße: H 0,32 m, H Abakus 0,08 m, H Kalathos 0,24 m, L Abakus 0,62 m, erh. B Abakus 0,32 m, L Kapitellbasis $0,415 \mathrm{~m}$, erh. B Kapitellbasis $0,29 \mathrm{~m}$

Erh.: am Oberlager zentrales Wolfsloch, vier Dübellöcher und ein Klammerloch, am Unterlager drei Dübellöcher, Versatzmarke (E) am Abakus, Teil des Kapitells abgebrochen Bearb.: mit dem Flachmeißel bearbeitet und anschließend geglättet, Ober- und Unterlager mit Zahneisen bearbeitet

KatNr. A 46

Taf. 136, 1. 2

InvNr. PR 47/07

Kämpfer

AO: im >Hestiasaal aufgelegt

FO: im Zerstörungsschutt des Prytaneions

Mat.: grauweißer Marmor

Maße: H 0,30 m, L 0,57 m, B 0,31 m

Erh.: vollständig erhalten

Bearb.: mit dem Zahneisen bearbeitet und anschließend geglättet 


\section{III.11 Metrologie}

Im Zuge des Entwurfsvorgangs eines antiken Gebäudes gilt es, ein Grundmaß festzulegen, an dem sich das gesamte Bauvorhaben orientiert. Zur Anwendung kommen dabei sowohl reale Fußmaße als auch Modul-

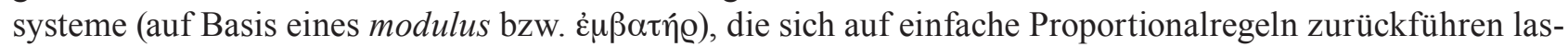
sen und die zeichnerische Planung sowie deren bauliche Umsetzung vereinfachen ${ }^{284}$. Solche Modulsysteme und ihre Proportionsverhältnisse werden ausführlich von Vitruv beschrieben ${ }^{285}$. Ein Modulsystem bot sich u. a. auch deshalb an, weil sich kleinere Strecken auf römischen Zollstöcken nicht ablesen ließen ${ }^{286}$. Das römische Fußmaß variiert zwischen 29,42 und 29,62 cm, wobei für das architektonische Fußmaß meist ein Mittelwert von $29,57 \mathrm{~cm}$ festgesetzt wird ${ }^{287}$. Für einen digitus, der 1/16 des pes Romanus ausmacht, würde dies einen absoluten Wert von $1,85 \mathrm{~cm}$ ergeben.

In Ephesos ist der Forschungsstand in Bezug auf Grundmaße bis dato nur gering und daher das Bild hinsichtlich Modulsystemen oder Fußmaßen uneinheitlich: H. Thür kann am Hadrianstor nachweisen, dass sich Grund- und Aufriss an einem modulus von $30 \mathrm{~cm}$ orientieren ${ }^{288}$. Ein analoges Maß sei nach Thür auch an der Domitiansterrasse und in den Hanghäusern 1 und 2 festzustellen ${ }^{289}$. Dass dieser modulus im Hanghaus 2 nicht durchgehalten wurde, zeigt ein Befund in der Wohneinheit 4, wo in Raum 10 des ersten Obergeschosses an den Schmuckfeldern des opus sectile-Paviments ein Grundmaß von 29,62 cm bestimmt werden konnte ${ }^{290}$. Am republikanisch/frühaugusteischen Memmiusbau wiederum kann nicht sicher entschieden werden, ob dem Konstruktionsraster ein Grundmaß von 29,4 oder 32,7 cm zugrunde lag ${ }^{291}$. Berechnungen zu einem Grundmaß am Nymphaeum Traiani führten zu keinem regelmäßigen modulus oder zu einem klar definierten Fußmaß ${ }^{292}$. Von einem einheitlichen ephesischen Grund- oder Fußmaß - vor allem zur Kaiserzeit - kann, wie dieses heterogene Bild belegt, somit keine Rede sein ${ }^{293}$.

Im Folgenden gilt es zu zeigen, inwieweit am Prytaneion Gesetzmäßigkeiten hinsichtlich eines modulus oder eines realen Fußmaßes zu bestimmen sind. Generell ist festzuhalten: Der Grundriss des Gebäudes ist durch die Parzellierung der Stadtflächen, die seit hellenistischer Zeit vorgegeben ist, bereits determiniert. Innerhalb der Parzellierung spielen wiederum topografische Voraussetzungen wie etwa die Terrainverhältnisse - im Prytaneion insbesondere der im Norden des Gebäudes sehr hoch anstehende Fels - eine entschei-

284 W. Müller-Wiener, Griechisches Bauwesen in der Antike (München 1988) $31 \mathrm{f}$.

${ }^{285} \mathrm{Zu}$ Entwurf und Proportionen im Tempelbau cf. Vitr. 3 und 4; s. auch Knell 1991, 63-114; H. Knell, Vitruvs metrologisches System, in: Bauplanung und Bautheorie der Antike. Bericht über ein Kolloquium in Berlin vom 16. 11.-18. 11. 1983, DiskAB 4 (Berlin 1984) 33-35; B. Wesenberg, Beiträge zur Rekonstruktion griechischer Architektur nach literarischen Quellen, AM Beih. 9 (Berlin 1983) 156.

${ }^{286}$ Cf. H. Büsing, Zur Genauigkeit der Skalen einiger römischer Zollstöcke, KölnJb 24, 1991, 271-285 bes. 283: »Wir glauben, daß die Drittelung des Daktylos und des digitus nicht üblich war. Die Verwendbarkeit und die Genauigkeit der zusammenklappbaren Meßstäbe war also sehr viel geringer als die unserer modernen Zollstöcke.«

287 Es handelt sich dabei um den Mittelwert gemäß F. Hultsch, Griechische und römische Metrologie (Berlin 1862) 71-77. Zur Problematik der Festsetzung des pes Romanus: J. A. de Waele, Der römische Fuß in Pompeji: der Tempel des Juppiter Capitolinus, BABesch 59, 1984, 1-8; zum Fußmaß allgemein: J.-P. Adam, Roman Building. Materials and Techniques ${ }^{2}$ (London 2001) 41. Für W. Hoepfner, Einführung. Maße - Proportionen - Zeichnungen, in: Bauplanung und Bautheorie der Antike. Bericht über ein Kolloquium in Berlin vom 16. 11.-18. 11. 1983, DiskAB 4 (Berlin 1984) 13 f. basiert der pes Romanus, den er mit 29,4 cm bestimmt, auf dem attisch-ionischen Fuß (s. dazu H. Bankel, Zum Fußmaß attischer Bauten des 5. Jahrhunderts v. Chr., AM 98, 1983, 65-99; H. Büsing, Metrologische Beiträge, JdI 97, 1982, 7; E. Buchner, Solarium Augusti und Ara Pacis, RM 83, 1976, 330). Ein entsprechendes Grundmaß kann M. Kadığlu, Die Scaenae frons des Theaters von Nysa am Mäander, Forschungen in Nysa am Mäander 1 (Mainz 2006) 151 nachweisen.

288 H. Thür, Das Hadrianstor in Ephesos, FiE 11, 1 (Wien 1989) 67.

289 Nach mündlicher Auskunft von H. Vetters. Im publizierten Baubefund des Hanghauses 1 ist ein solches Grundmaß allerdings ebenso wenig ausgewiesen wie in der Publikation der Wohneinheit 4 des Hanghauses 2: C. Lang-Auinger, Hanghaus 1 in Ephesos. Der Baubefund, FiE 8, 3 (Wien 1996) und Thür 2005.

290 Cf. K. Koller, Marmorausstattungen, in: Thür 2005, 150.

${ }^{291}$ Cf. A. Bammer, Das Bauwerk und seine Wiederherstellung, in: W. Alzinger - A. Bammer, Das Monument des C. Memmius, FiE 7 (Wien 1971) 43; A. Bammer, Zum Monument des C. Memmius in Ephesos, in: Meyer 2007, 57-61 mit weiterer Lit.

292 Mündliche Auskunft von U. Quatember.

${ }^{293}$ Am frühhellenistischen Mausoleum von Belevi beträgt das Fußmaß 29,6 cm: M. Theuer, Das Bauwerk und seine Wiederherstellung, in: C. Praschniker - M. Theuer, Das Mausoleum von Belevi, FiE 6 (Wien 1979) 69-71. 
dende Rolle. Der Grundriss der einzelnen Räume unterliegt weiters bauphysikalischen, funktionalen, aber auch ästhetischen Bedingungen.

\section{III.11.1 GRUNDRISS}

Die Dimensionen des Prytaneions im Grundriss (Taf. 31) sind durch den ephesischen Stadtraster definiert ${ }^{294}$. Folgt man dem Stadtraster von St. Groh, so ist das Gebäude in den Stadtflächen 618 und 718 der Regio II zu lokalisieren ${ }^{295}$. Das Prytaneion nimmt nach Groh - getrennt durch die hypothetische, $5 \mathrm{~m}$ breite Ost-WestStraße 11 - zwei ca. $20 \times 22$ m große $>$ Normalparzellen $<$ der hellenistisch-römischen Stadtflächen ein ${ }^{296}$. Die Ostmauern von Raum 2, des `Hestiasaales`, der Vorhalle und des Vorhofes würden mit der Mittelachse der Stadtflächen 618 und 718 fluchten ${ }^{297}$. Die von Groh postulierte Ost-West-Straße 11, die in der Flucht der Vorhalle gelegen sein müsste, ist im Bereich des Prytaneions und seiner benachbarten Gebäude unterbrochen ${ }^{298}$. Sie konnte auch im Rahmen der Sondagen der 1960er Jahre in der Vorhalle, die bis auf den gewachsenen Boden geführt wurden, nicht festgestellt werden ${ }^{299}$.

Die im Folgenden tabellarisch zusammengestellten Raummaße zeigen, dass keine direkten proportionalen Abhängigkeiten zwischen den Räumen erkennbar sind. Ebenso wenig ist ein Grundmaß - wie etwa im Aufriss - erkennbar. Wichtiger waren offenbar Parameter wie Topografie, Funktion, Bauphysik und Ästhetik. So galt es, auf einem durch die Parzellierung und den hoch anstehenden Felsboden vorgegebenen und limitierten Bauplatz ein Raumangebot zu schaffen, das den kultischen und repräsentativen Funktionen des Gebäudes gerecht wurde. Eine völlig freie grundrissliche Gestaltung wurde zudem durch das am südlichen Abhang des Panayırdağ auftretende Problem der Staunässe beschränkt. Dieses vor allem für in Steinbauweise ausgeführte Gebäude negative Phänomen versuchte man durch die Anlage eines Entlüftungskanals im Norden zu Lasten der Grundfläche zu mindern. Dem heterogenen Raumangebot, das durch die Betonung der Räume im Osten (`Hestiasaal<, Räume 2, 3 und 4) charakterisiert ist, wurde schließlich als verbindendes Element eine quergelagerte Stoa (Vorhalle) mit einer Säulenstellung dorischer Ordnung vorgeblendet, die eine Axialsymmetrie andeutete, die sich nach Betreten der Vorhalle als trügerisch erwies.

\section{Raummaße Prytaneion}

\begin{tabular}{|c|c|}
\hline Raum & $\begin{array}{c}\text { Innenmaße } \\
\text { (Nord-Süd } \times \text { Ost-West) }\end{array}$ \\
\hline 'Hestiasaak & $13,47 \times 13,41 \mathrm{~m}$ \\
\hline Räume 2, 3 und 4 & $3,61 \times 13,41 \mathrm{~m}$ \\
\hline Nördlicher Kanal & $1,26 \times 23,42 \mathrm{~m}$ \\
\hline Raum 5 & $8,83 \times 6,52 \mathrm{~m}$ \\
\hline Raum 6 & $7,98 \times 6,52 \mathrm{~m}$ \\
\hline Vorhalle & $7,20 \times 21,38 \mathrm{~m}$ \\
\hline Vorhof & $18,40 \times 21,65 \mathrm{~m}$ \\
\hline
\end{tabular}

294 Zum Stadtraster von Ephesos: Groh 2006, 47-116; P. Scherrer, The Historical Topography of Ephesos, in: D. Parrish (Hrsg.), Urbanism in Western Asia Minor. New Studies on Aphrodisias, Ephesos, Hierapolis, Pergamon, Perge and Xanthos, JRA Suppl. 45 (Portsmouth 2001) 58-93; F. Hueber, Ephesos. Gebaute Geschichte (Mainz 1997) 39-43. 49-53; A. Bammer, Zur Topographie und städtebaulichen Entwicklung von Ephesos, ÖJh 46, 1961-1963, 136-157; Karwiese 1995, 64 Karte 4.

295 Groh 2006, $90 \mathrm{f}$.

296 Exakte Maße (inkl. Außenmauern): nördliche Parzelle 718 (nördlicher Kanal, Räume 2, 3, 4, 5, 6 und >Hestiasaalı): 22,72 m (Nord-Süd) × 23,67 m (Ost-West); südliche Parzelle 618 (Vorhof): 19,09 m (Nord-Süd) $\times 23,06 \mathrm{~m}$ (Ost-West); Bereich Straße (Vorhalle): 7,59 m (Nord-Süd) $\times 23,67 \mathrm{~m}$ (Ost-West).

297 Zur Parzellierung der Stadtflächen: Groh 2006, 57-61. Er geht von ursprünglich zehn annähernd quadratischen Parzellen zu ca. $21 \times 21 \mathrm{~m}($ ca. $70 \times 70$ attische Fuß) Seitenlänge pro 104,7 $\times 40-45 \mathrm{~m}$ großer Stadtfläche aus.

298 Groh 2006, 73-79. $90 \mathrm{f}$.

299 Cf. M. Steskal, Kapitel II.3: Sondagen VIII und XVIII (1961), XXXI (1962), XXXII und XXXVI (1963). - Ist die Flucht der Ost-West-Straße 11 korrekt, so muss der Straßenkörper von Anfang an an dieser Stelle unterbrochen gewesen sein. 


\section{III.11.2 AufRISS}

Folgt man den Angaben Vitruvs zur dorischen Ordnung (Vitr. 4, 3), der den unteren Durchmesser einer dorischen Säule mit zwei moduli bemisst, so ergibt dies für das Prytaneion einen modulus von $60 \mathrm{~cm}$ (unterer Dm Säule 1,20 m). Stellt man die an der dorischen Front des Prytaneions gemessenen und in moduli à $60 \mathrm{~cm}$ umgerechneten Werte den Idealproportionen Vitruvs gegenüber, ergeben sich sowohl Überschneidungen als auch Abweichungen ${ }^{300}$.

moduli und Maße der dorischen Ordnung der Vorhalle ${ }^{301}$

\begin{tabular}{|c|c|c|c|}
\hline Objekt & Maße & moduli à $60 \mathrm{~cm}$ & moduli nach Vitr. \\
\hline L Stylobat & $23,67 \mathrm{~m}$ & $391 / 2$ & -302 \\
\hline unterer Dm Säule & $1,20 \mathrm{~m}$ & 2 & 2 \\
\hline oberer Dm Säule & $0,98 \mathrm{~m}$ & $12 / 3$ & $12 / 3$ \\
\hline H Säule (inkl. Kapitell) & $7,405 \mathrm{~m}$ & $12^{1 / 3}$ & 14 \\
\hline H Kapitell & $0,46 \mathrm{~m}$ & $3 / 4$ & 1 \\
\hline L Abakus & $1,26 \mathrm{~m}$ & $2 \frac{1}{10}$ & $21 / 6$ \\
\hline H Abakus & $0,168 \mathrm{~m}$ & $1 / 3$ & $1 / 3$ \\
\hline H Echinus & $0,137 \mathrm{~m}$ & $1 / 4$ & $1 / 3$ \\
\hline H Säulenhals & $0,105 \mathrm{~m}$ & $1 / 6$ & $1 / 3$ \\
\hline H Architrav & $0,75 \mathrm{~m}$ & $11 / 4$ & 1 \\
\hline H Architravtänie & $0,08 \mathrm{~m}$ & $1 / 7$ & $1 / 7$ \\
\hline H Regula samt Guttae & $0,075 \mathrm{~m}$ & $1 / 8$ & $1 / 6$ \\
\hline B Regula & $0,60 \mathrm{~m}$ & 1 & - \\
\hline H Fries & $0,88 \mathrm{~m}$ & $1 \frac{1 / 2}{2}$ & $11 / 2$ \\
\hline B Triglyphe & $0,60 \mathrm{~m}$ & 1 & 1 \\
\hline B Metope & $0,91 \mathrm{~m}$ & $1 \frac{1}{2}$ & - \\
\hline B erweiterte Außenmetope & $1,12 \mathrm{~m}$ & $15 \%$ & - \\
\hline H Geison & $0,35 \mathrm{~m}$ & $3 / 5$ & $1 / 2$ \\
\hline B Mutulus & $0,60 \mathrm{~m}$ & 1 & - \\
\hline B Normaljoch & $3,02 \mathrm{~m}$ & 5 & $71 / 2$ \\
\hline B Frontmitteljoch & $4,53 \mathrm{~m}$ & $71 / 2$ & 10 \\
\hline
\end{tabular}

In Bezug auf die Interkolumniumsweite, die 11/2 unteren Säulendurchmessern ( 3 moduli) entspricht, korreliert die dorische Fassade mit dem bei Vitr. 3, 3, 2 beschriebenen Pyknostylos, den er aufgrund des sehr engen Interkolumniums als nicht ideal bezeichnet ${ }^{303}$. Der untere Säulendurchmesser $(1,20 \mathrm{~m})$ verhält sich zur Weite des Normaljochs (3,02 m) folglich wie 2:5. Das Verhältnis unterer Säulendurchmesser (1,20 m) zur Weite des Frontmitteljochs $(4,53 \mathrm{~m})$ beträgt 2:71/2; die Weite des Normaljochs verhält sich somit zur Weite des Frontmitteljochs wie 5:71/2. Der modulus von $60 \mathrm{~cm}$ durchdringt die Konstruktion in weiten Bereichen: So entsprechen die Breiten von Regula, Triglyphe und Mutulus exakt einem modulus und somit dem der dorischen Ordnung immanenten Verhältnis von 1:1:1. Sehr klare Proportionsverhältnisse zeigen sich beispielsweise auch im Verhältnis der Höhe des Architravs zur Höhe des Metopen-Triglyphen-Frieses von 11/4:11/2. Eine deutliche Diskrepanz zu den Angaben bei Vitruv ist allerdings im Verhältnis unterer Säulendurchmesser zur Höhe der Säulen zu konstatieren: Dem Verhältnis von 1:61\% im Prytaneion steht das Idealverhältnis von 1:7 bei Vitruv gegenüber ${ }^{304}$. Die Säulen der dorischen Front des Prytaneions sind somit deutlich kürzer dimensioniert.

\footnotetext{
300 Exakte Überschneidungen fett gedruckt.

301 Am Beispiel der vollständig erhaltenen und wiederaufgestellten Säule mitsamt Gebälk KatNr. A 3. 5. 7-9.

302 Vitr. 4, 3, 3 bemisst den dorischen Hexastylos mit 42 und den dorischen Tetrastylos mit 27 moduli. Bei der dorischen Front des Prytaneions handelt es sich allerdings um eine Konstruktion mit sechs Säulen in antis.

303 Dass dies allerdings keine Frage der Proportionen, sondern absoluter Maße ist, bemerkt richtigerweise Knell $1991,81 \mathrm{f}$. 92-95.

304 Vitr. 4, 3, 4.
} 
Frappierend sind in diesem Kontext die Übereinstimmungen mit dem metrologischen Gerüst der ein halbes Jahrhundert nach dem Prytaneion errichteten `Neronischen Halle`, auf die G. A. Plattner im Detail eingeht ${ }^{305}$.

Die vier im >Hestiasaak aufgestellten Säulen befinden sich auf individuell hohen Sockelplinthen, die die natürlichen Niveauunterschiede des anstehenden Felsens ausgleichen. Der bereits an der dorischen Ordnung festgestellte modulus von $60 \mathrm{~cm}$ lässt sich auch an den >Herzsäulen` nachweisen. Ihre Säulenstühle befinden sich jeweils $0,90 \mathrm{~m}$ (11/2 moduli) von den Wänden des Raumes entfernt.

moduli und Maße der $>$ Herzsäulen` des $>$ Hestiasaales ${ }^{306}$

\begin{tabular}{|l|c|c|}
\hline \multicolumn{1}{|c|}{ Objekt } & Maße & moduli à $\mathbf{6 0} \mathbf{~ c m}$ \\
\hline H Säulenstuhl & $0,90 \mathrm{~m}$ & $1 \frac{1}{2}$ \\
\hline L Säulenstuhl & $1,19 \mathrm{~m}$ & 2 \\
\hline B Säulenstuhl & $1,20 \mathrm{~m}$ & 2 \\
\hline H Fußprofil & $0,23 \mathrm{~m}$ & $1 / 4$ \\
\hline H Deckprofil & $0,20 \mathrm{~m}$ & $1 / 3$ \\
\hline H sekundäre Basis & $0,46 \mathrm{~m}$ & $3 / 4$ \\
\hline L sekundäre Basis & $1,075 \mathrm{~m}$ & $14 / 5$ \\
\hline B sekundäre Basis & $1,075 \mathrm{~m}$ & $14 / 5$ \\
\hline H primäre Basis & $0,30 \mathrm{~m}$ & $1 / 2$ \\
\hline L primäre Basis & $1,04 \mathrm{~m}$ & $13 / 4$ \\
\hline B primäre Basis & $1,04 \mathrm{~m}$ & $13 / 4$ \\
\hline H Eck-Doppelhalbsäule & $4,23 \mathrm{~m}$ & 7 \\
\hline H Kapitell & $0,74 \mathrm{~m}$ & $1 \frac{1}{4}$ \\
\hline L Kapitellbasis & $0,80 \mathrm{~m}$ & $11 / 3$ \\
\hline B Kapitellbasis & $0,80 \mathrm{~m}$ & $11 / 3$ \\
\hline H Abakus & $0,13 \mathrm{~m}$ & $3 / 7$ \\
\hline L Abakus & $1,05 \mathrm{~m}$ & $13 / 4$ \\
\hline B Abakus & $1,04 \mathrm{~m}$ & $13 / 4$ \\
\hline H Echinus & $0,115 \mathrm{~m}$ & $1 / 5$ \\
\hline H Kalathos inkl. Kalathoslippe & $0,52 \mathrm{~m}$ & $7 / 8$ \\
\hline
\end{tabular}

Auch an den >Herzsäulen Basis, Schaft und Kapitell einem sekundären Kompositionsschema entspricht ${ }^{307}$ - ein klarer gestalterischer Wille nach Symmetrie und Proportionalität auszumachen. So verhalten sich die Höhe des Säulenstuhls zur Höhe der primären attischen Basis wie 3:1 bzw. zur Höhe der sekundären attischen Basis wie 2:1 sowie die Höhe des Säulenstuhls zur Höhe der Säule inklusive Kapitell wie 1:51/2. Die Höhe der primären attischen Basis verhält sich weiters zur Höhe der Säule inklusive Kapitell wie $1: 16^{2} / 3$, die Höhe der sekundären attischen Basis zur Höhe der Säule inklusive Kapitell wie 1:11. Die Höhe des Säulenstuhls verhält sich schließlich zu seiner Länge und Breite wie 3:4.

In Bezug auf das Entwurfskonzept des Prytaneions kann somit festgehalten werden, dass man sich an einem Grundmaß von $60 \mathrm{~cm}$ (1 modulus) orientierte und ein auf symmetrischen Proportionalverhältnissen basierender Gestaltungswille zu erkennen ist. Dieser durchdringt allerdings nicht das ganze Bauvorhaben. Der etwa zwei römischen Fuß entsprechende modulus wird nicht im gesamten Gebäude durchgehalten. Dieses Phänomen dokumentiert ein sehr praxisnahes und pragmatisches Bauen, das lokal-topografische Gegebenheiten berücksichtigt und individuelle Entscheidungen oder Modifikationen im Bauprozess ermöglicht.

Vom Aufgehenden der Säulenstellung des Vorhofes haben sich nur Aufschnürungen der ionischen Ordnung erhalten. Der fragmentarische architektonische Befund lässt es nur bedingt zu, einen modulus in die-

305 G. A. Plattner, Kapitel VII.4.3.1.

306 Am Beispiel der nordöstlichen 〉Herzsäuleく KatNr. A 17-20. Die Dimensionen der anderen Säulen variieren minimal.

307 So entsprechen die Säulenstühle und -schäfte der primären, augusteischen Bauphase 1, während die Basen und Kapitelle der sekundären Bauphase 2 (2. Viertel 3. Jh. n. Chr.) angehören; cf. dazu G. A. Plattner, Kapitel VII.4.1.2. 
sem Bereich zu bestimmen. Folgt man den Angaben Vitruvs zu den Proportionen attischer Basen, der für die Seitenlänge des Basisblockes 11/2 moduli annimmt, so kann ausgehend von den Aufschnürungen für die Säulenbasen und der ablesbaren Länge der Plinthen der Basen ein modulus von $\approx 41 \mathrm{~cm}$ vermutet werden ${ }^{308}$. Folgende Proportionalverhältnisse würden sich daraus ergeben:

moduli und Maße der ionischen Ordnung des Vorhofes

\begin{tabular}{|l|c|c|}
\hline \multicolumn{1}{|c|}{ Objekt } & Maße & moduli $\mathbf{~ a ̀ ~} \approx \mathbf{4 1} \mathbf{~ c m}$ \\
\hline L Stylobat der Ost- und Weststoa & $14,58 \mathrm{~m}$ & $35^{1 / 2}$ \\
\hline L Stylobat der Südstoa & $14,47 \mathrm{~m}$ & $35^{1 / 3}$ \\
\hline L und B Basis & $\approx 0,62 \mathrm{~m}$ & $1 \frac{1}{2}$ \\
\hline B Joch der Ost- und Weststoa & $2,98 \mathrm{~m}$ & $71 / 4$ \\
\hline B Joch der Südstoa & $2,77 \mathrm{~m}$ & $63 / 4$ \\
\hline
\end{tabular}

Die konstruktiven Veränderungen der byzantinischen Bauphase 3 folgen keinen auf moduli basierenden Gesetzmäßigkeiten.

\section{III.12 Rekonstruktion}

Für die zeichnerische Umsetzung der Rekonstruktion des ephesischen Prytaneions in Schnitten (Taf. 255-258) und mittels eines 3-D-Modells (Taf. 259-263) wurde Bauphase 2 (Taf. 160) aus dem zweiten Viertel des 3. Jahrhunderts n. Chr. gewählt, da sich in ihr die dichtesten und aussagekräftigsten archäologischen und architektonischen Befunde widerspiegeln. Zudem entspricht die Grundstruktur der Anlage zu dieser Zeit bis auf kleinere Adaptierungen und Reparaturen nach wie vor dem Konzept der bauzeitlichen augusteischen Phase 1 (Taf. 159). Zu diesen Adaptierungen, die bis in Bauphase 2 erfolgten $^{309}$, gehören insbesondere die Anlage der Türen 2 und 4 von der Vorhalle in den >Hestiasaak, die Verlegung eines polychromen Tessellats in der Vorhalle, die Errichtung der gemauerten Sitzbänke sowie eine Neuaufstellung der >Herzsäulen im >Hestiasaak, die Umgestaltung des Eingangs in den Querraum 2-4, sprich die vollständige Abdeckung des Keilsteinbogens, die Aufstellung von zentralen Stützen in den Räumen 5 und 6 sowie die Platzierung der >Großen Artemis` im Zentrum des Vorhofes und einer Ehrenbasis über der Regenrinne des östlichen Umgangs dieses Peristyls.

Vom Aufgehenden des Vorhofes sind uns nur drei Aufschnürungen der attischen Basen auf den verbliebenen Stylobatblöcken bekannt, die eine Rekonstruktion der Seitenlänge des Basisblockes mit 0,62 m möglich machen ${ }^{310}$. Ausgehend von diesem bekannten Wert lässt sich das Peristyl - trotz des vollständigen Fehlens der aufgehenden Architektur - hypothetisch und idealisiert rekonstruieren. Da an der Westseite zwei Auflagerspuren für Basen mit quadratischen Plinthen erkennbar sind, kann die Jochweite mit 2,98 m bestimmt werden. Auch am Stylobatblock der Südostecke findet sich eine Versatzspur für eine Basis. Während die Jochweiten der West- und Ostseite identisch und folglich mit je fünf Säulen ionischer Ordnung zu rekonstruieren sind, ergibt sich für die mit sechs Säulen ionischer Ordnung zu rekonstruierende Südseite aufgrund der geringeren Länge des Stylobats ein engeres Joch von 2,77 m (Gesamtzahl der Säulen: 14).

Folgt man nun Vitruvs Angaben zu den Proportionen attischer Basen (Vitr. 3, 5, 1 f.), so ergeben sich für die Basishöhe ein Wert von 0,205 m (1/2 modulus $)^{311}$ und für den unteren Säulendurchmesser 0,41 m (1 modulus). Setzt man eine ideale Säulenhöhe von 91/2 moduli voraus, ergibt dies einen Wert von 3,90 m für die wohl kannelierten Säulen des Vorhofes ${ }^{312}$. Das Gebälk ließe sich nach Vitr. 3, 5, 8-11 wie folgt rekonstruieren: Höhe des Kapitells 0,22 m ( ${ }^{19} / 36$ modulus), Höhe des Architravs 0,205 m (1/2 modulus), Höhe des

308 Vitr. 3, 5, 1 f.; cf. Knell 1991, 103-105.

309 Cf. M. Steskal, Kapitel V.4.

310 Cf. M. Steskal, Kapitel III.2.

311 Die Basis setzt sich aus einer $0,07 \mathrm{~m}$ hohen Plinthe ( $1 / 6$ modulus) und einem 0,14 $\mathrm{m}$ hohen Basisaufbau ( $1 / 3$ modulus) zusammen.

312 Es ist allerdings durchaus möglich, dass die heute nicht mehr erhaltenen Säulen des Vorhofes unkanneliert belassen wurden, um wie die dorischen Säulen der Vorhalle zur Aufnahme von Inschriften geeignet zu sein. Eine endgültige Entscheidung ist hier aufgrund der fehlenden Bauglieder nicht mehr zu treffen. 
unreliefierten Frieses $0,16 \mathrm{~m}$ (3/8 modulus), Höhe des Frieskymas $0,02 \mathrm{~m} \mathrm{(3/56} \mathrm{modulus),} \mathrm{Höhe} \mathrm{des} \mathrm{Zahn-}$ schnittes $0,06 \mathrm{~m}$ (1/7 modulus), Höhe des Zahnschnittkymas $0,01 \mathrm{~m}$ (1/42 modulus), Höhe der Corona 0,06 m (1/7 modulus) sowie Höhe der Sima $0,07 \mathrm{~m}$ (27/168 modulus). Für die lichte Raumhöhe in den Umgängen des Peristyls des Vorhofes ergibt dies einen Wert von 4,47 m. Über einem hölzernen Dachstuhl sind schließlich mit Ziegeln gedeckte Pultdächer zu rekonstruieren. In den Rekonstruktionszeichnungen sind an den kurzen Giebelseiten zudem geneigte Dachflächen, also Walme, dargestellt; ihre Existenz ist freilich nicht zu belegen und nur als Vorschlag zu verstehen. Ein seitlicher Abschluss der Pultdächer mit Ortgängen ist gleichermaßen möglich, wäre aber konstruktiv aufwendiger und würde zudem den Lichteinfall in die Vorhalle behindern. Der einfacheren Lösung mit Walmen wurde daher der Vorzug gegeben.

Auf Basis dieser idealisierten Werte erfolgte die zeichnerische Rekonstruktion des Vorhofes. Der Haupteingang des Gebäudes lag im Süden des Vorhofes: Eine 2,48 m breite Türöffnung war noch in seiner Südmauer ablesbar. $\mathrm{Ob}$ es sich dabei um ein Doppeltor mit einer äquivalenten, im Westen anschließenden Öffnung handelte, ist heute nicht mehr festzustellen. Daher wurde auf die Darstellung eines solchen - durchaus möglichen - Doppeltores verzichtet und die einfachere, aber gesicherte Variante mit nur einer, hypothetisch 2,93 m hohen Türöffnung gewählt. Über zwei 0,17 m hohe Stufen (inkl. Stylobat) gelangte man auf das Niveau des offenen Hofes. Die untere Stufe bildete zugleich die Abdeckung des Kanals, der das Regenwasser von den Dachflächen ableitete.

Die im Folgenden beschriebene Rekonstruktion der Vorhalle - insbesondere der Dachkonstruktion - unterscheidet sich wesentlich von früheren Lösungen, die über dem Gebälk eine Giebelkonstruktion mit Tympanon und in weiterer Folge ein Satteldach wiedergeben (cf. z. B. Taf. 29, 3) 313: Vom Gebälk der dorischen Ordnung mit ihren sechs unkannelierten Säulen in antis wurden im Areal des Prytaneions nur wenige Elemente gefunden: ein Architravblock (KatNr. A 7), ein Teil des Metopen-Triglyphen-Frieses (KatNr. A 8) und zwei Blöcke des Horizontalgeisons (KatNr. A 9. 10). Aufgrund der identen Breite der Mutuli und Triglyphen können die Geisonblöcke KatNr. A 9 sowie A 10 eindeutig der dorischen Ordnung zugewiesen werden. Auf Basis der bekannten Breite von Mutulus, Triglyphe, Metope und Regula ist eine Jochweite von 3,02 m zu berechnen. Da die Breite der Vorhalle durch die beiden Antenmauern definiert ist $(23,67 \mathrm{~m}$ inkl. Antenmauern), kann der Metopen-Triglyphen-Fries mit 15 Metopen (Normalmaß 0,91 m) und 16 Triglyphen (Normalmaß 0,60 m) rekonstruiert werden. Der überlange Architravblock KatNr. A 7 ist somit - entgegen seiner heutigen Anbringung - über ein um eine Metope und eine Triglyphe erweitertes Mitteljoch (4,53 m) zu setzen. Der sich daraus ergebende dorische Eckkonflikt wird durch Verbreiterung der jeweils äußersten Metopen um jeweils 0,21 m gelöst, wodurch sich für die östlichste und westlichste Metope ein Breitenmaß von 1,12 m ergibt. Ausgehend von der tatsächlichen Breite der Vorhalle von 23,67 m ergibt sich eine Differenz von $0,16 \mathrm{~m}$ auf die rekonstruierte Breite von 23,83 $\mathrm{m}(6 \times$ Normaljoch à $3,02 \mathrm{~m}+1 \times$ Mitteljoch à $4,53 \mathrm{~m}+2 \times \mathrm{B}$ eines halben Antenkopfes à $0,59 \mathrm{~m}$ ). Die Sima über den Horizontalgeisa der dorischen Ordnung ist nicht in Marmor, sondern in Ton ausgeführt; das Regenwasser, das sich auf den Walmen sammelte, wurde wohl in den Abwasserkanal unter der westlich angrenzenden >Akademiegasse selbst besitzen T-förmige Einlassungen für Holzbalken, die den Dachstuhl für das Walmdach aufnahmen. Die Säulentrommeln sind zwar innerhalb der Säulen und in den entsprechenden Zonen benachbarter Säulen unterschiedlich hoch, da aber die Zugehörigkeit einzelner Trommeln zu einer bestimmten Säule aufgrund der zu geringen Zahl vorhandener Trommeln nicht eruierbar ist, wurden in der zeichnerischen Rekonstruktion jeweils gleich hohe Trommeln in den jeweiligen Zonen der Säulen dargestellt. Dies muss mit dem tatsächlichen Aussehen der Säulen, die durchaus auch unterschiedlich hohe Trommeln in den jeweiligen Zonen aufweisen konnten, freilich nicht übereinstimmen ${ }^{314}$. Bis zum Dachstuhl ergibt sich somit eine lichte Raumhöhe von 9,33 m; die Abarbeitungen an der Rückseite des Architravs und die allgemein sehr rohe Struktur der Gebälkrückseite, die offenbar nicht auf Ansichtigkeit gestaltet war (Taf. 56, 2; 57, 2. 3; 58, 4; 59, 1. 2), lassen aber an eine Holzdecke, unter Umständen auch mit Kassetten, denken, die auf dem Oberlager

313 Cf. M. Steskal, Kapitel III.3. Giebelkonstruktionen werden etwa von A. Bammer, Architektur, ÖJh 50, 1972-1975, Beibl. 405; Bammer 1976/1977, 57; Bammer 2008, 168 Abb. 3 und Alzinger 1974, Taf. 34, 65a (nach W. John) vorgeschlagen; s. dazu die Stellungnahmen des Verf.: M. Steskal, Kapitel III.3.

314 Cf. auch G. A. Plattner, Kapitel VII.4.1.1. 
der dorischen Kapitelle auflag. Eine solche Lösung, die als einfache Linie in der Rekonstruktionszeichnung eingetragen ist, würde die lichte Raumhöhe der Vorhalle auf 7,49 m reduzieren.

Als wesentlichste Änderung im Vergleich zu allen früheren Darstellungen ist somit die Rekonstruktion eines flachgeneigten, mit Ziegeln gedeckten Walmdaches über einem 4,44 m hohen, hölzernen Dachstuhl $\mathrm{zu}$ betrachten $^{315}$. Gegen eine Giebelkonstruktion sprechen die T-förmigen Einlassungen auf den Oberlagern der Geisonblöcke (Taf. 56, 2; 57; 58, 4; 59; 60, 1. 2), die zur Aufnahme der Holzbalken der Dachkonstruktion dienten. Eine mögliche Vorgängerkonstruktion mit Tympanon und Giebel zu rekonstruieren und die Walmdach-Lösung als sekundär zu betrachten, ist in diesem Kontext als argumentum e silentio weder methodisch zulässig noch durch Befunde zu belegen. Wären die Einlassungen für die Holzbalken auf den Geisonblöcken sekundär, dann müssten etwa auch die auf den Oberlagern in den Führungen für die Holzbalken befindlichen Wolfslöcher deutlich seichter oder überhaupt herausgeschlagen sein; tatsächlich weist das Wolfsloch am Oberlager des vor der Nordwand der Vorhalle aufgelegten Geisonblockes KatNr. A 10 (Taf. 60, 1. 2) aber nach wie vor eine Tiefe von $12 \mathrm{~cm}$, ohne sekundäre Abarbeitungsspuren, auf. Ebenso $12 \mathrm{~cm}$ tief ist das Wolfsloch am Oberlager des in der Architekturprobe verbauten Geisons KatNr. A 9 (Taf. 57, 1; 58, 3. 4; 59). Dort befindet es sich nicht in der Vertiefung für die Holzbalken, sondern ist aufgrund der großen Aussparung für den schräg anlaufenden Holzbalken und um den Block beim Heben tatsächlich in der Waage halten zu können, leicht in Richtung Mutulus versetzt. Weitere bzw. ältere Hebelöcher sind auf den einzigen beiden erhaltenen Geisonblöcken nicht nachweisbar. Aus den eben genannten Gründen verbietet sich eine primäre Lösung mit einer Giebelkonstruktion daher grundsätzlich. Wir haben es hier nicht mehr mit dem singulären Fall einer Tempelfassade an einem Prytaneion zu tun, sondern - in Bezug auf die Vorhalle - vielmehr mit einer Stoa, die die nördlich davon liegenden Räume gliedert und rahmt. Der Vorhof mit seinem niedrigeren ionischen Peristyl erinnert in Verbindung mit der höheren dorischen Halle im Norden in seiner Gesamtkonzeption somit an den Bautypus des >rhodischen Peristyls`, wie er auch im östlich angrenzenden Gebäude zwischen Bouleuterion und Prytaneion zu finden ist.

Über jeweils 0,33 m hohe Stufen gelangte man von der Vorhalle in den >Hestiasaak und in Raum 6. Die lichten Höhen der Türen, die alle nicht bis zur Höhe des Türsturzes erhalten sind, wurden wiederum hypothetisch rekonstruiert und können in der Realität von diesen Werten leicht abweichen (H Tür 1: 3,90 m, H Tür 2: 2,95 m, H Tür 3: 5,41 m, H Tür 4: 2,95 m). Die Schwelle der sekundären Tür in der östlichen Antenmauer der Vorhalle, die in Richtung angrenzendes Temenos vermittelte, war über zwei 0,27 m hohe Stufen zu betreten und besaß eine hypothetische lichte Höhe von 2,61 m.

Der gute Erhaltungszustand der Befunde im >Hestiasaak ermöglicht es, ein sehr realitätsnahes Bild vom Aussehen dieses Raumes zu gewinnen: Auf dem vorhandenen 2,37 × 2,37 m großen Fundament im Zentrum des Raumes ist ein marmorner Tisch zu rekonstruieren, dessen Höhe von 1,00 m zwar spekulativ ist, mit dieser angenommenen Höhe jedoch eine praktikable Möglichkeit zum Anrichten der Speisen gewährleistete. Die L-förmigen, 2,22 und 3,99 m breiten und 10,12 m langen Sitzbänke zwischen den >Herzsäulen sind aufgrund des Befundes zweistufig zu rekonstruieren, wobei für die Höhe der unteren Stufe 0,58 m und die Höhe der oberen Stufe 0,47 m angenommen werden. Da auch an den vier 4,12-4,23 m hohen >Herzsäulen mit ihren 0,38-0,46 m hohen Sockelplinthen, den 0,89-0,90 m hohen Säulenstühlen und den 0,74 m hohen Kapitellen ein klarer gestalterischer Wille nach Symmetrie und Proportionalität mit einem modulus à $60 \mathrm{~cm}$ festzustellen ist, wurde das hypothetisch rekonstruierte, in die Wände des Raumes einbindende, kurze Gebälk, bestehend aus einem Dreifaszienarchitrav, einem unreliefierten Fries und einem Zahnschnittgeison

\footnotetext{
315 Die Rekonstruktion des Dachstuhls ist hypothetisch, da das Gebäude - abgesehen von den Horizontalgeisa - über der Kämpferlinie nicht erhalten ist. Es konnten daher keine weiteren Einlassungen für Dachbalken gefunden werden. Bei der Gestaltung des Dachstuhls stand somit eine konstruktiv und statisch korrekte Umsetzung im Vordergrund, für die ich M. La Torre zu Dank verpflichtet bin. Das Dach selbst entspricht konstruktiv dem des `Odeion` von Pompeji aus den 70er Jahren des 1. Jhs. v. Chr., cf. P. Gros, L'architecture romaine du début du III siècle av. J.-C. à la fin du Haut-Empire. 1 Les monuments publics ${ }^{2}$ (Paris 2002) 309 f. mit Abb. 366; M. Murolo, Il cosidetto >Odeo< di Pompei ed il problema della sua copertura, RendNap 34, 1959, 89-101; G. C. Izenour, Roofed Theaters of Classial Antiquity (London 1992) 66-72. Um 90 gedreht findet sich eine vergleichbare Lösung auch beim Bouleuterion von Aphrodisias, cf. Gros a. O. Abb. 372 sowie L. Bier, The Bouleuterion, in: Ch. Ratté - R. R. R. Smith (Hrsg.), Aphrodisias Papers 4. New Research on the City and its Monuments, JRA Suppl. 70 (Portsmouth 2008) 144-168 bes. 154-156; Izenour a. O. 99-107. Allgemein zu dieser Dachkonstruktion: R. Meinel, Das Odeion. Untersuchungen an überdachten antiken Theatergebäuden (Frankfurt 1980) 342-351.
} 
mit einer Höhe von 1,35 m, also 21/4 moduli à $60 \mathrm{~cm}$, rekonstruiert. Somit verhält sich die Höhe des Gebälks (ohne Kapitell) zur Höhe des Säulenstuhls wie 11/2:1. Die lichte Raumhöhe des $>$ Hestiasaales ist durch die bekannte Position des Horizontalgeisons der dorischen Ordnung der Vorhalle mit 8,59 m gesichert, wobei in der Rekonstruktionszeichnung aufgrund der hervorgehobenen Bedeutung des Raumes nunmehr eine hölzerne Kassettendecke vorgeschlagen wird ${ }^{316}$. Für eine ausreichende Lichtzufuhr in diesen Raum sind in jedem Fall Fenster in der Ostwand anzunehmen ${ }^{317}$, von denen sich aber keine Spuren erhalten haben. In der hier vorgestellten Rekonstruktion werden vier durch Sprossen gegliederte Fenster mit Maßen von 2,22 $\times$ $1,25 \mathrm{~m}$ vorgeschlagen. Ein baugleiches Fenster wird in der Ostwand des Querraumes 2-4 wiedergegeben, der so über ausreichend Helligkeit verfügte. Der in der Nordwand befindliche, bauzeitliche marmorne Keilsteinbogen war in Bauphase 2 nicht mehr sichtbar und von Marmorplatten verdeckt. Die Bereiche zwischen dem Bogen und der Flucht der im Rohbau 3,25 m breiten Tür in den Querraum 2-4 wurden in diesem Kontext aufgemauert und ein Türsturz wurde eingezogen, durch den eine Öffnung mit der hypothetischen lichten Höhe von 4,36 m entstand. Für ein besseres Verständnis dieser Situation wird der zu dieser Zeit nicht mehr sichtbare Keilsteinbogen, dessen Archivolte man im Zuge dieser Baumaßnahme extra abarbeitete, strichliert wiedergegeben (Taf. 258).

Die durch den Dachstuhl vorgegebene Deckenhöhe ergibt für den Querraum 2-4 lichte Raumhöhen von $8,47 \mathrm{~m}$ im Osten und 7,58 $\mathrm{m}$ im Westen, wo ein Niveauunterschied von 0,89 $\mathrm{m}$ durch drei knapp 0,30 $\mathrm{m}$ hohe Stufen zu überwinden war. Nördlich von Querraum 2-4 und Raum 5 entstand durch die Anlage des Kanals, der das Gebäude vor der Staunässe des anstehenden Abhanges schützen sollte, ein 1,81 m breiter, überdachter Bauwich, dessen lichte Höhe nunmehr mit 4,82 $\mathrm{m}$ zu rekonstruieren ist.

Durch die Errichtung zentraler Stützen in den Räumen 5 und 6 während der Bauphase 2 ist die lichte Raumhöhe in Raum 5, in welchem die dorische Säule (H 3,87 m) inklusive Plinthe und Basis (H zusammen $0,32 \mathrm{~m}$ ) heute noch erhalten ist, schließlich mit 5,09 $\mathrm{m}$ zu bemessen ( $\mathrm{H}$ des rekonstruierten dorischen Kapitells 0,23 m). Es entstand spätestens in diesem Zusammenhang ein Obergeschoss mit einer lichten Höhe von 3,12 m. Für Raum 6 sind ähnliche Raumhöhen anzunehmen, im Detail aber nicht zu belegen.

316 Einer noch von Miltner 1959, 290 postulierten Hypäthral-Lösung des `Hestiasaales` widersprach bereits W. Alzinger, Tagebucheintrag vom 18. 8. 1963 mit guten Gründen (später auch veröffentlicht: Alzinger 1972-1975, 241-249). Im >Hestiasaal gibt es nachweislich keine Möglichkeit, das unerwünschte Niederschlagswasser abzuführen. Ein dem Regen ausgesetzter Saal wäre als Versammlungs- und Bankettraum zudem völlig ungeeignet.

317 Cf. auch M. Steskal, Kapitel VII.3.2. 


\title{
IV STRATIGRAFISCHER BEFUND
}

\author{
(Martin Steskal)
}

\section{IV.1 Vorbemerkung}

Aufgrund der zahlreichen Grabungen, die vor allem in den 1950er und 1960er Jahren im Areal des Prytaneions durchgeführt worden waren (Taf. 16), verblieben nur noch wenige ungestörte Flächen für stratigrafische Untersuchungen. Zur Klärung der Nutzungsgeschichte und der Bauphasen des Prytaneions konnten aber dennoch in den Grabungskampagnen der Jahre 2007/2008 insgesamt sechs Sondagen angelegt werden ${ }^{318}$. Neben den Fragestellungen zu einem möglichen Vorgängerbau, den unterschiedlichen Nutzungsphasen, der Zerstörung, der Aufgabe und Nachnutzung des Gebäudes galt es, grundrisstypologische Probleme zu lösen.

Im Folgenden werden die Ergebnisse dieser Arbeiten dargestellt (Taf. 137) ${ }^{319}$.

\section{Sondagen-Übersicht}

\begin{tabular}{|c|c|c|}
\hline Schnittnummer & Raumnummer & Grabungsjahr \\
\hline $1 / 07$ & Vorhof & 2007 \\
\hline $2 / 07$ & Vorhof & 2007 \\
\hline $3 / 07$ & 'Hestiasaal & 2007 \\
\hline $4 / 07$ & $>$ Hestiasaak & 2007 \\
\hline $5 / 07$ & $>$ Hestiasaak & 2007 \\
\hline $1 / 08$ & Raum 3 & 2008 \\
\hline
\end{tabular}

\section{IV.2 Schnitt 1/07 (Taf. 138-140; Abb. 1)}

Um eine Datierung für die Errichtung der dorischen Vorhalle zu erhalten bzw. um einen potenziellen hellenistischen Vorgängerbau nachweisen zu können, wurde in der Nordostecke des Vorhofes eine 4,00 (NordSüd) $\times 2,25$ (Ost-West) $\mathrm{m}$ große Sondage angelegt ${ }^{320}$. Wie sich zeigte, war bereits bei den Ausgrabungen in den 1960er Jahren oder später ${ }^{321}$ eine 1,00 m breite Sondage entlang des Stereobats bis auf den gewachsenen Boden geführt (Taf. 16, 1) und wieder zugeschüttet worden, wodurch eine mögliche Baugrube nicht mehr nachzuweisen war. Von dieser Sondage gibt es keinerlei Dokumentation. Die bei der Anlage der Sondage entstandene Grube SE 117 (OK 45,40 m, UK 43,24 m) wurde mit der rezent gestörten Schicht SE 102 = SE 108 = SE 109 - wohl dem angefallenen Aushub - wieder verfüllt.

Die rezente Grasnarbe SE 101 = SE 103 (OK 45,31 m) fand sich bereits unter dem ursprünglichen Laufniveau, von dem sich im gesamten Vorhof keine Spuren erhalten haben. Über die ursprüngliche Gestalt dieses Nutzungshorizonts - insbesondere eine mögliche Pflasterung - kann daher nur gemutmaßt werden. Von einer kompakten Ausgleichsschicht unter der Grasnarbe (SE 104, OK 45,06-45,15 m) oder dem ur-

318 Kampagne 2007: An der vom 2. 6.-11. 8. 2007 dauernden Grabungskampagne nahmen neben dem Verf. in alphabetischer Reihenfolge teil: J. Eitler, N. M. High, A. Hochleitner, Ch. Kurtze, P. Mayrhofer, B. Stark. - Grabungskampagne 2008 (6. 7.-27. 7. 2008): N. M. High, D. Katzjäger, P. Mayrhofer, B. Stark. - Dokumentationskampagne 2009 (4. 5.-16. 5. 2009): L. Zabrana. - Allen Mitarbeiterinnen und Mitarbeitern sei herzlich für ihr großes Engagement gedankt.

319 Neben den Grabungsarbeiten wurden während der Kampagnen 2007-2009 die bereits in den 1950er und 1960er Jahren freigelegten Räume zur Unterstützung der Bauaufnahme nochmals großflächig gereinigt.

320 Cf. auch M. Steskal, Kapitel III.2.

${ }^{321}$ Der genaue Zeitpunkt der Anlage der Sondage war aufgrund fehlender Dokumentation nicht mehr zu eruieren. 
sprünglichen, nicht mehr erhaltenen Bodenniveau war an der Südseite der Sondage eine Grube gegraben worden (SE 118), um eine Ost-West orientierte Tonrohrleitung zu verlegen, die heute noch im Südprofil zu erkennen ist. Nach Installation der Leitung wurde die Grube mit SE 115 wieder aufgefüllt. Dieser Eingriff ist zwar mangels aussagekräftiger Funde absolut-chronologisch nicht zu datieren; relativ-chronologisch ist er aber nach der ersten Hälfte des 7. Jahrhunderts n. Chr. anzusetzen. Die Grube SE 118 stört nämlich wiederum eine ältere Ausrissgrube (SE 116), die beim Entfernen einer Tonrohrleitung angelegt worden war und von der noch ein Element im Westprofil der Sondage zeugt ${ }^{322}$. Sie wurde schließlich wieder mit dem angefallenen Aushub SE 105 $5^{323}$, einer Schicht aus lockerer Erde und wenigen kleinen Kalksteinen, verfüllt. Das Fundmaterial aus SE 105 datiert zwar in augusteische Zeit, da man die Grube in einen Horizont des ausgehenden 1. Jahrhunderts v. Chr. vertiefte und mit eben diesem Material wieder verfüllte; absolutchronologisch ist der Ausriss dieser Tonrohrleitung aber deutlich später anzusetzen, korrespondiert dieser Befund doch mit der Ausrissgrube SE 220 in Schnitt 2/07, deren Verfüllung SE $214^{324}$ aufgrund einiger weniger diagnostischer Stücke in die Mitte des 7. Jahrhunderts n. Chr. zu datieren ist.

Die in das ausgehende 1. Jahrhundert v. Chr. zu datierende Ausgleichsschicht SE $104^{325}$ schloss eine mächtige Schüttung horizontal ab, die vom Stylobat der Vorhalle aus bis an die Unterkante des aus fünf Kalksteinquaderlagen unter der Euthynterie bestehenden Stereobats (UK 43,44 m) eingebracht worden war: Es handelt sich dabei um die stark von Nord nach Süd abfallenden Straten SE 106 $6^{326}$, SE $107^{327}$ und SE $110^{328}$, Schichten aus rötlicher Erde mit zahlreichen kleinen Kalksteinen und Bruchstücken von Ziegeln und teilweise lehmigen Einschlüssen, die in das späte 1. Jahrhundert v. Chr., genauer noch in das letzte Jahrzehnt vor 0, weisen. In das jüngste dieser Terrassierungsstraten (SE 106) wurde eine heute noch gut erhaltene, Ost-West verlaufende Tonrohrleitung verlegt (SE 111) ${ }^{329}$. An der Unterkante der Tonrohrleitung wurde ein $53 \mathrm{~cm}$ breiter Steg belassen und die Sondage entsprechend verkleinert, um die Tonrohrleitung nicht entfernen zu müssen.

Unter den Terrassierungsschichten fand sich an der Unterkante des Stereobats ein fundleeres Stratum aus Kalksteinsplittern (SE 119), die von der Oberflächenbearbeitung der Kalksteinblöcke am Ende des 1. Jahrhunderts v. Chr. herrührten ${ }^{330}$. Unter zwei weiteren - und den zugleich ältesten - Planierungen (SE $112^{331}$ und SE $113^{332}$ ) aus dem ausgehenden 3. Jahrhundert v. Chr. wurde schließlich der sterile gewachsene Boden aus rötlicher, sehr kompakter Erde mit wenigen Kalksteinen angetroffen (SE 114, OK 42,82-43,15 m). Der gewachsene Boden - und somit das gesamte Terrain - fallen stark von Norden nach Süden ab; ein Phänomen, das im gesamten Gebäude nachzuweisen ist.

Es zeigte sich folglich: Das ursprüngliche Gelände des Vorhofes, das Planierungen über dem gewachsenen Boden aus dem ausgehenden 3. Jahrhundert v. Chr. aufwies, wurde nach der Errichtung des Stereobats und Stylobats der Vorhalle durch mächtige Aufschüttungen terrassiert. Die Analyse des Fundmaterials weist dieses Ereignis in das späte 1. Jahrhundert v. Chr., konkret in die letzte Dekade vor der Zeitenwende. Wie die Schüttrichtungen zeigen, erfolgten diese Aufschüttungen vom Stylobat der Vorhalle aus. Im Zuge der Terrassierungsarbeiten wurden auch Wasserinstallationen (Tonrohrleitungen) in die Schuttschichten verlegt, die zu einem späteren Zeitpunkt teilweise wieder entfernt, aber auch erneuert wurden. Von der Bearbeitung der Oberflächen der Kalksteinquader rührt eine Schicht mit Kalkkleinschlag her; die Ansichtsseiten der Quader wurden hingegen grob belassen. Ein mit dem Niveau der Euthynterie korrespondierender

322 Dm außen 20,5 cm, Dm innen 10,2 cm.

323 Cf. S. Ladstätter, Kapitel VI.1.6.1 (KatNr. K 703-752).

324 Cf. S. Ladstätter, Kapitel VI.1.6.4 (KatNr. K 783-794).

325 Cf. S. Ladstätter, Kapitel VI.1.3.1 (KatNr. K 140. 163. 321. 435).

326 Cf. S. Ladstätter, Kapitel VI.1.3.1 (KatNr. K 284. 323. 341. 412. 434. 478).

327 Cf. S. Ladstätter, Kapitel VI.1.3.1 (KatNr. K 134. 168. 193. 221. 226. 230. 235. 244. 296. 297. 322. 328. 371. 474. 477. 483.516. 547. 564. 602) sowie die beiden Münzen KatNr. M 1 (hellenistische Buntmetallmünze) und M 3 (nicht datierbare Buntmetallmünze).

328 Cf. S. Ladstätter, Kapitel VI.1.3.1 (KatNr. K 65. 117. 122. 134. 198. 206. 326. 368. 370. 487. 539).

329 Dm außen $17 \mathrm{~cm}$; entspricht Leitung SE 219 in Schnitt 2/07.

330 Eine kongruente Kleinschlagschicht aus Kalksteinsplittern an der Unterkante des Stereobats konnte 1960 in Sondage I sowie 1962 in Sondage XXXI nachgewiesen werden.

331 Cf. S. Ladstätter, Kapitel VI.1.2 (KatNr. K 53).

332 Cf. S. Ladstätter, Kapitel VI.1.2 (KatNr. K 7-12. 17-19. 22. 26. 27. 29. 35. 38. 39. 41-45. 47-50. 55). 
Nutzungshorizont des Vorhofes konnte nicht mehr nachgewiesen werden; dieser dürfte sich auf etwas höherem Niveau befunden haben. Ebenso waren auch keine hellenistischen Strukturen auszumachen, die ein voraugusteisches Gebäude in diesem Areal belegen würden. Funktion und Nutzen der frühhellenistischen Planierungen waren anhand der kleinräumigen Sondagen nicht zu klären ${ }^{333}$. Die Sondage wurde mit Erreichen des gewachsenen Bodens beendet und nach ihrer Dokumentation wieder zugeschüttet.

\section{Schnitt 1/07. Straten-Übersicht ${ }^{334}$}

\begin{tabular}{|c|c|c|c|c|}
\hline Schicht & OK (absolut) & UK (absolut) & Konsistenz/Interpretation & Farbe \\
\hline $\begin{array}{l}\text { SE } 101= \\
\text { SE } 103\end{array}$ & $45,31 \mathrm{~m}$ & $44,89-45,02 \mathrm{~m}$ & Rezente Grasnarbe & $\begin{array}{l}7.5 \mathrm{YR} 5 / 4^{6} \\
10 \mathrm{YR} 6 / 4\end{array}$ \\
\hline $\begin{array}{l}\text { SE } 102= \\
\text { SE } 108= \\
\text { SE } 109\end{array}$ & $45,40 \mathrm{~m}$ & $43,24 \mathrm{~m}$ & $\begin{array}{l}\text { Rezent gestörte Verfüllung der Sondage } \\
\text { SE } 117\end{array}$ & $\begin{array}{l}5 \mathrm{YR} 4 / 6 \\
7.5 \mathrm{YR} 5 / 4\end{array}$ \\
\hline SE 104 & $45,06-45,15 \mathrm{~m}$ & $44,86-44,96 \mathrm{~m}$ & $\begin{array}{l}\text { Ausgleichsschicht aus kompakter Erde mit } \\
\text { zahlreichen kleinen Kieselsteinen }\end{array}$ & $7.5 \mathrm{YR} 5 / 4$ \\
\hline SE 105 & $45,10 \mathrm{~m}$ & $44,42 \mathrm{~m}$ & $\begin{array}{l}\text { Lockere Erde mit wenigen kleinen Kalk- } \\
\text { steinen; Verfüllung der Ausrissgrube SE } \\
116\end{array}$ & 10YR5/4 \\
\hline SE 106 & $44,90-44,96 \mathrm{~m}$ & $44,35-44,96 \mathrm{~m}$ & $\begin{array}{l}\text { Sehr kompakte Erde mit zahlreichen klei- } \\
\text { nen Kalksteinen und Bruchstücken von } \\
\text { Ziegeln, Terrassierungsschicht }\end{array}$ & $7.5 \mathrm{YR} 5 / 6$ \\
\hline SE 107 & $44,35-44,98 \mathrm{~m}$ & $44,04-44,60 \mathrm{~m}$ & $\begin{array}{l}\text { Sehr kompakte, rötliche Erde mit zahl- } \\
\text { reichen kleinen Kalksteinen und Bruchstü- } \\
\text { cken von Ziegeln, Terrassierungsschicht }\end{array}$ & $5 Y$ Y 5/6 \\
\hline SE 110 & $44,04-44,60 \mathrm{~m}$ & $43,30-43,65 \mathrm{~m}$ & $\begin{array}{l}\text { Kompakte, rötliche Erde mit zahlreichen } \\
\text { kleinen Kalksteinen und Bruchstücken } \\
\text { von Ziegeln, lehmige Einschlüsse, Terras- } \\
\text { sierungsschicht }\end{array}$ & $5 Y R 4 / 6$ \\
\hline SE 111 & $44,42 \mathrm{~m}$ & - & Tonrohrleitung & $2.5 \mathrm{YR} 6 / 6$ \\
\hline SE 112 & $43,30-43,65 \mathrm{~m}$ & $43,10-43,40 \mathrm{~m}$ & Rötliche, lehmige Erde & $2.5 Y R 4 / 6$ \\
\hline SE 113 & $43,10-43,40 \mathrm{~m}$ & $42,82-43,15 \mathrm{~m}$ & Rötliche, kompakte Erde & $5 \mathrm{YR} 4 / 6$ \\
\hline SE 114 & $42,82-43,15 \mathrm{~m}$ & - & Gewachsener Boden & $5 \mathrm{YR} 4 / 6$ \\
\hline SE 115 & $45,10 \mathrm{~m}$ & $44,40 \mathrm{~m}$ & Verfüllung der Grube SE 118 & 10YR6/4 \\
\hline SE 116 & $45,10 \mathrm{~m}$ & $44,42 \mathrm{~m}$ & Ausrissgrube & - \\
\hline SE 117 & $45,40 \mathrm{~m}$ & $43,24 \mathrm{~m}$ & $\begin{array}{l}\text { Interface der Sondagenverfüllung SE } 102 \\
=\mathrm{SE} 108=\mathrm{SE} 109\end{array}$ & - \\
\hline SE 118 & $45,10 \mathrm{~m}$ & $44,40 \mathrm{~m}$ & $\begin{array}{l}\text { Grube zur Verlegung der Tonrohrleitung } \\
\text { im Südprofil }\end{array}$ & - \\
\hline SE 119 & $43,28-43,76 \mathrm{~m}$ & $43,20-43,76 \mathrm{~m}$ & Kalkkleinschlag & grauweiß \\
\hline
\end{tabular}

333 Größere ungestörte Flächen konnten aufgrund der zahlreichen Altgrabungen nicht mehr angetroffen werden. Cf. dazu den Sondagenplan Taf. 16.

334 Die Farbbestimmung richtet sich nach Munsell, Soil Color Charts (Edition 2000). 


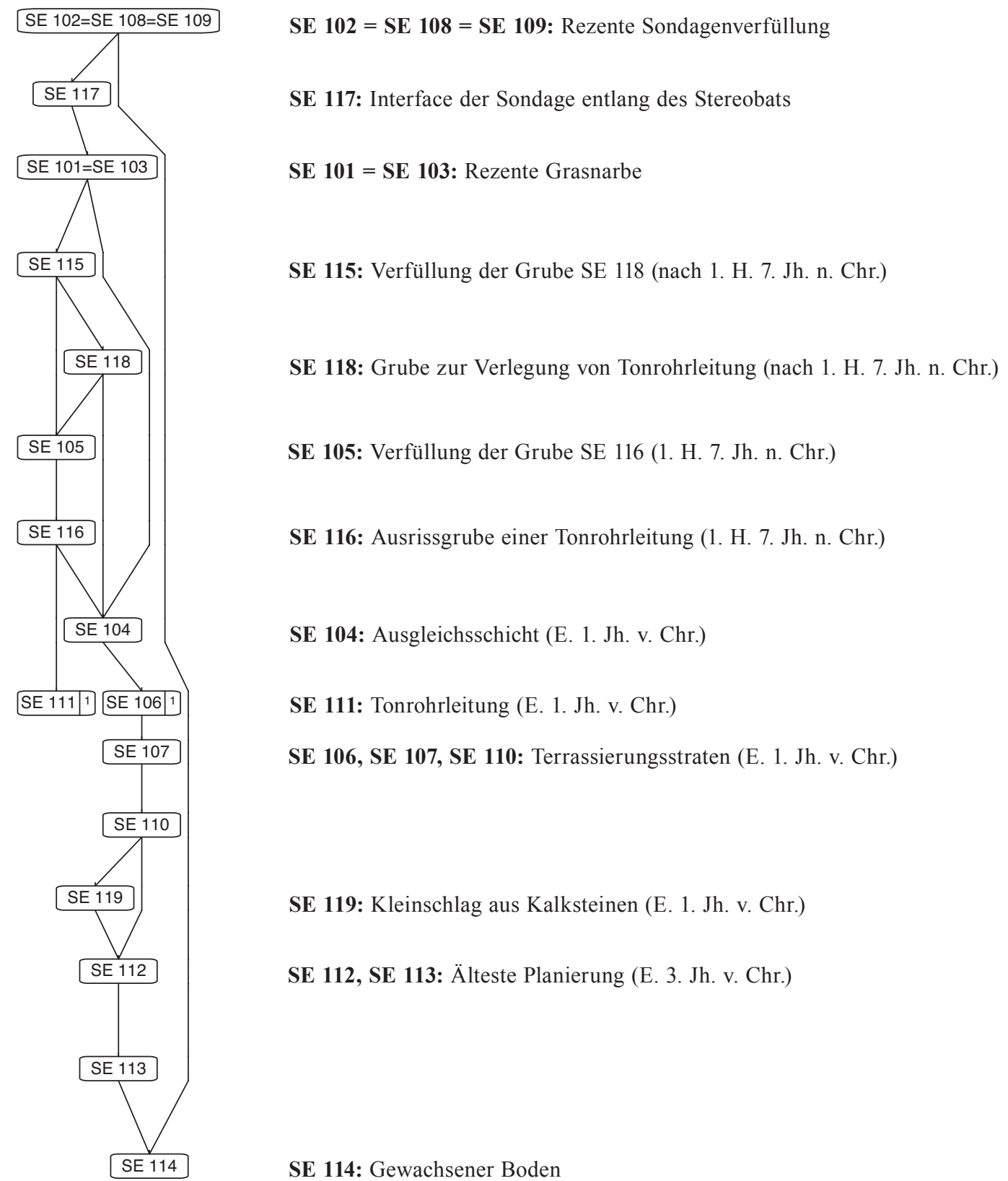


IV.3 Schnitt 2/07 (Taf. 141-143; Abb. 2)

Um die Errichtung der Triporticus des Vorhofes zeitlich einordnen zu können, wurde im Nordteil des östlichen Umgangs eine 4,00 (Nord-Süd) $\times 2,50$ (Ost-West) $\mathrm{m}$ große Sondage angelegt.

Unter der rezenten Grasnarbe (SE 201, OK 45,83-46,02 m) fand sich als jüngster antiker Horizont ein heterogenes Stratum (SE 203 ${ }^{335}$, OK 45,64-45,78 m), dessen geringes Sample an einordenbaren Fundstücken grob in augusteische Zeit weist und daher von geringer absolut-chronologischer Aussagekraft ist. Die Schicht, die als Nutzungshorizont oder Planierung zu interpretieren ist, wurde nämlich erst nach der Beraubung des darunterliegenden Marmorbodens angeschüttet und datiert daher wohl in spätantik/frühbyzantinische Zeit. In den unter SE 203 liegenden Kalkmörtelestrich SE 206 (OK 45,60-45,61 m) und eine ursprünglich wohl noch darüberliegende, im Bereich der Sondage aber nicht mehr erhaltene Schicht aus opus signinum wurde der bauzeitliche, heute nicht mehr vorhandene Marmorplattenboden der Umgänge versetzt. Dieses Nutzungsniveau korrespondiert mit der Errichtung der Ostwand der Triporticus, die ab diesem Niveau mit feinem Putzmörtel versehen ist. Im Fundament ist diese Mauer durch Kalkbruchsteine in grobem Kalkmörtelverband strukturiert ${ }^{336}$. Die Ostmauer wurde vom Temenos östlich des Prytaneions aus errichtet (cf. Taf. 24, 4). Eine Baugrube konnte daher in Schnitt 2/07 nicht nachgewiesen werden.

Vom ursprünglichen Marmorpaviment aus wurde in der Mitte des 7. Jahrhunderts n. Chr. eine Ausrissgrube zur Entfernung einer Tonrohrleitung angelegt (SE 220) ${ }^{337}$, von welcher noch zwei Elemente im Ost- und Westprofil der Sondage zeugen. Ein kongruenter Befund konnte mit der Ausrissgrube SE $116^{338}$ in Schnitt 1/07 nachgewiesen werden.

Unter der rezenten Grasnarbe fand sich auch ein sekundär angelegter, von Nordost nach Südwest verlaufender, ca. $25 \mathrm{~cm}$ tiefer und ca. $27 \mathrm{~cm}$ breiter Kanal (SE 204, Taf. 141, 2) mit Kanalwangen aus hochkant gestellten Kalksteinen, der in den unter dem östlichen Umgang Nord-Süd verlaufenden Kanal entwässerte. Wohl schon im 3. Jahrhundert n. Chr. wurde der Kanal wieder aufgegeben, wie das Fundmaterial der Kanalverfüllung SE $205^{339}$ (OK 45,69-45,70 m) nahelegt.

Mehrere horizontale Nutzungsniveaus, die im Zuge des Bauprozesses entstanden, und Planierungen zeugen schließlich von der Errichtung der Ostmauer des Vorhofes, die sukzessive mit der Terrassierung des Geländes hochgezogen wurde: Unter den annähernd horizontal abschließenden, heterogenen Planierschichten SE $207^{340}$, SE $208^{341}$ und SE $209^{342}$ aus dem Ende des 1. Jahrhunderts v. Chr. fand sich ein kurzfristig eingezogener Nutzungshorizont (SE $210^{343}$, OK 45,21 m), von dem aus der, unter dem östlichen Umgang NordSüd verlaufende Kanal angelegt wurde. In der Planierschicht SE 208 konnten zudem Elemente ehemaliger Tonrohrleitungen angetroffen werden, die in die Aufschüttung eingebracht worden waren.

335 Cf. S. Ladstätter, Kapitel VI.1.6.2 (KatNr. K 753-777).

336 Cf. M. Steskal, Kapitel III.2.

337 Tonrohrleitung: Dm außen 20,5 cm, Dm innen 10,2 cm. Die Verfüllung der Ausrissgrube SE 214 bestand aus lockerer Erde mit Fragmenten von Ziegeln (cf. auch SE 105 in Schnitt 1/07); S. Ladstätter, Kapitel VI.1.6.4 (KatNr. K 783-794).

338 Fundmaterial aus der Verfüllung dieser Grube (SE 105): S. Ladstätter, Kapitel VI.1.6.1 (KatNr. K 703-752).

339 Cf. S. Ladstätter, Kapitel VI.1.6.3 (KatNr. K 778-782).

340 Cf. S. Ladstätter, Kapitel VI.1.3.1 (KatNr. K 62-64. 66. 67. 70. 72. 77. 79-88. 103. 105. 106. 110. 111. 138. 142. 148.153 .175$. 176. 188. 191. 224. 237. 241. 259. 264-270. 300. 301. 305. 307. 309. 312. 331. 339. 372. 393. 403. 405. 436. 456. 457. 460.464. 475. 479. 500. 501. 503. 504. 506. 508. 511. 512. 514. 519. 530. 535. 542. 558. 568. 574. 576. 594-601. 606-609. 613-615. 621. 622. 626. 627.631. 632.635.643-648).

${ }^{341}$ Cf. S. Ladstätter, Kapitel VI.1.3.1 (KatNr. K 60. 61. 73. 89. 90. 112. 187. 282. 308. 432. 465. 510. 513. 592. 593. 611.625 .634$. 646).

${ }_{342}$ Cf. S. Ladstätter, Kapitel VI.1.3.1 (KatNr. K 68. 69. 71. 74-76. 78. 92. 107. 108. 135-137. 147. 202-204. 209. 227.263 .281$. 303-305. 310. 311. 392. 394. 395. 433. 449. 455. 461. 470. 482. 502. 507. 509. 515. 533. 541. 552. 567. 569-571. 573. $588-591$. 604. 605. 616. 619. 620.649) sowie die Münze KatNr. M 2 (hellenistische Buntmetallmünze).

${ }_{343}$ Cf. S. Ladstätter, Kapitel VI.1.3.1 (KatNr. K 91. 94. 99. 100. 109. 114. 115. 174. 192. 215. 242. 249. 261. 327. 330.400 .437 .438$. 491. 494. 498. 499. 505. 520. 528. 563. 572. 575. 584-587. 612. 617. 630. 650). 


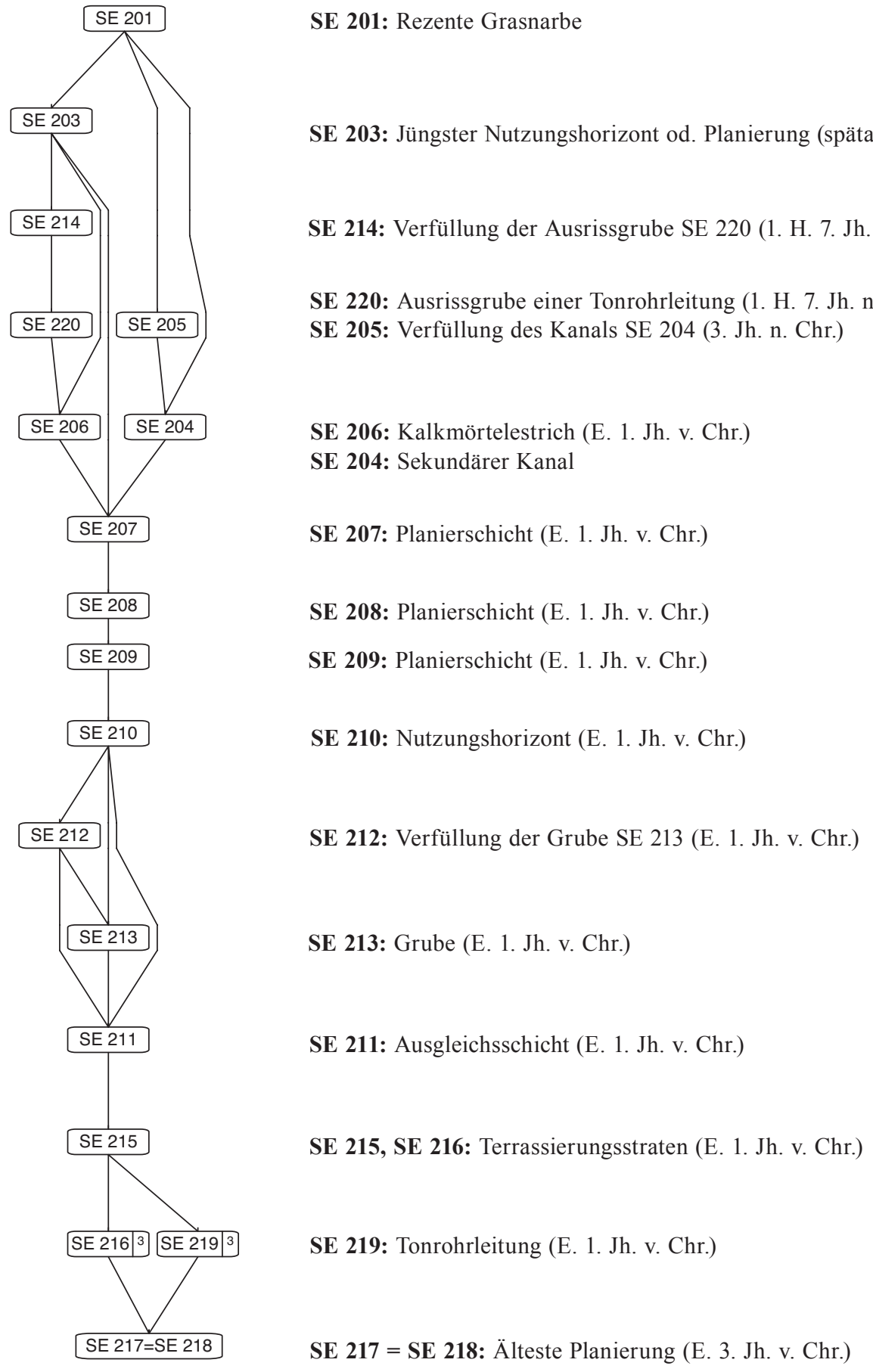

Abb. 2: Harris Matrix. Schnitt 2/07 
Schnitt 2/07. Straten-Übersicht

\begin{tabular}{|c|c|c|c|c|}
\hline Schicht & OK (absolut) & UK (absolut) & Konsistenz/Interpretation & Farbe \\
\hline SE 201 & $45,83-46,02 \mathrm{~m}$ & $45,64-45,89 \mathrm{~m}$ & Rezente Grasnarbe & $7.5 \mathrm{YR} 5 / 4$ \\
\hline SE 203 & $45,64-45,78 \mathrm{~m}$ & $45,60 \mathrm{~m}$ & $\begin{array}{l}\text { Heterogene Schicht aus lockerer Erde mit } \\
\text { Kalkmörtelbrocken und Fragmenten von } \\
\text { Ziegeln }\end{array}$ & $7.5 \mathrm{YR} 6 / 4$ \\
\hline SE 204 & $45,69-45,70 \mathrm{~m}$ & $45,44-45,56 \mathrm{~m}$ & Sekundärer Kanal & - \\
\hline SE 205 & $45,69-45,70 \mathrm{~m}$ & $45,44-45,56 \mathrm{~m}$ & $\begin{array}{l}\text { Kanalverfüllung aus lockerer, brauner } \\
\text { Erde }\end{array}$ & $7.5 \mathrm{YR} 5 / 4$ \\
\hline SE 206 & $45,60-45,61 \mathrm{~m}$ & $45,53-45,60 \mathrm{~m}$ & Kalkmörtelestrich & $2.5 \mathrm{Y} 7 / 3$ \\
\hline SE 207 & $45,53-45,60 \mathrm{~m}$ & $45,42-45,43 \mathrm{~m}$ & $\begin{array}{l}\text { Kompakte Erde mit wenigen kleinen Zie- } \\
\text { gelfragmenten und kleinen Kalksteinen, } \\
\text { Planierschicht }\end{array}$ & $7.5 \mathrm{YR} 5 / 3$ \\
\hline SE 208 & $45,42-45,43 \mathrm{~m}$ & $45,32-45,38 \mathrm{~m}$ & $\begin{array}{l}\text { Lockere, feine Erde mit Ziegelfragmenten, } \\
\text { Planierschicht }\end{array}$ & 10YR5/4 \\
\hline SE 209 & $45,32-45,38 \mathrm{~m}$ & $45,21 \mathrm{~m}$ & $\begin{array}{l}\text { Komprimierte, sandige Erde, Planier- } \\
\text { schicht }\end{array}$ & $2.5 \mathrm{YR} 5 / 4$ \\
\hline SE 210 & $45,21 \mathrm{~m}$ & $45,16 \mathrm{~m}$ & $\begin{array}{l}\text { Sehr kompakte Erde mit Kalkmörtelein- } \\
\text { schlüssen, Nutzungshorizont }\end{array}$ & $10 Y R 5 / 4$ \\
\hline SE 211 & $45,16-45,20 \mathrm{~m}$ & $44,93-45,05 \mathrm{~m}$ & $\begin{array}{l}\text { Ausgleichsschicht aus sandiger Erde mit } \\
\text { zahlreichen Fragmenten von Dachziegeln }\end{array}$ & $7.5 \mathrm{YR} 4 / 6$ \\
\hline SE 212 & $45,10 \mathrm{~m}$ & $44,89 \mathrm{~m}$ & $\begin{array}{l}\text { Lockere Erde, Verfüllung der Grube SE } \\
213\end{array}$ & $7.5 \mathrm{YR} 5 / 3$ \\
\hline SE 213 & $45,10 \mathrm{~m}$ & $44,89 \mathrm{~m}$ & Grube & - \\
\hline SE 214 & $45,55 \mathrm{~m}$ & $44,80 \mathrm{~m}$ & $\begin{array}{l}\text { Lockere Erde mit Fragmenten von Zie- } \\
\text { geln, Verfüllung der Grube SE } 220\end{array}$ & 7.5 YR5/4 \\
\hline SE 215 & $44,93-45,05 \mathrm{~m}$ & $44,90-44,91 \mathrm{~m}$ & $\begin{array}{l}\text { Lockere Erde mit Fragmenten von Ziegeln } \\
\text { und Kalkmörtelbrocken, Terrassierungs- } \\
\text { schicht }\end{array}$ & 10YR5/4 \\
\hline SE 216 & $44,90-44,91 \mathrm{~m}$ & $44,38 \mathrm{~m}$ & $\begin{array}{l}\text { Kompakte, rötliche Erde mit wenigen } \\
\text { kleinen Kalksteinen und Bruchstücken } \\
\text { von Ziegeln, lehmige Einschlüsse, Terras- } \\
\text { sierungsschicht }\end{array}$ & $7.5 \mathrm{YR} 4 / 6$ \\
\hline $\begin{array}{l}\text { SE } 217= \\
\text { SE } 218\end{array}$ & $45,85-45,90 \mathrm{~m}$ & $43,47-43,57 \mathrm{~m}$ & $\begin{array}{l}\text { Kompakte, rötliche Erde mit zahlreichen } \\
\text { kleinen Kalksteinen und Bruchstücken } \\
\text { von Ziegeln, lehmige Einschlüsse, Terras- } \\
\text { sierungsschicht }\end{array}$ & 7.5YR4/6 \\
\hline SE 219 & $44,64 \mathrm{~m}$ & - & Tonrohrleitung & $2.5 \mathrm{YR} 6 / 6$ \\
\hline SE 220 & $45,55 \mathrm{~m}$ & $44,80 \mathrm{~m}$ & Ausrissgrube & - \\
\hline
\end{tabular}

Unter einer dünnen Ausgleichsschicht aus sandiger Erde mit zahlreichen Fragmenten von Dachziegeln (SE 211344) konnten wiederum Aufschüttungsschichten festgestellt werden, die zur Terrassierung des Geländes dienten und bereits in Schnitt 1/07 nachgewiesen werden konnten. Auch die Unterkante der Ostmauer des Vorhofes ist in diese Aufschüttungsschichten gesetzt (UK 44,45 m). Es handelt sich um die heterogenen Straten SE $215^{345}$ und SE $216^{346}$ aus rötlicher Erde mit zahlreichen kleinen Kalksteinen und Bruchstücken

${ }_{344}$ Cf. S. Ladstätter, Kapitel VI.1.3.1 (KatNr. K 95. 96. 101. 104. 113. 116. 118. 121. 126. 128-130. 132. 133. 139. 141. 143-146. 149. 154-160. 162. 164-167. 169. 170. 172. 173. 178. 179. 182. 183. 185. 186. 190. 194-197. 199-201. 208. 209. 212-214. $217-219$. 223. 225. 228. 229. 231. 232. 236. 240. 246. 248. 250-253. 260. 261. 271. 273-275. 279. 280. 283. 285. 287. 291. 292. 295.299. 315-320. 332. 335. 343-346. 352. 353. 355. 357-361. 365. 366. 373. 374. 378. 389. 390. 396. 397. 401. 404. 406-411. 418.431. 439-441. 448. 452. 454. 458. 459. 462. 463. 466. 468. 469. 471. 473. 476. 480. 481. 484. 488. 490. 493. 495. 517. 518. 522. 523. 527. 529. 531. 532. 534. 536. 540. 543. 545. 546. 548-550. 555. 561. 562. 581-583. 610. 633. 636. 639. 640. 642). - Im südlichen Bereich der Sondage wurde im Zuge des Bauprozesses in Schicht SE 211 eine im Durchmesser 0,76 m große und 0,21 m tiefe Grube (SE 213, OK 45,10 m, UK 44,89 m) eingelassen, die mit lockerer Erde verfüllt war (SE 212), s. S. Ladstätter, Kapitel VI.1.3.1 (KatNr. K 306. 375. 413. 496. 497. 624).

345 Cf. S. Ladstätter, Kapitel VI.1.3.1 (KatNr. K 97. 131. 150. 152. 181. 184. 207. 220. 288. 290. 294. 363. 364. 376. 414. 415. 472. 521. 524. 551. 553. 566. 638. 641).

346 Cf. S. Ladstätter, Kapitel VI.1.3.1 (KatNr. K 93. 102. 119. 120. 123-125. 127. 151. 161. 171. 177. 180. 189. 205. 210.210 .211$. 
von Ziegeln und teilweise lehmigen Einschlüssen, die an das Ende des 1. Jahrhunderts v. Chr. datieren. In SE 216 wurde eine heute noch gut erhaltene, Ost-West verlaufende Tonrohrleitung verlegt (SE 219) ${ }^{347}$, die der Leitung SE 111 in Schnitt 1/07 entspricht. Bei SE $217=$ SE $218^{348}$ handelt es sich wiederum um die älteste Planierung des Geländes im ausgehenden 3. Jahrhundert v. Chr.

Die Aufschüttungsschichten wie auch die bauzeitlichen Nutzungsniveaus datieren nach Analyse des Fundmaterials in das späte 1. Jahrhundert v. Chr., konkret wiederum in das letzte Jahrzehnt vor 0. Entgegen früheren Meinungen gehört die Triporticus daher - wenn auch im Bauvorgang sekundär errichtet - der ursprünglichen, augusteischen Gesamtkonzeption des Prytaneions an. Wie in Schnitt 1/07 konnte eine Planierung aus dem ausgehenden 3. Jahrhundert v. Chr. über dem gewachsenen Boden nachgewiesen werden; architektonische Strukturen fanden sich jedoch auch an dieser Stelle nicht. Die Grabung wurde auf Höhe der Unterkante des Stereobats beendet (UK 43,47 m), ohne den gewachsenen Boden erreicht zu haben, und nach ihrer Dokumentation wieder zugeschüttet.

\section{IV.4 Schnitt 3/07 (Taf. 144-146; Abb. 3)}

Um eine Datierung für das Marmorplattenpaviment im `Hestiasaak zu gewinnen, wurde unmittelbar vor der Nordmauer des Raumes eine 3,00 (Nord-Süd) $\times$ 4,00 (Ost-West) $\mathrm{m}$ große Sondage angelegt ${ }^{349}$. Die Nordwestecke der Sondage erwies sich als bereits rezent gestört: Ein westlich der untersten Stufe der nach Norden führenden Treppe befindlicher Marmorquader, der als Spolie Teile einer auf dem Kopf stehenden Inschrift (IvE 740B) trägt, wurde bereits in den 1960er Jahren freigeputzt.

Unter der rezenten Grasnarbe (SE $301=$ SE 306, OK 46,37-46,44 m) und dem im Bereich der Sondage weitgehend nicht mehr erhaltenen Marmorplattenpaviment (SE 302, OK 46,47 m) - lediglich im Nordteil der Sondage lagen noch geringe Reste in situ - fand sich eine gut erhaltene Mörtelbettung aus opus signinum (SE 303, OK 46,35-46,45 m) sowie eine darunterliegende feine Schicht aus weißem Kalkmörtel (SE 308). Die Richtung Norden in den ehemaligen Querraum 2, 3 und 4 führenden Stufen wurden auf das originale Marmorplattenpaviment gesetzt; die Verlegung des Bodens und das Versetzen der Stufen erfolgten nachweislich in einem Bauvorgang. Der Estrich lag teilweise auf einer Fundamentschicht aus kleinteiligen Kalksteinen auf (SE 30450), die in eine wenige Zentimeter starke, fundleere Planierschicht aus kompakter Erde mit Einschlüssen von verbranntem Lehm (SE 305) gesetzt worden war. Teile des Estrichs wurden aber auch direkt auf den anstehenden Fels (SE 307, OK 46,05-46,36 m) aufgetragen. Unter der Planierschicht konnte schließlich ebenso der stark bearbeitete anstehende Fels festgestellt werden. Die bis zu $20 \mathrm{~cm}$ tiefen, kreisrunden Vertiefungen im Fels rühren unter Umständen von der Aufstellung eines Baugerüstes her. Das Fundmaterial der Planierschicht, das einen terminus post quem für die Errichtung des Marmorplattenpaviments bietet, weist nach eingehender Analyse in das späte 1. Jahrhundert v. Chr. ${ }^{351}$. Die Grabung wurde mit Erreichen des anstehenden Felsens beendet, die Sondage wieder zugeschüttet.

216. 222. 233. 234. 238. 239. 243. 245. 247. 254-258. 272. 276-278. 286. 288. 289. 293. 298. 302. 313. 314. 324. 325. 329.333. 334. 336-338. 340. 342. 347-351. 354. 356. 362. 367. 369. 377. 379-388. 391. 398. 399. 402. 416. 417. 419-430. 442-447. 450. 451. 453. 485. 486. 489. 492. 525. 526. 537. 538. 544. 554. 556. 557. 559. 560. 565. 577-580. 603. 618. 628. 629. 637); zudem fanden sich in dieser Schicht die beiden Münzen KatNr. M 4 (hellenistische Buntmetallmünze) und M 5 (nicht datierbare Buntmetallmünze).

347 Dm außen $17 \mathrm{~cm}$.

348 Cf. S. Ladstätter, Kapitel VI.1.2 (KatNr. K 1-6. 13-16. 20. 21. 23-25. 28. 30-34. 36. 37. 40. 46. 51. 52. 54. 56-59) sowie Münze KatNr. M 6 (nicht datierbare Buntmetallmünze). Das Stratum entspricht SE 112 und SE 113 in Schnitt 1/07.

349 Cf. auch M. Steskal, Kapitel III.4.

350 Cf. S. Ladstätter, Kapitel VI.1.3.2 (KatNr. K 652. 655. 657. 664).

351 Diese Datierung korreliert mit dem kontemporären Befund in der Sondage X an der Westwand des >Hestiasaales` aus dem Jahr 1961. 
Schnitt 3/07. Straten-Übersicht

\begin{tabular}{|c|c|c|c|c|}
\hline Schicht & OK (absolut) & UK (absolut) & Konsistenz/Interpretation & Farbe \\
\hline $\begin{array}{l}\text { SE } 301= \\
\text { SE } 306\end{array}$ & $46,37-46,44 \mathrm{~m}$ & $46,14-46,39 \mathrm{~m}$ & Rezente Grasnarbe & $\begin{array}{l}7.5 \mathrm{YR} 5 / 3 \\
7.5 \mathrm{YR} 4 / 5\end{array}$ \\
\hline SE 302 & $46,47 \mathrm{~m}$ & - & Originales Marmorplattenpaviment & weiß \\
\hline SE 303 & $46,35-46,45 \mathrm{~m}$ & $46,29-46,32 \mathrm{~m}$ & Estrich aus opus signinum & 5YR7/4 \\
\hline SE 304 & $46,28-46,31 \mathrm{~m}$ & $46,23-46,24 \mathrm{~m}$ & $\begin{array}{l}\text { Fundamentschicht aus kleinteiligen Kalk- } \\
\text { steinen }\end{array}$ & graublau \\
\hline SE 305 & $46,23-46,24 \mathrm{~m}$ & $46,05-46,12 \mathrm{~m}$ & $\begin{array}{l}\text { Planierschicht aus kompakter Erde mit } \\
\text { Einschlüssen verbrannten Lehms }\end{array}$ & $10 \mathrm{YR} 4 / 3$ \\
\hline SE 307 & $46,05-46,36 \mathrm{~m}$ & - & Anstehender Fels & - \\
\hline SE 308 & $46,29-46,32 \mathrm{~m}$ & $46,28-46,31 \mathrm{~m}$ & Kalkmörtelestrich & $10 Y R 6 / 3$ \\
\hline
\end{tabular}

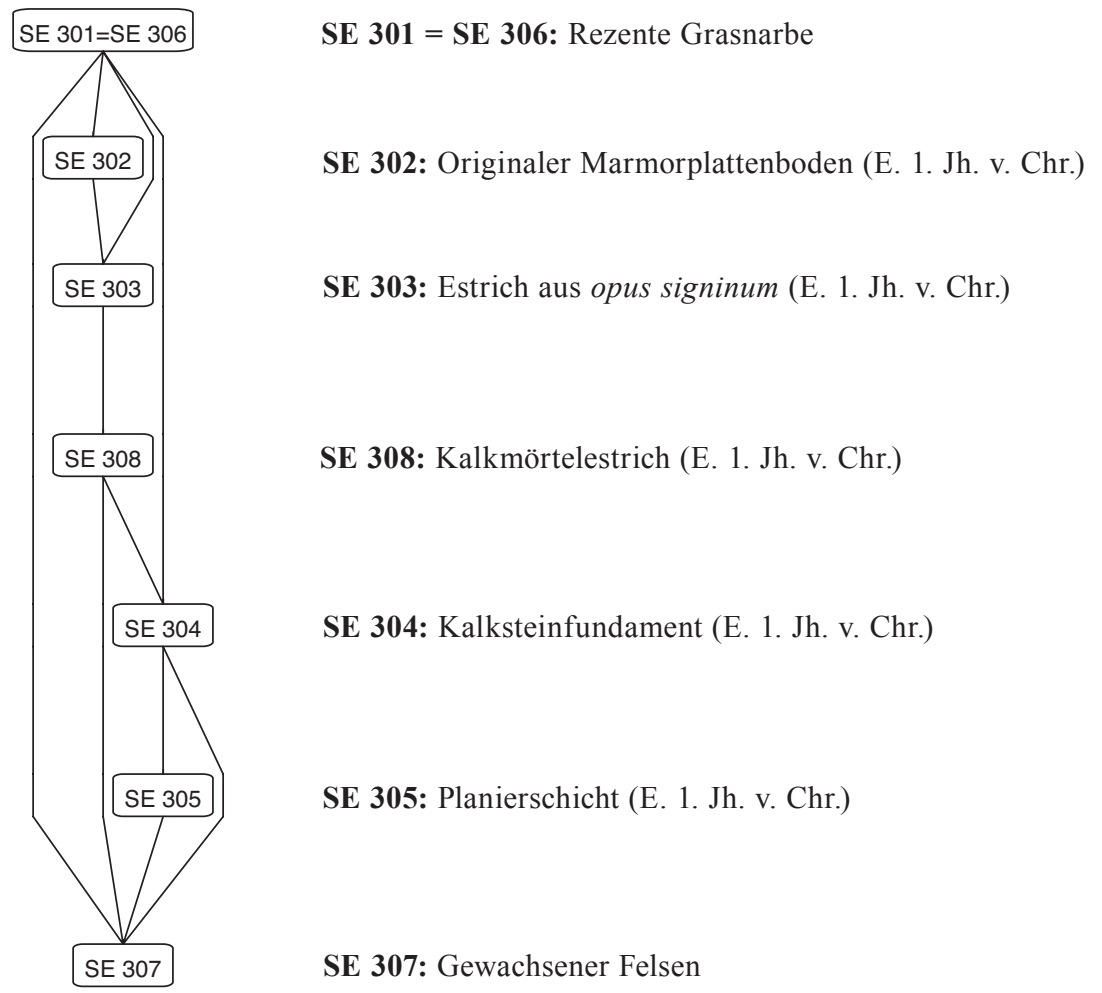

Abb. 3: Harris Matrix. Schnitt 3/07

\section{IV.5 Schnitt 4/07 (Taf. 147-149; Abb. 4)}

Um eine Datierung für das Marmorplattenpaviment im >Hestiasaak zu erhalten, wurde westlich des zentralen, quadratischen Fundaments eine 2,00 $\times 2,00 \mathrm{~m}$ große Sondage angelegt ${ }^{352}$.

Unter der rezenten Grasnarbe (SE $401=\mathrm{SE} 404$, OK 46,26-46,32 m) und der partiell noch vorhandenen Kalkmörtelbettung (SE 402353, OK 46,26-46,28 m) des im Bereich der Sondage nicht mehr erhaltenen Marmorplattenbodens fand sich - wie in Schnitt 3/07354 - eine Fundamentschicht aus kleinteiligen Kalksteinen (SE 403). Unter diesem Stratum konnte eine feine, aschige Planierschicht nachgewiesen werden (SE 405), die unmittelbar auf den gewachsenen Boden aufgetragen worden war (SE 408 = SE 409, OK 45,81-46,15 m).

352 Cf. auch M. Steskal, Kapitel III.4.

353 Cf. S. Ladstätter, Kapitel VI.1.3.2 (KatNr. K 651. 663. 665. 667).

354 Cf. SE 304. 
In den sterilen gewachsenen Boden war eine $71 \mathrm{~cm}$ tiefe Kalkgrube eingelassen (SE 407), aus der während des Bauvorgangs der zur Mörtelherstellung benötigte Kalk entnommen wurde. In den gewachsenen Boden, der leicht zu bearbeiten war, wurde auch das zentrale, quadratische Fundament, das wiederum einen $15 \mathrm{~cm}$ starken Fundamentvorsprung aus grob bearbeiteten Kalksteinblöcken (SE 410) aufweist, vertieft. Das Fundmaterial der Planierschicht SE $405^{355}$ und der Verfüllung der Kalkgrube (SE 406 $6^{356}$ ), das einen terminus post quem für die Errichtung des Marmorplattenpaviments bietet, weist in das späte 1. Jahrhundert v. Chr. Die Grabung wurde mit Erreichen des gewachsenen Bodens beendet und wieder zugeschüttet.

\section{Schnitt 4/07. Straten-Übersicht}

\begin{tabular}{|c|c|c|c|c|}
\hline Schicht & OK (absolut) & UK (absolut) & Konsistenz/Interpretation & Farbe \\
\hline $\begin{array}{l}\text { SE } 401= \\
\text { SE } 404\end{array}$ & $46,26-46,32 \mathrm{~m}$ & $46,25-46,28 \mathrm{~m}$ & Rezente Grasnarbe & $\begin{array}{l}5 \mathrm{YR} 5 / 3 \\
7.5 \mathrm{YR} 5 / 3\end{array}$ \\
\hline SE 402 & $46,26-46,28 \mathrm{~m}$ & $46,24-46,26 \mathrm{~m}$ & Kalkmörtelestrich & $2.5 \mathrm{Y} 8 / 1$ \\
\hline SE 403 & $46,24-46,26 \mathrm{~m}$ & $46,14-46,19 \mathrm{~m}$ & $\begin{array}{l}\text { Fundamentschicht aus kleinteiligen Kalk- } \\
\text { steinen }\end{array}$ & graublau \\
\hline SE 405 & $46,14-46,19 \mathrm{~m}$ & $46,12 \mathrm{~m}$ & Aschige Erde, Planierschicht & $7.5 \mathrm{YR} 4 / 3$ \\
\hline SE 406 & $46,12 \mathrm{~m}$ & $45,83 \mathrm{~m}$ & $\begin{array}{l}\text { Erde mit etwas Kalksplitt und Fragmenten } \\
\text { von Ziegeln, Verfüllung der Kalkgrube }\end{array}$ & $7.5 \mathrm{YR} 4 / 4$ \\
\hline SE 407 & $46,12 \mathrm{~m}$ & $45,83 \mathrm{~m}$ & Kalkgrube SE 407 & $2.5 Y 7 / 3$ \\
\hline $\begin{array}{l}\text { SE } 408= \\
\text { SE } 409\end{array}$ & $45,81-46,15 \mathrm{~m}$ & - & Gewachsener Boden & $2.5 \mathrm{YR} 3 / 4$ \\
\hline SE 410 & $46,25 \mathrm{~m}$ & - & $\begin{array}{l}\text { Vorsprung des zentralen, quadratischen } \\
\text { Fundaments }\end{array}$ & graublau \\
\hline
\end{tabular}

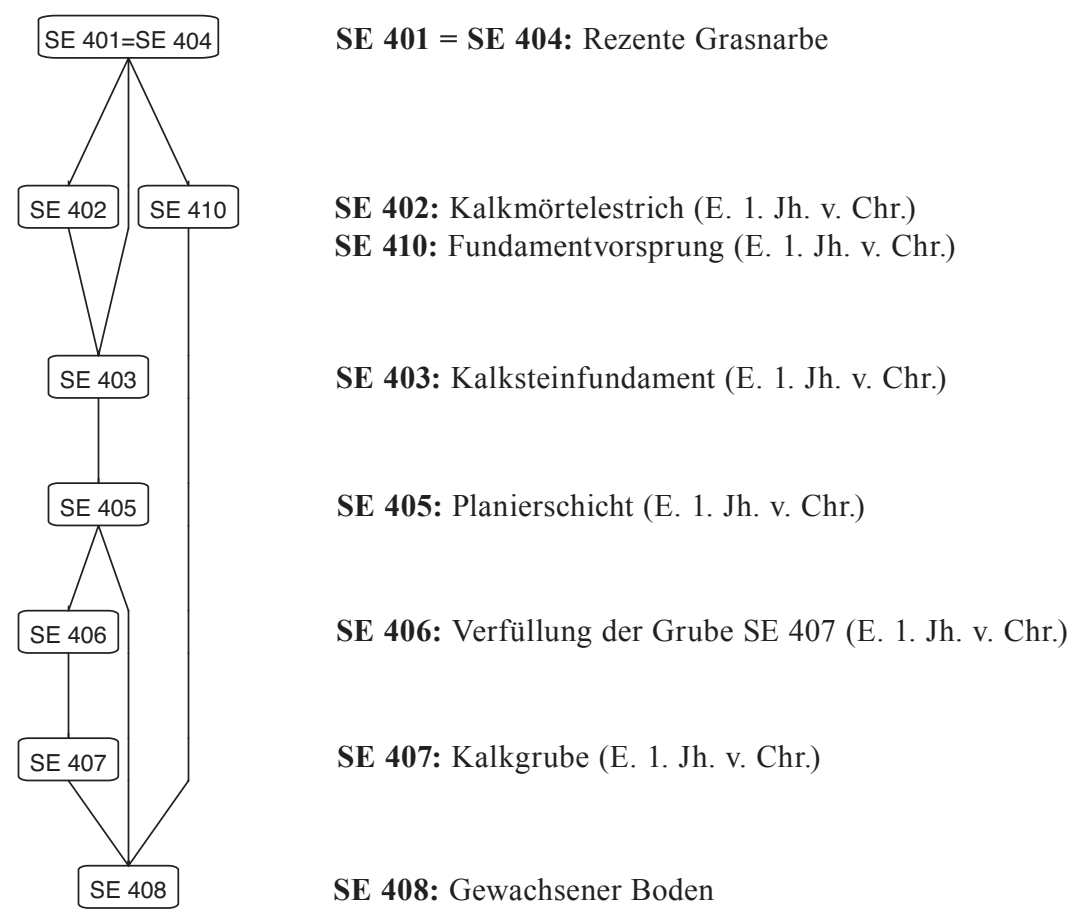

Abb. 4: Harris Matrix. Schnitt 4/07

355 Cf. S. Ladstätter, Kapitel VI.1.3.2 (KatNr. K 653. 660-662).

356 Cf. S. Ladstätter, Kapitel VI.1.3.2 (KatNr. K 654. 656. 658. 659. 666). 
IV.6 Schnitt 5/07 (Taf. 150-152; Abb. 5)

Um die sekundäre Unterkonstruktion von Sitzbänken im >Hestiasaak zeitlich einordnen zu können, wurde entlang der Ostmauer des Raumes eine 1,03 (Ost-West) $\times 1,80$ (Nord-Süd) $\mathrm{m}$ große Sondage angelegt ${ }^{357}$.

Unter dem sekundären Fußboden aus Fragmenten gebrannter Ziegel (SE 503, OK 46,57-46,64 m) konnte eine ca. 0,20 m hohe Aufschüttung aus lockerer, feiner Erde mit wenigen kleinen Kalksteinen festgestellt werden (SE 501 ${ }^{358}$ ), die unmittelbar auf den originalen Marmorplattenboden (SE 502, OK 46,34-46,36 m) aufgetragen worden war. Das Fundmaterial dieser Schicht, das einen terminus post quem für die Errichtung des Ziegelbodens sowie der Unterkonstruktionen bietet, weist nach eingehender Analyse in das zweite bzw. dritte Viertel des 3. Jahrhunderts n. Chr. Die Grabung wurde auf dem Niveau des Marmorplattenbodens beendet, die Sondage nach ihrer Dokumentation wieder zugeschüttet.

Schnitt 5/07. Straten-Übersicht

\begin{tabular}{|l|l|l|l|l|}
\hline Schicht & \multicolumn{1}{|c|}{ OK (absolut) } & \multicolumn{1}{|c|}{ UK (absolut) } & \multicolumn{1}{|c|}{ Konsistenz/Interpretation } & \multicolumn{1}{|c|}{ Farbe } \\
\hline SE 501 & $46,52-46,54 \mathrm{~m}$ & $46,34-46,36 \mathrm{~m}$ & $\begin{array}{l}\text { Aufschüttung aus lockerer, feiner Erde mit } \\
\text { wenigen kleinen Kalksteinen }\end{array}$ & 7.5 YR5/2 \\
\hline SE 502 & $46,34-46,36 \mathrm{~m}$ & - & Originales Marmorplattenpaviment & weiß \\
\hline SE 503 & $46,57-46,64 \mathrm{~m}$ & $46,52-46,54 \mathrm{~m}$ & $\begin{array}{l}\text { Sekundärer Boden aus Fragmenten ge- } \\
\text { brannter Ziegel }\end{array}$ & 7.5 YR6/3 \\
\hline
\end{tabular}

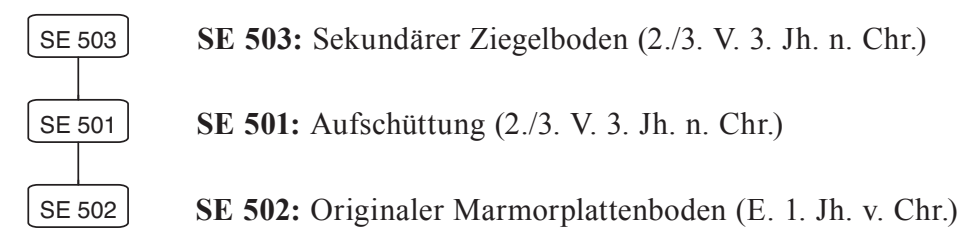

Abb. 5: Harris Matrix. Schnitt 5/07

IV.7 Schnitt 1/08 (Taf. 153-157; Abb. 6)

Schnitt 1/08 wurde angelegt, um die sekundäre Einrichtung eines Wasserreservoirs in den Räumen 3 und 4 klären zu können ${ }^{359}$. Dazu wurde im teilweise bereits bis auf das Bodenniveau freigelegten Raum 3 eine max. 3,25 (Ost-West) $\times$ 3,15 (Nord-Süd) $\mathrm{m}$ große Sondage angelegt.

Zunächst wurde in der Südwestecke des Raumes ein 1,18 $\times 1,80 \mathrm{~m}$ großes und 0,40 $\mathrm{m}$ hohes, rezentes Podest aus Bruchsteinen, Spolien und Ziegelbruchstücken abgetragen (OK 48,94 m), das den Ausgräbern der 1950er Jahre als Einstiegshilfe in diesen Raum gedient hatte. Unter der rezenten Schicht SE 601 (OK 48,58-48,80 m), die aus ehemaligem Aushubmaterial bestand, fand sich im Süden des Raumes der $1 \times 1,80 \mathrm{~m}$ große Rest eines Bodens aus fragmentierten gebrannten Ziegeln (SE 602, OK 48,41 m), der mit dem jüngeren Bodenniveau im Bereich der Pfeiler zwischen den Räumen 3 und 4 korrespondiert. Der Ziegelboden und die darunterliegende $0,65 \mathrm{~m}$ hohe, inhomogene Aufschüttung SE $603^{360}$ wurden zu einem Zeitpunkt eingebracht, da das Wasserreservoir bereits aufgegeben war. Seine Aufgabe datiert nach Analyse des Fundmaterials aus SE 603 in die Mitte des 7. Jahrhunderts n. Chr. Der Streufund einer Münze aus dem letzten Viertel des 8. Jahrhunderts n. Chr. in Raum 3 (KatNr. M 9) belegt eine Frequentierung des Areals bis zumindest in diese Zeit.

\footnotetext{
357 s. auch M. Steskal, Kapitel III.4.

358 Cf. S. Ladstätter, Kapitel VI.1.4 (KatNr. K 668-678).

359 s. auch M. Steskal, Kapitel III.8.

360 Cf. S. Ladstätter, Kapitel VI.1.5.1 (KatNr. K 681-702). Aus dieser Schicht stammen ferner zwei Buntmetallmünzen: KatNr. M 7 (337-340 n. Chr.) sowie KatNr. M 8 (395-401 n. Chr.).
} 
Unter der Aufschüttung lagen Reste des originalen Ziegelbodens des Wasserreservoirs (SE 604, OK $47,68 \mathrm{~m}$ ) aus 0,49 $\times 0,49 \times 0,05 \mathrm{~m}$ großen Ziegeln, deren Zwischenräume mit hydraulischem Estrich abgedichtet waren. An den Wänden selbst befand sich eine bis zu $5 \mathrm{~cm}$ starke Schicht aus opus signinum, das in Form einer Hohlkehle an den Ziegelboden anschloss. In der Südwestecke des Raumes gibt es auch heute noch eine $35 \mathrm{~cm}$ hohe und $35 \times 68 \mathrm{~cm}$ große Einfassung einer senkrechten Tonrohrleitung (OK 47,91 m; innerer Dm 9,5 cm, äußerer Dm $12 \mathrm{~cm}$ ), die außen mit opus signinum verstrichen ist, als Ausfluss des Wasserreservoirs diente und Wasser durch eine Öffnung in der Nordwand des \Hestiasaales`ableitete. Auf das Niveau des Wasserreservoirs führte eine zum Teil erhaltene Treppe in der Südwand von Raum 3. Über diese Treppe konnten der Ausfluss geschlossen oder geöffnet bzw. Revisionsarbeiten durchgeführt werden. Die Wasserentnahme im >Hestiasaak war wohl über einen Regler in Form eines Wasserhahns zu steuern ${ }^{361}$.

Unter dem nur noch in Teilen erhaltenen Ziegelboden des um 0,32-0,36 m vertieften und max. $1,78 \times 1,60 \mathrm{~m}$ großen Beckens (OK 47,32-47,36 m) fand sich eine bis zu 0,78 $\mathrm{m}$ hohe, kompakte und sehr feste Fundamentierung aus Kalksteinen in mit Ziegelmehl angereichertem Kalkmörtelverband (SE $605=$ SE $606=$ SE 607362). Diese Fundamentierung war bis auf den anstehenden Fels (SE 610, OK 46,58 m) geführt und beinhaltete zwei diagnostische Scherben einer Schale und eines Bechers, die ab dem späten 4. Jahrhundert n. Chr. verhandelt wurden.

Im Nordprofil kamen zwei Marmorblöcke (SE 608, OK 46,93 m) des ursprünglichen Bodenniveaus des Querraumes hinter der Nordwand des >Hestiasaales` (Räume 2, 3 und 4) zutage. Sie liegen auf einer dünnen, im Bereich der Sondage fundleeren Aufschüttung (SE 609), die ebenfalls auf dem stark bearbeiteten Fels SE 610 aufgetragen war.

Vom ursprünglichen Bodenbelag in diesem Raum hat sich nichts erhalten. In Richtung des Raumes 4 musste aber ein Niveauunterschied von $0,89 \mathrm{~m}$ mittels einer Treppe überwunden werden. Dazu wurde der Fels treppenförmig bearbeitet und außen verputzt.

Für die Einrichtung des Wasserreservoirs konnte nach Analyse des sehr geringen und daher nur bedingt aussagekräftigen Fundmaterials nur ein Zeitpunkt ab dem späten 4. Jahrhundert n. Chr. bestimmt werden. Dieser zeitliche Ansatz ist aber zumindst als terminus post quem für die Installation des Wassertanks und die Zumauerung der Nordwand des >Hestiasaales` zu verstehen.

Auf dem Niveau des anstehenden Felsens wurde die Grabung beendet.

\section{Schnitt 1/08. Straten-Übersicht}

\begin{tabular}{|c|c|c|c|c|}
\hline Schicht & OK (absolut) & UK (absolut) & Konsistenz/Interpretation & Farbe \\
\hline SE 601 & $48,58-48,80 \mathrm{~m}$ & $48,41 \mathrm{~m}$ & Ehemaliges Aushubmaterial & $5 Y R 5 / 2$ \\
\hline SE 602 & $48,41 \mathrm{~m}$ & $48,33 \mathrm{~m}$ & $\begin{array}{l}\text { Sekundärer Boden aus fragmentierten, ge- } \\
\text { brannten Ziegeln }\end{array}$ & $5 \mathrm{YR} 5 / 6$ \\
\hline SE 603 & $48,33 \mathrm{~m}$ & $47,68 \mathrm{~m}$ & $\begin{array}{l}\text { Aufschüttung unter sekundärem Ziegelboden aus } \\
\text { sandiger Erde mit zahlreichen Ziegelbruchstü- } \\
\text { cken, Mörtelbrocken und kleinen Steinen }\end{array}$ & 5YR6/1 \\
\hline SE 604 & $\begin{array}{l}47,68 \mathrm{~m} \\
\text { (Wasserreservoir) } \\
47,32-47,36 \mathrm{~m} \text { (Becken) }\end{array}$ & $\begin{array}{l}47,63 \mathrm{~m} \\
\text { (Wasserreservoir) } \\
47,22-47,27 \mathrm{~m} \text { (Becken) }\end{array}$ & Ziegelboden des Wasserreservoirs & $5 \mathrm{YR} 4 / 6$ \\
\hline $\begin{array}{l}\text { SE } 605= \\
\text { SE } 606= \\
\text { SE } 607\end{array}$ & $47,22 \mathrm{~m}$ & $46,58 \mathrm{~m}$ & $\begin{array}{l}\text { Fundament des Ziegelbodens aus Kalksteinen im } \\
\text { Kalkmörtelverband und opus signinum }\end{array}$ & $\begin{array}{l}5 \mathrm{YR} 5 / 5 \\
5 \mathrm{YR} 7 / 2 \\
5 \mathrm{Y} 5 / 1\end{array}$ \\
\hline SE 608 & $46,93 \mathrm{~m}$ & $46,70-46,71 \mathrm{~m}$ & $\begin{array}{l}\text { Marmorquader des bauzeitlichen Nutzungs- } \\
\text { niveaus }\end{array}$ & grauweiß \\
\hline SE 609 & $46,70-46,71 \mathrm{~m}$ & $46,58 \mathrm{~m}$ & $\begin{array}{l}\text { Ausgleichsschicht unter den Marmorquadern aus } \\
\text { Erde mit kleinen Kalksteinen, Ziegelsplitt und } \\
\text { Mörtelbrocken }\end{array}$ & $7.5 \mathrm{YR} 6 / 2$ \\
\hline SE 610 & $46,58 \mathrm{~m}$ & - & Anstehender Fels & - \\
\hline
\end{tabular}

\footnotetext{
361 Ähnliche sekundäre Wasserreservoirs sowie -entnahmestellen sind auch in den spätantik/frühbyzantinischen Bauten östlich des Prytaneions anzutreffen (cf. Raum 7; Taf. 158).

362 Cf. S. Ladstätter, Kapitel VI.1.5 (KatNr. K 679. 680).
} 


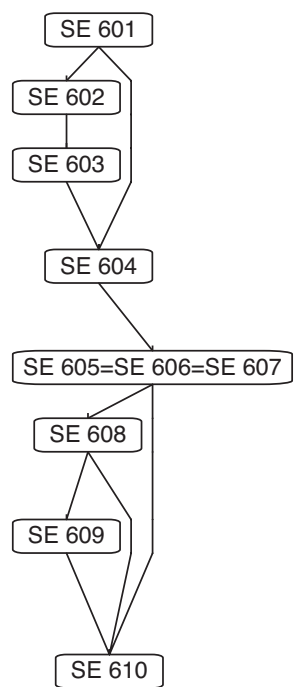

SE 601: Rezenter ehemaliger Aushub

SE 602: Sekundärer Ziegelboden (1. H./M. 7. Jh. n. Chr.)

SE 603: Aufschüttung unter sekundärem Ziegelboden (1. H./M. 7. Jh. n. Chr.)

SE 604: Boden des Wasserreservoirs (ab dem späten 4. Jh. n. Chr.)

SE 605 $=$ SE $606=$ SE 607: Fundament unter Boden des Wasserreservoirs (ab dem späten 4. Jh. n. Chr.)

SE 608: Marmorquader (E. 1. Jh. v. Chr.)

SE 609: Ausgleichsschicht unter Marmorquadern (E. 1. Jh. v. Chr.)

SE 610: Gewachsener Felsen

Abb. 6: Harris Matrix. Schnitt 1/08 



\title{
V BAUPHASEN UND CHRONOLOGIE
}

\author{
(Martin Steskal)
}

\section{V.1 Vorbemerkung}

Als Ergebnis der kontextuellen Analyse des stratigrafischen und architektonischen Befundes des Prytaneions können im Wesentlichen drei große Bauphasen unterschieden werden. Zusätzlich sind aber auch Baumaßnahmen zu konstatieren, die lediglich epigrafisch überliefert und nur mit Vorbehalt einer der großen Bauphasen zuzuordnen sind. Erschwert wird die definitive Zuweisung der jeweiligen Adaptierungen und Modifikationen durch die massiven Grabungsaktivitäten der 1950er und 1960er Jahre ohne entsprechende Dokumentation sowie durch den Umstand, dass bei der Neuuntersuchung nur noch wenige ungestörte Flächen für stratigrafische Grabungen zur Verfügung standen. Die großen Bauphasen sind daher zum Teil schwer, kleinere, nur punktuell lokalisierbare Interventionen kaum zu datieren. Die in den Jahren 2007-2009 gewonnenen Daten erlauben es in Verbindung mit den Ergebnissen der Altgrabungen aber dennoch, ein homogenes und stringentes Bild der Nutzungsgeschichte zu zeichnen.

Grundsätzlich liegen keine eindeutigen Erwähnungen öffentlicher Baumaßnahmen im Prytaneion nach seiner Errichtung vor. Die Bautätigkeit wurde wohl durch privates Mäzenatentum oder durch die einzelnen Prytanen selbst getragen, die Reparaturen und Renovierungen als zusätzliche Amtsverpflichtung übernehmen mussten ${ }^{363}$.

\section{V.2 Vornutzung}

In der umstrittenen Frage, ob es an der Stelle des Prytaneions einen hellenistischen Vorgängerbau gegeben haben könnte, konnten die abschließenden Ergebnisse der Untersuchungen W. Alzingers in den 1960er Jahren, der zu Beginn seiner Arbeiten noch von einem hellenistischen Vorgänger ausgegangen war $^{364}$, diese Meinung dann aber zu Recht änderte ${ }^{365}$, bestätigt werden: Die Existenz eines voraugusteischen Baus ist nicht nachzuweisen. Die zahlreichen Sondagen der 1960er (Taf. 16) und 2000er Jahre (Taf. 137) unter Bodenniveau zeigten einen im Wesentlichen unverbauten Platz, der lediglich hellenistische Aufschüttungen und Terrassierungen aufwies, die in das ausgehende 3. Jahrhundert v. Chr. datieren ${ }^{366}$.

Offenbleiben muss die Zeitstellung des zentralen Fundaments im Vorhof (Taf. 43. 44), auf dem später die >Große Artemisı-Statue (KatNr. SK 4) platziert wurde. Trotz erheblicher Bemühungen, diese Frage feldarchäologisch zu klären, konnte W. Alzinger die Stratigrafie in diesem Bereich nicht endgültig bewerten ${ }^{367}$; seine Eingriffe in diesem Bereich, konkret das Abtragen sämtlicher anlaufender Straten, machten zudem eine Nachuntersuchung unmöglich. So bleibt die Frage nach einer absoluten wie auch relativen Chronologie

363 Cf. St. Cramme, Die Bedeutung des Euergetismus für die Finanzierung städtischer Aufgaben in der Provinz Asia (ungedr. Diss. Universität Köln 2001) 115 f. 195.

364 Cf. Eichler 1962, 38-41; noch am Beginn der Grabungskampagne 1963 geht er von einem hellenistischen Vorgänger aus: W. Alzinger, Tagebucheintrag vom 14. 8. 1963.

365 Cf. Eichler 1964, 40, der Alzingers Ergebnisse in seinem Jahresbericht referiert, sowie später Alzinger 1970, 1646-1648; Alzinger 1974, 51-57; Alzinger 1972-1975, 241-249. Ihm folgt später auch Knibbe 1998, 113, während Miller 1978, 98-109 entgegen den veröffentlichten Grabungsergebnissen auf einem Vorgänger-Prytaneion insistiert. Aufgrund des Handbuchcharakters von Millers Publikation wird der nicht existente hellenistische Vorgänger bis heute rezipiert, so zuletzt von Schwarzer 2008, 124.

366 s. dazu S. Ladstätter, Kapitel VI.1.2 (KatNr. K 1-59); M. Steskal, Kapitel IV.2 und 3.

367 Cf. M. Steskal, Kapitel II.3 sowie Eichler 1963, 46. 
unbeantwortet. $\mathrm{Ob}$ das Fundament also schon vor der Errichtung des Prytaneions existiert hatte, wie es etwa D. Knibbe vermutete ${ }^{368}$, oder erst im Zuge seiner Anlage errichtet wurde, kann nicht mehr entschieden werden $^{369}$.

Ein Vorgänger-Prytaneion ist im Areal der augusteischen Anlage somit nicht nachzuweisen; die Lage des voraugusteischen Prytaneions von Ephesos, dessen Existenz vorausgesetzt werden kann, ist uns zum heutigen Zeitpunkt nicht bekannt ${ }^{370}$.

\section{V.3 Bauphase 1 - letztes Jahrzehnt vor 0}

Das Prytaneion von Ephesos wurde nach Auswertung der stratigrafischen Befunde der Jahre 2007/2008 in augusteischer Zeit, und zwar in der letzten Dekade vor der Zeitenwende ${ }^{371}$, errichtet (Taf. 159) ${ }^{372}$. Etwa in dieser Zeit wurden auch die ersten Kureteninschriften auf den Architekturgliedern der dorischen Ordnung angebracht ${ }^{373}$. Die Errichtung ist wohl als öffentliche Baumaßnahme zu verstehen, die in das Konzept der Etablierung eines Zentrums für Verwaltung, Kult und Repräsentation in dieser Zeit am oberen `Staatsmarkt< eingebunden war ${ }^{374}$. Durchaus vorstellbar ist, dass sich auch Privatpersonen am Bauvorhaben - vor allem an der Finanzierung - beteiligt hatten, wie dies P. Scherrer bereits ausführte, indem er italische Kaufleute oder kaiserliche Freigelassene als Stifter vermutete ${ }^{375}$. Die Errichtung des Vorhofes und des restlichen, nördlich davon gelegenen Gebäudes erfolgte wohl in zwei Baulosen, wobei die Gestaltung des Vorhofes die sekundäre Maßnahme darstellt. Da für den Bau des Prytaneions, insbesondere für die Aufstellung der dorischen Ordnung, ein Baukran nötig war, kann der Vorhof erst nach Abschluss der Arbeiten im nördlichen Teil des Gebäudes architektonisch ausgestaltet worden sein. Da aber auch schon mit der Errichtung der Basilike Stoa in spätaugusteischer Zeit (11 n. Chr.) $)^{376}$ ein Heranführen des Kranes kaum noch möglich war, ist aus bautechnischen Überlegungen ein terminus ante quem für die Bauarbeiten im Prytaneion gegeben. Dieser zeitliche Ansatz korreliert nun mit dem stratigrafischen Befund der Grabungen der Jahre 2007 und 2008, aber auch mit den Baugrubenbefunden des Jahres 1963 an den West- und Ostmauern in Raum 5 (Sondage XXXVII) und an der Ostmauer von Raum 6 (Sondage XXXVIII) ${ }^{377}$.

368 Knibbe - Langmann 1993, 11. 21; cf. auch Knibbe 1995, 143 f. 146 Anm. 8; Knibbe 1998, 113; Knibbe 1999, 451.

369 Cf. dazu die Auswirkungen auf die Funktion und Interpretation des Fundaments bei M. Steskal, Kapitel VIII.2.

370 H. Engelmann, Ephesische Inschriften, ZPE 84, 1990, 92-94 vermutete basierend auf IvE 859A aus dem Jahr 29 v. Chr. (ein gewisser Gaius Iulius Caesaris libertus stiftet einem Verein einen Geldbetrag für das jährliche Opfer an Roma und Artemis Ephesia am Herd der Hestia), dass das Prytaneion aufgrund des Fundortes der Inschrift bereits in voraugusteischer Zeit im Areal des `Staatsmarktes` gelegen haben müsste. Dem entgegnet Scherrer 2007, 68 zu Recht, dass die Inschrift nicht in Zusammenhang mit dem Prytaneion aufgestellt wurde, sondern im Kontext des Agons der Epheseia; s. dazu auch Scherrer 1997, 96. - Knibbe 1998, 112 deutet eine Lage im Bereich des Artemisions an, ohne dies aber belegen zu können.

371 s. dazu S. Ladstätter, Kapitel VI.1.3 (KatNr. K 60-667); M. Steskal, Kapitel IV.2-7.

372 Eine Datierung in augusteische Zeit, konkret um Christi Geburt, wurde von den Ausgräbern schon früh vermutet: Miltner 1956-1958, 33; Eichler 1962, 38-41; Eichler 1964, 40; Alzinger 1970, 1646-1648; Alzinger 1972-1975, 241-249; Alzinger $1974,51-57$.

373 Die ältesten im Gebäude verbauten Inschriften datieren in das frühe 1. Jh. n. Chr. (jeweils auf Säulentrommeln der dorischen Ordnung): Knibbe 1981, B 1 (IvE 1001). B 2 (IvE 1002) und B 3 (IvE 1003). Zu bedenken bleibt, dass nicht alle mit Kureteninschriften versehenen Bauglieder erhalten sind, somit auch durchweg noch ältere, unmittelbar in die Bauzeit des Gebäudes zu datierende Inschriften vorhanden gewesen sein können.

374 s. dazu grundlegend: Alzinger 1972-1975, 229-300.

375 Scherrer 2007, 69 f.; P. Scherrer, Von Apaša nach Hagios Theologos. Die Siedungsgeschichte des Raumes Ephesos von prähistorischer bis in byzantinische Zeit unter dem Aspekt der maritimen und fluvialen Bedingungen, ÖJh 76, $2007,335$.

376 E. A. Fossel-Peschl, Die Basilika am Staatsmarkt in Ephesos (Graz 1982); Alzinger 1974, 26-37; Alzinger 1972-1975, 87 f.; H. v. Hesberg, Die Basilika von Ephesos - die kulturelle Kompetenz der neuen Stifter, in: Berns - Hesberg - Vandeput - Waelkens 2002, 149-158; Ph. Stinson, Imitation and Adaptation in Architectural Design: Two Roman Basilicas at Ephesus and Aphrodisias, in: Meyer 2007, 91-100; M. Büyükkolanc1 - Ü. Yüğrük, Basilike Stoa, in: Scherrer 1995a, 82-84; Thür 2007, 82-84; G. A. Plattner - A. Schmidt-Colinet, Beobachtungen zu drei kaiserzeitlichen Bauten in Ephesos, in: Brandt - Gassner - Ladstätter 2005, 243-246; D. Knibbe - M. Büyükkolancı, Zur Bauinschrift der Basilica auf dem sog. Staatsmarkt von Ephesos, ÖJh 59, 1989, 43-45 sowie D. Knibbe - H. Englmann - B. İplikçioğlu, Neue Inschriften aus Ephesos XII, ÖJh 62, 1993, 148 f. Nr. 80 mit der nunmehr sicheren Datierung der Fertigstellung der Basilike Stoa im Jahr 11 n. Chr. (zuvor zwischen 4 und 14 n. Chr.), basierend auf der bilinguen Bauinschrift.

$377 \mathrm{Zu}$ letzteren Grabungen s. M. Steskal, Kapitel II.3. 
Von den bauzeitlichen Strukturen dieser augusteischen Phase haben sich bis heute erhalten: der Marmorsockel der Vorhalle und des \Hestiasaales` (Taf. 47, 1; 48; 50, 1; 51-53; 54, 1; 66; 68; 71; 73), das vor allem im >Hestiasaak noch gut erhaltene Mauerwerk aus opus vittatum (Taf. 71. 73), das Kalksteinquadermauerwerk in den Räumen 5 und 6 (Taf. 94-97; 103; 104, 1; 105; 107-109), das Marmorplattenpaviment im `Hestiasaak (Taf. 65, 2) sowie - nach ihrer Wiederaufstellung - die dorische Ordnung der Vorhalle (Taf. 45, 3; 56-62; 257). Entgegen früheren Meinungen ${ }^{378}$ erwies sich das ionische Peristyl des Vorhofes (Taf. 35. 36. 256), wie in den Schnitten 1/07 und 2/07 gezeigt werden konnte ${ }^{379}$, als bauzeitlich. In Bauphase 1a wurde es im Zuge einer Reparatur neu aufgestellt ${ }^{380}$.

\section{V.3.1 Bauphase $1 \mathrm{~A}-1 . / 2$. Jahrhundert N. Chr.}

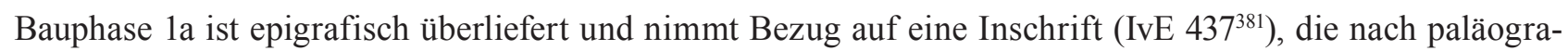
fischen Überlegungen grob in das 1./2. Jahrhundert n. Chr. datiert ${ }^{382}$. Die in dieser Inschrift belegte Stiftung von »14 Säulen samt Basen, Fries, Statuen und einem Tor« belegt eine erhebliche Reparatur bzw. einen völligen Neuaufbau des ionischen Peristyls des Vorhofes, der aber im Wesentlichen den bauzeitlichen Aufbau kopierte. Durch die vorgegebenen Aufschnürungen auf dem Stylobat (Taf. 35. 36. 256), der von dieser Neugestaltung nicht tangiert wurde, wie in den Schnitten 1/07 und 2/07 gezeigt werden konnte ${ }^{383}$, ist von der gleichen Rhythmisierung des architektonischen Aufbaus auszugehen. Der Grund für die beschriebene Baumaßnahme und Reparatur ist nicht gesichert, doch muss es erhebliche Beschädigungen gegeben haben, da nur so die massiven Eingriffe in das aufgehende Mauerwerk und die ionische Ordnung, die offenbar nötig waren, erklärt werden können. Es könnte sich in diesem Zusammenhang um eines der Erdbeben tiberischer Zeit (17 bzw. $23 \mathrm{n}$. Chr. $\left.{ }^{384}\right)$ gehandelt haben, dessen Spuren noch in claudischer Zeit im Stadtgebiet von Ephesos sichtbar waren. So waren auch zu dieser Zeit noch zahlreiche Devastierungen von Gebäuden durch Feuer oder Einsturz - expressis verbis auch von Tempeln - nachweisbar, wie aus dem Edikt des Prokonsuls Paullus Fabius Persicus hervorgeht (IvE 18b) ${ }^{385}$.

\section{V.3.2 BAUPHASE 1B - NACH 104 N. Chr.}

Ebenfalls epigrafisch überliefert ist Bauphase 1b: In IvE $1024^{386}$ ist zu erfahren, dass der Prytane Dionysodoros bald nach $104 \mathrm{n}$. Chr. Reparaturmaßnahmen am Gebäude durchführen ließ, nachdem sich lange Zeit niemand um die Renovierung des Gebäudes gekümmert hatte. Ihm wird auch die Einführung des Apollon Manteios-Kultes im Prytaneion zugeschrieben.

Da die Reparaturmaßnahmen nicht näher konkretisiert werden, können die einzelnen Aktivitäten nur schwer zugeordnet werden. Mit großer Wahrscheinlichkeit wurde aber in diesem Bauzusammenhang die in traianische Zeit zu datierende >Große Artemis`-Statue (KatNr. SK 4) auf dem zentralen Fundament des Vorhofes aufgestellt. Zu allen anderen im Folgenden aufgezählten Eingriffen gibt es keinen stratigrafischen Befund, wodurch sie auch alle erst in Bauphase 2 und somit im zweiten Viertel des 3. Jahrhunderts n. Chr. vorgenommen worden sein könnten. Allesamt deuten sie auf größere Beschädigungen an der Struktur des Gebäudes hin, die erhebliche Modifikationen bedingten.

378 Wie etwa Eichler 1962, 38-41 sowie Alzinger 1970, 1646-1648, der diese Meinung später modifizieren sollte.

379 Cf. M. Steskal, Kapitel IV.2 und 3.

380 Alzinger 1974, 51 deutet diese Bauabfolge und eine Existenz der Triporticus in Bauphase 1 bereits an. So sei das Peristyl seiner Meinung nach »ein Anbau späterer Zeit«, doch hätten »Tiefgrabungen an einigen Stellen ergeben, daß auch schon unter Augustus dieser Platz ähnlich gestaltet war.«

381 s. dazu J. Keil, Die Agora. Inschriften, in: FiE 3 (Wien 1923) 155; Keil 1939, 123; Miltner 1956-1958, 39 f. Anm. 41; Miltner 1959, 295 f.; Eichler 1965, 106; Alzinger 1970, 1646-1648; Miller 1978, 107 f.; Engelmann 1985, 155-157.

382 Mündliche Auskunft von H. Taeuber, dem herzlich gedankt sei. Alzinger 1972-1975, 241-249 datiert diese Inschrift aus paläografischen Überlegungen in das 3. Jh. n. Chr., ohne zu überzeugen.

383 Cf. M. Steskal, Kapitel IV.2 und 3.

384 Cf. S. Ladstätter, Die Chronologie des Hanghauses 2, in: Krinzinger 2002, 25; Karwiese 1995, 87; kritisch zu den Auswirkungen des Erdbebens von 17 n. Chr.: Knibbe 1998, $118 \mathrm{f}$.

385 Cf. Halfmann 2001, 36.

386 s. dazu Knibbe 1981, 165 f.; Engelmann 1985, 156 f.; cf. auch Halfmann 2001, 63. 
In Bauphase 1b (oder Bauphase 2) erfolgte ein weitgehender Neuaufbau der Westwand des `Hestiasaales`, indem man das ursprüngliche opus vittatum bis auf einen kleinen Bereich im Norden durch Mauerwerk aus opus testaceum ersetzte (Taf. 66. 67). Zugleich wurden die Nordwand der Vorhalle repariert und auch die zusätzlichen Eingänge in den `Hestiasaak (Tür 2 und 4; Taf. 52; 53; 54, 1) sowie eine Verbindung in das östlich angrenzende Temenos geschaffen (Taf. 50, 1; 51). Die wohl beträchtlichste optische Veränderung im Gebäude dürften die Baumaßnahmen an der Nordwand des 〉Hestiasaales〈 gewesen sein: Dort wurde die Archivolte des Keilsteinbogens abgearbeitet, ein Türsturz unterhalb des Bogenscheitels eingezogen und der Bereich unter dem Bogen bis zu den Türlaibungen abgemauert (Taf. 73. 258). Der Bogen verschwand daraufhin unter einer neuen Marmorverkleidung von der noch Eisenklammern im Mauerwerk der Nordwand wie auch der übrigen Wände des Raumes zeugen. Vielleicht ist dieser Phase auch eine Reparatur des Architravs der dorischen Ordnung (KatNr. A 7) zuzuordnen, der geklammert werden musste (Taf. 57, 1; 58, 3. 4).

\section{V.4 Bauphase 2 - zweites Viertel 3. Jahrhundert n. Chr.}

Die in das zweite Viertel des 3. Jahrhunderts n. Chr. zu datierende Bauphase 2 (Taf. 160) subsumiert Baumaßnahmen, die mit Sicherheit dieser Phase zuzuordnen sind, mitunter aber auch die Eingriffe, die in

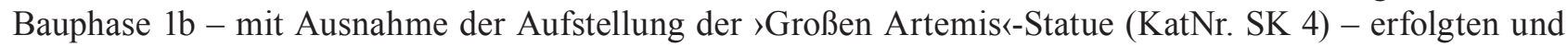
aufgrund fehlender eindeutiger Befunde nicht sicher von Bauphase 2 zu trennen sind. Als sicher in Bauphase 2 erfolgte Interventionen sind zu nennen: der Einbau der L-förmigen Sitzbänke im 〉Hestiasaak, von denen noch die partiell erhaltenen Unterkonstruktionen zeugen (Taf. 91), die Neuaufstellung der >Herzsäulen<, im Zuge derer neue attische Basen und Kompositkapitelle versetzt wurden (Taf. 75-85. 87), sowie die Verlegung eines polychromen Mosaiks in der Vorhalle (Taf. 64; 65, 1).

Das Fundspektrum aus Schnitt 1/05 - der einzigen Sondage, in der die Bauphase 2 noch stratigrafisch erfasst werden konnte, - datiert in die Zeit von 230-280 n. Chr. ${ }^{387}$. Eine genauere Eingrenzung dieser Datierung kann anhand stilistischer Kriterien und der Gesamtgestaltung der Dekorelemente der Kompositkapitelle im >Hestiasaak, der $>$ Herzkapitelle`, wie G. A. Plattner ausführt ${ }^{388}$, vorgenommen werden. Die Entwicklung des römischen korinthischen oder kompositen Kapitells ist in der Mitte des 2. Jahrhunderts prinzipiell abgeschlossen; eine exaktere Einordnung der Kapitelle innerhalb des durch die Grabungsbefunde eingegrenzten Zeitraumes im 3. Jahrhundert n. Chr. ist allein durch die Ornamentik daher nicht möglich. Wahrscheinlich ist jedoch, dass sie eher zu Beginn des in Frage kommenden Zeitraumes, also noch vor der Mitte des 3. Jahrhunderts n. Chr., hergestellt worden sind. Sie stehen damit in der Tradition (spät)severischer Architekturen. Zu nennen seien etwa typisch severische Stilphänomene an den Kapitellen wie das Auseinanderrücken von Dekorelementen, die in ihrer Form plumper und kantiger werden, oder der sägezahnartige Rand am Zwischenblatt. Eine Datierung der Bauphase in das zweite Viertel des 3. Jahrhunderts erscheint daher gerechtfertigt ${ }^{389}$.

Ein - allerdings nicht sicher - dem Prytaneion zuzuweisendes epigrafisches Zeugnis (IvE 3071) könnte eine weitere Baumaßnahme im Areal des Gebäudes in dieser Zeit belegen ${ }^{390}$ : In der Regierungszeit des Severus Alexander (222-235 n. Chr.) oder Maximinus Thrax (235-238 n. Chr.) hätte ein gewisser M. Aurelius Artemidorus Metrodorianus während seiner Prytanie den Weg zum Prytaneion (>Clivus sacer $)$ ) und eine >plateia< pflastern lassen. Bei der >plateia könnte es sich um den Vorhof des Prytaneions oder seine Säulenumgänge handeln. Endgültige Sicherheit ist hier aber nicht zu gewinnen. So widerspricht auch die Lesung der Herausgeber der Inschriften von Ephesos, R. Meriç, R. Merkelbach, J. Nollé und S. Şahin, diesen ört-

\footnotetext{
387 s. dazu S. Ladstätter, Kapitel VI.1.4 (KatNr. K 668-678); M. Steskal, Kapitel IV.6.

388 G. A. Plattner, Kapitel VII.4.1.2.

389 Eine Datierung dieser Bauphase in das 2. Viertel des 3. Jhs. n. Chr. wurde bereits im allerersten Vorbericht zu den Grabungen im Prytaneion von Miltner 1956-1958, 33 f. vorgeschlagen. Dieser Datierungsansatz wird in leicht modifizierter und erweiterter Form (1. Hälfte 3. Jh.) nochmals von Miltner 1959, 297 f. und Eichler 1962, 38-41 postuliert. W. Alzinger datiert diese Bauphase schließlich deutlich später und setzt sie in das 3./4. Jh. n. Chr.: Alzinger 1970, 1646-1648; Alzinger 1972-1975, 241-249; Alzinger 1974, 51-57; so auch Foss 1979, 80.

390 Cf. C. Schulte, Die Grammateis von Ephesos. Schreiberamt und Sozialstruktur in einer Provinzhauptstadt des römischen Kaiserreiches, Heidelberger althistorische Beiträge und epigrafische Studien 15 (Stuttgart 1994) 109.
} 
lichen Angaben ${ }^{391}$ : $\gg$ Die >plateia< ist wohl der Fahrweg Südgasse-Domitiansgasse-Embolos (= >Kuretenstraße <); die gepflasterte Straße ist die >obere Kuretenstraßeく vom Prytaneion bis zum Knick der >plateia an der Stelle, wo die Domitiansgasse auf den Embolos (die `Kuretenstraße $\measuredangle$ ) trifft; ...« Auch stratigrafisch ließ sich diese Baumaßnahme nicht nachweisen.

Inwieweit das gerade renovierte Prytaneion von dem starken Erdbeben des Jahres 262 n. Chr. ${ }^{392}$ getroffen wurde, ist schwer zu beurteilen. Ein eindeutiger stratigrafischer oder architektonischer Befund, der eine diesbezügliche Beschädigung belegen würde, konnte nicht festgestellt werden. Dass sich die Zerstörungen durch dieses Erdbeben nicht im gesamten Stadtgebiet als so verheerend erwiesen wie etwa im Hanghaus 2, konnte bereits am Beispiel des im Norden der Stadt gelegenen Vediusgymnasiums gezeigt werden ${ }^{393}$. Die noch wenige Jahre vor dem Erdbeben erfolgten Arbeiten am Gebäude belegen aber, dass die Einrichtung >Prytaneion < in dieser Zeit noch als so wichtig empfunden wurde, dass die Investitionen in das Gebäude als gerechtfertigt erschienen. In diesem Zusammenhang sind auch die anderen politischen Institutionen, nämlich die Volksversammlung ( $\delta \tilde{\eta} \mu \circ \varsigma)$ und der Rat ( $\beta o v \lambda \eta \tilde{)})$ zu nennen, die in Ephesos nachweislich bis weit in das 4. Jahrhundert existierten, wenngleich ihre Bedeutung seit traianischer Zeit zusehends geschwunden war ${ }^{394}$. Diesen kontinuierlichen Bedeutungsverlust teilen die beiden genannten Einrichtungen mit dem Prytaneion, das primär aufgrund seiner kultischen Funktionen über die Kaiserzeit hinaus überleben konnte.

\section{V.5 Aufgabe des Gebäudes - Mitte 4. Jahrhundert n. Chr.}

Die Aufgabe des ephesischen Prytaneions war, zumal das Gebäude in den 1950er Jahren bereits bis auf die kaiserzeitlichen Nutzungsniveaus ohne seriöse Dokumentation freigelegt worden war, feldarchäologisch nicht mehr zu fassen. Vieles deutet allerdings darauf hin, dass die Anlage im Zuge der Erdbebenereignisse in der Mitte des 4. Jahrhunderts n. Chr., konkret zwischen 358 und 368 ${ }^{395}$, beschädigt und danach nicht mehr instand gesetzt wurde ${ }^{396}$ :

Einen Einschnitt in der Geschichte des Prytaneions und zugleich einen Schlusspunkt stellt zweifellos das Verbot heidnischer Kultausübung durch Theodosius I. im Jahr 391/392 n. Chr. dar ${ }^{397}$. Spätestens mit diesem kaiserlichen Verbot war das Prytaneion seiner kultischen Funktionen entledigt und das Heilige Feuer, Пṽ@ ö $\varphi \theta \propto \varrho \tau o v$, am Herd der Hestia erloschen. Basierend auf den theodosianischen Gesetzen, die das Christentum zur Staatsreligion erhoben, und den nachfolgenden - angeblich systematischen - Zerstörungen paganer Monumente ${ }^{398}$ wurde von F. Miltner ${ }^{399}$ und später von W. Alzinger ${ }^{400}$ eine intentionelle Zerstörung der Anlage durch Christen vermutet. Dieser Konnex mit der theodosianischen Gesetzgebung wurde in der Folge verschiedentlich wiederholt oder zurückgewiesen ${ }^{401}$.

391 IvE 3071 ad Z. 22. - Scherrer 1995b, 19 Anm. 104 spricht in diesem Kontext von einem "pavement from the front of the Prytaneion«, ohne aber konkreter zu werden.

392 Zu dieser Erdbebenserie s. S. Ladstätter, Die Chronologie des Hanghauses 2, in: Krinzinger 2002, 26-29; St. Karwiese, Das Beben unter Gallien und seine anhaltenden Folgen, in: Lebendige Altertumswissenschaft. Festschrift Hermann Vetters (Wien 1985) 126-131; Knibbe 1998, 185, der dieses Erdbeben als »wichtige Zäsur in der langen Geschichte von Ephesos« bezeichnet.

393 M. Steskal, Stratigrafischer Befund, in: Steskal - La Torre 2008, 93.

394 Cf. Knibbe 1998, $196 \mathrm{f}$.

395 Zur Erdbebenserie in der Mitte des 4. Jhs. n. Chr. cf. Karwiese 1995, 127; S. Ladstätter, Die Chronologie des Hanghauses 2, in: Krinzinger 2002, 23-26. 29-31; Knibbe 1998, 197 sowie IvE 42, die einen Erlass der Kaiser Valentinian, Valens und Gratian an den procos. Asiae Eutropius beinhaltet, der sich auf diese Katastrophe bezieht.

396 So bereits Karwiese 1995, 131 f.; Scherrer 1995b, 19; D. Knibbe, Die zweite Kaiserneokorie und der Wandel des Erscheinungsbildes der Artemis Ephesia: Die Via Sacra in der Bildersprache ihres Polos?, in: Knibbe - Thür 1995, 96-99; Knibbe 1998, 197.

397 Cod. Theod. 16, 10, $10 \mathrm{f}$.

398 Cf. A. Demandt, Geschichte der Spätantike. Das Römische Reich von Diocletian bis Justinian 284-565 n. Chr. (München 1998) $106 \mathrm{f}$.

399 Miltner 1956-1958, 35 f.; Miltner 1958a, 100 f.; Miltner 1959, 309.

400 Eichler 1961, 68; Alzinger 1970, 1646-1648; Alzinger 1972-1975, 241-249; Alzinger 1974, 51-57.

401 So bezeichnete etwa Knibbe 1981, 165 f. die »endgültige Zerstörung« des schon zuvor durch Erdbeben beschädigten Prytaneions als »das Werk von fanatischen Christen«. - Gegen eine intentionelle Zerstörung durch Christen: Karwiese $1995,129$. 131 f.; Scherrer 1995b, 19; M. Büyükkolanc1 - Ü. Yüğrük, Prytaneion, in: Scherrer 1995a, 88. 
Die vor allem durch Kirchenschriftsteller ${ }^{402}$ immer wieder propagierte systematische Verwüstung oder Umweihung öffentlicher heidnischer Bauten und paganer Ausstattungselemente seit 391/392 n. Chr. wird in der jüngeren Forschung deutlich differenzierter gesehen ${ }^{403}$. Dies soll nicht ausschließen, dass es solche Devastierungen und Umweihungen auf ephesischem Stadtgebiet gegeben hat, wie das Beispiel des Christen Demeas zeigt, der eine Artemisstatue niederreißt, um sie durch ein Kreuz zu ersetzen (IvE 1351) ${ }^{404}$. Die Veränderung des ephesischen Stadtbildes infolge der fortschreitenden Christianisierung ist aber weniger auf die intentionelle Zerstörung paganer Monumente als vielmehr auf die extensive Nutzung von Spolien bereits zerstörter Gebäude zurückzuführen. Die Zerstörungen erfolgten oftmals schon zuvor durch Naturkatastrophen wie etwa Erdbeben. Die gründliche Beraubung des Baumaterials führte in vielen Fällen zur Demolierung von Bauwerken bis auf ihre Fundamente und zu ihrem vollständigen Verschwinden ${ }^{405}$. Die Beraubung des Baumaterials zerstörter Gebäude setzt einen entsprechenden Bedarf voraus: Laut den Vorschriften unter dem Titel De operibus publicis im >Codex Theodosianus ${ }^{406}$ wurde es in erster Linie zur Instandhaltung der öffentlichen Infrastruktur herangezogen ${ }^{407}$. So waren auch Neubauten nicht gestattet, solange noch beschädigte oder unfertige Gebäude existierten. Die Verwendung solcher Spolien charakterisiert die Bauweise der Spätantike.

Demnach ist auch für das Prytaneion anzunehmen, dass es im Zuge der Erdbebenserie in der Mitte des 4. Jahrhunderts beschädigt und danach nicht mehr aufgebaut wurde. Erste - wenn auch noch zögerlich umgesetzte - Verbote heidnischer Kulte unter Constantius, konkret seine beiden Edikte von 354 und 356 n. Chr. ${ }^{408}$, und die Aufforderung zur Schließung paganer Tempel scheinen den Schluss über ein natürliches Auslaufen der Institution >Prytaneion` nach den zu vermutenden Schäden durch die Erdbebenserie nahezulegen. Die erhaltene Struktur des Gebäudes lässt keine Reparatur mehr erkennen, die mit Sicherheit nach der Bauphase 2 erfolgt wäre. Spuren intentioneller Zerstörung, etwa durch Feuer oder mutwillige Devastierungen an der Ausstattung des Gebäudes, können augenscheinlich nicht nachgewiesen werden. In Verbindung mit der Tatsache, dass die Institution >Prytaneion ২ ihren Zenit zu dieser Zeit lange überschritten hatte, ist die Vermutung, dass das Gebäude zu dieser Zeit aufgegeben wurde, somit durchaus plausibel. Mit dem Jahr 391/392 n. Chr. ist zusätzlich eine definitive Grenze zu ziehen, die das Gebäude seiner zentralen Funktionen enthob. Bereits bald nach der Aufgabe des Gebäudes wird ein kontinuierlicher, aber zunächst noch verhaltener Abbau von Baumaterial begonnen haben, der sich über einen langen Zeitraum erstreckte. Die extensive Beraubung der Ruine erfolgte erst mit der Errichtung der \Kuretenhalle $<$ und der Renovierung der Scholastikiatherme in der ersten Hälfte des 6. Jahrhunderts n. Chr. ${ }^{409}$, im Zuge derer zahlreiche Bauglieder

402 Cf. etwa Rufinus in der Historia Ecclesiastica 2, 29, der berichtet, dass Bischof Theophilos von Alexandria im Auftrag von Theodosius I. sämtliche paganen Heiligtümer und Götterbilder Ägyptens zerstören ließ.

403 Cf. konkret zu Ephesos: Bauer 1996, 297, wonach »zeitlos gültige Standbilder, Niken, mythische Themen etc.« auch im spätantiken Stadtbild erhalten blieben; Ch. Roueché, The Image of Victory: New Evidence from Ephesus, in: Mélanges Gilbert Dagron, TravMem 14 (Paris 2002) 527-546; Ladstätter - Pülz 2007, 414-416; M. Steskal, Neuausstattung - Anfang 5. Jahrhundert n. Chr., in: Steskal - La Torre 2008, 310-312 sowie allgemein: O. Dally, »Pflege« und Umnutzung heidnischer Tempel in der Spätantike, in: Brands - Severin 2003, 97-114; G. Brands, Die spätantike Stadt und ihre Christianisierung, in: Brands - Severin 2003, 1-26 bes. 14-21.

404 s. dazu Knibbe 1998, 198. Ungeklärt bleibt der Aufstellungsort dieser Artemisstatue.

405 s. dazu Thür 2003, 259-273.

406 Cod. Theod. 15, 1.

407 s. dazu A. Demandt, Geschichte der Spätantike. Das Römische Reich von Diocletian bis Justinian 284-565 n. Chr. (München 1998) 372 f. - Besonders die Erdbebenserie in der Mitte des 4. Jhs. n. Chr. und die damit verbundenen Zerstörungen evozierten einen Bauboom in Ephesos für den nun ausreichend Baumaterial in Form von Spolien zur Verfügung stand; cf. Bauer 1996, 294; Karwiese 1995, 128-130; allgemein: F. W. Deichmann, Die Spolien in der spätantiken Architektur, SBMünchen (München 1975). Kritisch zur Erdbebenserie des 4. Jhs.: Foss 1979, 188-191.

408 Cod. Theod. 16, 10, 4 und 6; s. Knibbe 1998, 197.

409 s. dazu Waldner 2009a, 164-167. 207 f.; H. Thür, Die Ergebnisse der Arbeiten an der innerstädtischen Via Sacra im Embolosbereich, in: Knibbe - Thür 1995, 85. 90; Thür 1999, 115-117; H. Thür - W. Pietsch, Prozessionsstraße (Via Sacra) im Bereich Kuretenstraße/Heroa/Hadrianstor, ÖJh 66, 1997, Grabung 1996, 6-12; Thür 2003, 264 Anm. 36. - Cf. Miltner 1956-1958, 24; Alzinger 1970, 1619 f.; Bauer 1996, 24; Foss 1979, 70 mit der älteren, mittlerweile überzeugend widerlegten Datierung Ende 4. Jh. n. Chr. 
des Prytaneions als Spolien verbaut wurden ${ }^{410}$ (Taf. 12; 13, 1). W. Alzinger vermutete einen zeitlichen Konnex zur Zerstörung der benachbarten Basilike Stoa, die er um 500 n. Chr. ansetzte ${ }^{411}$.

Aus den angeführten Gründen ist eine Aufgabe des Gebäudes in der Mitte des 4. Jahrhunderts n. Chr. als sehr wahrscheinlich zu betrachten; bereits ab diesem Zeitpunkt wird das Prytaneion sporadisch als Steinbruch genutzt worden sein. Das Gebäude verwaiste zusehends und wurde in der ersten Hälfte des 6. Jahrhunderts als Lieferant für Baumaterial bei den großen Bauprojekten am unteren Embolos verwendet.

\section{V.6 Bauphase 3 - 5./6. Jahrhundert n. Chr.}

Bauphase 3 (Taf. 161) kann stratigrafisch aufgrund eines zu geringen Samples an aussagekräftigem Fundmaterial nur schwer bestimmt werden ${ }^{412}$. So gewähren die beiden einzigen datierbaren Stücke lediglich einen terminus post quem ab dem späten 4. Jahrhundert $\mathrm{n}$. Chr. Die Baugeschichte dieser Phase kann wie folgt skizziert werden:

Ab dem 5. Jahrhundert n. Chr. wurde das Gebäude massiv überformt und Teil eines Handwerksviertels, das sich zu dieser Zeit im Norden des >Staatsmarktes` etablierte. In diesem Zusammenhang wurde im schon stark beraubten Gebäude ein Wasserreservoir in den Räumen 3 und 4 eingerichtet (Taf. 115-125), das über eine Entnahmestelle im Norden des >Hestiasaales` verfügte (Taf. 125, 2). Im Zuge dieses Bauvorgangs wurde die Tür in der Nordwand des >Hestiasaales` vollständig unter Verwendung von Spolien, wie etwa des Torsos einer männlichen Ehrenstatue (KatNr. SK 10), abgemauert (Taf. 73). Ferner wurde eine Mauer zwischen den Räumen 2 und 3 aufgezogen (Taf. 124. 127) und die Tür zwischen den Räumen 4 und 5 verschlossen (Taf. 107. 108. 117). Im gesamten Gebäude wurden die Niveaus erhöht, wovon etwa die sekundäre Schwelle in Tür 4 zeugt (Taf. 54, 3), die eine Niveauerhöhung um 1,42 m im >Hestiasaal belegt. Im Kontext der Niveauerhöhungen wurden die Türen 1 und 2 (Taf. 29, 2; 52; 53, 1. 2; 69, 1) und der Haupteingang südlich des Vorhofes (Taf. 33) zugemauert. Als besonders massiv erweisen sich die Eingriffe in den Räumen 5 und 6, wo zunächst die Tür zwischen den Räumen 5 und 6 verschlossen wurde (Taf. 97. 103) und in die Westwände dieser Räume auf erhöhtem Niveau neue Türen in Richtung der westlich angrenzenden >Akademiegasser geschlagen wurden (Taf. 49. 94. 96. 104. 105). In Raum 6 wurde dazu auch im Westen des Raumes eine Rampe angelegt, die zur Tür in der Westwand führte (Taf. 25, 1; 100, 1). Der nördliche Bereich von Raum 5 wurde schließlich durch den Einzug einer Nord-Süd orientierten Mauer in zwei kleinere Raumkompartimente unterteilt (Taf. 107, 2; 109-112).

\section{V.6.1 Bauphase 3A - Mitte 7. Jahrhundert n. Chr.}

In Bauphase 3a, die nach Analyse des Fundmaterials aus Schnitt 1/08 in die Mitte des 7. Jahrhunderts n. Chr. datiert ${ }^{413}$, wurde das in Bauphase 3 installierte Wasserreservoir außer Funktion gesetzt, indem man einen Teil des Wassertanks aufschüttete; die Räume 3 und 4 wurden auf höherem Niveau aber weitergenutzt ${ }^{414}$. Dies trifft auch auf den >Hestiasaak zu, dessen Niveau nochmals um gut $60 \mathrm{~cm}$ erhöht wurde, wovon eine Verputzkante in der Nordwand des Raumes zeugt, die bereits über der nun funktionslosen Wasserentnahmestelle liegt (Taf. 73). Bis über die Mitte des 7. Jahrhunderts hinaus wurden aber nach wie vor Wasserleitungen, und zwar Tonrohrleitungen, im Areal des Prytaneions erneuert, wie im Vorhof gezeigt werden konnte $^{415}$. Eine fortgesetzte Nutzung des Gebiets nördlich des `Staatsmarktes`scheint somit belegt.

$410 \mathrm{Zu}$ den am unteren Embolos verbauten Baugliedern s. M. Steskal, Kapitel III.3 und VIII.3.

411 Cf. Alzinger 1970, 1646-1648; Alzinger 1972-1975, 299; Bauer 1996, 291.

412 s. dazu S. Ladstätter, Kapitel VI.1.5 (KatNr. K 679. 680); M. Steskal, Kapitel IV.7.

413 s. dazu S. Ladstätter, Kapitel VI.1.5.1 (KatNr. K 681-702); M. Steskal, Kapitel IV.7.

414 Es kann daher Foss 1979, 99. 103 nicht gefolgt werden, der annimmt, dass das Areal des \Staatsmarktes« schon am Beginn dieser »dunklen Jahrhunderte« völlig verlassen worden wäre. Es gibt auch keine Belege für ein generelles Verlassen des >Staatsmarktes< oder gar der ganzen Stadt Ephesos als Folge des Angriffes der Araber unter Muawija (654/655 n. Chr.) auf die ionischen Städte, wie dies mehrmals geäußert wurde, so von Karwiese 1995, 142 f.; St. Karwiese, Die Münzfunde aus dem sog. Sockelbau der Basilica von Ephesos, in: H. Emmerig (Hrsg.), Vindobona docet. 40 Jahre Institut für Numismatik und Geldgeschichte der Universität Wien 1965-2005, NumZ 113/114 (Wien 2005) 181-202.

415 Cf. Schnitt 1/07 und 2/07; M. Steskal, Kapitel IV.2 und 3. 
Eine letzte Frequentierung des Areals ist im letzten Viertel des 8. Jahrhunderts n. Chr. durch einen Münzfund belegt (KatNr. M 9).

\section{Übersicht der archäologisch nachweisbaren Fundkontexte (Sondagen 2007/08)}

\begin{tabular}{|c|c|c|c|c|c|}
\hline Raum & $\begin{array}{l}\text { Hellenistische } \\
\text { Terrassierung - } \\
\text { ausgehendes } \\
\text { 3. Jh. v. Chr. }\end{array}$ & $\begin{array}{l}\text { Bauphase } 1 \text { - } \\
\text { Ende 1. Jh. v. Chr. }\end{array}$ & $\begin{array}{l}\text { Bauphase } 2 \text { - } \\
\text { 2. Viertel 3. Jh. } \\
\text { n. Chr. }\end{array}$ & $\begin{array}{l}\text { Bauphase } 3 \\
\text { Einrichtung des } \\
\text { Wasserreservoirs - } \\
\text { 5./6. Jh. n. Chr. }\end{array}$ & $\begin{array}{l}\text { Bauphase 3a } \\
\text { Aufgabe des } \\
\text { Wasserreservoirs - } \\
\text { Mitte 7. Jh. n. Chr. }\end{array}$ \\
\hline $\begin{array}{l}\text { Vorhof } \\
\text { (Schnitt 1/07 } \\
\text { und 2/07) }\end{array}$ & $\begin{array}{l}\text { SE } 112 \\
\text { SE } 113 \\
\text { SE } 217=\text { SE } 218\end{array}$ & $\begin{array}{l}\text { SE } 104 \\
\text { SE } 106 \\
\text { SE } 107 \\
\text { SE } 110 \\
\text { SE } 111 \\
\text { SE } 119 \\
\text { SE } 206 \\
\text { SE } 207 \\
\text { SE } 208 \\
\text { SE } 209 \\
\text { SE } 210 \\
\text { SE } 211 \\
\text { SE } 212 \\
\text { SE } 213 \\
\text { SE } 215 \\
\text { SE } 216 \\
\text { SE } 219\end{array}$ & & & \\
\hline $\begin{array}{l}\text { >Hestiasaalk } \\
\text { (Schnitt 3/07, } \\
\text { 4/07 und 5/07) }\end{array}$ & & $\begin{array}{l}\text { SE } 302 \\
\text { SE } 303 \\
\text { SE } 304 \\
\text { SE } 305 \\
\text { SE } 308 \\
\text { SE } 402 \\
\text { SE } 403 \\
\text { SE } 405 \\
\text { SE } 406 \\
\text { SE } 407 \\
\text { SE } 410 \\
\text { SE } 502\end{array}$ & $\begin{array}{l}\text { SE } 501 \\
\text { SE } 503\end{array}$ & & \\
\hline $\begin{array}{l}\text { Raum } 3 \\
\text { (Schnitt 1/08) }\end{array}$ & & $\begin{array}{l}\text { SE } 608 \\
\text { SE } 609\end{array}$ & & $\begin{array}{l}\text { SE } 604 \\
\text { SE } 605=\text { SE } 606= \\
\text { SE } 607\end{array}$ & $\begin{array}{l}\text { SE } 602 \\
\text { SE } 603\end{array}$ \\
\hline
\end{tabular}




\section{FUNDE}

In den stratifizierten Kontexten im Areal des Prytaneions fanden sich an diagnostischen Fundstücken lediglich Objekte aus Keramik, Münzen und Fragmente von Architekturgliedern. Das Fehlen von Kleinfunden, Objekten aus Glas und anderem stellt somit kein Desiderat dar, sondern spiegelt lediglich das Fundspektrum der Grabungen 2007-2009 wider.

\section{VI.1 Keramik (Sabine Ladstätter)}

\section{VI.1.1 EINLEITUNG}

Die hier präsentierte Auswertung basiert auf 19106 diagnostischen Keramikfragmenten, die sich auf 30 stratigrafische Einheiten verteilen (Abb. 7) ${ }^{416}$. Sie wurden statistisch erfasst und grob klassifiziert, d. h. in Gattungen bzw. - wo möglich - Waren eingeteilt. Das Hauptaugenmerk bei der Bearbeitung lag auf einer zeitlichen Einordnung der einzelnen Fundkomplexe, wogegen keramologische Fragestellungen weitgehend unberücksichtigt blieben. Diese Vorgangsweise erklärt sich auch aus dem sehr heterogenen Fundbestand, der zudem meist aus Planierschichten geborgen wurde. Auf Basis der Befundanalyse konnten zahlreiche Straten zusammengefasst und drei große Bauphasen sowie eine Vor- und Nachnutzung definiert werden, darüber hinaus reflektieren einzelne Schichten individuelle Baumaßnahmen ${ }^{417}$. Von einer Aufnahme und Auswertung des Altbestandes wurde dagegen abgesehen, da aufgrund der damals vorherrschenden Grabungsmethodik keine geschlossenen oder gar homogenen Fundkomplexe zu erwarten waren ${ }^{418}$. Daraus erklärt sich aber auch der in Abb. 8 verdeutlichte Umstand, dass gerade aus den Zerstörungs- und Verfallszeiten des Gebäudes kaum bzw. überhaupt kein auswertbares Fundmaterial vorliegt und die jüngeren Bauphasen nur sehr allgemein chronologisch eingeordnet werden können. Die kontextuelle Analyse des keramischen Fundbestandes der Grabungen 2007/2008 ergab, dass ein Großteil des Materials aus der Bauzeit des Gebäudes stammt bzw. bauzeitlichen Schichten zuzuordnen ist. Für Bauphase 1 liegt mit 13303 Fragmenten ein äußerst umfangreicher Komplex vor, dagegen sind die Bauphasen 2 und 3 mit 136 bzw. 208 Stück deutlich unterrepräsentiert (Abb. 8). Ein deutlicher Anstieg ist dagegen erst wieder in der fortgeschrittenen Spätantike (686 Stück) zu beobachten, ein quantitativ auswertbares Spektrum (1 455 Stück) liegt auch für die deutlich vor dem Bau des Gebäudes anzusetzenden, hellenistischen Terrassierungsmaßnahmen vor. Die chronologische Zusammensetzung des keramischen Materials spiegelt sich auch eindrucksvoll im GesamtSigillataspektrum wider (Abb. 9). Auch hier dominieren mit der Eastern Sigillata A (ESA) und der Eastern Sigillata B (ESB) Waren des 1. Jahrhunderts v. bzw. n. Chr. Im ESB-Material fehlen beispielsweise jene ab flavischer Zeit charakteristischen Formen und Varianten, die den keramischen Markt in Ephesos über zwei Jahrhunderte dominierten ${ }^{419}$. Verschwindend klein ist auch der Anteil an spätantiken Sigillatagruppen, der sich auf die African Red Slip-Ware (ARS), die Late Roman C-Ware (LRC) sowie die Mäandertalsigillata verteilt.

\footnotetext{
416 Für die Aufnahme des keramischen Materials und die Mithilfe bei der statistischen Erfassung danke ich N. M. High, D. Katzjäger und vor allem L. Rembart. Bei der Einordnung der westlichen Sigillata war H. Sedlmayer behilflich. M. Lawall ist eine Durchsicht des Amphorenmaterials zu verdanken.

417 M. Steskal, Kapitel V.

418 Zur Grabungsgeschichte des Prytaneions s. M. Steskal, Kapitel II.

419 Ladstätter 2008, 98; Ladstätter 2010, 179-183.
} 


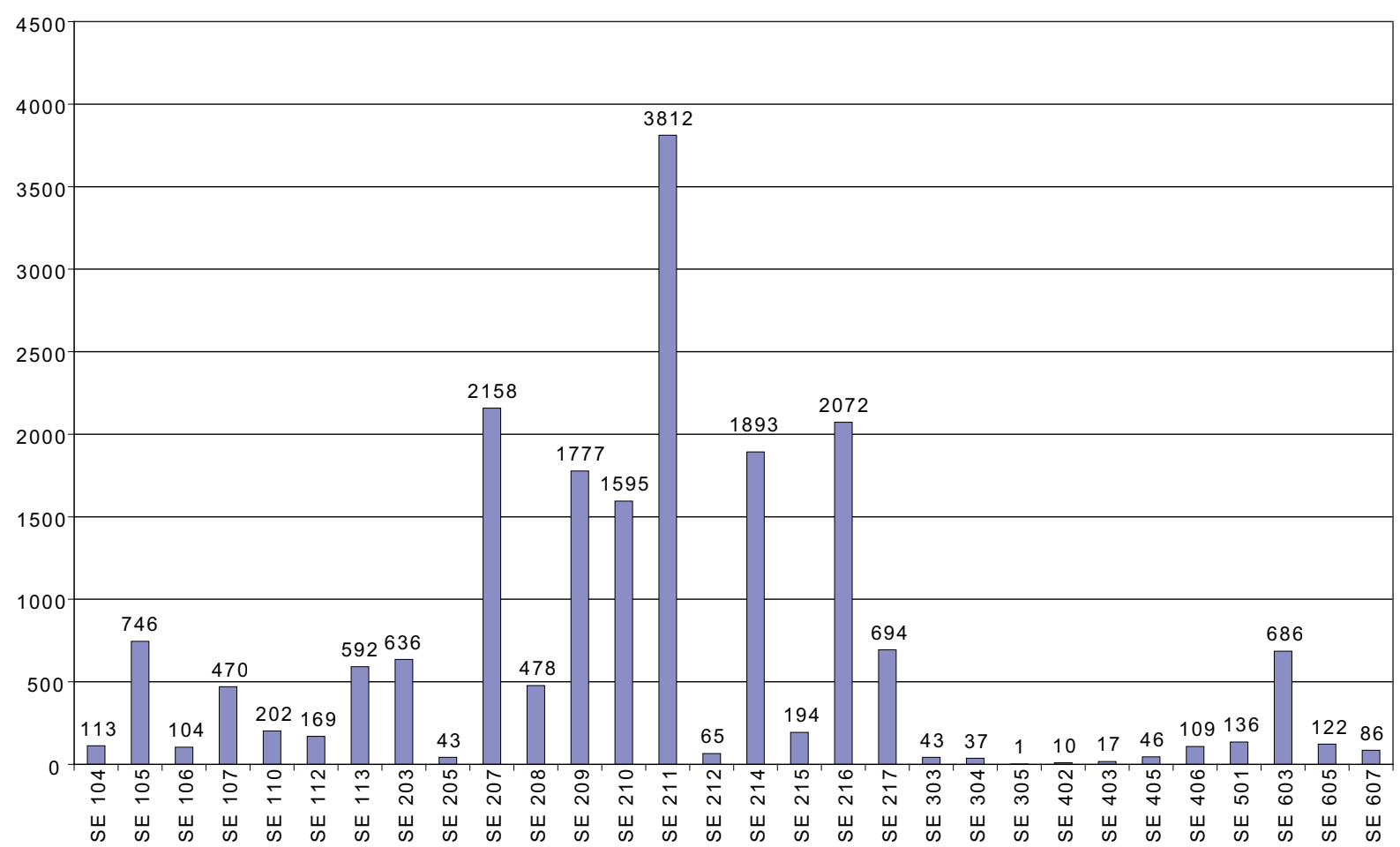

Abb. 7: Scherbenanzahl pro stratigrafischer Einheit

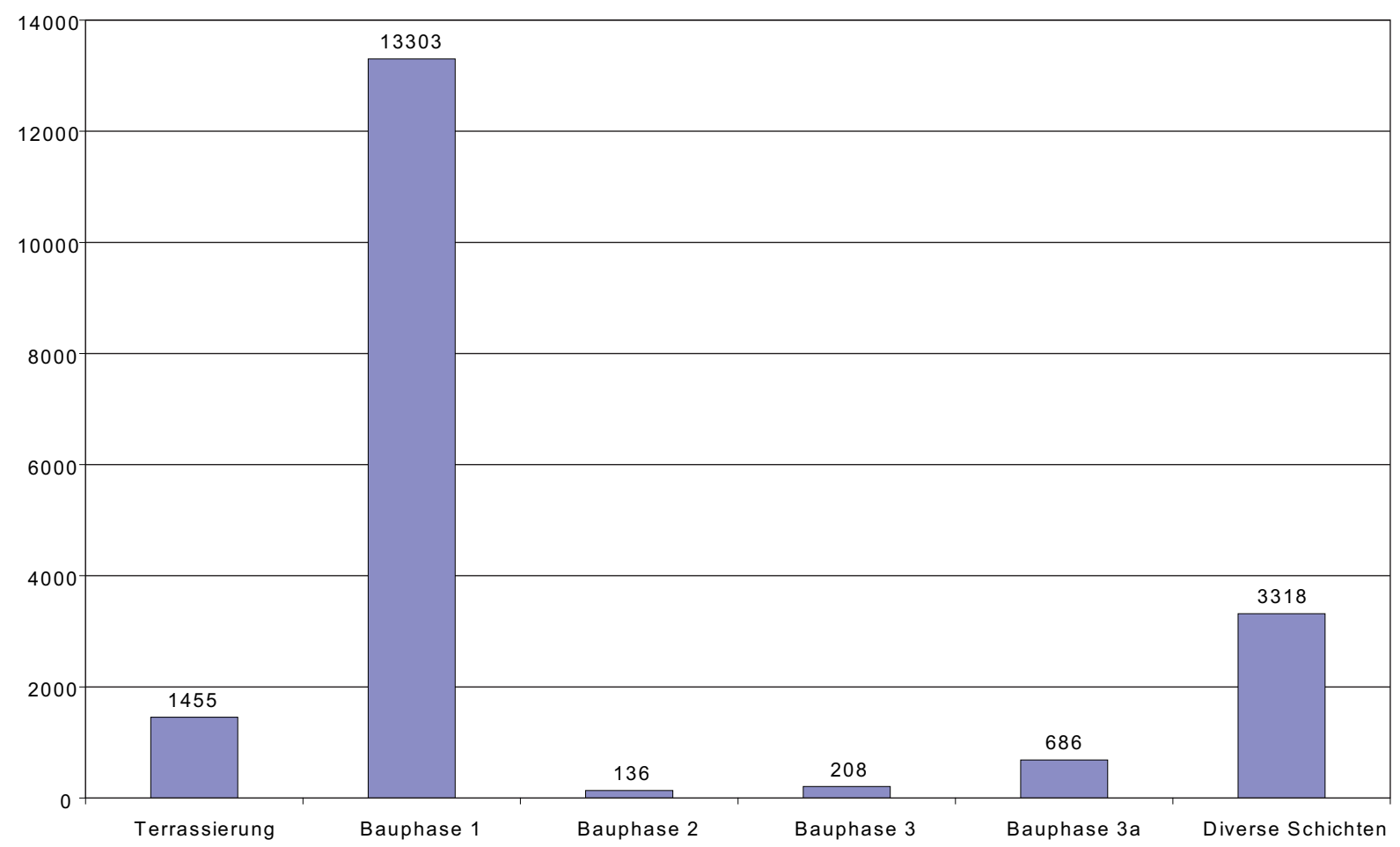

Abb. 8: Scherbenanzahl pro Bauphase 


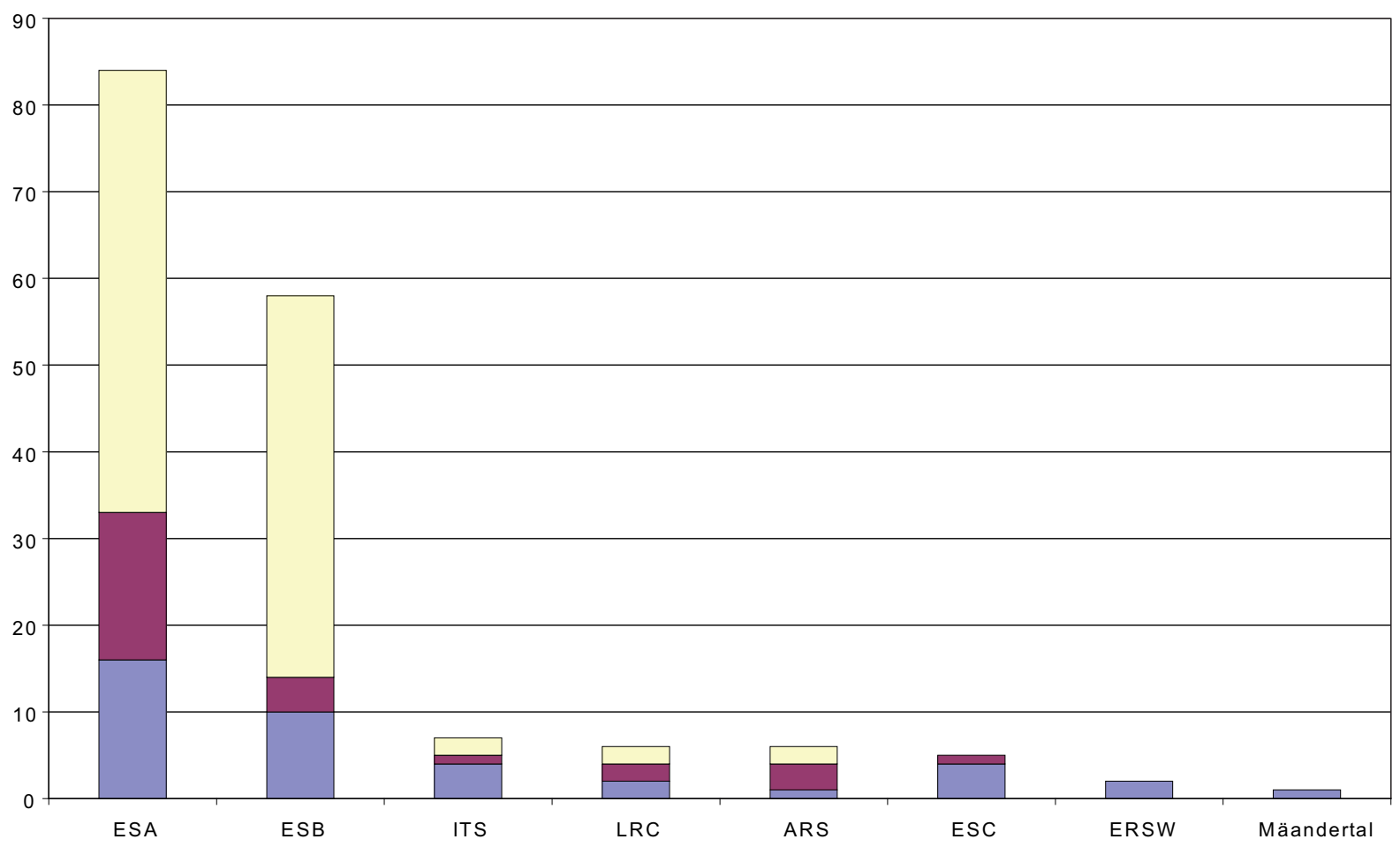

Abb. 9: Sigillataspektrum aus den Grabungen im Prytaneion 2007/2008 (blau: Randstücke, rot: Bodenstücke, gelb: Wandstücke)

\section{VI.1.2 TERrassierUnG ${ }^{420}$}

Das 1455 Fragmente umfassende keramische Fundspektrum aus Terrassierungsschichten, die im Areal des Prytaneions deutlich vor der Bauzeit des Gebäudes eingebracht wurden, zeigt mit $66 \%$ eine klare Dominanz der Gebrauchskeramik bzw. der lokalen Amphoren (Abb. 10). Diese beiden Gattungen sind aufgrund der gleichen Tonzusammensetzung, Wandstärke und Randgestaltung kaum voneinander zu trennen, bei Wandfragmenten ist eine Unterscheidung überhaupt unmöglich ${ }^{421}$. Aus diesem Grund wurden diese in der statistischen Erfassung in einer Gruppe zusammengefasst. Beträchtlich ist auch der Anteil an hellenistischen Feinwaren (24\%), während die Küchenware (7\%) und die eindeutig als Importe zu klassifizierenden Amphoren (3\%) einen nur geringen Anteil ausmachen. Als besonders aufschlussreich erwies sich eine genaue Analyse der hellenistischen Feinwaren (Abb. 11). Auch hier dominieren lokal produzierte Produkte, insbesondere das als Colour Coated Ware bezeichnete Tafelgeschirr (64\%). Damit ist eine Gruppe innerhalb der Feinkeramik umschrieben, die sich in Form und Dekor an die Glanztonware anlehnt, jedoch in der Tonzusammensetzung sowie der Oberflächenbehandlung der Gebrauchskeramik ähnelt ${ }^{422}$. Es handelt sich demnach um einfaches, anspruchsloses Tafelgeschirr, das in täglichem Gebrauch stand. Das Formenspektrum umfasst in erster Linie Schalen und Teller, wobei die Echinusschalen (KatNr. K 41-46) den weitaus größten Prozentanteil ausmachen. Ganz typisch für die ephesische Colour Coated Ware ist ein rotbrauner, matter Überzug, der meist nur bestimmte Gefäßabschnitte bedeckte. Sehr häufig sind beispielsweise bei den Tellern die Randoberseiten mit einem Überzug versehen, zudem konnten die Innenseiten mit einem Streifendekor dekoriert sein ${ }^{423}$. Bei den meisten Exemplaren ist der Überzug nur noch schlecht erhalten und weitgehend abgerieben, häufig lassen sich aufgrund der Bodenlagerung lediglich geringe Spuren nachweisen.

420 Zum Befund s. M. Steskal, Kapitel IV.2-3 und V.2.

421 Für die Herstellung von Amphoren und Krügen wurden dieselben Rohstoffquellen genutzt, ferner unterscheiden sich beide Gruppen weder in der Wandstärke noch in der Henkel- und Randgestaltung. Daher kann lediglich aufgrund charakteristischer Rand- und Fußbildungen zwischen Amphoren und Gebrauchskeramik unterschieden werden.

422 s. dazu bereits Ladstätter 2003, 30.

${ }^{423}$ Cf. etwa Ladstätter 2003, K 117. 121. 
Von deutlich höherer Qualität ist dagegen die Glanztonware, die im vorliegenden Fundspektrum 35\% ausmacht. Neben lokalen Produkten sind auch Importe, die meisten wohl aus Attika, zu verzeichnen. Äußerst gering ist dagegen der Anteil anderer hellenistischer Waren, wie der grauen Ware mit schwarzem Überzug, der dünnwandigen Keramik, der weißgrundigen Keramik, der Westabhangware sowie der ESA. Der Grund dafür ist zweifelsohne in der zeitlichen Stellung des Fundkomplexes zu suchen. So datiert der weitaus überwiegende Teil der Keramik aus den Terrassierungsschichten in das fortgeschrittene 3. Jahrhundert v. Chr., demnach klar vor dem erstmaligen Auftreten der gerade genannten Waren. Zudem fehlen charakteristische Waren des 2. Jahrhunderts v. Chr., wie beispielsweise die Reliefbecher. Die leichte Kontaminierung mit Fundmaterial des fortgeschrittenen 2. bzw. 1. Jahrhunderts v. Chr. ist folglich wohl auf die intensiven späteren Umbaumaßnahmen im Areal bzw. auf die Nutzung desselben zurückzuführen.

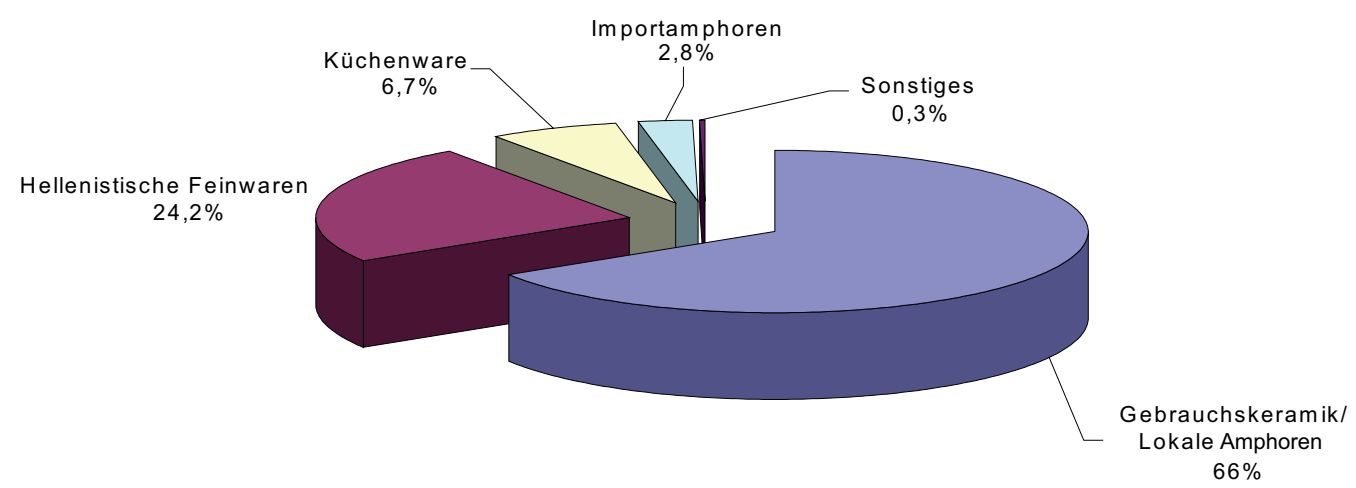

Abb. 10: Zusammensetzung des Fundspektrums des hellenistischen Terrassierungsstratums

Sieht man von einigen sresiduals $\measuredangle$, d. h. älteren Stücken (KatNr. K 6. 57. 59) ab, datiert das gesamte Material aus den Terrassierungsschichten in den Hellenismus. Bei der Glanztonware ist auf außerordentlich qualitätsvolle Gefäße hinzuweisen, wie die Echinusschalen (KatNr. K 1. 2. 13), die Schale mit breitem Horizontalrand (KatNr. K 3), eine Schale mit ausbiegendem Rand (KatNr. K 18), Kantharoi (KatNr. K 23. 28-30), einen Teller mit aufgebogenem Rand (KatNr. K 5), Teller mit breiter Lippe (KatNr. K 31. 32) und mit gerollter Lippe (KatNr. K 33), eine Lekanis (KatNr. K 7) sowie Böden eines Schälchens mit Palmettenstempel (KatNr. K 4) und eines weiteren Schälchens mit Riefeldekor (KatNr. K 36). Sie alle verfügen über einen metallisch glänzenden, kompakt haftenden schwarzen Überzug und über einen sehr fein aufbereiteten Tonrohstoff. Während einige dieser Stücke zweifelsohne als attische Importe anzusprechen sind (KatNr. K 1. 3. 9. 13. 29. 31), stammt wohl ein nicht unbeträchtlicher Teil aus lokaler Produktion ${ }^{424}$. Im Formenspektrum der Glanztonware machen wenig überraschend die Echinusschalen die Mehrheit aus (KatNr. K 1. 2. 11-15), wobei aufgrund der Kleinheit der Fragmente eine genaue formtypologische Einordnung ausbleiben muss. Lediglich für die Schale (KatNr. K 12) liegt ein gesamtes Profil vor. Charakteristische Elemente wie die geringe Schalentiefe, der nach innen abgeschrägte, relativ hohe Fuß sowie die deutlich verdickte Randlippe datieren das Stück in das 3. Jahrhundert v. Chr. Parallelen von der Athener Agora legen nahe, dass Schalen dieses Typs im ausgehenden 4. Jahrhundert entwickelt, allerdings bis zumindest um die Mitte des 3. Jahrhunderts hergestellt wurden ${ }^{425}$. Auch die übrigen Fragmente von Echinusschalen lassen durchweg niedrige Varianten erkennen, die für das 2. und 1. Jahrhundert v. Chr. charakteristischen tiefen Schalen scheinen dagegen ausnahmslos zu fehlen. KatNr. K 10 ist wohl als Schälchen mit gerilltem

${ }^{424}$ Zur Thematik importierter und lokaler Glanztonware klassischer Zeitstellung s. I. Kowalleck, Attische und attisierende Keramik, in: M. Kerschner - I. Kowalleck - M. Steskal, Archäologische Forschungen zur Siedlungsgeschichte von Ephesos in geometrischer, archaischer und klassischer Zeit, ÖJh Ergh. 9 (Wien 2008) 75-107 sowie E. Trink1, Schwarzfirniskeramik klassischer Zeit aus den Agoragrabungen, in: P. Scherrer - E. Trinkl, Die Tetragonos Agora in Ephesos. Grabungsergebnisse von archaischer bis in byzantinische Zeit - ein Überblick. Befunde und Funde klassischer Zeit, FiE 13, 2 (Wien 2006) 177-245 bes. 211-215.

425 Rotroff 1997, 162. 
Rand anzusprechen, wobei die Details der Randgestaltung auf Tellern wesentlich häufiger vertreten ist als auf Schälchen ${ }^{426}$. Zu halbkugeligen Schalen bzw. Schälchen gehören KatNr. K 8-9 sowie KatNr. K 16-17, ein Schälchen mit Horizontalrand ist aus dem Randfragment KatNr. K 3 zu erschließen. Von einer Lekanis stammt ein weiteres Randfragment, das seine besten Parallelen im Material der Athener Agora findet, die eine Datierung in das 3. Jahrhundert v. Chr. nahelegen ${ }^{427}$. KatNr. K 18-21 gehören zu Schalen/Schälchen halbkugeliger Formgebung, deren Randlippe allerdings deutlich verdickt ist. Zu Kantharoi/Skyphoi sind wiederum KatNr. K 22-24 zu ergänzen, wobei auch hier die exakte Form aufgrund der geringen Größe der Fragmente nicht rekonstruiert werden $\mathrm{kann}^{428}$. Zahlreich vertreten sind auch Schalen/Schälchen mit Wandknick und ausgebogenem Rand (KatNr. K 25-30), eine ephesische Standardform des späten Hellenismus $^{429}$. Eine weitere in Ephesos geläufige Form ist der Teller mit gerollter Lippe (KatNr. K 33), der wohl noch in das zweite Viertel des 3. Jahrhunderts datiert ${ }^{430}$. Einer etwas entwickelteren Form gehören Teller an (KatNr. K 31. 32), die Varianten der zweiten Hälfte des 3. Jahrhunderts nahestehen ${ }^{431}$. Abschließend sei auf große Schüsseln mit Horizontalrand hingewiesen (KatNr. K 34. 35). Neben KatNr. K 4, das sehr feinen Palmettendekor an der Bodeninnenseite zeigt, liegt mit KatNr. K 37 lediglich ein weiterer Tellerboden mit Stempeldekor vor. Ein weiteres Verzierungselement sind feine, vertikale Riefeln an der Gefäßaußenseite, wie bei Bodenfragment KatNr. K 36 zu sehen ist. Zu ergänzen ist eine konische Schale mit typischen Gestaltungsdetails des fortgeschrittenen 3. Jahrhunderts ${ }^{432}$. Aus hellenistischen Fundzusammenhängen bestens bekannt sind ein Töpfchen (KatNr. K 38) sowie zwei Krüge (KatNr. K 39. 40) ${ }^{433}$. Dem Formenspektrum der Glanztonware entspricht das gebrauchskeramische Tafelgeschirr, das als Colour Coated Ware bezeichnet wird. Vertreten sind Echinusschalen (KatNr. K 41-46), konische Teller (KatNr. K 47) sowie ein Teller mit breiter Randlippe (KatNr. K 48). Eine Schüssel mit Horizontalrand (KatNr. K 49) ${ }^{434}$ rundet das gebrauchskeramische Spektrum ab. Die Küchenware besteht aus Töpfen mit ausgebogenem, verdicktem Rand (KatNr. K 50. 51) $)^{435}$ und einer Schüssel bzw. Platten (KatNr. K 52-54). Charakteristisch für die Küchenware ist insbesondere der extrem grob gemagerte Ton mit einem hohen Anteil an Glimmerschiefer ${ }^{436}$. Die Amphoren ${ }^{437}$ verteilen sich auf einen Import (KatNr. K 55), der aufgrund des Fabrics eine mögliche parische Herkunft andeutet, auf lokale/regionale Produkte (KatNr. K 56. 58), ein Fragment aus Kos (KatNr. K 57) sowie ein nordägäisches Randfragment (KatNr. K 59), das wohl noch in das 4. Jahrhundert v. Chr. gehört.

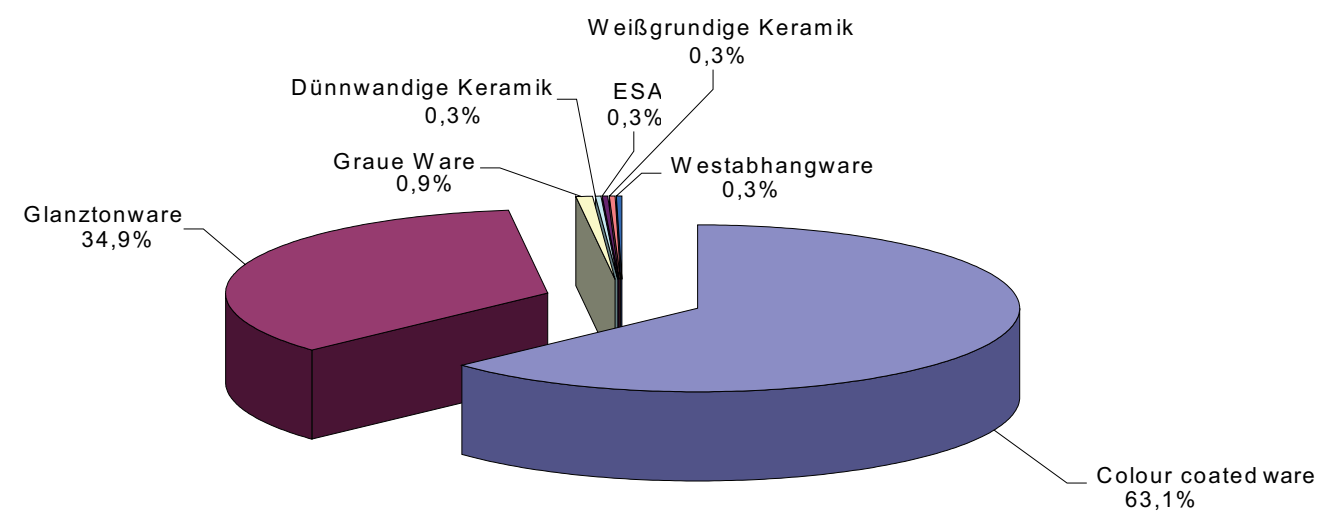

Abb. 11: Zusammensetzung der Feinware des hellenistischen Terrassierungsstratums

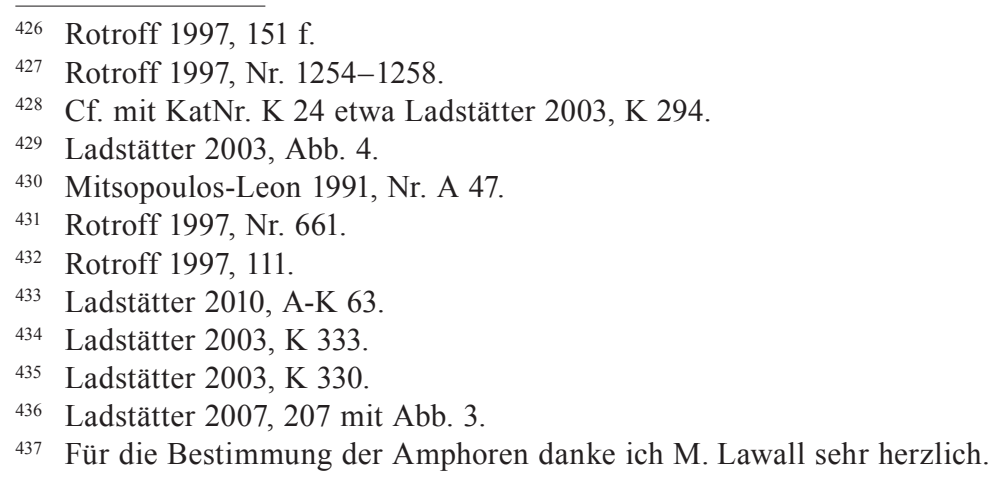


Betrachtet man das Fundspektrum aus den Terrassierungsschichten, so fällt in erster Linie dessen heterogene Zusammensetzung auf. Neben einigen wenigen Altstücken liegt allerdings ein deutlicher Schwerpunkt im Material auf dem 3. Jahrhundert v. Chr., einer Periode, die in Ephesos keramologisch bislang kaum erforscht ist ${ }^{438}$. Aus diesem Grund ist eine exakte zeitliche Einordnung der Terrassierungsmaßnahmen nicht unproblematisch. Zweifelsohne sind die wenigen deutlich späteren Fragmente - alle durchweg Wandscherben - auf eine spätere Kontamination zurückzuführen. Andererseits fehlen die für das 2. Jahrhundert so typischen Waren wie die Westabhangnachfolgeware oder die Reliefbecher, die anderswo in Ephesos häufig auftreten. Man wird daher nicht fehlgehen, die Baumaßnahmen vor $200 \mathrm{v}$. Chr. anzusetzen, wie dies auch in einem Vergleich mit einem zeitgleichen Fundkomplex aus dem Hanghaus 1, der ein deutlich anderes Warenspektrum zeigt, klar zum Ausdruck kommt ${ }^{439}$. Die wenigen formtypologisch genau auswertbaren Fragmente datieren um die Mitte bzw. in die zweite Hälfte des 3. Jahrhunderts und geben einen terminus post quem für die Terrassierungsmaßnahmen ${ }^{440}$.

\section{VI.1.3 BAUPHASE 1}

Die bauzeitlichen Schichten enthielten insgesamt 13303 Keramikfragmente und bilden damit den weitaus größten Fundkomplex der vorliegenden Studie (Abb. 8). Sie werden - getrennt nach den Fundorten Vorhof und `Hestiasaak - vorgelegt und einer genauen Analyse unterzogen, um ein möglichst genaues Datum für die Errichtungszeit des Gebäudes zu gewinnen. Auch in den Schichten der Bauphase 1 dominieren mit 62\% die Gebrauchskeramik bzw. die lokalen Amphoren, die sich scherbentypologisch großteils nicht voneinander unterscheiden (Abb. 12). Das Tafelgeschirr setzt sich aus hellenistischen Feinwaren (18\%) und Sigillaten (1\%) zusammen, ferner sind Küchenware (11\%) und Importamphoren (5\%) vertreten. Auffallend gering ist der Anteil an Sigillaten, vor allem im Vergleich zu den hellenistischen Feinwaren. Bei einer genaueren Analyse des 96 Stücke umfassenden Sigillataspektrums (Abb. 13) fällt auf, dass das Gros der Fragmente auf Waren und Formen des 1. Jahrhunderts v. Chr. entfällt. Mit 84\% hält die ESA den weitaus größten Prozentanteil, dagegen ist die regional produzierte ESB mit nur 11\% vertreten. In noch geringerer Quantität sind die ESC bzw. die pergamenische Sigillata (3\%) und die ITS ${ }^{441}$, die italische Sigillata (2\%), vertreten. Schon aufgrund des hier vorgelegten Sigillataspektrums scheint eine Datierung von Bauphase 1 in augusteische Zeit naheliegend $^{442}$, denn bereits Fundkomplexe neronisch-flavischer Zeit weisen eine deutlich andere Zusammensetzung auf ${ }^{443}$. Die Dominanz der ESA und der relativ geringe Anteil an ESB sind sichere Indizien für eine Entstehungszeit in den letzten beiden Jahrzehnten des 1. Jahrhunderts v. Chr.: Bereits um die Zeitenwende wurde der ephesische Keramikmarkt von der im großen Mäandertal produzierten ESB überschwemmt, die in weiterer Folge beinahe den gesamten Bedarf an Tafelgeschirr der kaiserzeitlichen Metropole abdeckte ${ }^{444}$. Diese zeitliche Einordnung wird auch durch den hohen Anteil an hellenistischen Feinwaren sowie deren Zusammensetzung unterstützt (Abb. 14). Zwar dominieren immer noch die Colour Coated Ware (49\%) sowie die Glanztonware (34\%), hinzu treten nun aber jene für das späte 2. und das 1. Jahrhundert v. Chr. typischen Waren wie die graue Ware mit schwarzem Überzug (6\%), die dünnwandige Keramik (5\%), die weißgrundige Keramik (3\%), die Westabhangnachfolgeware (2\%), die Reliefware (2\%) sowie die Applikenware. Auch wenn die Zusammensetzung der hellenistischen Feinwaren in sich heterogen ist, spricht der Anteil an grauer Ware sowie an dünnwandiger Keramik für eine Versiegelung im späten 1. Jahrhundert v. Chr.

\footnotetext{
438 In den Hanghäusern setzen die Fundkomplexe um 200 v. Chr. ein, allerdings datiert ein Großteil der hellenistischen Ensembles in die 2. Hälfte des 2. Jhs v. Chr. s. dazu ausführlich: Ladstätter 2003; Ladstätter 2005; Ladstätter 2010. Jüngst wurde Keramik aus dem Felsspalttempel in Ephesos publiziert, die in das 3. bzw. frühe 2. Jh. v. Chr. zu datieren ist: V. Gassner, Kultkeramik aus dem sgn. Felsspalttempel in Ephesos, in: SERES 2007 IV. Uluslararası Katılımlı Seramik, Cam, Emaye Sir ve Boya Semineri (Eskişehir 2007) 386-398.

439 Ladstätter 2003, 70-74.

${ }_{440}$ Cf. in diesem Zusammenhang auch die Häufigkeit von rhodischen Amphoren des 3. Jhs. am >Staatsmarkt: Lawall $2007,47 \mathrm{f}$. (table 2) sowie das Lampenspektrum: Mitsopoulos-Leon 2007, 65 und die Keramik aus der Basilika-Grabung: MitsopoulosLeon 1991, $13 \mathrm{f}$.

441 Zum Aufkommen italischer Sigillata in Ephesos s. Martin 2003; Martin 2006.

442 Lätzer (in Druck); Waldner 2009b, 294-299.

443 Ladstätter 2008, 98.

444 Dazu bereits ausführlich Ladstätter 2007, 208-211.
} 
Zusammengefasst kann demnach festgehalten werden, dass alleine schon die Waren- und Gattungsanalyse eine Einordnung von Bauphase 1 in augusteische Zeit nahelegt ${ }^{445}$.

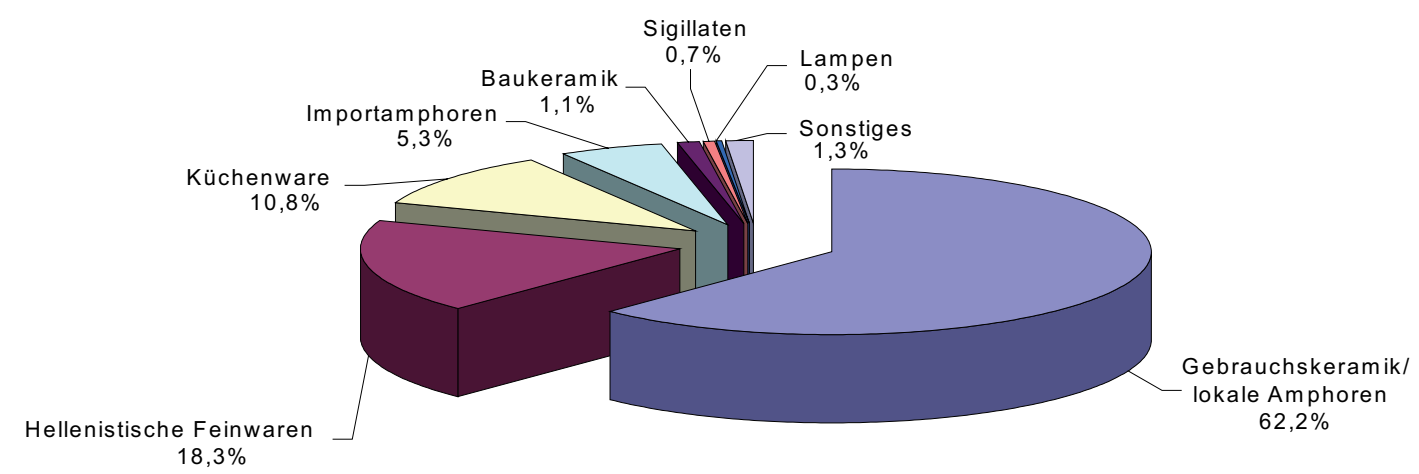

Abb. 12: Zusammensetzung des Fundspektrums von Bauphase 1

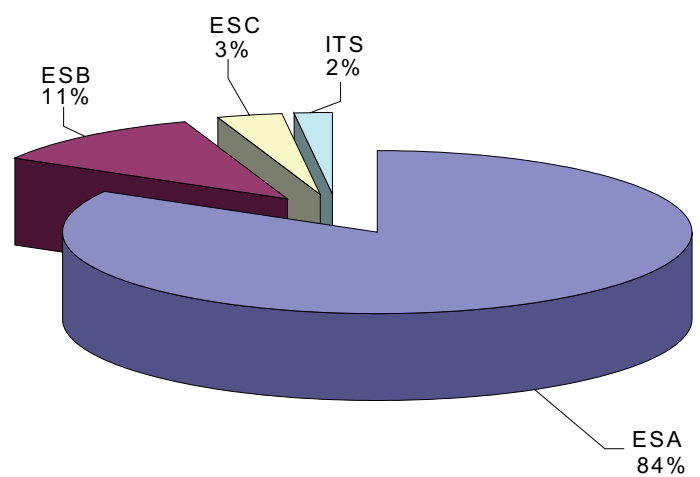

Abb. 13: Zusammensetzung der Sigillaten von Bauphase 1

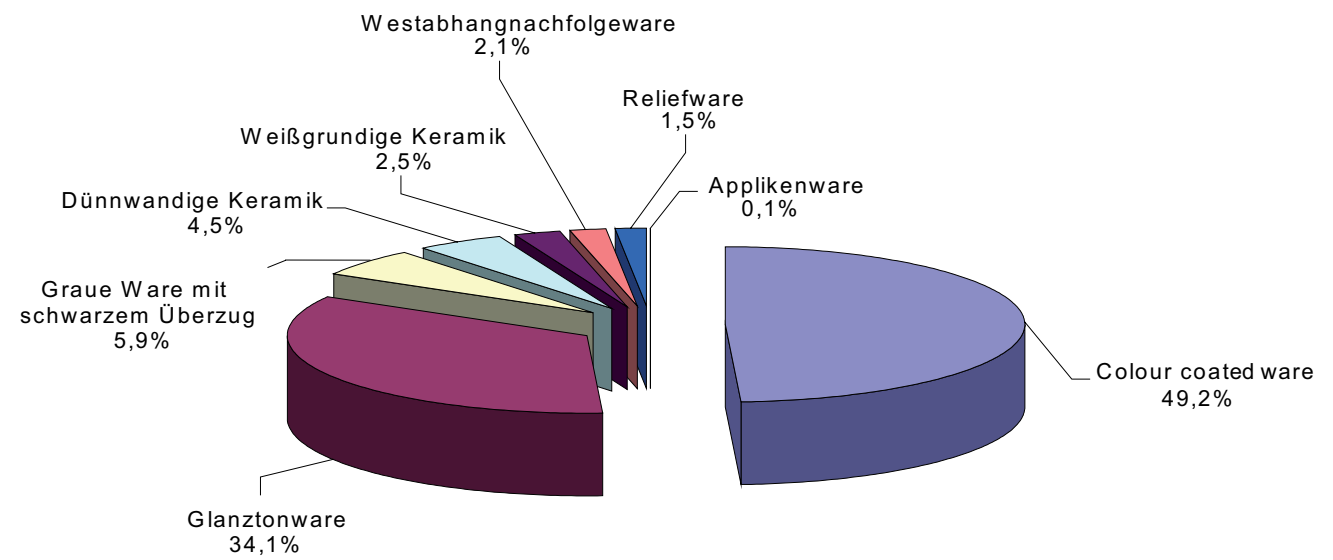

Abb. 14: Zusammensetzung der hellenistischen Feinware von Bauphase 1

445 Augusteische Fundkomplexe aus Ephesos sind vor allem aus dem Hanghaus 2 bekannt: Ladstätter 2005; Lätzer (in Druck). 


\section{VI.1.3.1 Bauphase 1 - Vorhof $f^{446}$}

Für die chronologische Einordnung von Bauphase 1 ist insbesondere die Zusammensetzung des feinkeramischen Spektrums von Bedeutung. Hervorragend in einen augusteischen Horizont passt das Wandfragment eines im östlichen Mittelmeerraum äußerst seltenen Surus-Bechers (KatNr. K 60). Diese aus Modeln gefertigte, dekorierte Ware gehört in einen Zeithorizont von $10 \mathrm{v}$. Chr. - $15 \mathrm{n}$. Chr. ${ }^{447}$. Der größte Anteil fällt allerdings auf die ESA, die mit Tellern der Formen Atlante 3 und 4 (KatNr. K 61-65. 72-76) und Schälchen der Formen Atlante 5A, 22 bzw. 22B (KatNr. K 66. 67. 69. 78-84) vertreten ist. Ferner ist eine Schale der Form TA 25A (KatNr. K 68) zu konstatieren. Formtypologisch nicht bestimmbar ist das Schälchen KatNr. $\mathrm{K} 71$, das sich auch in der Tonzusammensetzung von den übrigen ESA-Fragmenten unterscheidet, zweifelsohne aber dieser Gattung zuzurechnen ist ${ }^{448}$. Während die zitierten Formen eine lange Laufzeit aufweisen und im gesamten 1. Jahrhundert v. Chr. kursierten ${ }^{449}$, sind für die feinchronologische Auswertung des Fundkomplexes zwei weitere Fragmente von Bedeutung. Es handelt sich um zwei ESB-Teller der Form Atlante 12 bzw. tarda f (KatNr. K 70. 77), die in einem Rand- sowie einem Bodenfragment vorliegen. Auf Basis eines augusteischen Fundkomplexes im Hanghaus 2 konnte für diese Form eine augusteische Zeitstellung erschlossen werden ${ }^{450}$, ein Ansatz, der sich durch die hier vertretenen Exemplare zu bestätigen scheint. Die übrigen ESB-Fragmente können dagegen problemlos in die augusteische Zeit datiert werden. Es handelt sich ausnahmslos um ESB 1-Produkte, für die eine scharfe Gefäßprofilierung sowie sorgfältig und fein ausgeführte Gestaltungsdetails typisch sind. Neben einem Teller der Form Atlante 7 (KatNr. K 85) sowie den Schälchen Atlante 14 und 35 (KatNr. K 87. 88) ist insbesondere auf das fast zur Gänze erhaltene Schälchen der Form Atlante 22 (KatNr. K 89) hinzuweisen. Die Bodeninnenseite ziert ein zentral eingebrachter, runder Stempel, auf dem ein Siegeskranz dargestellt ist (Taf. 167. 218). Stempel dieser Art sind äußerst selten und kennzeichnen die erste Stempelphase der ESB, als man sich noch sehr deutlich an die italischen Vorbilder hielt ${ }^{451}$. Die Fragmente der ESC bzw. der pergamenischen Sigillata (KatNr. K 91-94) zeigen durchweg Formen des 1. Jahrhunderts v. Chr. ${ }^{452}$, das Bodenfragment KatNr. K 94 könnte durchaus bereits einer augusteischen Zeitstellung angehören und als Form Atlante A 1 angesprochen werden ${ }^{453}$.

Für den Zeithorizont typisch sind auch Gefäße in grauer Ware mit schwarzem Überzug ${ }^{454}$. Das Formenspektrum orientiert sich stark an der ephesischen Glanztonware, vertreten sind konische Schalen (KatNr. K 95), Echinusschalen (KatNr. K 96-98), Schalen mit Wandknick (KatNr. K 101), Teller mit breiter Lippe (KatNr. K 102. 115?), Teller mit gedrechseltem Rand (KatNr. K 104. 105) sowie ein massiver Teller mit stark überhängendem Rand (KatNr. K 106). Aus dem ephesischen Fundbestand bislang nicht bekannt ist dagegen ein konischer Teller (KatNr. K 103). Nicht zu entscheiden ist die gattungsmäßige Zuordnung eines sehr kleinen Bodenfragments mit Palmettenstempel (KatNr. K 116), es könnte sich sowohl um einen Vertreter der grauen Ware als auch der Glanztonware handeln. Charakteristische Produkte der grauen Ware mit

446 Zum Befund s. M. Steskal, Kapitel IV.2-3 sowie V.3.

447 OCK, Nr. 2013; Atlante II, 221 f.; E. Schindler-Kaudelka, Die römische Modelkeramik vom Magdalensberg, Archäologische Forschungen zu den Grabungen auf dem Magdalensberg 7 (Klagenfurt 1980) 81. Zum Anteil reliefverzierter italischer Sigillaten in Ephesos s. Martin 2003.

448 ESA wurde in zahlreichen Zentren produziert: J. Poblome - M. Zelle, The Table Ware Boom. A Socio-Economic Perspective from Western Asia Minor, in: Berns - Hesberg - Vandeput - Waelkens 2002, 275-287.

449 Warner Slane 1997, 310.

450 Ladstätter 2005, K 50 Abb. 39.

${ }^{451}$ Cf. etwa OCK, Nr. 2583. 2578 (beide um 10 v. Chr.). s. dazu bereits: S. Ladstätter, Viktoria, Apollon oder doch ein Athlet? Überlegungen zu den ITS-Stempeln OCK type 2574, in: E. Christof - G. Koiner - M. Lehner - E. Pochmarski (Hrsg.),

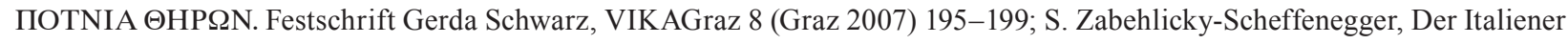
in Ephesos, ReiCretActa 34, 1995, 253-268. Zur Frühphase der ESB s. zuletzt Ladstätter 2007, 208 f. OCK, Nr. 2013.

452 Zur Warendefinition s. Meyer-Schlichtmann 1988, 13-17.

453 Atlante II, 73.

${ }^{454}$ Zur Warendefinition s. S. Ladstätter, Griechisch oder römisch? Ein Teller als Beispiel für die Komplexität gegenseitiger Beeinflussungen in der frühkaiserzeitlichen Keramik von Ephesos, in: G. Grabherr - B. Kainrath - A. Larcher - B. Welte, VIS IMAGINVM. Festschrift Elisabeth Walde (Innsbruck 2005) 199-207. Fälschlich als »schwarze Sigillata« angesprochen bei: C. Rogl, Zu dem Produktionsbeginn schwarzer Sigillata in Ephesos. Die Evidenz der Tetragonos Agora, ÖJh 73, 2004, 207-219; Waldner 2009b, 287. 
schwarzem Überzug sind aber insbesondere die Platten, die im vorliegenden Fundspektrum sowohl mit sichelförmigem Randprofil (KatNr. K 107-111) als auch mit rundem Rand (KatNr. K 112) vorliegen ${ }^{455}$, wogegen solche mit dreieckig verdicktem Rand fehlen. Letztere markieren den Endpunkt der formtypologischen Entwicklung und datieren in spätaugusteisch-tiberische Zeit ${ }^{456}$. Ihr Fehlen im vorliegenden Fundkomplex ist ein weiterer wichtiger Hinweis auf dessen chronologische Einordnung.

Bei der Glanztonware ist auf einige wenige Stücke hinzuweisen, die eindeutig einer älteren Zeitstellung angehören (KatNr. K 117-119) und wohl in das 3. Jahrhundert v. Chr. zu datieren sind. Sie dürften im Zuge der späthellenistischen Erdbewegungen in die höher gelegenen Schichten gelangt sein. Die Skyphoi und Kantharoi, teilweise im Stil des Westabhangnachfolgedekors verziert, datieren dagegen bereits in das 2. Jahrhundert v. Chr. (KatNr. K 120-125). Eine analoge Zeitstellung ist auch für die Krüge (KatNr. K 126-129. 131?) und einen Becher (KatNr. K 130) vorauszusetzen. Auch bei den Reliefbechern (KatNr. K 132-151) lassen sich unterschiedliche Zeithorizonte fassen ${ }^{457}$. Die vorliegenden Rand- und Wandfragmente zeigen jene für Ephesos typischen Randbordüren in Form von Eierstäben (KatNr. K 132. 133), lesbischem Kyma (KatNr. K 134), Blattranken (KatNr. K 150) und Mäander (KatNr. K 143). In der Hauptzone sind Akanthus- und Langblätter (KatNr. K 140-143) sowie Blattschuppen zu sehen. Häufig anzutreffen ist auch der sog. makedonische Schilddekor (KatNr. K 139), während figürliche Darstellungen (KatNr. K 132. 144) eher selten zu finden sind. Die hier zitierten Beispiele gehören zur Hauptserie der ephesischen Reliefbecherproduktion, die in der Mitte des 2. Jahrhunderts v. Chr. einsetzte und über die erste Hälfte des 1. Jahrhunderts v. Chr. andauerte. Einer bereits entwickelteren Produktionsphase gehören zwei weitere Fragmente an. Von einem Becher mit breiter Standfläche hat sich ein Boden-Wand-Fragment erhalten (KatNr. K 149), das eine deutliche Standfläche aufweist. Die Hauptdekorzone war mit linear ausgeführten Langblättern bedeckt, zwischen die Punktreihen gesetzt waren. Form- und Dekordetails weisen das Fragment der Werkstatt des Menemachos zu. Reliefbecher mit Standflächen bilden sich erst im Verlauf des 1. Jahrhunderts v. Chr. heraus, für eine solch späte Zeitstellung spricht auch der reduzierende Brand und der matt-graue Überzug. Es kann daher davon ausgegangen werden, dass der vorliegende Becher einer sehr späten Produktionsphase, die wahrscheinlich im dritten Viertel des 1. Jahrhunderts v. Chr. anzusetzen ist, zugeschrieben werden darf.

Hervorgehoben werden muss ein bislang singuläres Stück. Dabei handelt es sich um das Wandfragment eines Reliefbechers in grauer Ware mit schwarzem Überzug (KatNr. K 150). Erhalten haben sich Teile der Randbordüre, wohl Blattranken, sowie die Hauptdekorzone aus Langblättern. Der Becher ist auffallend klein, die Wandstärke liegt jedoch deutlich über jener typischer ephesischer Reliefbecher. Weitere Unterschiede lassen sich beim Stil des Dekors, der weniger plastisch und deutlich linearer geschnitten ist, sowie bei der Oberflächenbehandlung festmachen. Zweifelsohne liegt mit dem kleinen Wandfragment ein Beleg für die Experimentierfreude späthellenistischer Töpfer in Ephesos vor. Demnach versuchte man, in den auf die graue Ware spezialisierten Werkstätten auch Reliefbecher herzustellen, ein aufgrund des unpassenden Tonrohstoffes wenig erfolgreiches Unterfangen ${ }^{458}$.

Im Spektrum der späthellenistischen Glanztonware ist auf konische Schalen mit deutlicher Innenprofilierung (KatNr. K 152) hinzuweisen, die insbesondere für Pergamon typisch sind. Besonders häufig vertreten sind allerdings konische Schalen, die an der Innenseite einen Dekor in Mal- und/oder Ritztechnik zeigen (KatNr. K 153-166) ${ }^{459}$. Der Schalentyp mit Innendekor im Westabhangstil wird im 3. Jahrhundert v. Chr. entwickelt und erfreut sich bis in das frühe 2. Jahrhundert großer Beliebtheit. Während er in Festlandgriechenland aus der Mode kommt, findet er sich im östlichen Mittelmeer bis in das beginnende 1. Jahrhundert v. Chr. hinein. Die hier vorliegenden Stücke zeigen eine glatte Gefäßaußenwand, zudem sind die Ränder kaum oder gar nicht profiliert. Auch die wenigen erhaltenen Bodenfragmente (KatNr. K 287. 288) belegen,

455 S. Zabehlicky-Scheffenegger - R. Sauer - G. Schneider, Graue Platten aus Ephesos und vom Magdalensberg, in: M. HerfortKoch - U. Mandel - U. Schädler, Hellenistische und kaiserzeitliche Keramik des östlichen Mittelmeergebietes, Kolloquium Frankfurt 24.-25. April 1995 (Frankfurt 1996) 41-59.

456 Ladstätter 2005, 234; Meriç 2002, K 114-119.

$457 \mathrm{Zu}$ den Reliefbechern s. C. Rogl, Eine Vorschau zu den reliefverzierten Trinkbechern der ephesischen Monogramm-Werkstätte, in: Krinzinger 2001, 99-111.

458 Zur Experimentierfreude späthellenistischer Töpfer in Ephesos s. Ladstätter 2007, 210.

459 Gassner 1997, Nr. 192-193; Mitsopoulos-Leon 1991, B 80-95. 
dass die Außenseiten der Schalen über keine horizontale Rillung verfügten ${ }^{460}$. Zudem erinnert der Innendekor nur noch vage an die konischen Schalen im Westabhangstil. So zierte die Innenfläche von KatNr. K 158 ein einfacher Netzdekor in Ritztechnik, ferner finden sich gemalte bzw. geritzte Efeublattgirlanden (KatNr. K 162), eine Tropfengirlande (KatNr. K 164) sowie ein Wellenmäander (KatNr. K 165). Die Fabrics belegen, dass es sich bei allen Stücken um ephesische Produkte handelt, lediglich KatNr. K 164 ist eindeutig als Import anzusprechen. Das Stück unterscheidet sich sowohl in der Wahl des Rohstoffes, der Oberflächenbehandlung als auch in der Dekorwahl und entspricht den aus Sardis bekannt gemachten Exemplaren ${ }^{461}$. Auch in Ephesos ist eine chronologische Einordnung der konischen Schalen mit Innendekor nicht unproblematisch. Während für die Exemplare vom >Staatsmarkt k keine kontextuellen Datierungen vorliegen ${ }^{462}$, stammen jene von der Tetragonos Agora aus einem Fundkomplex des fortgeschrittenen 2. Jahrhunderts v. Chr. ${ }^{463}$. Dem entsprechen auch der zeitliche Ansatz für eine konische Schale in einer Brunnenfüllung im Hanghaus $2^{464}$, aber auch Exemplare aus Aufschüttungen im Bereich der späteren Wohneinheit $7^{465}$. In den augusteischen Fundkomplexen des Hanghauses $2^{466}$ wie auch in einem Brunnen auf dem $>$ Staatsmarkt $\ll$ fehlen sie dagegen ${ }^{467}$. Aus der ephesischen Evidenz ist zu schließen, dass sich die konischen Schalen im fortgeschrittenen 2. Jahrhundert v. Chr. zweifelsohne großer Beliebtheit erfreuten und wohl auch noch während der ersten Hälfte des 1. Jahrhunderts v. Chr. in Benutzung blieben. Wann sie letztendlich außer Gebrauch kamen, lässt sich nach dem derzeitigen Forschungsstand nicht mit Sicherheit beantworten; in der frühen Kaiserzeit waren sie bereits vollständig vom keramischen Markt verschwunden. Demgegenüber verfügte, wie frühkaiserzeitliche Fundkomplexe belegen, die Verzierungstechnik im Westabhangnachfolgestil über eine sehr lange Lebensdauer, allerdings mit einem deutlich unterschiedlichen Formenspektrum ${ }^{468}$. Die besten Parallelen für die hier vorgelegten konischen Schalen stammen aus einer Tumulusbestattung in der Nähe von Sardis ${ }^{469}$. Auch für diese Schalen ist aufgrund der spezifischen Vergesellschaftungen - insbesondere auch mit Ephesos-Lampen - eine Datierung im ausgehenden 2./frühen 1. Jahrhundert v. Chr. zu postulieren. Neben den konischen Schalen ist auf halbkugelige Schalen/Becher hinzuweisen (KatNr. K 167-183), die an der Außenseite meist feine, horizontale Rillen aufweisen, zudem konnte Dekor in Westabhangnachfolgestil angebracht sein. Sie sind in Ephesos häufig in späthellenistischen Fundkontexten anzutreffen und dürften gleichzeitig mit den konischen Schalen produziert worden $\operatorname{sein}^{470}$. Den hier vorliegenden Stücken fehlt zwar - sieht man von KatNr. K 167 ab - der typische Mal-Ritz-Dekor an der Gefäßaußenseite, die spezifische Oberflächenbehandlung erleichtert aber die typologische Einordnung.

$\mathrm{Zu}$ einem großen Skyphos mit breitem Schlaufenhenkel (KatNr. K 184) gehört ein Randfragment, während der weitaus größte Anteil an Glanztonware auf die Echinusschalen (KatNr. K 185-205) sowie die Schalen mit Wandknick (KatNr. K 209-225) entfällt. Eine dieser Schalen mit Wandknick (KatNr. K 214) verfügt über eine sekundär eingefügte, allerdings intentionelle Lochung an der Gefäßaußenseite, die als Aufhängevorrichtung gedient haben könnte. Dagegen handelt es sich bei einer halbkugeligen Schale mit verdicktem Rand (KatNr. K 206), einer Schale mit oben profiliertem Rand (KatNr. K 207) sowie einer konischen Schale mit ausgebogenem Rand (KatNr. K 208) um Einzelstücke. Echinusschalen und Schalen mit Wandknick prägen das Spektrum der ephesischen Glanztonware ab dem fortgeschrittenen 2. Jahrhundert v. Chr. ${ }^{471}$. Während sich Echinusschalen auch noch in augusteischen Fundhorizonten nachweisen lassen,

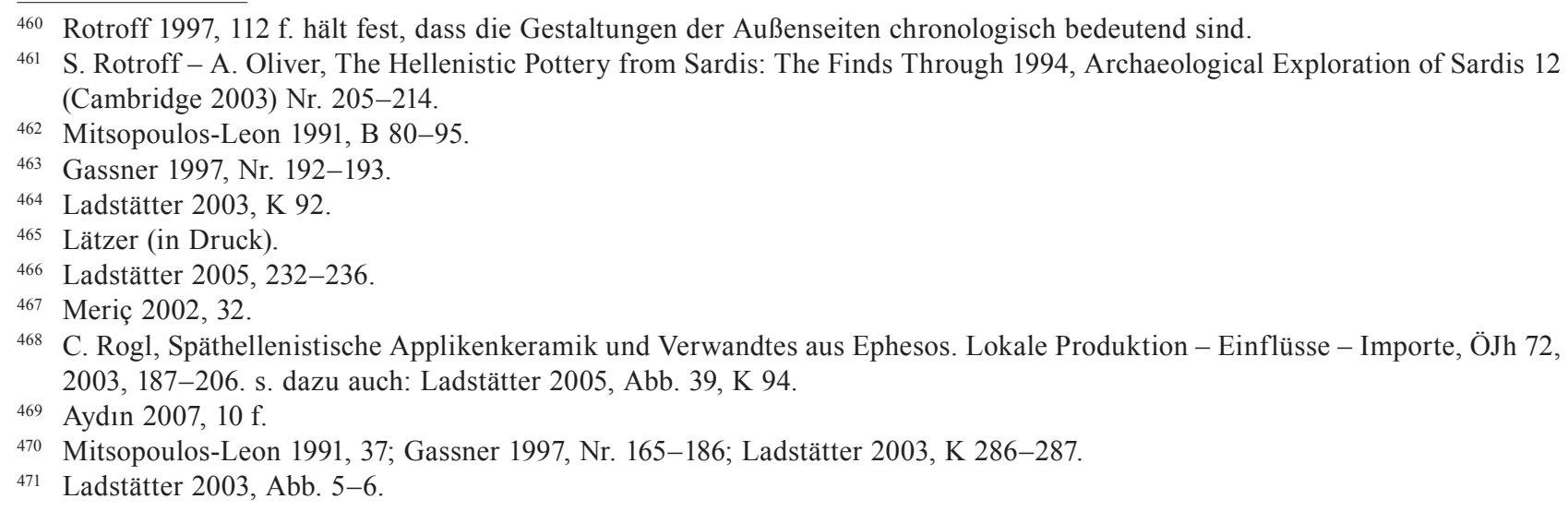


fehlen die Schalen mit Wandknick bereits ${ }^{472}$. Auch für diese sehr spezifische Form kann demnach ein Produktionsschwerpunkt in der ersten Hälfte des 1. Jahrhunderts v. Chr. erschlossen werden. Ein Schälchen mit deutlich überhängender, runder Lippe ist eindeutig als Import anzusprechen und ist wohl Pergamon zuzuordnen ${ }^{473}$. Zu sog. knidischen Schalen können KatNr. K 227 und 228 gezählt werden, wobei für beide Exemplare eine ephesische Produktion zu postulieren ist ${ }^{474}$. Auch sie erfreuten sich besonders im 1. Jahrhundert v. Chr. großer Beliebtheit und waren noch in augusteischer Zeit Bestandteil des Tafelservices ${ }^{475}$. Als Einzelstücke sind Teller mit aufgebogenem Rand (KatNr. K 229. 230) anzusprechen. Diese andernorts sehr beliebte Tellerform konnte sich in Ephesos kaum durchsetzen und ist bislang nur in Einzelstücken vorgelegt ${ }^{476}$. Zu großen Schüsseln/Krateren mit ausgebogenem Rand lassen sich wiederum die beiden Stücke KatNr. K 231 und 232 ergänzen. Neben einigen großen und groben Tellern/Schüsseln mit überhängender Randlippe (KatNr. K 233-235) ist auf einen Fischteller (KatNr. K 236) sowie auf zahlreiche Teller mit breitem Rand zu verweisen (KatNr. K 238-258). Letztere gehören zum Standardrepertoire der späthellenistischen Glanztonware in Ephesos und bildeten mit den Echinusschalen sowie den Schalen mit Wandknick wohl ein Service ${ }^{477}$. Weitere Tellervarianten zeigen beidseitig verdickte Randlippen (KatNr. K 259-266) sowie gedrechselte Ränder (KatNr. K 268-272). Gerade die Teller mit gedrechseltem Rand sind eine für Ephesos sehr charakteristische Form, die im ausgehenden 2. Jahrhundert entwickelt wurde ${ }^{478}$, allerdings eine lange Laufzeit bis in augusteische Zeit aufweist ${ }^{479}$.

Unter den erhaltenen Bodenfragmenten befinden sich sechs Importe aus Attika (KatNr. K 273-278), während Bodenfragmente mit grobem Palmettendekor (KatNr. K 279-284) einer ephesischen Produktion entstammen. Ferner haben sich von Schalen/Schälchen mit Muschelfüßchen zwei Bodenfragmente (KatNr. K 285. 286) erhalten. Zu Kantharoi und Skyphoi (KatNr. K 289-294) gehören mehrfach profilierte Füße, wohl zu einem Krater das Bodenfragment KatNr. K 295. Abgeschlossen werden die Glanztongefäße durch drei Bodenfragmente von Unguentarien (KatNr. K 296-298) sowie einem Amphoriskos (KatNr. K 299).

Spärlich ist der Anteil an weißgrundiger Keramik im vorliegenden Fundkomplex ${ }^{480}$. Neben mehreren insignifikanten Wandfragmenten können anhand der Rand- und Bodenstücke Amphoren (KatNr. K 300. 303) sowie Lagynoi (KatNr. K 301. 302) unterschieden werden. Auch für die weißgrundige Keramik gilt, dass sie sich während des 1. Jahrhunderts v. Chr. großer Beliebtheit erfreute, ihr Weiterlaufen in die frühe Kaiserzeit ist durch Fundkomplexe aus dem Hanghaus 2 gesichert ${ }^{481}$.

Ein besonders wichtiger Aspekt für die zeitliche Einordnung des Fundkomplexes erschließt sich durch die dünnwandige Keramik, die im Verlauf des 1. Jahrhunderts v. Chr. auch im östlichen Mittelmeerraum verstärkt anzutreffen ist. Im vorliegenden Ensemble kann zwischen zylindrischen (KatNr. K 304. 305) sowie bauchigen Bechern (KatNr. K 306-308) unterschieden werden. Hinzu kommen Becher mit kleiner Standfläche (KatNr. K 309. 310), deren weiterer Gefäßverlauf ein eiförmiges Profil ergibt. Neben der Gefäßform sind ausdrücklich auch die verwendeten Dekortechniken und Motive zu berücksichtigen. Ein rares Beispiel für Modelfertigung ist ein Henkel mit Netzdekor (KatNr. K 311). Dieses in Ephesos bislang singuläre Stück findet eine exakte Parallele in einem frühkaiserzeitlichen Fundkomplex in Priene ${ }^{482}$. Das zweite verzierte Exemplar (KatNr. K 312) zeigt den beliebten und weitaus häufiger anzutreffenden Gräten- oder

$\overline{472}$ Ladstätter 2005, Abb. 39.

473 Ähnlich in der Randgestaltung beispielsweise Meyer-Schlichtmann 1988, N 32.

474 Zur Chronologie der sog. knidischen Schalen zuletzt Ladstätter 2005, 234. Zum Forschungsstand s. auch: P. Kögler, Import, Export, Imitation. Trade and the Economic Power of Late Hellenistic and Early Imperial Knidos According to the Fine Pottery, in: M. Berg Briese - L. E. Vaag (Hrsg.), Trade Relations in the Eastern Mediterranean from the Late Hellenistic Period to Late Antiquity: The Ceramic Evidence, Halicarnassian Studies 3 (Odense 2005) 50-62.

475 Ladstätter 2005, K 108-110.

476 Gassner 1997, Nr. 113.

477 Dazu bereits ausführlich Ladstätter 2003, 33 f. mit Abb. 5.

478 Ladstätter 2003, 34.

479 Ladstätter 2005, 234.

480 Zur weißgrundigen Keramik in Ephesos s. E. Dereboylu, Weißgrundige Keramik und hellenistische Reliefbecher aus dem Hanghaus 2 in Ephesos, in: Krinzinger 2001, 21-44; Waldner 2009b, 289.

481 Ladstätter 2005, 234

482 Fenn 2008, Abb. 2. 
Kommadekor in Barbotinetechnik ${ }^{483}$. Die kleinen Standflächen der Becher KatNr. K 309 und 310 erinnern an hohe, eiförmige Becher, die speziell im beginnenden 1. Jahrhundert v. Chr. beliebt waren und sich direkt von westlichen Importen ableiten lassen bzw. überhaupt als solche anzusprechen $\operatorname{sind}^{484}$. Typisch für die augusteische Zeit sind dagegen die zylindrischen Becher (KatNr. K 305), die ihre nächsten Parallelen in der zeitgleichen ITS und ESB finden ${ }^{485}$. Die bereits festgestellte Heterogenität des Fundkomplexes kann demnach auch anhand der dünnwandigen Keramik nachvollzogen werden, deren Spektrum vom Beginn des 1. Jahrhunderts v. Chr. bis in augusteische Zeit streut. Den Endpunkt markieren frühkaiserzeitliche Formen, die sich von der im östlichen Mittelmeergebiet neu etablierten Sigillata ableiten lassen. Die dünnwandige Keramik wird als wichtiger Indikator für eine immer stärker werdende Romanisierung des Ostens angesehen, da hellenistische Vorläufer dafür fehlen ${ }^{486}$. Den hellenistischen Keramikmarkt von Ephesos charakterisiert ein starker Traditionalismus, griechisch beeinflusste Ess- und Trinkgewohnheiten hielten sich bis in die frühe Kaiserzeit, westlich-römische Einflüsse sind dagegen kaum fassbar. Erst für die spätaugusteischtiberische Zeit konnte ein Bruch mit diesen Traditionen beobachtet werden, der unter anderem auch das Ende der Produktion ephesischer Glanztonware bedeutete ${ }^{487}$.

Zur Gattung der lokalen Gebrauchskeramik ${ }^{488}$ gehören zahlreiche Krüge (KatNr. K 313-352), ein Unguentarium (KatNr. K 353), ein Becher (KatNr. K 354) und ein bauchiges, geschlossenes Gefäß (KatNr. $\mathrm{K}$ 356). Letzteres ist ein singuläres Stück, das an der Gefäßaußenseite mit polychromer Bemalung auf Tongrund versehen war. Auffallend hoch ist der Anteil an Tafelgeschirr in lokaler Gebrauchskeramik, das meist einen partiell aufgebrachten Überzug aufweist. Diese spezielle Ware wurde als Colour Coated Ware definiert und bereits diskutiert ${ }^{489}$. Die Ware lehnt sich im Formenspektrum eng an die Glanztonware an, allerdings lassen sich auch formtypologisch nicht verwandte Einzelstücke fassen. Das bauchige Schälchen mit ausgebogenem Rand (KatNr. K 355) findet beispielsweise seine nächsten Parallelen in der knidischen Glanztonware, der Steilrandteller (KatNr. K 357) ist dagegen zweifelsohne von westlichen Sigillaten beeinflusst. Formtypologisch eng verwandt mit der ephesischen Glanztonware sind freilich die Schalen mit Wandknick (KatNr. K 358-366) sowie die Echinusschälchen (KatNr. K 367-371. 373-384) und Schalen mit aufgebogenem Rand (KatNr. K 372. 386). Die Schale KatNr. K 385 könnte zudem durch die ESA-Teller der Form Atlante 3/4 inspiriert worden sein. Den Abschluss bilden konische Schalen bzw. Teller (KatNr. K 387-390) sowie Teller/Schüsseln mit verdicktem Rand (KatNr. K 391-398). Auch bei den Tellern dominieren - wie bei der Glanztonware - jene mit breitem Rand (KatNr. K 398-427), wobei bei den meisten Exemplaren die Randoberseiten mit einem matten, roten Überzug versehen sind, seltener kann auch die Gefäßinnenseite mit horizontalen Streifen dekoriert sein. Ein besonders interessantes Stück ist KatNr. K 428, an dessen Innenseite direkt unter dem Rand eine Reihe von Palmetten eingestempelt ist. Dem typischen späthellenistischen Formenrepertoire entsprechen die Schüsseln (KatNr. K 429-449. 452. 453), Teller (KatNr. K 450. 451) sowie die Töpfe (KatNr. K 454-457. 459-461). Abgeschlossen wird das gebrauchskeramische Spektrum durch Kasserollen (KatNr. K 458), Deckel (KatNr. K 462. 463) und Unguentarien (KatNr. K 464. 465). Drei interessante Wandfragmente (KatNr. K 467) gehören zu Schüsseln mit gemalter Innendekoration. $\mathrm{Zu}$ sehen ist ein in dunkelbrauner bzw. grauer Farbe direkt auf dem Tongrund aufgebrachter, horizontaler Blattkranz. Die Innendekoration gebrauchskeramischer Schüsseln findet sich in Ephesos extrem selten und blieb bisher unpubliziert.

Sehr wichtig für die zeitliche Einordnung des gesamten Fundkomplexes ist auch das Kochgeschirr. Typisch hellenistischen Formtraditionen folgen die Töpfe KatNr. K 469-477, die Parallelen im Hanghaus 2

\footnotetext{
${ }^{483} \mathrm{Zu}$ Bechern mit Komma- bzw. Grätendekor in Ephesos s. zusammenfassend Ladstätter 2005, 234 f. Das hier vorgelegte Fragment findet eine Parallele in Priene: Fenn 2008, Abb. 4.

484 Ladstätter 2007, Abb. 1-2.

485 Ladstätter 2005, 235 (K 174) mit weiteren Parallelen.

486 s. dazu Ladstätter 2007, 206; K. Roth-Rubi, Dünnwandige Ware (ceramica a pareti sottili) der frühen Kaiserzeit als Indikator der Romanisierung im Westen und im Osten, in: D. Malfitana - J. Poblome - J. Lund (Hrsg.), Old Pottery in a New Century. Innovating Perspectives on Roman Pottery Studies. Atti del Convegno Internazionale di Studi Catania, 22-24 Aprile 2004 (Catania 2006) 57-64.

487 Ladstätter 2005, 236; Ladstätter 2007, 211.

488 Zur Warendefinition s. Ladstätter 2003, 73; Ladstätter 2005, 235.

489 s. dazu bereits die Bemerkungen in Kapitel VI.1.2 zur Terrassierung.
} 
finden ${ }^{490}$. Eine lange Laufzeit weisen die groben Töpfe mit rundem, ausbiegendem Rand auf (KatNr. K 478-496), die sich in zahlreichen hellenistischen Horizonten finden und nicht zuletzt durch ihre grobe Magerung charakterisiert sind ${ }^{491}$. Töpfe/Kasserollen mit umgeschlagenem Rand (KatNr. K 497-499) finden sich dagegen vermehrt in augusteischen Horizonten wieder ${ }^{492}$. Während die Töpfe KatNr. K 500 und 501 chronologisch wenig auswertbar sind, finden jene mit Karniesrand (KatNr. K 502-504) ihre nächsten Vergleichsbeispiele in Fundkomplexen des ausgehenden 2./frühen 1. Jahrhunderts v. Chr. ${ }^{493}$. Typisch für eine augusteische Zeitstellung sind nun die Töpfe mit umgeschlagenem, profiliertem Rand (KatNr. K 505-508) sowie jene mit profiliertem Horizontalrand (KatNr. K 513. 514) ${ }^{494}$. Bislang singulär sind Töpfe mit gerilltem Horizontalrand (KatNr. K 509-512), doch weisen sie Ähnlichkeiten mit einem Topf im Hanghaus 2 auf ${ }^{495}$. Topf KatNr. K 515 wiederum findet seine nächste Parallele auf der Tetragonos Agora ${ }^{496}$. Das kleine Randfragment eines weiteren Topfes (KatNr. K 516) zeigt eine bislang in Ephesos völlig unbekannte Form, die allerdings aus späthellenistischen Fundkomplexen in Ägypten bekannt ist ${ }^{497}$. Um Einzelstücke handelt es sich auch bei dem Topf (KatNr. K 517) und der Schale mit eingezogenem Rand (KatNr. K 518), wohl ein missglückter Versuch, Tafelgeschirr im Fabric der Küchenware herzustellen. Ferner sind zahlreiche tiefe Schüsseln (KatNr. K 520-527) im Fundbestand vertreten. Kasserollen sind in zwei Formvarianten nachweisbar, wobei jene mit Wandknick (KatNr. K 528-534) (98 $^{4}$ aus einem grob aufbereiteten Rohstoff mit großen Glimmerpartikeln hergestellt wurden, während der Ton der Kasserollen mit Schrägrand und Deckelfalz (KatNr. K 535-537) ${ }^{499}$ wesentlich feiner gemagert ist. Beide Varianten finden zahlreiche Parallelen in späthellenistischen Fundkomplexen in Ephesos. Drei Randfragmente gehören wohl zu Tellern (KatNr. K 538-540), wobei im Einzelfall nicht ausgeschlossen werden kann, dass diese auch als Deckel benutzt wurden $^{500}$. Das kleine und zudem schlecht erhaltene Randfragment KatNr. K 541 kann entweder als Pfanne oder als Kasserolle angesprochen werden ${ }^{501}$. Zu Pfannen wiederum sind die Fragmente KatNr. K 542-545 sowie der Griff (KatNr. K 546) zu ergänzen. Auch dafür lassen sich zahlreiche Vergleichsbeispiele in späthellenistischen und kaiserzeitlichen Fundensembles finden ${ }^{502}$. Wohl auch zu einer Pfanne gehört das Randfragment KatNr. K $547^{503}$, wogegen die steile Gefäßwand von KatNr. K 548 eher auf eine tiefe Schüssel/Eimer schließen lässt ${ }^{504}$. Als Böden von Kasserollen sind KatNr. K 549-551, als Deckelknauf ist KatNr. K 552 anzusprechen.

Sämtliche im vorliegenden Fundkomplex vertretenen Amphoren ${ }^{505}$ datieren in den späten Hellenismus, sieht man von einigen Altstücken ab (KatNr. K 553-555. 603. 621. 637. 618?). Unbestimmter Herkunft ist das Fragment KatNr. K 556, auch wenn die Form an den ephesischen Lokaltyp erinnert. Hauptsächlich handelt es sich um den lokal-regionalen ephesischen Amphorentyp mit dreieckig verdicktem bzw. überhängendem Rand (KatNr. K 556-575). Eine außerephesische Herkunft deutet der hohe Feuerungsgrad des Stückes KatNr. K 563 an, auch wenn die genaue Provenienz nicht bestimmt werden kann. Nordionischer Herkunft, möglicherweise aus der Region von Erythrai, ist das Randfragment KatNr. K 547. Auch ein Großteil der Randfragmente mit rundem, verdicktem Rand (KatNr. K 577-609) entspringt einer kleinasiatischen Produktion, lediglich wenige Stücke (KatNr. K 594. 596. 601) dürfen als Importe angesprochen

490 Ladstätter 2003, K 251.

491 s. dazu Ladstätter 2007, 207; Ladstätter 2003, K 259.

492 Zabehlicky-Scheffenegger - Schneider 2005, Nr. 15-16; Ladstätter 2005, K 244.

493 Ladstätter 2003, K 245-247.

494 Zabehlicky-Scheffenegger - Schneider 2005, Nr. 17; Ladstätter 2005, Nr. 229-234. 237-238.

495 Ladstätter 2005, Nr. 236.

496 Zabehlicky-Scheffenegger - Schneider 2005, Nr. 10.

497 S. C. Herbert - A. Berlin, The Excavation: Occupation History and Ceramic Assemblages, in: S. C. Herbert - A. Berlin, Excavations at Coptos (Qift) in Upper Egypt, 1987-1992, JRA Suppl. 53 (Portsmouth 2003) 13-156, H3.40.

498 Ladstätter 2003, K 261; Ladstätter 2005, 245; Ladstätter 2007, Abb. 3, 2.

499 Ladstätter 2003, K 260; Ladstätter 2007, Abb. 3, 5.

500 Cf. etwa Ladstätter 2003, K 366.

501 Ladstätter 2005, K 244.

502 Ladstätter 2003, K 262-264; Ladstätter 2005, K 246-248; Ladstätter 2007, Abb. 3, 6.

503 Ladstätter 2003, K 263; Ladstätter 2005, K 250-252.

504 Ladstätter 2003, K 265.

505 Für die Bestimmung der Amphoren danke ich M. Lawall sehr herzlich. 
werden. Darunter sind zwei Exemplare aus Knidos (KatNr. K 583. 596) sowie eines aus Kos (KatNr. K 594) zu benennen. Als Altstück ist ein Randfragment des frühen 4. Jahrhunderts aus Chios (KatNr. K 603) anzusprechen. Aus der Region von Erythrai stammt das Exemplar der Form Dressel 26/frühe Variante (KatNr. K 613), während das Fabric eines weiteren Randfragments der Form Dressel 26 (KatNr. K 614) eine knidische Herkunft andeutet. Besonders aufschlussreich für die Herkunft, aber auch die Datierung sind die Stempel auf den Henkeln der Amphoren. Die Stempel KatNr. K 616. 617 sind zu Menophilos zu ergänzen und gehören zu einer kleinasiatischen Produktionsserie des frühen 1. Jahrhunderts v. Chr. Diese Amphoren wurden auch in der Region von Ephesos hergestellt; das Fabric der beiden erhaltenen Stempel weist die Exemplare als lokale Produkte aus ${ }^{506}$. Die Lesung des Stempels von KatNr. K 618 ist nicht unproblematisch, möglich wäre eine Ergänzung zu Phanidos, einem Namen der in Erythrai im 4. Jahrhundert v. Chr. auf Amphoren auftritt. Ephesischer Herkunft ist auch der langrechteckige Stempel KatNr. K 619, der einen Diodotos nennt, ein Name der auch auf rhodischen Amphoren auftritt. Ebenso dürfte der Stempel KatNr. K 620 mit der Lesung Tychon aufgrund der Tonzusammensetzung einer lokalen Produktion entstammen. Wohl auch zu lokalen Amphoren gehören kleine, quadratische Stempel (KatNr. K 622. 623), deren Lesung aufgrund des schlechten Erhaltungszustandes unklar bleiben muss ${ }^{507}$. Um einen rhodischen Import handelt es sich bei KatNr. K 621; der Stempel letztgenannter Amphore nennt wohl den Eponym Polykrates, das Gefäß gehört damit in das 3. Jahrhundert v. Chr. ${ }^{508}$. Lokal ephesischen Amphoren sind die Böden KatNr. K 624-626 und 628 zuzuordnen, wobei KatNr. K 628 noch in das späte 3. Jahrhundert v. Chr. datiert. Möglicherweise aus Knidos stammen KatNr. K 629-631, während KatNr. K 632 aus einer Produktionsstätte Südioniens, möglicherweise Milet, geliefert wurde. Als Import aus dem Westen (Nordafrika, Spanien?) ist KatNr. K 633 anzusprechen, KatNr. K 634 könnte zu einer Dressel 26-Amphore aus Nordionien gehören, KatNr. K 637 ist ein charakteristischer Fuß einer chiotischen Amphore des 3. Jahrhunderts v. Chr. Vielleicht aus Thasos stammt KatNr. K 636, auch wenn eine genaue typologische Zuordnung nicht möglich ist.

Zusammengefasst lässt sich festhalten, dass der weitaus größte Teil der Amphoren aus einer lokalen/ regionalen Produktion stammt und lediglich wenige Amphoren importiert wurden; dies entspricht dem allgemein bekannten Distributions- und Konsumationsmuster des späten Hellenismus im östlichen Mittelmeerraum ${ }^{509}$. Westliche Importe sind im vorliegenden Fundspektrum nur spärlich vertreten.

Abschließend soll noch auf das Lampenspektrum näher eingegangen werden, das sich hauptsächlich aus Ephesos-Lampen zusammensetzt (KatNr. K 640-646) ${ }^{510}$. Eine nicht näher klassifizierbare Lampe (KatNr. $\mathrm{K}$ 647) ist in ihrer Machart als hellenistisch einzustufen, weist aber bereits römische Elemente, wie den Ansatz einer Volutenschnauze, auf. Es könnte sich hierbei um eine Hybridform handeln, wie dies schon mehrfach in Ephesos beobachtet wurde ${ }^{511}$. Das jüngste Stück ist zweifelsohne das Bodenfragment einer römischen Bildlampe (KatNr. K 648), deren Produktion in augusteischer Zeit einsetzt ${ }^{512}$.

Den Abschluss des keramischen Spektrums bilden zwei Webgewichte (KatNr. K 649. 650), von denen eines den Stempel einer Muschel trägt ${ }^{513}$.

Abschließend kann zusammengefasst werden, dass die hier vorgelegte, genaue Fundanalyse in mehrfacher Hinsicht Interpretationsmöglichkeiten eröffnet. Zum einen wurde deutlich, dass das Fundmaterial keinesfalls homogen ist, sondern eine zeitliche Streuung von über etwa einem Jahrhundert aufweist. Die Masse des Keramikmaterials datiert zweifelsohne in das 1. Jahrhundert v. Chr. Die geringe Größe der Fragmente und das weitgehende Fehlen von Ganzformen deuten auf eine mehrfache Umlagerung des Materials hin, bevor es im Zuge von Planierungsvorgängen im Areal des Prytaneions eingeschüttet wurde. Eine

506 Lawall 2007, AH 60.

507 Lawall 2007, $49 \mathrm{f}$.

508 Lawall 2007, $35 \mathrm{f}$.

509 s. zu diesem Phänomen: T. Bezeczky, Consumer Behaviour in Ephesus in the First Century BC, in: D. Malfitana - J. Poblome J. Lund (Hrsg.), Old Pottery in a New Century. Innovating Perspectives on Roman Pottery Studies. Atti del Convegno Internazionale di Studi Catania, 22-24 Aprile 2004 (Catania 2006) 287-293.

$510 \mathrm{Zu}$ Ephesos-Lampen allgemein s. A. Giuliani, Untersuchungen zu Ephesos-Lampen an Beispielen aus der Werkstatt des Asklepiades, in: Krinzinger 2001, 45-49 sowie Mitsopoulos-Leon 2007, 75-80.

511 A. Giuliani, Innovationen im Beleuchtungswesen in Kleinasien, in: Meyer 2007, 171-180.

512 Zum Auftreten italischer Bildlampen in ephesischen Fundspektren s. Ladstätter 2005, 235 f.

$513 \mathrm{Zu}$ gestempelten Webgewichten in Ephesos s. allgemein: V. Mitsopoulos-Leon, Webgewichte, in: Mitsopoulos-Leon - LangAuinger 2007, 114-123 sowie E. Trinkl, Artefakte für die Textilverarbeitung, in: Lang-Auinger 2003, 313-327. 
Interpretation ursprünglicher Kontexte ist methodisch daher ebenso unzulässig wie Aussagen zur Funktion des Fundspektrums.

Für die zeitliche Einordnung des Prytaneions bzw. die Bestimmung der Bauvorgänge interessieren aber speziell die spätesten Stücke in der Aufschüttung, aus denen natürlich immer nur ein terminus post quem abgeleitet werden kann. Darunter sind folgende, für die Frage der Chronologie besonders charakteristische Fragmente anzuführen:

\begin{tabular}{|l|l|l|}
\hline KatNr. & \multicolumn{1}{|c|}{ Objekt } & \multicolumn{1}{c|}{ Datierung } \\
\hline K 60 & ITS Surus-Becher & 15 v. Chr. 10. n. Chr. \\
\hline K 70 & ESA-Teller Atlante 12/tarda f & augusteisch \\
\hline K 89 & ESB-Teller Atlante 22 & augusteisch \\
\hline K 305 & Zylindrischer Becher, dünnwandige Keramik & augusteisch \\
\hline K 505 & Kochtöpfe mit umgeschlagenem, profiliertem Rand & augusteisch \\
\hline K 648 & Italische Bildlampe & augusteisch \\
\hline
\end{tabular}

Die Tabelle macht deutlich, dass die jüngsten Stücke einer 13303 Scherben umfassenden Aufschüttung in augusteische Zeit datieren. Das Fehlen charakteristischer Formen und Varianten der spätaugusteischtiberischen Zeit - wie beispielsweise der grauen Platten mit dreieckigem Rand -, aber auch der geringe Anteil an ESB lassen auf einen Planierungsvorgang in den letzten Jahrzehnten des 1. Jahrhunderts v. Chr. schließen.

Damit datiert der Fundkomplex etwas früher als die bauzeitlichen Horizonte des Tempels am >Staatsmarkt ${ }^{514}$ sowie der Basilike Stoa ${ }^{515}$. Die besten Parallelen bieten die bauzeitlichen Fundkomplexe des Oktogons $s^{516}$.

\section{VI.1.3.2 Bauphase 1 - >Hestiasaal ${ }^{517}$}

Der zweite bauzeitliche Fundkomplex stammt aus dem `Hestiasaak, der deutlich geringere Fundquantitäten aufwies. Trotzdem lassen sich weitgehende Parallelitäten zwischen den beiden Bauphase 1 zugeschriebenen Fundkomplexen feststellen, sodass eine neuerliche typochronologische Einordnung einzelner Fundstücke obsolet ist. Das Sigillataspektrum besteht aus einem einzigen ITS-Teller der Form Consp. 20.1.(?) ${ }^{518}$ (KatNr. K 651), andere Sigillatagruppen sind nur durch Wandfragmente vertreten. Die übrigen feinkeramischen Fragmente gehören zur Glanztonware und verteilen sich auf eine halbkugelige Schale (KatNr. K 652), einen dickwandigen Skyphos (KatNr. K 653), einen konischen Teller (KatNr. K 654), einen Teller mit nach innen geknicktem Rand (KatNr. K 655) sowie einen Teller mit beidseitig verdickter Lippe (KatNr. K 656) und einen weiteren mit gedrechseltem Rand (KatNr. K 657). Der grauen Ware zuzuordnen ist eine konische Schale (KatNr. K 658), von dünnwandiger Keramik hat sich ein Randfragment eines bauchigen Bechers erhalten (KatNr. K 659). Auch die weißgrundige Keramik ist mit einer Lagynos vertreten (KatNr. K 660). Die Gebrauchs- und Küchenware (KatNr. K 661-665) spiegelt das bereits besprochene späthellenistische Spektrum wider. Die Lampen wiederum setzen sich aus einer Ephesos-Lampe (KatNr. K 666) sowie einer ROW-Lampe zusammen (KatNr. K 667). Die Chronologie der ROW-Lampen ist auf Basis des ephesischen Fundbestandes weitgehend geklärt. Entgegen dem ursprünglichen Zeitansatz ist nun zweifelsfrei erwiesen, dass die Red-on-White-Technik bereits in augusteischer Zeit entwickelt wurde ${ }^{519}$. Bislang war man davon ausgegangen, dass die frühesten Fundhorizonte mit ROW-Lampen in die spätaugusteisch-frühtiberische Zeit also doch etwas später als Bauphase 1 im Prytaneion - zu datieren sind.

14 V. Mitsopoulos-Leon, Zur Chronologie des kleinen Tempels auf dem Staatsmarkt in Ephesos, in: Brandt - Gassner - Ladstätter 2005, 203-211.

515 Mitsopoulos-Leon 1991, 155.

516 Waldner 2009b, 293-298 bes. 295.

517 Zum Befund s. M. Steskal, Kapitel IV.4-7 sowie V.3.

518 Consp., 86.

519 Ladstätter 2005, 235 f.; Ladstätter 2007, 211. 
Zusammengefasst lässt sich festhalten, dass auch für die bauzeitlichen Schichten im ১Hestiasaak eine augusteische Datierung zu postulieren ist. Der ITS-Teller der Form Consp. 20.1.(?) sowie die ROW-Lampe könnten Hinweise auf eine etwas jüngere, spätaugusteisch-frühtiberische Zeitstellung sein, sofern die derzeit gültigen Chronologieschemata für die beiden Gattungen einer weiteren Überprüfung standhalten. Möglicherweise erfolgte zu diesem Zeitpunkt der endgültige Bauabschluss des Prytaneions und die Versiegelung durch die Einbringung der Böden.

\section{VI.1.4 BAUPHASE $2^{520}$}

Nur wenige aussagekräftige Funde lassen sich in Bauphase 2 datieren. Neben einer ESC-Schale der Form Atlante L 19/H 3 (KatNr. K 668) ist auf einen bauchigen Becher (KatNr. K 669), einen dünnwandigen Trichterbecher (KatNr. K 670), einen sehr groben Teller (KatNr. K 671) sowie einen Teller/Deckel (KatNr. K 672) hinzuweisen. Steilrandschälchen der Form Atlante L 19/H 3 werden ab der Mitte des 2. Jahrhunderts hergestellt ${ }^{521}$, finden sich aber auch noch häufig in Fundkomplexen der ersten Hälfte des 3. Jahrhunderts ${ }^{522}$. Auch das Fußfragment der lokalen Peacock - Williams 45-Amphore (KatNr. K 673) zeigt Gestaltungsdetails des 3. Jahrhunderts n. Chr. ${ }^{523}$. Mit Sicherheit bereits in das 3. Jahrhundert zu datieren sind auch die zwei Doppelschnauzenlampen (KatNr. K 674. 675), die ihre nächsten Parallelen im Hanghaus 2 finden $^{524}$. Die übrigen Lampenfragmente (KatNr. K 676-678) sind feinchronologisch nicht auswertbar.

Trotz der wenigen Keramikfragmente kann für Bauphase 2 eine Datierung in das 3. Jahrhundert n. Chr. vorgeschlagen werden. Chronologisch vergleichbare Befunde liegen derzeit aus dem Vediusgymnasium ${ }^{525}$ sowie dem Hanghaus 2 vor. Im Hanghaus 2 datiert die Mehrzahl der Fundkomplexe in das 3. Jahrhundert n. Chr., wodurch eine feinchronologische Abfolge und Entwicklung erarbeitet werden konnte. Grundsätzlich lassen sich drei zeitliche Horizonte fassen, die als Bauphase IV (um $230 \mathrm{n}$. Chr.) ${ }^{526}$, als Bauphase IV' (um 250 n. Chr.) ${ }^{527}$ und als endgültige Zerstörung 270-280 n. Chr. ${ }^{528}$ bezeichnet wurden. Aufgrund der geringen Fundmengen und des wenig spezifischen Materials kann für den vorliegenden Fundkomplex aus dem Prytaneion keine exakte zeitliche Einordnung gegeben werden. Festzuhalten bleibt allerdings, dass das Gebäude zwischen 230 und 270/280 n. Chr. massive Schäden erlitten hatte und danach repariert werden musste.

\section{VI.1.5 BAUPHASE $3^{529}$}

Nur sehr wenige Fragmente eignen sich für eine zeitliche Einordnung von Bauphase 3. Das Material ist in seiner Zusammensetzung zudem stark heterogen und weist einen hohen Anteil an frühkaiserzeitlicher Keramik auf. Darunter fällt z. B. das Bodenfragment eines ESB-Schälchens (KatNr. K 679) und das Randfragment eines dünnwandigen Bechers (KatNr. K 680). Trotzdem datiert Bauphase 3 zweifelsohne in die Spätantike, da sich unter den 208 Keramikfragmenten auch charakteristische Wandfragmente von LRCWare befunden haben. Demnach kann die Baumaßnahme nicht vor dem ausgehenden 4. Jahrhundert n. Chr. durchgeführt worden sein. Aufgrund der Tatsache, dass die Tonzusammensetzung, aber auch die Oberflächenbehandlung der LRC über ihren gesamten Produktionszeitraum bis in das 7. Jahrhundert hinweg gleich bleibt, kann keine nähere zeitliche Eingrenzung erfolgen. Auf Basis des keramischen Fundmaterials lässt sich demnach lediglich sagen, dass die Bauphase frühestens im ausgehenden 4. Jahrhunderts anzusetzen ist, theoretisch ist allerdings ein weit späterer zeitlicher Ansatz durchaus vorstellbar.

\footnotetext{
${ }_{520}$ Zum Befund s. M. Steskal, Kapitel IV.6 sowie V.4.

${ }_{521}$ Ladstätter 2008, 99 (mit Diagramm); Ladstätter 2005, K 530; Ladstätter 2010, 188.

522 Ladstätter 2005, K 744; Ladstätter 2010, 190-192.

${ }_{523}$ Ladstätter 2010, A-K 713. 714.

524 Ladstätter 2005, K 843. K 847.

525 Ladstätter 2008, $111 \mathrm{f}$.

526 Ladstätter 2005, 240 f.; Ladstätter 2010, 189-192. 534 f.

527 Ladstätter 2005, 242.

528 Ladstätter 2005, 242-261; Ladstätter 2010, 193. 535-540.

${ }_{529}$ Zum Befund s. M. Steskal, Kapitel IV.7 sowie V.6.
} 


\section{VI.1.5.1 Bauphase $3 a^{530}$}

Zeitlich genauer einzugrenzen ist dagegen Bauphase 3a, für deren Auswertung 686 Keramikfragmente zur Verfügung standen. Die beiden ARS-Teller der Form Hayes 105 (KatNr. K 681. 682) datieren in das 7. Jahrhundert n. Chr. ${ }^{531}$, ein Zeithorizont, der auch durch die Existenz der LRC ${ }^{532}$ (KatNr. K 683-685) und der ERSW $^{533}$ (KatNr. K 686. 687) unterstützt wird. Insbesondere der Teller KatNr. K 687 ist ein sicherer Beleg für eine Datierung in das 7. Jahrhundert und gehört möglicherweise bereits in die Jahrhundertmitte, imitiert er doch LRC-Teller der Form Hayes $10 \mathrm{C}^{534}$. Neben einem dünnwandigen Becherfragment (KatNr. K 688), zwei gebrauchskeramischen Krügen (KatNr. K 689. 690) und dem Randfragment einer großen, gebrauchskeramischen Schüssel (KatNr. K 691) ${ }^{535}$ ist ausdrücklich auf die Küchenware hinzuweisen. Vertreten sind Töpfe mit leicht ausladendem, rund abgestrichenem Rand, wie sie für das späte 6. bzw. das 7. Jahrhundert n. Chr. typisch sind (KatNr. K 692. 693) ${ }^{536}$. Daneben finden sich aber auch solche mit hohem, zylindrischem Hals und schräg ausladendem Rand (KatNr. K 694-696), die nach Ausweis des Materials aus der Marienkirche in die erste Hälfte des 7. Jahrhunderts datieren ${ }^{537}$.

Eine Late Roman Amphorae 1 (KatNr. K 698) ${ }^{538}$ sowie zwei Bodenfragmente von Late Roman Amphorae 3 (KatNr. K 699. 700) ${ }^{539}$ fügen sich ebenso in den zeitlichen Horizont wie ein Lampe des byzantinischen Typs (KatNr. K 701) $)^{540}$ und eine Warzenlampe (KatNr. K 702) $)^{541}$.

Bauphase 3a ist demnach mit Sicherheit im Verlauf des 7. Jahrhunderts n. Chr. anzusetzen, wobei aufgrund der LRC-Imitation eines Hayes 10C-Tellers sowie des spezifischen Kochgeschirrs eine Datierung um die Jahrhundertmitte durchaus wahrscheinlich scheint.

\section{VI.1.6 Diverse FundKOMPLEXe}

\section{VI.1.6.1 Ausrissgrube - SE 105 542}

Das Stratum enthielt insgesamt 746 Keramikfragmente, die alle ausnahmslos einer späthellenistischen-frühkaiserzeitlichen Zeitstellung angehören. Neben einer ESA-Schale (KatNr. K 703) ist auf Glanztonware, vertreten durch einen Skyphos (KatNr. K 704), konische Schalen (KatNr. K 706. 707), einen Becher (KatNr. K 712), einen Teller mit aufgebogenem Rand (KatNr. K 713), Echinusschalen (KatNr. K 714-716), Teller mit breiter Lippe (KatNr. K 717-722) sowie Unguentarien (KatNr. K 723. 724), hinzuweisen. Ergänzt wird das späthellenistische Feinwarespektrum durch einen Henkel mit Applikendekor (KatNr. K 705) sowie mehrere Reliefbecher (KatNr. K 708-711). Das Formenspektrum der Glanztonware wiederholt sich in der Colour Coated Ware durch eine Schale mit ausgebogenem Rand (KatNr. K 727), Echinusschalen (KatNr. K 728-730) und Teller mit breiter Lippe (KatNr. K 731. 732). Krüge (KatNr. K 733. 734. 737. 739) und Schüsseln (KatNr. K 735. 736) ergänzen das gebrauchskeramische Spektrum. Auch bei der Küchenware (KatNr. K 740-744) finden sich ausschließlich Formen des späten Hellenismus und der frühen Kaiserzeit. Die Amphoren wiederum lassen sich in rhodische Importe (KatNr. K 745) und lokalen Produkte (KatNr. K 746-750) scheiden. Ein kleines, gestempeltes Henkelfragment (KatNr. K 751) gehört der regional-ephesischen Produktion an. Abgeschlossen wird das Fundspektrum auch hier durch ein linsenförmiges Webgewicht (KatNr. K 752).

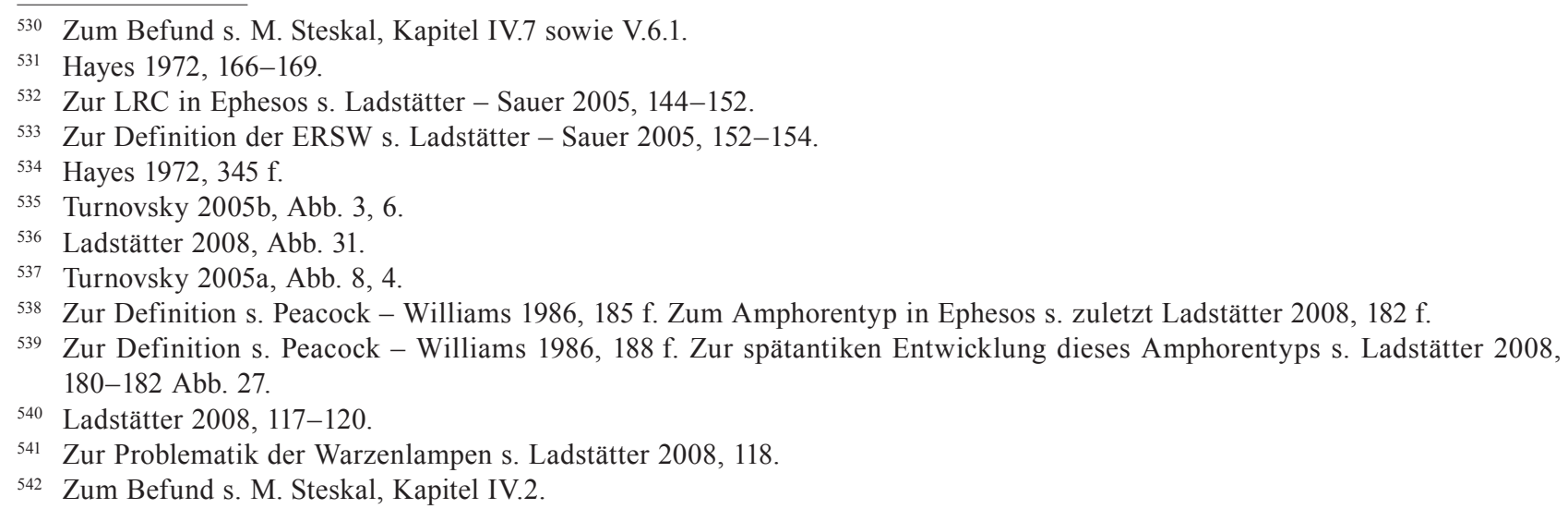


Aus dem archäologischen Befund geht eindeutig hervor, dass der Ausriss dieser Tonrohrleitung während der Spätantike erfolgt sein muss und eine Zeitstellung analog zu SE 214 vorauszusetzen wäre. Das Fundmaterial ist dagegen als homogen frühkaiserzeitlich anzusprechen. Allem Anschein nach verfüllte man die Grube sofort wieder mit dem zuvor ausgehobenen Material, wodurch es zu keiner Kontaminierung mit bauzeitlichem, d. h. spätantikem Fundmaterial kam.

\section{VI.1.6.2 Planierung (?) - SE $203^{543}$}

Ein mit 636 Scherben umfangreicher Fundkomplex liegt auch für SE 203 vor. Das Bodenfragment eines augusteischen ITS-Tellers (KatNr. K 753) zeigt einen Stempel, der aufgrund des schlechten Erhaltungszustandes nicht mehr lesbar ist ${ }^{544}$. Die ESB ist mit Formen der ersten Produktionsserie vertreten, wie Schalen der Formen Atlante 16 (KatNr. K 756), 22 (KatNr. K 755), 29 (KatNr. K 754), sowie mit nicht näher klassifizierbaren Bodenfragmenten (KatNr. K 757. 758). Der pergamenischen Sigillata ist eine Schale (KatNr. K 759) zuzuordnen, während KatNr. K 760 und 761 gängige Formen der Glanztonware wiedergeben. Dünnwandige Keramik (KatNr. K 762), Gebrauchskeramik (KatNr. K 763. 764) und Küchenware (KatNr. K 765-768) datieren ebenso in die frühe Kaiserzeit wie die Amphoren KatNr. K 769-772 und 776. Von lokal-ephesischen Peacock - Williams 45-Amphoren (KatNr. K 773-775) stammen drei Bodenfragmente, deren breite Standflächen auf die frühe Kaiserzeit hindeuten. In dieselbe Zeitspanne datiert auch das Schulterfragment einer Relieflampe (KatNr. K 777).

Zusammengefasst kann auch für SE 203 eine Datierung in augusteische Zeit postuliert werden.

\section{VI.1.6.3 Kanalverfüllung - SE $205^{545}$}

Bei der Kanalverfüllung handelt es sich um heterogenes Fundmaterial, das neben augusteischen Formen wie einem Kochtopf (KatNr. K 779) ${ }^{546}$ auch Material aus der mittleren Kaiserzeit enthält. Insbesondere ist dabei auf die lokal ephesischen Amphoren des Typs Peacock - Williams 45 (KatNr. K 780. 781) in typischen Formvarianten des 3. Jahrhunderts hinzuweisen ${ }^{54}$. Es ist demnach davon auszugehen, dass der Kanal im Verlauf des 3. Jahrhunderts außer Benutzung geriet und in weiterer Folge verfüllt wurde ${ }^{548}$.

\section{VI.1.6.4 Grubenverfüllung - SE $214^{549}$}

Durch das Randfragment eines Tellers der sog. Mäandertalsigillata ${ }^{550}$ (KatNr. K 783) ist der Fundkomplex problemlos in das 7. Jahrhundert einzureihen. Diesem Zeitansatz entsprechen auch die beiden großen Schüsseln KatNr. K 784 und 785, wogegen der Kochtopf KatNr. K 786 etwas früher datieren könnte ${ }^{551}$. Ebenfalls in das frühe 7. Jahrhundert n. Chr. gehören die Lampen des byzantinischen Typs, von dem sich im vorliegenden Fundkomplex Schulter- (KatNr. K 788-790), Schnauzen- (KatNr. K 791) und Bodenfragmente (KatNr. K 792-794) erhalten haben ${ }^{552}$.

Die Verfüllung der Grube fand demnach im Verlauf des 7. Jahrhunderts n. Chr. statt, wobei auch hier durchaus an eine Aktivität um die Jahrhundertmitte gedacht werden kann.

\footnotetext{
543 Zum Befund s. M. Steskal, Kapitel IV.3.

544 Martin 2003, 248 (Überblick der ITS-Stempel in Ephesos).

545 Zum Befund s. M. Steskal, Kapitel IV.3.

${ }_{546}$ Zabehlicky-Scheffenegger - Schneider 2005, Nr. 18.

547 Ladstätter 2010, A-K 713. 714. 913. 914.

548 Cf. etwa auch Quatember - Waldner - Pfisterer - Aurenhammer 2008, 278 f. (SE 35).

549 Zum Befund s. M. Steskal, Kapitel IV.3.

550 Turnovsky 2005a, Abb. 8, 1; Quatember - Waldner - Pfisterer - Aurenhammer 2008, 284.

551 Ladstätter 2008, K 526 (spätes 6. Jh.).

${ }_{552}$ Ladstätter 2008, 118-120; Iro - Schwaiger - Waldner 2009, Abb. 35, 3-6.
} 


\section{VI.1.7 Katalog (Sabine Ladstätter - Nicole M. High)}

Die Kataloganordnung folgt dem chronologisch strukturierten Textaufbau und ist in Bauperioden bzw. Fundkomplexe gegliedert. Innerhalb der Fundkomplexe wurde eine Einteilung nach Gattungen und Waren vorgenommen. Die Farbbestimmung richtet sich nach Munsell, Soil Color Charts (Edition 1992), die Tonbeschreibung umfasst lediglich die Farbangabe, da die einzelnen Waren bereits mehrfach definiert wurden ${ }^{553}$ und auch in der vorliegenden Arbeit im Text diskutiert werden. Der gute Publikationsstand zur Keramik des 2. Jahrhunderts v. Chr. bis in die Spätantike in Ephesos erlaubte es, für die meisten der hier vorliegenden Stücke Parallelen im ephesischen Fundbestand zu finden. Auch diese Angaben wurden in den Text integriert. Sieht man von einzelnen Ganzgefäßen ab, die im Efes Müzesi in Selçuk gelagert sind, befinden sich alle Funde im Depot des österreichischen Grabungshauses in Ephesos.

\section{Terrassierung (ausgehendes 3. Jahrhundert v. Chr.)}

\section{KatNr. K 1}

Gattung: Glanztonware (attisch)

Form: Echinusschale

InvNr. SE 217/20

AO: GHD

Überzug: flächig, kompakt, glänzend

Ton: 2.5YR6/6

Farbe außen: 5YR2.5/1, Farbe innen: 5YR2.5/1

Maße: DmRd $13 \mathrm{~cm}$, erh. H 1,65 cm

Erh.: 1 Rdfrgt.

\section{KatNr. K 2}

Gattung: Glanztonware (attisch)

Form: Echinusschale

InvNr. SE 217/14

AO: GHD

Überzug: flächig, kompakt, glänzend

Ton: 7.5YR6/4

Farbe außen: 5YR2.5/1, Farbe innen: 5YR2.5/1

Maße: DmRd 8,8 cm, erh. H 1,8 cm

Erh.: 1 Rdfrgt.

\section{KatNr. K 3}

Gattung: Glanztonware (attisch?)

Form: Schale mit Horizontalrand

InvNr. SE 217/13

AO: GHD

Überzug: flächig, kompakt, glänzend

Ton: 7.5YR6/3

Farbe außen: 5YR2.5/1, Farbe innen: 5YR2.5/1

Maße: DmRd 13,2 cm, erh. H 1,3 cm

Erh.: 1 Rdfrgt.

\section{KatNr. K 4}

Gattung: Glanztonware

Form: Skyphos/Kantharos

InvNr. SE 217/23

AO: GHD

Überzug: flächig, kompakt, glänzend

Ton: 5YR6/6

Farbe außen: 5YR2.5/1, Farbe innen: 5YR2.5/1

Maße: DmBd 4,5 cm, erh. H 1,75 cm

Dekor: feiner Palmettenstempel an der Bodeninnenseite

Erh.: 1 Bdfrgt.
Taf. 162

\section{KatNr. K 5}

Gattung: Glanztonware (attisch?)

Form: Schale

InvNr. SE 217/17

AO: GHD

Überzug: flächig, kompakt, glänzend

Ton: 5YR7/6

Farbe außen: 5YR2.5/1, Farbe innen: 5YR2.5/1

Maße: DmRd 21,2 cm, erh. H 1,1 cm

Erh.: 1 Rdfrgt.

Taf. 162

KatNr. K 6

Taf. 162

Gattung: Feinware

Form: Becher

InvNr. SE 217/12

AO: GHD

Ton: 2.5 YR5/4

Farbe außen: 5YR2.5/1, Farbe innen: 5YR2.5/1

Maße: DmRd 10,6 cm, erh. H 1,95 cm

Erh.: 1 Rdfrgt.

\section{KatNr. K 7}

Taf. 162

Taf. 162

Gattung: Glanztonware

Form: Lekanis

InvNr. SE 113/11

AO: GHD

Überzug: flächig, kompakt, glänzend

Ton: 10YR7/6

Farbe außen: 5YR2.5/1, Farbe innen: 5YR2.5/1

Maße: DmRd 8,1 cm, erh. H 2,1 cm

Erh.: 1 Rdfrgt.

\section{KatNr. K 8}

Taf. 162

Taf. 162.218

Gattung: Glanztonware (attisch?)

Form: Halbkugelige Schale

InvNr. SE $113 / 26$

AO: GHD

Überzug: flächig, kompakt, glänzend

Ton: 7.5 YR6/3

Farbe außen: 5YR7/4+5YR4/1, Farbe innen: 7.5YR5/

$1+7.5$ YR7/4

Maße: DmRd 17,8 cm, erh. H 2,2 cm

Erh.: 1 Rdfrgt.

553 Ladstätter 2003; Ladstätter 2005; Ladstätter 2008; Ladstätter 2010. 


\section{KatNr. K 9}

Gattung: Glanztonware

Form: Halbkugelige Schale

InvNr. SE 113/14

AO: GHD

Überzug: flächig, kompakt, glänzend

Ton: 2.5 YR6/8

Farbe außen: 5YR2.5/1, Farbe innen: 5YR2.5/1

Maße: DmRd 14,7 cm, erh. H 3,3 cm

Erh.: 1 Rdfrgt.

\section{KatNr. K 10}

Gattung: Glanztonware

Form: Halbkugelige Schale

InvNr. SE 113/2

AO: GHD

Überzug: flächig, kompakt, glänzend

Ton: $2.5 \mathrm{YR} 8 / 4$

Farbe außen: 7.5YR8/4, Farbe innen: 7.5YR8/4

Maße: DmRd 9,2 cm, erh. H 1,7 cm

Erh.: 1 Rdfrgt.

\section{KatNr. K 11}

Gattung: Glanztonware

Form: Echinusschale

InvNr. SE 113/8

AO: GHD

Überzug: flächig, kompakt, glänzend

Ton: 5YR7/4

Farbe außen: 5YR7/6+5YR4/1, Farbe innen: 5YR7/6+5YR4/1

Maße: DmRd nicht bestimmbar, erh. H 1,8 cm

Erh.: 1 Rdfrgt.

\section{KatNr. K 12}

Taf. 162

Gattung: Glanztonware

Form: Echinusschale

InvNr. SE 113/31

AO: GHD

Überzug: flächig, kompakt, glänzend

Ton: 7.5 YR6/3

Farbe außen: 7.5YR7/1, Farbe innen: 5YR2.5/1

Maße: DmBd 3,9 cm, erh. H 2,4 cm

Erh.: 1 Bdfrgt.

\section{KatNr. K 13}

Gattung: Glanztonware

Form: Echinusschale

InvNr. SE 217/27

AO: GHD

Überzug: flächig, kompakt, glänzend

Ton: 2.5 YR7/6

Farbe außen: 5YR2.5/1, Farbe innen: 5YR2.5/1

Maße: DmRd nicht bestimmbar, erh. H 2,95 cm

Erh.: 1 Rdfrgt.

\section{KatNr. K 14}

Gattung: Glanztonware

Form: Echinusschale

InvNr. SE 217/15

AO: GHD

Überzug: flächig, kompakt, glänzend

Taf. 162

Taf. 162
Taf. 162 Ton: 7.5 YR5/1

Farbe außen: 5YR2.5/1, Farbe innen: 5YR2.5/1

Maße: DmRd $12 \mathrm{~cm}$, erh. H 2,45 cm

Erh.: 1 Rdfrgt.

KatNr. K 15

Taf. 162

Gattung: Glanztonware

Form: Echinusschale

InvNr. SE 217/19

AO: GHD

Überzug: flächig, kompakt, glänzend

Ton: 5YR5/1

Farbe außen: 5YR2.5/1, Farbe innen: 5YR2.5/1

Maße: DmRd 11,2 cm, erh. H $2 \mathrm{~cm}$

Erh.: 1 Rdfrgt.

KatNr. K 16

Taf. 162

Gattung: Glanztonware

Form: Halbkugelige Schale

InvNr. SE 217/7

AO: GHD

Überzug: flächig, kompakt, glänzend

Ton: 5YR6/6

Farbe außen: 2.5YR6/6, Farbe innen: 2.5YR6/6

Maße: DmRd 17,6 cm, erh. H 1,9 cm

Erh.: 1 Rdfrgt.

KatNr. K 17

Taf. 162

Gattung: Glanztonware

Form: Halbkugelige Schale

InvNr. SE 113/15

AO: GHD

Überzug: flächig, kompakt, glänzend

Ton: 10 YR7/4

Farbe außen: 7.5YR7/4, Farbe innen: 5YR2.5/1

Maße: DmRd 25,9 cm, erh. H 2,1 cm

Erh.: 1 Rdfrgt.

\section{KatNr. K 18}

Taf. 163

Gattung: Glanztonware

Form: Halbkugelige Schale mit verdicktem Rand InvNr. SE 113/25

AO: GHD

Taf. 162 Überzug: flächig, kompakt, glänzend

Ton: 7.5 Y R7/3

Farbe außen: 5YR2.5/1, Farbe innen: 5YR2.5/1

Maße: DmRd 14,7 cm, erh. H 2 cm

Erh.: 1 Rdfrgt.

KatNr. K 19

Taf. 163

Gattung: Glanztonware

Form: Halbkugelige Schale mit verdicktem Rand

InvNr. SE 113/9

AO: GHD

Taf. 162 Überzug: flächig, kompakt, glänzend

Ton: 7.5 YR5/2

Farbe außen: 7.5YR8/3+7.5YR4/1, Farbe innen: 7.5YR8/3

$+7.5 \mathrm{YR} 4 / 1$

Maße: DmRd 17,2 cm, erh. H 2,4 cm

Erh.: 1 Rdfrgt. 


\section{KatNr. K 20}

Gattung: Glanztonware

Form: Halbkugelige Schale mit verdicktem Rand InvNr. SE 217/22

AO: GHD

Überzug: flächig, kompakt, glänzend

Ton: 2.5 YR5/6+2.5YR6/1

Farbe außen: 5YR2.5/1, Farbe innen: 5YR2.5/1

Maße: DmRd 14,2 cm, erh. H 2,2 cm

Erh.: 1 Rdfrgt.

\section{KatNr. K 21}

Gattung: Glanztonware

Form: Halbkugelige Schale mit verdicktem Rand InvNr. SE 217/8

AO: GHD

Überzug: flächig, kompakt, glänzend

Ton: 5YR6/8+7.5YR7/2

Farbe außen: 5YR2.5/1, Farbe innen: 5YR2.5/1

Maße: DmRd 20,8 cm, erh. H 2,6 cm

Erh.: 1 Rdfrgt.

\section{KatNr. K 22}

Gattung: Glanztonware

Form: Skyphos/Kantharos

InvNr. SE 113/32

AO: GHD

Überzug: flächig, kompakt, glänzend

Ton: 5YR7/6

Farbe außen: 7.5YR4/2, Farbe innen: 7.5YR4/2

Maße: DmRd 13,3 cm, erh. H 3,5 cm

Erh.: 1 Rdfrgt.

\section{KatNr. K 23}

Taf. 163

Gattung: Glanztonware

Form: Skyphos/Kantharos

InvNr. SE 217/24

AO: GHD

Überzug: flächig, kompakt, glänzend

Ton: 2.5YR6/4

Farbe außen: 5YR2.5/1, Farbe innen: 5YR2.5/1

Maße: DmRd 9,6 cm, erh. H 1,6 cm

Erh.: 1 Rdfrgt.

KatNr. K 24

Taf. 163

Gattung: Glanztonware

Form: Krug

InvNr. SE 217/31

AO: GHD

Überzug: flächig, kompakt, glänzend

Ton: 10YR6/2

Farbe außen: 10YR8/1, Farbe innen: 10YR8/1, Farbe Dekor am Rd: 5YR2.5/1

Maße: DmRd 10,6 cm, erh. H 2,05 cm

Erh.: 1 Rdfrgt.

KatNr. K 25

Taf. 163

Gattung: Glanztonware

Form: Schale mit Wandknick

InvNr. SE 217/26

AO: GHD

Taf. 163

Taf. 163
Taf. 163 Überzug: flächig, kompakt, glänzend

Ton: 5YR6/6

Farbe außen: 5YR2.5/1, Farbe innen: 5YR2.5/1

Maße: DmRd 19,8 cm, erh. H 2,1 cm

Erh.: 1 Rdfrgt.

\section{KatNr. K 26}

Taf. 163

Gattung: Glanztonware

Form: Schale mit Wandknick

InvNr. SE 113/27

AO: GHD

Überzug: flächig, kompakt, glänzend

Ton: 2.5 YR6/8

Farbe außen: 2.5YR5/6, Farbe innen: 2.5YR5/6

Maße: DmRd 23,6 cm, erh. H 1,8 cm

Erh.: 1 Rdfrgt.

\section{KatNr. K 27}

Taf. 163

Gattung: Glanztonware

Form: Schale mit Wandknick

InvNr. SE 113/12

AO: GHD

Überzug: flächig, kompakt, glänzend

Ton: $7.5 Y R 7 / 4$

Farbe außen: 5YR2.5/1, Farbe innen: 5YR2.5/1

Maße: DmRd nicht bestimmbar, erh. H 1,4 cm

Erh.: 1 Rdfrgt.

\section{KatNr. K 28}

Taf. 163

Gattung: Glanztonware

Form: Schale mit Wandknick

InvNr. SE 217/18

AO: GHD

Überzug: flächig, kompakt, glänzend

Ton: 5YR7/6

Farbe außen: 5YR2.5/1, Farbe innen: 5YR2.5/1

Maße: DmRd $21 \mathrm{~cm}$, erh. H 1,5 cm

Erh.: 1 Rdfrgt.

\section{KatNr. K 29}

Taf. 163

Gattung: Glanztonware

Form: Schale mit Wandknick

InvNr. SE 113/13

AO: GHD

Überzug: flächig, kompakt, glänzend

Ton: 5YR7/8

Farbe außen: 5YR2.5/1, Farbe innen: 5YR2.5/1

Maße: DmRd 18,6 cm, erh. H 1,3 cm

Erh.: 1 Rdfrgt.

\section{KatNr. K 30}

Taf. 163

Gattung: Glanztonware

Form: Schale mit Wandknick

InvNr. SE 217/25

AO: GHD

Überzug: flächig, kompakt, glänzend

Ton: 2.5 YR6/6

Farbe außen: 5YR2.5/1, Farbe innen: 5YR2.5/1

Maße: DmRd 27,6 cm, erh. H 1,95 cm

Erh.: 1 Rdfrgt. 


\section{KatNr. K 31}

Gattung: Glanztonware

Form: Teller mit verdickter Lippe

InvNr. SE 217/21

AO: GHD

Überzug: flächig, kompakt, glänzend

Ton: 2.5 YR6/8

Farbe außen: 5YR2.5/1, Farbe innen: 5YR2.5/1

Maße: DmRd 11,2 cm, erh. H 1,6 cm

Erh.: 1 Rdfrgt.

\section{KatNr. K 32}

Gattung: Glanztonware

Form: Teller mit verdickter Lippe

InvNr. SE 217/28

AO: GHD

Überzug: flächig, kompakt, glänzend

Ton: 7.5YR6/2

Farbe außen: 5YR2.5/1, Farbe innen: 7.5YR6/1

Maße: DmRd 18,4 cm, erh. H 1,5 cm

Erh.: 1 Rdfrgt.

\section{KatNr. K 33}

Gattung: Glanztonware (attisch)

Form: Teller mit gerollter Lippe

InvNr. SE 217/34

AO: GHD

Überzug: flächig, kompakt, glänzend

Ton: 7.5YR6/4

Farbe außen: 5YR2.5/1, Farbe innen: 5YR2.5/1

Maße: DmRd 21,9 cm, erh. H 2,05 cm

Erh.: 1 Rdfrgt.

\section{KatNr. K 34}

Gattung: Glanztonware

Form: Schale

InvNr. SE 217/33

AO: GHD

Überzug: flächig, kompakt, glänzend

Ton: 7.5 YR6/3

Farbe außen: 7.5YR4/1, Farbe innen: 7.5YR4/1

Maße: DmRd 12,4 cm, erh. H $1 \mathrm{~cm}$

Erh.: 1 Rdfrgt.

\section{KatNr. K 35}

Taf. 164

Gattung: Glanztonware

Form: Krater

InvNr. SE 113/24

AO: GHD

Überzug: flächig, kompakt, glänzend

Ton: 5YR6/6

Farbe außen: 7.5YR8/4+5YR6/6, Farbe innen: 2.5YR5/6

Maße: DmRd 33,4 cm, erh. H 3,9 cm

Erh.: 1 Rdfrgt.

\section{KatNr. K 36}

Taf. 164. 218

Gattung: Glanztonware

Form: Schale

InvNr. SE 217/16

AO: GHD

Überzug: flächig, kompakt, glänzend
Taf. 163 Ton: 5YR6/6

Farbe außen: 5YR2.5/1, Farbe innen: 5YR2.5/1

Maße: DmBd 1,5 cm, erh. H 0,8 cm

Dekor: feiner Riefeldekor an der Gefäßaußenseite

Erh.: 1 Bdfrgt.

KatNr. K 37

Taf. 164. 218

Gattung: Glanztonware

Form: Teller

InvNr. SE 217/11

AO: GHD

Taf. 163 Überzug: flächig, kompakt, glänzend

Ton: 5YR5/1

Farbe außen: 5YR2.5/1, Farbe innen: 5YR2.5/1

Maße: DmBd 5,9 cm, erh. H 1,25 cm

Dekor: Palmettenstempel an der Bodeninnenseite

Erh.: 1 Bdfrgt.

KatNr. K 38

Taf. 164

Gattung: Gebrauchskeramik

Form: Töpfchen

InvNr. SE $113 / 1$

Taf. 164 AO: GHD

Ton: $7.5 \mathrm{YR} 7 / 4$

Farbe außen: 10YR8/4, Farbe innen: 10YR8/4

Maße: DmRd 6 cm, erh. H $2 \mathrm{~cm}$

Erh.: 1 Rdfrgt.

KatNr. K 39

Taf. 164

Gattung: Gebrauchskeramik

Form: Krug

InvNr. SE 113/23

AO: GHD

Taf. 164 Ton: 7.5YR6/4

Farbe außen: 7.5YR8/4, Farbe innen: 7.5YR8/4

Maße: DmRd 9,6 cm, erh. H $3 \mathrm{~cm}$

Erh.: 1 Rdfrgt.

KatNr. K 40

Taf. 164

Gattung: Gebrauchskeramik

Form: Krug/Flasche

InvNr. SE 217/30

AO: GHD

Ton: 2.5YR6/6

Farbe außen: 5YR7/4, Farbe innen: 5YR7/4

Maße: DmRd 3,8 cm, erh. H 2,5 cm

Erh.: 1 Rdfrgt.

KatNr. K 41

Taf. 164

Gattung: Gebrauchskeramik

Form: Echinusschale

InvNr. SE 113/7

AO: GHD

Ton: $7.5 Y R 7 / 6$

Farbe außen: 7.5YR8/6, Farbe innen: 5YR7/6

Maße: DmRd 11,6 cm, erh. H 2 cm

Erh.: 1 Rdfrgt.

KatNr. K 42

Taf. 164

Form: Echinusschale 
InvNr. SE $113 / 6$

AO: GHD

Ton: $2.5 \mathrm{YR} 7 / 6$

Farbe außen: 7.5YR8/5+2.5YR6/6, Farbe innen: 7.5YR8/5

+2.5 YR6/6

Maße: DmRd 13,2 cm, erh. H 2,35 cm

Erh.: 1 Rdfrgt.

KatNr. K 43

Gattung: Gebrauchskeramik

Form: Echinusschale

InvNr. SE 113/4

AO: GHD

Ton: 5YR7/8

Farbe außen: 2.5YR6/6+5YR7/6, Farbe innen: 2.5YR6/6

+5 YR7/6

Maße: DmRd 14,4 cm, erh. H 2,2 cm

Erh.: 1 Rdfrgt.

\section{KatNr. K 44}

Taf. 164

Gattung: Gebrauchskeramik

Form: Echinusschale

InvNr. SE $113 / 3$

AO: GHD

Ton: 10YR6/4

Farbe außen: 7.5YR4/2+10YR7/4, Farbe innen: 7.5YR4/2

+10 YR7/4

Maße: DmRd 14,5 cm, erh. H 2,1 cm

Erh.: 1 Rdfrgt.

\section{KatNr. K 45}

Taf. 164

Gattung: Gebrauchskeramik

Form: Echinusschale

InvNr. SE 113/5

AO: GHD

Ton: 7.5 YR $7 / 4$

Farbe außen: 2.5YR6/6+7.5YR8/6, Farbe innen: 2.5YR6/6

+7.5 YR $8 / 6$

Maße: DmRd 11,3 cm, erh. H 2,8 cm

Erh.: 1 Rdfrgt.

\section{KatNr. K 46}

Gattung: Gebrauchskeramik

Form: Echinusschale

InvNr. SE 217/9

AO: GHD

Ton: 7.5YR6/4

Farbe außen: 5YR2.5/1, Farbe innen: 5YR2.5/1

Maße: DmRd 9,8 cm, erh. H 2,2 cm

Erh.: 1 Rdfrgt.

\section{KatNr. K 47}

Gattung: Gebrauchskeramik

Form: Teller

InvNr. SE 113/10

AO: GHD

Ton: 7.5YR7/4

Farbe außen: 7.5YR7/4, Farbe innen: 7.5YR7/4

Maße: DmRd 17,7 cm, erh. H 1,4 cm

Erh.: 1 Rdfrgt.

Taf. 164

Taf. 164

\section{KatNr. K 48}

Taf. 165

Gattung: Gebrauchskeramik

Form: Schüssel

InvNr. SE 113/17

AO: GHD

Ton: 5YR5/6

Farbe außen: 5YR7/6, Farbe innen: 5YR7/6

Maße: DmRd 27,4 cm, erh. H 0,8 cm

Erh.: 1 Rdfrgt.

\section{KatNr. K 49}

Taf. 165

Gattung: Gebrauchskeramik

Form: Schüssel

InvNr. SE 113/16

AO: GHD

Ton: $10 \mathrm{YR} 7 / 4$

Farbe außen: 5YR6/6+7.5YR8/6, Farbe innen: 5YR6/6

+7.5 YR $8 / 6$

Maße: DmRd 24,8 cm, erh. H 1,9 cm

Erh.: 1 Rdfrgt.

KatNr. K 50

Taf. 165

Gattung: Küchenware

Form: Topf

InvNr. SE 113/18

AO: GHD

Ton: $10 \mathrm{YR} 5 / 2$

Farbe außen: 10YR7/2, Farbe innen: 10YR7/2

Maße: DmRd 14,2 cm, erh. H 3,7 cm

Erh.: 1 Rdfrgt.

\section{KatNr. K 51}

Taf. 165

Gattung: Küchenware

Form: Topf

InvNr. SE 217/29

AO: GHD

Ton: 7.5YR6/4

Farbe außen: 5YR7/4, Farbe innen: 5YR7/4

Maße: DmRd 12,4 cm, erh. H 2,95 cm

Erh.: 1 Rdfrgt.

\section{KatNr. K 52}

Taf. 165

Gattung: Küchenware

Form: Schüssel (?)

InvNr. SE $217 / 5$

AO: GHD

Ton: 5YR4/6

Farbe außen: 7.5YR6/2, Farbe innen: 7.5YR6/2

Maße: DmRd 20,4 cm, erh. H 4,6 cm

Erh.: 1 Rdfrgt.

\section{KatNr. K 53}

Taf. 165

Gattung: Küchenware

Form: Teller

InvNr. SE 112/1

AO: GHD

Ton: 2.5 YR $5 / 8$

Farbe außen: 10YR7/4, Farbe innen: 10YR7/4

Maße: DmRd 28,6 cm, erh. H 3,2 cm

Erh.: 1 Rdfrgt. 


\section{KatNr. K 54}

Gattung: Küchenware

Form: Schüssel

InvNr. SE 217/6

AO: GHD

Ton: $2.5 \mathrm{YR} 5 / 8$

Farbe außen: 5YR6/6, Farbe innen: 5YR6/6

Maße: DmRd 20,2 cm, erh. H $3 \mathrm{~cm}$

Erh.: 1 Rdfrgt.

\section{KatNr. K 55}

Gattung: Amphore/rhodisch

InvNr. SE 113/19

AO: GHD

Ton: $2.5 \mathrm{YR} 6 / 8$

Farbe außen: 5YR7/6, Farbe innen: 5YR7/6

Maße: DmRd 8,3 cm, erh. H 6 cm

Erh.: 1 Rdfrgt.

\section{KatNr. K 56}

Gattung: Amphore

InvNr. SE 217/3

AO: GHD

Ton: $7.5 \mathrm{YR} 5 / 2$

Farbe außen: 10YR7/2, Farbe innen: 10YR7/2

Maße: DmRd 9,8 cm, erh. H 3,3 cm

Erh.: 1 Rdfrgt.

\section{KatNr. K 57}

Gattung: Amphore

InvNr. SE 217/4

AO: GHD

Ton: 5YR6/6

Farbe außen: 7.5YR7/4, Farbe innen: 7.5YR7/4

Maße: DmRd 9,6 cm, erh. H 2,95 cm

Erh.: 1 Rdfrgt.

\section{KatNr. K 58}

Gattung: Amphore

InvNr. SE 217/2

AO: GHD

Ton: $2.5 \mathrm{YR} 5 / 6$

Farbe außen: 5YR6/6, Farbe innen: 5YR6/6, Farbe Dekor am Rd: 5YR2.5/1

Maße: DmRd 10,8 cm, erh. H 3,05 cm

Erh.: 1 Rdfrgt.

\section{KatNr. K 59}

Taf. 165

Gattung: Amphore

InvNr. SE 217/1

AO: GHD

Ton: 7.5 YR6/3+2.5YR6/8

Farbe außen: 7.5YR8/6, Farbe innen: 7.5YR6/3

Maße: DmRd 10,4 cm, erh. H 4,2 cm

Erh.: 1 Rdfrgt.
Taf. 165

Taf. 165

Taf. 165

Taf. 165

Taf. 165

KatNr. K 62

Taf. 166

Gattung: Eastern Sigillata A

Form: Teller Atlante 3

InvNr. SE 207/24

AO: GHD

Überzug: flächig, teilweise abgerieben, matt glänzend

Ton: 5 YR7/6

Farbe außen: 2.5YR4/8, Farbe innen: 2.5YR4/8

Maße: DmRd 29,4 cm, erh. H 2,6 cm

Erh.: 1 Rdfrgt.

KatNr. K 63

Taf. 166

Gattung: Eastern Sigillata A

Form: Teller Atlante 4

InvNr. SE 207/95

AO: GHD

Überzug: flächig, teilweise abgerieben, matt glänzend Ton: $7.5 \mathrm{YR} 8 / 2$

Farbe außen: 2.5YR4/8, Farbe innen: 2.5 YR $4 / 8$

Maße: DmRd 23,8 cm, erh. H 2,1 cm

Erh.: 1 Rdfrgt.

KatNr. K 64

Taf. 166

Gattung: Eastern Sigillata A

Form: Teller Atlante 3/4

InvNr. SE 207/25

AO: GHD

Überzug: flächig, teilweise abgerieben, matt glänzend

Ton: 7.5 YR8/4

Farbe außen: 2.5YR4/6, Farbe innen: 2.5YR4/6

Maße: DmRd 19,4 cm, erh. H 2,4 cm

Erh.: 1 Rdfrgt. 


\section{KatNr. K 65}

Gattung: Eastern Sigillata A

Form: Teller Atlante 3

InvNr. SE 110/4

AO: GHD

Überzug: flächig, teilweise abgerieben, matt glänzend

Ton: 2.5 YR $4 / 8$

Farbe außen: 5YR8/3, Farbe innen: 5YR8/3

Maße: DmRd 17,8 cm, erh. H 1,8 cm

Erh.: 1 Rdfrgt.

\section{KatNr. K 66}

Gattung: Eastern Sigillata A

Form: Schälchen Atlante 22

InvNr. SE 207/71

AO: GHD

Überzug: flächig, teilweise abgerieben, matt glänzend

Ton: 5YR8/4

Farbe außen: 10R5/8, Farbe innen: 10R5/8

Maße: DmRd 8 cm, erh. H 3,6 cm

Erh.: 1 Rdfrgt.

\section{KatNr. K 67}

Gattung: Eastern Sigillata A

Form: Schale Atlante 5A

InvNr. SE 207/22

AO: GHD

Überzug: flächig, teilweise abgerieben, matt glänzend

Ton: 5YR7/6

Farbe außen: 10R5/8, Farbe innen: 10R5/8

Maße: DmRd 12,4 cm, erh. H 2,9 cm

Erh.: 1 Rdfrgt.

\section{KatNr. K 68}

Gattung: Eastern Sigillata A

Form: Schale TA 25a

InvNr. SE 209/23

AO: GHD

Überzug: flächig, teilweise abgerieben, matt glänzend

Ton: $7.5 \mathrm{YR} 8 / 4$

Farbe außen: 10R5/6, Farbe innen: 10R5/6

Maße: DmRd 12,2 cm, erh. H $3 \mathrm{~cm}$

Erh.: 1 Rdfrgt.

\section{KatNr. K 69}

Taf. 166

Gattung: Eastern Sigillata A

Form: Schale Atlante 22B/Atlante 14

InvNr. SE 209/37

AO: GHD

Überzug: flächig, teilweise abgerieben, matt glänzend

Ton: 5YR7/6

Farbe außen: 10R5/8, Farbe innen: 10R5/8

Maße: DmRd 7,6 cm, erh. H 2,55 cm

Erh.: 1 Rdfrgt.

\section{KatNr. K 70}

Gattung: Eastern Sigillata A

Form: Teller Atlante 12/tarda f

InvNr. SE 207/21

AO: GHD

Überzug: flächig, teilweise abgerieben, matt glänzend

Taf. 166
Taf. 166 Ton: 5YR7/6

Farbe außen: 2.5YR4/8, Farbe innen: 2.5YR4/8

Maße: DmRd 14 cm, erh. H 2,3 cm

Erh.: 2 Rdfrgt.

KatNr. K 71

Taf. 166

Gattung: Eastern Sigillata A

Form: Schale

InvNr. SE 209/36

AO: GHD

Überzug: flächig, teilweise abgerieben, matt glänzend

Ton: 10YR8/3 (heller)

Farbe außen: 10R5/6, Farbe innen: 10R5/6

Maße: DmRd 11,3 cm, erh. H 1,6 cm

Erh.: 1 Rdfrgt.

KatNr. K 72

Taf. 166

Gattung: Eastern Sigillata A

Form: Teller Atlante 3/4

InvNr. SE 207/101

AO: GHD

Taf. 166 Überzug: flächig, teilweise abgerieben, matt glänzend Ton: 7.5 YR $8 / 3$

Farbe außen: 10R4/6, Farbe innen: 10R4/6

Maße: DmBd 8,6 cm, erh. H 1,35 cm

Erh.: 1 Bdfrgt.

KatNr. K 73

Taf. 166

Gattung: Eastern Sigillata A

Form: Schale Atlante 5 (?)

InvNr. SE 208/3

AO: GHD

Überzug: flächig, teilweise abgerieben, matt glänzend

Ton: 5YR8/4

Farbe außen: 2.5YR4/8, Farbe innen: 2.5 YR4/8

Maße: DmBd 6,4 cm, erh. H $1,8 \mathrm{~cm}$

Erh.: 1 Bdfrgt.

\section{KatNr. K 74}

Taf. 166

Gattung: Eastern Sigillata A

Form: Teller Atlante 3

InvNr. SE 209/11

AO: GHD

Überzug: flächig, teilweise abgerieben, matt glänzend

Ton: $7.5 \mathrm{YR} 8 / 4$

Farbe außen: 10R4/8, Farbe innen: 10R4/8

Maße: DmBd 7,4 cm, erh. H 2,8 cm

Erh.: 1 Bdfrgt.

\section{KatNr, K 75}

Taf. 166

Gattung: Eastern Sigillata A

Form: Teller Atlante 3/4

InvNr. SE 209/33

Taf. 166 AO: GHD

Überzug: flächig, teilweise abgerieben, matt glänzend Ton: $10 \mathrm{YR} 8 / 2$

Farbe außen: 10R5/6, Farbe innen: 10R5/6

Maße: DmBd 8,3 cm, erh. H 3,1 cm

Erh.: 1 Bdfrgt. 


\section{KatNr. K 76}

Gattung: Eastern Sigillata A

Form: Teller Atlante 4

InvNr. SE 209/54

AO: GHD

Überzug: flächig, teilweise abgerieben, matt glänzend

Ton: $10 \mathrm{YR} 8 / 3$

Farbe außen: 2.5YR4/8, Farbe innen: 2.5YR4/8

Maße: DmBd 6,7 cm, erh. H 1,6 cm

Erh.: 1 Bdfrgt.

\section{KatNr. K 77}

Taf. 167

Gattung: Eastern Sigillata A

Form: Teller Atlante 12/tarda f

InvNr. SE 207/41

AO: GHD

Überzug: flächig, teilweise abgerieben, matt glänzend

Ton: 5YR7/6

Farbe außen: 2.5YR4/8, Farbe innen: 2.5YR4/8

Maße: DmBd 7,4 cm, erh. H 1,7 cm

Dekor: Rouletting an der Bodeninnenseite

Erh.: 1 Bdfrgt.

\section{KatNr. K 78}

Gattung: Eastern Sigillata A

Form: Schälchen Atlante 22

InvNr. SE 209/53

AO: GHD

Überzug: flächig, teilweise abgerieben, matt glänzend

Ton: $7.5 \mathrm{YR} 8 / 4$

Farbe außen: 10R5/8 (mehr orange), Farbe innen: 10R5/8

(mehr orange)

Maße: DmBd 4,5 cm, erh. H $2 \mathrm{~cm}$

Erh.: 1 Bdfrgt.

\section{KatNr. K 79}

Taf. 167

Gattung: Eastern Sigillata A

Form: Schälchen Atlante 22

InvNr. SE 207/105

AO: GHD

Überzug: flächig, teilweise abgerieben, matt glänzend

Ton: $7.5 \mathrm{YR} 8 / 4$

Farbe außen: 10R4/6, Farbe innen: 10R4/6

Maße: DmBd 3,2 cm, erh. H 1,5 cm

Erh.: 1 Bdfrgt.

\section{KatNr. K 80}

Taf. 167

Gattung: Eastern Sigillata A

Form: Schälchen Atlante 22

InvNr. SE 207/104

AO: GHD

Überzug: flächig, teilweise abgerieben, matt glänzend

Ton: 7.5YR $8 / 4$

Farbe außen: 10R4/6, Farbe innen: 10R4/6

Maße: DmBd 3,2 cm, erh. H 1,5 cm

Erh.: 1 Bdfrgt.

\section{KatNr. K 81}

Gattung: Eastern Sigillata A

Form: Schälchen Atlante 22

InvNr. SE 207/103
Taf. 167 AO: GHD

Überzug: flächig, teilweise abgerieben, matt glänzend

Ton: 7.5 YR $8 / 3$

Farbe außen: 10R4/6, Farbe innen: 10R4/6

Maße: DmBd 4 cm, erh. H 1,4 cm

Erh.: 1 Bdfrgt.

\section{KatNr. K 82}

Taf. 167

Gattung: Eastern Sigillata A

Form: Schälchen Atlante 22

InvNr. SE 207/44

AO: GHD

Überzug: flächig, teilweise abgerieben, matt glänzend

Ton: 5 YR $7 / 6$

Farbe außen: 2.5YR5/8, Farbe innen: 2.5YR5/8

Maße: DmBd 3,4 cm, erh. H 1,4 cm

Erh.: 1 Bdfrgt.

KatNr. K 83

Taf. 167

Gattung: Eastern Sigillata A

Form: Schälchen Atlante 22

InvNr. SE 207/43

AO: GHD

Taf. 167 Überzug: flächig, teilweise abgerieben, matt glänzend

Ton: 5YR6/2

Farbe außen: 10R5/8, Farbe innen: 10R5/8

Maße: DmBd 3,5 cm, erh. H 1,7 cm

Erh.: 1 Bdfrgt.

\section{KatNr. K 84}

Taf. 167

Gattung: Eastern Sigillata A

Form: Schälchen Atlante 22

InvNr. SE 207/39

AO: GHD

Überzug: flächig, teilweise abgerieben, matt glänzend

Ton: 7.5 YR $8 / 4$

Farbe außen: 2.5YR4/8, Farbe innen: 2.5YR4/8

Maße: DmBd 3,6 cm, erh. H 1,5 cm

Erh.: 1 Bdfrgt.

KatNr. K 85

Taf. 167

Gattung: Eastern Sigillata B

Form: Teller Atlante 7

InvNr. SE 207/30

AO: GHD

Überzug: flächig, teilweise abgerieben, matt glänzend Ton: 2.5 YR6/8

Farbe außen: 2.5YR4/8, Farbe innen: 2.5 YR4/8

Maße: DmRd 14,4 cm, erh. H 2,55 cm

Erh.: 1 Rdfrgt.

KatNr. K 86

Taf. 167

Gattung: Eastern Sigillata B

Form: Schale Atlante 22 ähnlich

InvNr. SE 207/29

AO: GHD

Überzug: flächig, teilweise abgerieben, matt glänzend

Taf. 167 Ton: 2.5 YR5/6

Farbe außen: 2.5YR4/8, Farbe innen: 2.5YR4/8

Maße: DmRd 12,2 cm, erh. H 3,1 cm

Erh.: 1 Rdfrgt. 


\section{KatNr. K 87}

Gattung: Eastern Sigillata B

Form: Schale Atlante 14 (?)

InvNr. SE 207/26

AO: GHD

Überzug: flächig, teilweise abgerieben, matt glänzend

Ton: 2.5YR6/6

Farbe außen: 2.5YR4/6, Farbe innen: 2.5YR4/6

Maße: DmRd 11,8 cm, erh. H 1,9 cm

Erh.: 1 Rdfrgt.

\section{KatNr. K 88}

Gattung: Eastern Sigillata B

Form: Schälchen Atlante 35 ähnlich

InvNr. SE 207/27

AO: GHD

Überzug: flächig, teilweise abgerieben, matt glänzend

Ton: 2.5 YR5/6

Farbe außen: 2.5YR4/8, Farbe innen: 2.5YR4/8

Maße: DmRd 6,6 cm, erh. H 2,1 cm

Erh.: 1 Rdfrgt.

\section{KatNr. K 89}

Gattung: Eastern Sigillata B

Form: Schale Atlante 22

InvNr. SE 208/18

AO: GHD

Überzug: flächig, teilweise abgerieben, matt glänzend

Ton: 2.5 YR6/6

Farbe außen: 10R4/8, Farbe innen: 10R4/8

Maße: DmRd 12,2 cm, erh. H 5,8 cm

Dekor: zentraler, runder Bodenstempel, Siegeskranz, darum feines Rouletting

Erh.: 6 Rdfrgt.

\section{KatNr. K 90}

Taf. 167

Gattung: Eastern Sigillata B

Form: Offenes Gefäß

InvNr. SE 208/14

AO: GHD

Überzug: flächig, teilweise abgerieben, matt glänzend

Ton: 5YR6/4

Farbe außen: 2.5YR5/8, Farbe innen: 2.5YR5/8

Maße: DmBd $3 \mathrm{~cm}$, erh. H 1,1 cm

Dekor: Rouletting an der Bodeninnenseite

Erh.: 1 Bdfrgt.

\section{KatNr. K 91}

Taf. 167

Gattung: Eastern Sigillata C (Pergamenische Ware)

Form: Schale (?) Meyer-Schlichtmann 1988, N4a (ähnlich)

InvNr. SE 210/20

AO: GHD

Überzug: flächig, teilweise abgerieben, matt glänzend

Ton: 2.5YR6/6

Farbe außen: 10R5/6, Farbe innen: 10R5/6

Maße: DmRd 28,6 cm, erh. H 2,55 cm

Erh.: 1 Rdfrgt.

KatNr. K 92

Taf. 167

Gattung: Pergamenische Ware

Form: Schale Meyer-Schlichtmann 1988, Sa 24b (ähnlich)
InvNr. SE 209/40

AO: GHD

Überzug: flächig, teilweise abgerieben, matt glänzend

Ton: $2.5 \mathrm{YR} 8 / 4$

Farbe außen: 10R6/6, Farbe innen: 10R5/4

Maße: DmRd 16,2 cm, erh. H 3,7 cm

Erh.: 1 Rdfrgt.

KatNr. K 93

Taf. 167

Gattung: Pergamenische Ware

Form: Teller Meyer-Schlichtmann 1988, T 28 (ähnlich)

InvNr. SE 216/20

AO: GHD

Überzug: flächig, teilweise abgerieben, matt glänzend Ton: 5YR6/6

Farbe außen: 2.5YR5/6, Farbe innen: 2.5YR5/6

Maße: DmRd 14,4 cm, erh. H 1,55 cm

Erh.: 1 Rdfrgt.

KatNr. K 94

Taf. 168

Gattung: Pergamenische Ware

Form: Schale Meyer-Schlichtmann 1988, N4a (ähnlich)

InvNr. SE 210/32

AO: GHD

Überzug: flächig, teilweise abgerieben, matt glänzend

Ton: 10R6/6

Farbe außen: 10R4/8, Farbe innen: 10R4/8

Maße: DmBd 24,8 cm, erh. H 3,1 cm

Erh.: 1 Bdfrgt.

\section{KatNr. K 95}

Taf. 168

Gattung: Graue Ware mit schwarzem Überzug

Form: Konische Schale

InvNr. SE 211/61

AO: GHD

Überzug: flächig, teilweise abgerieben, matt glänzend Ton: 5YR5/3

Farbe außen: 5YR2.5/1, Farbe innen: 5YR4/2

Maße: DmRd 16 cm, erh. H 3,4 cm

Erh.: 1 Rdfrgt.

\section{KatNr. K 96}

Taf. 168

Gattung: Graue Ware mit schwarzem Überzug

Form: Echinusschale

InvNr. SE 211/6

AO: GHD

Überzug: flächig, teilweise abgerieben, matt glänzend

Ton: 5YR5/1

Farbe außen: 10YR2/1, Farbe innen: 10YR2/1

Maße: DmRd 12,6 cm, erh. H 2,7 cm

Erh.: 1 Rdfrgt.

\section{KatNr. K 97}

Taf. 168

Gattung: Graue Ware mit schwarzem Überzug

Form: Echinusschale

InvNr. SE 215/10

AO: GHD

Überzug: flächig, teilweise abgerieben, matt glänzend

Ton: 5YR5/1

Farbe außen: 5YR2.5/1, Farbe innen: 5YR2.5/1

Maße: DmRd 18,3 cm, erh. H 3,7 cm

Erh.: 1 Rdfrgt. 


\section{KatNr. K 98}

Gattung: Graue Ware mit schwarzem Überzug

Form: Echinusschale

InvNr. SE 207/81

Überzug: flächig, teilweise abgerieben, matt glänzend

AO: GHD

Ton: 7.5 YR5/4

Farbe außen: 5YR2.5/1, Farbe innen: 5YR2.5/1

Maße: DmRd 27,6 cm, erh. H 2,3 cm

Erh.: 1 Rdfrgt.

\section{KatNr. K 99}

Gattung: Graue Ware mit schwarzem Überzug

Form: Schale

InvNr. SE 210/22

Überzug: flächig, teilweise abgerieben, matt glänzend

AO: GHD

Ton: $2.5 \mathrm{YR} 5 / 2$

Farbe außen: 5YR2.5/1, Farbe innen: 5YR2.5/1

Maße: DmRd 12,8 cm, erh. H 1,65 cm

Erh.: 1 Rdfrgt.

\section{KatNr. K 100}

Gattung: Graue Ware mit schwarzem Überzug

Form: Schale

InvNr. SE 210/23

AO: GHD

Überzug: flächig, teilweise abgerieben, matt glänzend

Ton: 5YR6/2

Farbe außen: 5YR2.5/1, Farbe innen: 5YR2.5/1

Maße: DmRd 19,5 cm, erh. H 1,3 cm

Erh.: 1 Rdfrgt.

\section{KatNr. K 101}

Taf. 168

Gattung: Graue Ware mit schwarzem Überzug

Form: Schale mit Wandknick

InvNr. SE 211/40

AO: GHD

Überzug: flächig, teilweise abgerieben, matt glänzend

Ton: 5YR3/1

Farbe außen: 5YR2.5/1, Farbe innen: 5YR2.5/1

Maße: DmRd 12,2 cm, erh. H 1,5 cm

Erh.: 1 Rdfrgt.

\section{KatNr. K 102}

Taf. 168

Gattung: Graue Ware mit schwarzem Überzug

Form: Teller mit breiter Lippe

InvNr. SE 216/25

AO: GHD

Überzug: flächig, teilweise abgerieben, matt glänzend

Ton: $10 \mathrm{YR} 5 / 2$

Farbe außen: 10YR5/2, Farbe innen: 5YR2.5/1

Maße: DmRd 20,4 cm, erh. H 2,45 cm

Erh.: 1 Rdfrgt.

\section{KatNr. K 103}

Taf. 168

Gattung: Graue Ware mit schwarzem Überzug

Form: Konischer Teller

InvNr. SE 207/96

AO: GHD

Überzug: flächig, teilweise abgerieben, matt glänzend

Ton: 7.5 YR6/1
Taf. 168 Farbe außen: 5YR2.5/1, Farbe innen: 5YR2.5/1

Maße: DmRd $20 \mathrm{~cm}$, erh. H $1,1 \mathrm{~cm}$

Erh.: 1 Rdfrgt.

KatNr. K 104

Taf. 168

Gattung: Graue Ware mit schwarzem Überzug

Form: Teller mit gedrechseltem Rand

InvNr. SE 211/150

AO: GHD

Überzug: flächig, teilweise abgerieben, matt glänzend

Ton: 10YR6/2

Taf. 168 Farbe außen: 5YR2.5/1, Farbe innen: 5YR2.5/1

Maße: DmRd 18,9 cm, erh. H 1,3 cm

Erh.: 1 Rdfrgt.

\section{KatNr. K 105}

Taf. 168

Gattung: Graue Ware (?) mit schwarzem Überzug

Form: Teller mit gedrechseltem Rand

InvNr. SE 207/50

AO: GHD

Überzug: flächig, teilweise abgerieben, matt glänzend Ton: 5YR4/1

Taf. 168 Farbe außen: 5YR4/1, Farbe innen: 5YR4/1

Maße: DmRd 18,8 cm, erh. H 2,3 cm

Erh.: 1 Rdfrgt.

\section{KatNr. K 106}

Taf. 169

Gattung: Graue Ware mit schwarzem Überzug

Form: Fischteller

InvNr. SE 207/47

AO: GHD

Überzug: flächig, teilweise abgerieben, matt glänzend Ton: 5YR5/2

Farbe außen: 5YR2.5/1, Farbe innen: 5YR2.5/1

Maße: DmRd $60 \mathrm{~cm}$, erh. H 2,2 cm

Erh.: 1 Rdfrgt.

\section{KatNr. K 107}

Taf. 169

Gattung: Graue Ware mit schwarzem Überzug

Form: Platte mit sichelförmigem Rand

InvNr. SE 209/27

AO: GHD

Überzug: flächig, teilweise abgerieben, matt glänzend

Ton: $10 \mathrm{YR} 5 / 2$

Farbe außen: 5YR2.5/1, Farbe innen: 5YR2.5/1

Maße: DmRd 28,8 cm, erh. H 2,5 cm

Erh.: 1 Rdfrgt.

\section{KatNr. K 108}

Taf. 169

Gattung: Graue Ware mit schwarzem Überzug

Form: Platte mit sichelförmigem Rand

InvNr. SE 209/9

AO: GHD

Überzug: flächig, teilweise abgerieben, matt glänzend Ton: 7.5YR6/4

Farbe außen: 5YR2.5/1, Farbe innen: 5YR2.5/1

Maße: DmRd 40,4 cm, erh. H 2,3 cm

Erh.: 1 Rdfrgt.

KatNr. K 109

Taf. 169

Gattung: Graue Ware mit schwarzem Überzug

Form: Platte mit sichelförmigem Rand 
InvNr. SE 210/25

AO: GHD

Überzug: flächig, teilweise abgerieben, matt glänzend Ton: 7.5YR6/2

Farbe außen: 5YR2.5/1, Farbe innen: 5YR2.5/1

Maße: DmRd 24,7 cm, erh. H 2,45 cm

Erh.: 1 Rdfrgt.

\section{KatNr. K 110}

Gattung: Graue Ware mit schwarzem Überzug

Form: Platte mit sichelförmigem Rand

InvNr. SE 207/79

AO: GHD

Überzug: flächig, teilweise abgerieben, matt glänzend

Ton: 7.5 YR5/4

Farbe außen: 5YR2.5/1, Farbe innen: 5YR2.5/1

Maße: DmRd 30,2 cm, erh. H 1,8 cm

Erh.: 1 Rdfrgt.

\section{KatNr. K 111}

Gattung: Graue Ware mit schwarzem Überzug

Form: Platte mit sichelförmigem Rand

InvNr. SE 207/80

AO: GHD

Überzug: flächig, teilweise abgerieben, matt glänzend

Ton: 7.5 YR $5 / 4$

Farbe außen: 5YR2.5/1, Farbe innen: 5YR2.5/1

Maße: DmRd 25,8 cm, erh. H 2,4 cm

Erh.: 1 Rdfrgt.

\section{KatNr. K 112}

Taf. 169

Gattung: Graue Ware mit schwarzem Überzug

Form: Platte mit rundem Rand

InvNr. SE 208/12

AO: GHD

Überzug: flächig, teilweise abgerieben, matt glänzend

Ton: 5YR5/4

Farbe außen: 5YR2.5/1, Farbe innen: 5YR2.5/1

Maße: DmRd $64 \mathrm{~cm}$, erh. H 1,5 cm

Erh.: 1 Rdfrgt.

\section{KatNr. K 113}

Taf. 169

Gattung: Graue Ware mit schwarzem Überzug

Form: Schale/Schüssel

InvNr. SE 211/130

AO: GHD

Überzug: flächig, teilweise abgerieben, matt glänzend

Ton: 10YR5/1

Farbe außen: 5YR2.5/1, Farbe innen: 2.5YR6/2

Maße: DmBd 10,9 cm, erh. H 3,85 cm

Erh.: 1 Bdfrgt.

\section{KatNr. K 114}

Taf. 169

Gattung: Graue Ware mit schwarzem Überzug

Form: Schale

InvNr. SE 210/31

AO: GHD

Überzug: flächig, teilweise abgerieben, matt glänzend

Ton: 5YR5/1

Farbe außen: 5YR2.5/1, Farbe innen: 5YR2.5/1

Maße: DmBd 8,2 cm, erh. H 2,1 cm

Erh.: 1 Bdfrgt.

Taf. 169

\section{KatNr. K 115}

ohne Abb.

Gattung: Glanztonware/Graue Ware

Form: Teller mit breiter Lippe

InvNr. SE 210/45

AO: GHD

Überzug: flächig, teilweise abgerieben, matt glänzend

Ton: $7.5 \mathrm{YR} 3 / 5$

Farbe außen: 5YR2.5/1, Farbe innen: 5YR2.5/1

Maße: DmRd $38 \mathrm{~cm}$, erh. H 2,8 cm

Erh.: 1 Rdfrgt.

KatNr. K 116

Taf. 218

Gattung: Glanztonware/Graue Ware

Form: Teller

InvNr. SE 211/S10

AO: GHD

Überzug: flächig, teilweise abgerieben, matt glänzend

Ton: $10 Y R 4 / 1$

Farbe außen: 2.5Y4/1, Farbe innen: 2.5Y4/1

Taf. 169 Maße: DmBd 2,3 cm, erh. H 2,8 cm

Dekor: Palmettenstempel an der Bodeninnenseite

Erh.: 1 Bdfrgt.

KatNr. K 117

Taf. 169

Gattung: Glanztonware (attisch)

Form: Schale

InvNr. SE 110/5

AO: GHD

Überzug: flächig, teilweise abgerieben, matt glänzend Ton: 5YR6/4

Farbe außen: 5YR2.5/1+5YR7/6, Farbe innen: 5YR2.5/1

+5 YR7/6

Maße: DmRd 15,8 cm, erh. H 1,6 cm

Erh.: 1 Rdfrgt.

KatNr. K 118

Taf. 169

Gattung: Glanztonware (attisch?)

Form: Schale

InvNr. SE 211/73

AO: GHD

Überzug: flächig, teilweise abgerieben, matt glänzend Ton: 2.5 YR7/8

Farbe außen: 5YR2.5/1, Farbe innen: 5YR2.5/1

Maße: DmRd 16,6 cm, erh. H 2,1 cm

Erh.: 1 Rdfrgt.

KatNr. K 119

Taf. 170

Gattung: Glanztonware (attisch?)

Form: Schale

InvNr. SE 216/8

AO: GHD

Überzug: flächig, teilweise abgerieben, matt glänzend

Ton: 7.5 YR6/4

Farbe außen: 5YR2.5/1, Farbe innen: 5YR2.5/1

Maße: DmRd 35,4 cm, erh. H 2,85 cm

Erh.: 1 Rdfrgt.

KatNr. K 120

Taf. 170. 218

Gattung: Glanztonware (Westabhangware)

Form: Skyphos/Kantharos

InvNr. SE 216/32

AO: GHD 
Überzug: flächig, kompakt, glänzend

Ton: 10YR6/3

Farbe außen: 5YR2.5/1, Farbe innen: 5YR2.5/1

Maße: DmRd 4,3 cm, erh. H 3,3 cm

Dekor: an der Gefäßaußenseite Efeublattgirlande

Erh.: 1 Rdfrgt.

\section{KatNr. K 121}

Gattung: Glanztonware (Westabhangware)

Form: Skyphos/Kantharos

InvNr. SE 211/58

AO: GHD

Überzug: flächig, kompakt, glänzend

Ton: 2.5 YR7/6

Farbe außen: schwarz glänzend, Farbe innen: 2.5YR4/3

Farbe Dekor: 2.5YR6/6

Maße: $2,6 \times 3,3 \mathrm{~cm}$

Dekor: in Mal-Ritztechnik Efeublattgirlande

Erh.: 1 Wdfrgt.

\section{KatNr. K 122}

Gattung: Glanztonware

Form: Skyphos/Kantharos

InvNr. SE 110/12

AO: GHD

Überzug: flächig, kompakt, glänzend

Ton: 7.5YR6/4

Farbe außen: 5YR2.5/1, Farbe innen: 5YR2.5/1

Maße: DmRd 19,6 cm, erh. H 2,1 cm

Erh.: 1 Rdfrgt.

\section{KatNr. K 123}

Gattung: Glanztonware

Form: Skyphos/Kantharos

InvNr. SE 216/66

AO: GHD

Überzug: flächig, kompakt, glänzend

Ton: $7.5 Y R 7 / 2$

Farbe außen: 5YR2.5/1, Farbe innen: 5YR2.5/1

Maße: DmRd 10,7 cm, erh. H 1,9 cm

Erh.: 1 Rdfrgt.

\section{KatNr. K 124}

Gattung: Glanztonware

Form: Skyphos/Kantharos

InvNr. SE 216/103

AO: GHD

Überzug: flächig, kompakt, glänzend

Ton: 5YR6/4

Farbe außen: 5YR2.5/1, Farbe innen: 5YR2.5/1

Maße: DmRd 10 cm, erh. H 2,4 cm

Erh.: 1 Rdfrgt.

\section{KatNr. K 125}

Taf. 170

Gattung: Glanztonware

Form: Kantharos

InvNr. SE 216/129

AO: GHD

Überzug: flächig, kompakt, glänzend

Ton: 7.5 Y R6/4

Farbe außen: 5YR2.5/1, Farbe innen: 5YR2.5/1

Taf. 170

Taf. 170
Maße: DmWd $11 \mathrm{~cm}$, erh. H 3,2 cm

Erh.: 1 Wdfrgt.

KatNr. K 126

Taf. 170

Gattung: Glanztonware

Form: Krug

InvNr. SE 211/161

Taf. 218 AO: GHD

Überzug: flächig, teilweise abgerieben, matt glänzend

Ton: 2.5 YR6/6

Farbe außen: 5YR2.5/1, Farbe innen: 5YR2.5/1

Maße: DmRd 4,6 cm, erh. H 2,6 cm

Erh.: 1 Rdfrgt.

KatNr. K 127

Taf. 170

Gattung: Glanztonware

Form: Krug

InvNr. SE 216/124

AO: GHD

Überzug: flächig, teilweise abgerieben, matt glänzend

Ton: 2.5 Y R6/8

Farbe außen: 2.5YR5/6, Farbe innen: 2.5 YR7/8

Maße: DmRd 4,2 cm, erh. H 3,4 cm

Erh.: 1 Rdfrgt.

KatNr. K 128

Taf. 170

Gattung: Glanztonware

Form: Krug

InvNr. SE 211/28

AO: GHD

Überzug: flächig, teilweise abgerieben, matt glänzend

Taf. 170 Ton: 2.5 YR6/8

Farbe außen: 5YR2.5/1, Farbe innen: 5YR6/3

Maße: DmRd 6,6 cm, erh. H 3,5 cm

Erh.: 1 Rdfrgt.

KatNr. K 129

Taf. 170

Gattung: Glanztonware

Form: Skyphos

InvNr. SE 211/43

AO: GHD

Überzug: flächig, teilweise abgerieben, matt glänzend

Ton: 5YR5/2

Farbe außen: 2.5YR5/1, Farbe innen: 2.5YR5/1

Maße: DmRd 4 cm, erh. H 0,8 cm

Erh.: 1 Rdfrgt.

KatNr. K 130

Taf. 170

Gattung: Glanztonware

Form: Becher

InvNr. SE 211/103

AO: GHD

Überzug: flächig, teilweise abgerieben, matt glänzend

Ton: 5YR7/6

Farbe außen: 5YR2.5/1, Farbe innen: 7.5YR8/3+5YR2.5/1

Maße: DmRd 6,4 cm, erh. H 1,4 cm

Erh.: 1 Rdfrgt.

KatNr. K 131

Taf. 170

Gattung: Glanztonware

Form: Krug (?) 
InvNr. SE 215/11

AO: GHD

Überzug: flächig, teilweise abgerieben, matt glänzend Ton: 10YR7/4

Farbe außen: 5YR2.5/1, Farbe innen: 5YR2.5/1

Maße: DmRd 3,6 cm, erh. H 2,2 cm

Erh.: 1 Rdfrgt.

KatNr. K 132

Taf. 170. 218

Gattung: Reliefkeramik

Form: Becher

InvNr. SE 211/72

AO: GHD

Überzug: flächig, teilweise abgerieben, matt glänzend

Ton: 7.5YR7/4

Farbe außen: 10YR4/1+10R5/8, Farbe innen: 10YR4/1

$+10 \mathrm{R} 5 / 8$

Maße: DmRd 14,8 cm, erh. H 4,4 cm

Dekor: Randbordüre: Eierstab, Hauptbordüre: Eroten (?)

Erh.: 1 Rdfrgt.

\section{KatNr. K 133}

Taf. 171

Gattung: Reliefkeramik

Form: Becher

InvNr. SE 211/49

AO: GHD

Überzug: flächig, teilweise abgerieben, matt glänzend

Ton: 5YR6/4+5YR5/2

Farbe außen: 5YR2.5/1, Farbe innen: 5YR2.5/1

Maße: DmRd 15,6 cm, erh. H 3,1 cm

Dekor: Randbordüre: Eierstab

Erh.: 2 Rdfrgt.

\section{KatNr. K 134}

Taf. 171.218

Gattung: Reliefkeramik

Form: Becher

InvNr. SE 107/9

AO: GHD

Überzug: flächig, teilweise abgerieben, matt glänzend

Ton: 7.5 YR5/3

Farbe außen: 7.5YR5/4, Farbe innen: 7.5YR5/4

Maße: DmRd 15,6 cm, erh. H 3,6 cm

Dekor: Randbordüre: lesbisches Kyma

Erh.: 2 Rdfrgt.

\section{KatNr. K 135}

Taf. 171

Gattung: Reliefkeramik

Form: Becher

InvNr. SE 209/6

AO: GHD

Überzug: flächig, teilweise abgerieben, matt glänzend

Ton: 5YR7/6

Farbe außen: 7.5YR5/1, Farbe innen: 2.5YR6/6

Maße: DmRd 11,8 cm, erh. H 3,1 cm

Dekorzone nicht erhalten

Erh.: 1 Rdfrgt.

KatNr. K 136

Taf. 171

Gattung: Reliefkeramik

Form: Becher

InvNr. SE 209/17
AO: GHD

Überzug: flächig, teilweise abgerieben, matt glänzend Ton: 2.5 YR6/6

Farbe außen: 2.5YR5/3, Farbe innen: 10R6/6

Maße: DmRd 12,8 cm, erh. H 2,15 cm

Erh.: 1 Rdfrgt.

KatNr. K 137

Taf. 171

Gattung: Reliefkeramik

Form: Becher

InvNr. SE 209/39

AO: GHD

Überzug: flächig, teilweise abgerieben, matt glänzend

Ton: 2.5 YR6/4

Farbe außen: 5YR2.5/1, Farbe innen: 5YR2.5/1

Maße: DmRd 19,8 cm, erh. H 2,6 cm

Erh.: 1 Rdfrgt.

\section{KatNr. K 138}

Taf. 171

Gattung: Reliefkeramik

Form: Becher

InvNr. SE 207/56

AO: GHD

Überzug: flächig, teilweise abgerieben, matt glänzend Ton: 7.5 YR5/2

Farbe außen: 7.5YR3/1, Farbe innen: 7.5YR3/1

Maße: DmRd $10 \mathrm{~cm}$, erh. H 3,7 cm

Erh.: 1 Rdfrgt.

KatNr. K 139

Taf. 218

Gattung: Reliefkeramik

Form: Becher

InvNr. SE 211/54

AO: GHD

Überzug: flächig, matt glänzend, kompakt

Ton: $2.5 \mathrm{YR} 5 / 6$

Farbe außen: 2.5YR4/4, Farbe innen: 2.5YR4/4

Maße: $5 \times 3,7 \mathrm{~cm}$

Dekor: Makedonischer Schild

Erh.: 1 Wdfrgt.

\section{KatNr. K 140}

Taf. 218

Gattung: Reliefkeramik

Form: Becher

InvNr. SE 104/51

AO: GHD

Überzug: flächig, matt glänzend, kompakt

Ton: 5YR6/6

Farbe außen: 2.5YR5/6, Farbe innen: 2.5YR5/6

Maße: $3 \times 2,8 \mathrm{~cm}$

Dekor: Akanthusblatt

Erh.: 1 Wdfrgt.

KatNr. K 141

Taf. 218

Gattung: Reliefkeramik

Form: Becher

InvNr. SE 211/59

AO: GHD

Überzug: flächig, matt glänzend, kompakt

Ton: 2.5 Y R5/6

Farbe außen: 2.5YR5/6, Farbe innen: 2.5YR5/6 
Maße: $2,5 \times 3 \mathrm{~cm}$

Dekor: Langblatt

Erh.: 1 Wdfrgt.

\section{KatNr. K 142}

Taf. 218

Gattung: Reliefkeramik

Form: Becher

InvNr. SE 207/51

AO: GHD

Überzug: flächig, matt glänzend, kompakt

Ton: 2.5 YR $5 / 6$

Farbe außen: 2.5YR5/6, Farbe innen: 2.5YR5/6

Maße: $2,6 \times 2,2 \mathrm{~cm}$

Dekor: Akanthusblatt

Erh.: 1 Wdfrgt.

\section{KatNr. K 143}

Taf. 218

Gattung: Reliefkeramik

Form: Becher

InvNr. SE 211/514

AO: GHD

Überzug: flächig, matt glänzend, kompakt

Ton: 2.5 YR $5 / 6$

Farbe außen: 2.5YR5/6, Farbe innen: 2.5YR5/6

Maße: $3,2 \times 2,3 \mathrm{~cm}$

Dekor: Randbordüre: Mäander, Hauptbordüre: Akanthusblatt Erh.: 1 Wdfrgt.

\section{KatNr. K 144}

Taf. 219

Gattung: Reliefkeramik

Form: Becher

InvNr. SE 211/52

AO: GHD

Überzug: flächig, matt glänzend, kompakt

Ton: 2.5 YR $5 / 6$

Farbe außen: 2.5YR5/6, Farbe innen: 2.5YR5/6

Maße: $5,3 \times 4,3 \mathrm{~cm}$

Dekor: Blattschuppen, darüber figürlicher Dekor, Eroten (?)

Erh.: 1 Wdfrgt.

\section{KatNr. K 145}

Gattung: Reliefkeramik

InvNr. SE 211/57

Zugehörig zu: KatNr. K 144

\section{KatNr. K 146}

Taf. 219

Gattung: Reliefkeramik

Form: Becher

InvNr. SE 211/513

AO: GHD

Überzug: flächig, matt glänzend, kompakt

Ton: 2.5 YR5/8

Farbe außen: 2.5YR5/6, Farbe innen: 2.5YR5/6

Maße: $3,2 \times 2 \mathrm{~cm}$

Dekor: Bodenrosette, Hauptzone: Blattschuppen

Erh.: 1 Bdfrgt.

\section{KatNr. K 147}

Taf. 219

Gattung: Reliefkeramik

Form: Becher

InvNr. SE 209/o. Nr.
AO: GHD

Überzug: flächig, matt, kompakt

Ton: Gley1 4/0

Farbe außen: Gley1 4/0, Farbe innen: Gley1 4/0

Maße: $5,3 \times 3,7 \mathrm{~cm}$

Dekor: Eierstabrandbordüre, Blattschuppen

Erh.: 1 Wdfrgt.

\section{KatNr. K 148}

Taf. 219

Gattung: Reliefkeramik

Form: Becher

InvNr. SE 207/52

AO: GHD

Überzug: flächig, matt, kompakt

Ton: Gley1 4/0

Farbe außen: Gley1 4/0, Farbe innen: Gley1 4/0

Maße: 4,3 × 3,3 cm

Dekor: unklar

Erh.: 2 Wdfrgt.

KatNr. K 149

Taf. 219

Gattung: Reliefkeramik

Form: Becher

InvNr. SE 211/51

AO: GHD

Überzug: flächig, matt, kompakt

Ton: Gley1 4/0

Farbe außen: Gley1 3/0 Farbe innen: Gleyl 3/0

Maße: $2,9 \times 2,5 \mathrm{~cm}$

Dekor: Akanthus-Langblatt, dazwischen Punktreihe

Erh.: 1 Bdfrgt.

KatNr. K 150

Taf. 219

Gattung: Graue Ware

Form: Reliefbecher

InvNr. SE 215/51

AO: GHD

Überzug: flächig, matt, teilweise abgerieben

Ton: 2.5 YR $4 / 1$

Farbe außen: Gley1 4/0, Farbe innen: Gleyl 4/0

Taf. 219 Maße: $3,6 \times 2,8 \mathrm{~cm}$

Dekor: Randbordüre: Blattranken, Hauptbordüre: Langblätter Erh.: 1 Wdfrgt.

\section{KatNr. K 151}

Taf. 171

Gattung: Reliefkeramik

Form: Becher

InvNr. SE 216/31

AO: GHD

Überzug: flächig, matt, teilweise abgerieben

Ton: 10YR6/3

Farbe außen: 5YR2.5/1, Farbe innen: 5YR2.5/1

Maße: DmRd 15,6 cm, erh. H 3,15 cm

Erh.: 1 Rdfrgt.

KatNr. K 152

Taf. 171

Gattung: Glanztonware

Form: Konische Schale

InvNr. SE 215/13

AO: GHD

Überzug: flächig, matt glänzend, kompakt 
Ton: 5YR7/4

Farbe außen: 5YR2.5/1, Farbe innen: 5YR2.5/1

Maße: DmRd 19,8 cm, erh. H 1,9 cm

Erh.: 1 Rdfrgt.

\section{KatNr. K 153}

Taf. 171

Gattung: Glanztonware/Westabhangnachfolgedekor

Form: Schale

InvNr. SE 207/34

AO: GHD

Überzug: flächig, matt glänzend, kompakt

Ton: 2.5 YR $5 / 6$

Farbe außen: 2.5YR4/8, Farbe innen: 2.5YR4/8

Maße: DmRd 17,2 cm, erh. H 2,4 cm

Erh.: 1 Rdfrgt.

\section{KatNr. K 154}

Gattung: Glanztonware

Form: Konische Schale

InvNr. SE 211/92

AO: GHD

Überzug: flächig, matt glänzend, kompakt

Ton: $2.5 \mathrm{YR} 5 / 6$

Farbe außen: 2.5YR4/8, Farbe innen: 2.5YR4/8

Maße: DmRd nicht bestimmbar, erh. H $3,8 \mathrm{~cm}$

Erh.: 1 Rdfrgt.

\section{KatNr. K 155}

Gattung: Glanztonware

Form: Konische Schale

InvNr. SE 211/98

AO: GHD

Überzug: flächig, matt glänzend, kompakt

Ton: 2.5 YR6/6

Farbe außen: 2.5YR5/6, Farbe innen: 2.5YR5/6

Maße: DmRd 23,6 cm, erh. H 5,45 cm

Erh.: 2 Rdfrgt.

\section{KatNr. K 156}

Gattung: Glanztonware

Form: Konische Schale

InvNr. SE 211/105

AO: GHD

Überzug: flächig, matt glänzend, kompakt

Ton: 5YR6/4

Farbe außen: 5YR5/6, Farbe innen: 2.5YR5/6

Maße: DmRd 37,6 cm, erh. H 4,05 cm

Erh.: 1 Rdfrgt.

\section{KatNr. K 157}

Gattung: Glanztonware

Form: Konische Schale

InvNr. SE 211/99

AO: GHD

Überzug: flächig, matt glänzend, kompakt

Ton: 2.5 YR6/6

Farbe außen: 2.5YR5/6, Farbe innen: 2.5YR5/6

Maße: DmRd $17 \mathrm{~cm}$, erh. H 2,5 cm

Erh.: 1 Rdfrgt.

Taf. 171

Taf. 172

\section{KatNr. K 158}

Taf. 172.219

Gattung: Glanztonware/Westabhangnachfolgedekor

Form: Konische Schale

InvNr. SE 211/151

AO: GHD

Überzug: flächig, matt glänzend, kompakt

Ton: 5YR6/4

Farbe außen: 2.5YR4/1+2.5YR5/6, Farbe innen: 2.5YR4/1

+2.5 YR $5 / 6$

Maße: DmRd 17,7 cm, erh. H 3,95 cm

Dekor: geometrische Ritzung an der Gefäßinnenseite

Erh.: 1 Rdfrgt.

KatNr. K 159

Taf. 172

Gattung: Glanztonware/Westabhangnachfolgedekor

Form: Konische Schale

InvNr. SE 211/152

AO: GHD

Überzug: flächig, matt glänzend, kompakt

Ton: 2.5 Y R6/6

Farbe außen: 10R5/6, Farbe innen: 10R5/6

Maße: DmRd 21,6 cm, erh. H 2,2 cm

Dekor: horizontale Rillen an der Gefäßinnenseite

Erh.: 1 Rdfrgt.

KatNr. K 160

Taf. 172

Gattung: Glanztonware/Westabhangnachfolgedekor

Form: Konische Schale

Taf. 171 InvNr. SE 211/156

AO: GHD

Überzug: flächig, matt glänzend, kompakt

Ton: 10YR7/3

Farbe außen: 5YR2.5/1, Farbe innen: 5YR2.5/1

Maße: DmRd 17,6 cm, erh. H 1,9 cm

Dekor: horizontale Rille an der Gefäßinnenseite

Erh.: 1 Rdfrgt.

KatNr. K 161

Taf. 172

Gattung: Glanztonware/Westabhangnachfolgedekor

Form: Konische Schale

InvNr. SE 216/34

AO: GHD

Überzug: flächig, matt glänzend, kompakt

Ton: 5YR5/6

Farbe außen: 5YR4/1, Farbe innen: 5YR4/1

Maße: DmRd 15,4 cm, erh. H 2,8 cm

Dekor: horizontale Rillen an der Gefäßinnenseite

Erh.: 1 Rdfrgt.

KatNr. K 162

Taf. 172. 219

Gattung: Glanztonware/Westabhangnachfolgedekor

Taf. 172 Form: Konische Schale

InvNr. SE 211/71

AO: GHD

Überzug: flächig, matt glänzend, kompakt

Ton: 5YR6/6

Farbe außen: 2.5 YR7/4+2.5YR4/8, Farbe innen: 2.5YR7/4

$+2.5 \mathrm{YR} 4 / 8$

Maße: DmRd 16,8 cm, erh. H 2,5 cm

Dekor: Efeublattgirlande

Erh.: 3 Rdfrgt. 
KatNr. K 163

Gattung: Glanztonware/Westabhangnachfolgedekor

Form: Konische Schale

InvNr. SE 104/3

AO: GHD

Überzug: flächig, matt glänzend, kompakt

Ton: 5YR6/4

Farbe außen: 5YR4/2+5YR6/6, Farbe innen: 5YR2.5/1

Maße: DmRd nicht bestimmbar, erh. H $3 \mathrm{~cm}$

Erh.: 1 Rdfrgt.

\section{KatNr. K 164}

Taf. 219

Gattung: Glanztonware/Westabhangnachfolgedekor Form: Konische Schale

InvNr. SE 211/55

AO: GHD

Überzug: flächig, matt, kompakt

Ton: 10YR6/2

Farbe außen: Gleyl 4/0, Farbe innen: Gley1 4/0

Farbe Dekor: 10YR6/2

Maße: $5,2 \times 3,5 \mathrm{~cm}$

Dekor: Tropfengirlande an der Gefäßinnenseite

Erh.: 1 Wdfrgt.

\section{KatNr. K 165}

Taf. 219

Gattung: Glanztonware/Westabhangnachfolgedekor Form: Konische Schale

InvNr. SE 211/56

AO: GHD

Überzug: flächig, matt, kompakt

Ton: 2.5 YR $4 / 8$

Farbe außen: 2.5YR5/6, Farbe innen: 10YR5/6

Maße: 4,6 × 4,5 cm

Dekor: Wellenmäander an der Gefäßinnenseite

Erh.: 1 Wdfrgt.

\section{KatNr. K 166}

Taf. 219

Gattung: Glanztonware/Westabhangnachfolgedekor

Form: Konische Schale

InvNr. SE 211/516

AO: GHD

Überzug: flächig, matt glänzend, kompakt

Ton: $2.5 \mathrm{YR} 5 / 4$

Farbe außen: 2.5YR5/6, Farbe innen: 2.5YR5/6

Maße: $3,8 \times 3,2 \mathrm{~cm}$

Dekor: Girlande an der Gefäßinnenseite

Erh.: 1 Wdfrgt.

\section{KatNr. K 167}

Taf. 172

Gattung: Glanztonware/Westabhangnachfolgedekor

Form: Halbkugelige Schale

InvNr. SE 211/157

AO: GHD

Überzug: flächig, matt glänzend, kompakt

Ton: 2.5 YR6/8

Farbe außen: 2.5 YR5/3+2.5YR5/8, Farbe innen: 2.5 YR5/3

+2.5 YR $5 / 8$

Maße: DmRd 10,8 cm, erh. H 3,1 cm

Dekor: Tropfengirlande an der Gefäßaußenseite

Erh.: 1 Rdfrgt.
KatNr. K 168

Taf. 172

Gattung: Glanztonware

Form: Halbkugelige Schale

InvNr. SE 107/10

AO: GHD

Überzug: flächig, matt glänzend, kompakt

Ton: 7.5 Y R5/6

Farbe außen: 7.5YR6/4+5YR2.5/1, Farbe innen: 5YR2.5/1

Maße: DmRd 12,8 cm, erh. H 3,6 cm

Erh.: 1 Rdfrgt.

\section{KatNr. K 169}

Taf. 172

Gattung: Glanztonware

Form: Halbkugelige Schale

InvNr. SE 211/23

AO: GHD

Überzug: flächig, matt glänzend, kompakt

Ton: 2.5YR6/6,

Farbe außen: 5YR2.5/1, Farbe innen: 5YR2.5/1

Maße: DmRd 19,4 cm, erh. H 2,65 cm

Erh.: 1 Rdfrgt.

KatNr. K 170

Taf. 172

Gattung: Glanztonware

Form: Halbkugelige Schale

InvNr. SE 211/32

AO: GHD

Überzug: flächig, matt glänzend, kompakt

Ton: 2.5 YR6/6

Farbe außen: 2.5YR4/1, Farbe innen: 2.5YR4/1

Maße: DmRd 17,6 cm, erh. H 1,9 cm

Erh.: 1 Rdfrgt.

\section{KatNr. K 171}

Taf. 173

Gattung: Glanztonware

Form: Halbkugelige Schale

InvNr. SE 216/58

AO: GHD

Überzug: flächig, matt glänzend, kompakt

Ton: 2.5 Y R6/6

Farbe außen: 10R5/6+2.5YR4/3, Farbe innen: 10R5/6

$+2.5 \mathrm{YR} 4 / 3$

Maße: DmRd 15,8 cm, erh. H 1,85 cm

Erh.: 1 Rdfrgt.

\section{KatNr. K 172}

Taf. 173

Gattung: Glanztonware

Form: Halbkugelige Schale

InvNr. SE 211/155

AO: GHD

Überzug: flächig, matt glänzend, kompakt

Ton: $2.5 \mathrm{YR} 6 / 4$

Farbe außen: 5YR6/4, Farbe innen: 5YR2.5/1

Maße: DmRd 10,3 cm, erh. H 2,6 cm

Erh.: 1 Rdfrgt.

KatNr. K 173

Taf. 173. 219

Gattung: Glanztonware/Westabhangnachfolgedekor

Form: Halbkugelige Schale

InvNr. SE 211/158

AO: GHD 
Überzug: flächig, matt glänzend, kompakt

Ton: 5YR6/4

Farbe außen: 10R6/6, Farbe innen: 10R6/6, Farbe Dekor am Rd: 5YR2.5/1

Maße: DmRd 19,6 cm, erh. H 3,2 cm

Dekor: Efeublattkranz an der Gefäßinnenseite Erh.: 1 Rdfrgt.

\section{KatNr. K 174}

Taf. 173

Gattung: Glanztonware

Form: Halbkugeliger Becher

InvNr. SE 210/24

AO: GHD

Überzug: flächig, matt glänzend, kompakt

Ton: 2.5 YR6/4

Farbe außen: 2.5YR4/1, Farbe innen: 2.5YR4/1

Maße: DmRd 11,6 cm, erh. H 3,6 cm

Erh.: 1 Rdfrgt.

\section{KatNr. K 175}

Gattung: Glanztonware

Form: Halbkugeliger Becher

InvNr. SE 207/97

AO: GHD

Überzug: flächig, matt glänzend, kompakt

Ton: $2.5 \mathrm{YR} 6 / 8$

Farbe außen: 2.5 YR4/8, Farbe innen: 2.5 YR $4 / 8$

Maße: DmRd $11 \mathrm{~cm}$, erh. H 2,9 cm

Erh.: 1 Rdfrgt.

\section{KatNr. K 176}

Gattung: Glanztonware

Form: Halbkugeliger Becher

InvNr. SE 207/32

AO: GHD

Überzug: flächig, matt glänzend, kompakt

Ton: 2.5 YR7/8+2.5YR6/4

Farbe außen: 5YR2.5/1, Farbe innen: 2.5YR5/6

Maße: DmRd 15,4 cm, erh. H 3,2 cm

Erh.: 1 Rdfrgt.

\section{KatNr. K 177}

Gattung: Glanztonware

Form: Halbkugeliger Becher

InvNr. SE 216/96

AO: GHD

Überzug: flächig, matt glänzend, kompakt

Ton: 5YR6/4

Farbe außen: 5YR2.5/1, Farbe innen: 5YR2.5/1

Maße: DmRd 9,4 cm, erh. H 3,7 cm

Erh.: 1 Rdfrgt.

\section{KatNr. K 178}

Gattung: Glanztonware

Form: Halbkugeliger Becher

InvNr. SE 211/106

AO: GHD

Überzug: flächig, matt glänzend, kompakt

Ton: 2.5 YR6/6

Farbe außen: 2.5YR5/6, Farbe innen: 2.5YR5/6

Maße: DmRd 4,8 cm, erh. H 2,8 cm

Erh.: 1 Rdfrgt.

Taf. 173

Taf. 173

\section{KatNr. K 179}

Taf. 173

Gattung: Glanztonware

Form: Halbkugeliger Becher

InvNr. SE 211/102

AO: GHD

Überzug: flächig, matt glänzend, kompakt

Ton: 7.5 YR7/3

Farbe außen: 5YR2.5/1, Farbe innen: 5YR2.5/1

Maße: DmRd 12,8 cm, erh. H 2,8 cm

Erh.: 1 Rdfrgt.

\section{KatNr. K 180}

Taf. 173

Gattung: Glanztonware

Form: Halbkugeliger Becher

InvNr. SE 216/95

AO: GHD

Überzug: flächig, matt glänzend, kompakt

Ton: 5YR7/4

Taf. 173 Farbe außen: 5YR2.5/1, Farbe innen: 5YR2.5/1

Maße: DmRd 10,2 cm, erh. H 4,3 cm

Erh.: 1 Rdfrgt.

\section{KatNr. K 181}

Taf. 173

Gattung: Glanztonware

Form: Halbkugeliger Becher

InvNr. SE 215/14

AO: GHD

Überzug: flächig, matt glänzend, kompakt

Ton: 5 YR7/3

Farbe außen: 2.5 YR4/3+2.5YR5/6, Farbe innen: 2.5 YR4/3

Maße: DmRd 12,6 cm, erh. H 1,8 cm

Erh.: 1 Rdfrgt.

\section{KatNr. K 182}

Taf. 173

Gattung: Glanztonware

Form: Halbkugeliger Becher

InvNr. SE 211/154

AO: GHD

Überzug: flächig, matt glänzend, kompakt

Ton: 5YR7/4

Farbe außen: 7.5YR5/2, Farbe innen: 7.5YR5/2

Maße: DmRd 12,3 cm, erh. H 2,3 cm

Erh.: 1 Rdfrgt.

\section{KatNr. K 183}

Taf. 173

Gattung: Glanztonware

Form: Halbkugeliger Becher

InvNr. SE 211/153

AO: GHD

Überzug: flächig, matt glänzend, kompakt

Ton: $7.5 \mathrm{YR} 7 / 3$

Taf. 173 Farbe außen: 5YR2,5/1, Farbe innen: 5YR2.5/1

Maße: DmRd 12,1 cm, erh. H 2,4 cm

Erh.: 1 Rdfrgt.

\section{KatNr. K 184}

Taf. 173

Gattung: Glanztonware

Form: Skyphos

InvNr. SE 215/15

AO: GHD

Überzug: flächig, matt glänzend, kompakt 
Ton: 5 YR7/6

Farbe außen: 2.5YR6/6, Farbe innen: 2.5YR5/6

Maße: DmRd 21,6 cm, erh. H 3,4 cm

Erh.: 1 Rdfrgt.

\section{KatNr. K 185}

Taf. 174

Gattung: Glanztonware

Form: Echinusschale

InvNr. SE 211/19

AO: GHD

Überzug: flächig, matt glänzend, teilweise abgerieben

Ton: 7.5 YR $5 / 6$

Farbe außen: 2.5YR4/8, Farbe innen: 5YR2.5/1+2.5YR4/8

Maße: DmRd 24,8 cm, erh. H 4,8 cm

Erh.: 2 Rdfrgt.

\section{KatNr. K 186}

Taf. 174

Gattung: Glanztonware

Form: Echinusschale

InvNr. SE 211/115

AO: GHD

Überzug: flächig, matt glänzend, teilweise abgerieben

Ton: 5YR6/6

Farbe außen: 2.5YR5/2, Farbe innen: 2.5YR5/2

Maße: DmRd 18,4 cm, erh. H 3,9 cm

Erh.: 1 Rdfrgt.

KatNr. K 187

Taf. 174

Gattung: Glanztonware

Form: Echinusschale

InvNr. SE 208/9

AO: GHD

Überzug: flächig, matt glänzend, teilweise abgerieben

Ton: 2.5 YR6/6

Farbe außen: 5YR2,5/1, Farbe innen: 10R5/6

Maße: DmRd 30,2 cm, erh. H 1,9 cm

Erh.: 1 Rdfrgt.

\section{KatNr. K 188}

Taf. 174

Gattung: Glanztonware

Form: Echinusschale

InvNr. SE 207/28

AO: GHD

Überzug: flächig, matt glänzend, teilweise abgerieben Ton: 2,5YR5/8

Farbe außen: 5YR2.5/1, Farbe innen: 5YR2.5/1

Maße: DmRd 11,2 cm, erh. H 1,8 cm

Erh.: 1 Rdfrgt.

\section{KatNr. K 189}

Taf. 174

Gattung: Glanztonware

Form: Echinusschale

InvNr. SE 216/67

AO: GHD

Überzug: flächig, matt glänzend, teilweise abgerieben

Ton: $7.5 Y R 7 / 4$

Farbe außen: 7.5YR8/4+5YR6/8+2.5YR5/6, Farbe innen: $10 \mathrm{R} 5 / 6$

Maße: DmRd 14,4 cm, erh. H 4,3 cm

Erh.: 1 Rdfrgt.
KatNr. K 190

Taf. 174

Gattung: Glanztonware

Form: Echinusschale

InvNr. SE 211/135

AO: GHD

Überzug: flächig, matt glänzend, teilweise abgerieben Ton: 5YR6/4

Farbe außen: 7.5YR7/3+2.5YR5/6, Farbe innen: 10R5/2

Maße: DmRd 11,3 cm, erh. H 3,65 cm

Erh.: 1 Rdfrgt.

KatNr. K 191

Taf. 174

Gattung: Glanztonware

Form: Echinusschale

InvNr. SE 207/99

AO: GHD

Überzug: flächig, matt glänzend, teilweise abgerieben Ton: 7.5YR6/4

Farbe außen: 7.5YR4/1+5YR6/1, Farbe innen: 7.5YR5/1

+7.5 Y R6/4

Maße: DmRd 19,4 cm, erh. H 3,4 cm

Erh.: 1 Rdfrgt.

\section{KatNr. K 192}

Taf. 174

Gattung: Glanztonware

Form: Echinusschale

InvNr. SE 210/21

AO: GHD

Überzug: flächig, matt glänzend, teilweise abgerieben

Ton: 2.5 YR6/8

Farbe außen: 2.5YR4/3, Farbe innen: 10R6/6

Maße: DmRd 18,7 cm, erh. H $3 \mathrm{~cm}$

Erh.: 1 Rdfrgt.

\section{KatNr. K 193}

Taf. 174

Gattung: Glanztonware

Form: Echinusschale

InvNr. SE 107/21

AO: GHD

Überzug: flächig, matt glänzend, teilweise abgerieben Ton: 10R6/4

Farbe außen: 5YR2.5/1, Farbe innen: 5YR2.5/1

Maße: DmRd 13,4 cm, erh. H 2 cm

Erh.: 1 Rdfrgt.

\section{KatNr. K 194}

Taf. 174

Gattung: Glanztonware

Form: Echinusschale

InvNr. SE 211/100

AO: GHD

Überzug: flächig, matt glänzend, teilweise abgerieben Ton: 7.5 YR $8 / 4$

Farbe außen: 2.5YR5/2, Farbe innen: 2.5YR5/6

Maße: DmRd 11,2 cm, erh. H 2,3 cm

Erh.: 1 Rdfrgt.

KatNr. K 195

Taf. 174

Gattung: Glanztonware

Form: Echinusschale

InvNr. SE 211/104

AO: GHD 
Überzug: flächig, matt glänzend, teilweise abgerieben Ton: 7.5 Y R7/4

Farbe außen: 7.5YR8/4+10R5/6, Farbe innen: 10R6/6

Maße: DmRd 11,8 cm, erh. H 3,65 cm

Erh.: 1 Rdfrgt.

\section{KatNr. K 196}

Taf. 174

Gattung: Glanztonware

Form: Echinusschale

InvNr. SE 211/136

AO: GHD

Überzug: flächig, matt glänzend, teilweise abgerieben

Ton: 5YR7/4

Farbe außen: 5YR7/3+2.5YR5/6+2.5YR3/1, Farbe innen:

2.5YR5/6+2.5YR3/1

Maße: DmRd 12,1 cm, erh. H 2,4 cm

Erh.: 1 Rdfrgt.

\section{KatNr. K 197}

Taf. 175

Gattung: Glanztonware

Form: Echinusschale

InvNr. SE 211/137

AO: GHD

Überzug: flächig, matt glänzend, teilweise abgerieben

Ton: 5YR6/6

Farbe außen: 5YR7/4+2.5YR6/4, Farbe innen: 10R6/6

+2.5 YR6/4

Maße: DmRd 14,8 cm, erh. H 2,7 cm

Erh.: 1 Rdfrgt.

\section{KatNr. K 198}

Taf. 175

Gattung: Glanztonware

Form: Echinusschale

InvNr. SE 110/3

AO: GHD

Überzug: flächig, matt glänzend, teilweise abgerieben

Ton: $7.5 \mathrm{YR} 6 / 2$

Farbe außen: 5YR2.5/1+2.5YR6/8, Farbe innen: 5YR2.5/1

+2.5 YR6/8

Maße: DmRd 13,4 cm, erh. H 2 cm

Erh.: 1 Rdfrgt.

\section{KatNr. K 199}

Taf. 175

Gattung: Glanztonware

Form: Echinusschale

InvNr. SE 211/138

AO: GHD

Überzug: flächig, matt glänzend, teilweise abgerieben

Ton: 5YR7/4

Farbe außen: 2.5YR6/6+5YR4/2+5YR7/4, Farbe innen: 2.5YR6/6+5YR4/2

Maße: DmRd 13,2 cm, erh. H 2,45 cm

Erh.: 1 Rdfrgt.

KatNr. K 200

Taf. 175

Gattung: Glanztonware

Form: Echinusschale

InvNr. SE 211/139

AO: GHD

Überzug: flächig, matt glänzend, teilweise abgerieben Ton: 5 YR7/4
Farbe außen: 10R6/6, Farbe innen: 10R6/6

Maße: DmRd 12,1 cm, erh. H 3,85 cm

Erh.: 1 Rdfrgt.

KatNr. K 201

Taf. 175

Gattung: Glanztonware

Form: Echinusschale

InvNr. SE 211/140

AO: GHD

Ton: 7.5 YR7/3

Überzug: flächig, matt glänzend, teilweise abgerieben

Farbe außen: 5YR5/2, Farbe innen: 5YR5/2

Maße: DmRd 14,2 cm, erh. H 1,9 cm

Erh.: 1 Rdfrgt.

KatNr. K 202

Taf. 175

Gattung: Glanztonware

Form: Echinusschale

InvNr. SE 209/24

AO: GHD

Überzug: flächig, matt glänzend, teilweise abgerieben

Ton: $7.5 \mathrm{YR} 6 / 4$

Farbe außen: 10R5/6, Farbe innen: 10R5/6, Farbe Dekor am Rd: 7.5 YR5/1

Maße: DmRd 8,8 cm, erh. H 1,85 cm

Erh.: 1 Rdfrgt.

KatNr. K 203

Taf. 175

Gattung: Glanztonware

Form: Echinusschale

InvNr. SE 209/7

AO: GHD

Überzug: flächig, matt glänzend, teilweise abgerieben

Ton: 5YR6/6

Farbe außen: 5YR7/6+2.5YR6/6, Farbe innen: 2.5YR6/6

Maße: DmRd 7,8 cm, erh. H 1,9 cm

Erh.: 1 Rdfrgt.

KatNr. K 204

Taf. 175

Gattung: Glanztonware

Form: Echinusschale

InvNr. SE 209/38

AO: GHD

Überzug: flächig, matt glänzend, teilweise abgerieben

Ton: 5YR6/6

Farbe außen: 2.5YR6/6, Farbe innen: 2.5YR7/6

Maße: DmRd 8,9 cm, erh. H $2 \mathrm{~cm}$

Erh.: 1 Rdfrgt.

KatNr. K 205

Taf. 175

Gattung: Glanztonware

Form: Echinusschale

InvNr. SE 216/130

AO: GHD

Überzug: flächig, matt glänzend, teilweise abgerieben

Ton: 5YR6/4

Farbe außen: 5YR2.5/1, Farbe innen: 5YR2.5/1

Maße: DmWd 16,2 cm, erh. H 2,6 cm

Erh.: 1 Wdfrgt. 


\section{KatNr. K 206}

Gattung: Glanztonware

Form: Schale mit verdicktem Rand

InvNr. SE 110/6

AO: GHD

Überzug: flächig, matt glänzend, teilweise abgerieben

Ton: 2.5 YR6/6

Farbe außen: 2.5 YR5/6, Farbe innen: 2.5 YR5/6

Maße: DmRd 19,2 cm, erh. H 2,5 cm

Erh.: 1 Rdfrgt.

\section{KatNr. K 207}

Taf. 175

Gattung: Glanztonware

Form: Schale (?)

InvNr. SE 215/12

AO: GHD

Überzug: flächig, matt glänzend, teilweise abgerieben Ton: 2.5YR6/6

Farbe außen: 5YR8/4+10R5/6, Farbe innen: 5YR8/4+10R5/6

Maße: DmRd 6,7 cm, erh. H 1,7 cm

Erh.: 1 Rdfrgt.

\section{KatNr. K 208}

Taf. 175

Gattung: Glanztonware

Form: Konische Schale mit ausgebogenem Rand InvNr. SE 211/20

AO: GHD

Überzug: flächig, matt glänzend, teilweise abgerieben Ton: 7.5 YR6/3+7.5YR7/8

Farbe außen: 7.5YR2.5/1, Farbe innen: 7.5YR2.5/1

Maße: DmRd 9,2 cm, erh. H 3,1 cm

Erh.: 1 Rdfrgt.

\section{KatNr. K 209}

Taf. 175

Gattung: Glanztonware

Form: Schale mit Wandknick

InvNr. SE 211/21

AO: GHD

Überzug: flächig, matt glänzend, teilweise abgerieben Ton: 7.5YR6/4

Farbe außen: 7.5YR2.5/1, Farbe innen: 7.5YR2.5/1

Maße: DmRd $15 \mathrm{~cm}$, erh. H 3,5 cm

Erh.: 1 Rdfrgt.

\section{KatNr. K 210}

Taf. 175

Gattung: Glanztonware

Form: Schale mit Wandknick

InvNr. SE 216/94

AO: GHD

Überzug: flächig, matt glänzend, teilweise abgerieben

Ton: 5YR7/6

Farbe außen: 5YR2.5/1, Farbe innen: 5YR2.5/1

Maße: DmRd $19 \mathrm{~cm}$, erh. H 3,6 cm

Erh.: 1 Rdfrgt.

\section{KatNr. K 211}

Taf. 175

Gattung: Glanztonware

Form: Schale mit Wandknick (?)

InvNr. SE 216/30

AO: GHD

Überzug: flächig, matt glänzend, teilweise abgerieben
Ton: 10 YR7/4

Farbe außen: 5YR2.5/1, Farbe innen: 5YR2.5/1

Maße: DmRd $10 \mathrm{~cm}$, erh. H 2,3 cm

Erh.: 1 Rdfrgt.

KatNr. K 212

Taf. 175

Gattung: Glanztonware

Form: Schale mit Wandknick

InvNr. SE 211/159

AO: GHD

Überzug: flächig, matt glänzend, teilweise abgerieben

Ton: 5YR6/4

Farbe außen: 5YR2.5/1, Farbe innen: 5YR2.5/1+2.5YR6/8

Maße: DmRd 15,5 cm, erh. H 2,2 cm

Erh.: 1 Rdfrgt.

KatNr. K 213

Taf. 175

Gattung: Glanztonware

Form: Schale mit Wandknick

InvNr. SE 211/101

AO: GHD

Überzug: flächig, matt glänzend, teilweise abgerieben

Ton: 5YR6/4

Farbe außen: 5YR2.5/1+2.5YR5/8, Farbe innen: 5YR2.5/1

Maße: DmRd 14,6 cm, erh. H 2,4 cm

Erh.: 1 Rdfrgt.

KatNr. K 214

Taf. 176. 220

Gattung: Glanztonware

Form: Schale mit Wandknick

InvNr. SE 211/126

AO: GHD

Überzug: flächig, außen abgeronnen, matt glänzend, teilweise abgerieben

Ton: 5YR7/6

Farbe außen: 5YR7/6+2.5YR6/8, Farbe innen: 2.5YR6/8

Maße: DmRd 7,9 cm, erh. H 2,85 cm

Erh.: 1 Rdfrgt.

KatNr. K 215

Taf. 176

Gattung: Glanztonware

Form: Schale mit Wandknick

InvNr. SE 210/30

AO: GHD

Überzug: flächig, matt glänzend, teilweise abgerieben

Ton: $7.5 Y R 7 / 3$

Farbe außen: 10YR8/2+5YR7/6, Farbe innen: 10R7/4

Maße: DmRd 8,4 cm, erh. H 2,75 cm

Erh.: 1 Rdfrgt.

\section{KatNr. K 216}

Taf. 176

Gattung: Glanztonware

Form: Schale mit Wandknick

InvNr. SE 216/121

AO: GHD

Überzug: flächig, matt glänzend, teilweise abgerieben

Ton: 5YR7/4

Farbe außen: 5YR2.5/1, Farbe innen: 5YR2.5/1

Maße: DmRd 19,8 cm, erh. H 2,25 cm

Erh.: 1 Rdfrgt. 


\section{KatNr. K 217}

Gattung: Glanztonware

Form: Schale mit Wandknick

InvNr. SE 211/107

AO: GHD

Überzug: flächig, matt glänzend, teilweise abgerieben

Ton: 5YR7/6

Farbe außen: 10YR7/4+5YR4/2, Farbe innen: 10R6/6

+5YR2.5/1

Maße: DmRd 8,4 cm, erh. H $1,7 \mathrm{~cm}$

Erh.: 1 Rdfrgt.

\section{KatNr. K 218}

Taf. 176

Gattung: Glanztonware

Form: Schale mit Wandknick

InvNr. SE 211/142

AO: GHD

Überzug: flächig, matt glänzend, teilweise abgerieben

Ton: 2.5YR6/6

Farbe außen: 5YR7/6+2.5YR5/6, Farbe innen: 10R5/6

Maße: DmRd 11,3 cm, erh. H 2,05 cm

Erh.: 1 Rdfrgt.

\section{KatNr. K 219}

Taf. 176

Gattung: Glanztonware

Form: Schale mit Wandknick

InvNr. SE 211/143

AO: GHD

Überzug: flächig, matt glänzend, teilweise abgerieben

Ton: 2.5YR6/6

Farbe außen: 5YR8/4, Farbe innen: 10YR6/2

Maße: DmRd 8,5 cm, erh. H 2,5 cm

Erh.: 1 Rdfrgt.

\section{KatNr. K 220}

Taf. 176

Gattung: Glanztonware

Form: Schale mit Wandknick

InvNr. SE 215/6

AO: GHD

Überzug: flächig, matt glänzend, teilweise abgerieben

Ton: $10 \mathrm{YR} 8 / 3$

Farbe außen: 10YR8/3+5YR2.5/1, Farbe innen: 5YR2.5/1

Maße: DmRd 8,7 cm, erh. H 2 cm

Erh.: 2 Rdfrgt.

\section{KatNr. K 221}

Taf. 176

Gattung: Glanztonware

Form: Schale mit Wandknick

InvNr. SE 107/4

AO: GHD

Überzug: flächig, matt glänzend, teilweise abgerieben

Ton: $7.5 \mathrm{YR} 7 / 4$

Farbe außen: 10YR8/4, Farbe innen: 5YR2.5/1

Maße: DmRd 9,2 cm, erh. H $3 \mathrm{~cm}$

Erh.: 1 Rdfrgt.

KatNr. K 222

Taf. 176

Gattung: Glanztonware

Form: Schale mit Wandknick

InvNr. SE 216/102

AO: GHD
Überzug: flächig, matt glänzend, teilweise abgerieben Ton: 7.5 YR7/4

Farbe außen: 7.5YR8/3, Farbe innen: 2.5YR6/8

Maße: DmBd 3,2 cm, erh. H 2,45 cm

Erh.: 1 Bdfrgt.

KatNr. K 223

Taf. 176

Gattung: Glanztonware

Form: Schale mit Wandknick

InvNr. SE 211/9

AO: GHD

Überzug: flächig, matt glänzend, teilweise abgerieben

Ton: 5YR7/6

Farbe außen: 5YR2.5/1, Farbe innen: 5YR2.5/1

Maße: DmRd 13,4 cm, erh. H 3,1 cm

Erh.: 1 Rdfrgt.

\section{KatNr. K 224}

Taf. 176

Gattung: Glanztonware/Import

Form: Schale mit Wandknick

InvNr. SE 207/89

AO: GHD

Überzug: flächig, matt glänzend, teilweise abgerieben Ton: 5 YR7/6

Farbe außen: 2.5YR4/6, Farbe innen: 2.5YR4/6

Maße: DmRd 14 cm, erh. H 1,7 cm

Erh.: 1 Rdfrgt.

KatNr. K 225

Taf. 176

Gattung: Glanztonware

Form: Schale mit Wandknick

InvNr. SE 211/160

AO: GHD

Überzug: flächig, matt glänzend, teilweise abgerieben

Ton: $2.5 \mathrm{YR} 6 / 6$

Farbe außen: 2.5YR5/6, Farbe innen: 2.5YR5/6

Maße: DmRd 11,6 cm, erh. H 1,95 cm

Erh.: 1 Rdfrgt.

\section{KatNr. K 226}

Taf. 176. 220

Gattung: Pergamenische Glanztonware

Form: Schale

InvNr. SE 107/1

AO: GHD

Überzug: innen und Rand außen, matt glänzend, teilweise abgerieben

Ton: $2.5 \mathrm{YR} 5 / 6$

Farbe außen: 5YR8/4+5YR2.5/1, Farbe innen: 2.5YR4/4

+5 YR2.5/1

Maße: DmRd 14 cm, erh. H 3,4 cm

Erh.: 1 Rdfrgt.

KatNr. K 227

Taf. 176

Gattung: Glanztonware

Form: Knidische Schale

InvNr. SE 209/26

AO: GHD

Überzug: flächig, matt glänzend, teilweise abgerieben

Ton: 2.5 YR6/6

Farbe außen: 10R6/6, Farbe innen: 10R6/6

Maße: DmRd 18,6 cm, erh. H 2,7 cm

Erh.: 1 Rdfrgt. 


\section{KatNr. K 228}

Gattung: Glanztonware

Form: Knidische Schale

InvNr. SE 211/15

AO: GHD

Überzug: flächig, matt glänzend, teilweise abgerieben

Ton: 2.5 YR $5 / 8$

Farbe außen: 2.5YR4/6+5YR2.5/1, Farbe innen: 2.5YR4/6

+5 YR2.5/1

Maße: DmRd 19,4 cm, erh. H 3 cm

Erh.: 1 Rdfrgt.

\section{KatNr. K 229}

Taf. 176

Gattung: Glanztonware

Form: Teller mit aufgebogenem Rand

InvNr. SE 211/74

AO: GHD

Überzug: flächig, matt glänzend, teilweise abgerieben

Ton: 2.5 YR5/6

Farbe außen: 10R5/6, Farbe innen: 10R5/6

Maße: DmRd 24,2 cm, erh. H 1,75 cm

Erh.: 1 Rdfrgt.

\section{KatNr. K 230}

Taf. 176

Gattung: Glanztonware

Form: Teller mit aufgebogenem Rand

InvNr. SE 107/7

AO: GHD

Überzug: flächig, matt glänzend, teilweise abgerieben

Ton: 2.5 YR $5 / 8$

Farbe außen: 2.5YR5/8, Farbe innen: 2.5YR5/6

Maße: DmRd 13,8 cm, erh. H 1,5 cm

Erh.: 1 Rdfrgt.

\section{KatNr. K 231}

Taf. 176

Gattung: Glanztonware

Form: Krater

InvNr. SE 211/22

AO: GHD

Überzug: flächig, matt glänzend, teilweise abgerieben

Ton: 2.5 YR $5 / 6$

Farbe außen: 2.5YR2.5/1, Farbe innen: 2.5YR2.5/1

Maße: DmRd 29,4 cm, erh. H 2,4 cm

Erh.: 1 Rdfrgt.

\section{KatNr. K 232}

Taf. 177

Gattung: Glanztonware

Form: Krater

InvNr. SE 211/51

AO: GHD

Überzug: flächig, matt glänzend, teilweise abgerieben

Ton: 2.5 YR6/8

Farbe außen: 5YR2.5/1, Farbe innen: 5YR2.5/1

Maße: DmRd 41,2 cm, erh. H $1 \mathrm{~cm}$

Erh.: 1 Rdfrgt.

KatNr. K 233

Taf. 177

Gattung: Glanztonware

Form: Teller

InvNr. SE 216/99

AO: GHD
Überzug: flächig, matt glänzend, teilweise abgerieben

Ton: 2.5 YR6/8

Farbe außen: 5YR2.5/1+2.5YR5/6, Farbe innen: 5YR2.5/1

+2.5 YR $5 / 6$

Maße: DmRd 32,2 cm, erh. H 3,6 cm

Erh.: 1 Rdfrgt.

KatNr. K 234

Taf. 177

Gattung: Glanztonware

Form: Schüssel

InvNr. SE 216/109

AO: GHD

Überzug: flächig, matt glänzend, teilweise abgerieben

Ton: 5 YR7/4

Farbe außen: 5YR2.5/1, Farbe innen: 5YR2.5/1

Maße: DmRd 27,3 cm, erh. H 1,3 cm

Erh.: 1 Rdfrgt.

KatNr. K 235

Taf. 177

Gattung: Glanztonware

Form: Schüssel

InvNr. SE 107/16

AO: GHD

Überzug: flächig, matt glänzend, teilweise abgerieben

Ton: $2.5 \mathrm{YR} 5 / 6$

Farbe außen: 10R5/6, Farbe innen: 10R5/6

Maße: DmRd 25,3 cm, erh. H 1,8 cm

Erh.: 1 Rdfrgt.

KatNr. K 236

Taf. 177

Gattung: Glanztonware

Form: Fischteller

InvNr. SE 211/5

AO: GHD

Überzug: flächig, matt glänzend, teilweise abgerieben

Ton: 2.5 YR6/8

Farbe außen: 2.5YR2.5/1+2.5YR3/6, Farbe innen: 2.5YR2.5/1 +2.5 YR $3 / 6$

Maße: DmRd 18,6 cm, erh. H 1,25 cm

Erh.: 1 Rdfrgt.

KatNr. K 237

Taf. 177

Gattung: Glanztonware

Form: Fischteller

InvNr. SE 207/31

AO: GHD

Überzug: flächig, matt glänzend, teilweise abgerieben

Ton: 2.5 YR6/6

Farbe außen: 5YR2.5/1, Farbe innen: 5YR2.5/1

Maße: DmRd $20 \mathrm{~cm}$, erh. H $1,3 \mathrm{~cm}$

Erh.: 1 Rdfrgt.

KatNr. K 238

Taf. 177

Gattung: Glanztonware

Form: Teller mit breitem Rand

InvNr. SE 216/97

AO: GHD

Überzug: flächig, matt glänzend, teilweise abgerieben

Ton: 5YR6/4

Farbe außen: 5YR6/8, Farbe innen: 5YR6/8

Maße: DmRd 13,4 cm, erh. H 2,45 cm

Erh.: 1 Rdfrgt. 


\section{KatNr. K 239}

Gattung: Glanztonware

Form: Teller mit breitem Rand

InvNr. SE 216/45

AO: GHD

Überzug: flächig, matt glänzend, teilweise abgerieben

Ton: 7.5 Y R $7 / 4$

Farbe außen: 7.5YR4/2, Farbe innen: 7.5YR4/2

Maße: DmRd 21,6 cm, erh. H 1,5 cm

Erh.: 1 Rdfrgt.

\section{KatNr. K 240}

Taf. 177

Gattung: Glanztonware

Form: Teller mit breitem Rand

InvNr. SE 211/148

AO: GHD

Überzug: flächig, matt glänzend, teilweise abgerieben

Ton: $7.5 Y R 7 / 4$

Farbe außen: $10 \mathrm{YR} 8 / 3+7.5 \mathrm{YR} 8 / 6$, Farbe innen: $10 \mathrm{YR} 8 / 3$

+7.5 YR $8 / 6$

Maße: DmRd 16,7 cm, erh. H 1,8 cm

Erh.: 1 Rdfrgt.

\section{KatNr. K 241}

Taf. 177

Gattung: Glanztonware

Form: Teller mit breitem Rand

InvNr. SE 207/23

AO: GHD

Überzug: flächig, matt glänzend, teilweise abgerieben

Ton: 5YR7/4

Farbe außen: 2.5YR5/6, Farbe innen: 2.5YR5/6

Maße: DmRd 17,2 cm, erh. H 1,8 cm

Erh.: 1 Rdfrgt.

\section{KatNr. K 242}

Taf. 177

Gattung: Glanztonware

Form: Teller mit breitem Rand

InvNr. SE 210/17

AO: GHD

Überzug: flächig, matt glänzend, teilweise abgerieben

Ton: 5YR7/4

Farbe außen: 5YR5/6+7.5YR8/4, Farbe innen: 5YR5/6

$+7.5 \mathrm{YR} 8 / 4$

Maße: DmRd 17,6 cm, erh. H 1,15 cm

Erh.: 1 Rdfrgt.

\section{KatNr. K 243}

Taf. 177

Gattung: Glanztonware

Form: Teller mit breitem Rand

InvNr. SE 216/59

AO: GHD

Überzug: flächig, matt glänzend, teilweise abgerieben

Ton: 5 YR7/4

Farbe außen: 2.5YR4/1, Farbe innen: 2.5YR4/1

Maße: DmRd 19,3 cm, erh. H 0,7 cm

Erh.: 1 Rdfrgt.

\section{KatNr. K 244}

Taf. 177

Gattung: Glanztonware

Form: Teller mit breitem Rand

InvNr. SE 107/2
AO: GHD

Überzug: flächig, matt glänzend, teilweise abgerieben Ton: 5YR7/6

Farbe außen: 7.5YR8/4, Farbe innen: 2.5YR5/8

Maße: DmRd 16,2 cm, erh. H 2,6 cm

Erh.: 1 Rdfrgt.

\section{KatNr. K 245}

Taf. 177

Gattung: Gebrauchskeramik

Form: Teller mit breitem Rand

InvNr. SE 216/81

AO: GHD

Überzug: flächig, matt glänzend, teilweise abgerieben

Ton: 10 YR $8 / 4$

Farbe außen: 10YR8/3, Farbe innen: 10YR8/3, Farbe Dekor am Rd: 10YR4/1

Maße: DmRd 19,6 cm, erh. H 1,4 cm

Erh.: 1 Rdfrgt.

\section{KatNr. K 246}

Taf. 177

Gattung: Glanztonware

Form: Teller mit breitem Rand

InvNr. SE 211/93

AO: GHD

Überzug: flächig, matt glänzend, teilweise abgerieben

Ton: $2.5 \mathrm{YR} 6 / 6$

Farbe außen: 7.5YR8/4, Farbe innen: 10R6/6

Maße: DmRd 16,4 cm, erh. H 2,4 cm

Erh.: 1 Rdfrgt.

KatNr. K 247

Taf. 178

Gattung: Glanztonware

Form: Teller mit breitem Rand

InvNr. SE 216/72

AO: GHD

Überzug: flächig, matt glänzend, teilweise abgerieben Ton: $2.5 \mathrm{YR} 6 / 6$

Farbe außen: 2.5YR5/6, Farbe innen: 2.5YR5/6

Maße: DmRd 20,9 cm, erh. H $1 \mathrm{~cm}$

Erh.: 1 Rdfrgt.

\section{KatNr. K 248}

Taf. 178

Gattung: Glanztonware

Form: Teller mit breitem Rand

InvNr. SE 211/145

AO: GHD

Überzug: flächig, matt glänzend, teilweise abgerieben

Ton: 10 YR7/3

Farbe außen: 10YR8/3+10YR4/1, Farbe innen: 10YR8/3

+10 YR $4 / 1$

Maße: DmRd 16,4 cm, erh. H 2,7 cm

Erh.: 1 Rdfrgt.

KatNr. K 249

Taf. 178

Gattung: Glanztonware

Form: Teller mit breitem Rand

InvNr. SE 210/18

AO: GHD

Überzug: flächig, matt glänzend, teilweise abgerieben

Ton: 7.5 YR7/4

Farbe außen: 2.5YR6/6, Farbe innen: 2.5YR6/6 
Maße: DmRd 17,4 cm, erh. H 1,1 cm Erh.: 1 Rdfrgt.

\section{KatNr. K 250}

Gattung: Glanztonware

Form: Teller mit breitem Rand

InvNr. SE 211/55

AO: GHD

Überzug: flächig, matt glänzend, teilweise abgerieben Ton: 2.5 YR6/6

Farbe außen: 10YR8/3, Farbe innen: 2.5YR5/6

Maße: DmRd 17,8 cm, erh. H 2,1 cm

Erh.: 1 Rdfrgt.

\section{KatNr. K 251}

Taf. 178

Gattung: Glanztonware

Form: Teller mit breitem Rand

InvNr. SE 211/147

AO: GHD

Überzug: flächig, matt glänzend, teilweise abgerieben Ton: 2.5 YR7/6

Farbe außen: 2.5YR6/6, Farbe innen: 2.5YR6/6

Maße: DmRd 17,2 cm, erh. H 1,05 cm

Erh.: 1 Rdfrgt.

\section{KatNr. K 252}

Taf. 178

Gattung: Glanztonware

Form: Teller mit breitem Rand

InvNr. SE 211/117

AO: GHD

Überzug: flächig, matt glänzend, teilweise abgerieben

Ton: 5YR7/4

Farbe außen: 7.5YR8/4, Farbe innen: 5YR2.5/1

Maße: DmRd $27 \mathrm{~cm}$, erh. H 1,8 cm

Erh.: 1 Rdfrgt.

\section{KatNr. K 253}

Taf. 178

Gattung: Glanztonware

Form: Teller mit breitem Rand

InvNr. SE 211/146

AO: GHD

Überzug: flächig, matt glänzend, teilweise abgerieben Ton: $7.5 Y R 7 / 4$

Farbe außen: 5YR8/4+10R5/6, Farbe innen: 10R5/6

Maße: DmRd 19,9 cm, erh. H 2,2 cm

Erh.: 1 Rdfrgt.

\section{KatNr. K 254}

Taf. 178

Gattung: Glanztonware

Form: Teller mit breitem Rand

InvNr. SE 216/60

AO: GHD

Überzug: flächig, matt glänzend, teilweise abgerieben

Ton: 5YR6/1

Farbe außen: 5YR4/1, Farbe innen: 5YR4/1

Maße: DmRd $17 \mathrm{~cm}$, erh. H 1,5 cm

Erh.: 1 Rdfrgt.

\section{KatNr. K 255}

Taf. 178

Gattung: Glanztonware

Form: Teller mit breitem Rand
InvNr. SE 216/61

AO: GHD

Überzug: flächig, matt glänzend, teilweise abgerieben Ton: $7.5 \mathrm{YR} 7 / 3$

Farbe außen: 5YR4/1+5YR5/3, Farbe innen: 5YR4/1

+5 YR $5 / 3$

Maße: DmRd 19,3 cm, erh. H 2,05 cm

Erh.: 1 Rdfrgt.

\section{KatNr. K 256}

Taf. 178

Gattung: Glanztonware

Form: Teller mit breitem Rand

InvNr. SE 216/82

AO: GHD

Überzug: flächig, matt glänzend, teilweise abgerieben

Ton: 2.5 YR6/6

Farbe außen: 10YR6/6+7.5YR8/4, Farbe innen: 10YR6/6

$+7.5 \mathrm{YR} 8 / 4$

Maße: DmRd 17,7 cm, erh. H 1,9 cm

Erh.: 1 Rdfrgt.

\section{KatNr. K 257}

Taf. 178

Gattung: Glanztonware

Form: Teller mit breitem Rand

InvNr. SE 216/83

AO: GHD

Überzug: flächig, matt glänzend, teilweise abgerieben

Ton: $2.5 Y R 7 / 4$

Farbe außen: 2.5 YR6/6+7.5YR8/4, Farbe innen: 2.5 YR6/6

$+7.5 \mathrm{YR} 8 / 4$

Maße: DmRd 17,4 cm, erh. H 1,45 cm

Erh.: 1 Rdfrgt.

\section{KatNr. K 258}

Taf. 178

Gattung: Glanztonware

Form: Teller mit breitem Rand

InvNr. SE 216/84

AO: GHD

Überzug: flächig, matt glänzend, teilweise abgerieben

Ton: $7.5 Y R 7 / 4$

Farbe außen: 5YR4/1+7.5YR8/3, Farbe innen: 5YR4/1

$+7.5 \mathrm{YR} 8 / 3$

Maße: DmRd 18,5 cm, erh. H 1,3 cm

Erh.: 1 Rdfrgt.

\section{KatNr. K 259}

Taf. 178

Gattung: Glanztonware

Form: Teller mit beidseitig verdickter Randlippe

InvNr. SE 207/93

AO: GHD

Überzug: flächig, matt glänzend, teilweise abgerieben

Ton: 7.5YR6/4

Farbe außen: 5YR2.5/1, Farbe innen: 5YR2.5/1

Maße: DmRd $28 \mathrm{~cm}$, erh. H $1,5 \mathrm{~cm}$

Erh.: 1 Rdfrgt.

KatNr. K 260

Taf. 178

Gattung: Glanztonware

Form: Teller mit beidseitig verdickter Randlippe

InvNr. SE 211/116

AO: GHD 
Überzug: flächig, matt glänzend, teilweise abgerieben Ton: 5YR6/4

Farbe außen: 5YR2.5/1, Farbe innen: 5YR2.5/1

Maße: DmRd 28,4 cm, erh. H 2,15 cm

Erh.: 1 Rdfrgt.

\section{KatNr. K 261}

Taf. 179

Gattung: Glanztonware

Form: Teller mit beidseitig verdickter Randlippe InvNr. SE 210/19

AO: GHD

Überzug: flächig, matt glänzend, teilweise abgerieben Ton: 2.5YR6/6

Farbe außen: 2.5YR3/3, Farbe innen: 2.5YR4/6

Maße: DmRd 34,5 cm, erh. H 1,1 cm

Erh.: 1 Rdfrgt.

\section{KatNr. K 262}

Taf. 179

Gattung: Glanztonware

Form: Teller mit beidseitig verdickter Randlippe

InvNr. SE 211/56

AO: GHD

Überzug: flächig, matt glänzend, teilweise abgerieben

Ton: 2.5YR6/6

Farbe außen: 5YR2.5/1, Farbe innen: 5YR2.5/1

Maße: DmRd 29,6 cm, erh. H 1,5 cm

Erh.: 1 Rdfrgt.

\section{KatNr. K 263}

Taf. 179

Gattung: Glanztonware

Form: Teller mit beidseitig verdickter Randlippe

InvNr. SE 209/22

AO: GHD

Überzug: flächig, matt glänzend, teilweise abgerieben

Ton: 7.5 Y R6/4

Farbe außen: 10YR5/1, Farbe innen: 10YR5/1

Maße: DmRd 22,4 cm, erh. H 1,05 cm

Erh.: 1 Rdfrgt.

\section{KatNr. K 264}

Taf. 179

Gattung: Glanztonware

Form: Teller mit beidseitig verdickter Randlippe

InvNr. SE 207/94

AO: GHD

Überzug: flächig, matt glänzend, teilweise abgerieben

Ton: 5YR7/6

Farbe außen: 7.5YR8/4, Farbe innen: 5YR4/1

Maße: DmRd $22 \mathrm{~cm}$, erh. H 0,9 cm

Erh.: 1 Rdfrgt.

\section{KatNr. K 265}

Taf. 179

Gattung: Glanztonware

Form: Teller mit beidseitig verdickter Randlippe

InvNr. SE 207/92

AO: GHD

Überzug: flächig, matt glänzend, teilweise abgerieben

Ton: 5YR6/6

Farbe außen: 7.5YR5/4+7.5YR3/1, Farbe innen: 7.5YR5/4

+7.5 YR $3 / 1$

Maße: DmRd 21,8 cm, erh. H 1,7 cm

Erh.: 1 Rdfrgt.
KatNr. K 266

Taf. 179

Gattung: Glanztonware

Form: Teller mit beidseitig verdickter Randlippe

InvNr. SE 207/91

AO: GHD

Überzug: flächig, matt glänzend, teilweise abgerieben Ton: 5YR7/6

Farbe außen: 2.5YR4/1, Farbe innen: 2.5YR4/1

Maße: DmRd 24 cm, erh. H 1,9 cm

Erh.: 1 Rdfrgt.

KatNr. K 267

Taf. 179

Gattung: Glanztonware

Form: Teller mit gedrechseltem Rand

InvNr. SE 207/90

AO: GHD

Überzug: flächig, matt glänzend, teilweise abgerieben

Ton: 5YR6/6

Farbe außen: 5YR5/4+2.5YR4/3, Farbe innen: 5YR5/4

+2.5 YR $4 / 3$

Maße: DmRd 23,6 cm, erh. H 1,1 cm

Erh.: 1 Rdfrgt.

KatNr. K 268

Taf. 179

Gattung: Glanztonware

Form: Teller mit gedrechseltem Rand

InvNr. SE 207/70

AO: GHD

Überzug: flächig, matt glänzend, teilweise abgerieben Ton: 5YR6/4

Farbe außen: 5YR2.5/1, Farbe innen: 5YR2.5/1

Maße: DmRd $22 \mathrm{~cm}$, erh. H $1 \mathrm{~cm}$

Erh.: 1 Rdfrgt.

KatNr. K 269

Taf. 179

Gattung: Glanztonware

Form: Teller mit gedrechseltem Rand

InvNr. SE 207/49

AO: GHD

Überzug: flächig, matt glänzend, teilweise abgerieben

Ton: 2.5 YR5/4+2.5YR6/8

Farbe außen: $2.5 \mathrm{YR} 3 / 3$, Farbe innen: $2.5 \mathrm{YR} 3 / 3$

Maße: DmRd $20 \mathrm{~cm}$, erh. H 1,25 cm

Erh.: 1 Rdfrgt.

\section{KatNr. K 270}

Taf. 179

Gattung: Glanztonware

Form: Teller mit gedrechseltem Rand

InvNr. SE 207/57

AO: GHD

Überzug: flächig, matt glänzend, teilweise abgerieben

Ton: $7.5 \mathrm{YR} 7 / 4$

Farbe außen: 7.5YR4/2, Farbe innen: 7.5YR4/2

Maße: DmRd 21,2 cm, erh. H 1,3 cm

Erh.: 1 Rdfrgt.

KatNr. K 271

Taf. 179

Gattung: Glanztonware

Form: Teller mit gedrechseltem Rand

InvNr. SE 211/149

AO: GHD 
Überzug: flächig, matt glänzend, teilweise abgerieben Ton: 7.5YR6/4

Farbe außen: 5YR2.5/1, Farbe innen: 5YR2.5/1

Maße: DmRd 20,2 cm, erh. H 1,3 cm

Erh.: 1 Rdfrgt.

\section{KatNr. K 272}

Taf. 179

Gattung: Glanztonware

Form: Teller mit gedrechseltem Rand

InvNr. SE 216/10

AO: GHD

Überzug: flächig, matt glänzend, teilweise abgerieben

Ton: 5YR6/6

Farbe außen: 2.5YR4/8, Farbe innen: 2.5YR4/8

Maße: DmRd 20,2 cm, erh. H 1,7 cm

Erh.: 1 Rdfrgt.

KatNr. K 273

Gattung: Glanztonware (attisch?)

Form: Teller

InvNr. SE 211/47

AO: GHD

Überzug: flächig, glänzend, teilweise abgerieben

Ton: 5YR6/4

Farbe außen: 5YR2.5/1, Farbe innen: 5YR6/4

Maße: DmBd 37,6 cm, erh. H 1,75 cm

Dekor: Rouletting auf der Bodeninnenseite

Erh.: 1 Bdfrgt.

\section{KatNr. K 274}

Gattung: Glanztonware (attisch?)

Form: Teller

InvNr. SE 211/82

AO: GHD

Überzug: flächig, glänzend, teilweise abgerieben

Ton: 5YR8/4

Farbe außen: 5YR2.5/1, Farbe innen: 5YR2.5/1

Maße: DmBd 6,8 cm, erh. H 2,35 cm

Dekor: Rouletting und Ansatz eines Palmettenstempels an der Bodeninnenseite

Erh.: 1 Bdfrgt.

\section{KatNr. K 275}

Taf. 179

Gattung: Glanztonware (attisch?)

Form: Teller

InvNr. SE 211/131

AO: GHD

Überzug: flächig, glänzend, teilweise abgerieben

Ton: 2.5YR6/6

Farbe außen: 5YR2.5/1, Farbe innen: 2.5YR2.5/1

Maße: DmBd 13,2 cm, erh. H 2,2 cm

Dekor: Rouletting an der Bodeninnenseite

Erh.: 1 Bdfrgt.

\section{KatNr. K 276}

Taf. 180

Gattung: Glanztonware (attisch?)

Form: Schale

InvNr. SE 216/126

AO: GHD

Überzug: flächig, glänzend, kompakt

Ton: 2.5 YR6/6

Taf. 179
Farbe außen: 5YR2.5/1, Farbe innen: 5YR8/4

Maße: DmBd 7 cm, erh. H 1,5 cm

Erh.: 1 Bdfrgt.

KatNr. K 277

Taf. 180

Gattung: Glanztonware (attisch)

Form: Skyphos

InvNr. SE 216/35

AO: GHD

Überzug: flächig, glänzend, kompakt

Ton: 5YR6/6

Farbe außen: 5YR2.5/1+5YR6/8, Farbe innen: 5YR2.5/1

+5 YR6/8

Maße: DmBd 7,2 cm, erh. H 1,25 cm

Erh.: 1 Bdfrgt.

\section{KatNr. K 278}

Taf. 180

Gattung: Glanztonware (attisch?)

Form: Becher

InvNr. SE 216/33

AO: GHD

Überzug: flächig, glänzend, teilweise abgerieben

Ton: 5YR6/1

Farbe außen: 5YR2.5/1, Farbe innen: 5YR2.5/1

Maße: DmBd 3,4 cm, erh. H 2,1 cm

Erh.: 1 Bdfrgt.

KatNr. K 279

Taf. 180. 220

Gattung: Glanztonware

Form: Teller

InvNr. SE 211/132

AO: GHD

Überzug: flächig, matt glänzend, teilweise abgerieben

Ton: 7.5YR6/4

Farbe außen: 5YR5/6+7.5YR5/3, Farbe innen: 5YR5/6 +7.5 YR $5 / 3$

Maße: DmBd 7,2 cm, erh. H 2,05 cm

Dekor: Palmettenstempel an der Bodeninnenseite

Erh.: 1 Bdfrgt.

KatNr. K 280

Taf. 180. 220

Gattung: Glanztonware

Form: Teller

InvNr. SE 211/133

AO: GHD

Überzug: flächig, matt glänzend, teilweise abgerieben

Ton: 10YR5/1

Farbe außen: 10YR4/1, Farbe innen: 10YR4/1

Maße: DmBd 6 cm, erh. H 1,8 cm

Dekor: Palmettenstempel an der Bodeninnenseite

Erh.: 1 Bdfrgt.

KatNr. K 281

Taf. 180. 220

Gattung: Glanztonware

Form: Teller

InvNr. SE 209/30

AO: GHD

Überzug: flächig, matt glänzend, teilweise abgerieben

Ton: 5 YR6/3

Farbe außen: 2.5YR7/4, Farbe innen: 2.5YR7/4

Maße: DmBd 4 cm, erh. H 1,35 cm 
Dekor: Palmettenstempel an der Bodeninnenseite Erh.: 1 Bdfrgt.

\section{KatNr. K 282}

Taf. 180. 220

Gattung: Glanztonware

Form: Teller

InvNr. SE 208/15

AO: GHD

Überzug: flächig, matt glänzend, teilweise abgerieben

Ton: 2.5 YR6 $/ 6+2.5$ YR $5 / 1$

Farbe außen: 5YR2.5/1, Farbe innen: 5YR2.5/1

Maße: DmBd 5,4 cm, erh. H 1,6 cm

Dekor: Palmettenstempel an der Bodeninnenseite

Erh.: 1 Bdfrgt.

\section{KatNr. K 283}

Taf. 220

Gattung: Glanztonware

Form: Teller (?)

InvNr. SE 211/515

AO: GHD

Überzug: innen, matt glänzend, kompakt

Ton: 10YR6/4

Farbe außen: 10YR7/3, Farbe innen: 5YR6/6

Maße: $4,5 \times 2,4 \mathrm{~cm}$

Dekor: Palmettenstempel an der Bodeninnenseite

Erh.: 1 Bdfrgt.

\section{KatNr. K 284}

Taf. 220

Gattung: Glanztonware

Form: Teller (?)

InvNr. SE 106/51

AO: GHD

Überzug: flächig, glänzend, kompakt

Ton: 10YR6/4

Farbe außen: Gley1 2.5N/0, Farbe innen: Gley1 2.5N/0

Maße: $3,1 \times 2,6 \mathrm{~cm}$

Dekor: Palmettenstempel, gefasst von Roulettkranz an der

Bodeninnenseite

Erh.: 1 Bdfrgt.

\section{KatNr. K 285}

Taf. 180. 220

Gattung: Glanztonware

Form: Schale mit Muschelfüßen

InvNr. SE 211/134

AO: GHD

Überzug: flächig, matt glänzend, teilweise abgerieben

Ton: 7.5YR7/4

Farbe außen: 7.5YR8/3, Farbe innen: 5YR2.5/1

Maße: DmBd 4,4 cm, erh. H 1,6 cm

Dekor: Muschelappliken als Füße

Erh.: 1 Bdfrgt.

\section{KatNr. K 286}

Taf. 180. 220

Gattung: Glanztonware

Form: Schale mit Muschelfüßen

InvNr. SE 216/36

AO: GHD

Überzug: flächig, matt glänzend, teilweise abgerieben

Ton: 5YR5/2

Farbe außen: 5YR2.5/1, Farbe innen: 5YR2.5/1

Maße: DmBd 1,8 cm, erh. H 1,95 cm
Dekor: Muschelappliken als Füße

Erh.: 1 Bdfrgt.

KatNr. K 287

Taf. 180. 221

Gattung: Glanztonware/Westabhangnachfolgedekor

Form: Konische Schale

InvNr. SE 211/177

AO: GHD

Überzug: flächig, matt glänzend, kompakt

Ton: 5YR6/4

Farbe außen: 10R6/6, Farbe innen: 10R6/6, Farbe Dekor (Strahlen innen): 5YR5/3

Maße: DmBd 3,6 cm, erh. H 2,3 cm

Dekor: Strahlen an der Gefäßinnenseite

Erh.: 1 Bdfrgt.

\section{KatNr. K 288}

Taf. 180. 221

Gattung: Glanztonware

Form: Schale mit Muschelfüßen

InvNr. SE 215/21

AO: GHD

Überzug: flächig, matt glänzend, teilweise abgerieben

Ton: 10 YR $8 / 4$

Farbe außen: 10R5/4, Farbe innen: 10R5/4

Maße: DmBd $5 \mathrm{~cm}$, erh. H 2,4 cm

Dekor: Muschelappliken als Füße

Erh.: 1 Bdfrgt.

KatNr. K 289

Taf. 180

Gattung: Glanztonware

Form: Skyphos/Kantharos

InvNr. SE 216/75

AO: GHD

Überzug: flächig, matt glänzend, teilweise abgerieben

Ton: 2.5 YR7/4

Farbe außen: 5YR2.5/1, Farbe innen: 7.5YR7/4

Maße: DmBd 10,8 cm, erh. H 1,9 cm

Erh.: 1 Bdfrgt.

KatNr. K 290

Taf. 180

Gattung: Glanztonware

Form: Kantharos

InvNr. SE 215/19

AO: GHD

Überzug: flächig, matt glänzend, teilweise abgerieben

Ton: 5YR7/6

Farbe außen: 2.5YR6/6, Farbe innen: 2.5YR6/6

Maße: DmBd $13 \mathrm{~cm}$, erh. H 2,25 cm

Erh.: 1 Bdfrgt.

KatNr. K 291

Taf. 180. 221

Gattung: Glanztonware

Form: Skyphos

InvNr. SE 211/128

AO: GHD

Überzug: flächig, matt glänzend, teilweise abgerieben

Ton: 10YR5/3

Farbe außen: 5YR2.5/1, Farbe innen: 5YR2.5/1

Maße: DmBd 4,8 cm, erh. H 7,4 cm

Erh.: 1 Bdfrgt. 


\section{KatNr. K 292}

Gattung: Glanztonware

Form: Skyphos (?)

InvNr. SE 211/175

AO: GHD

Überzug: flächig, matt glänzend, teilweise abgerieben

Ton: 10R6/4

Farbe außen: 10R6/6, Farbe innen: 2.5YR5/4

Maße: DmBd 4,5 cm, erh. H $3 \mathrm{~cm}$

Erh.: 1 Bdfrgt.

\section{KatNr. K 293}

Gattung: Glanztonware

Form: Skyphos

InvNr. SE 216/128

AO: GHD

Überzug: flächig, matt glänzend, teilweise abgerieben

Ton: 2.5YR6/4

Farbe außen: 5YR2.5/1, Farbe innen: 5YR2.5/1

Maße: DmBd 4,5 cm, erh. H 3,05 cm

Erh.: 1 Bdfrgt.

\section{KatNr. K 294}

Gattung: Glanztonware

Form: Skyphos

InvNr. SE 215/20

AO: GHD

Überzug: flächig, matt glänzend, teilweise abgerieben

Ton: 5YR6/1+5YR6/6

Farbe außen: 5YR2.5/1, Farbe innen: 5YR2.5/1

Maße: DmBd 5,1 cm, erh. H 5,05 cm

Erh.: 1 Bdfrgt.

\section{KatNr. K 295}

Taf. 181

Gattung: Glanztonware

Form: Krater (?)

InvNr. SE 211/174

\section{AO: GHD}

Überzug: flächig, matt glänzend, teilweise abgerieben Ton: 7.5 YR7/3

Farbe außen: 5YR2.5/1, Farbe innen: 5YR2.5/1

Maße: DmBd 5,5 cm, erh. H 4,3 cm

Dekor: Riefeln an der Gefäßaußenseite

Erh.: 1 Bdfrgt.

\section{KatNr. K 296}

Taf. 181

Gattung: Glanztonware

Form: Unguentarium

InvNr. SE 107/13

AO: GHD

Überzug: außen, matt glänzend, teilweise abgerieben

Ton: 7.5 Y R7/4

Farbe außen: 7.5YR8/4+2.5YR5/6, Farbe innen: 7.5YR8/4

+2.5 YR5 $/ 6$

Maße: DmBd 2,1 cm, erh. H 4,1 cm

Erh.: 1 Bdfrgt.

KatNr. K 297

Taf. 181

Gattung: Glanztonware

Form: Unguentarium

InvNr. SE 107/18
AO: GHD

Überzug: außen, matt glänzend, teilweise abgerieben

Ton: $7.5 Y R 7 / 4$

Farbe außen: 5YR2.5/1+5YR7/6, Farbe innen: 5YR2.5/1

+5 YR7/6

Maße: DmBd 2,3 cm, erh. H 2,7 cm

Erh.: 1 Bdfrgt.

KatNr. K 298

Taf. 181

Gattung: Glanztonware

Form: Unguentarium

InvNr. SE 216/78

AO: GHD

Überzug: außen, matt glänzend, teilweise abgerieben

Ton: 5YR7/4

Farbe außen: 5YR2.5/1, Farbe innen: 7.5YR7/4

Maße: DmBd 1,8 cm, erh. H $3 \mathrm{~cm}$

Erh.: 1 Bdfrgt.

KatNr. K 299

Taf. 181

Gattung: Glanztonware

Form: Amphoriskos

InvNr. SE 211/129

AO: GHD

Überzug: außen, matt glänzend, teilweise abgerieben

Ton: 7.5 YR7/4

Farbe außen: 5YR2.5/1, Farbe innen: 5YR7/6

Maße: DmBd 0,6 cm, erh. H 5,1 cm

Erh.: 1 Bdfrgt.

KatNr. K 300

Taf. 181

Gattung: Weißgrundige Keramik

Form: Krug/Amphore

InvNr. SE 207/54

AO: GHD

Überzug: außen, matt, teilweise abgerieben

Ton: 7.5 YR6/6

Farbe außen: 7.5YR7/4+weißer Überzug, Farbe innen: 7.5YR7/4

Maße: DmRd 7 cm, erh. H 2,9 cm

Erh.: 1 Rdfrgt.

KatNr. K 301

Taf. 181

Gattung: Weißgrundige Keramik

Form: Lagynos

InvNr. SE 207/102

AO: GHD

Überzug: außen, matt, teilweise abgerieben

Ton: 5YR5/6

Farbe außen: weiß+2.5YR5/6+2.5YR5/8, Farbe innen: 5YR7/6

Maße: DmBd 15,2 cm, erh. H 1,65 cm

Erh.: 1 Bdfrgt.

KatNr. K 302

Taf. 221

Gattung: Weißgrundige Keramik

Form: Lagynos

InvNr. SE 216/59

AO: GHD

Überzug: außen, matt, teilweise abgerieben

Ton: 7.5 YR6/4 
Farbe außen: Untergrund weiß, Bemalung: 5YR3/1 (sehr kompakt, matt), Farbe innen: 5YR6/6

Maße: $3,7 \times 3,1 \mathrm{~cm}$

Dekor: Girlande/Kranz

Erh.: 1 Wdfrgt.

\section{KatNr. K 303}

Taf. 221

Gattung: Weißgrundige Keramik

Form: Amphore

InvNr. SE 209/51

AO: GHD

Überzug: außen, kompakt, matt

Ton: 7.5YR5/3

Tongrund: weiß, Farbe Bemalung: 5YR6/6, Farbe innen: 7.5 YR $5 / 3$

Maße: 8,5 × 5,5 cm, sehr dickwandig: $1 \mathrm{~cm}$

Dekor: Palmette und Roulettingkreis

Erh.: 1 Wdfrgt.

\section{KatNr. K 304}

Taf. 181

Gattung: Dünnwandige Keramik

Form: Becher

InvNr. SE 209/25

AO: GHD

Ton: 2.5 YR6/8

Farbe außen: 2.5YR6/6, Farbe innen: 2.5YR6/6

Maße: DmRd 13,8 cm, erh. H 3,1 cm

Erh.: 1 Rdfrgt.

\section{KatNr. K 305}

Gattung: Dünnwandige Keramik

Form: Becher

InvNr. SE 207/36

AO: GHD

Ton: 5YR6/4

Farbe außen: 5YR6/3, Farbe innen: 5YR6/3

Maße: DmBd 6,4 cm, erh. H $1 \mathrm{~cm}$

Erh.: 1 Rdfrgt.

\section{KatNr. K 306}

Gattung: Dünnwandige Keramik

Form: Becher

InvNr. SE 212/6

AO: GHD

Ton: 2.5YR6/8

Farbe außen: 2.5YR7/6, Farbe innen: 2.5YR7/6

Maße: DmBd 4,8 cm, erh. H $1 \mathrm{~cm}$

Erh.: 1 Bdfrgt.

\section{KatNr. K 307}

Taf. 181

Gattung: Dünnwandige Keramik

Form: Becher

InvNr. SE 207/37

AO: GHD

Ton: 5YR5/1

Farbe außen: 5YR4/1+5YR5/1, Farbe innen: 5YR4/1

+5 YR $5 / 1$

Maße: DmRd 5,9 cm, erh. H 0,7 cm

Erh.: 1 Rdfrgt.

Taf. 181
KatNr. K 308

Taf. 181

Gattung: Dünnwandige Keramik

Form: Becher

InvNr. SE 208/16

AO: GHD

Ton: $2.5 \mathrm{YR} 5 / 8$

Farbe außen: 2.5YR6/6, Farbe innen: 2.5YR6/6

Maße: DmBd $4 \mathrm{~cm}$, erh. H 1,2 cm

Erh.: 1 Bdfrgt.

KatNr. K 309

Taf. 181

Gattung: Dünnwandige Keramik

Form: Becher

InvNr. SE 207/107

AO: GHD

Ton: 5 YR $5 / 8$

Farbe außen: 2.5YR6/6, Farbe innen: 2.5YR6/6

Maße: DmBd 4,2 cm, erh. H 1,8 cm

Erh.: 1 Bdfrgt.

KatNr. K 310

Taf. 181

Gattung: Dünnwandige Keramik

Form: Becher

InvNr. SE 209/35

AO: GHD

Ton: 2.5 YR $5 / 8$

Farbe außen: $2.5 Y R 7 / 4$, Farbe innen: 2.5 YR7/4

Maße: DmRd 2,6 cm, erh. H 2,9 cm

Erh.: 1 Rdfrgt.

\section{KatNr. K 311}

Taf. 221

Taf. 181 Gattung: Dünnwandige Keramik

Form: Henkel

InvNr. SE 209/o. Nr.

AO: GHD

Überzug: außen, kompakt, matt

Ton: 7.5 YR $5 / 3$

Farbe außen: 7.5YR4/3, Farbe innen: 7.5YR5/3

Maße: $3 \times 1,6 \mathrm{~cm}$

Dekor: modelgefertigter Netzdekor am Henkel

Erh.: 1 Henkelfrgt.

KatNr. K 312

Taf. 221

Gattung: Dünnwandige Keramik

Form: Becher

InvNr. SE 207/54

AO: GHD

Ton: $2.5 \mathrm{YR} 5 / 2$

Farbe außen: 5YR5/2 + 2.5YR6/4, Farbe innen: 2.5YR6/6

Maße: $6,9 \times 5,8 \mathrm{~cm}$ und $5,9 \times 4 \mathrm{~cm}$

Dekor: Gräten- und Dornen-Komma in Barbotinetechnik

Erh.: 11 Wdfrgt.

KatNr. K 313

Taf. 181

Gattung: Gebrauchskeramik

Form: Schale/Krug (?)

InvNr. SE 216/98

AO: GHD

Ton: 7.5 YR6/4

Farbe außen: 7.5YR7/6, Farbe innen: 7.5YR7/6

Maße: DmRd 10,2 cm, erh. H 3,2 cm

Erh.: 1 Rdfrgt. 


\section{KatNr. K 314}

Gattung: Gebrauchskeramik

Form: Krug

InvNr. SE 216/2

AO: GHD

Ton: $7.5 \mathrm{YR} 7 / 4$

Farbe außen: 10YR8/3, Farbe innen: 10YR8/3

Maße: DmRd 6,4 cm, erh. H 4,4 cm

Erh.: 1 Rdfrgt.

\section{KatNr. K 315}

Gattung: Gebrauchskeramik

Form: Krug

InvNr. SE 211/111

AO: GHD

Ton: 5YR6/6

Farbe außen: 7.5YR8/4, Farbe innen: 7.5YR8/4, Farbe Dekor am Rd: 2.5YR6/6

Maße: DmRd 7,4 cm, erh. H 3,3 cm

Erh.: 1 Rdfrgt.

\section{KatNr. K 316}

Taf. 181

Gattung: Gebrauchskeramik

Form: Krug

InvNr. SE 211/26

AO: GHD

Ton: 2.5YR6/6

Farbe außen: 2.5YR7/6, Farbe innen: 2.5YR7/6, Farbe Dekor am Rd: 2.5 YR4/6

Maße: DmRd 7,4 cm, erh. H 1,8 cm

Erh.: 1 Rdfrgt.

\section{KatNr. K 317}

Gattung: Gebrauchskeramik

Form: Krug

InvNr. SE 211/67

AO: GHD

Ton: $2.5 \mathrm{YR} 6 / 6$

Farbe außen: 5YR7/4, Farbe innen: 10R5/6

Maße: DmRd 7,6 cm, erh. H 1,75 cm

Erh.: 1 Rdfrgt.

\section{KatNr. K 318}

Gattung: Gebrauchskeramik

Form: Krug

InvNr. SE 211/14

AO: GHD

Ton: 5YR6/6

Farbe außen: 5YR7/4, Farbe innen: 5YR7/4

Maße: DmRd 8,4 cm, erh. H 3,1 cm

Erh.: 1 Rdfrgt.

\section{KatNr. K 319}

Gattung: Gebrauchskeramik

Form: Topf/Krug

InvNr. SE 211/11

AO: GHD

Ton: 5YR5/6

Farbe außen: 7.5YR6/6, Farbe innen: 7.5YR6/6

Maße: DmRd 9,2 cm, erh. H 4,7 cm

Erh.: 1 Rdfrgt.

Taf. 181

Taf. 181

Taf. 182

\section{KatNr. K 320}

Taf. 182

Gattung: Gebrauchskeramik

Form: Krug/Flasche

InvNr. SE 211/88

AO: GHD

Ton: 10YR8/4

Farbe außen: 5YR2.5/1, Farbe innen: 5YR2.5/1

Maße: DmRd 4,3 cm, erh. H 2,4 cm

Erh.: 1 Rdfrgt.

\section{Taf. $181 \quad$ KatNr. K 321}

Taf. 182

Gattung: Gebrauchskeramik

Form: Krug (?)

InvNr. SE 104/1

AO: GHD

Ton: 7.5 YR7/4

Farbe außen: 7.5YR8/2, Farbe innen: 7.5YR8/4

Maße: DmRd $12 \mathrm{~cm}$, erh. H 2,5 cm

Erh.: 3 Rdfrgt.

KatNr. K 322

Taf. 182

Gattung: Gebrauchskeramik

Form: Krug

InvNr. SE 107/19

AO: GHD

Ton: 7.5YR6/4

Farbe außen: 7.5YR7/4, Farbe innen: 7.5YR7/4

Maße: DmRd 42,9 cm, erh. H 4,5 cm

Erh.: 1 Rdfrgt.

KatNr. K 323

Taf. 182

Gattung: Gebrauchskeramik

Form: Krug

InvNr. SE 106/2

AO: GHD

Ton: $7.5 \mathrm{YR} 8 / 3$

Farbe außen: 10YR8/2, Farbe innen: 10YR8/2

Maße: DmRd $12 \mathrm{~cm}$, erh. H 2,8 cm

Erh.: 4 Rdfrgt.

KatNr. K 324

Taf. 182

Gattung: Gebrauchskeramik

Form: Krug

InvNr. SE 216/21

AO: GHD

Ton: $2.5 \mathrm{YR} 6 / 8$

Farbe außen: 5YR7/6+10YR6/8, Farbe innen: 5YR7/6

+10YR6/8

Maße: DmRd 10,6 cm, erh. H 2,6 cm

Erh.: 1 Rdfrgt.

KatNr. K 325

Taf. 182

Gattung: Gebrauchskeramik

Form: Krug

InvNr. SE 216/1

AO: GHD

Ton: 5YR7/6

Farbe außen: 2.5YR4/8, Farbe innen: 2.5YR4/8

Maße: DmRd 11,4 cm, erh. H 1,7 cm

Erh.: 1 Rdfrgt. 


\section{KatNr. K 326}

Gattung: Gebrauchskeramik

Form: Krug

InvNr. SE 110/1

AO: GHD

Ton: 5YR5/6

Farbe außen: 5YR7/6, Farbe innen: 5YR7/6

Maße: DmRd 15,9 cm, erh. H 3,3 cm

Erh.: 1 Rdfrgt.

\section{KatNr. K 327}

Gattung: Gebrauchskeramik (?)

Form: Krug

InvNr. SE 210/1

AO: GHD

Ton: 10YR6/3

Farbe außen: 10YR7/2, Farbe innen: 10YR7/2

Maße: DmRd $6 \mathrm{~cm}$, erh. H 2,3 cm

Erh.: 1 Rdfrgt.

\section{KatNr. K 328}

Gattung: Gebrauchskeramik

Form: Krug

InvNr. SE 107/3

AO: GHD

Ton: 5YR6/4

Farbe außen: 10YR8/4, Farbe innen: 10YR8/4

Maße: DmRd $11 \mathrm{~cm}$, erh. H 2,2 cm

Erh.: 1 Rdfrgt.

\section{KatNr. K 329}

Gattung: Gebrauchskeramik

Form: Krug

InvNr. SE 216/26

AO: GHD

Ton: 5YR7/6

Farbe außen: 10YR7/4, Farbe innen: 10YR7/4

Maße: DmRd 6,2 cm, erh. H 2,3 cm

Erh.: 1 Rdfrgt.

\section{KatNr. K 330}

Gattung: Gebrauchskeramik

Form: Krug

InvNr. SE 210/2

AO: GHD

Ton: 2.5 YR6/8

Farbe außen: 10YR8/2, Farbe innen: 10YR8/2

Maße: DmRd 9,4 cm, erh. H 1,7 cm

Erh.: 1 Rdfrgt.

\section{KatNr. K 331}

Gattung: Gebrauchskeramik

Form: Krug

InvNr. SE 207/69

AO: GHD

Ton: 7.5 YR6/4

Farbe außen: 7.5YR7/4, Farbe innen: 7.5YR7/4

Maße: DmRd 6,2 cm, erh. H 1,8 cm

Erh.: 1 Rdfrgt.
Taf. $182 \quad$ KatNr. K 332

Taf. 182

Gattung: Gebrauchskeramik

Form: Krug

InvNr. SE 211/172

AO: GHD

Ton: $2.5 \mathrm{YR} 6 / 6$

Farbe außen: 2.5YR8/4, Farbe innen: 2.5YR8/4

Maße: DmRd 8,4 cm, erh. H 2,9 cm

Erh.: 1 Rdfrgt.

Taf. 182

\section{KatNr. K 333}

Taf. 182

Gattung: Gebrauchskeramik

Form: Krug

InvNr. SE 216/54

AO: GHD

Ton: 5YR6/6

Farbe außen: 5YR7/4, Farbe innen: 5YR7/4

Maße: DmRd 7,5 cm, erh. H 2,8 cm

Erh.: 1 Rdfrgt.

Taf. 182

\section{KatNr. K 334}

Taf. 182

Gattung: Gebrauchskeramik

Form: Krug

InvNr. SE 216/55

AO: GHD

Ton: 5YR5/6

Farbe außen: 2.5YR5/6, Farbe innen: 2.5YR5/6

Maße: DmRd 5,2 cm, erh. H 2,45 cm

Erh.: 1 Rdfrgt.

Taf. 182

\section{KatNr. K 335}

Taf. 182

Gattung: Gebrauchskeramik

Form: Krug

InvNr. SE 211/114

AO: GHD

Ton: $2.5 \mathrm{YR} 6 / 6$

Farbe außen: 10YR8/6, Farbe innen: 10YR8/6

Maße: DmRd 15,4 cm, erh. H 5,2 cm

Erh.: 1 Rdfrgt.

KatNr. K 336

Taf. 183

Taf. 182

Gattung: Gebrauchskeramik

Form: Krug

InvNr. SE 216/110

AO: GHD

Ton: 5YR6/4

Farbe außen: 7.5YR8/3, Farbe innen: 7.5YR8/3, Farbe Dekor am Rd: 2.5 YR6/6

Maße: DmRd 14,2 cm, erh. H 3,35 cm

Erh.: 1 Rdfrgt.

Taf. 182

KatNr. K 337

Taf. 183

Gattung: Gebrauchskeramik

Form: Krug

InvNr. SE 216/13

AO: GHD

Ton: 5YR5/6

Farbe außen: 7.5YR7/4, Farbe innen: 7.5YR7/4

Maße: DmRd 9,4 cm, erh. H 2,8 cm

Erh.: 1 Rdfrgt. 


\section{KatNr. K 338}

Gattung: Gebrauchskeramik

Form: Krug

InvNr. SE 216/111

AO: GHD

Ton: 2.5 YR6/6

Farbe außen: 2.5YR6/8, Farbe innen: 2.5YR6/8

Maße: DmRd 13,6 cm, erh. H 2,6 cm

Erh.: 1 Rdfrgt.

KatNr. K 339

Gattung: Gebrauchskeramik

Form: Krug

InvNr. SE 207/16

AO: GHD

Ton: 5YR6/6

Farbe außen: 7.5YR8/4, Farbe innen: 5YR8/4, Farbe Dekor am Rd: 2.5 YR $4 / 8$

Maße: DmRd 15,2 cm, erh. H 2,5 cm

Erh.: 1 Rdfrgt.

\section{KatNr. K 340}

Gattung: Gebrauchskeramik

Form: Krug

InvNr. SE 216/14

AO: GHD

Ton: 5YR7/6

Farbe außen: 7.5YR8/4, Farbe innen: 7.5YR8/4

Maße: DmRd 9,4 cm, erh. H 2,85 cm

Erh.: 1 Rdfrgt.

\section{KatNr. K 341}

Gattung: Gebrauchskeramik

Form: Krug

InvNr. SE 106/3

AO: GHD

Ton: 5YR6/6

Farbe außen: 7.5YR7/4, Farbe innen: 7.5YR7/4

Maße: DmRd 9,6 cm, erh. H 5,4 cm

Erh.: 5 Rdfrgt.

\section{KatNr. K 342}

Gattung: Gebrauchskeramik

Form: Krug

InvNr. SE 216/79

AO: GHD

Ton: 5YR7/4

Farbe außen: 10YR8/3, Farbe innen: 10YR8/3

Maße: DmRd 6,3 cm, erh. H 3,2 cm

Erh.: 1 Rdfrgt.

\section{KatNr. K 343}

Gattung: Gebrauchskeramik

Form: Krug

InvNr. SE 211/42

AO: GHD

Ton: $2.5 \mathrm{YR} 5 / 8$

Farbe außen: 2.5YR6/6, Farbe innen: 2.5YR6/6

Maße: DmRd 6,8 cm, erh. H 2,7 cm

Erh.: 1 Rdfrgt.

Taf. 183

Taf. 183

Taf. 183

Taf. 183

Taf. 183

Taf. 183

\section{KatNr. K 344}

Taf. 183

Gattung: Gebrauchskeramik

Form: Krug

InvNr. SE 211/64

AO: GHD

Ton: 5YR6/6

Farbe außen: 7.5YR7/4, Farbe innen: 7.5YR7/4

Maße: DmRd 5,9 cm, erh. H 3,75 cm

Erh.: 1 Rdfrgt.

KatNr. K 345

Taf. 183

Gattung: Gebrauchskeramik

Form: Krug

InvNr. SE 211/110

AO: GHD

Ton: 5YR6/4

Farbe außen: 10YR8/2, Farbe innen: 10YR8/2, Farbe Dekor am Rd: 5YR2.5/1

Maße: DmRd 7,4 cm, erh. H 3,15 cm

Erh.: 1 Rdfrgt.

\section{KatNr. K 346}

Taf. 183

Gattung: Gebrauchskeramik

Form: Krug

InvNr. SE 211/165

AO: GHD

Ton: $2.5 \mathrm{YR} 6 / 6$

Farbe außen: 7.5YR8/3, Farbe innen: 7.5YR8/3

Maße: DmRd 8,4 cm, erh. H 2,35 cm

Erh.: 1 Rdfrgt.

KatNr. K 347

Taf. 183. 222

Gattung: Gebrauchskeramik

Form: Krug

InvNr. SE 216/56

AO: GHD

Ton: 7.5 YR7/4

Farbe außen: 10YR8/3, Farbe innen: 10YR8/3

Maße: DmRd 6,8 cm, erh. H $3 \mathrm{~cm}$

Erh.: 1 Rdfrgt.

KatNr. K 348

Taf. 183

Gattung: Gebrauchskeramik

Form: Krug

InvNr. SE 216/6

AO: GHD

Ton: $7.5 \mathrm{YR} 8 / 6$

Farbe außen: 10YR8/4, Farbe innen: 10YR8/4

Maße: DmRd 6,1 cm, erh. H 2,1 cm

Erh.: 1 Rdfrgt.

KatNr. K 349

Taf. 183

Gattung: Gebrauchskeramik

Form: Krug

InvNr. SE 216/122

AO: GHD

Ton: 7.5 YR7/4

Farbe außen: 7.5YR8/4, Farbe innen: 7.5YR8/4

Maße: DmRd 14,3 cm, erh. H 2,25 cm

Erh.: 1 Rdfrgt. 


\section{KatNr. K 350}

Gattung: Gebrauchskeramik

Form: Krug

InvNr. SE 216/27

AO: GHD

Ton: $7.5 \mathrm{YR} 7 / 6$

Farbe außen: 10YR8/3, Farbe innen: 10YR8/3

Maße: DmRd 6,4 cm, erh. H 1,75 cm

Erh.: 1 Rdfrgt.

\section{KatNr. K 351}

Gattung: Gebrauchskeramik

Form: Krug

InvNr. SE 216/70

AO: GHD

Ton: 5YR7/6

Farbe außen: 7.5YR7/4, Farbe innen: 7.5YR7/4

Maße: DmRd 25,7 cm, erh. H 4,4 cm

Erh.: 1 Rdfrgt.

\section{KatNr. K 352}

Gattung: Gebrauchskeramik

Form: Krug

InvNr. SE 211/45

AO: GHD

Ton: 5YR6/6

Farbe außen: 7.5YR7/6, Farbe innen: 7.5YR7/6

Maße: DmRd 6,2 cm, erh. H 2,3 cm

Erh.: 1 Rdfrgt.

\section{KatNr. K 353}

Taf. 183

Gattung: Gebrauchskeramik

Form: Unguentarium

InvNr. SE 211/39

AO: GHD

Ton: 5YR5/6

Farbe außen: 2.5YR6/6, Farbe innen: 2.5YR6/6

Maße: DmRd 1,6 cm, erh. H 2,1 cm

Erh.: 1 Rdfrgt.

\section{KatNr. K 354}

Gattung: Gebrauchskeramik

Form: Becher

InvNr. SE 216/28

AO: GHD

Ton: 5YR6/4

Farbe außen: 7.5YR6/3, Farbe innen: 7.5YR6/3

Maße: DmRd 8,6 cm, erh. H 1,6 cm

Erh.: 1 Rdfrgt.

\section{KatNr. K 355}

Taf. 183.222

Gattung: Gebrauchskeramik

Form: Dinos

InvNr. SE 211/87

AO: GHD

Ton: 5YR7/8

Farbe außen: 2.5YR7/8, Farbe innen: 2.5YR7/8, Farbe Dekor am Rd: 5YR2.5/1+weiß+2.5YR6/8

Maße: DmRd 5,4 cm, erh. H 3,2 cm

Dekor: Bemalung an der Gefäßaußenseite

Erh.: 2 Rdfrgt.
KatNr. K 356

Taf. 183

Gattung: Gebrauchskeramik

Form: Schale

InvNr. SE 216/123

AO: GHD

Ton: $2.5 \mathrm{YR} 6 / 8$

Farbe außen: 5YR6/6, Farbe innen: 5YR6/6

Maße: DmRd 15,7 cm, erh. H 3,15 cm

Erh.: 1 Rdfrgt.

\section{Taf. $183 \quad$ KatNr. K 357}

Taf. 184

Gattung: Gebrauchskeramik

Form: Steilrandteller/-schale

InvNr. SE 211/44

AO: GHD

Ton: 5 YR6/8

Farbe außen: 7.5YR6/6, Farbe innen: 7.5YR6/6

Maße: DmRd 8 cm, erh. H 1,4 cm

Erh.: 1 Rdfrgt.

\section{Taf. $183 \quad$ KatNr. K 358}

Taf. 184

Gattung: Gebrauchskeramik

Form: Schale mit Wandknick

InvNr. SE 211/109

AO: GHD

Überzug: innen partiell, matt, teilweise abgerieben

Ton: 5YR7/4

Farbe außen: 5YR7/4+5YR4/1, Farbe innen: 5YR4/1

Maße: DmRd $14 \mathrm{~cm}$, erh. H 4,35 cm

Erh.: 1 Rdfrgt.

\section{KatNr. K 359}

Taf. 184

Gattung: Gebrauchskeramik

Form: Schale mit Wandknick

InvNr. SE 211/30

AO: GHD

Überzug: innen partiell, matt, teilweise abgerieben Ton: $2.5 \mathrm{YR} 5 / 3$

Farbe außen: 2.5YR6/2, Farbe innen: 2.5YR6/2

Maße: DmRd 17,2 cm, erh. H $2 \mathrm{~cm}$

Taf. 183 Erh.: 1 Rdfrgt.

\section{KatNr. K 360}

Taf. 184

Gattung: Gebrauchskeramik

Form: Schale mit Wandknick

InvNr. SE 211/31

AO: GHD

Überzug: innen partiell, matt, teilweise abgerieben

Ton: 7.5 YR6/4

Farbe außen: 7.5YR6/4+7.5YR2.5/1, Farbe innen: 2.5 YR4/4

$+2.5 \mathrm{YR} 4 / 1$

Maße: DmRd 9,2 cm, erh. H 2,6 cm

Erh.: 1 Rdfrgt.

KatNr. K 361

Taf. 184

Gattung: Gebrauchskeramik

Form: Schale mit Wandknick

InvNr. SE 211/66

AO: GHD

Überzug: innen partiell, matt, teilweise abgerieben

Ton: 2.5 YR6/6 
Farbe außen: 2.5YR5/6+5YR7/4, Farbe innen: 2.5YR5/6

Maße: DmRd $8 \mathrm{~cm}$, erh. H $1,9 \mathrm{~cm}$

Erh.: 1 Rdfrgt.

\section{KatNr. K 362}

Gattung: Gebrauchskeramik

Form: Schale mit Wandknick

InvNr. SE 216/57

AO: GHD

Überzug: innen partiell, matt, teilweise abgerieben

Ton: 2.5 YR6/6

Farbe außen: 2.5 YR5/3+7.5YR8/3, Farbe innen: 2.5 YR5/3

$+7.5 \mathrm{YR} 8 / 3$

Maße: DmRd 8,6 cm, erh. H 1,35 cm

Erh.: 1 Rdfrgt.

\section{KatNr. K 363}

Taf. 184

Gattung: Gebrauchskeramik

Form: Schale mit Wandknick

InvNr. SE 215/7

AO: GHD

Überzug: innen partiell, matt, teilweise abgerieben

Ton: 5YR7/6+5YR4/1

Farbe außen: 2.5YR7/4, Farbe innen: 2.5YR7/4

Maße: DmRd 8,8 cm, erh. H $3 \mathrm{~cm}$

Erh.: 1 Rdfrgt.

\section{KatNr. K 364}

Taf. 184

Gattung: Gebrauchskeramik

Form: Schale mit Wandknick

InvNr. SE 215/8

AO: GHD

Überzug: innen partiell, matt, teilweise abgerieben Ton: 2.5 YR $5 / 6$

Farbe außen: 7.5YR8/3, Farbe innen: 7.5YR8/3

Maße: DmRd 14,2 cm, erh. H 2,7 cm

Erh.: 1 Rdfrgt.

\section{KatNr. K 365}

Taf. 184

Gattung: Gebrauchskeramik

Form: Schale mit Wandknick

InvNr. SE 211/65

AO: GHD

Überzug: innen partiell, matt, teilweise abgerieben

Ton: 5YR6/6

Farbe außen: 2.5YR6/6, Farbe innen: 2.5YR6/6+2.5YR5/1

Maße: DmRd 9,6 cm, erh. H 2,4 cm

Erh.: 1 Rdfrgt.

\section{KatNr. K 366}

Taf. 184

Gattung: Gebrauchskeramik

Form: Schale mit Wandknick

InvNr. SE 211/41

\section{AO: GHD}

Überzug: innen partiell, matt, teilweise abgerieben

Ton: 5YR7/6

Farbe außen: 7.5YR7/6, Farbe innen: 2.5 YR5/8

Maße: DmBd 3,2 cm, erh. H 2,3 cm

Erh.: 1 Bdfrgt.

\section{KatNr. K 367}

Taf. 184

Gattung: Gebrauchskeramik

Form: Echinusschale

InvNr. SE 216/119

Taf. 184 AO: GHD

Überzug: Rand innen und außen, matt, teilweise abgerieben

Ton: 2.5YR6/4

Farbe außen: 5YR2.5/1, Farbe innen: 5YR2.5/1

Maße: DmRd nicht bestimmbar, erh. H 3,25 cm

Erh.: 1 Rdfrgt.

\section{KatNr. K 368}

Taf. 184

Gattung: Gebrauchskeramik

Form: Echinusschale

InvNr. SE 110/2

AO: GHD

Überzug: Rand innen und außen, matt, teilweise abgerieben Ton: 5YR6/6

Farbe außen: 7.5YR7/6+5YR5/6, Farbe innen: 7.5YR7/6

+5 YR5/6

Maße: DmRd 13 cm, erh. H 2,7 cm

Erh.: 1 Rdfrgt.

KatNr. K 369

Taf. 184

Gattung: Gebrauchskeramik

Form: Echinusschale

InvNr. SE 216/118

AO: GHD

Überzug: Rand innen und außen, matt, teilweise abgerieben Ton: 2.5 YR6/8

Farbe außen: 2.5YR6/6, Farbe innen: 10R6/6

Maße: DmRd 12,2 cm, erh. H 3,35 cm

Erh.: 1 Rdfrgt.

KatNr. K 370

Taf. 184

Gattung: Gebrauchskeramik

Form: Echinusschale

InvNr. SE 110/8

AO: GHD

Überzug: Rand innen und außen, matt, teilweise abgerieben Ton: 5YR6/6

Farbe außen: 5YR7/6, Farbe innen: 5YR7/6

Maße: DmRd 10,6 cm, erh. H 2,2 cm

Erh.: 1 Rdfrgt.

KatNr. K 371

Taf. 184

Gattung: Gebrauchskeramik

Form: Echinusschale

InvNr. SE 107/17

AO: GHD

Überzug: Rand innen und außen, matt, teilweise abgerieben Ton: 5YR7/4

Farbe außen: 7.5YR8/2, Farbe innen: 7.5YR8/2

Maße: DmRd 12,2 cm, erh. H 1,9 cm

Erh.: 1 Rdfrgt.

KatNr. K 372

Taf. 184

Gattung: Gebrauchskeramik

Form: Schale mit aufgebogenem Rand

InvNr. SE 207/18

AO: GHD 
Überzug: Rand innen und außen, matt, teilweise abgerieben Ton: 7.5 Y R7/4

Farbe außen: 7.5YR8/3, Farbe innen: 7.5YR8/3

Maße: DmRd 17,2 cm, erh. H $2 \mathrm{~cm}$

Erh.: 1 Rdfrgt.

\section{KatNr. K 373}

Gattung: Gebrauchskeramik

Form: Echinusschale

InvNr. SE 211/13

AO: GHD

Ton: 10YR7/4

Farbe außen: 10YR8/4, Farbe innen: 10YR8/4

Maße: DmRd 11,4 cm, erh. H 2,3 cm

Erh.: 1 Rdfrgt.

\section{KatNr. K 374}

Taf. 185

Gattung: Gebrauchskeramik

Form: Echinusschale

InvNr. SE 211/70

AO: GHD

Überzug: Rand innen und außen, matt, teilweise abgerieben Ton: $7.5 Y R 7 / 4$

Farbe außen: 7.5YR5/3, Farbe innen: 7.5YR5/3

Maße: DmRd $11 \mathrm{~cm}$, erh. H 2,2 cm

Erh.: 1 Rdfrgt.

\section{KatNr. K 375}

Taf. 185

Gattung: Gebrauchskeramik

Form: Echinusschale

InvNr. SE 212/2

AO: GHD

Überzug: Rand innen und außen, matt, teilweise abgerieben Ton: 5YR6/6

Farbe außen: 2.5YR7/4, Farbe innen: 2.5YR7/4

Maße: DmRd $11 \mathrm{~cm}$, erh. H 2,8 cm

Erh.: 1 Rdfrgt.

\section{KatNr. K 376}

Taf. 185

Gattung: Gebrauchskeramik

Form: Echinusschale

InvNr. SE 215/9

AO: GHD

Überzug: Rand innen und außen, matt, teilweise abgerieben Ton: 2.5YR6/6

Farbe außen: 10YR8/3, Farbe innen: 10YR8/3

Maße: DmRd $16 \mathrm{~cm}$, erh. H 2,25 cm

Erh.: 1 Rdfrgt.

\section{KatNr. K 377}

Taf. 185

Gattung: Gebrauchskeramik

Form: Echinusschale

InvNr. SE 216/11

AO: GHD

Überzug: Rand innen und außen, matt, teilweise abgerieben Ton: 7.5 YR $7 / 4$

Farbe außen: 7.5YR7/4, Farbe innen: 7.5YR7/4

Maße: DmRd 9,4 cm, erh. H 2,1 cm

Erh.: 1 Rdfrgt.
KatNr. K 378

Taf. 185

Gattung: Gebrauchskeramik

Form: Echinusschale

InvNr. SE 211/141

AO: GHD

Überzug: Rand innen und außen, matt, teilweise abgerieben Ton: 2.5 Y R6/6

Farbe außen: 2.5YR7/4, Farbe innen: 2.5 YR7/4

Maße: DmRd 13,1 cm, erh. H 1,95 cm

Erh.: 1 Rdfrgt.

KatNr. K 379

Taf. 185

Gattung: Gebrauchskeramik

Form: Echinusschale

InvNr. SE 216/12

AO: GHD

Überzug: Rand innen und außen, matt, teilweise abgerieben Ton: 7.5 Y R7/4

Farbe außen: 10YR8/3+5YR2.5/1+7/5YR8/6, Farbe innen: 7.5YR $8 / 4$

Maße: DmRd 11,2 cm, erh. H 2,5 cm

Erh.: 1 Rdfrgt.

KatNr. K 380

Taf. 185

Gattung: Gebrauchskeramik

Form: Echinusschale

InvNr. SE 216/23

AO: GHD

Überzug: Rand innen und außen, matt, teilweise abgerieben Ton: $2.5 \mathrm{YR} 6 / 6$

Farbe außen: 5YR7/6, Farbe innen: 2.5YR7/6+2.5YR6/6

Maße: DmRd 10,4 cm, erh. H 3,2 cm

Erh.: 1 Rdfrgt.

KatNr. K 381

Taf. 185

Gattung: Gebrauchskeramik

Form: Echinusschale

InvNr. SE 216/53

AO: GHD

Überzug: Rand innen und außen, matt, teilweise abgerieben Ton: 5YR5/6

Farbe außen: 5YR7/4, Farbe innen: 5YR7/4

Maße: DmRd 15,4 cm, erh. H 2,4 cm

Erh.: 1 Rdfrgt.

KatNr. K 382

Taf. 185

Gattung: Gebrauchskeramik

Form: Echinusschale

InvNr. SE 216/68

AO: GHD

Überzug: Rand innen und außen, matt, teilweise abgerieben Ton: 2.5 Y R6/6

Farbe außen: 7.5YR7/4+7.5YR4/2, Farbe innen: 10R5/6

Maße: DmRd 4,8 cm, erh. H $1 \mathrm{~cm}$

Erh.: 1 Rdfrgt.

KatNr. K 383

Taf. 185

Gattung: Gebrauchskeramik

Form: Echinusschale

InvNr. SE 216/86

AO: GHD 
Überzug: Rand innen und außen, matt, teilweise abgerieben Ton: 5YR6/8

Farbe außen: 7.5YR8/5, Farbe innen: 2.5YR5/6+5YR7/6

Maße: DmRd 10,2 cm, erh. H 1,45 cm

Erh.: 1 Rdfrgt.

\section{KatNr. K 384}

Taf. 185

Gattung: Gebrauchskeramik

Form: Echinusschale

InvNr. SE 216/117

AO: GHD

Überzug: Rand innen und außen, matt, teilweise abgerieben Ton: 5YR7/4

Farbe außen: 7.5YR8/3, Farbe innen: 7.5YR8/3, Farbe Dekor am Rd: $2.5 Y R 4 / 1+10 R 5 / 6$

Maße: DmRd 10,3 cm, erh. H 2,2 cm

Erh.: 1 Rdfrgt.

\section{KatNr. K 385}

Taf. 185

Gattung: Gebrauchskeramik

Form: Schale mit aufgebogenem Rand

InvNr. SE 216/116

AO: GHD

Überzug: Rand innen und außen, matt, teilweise abgerieben Ton: $2.5 \mathrm{YR} 6 / 8$

Farbe außen: 5YR7/6, Farbe innen: 5YR7/6

Maße: DmRd 13,5 cm, erh. H 2,6 cm

Erh.: 1 Rdfrgt.

\section{KatNr. K 386}

Taf. 185

Gattung: Gebrauchskeramik

Form: Schale mit aufgebogenem Rand/Teller

InvNr. SE 216/120

AO: GHD

Überzug: Rand innen und außen, matt, teilweise abgerieben Ton: 5YR7/4

Farbe außen: 2.5YR6/6, Farbe innen: 2.5YR6/6

Maße: DmRd 21,8 cm, erh. H $1,85 \mathrm{~cm}$

Erh.: 1 Rdfrgt.

\section{KatNr. K 387}

Taf. 185

Gattung: Gebrauchskeramik

Form: Konische Schale mit leichtem Wandknick

InvNr. SE 216/85

AO: GHD

Überzug: Rand innen und außen, matt, teilweise abgerieben Ton: 2.5 YR6/6

Farbe außen: 7.5YR8/4, Farbe innen: 7.5YR8/4

Maße: DmRd 16,4 cm, erh. H 2,5 cm

Erh.: 1 Rdfrgt.

\section{KatNr. K 388}

Taf. 185

Gattung: Gebrauchskeramik

Form: Konische Schale

InvNr. SE 216/41

AO: GHD

Überzug: Rand innen und außen, matt, teilweise abgerieben Ton: 5YR5/6

Farbe außen: 5YR7/6, Farbe innen: 5YR7/6

Maße: DmRd 17,4 cm, erh. H 2,2 cm

Erh.: 1 Rdfrgt.
KatNr. K 389

Taf. 185

Gattung: Gebrauchskeramik

Form: Konische Schale

InvNr. SE 211/63

AO: GHD

Überzug: Rand innen und außen, matt, teilweise abgerieben Ton: $2.5 \mathrm{YR} 7 / 6$

Farbe außen: 5YR5/4+2.5YR4/8, Farbe innen: 5YR5/4

$+2.5 \mathrm{YR} 4 / 8$

Maße: DmRd 12,5 cm, erh. H 2,2 cm

Erh.: 1 Rdfrgt.

\section{KatNr. K 390}

Taf. 185

Gattung: Gebrauchskeramik

Form: Konische Schale/Teller

InvNr. SE 211/144

AO: GHD

Überzug: Rand innen und außen, matt, teilweise abgerieben Ton: 2.5YR6/6

Farbe außen: 5YR7/6, Farbe innen: 5YR7/6

Maße: DmRd 19,7 cm, erh. H 1,75 cm

Erh.: 1 Rdfrgt.

KatNr. K 391

Taf. 186

Gattung: Gebrauchskeramik

Form: Teller/Schüssel

InvNr. SE 216/108

AO: GHD

Überzug: Rand innen und außen, matt, teilweise abgerieben Ton: $2.5 \mathrm{YR} 8 / 3$

Farbe außen: 10YR4/1, Farbe innen: 10YR4/1

Maße: DmRd 27,4 cm, erh. H 2,2 cm

Erh.: 1 Rdfrgt.

KatNr. K 392

Taf. 186

Gattung: Gebrauchskeramik

Form: Teller mit verdicktem Rand

InvNr. SE 209/19

AO: GHD

Überzug: Rand innen und außen, matt, teilweise abgerieben Ton: 5YR6/6

Farbe außen: 7.5YR7/4, Farbe innen: 7.5YR7/4

Maße: DmRd 23,4 cm, erh. H 2,05 cm

Erh.: 1 Rdfrgt.

\section{KatNr. K 393}

Taf. 186

Gattung: Gebrauchskeramik

Form: Teller mit verdicktem Rand

InvNr. SE 207/11

AO: GHD

Überzug: Rand innen und außen, matt, teilweise abgerieben Ton: 7.5 Y R6/6

Farbe außen: 10YR7/4, Farbe innen: 10YR7/4

Maße: DmRd 23,8 cm, erh. H 1,9 cm

Erh.: 1 Rdfrgt.

KatNr. K 394

Taf. 186

Gattung: Gebrauchskeramik

Form: Teller mit verdicktem Rand

InvNr. SE 209/44

AO: GHD 
Überzug: Rand innen und außen, matt, teilweise abgerieben Ton: 7.5 YR6/4

Farbe außen: 2.5YR8/4, Farbe innen: 2.5YR8/4

Maße: DmRd 18,3 cm, erh. H 2,45 cm

Erh.: 1 Rdfrgt.

\section{KatNr. K 395}

Taf. 186

Gattung: Gebrauchskeramik

Form: Teller mit verdicktem Rand

InvNr. SE 209/21

AO: GHD

Überzug: Rand innen und außen, matt, teilweise abgerieben Ton: 5YR7/6

Farbe außen: 7.5YR8/2, Farbe innen: 7.5YR8/2

Maße: DmRd 26,3 cm, erh. H 3,2 cm

Erh.: 1 Rdfrgt.

\section{KatNr. K 396}

Taf. 186

Gattung: Gebrauchskeramik

Form: Teller mit verdicktem Rand

InvNr. SE 211/125

AO: GHD

Überzug: Rand innen und außen, matt, teilweise abgerieben Ton: 7.5 Y R7/6

Farbe außen: 7.5YR8/4, Farbe innen: 7.5YR8/4

Maße: DmRd 14,2 cm, erh. H 1,9 cm

Erh.: 1 Rdfrgt.

\section{KatNr. K 397}

Gattung: Gebrauchskeramik

Form: Teller mit verdicktem Rand

InvNr. SE 211/62

AO: GHD

Überzug: Rand innen und außen, matt, teilweise abgerieben Ton: 7.5 YR7/3+5YR6/6

Farbe außen: 7.5YR7/4, Farbe innen: 5YR2.5/1

Maße: DmRd 18,9 cm, erh. H 1,3 cm

Erh.: 1 Rdfrgt.

\section{KatNr. K 398}

Taf. 186

Gattung: Gebrauchskeramik

Form: Teller mit breitem Rand

InvNr. SE 216/44

AO: GHD

Überzug: Rand innen und außen, matt, teilweise abgerieben Ton: 10YR6/4

Farbe außen: 5YR2.5/1, Farbe innen: 5YR2.5/1

Maße: DmRd 21,7 cm, erh. H 1,4 cm

Erh.: 1 Rdfrgt.

\section{KatNr. K 399}

Taf. 186

Gattung: Gebrauchskeramik

Form: Teller mit breitem Rand

InvNr. SE 216/63

AO: GHD

Überzug: Randoberseite, matt, teilweise abgerieben

Ton: $7.5 \mathrm{YR} 8 / 4$

Farbe außen: 5YR5/2+10YR8/3, Farbe innen: 5YR5/2

$+10 \mathrm{YR} 8 / 3$

Maße: DmRd 18,1 cm, erh. H 3,7 cm

Erh.: 1 Rdfrgt.
KatNr. K 400

Taf. 186

Gattung: Gebrauchskeramik

Form: Teller/Schüssel mit breitem Rand

InvNr. SE 210/14

AO: GHD

Überzug: Randoberseite, matt, teilweise abgerieben Ton: 7.5 Y R7/4

Farbe außen: 7.5YR8/3, Farbe innen: 2.5YR5/6

Maße: DmRd 24,6 cm, erh. H 1,65 cm

Erh.: 1 Rdfrgt.

KatNr. K 401

Taf. 186

Gattung: Gebrauchskeramik

Form: Teller/Schüssel mit breitem Rand

InvNr. SE 211/168

AO: GHD

Überzug: Randoberseite, matt, teilweise abgerieben Ton: $2.5 \mathrm{YR} 6 / 6$

Farbe außen: 7.5YR8/3, Farbe innen: 7.5YR8/3

Maße: DmRd 26,4 cm, erh. H $3 \mathrm{~cm}$

Erh.: 1 Rdfrgt.

KatNr. K 402

Taf. 186

Gattung: Gebrauchskeramik

Form: Teller/Schüssel mit breitem Rand

InvNr. SE 216/105

AO: GHD

Überzug: Randoberseite, matt, teilweise abgerieben Ton: 7.5 YR7/6

Farbe außen: 2.5YR6/6, Farbe innen: 5YR7/4

Maße: DmRd 33,4 cm, erh. H 3,5 cm

Erh.: 1 Rdfrgt.

\section{KatNr. K 403}

Taf. 187

Gattung: Gebrauchskeramik

Form: Teller/Schüssel mit breitem Rand

InvNr. SE 207/2

AO: GHD

Überzug: Randoberseite, matt, teilweise abgerieben Ton: 5YR6/6

Farbe außen: 7.5YR8/4, Farbe innen: 5YR6/6

Maße: DmRd 27,6 cm, erh. H 1,9 cm

Erh.: 1 Rdfrgt.

\section{KatNr. K 404}

Taf. 187

Gattung: Gebrauchskeramik

Form: Teller mit breitem Rand

InvNr. SE 211/18

AO: GHD

Überzug: Randoberseite, matt, teilweise abgerieben Ton: 7.5 YR6/6

Farbe außen: 5YR7/6, Farbe innen: 5YR7/6

Maße: DmRd 36 cm, erh. H 2,8 cm

Erh.: 1 Rdfrgt.

\section{KatNr. K 405}

Taf. 187

Gattung: Gebrauchskeramik

Form: Teller mit breitem Rand

InvNr. SE 207/12

AO: GHD

Überzug: Randoberseite, matt, teilweise abgerieben 
Ton: 5YR6/6

Farbe außen: 7.5YR7/4, Farbe innen: 7.5YR7/4; Farbe Dekor: 5YR5/8

Maße: DmRd 24,6 cm, erh. H 1,4 cm

Erh.: 1 Rdfrgt.

\section{KatNr. K 406}

Taf. 187

Gattung: Gebrauchskeramik

Form: Teller mit breitem Rand

InvNr. SE 211/52

AO: GHD

Überzug: Randoberseite, matt, teilweise abgerieben

Ton: 5YR7/6+2.5YR7/6

Farbe außen: 7.5YR7/4, Farbe innen: 7.5YR7/4, Farbe Dekor am Rd: $2.5 Y R 4 / 8$

Maße: DmRd 34 cm, erh. H $3 \mathrm{~cm}$

Erh.: 3 Rdfrgt.

\section{KatNr. K 407}

Taf. 187

Gattung: Gebrauchskeramik

Form: Teller mit breitem Rand

InvNr. SE 211/3

AO: GHD

Überzug: Randoberseite, matt, teilweise abgerieben Ton: 5YR6/6

Farbe außen: 7.5YR7/6, Farbe innen: 5YR3/3

Maße: DmRd 16,8 cm, erh. H $3 \mathrm{~cm}$

Erh.: 1 Rdfrgt.

\section{KatNr. K 408}

Taf. 187

Gattung: Gebrauchskeramik

Form: Teller mit breitem Rand

InvNr. SE 211/2

AO: GHD

Überzug: Randoberseite, matt, teilweise abgerieben Ton: 2.5YR6/6

Farbe außen: 7.5YR8/6, Farbe innen: 2.5YR6/6

Maße: DmRd 19,2 cm, erh. H 2,75 cm

Erh.: 1 Rdfrgt.

\section{KatNr. K 409}

Gattung: Gebrauchskeramik

Form: Teller mit breitem Rand

InvNr. SE 211/53

AO: GHD

Überzug: Randoberseite, matt, teilweise abgerieben

Ton: $2.5 \mathrm{YR} 6 / 6+5 \mathrm{YR} 7 / 4$

Farbe außen: 7.5YR7/4, Farbe innen: 7.5YR7/4

Maße: DmRd 26,6 cm, erh. H 2,95 cm

Erh.: 1 Rdfrgt.

\section{KatNr. K 410}

Taf. 187

Gattung: Gebrauchskeramik

Form: Teller mit breitem Rand

InvNr. SE 211/54

AO: GHD

Überzug: Randoberseite, matt, teilweise abgerieben

Ton: 2.5 YR7/6

Farbe außen: 7.5YR8/3, Farbe innen: 2.5YR6/6

Maße: DmRd 17,6 cm, erh. H 1,5 cm

Erh.: 1 Rdfrgt.
KatNr. K 411

Taf. 187

Gattung: Gebrauchskeramik

Form: Teller mit breitem Rand

InvNr. SE 211/12

AO: GHD

Überzug: Randoberseite, matt, teilweise abgerieben

Ton: 7.5 YR7/6

Farbe außen: 7.5YR2.5/4, Farbe innen: 7.5YR2.5/4, Farbe

Dekor: 2,5YR2.5/4

Maße: DmRd 37,6 cm, erh. H 2,45 cm

Erh.: 1 Rdfrgt.

KatNr. K 412

Taf. 187

Gattung: Gebrauchskeramik

Form: Teller mit breitem Rand

InvNr. SE 106/1

AO: GHD

Überzug: Randoberseite, matt, teilweise abgerieben

Ton: $7.5 Y R 7 / 3$

Farbe außen: 5YR4/1, Farbe innen: 5YR4/1

Maße: DmRd 18,2 cm, erh. H 1,3 cm

Erh.: 1 Rdfrgt.

KatNr. K 413

Taf. 187

Gattung: Gebrauchskeramik

Form: Teller mit breitem Rand

InvNr. SE 212/1

AO: GHD

Überzug: Randoberseite, matt, teilweise abgerieben

Ton: 7.5 YR7/3

Farbe außen: 7.5YR8/3, Farbe innen: 7.5YR8/3, Farbe Dekor am Rd: 5YR2.5/1

Maße: DmRd 21,8 cm, erh. H 1,45 cm

Erh.: 1 Rdfrgt.

KatNr. K 414

Taf. 187

Gattung: Gebrauchskeramik

Form: Teller mit breitem Rand

InvNr. SE 215/5

AO: GHD

Taf. 187 Überzug: Randoberseite, matt, teilweise abgerieben

Ton: 10 YR7/4

Farbe außen: 10YR8/2, Farbe innen: 10YR8/2, Farbe Dekor am Rd: 5YR2.5/1

Maße: DmRd 24,5 cm, erh. H $1 \mathrm{~cm}$

Erh.: 2 Rdfrgt.

KatNr. K 415

Taf. 187

Gattung: Gebrauchskeramik

Form: Teller

InvNr. SE 215/4

AO: GHD

Ton: $10 \mathrm{YR} 8 / 3$

Farbe außen: 10YR8/2+5YR2.5/1, Farbe innen: 10YR8/2

+5 YR2.5/1

Maße: DmRd 15,5 cm, erh. H 2,1 cm

Erh.: 1 Rdfrgt.

KatNr. K 416

Taf. 188

Gattung: Gebrauchskeramik

Form: Teller mit breitem Rand 
InvNr. SE 216/3

AO: GHD

Überzug: Randoberseite, matt, teilweise abgerieben

Ton: 7.5 YR7/3

Farbe außen: 10YR7/3, Farbe innen: 10YR7/3

Maße: DmRd 23,6 cm, erh. H 1,35 cm

Erh.: 1 Rdfrgt.

\section{KatNr. K 417}

Gattung: Gebrauchskeramik

Form: Teller mit breitem Rand

InvNr. SE 216/4

AO: GHD

Überzug: Randoberseite, matt, teilweise abgerieben

Ton: 5YR6/6

Farbe außen: 7.5YR7/4+2.5YR5/8, Farbe innen: 7.5YR7/4

+2.5 YR $5 / 8$

Maße: DmRd $16 \mathrm{~cm}$, erh. H 1,5 cm

Erh.: 1 Rdfrgt.

\section{KatNr. K 418}

Taf. 188

Gattung: Gebrauchskeramik

Form: Teller mit breitem Rand

InvNr. SE 211/10

AO: GHD

Überzug: Randoberseite, matt, teilweise abgerieben

Ton: 7.5YR6/4

Farbe außen: 7.5YR8/4, Farbe innen: 5YR2.5/1, Farbe Dekor: 2.5YR4/8

Maße: DmRd 28,4 cm, erh. H 1,6 cm

Erh.: 1 Rdfrgt.

\section{KatNr. K 419}

Taf. 188

Gattung: Gebrauchskeramik

Form: Teller mit breitem Rand

InvNr. SE 216/5

AO: GHD

Überzug: Randoberseite, matt, teilweise abgerieben

Ton: 7.5 Y R7/3

Farbe außen: 10YR8/2, Farbe innen: 10YR8/2

Maße: DmRd 17,2 cm, erh. H 1,2 cm

Erh.: 1 Rdfrgt.

\section{KatNr. K 420}

Taf. 188

Gattung: Gebrauchskeramik

Form: Teller mit breitem Rand

InvNr. SE 216/15

AO: GHD

Überzug: Randoberseite, matt, teilweise abgerieben Ton: $7.5 \mathrm{YR} 7 / 4$

Farbe außen: 7.5YR8/4, Farbe innen: 7.5YR8/4

Maße: DmRd $22 \mathrm{~cm}$, erh. H 2,6 cm

Erh.: 1 Rdfrgt.

\section{KatNr. K 421}

Taf. 188

Gattung: Gebrauchskeramik

Form: Teller mit breitem Rand

InvNr. SE 216/22

AO: GHD

Überzug: Randoberseite, matt, teilweise abgerieben Ton: $7.5 Y R 7 / 4$
Farbe außen: 10YR7/3+5YR2.5/1, Farbe innen: 10YR7/3 +5 YR2.5/1

Maße: DmRd 16,6 cm, erh. H $3 \mathrm{~cm}$

Erh.: 1 Rdfrgt.

\section{KatNr. K 422}

Taf. 188

Gattung: Gebrauchskeramik

Form: Teller mit breitem Rand

InvNr. SE 216/39

AO: GHD

Überzug: Randoberseite, matt, teilweise abgerieben Ton: 5 YR5/6

Farbe außen: 5YR7/4+2.5YR5/6, Farbe innen: 5YR7/4 +2.5 YR $5 / 6$

Maße: DmRd 16,4 cm, erh. H 3,4 cm

Erh.: 10 Rdfrgt.

\section{KatNr. K 423}

Taf. 188

Gattung: Gebrauchskeramik

Form: Teller mit breitem Rand

InvNr. SE 216/43

AO: GHD

Überzug: Randoberseite, matt, teilweise abgerieben

Ton: 7.5 YR7/4

Farbe außen: 2.5YR8/2, Farbe innen: 2.5YR8/2, Farbe Dekor am Rd: 5YR4/2

Maße: DmRd 17,8 cm, erh. H 0,7 cm

Erh.: 1 Rdfrgt.

KatNr. K 424

Taf. 188

Gattung: Gebrauchskeramik

Form: Teller mit breitem Rand

InvNr. SE 216/62

AO: GHD

Überzug: Randoberseite, matt, teilweise abgerieben

Ton: 7.5 YR7/4

Farbe außen: 10YR8/2+2.5YR5/6, Farbe innen: 10YR8/2 +2.5 YR5/6

Maße: DmRd 14,2 cm, erh. H 2 cm

Erh.: 1 Rdfrgt.

\section{KatNr. K 425}

Taf. 188

Gattung: Gebrauchskeramik

Form: Teller mit breitem Rand

InvNr. SE 216/65

AO: GHD

Überzug: Randoberseite, matt, teilweise abgerieben Ton: $7.5 \mathrm{YR} 8 / 3$

Farbe außen: 10YR8/3, Farbe innen: 10YR8/3

Maße: DmRd 15,4 cm, erh. H 1,4 cm

Erh.: 1 Rdfrgt.

KatNr. K 426

Taf. 188

Gattung: Gebrauchskeramik

Form: Teller mit breitem Rand

InvNr. SE 216/64

AO: GHD

Überzug: Randoberseite, matt, teilweise abgerieben

Ton: 10 YR $8 / 3$

Farbe außen: 10YR8/4, Farbe innen: 10YR8/4

Maße: DmRd 20,4 cm, erh. H 1,5 cm

Erh.: 1 Rdfrgt. 


\section{KatNr. K 427}

Gattung: Gebrauchskeramik

Form: Teller mit breitem Rand

InvNr. SE 216/115

AO: GHD

Überzug: Randoberseite, matt, teilweise abgerieben

Ton: 2.5YR6/6

Farbe außen: 10R5/6, Farbe innen: 10R5/6

Maße: DmRd 17,2 cm, erh. H 1,1 cm

Erh.: 1 Rdfrgt.

\section{KatNr. K 428}

Taf. 188. 222

Gattung: Gebrauchskeramik

Form: Teller/Model (?)

InvNr. SE 216/29

AO: GHD

Überzug: Randoberseite, matt, teilweise abgerieben

Ton: 5YR5/6

Farbe außen: 5YR7/6, Farbe innen: 5YR7/6

Maße: DmRd 26,8 cm, erh. H 1,2 cm

Dekor (?): innen gestempelte Palmettenreihe

Erh.: 1 Rdfrgt.

\section{KatNr. K 429}

Taf. 189

Gattung: Gebrauchskeramik

Form: Schüssel

InvNr. SE 216/107

AO: GHD

Überzug: Randoberseite, matt, teilweise abgerieben

Ton: 7.5 YR7/4

Farbe außen: 7.5YR7/3, Farbe innen: 7.5YR7/3, Farbe Dekor

am Rd: 5YR2.5/1

Maße: DmRd 12,4 cm, erh. H 3,2 cm

Erh.: 1 Rdfrgt.

\section{KatNr. K 430}

Taf. 189

Gattung: Gebrauchskeramik

Form: Schüssel

InvNr. SE 216/71

AO: GHD

Ton: 5YR6/6

Farbe außen: 2.5YR6/6+2.5YR4/6, Farbe innen: 2.5YR6/6

$+2.5 \mathrm{YR} 4 / 6$

Maße: DmRd 14,3 cm, erh. H 3,1 cm

Erh.: 1 Rdfrgt.

\section{KatNr. K 431}

Taf. 189

Gattung: Gebrauchskeramik

Form: Schüssel

InvNr. SE 211/57

AO: GHD

Ton: 5YR5/8

Farbe außen: 7.5YR7/6, Farbe innen: 7.5YR7/6

Maße: DmRd 26,4 cm, erh. H 3,95 cm

Erh.: 1 Rdfrgt.

KatNr. K 432

Taf. 189

Gattung: Gebrauchskeramik

Form: Schüssel

InvNr. SE 208/1

AO: GHD
Ton: $2.5 \mathrm{YR} 5 / 8$

Farbe außen: 2.5YR5/6, Farbe innen: 2.5YR5/6

Maße: DmRd 17,4 cm, erh. H 1,6 cm

Erh.: 1 Rdfrgt.

KatNr. K 433

Taf. 189

Gattung: Gebrauchskeramik

Form: Schüssel

InvNr. SE 209/42

AO: GHD

Ton: 5YR7/6+7.5YR8/4

Farbe außen: 10YR8/3, Farbe innen: 5YR7/6

Maße: DmRd 27,8 cm, erh. H 3,7 cm

Erh.: 1 Rdfrgt.

\section{KatNr. K 434}

Taf. 189

Gattung: Gebrauchskeramik

Form: Schüssel

InvNr. SE 106/4

AO: GHD

Ton: 10YR $8 / 3$

Farbe außen: 7.5YR8/3, Farbe innen: 5YR5/3

Maße: DmRd 32,4 cm, erh. H 3,4 cm

Erh.: 1 Rdfrgt.

\section{KatNr. K 435}

Taf. 189

Gattung: Gebrauchskeramik

Form: Schüssel

InvNr. SE 104/2

AO: GHD

Ton: 10 YR7/4

Farbe außen: 10YR8/3, Farbe innen: 7.5YR5/2

Maße: DmRd 32,3 cm, erh. H 3,9 cm

Erh.: 2 Rdfrgt.

\section{KatNr. K 436}

Taf. 189

Gattung: Gebrauchskeramik

Form: Schüssel

InvNr. SE 207/55

AO: GHD

Ton: 5YR6/8

Farbe außen: 7.5YR7/6, Farbe innen: 7.5YR7/6

Maße: DmRd 30,8 cm, erh. H 2,4 cm

Erh.: 1 Rdfrgt.

\section{KatNr. K 437}

Taf. 189

Gattung: Gebrauchskeramik

Form: Schüssel

InvNr. SE 210/12

AO: GHD

Ton: 7.5 YR7/4

Farbe außen: 7.5YR8/4, Farbe innen: 7.5YR8/4

Maße: DmRd 33,5 cm, erh. H 2,55 cm

Erh.: 1 Rdfrgt.

\section{KatNr. K 438}

Taf. 189
Form: Schüssel

InvNr. SE 210/13

AO: GHD

Ton: 5YR7/4 
Farbe außen: 7.5YR8/3, Farbe innen: 7.5YR8/3 Maße: DmRd $33 \mathrm{~cm}$, erh. H 1,9 cm

Erh.: 1 Rdfrgt.

\section{KatNr. K 439}

Gattung: Gebrauchskeramik

Form: Schüssel

InvNr. SE 211/75

AO: GHD

Ton: $7.5 \mathrm{YR} 5 / 2$

Farbe außen: 7.5YR8/4, Farbe innen: 7.5YR8/4

Maße: DmRd 19,6 cm, erh. H 3 cm

Erh.: 1 Rdfrgt.

\section{KatNr. K 440}

Gattung: Gebrauchskeramik

Form: Schüssel

InvNr. SE 211/120

AO: GHD

Ton: 5YR6/6

Farbe außen: 7.5YR8/4, Farbe innen: 2.5YR5/6

Maße: DmRd 27 cm, erh. H 6,4 cm

Erh.: 1 Rdfrgt.

\section{KatNr. K 441}

Gattung: Gebrauchskeramik

Form: Schüssel

InvNr. SE 211/167

AO: GHD

Ton: 5YR7/4

Farbe außen: 7.5YR8/3, Farbe innen: 7.5YR8/3

Maße: DmRd 35,9 cm, erh. H 3,4 cm

Erh.: 1 Rdfrgt.

\section{KatNr. K 442}

Gattung: Gebrauchskeramik

Form: Schüssel

InvNr. SE 216/16

AO: GHD

Ton: 2.5YR6/6

Farbe außen: 2.5 YR7/6, Farbe innen: 2.5YR7/6

Maße: DmRd 34,2 cm, erh. H 1,5 cm

Erh.: 1 Rdfrgt.

\section{KatNr. K 443}

Gattung: Gebrauchskeramik

Form: Schüssel

InvNr. SE 216/47

AO: GHD

Ton: $2.5 \mathrm{YR} 6 / 8$

Farbe außen: 2.5YR4/8, Farbe innen: 2.5YR4/8

Maße: DmRd 28,2 cm, erh. H 2 cm

Erh.: 1 Rdfrgt.

\section{KatNr. K 444}

Gattung: Gebrauchskeramik

Form: Schüssel

InvNr. SE 216/46

AO: GHD

Ton: 5YR6/6

Farbe außen: 10R5/8, Farbe innen: 10R5/8
Maße: DmRd 31,8 cm, erh. H 1,8 cm

Erh.: 1 Rdfrgt.

\section{KatNr. K 445}

Taf. 190

Taf. 190

Gattung: Gebrauchskeramik

Form: Schüssel

InvNr. SE 216/73

AO: GHD

Ton: $2.5 \mathrm{YR} 6 / 6$

Farbe außen: 2.5YR7/4, Farbe innen: 2.5YR7/4

Maße: DmRd 22,6 cm, erh. H 1,8 cm

Erh.: 1 Rdfrgt.

\section{KatNr. K 446}

Taf. 190

Taf. 190

Gattung: Gebrauchskeramik

Form: Schüssel

InvNr. SE 216/87

AO: GHD

Überzug: Randoberseite, matt, teilweise abgerieben

Ton: 5YR7/4

Farbe außen: 7.5YR8/4, Farbe innen: 7.5YR8/4, Farbe Dekor am Rd: 5YR6/6

Maße: DmRd 23,3 cm, erh. H $5 \mathrm{~cm}$

Erh.: 1 Rdfrgt.

Taf. 190

KatNr. K 447

Taf. 190

Gattung: Gebrauchskeramik

Form: Schüssel

InvNr. SE 216/106

AO: GHD

Ton: 7.5 YR7/4

Farbe außen: 7.5YR8/3, Farbe innen: 5YR7/4+5YR5/1

+2.5 YR6/6

Maße: DmRd 26 cm, erh. H 2,6 cm

Taf. $190 \quad$ Erh.: 1 Rdfrgt.

KatNr. K 448

Taf. 190

Gattung: Gebrauchskeramik

Form: Schüssel

InvNr. SE 211/170

AO: GHD

Ton: 5 YR7/4

Farbe außen: 7.5YR7/4, Farbe innen: 5YR7/4

Maße: DmRd 39,6 cm, erh. H 4,25 cm

Taf. $190 \quad$ Erh.: 1 Rdfrgt.

\section{KatNr. K 449}

Taf. 191

Gattung: Gebrauchskeramik

Form: Schüssel

InvNr. SE 209/29

AO: GHD

Ton: $2.5 \mathrm{YR} 6 / 6$

Farbe außen: 7.5YR8/3, Farbe innen: 7.5YR8/3

Maße: DmRd $42 \mathrm{~cm}$, erh. H 3,7 cm

Taf. 190

Erh.: 1 Rdfrgt.

KatNr. K 450

Taf. 191

Gattung: Gebrauchskeramik

Form: Teller

InvNr. SE 216/104

AO: GHD 
Ton: $2.5 \mathrm{YR} 6 / 8$

Farbe außen: 7.5YR8/4, Farbe innen: 7.5YR8/4

Maße: DmRd 37,4 cm, erh. H 3,05 cm

Erh.: 1 Rdfrgt.

\section{KatNr. K 451}

Gattung: Gebrauchskeramik

Form: Teller

InvNr. SE 216/42

AO: GHD

Ton: 2.5 YR $5 / 8$

Farbe außen: 2.5YR8/4, Farbe innen: 2.5YR8/4

Maße: DmRd 37,4 cm, erh. H 2,25 cm

Erh.: 1 Rdfrgt.

\section{KatNr. K 452}

Gattung: Gebrauchskeramik

Form: Schüssel (?)

InvNr. SE 211/50

AO: GHD

Ton: 2.5 YR6/6

Farbe außen: 7.5YR7/4, Farbe innen: 7.5YR7/4

Maße: DmRd 45,6 cm, erh. H 2,1 cm

Erh.: 1 Rdfrgt.

\section{KatNr. K 453}

Gattung: Gebrauchskeramik

Form: Schüssel/Topf

InvNr. SE 216/74

AO: GHD

Ton: 5YR6/6

Farbe außen: 5YR7/6, Farbe innen: 10R5/6

Maße: DmRd 43 cm, erh. H 4,8 cm

Erh.: 1 Rdfrgt.

\section{KatNr. K 454}

Taf. 191

Gattung: Gebrauchskeramik

Form: Topf

InvNr. SE 211/121

AO: GHD

Ton: 5YR7/6

Farbe außen: 10YR8/3, Farbe innen: 10YR8/3

Maße: DmRd 33,6 cm, erh. H 2,9 cm

Erh.: 1 Rdfrgt.

\section{KatNr. K 455}

Taf. 191

Gattung: Gebrauchskeramik

Form: Topf

InvNr. SE 209/10

AO: GHD

Ton: $10 \mathrm{YR} 7 / 4$

Farbe außen: 10YR7/2, Farbe innen: 7.5YR7/6

Maße: DmRd $38 \mathrm{~cm}$, erh. H 3,6 cm

Erh.: 1 Rdfrgt.

\section{KatNr. K 456}

Gattung: Gebrauchskeramik

Form: Topf

InvNr. SE 207/9

AO: GHD

Ton: 5YR5/6

Taf. 191

Taf. 191

Taf. 191
Farbe außen: 2.5YR5/6, Farbe innen: 2.5YR5/6

Maße: DmRd 31,2 cm, erh. H 3,7 cm

Erh.: 1 Rdfrgt.

KatNr. K 457

Taf. 191

Gattung: Gebrauchskeramik

Form: Topf (?)

InvNr. SE 207/67

AO: GHD

Ton: 2.5 YR6/6

Farbe außen: 5YR7/4, Farbe innen: 5YR7/4

Maße: DmRd 19 cm, erh. H 2,8 cm

Erh.: 1 Rdfrgt.

\section{KatNr. K 458}

Taf. 191

Taf. 191 Gattung: Gebrauchskeramik

Form: Kasserolle

InvNr. SE 211/118

AO: GHD

Überzug: Randoberseite, matt, teilweise abgerieben

Ton: 5YR7/6

Farbe außen: 5YR8/4, Farbe innen: 5YR8/4, Farbe Dekor am

Rd: 2.5 YR4/6

Maße: DmRd 27,6 cm, erh. H 2,7 cm

Erh.: 1 Rdfrgt.

KatNr. K 459

Taf. 192

Gattung: Gebrauchskeramik

Form: Dinos/Topf (?)

InvNr. SE 211/37

AO: GHD

Ton: $2.5 \mathrm{YR} 5 / 6$

Farbe außen: 7.5YR7/6, Farbe innen: 7.5YR7/6

Maße: DmRd 28 cm, erh. H 1,8 cm

Erh.: 1 Rdfrgt.

KatNr. K 460

Taf. 192

Gattung: Gebrauchskeramik

Form: Topf

InvNr. SE 207/33

AO: GHD

Ton: $2.5 \mathrm{YR} 5 / 6$

Farbe außen: 5YR6/4, Farbe innen: 5YR6/4

Maße: DmRd 11,8 cm, erh. H 4,8 cm

Erh.: 1 Rdfrgt.

KatNr. K 461

Taf. 192

Gattung: Gebrauchskeramik

Form: Topf

InvNr. SE 209/50

AO: GHD

Ton: 2.5 YR6/3

Farbe außen: 10YR7/3, Farbe innen: 10YR7/3

Maße: DmRd 24,7 cm, erh. H 4,7 cm

Erh.: 1 Rdfrgt.

KatNr. K 462

Taf. 192. 222

Gattung: Gebrauchskeramik

Form: Deckel

InvNr. SE 211/85

AO: GHD 
Ton: 5YR6/6

Farbe außen: 7.5YR8/4, Farbe innen: 7.5YR8/4

Maße: DmRd 7,8 cm, erh. H 2,8 cm

Erh.: 1 Rdfrgt.

KatNr. K 463

Taf. 192

Gattung: Gebrauchskeramik

Form: Deckel (?)

InvNr. SE 211/84

AO: GHD

Ton: 5YR $5 / 8$

Farbe außen: 5YR6/6+2.5YR4/8, Farbe innen: 5YR6/6

$+2.5 \mathrm{YR} 4 / 8$

Maße: DmRd 5,6 cm, erh. H 2,6 cm

Erh.: 1 Rdfrgt.

\section{KatNr. K 464}

Taf. 192

Gattung: Gebrauchskeramik

Form: Unguentarium

InvNr. SE 207/38

AO: GHD

Ton: 7.5 YR7/4

Farbe außen: 7.5YR7/3, Farbe innen: 7.5YR7/3

Maße: DmBd 2,6 cm, erh. H 4,4 cm

Erh.: 1 Bdfrgt.

\section{KatNr. K 465}

Gattung: Gebrauchskeramik

Form: Unguentarium

InvNr. SE 208/17

AO: GHD

Ton: 2.5 YR7/4

Farbe außen: 7.5YR8/4, Farbe innen: 7.5YR8/4

Maße: DmBd 2 cm, erh. H $1,9 \mathrm{~cm}$

Erh.: 1 Bdfrgt.

\section{KatNr. K 466}

Gattung: Gebrauchskeramik

Form: Krug

InvNr. SE 211/127

AO: GHD

Ton: 2.5 YR6/8+7.5YR5/1

Farbe außen: 2.5YR6/6, Farbe innen: 10YR6/2

Maße: DmBd $3 \mathrm{~cm}$, erh. H 4,3 cm

Erh.: 1 Bdfrgt.

\section{KatNr. K 467}

Gattung: Gebrauchskeramik

Form: Schüssel (?)

InvNr. SE 214/57 (SE 214/53, SE 214/59)

AO: GHD

Ton: 5YR6/6

Farbe außen: 10YR7/4, Farbe innen (Tongrund): 10YR7/4

Farbe Bemalung: 7.5YR4/1 (matt, kompakt)

Maße: $6,3 \times 9 \mathrm{~cm}$ und $6,4 \times 4 \mathrm{~cm}$

Dekor: Girlande (auf der Innenseite)

Erh.: 3 Wdfrgt.

\section{KatNr. K 468}

Taf. 192

Gattung: Küchenware

Form: Topf
InvNr. SE 211/113

AO: GHD

Ton: 7.5YR6/4+7.5YR6/1

Farbe außen: 7.5YR7/4, Farbe innen: 7.5YR7/4

Maße: DmRd 20 cm, erh. H 3,1 cm

Erh.: 1 Rdfrgt.

KatNr. K 469

Taf. 192

Gattung: Küchenware

Form: Topf

InvNr. SE 211/60

AO: GHD

Ton: 5YR6/4

Farbe außen: 7.5YR7/4, Farbe innen: 7.5YR7/4

Maße: DmRd $16 \mathrm{~cm}$, erh. H 3,2 cm

Erh.: 1 Rdfrgt.

KatNr. K 470

Taf. 192

Gattung: Küchenware

Form: Topf

InvNr. SE 209/8

AO: GHD

Ton: 5 YR7/6

Farbe außen: 10YR6/1+5YR7/6, Farbe innen: 10YR6/1+ 5YR7/6

Maße: DmRd 15 cm, erh. H 2,75 cm

Taf. 192 Erh.: 1 Rdfrgt.

KatNr. K 471

Taf. 192

Gattung: Küchenware

Form: Topf

InvNr. SE 211/112

AO: GHD

Ton: 5YR7/6

Farbe außen: 7.5YR7/4, Farbe innen: 5YR7/4

Maße: DmRd 13,6 cm, erh. H 2,7 cm

Taf. 192 Erh.: 1 Rdfrgt.

KatNr. K 472

Taf. 192

Gattung: Küchenware

Form: Topf

InvNr. SE 215/1

AO: GHD

Ton: 2.5 YR5/6

Farbe außen: 7.5YR7/2, Farbe innen: 5YR7/4

Maße: DmRd 10,2 cm, erh. H 5,6 cm

Taf. 222 Erh.: 1 Rdfrgt.

KatNr. K 473

Taf. 193

Gattung: Küchenware

Form: Topf

InvNr. SE 211/7

AO: GHD

Ton: 5 YR $4 / 2$

Farbe außen: 5YR6/4, Farbe innen: 5YR6/4

Maße: DmRd 11,4 cm, erh. H 3,1 cm

Erh.: 1 Rdfrgt.

KatNr. K 474

Taf. 193

Gattung: Küchenware

Form: Topf 
InvNr. SE 107/6

AO: GHD

Ton: 5YR5/1+5YR6/6

Farbe außen: 5YR5/1, Farbe innen: 5YR7/4

Maße: DmRd 12,2 cm, erh. H 2,6 cm

Erh.: 1 Rdfrgt.

\section{KatNr. K 475}

Gattung: Küchenware

Form: Topf

InvNr. SE 207/98

AO: GHD

Ton: 5YR5/6

Farbe außen: 5YR7/4, Farbe innen: 5YR7/4

Maße: DmRd 12,8 cm, erh. H 2,4 cm

Erh.: 1 Rdfrgt.

KatNr. K 476

Gattung: Küchenware

Form: Topf

InvNr. SE 211/162

AO: GHD

Ton: 2.5 YR6/4

Farbe außen: 2.5YR6/6, Farbe innen: 2.5YR6/6

Maße: DmRd 9,5 cm, erh. H 3,1 cm

Erh.: 1 Rdfrgt.

\section{KatNr. K 477}

Gattung: Küchenware

Form: Topf

InvNr. SE 107/11

AO: GHD

Ton: $7.5 \mathrm{YR} / 4 / 4$

Farbe außen: 7.5YR5/2, Farbe innen: 5YR5/6

Maße: DmRd 12,3 cm, erh. H 1,7 cm

Erh.: 1 Rdfrgt.

\section{KatNr. K 478}

Gattung: Küchenware

Form: Topf

InvNr. SE 106/5

AO: GHD

Ton: 7.5 YR $4 / 3$

Farbe außen: 7.5YR5/2, Farbe innen: 7.5YR5/2

Maße: DmRd 24,4 cm, erh. H 10,3 cm

Erh.: 1 Rdfrgt.

\section{KatNr. K 479}

Gattung: Küchenware

Form: Topf

InvNr. SE 207/88

AO: GHD

Ton: 5YR6/6

Farbe außen: 2.5YR6/4, Farbe innen: 2.5YR6/4

Maße: DmRd 27,2 cm, erh. H 2,45 cm

Erh.: 1 Rdfrgt.

KatNr. K 480

Taf. 193

Gattung: Küchenware

Form: Topf

InvNr. SE 211/76

AO: GHD

Taf. 193

Taf. 193

Taf. 193

Taf. 193
Ton: 5YR4/1

Farbe außen: 5YR5/2+5YR7/4, Farbe innen: 5YR5/2 +5 YR7/4

Maße: DmRd 21,8 cm, erh. H 2,9 cm

Erh.: 1 Rdfrgt.

KatNr. K 481

Taf. 193

Taf. 193 Gattung: Küchenware

Form: Topf

InvNr. SE 211/24

AO: GHD

Ton: 2.5 YR5/6

Farbe außen: 2.5YR6/6, Farbe innen: 2.5YR6/6

Maße: DmRd 17 cm, erh. H 2,9 cm

Erh.: 1 Rdfrgt.

\section{KatNr. K 482}

Taf. 193

Gattung: Küchenware

Form: Topf

InvNr. SE 209/47

AO: GHD

Ton: $7.5 Y R 5 / 3$

Farbe außen: 2.5YR7/6+5YR6/2, Farbe innen: 2.5YR7/6

$+5 \mathrm{YR} 6 / 2$

Maße: DmRd 22,8 cm, erh. H 2,45 cm

Erh.: 1 Rdfrgt.

KatNr. K 483

Taf. 193

Gattung: Küchenware

Form: Topf

InvNr. SE 107/15

AO: GHD

Ton: 5YR6/3+2.5YR5/8

Farbe außen: 2.5YR6/6, Farbe innen: 2.5YR6/6

Maße: DmRd 19,2 cm, erh. H 3,1 cm

Erh.: 1 Rdfrgt.

\section{KatNr. K 484}

Taf. 194

Gattung: Küchenware

Form: Topf

InvNr. SE 211/163

AO: GHD

Ton: $2.5 \mathrm{YR} 4 / 8$

Farbe außen: 5YR7/4, Farbe innen: 5YR7/4

Maße: DmRd $15 \mathrm{~cm}$, erh. H 4,2 cm

Erh.: 1 Rdfrgt.

KatNr. K 485

Taf. 194

Gattung: Küchenware

Form: Topf

InvNr. SE 216/52

AO: GHD

Ton: 2.5 YR $5 / 6$

Farbe außen: 2.5YR6/4, Farbe innen: 2.5YR6/4

Maße: DmRd 12,5 cm, erh. H 3,4 cm

Erh.: 1 Rdfrgt.

KatNr. K 486

Taf. 194

Gattung: Küchenware

Form: Topf

InvNr. SE 216/113

AO: GHD 
Ton: 5YR5/2

Farbe außen: 5YR7/2+5YR5/1, Farbe innen: 5YR7/2

+5 YR5/1

Maße: DmRd 14,5 cm, erh. H 4,45 cm

Erh.: 1 Rdfrgt.

\section{KatNr. K 487}

Gattung: Küchenware

Form: Topf

InvNr. SE 110/11

AO: GHD

Ton: 5YR5/6

Farbe außen: 7.5YR6/2+7.5YR4/1+5YR7/4, Farbe innen:

7.5 YR6/2+7.5YR4/1+5YR7/4

Maße: DmRd 14,4 cm, erh. H $2 \mathrm{~cm}$

Erh.: 1 Rdfrgt.

\section{KatNr. K 488}

Gattung: Küchenware

Form: Topf

InvNr. SE 211/122

AO: GHD

Ton: 2.5 YR5/6

Farbe außen: 2.5YR4/2, Farbe innen: 2.5YR6/4

Maße: DmRd $14 \mathrm{~cm}$, erh. H 4,2 cm

Erh.: 1 Rdfrgt.

\section{KatNr. K 489}

Gattung: Küchenware

Form: Topf

InvNr. SE 216/93

AO: GHD

Ton: 2.5 YR6/8

Farbe außen: 7.5YR7/4, Farbe innen: 7.5YR7/4

Maße: DmRd 11,7 cm, erh. H 2,7 cm

Erh.: 1 Rdfrgt.

\section{KatNr. K 490}

Gattung: Küchenware

Form: Topf

InvNr. SE 211/4

AO: GHD

Ton: $2.5 \mathrm{YR} 4 / 8$

Farbe außen: 2.5YR5/6, Farbe innen: 2.5YR5/6

Maße: DmRd 14,6 cm, erh. H 2,9 cm

Erh.: 1 Rdfrgt.

\section{KatNr. K 491}

Gattung: Küchenware

Form: Topf

InvNr. SE 210/8

AO: GHD

Ton: 10YR6/2+5YR5/3

Farbe außen: 5YR7/4, Farbe innen: 5YR7/4

Maße: DmRd 10,9 cm, erh. H 2,7 cm

Erh.: 1 Rdfrgt.

KatNr. K 492

Taf. 194

Gattung: Küchenware

Form: Topf

InvNr. SE 216/17

AO: GHD

Taf. 194

Taf. 194

Taf. 194
Ton: 5YR5/6

Farbe außen: 5YR7/4, Farbe innen: 2.5YR5/2

Maße: DmRd 8,2 cm, erh. H 4,8 cm

Erh.: 1 Rdfrgt.

KatNr. K 493

Taf. 194

Taf. 194 Gattung: Küchenware

Form: Topf

InvNr. SE 211/94

AO: GHD

Ton: 7.5 YR6/2

Farbe außen: 7.5YR7/2+5YR7/4, Farbe innen: 7.5YR7/2

+5YR7/4

Maße: DmRd 10,8 cm, erh. H 2 cm

Erh.: 1 Rdfrgt.

\section{KatNr. K 494}

Taf. 194

Gattung: Küchenware

Form: Topf

InvNr. SE 210/28

AO: GHD

Ton: 7.5 YR6/4

Farbe außen: 5YR7/4, Farbe innen: 5YR7/4

Maße: DmRd 14,7 cm, erh. H 2,6 cm

Erh.: 1 Rdfrgt.

\section{KatNr. K 495}

Taf. 194

Gattung: Küchenware

Form: Topf

InvNr. SE 211/68

AO: GHD

Ton: 5YR3/1

Farbe außen: 5YR5/1, Farbe innen: 5YR5/1

Maße: DmRd $10 \mathrm{~cm}$, erh. H 2,4 cm

Erh.: 1 Rdfrgt.

\section{KatNr. K 496}

Taf. 194

Gattung: Küchenware

Form: Topf

InvNr. SE 212/4

AO: GHD

Ton: 2.5 YR $5 / 3$

Farbe außen: 2.5YR4/1, Farbe innen: 2.5YR6/4

Maße: DmRd 23,2 cm, erh. H 1,7 cm

Erh.: 1 Rdfrgt.

\section{KatNr. K 497}

Taf. 194

Gattung: Küchenware

Form: Topf

InvNr. SE 212/3

AO: GHD

Ton: $2.5 \mathrm{YR} 5 / 6$

Farbe außen: 2.5YR6/2, Farbe innen: 2.5YR6/6

Maße: DmRd 24,2 cm, erh. H 3,5 cm

Erh.: 1 Rdfrgt.

\section{KatNr. K 498}

Taf. 195

Gattung: Küchenware

Form: Topf

InvNr. SE 210/29

AO: GHD

Ton: 5YR5/1 
Farbe außen: 5YR5/1, Farbe innen: 5YR5/1

Maße: DmRd 15 cm, erh. H 1,75 cm

Erh.: 1 Rdfrgt.

KatNr. K 499

Gattung: Küchenware

Form: Topf

InvNr. SE 210/27

AO: GHD

Ton: $2.5 \mathrm{YR} 6 / 3$

Farbe außen: 2.5YR6/1, Farbe innen: 2.5YR6/1

Maße: DmRd 20,1 cm, erh. H 2,6 cm

Erh.: 1 Rdfrgt.

\section{KatNr. K 500}

Gattung: Küchenware

Form: Topf

InvNr. SE 207/15

AO: GHD

Ton: 2.5 YR $5 / 8$

Farbe außen: 2.5YR6/6, Farbe innen: 2.5YR6/6

Maße: DmRd 11,2 cm, erh. H 3,6 cm

Erh.: 1 Rdfrgt.

KatNr. K 501

Gattung: Küchenware

Form: Topf

InvNr. SE 207/84

AO: GHD

Ton: 5YR6/2+2.5YR6/8

Farbe außen: 5YR5/1, Farbe innen: 2.5YR6/4

Maße: DmRd 11,8 cm, erh. H 1,4 cm

Erh.: 1 Rdfrgt.

\section{KatNr. K 502}

Gattung: Küchenware

Form: Topf

InvNr. SE 209/4

AO: GHD

Ton: $10 \mathrm{YR} 5 / 2$

Farbe außen: 10YR6/3, Farbe innen: 10YR6/1

Maße: DmRd $13 \mathrm{~cm}$, erh. H 3,5 cm

Erh.: 1 Rdfrgt.

\section{KatNr. K 503}

Gattung: Küchenware

Form: Topf

InvNr. SE 207/85

AO: GHD

Ton: 5YR5/1

Farbe außen: 5YR4/1, Farbe innen: 5YR6/1

Maße: DmRd 14,6 cm, erh. H 3 cm

Erh.: 1 Rdfrgt.

\section{KatNr. K 504}

Gattung: Küchenware

Form: Topf

InvNr. SE 207/86

AO: GHD

Ton: 2.5 YR5/6

Farbe außen: 5YR6/3, Farbe innen: 2.5YR7/4
Maße: DmRd 17,2 cm, erh. H 2,4 cm

Erh.: 1 Rdfrgt.

KatNr. K 505

Taf. 195

Taf. 195

Gattung: Küchenware

Form: Topf

InvNr. SE 210/26

AO: GHD

Ton: 2.5 YR $5 / 6$

Farbe außen: 2.5YR6/4, Farbe innen: 2.5YR6/6

Maße: DmRd 24,5 cm, erh. H $2 \mathrm{~cm}$

Erh.: 1 Rdfrgt.

KatNr. K 506

Taf. 195

Taf. 195

Gattung: Küchenware

Form: Topf

InvNr. SE 207/62

AO: GHD

Ton: 2.5 YR $5 / 6$

Farbe außen: 2.5YR6/4, Farbe innen: 2.5YR6/4

Maße: DmRd 17,4 cm, erh. H 2,3 cm

Erh.: 1 Rdfrgt.

\section{KatNr. K 507}

Taf. 195

Taf. 195

Gattung: Küchenware

Form: Topf

InvNr. SE 209/5

AO: GHD

Ton: 5YR5/6

Farbe außen: 5YR7/6, Farbe innen: 5YR7/6

Maße: DmRd 21,4 cm, erh. H 1,9 cm

Erh.: 1 Rdfrgt.

KatNr. K 508

Taf. 195

Taf. 195

Gattung: Küchenware

Form: Topf

InvNr. SE 207/63

AO: GHD

Ton: 5YR4/4+5YR5/6

Farbe außen: 5YR6/6, Farbe innen: 5YR6/6

Maße: DmRd 22,2 cm, erh. H 2,2 cm

Erh.: 1 Rdfrgt.

\section{KatNr. K 509}

Taf. 195

Taf. 195

Gattung: Küchenware

Form: Topf

InvNr. SE 209/28

AO: GHD

Ton: $7.5 \mathrm{YR} 5 / 1$

Farbe außen: 7.5YR6/1, Farbe innen: 7.5YR6/1

Maße: DmRd 11,2 cm, erh. H 2,2 cm

Erh.: 1 Rdfrgt.

\section{KatNr. K 510}

Taf. 195

Taf. 195

Gattung: Küchenware

Form: Topf

InvNr. SE 208/8

AO: GHD

Ton: 2.5 YR5/4

Farbe außen: Gley5/5PB, Farbe innen: 10R5/3

Maße: DmRd 23 cm, erh. H 3,4 cm

Erh.: 1 Rdfrgt. 


\section{KatNr. K 511}

Gattung: Küchenware

Form: Topf

InvNr. SE 207/64

AO: GHD

Ton: $2.5 \mathrm{YR} 5 / 4$

Farbe außen: 2.5YR4/1, Farbe innen: 2.5YR5/3

Maße: DmRd 21,8 cm, erh. H 3,25 cm

Erh.: 1 Rdfrgt.

\section{KatNr. K 512}

Gattung: Küchenware

Form: Topf

InvNr. SE 207/14

AO: GHD

Ton: 2.5 YR5/1+2.5YR5/8

Farbe außen: 5YR6/2, Farbe innen: 5YR6/2

Maße: DmRd 10,6 cm, erh. H $2 \mathrm{~cm}$

Erh.: 1 Rdfrgt.

\section{KatNr. K 513}

Gattung: Küchenware

Form: Topf

InvNr. SE 208/7

AO: GHD

Ton: 2.5 YR5/6

Farbe außen: 5YR5/1, Farbe innen: 10R5/6

Maße: DmRd 21,6 cm, erh. H 2,3 cm

Erh.: 1 Rdfrgt.

\section{KatNr. K 514}

Gattung: Küchenware

Form: Topf

InvNr. SE 207/61

AO: GHD

Ton: $2.5 \mathrm{YR} 5 / 8$

Farbe außen: 2.5 YR5/6, Farbe innen: 2.5YR5/6

Maße: DmRd 19,2 cm, erh. H 2,2 cm

Erh.: 1 Rdfrgt.

\section{KatNr. K 515}

Gattung: Küchenware

Form: Topf

InvNr. SE 209/41

AO: GHD

Ton: 7.5 YR7/6

Farbe außen: 7.5YR8/4, Farbe innen: 7.5YR8/4

Maße: DmRd 19,8 cm, erh. H 21,5 cm

Erh.: 1 Rdfrgt.

\section{KatNr. K 516}

Gattung: Küchenware

Form: Topf

InvNr. SE 107/14

AO: GHD

Ton: 2.5YR5/8

Farbe außen: 5YR7/4, Farbe innen: 5YR7/4

Maße: DmRd 20 cm, erh. H 1,35 cm

Erh.: 1 Rdfrgt.
Taf. $196 \quad$ KatNr. K 517

Taf. 196

Gattung: Küchenware

Form: Topf

InvNr. SE 211/78

AO: GHD

Ton: $2.5 \mathrm{YR} 5 / 6$

Farbe außen: 2.5YR6/6, Farbe innen: 2.5YR6/6

Maße: DmRd 15,4 cm, erh. H 4,35 cm

Erh.: 1 Rdfrgt.

Taf. 196

\section{KatNr. K 518}

Taf. 196

Gattung: Küchenware

Form: Schale

InvNr. SE 211/29

AO: GHD

Ton: 5YR3/4

Farbe außen: 5YR2.5/1+5YR5/4, Farbe innen: 5YR2.5/1

+5 YR5/4

Maße: DmRd 8,6 cm, erh. H 2,9 cm

Erh.: 1 Rdfrgt.

Taf. 196

KatNr. K 519

Taf. 196

Gattung: Küchenware

Form: Schüssel

InvNr. SE 207/13

AO: GHD

Ton: 2.5 YR $5 / 8$

Farbe außen: 2.5YR6/8, Farbe innen: 2.5YR6/8

Maße: DmRd $18 \mathrm{~cm}$, erh. H 2,5 cm

Erh.: 1 Rdfrgt.

Taf. 196

KatNr. K 520

Taf. 196

Gattung: Küchenware

Form: Schüssel

InvNr. SE 210/15

AO: GHD

Ton: $2.5 \mathrm{YR} 5 / 8$

Farbe außen: 2.5YR5/6, Farbe innen: 2.5YR5/6

Maße: DmRd 21,4 cm, erh. H 7,4 cm

Erh.: 1 Rdfrgt.

Taf. 196

\section{KatNr. K 521}

Taf. 197

Gattung: Küchenware

Form: Schüssel

InvNr. SE 215/2

AO: GHD

Ton: 5YR4/1+7.5YR7/6

Farbe außen: 5YR7/4, Farbe innen: 5YR7/4

Maße: DmRd 23,2 cm, erh. H 4,95 cm

Erh.: 1 Rdfrgt.

Taf. 196

KatNr. K 522

Taf. 197

Gattung: Küchenware

Form: Schüssel

InvNr. SE 211/169

AO: GHD

Ton: $2.5 \mathrm{YR} 5 / 6$

Farbe außen: 7.5YR7/4, Farbe innen: 7.5YR7/4

Maße: DmRd 23,3 cm, erh. H 4,3 cm

Erh.: 1 Rdfrgt. 


\section{KatNr. K 523}

Gattung: Küchenware

Form: Schüssel

InvNr. SE 211/38

AO: GHD

Ton: 5YR5/6

Farbe außen: 7.5YR6/4, Farbe innen: 7.5YR6/4

Maße: DmRd 21,6 cm, erh. H 2,85 cm

Erh.: 1 Rdfrgt.

\section{KatNr. K 524}

Gattung: Küchenware

Form: Schüssel

InvNr. SE 215/3

AO: GHD

Ton: 5YR5/6

Farbe außen: 5YR6/4, Farbe innen: 5YR6/4

Maße: DmRd 23,9 cm, erh. H 3,3 cm

Erh.: 1 Rdfrgt.

\section{KatNr. K 525}

Gattung: Küchenware

Form: Schüssel

InvNr. SE 216/88

AO: GHD

Ton: 2.5 YR $5 / 8$

Farbe außen: 2.5YR6/6, Farbe innen: 2.5YR6/6

Maße: DmRd 26 cm, erh. H 2,15 cm

Erh.: 1 Rdfrgt.

\section{KatNr. K 526}

Gattung: Küchenware

Form: Schüssel

InvNr. SE 216/89

AO: GHD

Ton: 2.5 YR6/8

Farbe außen: 7.5YR7/4, Farbe innen: 7.5YR7/4

Maße: DmRd 21,7 cm, erh. H 2,9 cm

Erh.: 1 Rdfrgt.

\section{KatNr. K 527}

Gattung: Küchenware

Form: Schüssel

InvNr. SE 211/1

AO: GHD

Ton: 10R5/6+2.5YR5/3

Farbe außen: 2.5YR6/6, Farbe innen: 2.5YR6/6

Maße: DmRd 22,8 cm, erh. H 2,45 cm

Erh.: 1 Rdfrgt.

\section{KatNr. K 528}

Gattung: Küchenware

Form: Kasserolle

InvNr. SE 210/16

AO: GHD

Ton: 7.5 YR $6 / 4+2.5$ YR $5 / 6$

Farbe außen: 5YR7/4, Farbe innen: 5YR7/4

Maße: DmRd 30,6 cm, erh. H 6,85 cm

Erh.: 1 Rdfrgt.

KatNr. K 529

Taf. 198. 222

Gattung: Küchenware

Form: Kasserolle
Taf. 197 InvNr. SE 211/96

AO: GHD

Ton: 2.5 YR5/6

Farbe außen: 2.5YR6/2, Farbe innen: 2.5YR6/2

Maße: DmRd 25,6 cm, erh. H 6,9 cm

Erh.: 1 Rdfrgt.

KatNr. K 530

Taf. 198

Gattung: Küchenware

Form: Kasserolle

Taf. 197 InvNr. SE 207/87

AO: GHD

Ton: 5YR4/2+5YR5/6

Farbe außen: 2.5 YR6/6+2.5YR5/1, Farbe innen: 2.5 YR6/6

Maße: DmRd 23,8 cm, erh. H 3 cm

Erh.: 1 Rdfrgt.

KatNr. K 531

Taf. 198

Gattung: Küchenware

Form: Kasserolle

Taf. 197 InvNr. SE 211/108

AO: GHD

Ton: 2.5 YR6/6

Farbe außen: 5YR7/4, Farbe innen: 5YR7/4

Maße: DmRd 23,6 cm, erh. H 1,65 cm

Erh.: 1 Rdfrgt.

KatNr. K 532

Taf. 198

Gattung: Küchenware

Form: Kasserolle

Taf. 197 InvNr. SE 211/123

AO: GHD

Ton: $2.5 \mathrm{YR} 5 / 4$

Farbe außen: 5YR7/4+7.5YR5/1, Farbe innen: 5YR7/4

+7.5 YR $5 / 1$

Maße: DmRd 14,8 cm, erh. H 3,6 cm

Erh.: 1 Rdfrgt.

KatNr. K 533

Taf. 198

Gattung: Küchenware

Taf. 197 Form: Kasserolle

InvNr. SE 209/49

AO: GHD

Ton: 5YR4/2+5YR5/3

Farbe außen: 7.5YR5/2, Farbe innen: 2.5YR7/6

Maße: DmRd 22,2 cm, erh. H 4,35 cm

Erh.: 1 Rdfrgt.

KatNr. K 534

Taf. 198

Gattung: Küchenware

Taf. 197 Form: Kasserolle

InvNr. SE 211/80

AO: GHD

Ton: 7.5 YR5/4

Farbe außen: 7.5YR6/3, Farbe innen: 7.5YR6/3

Maße: DmRd 22,2 cm, erh. H 3,3 cm

Erh.: 1 Rdfrgt.

KatNr. K 535

Taf. 198

Gattung: Küchenware

Form: Kasserolle

InvNr. SE 207/45 
AO: GHD

Ton: 2.5 YR $4 / 4$

Farbe außen: 2.5YR6/4, Farbe innen: 2.5YR6/4

Maße: DmRd 41,6 cm, erh. H 2,8 cm

Erh.: 1 Rdfrgt.

\section{KatNr. K 536}

Gattung: Küchenware

Form: Kasserolle

InvNr. SE 211/119

AO: GHD

Ton: 2.5 YR $5 / 8$

Farbe außen: 2.5YR6/6, Farbe innen: 2.5YR6/6

Maße: DmRd 29,8 cm, erh. H 4,85 cm

Erh.: 1 Rdfrgt.

\section{KatNr. K 537}

Gattung: Küchenware

Form: Kasserolle

InvNr. SE 216/70

AO: GHD

Ton: 5YR7/6

Farbe außen: 7.5YR7/4, Farbe innen: 7.5YR7/4

Maße: DmRd 25,7 cm, erh. H 4,4 cm

Erh.: 1 Rdfrgt.

\section{KatNr. K 538}

Gattung: Küchenware

Form: Teller

InvNr. SE 216/48

AO: GHD

Ton: $2.5 \mathrm{YR} 4 / 8$

Farbe außen: 2.5YR5/6, Farbe innen: 2.5YR5/6

Maße: DmRd 28,2 cm, erh. H 3,2 cm

Erh.: 1 Rdfrgt.

\section{KatNr. K 539}

Gattung: Küchenware

Form: Teller

InvNr. SE 110/7

AO: GHD

Ton: 7.5 YR $5 / 2$

Farbe außen: 7.5YR6/3, Farbe innen: 7.5YR6/3

Maße: DmRd 17,6 cm, erh. H 1,8 cm

Erh.: 1 Rdfrgt.

\section{KatNr. K 540}

Gattung: Küchenware

Form: Teller

InvNr. SE 211/166

AO: GHD

Ton: 7.5YR6/4

Farbe außen: 5YR7/4, Farbe innen: 5YR7/4

Maße: DmRd 40,4 cm, erh. H 5,2 cm

Erh.: 1 Rdfrgt.

\section{KatNr. K 541}

Taf. 199

Gattung: Küchenware

Form: Pfanne

InvNr. SE 209/48

AO: GHD

Ton: 7.5 YR $3 / 1$

Taf. 199

Taf. 199

Taf. 199
Farbe außen: 7.5YR5/2, Farbe innen: 7.5YR6/2

Maße: DmRd 35,5 cm, erh. H 3,05 cm

Erh.: 1 Rdfrgt.

KatNr. K 542

Taf. 199

Gattung: Küchenware

Taf. 198 Form: Pfanne

InvNr. SE 207/65

AO: GHD

Ton: 5YR4/2+5YR5/3

Farbe außen: 7.5YR6/4+7.5YR5/2, Farbe innen: 7.5YR6/4

+7.5 YR $5 / 2$

Maße: DmRd 28,6 cm, erh. H $4 \mathrm{~cm}$

Erh.: 3 Rdfrgt.

\section{KatNr. K 543}

Taf. 199

Taf. 199 Gattung: Küchenware

Form: Pfanne

InvNr. SE 211/124

AO: GHD

Ton: $2.5 \mathrm{YR} 5 / 6$

Farbe außen: 2.5YR4/1, Farbe innen: 5YR7/6

Maße: DmRd 26,8 cm, erh. H 3,95 cm

Erh.: 1 Rdfrgt.

\section{KatNr. K 544}

Taf. 199

Gattung: Küchenware

Form: Pfanne

InvNr. SE 216/69

AO: GHD

Ton: 7.5 YR5/1

Farbe außen: 7.5YR6/3, Farbe innen: 7.5YR6/3

Maße: DmRd 14,3 cm, erh. H 3,35 cm

Erh.: 1 Rdfrgt.

\section{KatNr. K 545}

Taf. 199

Gattung: Küchenware

Form: Pfanne

InvNr. SE 211/77

AO: GHD

Ton: 5YR4/1+5YR6/6

Farbe außen: 5YR7/4, Farbe innen: 5YR7/4

Maße: DmRd 29,2 cm, erh. H 3,15 cm

Erh.: 1 Rdfrgt.

\section{KatNr. K 546}

Taf. 200

Gattung: Küchenware

Form: Pfanne

InvNr. SE 211/173

AO: GHD

Ton: 2.5 YR6/6

Farbe außen: 5YR7/4, Farbe innen: 5YR7/4

Maße: DmRd 4,4 cm, erh. L 5,5 cm

Erh.: 1 Griff

\section{KatNr. K 547}

Taf. 200

Gattung: Küchenware

Form: Pfanne

InvNr. SE $107 / 5$

AO: GHD

Ton: $7.5 \mathrm{YR} 6 / 2$

Farbe außen: 7.5YR6/2, Farbe innen: 5YR2.5/1 
Maße: DmRd 28,6 cm, erh. H 2,5 cm

Erh.: 1 Rdfrgt.

\section{KatNr. K 548}

Gattung: Küchenware

Form: Pfanne

InvNr. SE 211/33

AO: GHD

Ton: 2.5 YR $4 / 4$

Farbe außen: 2.5YR4/3, Farbe innen: 2.5YR4/3

Maße: DmRd 22,4 cm, erh. H 2,5 cm

Erh.: 1 Rdfrgt.

\section{KatNr. K 549}

Gattung: Küchenware

Form: Kasserolle

InvNr. SE 211/34

AO: GHD

Ton: 2.5 YR6/8

Farbe außen: 2.5YR6/8, Farbe innen: 2.5YR6/8

Maße: DmBd 11,2 cm, erh. H 3,35 cm

Erh.: 1 Bdfrgt.

\section{KatNr. K 550}

Gattung: Küchenware

Form: Kasserolle

InvNr. SE 211/35

AO: GHD

Ton: $2.5 \mathrm{YR} 6 / 6+5 \mathrm{YR} 6 / 4$

Farbe außen: 2.5YR6/8, Farbe innen: 5YR6/4

Maße: DmBd 14,8 cm, erh. H 2,9 cm

Erh.: 1 Bdfrgt.

\section{KatNr. K 551}

Gattung: Küchenware

Form: Kasserolle

InvNr. SE 215/18

AO: GHD

Ton: $7.5 \mathrm{YR} 5 / 2$

Farbe außen: 7.5YR7/3, Farbe innen: 7.5YR7/3

Maße: DmBd 13,6 cm, erh. H 3,65 cm

Erh.: 1 Bdfrgt.

\section{KatNr. K 552}

Gattung: Küchenware

Form: Deckel

InvNr. SE 209/31

AO: GHD

Ton: 7.5YR6/4

Farbe außen: 7.5YR7/4, Farbe innen: 7.5YR7/4

Maße: Dm Henkel 3,8 cm, erh. H 2,4 cm

Erh.: 1 Deckelfrgt.

\section{KatNr. K 553}

Gattung: Amphore

InvNr. SE 215/17

AO: GHD

Ton: 5YR6/4

Farbe außen: 7.5YR8/4, Farbe innen: 7.5YR8/4

Maße: DmRd 15,4 cm, erh. H 3,7 cm

Erh.: 1 Rdfrgt.

\section{KatNr. K 554}

Taf. 200

Gattung: Amphore (?)

Taf. 200

InvNr. SE 216/90

AO: GHD

Ton: 5YR6/6

Farbe außen: 7.5YR8/4, Farbe innen: 7.5YR8/4

Maße: DmRd 14,4 cm, erh. H 2,9 cm

Erh.: 1 Rdfrgt.

\section{KatNr. K 555}

Taf. 200

Gattung: Amphore (?)

InvNr. SE 211/69

AO: GHD

Taf. 200 Überzug: Randoberseite, matt, teilweise abgerieben

Ton: 5YR6/6

Farbe außen: 7.5YR8/4, Farbe innen: 7.5YR8/4, Farbe am

Rd: 2.5 YR5/6

Maße: DmRd $15 \mathrm{~cm}$, erh. H 3,45 cm

Erh.: 1 Rdfrgt.

KatNr. K 556

Taf. 200

Gattung: Amphore

InvNr. SE 216/92

Taf. 200

AO: GHD

Ton: 5YR6/6+5YR6/1

Farbe außen: 7.5YR7/4, Farbe innen: 7.5YR7/4

Maße: DmRd 8,6 cm, erh. H 4,5 cm

Erh.: 1 Rdfrgt.

KatNr. K 557

Taf. 200

Gattung: Amphore

InvNr. SE 216/19

AO: GHD

Taf. 200

Ton: 5YR7/6

Farbe außen: 10YR8/4, Farbe innen: 10YR8/4

Maße: DmRd 12,2 cm, erh. H 4,75 cm

Erh.: 1 Rdfrgt.

\section{KatNr. K 558}

Taf. 201

Gattung: Amphore

InvNr. SE 207/7

AO: GHD

Ton: 7.5 YR6/4

Taf. 200 Farbe außen: 7.5YR8/3, Farbe innen: 7.5YR8/3

Maße: DmRd $11 \mathrm{~cm}$, erh. H 2,8 cm

Erh.: 1 Rdfrgt.

\section{KatNr. K 559}

Taf. 201

Gattung: Amphore

InvNr. SE 216/91

AO: GHD

Ton: 5YR8/4

Farbe außen: 2.5Y8/2 (heller), Farbe innen: 2.5YR8/2 (hel-

Taf. 200 ler)

Maße: DmRd 10,3 cm, erh. H 2,5 cm

Erh.: 1 Rdfrgt.

KatNr. K 560

Taf. 201

Gattung: Amphore

InvNr. SE 216/50

AO: GHD 
Ton: $7.5 Y R 7 / 4$

Farbe außen: 10YR8/3, Farbe innen: 10YR8/3

Maße: DmRd 11,8 cm, erh. H 4,3 cm

Erh.: 1 Rdfrgt.

\section{KatNr. K 561}

Gattung: Amphore

InvNr. SE 211/25

AO: GHD

Ton: 2.5 YR6/6

Farbe außen: 7.5YR8/6, Farbe innen: 7.5YR8/6

Maße: DmRd $11 \mathrm{~cm}$, erh. H $5 \mathrm{~cm}$

Erh.: 1 Rdfrgt.

\section{KatNr. K 562}

Gattung: Amphore

InvNr. SE 211/8

AO: GHD

Ton: 5YR6/6+7.5YR7/4

Farbe außen: 10YR8/3, Farbe innen: 510YR8/3

Maße: DmRd 11,2 cm, erh. H 3,9 cm

Erh.: 1 Rdfrgt.

\section{KatNr. K 563}

Gattung: Amphore

InvNr. SE 210/9

AO: GHD

Ton: 5YR6/6

Farbe außen: 7.5YR8/4, Farbe innen: 7.5YR8/4

Maße: DmRd 12,2 cm, erh. H 4,6 cm

Erh.: 1 Rdfrgt.

\section{KatNr. K 564}

Gattung: Amphore

InvNr. SE 107/20

AO: GHD

Ton: 5YR7/4

Farbe außen: 7.5YR8/2, Farbe innen: 7.5YR8/2

Maße: DmRd 13,8 cm, erh. H 3,6 cm

Erh.: 1 Rdfrgt.

\section{KatNr. K 565}

Gattung: Amphore

InvNr. SE 216/112

AO: GHD

Ton: 2.5 YR6/6

Farbe außen: 7.5YR8/4, Farbe innen: 7.5YR8/4

Maße: DmRd 12,6 cm, erh. H 1,8 cm

Erh.: 1 Rdfrgt.

\section{KatNr. K 566}

Gattung: Amphore

InvNr. SE 215/16

AO: GHD

Ton: 2.5 YR6/6

Farbe außen: 10YR8/2, Farbe innen: 10YR8/2

Maße: DmRd 12,6 cm, erh. H 4,1 cm

Erh.: 1 Rdfrgt.

\section{KatNr. K 567}

Gattung: Amphore

InvNr. SE 209/51

\section{AO: GHD}

Ton: $2.5 \mathrm{YR} 8 / 3$

Farbe außen: 2.5YR8/2 (heller), Farbe innen: 2.5YR8/2 (heller)

Taf. 201

Maße: DmRd 10,7 cm, erh. H 10,4 cm

Erh.: 1 Rdfrgt. mit Henkelansatz

\section{KatNr. K 568}

Taf. 201

Gattung: Amphore

InvNr. SE 207/53

AO: GHD

Ton: 5YR6/6

Farbe außen: 7.5YR8/3, Farbe innen: 7.5YR8/3

Taf. 201

Maße: DmRd 9,2 cm, erh. H 3,2 cm

Erh.: 1 Rdfrgt.

KatNr. K 569

Taf. 201

Gattung: Amphore

InvNr. SE 209/3

AO: GHD

Ton: 2.5 YR6/6

Farbe außen: 10YR8/3, Farbe innen: 10YR8/3

Taf. 201 Maße: DmRd 11,4 cm, erh. H 4,1 cm

Erh.: 1 Rdfrgt.

KatNr. K 570

Taf. 201

Gattung: Amphore

InvNr. SE 209/16

AO: GHD

Ton: $10 Y R 7 / 4$

Farbe außen: 10YR8/3, Farbe innen: 10YR8/3

Taf. 201 Maße: DmRd 12,4 cm, erh. H 3,15 cm

Erh.: 1 Rdfrgt.

\section{KatNr. K 571}

Taf. 201

Gattung: Amphore

InvNr. SE 209/15

AO: GHD

Ton: 7.5 YR6/4

Taf. 201 Farbe außen: 7.5YR8/3, Farbe innen: 7.5YR8/3

Maße: DmRd 11,4 cm, erh. H 3,6 cm

Erh.: 1 Rdfrgt.

\section{KatNr. K 572}

Taf. 202

Gattung: Amphore

InvNr. SE 210/10

AO: GHD

Ton: $7.5 \mathrm{YR} 8 / 4$

Taf. 201 Farbe außen: 2.5 YR8/2, Farbe innen: 2.5 YR8/2

Maße: DmRd 11,9 cm, erh. H 3,15 cm

Erh.: 1 Rdfrgt.

\section{KatNr. K 573}

Taf. 202

Gattung: Amphore

InvNr. SE 209/52

AO: GHD

Ton: 5YR7/6

Taf. 201 Farbe außen: 10YR8/3, Farbe innen: 10YR8/3

Maße: DmRd 11,7 cm, erh. H 2,8 cm

Erh.: 1 Rdfrgt. 


\section{KatNr. K 574}

Gattung: Amphore

InvNr. SE 207/17

AO: GHD

Ton: 2.5 YR6/6

Farbe außen: 2.5YR7/6, Farbe innen: 2.5YR7/6

Maße: DmRd 12,6 cm, erh. H 3,9 cm

Erh.: 1 Rdfrgt.

\section{KatNr. K 575}

Gattung: Amphore

InvNr. SE 210/11

AO: GHD

Ton: $10 \mathrm{YR} 8 / 4$

Farbe außen: 10YR8/3, Farbe innen: 10YR8/3

Maße: DmRd 10,2 cm, erh. H 2 cm

Erh.: 1 Rdfrgt.

\section{KatNr. K 576}

Gattung: Amphore

InvNr. SE 207/10

AO: GHD

Ton: 5YR6/6

Farbe außen: 7.5YR7/4, Farbe innen: 7.5YR7/4

Maße: DmRd 9,4 cm, erh. H 2,6 cm

Erh.: 1 Rdfrgt.

\section{KatNr. K 577}

Gattung: Amphore

InvNr. SE 216/40

AO: GHD

Ton: 5YR6/6

Farbe außen: 5YR7/6+2.5YR4/6, Farbe innen: 5YR7/6 +2.5 YR $4 / 6$

Maße: DmRd 13,5 cm, erh. H 2,45 cm

Erh.: 1 Rdfrgt.

\section{KatNr. K 578}

Gattung: Amphore

InvNr. SE 216/114

AO: GHD

Ton: 5YR8/4

Farbe außen: 7.5YR8/4, Farbe innen: 7.5YR8/4

Maße: DmRd 8,8 cm, erh. H 2,2 cm

Erh.: 1 Rdfrgt.

\section{KatNr. K 579}

Gattung: Amphore

InvNr. SE 216/24

AO: GHD

Ton: 5YR5/6

Farbe außen: 7.5YR8/4, Farbe innen: 7.5YR8/4

Maße: DmRd 8,2 cm, erh. H 2,8 cm

Erh.: 1 Rdfrgt.

\section{KatNr. K 580}

Gattung: Amphore

InvNr. SE 216/18

AO: GHD

Ton: 5YR6/8

Farbe außen: 7.5YR8/6, Farbe innen: 7.5YR8/6
Taf. 202 Maße: DmRd 10,6 cm, erh. H 3,05 cm Erh.: 1 Rdfrgt.

\section{KatNr. K 581}

Taf. 202

Gattung: Amphore

InvNr. SE 211/164

AO: GHD

Ton: 2.5 YR6/6

Farbe außen: 10YR8/4, Farbe innen: 10YR8/4

Taf. 202 Maße: DmRd 8,9 cm, erh. H 6,7 cm

Erh.: 1 Rdfrgt.

\section{KatNr. K 582}

Taf. 202

Gattung: Amphore

InvNr. SE 211/58

AO: GHD

Ton: 5YR6/6

Farbe außen: 5YR7/6, Farbe innen: 5YR7/6

Taf. 202 Maße: DmRd 14 cm, erh. H 3,8 cm

Erh.: 1 Rdfrgt.

\section{KatNr. K 583}

Gattung: Amphore

InvNr. SE 211/17

AO: GHD

Ton: 2.5 YR6/8

Farbe außen: 5YR6/6, Farbe innen: 5YR6/6

Taf. 202 Maße: DmRd 9,6 cm, erh. H 3,4 cm

Erh.: 1 Rdfrgt.

\section{KatNr. K 584}

Taf. 202

Gattung: Amphore

InvNr. SE 210/6

AO: GHD

Ton: 2.5 YR7/6

Farbe außen: 10YR8/3, Farbe innen: 10YR8/3

Maße: DmRd $10 \mathrm{~cm}$, erh. H 3,8 cm

Taf. 202 Erh.: 1 Rdfrgt.

\section{KatNr. K 585}

Gattung: Amphore

InvNr. SE 210/4

AO: GHD

Ton: 7.5 YR8/4

Farbe außen: 10YR8/3, Farbe innen: 10YR8/3

Maße: DmRd $10 \mathrm{~cm}$, erh. H $3 \mathrm{~cm}$

Taf. 202 Erh.: 1 Rdfrgt.

\section{KatNr. K 586}

Taf. 202

Gattung: Amphore

InvNr. SE 210/5

AO: GHD

Ton: $2.5 \mathrm{YR} 8 / 3$

Farbe außen: $2.5 Y R 8 / 2$, Farbe innen: 2.5 YR8/2

Maße: DmRd 9,8 cm, erh. H 3,4 cm

Taf. 202 Erh.: 1 Rdfrgt.

KatNr. K 587

Taf. 202

Gattung: Amphore

InvNr. SE 210/3

AO: GHD 
Ton: $7.5 \mathrm{YR} 8 / 4$

Farbe außen: 10YR8/3, Farbe innen: 10YR8/3

Maße: DmRd $11 \mathrm{~cm}$, erh. H 4,2 cm

Erh.: 1 Rdfrgt.

\section{KatNr. K 588}

Gattung: Amphore

InvNr. SE 209/46

AO: GHD

Ton: 2.5 YR5/8

Farbe außen: 2.5YR7/6, Farbe innen: 2.5YR7/6

Maße: DmRd 8,2 cm, erh. H 4,9 cm

Erh.: 1 Rdfrgt.

\section{KatNr. K 589}

Gattung: Amphore

InvNr. SE 209/20

AO: GHD

Ton: $7.5 \mathrm{YR} 7 / 4$

Farbe außen: 10YR8/3, Farbe innen: 10YR8/3

Maße: DmRd 12,8 cm, erh. H 3,2 cm

Erh.: 1 Rdfrgt.

\section{KatNr. K 590}

Gattung: Amphore

InvNr. SE 209/43

AO: GHD

Ton: 10 YR7/4

Farbe außen: 2.5YR8/2 (heller), Farbe innen: 2.5YR8/2 (heller)

Maße: DmRd 9 cm, erh. H 2,4 cm

Erh.: 1 Rdfrgt.

\section{KatNr. K 591}

Taf. 203

Gattung: Amphore

InvNr. SE 209/1

AO: GHD

Ton: 7.5 YR7/4

Farbe außen: 2.5YR8/2, Farbe innen: 2.5YR8/2

Maße: DmRd $10 \mathrm{~cm}$, erh. H $5 \mathrm{~cm}$

Erh.: 1 Rdfrgt.

\section{KatNr. K 592}

Gattung: Amphore

InvNr. SE 208/5

AO: GHD

Ton: 5YR7/6

Farbe außen: 7.5YR7/4, Farbe innen: 7.5YR7/4

Maße: DmRd 10,2 cm, erh. H 6,1 cm

Erh.: 1 Rdfrgt.

\section{KatNr. K 593}

Gattung: Amphore

InvNr. SE 208/6

AO: GHD

Ton: 5YR6/6

Farbe außen: 7.5YR8/3, Farbe innen: 7.5YR8/3

Maße: DmRd 9,6 cm, erh. H 2,55 cm

Erh.: 1 Rdfrgt.

Taf. 203

Taf. 203

\section{KatNr. K 594}

Taf. 203

Gattung: Amphore

InvNr. SE 207/77

AO: GHD

Ton: 2.5 YR5/6

Taf. 202 Farbe außen: 10YR8/3, Farbe innen: 10YR8/3

Maße: DmRd 10,8 cm, erh. H 4,75 cm

Erh.: 1 Rdfrgt.

\section{KatNr. K 595}

Taf. 203

Gattung: Amphore

InvNr. SE 207/66

AO: GHD

Ton: 5YR6/6+10YR7/4

Farbe außen: 2.5YR7/3, Farbe innen: $2.5 Y R 7 / 3$

Taf. 202 Maße: DmRd 10,4 cm, erh. H 2,9 cm

Erh.: 1 Rdfrgt.

KatNr. K 596

Taf. 203

Gattung: Amphore

InvNr. SE 207/8

AO: GHD

Ton: 5YR6/6

Farbe außen: 5YR7/6, Farbe innen: 5YR7/6

Taf. 203 Maße: DmRd $7 \mathrm{~cm}$, erh. H 4,9 cm

Erh.: 1 Rdfrgt.

KatNr. K 597

Taf. 203

Gattung: Amphore

InvNr. SE 207/5

AO: GHD

Ton: $7.5 \mathrm{YR} 8 / 4$

Farbe außen: 7.5YR8/3, Farbe innen: 7.5YR8/3

Maße: DmRd 8,8 cm, erh. H 4,1 cm

Erh.: 1 Rdfrgt.

\section{KatNr. K 598}

Taf. 203

Gattung: Amphore

InvNr. SE 207/1

AO: GHD

Ton: 5YR6/6

Farbe außen: 7.5YR7/6, Farbe innen: 7.5YR7/6

Maße: DmRd 10,2 cm, erh. H 3 cm

Erh.: 1 Rdfrgt.

KatNr. K 599

Gattung: Amphore/Gebrauchskeramik (?)

InvNr. SE 207/83

AO: GHD

Ton: 7.5 YR7/4

Farbe außen: 2.5YR7/4, Farbe innen: 2.5YR7/4

Maße: DmRd 6,2 cm, erh. H 3,2 cm

Erh.: 1 Rdfrgt.

KatNr. K 600

Taf. 203

Gattung: Amphore

InvNr. SE 207/82

AO: GHD

Ton: 7.5 YR7/4

Farbe außen: 7.5YR8/2, Farbe innen: 7.5YR8/2

Maße: DmRd 11,2 cm, erh. H 2,9 cm

Erh.: 1 Rdfrgt. 


\section{KatNr. K 601}

Gattung: Amphore

InvNr. SE 207/4

AO: GHD

Ton: 2.5 YR6/6

Farbe außen: 5YR7/4, Farbe innen: 5YR7/4

Maße: DmRd 8,6 cm, erh. H 5,6 cm

Erh.: 1 Rdfrgt.

\section{KatNr. K 602}

Gattung: Amphore

InvNr. SE 107/8

AO: GHD

Ton: 7.5 Y $7 / 6$

Farbe außen: 7.5YR8/3, Farbe innen: 7.5YR8/3

Maße: DmRd $11 \mathrm{~cm}$, erh. H 6,1 cm

Erh.: 1 Rdfrgt.

\section{KatNr. K 603}

Gattung: Amphore

InvNr. SE 216/51

AO: GHD

Ton: $2.5 \mathrm{YR} 6 / 6$

Farbe außen: 5YR8/4, Farbe innen: 5YR8/4

Maße: DmRd 10,2 cm, erh. H 4,8 cm

Erh.: 1 Rdfrgt.

\section{KatNr. K 604}

Gattung: Amphore

InvNr. SE 209/18

AO: GHD

Ton: 5YR7/4

Farbe außen: 7.5YR7/4, Farbe innen: 7.5YR7/4

Maße: DmRd 11,2 cm, erh. H 3,8 cm

Erh.: 1 Rdfrgt.

\section{KatNr. K 605}

Gattung: Amphore

InvNr. SE 209/2

AO: GHD

Ton: 7.5 YR7/4

Farbe außen: 2.5YR8/2, Farbe innen: 2.5YR8/2

Maße: DmRd 9,2 cm, erh. H 3,4 cm

Erh.: 1 Rdfrgt.

\section{KatNr. K 606}

Gattung: Amphore

InvNr. SE 207/75

AO: GHD

Ton: 2.5 YR7/3+7.5YR $8 / 4$

Farbe außen: 2.5 YR $8 / 3+10$ YR8/3, Farbe innen: 2.5 YR $8 / 3$

+10 YR $8 / 3$

Maße: DmRd 10,8 cm, erh. H 6,1 cm

Erh.: 1 Rdfrgt.

\section{KatNr. K 607}

Gattung: Amphore

InvNr. SE 207/76

AO: GHD

Ton: 7.5 YR7/4

Farbe außen: 10YR8/3, Farbe innen: 10YR8/3
Taf. 203 Maße: DmRd 10 cm, erh. H 3,25 cm Erh.: 1 Rdfrgt.

\section{KatNr. K 608}

Taf. 204

Gattung: Amphore

InvNr. SE 207/78

AO: GHD

Ton: 7.5 YR6/4

Farbe außen: 7.5YR8/3, Farbe innen: 7.5YR8/3

Taf. 203 Maße: DmRd 10,4 cm, erh. H 3,3 cm

Erh.: 1 Rdfrgt.

\section{KatNr. K 609}

Taf. 204

Gattung: Amphore

InvNr. SE 207/68

AO: GHD

Ton: 5YR7/6

Farbe außen: 10YR8/3, Farbe innen: 10YR8/3

Taf. 203 Maße: DmRd $9 \mathrm{~cm}$, erh. H 3,7 cm

Erh.: 1 Rdfrgt.

\section{KatNr. K 610}

Gattung: Amphore

InvNr. SE 211/16

AO: GHD

Ton: 2.5 YR5/6+5YR6/6

Farbe außen: 7.5YR7/6, Farbe innen: 7.5YR7/6

Taf. 204 Maße: DmRd 6,6 cm, erh. H 4,1 cm

Erh.: 1 Rdfrgt.

\section{KatNr. K 611}

Taf. 204

Gattung: Amphore

InvNr. SE 208/2

AO: GHD

Ton: 2.5 YR6/6

Farbe außen: 5YR7/6, Farbe innen: 10YR8/3

Taf. 204 Maße: DmRd 11,2 cm, erh. H 3,3 cm

Erh.: 1 Rdfrgt.

\section{KatNr. K 612}

Gattung: Amphore

InvNr. SE 210/7

AO: GHD

Ton: 5YR7/4

Farbe außen: 7.5YR8/3, Farbe innen: 7.5YR8/3

Taf. 204 Maße: DmRd 12,2cm, erh. H 4,3 cm

Erh.: 1 Rdfrgt.

\section{KatNr. K 613}

Gattung: Amphore

InvNr. SE 207/6

AO: GHD

Ton: 5YR6/6+7.5YR6/4

Farbe außen: 5YR6/4, Farbe innen: 5YR6/4

Maße: DmRd 13,6 cm, erh. H 5,6 cm

Taf. $204 \quad$ Erh.: 1 Rdfrgt.

KatNr. K 614

Gattung: Amphore

InvNr. SE 207/3

AO: GHD
Taf. 204

Taf. 204

Taf. 204

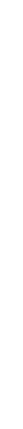


Ton: $7.5 Y R 7 / 4$

Farbe außen: 2.5 YR8/3, Farbe innen: 2.5 YR8/3

Maße: DmRd 9,4 cm, erh. H 4,1 cm

Erh.: 1 Rdfrgt.

\section{KatNr. K 615}

Gattung: Amphore

InvNr. SE 207/52

AO: GHD

Ton: 10 YR7/3

Farbe außen: 2.5YR8/2, Farbe innen: 2.5YR8/2

Maße: DmRd 9,6 cm, erh. H 2,9 cm

Erh.: 1 Rdfrgt.

\section{KatNr. K 616}

Taf. 204. 223

Gattung: Amphore

InvNr. SE 209/55

AO: GHD

Ton: 7.5 YR7/4

Farbe außen: 7.5YR8/2, Farbe innen: 7.5YR8/2

Maße: DmRd 3,4 cm, erh. H 2,9 cm

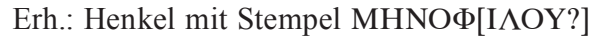

\section{KatNr. K 617}

Taf. 204. 223

Gattung: Amphore

InvNr. SE 210/34

AO: GHD

Ton: $10 \mathrm{YR} 8 / 3$

Farbe außen: 2.5YR8/2, Farbe innen: 2.5YR8/2

Maße: Dm 3,1 cm, erh. H 2,8 cm

Erh.: Henkel mit Stempel MHNO[ФI $\Lambda$ OY]

\section{KatNr. K 618}

Taf. 205. 223

Gattung: Amphore

InvNr. SE 216/80

AO: GHD

Ton: $7.5 \mathrm{YR} 7 / 4$

Farbe außen: 10YR8/3, Farbe innen: 10YR8/3

Maße: Dm 3,6 cm, erh. L 6,3 cm

Erh.: Henkel mit Stempel $\Phi[$.$] NI \Delta O C$

\section{KatNr. K 619}

Taf. 205. 223

Gattung: Amphore

InvNr. SE 209/12

AO: GHD

Ton: 7.5 YR6/4

Farbe außen: 7.5YR8/3, Farbe innen: 7.5YR8/3

Maße: Dm 3,35 cm, erh. H 6,4 cm

Erh.: Henkel mit Stempel links $\Delta \mathrm{IO} \Delta \mathrm{OT}[\mathrm{OY}]$, rechts Zusatzstempel: Zweig

\section{KatNr. K 620}

Taf. 205. 223

Gattung: Amphore

InvNr. SE 209/13

AO: GHD

Ton: $7.5 \mathrm{YR} 7 / 4$

Farbe außen: 10YR8/3, Farbe innen: 10YR8/3

Maße: Dm 3,3 cm, erh. H 3,8 cm

Erh.: Henkel mit Stempel TYX $\Omega[\mathrm{N}]$
KatNr. K 621

Taf. 205. 223

Gattung: Amphore

InvNr. SE 207/58

AO: GHD

Ton: 7.5 YR5/2

Taf. 204 Farbe außen: 7.5YR3/1, Farbe innen: 7.5YR3/1

Maße: Dm 2,4 cm, erh. L 6,3 cm

Erh.: Henkel mit Stempel [EПI] ПОАYК[РАTOY

KatNr. K 622

Taf. 205. 223

Gattung: Amphore

InvNr. SE 207/74

AO: GHD

Ton: $7.5 \mathrm{YR} 7 / 4$

Farbe außen: 10YR8/3

Maße: Dm 1,5 cm, erh. H 4,5 cm

Erh.: Henkel mit rechtwinkligem Stempel $(1,1 \times 1,3 \mathrm{~cm})$, darauf?

\section{KatNr. K 623}

Gattung: Amphore

InvNr.: SE 105/46

AO: GHD

Ton: $7.5 Y R 7 / 4$

Farbe außen: 7.5YR7/4

Maße: $2,9 \times 2,3 \mathrm{~cm}$

Erh.: Henkel mit rechtwinkligem Stempel $(0,8 \times 0,7 \mathrm{~cm})$, darauf?

KatNr. K 624

Taf. 205

Gattung: Amphore/Gebrauchskeramik

InvNr. SE 212/5

AO: GHD

Ton: 5YR5/6

Farbe außen: 5YR8/3, Farbe innen: 2.5YR7/4

Maße: DmBd 9 cm, erh. H 3,6 cm

Erh.: 1 Bdfrgt.

KatNr. K 625

Taf. 205

Gattung: Amphore

InvNr. SE 208/19

AO: GHD

Ton: 5 YR7/6+10YR7/3

Farbe außen: 10YR8/3, Farbe innen: 10YR8/3

Maße: DmBd 8,8 cm, erh. H 7,7 cm

Erh.: 1 Bdfrgt.

KatNr. K 626

Taf. 205

Gattung: Amphore/Gebrauchskeramik

InvNr. SE 207/106

AO: GHD

Ton: 5YR6/6

Farbe außen: 5YR7/6, Farbe innen: 5YR7/6

Maße: DmBd 8,2 cm, erh. H 2,55 cm

Erh.: 1 Bdfrgt.

KatNr. K 627

Taf. 206

Gattung: Amphore

InvNr. SE 207/20

AO: GHD

Ton: 2.5 YR5/6 
Farbe außen: 2.5YR6/6, Farbe innen: 2.5YR6/6 Maße: DmBd 1,9 cm, erh. H 6,8 cm

Erh.: 1 Bdfrgt.

\section{KatNr. K 628}

Gattung: Amphore

InvNr. SE 216/100

AO: GHD

Ton: 5YR7/6

Farbe außen: 7.5YR6/3, Farbe innen: 7.5YR8/3

Maße: Dm Fuß 1,8 cm, erh. H 11,9 cm

Erh.: 1 Fußfrgt.

\section{KatNr. K 629}

Gattung: Amphore

InvNr. SE 216/38

AO: GHD

Ton: 5YR6/6

Farbe außen: 5YR7/6, Farbe innen: 5YR7/6

Maße: Dm Fuß 1 cm, erh. H 10,7 cm

Erh.: 1 Fußfrgt.

\section{KatNr. K 630}

Gattung: Amphore

InvNr. SE 210/33

AO: GHD

Ton: $2.5 \mathrm{YR} 7 / 6+10 \mathrm{YR} 7 / 3$

Farbe außen: 2.5YR8/2, Farbe innen: 2.5YR8/2

Maße: Dm Fuß 0,6 cm, erh. H 4,4 cm

Erh.: 1 Fußfrgt.

\section{KatNr. K 631}

Gattung: Amphore

InvNr. SE 207/109

AO: GHD

Ton: $7.5 \mathrm{YR} 7 / 4$

Farbe außen: 10YR8/3, Farbe innen: 10YR8/3

Maße: Dm Fuß $1 \mathrm{~cm}$, erh. H 3,8 cm

Erh.: 1 Fußfrgt.

\section{KatNr. K 632}

Gattung: Amphore

InvNr. SE 207/73

AO: GHD

Ton: 7.5YR6/6

Farbe außen: 7.5YR8/4, Farbe innen: 7.5YR8/4

Maße: Dm Fuß 1,4 cm, erh. H 7,8 cm

Erh.: 1 Fußfrgt.

\section{KatNr. K 633}

Gattung: Amphore

InvNr. SE 211/48

AO: GHD

Ton: 2.5 YR6/4

Farbe außen: 10YR7/3, Farbe innen: 2.5YR7/4

Maße: Dm Fuß 2,7 cm, erh. H 11,85 cm

Erh.: 1 Fußfrgt.

\section{KatNr. K 634}

Gattung: Amphore

InvNr. SE 208/20
AO: GHD

Ton: 2.5 YR6/6

Farbe außen: 5YR8/4, Farbe innen: 5YR8/4

Maße: Dm Fuß 0,9 cm, erh. H 5,3 cm

Taf. $206 \quad$ Erh.: 1 Fußfrgt.

KatNr. K 635

Taf. 206

Gattung: Amphore

InvNr. SE 207/19

AO: GHD

Ton: 5YR6/6+5YR6/3

Farbe außen: 7.5YR8/4, Farbe innen: 7.5YR8/4

Maße: DmBd 2,1 cm, erh. H 9,7 cm

Taf. $206 \quad$ Erh.: 1 Bdfrgt.

\section{KatNr. K 636}

Taf. 206

Gattung: Amphore

InvNr. SE 211/81

AO: GHD

Ton: 2.5 YR6/8

Farbe außen: 5YR6/6, Farbe innen: 5YR6/6

Maße: Dm Fuß 1,8 cm, erh. H 6,6 cm

Taf. $206 \quad$ Erh.: 1 Fußfrgt.

\section{KatNr. K 637}

Taf. 206

Gattung: Amphore

InvNr. SE 216/49

AO: GHD

Ton: 2.5 YR6/6

Farbe außen: 5YR7/6, Farbe innen: 5YR7/6

Maße: Dm Fuß 1,2 cm, erh. H 7,1 cm

Taf. $206 \quad$ Erh.: 1 Fußfrgt.

\section{KatNr. K 638}

Taf. 207. 224

Gattung: Reliefkeramik

Form: Lampe

InvNr. SE 215/22

AO: GHD

Überzug: flächig, matt, kompakt

Ton: 10 YR7/2

Taf. 206 Farbe außen: 7.5YR5/1, Farbe innen: 7.5YR5/1

Maße: erh. L 5,6 cm, erh. B 2,25 cm, erh. H 1,5 cm

Erh.: 1 Schulter/Diskusfrgt.

\section{KatNr. K 639}

Taf. 224

Gattung: Reliefkeramik

Form: Ephesos-Lampe

InvNr. SE 211/53

AO: GHD

Taf. 206 Überzug: außen kompakt, innen partiell; matt, teilweise abgerieben

Ton: Gley2 5/1

Farbe außen: Gley1 3/0, Farbe innen: Gley2 5/1

Maße: $5,5 \times 3,2 \mathrm{~cm}$

Erh.: 1 Schulterfrgt., zentrales Füllloch, um das Loch ovuli mit Mittelrippen, darum Girlandenkranz, seitlicher Grifffortsatz (Metallimitation)

Taf. 206

KatNr. K 640

Taf. 207

Gattung: Reliefkeramik

Form: Lampe 
InvNr. SE 211/90

AO: GHD

Überzug: flächig, matt, teilweise abgerieben

Ton: 10YR5/1

Farbe außen: 10YR6/1+5YR2.5/1, Farbe innen: 10YR6/1

+5YR2.5/1

Maße: erh. L 4,3 cm, erh. B 3,4 cm, erh. H 2,45 cm

Erh.: 1 Schnauzenfrgt.

\section{KatNr. K 641}

Taf. 207. 224

Gattung: Reliefkeramik

Form: Ephesos-Lampe

InvNr. SE 215/23

AO: GHD

Überzug: flächig, matt, teilweise abgerieben

Ton: 2.5 YR6/6

Farbe außen: 2.5 YR5/2+2.5YR6/8, Farbe innen: 5YR7/6

$+10 \mathrm{R} 5 / 6$

Maße: erh. L 6,4 cm, erh. B $4 \mathrm{~cm}$, erh. H 1,2 cm

Dekor: auf dem Schnauzenkanal verschliffenes Motiv

Erh.: 1 Schnauzenfrgt.

\section{KatNr. K 642}

Gattung: Reliefkeramik

Form: Ephesos-Lampe

InvNr. SE 211/91

AO: GHD

Überzug: flächig, matt, teilweise abgerieben

Ton: 5YR5/1

Farbe außen: 5YR4/1, Farbe innen: 5YR4/1

Maße: erh. L 2,7 cm, erh. B 3,2 cm, erh. H 2,4 cm

Erh.: 1 Schnauzenfrgt.

\section{KatNr. K 643}

Taf. 207

Gattung: Reliefkeramik

Form: Ephesos-Lampe

InvNr. SE 207/51

AO: GHD

Überzug: flächig, matt, teilweise abgerieben

Ton: 7.5 YR5/1

Farbe außen: 2.5YR4/1, Farbe innen: 2.5YR4/1

Maße: erh. L 4,5 cm, erh. B 2,7 cm, erh. H 2,7 cm

Erh.: 1 Schnauzenfrgt.

\section{KatNr. K 644}

Taf. 207

Gattung: Reliefkeramik

Form: Ephesos-Lampe

InvNr. SE 207/112

AO: GHD

Überzug: flächig, matt, teilweise abgerieben

Ton: 7.5 YR5/1

Farbe außen: 5YR5/1, Farbe innen: 5YR5/1

Maße: erh. L. 2,7 cm, erh. B 5,6 cm, erh. H 1,8 cm

Dekor: auf der Schulter schräg zueinander gestellte Hasten

Erh.: 1 Schulter/Diskusfrgt.

\section{KatNr. K 645}

Taf. 207

Gattung: Reliefkeramik

Form: Ephesos-Lampe

InvNr. SE 207/111

AO: GHD
Überzug: flächig, matt, teilweise abgerieben Ton: 5YR6/1

Farbe außen: 7.5YR6/1, Farbe innen: 7.5YR6/1

Maße: erh. L 2,3 cm, erh. B 2,2 cm, erh. H 1,2 cm

Dekor: auf dem Schnauzenkanal Delfin

Erh.: 1 Schnauzenfrgt.

\section{KatNr. K 646}

Taf. 207

Gattung: Reliefkeramik

Form: Ephesos-Lampe

InvNr. SE 208/4

AO: GHD

Überzug: flächig, matt, teilweise abgerieben

Ton: Gley2 6/10B

Farbe außen: Gley2 6/5PB, Farbe innen: Gley2 6/5PB

Maße: erh. L 2,2 cm, erh. B 3,3 cm, erh. H 1,5 cm

Dekor: auf der Schulter konzentrische Kreise

Erh.: 1 Schulterfrgt.

\section{KatNr. K 647}

Taf. 207. 224

Gattung: Reliefkeramik

Form: Lampe

InvNr. SE 207/59

AO: GHD

Überzug: flächig, matt, teilweise abgerieben

Ton: 5YR5/6

Farbe außen: 5YR7/4, Farbe innen: 5YR7/4

Maße: erh. L 5,4 cm, erh. B 1,6 cm, erh. H 1,6 cm

Erh.: 1 Lampenfrgt.

\section{KatNr. K 648}

Taf. 207

Gattung: Reliefkeramik

Form: Italische Bildlampe

InvNr. SE 207/48

AO: GHD

Überzug: flächig, matt glänzend, teilweise abgerieben

Ton: 5YR7/3

Farbe außen: 2.5 YR3/3, Farbe innen: 2.5 YR3/3

Maße: erh. L 2,9 cm, erh. H 0,9 cm

Erh.: 1 Bdfrgt.

\section{KatNr. K 649}

Taf. 207. 224

Gattung: Gebrauchskeramik

Form: Webgewicht

InvNr. SE 209/56

AO: GHD

Ton: $7.5 \mathrm{YR} 8 / 3$

Farbe: $7.5 \mathrm{YR} 8 / 3$

Maße: Dm 5,3 cm

Erh.: Ganzform

\section{KatNr. K 650}

Taf. 207

Gattung: Gebrauchskeramik

Form: Webgewicht

InvNr. SE 210/35

AO: GHD

Ton: 5YR7/6

Farbe: 5 YR7/6

Maße: Dm 2,5 cm

Erh.: Ganzform 


\section{>Hestiasaal}

KatNr. K 651

Gattung: Italische Terra Sigillata

Form: Teller Consp. 20.1.

InvNr. SE 402/2

AO: GHD

Überzug: flächig, glänzend, kompakt

Ton: 2.5 YR6/6

Farbe außen: 2.5YR4/8, Farbe innen: 2.5YR4/8

Maße: DmRd 11,7 cm, erh. H 1,9 cm

Erh.: 1 Rdfrgt.

\section{KatNr. K 652}

Taf. 207. 224

Gattung: Glanztonware/Westabhangnachfolgedekor

Form: Halbkugelige Schale

InvNr. SE 304/3

AO: GHD

Überzug: flächig, matt glänzend, kompakt

Ton: 2.5YR6/8

Farbe außen: 10YR5/4, Farbe innen: 10YR5/4, Farbe Dekor: 5YR2.5/1+7.5YR $8 / 4$

Maße: DmRd 13,6 cm, erh. H 2,7 cm

Dekor: Tropfen an der Gefäßaußenseite

Erh.: 1 Rdfrgt.

\section{KatNr. K 653}

Taf. 207

Gattung: Glanztonware

Form: Skyphos

InvNr. SE 405/1

AO: GHD

Überzug: flächig, matt glänzend, teilweise abgerieben

Ton: 5YR6/6

Farbe außen: 5YR2.5/1, Farbe innen: 5YR2.5/1

Maße: DmRd 9,4 cm, erh. H 2,1 cm

Erh.: 1 Rdfrgt.

KatNr. K 654

Taf. 207

Gattung: Glanztonware

Form: Konischer Teller

InvNr. SE 406/5

AO: GHD

Überzug: flächig, matt glänzend, teilweise abgerieben

Ton: $2.5 \mathrm{YR} 6 / 8$

Farbe außen: 2.5YR4/8, Farbe innen: 2.5YR6/6

Maße: DmRd 13,8 cm, erh. H 1,25 cm

Erh.: 1 Rdfrgt.

\section{KatNr. K 655}

Taf. 207

Gattung: Glanztonware

Form: Teller mit nach innen geknicktem Rand

InvNr. SE 304/4

AO: GHD

Überzug: flächig, matt glänzend, teilweise abgerieben

Ton: 5YR6/6

Farbe außen: 5YR2.5/1, Farbe innen: 5YR2.5/1

Maße: DmRd 21,8 cm, erh. H 1,5 cm

Erh.: 1 Rdfrgt.

\section{KatNr. K 656}

Taf. 207

Gattung: Glanztonware

Form: Teller mit beidseitig verdickter Lippe
InvNr. SE 406/3

Überzug: flächig, matt glänzend, teilweise abgerieben

AO: GHD

Ton: 5YR7/6

Farbe außen: 7.5YR5/1, Farbe innen: 7.5YR5/1

Maße: DmRd 28,9 cm, erh. H 1,7 cm

Erh.: 1 Rdfrgt.

KatNr. K 657

Taf. 207

Gattung: Glanztonware

Form: Teller mit gedrechseltem Rand

InvNr. SE 304/2

AO: GHD

Überzug: flächig, matt glänzend, teilweise abgerieben

Ton: 7.5 YR7/4

Farbe außen: 10R5/6, Farbe innen: 10R5/6

Maße: DmRd 23,8 cm, erh. H 1,05 cm

Erh.: 1 Rdfrgt.

\section{KatNr. K 658}

Taf. 207

Gattung: Graue Ware

Form: Konische Schale

InvNr. SE 406/1

AO: GHD

Überzug: flächig, matt glänzend, teilweise abgerieben

Ton: 7.5 YR6/2

Farbe außen: 5YR2.5/1, Farbe innen: 5YR2.5/1

Maße: DmRd 10,4 cm, erh. H 1,7 cm

Erh.: 1 Rdfrgt.

KatNr. K 659

Taf. 208

Gattung: Dünnwandige Keramik

Form: Becher

InvNr. SE 406/2

AO: GHD

Ton: 2.5 YR6/8

Farbe außen: 2.5YR5/1, Farbe innen: 2.5YR5/1

Maße: DmRd 6 cm, erh. H 0,7 cm

Erh.: 1 Rdfrgt.

KatNr. K 660

Taf. 208

Gattung: Weißgrundige Keramik

Form: Lagynos

InvNr. SE 405/2

AO: GHD

Überzug: außen, matt, kompakt

Ton: 5YR6/6

Farbe außen: 5YR7/6, Farbe innen: 7.5YR4/2

Maße: DmRd 4,4 cm, erh. H 0,85 cm

Erh.: 1 Rdfrgt.

KatNr. K 661

Taf. 208

Gattung: Gebrauchskeramik

Form: Schale

InvNr. SE 405/3

AO: GHD

Überzug: Rand innen und außen, matt glänzend, teilweise abgerieben

Ton: 5YR6/4

Farbe außen: 7.5YR7/4, Farbe innen: 7.5YR7/4

Maße: DmRd 15,4 cm, erh. H 2,1 cm

Erh.: 1 Rdfrgt. 


\section{KatNr. K 662}

Gattung: Gebrauchskeramik

Form: Teller mit breiter Lippe

InvNr. SE 405/4

AO: GHD

Überzug: Rand innen und außen, matt glänzend, teilweise abgerieben

Ton: 7.5 YR7/4

Farbe außen: 10YR8/2, Farbe innen: 10YR8/2

Maße: DmRd 18,2 cm, erh. H 2,1 cm

Erh.: 1 Rdfrgt.

\section{KatNr. K 663}

Gattung: Küchenware

Form: Krug/Topf

InvNr. SE 402/4

AO: GHD

Ton: 2.5 YR5/6

Farbe außen: 5YR7/6, Farbe innen: 5YR7/6

Maße: DmRd 13,6 cm, erh. H 2 cm

Erh.: 1 Rdfrgt.

\section{KatNr. K 664}

Gattung: Küchenware

Form: Topf

InvNr. SE 304/1

AO: GHD

Ton: 5YR5/6+5YR6/2

Farbe außen: 5YR5/6, Farbe innen: 5YR5/6

Maße: DmRd 21,6 cm, erh. H 2,1 cm

Erh.: 1 Rdfrgt.

\section{KatNr. K 665}

Gattung: Küchenware

Form: Topf

InvNr. SE 402/1

AO: GHD

Ton: $2.5 \mathrm{YR} 5 / 8$

Farbe außen: 2.5YR6/4, Farbe innen: 2.5YR6/4

Maße: DmRd 24,2 cm, erh. H 2,3 cm

Erh.: 1 Rdfrgt.

\section{KatNr. K 666}

Gattung: Reliefkeramik

Form: Ephesos-Lampe

InvNr. SE 406/4

AO: GHD

Überzug: flächig, matt glänzend, teilweise abgerieben

Ton: 7.5 Y R $5 / 1$

Farbe außen: 2.5YR4/1, Farbe innen: 2.5YR4/1

Maße: erh. L 6,3 cm, erh. B 2,2 cm, erh. H 1,15 cm

Dekor: auf der Schulter Punktreihe (?)

Erh.: 1 Lampenspiegelfrgt.

\section{KatNr. K 667}

Taf. 208

Gattung: Reliefkeramik

Form: Red-on-White-Lampe

InvNr. SE 402/3

AO: GHD

Überzug: flächig, glänzend, teilweise abgerieben Ton: 5YR7/6

Taf. 208

Taf. 208
Taf. 208 Farbe außen: 2.5 YR4/6, Farbe innen: 2.5 YR4/6

Maße: DmRd 8 cm, erh. H $0,8 \mathrm{~cm}$

Erh.: 1 Rdfrgt.

\section{Bauphase 2 (230-280 n. Chr.)}

KatNr. K 668

Taf. 208

Gattung: Eastern Sigillata C

Form: Schale Atlante L 19/H 3

InvNr. SE 501/2

AO: GHD

Überzug: flächig, matt glänzend, teilweise abgerieben

Ton: 5 YR $8 / 4$

Farbe außen: 10R5/6, Farbe innen: 10R5/6

Maße: DmRd 13,8 cm, erh. H 1,95 cm

Erh.: 1 Rdfrgt.

KatNr. K 669

Taf. 208

Gattung: Dünnwandige Keramik

Form: Becher

InvNr. SE 501/1

AO: GHD

Ton: 2.5 YR5/6

Farbe außen: 5YR6/3, Farbe innen: 5YR6/3

Maße: DmRd 7 cm, erh. H 1,9 cm

Erh.: 1 Rdfrgt.

\section{KatNr. K 670}

Taf. 208

Gattung: Dünnwandige Keramik

Form: Becher

InvNr. SE 501/5

AO: GHD

Ton: 2.5 YR6/8

Farbe außen: 2.5YR6/6, Farbe innen: 2.5YR6/6

Maße: DmRd 6,7 cm, erh. H 1,7 cm

Erh.: 1 Rdfrgt.

\section{KatNr. K 671}

Taf. 208

Gattung: Gebrauchskeramik

Form: Teller (?)

InvNr. SE 501/4

AO: GHD

Taf. 208 Ton: 7.5 YR6/4

Farbe außen: 5YR7/6, Farbe innen: 5YR7/6

Maße: DmRd 25,8 cm, erh. H 4,65 cm

Erh.: 2 Rdfrgt.

KatNr. K 672

Taf. 208

Gattung: Gebrauchskeramik

Form: Teller/Deckel

InvNr. SE 501/3

AO: GHD

Ton: 5YR6/6

Farbe außen: 10YR8/3, Farbe innen: 10YR8/3

Maße: DmRd 18,2 cm, erh. H 2,95 cm

Erh.: 1 Rdfrgt.

KatNr. K 673

Taf. 208

Gattung: Amphore

InvNr. SE 501/6

AO: GHD 
Ton: 2.5 YR5/8

Farbe außen: 7.5YR8/4, Farbe innen: 7.5YR8/4

Maße: Dm Fuß 4,5 cm, erh. H 2,4 cm

Erh.: 1 Fußfrgt.

\section{KatNr. K 674}

Taf. 209. 224

Gattung: Reliefkeramik

Form: Doppelschnauzenlampe

InvNr. SE 501/11

AO: GHD

Überzug: flächig, matt, fast vollständig abgerieben Ton: 2.5 YR6/8

Farbe außen: 2.5YR6/4, Farbe innen: 2.5YR6/4

Maße: erh. L 11,4 cm, erh. B 5,9 cm, erh. H 1,8 cm Erh.: Hälfte

\section{KatNr. K 675}

Gattung: Reliefkeramik

Form: Doppelschnauzenlampe

InvNr. SE 501/9

AO: GHD

Überzug: flächig, matt, fast vollständig abgerieben Ton: 2.5 YR $5 / 6$

Farbe außen: 2.5YR6/6, Farbe innen: 2.5YR6/6

Maße: erh. L 3,9 cm, erh. B 5,3 cm, erh. H 0,7 cm

Erh.: 1 Schnauzen-/Schulterfrgt.

\section{KatNr. K 676}

Taf. 209

Gattung: Reliefkeramik

Form: Red-on-White Lampe

InvNr. SE 501/8

AO: GHD

Überzug: flächig, glänzend, teilweise abgerieben Ton: 2.5 YR6/8

Farbe außen: 2.5YR6/6, Farbe innen: 2.5YR6/6

Maße: erh. L 2,9 cm, erh. B 2,9 cm, erh. H 0,95 cm Dekor: an der Bodenunterseite planta pedis-Stempel Erh.: 1 Bdfrgt.

KatNr. K 677

Taf. 209

Gattung: Reliefkeramik

Form: Lampe

InvNr. SE 501/10

AO: GHD

Überzug: flächig, matt, fast vollständig abgerieben Ton: 2.5 YR6/8

Farbe außen: 2.5YR6/6, Farbe innen: 2.5YR6/6

Maße: erh. L $4 \mathrm{~cm}$, erh. B 4,9 cm, erh. H 1,8 cm

Erh.: 1 Bdfrgt.

\section{KatNr. K 678}

Gattung: Reliefkeramik

Form: Lampe

InvNr. SE 501/7

AO: GHD

Überzug: flächig, matt, fast vollständig abgerieben Ton: 2.5 YR6/8

Farbe außen: 2.5YR6/6, Farbe innen: 2.5YR6/6

Maße: DmBd 2,2 cm, erh. H 2,3 cm

Erh.: 1 Bdfrgt.
Bauphase 3 (ab spätem 4. Jahrhundert n. Chr., spätantik)

KatNr. K 679

Taf. 209

Gattung: Eastern Sigillata B

Form: Schale

InvNr. SE 607/2

AO: GHD

Überzug: flächig, matt glänzend, teilweise abgerieben

Ton: 2.5 YR5/6

Farbe außen: 10R6/8, Farbe innen: 10R6/8

Maße: DmBd 8,6 cm, erh. H 1,25 cm

Erh.: 1 Bdfrgt.

KatNr. K 680

Taf. 209

Gattung: Dünnwandige Keramik

Taf. 209 Form: Becher

InvNr. SE 607/1

AO: GHD

Ton: $2.5 \mathrm{YR} 5 / 8$

Farbe außen: 2.5YR6/6, Farbe innen: 2.5YR6/6

Maße: DmRd 7,6 cm, erh. H 1,9 cm

Erh.: 1 Rdfrgt.

Bauphase $3 a$ (Mitte 7. Jahrhundert n. Chr.)

KatNr. K 681

Taf. 209

Gattung: African Red Slip Ware

Form: Teller Hayes 105

InvNr. SE 603/5

AO: GHD

Überzug: flächig, matt glänzend, kompakt

Ton: 2.5 Y R6/8

Farbe außen: 2.5YR7/6, Farbe innen: 2.5YR7/6

Maße: DmRd nicht bestimmbar, erh. H 2,7 cm

Erh.: 1 Rdfrgt.

KatNr. K 682

Taf. 209

Gattung: African Red Slip Ware

Form: Teller Hayes 105

InvNr. SE 603/13

AO: GHD

Überzug: flächig, matt glänzend, kompakt

Ton: 2.5 YR $5 / 8$

Farbe außen: 10R6/6, Farbe innen: 10R6/6

Maße: DmBd 16,3 cm, erh. H 2,75 cm

Erh.: 1 Bdfrgt.

KatNr. K 683

Taf. 209

Gattung: Late Roman C-Ware

Form: Teller Hayes 6

InvNr. SE 603/19

AO: GHD

Überzug: flächig, matt glänzend, kompakt

Ton: $2.5 \mathrm{YR} 6 / 8$

Farbe außen: 2.5YR7/6, Farbe innen: 2.5YR7/6

Maße: DmRd 24 cm, erh. H 1,25 cm

Erh.: 1 Rdfrgt. 


\section{KatNr. K 684}

Gattung: Late Roman C-Ware

Form: Teller

InvNr. SE 603/12

AO: GHD

Überzug: flächig, matt glänzend, kompakt

Ton: 2.5 YR6/8

Farbe außen: 2.5YR7/8, Farbe innen: 2.5YR7/8

Maße: DmBd 11,7 cm, erh. H 1,5 cm

Erh.: 1 Bdfrgt.

\section{KatNr. K 685}

Gattung: Late Roman C-Ware

Form: Teller

InvNr. SE 603/20

AO: GHD

Überzug: flächig, matt glänzend, kompakt

Ton: 2.5YR6/8,

Farbe außen: 10R6/6, Farbe innen: 10R6/6

Maße: DmBd 7,2 cm, erh. H 1,2 cm

Erh.: 1 Bdfrgt.

\section{KatNr. K 686}

Gattung: Ephesian Red Slip Ware

Form: Teller LRC-Hayes 3

InvNr. SE 603/3

AO: GHD

Überzug: flächig, matt, fast vollständig abgerieben Ton: 5YR6/8

Farbe außen: 2.5YR6/8, Farbe innen: 2.5YR6/8

Maße: DmRd 29 cm, erh. H 3,65 cm

Erh.: 1 Rdfrgt.

\section{KatNr. K 687}

Gattung: Ephesian Red Slip Ware

Form: Teller LRC-Hayes 10

InvNr. SE 603/4

AO: GHD

Überzug: flächig, matt, fast vollständig abgerieben Ton: 5YR6/6

Farbe außen: 2.5YR5/8, Farbe innen: 2.5YR5/8

Maße: DmRd 25,6 cm, erh. H 2,9 cm

Erh.: 1 Rdfrgt.

\section{KatNr. K 688}

Taf. 210

Gattung: Dünnwandige Keramik

Form: Becher

InvNr. SE 603/18

AO: GHD

Überzug: außen, glänzend, kompakt

Ton: 7.5 YR5/1

Farbe außen: 7.5YR5/1, Farbe innen: 7.5YR5/1

Maße: DmRd 11,8 cm, erh. H 2,2 cm

Erh.: 1 Rdfrgt.

KatNr. K 689

Taf. 210

Gattung: Gebrauchskeramik/Import

Form: Krug (?)

InvNr. SE 603/7

AO: GHD

Ton: 10 YR7/2
Taf. 209 Farbe außen: 10YR8/2, Farbe innen: 10YR8/2

Maße: DmRd $11 \mathrm{~cm}$, erh. H 2,7 cm

Erh.: 1 Rdfrgt.

KatNr. K 690

Taf. 210

Gattung: Gebrauchskeramik

Form: Krug

InvNr. SE 603/6

AO: GHD

Ton: 7.5 YR6/6

Farbe außen: 7.5YR8/4, Farbe innen: 7.5YR8/4

Taf. 209 Maße: DmRd 7,1 cm, erh. H 2,95 cm

Erh.: 1 Rdfrgt.

KatNr. K 691

Taf. 210

Gattung: Gebrauchskeramik

Form: Schüssel

InvNr. SE 603/11

AO: GHD

Ton: 5YR6/6

Farbe außen: 7.5YR8/3+2.5YR7/6, Farbe innen: 7.5YR8/3 +2.5 YR7/6

Taf. 209 Maße: DmRd 59,2 cm, erh. H 7,5 cm

Erh.: 1 Rdfrgt.

KatNr. K 692

Taf. 210

Gattung: Küchenware

Form: Topf

InvNr. SE 603/9

AO: GHD

Ton: 5 YR4/3

Farbe außen: 5YR6/3, Farbe innen: 5YR6/3

Maße: DmRd 9,6 cm, erh. H 4,45 cm

Taf. $210 \quad$ Erh.: 1 Rdfrgt.

\section{KatNr. K 693}

Taf. 210

Gattung: Küchenware/Gebrauchskeramik

Form: Topf

InvNr. SE 603/8

AO: GHD

Ton: 2.5 YR5/8

Farbe außen: 10R6/6, Farbe innen: 10R6/6

Maße: DmRd 9,4 cm, erh. H 3,4 cm

Erh.: 1 Rdfrgt.

\section{KatNr. K 694}

Taf. 210

Gattung: Küchenware

Form: Topf

InvNr. SE 603/1

AO: GHD

Ton: $7.5 \mathrm{YR} 6 / 3$

Farbe außen: 5YR4/1, Farbe innen: 5YR4/1

Maße: DmRd 15,6 cm, erh. H 8,4 cm

Erh.: 1 Rdfrgt.

KatNr. K 695

Taf. 210

Gattung: Küchenware

Form: Topf

InvNr. SE 603/2

AO: GHD

Ton: 7.5YR5/2 
Farbe außen: 5YR4/1, Farbe innen: 5YR4/1

Maße: DmRd 13,7 cm, erh. H 3,9 cm

Erh.: 1 Rdfrgt.

\section{KatNr. K 696}

Gattung: Küchenware

Form: Topf

InvNr. SE 603/16

AO: GHD

Ton: 2.5 YR $5 / 6$

Farbe außen: 2.5 YR5/2, Farbe innen: 2.5 YR5/2

Maße: DmRd 16,8 cm, erh. H 2,4 cm

Erh.: 1 Rdfrgt.

\section{KatNr. K 697}

Gattung: Küchenware

Form: Schüssel

InvNr. SE 603/17

AO: GHD

Ton: $2.5 \mathrm{YR} 4 / 6$

Farbe außen: 5YR2.5/1, Farbe innen: 5YR2.5/1

Maße: DmRd $18 \mathrm{~cm}$, erh. H $3 \mathrm{~cm}$

Erh.: 1 Rdfrgt.

\section{KatNr. K 698}

Gattung: Amphore

InvNr. SE 603/10

AO: GHD

Ton: $7.5 \mathrm{YR} 7 / 4$

Farbe außen: 7.5YR8/3, Farbe innen: 7.5YR8/3

Maße: DmRd 7,6 cm, erh. H 7,6 cm

Erh.: 1 Rdfrgt.

\section{KatNr. K 699}

Gattung: Amphore

InvNr. SE 603/14

AO: GHD

Ton: 2.5 YR $5 / 6$

Farbe außen: 10YR7/2, Farbe innen: 10YR7/2

Maße: Dm Fuß 3,4 cm, erh. H 2,1 cm

Erh.: 1 Fußfrgt.

\section{KatNr. K 700}

Gattung: Amphore

InvNr. SE 603/15

AO: GHD

Ton: 2.5 YR $5 / 6$

Farbe außen: 2.5YR6/6, Farbe innen: 2.5YR6/6

Maße: Dm Fuß 1,6 cm, erh. H 4,35 cm

Erh.: 1 Fußfrgt.

\section{KatNr. K 701}

Gattung: Reliefkeramik

Form: Lampe des byzantinischen Typs

InvNr. SE 603/15a

AO: GHD

Überzug: flächig, matt, fast vollständig abgerieben Ton: 5YR6/4

Farbe außen: 10R7/4, Farbe innen: 10R7/4

Maße: erh. L 5,6 cm, erh. B 5,2 cm, erh. H 3,95 cm

Erh.: 1 Bdfrgt. und Griffansatz

\section{KatNr. K 702}

Taf. 211

Gattung: Reliefkeramik

Form: Warzenlampe

InvNr. SE 603/21

Taf. 210 Überzug: flächig, matt, fast vollständig abgerieben

AO: GHD

Ton: 7.5 YR7/2

Farbe außen: 7.5YR6/1, Farbe innen: 7.5YR6/1

Maße: erh. L 4,3 cm, erh. B 2,2 cm, erh. H 1,4 cm

Erh.: 1 Schulterfrgt.

\section{Diverse Fundkomplexe}

Taf. 210

Ausrissgrube - SE 105 (1. Jahrhundert v. Chr. augusteisch)

KatNr. K 703

Taf. 211

Gattung: Eastern Sigillata A

Form: Schale unbekannter Form

InvNr. SE 105/41

AO: GHD

Überzug: flächig, matt glänzend, teilweise abgerieben Ton: 7.5 Y R $8 / 4$

Farbe außen: 10R5/6, Farbe innen: 10R5/6

Taf. 211 Maße: DmRd nicht bestimmbar, erh. H 1,9 cm

Erh.: 1 Rdfrgt.

\section{KatNr. K 704}

Taf. 211

Gattung: Glanztonware

Form: Skyphos

InvNr. SE 105/42

AO: GHD

Überzug: flächig, matt glänzend, teilweise abgerieben

Taf. 211 Ton: 2.5 YR6/6

Farbe außen: 5YR2.5/1, Farbe innen: 5YR2.5/1

Maße: DmRd 11,6 cm, erh. H 2,1 cm

Erh.: 1 Rdfrgt.

KatNr. K 705

Taf. 224

Gattung: Applikenware

Form: Becher

InvNr. SE 105/54

Taf. 211 AO: GHD

Überzug: flächig, matt glänzend, teilweise abgerieben

Ton: 7.5YR6/4

Farbe außen: Gley1 3/0

Maße: $2 \times 1,5 \mathrm{~cm}$

Dekor: Herzblatt (?)

Erh.: 1 Henkelfrgt.

\section{KatNr. K 706}

Taf. 211

Taf. 211

Gattung: Glanztonware

Form: Konische Schale

InvNr. SE 105/38

AO: GHD

Überzug: flächig, matt glänzend, kompakt

Ton: $2.5 \mathrm{YR} 5 / 6$

Farbe außen: 5YR2.5/1+2.5YR4/9, Farbe innen: 5YR2.5/1

$+2.5 \mathrm{YR} 4 / 8$

Maße: DmRd 21,6 cm, erh. H 3,7 cm

Erh.: 1 Rdfrgt. 


\section{KatNr. K 707}

Gattung: Glanztonware

Form: Konische Schale

InvNr. SE 105/37

AO: GHD

Überzug: flächig, matt glänzend, teilweise abgerieben

Ton: 5YR7/4

Farbe außen: 5YR2.5/1, Farbe innen: 2.5YR7/6

Maße: DmRd 21,7 cm, erh. H 2,2 cm

Erh.: 1 Rdfrgt.

\section{KatNr. K 708}

Taf. 211. 224

Gattung: Reliefkeramik

Form: Becher

InvNr. SE 105/39

AO: GHD

Überzug: flächig, matt glänzend, teilweise abgerieben

Ton: 5YR5/1

Farbe außen: 5YR2.5/1, Farbe innen: 5YR2.5/1

Maße: DmRd 11,7 cm, erh. H 3,9 cm

Dekor: Randbordüre: hochgestellte Quadrate

Erh.: 1 Rdfrgt.

\section{KatNr. K 709}

Taf. 224

Gattung: Reliefkeramik

Form: Becher

InvNr. SE 105/53

AO: GHD

Überzug: flächig, kompakt, teilweise abgerieben, matt glänzend

Ton: 2.5YR6/6

Farbe außen: 5YR4/3, Farbe innen: 5YR4/4

Maße: $3,9 \times 3,2 \mathrm{~cm}$

Dekor: Bodenrosette, Hauptzone: Blattschuppen

Erh.: 1 Wdfrgt.

\section{KatNr. K 710}

Taf. 224

Gattung: Reliefkeramik

Form: Becher

InvNr. SE 105/51

AO: GHD

Überzug: flächig, kompakt, matt glänzend

Ton: Gley2 4/1

Farbe außen: Gleyl 3/0, Farbe innen: Gley1 3/0

Maße: $3,8 \times 2,6 \mathrm{~cm}$

Dekor: hochgestellte Quadrate

Erh.: 1 Wdfrgt.

\section{KatNr. K 711}

Taf. 224

Gattung: Reliefkeramik

Form: Becher

InvNr. SE 105/52

AO: GHD

Überzug: flächig, kompakt, matt glänzend

Ton: Gley2 4/1

Farbe außen: Gley1 3/0, Farbe innen: Gley1 3/0

Maße: $3,2 \times 2,5 \mathrm{~cm}$

Motiv: Randbordüre: siebenblättrige Blütenrosette, Hauptzone: Rankenwerk

Erh.: 1 Wdfrgt.
KatNr. K 712

Taf. 211

Gattung: Glanztonware

Form: Becher

InvNr. SE 105/40

AO: GHD

Überzug: flächig, kompakt, matt glänzend

Ton: 5YR6/6

Farbe außen: 5YR2.5/1, Farbe innen: 5YR2.5/1

Maße: DmRd nicht bestimmbar, erh. H 3,4 cm

Erh.: 1 Rdfrgt.

\section{KatNr. K 713}

Taf. 211

Gattung: Glanztonware

Form: Teller mit aufgebogener Randlippe

InvNr. SE 105/11

AO: GHD

Überzug: flächig, matt glänzend, teilweise abgerieben Ton: 5YR7/6

Farbe außen: 7.5YR5/2, Farbe innen: 7.5YR5/2

Maße: DmRd 13,4 cm, erh. H 1,3 cm

Erh.: 1 Rdfrgt.

\section{KatNr. K 714}

Taf. 211

Gattung: Glanztonware

Form: Echinusschale

InvNr. SE 105/36

AO: GHD

Überzug: flächig, matt glänzend, teilweise abgerieben Ton: 5YR6/6

Farbe außen: 5YR4/2, Farbe innen: 2.5YR5/6

Maße: DmRd 18,6 cm, erh. H 2,5 cm

Erh.: 1 Rdfrgt.

\section{KatNr. K 715}

Taf. 212

Gattung: Glanztonware

Form: Echinusschale

InvNr. SE 105/30

AO: GHD

Überzug: flächig, matt glänzend, teilweise abgerieben Ton: 5YR7/4

Farbe außen: 5YR6/6, Farbe innen:10R6/8

Maße: DmRd 11,4 cm, erh. H 3,1 cm

Erh.: 1 Rdfrgt.

\section{KatNr. K 716}

Taf. 212

Gattung: Glanztonware

Form: Echinusschale

InvNr. SE 105/19

AO: GHD

Überzug: flächig, matt glänzend, teilweise abgerieben

Ton: 2.5YR6/6

Farbe außen: 10R5/8, Farbe innen: 10R5/8

Maße: DmRd 12,8 cm, erh. H 2,6 cm

Erh.: 1 Rdfrgt.

KatNr. K 717

Taf. 212

Gattung: Glanztonware

Form: Teller mit breiter Lippe

InvNr. SE 105/9

AO: GHD

Überzug: flächig, matt glänzend, teilweise abgerieben 
Ton: 5YR6/6

Farbe außen: 7.5YR8/6, Farbe innen: 2.5YR5/6

Maße: DmRd $17 \mathrm{~cm}$, erh. H 1,9 cm

Erh.: 1 Rdfrgt.

\section{KatNr. K 718}

Taf. 212

Gattung: Glanztonware

Form: Teller mit breiter Lippe

InvNr. SE 105/32

AO: GHD

Überzug: flächig, matt glänzend, teilweise abgerieben Ton: 5YR7/4

Farbe außen: 5YR7/4+2.5YR5/6, Farbe innen: 10R6/6

Maße: DmRd 16,6 cm, erh. H 1,9 cm

Erh.: 1 Rdfrgt.

\section{KatNr. K 719}

Taf. 212

Gattung: Glanztonware

Form: Teller mit breiter Lippe

InvNr. SE 105/16

AO: GHD

Überzug: flächig, matt glänzend, teilweise abgerieben

Ton: $7.5 \mathrm{YR} 8 / 4$

Farbe außen: 10YR8/3+5YR5/6, Farbe innen: 2.5 YR5/6

Maße: DmRd 18,6 cm, erh. H 1,6 cm

Erh.: 1 Rdfrgt.

\section{KatNr. K 720}

Taf. 212

Gattung: Glanztonware

Form: Teller mit breiter Lippe

InvNr. SE 105/15

AO: GHD

Überzug: flächig, matt glänzend, teilweise abgerieben

Ton: 2.5YR6/6

Farbe außen: 5YR7/6+10R6/6, Farbe innen: 10R6/6

Maße: DmRd 17,4 cm, erh. H 1,4 cm

Erh.: 1 Rdfrgt.

\section{KatNr. K 721}

Taf. 212

Gattung: Glanztonware

Form: Teller mit breiter Lippe

InvNr. SE 105/34

AO: GHD

Überzug: flächig, matt glänzend, teilweise abgerieben

Ton: 5YR7/4

Farbe außen: 5YR7/4+5YR4/2, Farbe innen: 5YR4/2

Maße: DmRd 15,5 cm, erh. H 1,2 cm

Erh.: 1 Rdfrgt.

\section{KatNr. K 722}

Taf. 212

Gattung: Glanztonware

Form: Teller mit breiter Lippe

InvNr. SE 105/10

AO: GHD

Überzug: flächig, matt glänzend, teilweise abgerieben

Ton: 5YR7/6

Farbe außen: 10R6/6, Farbe innen: 10R6/6

Maße: DmRd 16,8 cm, erh. H 1,4 cm

Erh.: 1 Rdfrgt.
KatNr. K 723

Taf. 212

Gattung: Glanztonware

Form: Unguentarium

InvNr. SE 105/13

AO: GHD

Überzug: außen, matt glänzend, teilweise abgerieben

Ton: 7.5 YR $8 / 4$

Farbe außen: 7.5YR4/1+5YR7/4, Farbe innen: 7.5YR4/1

$+5 Y R 7 / 4$

Maße: DmBd 2,4 cm, erh. H 3,3 cm

Erh.: 1 Bdfrgt.

KatNr. K 724

Taf. 212

Gattung: Glanztonware

Form: Unguentarium

InvNr. SE 105/12

AO: GHD

Überzug: außen, matt glänzend, teilweise abgerieben

Ton: 10 YR5/1+7.5YR6/3

Farbe außen: 10YR6/1, Farbe innen: 10YR6/1

Maße: DmBd 2,8 cm, erh. H 3,1 cm

Erh.: 1 Bdfrgt.

KatNr. K 725

Taf. 212

Gattung: Glanztonware

Form: Teller

InvNr. SE 105/4

AO: GHD

Überzug: flächig, matt glänzend, teilweise abgerieben

Ton: 7.5 YR6/3

Farbe außen: 5YR2.5/1, Farbe innen: 5YR7/4

Maße: DmBd 7,9 cm, erh. H 1,6 cm

Erh.: 1 Bdfrgt.

KatNr. K 726

Taf. 212

Gattung: Glanztonware

Form: Teller

InvNr. SE 105/43

AO: GHD

Überzug: flächig, matt glänzend, teilweise abgerieben

Ton: 10R7/6

Farbe außen: 10R6/6, Farbe innen: 10R5/6

Maße: DmBd 8,5 cm, erh. H 2,5 cm

Erh.: 1 Bdfrgt.

KatNr. K 727

Taf. 212

Gattung: Gebrauchskeramik

Form: Schale mit ausgebogener Lippe

InvNr. SE 105/35

AO: GHD

Überzug: flächig, matt, teilweise abgerieben

Ton: 7.5 YR6/4

Farbe außen: 5YR4/2+10YR8/3, Farbe innen: 5YR4/2 +10 YR8/3

Maße: DmRd 8,8 cm, erh. H 1,6 cm

Erh.: 1 Rdfrgt.

KatNr. K 728

Taf. 212

Gattung: Gebrauchskeramik

Form: Echinusschale

InvNr. SE 105/5 
AO: GHD

Überzug: flächig, matt, teilweise abgerieben Ton: 2.5YR6/8

Farbe außen: 7.5YR8/4, Farbe innen: 7.5YR8/4

Maße: DmRd 13,4 cm, erh. H 1,6 cm

Erh.: 1 Rdfrgt.

\section{KatNr. K 729}

Gattung: Gebrauchskeramik

Form: Echinusschale

InvNr. SE 105/31

AO: GHD

Überzug: flächig, matt, teilweise abgerieben

Ton: 5YR7/4

Farbe außen: 5YR7/4, Farbe innen: 5YR7/4

Maße: DmRd 10,5 cm, erh. H 2,3 cm

Erh.: 1 Rdfrgt.

\section{KatNr. K 730}

Gattung: Gebrauchskeramik

Form: Echinusschale

InvNr. SE 105/29

AO: GHD

Überzug: flächig, matt, teilweise abgerieben

Ton: 5YR6/6

Farbe außen: 7.5YR8/4, Farbe innen: 5YR7/4

Maße: DmRd 15,1 cm, erh. H 3,8 cm

Erh.: 1 Rdfrgt.

\section{KatNr. K 731}

Gattung: Gebrauchskeramik

Form: Teller mit breiter Lippe

InvNr. SE 105/33

AO: GHD

Überzug: Randoberseite, matt, teilweise abgerieben

Ton: 5YR5/4

Farbe außen: 5YR6/4, Farbe innen: 5YR6/4

Maße: DmRd 22,3 cm, erh. H 2,2 cm

Erh.: 1 Rdfrgt.

\section{KatNr. K 732}

Taf. 213

Gattung: Gebrauchskeramik

Form: Teller mit breiter Lippe

InvNr. SE 105/3

AO: GHD

Überzug: Randoberseite, matt, teilweise abgerieben

Ton: 7.5YR7/4

Farbe außen: 2.5YR8/2, Farbe innen: 2.5YR8/2, Farbe am Rd: 5YR5/3

Maße: DmRd 19 cm, erh. H 0,9 cm

Erh.: 1 Rdfrgt.

KatNr. K 733

Taf. 213

Gattung: Gebrauchskeramik/Amphore

Form: Krug

InvNr. SE 105/22

AO: GHD

Ton: 10YR7/4

Farbe außen: 10YR8/3, Farbe innen: 10YR8/4

Maße: DmRd 13,8 cm, erh. H 7,8 cm

Erh.: 1 Rdfrgt.

Taf. 213
KatNr. K 734

Taf. 213

Gattung: Gebrauchskeramik

Form: Krug

InvNr. SE 105/26

AO: GHD

Ton: 5YR5/6

Farbe außen: 7.5YR8/4, Farbe innen: 7.5YR8/4

Taf. 212 Maße: DmRd 9,3 cm, erh. H $3 \mathrm{~cm}$

Erh.: 1 Rdfrgt.

\section{KatNr. K 735}

Taf. 213

Gattung: Gebrauchskeramik

Form: Schüssel/Teller

InvNr. SE 105/23

AO: GHD

Ton: 10YR8/2

Farbe außen: $2.5 \mathrm{YR} 8 / 2$, Farbe innen: $2.5 \mathrm{YR} 8 / 2$

Maße: DmRd 29,7 cm, erh. H 4,7 cm

Taf. 212 Erh.: 1 Rdfrgt.

KatNr. K 736

Taf. 213

Gattung: Gebrauchskeramik

Form: Schüssel/Teller

InvNr. SE 105/45

AO: GHD

Ton: 7.5 YR $8 / 4$

Farbe außen: 7.5YR8/3, Farbe innen: 7.5YR8/3

Maße: DmRd 40,4 cm, erh. H 5,9 cm

Erh.: 1 Rdfrgt.

KatNr. K 737

Taf. 213

Gattung: Gebrauchskeramik

Form: Krug

InvNr. SE 105/8

AO: GHD

Überzug: Rand, matt, teilweise abgerieben

Ton: 5YR7/4

Farbe außen: 7.5YR8/3, Farbe innen: 7.5YR8/3, Farbe Dekor am Rd: 10 Y R5/2

Maße: DmRd 7,6 cm, erh. H 1,9 cm

Erh.: 1 Rdfrgt.

KatNr. K 738

Taf. 213

Gattung: Gebrauchskeramik

Form: Unguentarium/Krug

InvNr. SE 105/44

AO: GHD

Ton: 5 YR7/4

Farbe außen: 7.5YR8/4, Farbe innen: 7.5YR8/4

Maße: DmBd $3 \mathrm{~cm}$, erh. H $7 \mathrm{~cm}$

Erh.: 1 Bdfrgt.

KatNr. K 739

Taf. 213

Gattung: Küchenware

Form: Topf

InvNr. SE 105/14

AO: GHD

Ton: 2.5 YR5/6

Farbe außen: 5YR5/2, Farbe innen: 5YR7/4

Maße: DmRd 10,4 cm, erh. H 2,4 cm

Erh.: 1 Rdfrgt. 


\section{KatNr. K 740}

Gattung: Küchenware

Form: Topf

InvNr. SE 105/28

AO: GHD

Ton: $2.5 \mathrm{YR} 6 / 8$

Farbe außen: 2.5YR6/1, Farbe innen: 2.5YR7/8

Maße: DmRd 15,4 cm, erh. H 2,9 cm

Erh.: 1 Rdfrgt.

\section{KatNr. K 741}

Gattung: Küchenware

Form: Topf

InvNr. SE 105/24

AO: GHD

Ton: 5YR6/8+5YR5/2

Farbe außen: 5YR7/8, Farbe innen: 5YR7/8

Maße: DmRd 33,8 cm, erh. H 4,8 cm

Erh.: 1 Rdfrgt.

\section{KatNr. K 742}

Gattung: Küchenware

Form: Topf

InvNr. SE 105/21

AO: GHD

Ton: 5YR5/6

Farbe außen: 5YR5/6, Farbe innen: 5YR5/6

Maße: DmRd 15,4 cm, erh. H 2,3 cm

Erh.: 1 Rdfrgt.

\section{KatNr. K 743}

Gattung: Küchenware

Form: Kasserolle

InvNr. SE 105/20

AO: GHD

Ton: 2.5 YR5/6

Farbe außen: 5YR5/3, Farbe innen: 2.5YR6/6

Maße: DmRd 21,2 cm, erh. H 6,1 cm

Erh.: 1 Rdfrgt.

\section{KatNr. K 744}

Gattung: Küchenware

Form: Schüssel

InvNr. SE 105/17

AO: GHD

Ton: 2.5 YR5/8

Farbe außen: 2.5YR5/8, Farbe innen: 2.5YR6/8

Maße: DmRd 29,4 cm, erh. H 2,2 cm

Erh.: 1 Rdfrgt.

\section{KatNr. K 745}

Gattung: Amphore

InvNr. SE 105/18

AO: GHD

Ton: $2.5 \mathrm{YR} 5 / 2$

Farbe außen: 2.5YR8/4, Farbe innen: 2.5YR8/4

Maße: DmRd $11 \mathrm{~cm}$, erh. H 8,5 cm

Erh.: 1 Rdfrgt.

KatNr. K 746

Gattung: Amphore

InvNr. SE 105/25

\author{
Taf. $213 \quad$ AO: GHD \\ Ton: 2.5 YR6/6 \\ Farbe außen: 10YR8/2, Farbe innen: 10YR8/2 \\ Maße: DmRd 10,2 cm, erh. H 3,9 cm \\ Erh.: 1 Rdfrgt.
}

KatNr. K 747

Taf. 214

Gattung: Amphore

InvNr. SE 105/6

Taf. 214 AO: GHD

Ton: $2.5 \mathrm{YR} 6 / 6$

Farbe außen: 2.5 YR8/2, Farbe innen: 2.5 YR8/2

Maße: DmRd 11,5 cm, erh. H 5,1 cm

Erh.: 1 Rdfrgt.

\section{KatNr. K 748}

Taf. 214

Gattung: Amphore

InvNr. SE 105/7

AO: GHD

Taf. 214 Ton: 10 YR $8 / 3$

Farbe außen: 2.5YR8/2, Farbe innen: 2.5YR8/2

Maße: DmRd 12,7 cm, erh. H 3,6 cm

Erh.: 1 Rdfrgt.

KatNr. K 749

Taf. 214

Gattung: Amphore

InvNr. SE 105/27

AO: GHD

Taf. 214 Ton: 7.5 YR7/4

Farbe außen: 10YR8/3, Farbe innen: 10YR8/3

Maße: DmRd 10,2 cm, erh. H 2,5 cm

Erh.: 1 Rdfrgt.

KatNr. K 750

Taf. 214

Gattung: Amphore

InvNr. SE 105/2

AO: GHD

Ton: 7.5YR6/5

Taf. 214 Farbe außen: 7.5YR8/3, Farbe innen: 7.5YR8/3

Maße: DmRd 10,6 cm, erh. H 2,4 cm

Erh.: 1 Rdfrgt.

\section{KatNr. K 751}

Taf. 214. 225

Gattung: Amphore

InvNr. SE 105/46

AO: GHD

Ton: 5YR7/6

Taf. 214 Farbe: 5 YR $8 / 4$

Maße: Dm 1,5 cm, erh. H $2,9 \mathrm{~cm}$

Erh.: Henkel mit unleserlichem Stempel

KatNr. K 752

Taf. 214

Gattung: Gebrauchskeramik

Form: Webgewicht

InvNr. SE 105/1

AO: GHD

Taf. 214

Ton: 5 YR7/4

Maße: Dm 5,7 cm

Erh.: Ganzform 
Planierung (?) - SE 203 (augusteisch)

KatNr. K 753

Gattung: Italische Terra Sigillata

InvNr. SE 203/25

AO: GHD

Überzug: flächig, glänzend, kompakt

Ton: 2.5 YR6/6

Farbe: 10R5/8

Maße: erh. H 2,4 cm

Dekor: an der Bodeninnenseite rechteckiger, unleserlicher Namensstempel

Erh.: 1 Bdfrgt.

\section{KatNr. K 754}

Gattung: Eastern Sigillata B

Form: Schale Atlante 29

InvNr. SE 203/1

AO: GHD

Überzug: flächig, matt, teilweise abgerieben

Ton: 2.5 YR6/8

Farbe außen: 2.5YR4/8, Farbe innen: 2.5YR4/8

Maße: DmRd 11,8 cm, erh. H 2,9 cm

Dekor: Rouletting an der Gefäßaußenseite

Erh.: 1 Rdfrgt.

\section{KatNr. K 755}

Gattung: Eastern Sigillata B

Form: Schale Atlante 22

InvNr. SE 203/19

AO: GHD

Überzug: flächig, matt, teilweise abgerieben

Ton: 2.5 YR7/6

Farbe außen: 10R5/8, Farbe innen: 10R5/8

Maße: DmRd 9,3 cm, erh. H 1,9 cm

Erh.: 1 Rdfrgt.

\section{KatNr. K 756}

Gattung: Eastern Sigillata B

Form: Schale Atlante 16 (?)

InvNr. SE 203/18

AO: GHD

Überzug: flächig, matt, teilweise abgerieben

Ton: 5YR6/6

Farbe außen: 10R5/8, Farbe innen: 10R5/8

Maße: DmRd 13,2 cm, erh. H 1,95 cm

Erh.: 1 Rdfrgt.

\section{KatNr. K 757}

Gattung: Eastern Sigillata B

Form: Schale/Teller

InvNr. SE 203/8

AO: GHD

Überzug: flächig, matt, teilweise abgerieben

Ton: 5YR6/8

Farbe außen: 10YR5/6, Farbe innen: 10YR5/6

Maße: DmBd 5,2 cm, erh. H 0,9 cm

Erh.: 1 Bdfrgt.

\section{KatNr. K 758}

Gattung: Eastern Sigillata B

Form: Schale/Teller

Taf. 215

Taf. 215

Taf. 215
InvNr. SE 203/24

AO: GHD

Taf. 215 Überzug: flächig, matt, teilweise abgerieben

Ton: 5YR7/6

Farbe außen: 10R5/8, Farbe innen: 10R5/8

Maße: DmBd 5,4 cm, erh. H 1,4 cm

Erh.: 1 Bdfrgt.

KatNr. K 759

Taf. 215

Gattung: Eastern Sigillata C (pergamenisch?)

Form: Schale Meyer-Schlichtmann 1988, TA 17 (ähnlich)

InvNr. SE 203/17

AO: GHD

Überzug: flächig, matt, kompakt

Ton: $10 \mathrm{R} 7 / 6$

Farbe außen: 10R5/6, Farbe innen: 10R5/6

Maße: DmRd 32,3 cm, erh. H 1,6 cm

Erh.: 1 Rdfrgt.

KatNr. K 760

Taf. 215

Gattung: Glanztonware

Form: Kantharos

InvNr. SE 203/15

AO: GHD

Überzug: flächig, matt, teilweise abgerieben

Ton: $7.5 \mathrm{YR} 6 / 2$

Farbe außen: 2.5 YR5/1+2.5YR4/1, Farbe innen: 2.5YR5/1

$+2.5 \mathrm{YR} 4 / 1$

Maße: DmRd 18,9 cm, erh. H 1,8 cm

Erh.: 1 Rdfrgt.

KatNr. K 761

Taf. 215

Gattung: Glanztonware

Form: Teller mit breiter Lippe

InvNr. SE 203/16

AO: GHD

Taf. 215 Überzug: flächig, matt, teilweise abgerieben

Ton: 5YR6/6

Farbe außen: 5YR2.5/1, Farbe innen: 5YR5/3

Maße: DmRd $16 \mathrm{~cm}$, erh. H 1,2 cm

Erh.: 1 Rdfrgt.

KatNr. K 762

Taf. 215

Gattung: Dünnwandige Keramik

Form: Becher

InvNr. SE 203/20

AO: GHD

Ton: $2.5 \mathrm{YR} 5 / 6$

Farbe außen: 5YR5/1, Farbe innen: 2.5YR5/6

Maße: DmRd 4,3 cm, erh. H 1,9 cm

Erh.: 1 Rdfrgt.

KatNr. K 763

Taf. 215

Gattung: Gebrauchskeramik

Form: Teller

InvNr. SE 203/10

AO: GHD

Ton: 5YR6/6

Taf. 215 Farbe außen: 5YR7/4, Farbe innen: 5YR7/4

Maße: DmRd 25,8 cm, erh. H 3,9 cm

Erh.: 1 Fußfrgt. 


\section{KatNr. K 764}

Gattung: Gebrauchskeramik

Form: Schüssel

InvNr. SE 203/26

AO: GHD

Ton: 5YR6/6

Farbe außen: 2.5YR8/2, Farbe innen: 2.5YR8/2

Maße: DmRd $22 \mathrm{~cm}$, erh. H 3,3 cm

Erh.: 1 Rdfrgt.

\section{KatNr. K 765}

Gattung: Küchenware

Form: Topf

InvNr. SE 203/5

AO: GHD

Ton: 5YR3/1

Farbe außen: 5YR3/1, Farbe innen: 5YR3/1

Maße: DmRd $22 \mathrm{~cm}$, erh. H 4,45 cm

Erh.: 1 Rdfrgt.

\section{KatNr. K 766}

Taf. 215

Gattung: Küchenware

Form: Topf

InvNr. SE 203/13

AO: GHD

Ton: 10R5/4

Farbe außen: 5YR5/1+10R5/4, Farbe innen: 5YR5/1+10R5/4

Maße: DmRd 30,3 cm, erh. H 1,85 cm

Erh.: 1 Rdfrgt.

\section{KatNr. K 767}

Taf. 216

Gattung: Küchenware

Form: Topf

InvNr. SE 203/14

AO: GHD

Ton: 2.5 YR5/6

Farbe außen: 10R6/6+2.5YR5/2, Farbe innen: 10R6/6

$+2.5 \mathrm{YR} 5 / 2$

Maße: DmRd 26,3 cm, erh. H 3,7 cm

Erh.: 1 Rdfrgt.

\section{KatNr. K 768}

Taf. 216

Gattung: Küchenware

Form: Topf

InvNr. SE 203/6

AO: GHD

Ton: $2.5 \mathrm{YR} 5 / 8$

Farbe außen: 2.5YR6/6, Farbe innen: 2.5YR6/6

Maße: DmRd 20,2 cm, erh. H 1,4 cm

Erh.: 1 Rdfrgt.

\section{KatNr. K 769}

Gattung: Amphore

InvNr. SE 203/12

AO: GHD

Ton: 5YR8/4

Farbe außen: 10YR8/3, Farbe innen: 10YR8/3

Maße: DmRd 8,3 cm, erh. H 3,6 cm

Erh.: 1 Rdfrgt.

Taf. 216

\section{Taf. $215 \quad$ KatNr. K 770}

Taf. 216

Gattung: Amphore

InvNr. SE 203/3

AO: GHD

Ton: $2.5 \mathrm{YR} 7 / 6$

Farbe außen: 5YR7/6, Farbe innen: 5YR7/6

Maße: DmRd $12 \mathrm{~cm}$, erh. H 3,5 cm

Erh.: 1 Rdfrgt.

\section{KatNr. K 771}

Taf. 216

Taf. 215 Gattung: Amphore

InvNr. SE 203/11

AO: GHD

Ton: $2.5 \mathrm{YR} 7 / 6$

Farbe außen: 5YR8/3, Farbe innen: 5YR8/3

Maße: DmRd 17,1 cm, erh. H 4,4 cm

Erh.: 1 Rdfrgt.

\section{KatNr. K 772}

Taf. 216

Gattung: Amphore

InvNr. SE 203/4

AO: GHD

Ton: 5YR7/6

Farbe außen: 10YR8/2, Farbe innen: 5YR7/6

Maße: DmRd 20,8 cm, erh. H 3,3 cm

Erh.: 1 Rdfrgt.

KatNr. K 773

Taf. 216

Gattung: Amphore

InvNr. SE 203/22

AO: GHD

Ton: $2.5 \mathrm{YR} 4 / 6$

Farbe außen: 2.5YR5/4, Farbe innen: 2.5YR5/4

Maße: DmBd 5,6 cm, erh. H 2,5 cm

Erh.: 1 Bdfrgt.

\section{KatNr. K 774}

Taf. 216

Gattung: Amphore

InvNr. SE 203/7

AO: GHD

Ton: 2.5 YR6/8+2.5YR5/1

Farbe außen: 10YR7/1, Farbe innen: 10YR7/1

Maße: DmBd 5,8 cm, erh. H 1,5 cm

Erh.: 1 Bdfrgt.

KatNr. K 775

Gattung: Amphore

InvNr. SE 203/23

AO: GHD

Ton: 2.5 YR6/8

Farbe außen: 2.5YR6/4, Farbe innen: 2.5YR6/4

Maße: DmBd 5,4 cm, erh. H 1,5 cm

Erh.: 1 Bdfrgt.

KatNr. K 776

Taf. 216

Gattung: Amphore

InvNr. SE 203/9

AO: GHD

Ton: 5YR6/4

Farbe außen: 7.5YR8/3, Farbe innen: 7.5YR8/3

Maße: DmBd 0,9 cm, erh. H 4 cm

Erh.: 1 Fußfrgt. 


\section{KatNr. K 777}

Gattung: Reliefkeramik

Form: Lampe

InvNr. SE 203/21

AO: GHD

Überzug: flächig, matt, teilweise abgerieben

Ton: $2.5 \mathrm{Y} 8 / 4$

Farbe außen: 2.5 YR $4 / 3+2.5 Y 8 / 3$, Farbe innen: $2.5 Y R 4 / 3$

$+2.5 \mathrm{Y} 8 / 3$

Maße: DmRd 6,4 cm, erh. H 1,6 cm

Erh.: 2 Schulter-/Diskusfrgt.

\section{Kanalverfüllung - SE 205 (3. Jahrhundert n. Chr.)}

\section{KatNr. K 778}

Gattung: Gebrauchskeramik

Form: Topf

InvNr. SE 205/1

AO: GHD

Ton: 2.5 YR6/6

Farbe außen: 5YR7/6, Farbe innen: 5YR7/6

Maße: DmRd 10,3 cm, erh. H 2,9 cm

Erh.: 1 Rdfrgt.

\section{KatNr. K 779}

Gattung: Küchenware

Form: Topf

InvNr. SE 205/3

AO: GHD

Ton: 10R5/6+2.5YR4/1

Farbe außen: 2.5YR5/1, Farbe innen: 2.5YR5/3

Maße: DmRd 26,8 cm, erh. H 3,1 cm

Erh.: 2 Rdfrgt.

\section{KatNr. K 780}

Gattung: Amphore

InvNr. SE 205/2

AO: GHD

Ton: 2.5 YR $4 / 4$

Farbe außen: 2.5YR5/2, Farbe innen: 5YR2.5/1

Maße: DmRd 2,2 cm, erh. H 4,6 cm

Erh.: 1 Rdfrgt.

\section{KatNr. K 781}

Gattung: Amphore

InvNr. SE 205/4

AO: GHD

Ton: $2.5 \mathrm{YR} 4 / 8$

Farbe außen: 2.5YR5/6, Farbe innen: 2.5YR5/6

Maße: DmRd 3,4 cm, erh. H 1,95 cm

Erh.: 1 Rdfrgt.

\section{KatNr. K 782}

Gattung: Amphore

InvNr. SE 205/5

AO: GHD

Ton: $7.5 \mathrm{YR} 8 / 2$

Farbe außen: 7.5YR8/2, Farbe innen: 5YR7/3

Maße: DmBd 0,8 cm, erh. H 6,5 cm

Erh.: 1 Bdfrgt.
Taf. 217

Taf. 216

Taf. 216

Taf. 217

Taf. 217

\section{KatNr. K 787}

Gattung: Amphore

InvNr. SE 214/57

AO: GHD

Ton: 2,5 YR5/6+2.5YR4/1

Farbe außen: 10R5/6, Farbe innen: 10R5/6

Maße: $6,6 \times 4,8 \mathrm{~cm}$

Graffito auf der Gefäßwand: $\Phi$ NO

Erh.: 1 Wdfrgt.

\section{KatNr. K 788}

Taf. 217. 225

Gattung: Reliefkeramik

Form: Lampe des byzantinischen Typs

InvNr. SE 214/65

AO: GHD

Überzug: flächig, matt glänzend, kompakt

Ton: 5YR7/6
Taf. 225

Taf. 217

Taf. 217

Taf. 217

Taf. 217 
Farbe außen: 2.5YR6/6, Farbe innen: 2.5YR6/6

Maße: erh. L 4,9 cm, erh. B 2,5 cm, erh. H 1,4 cm

Dekor: auf der Schulter Ranken

Erh.: 1 Schulterfrgt.

KatNr. K 789

Taf. 217. 225

Gattung: Reliefkeramik

Form: Lampe des byzantinischen Typs

InvNr. SE 214/66

AO: GHD

Überzug: flächig, matt glänzend, kompakt

Ton: 2.5 YR6/8

Farbe außen: 2.5YR7/6, Farbe innen: 2.5YR7/6

Maße: erh. L. 3,45 cm, erh. B $3 \mathrm{~cm}$, erh. H 1,6 cm

Dekor: auf der Schulter alternierend konzentrische Kreise und Hasten

Erh.: 1 Schulterfrgt.

\section{KatNr. K 790}

Taf. 217

Gattung: Reliefkeramik

Form: Lampe

InvNr. SE 214/71

AO: GHD

Überzug: flächig, matt glänzend, kompakt

Ton: 5YR6/6

Farbe außen: 10R6/6, Farbe innen: 10R6/6

Maße: erh. L 4,3 cm, erh. B 2,1 cm, erh. H 1,4 cm

Dekor: auf der Schulter Hasten

Erh.: 1 Lampenspiegelfrgt.

\section{KatNr. K 791}

Taf. 217

Gattung: Reliefkeramik

Form: Lampe des byzantinischen Typs

InvNr. SE 214/68

AO: GHD

Überzug: flächig, matt glänzend, kompakt

Ton: 5YR7/6
Farbe außen: 2.5YR5/4, Farbe innen: 2.5YR5/4 Maße: erh. L 2,8 cm, erh. B 2 cm, erh. H 1,4 cm Erh.: 1 Schnauzenfrgt.

\section{KatNr. K 792}

Taf. 217. 225

Gattung: Reliefkeramik

Form: Lampe des byzantinischen Typs

InvNr. SE 214/70

AO: GHD

Überzug: flächig, matt glänzend, kompakt

Ton: 2.5 YR7/6

Farbe außen: 5YR6/6, Farbe innen: 5YR6/6

Maße: erh. L 3,3 cm, erh. B 5,05 cm, erh. H 1,5 cm

Erh.: 2 Bdfrgt.

\section{KatNr. K 793}

Taf. 217

Gattung: Reliefkeramik

Form: Lampe des byzantinischen Typs

InvNr. SE 214/69

AO: GHD

Überzug: flächig, matt glänzend, kompakt

Ton: 5YR6/6

Farbe außen: 2.5 YR5/3+2.5YR6/4, Farbe innen: 7.5YR7/4

+2.5 YR $5 / 3$

Maße: erh. L $3 \mathrm{~cm}$, erh. H 1,6 cm

Erh.: 1 Bdfrgt.

\section{KatNr. K 794}

Taf. 217

Gattung: Reliefkeramik

Form: Lampe des byzantinischen Typs

InvNr. SE 214/67

AO: GHD

Überzug: flächig, matt glänzend, kompakt

Ton: 2.5 YR6/8

Farbe außen: 10R5/8, Farbe innen: 10R5/8

Maße: erh. L 4,6 cm, erh. B 5,5 cm, erh. H $2 \mathrm{~cm}$

Erh.: 1 Bdfrgt.

\section{VI.2 Münzen (Matthias Pfisterer)}

\section{ABKÜRZUNGEN}

Im Katalog werden neben den allgemeinen Abkürzungen folgende Kürzel verwendet:

$\mathrm{AE}$

Av.

Cen

Con

Fol

front.

h

Kyz

1.

Leg.

PDiad2PCV

\section{r.}

Rv.

sitz.

st.

v.
Buntmetallmünze

Avers

Centenionalis

Constantinopolis

Follis

frontal

Uhrzeit zur Angabe der Stempelstellung

Kyzikos

nach links

Legende

Büste rechts mit Perldiadem, beide Bänder freihängend; Paludamentum über Kürass von vorn gesehen

nach rechts

Revers

sitzend

stehend

vorne 


\section{VI.2.1 Katalog}

\section{KatNr. M 1}

InvNr. EPR 2007/13

AO: EM

Kolophon, autonom

AE; hellenistisch; ?h; 2,53 g

Av.: Unkenntlich

Rv.: Kesseldreifuß

SNG Tüb. 2902 (?)

\section{KatNr. M 2}

InvNr. EPR 2007/15

AO: EM

Ephesos, autonom

AE; hellenistisch; $12^{\mathrm{h}} ; 1,98 \mathrm{~g}$

Av.: Biene (in Kranz?); Leg. unkenntlich

Rv.: R. äsender Hirsch, darüber Köcher; Leg. unkenntlich

SNG Tüb. 2774 ff.

\section{KatNr. M 3}

InvNr. EPR 2007/16

AO: EM

Prägeherrschaft unbestimmbar

AE; Dat.?; ?h; 2,62 g

Av.: Unbestimmbarer Kopf $r$.

Rv.: Unkenntlich

\section{KatNr. M 4}

InvNr. EPR 2007/21

AO: EM

Teos (?), autonom

AE; hellenistisch; ?h; 1,20 g

Av.: Unkenntlich

Rv.: Sphinx (?) r. sitz.

\section{KatNr. M 5}

InvNr. EPR 2007/22

AO: EM

Prägeherrschaft unbestimmbar

AE; Dat.?; ?h; 5,59 g

Av.: Unkenntlich

Rv.: Unkenntlich

\section{KatNr. M 6}

InvNr. EPR 2007/23

AO: EM

Prägeherrschaft unbestimmbar AE; Dat.?; ?h; 2,04 g

Av.: Unkenntlich

Rv.: Unkenntlich

\section{KatNr. M 7}

InvNr. EPR 2008/2

AO: EM

Constantinssöhne f. POP ROMANVS

Fol; 337-340 n. Chr.; Con; 12 ; 1,32 g

Av.: Leg. unkenntlich; Büste 1.

Rv.: - -//CON??; Stern in Kranz

RIC 22

\section{KatNr. M 8}

InvNr. EPR 2008/3

AO: EM

Arcadius od. f. Honorius

Cen; 395-401 n. Chr.; Kyz; 12h ; 1,57 g

Av.: ...]SPFAVG; PDiad2PCv

Rv.: ...]-EXERCITI; - -//?MK?; Kaiser front. st., v. Victoria bekränzt

RIC 66-69

\section{KatNr. M 9}

InvNr. EPR 2008/1

AO: EM

Leo IV.

Fol; 778-780 n. Chr.; Con; 6 ${ }^{\text {h }}$ 4,87 g

Av.: Leo IV. und Constantinus VI. nebeneinander frontal thronend, oben Kreuz

Rv.: Auf horizontaler Linie Frontalbüsten von Leo IV. und Constantinus VI. nebeneinander, oben Kreuz; unter der Linie M, 1. u. r. X N, unten A. Unklar, ob Punkte.

Grierson 6 (Klasse 2) 



\section{AUSSTATTUNG}

\section{VII.1 Böden (Martin Steskal)}

\section{VII.1.1 MARMORBÖDEN}

An Marmorböden hat sich lediglich im >Hestiasaak ein entsprechendes Paviment zu knapp 50\% erhalten (Taf. 65, 2). Der zur ersten, augusteischen Bauphase gehörige Boden besteht aus langrechteckigen, ca. $3 \mathrm{~cm}$ starken Platten aus lokalem, fast weißem Marmor. Die Eckverbindungen der Platten sind teilweise in Form von Gehrungen ausgebildet. Der Boden weist südlich des zentralen Fundaments eine U-förmige Gliederung durch schmälere Platten auf, die den Eingangsbereich nördlich von Tür 3 bis zum zentralen Fundament betont (Taf. 30). Im Raum zwischen den Unterkonstruktionen der östlichen Sitzbänke ist noch eine Versatzmarke zu erkennen, die von der Aufstellung der ursprünglich wohl hölzernen Sitzbänke herrühren könnte. Auch die beschriebene Gliederung des Marmorplattenpaviments könnte noch auf die Aufstellung der hölzernen Sitzbänke zurückzuführen sein; aufgrund der geringen Erhaltung des Befundes ist eine vollständige Rekonstruktion der originalen Sitzbänke jedoch nicht möglich.

Das Paviment wurde über einer Mörtelbettung aus opus signinum und einem darunter befindlichen Kalkmörtelestrich verlegt. Der sehr hoch anstehende Fels wurde dazu zunächst mit einer Planierschicht ausgeglichen ${ }^{54}$. Abgesehen von den langrechteckigen Platten wurden im südöstlichen Teil des Bodens im Zuge einer antiken Reparatur zu Platten zersägte Blöcke, die durch jeweils zwei Faszien gegliedert waren, als Belag versetzt. Im südlichen Bereich des `Hestiasaales` vor Tür 3 erweist sich das Paviment heute als stark modern restauriert.

Im Umgang des Peristyls des Vorhofes ist ebenfalls ein Marmorplattenpaviment anzunehmen, von dem sich aber nur die Bettung in Form eines Kalkmörtelestrichs erhalten hat ${ }^{555}$. Von einer Pflasterung des Vorhofes haben sich keine Spuren gefunden. Ungeklärt bleibt auch - mangels erhaltener Reste - die bauzeitliche Gestalt der Böden in den Räumen 2, 3, 4, 5 und 6 sowie in der Vorhalle. Während der ursprüngliche Boden der Vorhalle archäologisch nicht nachweisbar war, wurden die Böden der Räume 2, 3, 4, 5 und 6 sowie der Umgänge des Vorhofes bei der Devastierung des Gebäudes offenbar völlig beraubt.

\section{VII.1.2 MosAIKBÖDEN}

Der bauzeitliche Boden der Vorhalle ist nicht mehr erhalten und konnte auch während der Tiefgrabungen der 1960er Jahre nicht nachgewiesen werden ${ }^{556}$. Die Vorhalle war in der zweiten Bauphase im zweiten Viertel des 3. Jahrhunderts n. Chr. jedoch vollflächig mit polychromem Mosaik ausgelegt: Sowohl im westlichen als auch im östlichen Teil der Halle haben sich größere, mit mehreren Lücken durchsetzte Reste dieses Mosaiks erhalten, die heute in Beton gegossen sind (Taf. 45, 1. 2). Das polychrome Tessellat aus schwarzen, weißen, gelben und violetten Tesserae (Kantenlänge 1-1,5 cm) war ursprünglich in einen grauen

${ }_{554}$ Cf. die Schnitte 3/07 und 4/07.

555 Cf. die Sondagen II, III und XXI der 1960er Jahre sowie Schnitt 2/07.

556 Cf. M. Steskal, Kapitel II.3 (Sondagen VIII, XVIII, XXXI und XXXVI der 1960er Jahre). - In einer Erdaufschüttung in Sondage VIII (1961) unmittelbar vor Tür 2 fand W. Alzinger über einem von ihm postulierten ursprünglichen Marmorboden eine Münze eines der Söhne des Septimius Severus, die er als terminus post quem für den - an dieser Stelle fehlenden - Mosaikboden heranzog; s. dazu Eichler 1962, 39 f. Von diesem hypothetischen Marmorboden fand Alzinger allerdings auch in den weiteren Schnitten in der Vorhalle keine Spuren, da auch das bauzeitliche - und später vollständig entfernte - Paviment auf demselben Niveau wie der Mosaikboden gelegen sein muss; cf. die Sondagen XVIII (1961), XXXI (1962) und XXXVI (1963). 
Kalkmörtelestrich gebettet ${ }^{57}$ (Taf. 64; 65, 1). Die 1-1,85 m breite, weiße Außenzone ist durch jeweils zwei Reihen weißer Tesserae von den Hallenwänden abgesetzt und mit je zwei Reihen schwarzer Quadrate (L 5-6 cm) verziert. Das Musterfeld ist von einer Bordüre aus zwei schwarzen und einer dazwischenliegenden weißen Leiste gerahmt (B der schwarzen Leisten 7,10 bzw. 5,50 cm). Auf dem weißen Grund des Musterfeldes befinden sich fünf Reihen gegengleich ausgerichteter Peltenwirbel von 52-54 cm Durchmesser, die einander nicht berühren. Im Zentrum der Wirbel sind Salomonsknoten eingesetzt. Das ursprünglich $17,60 \times 3,25 \mathrm{~m}$ große Musterfeld reicht im Süden knapp an die Säulenfront der Halle heran ${ }^{558}$. Inwieweit die Peltenwirbel das gesamte Musterfeld einnahmen, kann aufgrund des fragmentarischen Zustandes nicht mehr geklärt werden 55 .

\section{VII.2 Wanddekoration (Martin Steskal)}

\section{VII.2.1 WandDEKoration aus Marmor}

An dekorativer Wandausstattung hat sich primär der graugeäderte Marmorsockel des $\gg$ Hestiasaales und der Vorhalle erhalten ${ }^{560}$. Seine Oberfläche wurde mit dem Zahneisen bearbeitet und anschließend geglättet. Während der Sockel in der Vorhalle starke antike Reparaturspuren aufweist, sind die Werksteine im >Hestiasaal vor allem an der West-, Nord- und Ostmauer sehr gut erhalten. Der Sockel des >Hestiasaales ist durch eine untere, $0,61 \mathrm{~m}$ hohe Quaderschicht, eine mittlere Lage 0,725 $\mathrm{m}$ hoher Orthostaten sowie eine $0,285 \mathrm{~m}$ hohe, bekrönende Quaderschicht aufgebaut (Taf. 66, 1). Die Orthostaten springen gegenüber der oberen Quaderschicht um etwa $18 \mathrm{~mm}$ zurück. Unmittelbar über der oberen Quaderschicht des Sockels des $>$ Hestiasaales` findet sich ein 5-6 cm tiefer Rücksprung, auf dem ein $11 \mathrm{~cm}$ hohes Gesims versetzt war. Vom Gesims in Form einer Profilleiste aus glatt poliertem Marmor sind heute noch Reste in der Nordostecke des $>$ Hestiasaales $<$ in situ erhalten ${ }^{561}$ (Taf. 72, 1).

Über dem Sockel der Nordwand des >Hestiasaales` befindet sich als dekorative Wandgliederung ein bauzeitlicher, halbkreisförmiger Keilsteinbogen aus grauweißem, mittelkörnigem Marmor mit einer lichten Weite von 8,54 m, dessen Scheitelstück heute in einer Länge von 4,90 m fehlt (Taf. 73. 74). Die Stärke des Bogens beträgt 0,44-0,50 m; seine Tiefe misst 1,14-1,20 m. Die einzelnen Keilsteine sind an den Sichtflächen teilweise mit kleinen Dübellöchern und vereinzelt mit Versatzmarken versehen (Westseite: 8. Keilstein: $\Delta$; Ostseite: 3 . Keilstein: O; 4. Keilstein: $\Lambda$; 5. Keilstein: $\Delta$; jeweils vom Sockel gezählt). Das Profil der Sichtflächen des Bogens ist sekundär abgearbeitet. In der Mitte der Innenseite befindet sich eine 0,15 m breite Soffitte.

Von der weiteren über dem Sockel des ১Hestiasaales« befindlichen marmornen Wanddekoration hat sich lediglich an der Ostwand ein kleines Bruchstück einer Marmorverkleidung aus rötlich geädertem, feinkörnigem Marmor mit einer Stärke von $0,9 \mathrm{~cm}$ erhalten (Taf. 72, 1). Eine Rekonstruktion der Wanddekorationssysteme ist aufgrund der spärlichen Reste sowie der geringen Befestigungsspuren in Form von Klammern, Klammerlöchern und Mörtelhinterfüllungen nicht zu realisieren. Doch zeigt sich anhand der Klammerbefunde, dass nicht nur in der ersten Bauphase das Mauerwerk aus opus vittatum, sondern auch nach der Reparatur in Bauphase 1b (oder 2) das Mauerwerk aus opus testaceum Marmorwandverkleidung aufwiesen. Selbst die stark modifizierte Südwand des Raumes besitzt in all ihren Phasen Klammerlöcher zur Befestigung einer Marmorvertäfelung über dem Sockel.

Der Marmorsockel der Vorhalle besteht aus einer 0,29 $\mathrm{m}$ hohen Fundamentschicht, einer 0,75 $\mathrm{m}$ hohen Orthostatenlage und einer 0,44 m hohen Quaderschicht mit Gesims (Taf. 53; 54, 1). Das $14 \mathrm{~cm}$ hohe Gesims

557 Cf. M. Steskal, Kapitel III.3. Freundliche Hinweise: W. Jobst und V. Scheibelreiter.

558 Cf. auch Miltner 1959, 290-314; Eichler 1962, 38-41; Alzinger 1970, 1646-1648; Alzinger 1974, 51-55; Alzinger 1972-1975, 235-249; Jobst 1977, 49 Abb. 86; Knibbe 1981, 75-78; W. Jobst, Antike Tessellatpavimente in Ephesos, in: Friesinger - Krinzinger 1999, $573 \mathrm{f}$.

559 Ähnliche Peltenwirbel wie im Prytaneion finden sich in Ephesos im sog. Freudenhaus auf dem Gelagemosaik oder im Gewölberaum C des Hanghauses 2; cf. W. Jobst, Das »öffentliche Freudenhaus« in Ephesos, ÖJh 51, 1976/77, 76-82; Jobst 1977, $48-50$.

560 Cf. M. Steskal, Kapitel III.3 und 4.

${ }_{561}$ Darüber hinaus fanden sich Reste dieses Gesimses im Grabungsschutt der 1950er Jahre: KatNr. A 26. 
ist allerdings nicht aufgesetzt; die bekrönende Quaderschicht und das Gesims sind aus einem Block gearbeitet. Die Orthostaten springen wie im `Hestiasaak gegenüber der oberen Quaderschicht und der Fundamentschicht um etwa $18 \mathrm{~mm}$ zurück. Die Orthostaten und Quader sind mit zahlreichen Kureteninschriften versehen (IvE 1013. 1018. 1022. 1023. 1024. 1051. 1062 $2^{562}$ ).

Zur weiteren Wanddekoration über dem Sockel der Vorhalle kann aufgrund der geringen erhaltenen Höhe der Wände nichts gesagt werden. Auch in den Räumen 2, 3 und 4 sowie an den Rückwänden der Umgänge des Vorhofes ist die ursprüngliche Wandverkleidung aufgrund der Veränderungen in byzantinischer Zeit oder der geringen Erhaltung nicht mehr zu rekonstruieren. Die in Raum 6 vor dem Fundament des Quadermauerwerks hochkant aufgestellten Marmorplatten mit einem Falz an der der Wand zugewandten Seite könnten als Sockel für eine marmorne Wandverkleidung gedient haben ${ }^{563}$.

\section{VII.2.2 WANDMALEREI}

In Raum 6 hat sich an der Nordwand östlich der Tür zu Raum 5 unter einer Putzschicht eine ältere Schicht Wandverputz mit teilweise noch sichtbarer roter Wandmalerei erhalten (Taf. 93, 2; 97, 1). Da weder in Raum 6 noch in Raum 5 eine marmorne Wandverkleidung anzutreffen war und auch Befestigungsspuren in Form von Klammern und Klammerlöchern gänzlich fehlen, ist in diesen beiden Räumen Wandverputz mit Wandmalerei anzunehmen. Diese Annahme wird durch den Fund zahlreicher Reste teils figürlich verzierter Wandmalerei im Zerstörungsschutt des Prytaneions im Zuge der Grabung des Jahres 1956 vor allem in Raum 5 bestärkt ${ }^{564}$. Die Funde dieser Wandmalerei sind heute verloren oder nicht mehr zuweisbar.

\section{VII.3 Türen und Fenster (Martin Steskal)}

\section{VII.3.1 TÜREN}

Die erhaltenen architektonischen Reste von Türen und ihren dekorierten Elementen sind überaus spärlich. Keine der im Prytaneion verbauten Türen ist bis auf das Niveau des Türsturzes erhalten, ihre Höhen sind daher nicht exakt zu bestimmen. Abgesehen von wenigen noch in situ befindlichen, originalen oder sekundären Türschwellen ${ }^{565}$ sind weder Türstürze, Türverdachungen, Türkonsolen oder Teile der Türflügel in ihrer originalen Lage nachweisbar. Von den Türgewänden haben sich nur drei, ursprünglich an die Schwelle angearbeitete, undekorierte, ca. $29 \mathrm{~cm}$ hohe Gewändesteine erhalten: Zwei davon fanden sich in der Tür zwischen den Räumen 5 und 6 (Taf. 97, 1; 98), ein fragmentarisch erhaltener, baugleicher Gewändestein an der Westseite der Tür zwischen Raum 6 und der Vorhalle.

Die als Spolien verbauten oder im Zerstörungsschutt des Gebäudes gefundenen Elemente von Türen sind ebenfalls gering. Auch in diesem Kontext fehlen dekorierte Türgewände, Türverdachungen, Türkonsolen oder Teile der Türflügel. Spezifische Charakteristika von Türen, wie etwa der Nachweis einer Neigung der Türgewände nach innen oder eine Unterscheidung zwischen dorischen und ionischen Türen, sind daher nicht zu bestimmen ${ }^{566}$. Im Zerstörungsschutt des Prytaneions fand sich jedoch ein undekoriertes Türgewände aus weißem Marmor, das der östlichen Laibung von Tür 2 zugewiesen werden kann (Taf. 69, 1).

562 Entspricht Knibbe 1981, B 13. B 18. B 22. B 23. B 24. B 51. F 1.

563 Cf. M. Steskal, Kapitel III.5.

564 Cf. F. Miltner, Tagebucheintrag vom 17. 9. 1956: »In dem Raum, in welchem die vielen Näpfe gefunden wurden (Raum 5, Anm. d. Verf.), zahlreiche Reste von Wandmalerei, darunter auch figürliche Darstellungen.«

565 So etwa eine originale Schwelle zwischen Raum 5 und Raum 6 (mit angearbeiteten Gewändesteinen), eine sekundäre Schwelle in der Westwand von Raum 5 zur >Akademiegasse`, eine sekundäre Schwelle in der Westwand von Raum 6 zur >Akademiegasseく, eine sekundäre Schwelle im Bereich von Tür 2 zwischen dem `Hestiasaal und der Vorhalle, eine sekundäre Schwelle in der östlichen Antenmauer der Vorhalle sowie eine etwa zur Hälfte erhaltene, sekundäre Schwelle in der Ostmauer des Vorhofes. Zwischen Raum 6 und der Vorhalle ist der westliche originale Gewändestein teilweise noch erhalten; eine sekundäre, $0,31 \mathrm{~cm}$ höher positionierte Türschwelle in Tür 1 ist fragmentarisch erhalten. In Tür 4 zwischen dem >Hestiasaal und der Vorhalle fand sich 1,42 m über der ursprünglichen Schwelle eine sekundäre, aus zwei Marmorspolien gefertigte Türschwelle.

$566 \mathrm{Zu}$ den spezifischen Charakteristika antiker Türen s. vor allem A. Büsing-Kolbe, Frühe griechische Türen, JdI 93, 1978, 66-174; s. auch U. Wulf - C. Meyer-Schlichtmann, Die Stadtgrabung. Die hellenistischen und römischen Wohnhäuser von 
Unter den Spolien der östlichen Türlaibung von Tür 2 zwischen dem >Hestiasaalı und der Vorhalle befindet sich auch heute noch ein profilierter Türsturz aus grauweißem Marmor (KatNr. A 30), der eine Inschrift trägt (IvE 643; Taf. 69, 1-4). Der Dekor besteht aus einer Profilleiste sowie zwei Faszien. Aus zwei Fragmenten besteht ein weiterer Türsturz (KatNr. A 31; Taf. 69, 1. 5. 6), von dem ein Teil als Spolie in der sekundären Vermauerung von Tür 2 angetroffen wurde ${ }^{567}$. Er trägt ebenso eine Inschrift (IvE $1065^{568}$ ) und besteht aus einer Profilleiste sowie zwei Faszien. Während Türsturz KatNr. A 30 aufgrund seiner unbekannten Länge keiner Türöffnung im Prytaneion zugewiesen werden kann, war der Türsturz KatNr. A 31 wohl in einer der Nebentüren zwischen dem >Hestiasaak und der Vorhalle (Tür 2 oder 4) oder in der Tür zwischen Raum 4 und 5 verbaut. Die Verbindung zum Gebäude ist auch deswegen gesichert, da in der Inschrift auf dem Türsturz Hestia Boulaia und das Prytaneion genannt werden.

Von einer Türkonsole, die unter Umständen im Prytaneion verbaut gewesen sein könnte, zeugt vielleicht ein Werkriss an der Südseite des südwestlichen Säulenstuhls (KatNr. A 12), der zwei S-förmig angeordnete Voluten wiedergibt ${ }^{569}$ (Taf. 88. 89). Bei dem Werkriss handelt es sich um die Konstruktionszeichnung einer Doppelvolute eines Volutenakroters, des seitlichen Schmucks eines Geisons mit Volutenkonsole oder einer Türkonsole, genauer gesagt, um die Volutenglieder eines ionischen Türrahmens, die an beiden Seiten den Türsturz und das Hyperthyron begrenzten. Lediglich die Türkonsole könnte tatsächlich im Prytaneion baulich umgesetzt gewesen sein, da Volutenakrotere und Konsolengeisa im Prytaneion zu keiner Zeit verbaut waren. Ein materieller Beleg dafür ist aber aufgrund des Erhaltungszustandes des Monuments nicht gegeben.

\section{VII.3.2 FENSTER}

Aufgrund der niedrigen Erhaltungshöhe des Gebäudes haben sich keine Fenster erhalten ${ }^{570}$. Abgesehen von den fehlenden Fensteröffnungen konnten weder bei der Freilegung des Gebäudes in den 1950er und 1960er Jahren noch im Zuge der Neuuntersuchung seit 2007 Funde von Fensterglas oder Fenstersprossen getätigt werden $^{571}$. Um eine ausreichende Lichtzufuhr zu gewährleisten, sind Fenster jedoch für die Ostwand des >Hestiasaales`, die Ostwand von Raum $2^{572}$ sowie für die Westwände der Räume 5 und 6 zu postulieren. Die Umgänge des Vorhofes wurden über den offenen Hof, die Vorhalle wurde über die Interkolumnien der Säulenstellung der dorischen Ordnung ausreichend mit Licht versorgt.

\section{VII.4 Bauornamentik (Georg A. Plattner)}

Der Beitrag zur Bauornamentik soll nicht Baubeschreibung und Katalog wiederholen, vielmehr werden die verbauten sowie im Gebäude gefundenen Bauteile in ihrer Gesamtheit behandelt und im Vergleich mit der Architekturdekoration des kaiserzeitlichen Ephesos in Hinblick auf Syntax und Ornament eingeordnet. In

Pergamon, AvP 15, 3 (Berlin 1999) 12-14; M. N. Filgis - W. Radt, Die Stadtgrabung. Das Heroon, AvP 15, 1 (Berlin 1986) 42-46; W. Müller-Wiener, Griechisches Bauwesen in der Antike (München 1988) 104-106. 155 f. 221; E. L. Schwandner, Türen, in: W. Hoepfner (Hrsg.), Geschichte des Wohnens. 5000 v. Chr. - 500 n. Chr. Vorgeschichte - Frühgeschichte - Antike (Stuttgart 1999) $531 \mathrm{f}$.

567 Das vermauerte Element des Türsturzes wurde geborgen, und die beiden Fragmente wurden wieder zusammengesetzt.

568 Entspricht Knibbe 1981, F 6. Das von D. Knibbe als »heute nicht mehr auffindbar« bezeichnete linke Drittel des Türsturzes konnte 2007 unter den im >Hestiasaal aufgelegten Architekturgliedern aufgefunden werden.

569 s. dazu ausführlich Steskal 2007, 371-392; M. Steskal, Kapitel III.4.

570 Zu antiken Fenstern: Hoepfner - Schwandner 1994, 315 f.; U. Wulf - C. Meyer-Schlichtmann, Die Stadtgrabung. Die hellenistischen und römischen Wohnhäuser von Pergamon, AvP 15, 3 (Berlin 1999) 14-17; M. N. Filgis - W. Radt, Die Stadtgrabung. Das Heroon, AvP 15, 1 (Berlin 1986) $46 \mathrm{f}$.

571 Inwieweit im Rahmen der Altgrabungen solche Funde gemacht, aber nicht im Tagebuch vermerkt wurden, ist heute nicht mehr $\mathrm{zu}$ verifizieren.

$572 \mathrm{Ob}$ in den Ostwänden des >Hestiasaales` und von Raum 2 tatsächlich Fenster vorhanden waren, ist in erster Linie von den Raumhöhen des östlich anschließenden Temenos abhängig. Diese sind uns allerdings nicht bekannt. Um eine ausreichende Lichtzufuhr dieser Räume zu gewährleisten, ist aber davon auszugehen, dass die Möglichkeit der Anlage von Fenstern bei der Errichtung des Prytaneions und des Temenos berücksichtigt wurde. Cf. auch M. Steskal, Kapitel III.12. 
sich selbst wenig aussagekräftige Bauteile wie etwa Fragmente von Säulentrommeln werden hier dementsprechend nicht weiter behandelt.

In der getrennten Behandlung der Ornamentik ergibt sich die Möglichkeit, abgesehen von den architektonischen Details (Maße, modulus, Proportionen), den Dekor selbst zu bewerten und somit bei der Bewertung von `Stik und `Handschrift` der Gefahr einer Vermischung von künstlerischem Willen und technischen Notwendigkeiten zu entgehen.

\section{VII.4.1 Im GebÄUde Verbaute ARChiteKtURGLIEDER}

Aus der primären Phase des Prytaneions kann im Hinblick auf die Bauornamentik nur die dorische Vorhalle einigermaßen geschlossen bearbeitet werden. In der Ausstattung des $>$ Hestiasaales` sind Elemente der Bauphasen gemischt, von dem Vorhof vor dem Prytaneion sind keine Bauteile erhalten, die diesem mit Sicherheit zuzuordnen wären.

\section{VII.4.1.1 Die dorische Vorhalle (KatNr. A 1-11)}

Die dorische Vorhalle des Prytaneions folgt in Aufbau und Proportion der Tradition kleinasiatischer dorischer Architekturen ${ }^{573}$ (Taf. 56-59; 60, 1. 2; 61; 62). Auf dem Stylobat stehen die dorischen Säulen, die aus je fünf Säulentrommeln aufgeschichtet sind. Diese sind sowohl innerhalb einer Säule als auch in entsprechenden Zonen benachbarter Säulen unterschiedlich hoch, die untersten messen über 1,5 m, die kleinsten in den oberen Bereichen nur $85 \mathrm{~cm}$. Die Säulentrommeln, die durchweg in sekundärer Verwendung am unteren Embolos gefunden wurden, sind unkanneliert. Die zum Prytaneion hin orientierten Seiten der Trommeln, sofern diese vor allem aufgrund der Positionierung der Inschriften zu definieren sind, waren weniger sorgfältig ausgearbeitet und geglättet als die nach vorn in den Vorhof gerichteten Flächen.

In die jeweils dritten Säulentrommeln von unten sind sekundär je mindestens zwei Profile eingeschnitten, die den Anschluss eines Gebälkblockes an die Säulen belegen (Taf. 62, 2-4). Das Profil besteht (von unten nach oben) aus einem Rundstab/ionischem Kyma, kyma reversa und einer Kehle mit Platte. Die Gesamthöhe des Profils beträgt 27-28 cm. Die Tiefe der Einarbeitung in die Säulentrommeln ist unregelmäßig, im Wesentlichen aber so, dass die auskragende obere Spitze des Profils nur seicht, die >Basis`vor allem am unteren Rand deutlich tiefer eingemeißelt ist, entsprechend der tangentialen Berührung eines rechtwinkeligen Blockes an der runden Säule.

Es muss sich bei diesen Einarbeitungen um einen Anschluss von Deckprofilen handeln, die den oberen Abschluss einer Brüstung gebildet haben könnten. Allerdings sind an den Säulen unter den Profilen keine Spuren einer Abarbeitung für den Anschluss von Schrankenplatten auszumachen, sodass zu vermuten ist, dass es sich um Querbalken in der Art eines Türsturzes gehandelt hat, wobei auch das Feld darüber als Fenster offen geblieben wäre. Vergleichbar sind etwa die Türen im Untergeschoss der Celsusbibliothek, auch hier schließt ein Türsturz die Türlaibung ab, darüber ist ein Fenster mit einer eigenen Rahmung mit Marmorgitter geschlossen ${ }^{574}$.

Die Einziehung einer Brüstung oder auch von Tordurchgängen wäre in der Vorhalle des Prytaneions wenig sinnvoll gewesen, auch sind die Einarbeitungen an den Säulentrommeln, wenn sie entsprechend den Inschriften ausgerichtet sind, nicht so positioniert, dass sie einander zugewandt gewesen wären. Die Profile müssen also während der sekundären Verwendung der Trommeln in der `Kuretenhalle` angelegt worden sein. Bei der Wiederverwendung der Säulen wurden nur die jeweils zweiten und dritten Säulentrommeln in den Hallen am unteren Embolos verwendet. Dabei ergibt sich eine Höhe des unteren Profilrandes von etwa 2,50 m über dem Boden, was für eine Verwendung als Türsturz durchaus sinnvoll wäre. Zu diesen Negativformen passende Profilblöcke konnten in Ephesos bisher nicht gefunden werden.

\footnotetext{
573 Cf. M. Steskal, Kapitel III.11.

574 W. Wilberg, Das Gebäude, in: W. Wilberg - M. Theuer - F. Eichler - J. Keil, Die Bibliothek, FiE 5, 1 (Wien 1944$) 20$ f. Abb. 45-47 Taf. 1. 2.
} 
Von den dorischen Kapitellen der Vorhalle sind nur zwei Exemplare erhalten, auch diese waren in sekundären Zusammenhängen am unteren Embolos verbaut ${ }^{575}$. Allein an einem Exemplar (KatNr. A 5; Taf. 45, 3; 56; 61, 2) ist auch der Säulenhals (Hypotrachelion) erhalten. Hier sind 20 Kanneluren ausgeführt. Die Grate sind entsprechend der dorischen Ordnung scharfkantig, die Kanneluren flach, aber sorgfältig und gleichmäßig gerundet ausgeführt. Ausgehend vom Hypotrachelion hätten dann die Kanneluren an den bereits versetzten Säulentrommeln heruntergezogen werden sollen. Die Kanneluren am Kapitell sind bereits am Boden vor dem Versetzen ausgeführt worden. Auf dem Unterlager des auf dem Kopf liegenden Rohlings könnten die strahlenförmigen Risslinien für die Position der Kanneluren einfach angeritzt und die Aufteilung konstruiert worden sein. Der Durchmesser der erhaltenen obersten Säulentrommel entspricht jenem, gemessen an den Graten der Kanneluren des Hypotrachelions, die Trommel hätte dementsprechend genug >Fleisch gehabt, um die Kanneluren auszuführen. Möglich ist, dass das Kannelieren der Säulen absichtlich unterblieben ist, um die Flächen später als Träger für die Kuretenlisten zur Verfügung zu haben.

Die dorischen Kapitelle folgen Formen, wie sie für die römische Zeit charakteristisch sind. Der Echinus ist nur sehr sanft gerundet und kaum noch als Polster gespannt, sondern als schräge Fläche bis zum äußeren Rand der Abakusplatte geführt. Die dennoch sehr sorgfältige Rundung ist mit Meißel und Zahneisen ausgeführt und nicht weiter geglättet, der Echinus lädt etwas weniger über den Säulenhals aus, als er hoch ist.

Unter dem Echinus fassen vier Anuli den Säulenhals ein. Diese sind bei dem Kapitell KatNr. A 5 scharfgratig und im Querschnitt als Kantenstab ausgeführt. Für die Kureteninschriften wurden hier die Anuli an der Vorderseite abgearbeitet. Die Anuli des Kapitells KatNr. A 6 (Taf. 45, 3; 56; 61, 1) hingegen sind an den Außenkanten abgerundet und weicher gestaltet, wie auch der Echinus gespannter und runder ist; beträgt die Stichhöhe des Polsters am Kapitell KatNr. A 5 nur knapp $5 \mathrm{~mm}$, so sind es bei dem anderen Exemplar etwa $1,5 \mathrm{~cm}$. Diese kleinen Differenzen bleiben aber offenbar innerhalb der Toleranzgrenzen der Werkstatt und wurden nicht als störend empfunden.

Der Echinus endet in den Achsen der Kapitelle knapp hinter oder direkt an der Unterkante des quadratischen Abakus. Am nur teilweise - entsprechend dem Auflager der Architrave - geglätteten Oberlager sind an der Vorderseite Steinmetzzeichen erhalten ${ }^{576}$. Die Buchstaben AI $\Xi$ und YI können dabei kaum Versatzmarken sein, da sie weder als Zahlenwert noch als Abkürzung einen Sinn ergeben. Sie sind eher als Signaturen oder Abrechnungskürzel zu deuten ${ }^{577}$. Vergleichbare Signaturen aus hadrianischer Zeit in Italien und Spanien wurden als Namenskürzel der Handwerker gedeutet, die eine Abrechnung nach Stückzahl der hergestellten Bauteile erleichtern sollten ${ }^{578}$.

Der Architrav, von dem nur der längste Balken des Mitteljochs erhalten ist, ist glatt und verfügt kanonisch am oberen Rand über die Tänie, die von Regulae mit Guttae begleitet wird. Die Vorderseite des Architravs ist mit dem Zahneisen bearbeitet, deutlich glatter sind hingegen die Ränder der seitlichen Stoßflächen, die ein fugenloses Anschließen der benachbarten Blöcke sicherstellten. Der Architrav war bereits in der Antike durch einen Bruch beschädigt und mit horizontalen Klammern repariert worden. Der auf einer Länge von 3,54 m erhaltene Architravblock KatNr. A 7 (Taf. 45, 3; 56; 57; 58, 3. 4; 59, 1. 2) scheint in einer leichten Kurvatur um wenige Millimeter nach oben aufgebogen zu sein, ohne dass damit - aufgrund der zu wenig erhaltenen Bauteile - optische Korrekturen an der Fassade argumentiert und errechnet werden könnten.

Über dem Architrav folgt der Metopen-Triglyphen-Fries, von dem lediglich eine Achse erhalten ist. Bei der Platte KatNr. A 8 (Taf. 45, 3; 56; 57; 58, 3. 4; 59, 1. 2) waren das undekorierte Metopenfeld und das links anschließende Triglyphon in einem Block gearbeitet. Da vom Triglyphon die linke Glyphe ganz, von

\footnotetext{
575 Alzinger 1974, 68.

576 Das Kapitell KatNr. A 6 ist $90^{\circ}$ gegen den Uhrzeigersinn wiederversetzt, sodass das Steinmetzzeichen nun nach Osten hin orientiert ist.

$577 \mathrm{Zu}$ den unterschiedlichen Bedeutungen der Marken cf. J. B. Ward-Perkins, Tripolitania and the Marble Trade, JRS 41, 1951, 89-104; R. Martin, Manuel d'architécture grecque I (Paris 1965) 221-238. - Der Brauch, Quader zu `signieren`, ist vornehmlich im griechischen Raum in vorrömischer Zeit aufgetreten und für die Kaiserzeit unwahrscheinlich; cf. J.-P. Adam, Roman Building (London 1994) 40.

578 P. Pensabene, I capitelli, Scavi di Ostia 7 (Rom 1973) 194 f. mit Anm. 45; S. Ahrens, Die Architekturdekoration von Italica, Iberia Archaeologica 6 (Mainz 2005) 122-124.
} 
der rechten die obere Ecke verloren ist, lässt sich nicht entscheiden, ob die Glyphen mit den für Kleinasien charakteristischen $>$ Ohren $<$ dekoriert waren ${ }^{579}$.

Das dorische Geison ist einfach gehalten (KatNr. A 9. 10; Taf. 45, 3; 56; 57; 58, 3. 4; 59; 60, 1. 2). Über einer niedrigen Leiste leitet ein schräges Profil zur Hängeplatte über. Dieses muss als ionisches Kyma verstanden werden; W. Alzinger beschreibt in seiner Vorlage der augusteischen Architektur in den frühen 1970er Jahren noch Farbreste eines aufgemalten Eierstabes, der in den beigefügten Abbildungen mit Mühe zu erkennen ist ${ }^{580}$. An den Blöcken, die seither der Witterung ausgesetzt waren, können heute keine Farbspuren mehr ausgemacht werden.

Auf dem Geison sind die Mutuli mit $3 \times 6$ Guttae angeordnet. Die Traufleiste der unverzierten Corona ist durch eine Rille charakteristisch von der Hängeplatte abgesetzt. Der obere Abschluss besteht aus einer Hohlkehle und einer Platte. Der Steinschnitt der Geisonblöcke wurde so geführt, dass auf jedem Block immer ein vollständiger Mutulus mit $3 \times 6$ Guttae und ein halber mit $3 \times 3$ Guttae zu liegen kamen. Bei manchen der Blöcke stand neben dem vollständigen Mutulus eine weitere Via. Durch diese Aufteilung in halbe und ganze Mutuli wurde erreicht, dass die Stoßfugen des Frieses und des Geisons nie übereinander zu liegen kamen.

Die dorische Architektur der Vorhalle zeichnet sich insgesamt durch ihre Großflächigkeit aus, wobei alle Elemente und insbesondere die Anschlüsse sehr exakt gearbeitet sind. Dabei bleibt der Dekor auf das Wesentlichste beschränkt, es sind keine zusätzlichen Profile oder Verzierungen ausgearbeitet, lediglich - so scheint es - waren sie teilweise aufgemalt. Die Vorhalle steht damit gleichermaßen in der Tradition des hellenistisch-kleinasiatischen Werksteinbaus wie in der klassizistischen Tradition augusteischer Architektur ${ }^{581}$.

\section{VII.4.1.2 Der >Hestiasaak (KatNr. A 12-26)}

Knapp vor die Wände sind an den vier Ecken des Saales Säulenstühle mit Doppelhalbsäulen über einen >herzförmigen` Grundriss gestellt. Die Säulenstühle, die sorgfältig mit dem Zahneisen bearbeitet sind und an allen Rändern einen geglätteten Saum aufweisen, stehen auf einfachen Plinthen aus grau gesprenkeltem Marmor. Lediglich bei der Platte in der Südwestecke ist am oberen Rand an drei Seiten der Werkzoll stehen geblieben und nicht mehr weggearbeitet worden.

Die Säulenstühle sind sehr präzise aus einem dichten, grauen Marmor gehauen, die Oberfläche ist sorgfältig geglättet (KatNr. A 12. 14. 17. 21; Taf. 75-80. 82. 83). Das Fußprofil des Sockels besteht aus Rundstab, Platte, kyma reversa und einem Stab, das Kopfprofil aus Anlauf, Kyma, Kehle und Platte. Entsprechend der darüber aufgestellten Säule ist auch der Säulenstuhl im Grundriss nicht quadratisch, sondern L-förmig mit zwei kurzen Auslegern an den benachbarten Seiten, die die Halbsäulen tragen sollen.

Hervorzuheben ist die nahezu perfekte Behandlung der Oberflächen, die offenbar mit großem Aufwand geglättet worden sind, sodass sich die Fläche sogar als Träger einer Konstruktionszeichnung eignete ${ }^{582}$.

Umso mehr hebt sich die sehr grobe und fast plumpe Ausführung der attischen Basen ab, die auf den Säulenstühlen liegen (KatNr. A 13. 15. 18. 22; Taf. 75-80. 82. 83). Die Basen bestehen kanonisch aus Plinthe, Torus, Trochilus und Torus. Alle vier Elemente sind sehr hoch, die Rundungen mangelhaft und sehr ungleichmäßig ausgeführt. Zwar sind die deutlich in die Höhe gezogenen Proportionen und die Ausführung der Basen in geringerer Qualität an sich kein Datierungskriterium, dennoch ist es wenig wahrscheinlich, dass Säulenstühle und Basen in derselben Bauphase entstanden sind.

Diese Vermutung wird durch die Auffindung einer Säulenbasis gleichen Grundrisses erhärtet, die heute im Bereich der Kryptoportiken der Domitiansterrasse liegt (KatNr. A 47; Taf. 86). Auch hier handelt es sich um eine attische Basis mit kanonischem Aufbau. Die Maße in der Horizontalen entsprechen weitgehend jenen der im >Hestiasaak versetzten Basen. Diese sind hingegen weniger sorgfältig ausgeführt, in allen Dimensionen etwas zu groß und ragen meist knapp über die Profile der Säulenstühle hinaus. Die Maße der Basis KatNr. A 47 zeigen größere Übereinstimmungen mit den Säulenstühlen. Die Höhe der Basis ist geringer als

\footnotetext{
Thür 1996, 356 .

580 Alzinger 1974, 100 Abb. 141-142.

581 Vgl. dazu den Exkurs zu den dorischen Ordnungen in Ephesos: G. A. Plattner, Kapitel VII.4.3.

582 Steskal 2007.
} 
die der versetzten und entspricht den kanonischen Proportionen von Breite:Höhe $=2: 1^{583}$. Auch die Profile sind viel sorgfältiger und gleichmäßiger ausgeführt, die exakte Bearbeitung und der Randschlag an der Plinthe der Basis erinnern zudem an die Zurichtung der Säulenstühle und der Platten unter den Säulenstühlen. Es ist daher wahrscheinlich, dass KatNr. A 47 eine der primären attischen Basen des $>$ Hestiasaales` gewesen ist, die später durch neue, höhere, aber weniger qualitätsvolle Bauteile ersetzt worden sind. Damit wird auch deutlich, dass man sich bei der Wiederaufrichtung der Architektur im 3. Jahrhundert n. Chr. offenbar bemüht hat, die Höhe der Ordnung zu vergrößern; dies ist sowohl durch die Verwendung höherer Basen als auch durch die Syntax der Kapitelle geschehen, die auf kleinem Grundriss ein hohes Bauteil ermöglicht (s. u.).

Ausgehend von der sehr exakten und qualitätsvollen Ausführung der Säulenstühle kann geschlossen werden, dass diese der primären Bauphase augusteischer Zeit angehört haben. Eine solche Qualität wäre für das 3. Jahrhundert n. Chr. jedenfalls höchst unwahrscheinlich. Bestätigt wird diese Vermutung auch durch die zwei Gruppen attischer Basen, deren qualitätsvollerer und in der späteren Bauphase verworfener Vertreter besser zu den Maßen der Säulenstühle passt.

Die Säulen bilden die komplexe Form zweier Halbsäulen, die an zwei benachbarten Seiten eines quadratischen Pfeilers angelegt sind. Der Pfeiler springt dabei minimal vor. Der Ablauf unten besteht aus einer hohen Platte, der Anlauf oben aus einem Rundstab. Zwei der Säulen sind aus schwarz-weiß gesprenkeltem Granit (KatNr. A 19. 23; Taf. 79. 80. 82. 83), eine aus grauem Marmor mit dünnen, weißen Adern (KatNr. A 16; Taf. 77. 78).

Es ist nicht zu entscheiden, ob die Säulen bereits der ersten Ausstattungsphase angehört haben. Die Tatsache, dass zwei verschiedene Materialien zum Einsatz kamen, macht es möglich, dass entweder die Granitsäulen oder die Marmorsäule bereits in augusteischer Zeit im >Hestiasaak verbaut gewesen sind. Belege für die Existenz beider Materialien in Ephesos schon in der frühen Kaiserzeit könnten nur umfangreiche Analysen der Steinbrüche erbringen.

Der graue Marmor ähnelt in seinem Aussehen jenem Material, das in Westkleinasien und den vorgelagerten Inseln häufig vorkommt und als bigio antico angesprochen wird ${ }^{584}$. Seit spätestens flavischer Zeit wurde dieses Material auch im größeren Stil in den Westen exportiert, muss aber bereits davor verfügbar gewesen sein. In Zusammenschau mit den technischen Zurichtungen könnten diese Säulen bereits aus der augusteischen Phase stammen ${ }^{585}$.

Der graue Granit stammt wohl aus der östlichen ägyptischen Wüste ${ }^{586}$, vielleicht vom Mons Claudianus. Der dort gebrochene Granito del Forum ist spätestens mit der massiven Verwendung am Traiansforum weit verbreitet $^{587}$. Ein ähnlicher Granit wurde im Hanghaus 2 im Peristyl der Wohneinheit 4 verwendet, ein weiteres Stück gleicher Größe in der spätseverischen Reparatur im Peristyl der Wohneinheit 1 eingesetzt ${ }^{588}$. Damit ist für den Granit die Verfügbarkeit im frühen 3. Jahrhundert n. Chr. wahrscheinlich und weiters zu vermuten, dass die beiden Granitsäulen im >Hestiasaalı der späteren Ausstattungsphase im 3. Jahrhundert n. Chr. angehören.

Die Säulen werden von im Grundriss ebenso komplexen kompositen Kapitellen bekrönt (KatNr. A 20. 24. 25; Taf. 79-85. 87). Wie schon bei den Basen, deren Proportionen zugunsten der Höhe verschoben sind, wurde offenbar auch bei den Kapitellen versucht, das Bauteil in der Höhe zu strecken. So wurde als Basis um das ganze Kapitell ein Kranz aus horizontalen, kleinen Lanzettblättchen in fünf Reihen übereinander

583 Cf. M. Steskal, Kapitel III.11.2.

584 Die Bewertung des Marmors kann hier zunächst nur durch makroskopische Beurteilung der Oberflächen erfolgen und muss daher als Vorschlag verstanden werden. - H. Mielsch, Buntmarmore aus Rom im Antikenmuseum Berlin (Berlin 1985) 59 f.; G. Borghini, Marmi antichi (Rom 1992) $158 \mathrm{f}$.

585 Laut der Typologie der antiken Wolfslöcher von W. Aylward gehört die Zurichtung der beiden Hebelöcher an der Granitsäule zur Gruppe A, vergleichbar mit dem Mazaeus-Mithridates-Tor und zeitgleichen Gebäuden; für Diskussion und Anregungen gilt der Dank W. Aylward, der die vorläufigen Ergebnisse in seinem Vortrag »Lifting Technology as a Diagnostic Tool for the Study of Monumental Architecture« auf der 8th Roman Archaeology Conference, University of Michigan, Ann Arbor, am 3. April 2009 vorgestellt hat.

586 Freundlicher Hinweis W. Prochaska.

587 H. Mielsch, Buntmarmore aus Rom im Antikenmuseum Berlin (Berlin 1985) 69; G. Borghini, Marmi antichi (Rom 1992) $222 \mathrm{f}$.

588 Thür 2005, 101 f. 166 Kat. A 20; G. Wiplinger, Die Bauphasen der Wohneinheiten 1 und 2, in: Krinzinger 2002, 83, dort als »Gabbro« bezeichnet; Plattner 2010, 150 f. Kat. A-A 2 Taf. 40. 
gelegt, über dem der eigentliche Kalathos aufwächst. Ein solcher Kranz unter dem Kalathos ist für Kapitelle in Ephesos sonst nicht belegt. Auch außerhalb von Ephesos ist diese Erweiterung höchst selten ${ }^{589}$.

Die Halbsäulenkapitelle folgen der kanonischen Form des Kompositkapitells, allerdings mit nur einem Blattkranz. Dementsprechend wachsen die je drei Akanthusblätter der Halbsäulenkapitelle breit und hoch auf. Das zentrale Blatt wird aus fünf Blattlappen gebildet, deren untere und mittlere aus vier Blattfingern bestehen, die tief gekehlt und weit aufgefächert sind. Die Blätter unter den Eckvoluten ( $>$ Hochblatt $<$ besitzen ein Blattlappenpaar mehr. Bei mehreren Blättern ist sogar der Blattüberfall erhalten, an dem außen Bohrlöcher gesetzt sind.

Auf der breiten Kalathoslippe liegt der Echinus, aus dem die Voluten herauswachsen. Zweifingrige Zwickelpalmetten legen sich über den Eierstab, von dem drei vollständige Achsen ausgeführt sind.

Im Zwickel, in dem die beiden Halbkapitelle zusammenstoßen, steht einmal eine fünffingrige Palmette in einem Blätterkranz, deren oberster Blattfinger nach rechts umknickt (KatNr. A 24). Bei dem zweiten Kapitell, an dem diese Partie erhalten ist (KatNr. A 20), ist hingegen ein Akanthusblatt angegeben, das an einer breiten Rippe drei Paare von Blattlappen mit gezackt aufgebohrten Rändern ausbildet. Während bei diesem Kapitell der Übergang im Echinus von zwei Achsen des Eierstabes begleitet wird, ist er bei dem anderen auf ein sehr breites Ei beschränkt, das in der Mitte leicht vertikal eingekerbt ist.

Der Abakus besteht aus Kehle, Platte und Kyma. Die erhaltenen Abakusblüten sind mehrmals einfache, von unten aufwachsende Blattbüschel aus dicken Blattfingern, sonst Rosetten. Das aufwendigste Motiv (KatNr. A 24 Südseite) ist ein um eine U-förmige Rille gebildeter Blätterkelch; zu beiden Seiten der Rille wachsen kleine, zum Teil unterteilte Blättchen heraus.

Auch das Kapitell ist über dem Pfeiler etwas breiter und gegen das Halbsäulenkapitell leicht nach außen versetzt. Die Kante am Übergang zwischen Halbsäulenkapitell und Pfeilerkapitell wird von Rankenästen verdeckt, die von unten aufwachsen. Die Ranke ist ein breiter, glatter Stamm, der an jedem Wendepunkt einen kleinen Seitenarm ausbildet.

Das Pfeilerkapitell ist mit einfachem, korinthisierendem Dekor verziert: Der Echinus wird in gleicher Weise wie an den Halbsäulenkapitellen fortgesetzt, entsprechend der Grundform des Kapitells hier aber wesentlich flacher umgesetzt. Die drei Achsen des Eierstabes treten ebenso wenig aus dem Kapitell hervor wie die Volutenschnecken. Der Kalathos wird von flachen, durch eine Mittelrille gegliederten Lanzettblättern bedeckt, die oben abgerundet sind und leicht überfallen. An jeder Seite stehen fünf vollständige Blätter. An der Seite, an der die Pfeilerflächen aneinander grenzen, steht ein Blatt über Eck, das bei dem Kapitell KatNr. A 24 durch zwei vertikale Rillen gegliedert ist. An den Kanten zu den Halbsäulenkapitellen bleibt hingegen nur ein halbes Blatt, die zweite, umknickende Hälfte ist nur angedeutet.

Die handwerkliche Qualität der Kapitelle ist hoch, wenn auch die Seitenflächen über den Pfeilern, die durch die Positionierung der Säulen unmittelbar vor den Wänden des \Hestiasaales〈 kaum gesehen werden konnten, bewusst reduziert und einfach ausgeführt sind. Die Zeitstellung der Kapitelle kann aufgrund stilistischer Kriterien und der Gestaltung der Dekorelemente wie folgt bewertet werden: Wie seit der frühen Kaiserzeit in Kleinasien üblich, sind die Blattlappen der Akanthusblätter in einzelne, V-förmig gekehlte Blattfinger unterteilt. Im Gegensatz zu frühen Kapitellen stehen hier die Blattfinger in fast gleicher Größe geometrisch aufgefächert nebeneinander, der ursprünglich plastisch gestaffelte Blattlappen ist bereits zu einem rhythmischen Dekor reduziert, wie dies seit dem mittleren 2. Jahrhundert n. Chr. die Regel ist. Schon bei den Kompositkapitellen des Vediusgymnasiums folgt der Akanthus diesen Vorgaben ${ }^{590}$, freilich erlangt hier der Blattlappen durch tiefe und markante Bohrrillen größere Plastizität (Taf. 236, 1). Die Reduktion des Blattes in der Tiefe, wobei die einzelnen Blattteile auf derselben Ebene zu liegen kommen, begegnet insbesondere bei Kapitellen der zweiten Hälfte des 2. Jahrhunderts n. Chr. Als Beispiel seien die kleinformatigen korinthischen Kapitelle des Peristylhofes der Wohneinheit 4 im Hanghaus 2 genannt $^{591}$ : Die Blattlappen

589 Ein korinthisches Kapitell mit zwei Akanthuskränzen und allen Elementen eines ^Normalkapitells` aus dem fortgeschrittenen 2. Jh. n. Chr., das um einen ebensolchen Kranz aus liegenden Blättchen erweitert worden ist, liegt im Bouleuterion von Aphrodisias.

590 Plattner 2003, 115-122; Plattner 2008, 276-278.

591 H. Thür, Die Bauphasen der Wohneinheit 4 (und 6), in: Krinzinger 2002, 58 noch mit severischer Datierung, inzwischen aber nach mündlicher Auskunft für eine Zeitstellung um 150-170 n. Chr.; cf. Thür 2005, 160-162. 166 f. 169 Kat. A 21-26. 37-41. 
sind hier so aufgebreitet, dass der ganze Kalathos überzogen wird und die benachbarten Blätter einander berühren. Auch in severischer Zeit bleibt es bei dieser Gestaltung der Akanthusblätter. Die korinthischen Kapitelle des großen Peristylhofes der Wohneinheit 2 im Hanghaus 2 folgen denselben Vorgaben, allerdings sind hier die Einzelelemente nochmals reduzierter, und die Zahl der Blattlappen und Blattfinger ist auf ein Minimum beschränkt ${ }^{592}$.

Die Qualität der genannten Kapitellgruppen aus den Hanghäusern unterscheidet sich grundsätzlich von jener der Prytaneion-Kapitelle. Die Oberfläche der Kapitelle im Hanghaus wirkt wie aus Holz geschnitzt und wurde nicht weiter geglättet. Die Elemente der korinthischen Kapitelle sind zwar vollständig umgesetzt, im Detail aber reduziert. Das heißt, man verzichtete lieber auf eine in den Proportionen befriedigende Aufteilung der Elemente, als eines davon gänzlich ausfallen zu lassen. Abgesehen von diesen Entwicklungen in der `Arbeitseffizienzく ist die Entwicklung des römischen korinthischen oder kompositen Kapitells in der Mitte des 2. Jahrhunderts n. Chr. im Wesentlichen abgeschlossen ${ }^{593}$. Umso schwerer fällt eine Beurteilung der Zeitstellung der Kapitelle des Prytaneions.

Die Kapitelle des severischen `Südlichen Hafentores` in Ephesos, das inschriftlich in die Zeit des Caracalla datiert ist, ließen sich ohne diese schriftliche Quelle nur schwer von den Bauteilen des Vedius- und Ostgymnasiums unterscheiden (Taf. 236). Während die Ikonografie der Kompositkapitelle fast dieselbe geblieben ist, lässt sich auch hier vor allem ein Unterschied in der Qualität der Ausführung feststellen. Im Gegensatz zu den Bauteilen der Thermen ist etwa bei dem im Grundriss trapezoiden Pfeilerkapitell des Hafentores, das sich heute im Wiener Ephesosmuseum befindet, die Überarbeitung der Oberfläche weniger sorgfältig (Taf. 237 ${ }^{594}$. Unebenheiten am Kalathosgrund und insbesondere in den Tälern der Bohrrillen wurden stehen gelassen. $\mathrm{Zu}$ differenzieren ist auch die Ausführung des Eierstabes, der bei den Kapitellen der Thermen noch geschlossener wirkt; die Schalen am Hafentor-Kapitell sind hingegen schon weit aufgebohrt und wirken fast nicht mehr den Eiern zugehörig. Besonders der Zwischenraum zwischen Schalen und Pfeilblättern ist größer. Bei den Kapitellen der Thermen sind die lanzett- oder leicht pfeilspitzenförmigen Zwischenblätter nur durch eine nicht sehr tiefe Bohrrille von den Schalen getrennt; beim Hafentor hingegen ist bereits ein großer Abstand zwischen Schale und Pfeilspitzenblatt. Dieses Auseinanderrücken der Elemente, die in ihren Formen plumper und kantiger werden, ist für die severische Epoche charakteristisch. $\mathrm{Zu}$ erkennen ist diese Tendenz auch an den Gebälken des >Südlichen Hafentores` und an den Architravbalken auf der Tetragonos Agora, deren Inschrift sie ebenfalls in die Zeit Caracallas weist (Taf. 238, 1) ${ }^{595}$. Vergleichbar sind hier die weit von den Eiern gelösten Schalen und die großen Abstände und Hohlräume zwischen Pfeilspitzenzwischenblättern und den Schalen. In gleicher Weise sind die Astragale reduziert: Die Walzen sind breit und an den Seitenflächen spitz abgeschlossen, die Perlen im Grunde zu Rhomben reduziert.

Auffallend ist, dass bei den Kapitellen des Prytaneions die Zwischenblätter als schmale, an den Schalen anliegende Lanzettblätter ausgeführt sind. Bei einer Beurteilung dieser Tatsache ist zu berücksichtigen, dass die Kapitelle sehr schmal und hoch sind, eine Streckung des Eierstabes sich daher verbietet. Deshalb sind hier die abgeflachten Eier mit einer tiefen Bohrrille von den Schalen getrennt, die ihrerseits eng an das schmale Lanzettblatt gedrängt sind. Besser in der späten Zeitstellung zu beurteilen ist hingegen der sägezahnartige Rand am schon genannten Zwischenblatt, das bei dem Kapitell KatNr. A 20 zwischen den Halbkapitellen vermittelt. Es entspricht den vegetabilen Motiven mit ebenfalls kleingezackt aufgebohrtem Rand an der Konsole des schon genannten Pfeilerkapitells im Ephesosmuseum (Taf. 237, 2). Dieses Stilelement, das in Ephesos in spättraianisch-hadrianischer Zeit geprägt wurde, verschwand im Laufe der zweiten

592 Plattner 2003, 85 f.; Plattner 2010, 513 f.

${ }_{593}$ Cf. K. S. Freyberger, Stadtrömische Kapitelle aus der Zeit von Domitian bis Alexander Severus (Mainz 1990) 133-135; Plattner 2003, 101-105. 139-141.

594 W. Oberleitner (Hrsg.), Funde aus Ephesos und Samothrake, KHM Katalog der Antikensammlung II (Wien 1978$) 102$ f. Nr. 126; Plattner 2003, 127-129.

595 IvE 3001; ob die Architrave eine severische Bauphase der Tetragonos Agora anzeigen oder hier als Spolien in der spätantiken Agora wiederverwendet worden sind, ist unklar; cf. P. Scherrer, Die Tetragonos Agora in Ephesos, in: P. Scherrer - E. Trinkl, Die Tetragonos Agora in Ephesos. Grabungsergebnisse von archaischer bis in byzantinische Zeit - ein Überblick. Befunde und Funde klassischer Zeit, FiE 13, 2 (Wien 2006) 49-51. 
Hälfte des 2. Jahrhunderts n. Chr. weitgehend und wird erst in severischer Zeit in Kleinasien wieder häufig angetroffen ${ }^{596}$.

Die Kombination von korinthischem Halbsäulenkapitell mit einem von einfachen Blättern bedeckten Pfeilerkapitell wurde schon in der frühen Kaiserzeit verwendet: Das um ein Geschoss überhöhte Mittelschiff der Basilike Stoa auf dem `Staatsmarkt` wird von Pfeilern mit nach innen orientierten Halbsäulen getragen (Taf. 238, 2) ${ }^{597}$. Die Pfeiler sind hier von Hohlblättern bedeckt. Die Bauteile des Obergeschosses wurden in der Spätantike (?) wiederverwendet und im ehemaligen Ost-Chalkidikum der Basilika zu einem Peristyl gruppiert ${ }^{598}$. Es ist denkbar, dass diese Kombination als Vorbild für die neuen Kapitelle des $>$ Hestiasaales` gedient haben könnte. Die Kapitelle des Basilika-Obergeschosses waren wohl jedenfalls vom Vorhof des Prytaneions aus zu sehen.

Aus der Auswertung der Grabungsbefunde im Prytaneion geht hervor, dass es im zweiten oder dritten Viertel des 3. Jahrhunderts n. Chr. eine Umbauphase gegeben haben muss (Bauphase 2). Die komplexe Form der Kapitelle des `Hestiasaales` macht es äußerst unwahrscheinlich, dass diese als Spolien aus einem anderen Gebäude geholt wurden. Eine Zeitstellung in der frühen Kaiserzeit, also ein Zusammenhang mit einer früheren Ausstattungsphase des Prytaneions, ist aufgrund der Gestaltung und des Stils der Kapitelle auszuschließen. So muss davon ausgegangen werden, dass diese Kapitelle im Zuge des Umbaus des Prytaneions für diesen Zweck im 3. Jahrhundert neu hergestellt worden sind. Damit gehören diese Exemplare zu den für Ephesos nicht sehr zahlreichen Kapitellen, die sich mit einiger Sicherheit in diese Epoche datieren lassen. Nach der überreichen Produktion im 1. und 2. Jahrhundert n. Chr. wurden in der späten Kaiserzeit und der Spätantike offenbar fast ausschließlich Spolien verwendet; die Produktion neuer Bauteile scheint hingegen stark zurückgegangen zu sein ${ }^{599}$. Umso beachtlicher ist die hohe Qualität und Originalität, die an den Kapitellen des Prytaneions zu beobachten sind. Einerseits konnte unter Verfügbarkeit kundiger Handwerker offenbar vor Ort auf die komplexen Gegebenheiten des ungewöhnlichen Grundrisses und der durch Zusatzelemente gestreckten Höhe reagiert werden. Andererseits sind die Qualität und Sorgfalt beachtlich, die offenbar über schon kanonische Reduzierungen und Vereinfachungen zurück zu Detaillösungen und Stilstufen der zweiten Hälfte des 2. Jahrhunderts n. Chr. finden. Ein klarer Hinweis für die späte Zeitstellung bleibt insbesondere die reduzierte Ausführung der schlecht einsehbaren Abschnitte über den Pfeilern. Diese sehr ökonomische Reduzierung des Dekors wurde schon mehrfach als Charakteristikum spätantikfrühbyzantinischer Kapitelle betont ${ }^{600}$. Eine genauere Einordnung der Kapitelle innerhalb des durch die Grabungsbefunde eingegrenzten Zeitraumes im 3. Jahrundert n. Chr. ist aus der Ornamentik heraus nicht möglich; wahrscheinlich ist jedoch, dass sie eher zu Beginn des in Frage kommenden Zeitraumes, also noch vor der Mitte des 3. Jahrhunderts n. Chr. hergestellt worden sind. Sie stehen damit in der Tradition (spät)severischer Architekturen.

Keine Rückschlüsse sind auf die ursprünglichen Kapitelle des >Hestiasaales` möglich, wenngleich auch hier eine ähnliche Lösung wie in der augusteischen Basilika denkbar ist. In diesem Fall wären die Kapitelle des 3. Jahrhunderts n. Chr. eine direkte Wiederaufnahme der ursprünglichen Ausstattung. Da die Säulen-

596 Cf. die Konsole des Pfeilerkapitells vom `Südlichen Hafentorく in Ephesos, W. Oberleitner (Hrsg.), Funde aus Ephesos und Samothrake, KHM Katalog der Antikensammlung II (Wien 1978) 102 f. Nr. 126 oder die Akanthusbasen im `Marble Court des Bad-Gymnasium-Komplexes in Sardes, F. K. Yegül, The Bath-Gymnasium Complex at Sardis, Archeological Exploration of Sardis. Reports 3 (Cambridge 1986) Abb. 136.

597 Alzinger 1974, 88; Plattner 2003, 28-30.

598 Alzinger 1972-1975, $258 \mathrm{f}$.

599 Plattner 2003, 140 f.; einzelne Kapitellgruppen und -formen können aufgrund stilistischer Kriterien relativchronologisch später als die mittelkaiserzeitlichen Kapitelle erkannt werden, sind aber mangels benennbarer Kontexte vorerst nicht absolut datierbar. Aufschlüsse sind hier aus der Bearbeitung der Spolien im sog. Sarhoş Hamam zu erwarten, cf. zunächst Jahresbericht 2005 des Österreichischen Archäologischen Instituts, ÖJh 75, 2006, 334; Jahresbericht 2006 des Österreichischen Archäologischen Instituts, ÖJh 76, 2007, 408. 419.

600 J. Kramer, Stilmerkmale korinthischer Kapitelle des ausgehenden 3. und 4. Jh. n. Chr. in Kleinasien, in: O. Feld - U. Peschlow (Hrsg.), Studien zur spätantiken und byzantinischen Kunst, Friedrich Wilhelm Deichmann gewidmet, Monographien RömischGermanisches Zentralmuseum 10, 2 (Bonn 1986) 112 f. Taf. 21, 4 mit einer Datierung in tetrarchische Zeit. Die Kapitelle des `Hestiasaales` werden hier als Beleg für Stilmerkmale des späten 3. und 4. Jhs. n. Chr. angeführt; nicht zuletzt wegen der nun besser belegbaren Datierung in das 2. (oder 3.) Viertel des 3. Jhs. n. Chr. ist die Zeitstellung vergleichbarer Bauteile in die tetrarchische Zeit und später zu hinterfragen. 
stühle und vielleicht auch die Säulen aus der frühkaiserzeitlichen Bauphase 1 stammen, müssen damals schon entsprechend komplexe Bauteile existiert haben.

VII.4.1.3 Raum 5 (KatNr. A 27. 28)

In der Mitte von Raum 5 steht eine Säule mit dorischen Kanneluren (Taf. 107, 2; 113, 2). An beiden Säulentrommeln sind diese sehr flach und wohl nicht fertig ausgeführt. Lediglich die 20 Grate sind in der mit dem Zahneisen bearbeiteten Oberfläche zu erkennen. Am unteren Ende der unteren Trommel ist an der heute nach Osten gewandten Seite eine ca. $50 \times 50 \mathrm{~cm}$ große und bis zu $5 \mathrm{~cm}$ hohe Bosse stehen geblieben. Diese kann kaum sinnvoll erklärt werden, vielleicht handelt es sich um eine vorspringende Konsole aus einer primären Verwendung der Säule.

Ungewöhnlich ist die Basis KatNr. A 27. Während dorische Säulen in der Regel ohne Basis auf einem Stylobat versetzt sind, ruht der Schaft hier auf einer in ihren Profilen unkanonischen Basis. Auf einer quadratischen Plinthe liegt ein Torus, der mit Rundstab und Leiste in einen kehlenförmigen Absatz überleitet. Dieser bildet dann gleichsam den Säulenfuß. Es ist nicht zu entscheiden, ob es sich um eine umgearbeitete attische Basis handelt - der obere Torus würde hier fehlen und der Trochilus wäre in der oberen Hälfte abgemeißelt - oder um eine einfache Torus-Basis in Anlehnung an die Tradition der achämenidischen Wulstbasen, die auch für Westkleinasien und die griechischen Inseln belegt sind ${ }^{601}$. Ähnlichen Gestaltungskriterien folgen auch tuskanische Basen, die in der Regel aus einem Torus auf einer allerdings kreisrunden Plinthe bestehen ${ }^{602}$.

Vorläufer für diese Syntax gibt es in Ephesos im ausgehenden Hellenismus. Am Heroon am unteren Embolos ist das Untergeschoss in dorischer Ordnung gestaltet ${ }^{603}$. Vor eine geschlossene Wand sind hier an den Seiten Halbsäulen vorgeblendet. Wand und Säulen ruhen auf einem umlaufenden, verkröpften Profil aus Platte, Torus und einer Kehle (Kyma?) ${ }^{604}$. Die Platte ist unter den Halbsäulen zu einer rechteckigen Plinthe erweitert, sodass sich für diese Halbsäulen eine Basis mit derselben Profilabfolge wie bei KatNr. A 27 ergibt.

\section{VII.4.2 Im ZerstöRungsschutt des GebäUdes gefundene Architekturglieder (KatNr. A 32-46)}

Die im folgenden Kapitel behandelten Bauteile können in keinen baulichen Zusammenhang mit dem Prytaneion gebracht werden. Vorgestellt werden demnach auch nicht alle im Katalog aufgenommenen Stücke ${ }^{605}$, sondern allein jene, die auch als Einzelstücke für die Architekturdekoration in Ephesos von Interesse sind. Darüber hinaus werden Gruppen gleichartiger Bauteile summarisch behandelt.

\section{VII.4.2.1 Basen}

$\mathrm{Zu}$ den gefundenen Bauteilen gehört eine Reihe von Säulenbasen unterschiedlicher Dimension. Sie folgen fast durchweg dem Aufbau der attischen Basis: Über der Plinthe liegen Torus, Trochilus und Torus. Fast alle Stücke weisen Spuren von zumindest zwei unterschiedlichen Verwendungen auf oder sind zu einem großen Teil abgearbeitet.

Den attischen Basen KatNr. A 32 (Taf. 131, 1. 2), A 33 (Taf. 131, 3. 4) und A 34 (Taf. 131, 5. 6) wurde sekundär der obere Torus abgearbeitet. Die Basis KatNr. A 34 wurde offenbar auf dem Kopf stehend als kleines Becken verwendet, wofür in die einstige Unterseite eine rechteckige Vertiefung und an einer Seite eine Abflussöffnung gemeißelt worden sind. Während bei der Basis KatNr. A 35 (Taf. 132, 1. 2) die in der Höhe gestreckten Proportionen auffallen, ist es bei KatNr. A 36 der Grundriss (Taf. 132, 3. 4): Diese Basis mit äußerst niedrigem oberem Torus gehörte zu einer Dreiviertelsäule. Basis und Säule waren also Teil

601 B. Wesenberg, Kapitelle und Basen, BJb Beih. 32 (Düsseldorf 1971) 104-106. $111 \mathrm{f}$.

${ }^{602}$ Vitr. 4, 7, 3; F. Prayon, Zur Genese der tuskanischen Säule, in: H. Knell - B. Wesenberg (Hrsg.), Vitruv-Kolloquium (Darmstadt 1984) $141-162$.

${ }^{603}$ Thür 1995, 63-103; zur Datierung in die 1. Hälfte des 1. Jhs. v. Chr. cf. Waldner 2009a; Waldner 2009b, $283-293$.

604 Thür 1995, $83 \mathrm{f}$.

${ }^{605}$ Cf. M. Steskal, Kapitel III.10. 
einer geschlossenen oder zumindest in der unteren Hälfte durch Schranken geschlossenen Wand, der Halbsäulen und über Eck Dreiviertelsäulen vorgeblendet waren.

Bei KatNr. A 38 (Taf. 133, 1. 2) und A 39 (Taf. 133, 3. 4) handelt es sich um rechteckige Basen attischer Ordnung. Das Bauteil KatNr. A 38 ist gebrochen und war ursprünglich wohl eine im Grundriss quadratische Pfeilerbasis. Während die Profile zwar in ihrer Form grobschlächtig wirken, sind sie doch sorgfältig ausgeführt, besonders auch die Plinthe, die mit dem Zahneisen bearbeitet und am oberen Abschluss mit einem geglätteten Saum verziert ist.

Die Profile der Basis KatNr. A 39 sind hingegen nur an drei Seiten ausgeführt, die Rückseite ist grob geglättet. Basis und der darauf ruhende Pilaster von etwa $30 \times 52 \mathrm{~cm}$ Grundfläche müssen also vor einer Wand gestanden sein.

Die Basen weisen allesamt sehr unterschiedliche Maße und Proportionen auf, sodass sie aus verschiedenen primären Bauzusammenhängen stammen müssen. Die Breite der Plinthen variiert zwischen 35 und $72 \mathrm{~cm}$, der obere Durchmesser zwischen 17 und $44 \mathrm{~cm}$.

Proportionen attischer Basen sind per se kein Datierungskriterium, auch die Qualität der Bauteile kann in der Kaiserzeit durchaus variieren, sodass für alle hier gefundenen Basen keine Datierung genannt und als Entstehungszeit lediglich die römische Kaiserzeit angegeben werden kann ${ }^{606}$.

\section{VII.4.2.2 Kapitelle}

Zwei Kapitelle wurden im Bereich des Prytaneions gefunden, die aufgrund ihrer Maße und vor allem aufgrund der Zurichtung nicht zur Vorhalle gehören können. Das Kapitell KatNr. A 43 (Taf. 134, 5. 6) besteht aus Säulenhals, kaum gespanntem Echinus und quadratischem Abakus. Unter dem Säulenhals ist noch ein sich verjüngender Absatz zu erkennen, sodass das Auflager der Säule darunter um etwa 2,5 cm schmäler ist als der Durchmesser des Hypotrachelions. Es ist unwahrscheinlich, dass dieser Rücksprung etwas mit der Unfertigkeit des Stückes zu tun haben kann. Zwar hätten in das Hypotrachelion noch die Kannelurenköpfe eingearbeitet werden müssen, die Grate der Kanneluren würden dabei aber auf der Höhe des ursprünglichen Durchmessers zu liegen kommen. Damit muss entweder der Durchmesser der Säule geringer sein als jener des Hypotrachelions, oder es ergäbe sich bei gleicher Größe eine deutliche Fuge. Beide Lösungen sind unbefriedigend, sodass man das Bauteil wohl als tuskanisches Kapitell anzusprechen hat. Das Vorkommen dieser explizit westlichen, italischen Kapitellform ${ }^{607}$ mag für Ephesos zwar verwundern, allerdings gibt es weitere tuskanische Kapitelle, die als Spolien im großen Peristyl der Wohneinheit 2 im Hanghaus 2 verbaut worden sind ${ }^{608}$. Primäre Bauzusammenhänge sind für all diese Teile nicht bekannt. Das als Basis in der südlichen Säulenstellung wiederverwendete tuskanische Kapitell im Peristyl des Hanghauses hat unter dem 'Säulenhals` als unteren Abschluss einen Rundstab und ist insofern mit dem hier besprochenen Kapitell vergleichbar, als dass die Säule damit einen geringeren Durchmesser hatte als das Unterlager des Kapitells. Das Bauteil ist jedenfalls als Rohling zu bezeichnen, aus dem sowohl ein dorisches als auch ein tuskanisches Kapitell kleinen Formats hätte hergestellt werden können.

Das Kapitell KatNr. A 42 ist hingegen als dorisches Kapitell anzusprechen (Taf. 134, 3. 4). Wie das zuvor besprochene Exemplar ist auch hier die Form angelegt, die Oberfläche hingegen noch nicht abschließend überarbeitet. Der Echinus ist leicht gespannt, der Säulenhals vor allem am unteren Abschluss in Form eines Saumes geglättet. Die Unfertigkeit drückt sich besonders an einer Seite aus, wo unter dem Abakus auf Echinus und Säulenhals noch eine mehrere Zentimeter dicke Bosse stehen geblieben ist. Ein primärer Bauzusammenhang kann auch für dieses Bauteil nicht festgestellt werden.

606 Die wenigen übergreifenden Arbeiten zu attischen Basen bestätigen dies, cf. L. S. Meritt, The Geographical Distribution of Greek and Roman Ionic Bases, Hesperia 38, 1969, 186-204; B. Wesenberg, Kapitelle und Basen, BJb Beih. 32 (Düsseldorf 1971) 130.

607 EAA, Atlante dei complessi figurati e degli ordini architettonici (Rom 1973) 19 f. Taf. 303-306; F. Prayon, Zur Genese der tuskanischen Säule, in: H. Knell - B. Wesenberg (Hrsg.), Vitruv-Kolloquium (Darmstadt 1984) 151; R. Ginouvès - R. Martin, Dictionnaire méthodique de l'architecture grecque et romaine II (Rom 1992) 83-85 Taf. 43 s. v. chapiteau toscan; A. Paul, Toskanische Kapitelle aus Trier und Umgebung, TrZ 57, 1994, 147-273; A. Schäfer, Die tuskanischen Kapitelle des römischen Köln, KölnJb 32, 1999, 689-702.

608 Plattner 2010, 514. 522 Kat. B-A 32. 33 Taf. 203. 
$\mathrm{Zu}$ den Kapitellen ist auch der glatte, trapezoid geschnittene Block KatNr. A 46 zu zählen, der als Kämpferaufsatz anzusprechen ist (Taf. 136, 1. 2). Das Bauteil ist in seiner Geometrie unregelmäßig gearbeitet. Eine der Langseiten ist in rechtem Winkel auf das Unterlager, die andere leicht ausladend gearbeitet. Die schmäleren Seitenflächen sind hingegen deutlich, aber auch unterschiedlich ausladend. Als oberer Abschluss des Blockes ist eine vertikale Zone gleichsam als >Abakus` abgesetzt. Der Kämpfer weist keinerlei technische Anschlüsse auf. Eine Datierung und eine Zuweisung zu einem primären Bauzusammenhang sind für dieses Bauteil nicht möglich.

Ein ähnliches, aber viel flacheres Bauteil wurde nach den Erdbebenzerstörungen im Hanghaus 2 im ehemaligen Peristyl der Wohneinheit 2 verwendet, um die südliche Säulenstellung wieder aufzurichten ${ }^{609}$. Mehrere, auch im Format vergleichbare Kämpfer wurden in der Ruine des sog. Byzantinischen Palastes gefunden; auch für diese Bauteile ist aber eine Datierung und eine sichere Zuweisung zum Palast als primärer Bauzusammenhang nicht möglich ${ }^{610}$. In der Johannesbasilika wurde ein solcher Kämpferaufsatz der iustinianischen Basilika zugeordnet ${ }^{611}$.

Von sehr hoher Qualität ist das korinthisierende Pilasterkapitell KatNr. A 45 (Taf. 135, 3. 4). An drei Seiten bearbeitet, muss es in einer verkröpften Architektur einen Pilaster bekrönt haben. Die grob gepickte Rückseite und die hinteren Kanten des Kalathos sind stark bestoßen. Dennoch ist klar zu erkennen, dass eine dreiseitige Ausarbeitung intendiert war und nicht nur das Fragment eines vierseitigen Pfeilerkapitells vorliegt. Als Beleg dienen neben dem Dekor auch die technischen Anschlüsse. Das Wolfsloch liegt nicht im Zentrum des Blockes, sondern so weit zur hinteren Kante verschoben, dass der durch den Dekor vorn im Gewicht verringerte Block dennoch in der Waage hängt. Auch die drei Dübellöcher am Unterlager nehmen in ihrer Anordnung auf die erhaltene Größe des Kapitells Bezug. Zumindest einige der Klammerlöcher am Oberlager müssen aus einer späteren Wiederverwendung des Bauteils stammen, da eines etwa für eine Klammer, die über die Vorderseite hinauskragt, angelegt wurde. Der Dekor folgt bekannten Kompositionsschemata korinthisierender Kapitelle: Über Eck steht je ein weit aufgefächertes Akanthusblatt, gebildet aus sieben Blattlappen, die von langen, schmalen Ösen getrennt sind. Die Ausführung der Blattfinger entspricht Formen der mittleren Kaiserzeit. Die Blattfinger sind einzeln V-förmig gekehlt, etwa in einem Viertelkreis aufgefächert und im jeweils dritten Blattfinger von unten von einer Bohrrille begleitet. An der Basis des Kapitells zwischen den Akanthusblättern und an den Schmalseiten steht ein Eierstab. An der Vorderseite sind drei vollständige Achsen ausgeführt, an den Schmalseiten zwei und nur eine Schale der dritten Achse. Die Eier sind weit umbohrt und die Schalen damit weit geöffnet, sie werden unter den Ei-Elementen fast durchgezogen. Die Zwischenblätter sind lanzettförmig und nur durch den weiten Abstand der Elemente auf der Vorderseite in der Mitte leicht zu einer Pfeilspitze (rhomboid) verdickt. Das Hauptmotiv der Vorderseite bildet ein zweiteiliger, vegetabiler Hüllkelch, aus dem symmetrisch zwei Rankenarme herauswachsen. Diese bestehen aus einem trompetenförmigen Kelch, aus dem ein langes, mehrfach durch Blattlappen gestaffeltes Akanthusblatt wächst und sich in mehr als einer Windung zur Mitte hin eindreht. Aus dem Ende wächst eine dreiblättrige Blüte, deren Stempel mit einer Bohrrille abgesetzt ist. An den Schmalseiten wird dieses Dekorationsschema variiert: Hier wächst hinter dem Akanthusblatt auf halber Höhe ein schmaler Kelch hervor, aus dem sich ein vergleichbarer Rankenast entwickelt. Er endet in einem einfachen Vierblatt. Zusätzlich wächst aus der Ranke ein Nebenarm auf, an dem sich aus einem Kelch eine zweifingrige Halbpalmette entwickelt und den freien Raum bis zum Ende des Blockes einnimmt. Die Qualität in der Ausführung ist an der Vorderseite höher als an den Seiten. Das wird in der detailreicheren Gestaltung der Ranken deutlich. Während an den Schmalseiten das Motiv zwar vollständig angelegt, aber wenig detailfreudig ausgeführt ist, sind die Blätter der Ranke an der Vorderseite sehr lebendig gezeichnet. Erreicht wird dieser Eindruck insbesondere durch das Aufbohren der Ränder und die Gestaltung der Oberfläche, die in feinen Absätzen wie facettiert wirkt. Auch die zentralen Blüten, die an den Seiten einfache Vierblätter sind, wurden vorn mit Binnenzeichnungen in den Blättern und einem aufwendigeren Blütenmuster bereichert. Diese `Verlebendigung ‘ der Oberfläche und die zackig aufgebohrten Blattränder sind Stilmerkmale, die in

609 Plattner 2010, 522 Kat. B-A 34 Taf. 196.

610 Spolien 116. 118-120. 186.

${ }^{611}$ H. Hörmann, Die Johanneskirche Jusitinians, in: J. Keil - G. A. Sotiriou - H. Hörmann - F. Miltner, Die Johanneskirche, FiE 4, 3 (Wien 1951) 134 Abb. 25, 5. 
Ephesos erstmals in spättraianisch-hadrianischer Zeit auftreten und hier zu weiter Verbreitung gelangen ${ }^{612}$. Prominente Vertreter sind das Serapeion mit den reich dekorierten Türkonsolen ${ }^{613}$ und insbesondere vegetabilisierte Pilasterkapitelle, wie sie schon in den Nischen der Celsusbibliothek ${ }^{614}$ vorkommen und dann zahlreich verbreitet sind, etwa die Pilasterkapitelle von Marmorwandvertäfelungen im Hanghaus 2 (Wohneinheit 6$)^{615}$ oder im Vediusgymnasium ${ }^{616}$. Auch die Akanthusblätter weisen in dieselbe Zeit: Die sehr plastische und variantenreiche Staffelung der Blattlappen wird in traianischer Zeit, etwa an der Celsusbibliothek, perfektioniert und nimmt dann bis zur Mitte des 2. Jahrhunderts n. Chr. wieder ab, wie dies an den Bauteilen des Vediusgymnasiums ablesbar ist. Während die Blattfinger der einzelnen Lappen in der frühen Kaiserzeit sehr in ihrer Größe variieren, sind jene des hier diskutierten Pfeilerkapitells bereits annähernd gleich lang - eine Entwicklung, die ebenfalls zur Mitte des 2. Jahrhunderts n. Chr. hin geschieht. Aufgrund dieser Kriterien kann das Kapitell KatNr. A 45 in das zweite Viertel des 2. Jahrhunderts n. Chr. datiert werden. Ein primärer Bauzusammenhang dieses zumindest einmal wiederverwendeten Kapitells kann nach heutigem Wissensstand nicht angeführt werden.

Das korinthische Kapitell KatNr. A 44 (Taf. 135, 1. 2) kann anhand seiner stilistischen Merkmale in die spätantike oder frühbyzantinische Zeit datiert werden. Den kaum noch sichtbaren Kalathos bedecken letztlich nur noch vier Akanthusblätter, die jeweils unter den Abakusecken angeordnet sind. Die Zwischenräume sind aber nicht als flacher Körper des Kalathos belassen, sondern jeweils unter die Abakusblüte als Spitze hinaufgezogen, unter der sich ein Grat bis zur Kapitellbasis entwickelt. An einer der vier Seiten ist erkennbar, dass auch in dieser Form ein Blatt gemeint ist: Neben der Spitze des an sich ungegliederten Blattes ( $\gg$ Lanzettblatt $\varsigma$ ) ist durch Bohrrillen auf jeder Seite zumindest ein Blattfinger angegeben. Die Akanthusblätter bestehen wie in der Kaiserzeit aus fünf Blattlappen, deren oberster in einem Blattüberfall nach außen gezogen wird. Die Blattlappen setzen sich dabei jeweils aus nur drei - dementsprechend großen - Blattfingern zusammen. Anders als in der Kaiserzeit ist hier jeder der Blattfinger gleich tief gekehlt und fast gleich lang, auch eine Staffelung in die Tiefe gibt es kaum noch. Alle Blattfinger und -lappen liegen auf derselben Ebene, die nur durch die Kehlung und die Ösen zwischen den Blattlappen durchstoßen wird. Die Blattüberfälle sind etwas unbeholfen ausgeführt, fast hat man das Gefühl, dass die Struktur des Blattes und der Perspektive hier nicht mehr verstanden und grafisch Kerben gegen die Richtung der Blattfinger angelegt worden sind. An einer der Blattspitzen wird deutlich, dass hier der Blattüberfall und eine Volutenschnecke, die sich ja bei einem korinthischen Kapitell an dieser Stelle unter dem Abakus befinden sollte, vermischt worden sind, die Blattspitzen also in kleinen Schnecken enden. Der Abakus folgt dem Profil der kaiserzeitlichen Kapitelle, das hier auf zwei übereinander liegende Platten reduziert ist. Die Abakusblüten sind fast nur noch >verkröpfte Elemente<; das Abakusprofil wird demnach herausgezogen, ohne dass wirklich eine Blüte zu erkennen wäre. Die grob zugerichteten Ober- und Unterlager weisen je ein Dübelloch auf. Die Detailformen folgen damit durchweg Vorlagen aus der römischen Kaiserzeit, setzen diese aber schon sehr stark reduziert oder geradezu missverstanden um. Eine Zeitstellung für das Bauteil ist ohne Zusammenhang kaum zu gewinnen. Ähnlich sind etwa Templonkapitelle geringfügig kleineren Formats aus Kütahya, die in der Ausführung des Akanthus sogar noch größere Nähe zu kaiserzeitlichen Formen zeigen $^{617}$. Im 5. und 6. Jahrhundert n. Chr. wird ein ähnlich großfingriger Akanthus die Regel, die Blattlappen bestehen dabei meist aus nur drei weit ausgreifenden Blattfingern, deren obere und untere Finger sich nach außen biegen und so große, kreisrunde Ösen ausbilden ${ }^{618}$. Diese Entwicklungsstufe wurde hier nicht erreicht. Es ist aber nicht zu entscheiden, ob in diesem Fall eine chronologische Unterscheidung zu treffen

612 Plattner 2008, $278 \mathrm{f}$.

${ }_{613}$ Plattner 2008, Taf. 380, 1; Schräggeison mit aufgebohrten Blatträndern im Anthemion: cf. V. M. Strocka, Wechselwirkungen der stadtrömischen und kleinasiatischen Architektur unter Trajan und Hadrian, IstMitt 38, 1988, Taf. 46, 5.

${ }_{614}$ W. Wilberg, Das Gebäude, in: W. Wilberg - M. Theuer - F. Eichler - J. Keil, Die Bibliothek, FiE 5, 1 (Wien 1944) 11-13 Abb. 18-20; V. M. Strocka, Wechselwirkungen der stadtrömischen und kleinasiatischen Architektur unter Trajan und Hadrian, IstMitt 38, 1988, 296 f. Taf. 41, 1.

615 K. Koller, Die Pilasterkapitelle aus dem >Marmorsaak der Wohneinheit 6. Bemerkungen zu Dekoration und Zeitstellung, in: Krinzinger 2002, 119-136 noch mit einer Datierung in traianische Zeit, die aber aufgrund neuerer Beobachtungen im Zuge der Wiederversetzung der Marmorfragmente in hadrianische Zeit korrigiert werden kann.

616 Plattner 2008, $278 \mathrm{f}$.

$617 \mathrm{Ph}$. Niewöhner, Frühbyzantinische Steinmetzarbeiten in Kütahya, IstMitt 25, 2006, 446 f. Kat. 64-65 Abb. $29-30$.

618 RAC 20 (2004) 90-100 bes. 93 f. s. v. Kapitell (U. Peschlow). 
und das Kapitell damit vor $400 \mathrm{n}$. Chr. zu datieren ist, oder ob auch diese Form des - im Vergleich mit der Kaiserzeit reduzierten - Akanthus in das 5./6. Jahrhundert n. Chr. zu setzen ist ${ }^{619}$. Als Vorläufer sind Kapitelle der Kaiserzeit anzuführen, wie sie in Ephesos, meist ohne Bauzusammenhang, oftmals vorkommen. Ein Kapitell, das heute im Bereich des \Domitiansplatzes $<$ liegt, weist die gleiche Syntax auf (Taf. 238, 3) ${ }^{620}$ : Nur vier Akanthusblätter stehen unter je einem sorgfältig ausgeführten Volutenpaar. Die unteren Enden der Voluten auf einer Seite treffen einander und bilden ein kleines Stützblatt aus. Die Abakusblüte besteht aus einfachen, gestaffelten Plättchen. Ebenfalls nur einen Blattkranz, aber acht Akanthusblätter haben die Kapitelle vom zweiten Obergeschoss des Peristyls in Wohneinheit 4 im Hanghaus $2^{621}$. Hier sind allerdings auch die restlichen kanonischen Elemente eines korinthischen Kapitells wie Hüllkelche, Stützblatt und Helices ausgeführt. Somit sind diese Exemplare nur sehr bedingt zu vergleichen. Die Kapitelle des Hanghauses sind in das ausgehende 2. Jahrhundert n. Chr., das Kapitell vom `Domitiansplatz darüber hinaus wohl schon in das beginnende 3. Jahrhundert $\mathrm{n}$. Chr. zu datieren.

\section{VII.4.2.3 Diverse Bauteile}

Das Fragment KatNr. A 41 ist Teil eines Zahnschnittgeisons (Taf. 134, 1. 2). Die Zahnelemente sind deutlich breiter als die quaderförmigen Zwischenräume, wie das in der fortgeschrittenen Kaiserzeit meist der Fall ist ${ }^{622}$. Ein schräges Profil leitet zur Hängeplatte über, die mit dem Zahneisen bearbeitet ist. Über der unverzierten Corona folgt eine ebenso dekorlose Sima. Die Profile und Elemente sind scharf und exakt ausgeführt. Dennoch entsteht durch die kaum geschwungenen und eher schrägen als runden Flächen ein grober Eindruck, verstärkt durch das Fehlen von Dekor. Mit einer Höhe von $38 \mathrm{~cm}$ muss das Bauteil zu einer Ordnung gehört haben, deren gesamtes Gebälk mit Architrav und Fries deutlich über $1 \mathrm{~m}$ hoch gewesen ist. Ungewöhnlich ist ein eingearbeitetes Kassettenfeld mit einem liegenden Vierblatt mit spitzen Blättern, das am sonst nur gespitzten Unterlager des Blockes zu erkennen ist. Der fragmentarische Zustand des Bauteils lässt eine weitere Beurteilung kaum zu, dennoch ist zu vermuten, dass dieses Kassettenfeld sekundär eingearbeitet worden sein muss. Eine Kassette am Unterlager konnte bei einem solchen Geisonblock in primärer Verwendung nicht sichtbar gewesen sein, da in diesem Fall Fries und Architrav hätten fehlen und das Geison damit einen Freiraum hätte überspannen müssen.

Zur Funktion der Rundbasis KatNr. A 37 (Taf. 132, 5. 6) können kaum Aussagen getroffen werden. Anund Ablauf bestehen in gleicher Weise aus Platte und Rundstab, Dübellöcher im Ober- und Unterlager belegen, dass auf der Basis ein weiteres Profil befestigt gewesen sein muss. Die Höhe von knapp $70 \mathrm{~cm}$ lässt das Bauteil als Basis geeignet erscheinen; ähnliche Rundbasen im Hanghaus, deren oberes Profil erhalten ist, waren hingegen nicht für die Aufstellung irgendwelcher Objekte gedacht, sondern wohl in einer altarähnlichen Funktion in Verwendung ${ }^{623}$. Eine Deutung der in das Oberlager eingravierten Buchstaben und Zeichen ist kaum möglich, es kann sich um Versatzmarken oder Steinmetzzeichen handeln (s. o.).

\section{VII.4.3 EXKURS ZU DEN DORISCHEN ARChiteKTUREN In EPHESOS}

Während die dorische Ordnung in der Archaik und Klassik in Griechenland und den Kolonien im Westen vorherrschend war, ist diese Tradition auf kleinasiatischem, namentlich ionischem Boden nicht so ausge-

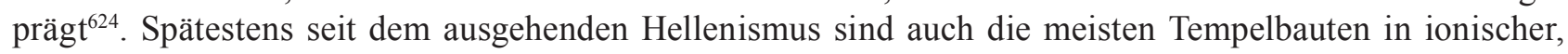
später in korinthischer Ordnung errichtet. Bauten dorischer Ordnung in Ephesos selbst sind selten. Das hellenistische Heroon am Embolos aus dem 1. Jahrhundert v. Chr. wurde in dieser Ordnung errichtet ${ }^{625}$.

619 Für Diskussion und Anregungen danke ich Ph. Niewöhner.

620 Kapitell D 1022: H 34 cm, Dm unten 26 cm, unpubliziert.

621 Thür 2005, 169 Kat. A 37-41.

${ }^{622}$ Cf. die Zahnschnittgeisa des Vedius- und des Ostgymnasiums, Plattner 2008, 281.

623 Plattner 2010, 521 Kat. B-A 20 Taf. 203.

${ }^{624}$ Zur dorischen Architektur in Westkleinasien cf. jetzt: T. Ismaelli, Architettura Dorica a Hierapolis di Frigia, Hierapolis di Frigia 3 (Istanbul 2009).

${ }^{625}$ Thür 1995, 63-103; jüngst konnte die Datierung des Heroons durch die Auswertung der Keramikbefunde in die 1. Hälfte des 1. Jhs. v. Chr. konkretisiert werden, cf. Waldner 2009a; Waldner 2009b, 283-293. 
Weitere Architekturen stammen aus späthellenistischer oder augusteischer Zeit. Zu nennen ist das Südtor der oberen Agora (২Staatsmarkt $)^{626}$, das mit Säulen, Gebälk und Giebel dem dorischen Tempelbau entlehnt ist. Auch die Südhalle des >Staatsmarktes〈war in dorischer Ordnung errichtet ${ }^{627}$. Hier scheinen die Säulen, entgegen der kanonischen Anordnung, allerdings auf einfachen Basen gestanden zu haben, die aus einem oder zwei Tori bestanden haben. Vor der Rückwand, die von Orthostatenplatten gebildet worden ist, verlief eine Sitzbank. Noch ungeklärt ist bisher die Datierung der Südhalle. Topografische Überlegungen weisen in die hellenistische Epoche ${ }^{628}$. Von einem dorischen Tor am Westende der Halle sind Teile der aufgehenden Architektur erhalten ${ }^{629}$. Bei deutlich kleineren Dimensionen des Gebälks gleichen etwa die Geisa weitgehend jenen des Prytaneions. Die Profilabfolge ist dieselbe, mit einer schmalen Schräge als Übergang zwischen der vertikalen Fläche und der Hängeplatte; insbesondere auch die charakteristisch unterschnittene Traufleiste entspricht den Formen am Prytaneion. Diese Übereinstimmungen machen auch eine zeitliche Nähe des Westtores zum Prytaneion wahrscheinlich und können mit einer umfassenden Neugestaltung des >Staatsmarktes in augusteischer Zeit in Zusammenhang gebracht werden ${ }^{630}$.

\section{VII.4.3.1 Die >Neronische Haller}

Das einzige in der Monumentalität vergleichbare Gebäude dorischer Ordnung, das in Ephesos bekannt ist, ist die `Neronische Halleく, eine Stoa, die das Obergeschoss der Osthalle der Tetragonos Agora bildet und zur \Marmorstraßeく nach Osten hin geöffnet ist (Taf. 226, 1) ${ }^{631}$. Der Zugang zur zweischiffigen Halle scheint von Süden aus erfolgt zu sein, wo man über eine Freitreppe vom Platz der (späteren) Celsusbibliothek zwei Türen in einer geschlossenen Südfassade erreichen konnte, die von einem Giebel bekrönt war ${ }^{632}$.

Bekannt ist insbesondere die Ordnung der südlichen Schmalseite und der östlichen Langseite, die die Halle als Fassade zur `Marmorstraßeく hin gebildet hat. Der Niveauunterschied zwischen Straße und Hallen wird durch einen massiven Sockel ausgeglichen. Über einer Lage glatter Quader folgen zwei Lagen von Polsterquadern. Die Polster sind sorgfältig geglättet und leicht bombiert. An den Stoßfugen wurde ein schmaler, keilförmiger Abstand mit ebenen vertikalen Flächen herausgearbeitet. Alle Flächen, das Polster wie die Seitenflächen, sind mit dem Zahneisen geglättet und von einem polierten Saum eingefasst (Taf. 226, 2; $227,1)$. Darüber liegt ein wieder rechtwinkelig geglätteter Stylobat mit etwa der halben Höhe wie die Polsterquader, auf der die Säulen ohne Basen zu stehen kommen. Auf dem Stylobat sind zahlreiche Risslinien gut zu erkennen, die die Achsen der Säulen markieren und so das Joch mit 2,8 m rekonstruieren lassen (Taf. 227, 2). Die Säulen sind, soweit erhalten, unkanneliert und aus mehreren Trommeln aufgeschichtet, der untere Durchmesser beträgt 76-77 cm. Der Radius von 38/38,5 cm wird als modulus noch öfter am Bau begegnen. Durchmesser zu Joch verhält sich damit wie 2:7,5633.

626 Thür 1996, 345-361.

627 Alzinger 1972-1975, 281 f.; Alzinger 1974, 50; Abb. 41.

${ }_{628}$ Alzinger 1972-1975, 283 ging noch von einer Neugestaltung des Platzes in der 2. Hälfte des 1. Jhs. v. Chr. aus, ohne dies aber explizit auf die Südhalle zu beziehen; Alzinger 1974, 50 Anm. 187 nennt die Halle »hellenistisch« und verweist auf eine relative Abfolge von Südhalle, Marktbasilika und Osthalle.

${ }^{629}$ Alzinger 1974, 51.

${ }_{630}$ Alzinger 1974, 51 hält den Torbau für »wohl nachaugusteisch«; zur augusteischen Platzgestaltung cf. Thür $2007,84 \mathrm{f}$.

${ }_{631}$ R. Heberdey, Vorläufiger Bericht über die Ausgrabung in Ephesus 1905/06 (VIII), ÖJh 10, 1907, Beibl. 66-70; Wilberg 1923, 76-88; H. Vetters, Ephesos: Vorläufiger Grabungsbericht 1983, AnzWien 121, 1984, 213-215; F. Hueber, Beobachtungen zur Kurvatur und Scheinperspektive an der Celsusbibliothek und anderen kaiserzeitlichen Bauten, in: Bauplanung und Bautheorie der Antike. Bericht über ein Kolloquium in Berlin vom 16. 11.-18. 11. 1983, DiskAB 4 (Berlin 1984) 192-200; Lang 1985, 176-180; F. Hueber, Gestaltungsfeinheiten und Quaderbautechnik an Bauten der frühen Kaiserzeit, in: H. Geertman - J. J. De Jong (Hrsg.), Munus non ingratum, BABesch Suppl. 2 (Leiden 1989) 226-229; P. Scherrer, Die Tetragonos Agora in Ephesos, in: P. Scherrer - E. Trinkl, Die Tetragonos Agora in Ephesos. Grabungsergebnisse von archaischer bis in byzantinische Zeit ein Überblick. Befunde und Funde klassischer Zeit, FiE 13, 2 (Wien 2006) 36-42.

${ }^{632}$ Lang 1985.

${ }_{633}$ Lang 1985, $178 \mathrm{f}$. bedient sich erstaunlicherweise eines modulus von 30,186 m, obwohl er zunächst selbst von den Proportionsangaben Vitruvs ausgeht und seine Überlegungen besonders auf das Joch als Grundeinheit stützt; gerade dieses ist aber mit Vitruv $71 \frac{1}{2}$ moduli breit und damit $38,5 \mathrm{~cm}$, ein modulus, der sich auf die anderen Maße besser umlegen lässt als die etwas holprigen Werte bei Lang 1985, 178 f. Aufgrund dieser Annahme muss G. Lang dann auch »größere Maßdifferenzen« konstatieren und überlegen, ob diese auf »mit der größeren Wirtschaftlichkeit römischen Bauens verbundene ১Schlamperei« 
Die dorischen Kapitelle der Halle sind in großer Stückzahl erhalten ${ }^{634}$. Das angearbeitete Hypotrachelion, also der Säulenhals, weist hier ebenso wie bei den Bauteilen vom Prytaneion 20 scharfgratige Kanneluren auf, deren oberer Abschluss horizontal ist. Nur in Ausnahmefällen ist der Kopf der Kannelur oben abgerundet (Taf. 228, 1). Der untere Durchmesser von $66 \mathrm{~cm}$ entspricht wie beim Prytaneion in etwa den Vorgaben Vitruvs, nämlich dass sich die Säule von 2 moduli am unteren Durchmesser auf 12/3 moduli am oberen Durchmesser verjüngt ${ }^{635}$. Die Höhe des Kapitells von 30-30,5 cm entspricht nicht dem bei Vitruv geforderten Wert von einem modulus, sondern weicht im gleichen Maße davon ab wie die Bauteile des Prytaneions: Auch an der dorischen Halle beträgt die Höhe ca. drei Viertel des modulus.

Der quadratische Echinus der Kapitelle wird von einer kyma reversa und einer Platte bekrönt. In der Gestaltung der Anuli unterscheiden sich die Kapitelle und können in zwei Varianten geschieden werden ${ }^{636}$. Bei der ersten Variante stehen unter dem Echinus zwei Anuli mit dem Profil von Rundstäben, der obere kann dabei etwas abgekantet sein. Der untere Ring wird durch einen schmalen Steg vom Ende der Kanneluren abgesetzt (Taf. 228, 2). Bei der zweiten Variante folgen unter dem Echinus eine Platte und darunter eine Kehle, die ebenfalls wieder vom Ansatz der Kanneluren abgesetzt ist (Taf. 228, 3). Beide Varianten sind in ähnlich großer Zahl erhalten.

Die Kapitelle weisen am Unterlager durchweg eine vertiefte kreisrunde Fläche in der Mitte auf, im Zentrum ist der Mittelpunkt des Kapitells markiert. In einer Achse stehen nahe am Rand des Säulenhalses zwei Dübellöcher. Die Befestigung von Bauteilen nicht mit einem zentralen Dübel, sondern mit zwei Dübeln am Rand des Bauteils in einer Achse mit dem Mittelpunkt scheint eine Eigenheit frühkaiserzeitlicher Bauten zu sein. So können zahlreiche weitere Beispiele für diese Technik angeführt werden, etwa die Bauteile des sog. Rhodischen Peristyls auf dem $>$ Staatsmarkt ${ }^{637}$ oder des Oktogons ${ }^{638}$ sowie viele frühkaiserzeitliche Kapitelle auch ohne Bauzusammenhang, darunter Blattkelchkapitelle des frühen 1. Jahrhunderts n. Chr. auf der $>$ Marmorstraße`, der Tetragonos Agora ${ }^{639}$, im Sarhos Hamam $^{640}$, im $>$ Lukasgrab ${ }^{641}$ oder in der Marienkirche $^{642}$. Bereits im Laufe der zweiten Hälfte des 1. Jahrhunderts n. Chr. scheint diese technische Verbindung mit zwei Dübellöchern in einer Achse nicht mehr in Gebrauch gewesen zu sein.

Der glatte dorische Architrav weist eine Höhe von 48,5 cm auf und weicht damit erneut in gleicher Weise von den Vorgaben Vitruvs ab wie der Architrav des Prytaneions. Die Breite der Regula entspricht einem modulus, der Abstand zwischen den Regulae mit 55,5 cm etwa 1 1/2 moduli. Die Tänie ist teilweise von einem sorgfältig geglätteten Saum gerahmt (Taf. 229, 1). Die Unterseite der Architrave ist mit einer Soffitte geschmückt (Taf. 229, 2). Ein flacher Segmentstab wird von einem Kyma gerahmt, die Schmalseiten sind nach innen eingezogen. Soffitten an dorischen Gebälken sind ungewöhnlich und kommen etwa am Prytaneion nicht vor. Die Soffitte nimmt in der Breite etwas weniger als ein Viertel des Architravs ein. Damit gehören diese Architrave zu der in Ephesos kleinen Gruppe von Bauteilen, an denen die Soffitten nicht mehr als ein Drittel der Breite einnehmen oder - im Gegenteil - wesentlich schmäler sind (unter einem Fünftel der Breite ${ }^{643}$. Die Breite der Soffitte von etwa einem Viertel des Architravs entspricht Vergleichs-

zurückzuführen wäre; es scheint auch hier wieder entscheidend, dass nicht eines der zahlreichen inzwischen postulierten Fußmaße die Grundlage ist, sondern ein entsprechend dem Bauplatz gewählter modulus.

634 Wilberg 1923, 79; Ch. Vasdaris, Das dorische Kapitell in der hellenistisch-römischen Zeit im östlichen Mittelmeerraum (Athen 1987) 305 Nr. 45.

${ }^{635}$ Vitr. 4, 3, 4; cf. M. Steskal, Kapitel III.11.2; bei einem modulus der Halle von 38,5 cm wäre der obere Durchmesser mit 64,2 cm zu berechnen.

${ }^{636}$ Wilberg 1923, 79 Abb. 131.

637 Alzinger 1974, Abb. 80. 84.

638 Plattner 2003, 142 Kat. 1.

639 Korinthisches Kapitell von der Tetragonos Agora: Plattner 2003, 146 Kat. 25; W. Jobst, Embolosforschungen I, ÖJh 54, 1983 , Beibl. 223 f. Abb. 45. - Blattkelchkapitell auf der Prozessionsstraße beim Theater: Plattner 2003, 146 Kat. 27.

640 Frühkaiserzeitliches Blattkelchkapitell BP05-07A, unpubliziert.

${ }^{641}$ Frühkaiserzeitliches Blattkelchkapitell aus der Nähe des `Lukasgrabes`: Plattner 2003, 148 Kat. 36.

${ }^{642}$ Im Presbyterium der östlichen Kirche wiederverwendete frühkaiserzeitliche Blattkelchkapitelle: Plattner 2003, 148 f. Kat. 42 ; bei Ch. Berns, Untersuchungen zu den Grabbauten der frühen Kaiserzeit in Kleinasien, AMS 51 (Bonn 2003) 68 fälschlich als Spolien aus der Basilika auf dem 〉Staatsmarkt bezeichnet, cf. dazu G. A. Plattner, Rez. zu: »Ch. Berns, Untersuchungen zu den Grabbauten der frühen Kaiserzeit in Kleinasien«, BJb 205, 2005, 385.

${ }^{643}$ M. Wegner, Soffitten von Ephesos und Asia Minor, ÖJh 52, 1978-1980, 104. 
beispielen besonders aus flavischer Zeit, so dem ephesischen Theater, dem Vespasiansmonument in Side ${ }^{644}$ oder dem Markttor in Milet ${ }^{645}$. Auch werden die Segmentstäbe der Soffitten ab dem späten 1. Jahrhundert n. Chr. in der Regel mit unterschiedlichem Dekor geschmückt, während an der dorischen Halle noch eine undekorierte Fläche stehen blieb.

Die Ecklösung des Architravs ist mit einer einfachen Kontraktion gestaltet. Am erhaltenen Architravblock der Südostecke ist der Abstand zwischen den Regulae auf $52 \mathrm{~cm}$ verringert, die Regula über Eck auf die Hälfte verkleinert (B 19,5 cm; Taf. 229, 1).

Die Rückseite der Architravblöcke bleibt ohne Fasziengliederung, das Kopfprofil besteht aus einer Leiste, einer Schräge (Kyma?) und einer weiteren Platte, bleibt aber in der Gesamthöhe 8,5 cm unter dem Oberlager des Architravs, womit ein Auflager für Deckenbalken gewonnen werden konnte (Taf. 229, 3).

Der Fries besteht aus unverzierten, glatten Metopen und sorgfältig ausgearbeiteten Triglyphen, die von einem glatten Saum am Rand der Metopen gerahmt sind (Taf. 230). Die Breite des Triglyphons beträgt einen modulus, das Kopfband ist dementsprechend breiter; es besteht aus einer Platte und darauf einer kyma reversa und einer Platte. Die Zwischenräume zwischen den Triglyphen sind in der Mitte höher hinaufgezogen als an den Rändern des Triglyphons und unterschiedlich mit horizontalem oberem Abschluss oder mit als Dreieck herabgezogenem Ende ausgeführt (Taf. 230). Die äußeren Abschrägungen der Triglyphen enden hingegen etwa $4 \mathrm{~cm}$ tiefer als die mittleren, sodass sie an die heruntergezogener >Ohren an etwa der Hälfte aller hellenistischen kleinasiatischen dorischen Friese vorhanden waren ${ }^{646}$. Am dorischen Torbau am `Staatsmarkt` noch angelegt, fehlen sie ab der frühen Kaiserzeit in der Regel bereits und sind hier in einem glatten Abschluss aufgegangen. Das erhaltene Triglyphon des Prytaneions ist so fragmentiert, dass nicht erkennbar ist, wie diese Stelle hier gelöst wurde.

Der Steinschnitt bei den Friesblöcken ist stets so aufgeteilt, dass die Stoßfuge zwischen Metope und Triglyphe liegt. Die Verbindung ist leicht auf Gehrung geschnitten, wobei die Metope hinter das Triglyphon geschoben wird. Die Blöcke kommen in unterschiedlicher Breite vor, mindestens immer mit drei Elementen, also zwei Metopen und einer Triglyphe oder zwei Triglyphen und einer Metope. Der größte Block umfasst drei Triglyphen und zwei Metopen.

Das dorische Geison ist an der Front etwas niedriger als ein modulus, steigt aber über der Sima noch an und erreicht eine Gesamthöhe von $45 \mathrm{~cm}$ (Taf. 231, 1). Über dem Unterlager leitet ein Kyma zur Hängeplatte über. Corona und Sima sind durch Kyma und Platte getrennt. Die Löwenkopfwasserspeier sind mit Ausnahme des Eckblockes alle durchbohrt und somit auch in Funktion gewesen, wie auch die Wasserrinne an der Oberseite des Geisons beweist (Taf. 231, 2). Die Mutuli haben die Breite von einem modulus, die Via dazwischen misst 7,7 cm, also exakt ein Fünftel eines modulus.

Der Steinschnitt verläuft in der Regel am Rand eines Mutulus, wobei die Blöcke mit einer Breite von $93 \mathrm{~cm}$ immer zwei Mutuli und Viae umfassen oder doppelt so breit sind. An den Stoßfugen führen vertikale Gusskanäle nach unten, die in einer Aussparung für einen Kantendübel enden (Taf. 231, 3).

Erhalten sind auch zwei Eckblöcke des Geisons, einer davon mit dem Ansatz des Giebels, der einst die Südfassade überspannt hat (Taf. 232, 1). Bei diesem wurde über Eck auf der Hängeplatte eine siebenfingrige Palmette gesetzt, die aus einem zweiteiligen Akanthus-Hüllkelch aufwächst. Die Palmette liegt auf der Fläche eines Mutulus auf, der (erhalten nur auf der Südseite) mit nur noch $3 \times 3$ Guttae fortgesetzt wird. Bei dem zweiten Eckblock, der zur Nordseite gehören muss, wurde hingegen der letzte Mutulus um wenige Zentimeter verbreitert und vollständig mit $3 \times 6$ Guttae ausgeführt; daneben liegt eine Palmette mit Hüllkelch auf der Ebene der Hängeplatte selbst über Eck (Taf. 232, 2). Der Löwenkopfwasserspeier, an dieser Stelle nicht durchbohrt, ist aus der Achse des Mutulus in Richtung Ecke des Geisons verschoben.

644 A. M. Mansel, Das Vespasiansmonument in Side, in: D. Ahrens (Hrsg.), Festschrift Max Wegner (Münster 1962) 38-41; A. M. Mansel, Die Ruinen von Side (Berlin 1963) 70-76.

${ }^{645}$ Die von V. M. Strocka, Das Markttor von Milet, BWPr 128 (Berlin 1981) 19-41. 46 f. vorgeschlagene Datierung in hadrianische Zeit wurde jüngst angezweifelt und durch Vergleiche mit der Ornamentik des milesischen Nymphäums wurde das Markttor überzeugend in (spätflavisch-)traianische Zeit datiert, cf. M. Maischberger, Das Nordtor des Südmarktes, sog. Markttor, in: O. Dally - M. Maischberger - P. I. Schneider - A. Scholl (Hrsg.), ZeitRäume. Milet in Kaiserzeit und Spätantike (Regensburg 2009) 115-117.

646 W. Martini, Das Gymnasium von Samos, Samos 16 (Bonn 1984) 81-83 Tab. D; Thür 1996, 353. 
Die Säulenreihe im Osten ist nahe des nördlichen Endes der Halle von einem Zugang unterbrochen (Taf. 233, 1) $)^{647}$. An gemauerte Halbsäulen schließen hier Pfeiler an, zwischen denen eine Archivolte den Durchgang überspannt. Die Archivolte ist in drei Faszien gegliedert, als Faszienfüllung dienen Rundstäbe, das Kopfprofil besteht aus Kyma und Platte. Die schmale Soffitte wird bis in die untersten Keilsteine geführt und hier gerade abgeschlossen. Die Archivolte ruht auf einem Kämpfer mit einfachem Profil aus Anlauf, Kyma und Kehle.

Der Pfeiler, der die Archivolte begleitet, ist mit einem Antenkapitell bekrönt. Am Kopf des Pfeilers, der an den Block des Pfeilerkapitells angearbeitet ist, sind unverzierte Scheiben aufgelegt (Taf. 233, 2). Diese stehen in der Tradition der Rosetten auf Antenkapitellen, die hier in reduzierter Weise gestaltet sind. Der Echinus, durch zwei Anuli vom Säulenhals getrennt, ist als schräge Fläche ohne Spannung ausgeführt, darüber schließen Platte, Kyma (?) und Platte das Kapitell ab.

Keine der Säulen ist in voller Höhe erhalten, die Maße der Ordnung sind also zunächst unklar. Schon nach der Ausgrabung wurde anhand der aufgefundenen Quader und Bauteile der Südwand die Säulenhöhe mit Kapitell auf 4,81 m berechnet ${ }^{648}$, wenngleich auch hier nicht durchgehend antike Bauteile erhalten sind. Die Bauteile der Südfront wurden 1955 als Architekturprobe aufgestellt ${ }^{649}$. Der Vorschlag, eine Säulenhöhe von zwei Joch, also $5,66 \mathrm{~m}$, nach Vitruv zu postulieren, ist nicht überzeugend ${ }^{650}$ : Zum einen ist die Höhe von 4,81 m mit den erhaltenen Bauteilen besser zu begründen, zum anderen bestätigt gerade der Vergleich mit dem Prytaneion diese Maßangaben. Auch beim Prytaneion erreichen die Säulen nicht die von Vitruv geforderte Höhe von 14 moduli, sondern bleiben in gleicher Weise wie an der `Neronischen Halle darunter. Zusätzlich stimmen, wie gezeigt werden konnte, an vielen Bauteilen die Abweichungen der tatsächlichen Maße von jenen bei Vitruv an beiden Bauten überein. Eine solche >Verkürzung`der Säulen ist damit für Ephesos belegt, die ursprünglich errechnete Höhe von 4,81 m für die Architektur der dorischen Säulen der `Neronischen Halle< also wahrscheinlich.

Der Architrav an der südlichen Schmalseite trug eine Inschrift, die über die Errichtung des Baus und seine Datierung Aufschluss gibt ${ }^{651}$ : Claudia Metrodora und ihr Mann errichten dem Kaiser, der Artemis und dem Volk die Halle. Aufgrund prosopografischer Überlegungen wird die Erbauung in den Jahren zwischen 54 und 59 n. Chr. angenommen. Die Südwand wird als die eigentliche Front des Gebäudes interpretiert, an der auch der Zugang durch zwei Türen und mittels einer Treppe am Vorplatz der Celsusbibliothek möglich gewesen sein muss ${ }^{652}$.

Viele Übereinstimmungen in den Detailmaßen lassen sich im Vergleich mit dem oben schon erwähnten dorischen Torbau am `Staatsmarkt` erkennen. Durchmesser und Höhe des Kapitells, Höhe des Frieses und Breite der Metopen sowie der untere Durchmesser der Säulen entsprechen den Maßen der $>$ Neronischen Halle ${ }^{653}$. Vielleicht legen diese Übereinstimmungen in den Proportionen nahe, den Torbau doch an das Ende des von H. Thür vorgeschlagenen chronologischen Spektrums, nämlich in den späten Hellenismus oder in augusteische Zeit, zu setzen ${ }^{654}$.

\footnotetext{
${ }^{647}$ Lang 1985, 177 verweist auf ein negatives Grabungsergebnis, das keine Hinweise auf Treppen erbracht hat, sodass die Vermutung geäußert wurde, es könnte sich um den Einbau eines Nymphäums handeln.

648 Wilberg 1923, 83.

649 Miltner 1956-1958, 61 f. Abb. 32.

650 Lang 1985, $178 \mathrm{f}$.

651 IvE 3003.

652 Lang 1985, 176 f. Taf. 21, 4.

653 Thür 1996, 349-352.

${ }_{654}$ Thür 1996, 361: Es »kann aber nicht entschieden werden, ob der Torbau« in der 2. Hälfte des 2. Jhs. v. Chr. oder in der 2. Hälfte des 1. Jhs. v. Chr. errichtet worden ist.
} 


\begin{tabular}{|c|c|c|c|c|c|}
\hline Objekt & $\begin{array}{c}\text { Maße } \\
\text { >Neron. Halle }\end{array}$ & $\begin{array}{c}m o d u l i \\
\text { à } 38,5 \mathrm{~cm}\end{array}$ & $\begin{array}{c}\text { Maße } \\
\text { Prytaneion }\end{array}$ & $\begin{array}{c}m o d u l i \\
\text { à } 60 \mathrm{~cm}\end{array}$ & $\begin{array}{c}\text { moduli } \\
\text { nach Vitr. }\end{array}$ \\
\hline L Stylobat & & & $23,67 \mathrm{~m}$ & $391 / 2$ & - \\
\hline unterer Dm Säule & $0,77 \mathrm{~m}$ & 2 & $1,20 \mathrm{~m}$ & 2 & 2 \\
\hline oberer Dm Säule & $0,66 \mathrm{~m}$ & $12 / 3$ & $0,98 \mathrm{~m}$ & $12 / 3$ & $12 / 3$ \\
\hline $\begin{array}{l}\text { H Säule (inkl. Ka- } \\
\text { pitell) }\end{array}$ & $4,81 \mathrm{~m}^{655}$ & $12^{1 / 2}$ & $7,405 \mathrm{~m}$ & $12^{1 / 3}$ & 14 \\
\hline H Kapitell & $0,30 \mathrm{~m}$ & $3 / 4$ & $0,46 \mathrm{~m}$ & $3 / 4$ & 1 \\
\hline L Abakus & $0,906 \mathrm{~m}$ & $2 \frac{1 / 3}{3}$ & $1,26 \mathrm{~m}$ & $2 \frac{1}{10}$ & $21 / 6$ \\
\hline H Abakus & $0,115 \mathrm{~m}$ & $<1 / 3$ & $0,168 \mathrm{~m}$ & $1 / 3$ & $1 / 3$ \\
\hline H Echinus & $0,085 \mathrm{~m}$ & $<1 / 4$ & $0,137 \mathrm{~m}$ & $1 / 4$ & $1 / 3$ \\
\hline H Säulenhals & $0,055 \mathrm{~m}^{656}$ & $<1 / 6$ & $0,105 \mathrm{~m}$ & $1 / 6$ & $1 / 3$ \\
\hline H Architrav & $0,485 \mathrm{~m}$ & $1 \frac{1}{4}$ & $0,75 \mathrm{~m}$ & $1 \frac{1}{4}$ & 1 \\
\hline H Architravtänie & $0,051 \mathrm{~m}$ & $\approx 1 / 7$ & $0,08 \mathrm{~m}$ & $1 / 7$ & $1 / 7$ \\
\hline $\begin{array}{l}\text { H Regula samt Gut- } \\
\text { tae }\end{array}$ & $0,04 \mathrm{~m}$ & $1 / 9$ & $0,075 \mathrm{~m}$ & $1 / 8$ & $1 / 6$ \\
\hline B Regula & $0,385 \mathrm{~m}$ & 1 & $0,60 \mathrm{~m}$ & 1 & - \\
\hline H Fries & $0,56 \mathrm{~m}$ & $1 \frac{1}{2}$ & $0,88 \mathrm{~m}$ & $11 / 2$ & $11 / 2$ \\
\hline B Triglyphe & $0,385 \mathrm{~m}$ & 1 & $0,60 \mathrm{~m}$ & 1 & 1 \\
\hline B Metope & $0,55 \mathrm{~m}$ & $1 \frac{1}{2}$ & $0,91 \mathrm{~m}$ & $1 \frac{1}{2}$ & - \\
\hline $\begin{array}{l}\text { B erweiterte Außen- } \\
\text { metope }\end{array}$ & & & $1,12 \mathrm{~m}$ & $15 \%$ & - \\
\hline H Geison & $0,36 \mathrm{~m}$ & $\approx 1(!)$ & $0,35 \mathrm{~m}$ & $3 / 5$ & $1 / 2$ \\
\hline B Mutulus & $0,39 \mathrm{~m}$ & 1 & $0,60 \mathrm{~m}$ & 1 & - \\
\hline B Normaljoch & $2,805 \mathrm{~m}$ & $\approx 71 / 2$ & $3,02 \mathrm{~m}$ & 5 & $71 / 2$ \\
\hline B Frontmitteljoch & - & & $4,53 \mathrm{~m}$ & $71 / 2$ & 10 \\
\hline
\end{tabular}

\section{VII.4.3.2 Kleinere dorische Ordnungen in Ephesos}

Ein dorisches Peristyl wohl hellenistischer Zeitstellung ist aus dem Villenkomplex vom Panayırdağ über dem Theater bekannt ${ }^{657}$. Erhalten sind seicht kannelierte Säulentrommeln sowie insbesondere Fragmente vom Gebälk, darunter ein Geison mit Mutuli auf der Hängeplatte und einer abgearbeiteten Sima.

In flavische Zeit fällt die Errichtung des Domitianstempels, für den eine gewaltige Terrasse aufgeführt wurde $^{658}$. Die architektonische Rahmung dieser Terrasse nach Norden, zum $>$ Domitiansplatz $<$ hin, wurde in Form einer dreigeschossigen Fassade gestaltet; die beiden unteren Geschosse entsprechen der Höhe der Terrassierung an deren Nordflanke, das dritte Geschoss hingegen ragte darüber hinaus und war damit zugleich auch die rahmende Halle des Platzes auf der Terrasse selbst ${ }^{659}$. Aufgefunden in einem sekundären Zusammenhang auf der Tetragonos Agora konnten Teile des dorisierenden unteren und des (wohl ionischen?) mittleren Geschosses in ihren primären Kontext zurückgebracht und in einer Architekturprobe aufgestellt werden (Taf. 234) ${ }^{660}$. Schon die dorisierenden Halbsäulenpfeilerkapitelle mit einem Eierstab auf dem Echinus zeigen aber, dass man sich hier nicht allen kanonischen Regeln dorischer Ordnungen verpflichtet fühlte (Taf. 235, 1). Der ungewöhnlich niedrige Fries zeigt in den Metopenfeldern Rosetten und Blüten; Mutuli und Guttae der nur wenig unterschnittenen Hängeplatte sind sehr flach gearbeitet. Die Viae sind aufgrund

655 Gemessen an der Höhe der Marmorquader aus der Südwand, cf. Wilberg 1923, 83.

${ }^{656}$ Höhe des Säulenhalses mit den Anuli $=11,5 \mathrm{~cm}=$ annähernd $1 / 3$ modulus .

${ }^{657}$ H. Thür, Kontinuität und Diskontinuität im ephesischen Wohnbau der frühen Kaiserzeit, in: Berns - Hesberg - Vandeput Waelkens 2002, 257-260.

658 H. Vetters, Domitianterrasse und Domitiangasse, ÖJh 50, 1972-1975, Beibl. 311-330.

659 A. Bammer, Architektur, ÖJh 50, 1972-1975, Beibl. 399 f. Abb. 11; A. Bammer, Elemente flavisch-trajanischer Architekturfassaden von Ephesos, ÖJh 52, 1978-1980, 81-88.

${ }_{660}$ Wilberg 1923, 15-17 Abb. 21-27; A. Bammer, Elemente flavisch-trajanischer Architekturfassaden von Ephesos, ÖJh 52, 1978-1980, 84-88; Aufschnürungen am Stylobat erlauben, die auf der Tetragonos Agora gefundenen Bauteile eindeutig zuzuweisen, cf. A. Bammer, Ephesos, Stadt an Fluß und Meer (Graz 1988) 153. 
des kleinen Frieses extrem schmal, sodass die Guttae der benachbarten Mutuli denselben Abstand aufweisen wie auf den Platten selbst (Taf. 235, 2). Ein Reliefband bildet den Sockel des zweiten Geschosses; unter den Stützen, die hier als Pfeiler mit davorstehender Figur gestaltet sind, verkröpft das Band halbkreisförmig zum Platz hin (Taf. 235, 3). Die Ornamente unter den Stützen, offene und geschlossene Palmetten, sind flach und wie ausgestochen angelegt. Das einfache Rankenmotiv auf dem geraden Teil ist hier qualitätsvoller. Von den Stützfiguren sind eine in orientalische Tracht gekleidete männliche sowie eine deutlich schlechter erhaltene weibliche Figur erhalten ${ }^{661}$. Gefunden wurden beide in sekundärer Verwendung auf der Tetragonos Agora $^{662}$. Über den Köpfen der Figuren, die gleichsam aus dem Halbrund der Säulen herausgearbeitet sind, stehen im >Säulenhals`schmale Kanneluren, die mit kleinen Füllmotiven, die in ihrer Form als \Sanduhr` oder `Kantharos` angesprochen wurden, verziert sind. Dieser ungewöhnliche Dekor, der auch in Kleinasien selten vorkommt, hat insofern für Irritation gesorgt, als dass vergleichbare Motive zunächst in (traianisch-)hadrianische Zeit datiert worden sind. Durch die Neudatierung des prominentesten Vergleichs, des Zeustempels in Aizanoi ${ }^{663}$, nunmehr in flavische Zeit ${ }^{664}$ kann dieser Widerspruch aufgehoben werden. Am Tempel treten doppelhenkelige Vasen in den oberen Rundungen der Säulenkanneluren auf, vergleichbar mit Säulen aus Notion und Kyzikos ${ }^{665}$. Während der zeitliche Abstand der Fassadenarchitektur der Domitiansterrasse von der $\gg$ Neronischen Halle deutlich geringer ist als jener zwischen Halle und Prytaneion, wurde offenbar in flavischer Zeit ein grundlegender Wandel im Umgang mit der dorischen Ordnung gewagt. Die kanonischen Elemente wurden hier frei interpretiert und stilisiert. Auch metrologisch wurden die Vorlagen sehr kreativ umgesetzt, sodass man hier eher von einer dorisierenden als von einer dorischen Fassade sprechen muss. Die Terrasse stellt somit einen Wendepunkt dar, in den nachfolgenden Jahrhunderten wurden offenbar keine monumentalen öffentlichen Gebäude dorischer Ordnung mehr in Ephesos errichtet.

Dorische Peristyle kleinerer Dimensionierungen finden als Innenarchitektur in den Hanghäusern Verwendung $^{666}$. In den Wohneinheiten 2 und 7 im Hanghaus 2 wurden Höfe mit dorischen Säulen gestaltet. Gebälke sind hier nicht erhalten, da wohl Holzbalken über die sehr einfachen und reduziert ausgeführten Kapitelle gelegt worden sind.

Zahlreiche weitere Bauteile dorischer Ordnung wurden als Spolien in Ephesos aufgefunden und teilweise etwa in den an die Hanghäuser angrenzenden Stiegengassen verbaut ${ }^{667}$. Für diese Bauteile kann keine primäre Verwendung benannt werden.

Der dorische Fries in der nördlichen Parodos des Theaters, dessen Metopenfelder mit Rosetten dekoriert sind, stammt wohl aus einer hellenistischen Phase des Proskenions und soll hier nicht weiter behandelt wer$\operatorname{den}^{668}$. Weitere dorische Bauteile liegen heute auf der Tetragonos Agora, an der Prozessionsstraße nördlich des Theaters (Kapitelle und Fries) sowie auf dem >Staatsmarkt` (dorische Kapitelle von sehr qualitätsvoller Ausführung).

Der Spielraum bei der Gestaltung dorischer Architekturen ist gering. Das Schema der Bauteile und der ohnehin schon wenigen dekorierbaren Flächen ist relativ starr und weit weniger abwandelbar als bei ionischen oder korinthischen Ordnungen. Bemerkenswert sind dabei vor allem die metrologischen Feinheiten, die sich in Abwandlung der bei Vitruv genannten Verhältnisse etwa am Prytaneion und der `Neronischen Halle` auffällig gleichen. Während man hier also auf ein bewährtes Konzept zurückgegriffen hat, zeigt sich die zeitliche Differenz der beiden genannten Bauten nur in den wenigen variierbaren Details, etwa der

661 A. Landskron, Die Pfeilerfiguren der Domitiansterrasse in Ephesos, in: Brandt - Gassner - Ladstätter 2005, $187-195$.

${ }_{662}$ Wilberg 1923, 15-17 Abb. 25-27.

${ }_{663}$ R. Naumann, Der Zeustempel zu Aizanoi nach den Ausgrabungen von Daniel Krencker und Martin Schede, DAA 12 (Berlin 1979).

${ }^{664}$ Aus der neuen Lesung der Inschrift des Tempels aufgrund der Dübellöcher der Bronzebuchstaben ergibt sich eine Datierung in die Zeit des Domitian, cf. R. Posamentir - M. Wörrle, Der Zeustempel in Aizanoi, ein Großbau flavischer Zeit, IstMitt 56, 2006, 227-246.

${ }_{665}$ R. Naumann, Der Zeustempel zu Aizanoi nach den Ausgrabungen von Daniel Krencker und Martin Schede, DAA 12 (Berlin 1979) 68 Abb. 34-35 Taf. 53 b-f noch mit einer Datierung dieses Motivs allgemein in das 2. Jh. n. Chr.

666 Hanghaus 2, Wohneinheiten 1, 2 und 7: cf. Plattner 2010, 149 f. 516-519.

667 G. Wiplinger, Der Weg eines Inschriftensteines (Inv.-Nr. 4369), in: Scherrer - Taeuber - Thür 1999, $181-184$.

668 R. Heberdey - W. Wilberg, Beschreibung und Geschichte des Baues, in: R. Heberdey - G. Niemann - W. Wilberg, Das Theater, FiE 2 (Wien 1912) 24-29 Abb. 45-51; D. De Bernardi Ferrero, Teatri Classici in Asia Minore 3, Studi di Architettura Antica 4 (Rom 1970) 55 Abb. 48. 
Einführung einer Soffitte an der Halle, oder an individuellen Lösungen wie dem Zugang an der östlichen Längsseite und der geschlossenen Wand mit zwei Türen an der Südseite der Halle.

\section{VII.5 Skulpturenausstattung (Nicole M. High - Martin Steskal)}

Obwohl im Zuge der Freilegung des Prytaneions in den 1950er und 1960er Jahren immer wieder Funde fragmentierter Skulpturen getätigt und in den Grabungstagebüchern vermerkt wurden ${ }^{669}$, nimmt sich die Zahl der sicher dem Gebäude zuzuweisenden Objekte sehr gering aus. Dies liegt vor allem daran, dass die Objekte während der Ausgrabung - der Großteil der Funde kam in den Jahren 1955/56 ans Tageslicht - einerseits nur sehr rudimentär beschrieben und andererseits nicht nachvollziehbar inventarisiert wurden. Heute können die einzelnen Funde daher nur noch in wenigen Fällen dem Fundplatz 〉Prytaneion` zugewiesen werden. Einige Objekte der Altgrabung sind zudem nicht mehr auffindbar ${ }^{670}$.

Innerhalb der Skulpturenfunde des Prytaneions gilt es, zwischen Objekten zu unterscheiden, die nachweislich oder mit großer Sicherheit im Gebäude aufgestellt waren, oder die im Zerstörungsschutt der Anlage gefunden wurden oder als Spolien sekundär verbaut waren. Bei Letzteren ist die ursprüngliche Zugehörigkeit zum Prytaneion nicht gesichert.

\section{VII.5.1 Im Gebäude Aufgestellte Skulpturen}

Von den im Prytaneion gefundenen Skulpturen ist vor allem für die Gruppe der Artemis Ephesia-Statuen mit hoher Wahrscheinlichkeit ein originaler Aufstellungsplatz im Gebäude zu postulieren. Dafür spricht in erster Linie die Fundposition der `Großen Artemis` (KatNr. SK 4; Taf. 10, 2. 3), die in Sturzlage südlich vor dem Fundamentsockel des Vorhofes gefunden wurde und offensichtlich auf diesem aufgestellt gewesen war ${ }^{671}$. Die ebenfalls im Prytaneion gefundenen Statuen vom Typus der `Schönen Artemis` (KatNr. SK 1; Taf. 9 , 1. 2) und der `Kleinen Artemis` (KatNr. SK 2. 3; Taf. 9, 3; 10, 1), die allerdings nicht in Sturzlage, sondern lediglich in der Position ihrer endgültigen Deponierung angetroffen wurden ${ }^{672}$, waren offenbar Teil eines Statuenprogrammes, welches das Gebäude neben seiner Funktion als Heiligtum der Hestia als Dependance des Artemisions definierte. Die Bedeutung des Prytaneions als Kultstätte der Artemis wurde vor allem von D. Knibbe überzeugend herausgearbeitet ${ }^{673}$ : Der Machtanspruch der Artemis innerhalb der Stadt sei durch die intentionelle Platzierung von Altären an strategisch wichtigen Punkten manifestiert worden. Einer dieser Punkte sei im Areal des späteren Prytaneions gelegen, das somit ganz bewusst an dieser Stelle errichtet worden wäre. Dass das Prytaneion auch als Artemisheiligtum fungierte, wäre letztlich auch durch das epigrafische Quellenmaterial zu belegen, in dem Artemis nahezu gleichberechtigt mit Hestia aufscheinen würde ${ }^{674}$.

Der Typus der Artemis Ephesia ist seit geraumer Zeit bekannt ${ }^{675}$. Das Auffinden der Artemis Ephesia-Statuen im Jahr 1956 im Prytaneion von Ephesos stellte somit keine gänzliche Neuentdeckung dar,

669 S. etwa F. Miltner, Tagebucheinträge vom 24. 8. 1956 (»verschiedene Skulpturenfragmente«) oder vom 26. 8. 1956 (»einige kleine Statuenfragmente«). - Für zahlreiche Hinweise in diesem Kapitel sei M. Aurenhammer gedankt. Ausführlich werden die im Folgenden großteils nur summarisch angeführten Skulpturen bei Aurenhammer (in Druckvorbereitung) diskutiert. Allgemein zur Skulpturenausstattung des Prytaneions: Aurenhammer - Sokolicek (in Druck).

${ }^{670}$ So werden im Grabungstagebuch beispielsweise der Oberschenkel einer unterlebensgroßen Statue oder das linke Knie eines sitzenden, nackten Jünglings erwähnt; cf. F. Miltner, Tagebucheinträge vom 24. 10. 1955 und 9. 8. 1956. Der heutige Aufbewahrungsort dieser Stücke ist unbekannt.

${ }_{671}$ F. Miltner, Tagebucheintrag vom 2./3. und 4. 10. 1956; Miltner 1959, 305-307.

${ }_{672} \mathrm{Zu}$ den Fundumständen der Artemis Ephesia-Statuen s. insbesondere Steskal 2008, 363-373 mit weiterer Lit.; M. Steskal, Kapitel II.2.

${ }_{673}$ Knibbe - Langmann 1993, 11. 21; cf. auch Knibbe 1995, 143 f. 146 Anm. 8; Knibbe 1998, 113; Knibbe 1999, 451; M. Steskal, Kapitel II.4.

${ }^{674}$ Knibbe - Langmann 1993, 21; cf. auch Karwiese 1995, 82; Karwiese 1999, 397; Scherrer 1990, 91 f.; Groh 2006, 66; Witetschek 2008, 26.

675 Cf. etwa C. Menetreius, Symbolica Dianae Ephesiae statua (Rom 1688) sowie die Typologie von H. Thiersch, Artemis Ephesia: eine archäologische Untersuchung (Berlin 1935) oder auch M. E. Lichtenecker, Die Kultbilder der Artemis von Ephesos (ungedr. Diss. Tübingen 1952); für eine ausführliche Forschungsgeschichte der bis 1973 vertretenen Meinungen s. Fleischer 1973, 74-88. 
doch schmälert dieser Umstand keinesfalls die Bedeutung der Statuen und der Funde. Im Gegenteil: Die neuentdeckten Statuen entfachten sogar die Diskussion von Neuem und werden seitdem als Argumentationsgrundlage in allen den Artemiskult betreffenden Fragestellungen herangezogen ${ }^{676}$. Grund hierfür sind die Größe und der Erhaltungszustand der Statuen sowie der Faktor, dass diese zu den ersten größeren vollplastischen Wiedergaben der ephesischen Artemis zu zählen sind, die nachweislich aus Ephesos stammen ${ }^{677}$. Durch ihre Auffindung in Ephesos, im Speziellen aber im Prytaneion, wo Artemis inschriftlich gemeinsam mit Hestia genannt wird ${ }^{67}$, ist man dazu geneigt, in ihnen aufgrund ihres Detailreichtums die bessere Überlieferung der verlorenen Kultstatue der Artemis Ephesia zu sehen ${ }^{679}$. So besitzen beispielsweise zwei der drei Artemisstatuen Köpfe, die >Große Artemis` (KatNr. SK 2) sogar einen Polos. Ferner wird diese Annahme durch gewisse Details bestätigt, die nur an den ephesischen Exemplaren auszumachen sind, wie etwa die geknoteten Wollbinden der >Schönen Artemis` (KatNr. SK 1), die sonst nur auf Münzen und Gemmen auftauchen ${ }^{680}$. Aus diesem Grund kommt den Artemisstatuen aus dem Prytaneion gerade in der Rekonstruktion und Interpretation der Kultstatue im Artemision und dem damit verbunden Kult ${ }^{681}$, darüber hinaus auch in der Frage nach der Bedeutung der Göttin Artemis für die Stadt Ephesos selbst ${ }^{682}$, eine besondere Rolle zu. Dass diese Aspekte bereits in zahllosen Veröffentlichungen diskutiert wurden, ist wenig überraschend. Eine Zusammenfassung des Forschungsstandes mit speziellem Augenmerk auf die Artemisstatuen des Prytaneions ist im Folgenden beabsichtigt.

Die Entdeckung der Statuen wurde in den entsprechenden Vorberichten sofort erwähnt und durch ausgewählte Fotografien ergänzt ${ }^{683}$. Als Zusatz zu den spärlichen Kommentaren in den Vorberichten widmete der Ausgräber F. Miltner zwei Jahre nach der Entdeckung den neuen Artemis Ephesia-Statuen einen eigenen Aufsatz. Er beschreibt die Statuen detailliert und beruft sich dabei im Wesentlichen auf die Ergebnisse und die Terminologie von $\mathrm{H}$. Thiersch ${ }^{684}$.

Eine systematische Aufarbeitung aller Artemis Ephesia-Darstellungen konnte R. Fleischer vorlegen. Ausgangspunkt für diese Arbeit waren eben die Statuen aus dem Prytaneion ${ }^{685}$. Auf Grundlage des Katalogs von Thiersch und mehrerer Ergänzungen analysiert Fleischer die einzelnen Trachtbestandteile der Statuen. Er geht davon aus, dass die einstige Kultstatue des Artemisions aus Holz bestand und mit echten Gewändern und Schmuckstücken ausgestattet wurde. Rückschlüsse auf diese Gewänder seien aufgrund der Artemisdarstellungen möglich, die alle nach einem strikten Kanon bekleidet sind; die Abweichungen zwischen den verschiedenen Darstellungen seien ein Beweis für das Austauschen der Kultgewänder. Die einzelnen Trachtbestandteile würden Einflüsse anderer Kulturen und Ergänzungen unterschiedlicher Epochen wiedergeben. Durch Münzvergleiche, Darstellungen auf Reliefs u. Ä. ist es Fleischer möglich, die verschiedenen Trachtbestandteile der Kultstatue in einen zeitlichen Rahmen zu setzen und Rückschlüsse auf das verlorene Kultbild zu ziehen. Die unterschiedlichen Trachtelemente dürften auf anatolischer Kultkontinuität basieren und seien $a b$ der römischen Kaiserzeit standardisiert worden. Als Beleg für das frühere Aussehen der Statue werden gerne die ephesischen Münzen, speziell die Kistophoren ab 159 v. Chr., herangezogen ${ }^{686}$.

Im Mittelpunkt der Diskussion um die Artemis Ephesia-Darstellungen steht seit langer Zeit die Frage nach der Herkunft und Bedeutung der $>$ Brüste $^{687}{ }^{68}$. Die erste derartige nachweisliche Bezeichnung stammt

\footnotetext{
676 s. die wiederholte Abbildung der \Schönen Artemis` (KatNr. SK 1) in allen den Artemiskult behandelnden Publikationen.

677 Fleischer 2002, 208; cf. auch M. Aurenhammer, Sculptures of Gods and Heroes from Ephesos, in: Koester 1995, 252.

678 Knibbe 1981, $101 \mathrm{f}$.

679 Fleischer 1973, 47.

680 Fleischer 2002, 208-213; Fleischer 2008, 25-41.

681 Miltner 1958b, 33.

682 R. Oster, Ephesus as a Religious Center Under the Principate, in: ANRW II 18, 3 (Berlin 1990) 1699-1706.

683 Miltner 1957, 24 f.; Miltner 1959, 305-310.

${ }^{684}$ Miltner 1958b, 21-34 schließt sich in der Argumentation um die `Brüste`C. Seltman, The Wardrobe of Artemis, NumChron $6,12,1952,33-44$ an.

685 Fleischer 1973, XIII: »Die vorliegende Arbeit geht auf eine Anregung von H. Kenner zurück, die unter F. Miltner in Ephesos gefundenen Statuen und Statuetten der Artemis Ephesia E 45, E 46 und E 47 (entspricht KatNr. SK 4. 1. 2; Anm. der Verf.) neu zu bearbeiten. Im Zuge der Untersuchung erwies sich bald eine Erweiterung vorerst auf alle erhaltenen Darstellungen der ephesischen Göttin, später auf alle ähnlichen Kultbilder überhaupt als notwendig.«

686 Fleischer 1983, 87; Ergänzungen: Fleischer 1978, 324-358; s. auch Fleischer 2008, 25-41.

687 Der Begriff 〉Brüste< beschreibt im Weiteren den Oberkörperbehang mit zahlreichen eierförmigen Gebilden, der charakteristisch für die Artemis Ephesia-Darstellungen ist; cf. auch die Forschungsgeschichte zu den >Brüsten in: Fleischer 1973, 74-88.
} 
wahrscheinlich von einem christlichen Schriftsteller des 3. Jahrhunderts n. Chr. ${ }^{688}$. Bereits F. Miltner hat die Identifikation als >Brüste` verworfen, da diese keine Ähnlichkeiten zu weiblichen Brüsten besitzen würden und anatomisch inkorrekt platziert seien ${ }^{689}$. Auch Fleischer versteht die $>$ Brüste $<$ nicht als solche, sondern argumentiert, dass an manchen Artemisstatuen die Inkarnatteile andersfärbig wiedergegeben worden wären; doch seien die `Brüste` in keiner erhaltenen Statue farblich als Inkarnat gekennzeichnet. Außerdem seien ähnliche Motive auf anderen Götterbildern zu finden. Mit Verweis auf Zeus Labraundos beschreibt er diese als allgemeines Motiv anatolischer Gottheiten, das erstmals 351/344 v. Chr. auftaucht. Es könnte sich bei den >Brüsten lichen Göttern auftreten würden ${ }^{690}$. Eine Deutung von G. Seiterle hat die Diskussion um einen weiteren möglichen Lösungsansatz erweitert ${ }^{691}$ : Er argumentiert, dass es sich um Stierhoden handeln könnte, die an der Kultstatue fixiert worden wären. Angesichts der Stiere und einer möglicherweise größer angelegten Opferschlachtung von Stieren versucht er, den Kultablauf zu rekonstruieren. Seine These kann er durch ein selbst entworfenes Modell untermauern, welches wohl auch das überzeugendste Argument seiner Theorie darstellt ${ }^{692}$. Obwohl Fleischer den Vorschlag der Stierhoden als »die Lösung einer oft gestellten Frage « bezeichnet, stimmt er den daraus gezogenen Schlüssen nicht unbedingt $\mathrm{zu}^{693}$ : Er begründet dies damit, dass die Knochenfunde im Artemision für eine groß angelegte Opferzeremonie, wie dies vorgeschlagen wird, nicht in ausreichendem Maße aufgetreten wären ${ }^{694}$. Einen weiteren Vorschlag bietet W. Helck: Er vergleicht die `Brüste` mit Vertiefungen und Kreisen auf altanatolischen Idolen neolithischer Zeit. Bestätigung dafür sieht er in den hohen Poloi, die ebenfalls auf alte Vorbilder zurückzuführen wären ${ }^{695}$. Der anatolische Ansatz in der Erklärung der >Brüste ist in der Forschung ein überaus beliebter. Ein neuerer Interpretationsvorschlag kommt von S. Szidat: Sie bezeichnet die Behänge als `Buckeln` und legt nahe, dass es sich dabei um Bergkuppen handeln würde, da der Begriff `Brüste`mit `Bergkuppen`seit frühklassischer Zeit homonym sei ${ }^{66}$. Wären mit dem Bauchbehang tatsächlich Bergkuppen gemeint, würde das auf die Bedeutung von Artemis als Berggöttin hindeuten. Als Beweis für diese Theorie nennt Szidat frühgriechische Vasendarstellungen, in welchen sie eine Verbindung zum ionischen Mutterland bestätigt sieht. Einzig L. R. LiDonnici versteht die >Brüsteく als tatsächliche weibliche Brüste. Die politischen und sozialen Veränderungen am Ende des Hellenismus seien dafür ausschlaggebend gewesen, dass die Ephesier mit dem Isiskult und der nährenden Isis näher in Kontakt gekommen wären. Dieses Bild hätte den Ephesiern eine neue Interpretation gegeben, wodurch eine zunehmende Angleichung der `Brüste` zu tatsächlichen weiblichen Brüsten zu erklären wäre. Zusätzlich würde durch üppige Brüste auf eine Mutter und legitime Ehefrau angespielt werden, wodurch Artemis als rechtmäßige Mutter von Ephesos erscheinen würde ${ }^{697}$. Neuerdings hat S. P. Morris einen weiteren Lösungsansatz vorgelegt, der wieder den anatolischen Ursprung des Kultes berücksichtigt, wobei sie sich in ihrer Argumentation nicht allein auf die bildlichen Quellen beschränkt $t^{698}$. Sie erkannte, dass zwischen den Dekorelementen der charakteristischen Kleidung der Artemis Ephesia und den anatolisch-hethitischen Mythen Parallelen bestehen. Die Biene, der Falke oder die Wolle der Wollbinden würden wiederholt als bedeutungsträchtige Bilder in den bekanntesten anatolischen Mythen auftauchen. Anhand der Beinamen von Artemis ist es Morris ebenfalls möglich, diese auf hethitische Wörter rückzuführen. Wenig überraschend ist daher ihre Erklärung der `Brüsteく als weiterentwickelte Form des hethitischen kuršaš. Dieser

${ }_{688}$ Min. Fel., Oct. 21; später auch Hier., comm. in epist. Paul ad Eph. prooem.

689 Miltner 1958b, 25. 29.

690 Fleischer 1983, 87-89.

${ }^{691}$ Seiterle 1979, 3-16.

${ }^{692}$ Fleischer 1983, 81.

${ }^{693}$ Fleischer 1983, 82; Fleischer verwirft nicht die gesamte Theorie, wie dies etwa LiDonnici 1992, 393 behauptet.

694 Dass eine Kastration nicht unbedingt das Schlachten voraussetzt, wurde bereits angemerkt: Fleischer 1999, 605 Anm. 5.

695 W. Helck, Zur Gestalt der ephesischen Artemis, AA 1984, 281 f.

696 S. Szidat, Die »Buckel« der Artemis Ephesia. Zur Bedeutung des Motivs und zu seinen ikonographischen Vorläufern, JdI 119, 2004, 83-129: Sie beruft sich dabei auf Morris 2001, 135-151 und behauptet, dass die vorherrschende Forschungsmeinung die Interpretation als `Brüsteく bevorzugt. Lediglich LiDonnici 1992, 393 spricht sich seit der Publikation von C. Seltman, The Wardrobe of Artemis, NumChron 6, 12, 1952, 33-44 für eine Interpretation als >Brüsteく aus.

697 LiDonnici 1992, 408-411; cf. dazu auch Fleischer 1999, 605 Anm. 5.

${ }_{698}$ Morris 2001, 135-151; s. dazu auch P. Scherrer, Von Apaša nach Hagios Theologos. Die Siedungsgeschichte des Raumes Ephesos von prähistorischer bis in byzantinische Zeit unter dem Aspekt der maritimen und fluvialen Bedingungen, ÖJh 76, $2007,325$. 
kuršaš ist eine Ledertasche aus mehreren Ziegenhäuten, die laut den rituellen und mythologischen Texten von Boğazköy (Hattuša) für religiöse Zwecke verwendet wurde und einen ähnlichen symbolischen Gehalt wie ein Füllhorn besaß. Diese Texte würden ein Objekt vor Augen führen, das gewisse Ähnlichkeiten zur Ägis im griechischen Mythos aufweisen würde. So werden etwa sowohl Ägis als auch kuršaš von Göttern getragen, die unter Ausnützung der Kräfte dieser beiden Objekte den Menschen helfen und sie beschützen konnten ${ }^{699}$. Auch in der Darstellung wären gewisse Ähnlichkeiten gegeben: Da ein kuršaš beschützen, helfen und den Menschen ähnlich einem Füllhorn Fruchtbarkeit bringen sollte, wäre daraus auf Artemis als die beschützende und nährende Gottheit von Ephesos zu schließen. Zuletzt wurden die >Brüsteく von J. L. Schmitz als Feigen, konkret als »fresh figs«, interpretiert ${ }^{700}$; die Göttin hätte daher auch eine zentrale Rolle in der lokalen Feigenproduktion gespielt.

Zahlreiche Hypothesen hat auch die Symbolik der Zierelemente hervorgerufen. E. Heinzel ist eine der Ersten, die ausgehend von den Dekorteilen die Statue mit dem Kultgeschehen im Artemision direkt in Verbindung setzt $\mathrm{t}^{701}$. Sie versucht, aus der Symbolik des Dekors den Kultablauf herauszulesen, da die üppige Ausstattung der Statue nicht alleine auf ästhetische Gründe rückzuführen wäre. Konkret versteht sie die Artemisstatue als astrologischen Kalender. Auch L. Portefaix sieht einige Zierelemente, vor allem aber die Biene, im Zusammenhang mit den möglichen Stieropfern, wie sie von G. Seiterle vorgeschlagen wurden. Die Verbindung von Bienen und Stieren dürfte in der Antike eine symbolträchtige Kombination gewesen sein, in der sich Artemis im Hinblick auf die Wiedergeburt der in ihren Kult eintretenden Gläubigen manifestieren würde ${ }^{702}$. Auch den Wollbinden, die einige Artemisdarstellungen an den Handgelenken tragen, ist größere Aufmerksamkeit zuteil geworden. R. Fleischer setzt sich mit ihrer Bedeutung auseinander und interpretiert sie als Attribut der Schutzflehenden, die bei der Gottheit um Hilfe baten. Beweis dafür seien die Artemisdarstellungen auf Kistophoren und die häufige Darstellung eines Falkens, der gemeinsam mit den Wollbinden auftritt, sowie die Bedeutung von Wolle ${ }^{703}$. Der Komposition des dreistöckigen Polos, der sich an der >Großen Artemis $<-S t a t u e$ erhalten hat, mit der Darstellung der beiden Kaisertempel bescheinigt D. Knibbe wiederum ein »genau kalkuliertes, wohldurchdachtes politisches Programm«, das als »sichtbarer Ausdruck der Unterordnung der höchsten weltlichen Machtpotenz (des Kaisers, Anm. des Verf.) unter die höchste religiöse Autorität (Artemis, Anm. des Verf.)« dem Zeitgenossen völlig verständlich gewesen wäre ${ }^{704}$. Die hohe Anzahl an diversen Attributen und Schmuckelementen der Artemis Ephesia ist eine große Herausforderung an die Wissenschaft, die noch lange Zeit für Diskussion sorgen wird ${ }^{705}$.

Die immer wieder ins Treffen geführte »rituelle Bestattung « der Artemis Ephesia-Statuen ist indes nicht zu belegen ${ }^{706}$ : Eine Evaluierung der Fundsituation der $>$ Schönen Artemis $`$ - der einzigen Statue, der der Ausgräber

699 S. P. Morris, Zur Vorgeschichte der Artemis Ephesia, in: U. Muss, Die Archäologie der ephesischen Artemis: Gestalt und Ritual eines Heiligtums (Wien 2008) 59.

700 J. L. Schmitz in ihrem Vortrag »The »Breast«, the Bug, and the Babe: Reevaluating the Imagery of Artemis of Ephesus« beim 110th Annual Meeting des Archaeological Institute of America in Philadelphia im Jänner 2009: »As a goddess of transitions such as childbirth, Artemis was the clear choice for patroness of the precarious crop in that its fruition relied on the successful performance of caprification, ... A key component of this biological mystery is the fig-wasp, and I assert that this necessary creature is also to be found in association with Artemis of Ephesus, though long mislabeled a $>$ bee. .

701 E. Heinzel, Zum Kult der Artemis von Ephesos, ÖJh 50, 1972-1975, 243-251.

702 Portefaix 1999, 611-617.

703 Fleischer 2002, 213.

704 D. Knibbe, Die zweite Kaiserneokorie und der Wandel des Erscheinungsbildes der Artemis Ephesia: Die Via Sacra in der Bildersprache ihres Polos?, in: Knibbe - Thür 1995, 96-99 bes. 99.

${ }^{705}$ Cf. etwa auch den Vorschlag von St. Karwiese, Artemis Ephesia »Sebasteia«: Ein Entzifferungsbeitrag, in: Scherrer - Taeuber - Thür 1999, 61-75 bzw. neuerdings zum Schmuck der Artemis Ephesia: D. Aversano-Schreiber, Der Schmuck der Artemis Ephesia, in: Seipel 2008, 43-48.

706 s. dazu vor allem Steskal 2008, 363-373; cf. auch Aurenhammer - Sokolicek (in Druck). - Vertreter der Theorie einer »rituellen Bestattung« sind: Alzinger 1962, 224; E. Lessing - W. Oberleitner, Ephesos. Weltstadt der Antike (Wien 1978$) 188$. 239-241; Seiterle 1979, 7; M. Donderer, Irreversible Deponierung von Großplastik bei Griechen, Etruskern und Römern, ÖJh 61, 1991/1992, Beibl. 248 f. Nr. 35; W. Elliger, Ephesos. Geschichte einer antiken Weltstadt ${ }^{2}$ (Stuttgart 1992) 62 f.; Knibbe 1995, 146 Anm. 8; D. Knibbe, Die zweite Kaiserneokorie und der Wandel des Erscheinungsbildes der Artemis Ephesia: Die Via Sacra in der Bildersprache ihres Polos?, in: Knibbe - Thür 1995, 97; T. Wohlers-Scharf, Die Forschungsgeschichte von Ephesos. Entdeckungen, Grabungen und Persönlichkeiten, Europäische Hochschulschriften 38, 54 ²(Frankfurt 1996) 200 f.; Knibbe 1998, 29; W. Burkert, Die Artemis der Epheser: Wirkungsmacht und Gestalt einer Großen Göttin, in: Friesinger - Krinzinger 
F. Miltner eine »rituelle Bestattung« attestierte - ergab, dass sowohl die Fundumstände als auch der stratigrafische Befund einer solchen Vermutung widersprechen. So beschreibt Miltner im Zusammenhang mit ihrem Fund ein »Artemisniveau«, etwa $30 \mathrm{~cm}$ über dem ursprünglichen Nutzungsniveau, auf dem die Statue angetroffen worden wäre ${ }^{707}$. Tatsächlich wurden aber auch Fragmente unter dem als »Artemisniveau« bezeichneten Nutzungshorizont, ja sogar in unterschiedlichen Räumen gefunden ${ }^{708}$. Teile der Statue wären folglich vergraben gewesen, während der Großteil der Statue auf dem Nutzungshorizont gelegen wäre. Andere Teile, wie etwa der Kopfaufsatz, fehlen überhaupt. Der Großteil der Statue war also nicht vergraben oder gar bestattet, sondern kam - aus Gründen, die uns nicht bekannt sind, - auf dem »Artemisniveau« zu liegen. Vergraben und bestattet hätte die Statue demnach nur von einem noch jüngeren und höher gelegenen Nutzungsniveau werden können. Bei der Anlage der byzantinischen Nutzungsniveaus auf den Zerstörungsstraten des Prytaneions war das Gebäude allerdings schon devastiert, sein Aufgehendes großteils eingerissen, und die Räume der Anlage waren mit bis zu 2 m hohem Schutt bedeckt; auch die Statue wird zu diesem Zeitpunkt kaum mehr sichtbar auf ihrem ursprünglichen Platz gestanden sein. Aus der Fundlage ist somit kein wie auch immer gearteter Beleg für eine $»$ kultische Bestattung« abzulesen. Auch zum Zeitpunkt der Auffindung ist sich der Ausgräber - wie aus dem Tagebucheintrag hervorgeht - über die Form der Deponierung im Unklaren. Eine gesicherte Beurteilung des Befundes wäre auch nur dann möglich gewesen, wenn die Grabungsarbeiten unter permanenter archäologischer Aufsicht vonstatten gegangen wären, was aber keineswegs der Fall gewesen zu sein scheint, wie eine Beschreibung der Fundumstände von W. Alzinger ergibt ${ }^{709}$. Eine profunde Analyse der Stratigrafie kann unter diesen Voraussetzungen und einer erst nachträglichen Autopsie der Fundstelle nicht erfolgt sein, wie auch der spärliche Dokumentationsgrad der Arbeiten Miltners in den 1950er Jahren belegt ${ }^{710}$. Von einer gesicherten »Bestattung« der Statue kann anhand der Fundlage und des Befundes somit keine Rede sein, im Gegenteil ist sie rein spekulativ. Nicht klären kann Miltner ferner, warum die »letzten Anhänger« der Göttin nur eine der vier im Prytaneion aufgestellten Artemis Ephesia-Statuen bestattet und die übrigen drei in ihrer Sturz- oder Deponierungslage zurückgelassen hätten.

Für die Bestattung der \Schönen Artemis« macht Miltner die »letzten Anhänger« der Göttin verantwortlich, die die Statue vor der Zerstörungswut der Christen retten wollten ${ }^{71}$. Namentlich schreibt er der Christin Scholastikia die Devastierung des Gebäudes $\mathrm{zu}^{712}: »$ Es ist aber auch zu erwägen, ob nicht Scholastikia dieses Heiligtum in ihrem heiligen Eifer für die Lehre des Evangeliums alles, was heidnisch war, zu verdammen, selbst zerstört hat.« Dem nicht genug, macht F. Miltner Scholastikia auch für das Umstürzen der im Vorhof aufgestellten >Großen Artemis` persönlich verantwortlich ${ }^{713}$ : »Die Christin ließ die Statue wohl stürzen, doch die Trümmer blieben unberührt am alten Platze liegen, denn das Geheimnis mystischen Glaubens umwehte auch noch das gestürzte Bild der Gottheit." Man hätte es aus diesen Gründen auch nicht gewagt, die Statue nach ihrem Sturz völlig zu zerschlagen oder zu Kalk zu verbrennen ${ }^{714}$. Die Christin Scholastikia, die uns lediglich als Stifterin der Renovierung des Variusbades am unteren Embolos bekannt ist (IvE 453), aber an keiner Stelle als christliche »Eiferin« dargestellt wird, lässt zwar Bauglieder des Prytaneions in der Therme versetzen, sie mit der Zerstörung des Prytaneions in Verbindung zu bringen, basiert

1999, 59; Portefaix 1999, 617; W. Alzinger, Das Zentrum der lysimachischen Stadt, in: Friesinger - Krinzinger 1999, 390; St. Karwiese, Die Münzfunde aus dem sog. Sockelbau der Basilica von Ephesos, in: H. Emmerig (Hrsg.), Vindobona docet. 40 Jahre Institut für Numismatik und Geldgeschichte der Universität Wien 1965-2005 (Wien 2005) 181 Anm. 6; I. Jacobs, Production to Destruction? Pagan and Mythological Statuary in Asia Minor, AJA 114, 2010, 297.

707 Cf. F. Miltner, Tagebucheinträge vom 28. 9. und 2./3. 10. 1956.

708 Cf. F. Miltner, Tagebucheintrag vom 26. 10. 1956 und W. Alzinger, Tagebucheintrag vom 9. 8. 1961.

709 Cf. die Beschreibung des Fundes von Alzinger 1962, 224, der im Fundjahr 1956 bereits Teilnehmer der Ausgrabungen in Ephesos war.

710 Auch auf der Fotografie der >Schönen Artemis in Fundlage (Taf. 9, 1) ist keine Änderung der Stratigrafie erkennbar. - Zu der Grabungstätigkeit Miltners und der Kritik an seiner raschen Arbeitsmethode s. U. Quatember, Zur Grabungstätigkeit Franz Miltners an der Kuretenstraße, in: Brandt - Gassner - Ladstätter 2005, 271-278 bes. 278.

711 Miltner 1959, 309.

712 Miltner 1958a, 100.

713 Miltner 1958a, 101.

714 Auch Knibbe 1981, 165 f. bezeichnet die »endgültige Zerstörung« des schon zuvor durch Erdbeben beschädigten Prytaneions als »das Werk von fanatischen Christen«. - Gegen eine intentionelle Zerstörung durch Christen: Karwiese 1995, 129. 131 f.; Scherrer 1995b, 19; M. Büyükkolanc1 - Ü. Yüğrük, Prytaneion, in: Scherrer 1995a, 88. 
hingegen auf reinen Vermutungen. Dies umso mehr, als der Zeitpunkt der Zerstörung und des tatsächlichen Beginns der extensiven Beraubung der Ruine eine erhebliche Diskrepanz aufweisen. So vermutete bereits W. Alzinger, dass die Zerstörung der Anlage zwar in theodosianische Zeit datieren würde ${ }^{715}$, die Beraubung des Gebäudes und die Verbauung seiner Architekturglieder aber erst später, als von Miltner angenommen, erfolgt wären oder sich über einen deutlich längeren Zeitraum erstreckt hätten ${ }^{716}$. Diese Vermutung wird durch die Analyse des architektonischen und archäologischen Befundes der \Kuretenhalle stärkt $^{717}$. Die Errichtung dieser Halle erfolgte erst in der ersten Hälfte des 6. Jahrhunderts n. Chr. Zudem ist die Annahme, dass das Gebäude überhaupt von Christen am Ende des 4. Jahrhunderts zerstört wurde, rein spekulativ. Es wird wohl schon früher einer Naturkatastrophe, wie etwa der Erdbebenserie der zweiten Hälfte des 4. Jahrhunderts n. Chr., zum Opfer gefallen und danach schlicht nicht wieder aufgebaut worden $\operatorname{sein}^{718}$. Spätestens mit dem kaiserlichen Verbot heidnischer Kultausübung durch Theodosius I. in den Jahren 391/392 n. Chr. ${ }^{719}$ war das Prytaneion jedenfalls wesentlicher Funktionen - insbesondere der kultischen entledigt.

Obwohl F. Miltner nur die \Schöne Artemis« mit »kultischer Bestattung« in Verbindung bringt, wird dieses Phänomen von mehreren Forschern auch auf die anderen im Prytaneion gefundenen Artemis Ephesia-Statuen umgelegt, ohne dass während der Freilegungsarbeiten entsprechende Beobachtungen gemacht oder später vom Ausgräber veröffentlicht worden wären ${ }^{720}$. Ihre »kultische Bestattung« ist somit mangels positiver Beweise ebenso abzulehnen wie im Fall der \Schönen Artemis ${ }^{721}$.

715 Er folgt dabei Miltner 1956-1958, $35 \mathrm{f}$.

716 Und zwar »etwa gleichzeitig mit der Zerstörung der Basilika (Basilike Stoa, Anm. d. Verf.) um 500 n. Chr.«; cf. Alzinger 1970 , 1646-1648; Alzinger 1972-1975, 299; Bauer 1996, 291. - Der Zeitpunkt der endgültigen Zerstörung der Basilike Stoa ist bis dato nicht zufriedenstellend geklärt. Nach C. Lang-Auinger, Zusammenfassung, in: Mitsopoulos-Leon - Lang-Auinger 2007, 206 dürfte die Nutzung der Basilika über die Zeit »um 500 n. Chr.« hinausgehen: »Die Glasfunde, ein Teil der Lampen und etwa die Hälfte der Münzfunde belegen innerhalb der Basilika Baumaßnahmen bis in die Spätantike und eine Nutzung bis in das frühe 7. Jh. n. Chr. Bauliche Veränderungen innerhalb der Basilika lassen sich in diesem langen Nutzungszeitraum nur schwer fassen, auffallend sind jedoch die spätantiken Funde.«; cf. auch Mitsopoulos-Leon 1991, 13; allgemein: E. A. FosselPeschl, Die Basilika am Staatsmarkt in Ephesos (Graz 1982); H. v. Hesberg, Die Basilika von Ephesos - die kulturelle Kompetenz der neuen Stifter, in: Berns - Hesberg - Vandeput - Waelkens 2002, 149-158; Ph. Stinson, Imitation and Adaptation in Architectural Design: Two Roman Basilicas at Ephesus and Aphrodisias, in: Meyer 2007, 91-100; Alzinger 1974, 26-37; Alzinger 1972-1975, 87 f.; M. Büyükkolanc1 - Ü. Yüğrük, Basilike Stoa, in: Scherrer 1995a, 82-84; Thür 2007, 82-84; G. A. Plattner - A. Schmidt-Colinet, Beobachtungen zu drei kaiserzeitlichen Bauten in Ephesos, in: Brandt - Gassner - Ladstätter 2005, 243-246; D. Knibbe - M. Büyükkolanc1, Zur Bauinschrift der Basilica auf dem sog. Staatsmarkt von Ephesos, ÖJh 59, 1989, 43-45; D. Knibbe - H. Engelmann - B. İplikçioğlu, Neue Inschriften aus Ephesos XII, ÖJh 62, 1993,148 f.

717 s. dazu Waldner 2009, 164-167. 207 f.; H. Thür, Die Ergebnisse der Arbeiten an der innerstädtischen Via Sacra im Embolosbereich, in: Knibbe - Thür 1995, 85. 90; Thür 1999, 115 f.; H. Thür - W. Pietsch, Prozessionsstraße (Via Sacra) im Bereich Kuretenstraße/Heroa/Hadrianstor, ÖJh 66, 1997, Grabung 1996, 6-12; Thür 2003, 264 Anm. 36.

718 So bereits Karwiese 1995, 131 f.; Scherrer 1995b, 19. Zu dieser Erdbebenserie s. S. Ladstätter, Die Chronologie des Hanghauses 2, in: Krinzinger 2002, 23-26. 29-31. - Kritisch zu den Zerstörungen durch Christen in Ephesos: Ladstätter - Pülz 2007, 414-416 sowie allgemein: O. Dally, »Pflege« und Umnutzung heidnischer Tempel in der Spätantike, in: Brands - Severin 2003, 97-114. - s. auch M. Steskal, Kapitel V.5.

719 Cod. Theod. 16.10, $10 \mathrm{f}$.

720 So etwa von M. Büyükkolanc1 - Ü. Yüğrük, Prytaneion, in: Scherrer 1995a, 86-88; Karwiese 1995, 131 f.; Knibbe 1999,451 (kurz zuvor attestiert er nur der \Schönen Artemis〈 eine kultische Bestattung: Knibbe 1998, 198); Scherrer 1995b, 19; Thür 2003, 264. - Indifferent: Foss 1979, 80. D. Knibbe, Die zweite Kaiserneokorie und der Wandel des Erscheinungsbildes der Artemis Ephesia: Die Via Sacra in der Bildersprache ihres Polos?, in: Knibbe - Thür 1995, 96-99 bevorzugt in Bezug auf die >Große Artemis〈- sowie die `Kleine Artemis〈-Statue mit Vorsicht ein Umstürzen durch ein Erdbeben.

${ }^{721}$ Dass solche »rituellen Bestattungen« in der Antike - wenn auch nicht im Prytaneion von Ephesos - tatsächlich vollzogen wurden, wird von M. Donderer, Irreversible Deponierung von Großplastik bei Griechen, Etruskern und Römern, ÖJh 61, 1991/1992, Beibl. 193-276 demonstriert; cf. auch M. Donderer, Irreversible Deponierung von Architekturteilen bei Griechen, Etruskern und Römern, ÖJh 62, 1993, Beibl. 93-134. 


\section{VII.5.2 SekUndÄr Verbaute oder Im Zerstörungsschutt Gefundene SkUlpturen}

Da die unter den Katalognummern SK 5-11 angeführten Skulpturen hinsichtlich ihres ursprünglichen Aufstellungsortes nicht sicher dem Prytaneion zugewiesen werden können, werden sie im Folgenden nur summarisch angeführt. Im Zerstörungsschutt des Gebäudes fanden sich: KatNr. SK 5-7. 11; als Spolien verbaut: KatNr. SK 8-10.

Obwohl bei keiner dieser Statuen die Provenienz oder gar der ursprüngliche Aufstellungsort im Prytaneion gesichert ist, fällt doch die Häufung von Porträts aus dem 3. Jahrhundert n. Chr. auf (KatNr. SK 5-8). Inwiefern dies mit den Umbauten im Prytaneion im zweiten Viertel des 3. Jahrhunderts in Zusammenhang zu sehen ist, kann allerdings nicht geklärt werden. Ebensowenig ist letztlich zu entscheiden, ob die in hellenistische Zeit zu datierenden Objekte (KatNr. SK 9 und 10?) in Verbindung mit dem auf der oberen Agora von Ephesos vermuteten, hellenistischen Gymnasium zu verstehen sind ${ }^{722}$.

\section{VII.5.3 Statuen- Und Ehrenbasen}

Im Prytaneion fanden sich insgesamt drei Ehrenbasen (KatNr. SK 12-15). Sie entsprechen dem Typus der zusammengesetzten Quaderbasen, bestehend aus einem Basissockel, einem Basiskörper und einem Basisaufsatz ${ }^{723}$. Keine dieser Ehrenbasen ist jedoch vollständig erhalten: So fehlen durchweg die Basiskörper, aber auch die aufgesetzten Statuen.

Von KatNr. SK 12 und 13 haben sich sowohl der Sockel als auch der Aufsatz erhalten (Taf. 38-41). Der profilierte Sockel befindet sich noch in situ im Vorhof über der Regenrinne vor dem östlichen Umgang des Peristyls; der dazugehörige profilierte Aufsatz wurde in unmittelbarer Nähe gefunden. Am Oberlager des Aufsatzes fanden sich Einarbeitungsspuren für die Statuen der auf den Schmalseiten inschriftlich genannten Kureten Alexandros und Dieos. An der Längsseite war eine Ehreninschrift angebracht (IvE 613a). Nach D. Knibbe ist die Inschrift - und somit auch die Basis - in die zweite Hälfte des 2. Jahrhunderts n. Chr. zu datieren ${ }^{724}$.

Ebenfalls im Vorhof wurde der fragmentarisch erhaltene, profilierte Aufsatz einer weiteren Basis gefunden (KatNr. SK 14; Taf. 42), deren Inschrift eine gewisse Larcia Theogenis Iuliane ehrt (IvE 985). Der ursprüngliche Aufstellungsort der Basis ist nicht mehr bekannt; aufgrund der inschriftlichen Nennung der zweiten Neokorie kann sie aber frühestens $128 \mathrm{n}$. Chr. aufgestellt worden sein ${ }^{725}$.

In der Vorhalle, westlich des Haupteingangs in den >Hestiasaal (Tür 3), fand sich schließlich in situ der Sockel einer weiteren Ehrenbasis (KatNr. SK 15; Taf. 63, 2. 3). Von ihr fehlen sowohl der Basiskörper als auch der Aufsatz, wodurch keine näheren Aussagen über das Aussehen der Basis oder den Geehrten getätigt werden können.

Ein weiteres Objekt kann aufgrund des fragmentarischen Erhaltungszustandes nicht sicher als Ehrenbasis identifiziert werden (KatNr. SK 16; Taf. 136, 3. 4).

\footnotetext{
722 Zum hellenistischen Gymnasium auf der oberen Agora s. H. Thür, Das Gymnasion an der oberen Agora in Ephesos, in: E. Christof - G. Koiner - M. Lehner - E. Pochmarski (Hrsg.), ПOTNIA $\Theta H P \Omega N$. Festschrift Gerda Schwarz, VIKAGraz 8 (Graz 2007) 403-414.

723 Cf. etwa die Typologie bei M. Jacob-Felsch, Die Entwicklung griechischer Statuenbasen und die Aufstellung der Statuen (Waldsassen 1969); O. Dräger, Religionem Significare. Studien zu reich verzierten römischen Altären und Basen aus Marmor, RM Ergh. 33 (Mainz 1994) 53-61.

724 Knibbe 1981, D 7.

725 Cf. J. Keil - G. Maresch, Epigraphische Nachlese zu Miltners Ausgrabungsberichten aus Ephesos, ÖJh 45, 1960, Beibl. 93 f. Nr. 21.
} 


\section{VII.5.4 KATALOG}

KatNr. SK 1

Objekt: `Schöne Artemis

InvNr. EM 718

FO: Raum 5

FJ: 1956 und 1961

Mat.: feinkörniger, hellgrauer, leicht durchscheinender Marmor

Maße: $\mathrm{H}$ inkl. Basis $1,745 \mathrm{~m}, \mathrm{H}$ Basis $0,17 \mathrm{~m}$

Erh.: Die Nase, die geknoteten Wollbinden, der hintere Teil der Plinthe und Teile der Hirschkühe fehlen, die Hände und einige Tierprotome sind verstümmelt. Die Statue ist an einigen Stellen leicht bestoßen, die Rückseite ist stellenweise versintert. Reste von Vergoldung sind an den Haaren, dem Gesicht, dem Nimbus, dem Hals, den Ohren und dem Kranz am Hals erkennbar. Fragmente der Wollbinden und einer der Falken oder Habichte, die die Wollbinden bekrönen, befinden sich im Depot des Efes Müzesi Selçuk ${ }^{726}$.

Beschreibung 727 : Die Statue steht auf einer profilierten, rechteckigen Basis. Sie wird von zwei Hirschkühen flankiert, die jeweils den äußeren Vorder- und den inneren Hinterlauf vorsetzen. An beiden Seiten der Statue befindet sich je eine Basis, die die Form eines umgedrehten Korbes besitzt. Die Statue trägt Sandalen. Ein schürzenartiges, hinten offenes Gewand ${ }^{728}$, das aus drei vertikalen Abschnitten und sieben horizontalen Zonen besteht, ist um die Beine gelegt. Im mittleren Abschnitt befinden sich oberhalb der Füße zwei Rosetten, gefolgt von Dreiergruppen aus Löwen, geflügelten Stiergreifen, Flügelgreifen, Löwinnen, Hirschkühen und Rindern. An den Seiten sind ebenfalls Motive in rechteckigen Feldern übereinander angeordnet. $\mathrm{Zu}$ unterst ist eine Rosette zu finden, darüber eine Biene, eine weitere Rosette, eine Rankenfrau, eine Biene, eine Rosette und zu oberst eine weitere Rankenfrau. An den Seiten sind neben der Rosette des drittuntersten Bildfeldes Spuren von Stützen erkennbar. Unter dem Saum des Schurzes lugt an den Knöcheln der gefaltete Chiton hervor. An der Taille wird der Schurz von einem Gürtel gehalten. Das markanteste Element der Statue sind die eierförmigen Gebilde, die den unteren Teil des Oberkörpers in drei Reihen bedecken. Darüber erscheinen in einem Bogen von einer Schulter zur anderen neun Tierkreiszeichen: Fische, Wassermann, Steinbock, Schütze, Skorpion, Waage, Jungfrau, Löwe und Krebs. Um den Hals liegt ein schwerer Kranz aus gleichmäßigen kleinen Kugeln,

726 R. Fleischer, Artemis Ephesia, in: Bammer - Fleischer - Knibbe 1974, 18 f.

727 Cf. auch die Typologie und Beschreibung der für Artemis Ephesia typischen Elemente in: Fleischer 1973, 46-137.

728 Seit H. Thiersch, Ependytes und Ephod: Gottesbild und Priesterkleid im alten Vorderasien (Stuttgart 1936) 1-3. 59. 108-110 wird dieser Schurz als `Ependytes` angesprochen. Da dieser Begriff nur selten in der antiken Literatur vorkommt und die Erwähnungen auf keinerlei kultische Bedeutung hinweisen, wird dieser Begriff im Folgenden vermieden. Dazu auch: M. C. Miller, The Ependytes in Classical Athens, Hesperia 58, 1989, 313-329; Morris 2001, 138; A. M. Pülz, Zu den Goldappliken aus dem Artemision von Ephesos und ihrer Verwendung, Forum Archaeologiae 28/IX/2003, Anm. $21<$ http://farch.net>. der häufig als Immortellenkranz angesprochen wird. Darüber befinden sich vier antithetisch angeordnete Niken: Zwei halten in der Mitte einen fackelähnlichen Gegenstand hoch, zwei tragen Palmzweige heran. Auf beiden Oberarmen sitzen Löwen, und die Unterarme schmückt jeweils ein Paar Armreifen mit Löwenkopfenden. Hinter dem Kopf erscheint der sog. Nimbus, womöglich ein hochgezogenes Tuch. Das ideal gestaltete Gesicht der Göttin ist umgeben von Löwengreifenund Greifenprotomen. Die Augen zeigen Binnengestaltung. Die Göttin trägt lange, zapfenförmige Ohrringe. Der Kopf wird von verzierten Bändern geschmückt, die das Haar fixieren, wie etwa die Haarsträhnen vor den Ohren. Ein Band aus zwei Reihen mit Rosetten ist über die Stirn geführt und am Hinterkopf verknotet. Darüber befinden sich drei im Gegensinn gedrehte Wulstringe, auf denen der verlorene Polos aufsaß. Am Hinterkopf fällt das Haar in vier gedrehten Zöpfen herab. An der Rückseite des sog. Nimbus befindet sich eine nach oben zeigende Mondsichel ${ }^{729}$.

Ursprünglicher Aufstellungsort: Prytaneion

AO: EM

Datierung: hadrianisch-frühantoninisch ${ }^{730}$

Zitat: F. Miltner, Tagebucheintrag vom 18. 9. 1956; Miltner 1957, 25 Taf. 2; Miltner 1958b, 30-33 Taf. 10-12; Miltner 1959, 307-309 Abb. 150. 151; Cook 1959/1960, 46 Abb. 19. 20; E. Akurgal, Die Kunst Anatoliens von Homer bis Alexander (Berlin 1961) 159 Abb. 108. 109; Alzinger 1962, 224; E. Heinzel, Zum Kult der Artemis von Ephesos, ÖJh 50, 1972-1975, 244-246 Abb. 1; Fleischer 1973, 14 f. E 46 Taf. 18-23; Fleischer 1978, 332 E 46; Seiterle 1979, 7 Abb. 12. 13; LIMC II 1 (1984) 760 Nr. 74 s. v. Artemis Ephesia (R. Fleischer); LiDonnici 1992, 396 Abb. 6; Portefaix 1999, 612 Taf. 152 Abb. 1. 2; Morris 2001, 136 Abb. 2; R. Fleischer, Die Amazonen und das Asyl des Artemisions von Ephesos, JdI 117, 2002, 208-215 Abb. 11; Fleischer 2008, 25-41; D. Aversano-Schreiber, Der Schmuck der Artemis Ephesia, in: Seipel 2008, 43-48; Steskal 2008, 363-373.

KatNr. SK 2

Taf. 9,3

Objekt: `Kleine Artemis

InvNr. EM 717

FO: Vorhalle, Ostecke

FJ: 1956

Mat.: mittelkörniger, hellgrauer Marmor

Maße: H 1,03 m

Erh.: Es fehlen die rechte Schulter mit Hals und Kopf, der Polos und der linke Teil des `Nimbus`. Die Hände, Füße und der Kopf waren gesondert angesetzt. Die Köpfe fast aller Tierprotomen und Fabelwesen sind abgeschlagen ${ }^{731}$.

Beschreibung: Trotz großer Übereinstimmungen mit KatNr. SK 1 weist diese Statuette einige Eigenheiten auf. Besonders auffallend sind die Unterschiede etwa in der Gestaltung des Schurzes, der nicht aus drei, sondern aus fünf vertikalen Ab-

${ }_{729}$ Miltner 1958b, 30-33; R. Fleischer, Artemis Ephesia, in: Bammer - Fleischer - Knibbe 1974, 18-21.

730 R. Fleischer, Artemis Ephesia, in: Bammer - Fleischer - Knibbe 1974, 21.

731 R. Fleischer, Artemis Ephesia, in: Bammer - Fleischer - Knibbe 1974, 44. 
schnitten besteht und mit einem glatten Gürtel um die Taille gebunden ist. Im mittleren Abschnitt erscheinen im ersten, zweiten, vierten und sechsten Feld von oben Gruppen ungeflügelter Tiere, im dritten und fünften hingegen geflügelte Tiere; ihr Zustand lässt keine genauere Identifizierung zu. Seitlich neben dem mittleren Abschnitt sind abwechselnd Rankenfrauen und Bienen zu erkennen, den äußeren Abschnitt zieren Bienen und Rosetten. Unter dem Rand des Schurzes sind Säume zweier Untergewänder sichtbar. Auf der Brust sitzen in drei Reihen die für Artemis Ephesia charakteristischen eierförmigen Gebilde. Auf den angewinkelten Unterarmen, die mit zwei Armreifen geschmückt sind, thront jeweils ein Löwe. Ähnlich KatNr. SK 1 sind über dem sog. Immortellenkranz mit Eichelbesatz Tierkreiszeichen zu entdecken: Widder, Stier, Zwillinge, Krebs, Löwe, Jungfrau, Waage, Skorpion sowie vier Niken mit Palmzweigen und Fackeln. Eine eng am Hals anliegende Kette weist ebenfalls einen Eichelbesatz auf. Ein schlecht erhaltenes Fragment des sog. Nimbus führt die übliche Zier aus geflügelten Greifen oder Sphingen vor Augen, jedoch sind die Tiere hier teilweise gedreht und in Seitenansicht zu sehen. An der Rückseite der Statue fällt ein Stoffstreifen mit Fransenenden herab ${ }^{732}$. Ursprünglicher Aufstellungsort: Prytaneion

\section{AO: EM}

Datierung: 2. H. 2. Jh. n. Chr. ${ }^{733}$

Zitat: F. Miltner, Tagebucheintrag vom 28. 9. 1956; Miltner 1957, 25; Miltner 1958b, 28-30 Taf. 7-9; Miltner 1959, 307 f. Abb. 149; Cook 1959/1960, 46; Alzinger 1962, 229; Fleischer 1973, 15 E 47 Taf. 24-28; Fleischer 1978, 332 E 47; Fleischer 2008, 25-41; Steskal 2008, 363-373.

\section{KatNr. SK 3}

Taf. 10,1

Objekt: Kopie der $>$ Kleinen Artemis

Fundnr. EM 231/56

FO: Vorhof, Nordteil des östlichen Umgangs

FJ: 1956

Mat.: feinkörniger, hellgrauer Marmor

Maße: H 0,285 m

Beschreibung: Lediglich die Fußpartie ist erhalten, wobei auf die Ähnlichkeit mit der Fußpartie von KatNr. SK 2 bereits von F. Miltner hingewiesen wurde ${ }^{734}$. Ein Teil der untersten, doppelt umrahmten Zone des Schurzes mit zwei Fabeltieren in der Mitte und jeweils einer Rankenfrau und einer Biene an den Seiten ist erhalten. Darunter treten die symmetrischen Chitonfalten hervor. Die Anschlussfläche für die gesondert gearbeiteten Fußspitzen ist grob behauen ${ }^{735}$.

Ursprünglicher Aufstellungsort: Prytaneion

AO: EM

Datierung: 2. H. 2. Jh. n. Chr.

Zitat: F. Miltner, Tagebucheintrag vom 13. 10. 1956; Miltner 1957, 25; Miltner 1958b, 30; Miltner 1959, 308; Cook 1959/1960, 46; Alzinger 1962, 229; Fleischer 1973, 15 E 48 Taf. 29a; Fleischer 1978, 332 E 48; Fleischer 2008, 25-41; Steskal 2008, 363-373.

732 R. Fleischer, Artemis Ephesia, in: Bammer - Fleischer Knibbe 1974, 44 f.

733 R. Fleischer, Artemis Ephesia, in: Bammer - Fleischer Knibbe 1974, 45

734 Miltner 1958b, 30; Miltner 1959, 308.

735 Fleischer 1973, 15.

\section{KatNr. SK 4}

Taf. 10, 2. 3

Objekt: >Große Artemis`

InvNr. EM 712

FO: Vorhof, südlich des quadratischen Fundaments

FJ: 1956

Mat.: mittelkörniger, hellgrauer Marmor

Maße: H ink1. Polos 2,92 m, H bis Scheitel 2,27 m

Erh.: Die Füße und ein Teil des Schurzes, beide Unterarme mit den Wollbinden und den zwei Stützen am Schurz sowie Teile des sog. Nimbus und des Polos fehlen. Die Tierprotomen des Schurzes sind teilweise verstümmelt. Das Kinn, der Mund, die Nase, die Augen und die Ohrgehänge sind leicht beschädigt ${ }^{736}$.

Beschreibung: Die weit überlebensgroße Statue folgt den üblichen Darstellungskonventionen der Artemis Ephesia: So trägt sie etwa einen Schurz, auf dem sich von oben nach unten Flügelsphingen, Löwengreifen, Hirschkühe, Equiden, Löwinnen und Stiere befinden. Rankenfrauen, Bienen und Rosetten schmücken die annähernd quadratischen Seitenfelder. Eine Reihe abwechselnder Rosetten- und Bienenmotive sowie seitlich platzierte, schlangenschwänzige Seewesen dienen als Verzierung des Gürtels, dessen Schließe am Rücken zu finden ist. Die Arme sind angewinkelt, auf den Unterarmen sitzt jeweils ein Löwe, der Ärmel weist Rosetten auf. Um den Hals liegt eine Perlenkette mit abwechselnd rundovalen und runden Anhängern. Am Halsansatz darüber befinden sich Rauten. Darunter folgt ein schwerer Kranz aus kleinen Kugeln und eine Reihe spitz zulaufender Anhänger mit Kugelknöpfen alternierend mit Zapfen. Dieser Dekor geht direkt in drei Reihen eierförmiger Gebilde über, die den Rumpf zieren. Der Kopfaufsatz besteht aus einem tief auf der Stirn sitzenden, verzierten Reif und zwei darüber befindlichen Wulstringen. Unter dem Reif treten an der Seite mehrere starre Locken und reich verzierte Ohrringe hervor. Der Kopfaufsatz trägt den hohen Polos, der in drei Zonen gegliedert ist. Im unteren Teil erscheinen vorn Flügelgreifen, hinten eine Fackel. Den mittleren Bereich prägen Säulen, die durch Bögen miteinander verbunden sind. In den Säulenzwischenräumen stehen Sphingen mit ausgebreiteten Flügeln, an der Rückseite wird ein quadratisches Gebilde, vermutlich ein Altar, von zinnenbekrönten Quadermauern flankiert. Die oberste Zone zeigt drei Tempel mit jeweils vier Säulen ionischer Ordnung in antis, auf der Rückseite wird ein Stadttor von zwei Tempeln mit zwei in antis stehenden Säulen umgeben. Den Kopf der Figur umrahmt der sog. Nimbus mit seinen geflügelten Greifenprotomen ${ }^{737}$. Die Statue zeigt weder gebohrte Pupillen noch polierte Oberflächen, sondern sehr trockene Raspelarbeit ${ }^{738}$.

Ursprünglicher Aufstellungsort: Vorhof Prytaneion

AO: EM

Datierung: traianisch ${ }^{739}$

Zitat: F. Miltner, Tagebucheintrag vom 2.-4. 10. 1956; Miltner 1957, 24; Miltner 1958b, 21-28 Taf. 5. 6; Miltner 1959, 306 f. Abb. 147. 148; Cook 1959/1960, 46; Alzinger 1962,

736 R. Fleischer, Artemis Ephesia, in: Bammer - Fleischer Knibbe 1974, 42 f.

737 R. Fleischer, Artemis Ephesia, in: Bammer - Fleischer Knibbe 1974, 43 f.

738 Fleischer 1973, 15.

739 R. Fleischer, Artemis Ephesia, in: Bammer - Fleischer Knibbe 1974, 44. 
225 f.; Fleischer 1973, 14 E 45 Taf. 12-17; Fleischer 1978, 331 f. E 45; LIMC II 1 (1984) 760 Nr. 73 s. v. Artemis Ephesia (R. Fleischer); LiDonnici 1992, 396 Abb. 5; D. Knibbe, Die zweite Kaiserneokorie und der Wandel des Erscheinungsbildes der Artemis Ephesia: Die Via Sacra in der Bildersprache ihres Polos, in: Knibbe - Thür 1995, 96-99; Fleischer 1999, 608 f.; Fleischer 2008, 25-41; D. Aversano-Schreiber, Der Schmuck der Artemis Ephesia, in: Seipel 2008, 43-48; Steskal 2008, 363-373.

\section{KatNr. SK 5}

Objekt: Männlicher Porträtkopf

InvNr. EM 643

FO: ২Hestiasaal<, Südwestecke

FJ: 1955

Mat.: mittelkörniger, hellgrauer Marmor

Maße: H $0,32 \mathrm{~m}$

Erh.: Die Nasenspitze fehlt, beide Ohren, Bart und Haar sind bestoßen. Der Hals ist schräg abgeschnitten ${ }^{740}$.

Beschreibung: Ein bärtiger Mann trägt eine Wulstbinde im Haar, darüber liegt ein Lorbeerkranz. Der Bart bedeckt Unterkiefer, Kinn und Oberlippe, die Wangen sind leicht eingesunken. Unter den buschigen Augenbrauen stechen die ungleichmäßig geformten Augen mit starker Bohrung der Pupillen hervor, wobei die rechte Augenbraue höher zu sitzen scheint als die linke. Die Stirn wird von asymmetrischen Falten zerfurcht, Geheimratsecken sind zu erkennen. Die Ohren sind nur flach wiedergegeben und heben sich kaum vom Haupthaar ab.

Ursprünglicher Aufstellungsort: unbekannt

AO: EM

Datierung: 3. Jh. n. Chr. (severisch nach Fittschen 1973, 52)

Zitat: F. Miltner, Tagebucheintrag vom 21. 10. 1955; Miltner 1956-1958, 33 f.; İnan - Rosenbaum 1966, 141 f. Nr. 178; Fittschen 1973, 52; R. Fleischer, Kopf eines Priesters, in: Bammer - Fleischer - Knibbe 1974, 74 f.; Aurenhammer (in Druckvorbereitung).

\section{KatNr. SK 6}

Objekt: Porträt einer jungen Frau

Taf. 239, 2

InvNr. EM 740

FO: Raum 6

FJ: 1956

Mat.: feinkörniger, weißer Marmor

Maße: H 0,225 m

Erh.: Der Kopf war in zwei Teile gebrochen; die linke Wange, gemeinsam mit einem Teil der Haare und des Ohrs, ist angesetzt. Am Hals befindet sich eine Bruchkante. Die Nase und das Kinn sind bestoßen, das linke Auge ist stark beschädigt.

Beschreibung: Es handelt sich um das leicht ovale Gesicht einer jungen Frau. Sie besitzt einen feinen, schmalen, leicht geöffneten Mund, dessen Mundspalt gebohrt ist. Unter schweren Augenlidern blickt das unbeschädigte rechte Auge mit tief gebohrter Pupille hervor. Die Haare sind sorgfältig aus dem Gesicht hinter die Ohren gestrichen. Sie trägt einen Mittelscheitel, die Haare sind sorgfältig zu einer aufwen-

${ }_{740}$ R. Fleischer, Artemis Ephesia, in: Bammer - Fleischer Knibbe 1974, 74. digen Nestfrisur aufgesteckt, wobei die Flechten der Frisur in der Ausarbeitung besonders genau herausgearbeitet sind. Ursprünglicher Aufstellungsort: unbekannt

AO: EM

Datierung: severisch

Zitat: İnan - Rosenbaum 1966, 138 Nr. 172 Taf. 100 Abb. 1-3; Fittschen 1973, 62; Aurenhammer (in Druckvorbereitung).

\section{KatNr. SK 7}

Taf. 239, 3

Objekt: Porträt einer Frau

InvNr. EM 705

FO: Vorhof

FJ: 1956

Mat.: mittelkörniger, hellgrauer, leicht blaustichiger Marmor Maße: H 0,28 m

Erh.: Kinn, Mund, Nase und beide Augenbrauen sind bestoßen, zusätzliche kleinere Verletzungen sind erkennbar. Seitlich im Haar und am Hinterkopf befinden sich drei Dübellöcher mit Resten von Eisendübeln in Bleiverguss ${ }^{741}$.

Beschreibung: Das annähernd runde Gesicht einer Frau wird von ihrem Haar eingerahmt. Der Mund ist fein und schmal, ein dünner Bohrkanal trennt die Lippen. Die Augen werden durch die Angabe von Pupille und Iris charakterisiert, die schweren Augenlider und die abgetieften Augenringe unterhalb des Auges vermitteln dem Gesicht im Vergleich zu KatNr. SK 6 den Anschein von Schwermut und Alter. Das Haar ist mittig gescheitelt und nach hinten zu einer Nestfrisur zurückgezogen. Die Ohren sind bedeckt. Das Haar umschließt kappenartig den Kopf, lediglich einige parallele Wellenlinien geben einzelne Haarsträhnen wieder, die Flechten der Nestfrisur werden nur durch sich kreuzende Linien angedeutet. Von der Stirnmitte fallen Fransen. Drei Eisendübel sind am Hinterkopf erkennbar, einer ist in die Mitte der Nestfrisur gesetzt, die anderen beiden in annähernd gleichem Abstand seitlich davon.

Ursprünglicher Aufstellungsort: unbekannt

AO: EM

Datierung: severisch

Zitat: J. Meischner, Das Frauenporträt der Severerzeit (ungedr. Diss. Freie Universität Berlin 1964) 144 Nr. 55; İnan - Rosenbaum 1966, 128 f. Nr. 153 Taf 89 Abb. 1. 2; R. Fleischer, Kopf einer Frau, in: Bammer - Fleischer - Knibbe 1974, 73 f.; Aurenhammer (in Druckvorbereitung).

\section{KatNr. SK 8}

Taf. 240,1

Objekt: Männliche Porträtbüste

InvNr. EM 2359 und 742

FO: Raum 5A, als Spolie in abgestürzter Ostwand FJ: 1961

Mat.: mittelkörniger, hellgrauer Marmor

Maße: H Kopf 0,315 m, H Büste 0,595 m

Erh.: Ein Bruch trennt den Kopf von der Büste. Das Gesicht wurde abgeschlagen; lediglich ein Teil der linken Wange sowie beide Ohren sind erhalten. Der Hals ist in der Umgebung des Bruchs verletzt, ebenso die linke Seite der Büste. Der linke Oberarm ist bis auf die Schulter abgebrochen.

${ }_{741}$ R. Fleischer, Porträt einer Frau, in: Bammer - Fleischer Knibbe 1974, 73 f. 
Beschreibung: Die gesichtslose, männliche Büste steht auf einem runden, profilierten $\mathrm{Fuß}$ mit Akanthusblätteraufsatz. Das Gesicht ist nicht mehr erhalten, nur an der linken Seite des Kopfes sind Reste des Bartes festzustellen. Dieser ist leicht kraus, das Haupthaar recht kurz und lediglich durch Kerben in den Kopf angegeben. Der Büstenausschnitt reicht bis zum Bauchansatz und zeigt die Oberarmansätze des Porträtierten. Der Mann trägt eine Tunika und darüber eine kontabulierte Toga, deren Falten teilweise durch Bohrrillen starr angegeben werden, teilweise aber plastischer herausgearbeitet sind.

Ursprünglicher Aufstellungsort: unbekannt AO: EM

Datierung: spätseverisch

Zitat: W. Alzinger, Tagebucheintrag vom 7. 8. 1961; Aurenhammer - Sokolicek (in Druck); Aurenhammer (in Druckvorbereitung).

\section{KatNr. SK 9}

Taf. 240, 2

Objekt: Männliche, hermenförmige Büste

InvNr. EM 1833

FO: Vorhof, als Spolie in Ostmauer

FJ: 1963

Mat.: feinkörniger, hellgrauer Marmor

Maße: H ges. 0,52 m, H Kopf 0,29 m, B 0,31 m

Erh.: Die Nase ist abgebrochen, weitere Ausbrüche sind an der Büste zu konstatieren. Mund, Brauen, Haare und Ohren weisen ebenfalls leichte Verletzungen auf.

Beschreibung: Die Büste zeigt den Kopf und Halsausschnitt eines Mannes im jugendlichen Alter. Das breite, volle Gesicht wird an der Stirn von Locken umrahmt. Oberhalb der Lockenreihe sind Ausarbeitungen für eine Haarbinde erhalten. Die Augen sitzen tief, das linke Auge scheint kleiner als das rechte. Die Augenbrauen treten stark hervor. Der Mund ist klein, ein breiter Bohrkanal trennt die Lippen. Das Bildnis gibt kaum personalisierte Züge wieder und scheint eher einem Ideal zu entsprechen ${ }^{742}$.

Ursprünglicher Aufstellungsort: unbekannt

AO: EM

Datierung: hellenistisch

Zitat: Eichler 1964, 40 f. Taf. 1; R. Fleischer, Hermenbüste, in: Bammer - Fleischer - Knibbe 1974, 16 f.; M. J. Mellink, Archaeology in Asia Minor, AJA 69, 1965, 146 f. Taf. 40 Abb. 16; R. Hanslmayr, Hermen aus Ephesos (in Druckvorbereitung).

\section{KatNr. SK 10}

Taf. 240,4

Objekt: Torso einer männlichen Ehrenstatue

InvNr. EM 776

FO: >Hestiasaalく, als Spolie in Nordmauer

FJ: 1957

Mat.: feinkörniger, hellgrauer bis blaustichiger Marmor Maße: H 1,275 m

Erh.: Die Schulterpartie und beide Arme waren angestückt; abgebrochen sind die Füße und Teile der Unterschenkel. Der untere Teil des herabhängenden Mantels ist ebenfalls beschädigt.

742 R. Fleischer, Hermenbüste, in: Bammer - Fleischer Knibbe 1974, 16 f.
Beschreibung: Die kopflose, männliche Statue trägt ein langes Untergewand, das den gesamten erhaltenen Körper bedeckt. Die leichten Falten des Stoffes lassen die Körperkonturen stärker hervortreten, etwa das Knie oder den Oberkörper. Darüber ist ein Mantel gelegt, der aufgrund der Trageweise als griechisches Himation zu identifizieren ist. Der Mantel ist über die linke Schulter und unter den rechten Arm drapiert. Das rechte Ende ist leicht gedreht über die Brust zur linken Schulter geführt. Der linke Zipfel hängt über das rechte Ende herab. Das Himation weist einen dreieckigen Überfall an der Körpervorderseite auf. Der Mantel dürfte zusätzlich den Unterleib bedeckt haben, da man an den Beinen verschiedene Falten beobachten kann. Die leicht angedeuteten Falten geben die stofflichen Begebenheiten des darunter befindlichen Chitons wieder.

Ursprünglicher Aufstellungsort: unbekannt

AO: EM

Datierung: späthellenistisch ${ }^{743}$ oder 2. Jh. n. Chr. (s. Anmerkung)

Zitat: F. Miltner, Tagebucheintrag vom 13. 8. 1957; Aurenhammer (in Druckvorbereitung) (J. Auinger); Aurenhammer - Sokolicek (in Druck).

Anmerkung: Bei der Betrachtung dieser Statue fällt eine Inkongruenz in der stofflichen Wiedergabe auf. Einerseits sind der Chiton, der den Oberkörper bedeckt, und der Mantel im Bereich der Beine sehr plastisch und realistisch geformt. Als Kontrast scheint der Mantel im oberen Bereich zu dienen, der unförmig, grob und klotzig von der linken Schulter hängt und über die Brust gelegt ist. Anstatt die einzelnen Falten in unterschiedlichen Tiefenstaffelungen differenziert und lebendig zu gestalten, dienen lediglich annähernd parallele Bohrkanäle zur Auflockerung und Andeutung des Stoffes. Wie A. Lewerentz zeigen konnte, hat sich die Kombination des Chitons mit einem Himation in dieser Trageweise für Statuen erst ab der Mitte des 2. Jhs. v. Chr. etabliert ${ }^{744}$. Auch der dreieckige Mantelüberschlag ist eine typische Zutat des Hellenismus, der für Himationdarstellungen des 3. Jhs. v. Chr. charakteristisch ist, im 1. Jh. v. Chr. nicht vorkommt und in der Kaiserzeit wieder aufgegriffen wird ${ }^{745}$. In Kleinasien ist die Kombination von Chiton und Himation besonders häufig an stehenden, männlichen Gewandstatuen in Aphrodisias anzutreffen, die teilweise inschriftlich in das 2. Jh. n. Chr. datiert werden ${ }^{746}$. Für eine Datierung unserer Statue bleiben

${ }_{743}$ s. Aurenhammer - Sokolicek (in Druck) und Aurenhammer (in Druckvorbereitung) (J. Auinger), die darauf verweisen, dass vor allem die für den Späthellenismus typischen Anstückungen (hier im Schulterbereich und an den Armen) sowie die Diskrepanz in der Trachtwiedergabe mit den scharfen Bohrrillen eine späthellenistische Datierung belegen würden.

744 A. Lewerentz, Stehende männliche Gewandstatuen im Hellenismus: ein Beitrag zur Stilgeschichte und Ikonologie hellenistischer Plastik (Hamburg 1993) 78; cf. Typus II.

745 A. Lewerentz, Stehende männliche Gewandstatuen im Hellenismus: ein Beitrag zur Stilgeschichte und Ikonologie hellenistischer Plastik (Hamburg 1993) 94; cf. Typus III.

746 R. R. R. Smith, Cultural Choice and Political Identity in Honorific Portrait Statues in the Greek East in the Second Century A.D., JRS 88, 1998, 65. 
jedoch nicht allzu viele Anhaltspunkte. Das Himation, wie soeben erwähnt, ist sowohl in hellenistischer wie auch in römischer Zeit eine übliche Tracht. Als Datierungskriterium kann man die zuvor angesprochene Diskrepanz in der Ausarbeitung der Trachtelemente anführen. Der Chiton ist in üblicher hellenistischer Manier gestaltet (cf. etwa die Dioskuridesgruppe aus Delos ${ }^{747}$ ). Andererseits wird der Mantelwulst von sehr tiefen, parallelen Bohrkanälen unterteilt. Der groß angelegte Einsatz des Bohrers ist erst ab antoninischer Zeit belegt, um in der Haargestaltung einen stärkeren Kontrast zu erzielen ${ }^{748}$. Dass man den Bohrer aber nicht nur für die Haargestaltung verwendet und dass er auch in den Provinzen Anklang gefunden hat, zeigen die Reliefs des Septimius Severus-Bogens in Leptis Magna ${ }^{749}$. Dort werden die Mäntel in diesem Fall handelt es sich aber um togae - auf ähnliche Weise charakterisiert. Da eine derartige Faltengestaltung im Hellenismus nicht bekannt ist, kann man folgern, dass es sich bei der vorliegenden Statue um ein römisch-kaiserzeitliches Stück handeln muss. Bestätigt wird eine Datierung in das 2. Jh. n. Chr. durch eine überdurchschnittlich hohe Anzahl ebensolcher stehender männlicher Ehrenstatuen mit Chiton und Himation in Aphrodisias in diesem Zeitraum ${ }^{750}$. Als zusätzliches Argument können zumindest zwei weitere Manteldarstellungen aus Ephesos mit ähnlicher Inkongruenz in der stofflichen Wiedergabe angeführt werden: Eine kleine Statue aus dem Efes Müzesi in Selçuk weist ein fein gearbeitetes Himation auf, das ebenfalls in einem Wulst vor den Unterkörper geführt wird ${ }^{751}$. Während der Mantel im Unterkörperbereich aufwendig gearbeitete Falten besitzt, lassen nur ein paar Bohrkanäle im Wulst Falten vermuten. Nach demselben Schema sind ebenfalls die Mäntel der sog. Kaiserplatte des Partherdenkmals gearbeitet ${ }^{752}$.

\section{KatNr. SK 11}

Taf. 240,3

Objekt: Fragment des linken Unterarms einer kolossalen, männlichen Statue

InvNr. -

FO: >Hestiasaal<, Nordostecke

FJ: 1955

Mat.: mittelkörniger, hellgrauer Marmor

Maße: non vidi

Beschreibung: linker, verbrochener Unterarm einer männlichen Kolossalstatue von etwa dreifacher Lebensgröße

747 B. Andreae, Die Skulptur des Hellenismus (München 2001) KatNr. 171.

748 İnan - Rosenbaum 1966, 24; M. Pfanner, Vom laufenden Bohrer bis zum bohrlosen Stil. Überlegungen zur Bohrtechnik in der Antike, AA 1988, 667-676.

749 B. Andreae, Die römische Kunst ${ }^{2}$ (Freiburg 1999) 444; A. M. McCann, The Portraits of Septimius Severus, MemAmAc 30 (Rom 1968).

750 Cf. R. R. R. Smith, Cultural Choice and Political Identity in Honorific Portrait Statues in the Greek East in the Second Century A.D., JRS 88, 1998, 56-93.

751 Ephesos Museum InvNr. 711; cf. Abb. im Museumsführer: S. Erdemgil (Hrsg.), Ephesus Museum (Istanbul ohne Jahresangabe) 17; R. Fleischer, Gott, in: Bammer - Fleischer Knibbe 1974, 92 f.

752 E. Lessing - W. Oberleitner, Ephesos. Weltstadt der Antike (Wien 1978) Abb. 149.
Ursprünglicher Aufstellungsort: unbekannt

AO: EM

Datierung: -

Zitat: Miltner 1956-1958, 33 Anm. 33.

KatNr. SK 12

Taf. 38.39

Objekt: Sockel Ehrenbasis

InvNr. PR 01/07

FO: Vorhof, über Regenrinne des östlichen Umgangs

FJ: 1956

Mat.: grauweißer Marmor

Maße: L 1,50 m, B 0,77 m, H 0,37 m

Beschreibung: unterer Teil von KatNr. SK 13 mit dreiseitig gekehltem Sockelprofil, Oberlager ohne Dübellöcher, leicht bestoßen, zusammengesetzte Quaderbasis, Basiskörper fehlt, mit dem Zahneisen bearbeitet und anschließend geglättet

Ursprünglicher Aufstellungsort: Vorhof, über Regenrinne des östlichen Umgangs

AO: in situ

Datierung: 2. H. 2. Jh. n. Chr.

Zitat: Knibbe 1981, D 7.

\section{KatNr. SK 13}

Taf. 38. 40. 41

Objekt: Aufsatz Ehrenbasis

InvNr. PR 02/07

FO: Vorhof

FJ: 1956

Mat.: grauweißer Marmor

Maße: L 1,52 m, B 0,76 m, H 0,50 m

Beschreibung: oberer Teil von KatNr. SK 12, dreiseitig profilierter Block mit Einarbeitungsspuren für Statuen der inschriftlich genannten Kureten Alexandros und Dieos (auf Schmalseiten), Profil bestehend aus Schräge, kyma reversa, kyma recta und einer Kehle, an den Ecken des Aufsatzes hornförmige Akrotere, Ehreninschrift an der Längsseite (IvE 613a), Rückseite schräg abgearbeitet, zusammengesetzte Quaderbasis, Basiskörper fehlt, mit dem Zahneisen bearbeitet und anschließend geglättet

Ursprünglicher Aufstellungsort: Vorhof, über Regenrinne des östlichen Umgangs

AO: Prytaneion

Datierung: 2. H. 2. Jh. n. Chr.

Zitat: Knibbe 1981, D 7.

\section{KatNr. SK 14}

Taf. 42

Objekt: Aufsatz Ehrenbasis

InvNr. PR 03/07

FO: Vorhof

FJ: 1956

Mat.: grauweißer Marmor

Maße: erh. L 0,58 m, B 0,83 m, H 0,44 m

Beschreibung: leicht bestoßen, Rückseite abgebrochen, Inschrift auf Schmalseite (IvE 985), Profil bestehend aus kyma recta, Platte, kyma reversa, an den Ecken des Aufsatzes hornförmige Akrotere, zwei Dübellöcher am Oberlager, zusammengesetzte Quaderbasis, Sockel und Basiskörper fehlen, mit dem Zahneisen bearbeitet und anschließend geglättet Ursprünglicher Aufstellungsort: Prytaneion AO: Prytaneion

Datierung: nach $128 \mathrm{n}$. Chr. (wegen inschriftlicher Nennung der zweiten Neokorie) 
Zitat: J. Keil - G. Maresch, Epigraphische Nachlese zu Miltners Ausgrabungsberichten aus Ephesos, ÖJh 45, 1960, Beibl. 93 f. Nr. 21.

KatNr. SK 15

Taf. 63, 2.3

Objekt: Sockel Ehrenbasis

InvNr. PR 40/07

FO: Vorhalle, westlich der Tür 3

FJ: 1956

Mat.: grauweißer Marmor

Maße: L 0,85 m, B 0,85 m, ragt ca. 0,30 m aus dem Boden heraus

Beschreibung: zusammengesetzte Quaderbasis, Basiskörper und Aufsatz fehlen, keine Dübellöcher am Oberlager, dreiseitig gekehltes Sockelprofil, mit dem Zahneisen bearbeitet und anschließend geglättet, Rückseite grob belassen

Ursprünglicher Aufstellungsort: Vorhalle, westlich der Tür 3 AO: in situ

Datierung: -

Zitat: -

\section{KatNr. SK 16}

Taf. 136, 3. 4

Objekt: Sockel Ehrenbasis (?)

InvNr. PR 46/07

FO: Prytaneion

FJ: 1956

Mat.: grauweißer Marmor

Maße: erh. L 0,48 m, B 0,60 m, erh. H 0,30 m

Beschreibung: an allen Seiten verbrochen, zusammengesetz-

te Quaderbasis, Basiskörper und Aufsatz fehlen, mit dem Zahneisen bearbeitet und anschließend geglättet

Ursprünglicher Aufstellungsort: Prytaneion (?)

AO: Prytaneion

Datierung: -

Zitat: - 



\title{
VIII FUNKTION DER RÄUME
}

\author{
(Martin Steskal)
}

\section{VIII.1 Vorbemerkung}

Die funktionsmäßige Bestimmung der Anlage ist epigrafisch gesichert: Es handelt sich um das Heiligtum der Hestia Boulaia ${ }^{753}$ und somit um das Prytaneion von Ephesos. Der Bau beheimatete die Hestia der Stadt, auf der das ewige Feuer brannte. Er diente als Amtslokal der Prytanen; er war zudem das Gebäude, in dem die Prytanen sowie ausgewählte Bürger und Fremde auf Staatskosten verköstigt wurden.

Somit beinhaltete die ephesische Anlage alle drei Grundfunktionen eines Prytaneions: Sie war Ort der Hestia, Amtslokal der Prytanen und Lokal ehrenvoller Speisungen auf Staatskosten. Auch die urbanistische Einbindung des Gebäudes, und zwar die Lage an der Agora, dem politischen Zentrum der Stadt, sowie die unmittelbare Nähe zum benachbarten Bouleuterion entsprechen den Vorgaben für die Anlegung eines Prytaneions.

Die spezifische Funktion der einzelnen Räume lässt sich wie folgt charakterisieren ${ }^{754}$ :

\section{VIII.2 Vorhof}

Der als rechteckige Triporticus ionischer Ordnung gestaltete Vorhof des Prytaneions datiert nach Analyse des archäologischen und architektonischen Befundes in die Bauzeit des Gebäudes und somit an das Ende des 1. Jahrhunderts v. Chr. ${ }^{755}$ (Taf. 32-44). Durch eine inschriftlich belegte Stiftung (IvE 437), die grob dem 1./2. Jahrhundert n. Chr. zugewiesen werden kann, ist eine erhebliche Reparatur bzw. ein völliger Neuaufbau des Peristyls belegt; im Wesentlichen wird dabei aber der bauzeitliche Aufbau kopiert (Bauphase 1a). Durch die vorgegebenen Aufschnürungen auf dem Stylobat, der von dieser Neugestaltung nicht tangiert wurde, ist von der gleichen Rhythmisierung des architektonischen Aufbaus auszugehen. Das Peristyl des Vorhofes wurde nach der Aufgabe des Gebäudes bis auf wenige Stylobatblöcke völlig abgetragen und das Baumaterial anderweitig verwendet. Auch die Rückwände der Hallen wurden großteils abgetragen; so fehlt die Rückwand im Westen vollständig, die Südwand ist lediglich bis zu einer max. Höhe von 0,93 m über dem Niveau des Stylobats (absolut: 45,96 m) erhalten. Die Ostwand, die in die byzantinischen Strukturen östlich des Prytaneions integriert wurde, ist mit max. 1,45 m über dem Stylobat am Höchsten erhalten.

Der Vorhof diente zunächst der Erschließung des Gebäudes; er vermittelte zwischen den im Süden und Westen - dort allerdings aufgrund des heute nicht mehr nachweisbaren Zugangs nicht gesichert - laufenden Straßen und der Vorhalle des Prytaneions. Die Hallen selbst und der Hof scheinen der Auf- und Ausstellung von Ehrenbasen und Ehrenstatuen gedient zu haben; zwei Ehrenbasen samt Inschriften zeugen von dieser repräsentativen Funktion (KatNr. SK 12. 13 aus der zweiten Hälfte des 2. Jahrhunderts n. Chr. sowie SK 14 nach 128 n. Chr.). Wenn H. Engelmann in Bezug auf die Hallen des Vorhofes von einer »Porticus ambulatoria « spricht ${ }^{756}$, so beschreibt dies treffend den multifunktionalen Charakter der Stoai.

\footnotetext{
753 IvE 1058-1060. 1062-1073. 1077-1079. 1597. - Eine Zusammenstellung der inschriftlichen Zeugnisse von Ephesos mit Nennung der Hestia bietet C. R. Dethloff, Corpus of Inscriptions of the Goddess Hestia (ungedr. Diss. The Johns Hopkins University of Baltimore 2003) Nr. 132-151.

754 Zur wechselhaften Beurteilung der einzelnen Raumfunktionen während der Ausgrabung und Erforschung des Gebäudes s. M. Steskal, Kapitel II.

755 Cf. M. Steskal, Kapitel III.2.

756 Engelmann 1985, 155.
} 
Von großer Bedeutung für den Vorhof, vor allem aber für das Prytaneion selbst, ist die Manifestation des Artemiskultes an der Stelle des zentralen Fundaments in Form der traianisch zu datierenden >Großen Artemis<-Statue (KatNr. SK 4). Obwohl sich W. Alzinger der Stratigrafie des Vorhofes im Bereich des Bothros und des Fundaments besonders eingehend widmete ${ }^{757}$, bleiben bis heute grundsätzliche Fragen offen. Für das Fundament konstatierte er zwei Bauperioden, wobei er die ältere in hellenistische Zeit datierte, ohne dafür Belege beizubringen ${ }^{758}$. Würde das Fundament in seiner älteren Phase tatsächlich in hellenistische Zeit gehören, so bliebe zu klären, was sich in vortraianischer Zeit, d. h. vor dem Zeitpunkt der Aufstellung der `Großen Artemis`, auf diesem Fundament befunden haben könnte. Da der Bothros im Rücken der Artemisstatue liegt, ist es vorstellbar, dass es sich bei dem Fundament zunächst um die Unterkonstruktion eines Altars gehandelt haben könnte, wie es W. Alzinger, der eine Aufstellung der `Großen Artemis` auf diesem Fundament zunächst negierte, bis in die 1970er Jahre vermutete ${ }^{759}$. Von einer ebenso möglichen Vorgängerstatue haben sich weder Reste noch Hinweise erhalten. Dass die Chronologie und die Bauphasen des Fundaments nicht endgültig geklärt sind, ist insofern ein Dilemma, als nur dadurch Rückschlüsse, warum dieses Fundament leicht aus der Achse des Stadtrasters gedreht ist, gewonnen werden könnten. Wäre das Fundament hellenistisch, müsste es zunächst völlig losgelöst vom augusteischen Prytaneion betrachtet werden. Für eine voraugusteische Datierung von Fundament und Bothros spräche, dass beide nicht exakt in der Mitte des Vorhofes, sondern leicht nach Osten verschoben liegen; wären das Fundament und der Bothros zeitgleich mit dem Gebäude oder danach entstanden, hätte man sie - wenn gewünscht - ohne Probleme im Zentrum des Hofes platzieren können. Datiert das Fundament jünger und wurde erst im Zuge der Aufstellung einer möglichen Vorgängerstatue oder der >Großen Artemis` errichtet, so wäre entweder der Hauptzugang im Süden des Vorhofes am Fundament ausgerichtet oder das Fundament auf den bereits existierenden Haupteingang hin orientiert ${ }^{760}$. Obwohl die Sichtachse $>$ Große Artemis $<$ - Haupteingang bewusst konstruiert zu sein scheint, kann die Frage der Bauabfolge durch die bereits vollständig erfolgte Freilegung dieses Bereiches nicht mehr geklärt werden.

Dass aber bereits im Vorhof die Bedeutung des Prytaneions als Kultstätte der Artemis demonstriert werden sollte, ist evident. Es ist hier mit Sicherheit D. Knibbe und G. Langmann zu folgen, die das Prytaneion neben weiteren Funktionen als Dependance des Artemisions innerhalb der Stadt interpretierten ${ }^{761}$. Den beiden Autoren zufolge wäre der Machtanspruch der Artemis innerhalb der Stadt durch die bewusste Platzierung von Altären an strategisch wichtigen Punkten manifestiert worden, die dann im Verlauf der jährlichen Prozession zentrale Landmarken dargestellt hätten. Einer dieser wichtigen Punkte wäre im Areal des späteren Prytaneions gelegen ${ }^{762}$. Dies würde die de facto gleichberechtigte Stellung der Artemis Ephesia im Hestiaheiligtum erklären ${ }^{763}$. Dass die Etablierung eines Hestiaheiligtums in der Stadt überhaupt erst im Zuge der Neukonstituierung von Ephesos unter Augustus erfolgt worden wäre, wie die Autoren weiter ausführten ${ }^{764}$, scheint aus Sicht des Verfassers hingegen nicht begründbar. Wenn auch im Areal des auguste-

757 Cf. M. Steskal, Kapitel II.3.

758 s. dazu Eichler 1963, 46. - Das Fundament wurde an allen Seiten bis zum gewachsenen Boden freigelegt; eine Nachuntersuchung des stratigrafischen Befundes war daher nicht mehr möglich.

759 s. Alzinger 1972-1975, 242. Diese Sicht der Dinge relativierte er letztlich wieder, cf. W. Alzinger, Das Zentrum der lysimachischen Stadt, in: Friesinger - Krinzinger 1999, 390: »Der Platz vor dem Prytaneion war wohl für die im Frühherbst 1956 gefundene kolossale Marmorstatue der Artemis vorgesehen; ...«.

${ }^{760}$ Cf. in diesem Kontext einen parallelen Befund in der Tholos von Athen, auf den Miller 1978, 57 hinweist: »It is striking to note the relationship of the orientation of the base with the position of the restored north door. One is tempted to think, as already mentioned, that the north door provided communication not only for servants between tholos and kitchen, but also for prytaneis between tholos and Bouleuterion. The altar in the center of the tholos would have directly confronted prytaneis entering from the Bouleuterion."

761 Knibbe - Langmann 1993, 11. 21; cf. auch Knibbe 1995, 143 f. 146 Anm. 8; Knibbe 1998, 113; Knibbe 1999, 451. - Keineswegs ist daher auch der Charakter des Prytaneions als »pseudoreligiös« zu bezeichnen, wie dies Bammer 2008, $178 \mathrm{f}$. macht. Dem widerspricht die große Zahl an im Prytaneion, das gleichsam als Hauptkultgebäude der Stadt fungierte, beheimateten Kulten.

762 Knibbe - Langmann 1993, 21; cf. auch Karwiese 1995, 82; Karwiese 1999, 397; Scherrer 1990, 91 f.; Groh 2006, 66; Witetschek 2008, 26.

763 Cf. in diesem Kontext auch die gemeinsame Nennung von Hestia und Artemis in IvE 1064 und 1068; cf. auch Rogers 2007, 144.

764 Knibbe - Langmann 1993, 21. 
ischen Prytaneions kein Vorgängerbau nachgewiesen werden konnte, so ist doch von einem Hestiaheiligtum innerhalb der hellenistischen Stadt auszugehen. Seine Identifizierung steht freilich noch aus.

\section{VIII.3 Vorhalle}

Die im Grundriss langrechteckige Vorhalle des Prytaneions wird von der mächtigen dorischen Fassade dominiert $^{765}$ (Taf. 45-64; 65, 1). Die Fassade mit ihren sechs Säulen in antis und die dahinterliegende, quergelagerte Halle gliedern und umfassen das nicht mehr der zentralen Mittelachse folgende Raumensemble nördlich davon, dessen Eingänge allesamt aus der Hauptachse verschoben sind. Sowohl das Peristyl des Vorhofes als auch die Vorhalle geben eine Axialität vor, die durch das heterogene Raumprogramm im Norden der Anlage aufgelöst wird. Die unkonventionelle Grundrisslösung wird durch die lokalen topografischen Gegebenheiten bedingt: Die Baufläche des Prytaneions ist durch die angrenzenden Straßen im Westen und Süden sowie den anstehenden Fels im Norden klar definiert und beschränkt; sie nimmt nach St. Groh - getrennt durch eine hypothetische, an dieser Stelle allerdings nicht vorhandene Ost-West-Straße im Bereich der Vorhalle - zwei `Normalparzellen der hellenistisch-römischen Stadtflächen ein ${ }^{766}$. Ob auch das Temenos mit dem >Doppelmonument< östlich des Prytaneions schon vor der Anlage desselben bestanden hat, oder es sich um ein gemeinsames Bauprojekt handelte, ist nicht geklärt. Die relative Abfolge der beiden Gebäude ist bis dato unzureichend erforscht. P. Scherrer vermutete allerdings, dass das Temenos schon vor der Errichtung des Prytaneions bestanden haben könnte ${ }^{767}: »$ Tatsächlich ist in Ephesos wohl fast unmittelbar nach der Wandlung des Octavianus zu Augustus am Nordrand des sog. (späteren) Staatsmarktes ... der Kult des neuen Herrschers fassbar. Wahrscheinlich erhielt er seine mit der alteingesessenen ephesischen Familie Passalas verbundene Heimstätte in dem ... Temenos zwischen dem (späteren?) Prytaneion und dem (späteren) Bouleuterion ... Bereits in der Zeit zwischen 27 und 25 v. Chr. weihte Apollonios Passalas (Prytane des Jahres 20/19 oder 19/18 v. Chr.) dieses Temenos und eine Statue des Augustus im Auftrag eines unbekannten Gremiums (IvE 902, Anm. d. Verf.).« Die asymmetrische Form des Grundrisses ist aber auch funktionsbedingt, wie W. Alzinger bereits richtig erkannte ${ }^{768}$, $\gg$ da hinter einer Fassade einerseits ein großer Hauptsaal und andererseits auch notwendige Nebenräume untergebracht« werden mussten. Der größere >Hestiasaak benötigte eine entsprechende Fläche, um ausreichend Raum für Versammlungen und Bewirtungen bieten zu können; daraus ergibt sich vice versa die geringere Fläche der westlichen Nebenräume. Eine ähnlich funktionsbedingte Asymmetrie findet sich bei Anlagen, die Banketten dienten und deren Räume eine bestimmte Anzahl von Klinen aufnehmen mussten. Auch in solchen Gebäuden entstehen bisweilen Asymmetrien, die aber durch vorgeblendete Hallenkonstruktionen gegliedert werden können, wie die spätklassischen 〉Oikoiく in Labraunda zeigen ${ }^{769}$. Die Halle in Ephesos vermittelt zudem zwischen dem Vorhof und den Haupträumen des Gebäudes im Norden; in einer späteren Bauphase (Bauphase 1b oder 2) erschloss sie auch das angrenzende Temenos durch eine neu geschaffene Tür in der östlichen Antenmauer.

Generell zeichnet sich die dorischen Ordnung durch ihre Großflächigkeit aus; der Dekor bleibt auf das Wesentliche beschränkt. Die Vorhalle steht damit sowohl in der Tradition des hellenistisch-kleinasiatischen Werksteinbaus als auch in der klassizistischen Tradition augusteischer Architektur ${ }^{770}$. Da sich dorische Ordnungen in Ephesos, wie auch im übrigen Kleinasien, als überaus selten erweisen, ist die wuchtige Fassade des Prytaneions der Bedeutung des Gebäudes entsprechend sicher als exzeptionell und hervorgehoben zu bezeichnen. Die Wahl einer Architekturtradition, die nicht nur auf das griechische Mutterland verweist,

765 Cf. M. Steskal, Kapitel III.3.

766 Größe der >Normalparzellen` nach Groh 2006, 90 f. ca. $20 \times 22$ m. Exakte Maße (inkl. Außenmauern): nördliche Parzelle 718 (nördlicher Kanal, Raum 2, 3, 4, 5, 6 und `Hestiasaal`): 22,72 m (Nord-Süd) × 23,67 m (Ost-West); südliche Parzelle 618 (Vorhof): 19,09 m (Nord-Süd) × 23,06 m (Ost-West); Bereich Straße (Vorhalle): 7,59 m (Nord-Süd) × 23,67 m (Ost-West).

767 Scherrer 2007, 66 f.; Scherrer 1997, 93 f.; s. dazu auch H. Engelmann, Zum Kaiserkult in Ephesos, ZPE 97, $1993,284$.

768 Alzinger 1974, 52.

769 Cf. A. Westholm, Labraunda. Swedish Excavations and Researches. The Architecture of the Hieron, ActaAth 5, 1, 2 (Lund 1963) 69 Abb. 59; P. Hellström, Dessin d'architecture hécatomnide à Labraunda, in: Le dessin d'architecture dans les sociétés antiques. Actes du colloque de Strasbourg 26-28 janvier 1984 (Strasbourg 1985) 153-165.

770 Cf. die diesbezüglich überzeugenden Ausführungen von G. A. Plattner, Kapitel VII.4.3.2. 
sondern auch das hohe Alter der durch und durch griechischen Institution \Prytaneion lich bewusst gewählt.

Die Vorhalle wurde in den Bauphasen 1b (kurz nach 104 n. Chr.) und 2 (zweites Viertel 3. Jahrhundert n. Chr.) mehrfach modifiziert. Wahrscheinlich in der epigrafisch überlieferten Bauphase $1 \mathrm{~b}$ (oder 2) wurde die Nordwand der Vorhalle repariert. In diesem Zuge wurden auch die zusätzlichen Eingänge in den >Hestiasaak (Tür 2 und 4) und eine Verbindung in das östlich angrenzende Temenos geschaffen. In Bauphase 2 erhielt die Vorhalle einen polychromen Mosaikboden; vom ursprünglichen Paviment haben sich keine Spuren erhalten. Nach Aufgabe des Gebäudes in der Spätantike wurde die dorische Fassade sukzessive abgetragen und Teile ihrer Architektur wurden in der Scholastikiatherme und in der `Kuretenhalle $<$ am unteren Embolos verbaut. Nur vier Architekturglieder der dorischen Ordnung verblieben in Sturzlage vor Ort: ein Teil des Architravs (KatNr. A 7), ein Teil des Metopen-Triglyphen-Frieses (KatNr. A 8) sowie zwei Blöcke des Horizontalgeisons (KatNr A 9. 10) ${ }^{771}$. Die Teile sind - abgesehen vom Geisonblock KatNr. A 10 in den 1960er Jahren zu einer Architekturprobe zusammengeführt worden. Der Verbleib der weiteren fehlenden Glieder der dorischen Ordnung ist indes ungeklärt. In byzantinischer Zeit (Bauphase 3) wurden die Türen 1 und 2 zugesetzt. Vom fortgesetzten Steinraub bzw. Verfall des Gebäudes zeugen die geringen Höhen des aufgehenden Mauerwerks: Die westliche Antenmauer ist max. 2,10 m über dem Niveau des Stylobats der dorischen Fassade (absolut: 46,04 m) erhalten, die östliche Antenmauer max. 2,35 m sowie die Nordmauer max. 2,56 m.

Der repräsentative Charakter der Vorhalle zeigt sich an der Monumentalität und Wuchtigkeit der dorischen Ordnung sowie an der Ausstattung mit einem Mosaikboden und dem fein gearbeiteten Marmorsockel der Seitenwände und der Rückwand. Die Architekturglieder der dorischen Ordnung und die Rückwand der Vorhalle wurden bis in die erste Hälfte des 3. Jahrhunderts n. Chr. mit Kuretenlisten versehen ${ }^{772}$. Mit der für jeden Besucher des Gebäudes deutlich sichtbaren Auflistung der Mitglieder des kaiserzeitlichen Kure-

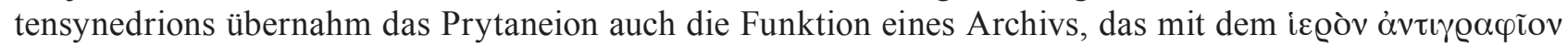
(IvE 1024 Z. 12) aus einer Kureteninschrift traianischer Zeit gemeint sein könnte ${ }^{773}$. Die Inschrift selbst befindet sich in der Rückwand der Vorhalle an einem Block der oberen Quaderschicht westlich des Eingangs in den >Hestiasaak. Die Funktion des städtischen Archivs zählte zwar zu den Nebenaufgaben eines Prytaneions, doch war sie ein charakteristisches Element solcher Gebäude, die damit ihre Wichtigkeit für das Funktionieren der Stadtverwaltung, aber auch der zentralen Kultaufgaben demonstrierten ${ }^{774}$. Die inschriftliche Dokumentation der Kuretenlisten stellte in diesem Kontext einen Teilaspekt der Archivfunktion des ephesischen Prytaneions dar.

Wie die zahlreichen Kureteninschriften bezeugen, diente das Gebäude auch als Heimstätte des Kuretensynedrions $^{775}$. Die Rolle der Kureten bestand primär in der Realisierung des bei Strabon (Strab. 14, 1, 20) beschriebenen jährlichen Mysterienspiels, das die Niederkunft Letos thematisierte ${ }^{776}$. Es handelte sich dabei um ein zentrales Ereignis im kultischen Jahresablauf von Ephesos, vergleichbar nur noch mit der jährlichen Artemisprozession um den Panayırdağ. Der Ablauf der Feier selbst ist uns weitgehend unbekannt. Das Synedrion, dessen Sitz in hellenistischer Zeit noch im Artemision lag, verlagerte seine Heimstätte mit der Errichtung des Prytaneions in augusteischer Zeit in das Stadtgebiet von Ephesos. Dadurch verlor es

771 Der ebenfalls vor Ort gefundene Block des Horizontalgeisons KatNr. A 11 war ursprünglich in keinem der Gebälke des Gebäudes verbaut, sondern könnte - sofern dieses Architekturglied überhaupt jemals im Prytaneion untergebracht gewesen war - lediglich als Spolie gedient haben. Auffallend ist, dass der Ausgräber F. Miltner, Tagebucheinträge vom 5. 10. 1956 und 13. 10. 1956, lediglich den Fund der Geisonblöcke KatNr. A 9 und A 10 in seinen Unterlagen notiert. Die Zugehörigkeit des Blockes KatNr. A 11 zum Prytaneion ist somit selbst als Spolie in Zweifel zu ziehen.

772 Zur absoluten Chronologie der Kuretenlisten s. Knibbe 1981, 93-95.

773 Knibbe 1981, B 24; Halfmann 2001, 23 Anm. 69. - McDonald 1943, 156 konstatiert eine sukzessive Verlagerung der Archive vom Prytaneion in das Bouleuterion.

774 Zu Archiven in Prytaneia: Miller 1978, 16-19; McDonald 1943, 156.

775 Ursprung, Funktion und Organisation des ephesischen Kultvereins behandelt in erster Linie Knibbe 1981; RE Suppl. XII (1970) 286 f. s. v. Ephesos: A. Historisch-epigrafischer Teil (D. Knibbe); s. aber auch J. Poerner, De Curetibus et Corybantibus (Halle 1913); Ch. Picard, Ephèse et Claros. Recherches sur les sanctuaires et les cultes de l'Ionie du nord, BEFAR 123 (Paris 1922) 277 f.; Keil 1939, 119-128; Graf 1999, 255-262; Rogers 1999a, 241-250; Rogers 1999b, 125-130; Rogers 2007, $137-145$.

776 Knibbe 1981, 70-73; Portefaix 1999, 613; Rogers 2007, 139 f. 
zwar seine administrativen Funktionen im Artemision ${ }^{777}$, nach wie vor zeichnete es aber für die Veranstaltung der ortygischen Mysterien und der jährlichen Wiederholung des Geburtsdramas verantwortlich ${ }^{778}$. Der Abzug der Kureten aus dem extraurbanen Heiligtum bedeutete zugleich einen Machtverlust für das

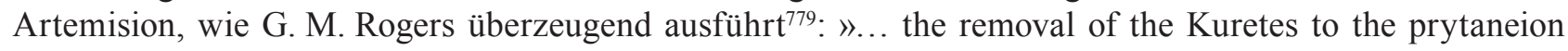
also simultaneously robbed the Artemision of some of its power. What Augustus did was to take control of at least part of the central foundation myth of the city away from the administration of the temple. ... While the temple of Artemis remained the center for the overall cult of the goddess, the prytaneion became the office for the celebration of her birth and the mysteries of Artemis. The boule and demos of the polis now controlled how the birth of Artemis at Ephesos would be celebrated. Augustus did not just strip the Artemision of some of its political power; rather Augustus diminished the overall power of the sanctuary with respect to the polis of Ephesos.« Der Etablierung des Kuretensynedrions im Prytaneion bedeutete somit nicht nur einen Prestigeverlust für das Artemision, sondern auch eine bewusste Schwächung des Heiligtums, die Augustus auch in anderen Bereichen, wie etwa der Eingrenzung des Asylbereiches auf ein Stadion, forcierte ${ }^{780}$. Im Prytaneion hätten die Kureten nach D. Knibbe als »Opferassistenten« des Prytanen bei der Durchführung der zahlreichen kultischen Handlungen, die in diesem Gebäude beheimatet waren, fungiert ${ }^{781}$. Ein wesentlicher Aufgabenbereich der Kureten war schließlich auch die Sorge um das ewige Feuer $^{782}$. Besondere Bedeutung kam ihnen in den ersten beiden nachchristlichen Jahrhunderten zu. Mit dem Beginn des 3. Jahrhunderts n. Chr. verlaufen sich langsam die Spuren der Kureten im Prytaneion; auch die Kuretenlisten wurden dann nicht mehr auf den Architekturgliedern des Gebäudes verewigt. Die Gründe dafür werden in der sinkenden wirtschaftlichen Prosperität und dem Bedeutungsverlust der ortygischen Mysterien gegenüber anderen Kulten ab dieser Zeit zu suchen $\operatorname{sein}^{783}$. Obwohl die Möglichkeit besteht, dass die Kuretenlisten dann in anderer und weniger prominenter Form geführt wurden, so ist das Auslaufen der Kureteninschriften als weiteres Indiz für den kontinuierlichen Bedeutungsverlust des Prytaneions zu werten. Die soziale Struktur des Kollegiums ist nicht gesichert. Während Knibbe »das ganze reichhaltige Spektrum des bunten Demos« von Ephesos als Herkunft der Mitglieder vermutete, sahen andere die Kureten eher in der städtischen Oberschicht angesiedelt und das Kollegium folglich als $»$ Honoratiorengremium $\ll^{784}$. Zum Ausdruck ihrer religiösen Aufgaben würden sie in den Inschriften als $\varepsilon \dot{v} \sigma \varepsilon \beta \varepsilon \tau \zeta \zeta$ bezeichnet, zum Ausdruck der Loyalität gegenüber dem Kaiserhaus darüber hinaus als $\varphi \iota \lambda$ $\_\hat{\varepsilon} \beta \alpha \sigma \tau o$. Die aktive Funktionsperiode der Kureten war prinzipiell auf ein Jahr begrenzt; doch scheint es auch »Altmitglieder« gegeben zu haben, die dem Verein auf Lebenszeit angehörten ${ }^{785}$.

Wie der Vorhof diente auch die Vorhalle zur Aufstellung von Ehrenstatuen und Ehrenbasen. Der Unterteil einer solchen Ehrenbasis (KatNr. SK 15) befindet sich heute noch in situ westlich des Eingangs in den 〉Hestiasaak (Tür 3). Östlich und westlich von Tür 3 liegen drei Marmorplatten bzw. -blöcke, die als Fundament für die Aufstellung von Basen oder Statuen gedient haben könnten. Von zentraler Bedeutung ist in diesem Zusammenhang der Fund der `Kleinen Artemis` (KatNr. SK 2) aus der zweiten Hälfte des 2. Jahrhunderts n. Chr. in der Ostecke der Vorhalle sowie einer Kopie der `Kleinen Artemis` (KatNr. SK 3) unmittelbar südlich davon im östlichen Umgang des Vorhofes. Es ist durchaus vorstellbar, dass diese Statuen tatsächlich in der Vorhalle aufgestellt waren; diese Vermutung kann mit allen Vorbehalten auch auf die `Schöne Artemis` (KatNr. SK 1) hadrianisch-frühantoninischer Zeit ausgeweitet werden, die in Raum 5

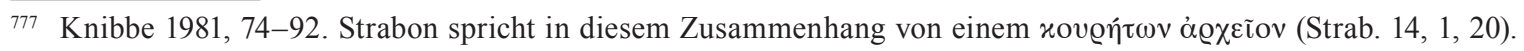

778 Knibbe 1981, 78; Knibbe 1999, 451; cf. Rogers 2007, 138: »Augustus' transfer of the celebration of the mysteries of Artemis from the Artemision to the prytaneion of Ephesos represents one of the decisive moments in the story of how and why the Greek mysteries of Artemis became Graeco-Roman mysteries. At the same time, the transition from Greek mysteries of Artemis to Graeco-Roman mysteries is part of the larger story of how and why the Greek polis of Ephesos became a GraecoRoman polis within a Roman province.巛

779 Rogers 2007, 145.

780 Cf. Rogers 2007, 137-145; Knibbe 1998, 113; Knibbe 1981, 75 f. Der Asylbereich war zuvor von Mithridates VI. und Marcus Antonius vergrößert worden.

781 Knibbe 1981, 76.

782 Cf. Rogers 1991, 88.

783 Knibbe 1981, 92.

${ }^{784}$ Graf 1999, 255 f.; Rogers 1999a, 241-250; Rogers 1999b, 125-130.

785 Knibbe 1981, 96-100. 
gefunden wurde. Auch wenn der Aufstellungsort dieser Statuen innerhalb des Gebäudes nicht endgültig gesichert ist, zeigt ihre gehäufte Präsenz die übergeordnete Rolle der Artemis Ephesia im Prytaneion von Ephesos.

\section{VIII.4 >Hestiasaak (Raum 1)}

Der fast quadratische Raum 1, der vom Ausgräber der 1950er Jahre, F. Miltner, als »Herdsaal« bzw. »Hestiasaal« angesprochen wurde ${ }^{786}$, bildete in Verbindung mit dem nördlich anschließenden Querraum (Räume 2-4) das funktionale Zentrum des Prytaneions ${ }^{787}$ (Taf. 65, 2; 66-91). Der repräsentative Charakter dieses Raumes zeigt sich einerseits anhand der ursprünglich reichen Marmorausstattung - sowohl der Boden als auch die Wände waren mit Marmorplatten versehen -, andererseits an der architektonischen Gliederung des Raumes mit einem fein gearbeiteten Marmorsockel an allen vier Wänden, einem dominierenden marmornen Keilsteinbogen in der Nordwand, vier vor die Raumecken gestellten Eck-Doppelhalbsäulen auf Stühlen und verbreiterten Eingängen im Norden und Süden des Raumes. Der bereits zur ursprünglichen Konzeption des Gebäudes gehörige Raum wurde in Bauphase $1 b$ bald nach 104 n. Chr. größeren Reparaturen unterzogen ${ }^{788}$. In diesem Zusammenhang wurde die Westwand des Raumes erneuert und mit Marmor verkleidet. Zur selben Zeit wurden auch die Südwand neu aufgerichtet und die beiden seitlichen Zugänge (Tür 2 und 4) geschaffen. Zudem wurden die Archivolte des Keilsteinbogens abgearbeitet und der Bereich unter dem Bogen bis zu den Türlaibungen vermauert. Der Keilsteinbogen verschwand in dieser Phase vollständig hinter der neuen Marmorwandverkleidung der Nordwand des Raumes. In Bauphase 2 im zweiten Viertel des 3. Jahrhunderts n. Chr. wurden die L-förmigen Unterkonstruktionen der Sitzbänke errichtet sowie die Eck-Doppelhalbsäulen, die sog. >Herzsäulen<, neu aufgestellt. Es ist davon auszugehen, dass auch schon zur Bauzeit - wahrscheinlich hölzerne - Sitzbänke im `Hestiasaak untergebracht waren; von ihnen haben sich allerdings keine Spuren erhalten. In der byzantinischen Bauphase 3 (5./6. Jahrhundert n. Chr.) wurden schließlich die Tür in der Nordwand sowie Tür 2 in der Südwestecke des Raumes zugemauert. Der Raum fungierte dann u. a. als Wasserentnahmestelle: Über eine sekundäre Öffnung in der Nordwand des ^Hestiasaales` konnte das Wasserreservoir in den Räumen 3 und 4 angezapft werden. Trotz eines fortgesetzten Steinraubes ist das Mauerwerk vor allem im Norden des Raumes noch in beachtlicher Höhe erhalten: So ist die Nordwand bis zu einer max. Höhe von 5,37 m über dem Marmorplattenpaviment (absolut: 46,36 m) erhalten, die Ostwand bis zu einer max. Höhe von 5,19 m und die Westwand bis zu 5,37 m. Der Mauerwerkbestand fällt nach Süden stark $a b$ - so ist die Südmauer nur noch bis zu einer max. Höhe von 2,15 m über dem Boden erhalten.

Der `Hestiasaak übernahm zwei der wesentlichsten Funktionen eines Prytaneions: Mit seinen Sitzbänken fungierte er als Versammlungsort der Prytanen und anfänglich vielleicht auch als Ort der Ratsversammlung. Mit Errichtung des benachbarten Bouleuterions wurde die Ratsversammlung in erster Linie aber dort abgehalten ${ }^{789}$. Ein Indiz dafür, dass das ephesische Prytaneion oder ein in der Nähe befindlicher - uns aber unbekannter - Vorgängerbau zunächst auch Aufgaben eines Bouleuterions übernommen hat, könnte anhand einer fragmentarisch erhaltenen Inschrift aus dem 1. Jahrhundert v. Chr. festzumachen sein (IvE 740B): Auf einem Marmorquader unmittelbar vor der Nordwand des >Hestiasaales`, westlich der zwei

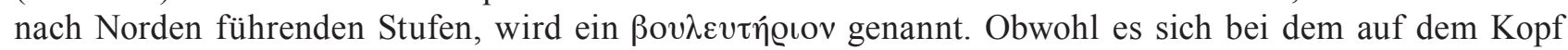
stehenden Marmorquader um eine Spolie handelt, könnte diese Inschrift als Hinweis auf die Existenz eines hellenistischen Bouleuterions oder Prytaneions im Areal des oberen $>$ Staatsmarktes〈 zu werten sein ${ }^{790}$.

\footnotetext{
786 Miltner 1956-1958, 27-36. Die vom Ausgräber F. Miltner eingeführte Bezeichnung >Hestiasaal für Raum 1 wird in der Sekundärliteratur - und daher auch in diesem Manuskript - beibehalten, obwohl sie für den ursprünglichen Querraum 2-4 zutreffender wäre; s. dazu M. Steskal, Kapitel VIII.5.

787 Cf. M. Steskal, Kapitel III.4.

788 Die für Bauphase $1 \mathrm{~b}$ geltend gemachten Modifikationen könnten auch in Bauphase 2 erfolgt sein.

789 Zur Funktion als Versammlungsort des Rates: McDonald 1943, 127. 137 f. 156, wonach die Ratsversammlungen sukzessive von den Prytaneia in die Bouleuteria verlagert wurden.

790 Cf. dazu L. Bier, The Bouleuterion at Ephesos: Some Observations for a New Survey, in: Scherrer - Taeuber - Thür 1999, 16; Eichler 1962, 41; W. Alzinger, Die Lokalisierung des hellenistischen Rathauses von Ephesos, in: Bathron. Beiträge zur Architektur und verwandten Künsten. Festschrift Heinrich Drerup, Saarbrücker Studien zur Archäologie und Alten Geschichte 3 (Saarbrücken 1988) 21-29; Bier (in Druck). - Kritisch dazu: Thür 2007, 80.
} 
Die sekundären Sitzbänke gewährten bei zweistufiger Rekonstruktion jedenfalls etwa 100-120 Personen Platz $^{791}$, womit sich auch die zweite wichtige Funktion des Repräsentationssaales erschließt: Er diente als Ort der ehrenvollen Speisungen verdienter Bürger und Fremder auf Staatskosten, die diese Kultmähler nach alter Sitte wohl im Sitzen einnahmen; aber auch die Prytanen selbst wurden hier verköstigt. Die untere Stufe konnte zudem als Liegepodium für weitere Gelage genutzt werden ${ }^{792}$. Folglich übernahm der $>$ Hestiasaak die Funktion des Prytaneions, »stellvertretend für alle Häuser der Stadt als das Repräsentationsgebäude zu gelten, wo die offiziellen Gäste der Stadt empfangen und bewirtet wurden « ${ }^{793}$. Das zentrale Fundament ist daher entgegen älteren Meinungen ${ }^{794}$ als Anrichte für die Festmähler zu interpretieren ${ }^{795}$. Das Essen selbst musste angeliefert werden, da - analog zu den meisten anderen Prytaneia - keine Küche vorhanden war. Ob das westlich anschließende - allerdings durch die >Akademiegasseく und einen beträchtlichen Niveauunterschied getrennte - >Banketthaus in diesem Kontext in funktionalem Zusammenhang mit dem Prytaneion stand, ist beim aktuellen Wissensstand nicht zu entscheiden ${ }^{796}$.

Inwieweit die zahlreichen unterschiedlichen Kulte, die im ephesischen Prytaneion untergebracht waren, ihren Sitz im >Hestiasaak oder in einem der anderen Räume des Gebäudes hatten, ist nicht immer zu klären. Die neben Hestia Boulaia und Artemis Ephesia im Prytaneion verehrten Gottheiten ${ }^{797}$ - genannt seien Demeter Karpophoros und ihre Tochter Kore ${ }^{798}$, Sosipolis ${ }^{799}$, der Orakelgott Apollon Klarios ${ }^{800}$, Apollon Manteios $^{801}$, Theos Kinnaios ${ }^{802}$, Tyche ${ }^{803}$ und das personifizierte Heilige Feuer ${ }^{804}$ - verdeutlichen aber die kultische und religiöse Bedeutung des Gebäudes in der römischen Kaiserzeit. Diese Zunahme der im Prytaneion beheimateten Gottheiten ist besonders ab dem frühen 2. Jahrhundert $\mathrm{n}$. Chr. nachzuweisen ${ }^{805}$.

791 Bei hypothetischen Breiten eines Sitzplatzes von 40 bzw. $50 \mathrm{~cm}$, wie sie auch für das Theater von Ephesos angenommen werden.

792 Wie auch von Schwarzer 2008, 124. 155-163 vermutet.

793 Cf. Alzinger 1972-1975, 234; zur Funktion als Ort der ehrenvollen Speisungen: Miller 1978, 4-13, der auch die zahlreichen antiken literarischen Testimonien zusammenstellt, sowie Preuner 1864, 95-102; Frazer 1885, 145 f.; McDonald 1943, 127; Merkelbach 1980, $81 \mathrm{f}$.

794 Miltner 1959, 290-293 sah auf dem Fundament den Herd der Hestia.

795 So schon von Alzinger 1970, 1646-1648; Alzinger 1974, 53 f. und Alzinger 1972-1975, 241-249 interpretiert. Alzinger 1972-1975, 235 f. betrachtet in diesem Kontext den Klinenraum im Prytaneion von Lato auf Kreta als direktes Vergleichsbeispiel. Auch dort hätte sich im Zentrum ein Anrichtetisch befunden. Er folgt dabei A. Frickenhaus, Griechische Banketthäuser, JdI 32, 1917, 131 Anm. 2. Kritisch dazu und ohne Festlegung: Miller 1978, $82-85$ (zu Lato); 101-103 (zu Ephesos).

$796 \mathrm{Zu}$ dem vom Efes Müzesi Selçuk freigelegten Gebäude s. M. Büyükkolanc1 - Ü. Yüğrük, Banketthaus, in: Scherrer 1995a, 88.

797 s. dazu Knibbe 1981, 101-105; Keil 1939, 119-128.

798 IvE 10. 1060. 1071. 1072. 1210. - Knibbe 1981, 58 f. vermutete, dass Demeter Karpophoros in einem der Nebenräume des `Hestiasaales`, also Raum 5 oder 6, ein separiertes Heiligtum besaß. Daraufhin würde die Erwähnung eines veẃ im Opfergesetz IvE 10 Z. 28 f. deuten. Dieser sei nach IvE 1210 von P. Rutilius Bassus 120 n. Chr. aus seinen eigenen Mitteln errichtet worden. Scherrer 1997, 97 Anm. 36 erscheint D. Knibbes zeitlicher Ansatz der Einführung des Demeterkultes im Prytaneion im 2. Jh. als zu spät, da sich seiner Meinung nach das Opfergesetz IvE 10 auf spätrepublikanische Verhältnisse beziehen würde. - Zum Demeterkult in Ephesos s. D. Knibbe, Ephesos - Nicht nur die Stadt der Artemis, in: S. Şahin - E. Schwertheim J. Wagner (Hrsg.), Studien zur Religion und Kultur Kleinasiens. Festschrift Friedrich Karl Dörner, EPRO 66, 2 (Leiden 1978) 496-498; zur Bedeutung der Demeter im Prytaneion von Ephesos s. V. Suys, Déméter et le prytanée d’Éphèse, in: Actes du VI $^{\text {e }}$ Colloque international du C.I.E.R.G.A. Les panthéons des cités. Origines et développements (1 ${ }^{\text {re }}$ partie), Kernos. Revue internationale et pluridisciplinaire de religion grecque antique 11, 1998, 173-188.

799 IvE 1060.

${ }^{800}$ IvE 1060. 1071. 1072.

${ }^{801}$ IvE 1024. Dieser weissagende Apoll sei nach Knibbe 1981, 102 f. Anm. 203 als ephesischer Apoll zu verstehen und nicht

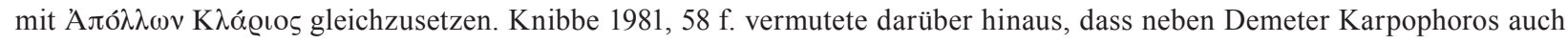
Apollon Manteios in einem der Nebenräume des >Hestiasaales〈 untergebracht gewesen war, da er nach IvE 1024 Z. 6 f. in einer eigens dafür im Prytaneion errichteten $\theta \alpha \lambda \alpha \mu$ í seine Aufstellung gefunden hätte.

802 IvE 1072.

803 IvE 1069.

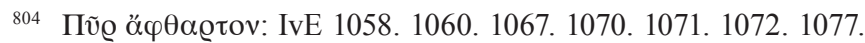

${ }^{805}$ Cf. Knibbe 1981, 102 beschreibt dieses Phänomen wie folgt: »Bald nach dem Beginn des 2. Jh.s setzt vor dem Hintergrund einer Zeit, in der die >großen< Gottheiten langsam unglaubwürdig zu werden beginnen und eine auf der Suche nach neuen Heilsgöttern befindliche Menschheit sich in zunehmendem Maße an Erlösung versprechende orientalische Gottheiten und Mysterien - und wohl auch schon an das Christentum - klammert, eine beachtliche Zunahme der Prytaneiongottheiten ein.« 
Im Bereich nördlich des \Staatsmarktes` etablierte sich in augusteischer Zeit ein innerstädtisches Zentrum für den Kaiserkult, das vor allem im Temenos zwischen dem Prytaneion und dem Bouleuterion sowie in der Basilike Stoa zu lokalisieren ist ${ }^{806}$. Doch auch das Prytaneion selbst fungierte als Stätte des Kaiserkultes der iulisch-claudischen Dynastie: So wird nach epigrafischer Überlieferung um $20 \mathrm{n}$. Chr. Livia, die Gattin des Augustus, als Personifizierung der Demeter Karpophoros in das Prytaneion eingeführt (IvE $4337)^{807}$.

\section{VIII.5 Räume 2, 3 und 4}

Der in augusteischer Zeit (Bauphase 1) als im Grundriss rechteckiger Querraum angelegte Komplex nördlich des $>$ Hestiasaales ${ }^{808}$ ist als Kultraum der Hestia zu interpretieren ${ }^{809}$, in dem auch das personifizierte Heilige

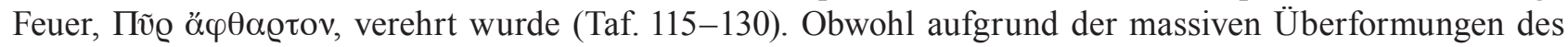
Raumes in byzantinischer Zeit die Herdstelle selbst nicht mehr nachzuweisen ist, zeugten der breite, durch den Keilsteinbogen und die nach oben führenden Stufen betonte Zugang im Süden von der hervorgehobenen Bedeutung dieses Raumes. So ist der an eine Cella erinnernde Raum als Ort des ewigen Feuers zu deuten, das das Leben der Stadt symbolisierte ${ }^{810}$. Es ist der Ort, an dem sich der gesamte Staat bzw. die Polis als Abbild der einfachen Familie an der Herdstelle des Prytaneions verdichtete ${ }^{811}$. Der häusliche Herd,

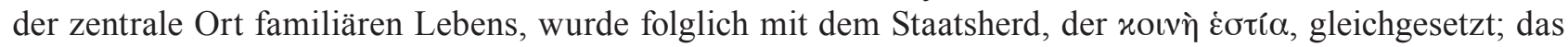
Prytaneion symbolisierte daher den gesamten Staat, die gesamte Polis. Das Gebäude selbst ist somit als Hauptkultgebäude der Stadt zu verstehen; in Ephesos umso mehr, als dort auch die Hauptgöttin der Stadt, Artemis Ephesia, in besonderem Maße verehrt wurde. Die Pflege des ewigen Feuers und die Verehrung der im Gebäude beheimateten Gottheiten, also die religiösen und kultischen Funktionen des Prytaneions, die sich an der $\dot{\varepsilon} \sigma \tau i ́ \alpha$ und den mit ihr verbundenen ehrenvollen Speisungen manifestierten, überlebten die politischen Funktionen bei Weitem. Es waren diese religiösen Funktionen, die trotz des kontinuierlichen politischen Bedeutungsverlustes derartiger Einrichtungen, deren Ursprünge immerhin bis in geometrische Zeit zurückreichen, ein Überleben des Gebäudekonzeptes $>$ Prytaneion` bis in die römische Zeit gewährleisteten ${ }^{812}$. Der Verlust seiner Bedeutung als Verwaltungsgebäude oder die vollständige Aufgabe eines Prytaneions markierten aber nicht notwendigerweise den Verfall einer Stadt, sondern können auch auf ein geändertes politisches Umfeld zurückzuführen $\operatorname{sein}^{813}$.

Der Querraum, der zunächst noch über eine Tür mit dem westlich angrenzenden Raum 5 verbunden war, wurde in der byzantinischen Bauphase 3 (5./6. Jahrhundert $n$. Chr.) massiv verändert. So wurden zunächst die Tür in Raum 5 sowie der Durchgang in den >Hestiasaak verschlossen und zwischen den Räumen 2 und

806 s. dazu Scherrer 1997, 93-100.

807 Cf. Scherrer 2007, 67; Scherrer 1997, 93.96 f.

808 Cf. M. Steskal, Kapitel III.7-9.

809 So schon Alzinger 1974, 54; Alzinger 1972-1975, 241-249; zur kultischen Funktion der Prytaneia: Miller 1978, 13-16 mit Verweisen zu den antiken literarischen Testimonien sowie Preuner 1864, 106; Frazer 1885, 145 f.; McDonald 1943, 127; Merkelbach 1980, 81 f.; Knibbe 1981, 101-105.

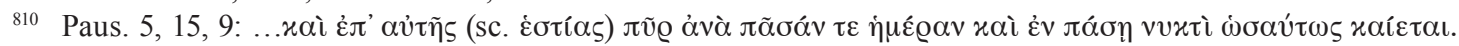

811 s. dazu Merkelbach 1980, 79; Preuner 1864, 113. 115. 215.

812 Cf. Miller 1978, 24. 128-131 oder Witetschek 2008, 46. Wie schwierig es allerdings ist, den genauen Zeitpunkt der tatsächlichen Institutionalisierung des Prytaneions und der Prytanen zu bestimmen, zeigt sich am Beispiel von Athen. s. dazu P. J. Rhodes, The Athenian Boule (Oxford 1972) 16-19, der vermutet, dass die Prytanen erst zur Zeit des Ephialtes Teil der Boule wurden; die Tholos sei in diesem Kontext die archtektonische Manifestation dieser Verfassungsänderung. Miller 1978, 65 Anm. 77 geht davon aus, dass Prytanen schon in vorkleisthenischer Zeit existiert hätten; fraglich bliebe aber, ob sie zu diesem Zeitpunkt auch Teil der Boule gewesen wären: »The existence of prytaneis much earlier in Athenian history can probably be taken for granted on analogy with, for example, the previous existence of archons. But when did the prytaneis become part of the constitutional scheme; when did they become a commitee of the Boule? Since even the existence of a Boule before Kleisthenes is not secure, one cannot assume that there was a commitee of prytaneis as a part of such an earlier Boule."

813 Cf. Liebeschuetz 2001, 29: »Abandonment or downgrading of buildings may not reflect deurbanization, but only a transformation of the character of urban life, as for instance the change from government by the curia to government by notables, or the rise of the bishop. So buildings which had served local self-government, for example the curia (bouleuterion), the prytaneion, or the civic basilica might be allowed to fall into decay, or be adapted to serve a different purpose, or simply quarried for building materials.«; cf. in diesem Zusammenhang auch G. Brands, Die spätantike Stadt und ihre Christianisierung, in: Brands Severin 2003, 19 f.; W. Hoepfner, Das Ende der Agora, in: Brands - Severin 2003, 145-150. 
3 eine Mauer hochgezogen. Die Räume 3 und 4 wurden in der Folge als Wasserreservoir genutzt, während der ebenfalls eingangslose Raum 2 wohl als Keller für die darüber befindlichen byzantinischen Strukturen gedient hat. Obwohl die Zuleitung des Wasserreservoirs nicht mehr angetroffen wurde, ist davon auszugehen, dass es sich um einen Wassertank handelte, der künstlich befüllt wurde. Ob darin auch Regenwasser gesammelt wurde und es sich somit um eine Zwischenform aus Zisterne und Wasserreservoir handelte, kann weder bestätigt noch verneint werden - die Befunde sind in diesem Kontext nicht aussagekräftig genug. Da Wasserreservoirs immer dann erforderlich sind, wenn der Wasserbedarf den Zufluss zeitweise übersteigt ${ }^{814}$, ist also davon auszugehen, dass es einen erheblichen Wasserverbrauch im Areal nördlich des >Staatsmarktes $<$ in byzantinischer Zeit gegeben haben muss bzw. das Wasserleitungssystem die notwendigen Kapazitäten nicht mehr zur Verfügung stellen konnte. Es ist zu vermuten, dass die Ton- und Bleirohrleitungen in dieser Zeit schon erheblich in Mitleidenschaft gezogen oder einzelne Stränge überhaupt nicht mehr intakt waren. All diese Faktoren bedingten die Einrichtung des Wasserreservoirs in den Räumen nördlich des 〉Hestiasaales`, aber auch im Areal östlich des Prytaneions, wo ebenfalls kleinere Wasserreservoirs in den nur sporadisch untersuchten byzantinischen Strukturen nachzuweisen sind ${ }^{815}$. Will man Trinkwasser allerdings über eine längere Zeit genießbar halten, muss man es kühl und dunkel lagern. Daher werden Zisternen und Wasserreservoirs oft unterirdisch angelegt. Die suboptimale oberirdische Anlage des Wasserreservoirs im Prytaneion von Ephesos und im Bereich östlich davon könnte somit ein Beleg dafür sein, dass hier eher Brauch- als Trinkwasser gespeichert wurde. Das große Wasserangebot deutet zudem auf eine handwerkliche Nutzung des Areals hin, die freilich in Kombination mit einfachen Wohnmöglichkeiten $\mathrm{zu}$ verstehen sein wird ${ }^{816}$.

Die Nutzung des Areals in byzantinischer Zeit ist, unabhängig von der Frage, ob es innerhalb oder außerhalb der byzantinischen Stadtmauern gelegen war - konkret ob die byzantinische Stadtmauer zu diesem Zeitpunkt schon existierte -, zumindest bis an den Beginn des 7. Jahrhunderts durch den Einbau der Wasserreservoirs und der weiteren im Norden und Osten anschließenden baulichen Strukturen gesichert ${ }^{817}$. Das Reservoir, das sein Wasser über eine Öffnung in der Nordwand des >Hestiasaales` ableitete, wurde in der Mitte des 7. Jahrhunderts n. Chr. wieder aufgegeben (Bauphase 3a); die Räume 3 und 4 wurden jedoch auf erhöhtem Niveau weiter genutzt. Die Art der Nutzung ist in diesem Zusammenhang nicht mehr eindeutig $\mathrm{zu}$ bestimmen. Eine Frequentierung des Areals ist aber zumindest bis in das letzte Viertel des 8. Jahrhunderts belegt. Darüber hinaus ist ein fortgesetzter Abbruch von Baumaterial zu konstatieren, der aber nicht so eklatant ausfällt wie in den südlichen Teilen des Gebäudes. Das Mauerwerk ist daher noch durchweg hoch erhalten: die Ostwand bis zu einer max. Höhe von 6,95 m über dem Niveau des >Hestiasaales` (absolut: 46,36 m), die Nordwand 8,34 m, die Westwand 6,91 m und die Südwand 5,25 m. In diesem Zusammenhang ist F. A. Bauer zu folgen, wenn er betont, dass am ephesischen Prytaneion der Bedeutungsverlust der klassischen politischen Institutionen besonders eindrucksvoll abgelesen werden könnte: Er manifestiert sich in der Entnahme von Baumaterial und der Umfunktionierung zu einem Wasserreservoir ${ }^{818}$.

Nördlich des Querraumes 2-4 und des Raumes 5 befand sich schließlich ein Ost-West verlaufender, überwölbter Kanal (Taf. 114), der kein Wasser führte, sondern als Entlüftungsstollen dazu diente, die Nordmauer des Gebäudes trocken zu halten ${ }^{819}$. Dies war deswegen nötig, da sich sonst das an der Südseite des Panayırdağ sammelnde Regenwasser die Nordwand der Cella in Form von Staunässe beeinträchtigt hätte. Über dem Gewölbescheitel entstand dadurch ein begehbarer Bauwich mit einem Boden aus Kalksteinplatten, der die gesamte Nordwand des Prytaneions entlangführt.

814 Cf. M. Döring, Römische Aquädukte und Großzisternen der Phlegräischen Felder, in: Ch. Ohlig (Hrsg.), Antike Zisternen, Schriften der Deutschen Wasserhistorischen Gesellschaft 9 (Siegburg 2007) 9.

815 So etwa im östlich an den >Hestiasaal angrenzenden Raum 7.

816 Cf. Eichler 1965, 96.

817 Zur Verlagerung der ephesischen Bevölkerung in die Areale innerhalb der byzantinischen Stadtmauer s. Ladstätter - Pülz 2007, 391-433, aber auch Liebeschuetz 2001, 49: »But so far too little of the residential areas of Ephesus has been excavated to establish with any degree of precision when any of the quarters of the city became depopulated. But even if a large number of people continued to live outside the new wall, the fact that so much of the old city was left outside the fortifications must be significant."

818 Bauer 1996, 297 mit allerdings abweichenden und nicht belegten Datierungen der Bauphasen.

819 Cf. M. Steskal, Kapitel III.6. 


\section{VIII.6 Räume 5 und 6}

Die beiden westlich des >Hestiasaales` gelegenen Räume 5 und 6 unterscheiden sich von der Vorhalle und dem >Hestiasaal nicht nur durch ihre kleineren Dimensionen, sondern auch durch eine weniger repräsentative Ausstattung ${ }^{820}$ (Taf. 92-113). Die Wände besaßen keine Marmorverkleidung, sondern waren mit Wandmalerei versehen; die Böden selbst sind nicht mehr erhalten. Die gut erhaltene, fein gearbeitete, marmorne Türschwelle zwischen den Räumen 5 und 6, die Reste einer baugleichen Schwelle zwischen Raum 6 und der Vorhalle (Tür 1) und die Reste von polychromer Wandmalerei in Raum 6 lassen zwar einen gehobenen Anspruch dieser Räume erkennen; gegenüber den benachbarten Räumen sind sie aber ausstattungstechnisch und somit auch funktional als sekundär zu betrachten.

Abgesehen von ihrer Verbindung mit der Vorhalle über Tür 1 im Süden von Raum 6 besaßen die beiden Räume an der Ostseite von Raum 5 ursprünglich eine Tür in den Querraum 2-4. In Bauphase 1b, knapp nach 104 n. Chr., (oder Bauphase 2) wurden die Ostwände der beiden Räume repariert sowie zentrale Stützen in beiden Räumen errichtet. Tiefgreifende Veränderungen zeichnen sich schließlich in der byzantinischen Bauphase 3 (5./6. Jahrhundert n. Chr.) ab. Die starke Überformung der Räume in dieser Zeit erschwert auch ihre Funktionsbestimmung für den Zeitraum, als das Gebäude noch als Prytaneion in Nutzung stand. Zunächst wurden sämtliche vorhandenen Türen zugemauert, und zwar die Türen zwischen Raum 5 und Raum 4, zwischen Raum 5 und Raum 6 sowie zwischen Raum 6 und der Vorhalle. Daraufhin wurden durch Aufschüttungen die Raumniveaus erhöht und die beiden Räume auf diesen neu geschaffenen Nutzungshorizonten weiter genutzt. Von dieser Verwendung zeugen zwei Türen in der stark reparierten Westwand von Raum 5 und Raum 6, welche die `Akademiegasse < erschlossen. Zur Tür in der Westwand von Raum 6 führte eine Rampe, die von den Ausgräbern der 1950er und 1960er Jahre noch vorgefunden wurde, heute aber verloren ist. Raum 5 wurde durch den Einbau einer Nord-Süd-Tonne in der Nordostecke in insgesamt drei Raumkompartimente unterteilt. Der nach der Aufgabe des Gebäudes einsetzende Steinraub, der sich nach der byzantinischen Nutzung weiter fortsetzte, ist wiederum vor allem im südlicheren dieser beiden Räume festzustellen, während das Mauerwerk des nördlicheren Raumes 5 noch durchweg hoch erhalten ist: In Raum 5 ist die Ostwand bis zu einer max. Höhe von 4,28 m über dem Niveau der Türschwelle zwischen Raum 5 und 6 (absolut: 46,53 m) erhalten, die Nordwand bis zu 5,62 m, die Westwand bis zu 4,98 m und die Südwand bis zu 3,81 m. Das Mauerwerk in Raum 6 fällt stark nach Süden ab: So ist die Ostwand bis zu einer max. Höhe von 3,02 m über dem Niveau der Türschwelle erhalten, die Nordwand bis zu 3,72 m, die Westwand bis zu 3,41 m und die Südwand bis zu 1,38 m.

Die Funktion der Räume 5 und 6 ist nur schwer konkret zu benennen. Einerseits ist es vorstellbar, dass einige der im ephesischen Prytaneion untergebrachten Kulte hier beheimatet waren. Vor allem Demeter Karpophoros und Apollon Manteios könnten sich dafür anbieten, wie D. Knibbe bereits früher ausführte ${ }^{821}$ : So hätte Apollon Manteios nach IvE 1024 Z. 6 f. in einer eigens dafür im Prytaneion errichteten $\theta \alpha \lambda \alpha \mu$ í seine Aufstellung gefunden; für Demeter Karpophoros wäre überhaupt ein separiertes Heiligtum überliefert, worauf die Erwähnung eines vews im Opfergesetz IvE 10 Z. 28 f. hindeuten würde. Obwohl die >Schöne Artemis` (KatNr. SK 1) zwar in Raum 5 in ihrer endgültigen Deponierungslage gefunden wurde, ist nicht zu entscheiden, ob sie in einem der Räume westlich des >Hestiasaales` auch verehrt wurde. Darüber hinaus sind auch weitere Funktionen für diese beiden Räume zu postulieren: Es ist anzunehmen, dass in den Räumen 5 und 6 Platz für das Kultpersonal - und somit für das Kuretensynedrion - vorhanden war, das an den zahlreichen Kulthandlungen im Prytaneion beteiligt war bzw. bei diesen behilflich sein musste. Auch die für Prytaneia überlieferten Archive, die später großteils in das Bouleuterion verlagert wurden, könnten hier

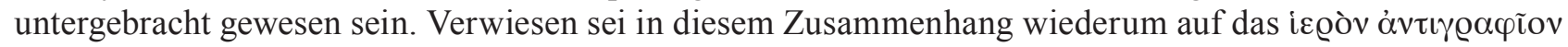
(IvE 1024 Z. 12) aus einer der Kureteninschriften des Prytaneions ${ }^{822}$. Es wäre denkbar, dass die bauzeitlichen vertikalen Rinnen in der Ost- und Westwand von Raum 6, die in Bauphase $1 \mathrm{~b}$ bereits funktionslos wurden, in diesem Kontext als Einlassungen für Regale dienten, oder aber den Raum in kleinere Kompartimente teilten, um so mehr Platz für die unterschiedlichen Nutzungsansprüche zu gewinnen.

\footnotetext{
${ }_{820}$ Cf. M. Steskal, Kapitel III.5 und 6.

821 Knibbe 1981, $58 \mathrm{f}$.

${ }_{822}$ Cf. Knibbe 1981, B 24; Halfmann 2001, 23 Anm. 69; McDonald 1943, 156.
} 


\section{VIII.7 Synthese}

Die Funktionsanalyse der einzelnen Räume des Prytaneions in Ephesos zeigt, dass das Gebäude neben den einem Prytaneion immanenten Hauptfunktionen zahlreiche andere Aufgaben übernommen hatte. Die unterschiedlichen Formen der Nutzung sind einerseits epigrafisch überliefert, andererseits am Monument anhand spezifischer Ausstattungselemente oder des architektonischen Aufbaus ablesbar. Die hohe Informationsdichte der genannten Quellen ermöglicht eine weitgehend gesicherte Funktionszuweisung, die wiederum ein heterogenes Bild von den unterschiedlichen Nutzungsmöglichkeiten dieses Gebäudes zeichnet. Dass die Identifizierung des Gebäudes als Prytaneion erwiesen ist, belegt das umfangreiche epigrafische Material, welches das Gebäude als Heiligtum der Hestia Boulaia und folglich als Prytaneion ausweist. Es handelt sich somit um eines der wenigen unzweifelhaft als Prytaneion zu deutenden Bauwerke in der antiken griechischen und römischen Welt ${ }^{823}$. Diese Interpretation wird durch die urbanistische Einbindung des Gebäudes, und zwar seine Lage am `Staatsmarkt , dem politischen Zentrum der Stadt, sowie die unmittelbare Nähe zum Bouleuterion gestützt.

Zu den Hauptfunktionen des Prytaneions zählen die Beherbergung des Herdes der Hestia und des Amtslokals der Prytanen sowie die Veranstaltung der ehrenvollen Speisungen verdienter Bürger auf Staatskosten. All diese Funktionen werden in dem repräsentativen ephesischen Gebäude zusammengefasst.

Der Herd der Hestia, auf dem das ewige Feuer brannte, das das Leben der Stadt symbolisieren sollte, war im ursprünglichen Querraum 2-4 untergebracht. Diese Cella ist als Kultraum der Hestia zu verstehen. Der häusliche Herd, der zentrale Ort familiären Lebens, wird an dieser Stelle mit dem Staatsherd, der xouv̀ $\dot{\varepsilon} \sigma \tau i \alpha$, gleichgesetzt. Der gesamte Staat bzw. die Polis konzentriert sich an dieser Herdstelle als Abbild der einfachen Familie. Um dieses Feuer sorgte sich das Synedrion der Kureten, die in zahlreichen listenförmigen Inschriften am Gebäude nachgewiesen sind. Die Kureten dienten auch als Opferassistenten des Prytanen bei der Durchführung der regelmäßigen und oft komplizierten Kulthandlungen, die im Prytaneion vorgenommen wurden. Das zumindest bis an den Beginn des 3. Jahrhunderts n. Chr. belegte Kollegium, das in augusteischer Zeit vom Artemision ins Prytaneion transferiert wurde, war aber auch mit der Realisierung der jährlich stattfindenden ortygischen Mysterien betraut. Dieses Mysterienspiel gab die Niederkunft Letos wieder und bildete einen Fixpunkt im kultischen Jahresablauf von Ephesos. Die Verlagerung der Organisation dieses Mysterienspiels vom Artemision in die Stadt bedeutete einen erheblichen Macht- und Prestigeverlust für das Artemision. Untergebracht könnte dieses Synedrion in den Räumen 5 und 6 gewesen sein - ohne dies jedoch eindeutig beweisen zu können. In diesen beiden Räumen könnte auch das städtische

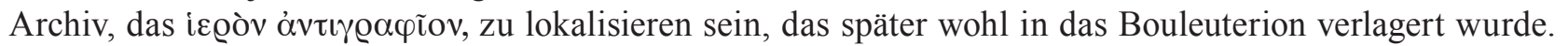

In dem mit Sitzbänken ausgestatteten 〉Hestiasaak versammelten sich die Prytanen. Vielleicht diente dieser Raum anfänglich auch als der Ort, in dem der ephesische Rat zusammenkam, ehe diese Aufgabe vollständig vom benachbarten Bouleuterion übernommen wurde. Der `Hestiasaal diente vor allem aber auch als der Ort ehrenvoller Speisungen verdienter und herausragender Bürger und Fremder auf Staatskosten. In ihm wurden die offiziellen Gäste der Stadt empfangen und bewirtet - das Prytaneion fungierte in diesem Kontext als Stellvertreter für alle Häuser der Stadt.

Neben dem Kult für Hestia Boulaia waren zahlreiche weitere Kulte im Prytaneion untergebracht. Zu nennen sind Demeter Karpophoros und ihre Tochter Kore, Sosipolis, Apollon Klarios, Apollon Manteios, Theos Kinnaios, Tyche und das personifizierte Heilige Feuer. Sie alle demonstrieren die eminente kultische und religiöse Bedeutung des Gebäudes, die sich vor allem ab dem frühen 2. Jahrhundert n. Chr. durch die Einführung dieser neuen Kulte verstärkte. In welchen Räumen die einzelnen Gottheiten verehrt wurden, ist im Detail nicht immer zu klären. Vieles spricht jedoch dafür, dass Demeter Karpophoros und Apollon Manteios, für die ein eigener veẃs bzw. eine $\theta \alpha \lambda \alpha \mu$ í überliefert sind, in einem der Nebenräume des >Hestiasaales` untergebracht waren (Räume 5 und 6). Das personifizierte Heilige Feuer hatte im Querraum 2-4 und somit im Heiligtum der Hestia seinen Platz. Neben dem Hauptkult für Hestia Boulaia und den genannten sekundären Kulten scheint das ephesische Prytaneion als Dependance des Artemisions fungiert zu haben, worauf die übergeordnete Bedeutung und Präsenz der Artemis Ephesia im Gebäude hindeuten. Sie nahm im Prytaneion eine der Hestia Boulaia de facto gleichwertige Stellung ein. Die vier in unterschied-

\footnotetext{
${ }^{823}$ s. dazu auch M. Steskal, Kapitel IX.
} 
licher Qualität erhaltenen Statuen der Artemis Ephesia, die wohl im Vorhof und in der Vorhalle aufgestellt waren, manifestierten den Machtanspruch der Artemis, die ihren Sitz in einem extraurbanen Heiligtum besaß, innerhalb der Stadt.

Das Prytaneion diente aber auch als Ort der Repräsentation: Ehrenstatuen und Ehrenbasen, die im Vorhof und in der Vorhalle aufgestellt waren, zeugen von diesem Anspruch. Im benachbarten Temenos und in der Basilike Stoa etablierte sich in augusteischer Zeit ein innerstädtisches Zentrum für den Kaiserkult, doch auch im Prytaneion ist als Sekundärfunktion die Verehrung des Kaiserhauses nachgewiesen: So wurde, wie schon erwähnt, Livia um 20 n. Chr. als Personifizierung der Demeter Karpophoros in das Prytaneion eingeführt. Mit dem Kaiserkult könnten auch die Kureten in unmittelbarem Zusammenhang gestanden sein,

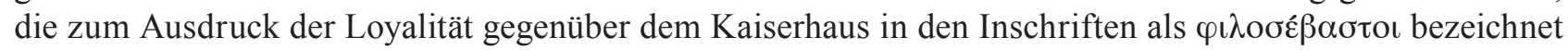
wurden.

Generell ist festzuhalten, dass die religiösen und kultischen Funktionen des Gebäudes gegenüber den politischen bei Weitem dominierten. Der kontinuierliche Bedeutungsverlust dieser Einrichtung in politischen Belangen, die in der römischen Kaiserzeit ihren Höhepunkt längst überschritten hat, wird am ephesischen Prytaneion eindrucksvoll dokumentiert.

Das Gebäude wurde in der Mitte des 4. Jahrhunderts aufgegeben und das Baumaterial sukzessive abgetragen. Ab dem 5./6. Jahrhundert wurde das Areal nördlich des \Staatsmarktes` wohl als Handwerksviertel mit einfacher Wohnbebauung genutzt. Von dieser Periode zeugen die byzantinische Überbauung des Prytaneions und insbesondere die Einrichtung des Wasserreservoirs in den Räumen 3 und 4. 


\title{
IX EXKURS ZU DEN PRYTANEIA IN KLEINASIEN - EINE VERGLEICHSSTUDIE
}

\author{
(Martin Steskal)
}

\section{IX.1 Vorbemerkung}

Die folgende Zusammenstellung soll einen Überblick über die weiteren bekannten und vermuteten Prytaneia in Kleinasien bieten. Der Publikationsstand erweist sich auch in diesem Kontext als überaus heterogen; die tatsächliche Identifizierung der hier vorgestellten Gebäude als Prytaneia ist zudem, wie gezeigt wird, nicht immer sicher. Dargestellt werden die relevanten Bauten von Aigai, Herakleia am Latmos, Kolophon, Magnesia am Mäander, Milet, Pergamon und Priene.

\section{IX.2 Aigai}

Das zwischen den Städten Izmir und Bergama gelegene äolische Aigai, in dem aktuell groß angelegte Feldforschungen von der Ege Üniversitesi in Izmir vorgenommen werden ${ }^{824}$, beheimatet an der Nordwestecke der Agora ein Gebäude, das vor seiner Freilegung u. a. als Prytaneion angesprochen wurde. Aufgrund des Fundes einer Bauinschrift auf einem Architrav, die Zeus Boulaios und Hestia Boulaia nennt, vermutete R. Bohn am Ende des 19. Jahrhunderts in diesem Gebäude eine Kombination aus Prytaneion und Bouleuterion $^{825}$. Die neu angelegten Grabungen zeigen nunmehr deutlich, dass es sich um ein Bouleuterion handelt, dessen nicht ganz halbkreisförmigen Sitzreihen noch gut erhalten sind (Taf. 241, 1). Für das Vorhandensein eines Prytaneions an dieser Stelle gibt es bis dato keine Evidenzen. Es bleibt abzuwarten, ob die aktuellen Grabungen ein Prytaneion in unmittelbarer Nähe dieses Bouleuterions nachweisen können.

\section{IX.3 Herakleia am Latmos}

Westlich an das Bouleuterion von Herakleia anschließend befindet sich ein Raum (ca. 6,80×7,20 m), den K. Wulzinger 1941 als kleinen Tempel interpretierte, in dem er einen Kult für Zeus Boulaios oder Athena Boulaia vermutete $^{826}$ (Taf. 241, 2). Weder dafür noch für eine Interpretation des Raumes als Kultplatz der Hestia sind jedoch positive Belege beizubringen. Wiewohl die unmittelbare Nähe zu Bouleuterion und Agora eine Identifikation als Prytaneion prinzipiell möglich macht, kann dieser Hypothese beim jetzigen Wissensstand nicht beigepflichtet werden.

\section{IX.4 Kolophon}

In der Nordostecke der Agora von Kolophon befindet sich ein Gebäude, das gleichsam als östlicher Annex der nördlichen Stoa diente ${ }^{827}$ (Taf. 242, 1). Die nur oberflächlich untersuchte Anlage besteht aus der Verlängerung der angrenzenden Stoa im Süden sowie drei Räumen, von denen sich der östliche als der

824 s. dazu E. Doğer u. a., Aigai 2004-2006 y1lı kazıları, KST 29, 2008, 214-218. Für die freundliche Abbildungserlaubnis des Bouleuterions sei E. Doğer herzlich gedankt.

${ }^{825}$ R. Bohn, Altertümer von Aegae, JdI Ergh. 2 (Berlin 1889) 33-35. Dass eine solche Kombination auch explizit nur in Bouleuteria zu finden ist, zeigt Miller 1978, $225 \mathrm{f}$. am Beispiel von Athen.

826 K. Wulzinger, Das Rathaus von Herakleia am Latmos, in: F. Krischen, Antike Rathäuser (Berlin 1941) 25; zur Agora: A. Peschlow-Bindokat, Der Latmos. Eine unbekannte Gebirgslandschaft an der türkischen Westküste (Mainz 1996) 37; A. Peschlow-Bindokat, Herakleia am Latmos. Stadt und Umgebung (Istanbul 2005) 119-121.

827 Holland 1944, 91-171 bes. 103-107; Miller 1978, 109-112. 
Hauptraum (ca. 10,35 × 12,80 m) erwies. Die Verbindung zu den westlich anschließenden, kleineren Räumen (ca. 3,85 $\times 5,70 \mathrm{~m}$ im Norden bzw. ca. 5,25 × 7,20 m im Süden) ist durch den schlechten Erhaltungszustand des Monuments nicht geklärt. Sechs Münzfunde aus der ersten Hälfte des 4. Jahrhunderts v. Chr., deren stratigrafischer Kontext allerdings nicht gesichert ist, könnten einen terminus post quem für die Errichtung dieses Gebäudes bieten. Es kann daher nur kurze Zeit - und zwar in der zweiten Hälfte des 4. Jahrhunderts v. Chr. - in Nutzung gestanden sein, da ja bereits unter Lysimachos die Bevölkerung von Kolophon um 300 v. Chr. nach Ephesos transferiert wurde ${ }^{828}$. Die Funktion des Gebäudes blieb nach L. B. Holland zunächst unklar ${ }^{829}$ : »The function of the large room and its dependencies, or of the separate building which preceeded it, can only be guessed. It seems rather too important for a commercial structure and too closely linked to the rest of the stoa to be a religious one ... A civic function of some sort seems most probable." Der Fund dreier Bleigewichte innerhalb des Gebäudes ermunterte Holland jedoch zu folgendem Schluss ${ }^{830}$ : »These weights were below the floor level of the later building and probably above that of the earlier one. If they indicate that the official weights and measures of the city were kept in the earlier building, then it and its successor, the east section of the stoa, may have been a prytaneum, and the foundations against the south wall may have been for enclosures in which the official standards were stored.« Der Ansicht, dass ausschließlich in Prytaneia die offiziellen Gewichte und Maßeinheiten der Stadt aufbewahrt worden wären, widerspricht allerdings bereits St. G. Miller ${ }^{831}$. Da kein Raum für den Hestiakult oder für die Ehrenmähler explizit nachzuweisen ist, bleibt eine Identifizierung dieses Gebäudes als Prytaneion rein spekulativ; beim jetzigen Wissensstand ist die Funktion des Gebäudes daher nicht zu klären.

\section{IX.5 Magnesia am Mäander}

An der Südwestecke der Agora von Magnesia am Mäander befindet sich ein heute im Gelände nicht mehr ablesbares Gebäude ${ }^{832}$ (Taf. 242, 2), das aufgrund eines Inschriftenfundes als Prytaneion interpretiert wur$\mathrm{de}^{833}$. Die Anlage wird von einem 34,20 × 25,90 m großen Peristylhof mit einer Säulenstellung dorischer Ordnung dominiert, deren südwestliche Ecksäule als Eck-Doppelhalbsäulen ausgebildet war. Das Gebäude konnte über ein Propylon im Norden, das durch zwei ionische Säulen in antis charakterisiert war, von der Agora her erschlossen werden. Westlich an das Propylon schloss eine 14,60 × 9,20 m große Exedra an, die durch eine ionische Säulenstellung vom Peristyl getrennt war. In ihr standen ursprünglich zahlreiche Ehrendenkmäler, von denen sich noch die Basis einer Statue des Lucius Aphranios erhalten hat. Den westlich anschließenden Raum interpretierte St. G. Miller wegen der aus der Achse versetzten Tür als Speisesaal mit $20 \mathrm{zu}$ rekonstruierenden Klinen ${ }^{834}$. In der Mitte der Ostseite befand sich schließlich ein Raum, der nur über die Südostecke des Peristylhofes und über zwei Vorräume zu betreten war. In ihm lag ein Herd in Form eines 1,37 × 1,37 m großen und $1 \mathrm{~m}$ hohen, reliefierten Altars, der den Raum als Kultraum der Hestia ausweist. Die Weihinschrift des Themison und Nikanor auf dem Altar datiert diesen in die Zeit um $100 \mathrm{v}$. $\mathrm{Chr}^{835}$. Die Datierung des Gebäudes selbst ist in Zusammenhang mit der Errichtung der südlichen Stoa der Agora zu sehen; sie könnte daher in der zweiten Hälfte des 3. Jahrhunderts v. Chr. erfolgt sein ${ }^{836}$. Obwohl

828 s. Paus. 1, 9, 7 und 7, 3, 1-4.

829 Holland 1944, 106.

830 Holland 1944, 106.

831 Miller 1978, 35.

832 Humann 1904, 112. 137 f.; Abb. 115; Miller 1978, 112-115; O. Bingöl, Magnesia am Mäander. Magnesia ad Maeandrum (Istanbul 2007) 104 f.; zur Agora: O. Bingöl, Die Agora von Magnesia am Mäander, in: Hoepfner - Lehmann 2006, 59-65.

833 O. Kern, Die Inschriften von Magnesia am Maeander (Berlin 1900) Nr. 143. 220. - Zu Recht widerspricht M. Trümper, Graeco-Roman Slave Markets - Fact or Fiction? (Oxford 2010) 68-73 der von F. Coarelli, L'>Agora des Italiens« a Delo. Il mercato degli schiavi?, OpFin 2, 1982, 136 f. und E. Fentress, On the Block: catastatae, chalcidica and cryptae in Early Imperial Italy, JRA 18, 2005, 228. 231 vorgetragenen Meinung, dass es sich beim magnesischen Prytaneion um einen Sklavenmarkt handeln würde: »In summary, the building offers no conclusive evidence for its identification as a slave market. On the contrary, other functions, such as a prytaneion, as a lavishly decorated public building of unknown purpose, or as some kind of semipublic clubhouse of an association, cannot be excluded and, indeed, seem much more likely."

834 Miller 1978, 113 f.; cf. auch B. Bergquist, Sympotic Space: A Functional Aspect of Greek Dining-Rooms, in: Murray 1990, 52 f. Der Ausgräber C. Humann macht allerdings keine derartige Beobachtung.

835 O. Kern, Die Inschriften von Magnesia am Maeander (Berlin 1900) Nr. 220; Miller 1978, 114.

836 Humann 1904, 22. 
eine endgültige Beurteilung des Gebäudes nur durch eine neuerliche Freilegung gelingen könnte, sprechen mehrere Argumente dafür, die Anlage tatsächlich als Prytaneion zu identifizieren: So liegt sie unmittelbar an der Agora, hat ein ausreichendes Raumangebot mit repräsentativem Grundriss, verfügt unter Umständen über einen Speisesaal und über eine inschriftlich belegte Hestia. Funde von Stuck und Malereien des ersten pompejanischen Stils weisen zudem auf den gehobenen Anspruch der Dekoration hin. Wenn auch die dezentrale Lage und Größe der Hestia Fragen offenlassen, so scheint eine Interpretation als Prytaneion gerechtfertigt.

\section{IX.6 Milet}

In Milet stehen forschungsgeschichtlich zwei Komplexe als Prytaneion zur Diskussion: einerseits das an der Südwestecke des Nordmarktes von Milet, etwa $25 \mathrm{~m}$ vom Bouleuterion entfernt gelegene, etwa zur Hälfte freigelegte Gebäude, in dem A. v. Gerkan das milesische Prytaneion vermutete ${ }^{837}$ (Taf. 243, 1. 2); andererseits die Südhalle des Delphinions, in der A. Herda das sog. Molpon-Prytaneion lokalisierte ${ }^{838}$ (Taf. 243, 1. 3).

In Bezug auf ersteren Bau fehlen grundlegende Daten, um eine Identifizierung als Prytaneion zu rechtfertigen: Die Datierung des aus Gneis und Poros errichteten Gebäudes, das mit seinen Ausmaßen von circa 28,70 $\times 52,40 \mathrm{~m}$ zwei Insulae einnimmt, konnte im Zuge der Grabungen nicht exakt geklärt werden. Doch gilt die Anlage als eines der ältesten Gebäude des nachpersischen Milet ${ }^{839}$. Der Grundriss, der in weiten Bereichen ergänzt ist, zeigt einen großen, zentralen Mittelraum, um den sich an allen Seiten kleinere Raumeinheiten gruppieren. Der Haupteingang des Gebäudes lag im Osten der Anlage und besaß wahrscheinlich eine Treppe, um den Niveauunterschied zur Agora überwinden zu können. In hellenistischer Zeit wurde im Norden des Gebäudes eine viersäulige Halle ionischer Ordnung eingebaut, hinter der sich ein ca. $10 \times 8,50 \mathrm{~m}$ großer Raum befand. In diesem Raum fand sich an drei Seiten ein bankartiges Fundament aus Breccia. G. Kleiner spricht in diesem Zusammenhang von der Möglichkeit, in dieser Anlage ein neues Prytaneion zu sehen ${ }^{840}$. Die Identifizierung des Gebäudes als Prytaneion erfolgte freilich nur aufgrund der Nähe zum Bouleuterion und der Agora sowie seines grundrisstypologisch öffentlichen Charakters. Es fehlen beim derzeitigen Wissensstand jedoch jegliche Hinweise auf die nötige Herdstelle sowie auf einen Speise- oder Versammlungssaal. Weitere Grabungen in dem nur partiell untersuchten Gebäude könnten hier wichtige neue Erkenntnisse liefern. Eine Interpretation dieser Anlage als Prytaneion oder eine andere Funktionszuweisung bleiben bis zu diesem Zeitpunkt rein spekulativ ${ }^{841}$.

Anders verhalten sich die Dinge in Bezug auf einen spezifischen Bereich im milesischen Apollon-Delphinios-Heiligtum, nämlich die Südhalle dieses Komplexes. Das 28,10 $\times 50,40 \mathrm{~m}$ große Delphinion weist vier Hauptphasen auf $^{842}$ : eine spätarchaische, eine frühklassische, eine frühhellenistische und eine kaiserzeitliche. Im Zentrum dieses rechteckigen Gebäudes, das von einem offenen Hof dominiert wurde, fanden sich ein leicht aus der Achse gedrehter Volutenaltar des Apollon Delphinios sowie - im Gebäude verteilt vier weitere Rundaltäre des Zeus Soter, der Artemis, der Hekate und einer unbekannten Gottheit. Jeweils 7,80 m tiefe Hallen im Norden und Süden rahmten den Komplex. In diesem Gebäude war - offenbar bereits seit spätarchaischer Zeit ${ }^{843}$ - der Kultverein der Molpoi beheimatet, deren Vorsitzender, der AisymnetesStephanephoros, eponoymer Beamter war, wie A. Herda nach Analyse eines in Milet gefundenen, spät-

\footnotetext{
37 A. v. Gerkan, Der Nordmarkt und der Hafen an der Löwenbucht, Milet 1, 6 (Berlin 1922) 89 f.; s. auch Kleiner 1968, 50-54; Miller 1978, 231.

838 Herda 2005, 243-294; s. dazu F. Graf, Apollon Delphinios, MusHelv 36, 1979, 2-22; G. Kawerau - A. Rehm, Das Delphinion in Milet, Milet 1, 3 (Berlin 1914); zum Gebäude s. ferner Kleiner 1968, 33-35.

839 Kleiner 1968, 51.

840 Kleiner 1968, 54.

841 So auch Herda 2005, 273.

842 Cf. Herda 2005, 259-263.

${ }^{843}$ Cf. Herda 2005, 268. Zu weit geht Herda, wenn er an dieser Stelle mittels Zirkelschluss die allgemeine Unverrückbarkeit des Herdes der Hestia argumentiert: »Unter der Voraussetzung, die frühklassische Südhalle ist tatsächlich das Molpon-Prytaneion, kann ein weiteres Argument für die funktionale Gleichstellung mit der spätarchaischen Südhalle angeführt werden: Der Herdaltar, die Hestia eines griechischen Prytaneions, galt in der Regel als unverrückbar, ... Auch in Milet wäre daher zu fordern, daß das Prytaneion des Wiederaufbaus exakt an der Stelle seines von den Persern zerstörten Vorgängers gelegen hätte.«
} 
archaischen Kultgesetzes, der sog. Molpoi-Satzung, eindrucksvoll zeigen kann ${ }^{844}$ : $\gg$ Die Inschrift regelte im besonderen den Ablauf des milesischen Neujahrsfests, das zu Ehren des Apollon Delphinios stattfand und das mit einer großen Staatsprozession nach Didyma und dortigen Opfern an Apollon Didymeus endete. Sie gewährt einen einmaligen Einblick in die Organisation dieses Kults, der für das Staatswesen der Stadt seit ca. 700 v. Chr. bis zum Ende der paganen Antike gegen 400 n. Chr. zentrale Bedeutung besaß, die nicht zuletzt durch die neue Feststellung bestätigt wird, daß das Prytaneion, der kultische und politische Nukleus des Polisstaats, im Delphinion lag und der Vereinsvorstand der Molpoi das Prytanenkollegium und damit die Stadtregierung Milets darstellte.« Abgesehen von seiner kultischen Bedeutung ist die Aufstellung der Staatsverträge im Delphinion, die auch die Einladung ins Prytaneion von Milet vorsahen, sowie der Eponymenlisten von eminenter Bedeutung und belegen den politischen Charakter der Anlage ${ }^{845}$. Da im Prytaneion die Staatsbankette abgehalten wurden, musste ausreichend Platz für die Veranstaltung solcher Ehrenmähler zur Verfügung stehen. Dafür bot sich insbesondere die Südhalle an, deren Innenwände wohl $60 \mathrm{~cm}$ breite Bänke aufwiesen ${ }^{846}$. Diese Bänke konnten somit auch während der Versammlungen der Prytanen genutzt werden ${ }^{847}$. Sowohl die epigrafische Evidenz als auch das Raumangebot sowie die urbanistische Einbindung in offenbar unmittelbarer Nähe zur spätarchaischen und klassischen Agora ${ }^{848}$ machen eine Deutung als Prytaneion daher sehr wahrscheinlich. Eine solche Interpretation wird lediglich durch das Fehlen eines Herdes für Hestia, das aber auch durch den schlechten Erhaltungszustand des Monuments bedingt sein kann, eingeschränkt.

\section{IX.7 Pergamon}

Nachdem auf der pergamenischen Demeterterrasse und in ihrem Vorhof, westlich an den Bau Z anschlieBend Weihinschriften von Prytanen gefunden worden waren, wurde zunächst angenommen, dass es sich bei Bau Z um das Prytaneion von Pergamon handeln könnte ${ }^{849}$. Nach der vollständigen Freilegung von Bau $\mathrm{Z}$ am Beginn der 1990er Jahre zeigte sich jedoch, dass für eine solche Identifizierung die positiven Belege fehlen; viel eher ist es als das Vereinshaus eines dionysischen Kultvereins zu verstehen ${ }^{850}$. Zuletzt wurde daher der unmittelbar benachbarte, südlich von Bau $Z$ und zwischen dem Demeterheiligtum und der Oberen Terrasse des Großen Gymnasions gelegene Bau H mit dem pergamenischen Prytaneion in Verbindung gebracht $^{851}$ (Taf. 244). Dieses am Beginn des 20. Jahrhunderts freigelegte und 1999 nachuntersuchte Gebäude wurde nach seiner pseudo-isodomen Mauertechnik wahrscheinlich in der ersten Hälfte des 2. Jahrhunderts v. Chr. errichtet. Der repräsentative Bau besteht aus einer 20,75 $\times 4,20 \mathrm{~m}$ großen Vorhalle im Süden und einem 20,75 × 8,10 m großen Saal im Norden; die Vorhalle öffnete sich mit rekonstruierten sieben Säulen auf eine ca. $22,50 \times 6 \mathrm{~m}$ große Terrasse ${ }^{852}$. Vor den Innenwänden des Hauptsaales befand sich ein 1,30 m

${ }_{844}$ Herda 2005, 246 f.; s. auch F. Graf, Das Kollegium der Moגлoí von Olbia, MusHelv 31, 1974, 209-215. - Auch U. von Wilamowitz-Moellendorff, GGA 1914, 65-109 bes. 77 erkannte bereits die Verbindung zwischen dem Vereinshaus der Molpoi und dem milesischen Prytaneion, dessen Lokalisierung im Delphinion erschloss sich ihm aber noch nicht.

845 Cf. Herda 2005, 248-250.

846 Cf. Herda 2005, 263.

847 Inwieweit Herda 2005, 265-267 zu folgen ist, der in der Wiederverwendung von Baugliedern mit Inschriften des archaischen Delphinions in den Wänden der frühklassischen Südhalle ein Mahnmal an den Perserkrieg sieht, möchte der Verf. offenlassen. Eine diesbezügliche Interpretation scheint spekulativ. A. Herda spricht in diesem Zusammenhang von einer »Erinnerungsarchitektur«.

848 Zur Lage der spätarchischen und klassischen Agora von Milet, die allerdings nicht endgültig gesichert ist, s. Herda 2005, 272-278 mit älterer Lit. Die von Herda 2005, 275 f. vorgeschlagene Parallelisierung mit den Befunden der milesischen Kolonie Olbia an der Schwarzmeerküste bedarf weiterer eingehender Studien, ehe ein Prytaneion im Delphinion zu lokalisieren ist.

849 W. Dörpfeld, Die Arbeiten zu Pergamon 1910-1911, AM 37, 1912, 270. Zu den Inschriften: H. Hepding, Die Arbeiten zu Pergamon 1908-1909. Die Inschriften, AM 35, 1910, Nr. 25. 31. 38; A. Ippel, Die Arbeiten zu Pergamon 1910-1911. Die Inschriften, AM 37, 1912, Nr. 24. 25; zur Forschungsgeschichte: Schwarzer 2004, 178-180.

850 Cf. W. Radt, Pergamon. Geschichte und Bauten einer antiken Metropole (Darmstadt 1999) 109; Schwarzer 2004, 180; D. Salzmann, Mosaiken und Pavimente in Pergamon. Vorbericht der Kampagnen 1989 und 1990, AA 1991, 451 f.; s. auch Miller 1978, 233 f. - Zum Gebäude: M. Bachmann, Bau Z in Pergamon - Analyse einer Langfristnutzung, in: Ladstätter - Scheibelreiter 2010, 179-192.

851 Schwarzer 2004, 173-182; Schwarzer 2008, 116-118.

${ }_{852}$ Schwarzer 2004, 174. 
breites und ca. $1 \mathrm{~m}$ hohes Podium, das in der Mitte einen 4,23 $\mathrm{m}$ breiten und ebenso tiefen Vorsprung besaß. Das Podium diente nach H. Schwarzer als Sockel zur Aufstellung von Statuen, Weihgaben und Inschriften; der mittlere Vorsprung des Podiums hätte als Herdstelle dienen können ${ }^{853}$. Das Fragment eines Architravs, das 1985 von W. Radt in einem kaiserzeitlichen Kultgebäude östlich des Heraheiligtums gefunden wurde und eine Inschrift mit der Weihung an die Göttin Hestia trägt ${ }^{854}$, sei nach Schwarzer, obwohl das Architekturglied an anderer Stelle gefunden wurde, nun der entscheidende Beleg, Bau H als Prytaneion zu identifizieren $^{855}$ : »Es dürfte daher wahrscheinlicher sein, daß das Architekturteil einst zur Vorhalle des Baues H, dem mutmaßlichen Prytaneion, gehörte und im Zuge der spätantiken und frühbyzantinischen Bauaktivitäten hierher verschleppt wurde.«

Ginge man nun von einer Identifizierung des Baus $\mathrm{H}$ als Prytaneion aus, so müsste es nach Schwarzer einen Vorgänger an anderer Stelle besessen haben, da das Gebäude außerhalb der philetairischen Wehrmauer gelegen und erst im Zuge der eumenischen Erweiterung in das Stadtgebiet einbezogen worden wäre ${ }^{856}$. Das Gebäude, das in der Kaiserzeit einen Umbau erfahren hätte und bei der Erdbebenzerstörung von $262 \mathrm{n}$. Chr. zerstört worden wäre, müsste daher als das jüngere Prytaneion von Pergamon angesprochen werden. Obwohl Schwarzer von seiner Hypothese überzeugt ist, schränkt er letztlich ein ${ }^{857}$ : »Dennoch bleibt ein leiser Zweifel, vor allem wegen der fehlenden Nähe zur Oberen Agora und zum (noch unbekannten) Bouleuterion." Dieses letzte Argument, aber auch andere Unsicherheiten scheinen m. E. eine Identifizierung des Prytaneions mit Bau H nicht zu rechtfertigen: Das zu geringe Raumangebot, das Fehlen einer sicher nachzuweisenden Herdstelle, die problematische Zuweisung der relevanten Architekturglieder sowie die generell unsichere Datierung des Gebäudes und seiner Nutzungsgeschichte ermöglichen keine Interpretation des Baus H als Hauptkultgebäude der Stadt. Die urbanistische Einbindung des Gebäudes verstärkt diese Unsicherheiten. Nach aktuellem Wissensstand ist weder in Bau Z noch in Bau H das pergamenische Prytaneion zu finden ${ }^{858}$.

\section{IX.8 Priene}

Das Prytaneion von Priene, das sich heute im Zustand einer römischen Renovierung präsentiert, schließt unmittelbar östlich an das Bouleuterion an; beide Bauten liegen an der Nordostecke der Agora hinter der nördlichen Stoa, der $>$ Heiligen Halle ${ }^{859}$ (Taf. 245. 246). Unter der ca. 17,50 $\times 24 \mathrm{~m}$ großen, kaiserzeitlichen Anlage sind die Reste einer älteren Anlage zu erkennen. Die Reste sind allerdings so gering, dass eine Rekonstruktion des ursprünglichen Grundrisses unmöglich ist. Durch die >Heilige Halle gelangte man in die drei südlichen Räume des Gebäudes. Über den mittleren Raum, der als Propylon diente, erschloss sich der zentrale Peristylhof mit Hallen an allen vier Seiten. Im östlichen dieser Räume fanden sich in der Südostecke die 0,30 m hohen Reste eines Herdes aus Bruchsteinen mit einem von Knochensplittern durchsetzten Mörtel, der an den Rändern mit hochkant gestellten Steinplatten eingefasst und an der Oberfläche mit Ziegelplatten belegt war. Da das Gebäude seit seiner Freilegung am Beginn des 20. Jahrhunderts kontinuierlich an Bausubstanz verloren hat, ist der Herd heute nur noch schwer auszumachen. Raum und Herdstelle sind jedoch als Heiligtum der Hestia zu deuten. In der Nordwestecke des gepflasterten, 6,97 × 6,97 m großen, quadratischen Peristylhofes, an dessen Seiten je drei unkannelierte Säulen standen, befand sich ein Wasserbecken aus wiederverwendeten Balustradenplatten zum Auffangen des Dachwassers. Das überlaufende Wasser

853 Schwarzer 2004, 177 f. 182, der sich gegen eine Interpretation als Lagerstatt bei Banketten ausspricht.

854 W. Radt, Pergamon. Vorbericht über die Kampagne 1985, AA 1986, 422-425, der das Gebäude, in dem die Inschrift gefunden wurde, als »Hestiaion« bezeichnete; cf. auch Schwarzer 2008, 116-118.

855 Schwarzer 2004, 181.

856 s. dazu U. Wulf-Rheidt, Der Stadtplan von Pergamon. Zu Entwicklung und Stadtstruktur von der Neugründung unter Philetairos bis in spätantike Zeit, IstMitt 44, 1994, 135-175.

857 Schwarzer 2004, 182.

858 Dass die Suche nach dem pergamenischen Prytaneion noch nicht abgeschlossen ist, bestätigt F. Pirson (mündliche Auskunft). Eine ähnlich ablehnende Haltung wie der Verf. nimmt W. Raeck, Das hellenistische Pergamon als Residenzstadt und Polis. Kenntnisstand und offene Fragen, IstMitt 54, 2004, 23-34 bes. 33 ein.

859 Miller 1978, 117-127; Th. Wiegand - H. Schrader, Priene. Ergebnisse der Ausgrabungen und Untersuchungen in den Jahren 1895-1898 (Berlin 1904) 231-234; M. Schede, Die Ruinen von Priene ²(Berlin 1964) 63-67; Rumscheid 1998, 46-59; RE Suppl. IX (1962) 1202-1205 s. v. Priene (G. Kleiner); K. Ferla (Hrsg.), Priene, Hellenic Studies 5 2(Cambridge 2005) 82-85. 
floss in einen steinernen Trog vor diesem Becken und schließlich über das leicht nach Südosten geneigte Hofpflaster und eine Wasserrinne zur östlich angrenzenden Gasse. Vor der Nordhalle stehen heute noch die 0,68 m hohen Füße eines Marmortisches, der einst wohl als Anrichte diente. Aufgrund der beschränkten Dimensionen des Gebäudes ist es vorstellbar, dass größere Bankette auf die benachbarte `Heilige Halleく oder das angrenzende Bouleuterion ausgedehnt wurden ${ }^{860}$. Westlich des Peristylhofes liegen zwei langgestreckte Räume unbekannter Funktion, an deren Schmalseiten sich nischenartige Einbauten und Reste von Ziegelgewölben befinden. Nördlich des Peristylhofes finden sich an der >Athena-Straßeく auf 0,60-0,75 m höherem Niveau drei 5,05 m tiefe, in den Fels geschnittene Räume ebenso unklarer Funktion. Der westliche Raum war mit einer Ziegeltonne überwölbt, deren 1,50 m hohes Auflager sich in Form einer 0,47 m starken Mauer an das Bouleuterion anlehnte. Am Eingang des südlichen der beiden Westräume steht auch heute noch eine ehemalige Säulentrommel auf einem umgedrehten dorischen Kapitell, die eine spätkaiserzeitliche Ehreninschrift des 3. Jahrhunderts n. Chr. für M. Aurelius Tatianus den Jüngeren trägt ${ }^{861}$ (Taf. 246, 2). Er ist darin neben anderen Funktionen auch als Archiprytanis, sprich als Vorsitzender der Prytanen, genannt.

Grundrisstypologisch erinnert die Anlage an ein Peristylhaus ${ }^{862}$; unmittelbar vergleichbar ist sie damit mit dem sog. Prytaneion von Morgantina ${ }^{863}$, dessen Identifizierung als Hauptkultgebäude der Stadt allerdings nicht gesichert ist, bzw. mit den Anlagen in $\operatorname{Delos}^{864}$ (Taf. 247, 1), Lato ${ }^{865}$ (Taf. 247, 2. 3), Dodona ${ }^{866}$ (Taf. 248, 1) oder Kassope ${ }^{867}$ (Taf. 248, 2).

Zur Baugeschichte ließen sich nach F. Rumscheid trotz des Fehlens datierender Sondagen unter Bodenniveau folgende Überlegungen zusammenführen ${ }^{868}$ : Das Vorhandensein von Mauern mit Ziegeln in Kalkmörtelverband sowie von Ansätzen von Ziegelgewölben und Spolien würde auf eine kaiserzeitliche Datierung der heute noch erkennbaren Reste deuten; die Ehreninschrift zeige zudem, dass das Gebäude im 3. Jahrhundert n. Chr. noch in Verwendung stand. Ältere Mauern im Westen der Anlage würden an die geglättete Ostwand des um 200 v. Chr. errichteten Bouleuterions anschließen; auch das ältere Prytaneion

860 Cf. Alzinger 1974, 53 Anm. 203.

861 Th. Wiegand - H. Schrader, Priene. Ergebnisse der Ausgrabungen und Untersuchungen in den Jahren 1895-1898 (Berlin 1904) 233; F. Hiller von Gaertringen (Hrsg.), Inschriften von Priene (Berlin 1906) 246.

${ }^{862}$ Cf. Hoepfner - Schwandner 1994, 200, die vor allem auf die grundrisslichen Ähnlichkeiten mit den Prytaneia in Delos und Kassope verweisen, sowie Hansen - Fischer-Hansen 1994, 36.

863 s. dazu E. Sjöqvist, Excavations at Serra Orlando (Morgantina). Preliminary Report II, AJA 62, 1958, 161; E. Sjöqvist, Excavations at Serra Orlando. Preliminary Report III, AJA 63, 1959, 137-147; Miller 1978, 115-117.

864 Miller 1978, 67-78 mit älterer Lit.; Ph. Bruneau - J. Ducat, Guide de Délos, École Française d'Athènes. Sites et monuments $1{ }^{3}$ (Paris 1983) 135-137; H. Lauter, Die Architektur des Hellenismus (Darmstadt 1986) 130; Abb. 37; R. Étienne, Le Prytanée de Délos, REA 99, 1997, 305-324; D. Williams, Captain Donnelly's Altar and the Delian Prytaneion, RA 2004, 51-68.

865 Miller 1978, 78-86 mit älterer Lit.; P. Ducrey - O. Picard, Recherches à Latô 5. Le prytanée, BCH 96, 1972, 567-592; J. Tréheux, Les Cosmes à Latô, in: Aux origines de l'hellénisme: La Crète et la Grèce. Hommage à Henri van Effenterre (Paris 1984) 335-337.

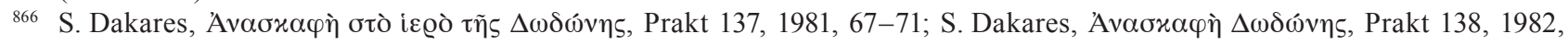

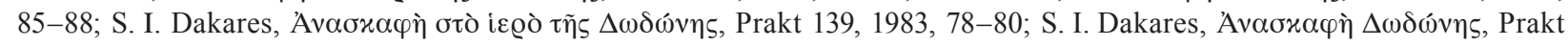

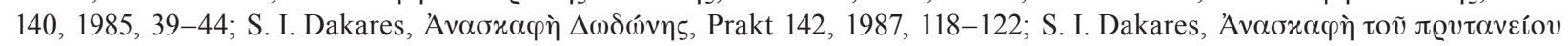

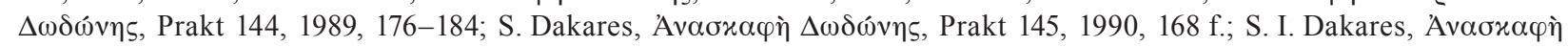

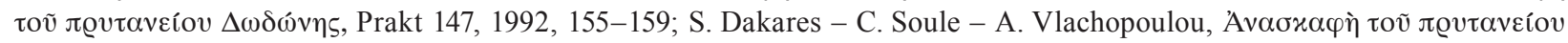

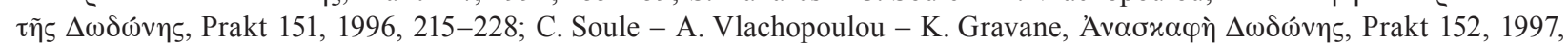

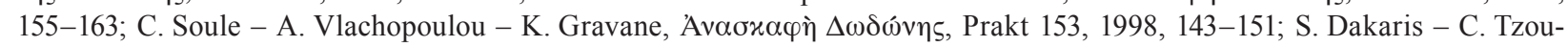
vara-Souli - A. Vlachopoulou-Oikonomou - K. Gravani-Katsiki, The Prytaneion of Dodona, in: P. Cabanes (Hrsg.), L'Illyrie méridionale et l'Epire dans l'antiquité, 3. Actes du IIIe Colloque international de Chantilly. 16-19 octobre 1996 (Paris 1999)

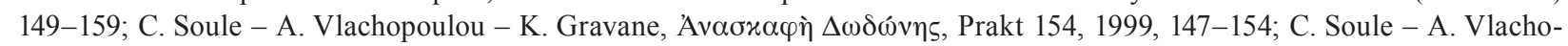

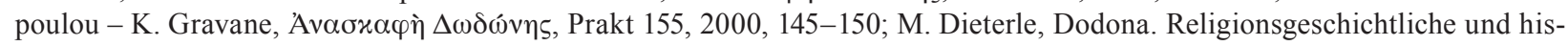
torische Untersuchungen zur Entstehung und Entwicklung des Zeus-Heiligtums, Spudasmata 116 (Hildesheim 2007) $139-141$. $162-164$.

867 Hansen - Fischer-Hansen 1994, 35 f.; Hoepfner - Schwandner 1994, 137-139.

${ }^{868}$ Cf. Rumscheid 1998, 50. Die Ergebnisse einer neu angelegten Bauuntersuchung des Prytaneions von Priene durch A. von Kienlin bleiben in diesem Kontext abzuwarten; s. vorab: W. Raeck, 2006 Y1lı Çalışmaları, KST 29, 2008, 342; Abb. 9-10 sowie A. von Kienlin, Zur baulichen Entwicklung der Agora von Priene, Boreas 21/22, 1998/99, 241-259 bes. 253 f. zum Bouleuterion (»Baubeginn vor oder um 200 v. Chr. ist [...] wahrscheinlich«) bzw. zum Prytaneion (»Über Gestalt des Prytaneion zu dieser Zeit wissen wir nichts. Die überkommene Form stammt aus der Kaiserzeit und es ist lediglich zu vermuten, daß der Bau an dieser Stelle bereits einen Vorgänger gehabt hat.«). 
wäre somit jünger als das Bouleuterion ${ }^{869}$. Da in die Rückwand der inschriftlich in die Zeit von 155-130 v. Chr. datierten 〉Heiligen Halle $<$ die Türschwelle des Haupteingangs des Prytaneions eingelassen und offenbar schon von Anfang an vorgesehen wäre, würde die Halle augenscheinlich auf das Prytaneion in seiner ältesten Phase Rücksicht nehmen. Es würde sich daher zusammenfassend zeigen ${ }^{870}: » A l s$ Bauabfolge ergibt sich: Buleuterion (ca. 200 v. Chr.), älteres Prytaneion, Heilige Halle (ca. 155-130 v. Chr.), jüngeres Prytaneion (kaiserzeitlich). Die ältesten, noch aus dem 4. Jh. v. Chr. stammenden Inschriften Prienes erwähnen jedoch schon Ehrenmahlzeiten in einem Prytaneion ${ }^{871}$. Es muß also, wenn auch nicht unbedingt am uns heute bekannten Platz, einen weiteren Vorgängerbau gegeben haben ${ }^{872} . \ll$

Die Ehreninschrift mit der Nennung des Archiprytanis, die den öffentlichen Charakter des Gebäudes verdeutlicht, die Lage unmittelbar an der Agora neben dem Bouleuterion und das Vorhandensein einer Herdstelle belegen unbeschadet des Fehlens weiterer epigrafischer oder literarischer Quellen eine Identifizierung des Gebäudes als Prytaneion von Priene ${ }^{873}$. Unklar bleiben freilich die Datierungen der Bauphasen, die ohne feldarchäologische Untersuchungen nur mit Vorbehalt zu rekonstruieren sind.

\section{IX.9 Synthese}

Wie sich zeigt, können in Kleinasien neben der Anlage in Ephesos nur die Bauten in Magnesia am Mäander, Priene und Milet mit großer Sicherheit als Prytaneia bestimmt werden. Bei den anderen immer wieder als Prytaneia bezeichneten Gebäuden in Aigai, Herakleia am Latmos, Kolophon und Pergamon fehlen die spezifischen Charakteristika eines Prytaneions; ebensowenig lässt der Forschungsstand eine eingehendere Beurteilung zu. Auch außerhalb von Kleinasien sind nur wenige Gebäude tatsächlich als Prytaneia zu identifizieren. Zu nennen sind in diesem Kontext die Anlagen von Delos, Dreros, Lato, Olympia, Dodona, Kassope sowie - als Teil des Prytaneions - die Tholos der Athener Agora ${ }^{874}$ (Taf. 248, 3). Der diametrale Widerspruch

869 Der relativchronologische Status des älteren Prytaneions zum Bouleuterion sei nach freundlicher Auskunft von A. von Kienlin allerdings unsicher. Dies erkläre sich daraus, dass das hellenistische Prytaneion derzeit weder baulich noch zeitlich fassbar wäre. Dies trifft im Wesentlichen auch auf das Bouleuterion zu, s. dazu W. Raeck, Neue Forschungen zum spätklassischen und hellenistischen Priene, in: E. Schwertheim - E. Winter (Hrsg.), Neue Forschungen zu Ionien, AMS 54 (Bonn 2005) 160; W. Raeck, Priene, in: W. Radt (Hrsg.), Stadtgrabungen und Stadtforschung im westlichen Kleinasien. Geplantes und Erreichtes. Internationales Symposion 6./7. August 2004 in Bergama (Türkei), Byzas 3 (Istanbul 2006) 321 sowie W. Raeck mit Beiträgen von H. Bankel - H. Fahlbusch - A. Hennemeyer - A. von Kienlin - A. Leibhammer - E. Nagel - F. Rumscheid - C. Schneider, Priene. Neue Forschungen an einem alten Grabungsort, IstMitt 53, 2003, 313-423 bes. 330 (W. Raeck). 346 (A. von Kienlin mit relativchronologischer Einordnung: »Kurze Zeit vor der alten Nordhalle dürfte das Bouleuterion errichtet worden sein. In der 2. Hälfte des 2. Jhs. v. Chr. führte schließlich vermutlich die Zerstörung der alten Nordhalle zu umfangreichen baulichen Aktivitäten auf der Agora, im Zuge derer auch die bekannte >Heilige Halle $<$ im Norden der Agora errichtet wurde ... «).

870 Rumscheid 1998, 51; cf. auch F. Rumscheid, Den Anschluß verpaßt: Priene in der (frühen) Kaiserzeit, in: Berns - Hesberg Vandeput - Waelkens 2002, 78. 83.

871 s. dazu Miller 1978, 205 f. A 392-395; F. Hiller von Gaertringen (Hrsg.), Inschriften von Priene (Berlin 1906) 3, 16; 4, 35 f.; 7, 19 f.; 8, 39-41.

872 Anders: Miller 1978, 121-124, der eine Datierung um 325 v. Chr. annimmt, wodurch ein Vorgängerbau an anderer Stelle obsolet werden würde.

873 Dazu kritisch: Miller 1978, 125 f.; Tosi 1966, 162; McDonald 1948, 375.

874 Zur Diskussion um die Tholos der Athener Agora bzw. die Lokalisierung des athenischen Prytaneions im Speziellen s. Miller 1978, 54-66 mit älterer Lit. sowie J. S. Boersma, Athenian Building Policy from 561/0 to 405/4 B.C. (Groningen 1970$) 54 \mathrm{f}$. 212; P. Schmitt-Pantel, Les repas au prytanée et à la tholos dans l'Athènes classique. Sitesis, trophè, misthos. Réflexions sur le mode de nourriture démocratique, AnnAStorAnt 2, 1980, 55-68; A. S. Henry, Invitations to the Prytaneion at Athens, Antichthon 15, 1981, 100-110; M. J. Osborne, Entertainment in the Prytaneion at Athens, ZPE 41, 1981, 153-170; G. S. Dontas, The True Aglaurion, Hesperia 52, 1983, 48-63; J. M. Camp, The Athenian Agora. Excavations in the Heart of Classical Athens (London 1986) 76 f. 94-97. 126; F. Cooper - S. Morris, Dining in Round Buildings, in: Murray 1990, 75-79; Schmitt Pantel 1992, 145-227; K.-W. Welwei, Athen. Vom neolithischen Siedlungsplatz zur archaischen Großpolis (Darmstadt 1992) 216; C. Schnurr, Die alte Agora Athens, ZPE 105, 1995, 131-138; W. Hoepfner, Die Epoche der Griechen, in: W. Hoepfner (Hrsg.), Geschichte des Wohnens I. 5000 v. Chr. - 500 n. Chr. Vorgeschichte. Frühgeschichte. Antike (Stuttgart 1999) 228 f.; Kenzler 1999, 283-285; H. Knell, Athen im 4. Jahrhundert v. Chr. - eine Stadt verändert ihr Gesicht. Archäologisch-kulturgeschichtliche Betrachtungen (Darmstadt 2000) 67-70; J. M. Camp, The Archaeology of Athens (New Haven 2001) 27. 147; M. Rausch, Isonomia in Athen. Veränderungen des öffentlichen Lebens vom Sturz der Tyrannis bis zur zweiten Perserabwehr, Europäische Hochschulschriften III 821 (Frankfurt 1999) 326 f.; H. R. Goette - J. Hammerstaedt, Das antike Athen. Ein literarischer Stadtführer (München 2004) 94-96; Herda 2005, 275; G. C. R. Schmalz, The Athenian Prytaneion Discovered?, Hesperia 75, 2006, 
zwischen der großen Zahl literarisch und epigrafisch überlieferter Prytaneia und der überaus geringen Zahl tatsächlich fassbarer Anlagen wird aus Sicht des Verfassers am Deutlichsten von W. A. McDonald aufgelöst, indem er klar macht ${ }^{875}$ : $\gg \mathrm{A}$ review of the pertinent literary and epigrafical information suggests that the prytaneion was regularly located among other public buildings and constructed on a moderately monumental scale.« In dasselbe Horn stoßen M. Hansen und T. Fischer-Hansen, welche, die Prytaneia in Kassope, Ephesos und Magnesia ausnehmend, konstatieren ${ }^{876}$ : $»$ With this exception our scanty evidence indicates that the archaic and classical prytaneion was a modest building of ordinary materials and without the architectural and sculptural embellishments characteristic of many temples and stoas. The city's guests were invited to a rather unpretentious place and not a monumental building that could shed lustre on the city."

Können an den sicher identifizierten kleinasiatischen Anlagen nun bautypologische Gemeinsamkeiten festgestellt werden? Die grundrissliche Durchgestaltung der sicher identifizierten Bauten ist überaus unterschiedlich $^{877}$. Gemeinsam ist ihnen aber die Lage innerhalb der Stadt: Sie sind in unmittelbarer Nähe der Agora gelegen und stehen folglich in funktionalem Zusammenhang mit den politischen Aktivitäten auf diesen Plätzen ${ }^{878}$. Die Anlagen von Priene und Ephesos finden sich zudem in direkter Nachbarschaft zum jeweiligen Bouleuterion der Stadt. Als differenziert erweist sich jedoch das zur Verfügung gestellte Raumangebot: Während in Ephesos ein eigener Raum vorgesehen war, in dem sich die Prytanen versammelten, aber auch verdiente Bürger bewirtet werden konnten, scheint diese Funktion in Priene teilweise das Peristyl übernommen zu haben. Der offene Hof und die überdachten Hallen - wahrscheinlich aber auch die benachbarte >Heilige Halle und das Bouleuterion - konnten dafür genutzt werden. Der Grundriss in Magnesia am Mäander lässt mehrere Möglichkeiten für die Unterbringung des Versammlungs- und Speisesaales offen: Neben dem Peristyl kommen die Exedra im Norden des Gebäudes sowie der westlich an die Exedra anschließende Raum in Frage, in dem St. G. Miller einen Klinensaal sehen wollte. In Milet fungierte die Südhalle des Delphinions sowohl als Versammlungs- als auch Speisesaal. Das zweite wesentliche Charakteristikum eines Prytaneions, nämlich die Beheimatung der Kultstätte der Hestia mit dem Staatsherd, findet sich sowohl in Magnesia als auch in Priene. In Ephesos ist diese Kultstätte im Querraum 2-4 zu rekonstruieren. In Magnesia lassen die Dimension und die Disloziertheit der Herdstelle allerdings vermuten, dass sich der Hauptherd für den Hestiakult an einer anderen Stelle im Gebäude befunden hat ${ }^{879}$. In Milet war die Herdstelle nicht mehr nachzuweisen, ihr Vorhandensein ist aber aufgrund des Erhaltungszustandes des Monuments nicht auszuschließen.

Die übrigen Räume in Prytaneia, die den Hauptsaal oder das Peristyl umgeben, sind nur bedingt als grundrisstypologisch charakteristisch anzusehen. Für das Funktionieren eines Prytaneions war jedoch neben den genannten Primäraufgaben Raum für das Kultpersonal und die Lagerung von Gegenständen für die Kulthandlungen vonnöten; wann immer Archive in Prytaneia untergebracht waren, benötigten diese ebenfalls entsprechende Flächen. Sowohl in Ephesos als auch in Priene, Milet und Magnesia war für diese Primär- und Sekundärfunktionen ausreichend Platz vorhanden. Küchen konnten - anders als etwa im Bereich der Tholos

33-81; W. Hoepfner, Die griechische Agora im Überblick, in: Hoepfner - Lehmann 2006, 16 f.; J. Losehand, Häuser für die Herrscher Roms und Athens? Überlegungen zu Funktion und Bedeutung von Gebäude F auf der Athener Agora und der Regia auf dem Forum Romanum, Antiquitates 42 (Hamburg 2007); J. McK. Camp II, Einführung in die Geschichte der Agora von Athen, in: J. McK. Camp II - C. A. Mauzy (Hrsg.), Die Agora von Athen. Neue Perspektiven für eine archäologische Stätte (Mainz 2009) 19.

875 McDonald 1948, 374.

876 Hansen - Fischer-Hansen 1994, 36.

877 Cf. in diesem Kontext die älteren Lehrmeinungen, die auf einer noch geringeren Zahl sicher identifizierter Prytaneia basierten: So gingen K. Th. Pyl, Die griechischen Rundbauten im Zusammenhange mit dem Götter- und Heroencultus (Greifswald 1861) 88; Hagemann 1880, 37; Frazer 1885, 150; G. Leroux, Les origines de l'edifice hypostyle en Grèce, en Orient et chez les Romains (Paris 1913) 183 oder F. Robert, Thymélè. Recherches sur la signification et la destination des monuments circulaires dans l'architecture religieuse de la Grèce (Paris 1939) 394 in Bezug auf Prytaneia noch generell von Rundbauten aus. Anders jedoch bereits J. Charbonneaux, Tholos et Prytanée, BCH 49, 1925, 158-178 bes. 168 sowie später Miller 1978, 25-37; F. Cooper - S. Morris, Dining in Round Buildings, in: Murray 1990, 66-85.

878 Cf. T. Hölscher, Öffentliche Räume in frühen griechischen Städten ${ }^{2}$ (Heidelberg 1999) $44 \mathrm{f}$.

879 Miller 1978, 115: »Then too, the discovery of the small inscribed hearth in one of the eastern rooms, rather than in the exedra, is disturbing to any attempt to identify the exedra with the area sacred to Hestia (although the small hearth can scarcely have been the hearth of Hestia).« 
auf der Athener Agora ${ }^{880}$, des Prytaneions von Olympia ${ }^{881}$ oder von Kassope ${ }^{882}$ - indes in keinem kleinasiatischen Prytaneion nachgewiesen werden; die Speisen dürften somit von spezialisierten Betrieben angeliefert worden $\operatorname{sein}^{883}$. Auffallend ist, dass sowohl in Magnesia als auch in Ephesos repräsentative Räume zur Aufstellung von Ehrendenkmälern vorgesehen waren. In Priene dürfte - wie das Ehrendenkmal für M. Aurelius Tatianus zeigt - ebenfalls Raum zur Aufstellung von Ehrendenkmälern vorhanden gewesen sein.

Die Zusammengehörigkeit von Prytaneion und Hestiakult, die sich in der Herdstelle manifestiert, ist in Magnesia und Priene gesichert; in Ephesos ist dieser Konnex alleine schon aufgrund der epigrafischen Evidenz zu rekonstruieren.

Wenn hier auch wesentliche Merkmale der genannten Prytaneia übereinstimmen, so betreffen diese in erster Linie die Funktion der Gebäude. Die grundrissliche Durchgestaltung der Bauten ist aber so verschieden, dass aus architektonischer Sicht nicht von einem einheitlichen Gebäudetypus >Prytaneion` gesprochen werden kann $^{884}$. Während die Anlage in Ephesos mit ihrer wuchtigen dorischen Fassade an einen öffentlichen und repräsentativen Bau erinnert, ist der Grundriss in Priene - ähnlich wie die Anlagen in Kassope, Dodona, Lato oder Delos - einem privaten Peristylhaus entlehnt ${ }^{885}$. Der Grundriss des Gebäudes in Magnesia mit seinem dominierenden Peristyl ist als individuelle Lösung zu bezeichnen, die die repräsentative Funktion der Anlage ins Zentrum stellt. In Milet handelt es sich wiederum um eine repräsentativ dimensionierte, langrechteckige Stoa, integriert in einen größeren Komplex mit erweitertem Funktionsspektrum. Vergleicht man die kleinasiatischen Bauten mit den anderen bekannten Prytaneia, so verstärkt sich die Vermutung, dass bei derzeitigem Forschungsstand ein architektonisch uniformer Gebäudetypus >Prytaneion< nicht nachzuweisen ist ${ }^{886}$.

880 Cf. Miller 1978, 33; H. A. Thompson, The Tholos and its Predecessors, Hesperia Suppl. 4 (Athen 1940) $73-84$.

881 Cf. Miller 1978, 91.

882 Hoepfner - Schwandner 1994, 137-139; Hansen - Fischer-Hansen 1994, 36.

883 Anders Hansen - Fischer-Hansen 1994, 34, die das Vorhandensein einer Küche als conditio sine qua non betrachten.

884 So auch Tosi 1966, 163 f.; R. E. Wycherley, How the Greeks built cities ²(London 1967) 134-138.

${ }_{885}$ Zur überzeugenden Darstellung, dass sich durch die Einführung von Peristylen in die öffentliche und private Architektur die Unterschiede zwischen Privatem und Öffentlichem verwischen, s. M. Tombrägel, Überlegungen zum Luxus in der hellenistischen Wohnarchitektur: Das Bild der römischen Otiumvillen, in: Ladstätter - Scheibelreiter 2010, 608: »Auch wenn die funktionalen Unterschiede zwischen einer öffentlichen Anlage, einem hellenistischen Palast und einem reichen Stadthaus natürlich weiterhin bestanden, wird dort architektonisch gesehen eine gemeinsame Sprache auf vergleichbarem Niveau gesprochen.«

886 So auch Kenzler 1999, 295 bzw. Hansen - Fischer-Hansen 1994, 36: »Again, unlike the temple and the stoa, the prytaneion never gained a fixed architectural form which, with variations, could spread over the Hellenic world.« - Gestützt wird diese Hypothese durch die heterogene grundrissliche Durchgestaltung der anderen bekannten - und allesamt im heutigen Griechenland befindlichen - Prytaneia in Delos, Dodona, Dreros, Lato, Kassope und Olympia, auf die im Zuge dieser Studie nicht in extenso eingegangen werden kann. 



\section{ZUSAMMENFASSUNG}

Im letzten Jahrzehnt vor der Zeitenwende wird im Norden des ephesischen `Staatsmarktes` ein Gebäude errichtet, das uns heute als eines der wenigen sicher identifizierten Prytaneia der griechisch-römischen Welt bekannt ist. Die überzeugende Deutung des Baus als Prytaneion und Heiligtum der Hestia Boulaia gelang bereits im Zuge der Ausgrabungen von F. Miltner in den Jahren 1955 und 1956, der die Anlage in zügigen Arbeitsschritten bis auf das jeweils jüngste erhaltene Bodenniveau freilegte. Neben dieser heute weitgehend akzeptierten Identifizierung des Komplexes als Amtssitz der Prytanen und zentrales städtisches Kultgebäude, die epigrafisch belegt ist, konnte bereits Miltner mehrere Bauphasen unterscheiden. Trotz weiterer eingehender Untersuchungen in den frühen 1960er Jahren unter der Leitung von W. Alzinger, der zahlreiche Sondagen unter Bodenniveau anlegte, oder in den frühen 1990er Jahren durch das Efes Müzesi Selçuk blieben aber zentrale Fragen zu Nutzungsgeschichte, Aussehen, Funktion und Beziehung zum benachbarten ephesischen Regierungsviertel unbeantwortet. Die ausführliche Vorlage der Inschriften des Prytaneions durch D. Knibbe im Jahr 1981 erweiterte unser Wissen - vor allem um den im Gebäude beheimateten Kultverein der Kureten - zwar beträchtlich, Baubefund und archäologische Auswertung lagen bei Beginn der Neuuntersuchung der Anlage im Jahr 2007 aber nicht vor. Die exzeptionelle Bedeutung des Gebäudes innerhalb des Stadtgefüges und des administrativen Zentrums von Ephesos sowie die Aussicht auf tiefgreifende neue Erkenntnisse in einem Gebiet, in dem grundsätzliche topografische und chronologische Fragen noch ungeklärt sind, führten schließlich zur Wiederaufnahme der Forschungen am ephesischen Prytaneion, die eine grundlegende Analyse des architektonischen und stratigrafischen Befundes mitsamt seiner Ausstattung unter Berücksichtigung der Resultate der Altgrabungen beinhalten sollte. Die Ergebnisse dieser Forschungen lassen sich wie folgt zusammenfassen:

Das $1170 \mathrm{~m}^{2}$ große, in augusteischer Zeit errichtete Prytaneion in Ephesos besaß einen klar gegliederten Grundriss, der erst in spätantiker Zeit komplex überformt wurde: Über den Haupteingang im Süden des Gebäudes gelangte man in den 18,40 $\times 21,65 \mathrm{~m}$ großen Vorhof in Form einer Triporticus mit $14 \mathrm{zu}$ rekonstruierenden Säulen ionischer Ordnung. Im Zentrum des Hofes fand sich ein leicht aus der Achse des Gebäudes gedrehtes Fundament, das ab traianischer Zeit als Basis der `Großen Artemis «-Statue diente. Die wuchtige dorische Fassade der nördlich des Vorhofes gelegenen, quergelagerten, 7,20 × 21,38 m großen Stoa (Vorhalle), deren Säulen in den 1960er Jahren teilweise wieder aufgestellt wurden, vermittelte in den Kernbau des Prytaneions. Die Fassade mit ihren sechs Säulen in antis und einem erweiterten Mitteljoch sowie die dahinterliegende, langrechteckige Halle gliederten und umfassten das nicht mehr der zentralen Mittelachse folgende Raumensemble nördlich davon, dessen Eingänge allesamt aus der Hauptachse verschoben waren. Sowohl das ionische Peristyl des Vorhofes als auch die dorische Vorhalle gaben somit eine Axialität vor, die durch das heterogene Raumprogramm im Norden der Anlage aufgelöst wurde. Die unkonventionelle Grundrisslösung war, wie gezeigt werden konnte, durch die begrenzten lokalen topografischen Gegebenheiten einerseits und das benötigte Raumangebot andererseits bedingt. Am Gebälk der das Gebäude dominierenden dorischen Fassade befanden sich an den Oberlagern der Geisa Einlassungen für die anlaufenden Holzbalken des Dachstuhls. Daher ist das Gebäude auch entgegen früheren Meinungen, die über dem Gebälk - entsprechend einer `Tempelfassade` - ein Tympanon und einen Giebel vermuteten, mit einem Walmdach zu rekonstruieren. Das ephesische Prytaneion verliert damit seinen Status als Einzelfall in der Serie anderer bekannter Prytaneia und imitiert keinen Tempel mehr. Die dorische Architektur der Vorhalle steht mit ihrer Großflächigkeit und ihrem reduzierten Dekor gleichermaßen in der Tradition des hellenistisch-kleinasiatischen Werksteinbaus wie auch in der klassizistischen Tradition augusteischer Architektur. Da sich dorische Ordnungen in Ephesos, wie auch im übrigen Kleinasien, als überaus selten erweisen, ist die wuchtige Fassade des Prytaneions sicher als Besonderheit zu bezeichnen. So werden bereits ab flavischer Zeit in Ephesos keine monumentalen Gebäude in dorischer Ordnung mehr errichtet. Die 
Wahl einer Architekturtradition, die nicht nur auf das griechische Mutterland verweist, sondern auch das hohe Alter dieser vollends griechischen Institution betont, ist folglich bewusst erfolgt. Über die Vorhalle gelangte man in den im Nordosten befindlichen, 13,47 × 13,41 m großen >Hestiasaal (Raum 1), dessen architektonische Charakteristika vier Eck-Doppelhalbsäulen auf Säulenstühlen, die mit Kompositkapitellen und einem kurzen, in die Raumwände einbindenden Gebälk bekrönt waren, sowie ein offener Keilsteinbogen in der Nordwand darstellten. Zwischen den Säulenstühlen befanden sich L-förmige, zweistufige, in Bauphase 2 auch gemauerte Sitzbänke, die Platz für 100-120 Personen boten. Auf dem quadratischen Fundament im Zentrum des Raumes stand ursprünglich ein marmorner Tisch, auf dem die Speisen der Staatsbankette angerichtet wurden. Nördlich des $\gg$ Hestiasaales lag ein in der spätantik/frühbyzantinischen Bauphase 3 abgemauerter, ursprünglich aber 13,41 × 3,94 m großer Querraum (Räume 2, 3 und 4). In den westlichen Räumen 3 und 4 wurde in Bauphase 3 ein Wasserreservoir eingerichtet. Westlich des $>$ Hestiasaales $<$ befanden sich ursprünglich zwei Räume mit Maßen von 7,98 × 6,52 m (Raum 6 im Süden) und 8,83 × 6,52 m (Raum $5 \mathrm{im}$ Norden). Der nördliche Teil von Raum 5 wurde in der Spätantike in zwei kleinere Raumkompartimente unterteilt (Raum 5A und 5B). Das stark von Süden nach Norden ansteigende Gelände bedingte auch unterschiedliche Nutzungsniveaus: So lag das Nutzungsniveau der nördlichen Räume 2, 3 und 4 teilweise um bis zu 1,30 m höher als in den benachbarten Räumen 5 und 6 sowie dem ^Hestiasaal und war nur über Treppen zu erreichen.

Insgesamt ließen sich nach Analyse der stratigrafischen und architektonischen Befunde neben mehreren kleineren Reparaturmaßnahmen drei große Bauphasen im Prytaneion unterscheiden. Erschwert wurde die Periodisierung der jeweiligen Baumaßnahmen durch die massiven und großteils ungenügend dokumentierten Grabungsaktivitäten der 1950er und 1960er Jahre sowie durch den Umstand, dass bei der Neuuntersuchung nur noch wenige ungestörte Flächen für stratigrafische Grabungen zur Verfügung standen. Dennoch ließ sich die Nutzungsgeschichte der Anlage in weiten Bereichen nachzeichnen: Das Gebäude wurde in augusteischer Zeit, und zwar in der letzten Dekade vor dem Jahr 0 (Bauphase 1), in einem Areal errichtet, das weitgehend unverbaut gewesen zu sein scheint. Lediglich Terrassierungen, die in das ausgehende 3. Jahrhundert v. Chr. weisen, ließen sich im Bereich des Prytaneions dokumentieren. Ein Vorgänger-Prytaneion war im Areal der augusteischen Anlage somit nicht nachzuweisen; die Lage des voraugusteischen Prytaneions von Ephesos, dessen Existenz vorausgesetzt werden kann, ist uns zum heutigen Zeitpunkt nicht bekannt. In Bauphase 1a, die aus paläografischen Überlegungen zur Inschrift IvE 437 grob in das 1./2. Jahrhundert n. Chr. datiert, wurde das ionische Peristyl des Vorhofes von einem uns unbekannten Stifter repariert oder überhaupt gänzlich neu aufgebaut. Dabei wurde im Wesentlichen die Konstruktion der augusteischen Bauphase 1 kopiert. Gemäß der Inschrift IvE 1024 wurden bald nach 104 n. Chr. von einem Prytanen namens Dionysodoros weitere Reparaturen am Gebäude durchgeführt, wobei die einzelnen Maßnahmen nur noch schwer konkret zuzuordnen sind und kaum von der nachfolgenden Bauphase 2, die in das zweite Viertel des 3. Jahrhunderts n. Chr. datiert, unterschieden werden können. Allesamt deuten sie auf größere Beschädigungen an der Struktur des Gebäudes hin, die erhebliche Modifikationen bedingten. $\mathrm{Zu}$ nennen sind vor allem Maßnahmen im >Hestiasaak wie etwa Reparaturen am aufgehenden Mauerwerk, die Schaffung zusätzlicher Eingänge von der Vorhalle oder der Einbau einer neuen Tür in den Querraum 2-4, im Zuge dessen der Keilsteinbogen der Nordwand optisch hinter einer neuen Marmorverkleidung verschwinden sollte. Als die mit Sicherheit in Bauphase 2 erfolgten Interventionen konnten der Einbau der L-förmigen, gemauerten Sitzbänke im `Hestiasaak, die Neuaufstellung der 〉Herzsäulen` sowie die Verlegung eines polychromen Mosaiks in der Vorhalle definiert werden. In der Mitte des 4. Jahrhunderts n. Chr. wurde das Gebäude wohl als Folge von Beschädigungen durch die Erdbebenserie zwischen den Jahren 358 und 368 aufgegeben und danach nicht mehr instand gesetzt. Erste, wenn auch zunächst nur sporadisch umgesetzte Verbote heidnischer Kulte unter Constantius, konkret seine beiden Edikte von 354 und 356 n. Chr., die eine Aufforderung zur Schließung paganer Tempel beinhalteten, deuten auf ein natürliches Auslaufen der Institution >Prytaneion` nach den zu vermutenden Erdbebenschäden hin. Eine intentionelle Zerstörung des Gebäudes durch Christen ist in jedem Fall nicht zu belegen; diesbezüglich geäußerte Vermutungen sind als rein hypothetisch zu betrachten. Den Schlusspunkt in der Geschichte des Prytaneions, einer Institution, die im 4. Jahrhundert $n$. Chr. ihren Zenit lange überschritten hatte, stellte zweifellos das Verbot heidnischer Kultausübung durch Theodosius I. im Jahr 391/392 n. Chr. dar. Spätestens mit diesem kaiserlichen Verbot war das Prytaneion seiner kultischen Funktionen entledigt und das Heilige Feuer am Herd der Hestia er- 
loschen. Ihr politisches Gewicht hatte die Einrichtung jedoch schon viel früher verloren - ein Schicksal, das später auch die anderen politischen Institutionen, nämlich die Volksversammlung ( $\delta \tilde{\eta} \mu \circ \varsigma)$ und den Rat

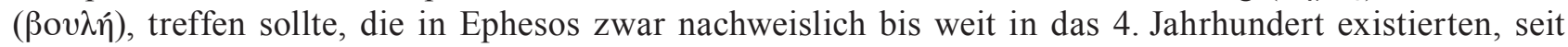
traianischer Zeit aber zusehends an Einfluss verloren hatten. Bereits bald nach der Aufgabe des Gebäudes setzte ein kontinuierlicher, aber zunächst noch zögerlicher Abbau von Baumaterial ein, der sich über einen langen Zeitraum erstreckte. Die extensive Beraubung der Ruine erfolgte erst mit der Errichtung der ২Kuretenhalle` und der Renovierung der Scholastikiatherme in der ersten Hälfte des 6. Jahrhunderts n. Chr., im Zuge derer zahlreiche Bauglieder des Prytaneions als Spolien verbaut wurden. Bereits ab dem 5./6. Jahrhundert wurde das Areal nördlich des \Staatsmarktes` wohl als Handwerksviertel mit einfacher Wohnbebauung weiter genutzt (Bauphase 3). Von dieser Periode zeugen die byzantinische Überbauung des Prytaneions und insbesondere die Einrichtung eines Wasserreservoirs in den Räumen 3 und 4, das bis in die Mitte des 7. Jahrhunderts in Betrieb stand (Bauphase 3a). Eine letzte Frequentierung des Areals ist im letzten Viertel des 8. Jahrhunderts n. Chr. belegt.

Im Prytaneion von Ephesos lassen sich sämtliche einer solchen Institution immanenten Hauptfunktionen nachweisen: Dazu zählen die Beherbergung des Herdes der Hestia und des Amtslokals der Prytanen sowie die Veranstaltung der ehrenvollen Speisungen verdienter Bürger auf Staatskosten. All diese Funktionen werden in dem repräsentativen ephesischen Gebäude zusammengefasst. Die Deutung des Baus als Prytaneion wird durch die urbanistische Einbindung des Gebäudes, und zwar seine Lage am `Staatsmarktı, dem politischen Zentrum der Stadt, sowie durch seine unmittelbare Nähe zum Bouleuterion gestützt. Die Funktionsanalyse der einzelnen Räume des Prytaneions zeigte, dass das Gebäude neben diesen Hauptfunktionen aber auch zahlreiche andere Aufgaben übernommen hatte. Die unterschiedlichen Formen der Nutzung sind einerseits epigrafisch überliefert, andererseits am Monument anhand spezifischer Ausstattungselemente oder des architektonischen Aufbaus ablesbar.

Der Herd der Hestia, auf dem das ewige Feuer brannte, das das Leben der Stadt symbolisieren sollte, war im ursprünglichen Querraum 2-4 untergebracht. Der Querraum ist durch die architektonische Betonung seiner Eingangssituation mit einem Keilsteinbogen und seine zugleich dezentrale Lage innerhalb

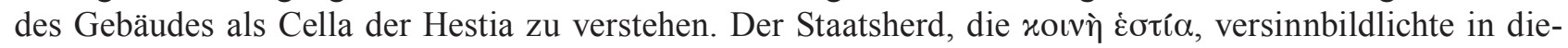
sem Kontext den häuslichen Herd, den zentralen Ort familiären Lebens. Der gesamte Staat bzw. die Polis konzentrierte sich an dieser Herdstelle folglich als Abbild der einfachen Familie. Die offiziellen Gäste der Polis wurden somit in einem Gebäude empfangen, das als Stellvertreter für alle Häuser der Stadt fungierte. Um dieses Feuer sorgte sich das Synedrion der Kureten, die in augusteischer Zeit vom Artemision in das ephesische Prytaneion verlagert und in zahlreichen formelhaften Inschriften am Gebäude verewigt wurden. Sie dienten auch als Opferassistenten des Prytanen bei der Durchführung der oft komplizierten Kulthandlungen, die im Prytaneion regelmäßig vorgenommen wurden. Das zumindest bis an den Beginn des 3. Jahrhunderts n. Chr. belegte Kollegium war aber auch mit der Gestaltung der jährlich stattfindenden ortygischen Mysterien betraut. Dieses Mysterienspiel gab die Geburt von Artemis und Apollon wieder und bildete einen Fixpunkt im kultischen Jahresablauf von Ephesos. Die Verlagerung der Organisation dieses Mysterienspiels vom Artemision in die Stadt bedeutete einen erheblichen Macht- und Prestigeverlust für das Artemision. Untergebracht könnte dieses Synedrion in den Räumen 5 und 6 gewesen sein, was jedoch nicht eindeutig zu beweisen ist. In diesen beiden Räumen könnte auch das städtische Archiv, das iє@òv $\dot{\alpha} v \tau \iota \gamma \varrho \alpha \varphi \tau ̃ o v, z u$ lokalisieren sein, das später wohl in das Bouleuterion verlagert wurde.

Im >Hestiasaak versammelten sich die Prytanen. Vielleicht hatte dieser Raum anfänglich auch als der Ort, in dem der ephesische Rat zusammentrat, fungiert, ehe diese Aufgabe vollständig vom benachbarten Bouleuterion übernommen wurde. Der ১Hestiasaak diente vor allem aber auch als der Ort ehrenvoller Speisungen verdienter und herausragender Bürger und Fremder auf Staatskosten. In ihm wurden die offiziellen Gäste der Stadt empfangen und bewirtet. Auch die Prytanen selbst wurden hier verköstigt.

Neben dem Kult für Hestia Boulaia waren zahlreiche weitere Kulte im Prytaneion untergebracht. Epigrafisch sind Demeter Karpophoros und ihre Tochter Kore, Sosipolis, Apollon Klarios, Apollon Manteios, Theos Kinnaios, Tyche und das personifizierte Heilige Feuer überliefert. Sie alle demonstrieren die außerordentliche kultische und religiöse Bedeutung des Gebäudes, die sich vor allem ab dem frühen 2. Jahrhundert n. Chr. durch die Einführung dieser neuen Kulte verstärkte. Die Steigerung der kultischen Relevanz verhielt sich exakt reziprok zum kontinuierlichen politischen Bedeutungsverlust der Institution `Prytaneion<. 
In welchen Räumen die einzelnen Gottheiten verehrt wurden, ist im Detail nicht immer zu klären. Vieles weist jedoch darauf hin, dass Demeter Karpophoros und Apollon Manteios, für die ein eigener veต́ bzw. eine $\theta \alpha \lambda \alpha \mu$ í überliefert sind, in einem der Nebenräume des >Hestiasaales` untergebracht waren (Räume 5 und 6). Das personifizierte Heilige Feuer hatte im Querraum 2-4 und somit im Heiligtum der Hestia seinen Platz. Neben dem Hauptkult für Hestia Boulaia und den genannten sekundären Kulten scheint das ephesische Prytaneion als Dependance des Artemisions fungiert zu haben, worauf die übergeordnete Bedeutung und Präsenz der Artemis Ephesia im Gebäude hindeuten. Sie nimmt im Prytaneion eine de facto gleichwertige Stellung mit Hestia Boulaia ein. Die vier erhaltenen Statuen der Artemis Ephesia, die wohl im Vorhof und in der Vorhalle aufgestellt waren, manifestierten den Machtanspruch der Artemis, die ihren Sitz in einem extraurbanen Heiligtum besaß, innerhalb der Stadt.

Das Prytaneion diente aber auch als Ort der Repräsentation und Selbstdarstellung: Ehrenstatuen und Ehrenbasen, die im Vorhof und in der Vorhalle aufgestellt waren, zeugen von diesem Anspruch. Im benachbarten Temenos und in der Basilike Stoa etablierte sich in augusteischer Zeit ein innerstädtisches Zentrum für den Kaiserkult; doch auch im Prytaneion ist als Sekundärfunktion die Verehrung des Kaiserhauses nachgewiesen: So wurde Livia um 20 n. Chr. als Personifizierung der Demeter Karpophoros in das Prytaneion eingeführt. Mit dem Kaiserkult könnten auch die Kureten in unmittelbarem Zusammenhang gestan-

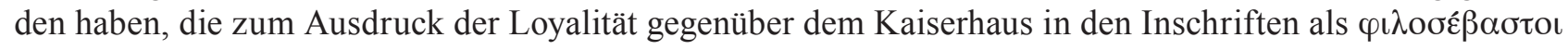
bezeichnet wurden.

Wie sich zeigte, können in Kleinasien neben der Anlage in Ephesos nur die Bauten in Magnesia am Mäander, in Milet und in Priene mit großer Sicherheit als Prytaneia bestimmt werden. Bei den anderen immer wieder als Prytaneia bezeichneten Gebäuden in Aigai, Herakleia am Latmos, Kolophon und Pergamon fehlen die spezifischen Charakteristika eines Prytaneions; ebensowenig lässt der Forschungsstand eine eingehendere Beurteilung zu. Auch außerhalb von Kleinasien sind nur wenige Gebäude tatsächlich als Prytaneia zu identifizieren. Zu nennen sind in diesem Kontext die Anlagen von Delos, Dreros, Lato, Olympia, Dodona, Kassope sowie - als Teil des Prytaneions - die Tholos der Athener Agora. Der diametrale Widerspruch zwischen der großen Zahl literarisch und epigrafisch überlieferter Prytaneia und der überaus geringen Zahl tatsächlich fassbarer Anlagen erklärt sich generell aus ihrer architektonischen Unauffälligkeit, scheinen sie doch in den meisten Fällen von geringer Monumentalität und sekundärer Ausstattung gewesen zu sein. Die sichere Identifizierung der Gebäude wird zudem durch die nur geringen bautypologischen Gemeinsamkeiten erschwert: So erwies sich die grundrissliche Durchgestaltung der sicher identifizierten Anlagen als überaus unterschiedlich. Gemeinsam war ihnen aber die Lage innerhalb der Stadt, nämlich die unmittelbare Nähe zur Agora sowie in den meisten Fällen eine direkte Nachbarschaft zum jeweiligen Bouleuterion der Stadt. Das zur Verfügung gestellte Raumangebot erwies sich bei allen Prytaneia, vor allem aber bei den genauer betrachteten kleinasiatischen Anlagen, als generell uneinheitlich: Während etwa in Ephesos ein eigener Raum vorgesehen war, in dem sich die Prytanen versammelten, aber auch die Staatsbankette abgehalten werden konnten, scheinen in Priene diese Funktion die Hallen und der Hof des Peristyls oder überhaupt die angrenzende `Heilige Halleく bzw. das Bouleuterion übernommen zu haben. Der Grundriss in Magnesia am Mäander ließ mehrere Möglichkeiten für die Unterbringung des Versammlungs- und Speisesaales offen: Neben dem Peristyl kommen die Exedra im Norden des Gebäudes sowie der westlich an die Exedra anschließende Raum in Frage, der u. a. als Klinensaal interpretiert wurde. In Milet fungierte die Südhalle des Delphinions sowohl als Versammlungs- als auch Speisesaal. Das zweite wesentliche Charakteristikum eines Prytaneions, nämlich die Beheimatung der Kultstätte der Hestia mit dem Staatsherd, fand sich - archäologisch oder epigrafisch belegt - sowohl in Magnesia als auch in Priene und Ephesos.

Die übrigen Räume in Prytaneia, die den Hauptsaal oder den Platz der Herdstelle umgaben, zeigten sich nur bedingt als grundrisstypologisch charakteristisch. Für das Funktionieren eines Prytaneions war jedoch neben den genannten Primäraufgaben Raum für das Kultpersonal und die Lagerung von Gegenständen für die Kulthandlungen vonnöten; wann immer Archive in Prytaneia untergebracht waren, benötigten diese ebenfalls entsprechende Flächen. Sowohl in Ephesos als auch in Priene, Milet und Magnesia war für diese Primär- und Sekundärfunktionen ausreichend Platz vorhanden. Küchen konnten hingegen - anders als etwa im Bereich der Tholos auf der Athener Agora, des Prytaneions von Olympia oder von Kassope - in keinem kleinasiatischen Prytaneion nachgewiesen werden; die Speisen dürften somit von spezialisierten Betrieben angeliefert worden sein. Raum zur Aufstellung von Ehrendenkmälern in repräsentativem Ambiente dürfte 
ebenfalls ein Charakteristikum von Prytaneia gewesen sein, wie an den Beispielen in Ephesos, Magnesia und Priene zu zeigen war.

Trotz Übereinstimmung wesentlicher funktionaler Merkmale von Prytaneia und ihrer vergleichbaren urbanistischen Einbindung erwies sich die grundrissliche Durchgestaltung der Bauten aber als so unterschiedlich, dass aus architektonischer Sicht von keinem einheitlichen Gebäudetypus >Prytaneion` gesprochen werden kann. Grund- und Aufriss oszillieren zwischen dem Einsatz von Architekturen öffentlicher Repräsentativbauten wie etwa in Ephesos, Milet und Magnesia, oder aber privater Peristylhäuser wie etwa in Priene, Kassope, Dodona, Lato oder Delos; dazu kommen Sonderformen wie die Tholos der Athener Agora. Beim derzeitigen Forschungsstand ist ein architektonisch uniformer Gebäudetypus >Prytaneion mithin nicht nachzuweisen.

Die Neuaufnahme der Erforschung des Prytaneions von Ephesos widmete sich einem Desiderat der ephesischen Forschungsgeschichte und konzentrierte sich auf eines der wichtigsten Gebäude im administrativen Zentrum von Ephesos, dessen Geschichte von augusteischer Zeit bis in das 4. Jahrhundert n. Chr. sowie - in einer Nachnutzung - bis in das 8 . Jahrhundert $n$. Chr. zurückverfolgt werden konnte. Wenn das Prytaneion danach auch mehrere Jahrhunderte in Vergessenheit geraten sollte, so bildet es seit seiner Freilegung in der zweiten Hälfte des 20. Jahrhunderts heute wieder einen Anziehungspunkt für die Gäste der Stadt, ist es doch einer der ersten Besuchermagnete auf den Touren durch die antiken Ruinen. In gewisser Weise wird es damit seiner ursprünglichen Bedeutung wieder gerecht. 



\section{SUMMARY}

In the last decades of the $1^{\text {st }}$ century $\mathrm{BCE}$ a building was constructed to the north of the Ephesian $>$ State Agorar. This building is one of the few securely identified prytaneia known from the Greco-Roman world. An interpretation of the building as a prytaneion and sanctuary of Hestia Boulaia was already convincingly argued during the excavations in 1955 and 1956 by F. Miltner who in his fast paced excavations reached the youngest preserved levels of the structure. Besides this widely accepted identification of the structure as the seat of the prytaneis and central cult building, which is attested epigraphically, Miltner was also able to discern different building phases. Despite further intensive study in the early 1960s lead by W. Alzinger who excavated numerous trenches under floor level and also in the early 1990s by the Efes Müzesi Selcuk, many questions of usage, appearance, function and relationship to neighboring Ephesian governmental buildings were still open. The publication of the inscriptions of the prytaneion by D. Knibbe in 1981 considerably expanded our knowledge especially concerning the collegium of Curetes installed in this building; the architectural and archaeological aspects of this monument had not yet been addressed at the start of the reexamination of the structure in 2007. A renewed interest and study of the Ephesian prytaneion was prompted by the unique importance of the building within the city limits and the administrative center of Ephesus as well as the prospect of further insight in an area where basic topographical and chronological questions remained unanswered. This study therefore includes the fundamental analysis of the architectural and stratigraphic finding including the decoration and results of the previous excavations. The following is a summary of the results:

The $1170 \mathrm{~m}^{2}$ large prytaneion of Ephesus was constructed in the Augustan period and has a clearly defined floor plan that was only altered in Late Antiquity: The entrance to the south of the building leads into the $18,40 \times 21,65 \mathrm{~m}$ measuring courtyard in the form of a triporticus with 14 reconstructed columns of Ionic order. In the center of the courtyard a foundation was found that is slightly out of line with the axis of the building and that from the time of Trajan probably functioned as the basis of the >Great-Artemis` statue. The imposing Doric façade of the 7,20 $\times 21,38 \mathrm{~m}$ large stoa that is situated to the north of the courtyard leads into the heart of the prytaneion. The columns of this stoa were restored and set up in the 1960s. The façade with its six columns in antis and an extended central bay as well as the rectangular hall behind it comprised the subsequent room ensemble to the north that did not adhere to the central axis and whose entrances all departed from the main axis. Both the Ionic peristyle of the courtyard and the Doric hall mark the axiality of the building that is broken up by the heterogeneous program of rooms to the north. The unconventional floor plan, as was shown, resulted from the locally limited topographical availability and the needed assemblage of rooms. The entablature of the overbearing Doric façade was outfitted with geisa that held the trusses of the roof construction. Therefore the building must be reconstructed with a hip roof contrary to previous opinions that assumed there to be a tympanum and raking sima according to temple façades. The Ephesian prytaneion is consequently divested of its unique status in the series of known prytaneia and does not imitate a temple. The large scale Doric architecture of the hall follows in the tradition of both the Hellenistic, Asian Minor ashlar construction as well as the classicistic traditions of Augustan architecture. Given that the Doric order is extremely rare in Ephesus as well as the rest of Asia Minor, the façade of the prytaneion would have been a special feature. Already by the Flavian period no monumental buildings of the Doric order were being constructed in Ephesus. The choice of an architectural tradition would have been purposeful in that it not only refers to the Greek motherland but also emphasizes the old age of this wholly Greek tradition. The 13,47 $\times 13,41 \mathrm{~m}$ large $>$ Hestia Halk to the north-east of the building could be accessed through the hall. The architectural characteristics of this room are the four double-half columns in the corners on podia that were crowned by composite capitals and short entablature joining into the walls of the room, as well as an open masonry arch in the north wall. Between the column podia two- 
stepped benches of seats were arranged in an L-shape and in a second building phase laid in brick. They could accommodate between 100 and 120 people. On the square foundation in the middle of the room stood an originally marble table where the food of the government banquettes was arranged. A 13,41 $\times 3,94 \mathrm{~m}$ large room (rooms 2, 3, 4) to the north of the $>$ Hestia Halk was closed off in the late antique/early Byzantine building phase 3 . In the western rooms 3 and 4 a water reservoir was installed in the building phase 3 . To the west of the $>$ Hestia Halk originally two rooms were located, measuring 7,98 $\times 6,52 \mathrm{~m}$ (room 6, in the south) and $8,83 \times 6,52 \mathrm{~m}$ (room 5, in the north). The northern part of room 5 was divided into two smaller room sections in Late Antiquity (room 5A and 5B). The extreme rise in elevation from south to north resulted in different levels of usage: The levels of usage in the northern rooms 2, 3 and 4 were partly up to $1,30 \mathrm{~m}$ higher than in the neighboring rooms 5 and 6 as well as the >Hestia Halk and were only accessible by stairs.

After analyzing the stratigraphic and architectural findings three major building phases could be discerned in addition to many small repairs. The ascertaining of building periods was complicated by the massive and mainly insufficiently documented archaeological activity of the 1950s and the 1960s as well as by the dearth of undisturbed areas needed for the reexamination process. Nonetheless for many areas the history of usage of the building could be recovered: The building was constructed in the Augustan period, in the last decade of the $1^{\text {st }}$ century BCE (building phase 1), in an area that at this point was undeveloped. Merely terraces were documented in the area of the prytaneion that date to the end of the $3^{\text {rd }}$ century BCE. An earlier prytaneion could not be localized within the Augustan precinct; the place of the pre-Augustan prytaneion of Ephesus is not unknown to date but its existence must be assumed. In the building phase 1a that is dated due to paleographic criteria of the inscription $\operatorname{IvE} 437$ roughly to the $1^{\text {st }} 2^{\text {nd }}$ century CE, the Ionic peristyle was repaired or completely rebuilt by an unknown donor. Essentially the construction of the Augustan building phase 1 was copied. According to the inscription IvE 1024 shortly after 104 CE the prytanis Dionysodoros completed further repairs. These repairs are not exactly distinguishable and can hardly be differentiated from the following building phase 2 that dates to the $2^{\text {nd }}$ quarter of the $3^{\text {rd }}$ century CE. All of these repairs indicate large damages to the building that required a great amount of alterations. Foremost the modifications undertaken in the >Hestia Halk must be mentioned as well as repairs to the walls, the creation of additional entrances to the hall or also the mounting of a new door in the room 2-4 in the course of which the arch of the north wall was hidden behind a new marble fronting. The addition of the L-shaped, brick built benches in the >Hestia Hall, the construction of the sheart columns< as well as the decoration of the hall with polychrome mosaics can be securely dated to the second building phase. In the middle of the $4^{\text {th }}$ century CE the building was abandoned as a result of damage through the series of earthquakes in 358 and 368 and never fixed up again. Early, sporadic interdictions of pagan cults under Constantius, especially the edicts of 354 and $356 \mathrm{CE}$ that demanded the closure of pagan temples, seem to have lead to a natural extinction of the institution sprytaneion in addition to the damage through the earthquakes. An intentional destruction of the buildings through Christians cannot be confirmed; all assumptions made concerning this remain solely hypothetical. The conclusion of the history of the prytaneion, a building that in the $4^{\text {th }}$ century had long surpassed its peak, is without a doubt the law prohibiting all pagan cult activity through Theodosius I in 391/392 CE. At the very latest the prytaneion lost all its cultic functions through this imperial ordinance and the holy fire on the hearth of Hestia expired. The institution had lost its political importance much earlier $-\mathrm{a}$ fate that the other political institutions later shared, i. e. the assembly $(\delta \tilde{\eta} \mu \mathrm{s})$ and the

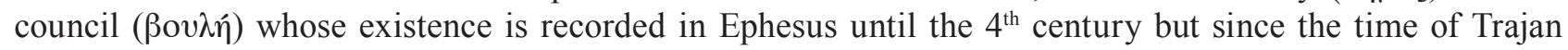
were noticeably deprived of their influence. Already soon after the abandonment of the building a slow but steady removal of building material began that continued for a long time. The extensive robbing of stones did not commence until the construction of the >Stoa of the Curetes` and the renovation of the Scholastikia Baths in the first half of the $6^{\text {th }}$ century CE in the course of which many architectural elements of the prytaneion were used as spolia. Already at the outset of the $5^{\text {th }} / 6^{\text {th }}$ century the area north of the $>$ State Agora was used as a craftsman quarter with simple housing structures (building phase 3). Evidence for this phase are the Byzantine constructions over the prytaneion and especially the installation of a water reservoir in the rooms 3 and 4 that was in use until the middle of the $7^{\text {th }}$ century (building phase 3a). The last usage of the site took place in the last quarter of the $8^{\text {th }}$ century CE. 
In the prytaneion of Ephesus many of the important functions of such an institution can be verified: Among these are the home of the hearth of Hestia, the seat of the prytaneis as well as the reception and provision of meals for honored citizens financed by the government. All of these functions are brought together by this representative Ephesian building. The interpretation of the building as a prytaneion is supported by its integration into the city, i. e. right on the >State Agora<, the political center of the city, as well as through its immediate proximity to the bouleuterion. The functional analysis of the separate rooms of the prytaneion demonstrates that in addition to this main function the building had incorporated many other functions. The different modes of usage are on the one hand transmitted epigraphically, on the other hand though visible through specific decorational elements of the architectural assemblage.

The hearth of Hestia was initially housed in the room 2-4 where the eternal fire burned that should symbolize the life of the city. This room must be understood as architecturally emphasized due to its entrance through the arch and decentralized placement within the building. As such it represents the cella of Hestia. The official hearth, the xoıvì $\dot{\varepsilon} \sigma \tau i \alpha$, in this context embodies the domestic hearth, the central place of family life. The entire state or rather the polis viewed itself in respect to this hearth as a simple family. The official guests of the polis were therefore received in a house representing all the houses of the city. The fire was cared for by the synedrion of Curetes that in Augustan time was relocated from the Artemision to the Ephesian prytaneion and is attested by many formulaic inscriptions on the building. They also acted as sacrifice assistants of the prytaneis during the often complicated cult practices that were regularly conducted in the prytaneion. The collegium is attested until at least the beginning of the $3^{\text {rd }}$ century CE and also organized the yearly Ortygian mysteries. This mystery reflected the birth of Artemis and Apollo and formed an important point in the cultic year of Ephesus. The shift in the organization of these mysteries from the Artemision to the city meant a loss of power and prestige for the Artemision. This synedrion could have been housed in the rooms 5 and 6 without being able to exactly prove this. In these rooms the city's

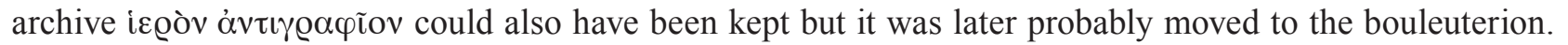

In the >Hestia Halk the prytaneis assembled. In the beginning this room maybe was also used as the place where the Ephesian council met before this duty was completely assumed by the bouleuterion. The >Hestia Halk was mainly used as the location for the highly esteemed banquettes for outstanding and honored citizens and foreigners paid for by the government. Not only the prytaneis themselves were fed here but also the official guests of the city received and hosted.

In addition to the cult of Hestia Boulaia the prytaneion was home to numerous other cults. Epigraphically Demeter Karpophoros and her daughter Kore, Sosipolis, Apollon Klarios, Apollon Manteios, Theos Kinnaios, Tyche and the personified holy fire are attested. They demonstrate the immense cultic and religious importance of the building that was intensified especially after the early $2^{\text {nd }}$ century CE through the integration of these new cults. The growth in cultic relevance took place contrary to the continual loss of political importance of the institution sprytaneion<. In which room which god was honored cannot always be answered in detail. But there are many indications that Demeter Karpophoros and Apollon Manteios

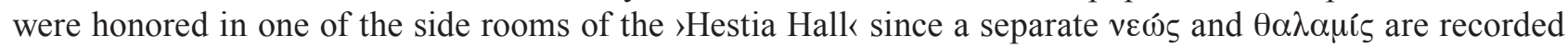
for these gods (rooms 5-6). The personified holy fire was housed in room 2-4 within the sanctuary of Hestia. Aside from the main cult of Hestia Boulaia and the afore mentioned secondary cults, the Ephesian prytaneion seems to have served as a dependance of the Artemision indicated by the essential meaning and presence of Artemis Ephesia in the building. She holds a de facto equal position within the prytaneion as Hestia Boulaia. The four preserved statues of Artemis Ephesia that were probably set up in the courtyard and hall, manifest to the power that Artemis held within the city, her actual residence though was in an extra urban sanctuary.

The prytaneion also functioned as a place of exhibition and self-representation: this is suggested by honorific statues and bases that were erected in the courtyard and hall. In the neighboring temenos and in the Basilike Stoa a downtown center for the emperor's cult was established in Augustan time; but the worship of the emperor's family has been corroborated as a secondary function of the prytaneion: In $20 \mathrm{CE}$ Livia was introduced into the prytaneion as a personification of Demeter Karpophoros. The Curetes could have had an immediate tie to the cult of the emperor who as sign of their loyalty towards the family of the

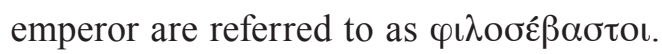


Moreover the evidence showed that in Asia Minor only the buildings in Magnesia on the Maeander, in Miletus and in Priene can be securely recognized as prytaneia besides the complex in Ephesus. The other buildings frequently identified as prytaneia in Aigai, Herakleia under the Latmos, Colophon and Pergamon are missing specific characteristics of a prytaneion; neither does the current state of research allow more in depth evaluation. Also outside of Asia Minor only a few buildings can be really identified as prytaneia. The notable complexes in this context are Delos, Dreros, Lato, Olympia, Dodona, Kassope as well as - as part of the prytaneion - the tholos of the Athenian agora. The contradiction between the large number of literary and epigraphical mentions of prytaneia and the very small number of actually found complexes becomes understandable considering the inconspicuous architecture. In many cases they were of limited monumentality and had later decorational elements. The secure identification of the buildings is further complicated by the few architectural similarities: The design of the floor plan of all securely identified complexes turned out to be very diverse. Their placement within the city though was similar, more precisely the immediate proximity to the agora as well as directly neighboring the respective bouleuterion of the city. The contingency of rooms among all prytaneia offered a very disparate picture, especially among the more exactly studied structures from Asia Minor: While e. g. in Ephesus an own room was specifically used for assemblies of the prytaneis and also for government banquettes, in Priene this function seems to have been assumed by the halls and the courtyard of the peristyle or even by the adjoining sholy hall or bouleuterion. The floor plan in Magnesia on the Maeander allows many different possibilities in accommodating an assembly and dining room: Adjacent to the peristyle an exedra to the north of the building may be considered as well as a room bordering the exedra to the west that has been interpreted inter alia as a hall with klinai. In Miletus the south hall of the Delphinion was used both as meeting as well as dining room. The second significant characteristic of a prytaneion is housing the cult place of Hestia with the hearth of the government and this could be located in either archaeological or epigraphical terms in Magnesia as well as Priene and Ephesus.

The remaining rooms of the prytaneion that surround the main hall or the place of the hearth turned out to be only a mean characteristic within the floor plan typology. The operation of the prytaneion depended not only on the above mentioned primary function but also on space for the cult staff and the storage of objects used in the cult activities; when archives were stored in prytaneia these equally needed adequate space. In Ephesus as well as in Priene, Miletus and Magnesia there was enough space for both the primary and secondary functions. However no kitchen was discovered in any example from Asia Minor contrary to the area of the tholos on the Athenian agora, the prytaneion of Olympia or of Kassope; the meals seem to have been delivered by specialized businesses. Space for setting up statues in a representative environment might have been an additional characteristic of prytaneia as can be shown on the examples from Ephesus, Magnesia and Priene.

Despite the correlation of essential functional attributes of prytaneia and their comparable urbanistic integration, the concept of their floor plan is so diverse that from an architectural stand point no uniform building type sprytaneion can be proposed. The floor plan and view oscillate between the appropriation of architecture from representative buildings as in Ephesus, Miletus and Magnesia and that from private peristyle houses e. g. Priene, Kassope, Dodona, Lato or Delos; also some more unusual forms exist, e. g. the tholos of the Athenian agora. According to our current state of research no architecturally uniform building type sprytaneion< can be proposed.

The reexamination of the prytaneion of Ephesus addressed a deficit within the Ephesian research history and concentrated on one of the most important buildings within the administrative center of Ephesus, its past reached from the Augustan period to the $4^{\text {th }}$ century CE with a later usage up until the $8^{\text {th }}$ century $\mathrm{CE}$. Although the prytaneion was then forgotten for many centuries since its exposure in the second half of the $20^{\text {th }}$ century it has now again become the first attraction for visitors touring the ancient ruins. In some sense it is once again fulfilling its initial purpose. 


\section{ÖZET}

İ.Ö. 1. yüzyılın son on yıllık zaman dilimi içerisinde Efes'in devlet agorasının kuzeyinde, bugün YunanRoma dünyasının kesin olarak teşhis edilebilen az sayıdaki Prytaneion'larından olan bir yapı inşa edilmiştir. F. Miltner'in 1955 ve 1956 yıllarında yaptığ 1 ve hızlı bir çalışma temposu ile en erken taban seviyesine kadar indiği kazılar sonucunda yapı Prytaneion ve Hestia Boulaia'nın kutsal alanı olarak tanımlanmıştır. Günümüzde genel olarak kabul görmüş olan Prytanların ana binası ve epigrafik yönden de kanıtlanan, şehrin ana kült yapısı gibi tanımlamaların yanı sıra Miltner birçok yapı evresini de ayırt edebilmiştir. 1960'ların başlarında W. Alzinger yönetiminde yapılan, taban seviyesinin altına inen birçok sondajın açıldığı araştırmalara ve 1990'ların başlarında Efes Müzesi tarafından yapılan incelemelere rağmen yapının kullanım tarihi, görünüşü, işlevi ve yapıya komşu olan Efes yönetim bölgesiyle olan ilişkisi gibi, yapıya yöneltilebilecek ana sorular yanıtsız kalmıştır. 1981 yılında D. Knibbe tarafından yayınlanan Prytaneion yazıtlarının ayrıntılı sunumu, konu ile ilgili bilgilerimizi (özellikle de Kuretler'in bu binada bulunan Kült Derneği ile ilgili olan bilgileri) önemli ölçüde genişletmiştir. Ancak 2007'de buradaki çalışmalar yeniden ele alındığında arkeolojik ve yapısal verilerin değerlendirilmeleri henüz yayınlanmamıştı. Yapının, şehir sistemi ve Efes’in idari merkezi içindeki olağanüstü önemi, topografisi ve kronolojisi ile ilgili ana soruların tam olarak aydınlatılmamış olması ve bu yönde derinlemesine yeni bilgilere ulaşma beklentisi Efes Prytaneion'undaki incelemelerin tekrar ele alınmasına yol açmıştır. Bu araştırmada yapının donanımıyla birlikte stratigrafik ve mimari buluntularının, daha önce yapılmış kazıların sonuçları da dikkate alınarak analiz edilmesi amaçlanmıştır.

Araştırmaların sonuçları aşağıdaki gibi özetlenebilir:

Augustus döneminde inşa edilmiş olan, $1170 \mathrm{~m}^{2}$ büyüklüğündeki Efes Prytaneionu, daha sonra Geç Antik Dönem'de eklenen yapılanmalarla karmaşık bir hale gelen, belirgin olarak düzenlenmiş bir plana sahiptir. Yapının güneyinde bulunan ana girişten, 18,40 $\times 21,65 \mathrm{~m}$ büyüklüğündeki, 14 adet Ion düzenindeki sütunuyla rekonstrüksiyonu yapılabilen Tripoticus şeklindeki ön avluya girilir. Avlunun merkezinde, Traianus döneminden itibaren >Büyük Artemis` heykelinin kaidesi görevini üstlenen, yapının aksından hafif çıkmış bir temel bulunur. Ön avlunun kuzeyinde bulunan enine yapılmış, 7,20 × 21,38 m büyüklüğündeki stoa'nın (ön hol) ağır, Dor düzenindeki cephesi bize Prytaneion'un esas yapısını verir. Stoanın sütunları 1960'larda kısmen tekrar yerlerine yerleştirilmişlerdir. Orta sütun aralığı genişletilmiş olan altı in-antis sütunlu cephe ve arkasında bulunan enine uzanmış dikdörtgen hol, bunlara göre düzenlenmiş, holün kuzeyindeki, merkezi orta aksın üzerinde bulunmayan oda grubunu kapsamaktadır. Bu oda grubunun bütün girişleri ana akstan çıkmıştır. Ion düzenindeki peristyl avlu ve Dor düzenindeki stoa aynı aks üzerinde bulunurlar. Ancak bu aksiyallik yapının kuzeyinde bulunan heterojen oda yapısıyla bozulur. Yukarıda görülen bu alışılmadık plan açılımı bir taraftan sınırlı topografik unsurlara, diğer taraftan gerekli olan oda yapılanmasına bağlıdır. Bütün yapıya hakim olan Dor düzenindeki cephenin üst yapısında geisonun en üst kısımlarında, çatının ahşap kirişlerinin giriş yerleri bulunur. Bu nedenle yapı, daha önceki tapınak cephesine uygun olan yapının cephesinin üst kısmının bir alınlık ve alınlık tablası ile bitirilmesi yönündeki görüşlerin aksine basit kırma çatı ile rekonstüre edilmelidir. Bununla birlikte Efes Prytaneionu diğer bilinen Prytaneionlar arasındaki istisnai statüsünü kaybeder ve tapınak mimarisini taklit etmediği görülür. Geniş yapısı ve indirgenmiş süslemesiyle ön holün Dor düzenindeki mimarisi Hellenistik Küçük Asya taş bina yapımı ve Augustus dönemi mimarisinin klasistik geleneklerine uygundur. Küçük Asya’nın geri kalanında da olduğu gibi Efes'te de Dor düzeninin çok az görülmesi Prytaneion'un ağır cephesini sıradışı bir özellik durumuna sokar. Flaviuslar döneminden itibaren Efes'te Dor düzeninde anıtsal bir yapı inşa edilmemiştir. Sadece Yunan anavatanına gönderme yapmayan, bunun yanında tamamen Yunanlı olan Prtaneion kurumunun eskiliğini de vurgulayan bu mimari geleneğin uygulanması bilinçli bir seçimdir. Stoa'dan kuzeydoğusunda yer alan, 13,47 $\times 13,41 \mathrm{~m}$ büyüklüğündeki Hestia Salonu'na (Oda 1) ulaşılır. Kaide üzerinde yükselen, kompozit başlıklı, oda duvarına bağlantı sağlayan bir üst yapı elamanıyla taçlandırılmış, iki yarım sütunun birleştirilmesiyle oluşmuş dört adet köşe sü- 
tunu ve kuzey duvardaki açık kemer, Hestia Salonu'nun kendine has mimari karakterini oluştururlar. Sütun kaidelerinin arasında taştan, L şeklinde, iki basamaklı, ikinci yapı evresinde oluşturulmuş, 100-120 kişilik oturma kapasitesine sahip banklar bulunurdu. Salonun merkezindeki kare temel üzerinde orjinalinde devlet ziyafetlerinde yiyeceklerin konulduğu mermer bir masa bulunmaktaydı. Hestia Salonu'nun kuzeyinde Geç Antik/Erken Bizans dönemine tarihlenen, 3. Yapım Evresinde duvarlarla bölünmüş ancak orjinalinde 13,41 $\times$ 3,94 m büyüklüğünde enine yapılmış bir oda (Oda 2, 3 ve 4) bulunurdu. Batıda bulunan Oda 3 ve Oda 4'te 3. Yapım Evresinde bir su deposu inşa edilmiştir. Hestia salonunun batısında ise esasen biri 7,98 $\times 6,52 \mathrm{~m}$ (Güneyde Oda 6) büyüklüğünde, diğeri 8,83 × 6,52 m (Kuzeyde, Oda 5) büyüklüğünde olmak üzere iki oda bulunmaktaydı. Oda 5'in kuzey bölümü Geç Antik dönemde iki küçük bölmeye ayrılmıştır (Oda 5A ve 5B). Güneyden kuzeye doğru sert bir şekilde yükselen araziye bağlı olarak kullanım seviyelerinde de farklılıklar vardır. Buna göre kuzeydeki odalar 2, 3 ve 4'ün taban seviyesi, komşu odalar 5 ve 6'dan ve Hestia salonundan, kısmen 1,30 m. yüksekti. Buna bağlı olarak bu odalara sadece bir merdiven vasıtasıyla ulaşılırdı.

Stratigrafik ve mimari buluntuların analizi sonucunda, birçok küçük tamir evresinin yanında Prytaneion'da üç büyük yapım evresi ayırt edilebilmiştir. 1950'lerde ve 1960'larda yapılan yoğun, çoğunlukla iyi belgelenmemiş kazılar ve yeni yapılan kazı çalışmalarında stratigrafik kazıya uygun, tahribe uğramamış çok az alanın bulunması bu yapı evrelerinin sınıflandırılmasını zorlaştırmıştır. Buna rağmen yapının kullanım tarihi büyük oranda tasarlanabilmiştir. Yapı Augustus döneminde, tam olarak I.Ö. 1. yüzyılın son 10 yılı içerisinde (Yapım Evresi 1), büyük oranda daha önceden inşa görmediği anlaşılan bir alana yapılmıştır. I.Ö. 3. yüzyılın sonlarında Prytaneion'un bulunduğu alanda sadece teraslama yapıldığı belgelenebilir. Buna göre Augustus dönemi Prytaneion'unun bulunduğu alanda daha önceki bir tarihe ait bir Pytaneion'un izlerine rastlanmamıştır. Efes'te bulunduğundan yola çıkabileceğimiz Augustus dönemi öncesine ait Efes Prytaneion'unun yeri bilinmemektedir. Yazıt IvE 437'nin paleografik açıdan incelenmesi sonucunda kabaca İ.S. 1.-2. yüzyıla tarihlenen Yapım Evresi 1a'da ön avlunun Ion düzenindeki peristylü bilmediğimiz bir kişi tarafından tamir ettirilmiş ya da tamamen yeni yaptırılmıştır. Bu evrede Augustus dönemi (Yapım Evresi 1) yapısı esas al1narak kopya edilmiştir. IvE 1024 yazıtına göre İ.S. 104’ten hemen sonra Dionysodoros adındaki bir Prytan tarafından binada ilave tamir çalışmaları yaptırılmıştır. Ancak bu tamir çalışmaları sırasında binaya yapılan müdehaleler güçlükle tespit edilebilir ve bu yapı evresini takip eden, İ.S. 3. yüzyılın ikinci çeyreğine tarihlenen Yapım Evresi 2'den ayırt etmek neredeyse mümkün değildir. Bütün veriler yapının bünyesindeki, tekrar yapılandırılmasını gerektirmiş büyük tahribatlara işaret eder. Özellikle Hestia salonundaki müdahaleler dikkati çeker. Salonun duvarlarındaki tamirler, ön holden salona ilave girişler yapılması, enine Oda 2-4'e yeni bir giriş kapısının yapılması ve buna bağlı olarak kuzey duvardaki kemerin mermer bir kaplamanın arkasına gizlenmesi sözü edilebilecek uygulamalardır. Hestia salonunda taştan, L şeklinde oturma banklarının yapılması, >Kalp sütunlar'’n yeniden yerlerine konulması ve ön hole çok renkli bir mozaiğin döşenmesi, 2. Yapım Evresi'nde gerçekleştikleri kesin olarak tespit edilebilmiş müdahalelerdir. İ.S. 358 ve 368 yılları arasında gerçekleşen depremlerde tahrip olması sonucunda yapı, İ.S. 4. yüzyılın ortasında terk edilmiştir ve daha sonra tekrar ayağa kaldırılmamıştır. Başta nadiren uygulansalar da Constantius dönemindeki Pagan kültlerine gelen ilk yasaklar, (İ.S. 354'te ve İ.S. 356'da yayınlanan Pagan tapınaklarının kapatılması talebini içeren yasalar) olası deprem hasarlarından sonra Prytanlık kurumunun zamanla doğal yollarla bittiğine işaret ederler. Ayrıca yapılan çalışmalarda Hırıstiyanlar tarafından yapılmış bilinçli bir tahribin izlerine rastlanmamıştır. Bu yönde açıklanmış görüşler varsayım niteliğini taşımaktadırlar. İ.S. 4. yüzyılda, altın çağını çoktan geride bırakmış bir kurum olan Prytaneion'un tarihinin bitiş noktasını I. Theodosius'un İ.S. 391/392'de çıkarmış olduğu pagan ayinlerini yasaklayan yasa oluşturur. Bu imparatorluk yasağıyla artık Prytaneion'un kültsel işlevi sona ermiş ve Hestina ocağındaki kutsal ateş sönmüştür. Prytaneion politik açıdan etkisini ise çok daha önce kaybetmiştir. Bu kaderi Prytaneion'la birlikte, Efes'teki varlıkları İ.S. 4. yüzyılda hala devam ettiği kanıtlanabilir olsa da etkileri Traianus döneminden itibaren giderek azalan Halk Meclisi ( $\delta \tilde{\eta} \mu \circ \varsigma)$ ve Danışma

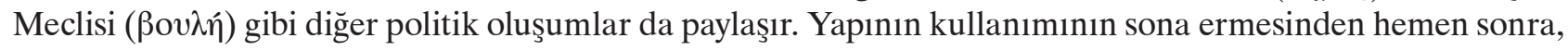
başlarda çekinerek de olsa uzun zaman devam eden yapı malzemelerinin sürekli çalındığı bir dönemin içine girilmiştir. Harabenin malzemelerinin yoğun bir şekilde yağmalanması ise Kuretler Holü’nün yapımı ve İ.S. 6. yüzyılda Scholastikia Hamamı'nın tamiri sürecinde gerçekleşir. Bu yapılarda Prytaneion'un pek çok yapı taşı devsirme olarak kullanılmıştır. İ.S. 5.-6. yüzyıllarda devlet agorasının kuzeyinde yer alan bölge basit ev yapılarıyla zanaat muhiti olarak kullanım görmüştür (Yapım Evresi 3). Prytaneion'daki Bizans dönemine ait mimari müdahaleler ve özellikle de Oda 3 ve Oda 4’te yapılmış, İ.S. 7. yüzyılın ortalarına (Yapım Evresi 
1a) kadar kullanım görmüş olan su deposu bu döneme tanıklık ederler. Alanın son olarak yoğun bir şekilde kullanımı İ.S. 8. yüzyılın son çeyreğine tarihlenir.

Efes Prytaneion'unda Prytanlık kurumunun içindeki bütün ana işlevlerin kanıtlarına rastlanır. Buna Hestia'nın ocağının burada yer alması, Prytanların resmi lokallerinin burada bulunması ve devlet bütçesinden buna layık görülen vatandaşlara verilen ziyafetler de dahildir. Bütün bu işlevler Efes’i temsil eden bu binada aynı çatı altında buluşturulmuştur. Yapının Prytaneion olarak tanımlanması, şehrin politik merkezi olan devlet agorasında bulunması ve Bouleuterion'un hemen yakınında olması gibi, yapının şehir içindeki konumuyla da desteklenir. Prytaneion'un odalarının kendi başlarına işlevlerinin incelenmesi, bize yapının bu ana görevleri dışında pek çok başka işlevler de üstlendiğini gösterir. Epikrafik kaynaklardan da bize aktarılan farklı kullanım şekilleri, anıtın mimari yapılanmasından veya yapıdaki bu kullanım şekillerine özgü belirli donamın elemanlarından anlaşılabilir.

Şehirdeki hayatı temsil eden, sonsuz ateşin yandığı Hestia'nın ocağı, yapının orjinalinda Enine Oda 24'te bulunuyordu. Girişinin bir kemer yardımı ile mimari açıdan vurgulanması ve aynı zamanda bina içindeki merkezden uzaklaştırılmış konumu odanın Hestia'nın cellası olarak kabul edilmesini gerektirir. Devlet ocağı

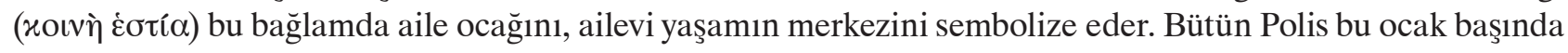
basit bir ailenin sureti olarak toplanır. Polisin resmi misafirleri şehrin bütün evlerini temsilen bu binada kabul edilirdi. Bu ocakla ilgilenme görevini, Augustus Döneminde Artemision'dan Efes Prytaneionu'na taşınan ve yapıdaki pek çok yazıtla ölümsüzleştirilmiş Kuretler Synedrion'u üstlenmiştir. Ayrıca Prytanlar tarafından Prytaneion'da düzenli olarak yapılan, çoğu zaman karmaşık kült ayinlerinde Prytanlara, kurban törenlerinde yardımcılık görevini üstlenmişlerdir. En az İ.S. 3. yüzyılın başlarına kadar varlığı kanıtlanabilmiş dernek, her yıl yapılan Ortygia mistik oyunlarının düzenlenmesinde de görev almıştır. Artemis ve Apollon'un doğumunu yineleyen bu mistik oyun, Efes’in kült takviminde beğişmez bir noktayı oluştururdu. Bu mistik oyunun organizasyonunun Artemision'dan şehre taşınması Artemision için büyük bir prestij ve güç kaybı anlamına geliyordu. Synedrion, tam olarak kanıtlanmasa da Oda 5 ve Oda 6'da yer almış olabilir. Bu iki odada, daha sonra

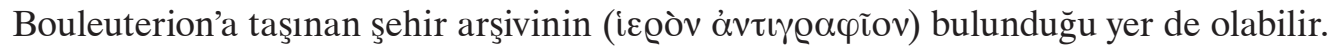

Hestia Salonu Prytanların toplantı yeriydi. Bu salon, bu görevi buraya komşu olan Boleuterion tamamen üstlenmeden önce, Efes danışma meclisinin toplantı yeri olarak da işlev görmüş olabilir. Hestia salonu herşeyden önce kendini göstermiş, bunu haketmiş vatandaşlar ve yabancılar için devlet tarafından verilen onur ziyefetlerine ev sahipliği yapmakla yükümlüydü. Burada şehrin resmi misafirleri kabul edilir ve ağırlanırdı. Prytanlar da burada yer içerlerdi.

Prytaneion, Hestia Boulaia kültünün yanısıra bir çok başka kültü de içinde barındırmıştır. Demeter Karpophoros ve kızı Kore, Sosipolis, Apollon Klarios, Apollon Manteios, Theos Kinnaios, Tyche ve kutsal atesin personifikasyonu epigrafik olarak bize aktarılan kültlerdir. Bütün bu kültler bize, yapının özellikle İ.S. 2 . yüzyılın başlarından itibaren yeni kültlerin eklenmesiyle güçlenen kültsel ve dini açıdan fevkalade anlamını gösterir. Yapının dinsel açıdan önemini ile Prytaneion kurumunun politik anlamı ters orantı yapar. Yapının dinsel önemi arttıkça Prytaneion kurumunun politik öneminin azalmaya yüz tuttuğu görülür. Hangi odanın hangi tanrıya ait olduğunu detayda açılığa kavuşturmak her durumda mümkün değildir. Birçok veri, ken-

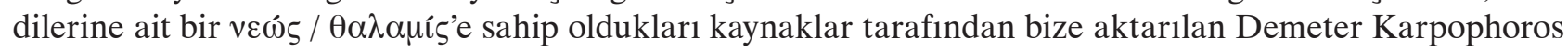
ve Apollon Manteios kültlerinin Hestia salonunun yan odalarından birinde (Oda 5 ve Oda 6) bulunduğuna işaret eder. Kutsal ateşin personifikasyonunun yeri, Hestia'nın kutsal mekanı olan Enine Oda 2-4'teydi. Hestia Boulaia'nın ana kültü ve yukarıda belirtilen ikinci derecedeki kültlerin yanında, Efes Prytaneionu'nun Artemision'a bağlı olarak görev yaptığı görülür. Bunu, Artemis Ephesia'nın yapıdaki herşeyin üstünde olan varlığı ve anlamı gösterir. Artemis Ephesia, aslında Prytaneion'da Hestia Boulaia ile aynı seviyede yer alır. Orjinalinde ön avluda ve ön holde yer almış olan Artemis'in ele geçen dört heykeli, asıl kutsal alanı şehir dışında bulunan Artemis'in şehir içindeki iktidar talebini gösterir.

Bunların dışında Prytaneion ayrıca kendini gösterme ve ifade etme yeri olarak da kullanılmıştır. Ön avluya ve ön hole dikilmiş olan onur heykelleri ve kaideleri bu talebi yansıtırlar. Yapının hemen yan tarafındaki Temenosda ve Bazilika Stoa'da, Augustus Döneminde imparatorluk kültü için şehir içinde bir merkez kurulmuştur. Prytaneion'da da ikincil işlev olarak imparator ailesinin saygı gördüğü kanıtlanmıştır. Buna bağlı olarak İ.S. 20'lerde Livia, Demeter Karpophoros'un personifikasyonu olarak Prytaneion'a girmiştir.

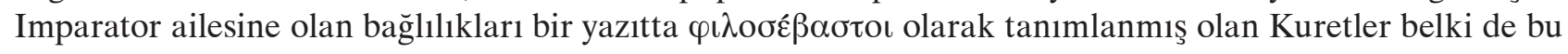
imparator kültü ile doğrudan bağlantılıydılar. 
Küçük Asya'da Efes'in dişında sadece Menderes Magnesia'sındaki, Milet’teki ve Priene'deki yapılar, kesin bir şekilde Prytaneion olarak tanımlanabilir. Prytaneion olarak tanımlanan Aigai, Herakleia Latmos, Kolophon ve Bergama'daki diğer yapılarda bir Prytaneion'da olması gereken özellikler bulunmadığından ve bunu yorumlayacak derecede araştırma yapılmamış olduğundan, bu yapılar Prytaneion olarak tanımlanamazlar. Küçük Asya'nın dışında da çok az sayıda bina Prytaneion olarak tanımlanabilir. Bunların arasında Delos, Dreros, Lato, Olympia, Dodona, Kassope'deki yapılar ve Prytaneion'un bir bölümünü oluşturan Atina agorasondaki Tholos bulunur. Antik literaturlerde ve yazıtlarda bize aktarılan çok sayıdaki Prytaneion'a karşın, günümüzde tespit edilebilen Prytaneion'ların çok az olması genel olarak, bir çok durumda anıtsallıktan uzak, kısmen kötü dekorasyona bağlı göze batmayan, gösterişsiz bir mimariye sahip olmalarına bağlanır. Yapı tipolojisi açısından ortak özelliklerinin az sayıda olması, yapıların kesin bir şekilde tanımlanmalarını güçleştirir.

Buna göre kesin bir şekilde Prytaneion olarak tanımlanmış yapıların planlarının birbirinden oldukça fark11 olduğu görülür. Agoranın hemen yakınında, bir çoğunun da bulundukları şehrin Bouleuterion'una komşu olmaları gibi şehir içindeki konumları Prtytaneion'ların ortak özellikleridir. Prytaneion'lardaki odaların sayısı ve dağılımı, özellikle de Küçük Asya'daki örneklerde farklılıklar gösterir: Efes'te Prytanların toplanması ve devlet ziyafetlerinin düzenlenmesi için bir salon bulunurken Priene'de bu görevi holler ve peristyl avlu ya da hemen onun yanındaki `Kutsal Stoa<ve Boleuterion üstlenmiştir. Menderes Magnesia'sındaki yapı pla$\mathrm{n} ı$ ise toplantı ve ziyafet salonu için birçok olasılık sunar. Peristylün yanında binanın kuzeyindeki exedra ve exadranın batısındaki diğer nitelendirilmelerin yanında kline salonu olarak da tanımlanmış olan oda olasılıklar içerisindedirler. Milet’te Delphinion'un güney holü hem toplantı hem de yemek salonu olarak görev yapmıştır. Bir Prytaneion'un ikinci karekteristik özelliği olan devlet ateşini içinde bulunduran Hestia kült alanı, hem Magnesia'da hem Priene'de hem de Efes'te arkeolojik ya da epigrafik açıdan kanıtlanmıştır.

Ana salonu ya da ocağın bulunduğu alanı çevreleyen Prytaneion'lardaki diğer odalar şartlara bağlı olarak plan tipolojisinde yerlerini alırlar. Ancak bir Prytaneion'un işlevlerini görebilmesi için yukarıda belirtilen birincil derecedeki görevlerin yerine getirildiği odaların yanında, kült personelinin kullandığ 1 ve dinsel törenlerde gerekli malzemelerin depolandığı alanlara ihtiyaç vardır. Ayrıca Prytaneion'larda bir arşivin bulunması durumunda bu arşivin konulduğu, uygun alanların da bulunması gerekir. Hem Efes'te hem Priene'de hem Milet'te hem de Magnesia'da bu birincil ve ikincil kullanım amaçları için yeterince alan mevcuttur. Ancak mutfak Atina Agorası'ndaki Tholos bölümü, Kassope ya da Olympia Prytaneionlarından farklı olarak hiçbir Küçük Asya Prytaneion'unda kanıtlanamamıştır. Buna göre yiyecekler bu konuda uzmanlaşmış işletmelerden geliyor olmalıydı. Onur anıtlarının temsili bir ambiyansda yerleştirildiği bir odaya sahip olmaları da Prytaneion'ların karekteristik özellikleri arasında yer alıyor olmalıdır. Bunu Efes, Magnesia ve Priene örneklerinde görebiliriz.

Prytaneion'ların ana işlevsel nitelikleri ve şehir yapısı içindeki birbirine benzer konumları büyük bir oranda bağdaşıyor olsa da yapıların plan oluşumları o kadar farklılık gösterir ki mimari açıdan tek bir yapı tipi >Prytaneion'dan bahsetmek mümkün değildir. Görünüş ve plan Magnesia, Milet ve Efes’te olduğu gibi kamusal bina mimarisinin uygulanması ya da Priene, Kassope, Dodona, Lato ve Delos'ta görülen özel peristyl ev mimarisinin uygulanması arasında gidip gelir. Buna Atina Agorası'ndaki Tholos'da görüldüğü gibi özel formlarda eklenir. Buradan da anlaşılacağı gibi bugüne kadar yapılan araştırmaların ışığında genel geçer bir yapı tipi Prytaneion ortaya konulamaz.

Efes'in Prytaneion'una dair yeniden yapılan araştırmalar, Efes araştırma tarihinin ihtiyaç duyulan boş kalmış bir bölümüne kendini vakfetmiştir ve bununla birlikte tarihi Augustus Döneminden İ.S. 4. yüzyılın içlerine, daha sonraki farkli kullanımlarıyla İ.S. 8. yüzyıla kadar giden, Efes’in yönetim merkezindeki en önemli yapılardan birine yoğunlaşmıştır. Prytaneion daha sonraki yüzyıllar boyunca unutulmuş olsa da 20 . yüzyılın ikinci yarısında ortaya çıkarılmasıyla bugün yine ziyaretçilerden rağbet gören, antik harabelerdeki turlarda en çok ilgi çeken yapıtların arasında yer alan bir konumdadır. Bununla birlikte bir anlamda asıl işlevine uygun bir konum üstlenmiştir.

(Çeviri: Neşe Kul-Berndt) 


\section{REGISTER}

Agora 1, 3, 5, 6, 22, 88 f., 94, 184, 191 f., 195 f., 203, 211, $223-227,229-231,236 \mathrm{f}$.

\section{Agrigent 3}

Aigai 5, 223, 229, 236

Altar 2, 21 f., 25, 190, 197, 205, 212, $224 \mathrm{f}$.

Anrichte 21, 217, 228

Apollon Klarios 24, 217, 221, 235

Apollon Manteios 24 f., 79, 217, 220 f., 235 f.

Architektur

-probe 17-20, 33, 35, 48 f., 61, 194 f., 214 Anastylose 20

Ante 13, 18 f., 26, 29 f., 32-34, 36, 60 f., 177, 194, 213 f. Architrav 10, 12, 17, 20, 25, 33-35, 38, 40, 49, 57, 59-61, 80, 180, 184, 190, 192-195, 214, 223, 227

Aufschnürung 32, 58 f., 79, 195, 211

Basis 12, 21 f., 25, 31 f., 39 f., 42, 44, 50-54, 58 f., 62, 79, 179, 181 f., 185-191, 203 f., 208 f., 215, 224, 233 attisch 39 f., 50-54, 58 f., 80, 181 f., 186 f.

Ehrenbasis 31, 36, 59, 203, 208 f., 211, 215, 222, 236

Pfeiler-/Pilasterbasis 53, 187

Rundbasis 53, 190

Bogen 14, 21, 38 f., 45, 47, 62, 80, 176, 205, 208, 216 Keilsteinbogen 17, 20, 38, 45, 59, 62, 80, 176, 216, 218, $234 \mathrm{f}$.

Dach 25, 30, $60 \mathrm{f}$.

-stuhl 60-62, 233

-ziegel 69

Giebel 22, 60 f., 191, 193, 233

Ortgang 31, 60

Pultdach 31, 60

Satteldach 19, 60

Walmdach 60 f., 233

Dübel 32, 34, 36 f., 40, 52 f., 192, 206

-loch 32, 36, 38, 40, 48-54, 176, 188-190, 192, 196, 206, $208 \mathrm{f}$.

Kantendübel 32, 34, 49, 53, 193

Eckkonflikt 34, 60

Euthynterie 26, 31 f., 64

Fenster 44, 47, 62, 177-179

Fries 21, 31, 34, 49, 57, 60 f., 79, 181, 190, 193-196

Metopen-Triglyphen-Fries 12, 17, 20, 33-35, 49, 57, 60, 180, 214

Geison 20, 33 f., 40, 50, 57, 60 f., 178, 181, 189 f., 193, 195,214

Horizontalgeison 12, 17, 33 f., 49 f., 60, 62, 214

Zahnschnittgeison 53, 61, 190

Gesims 32 f., 37-39, 52, 176 f.

Gerüst 58, 70

Rüstloch 38, 43-47

Gewölbe 44, 46, 219, 228

Korbbogentonne 47

Tonnengewölbe 44-46, 220, 228
Gusskanal 36, 38, 40, 48, 50-54, 193

Interkolumnium 13, 34, 57, 178

Joch 19 f., 22, 31, 34, 49, 57, 59 f., 180, 191, 194 f., 233

Kämpfer 44 f., 54, 61, 188, 194

Kapitell 10 f., 17, 20, 34 f., 40, 48 f., 51, 54, 57-59, 61 f., 80, 180, 182-185, 187-190, 192, 194-196

Antenkapitell 194

Blattkelchkapitell 192

dorisch 12, 48 f., 53, 61 f., 180, 187, 192, 196, 228

Kompositkapitell 10 f., 26, 40, 51, 80, 182-184, 234

korinthisch 26, 54, 80, 183-185, 188-190, 192

Pfeilerkapitell 183-185, $188 \mathrm{f} ., 194 \mathrm{f}$.

Pilasterkapitell 54, $188 \mathrm{f}$.

tuskanisch 54, 187

Klammer 34, 49, 80, 176 f., 180, 188

-loch 38, 40, 42, 48 f., 54, 176 f., 188

U-Eisenklammer 32, 34, 37, $49 \mathrm{f}$.

Metope 33 f., 49, 57, 60, 180, 193-196

Orthostat 32 f., 36-38, 176 f., 191

Pfeiler 13, 20, 39, 41, 44-47, 53, 73, 182 f., 185, 194, 196

Plinthe 31, 44, 50-54, 59, 62, 181 f., 186 f., 204

Sockelplinthe 39, 41, 50 f., 58, 61

Profil 31, 38 f., 50 f., 53, 58, 176, 178 f., 181 f., 186 f., 189-194, $208 \mathrm{f}$.

Rampe 19, 42, 83, 220

Säule 10-14, 19-22, 25, 27, 30 f., 33-36, 39 f., 44, 48-53, 56-60, 79, 176, 178-183, 185-188, 191 f., 194-196, 205, 213, 224, 226 f., 233

-nschaft 9, 11, 39 f., $50 \mathrm{f}$.

-nstuhl 16, 23, 39 f., 50 f., 58, 61 f., 178, 181 f., 186, 234

-ntrommel 10, 18, 20, 25 f., 35 f., 42, 44, 48, 52, 60, 78, 179 f., 186, 195, 228

dorisch 23, 48, 52, 57, 59, 62, 179, 186, 196

Eck-Doppelhalbsäule (〉Herzsäule $<$ f., 16 f., 21-23, 26, 40 f., 50 f., 54, 58 f., 61, 80, 216, 224, 234

ionisch 31, $58 \mathrm{f}$., 205, $224 \mathrm{f}$., 233

Schrankenplatte 15,179

Sima 34, 53, 60, 190, 193, 195

Sitzbank 14, 23, 27, 59, 61, 73, 80, 175, 191, 216 f., 221, 234

Sockel 10, 12-14, 16 f., 20 f., 23, 25, 31-33, 36-39, 41-43, 50-52, 58, 61, 79, 176 f., 188, 191, 196 f., 203, 208 f., $214,216,227$

Soffitte 38, 176, 192-194, 197

Stemmloch 49-51

Stereobat 10, 14, 18 f., 29-32, 63 f., 70

Stylobat 19 f., 29-33, 42, 52, 57, 59 f., 64, 79, 179, 186, $191,195,211,214$

Treppe 13, 29, 42-44, 46, 70, 74, 191, 194, 225, 234

Triglyphe 33 f., 49, 57, 60, 180, 193, 195

Tür 11, 14, 16, 19, 23, 30, 32 f., 36-38, 40-44, 52, 59-62, 
$80,83,175,177-179,191,194,197,203,209,213-216$, $218,220,224,234$

-gewände 37, 177

-konsole 40, 177 f., 189

-laibung 30, 37, 41, 80, 178 f., 216

-rahmen 40, 178

-schwelle 16, 19, 30, 33, 37, 41-44, 177, 220, 229

-sturz 10, 37, 40, 52, 61 f., 80, 177-179

Doppeltür 32

Hyperthyron 40, 178

Wolfsloch 37 f., 40, 49 f., 54, 61, 182, 188

Archiv 3, 5, 214, 220 f., 230, 235 f.

Artemis Ephesia 12, 25 f., 78, 81, 197-202, 204 f., 212, 216-218, 221 f., 236

>Große Artemis< 12 f., 18, 21 f., 32, 59, 77, 79 f., 197 f., 200-202, 205 f., 212, 233

,Kleine Artemis« 12, 197, 202, 204 f., 215

>Schöne Artemisく 11 f., 44, 197 f., 200-202, 204, 215, 220

Athen 1-5, 88 f., 212, 218, 223, 229, 231, $236 \mathrm{f}$.

Bothros 12, 18, 31 f., 212

Bouleuterion 2 f., 10 f., 13, 16, 18-22, 61, 183, 211-214, 216, 218, 220 f., 223, 225, 227-230, 235 f.

Cella 13, 21, 27, 218 f., 221, 224, 235

Delos 3-5, 208, 228 f., 231, 236 f.

Delphi $4 \mathrm{f}$.

Demeter Karpophoros 24 f., 217 f., 220-222, 235 f.

Dionysodoros 25, 79, 234

Dodona 4, 228 f., 231, $236 \mathrm{f}$.

Dreros 3, 5, 229, 231, 236

Ehrenspeisung 1, 4, 6, 21 f., 211, 217 f., 221, 224, 226, 235

Deipnon 4

Sitesis 4

Xenia 4

Ephesos

>Akademiegasse 14 f., 18, 20, 29 f., 42-44, 60, 83, 177, 217, 220

Artemision 24-26, 78, 197-200, 212, 214 f., 221, 235 f.

Banketthaus 20, 217

Basilike Stoa 20 f., 78, 83, 90, 99, 185, 192, 202, 218, 222, 236

Bouleuterion 13, 16, 18-22, 61, 211, 213, 216, 218, 221, 230, 235

Bülbüldağ 22

Byzantinischer Palast s. Sarhoş Hamam

Celsusbibliothek 179, 189, 191, 194

Chalkidikum 13, 185

>Clivus sacer $15,30,80$

Domitiansplatz 190, 195

Domitianstempel 195

Domitiansterrasse 39, 54 f., 181, 196

>Doppelmonument $<17,30,213$

Embolos s. >Kuretenstraße

Hadrianstor 55

Hanghaus 155,90

Hanghaus 2 55, 81, 90-92, 94-97, 100, 176, 182-184, 187-190, 196
Heroon 186, 190

Johannesbasilika 188

\Kuretenhalle< 12, 20, 35, 48, 82, 179, 202, 214, 235

>Kuretenstraße 12 f., 18, 21, 25, 35, 48, 81, 83, 179 f., 186, 190, 201 f., 214

>Lukasgrab< 192

Macellum 9

Marienkirche 101, 192

>Marmorstraße< $191 \mathrm{f}$.

Mazaeus-Mithridates-Tor 182

`Neronische Halle $58,191,194,196$

Oberer >Staatsmarkt $/$ Obere Agora 13, 18, 20, 22, 25, 48, 78, 83, 90, 94, 99, 185, 191-194, 196, 203, 213, 216, 218 f., 221 f., 233, 235

Dorischer Torbau 191, 193 f.

Südhalle 191

Südtor 191

Therme 25

Oktogon 12, 99, 192

Ostgymnasium 184, 190

Panayırdağ 22 f., 56, 214, 219

Peristylhaus über dem Theater 9

Prozessionsstraße 192, 196

Rhodisches Peristyl 192

Sarhoş Hamam 185, 188, 192

Scholastikiatherme 11-13, 15, 20 f., 23, 35, 48 f., 82, 201, 214, 235

Serapeion 189

Stadion 9

,Südliches Hafentor` $184 \mathrm{f}$.

Temenos 17, 30, 61, 67, 80, 178, 213 f., 218, 222, 236

Tetragonos Agora 12, 94, 97, 184, 191 f., 195 f.

Theater 9, 192 f., 195 f., 217

Theatergymnasium 9

Theaterplatz 12

Variusbad s. Scholastikiatherme

Vediusgymnasium 81, 100, 183, $189 \mathrm{f}$.

Verulanushallen 9

Erdbeben 79, 81 f., 188, 201 f., 227, 234

Granit 33, 40, 51, 182

Heiliges Feuer 2, 6, 10, 13, 24, 81, 211, 215, 217 f., 221, 234-236

Herakleia/Latmos 223, 229, 236

Herd/Hestia 1 f., 5 f., 10, 13, 23, 27, 78, 81, 211, 217 f., 221, 224-227, 229-231, 234-236,

Hestia Boulaia 2 f., 5-7, 10, 13, 21-25, 27, 178, 197 f., 211-213, 217 f., 221, 223 f., 227, 230 f., 233, 235 f.

Inschrift 9 f., 13 f., 18, 20-25, 31, 33, 35, 37-39, 48 f., 52 f., 59, 70, 78-80, 108, 178 f., 184, 194, 196, 198, 203, 207 f., 211, 214-216, 221-229, 233-236

Kureteninschrift 12, 20, 23 f., 33, 35, 37, 78, 177, 180, 214 f., 220

Kuretenliste 11 f., 19, 24, 35, 180, 214 f.

Kaiserkult 218, 222, 236

Kassope 4 f., 7, 228-231, 236 f.

Keramik

Amphore 85, 87-91, 95, 97 f., 100-102, 108, 130 f., 
152-158, 161, 164, 167 f., 170 f.

Applikenware 90 f., 164

African Red Slip Ware (ARS) 85, 87, 101, 162

Dünnwandige Keramik 88-91, 95 f., 99-102, 131, 160-163, 169

Eastern Sigillata A (ESA) 85, 87-92, 96, 99, 101, 108-110, 164

Eastern Sigillata B (ESB) 85, 87, 90-92, 96, 99 f., 102, 110 f., 162, 169

Eastern Sigillata C (ESC) 87, 90-92, 100, 111, 161, 169

Ephesian Red Slip Ware (ERSW) 87, 101, 163

Feinware 87-91, 101, 103

Gebrauchskeramik 14, 87 f., 90 f., 96, 99, 102, 106 f., 125, $131-145,155,157,159-161,163,166-171$

Glanztonware 87-96, 99, 101-106, 113 f., 116-130, 160, 164-166, 169

Graue Ware 89-91, 93, 111-113, 116, 160

Italische Sigillata (ITS) 87, 90-92, 96, 99 f., 102, 108, 160, 169

Küchenware 87-91, 97, 99, 101 f., 107 f., 145-152, 161, 163 f., 167 f., $170 \mathrm{f}$.

Lampe 11, 90 f., 94, 98-102, 158 f., 161 f., 164, 171 f.

Late Roman C-Ware (LRC) 85, 87, 100 f., $162 \mathrm{f}$.

Mäandertalsigillata 85, 87, 90, 102, 171

Reliefkeramik 115 f., 158 f., 161 f., 164 f., 171 f.

Weißgrundige Keramik 88-91, 95, 99, 130 f., 160

Westabhangnachfolge 90 f., 93 f., 117 f., 129, 160

Kline 18, 23, 213, 217, 224, 230, 236

Kolophon 5, 173, 223 f., 229, 236

Kore 21, 24, 217, 221, 235

Küche 6, 217, 230 f., 236

Kultraum s. Cella

Kureten 10, 21, 23 f., 31, 203, 208, 214 f., 221 f., 233, 235 f. -synedrion 11, 24, 214 f., 220 f., 235

Labraunda 22, 213

Lato 3, 5, 21, 217, $228 \mathrm{f}$., 231, $236 \mathrm{f}$.

Leto 23, 214, 221

Magnesia/Mäander 3, 5, 223 f., 229-231, 236 f.

Marmor 11-14, 16-19, 23, 30-33, 36-44, 46, 48-54, 60-62, 70, 74, 79, 175-179, 181 f., 189, 195, 204-209, 212, 214-216, 220, 228, 234

-plattenpaviment 13-17, 23, 25, 39 f., 45, 67, 70-73, 79, 175,216

-wandverkleidung 14, 37, 39, 176, 189, 216, 220, 234

Mauerwerk

opus caementicium 17, 30, 46

opus rusticum 32

opus testaceum $37,41-43,47,80,176$

opus vittatum 37-39, 41, 43, 79 f., 176

Metrologie 55

Milet 6, 98, 193, 223, 225 f., 229-231, 236 f.

Mörtel 14, 29, 31 f., 36, 39-47, 52 f., 67, 69-72, 74, 175 f., $227 \mathrm{f}$.

Estrich 15-17, 31 f., 36, 40, 45, 47, 67, 69-72, 74, $175 \mathrm{f}$. opus signinum 31, 36, 38-40, 45-47, 67, 70 f., 74, 175

Putz 30 f., 39-41, 45-47, 67, 74, 83, 177

Vouten $45 \mathrm{f}$.

Morgantina 5, 228

Mosaik 12, 16-19, 32, 36, 41, 59, 80, 175 f., 214, 234
Münze 16, 64, 67, 70, 73, 172, 175, 198

Mysterienspiel 23, 214, 221, 235

Olympia 3-5, 229, 231, 236

Opfer 2, 6, 78, 199 f., 202, 217, 220, 226

Opferassistent/Hierophant 24, 215, 221, 235

Pergamon 4, 6, 93, 95, 223, 226 f., 229, 236

Peristyl 9, 15, 17, 21, 29, 31, 59-61, 79, 175, 182-185, 187 f., 190, 192, 195 f., 203, 211, 213, 224, 227 f., 230 f., 233 f., $236 \mathrm{f}$.

Priene 3-5, 21, 95 f., 223, 227-231, 236 f.

Prytane/Prytanis/Prytanie 2, 4, 6 f., 9, 24 f., 77, 79 f., 211, 213, 215-218, 221, 226, 228-230, 233-236

Ratsversammlung/Boule 3, 81, 215 f., 218

Rekonstruktion 20, 22, 27, 34, 50, 59-62, 175 f., 198, 217, 227

Scholastikia 12 f., 15, 201

Skulptur/Statue 10-14, 21 f., 25 f., 31 f., 77, 79 f., 82 f., 197-205, 207 f., 211-213, 215 f., 222, 224, 227, 233, 236 Porträt $10,203,206 \mathrm{f}$.

Sosipolis 24, 217, 221, 235

Steinmetzzeichen 49, 180, 190

Tessellat s. Mosaik

Theos Kinnaios 24, 217, 221, 235

Triporticus 29-31, 67, 70, 79, 211, 233

Tyche 24, 217, 221, 235

Versatzmarke 32, 38, 40, 49, 53 f., 175 f., 180, 190

Versatzspur 30-32, 59

Volksversammlung/Demos 24, 81, 215, 235

Wandmalerei 41, 177, 220

Wasser 17, 21, 30 f., 44-46, 60, 62, 74, 219, 227

-entnahmestelle 74, 83, 216

-reservoir 39, 45-47, 73 f., 83 f., 216, 219, 222, 234 f.

-speicher 11

-tank 74, 83, 219

Kanal 17 f., 30 f., 44, 60, 67, 69, 102

Regenrinne 17, 30 f., 59, 203, 208

Tonrohr 15, 30 f., 33, 41-43, 46, 64 f., 67, 69 f., 74, 83, 102

Zisterne 11, 21 f., 219

Werkriss 40, 50, 178 

TAFELN 



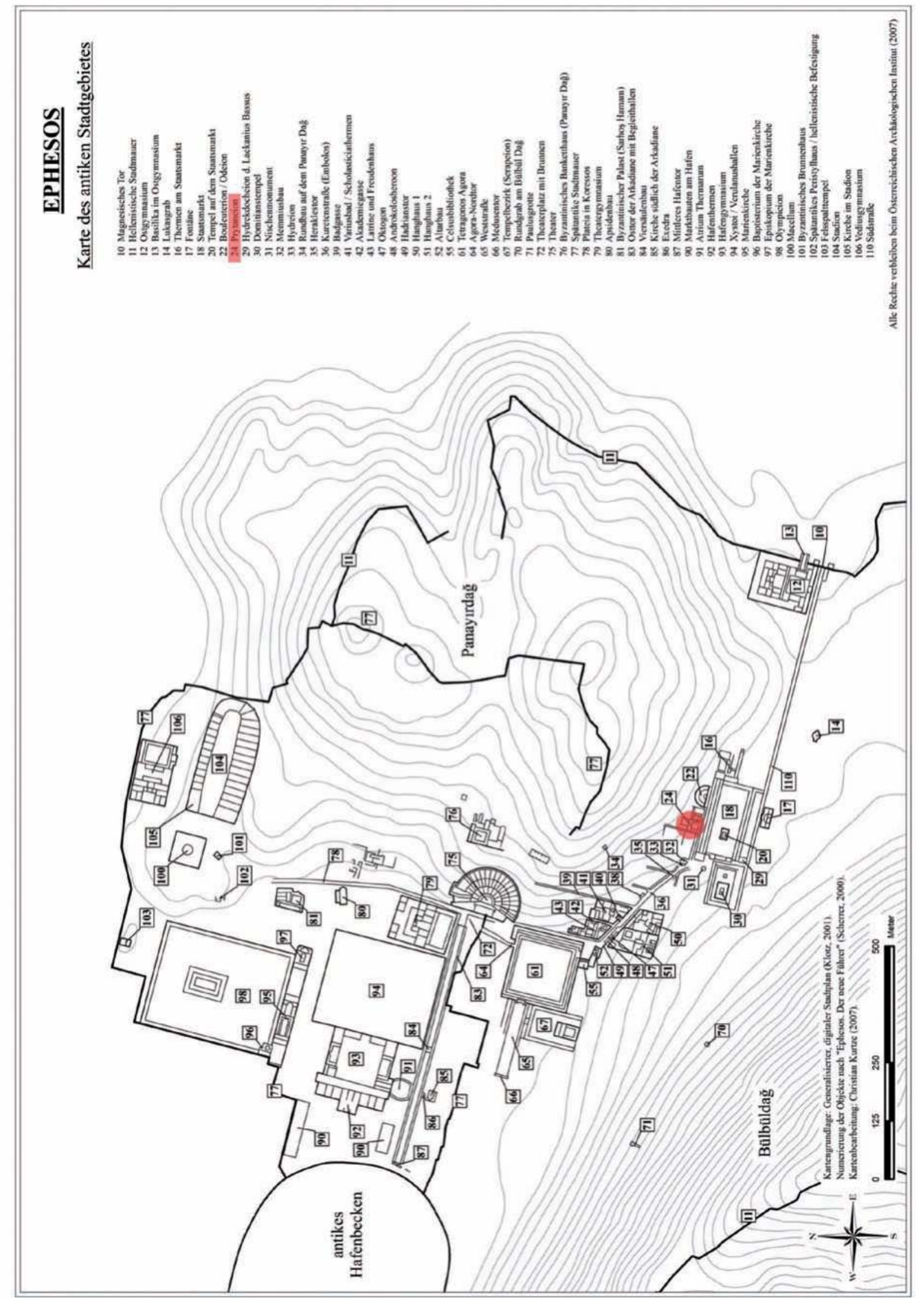

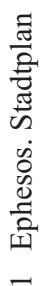




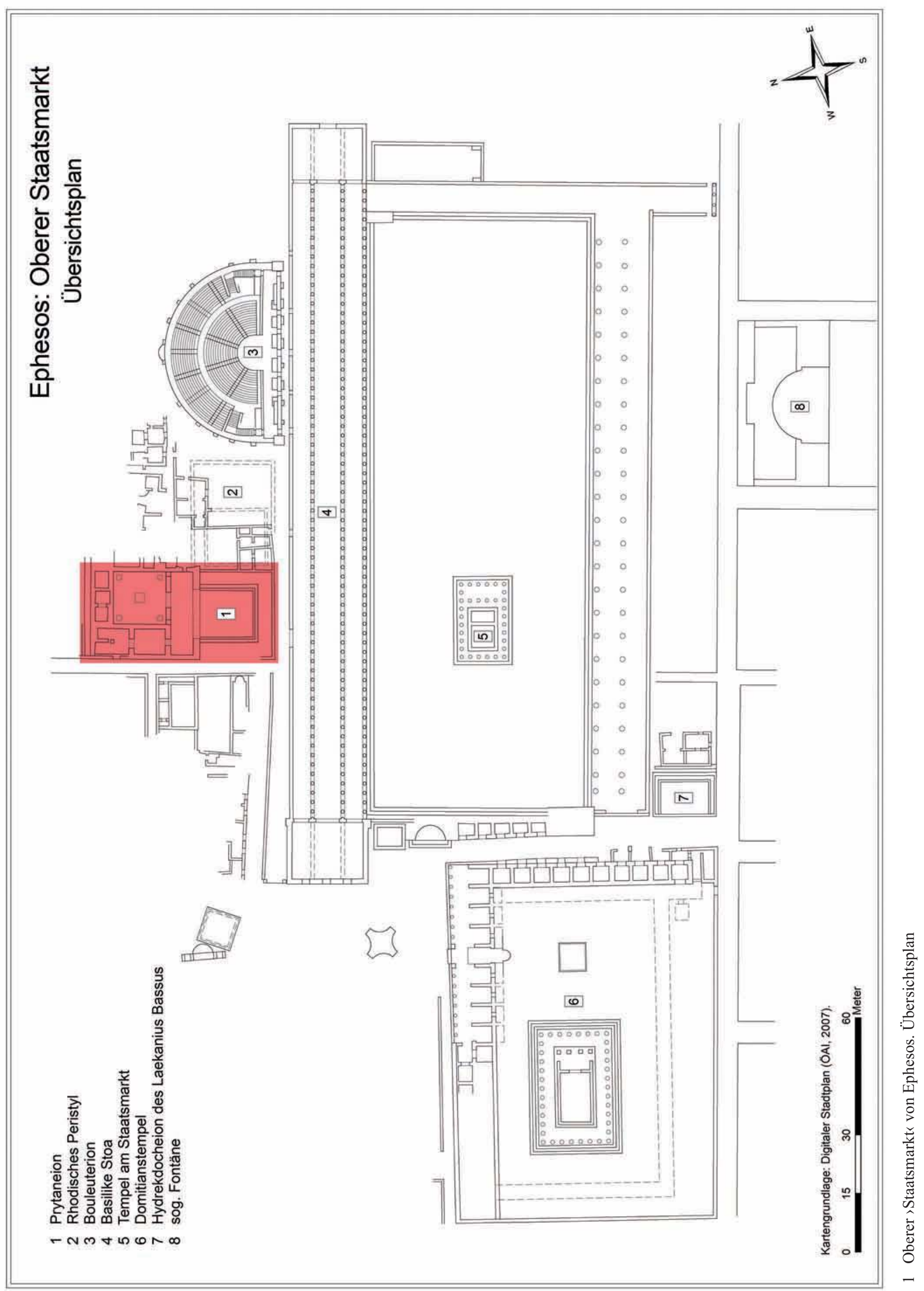


Tafel 3

\section{PRYTANEION}

BAUPHASENPLAN - Erhaltungszustand

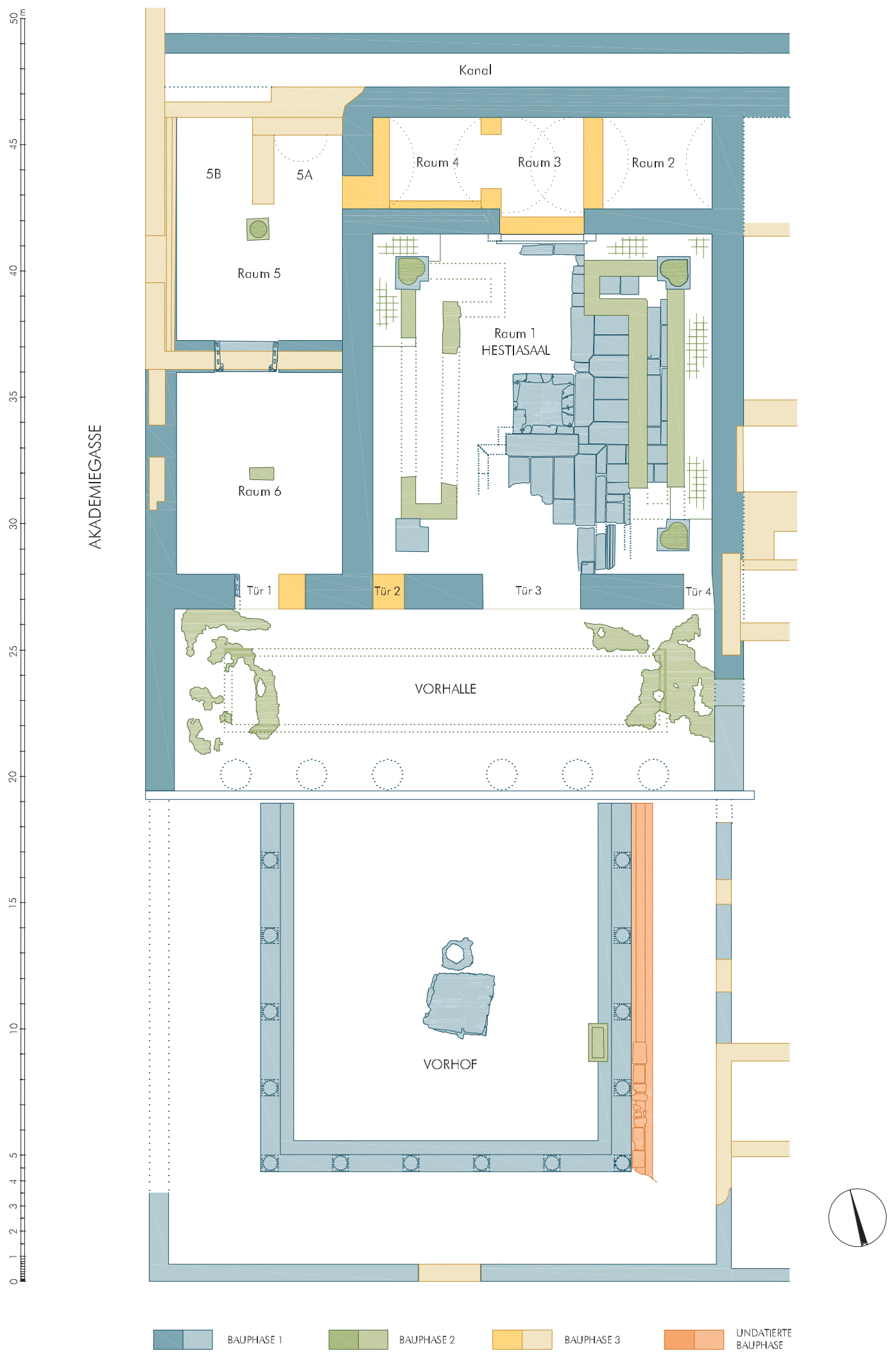

1 Prytaneion. Generalisierter Grundriss mit Raumnummern (1:250) - geschnittene Bauteile dunkel, aufsichtige Bauteile hell 


\section{Tafel 4}

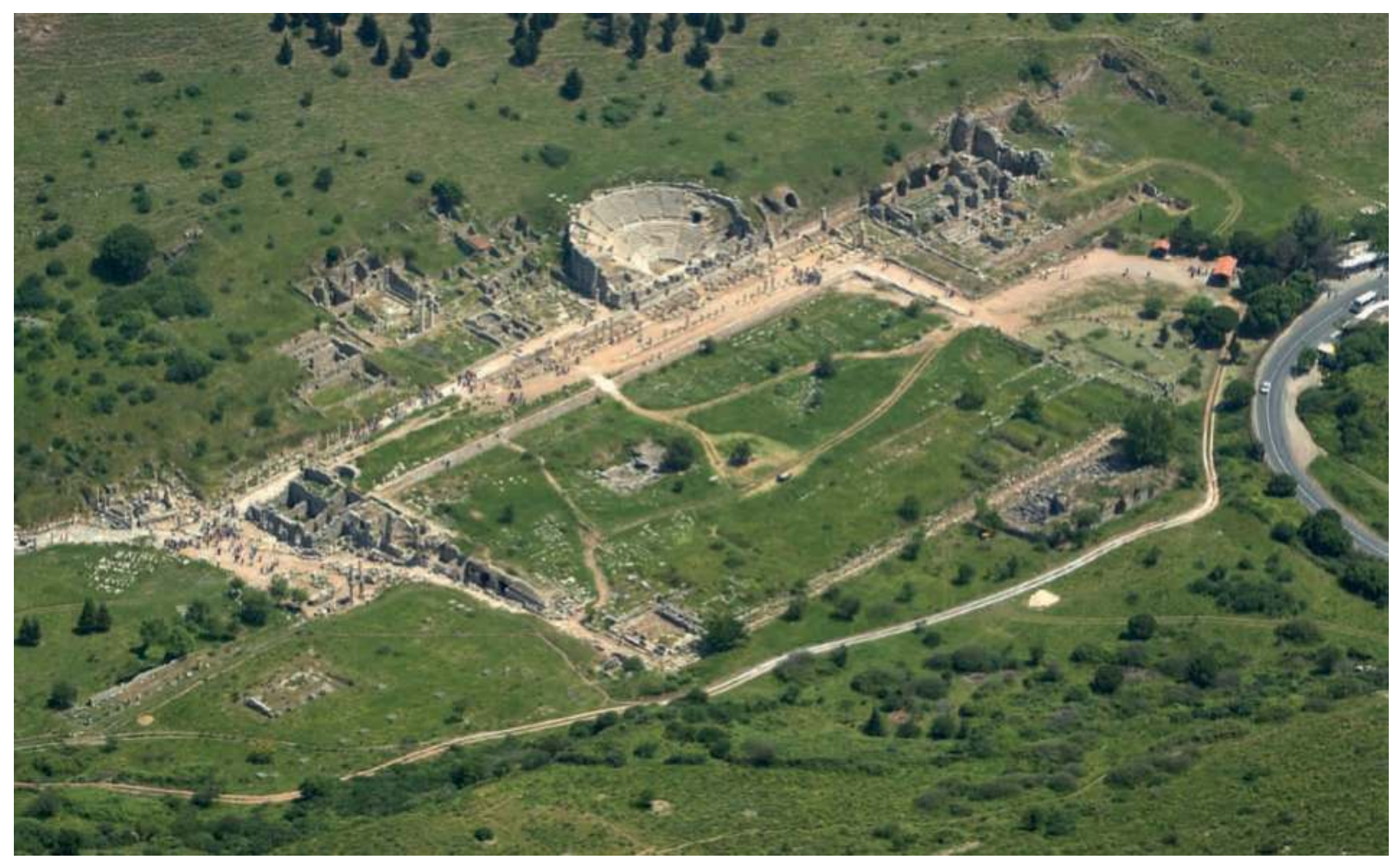

1 Oberer >Staatsmarkt` von Ephesos. Luftbild

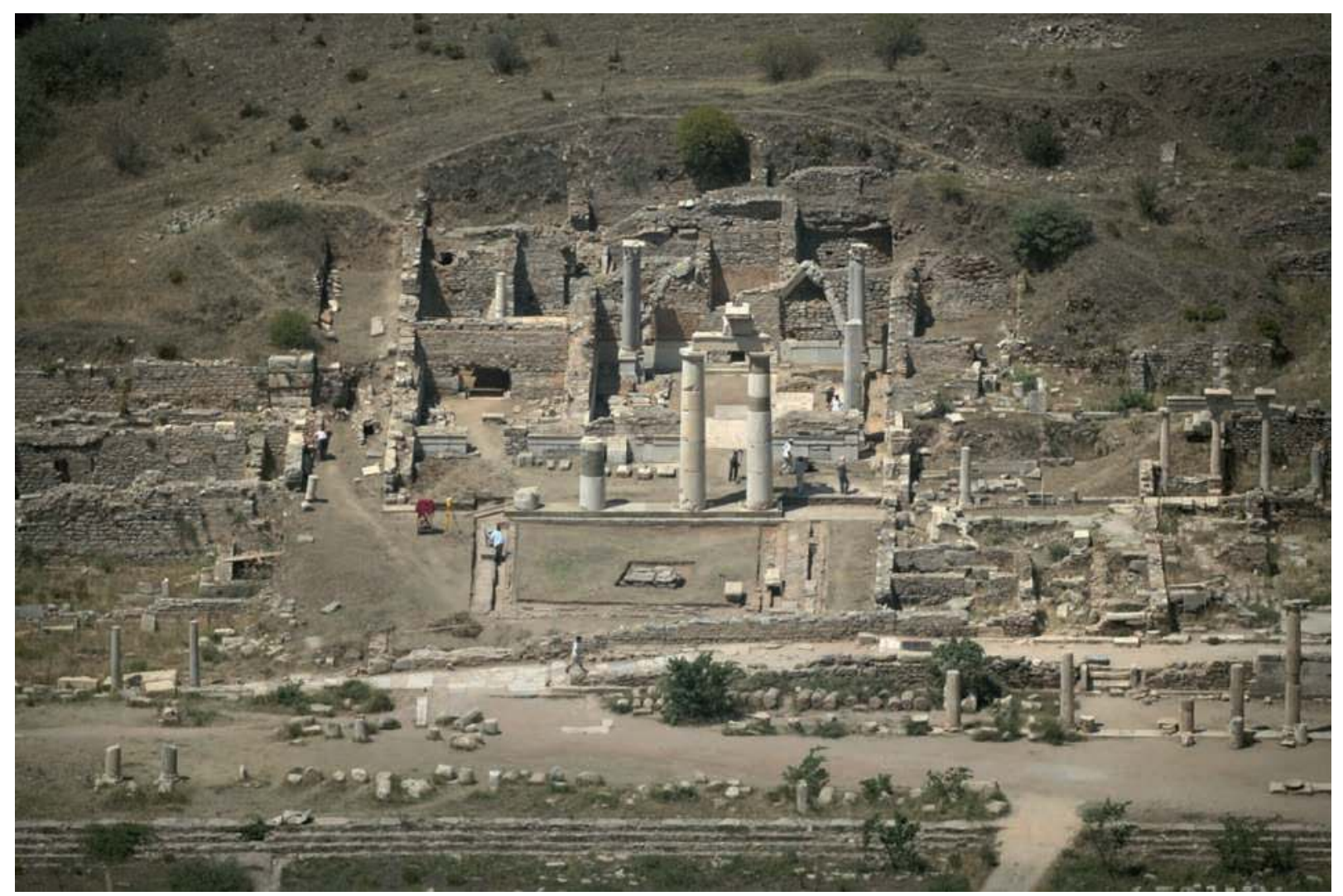

2 Prytaneion. Aufnahme vom Bülbüldağ 
Tafel 5

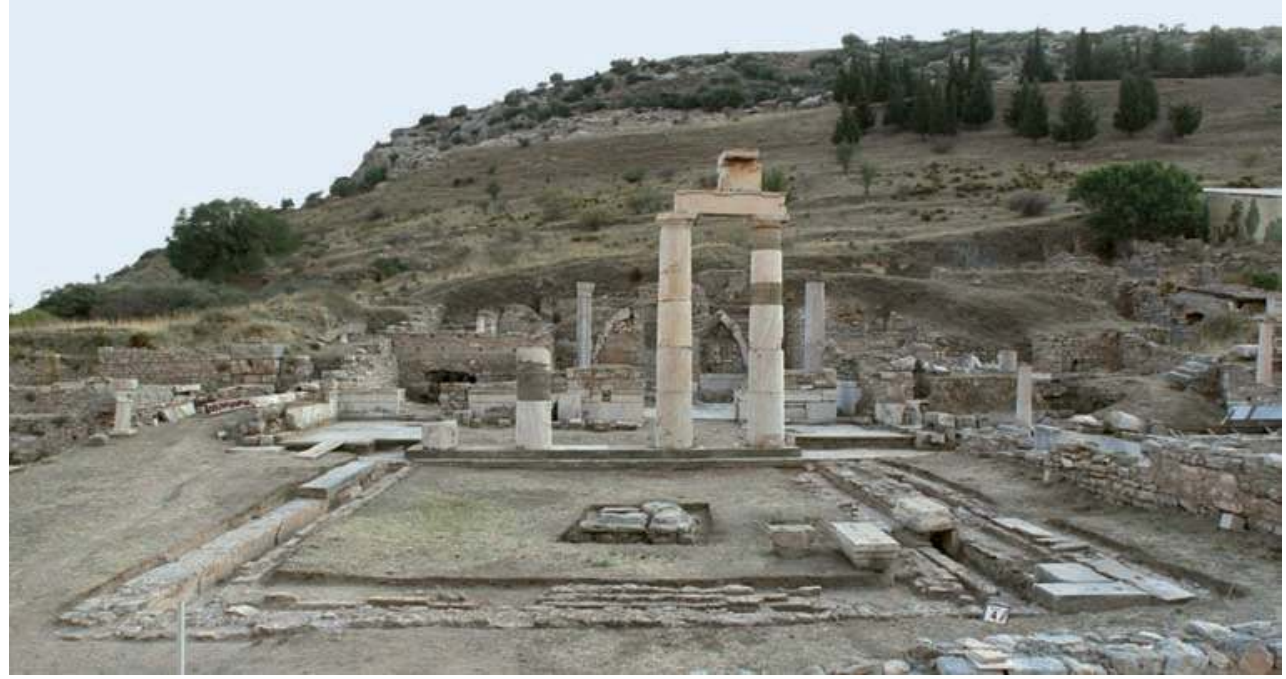

1 Prytaneion von Süden

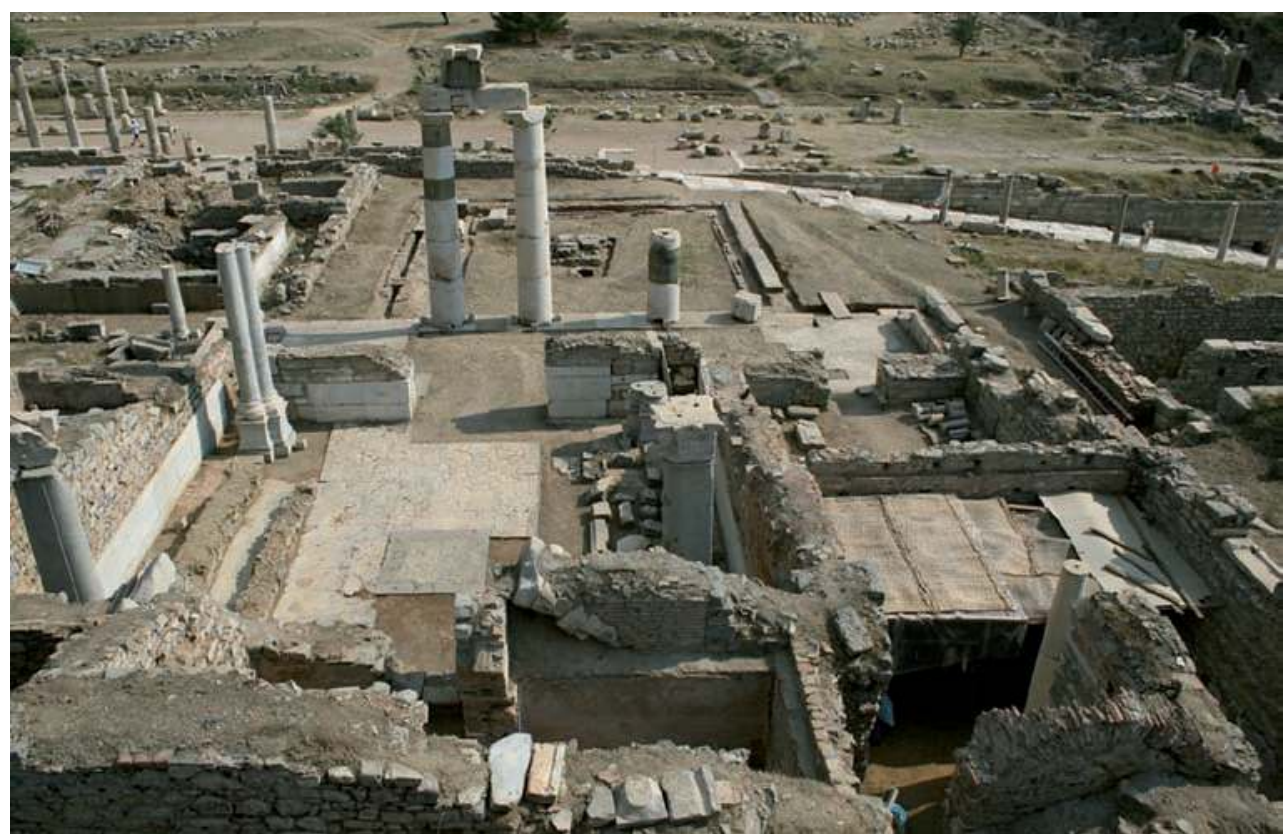

2 Prytaneion von Norden

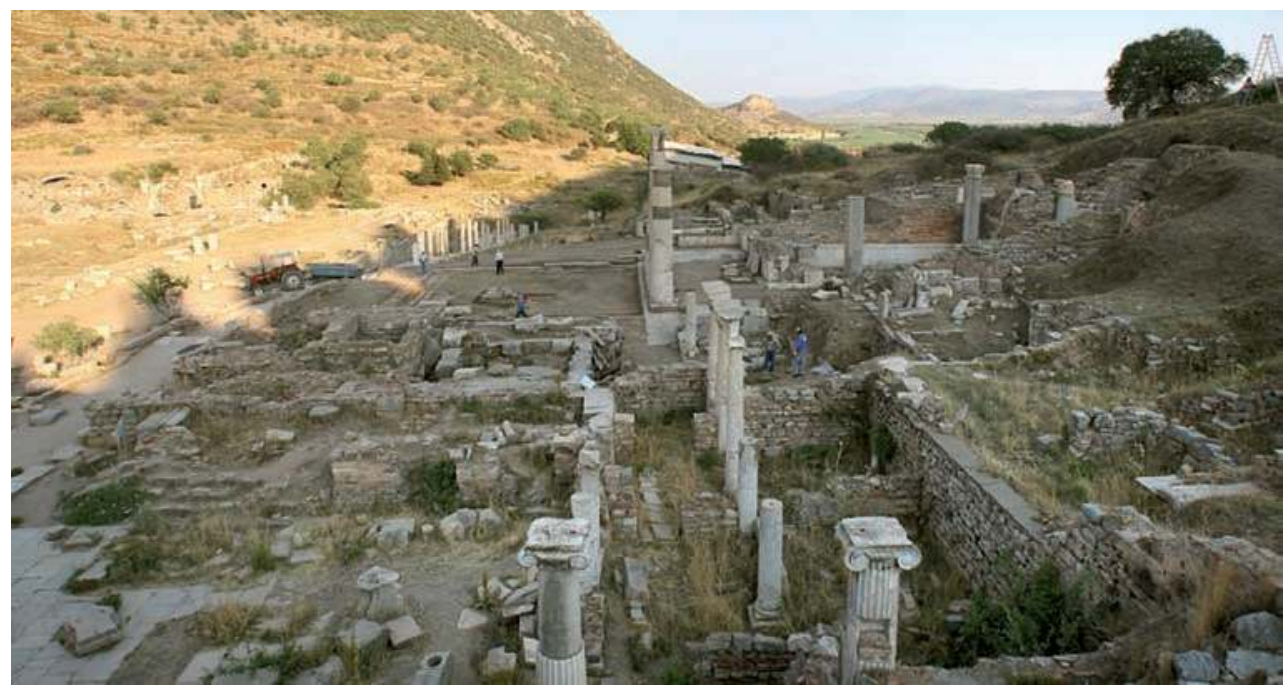

3 Prytaneion von Osten 
Tafel 6
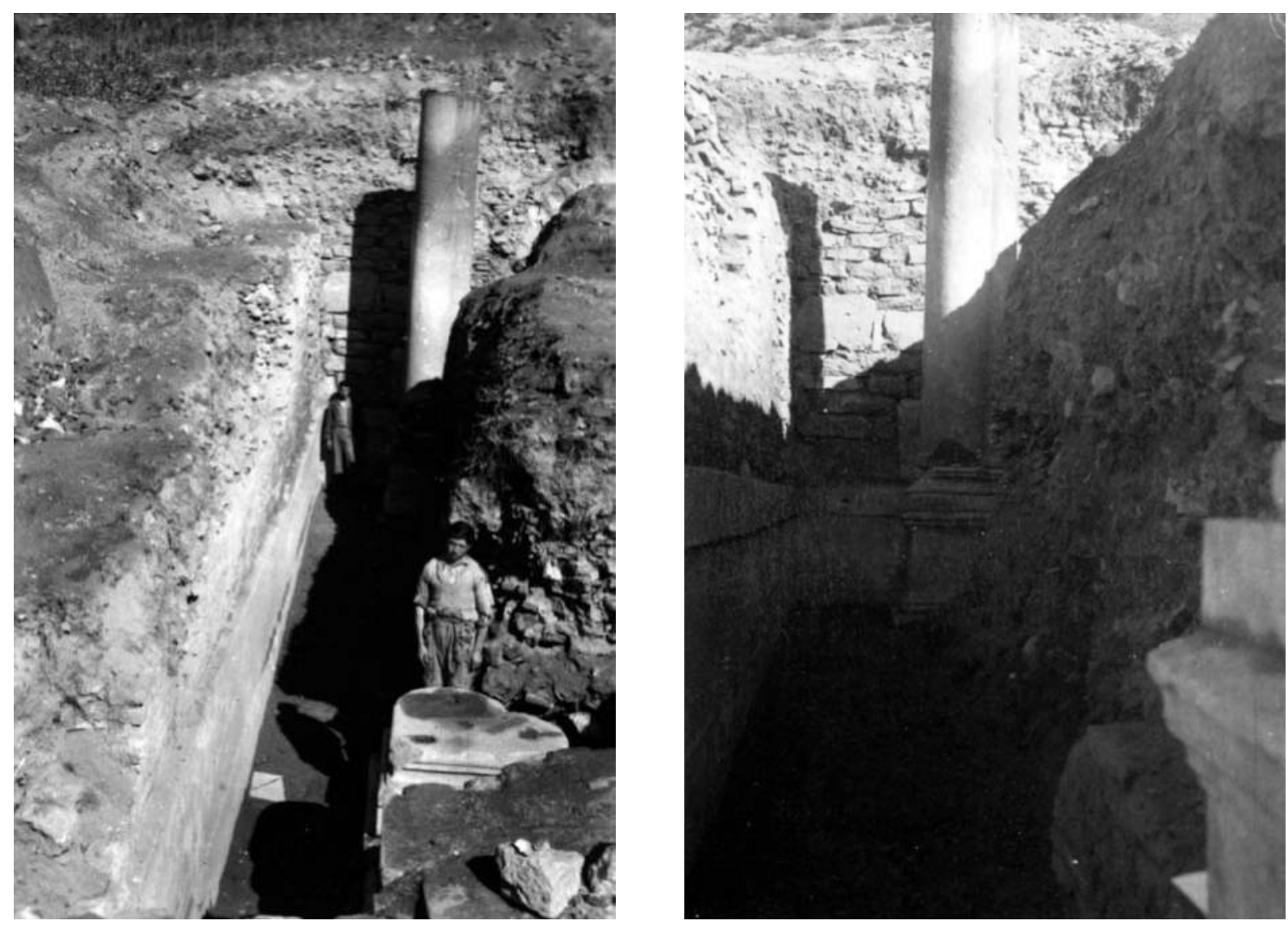

1. 2 Prytaneion 1955. Freilegung des `Hestiasaales` entlang der Westwand

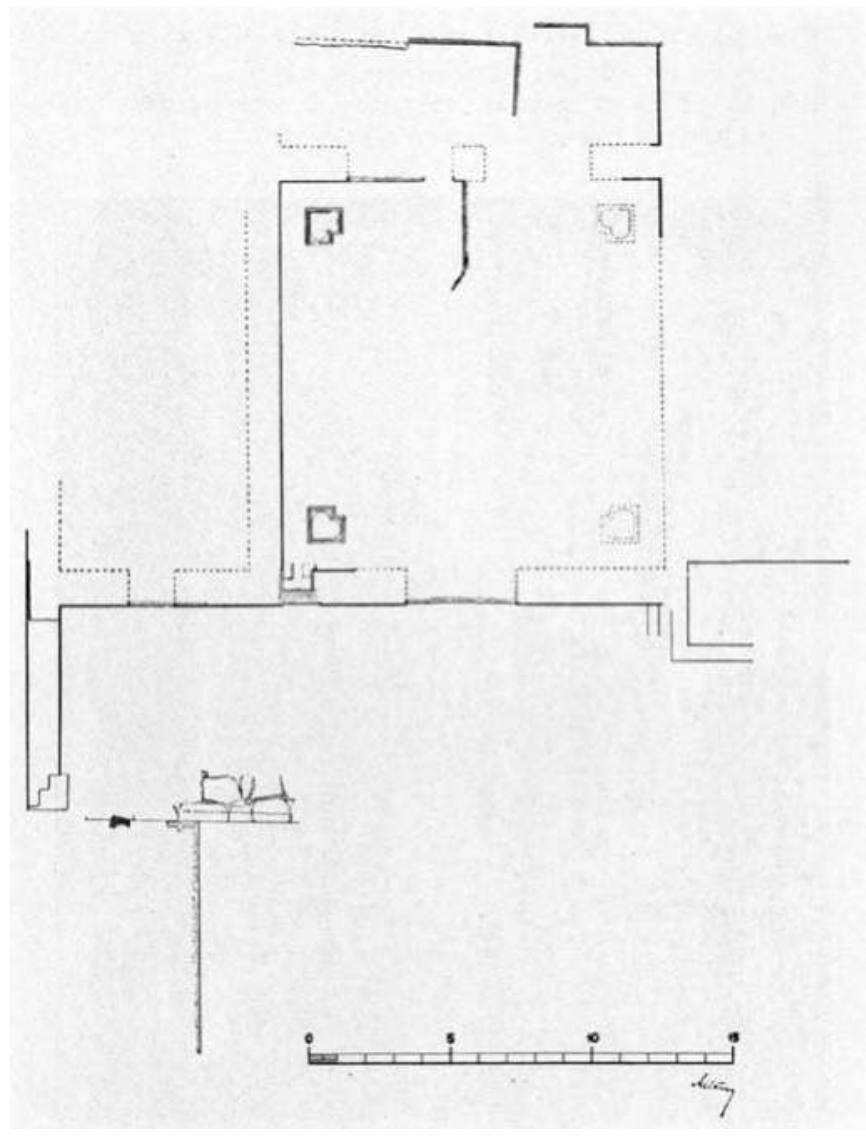

3 Prytaneion 1955.

Grundriss 
Tafel 7

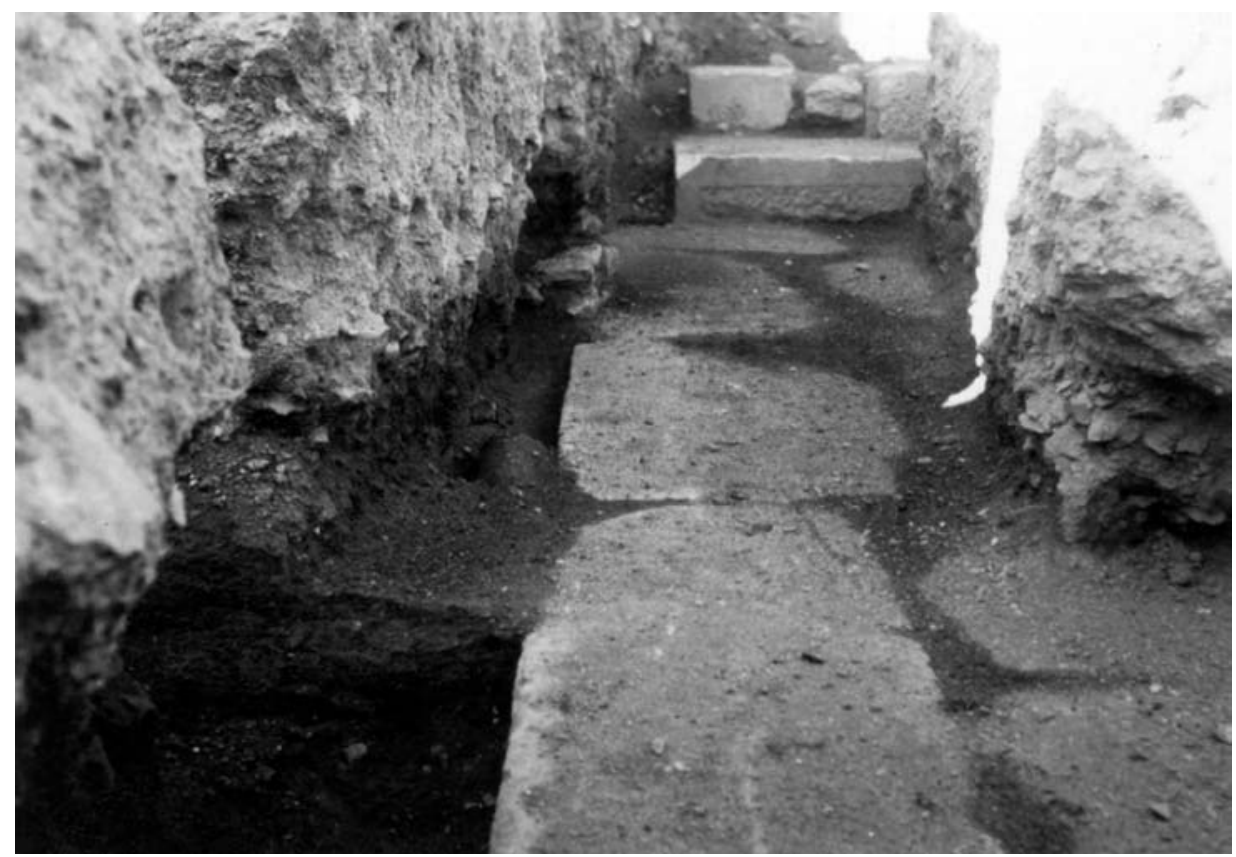

1 Prytaneion 1955. Freilegung des Stereobats der Vorhalle

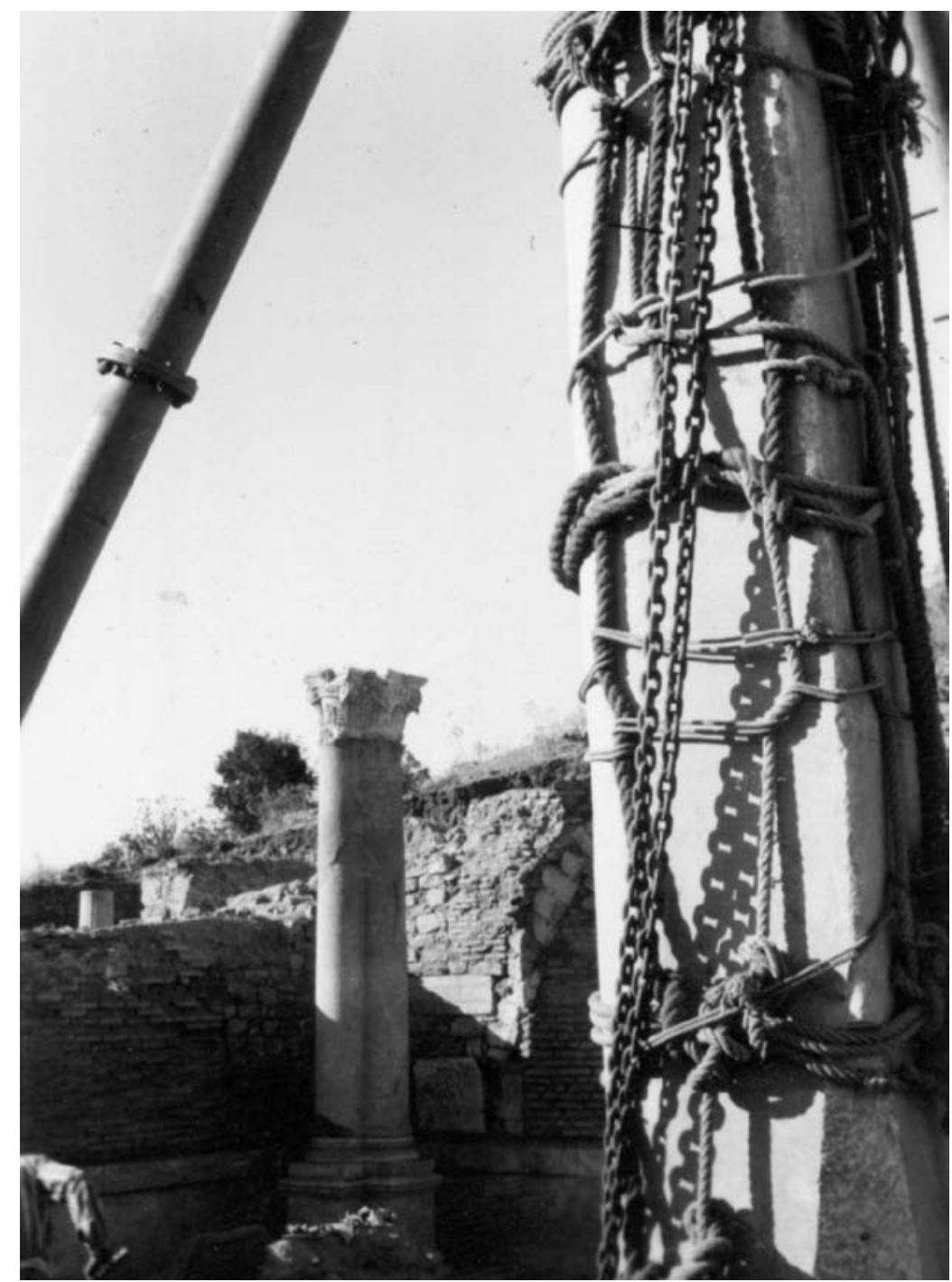

2 Anastylose des südöstlichen Säulenschaftes (A 16) des >Hestiasaales` 
Tafel 8

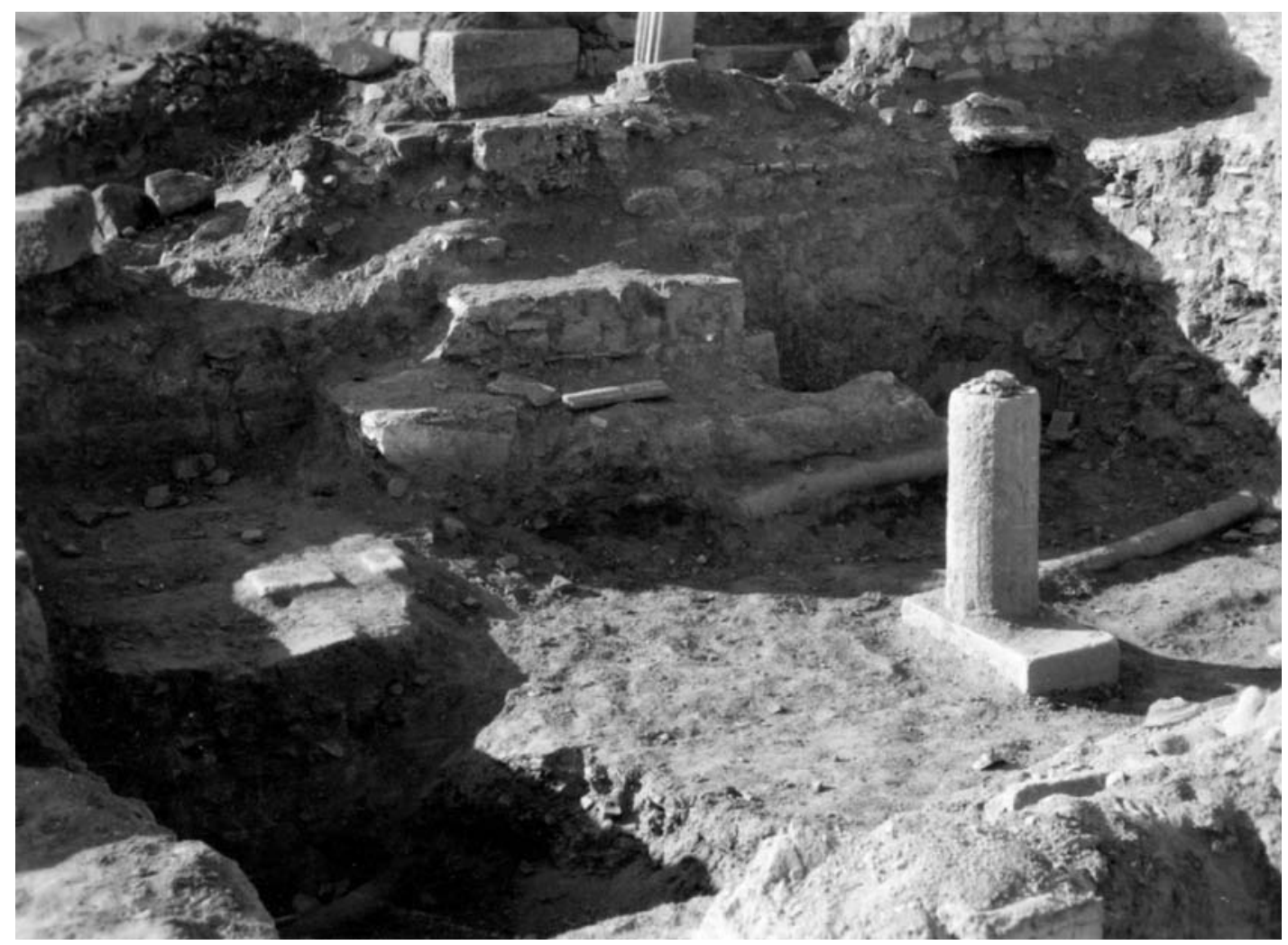

1 Freilegung von Raum 6

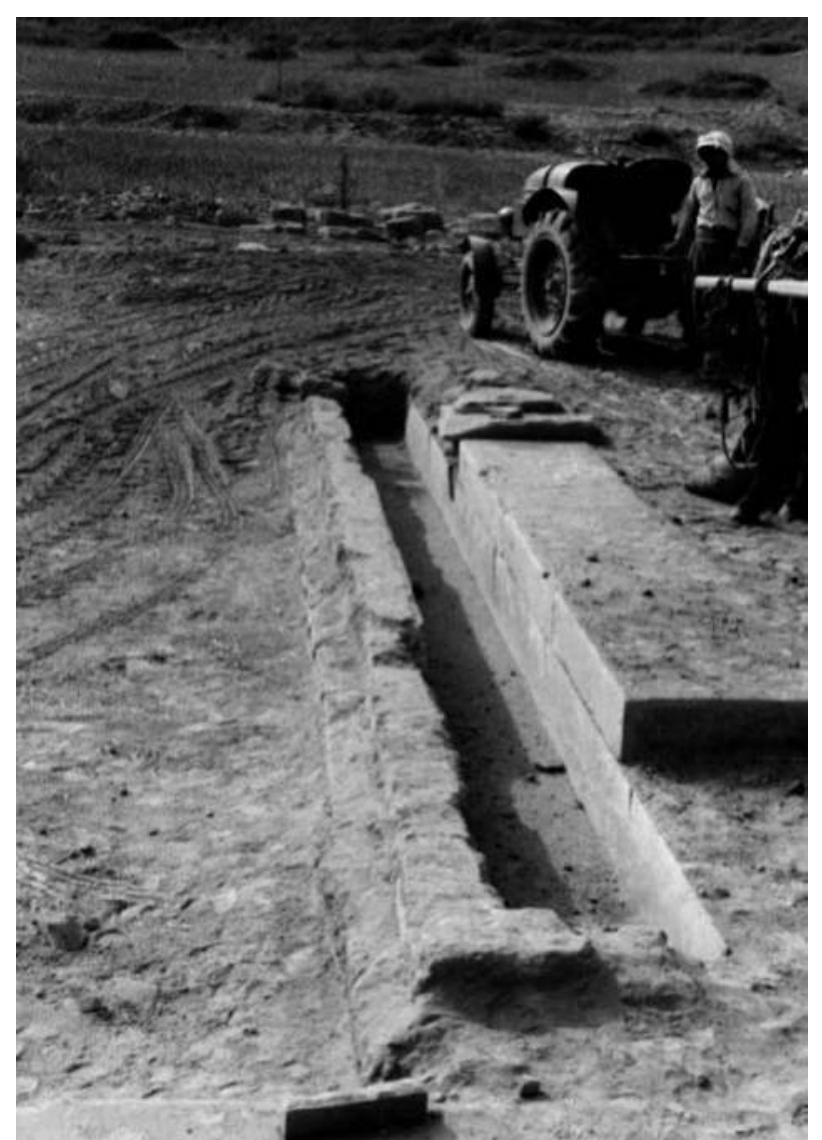

2 Freilegung des westlichen Stylobats des Vorhofes

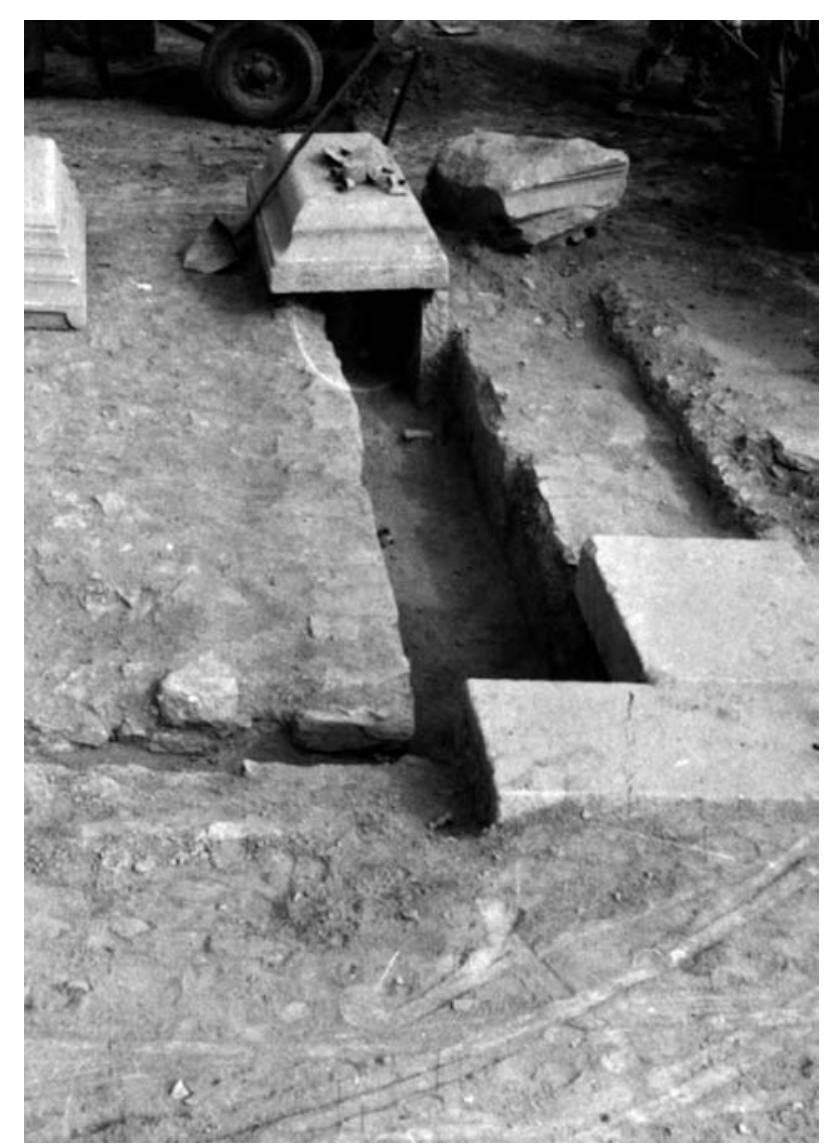

3 Freilegung der Südostecke des Stylobats des Vorhofes 
Tafel 9

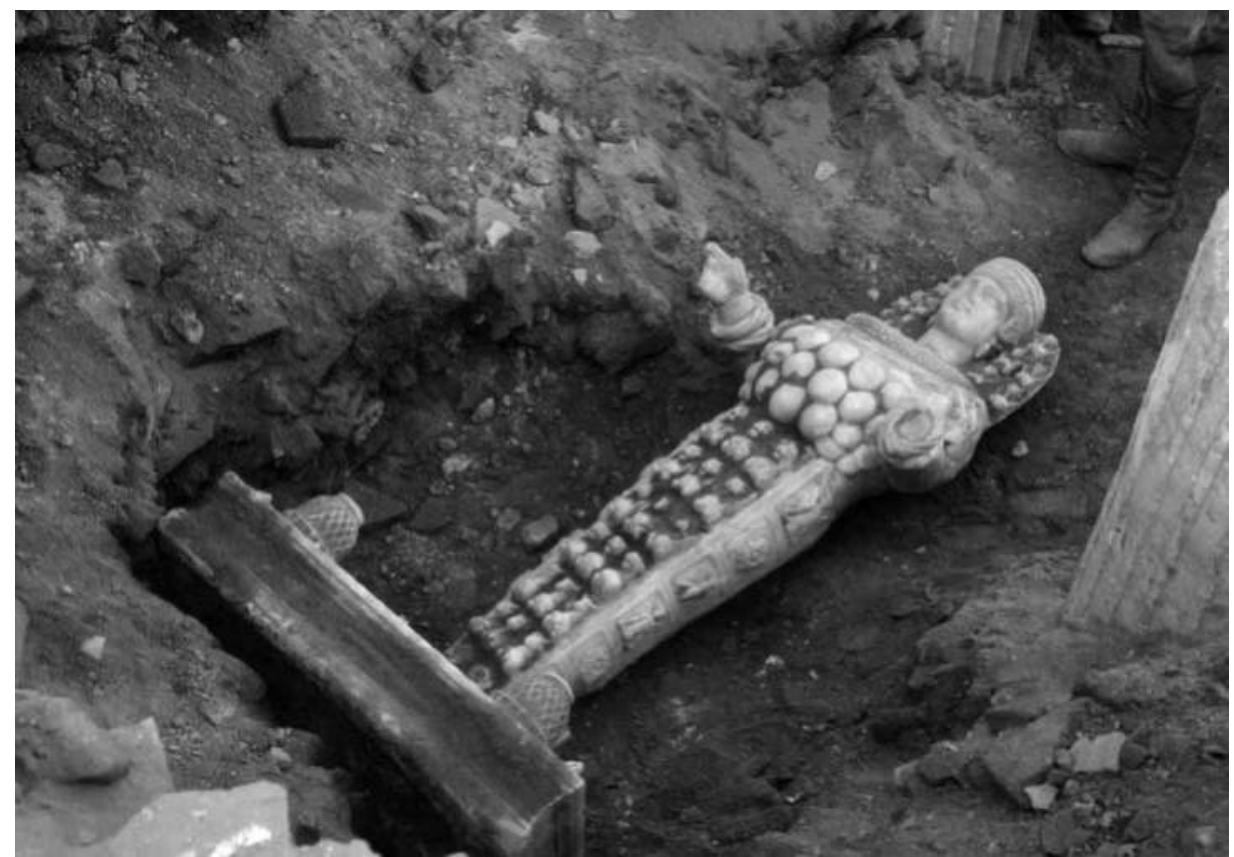

1 >Schöne Artemis $<$ in Fundlage (Raum 5)

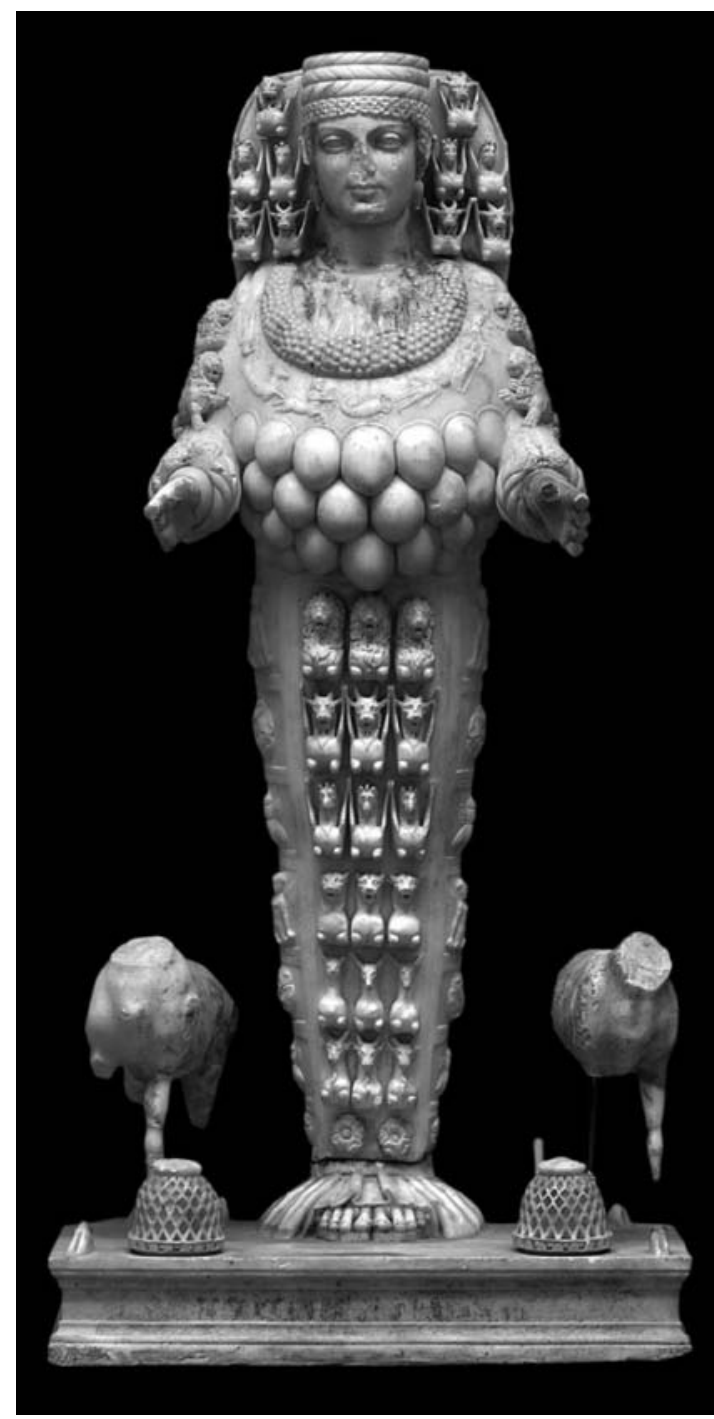

2 >Schöne Artemis` (EM InvNr. 718)

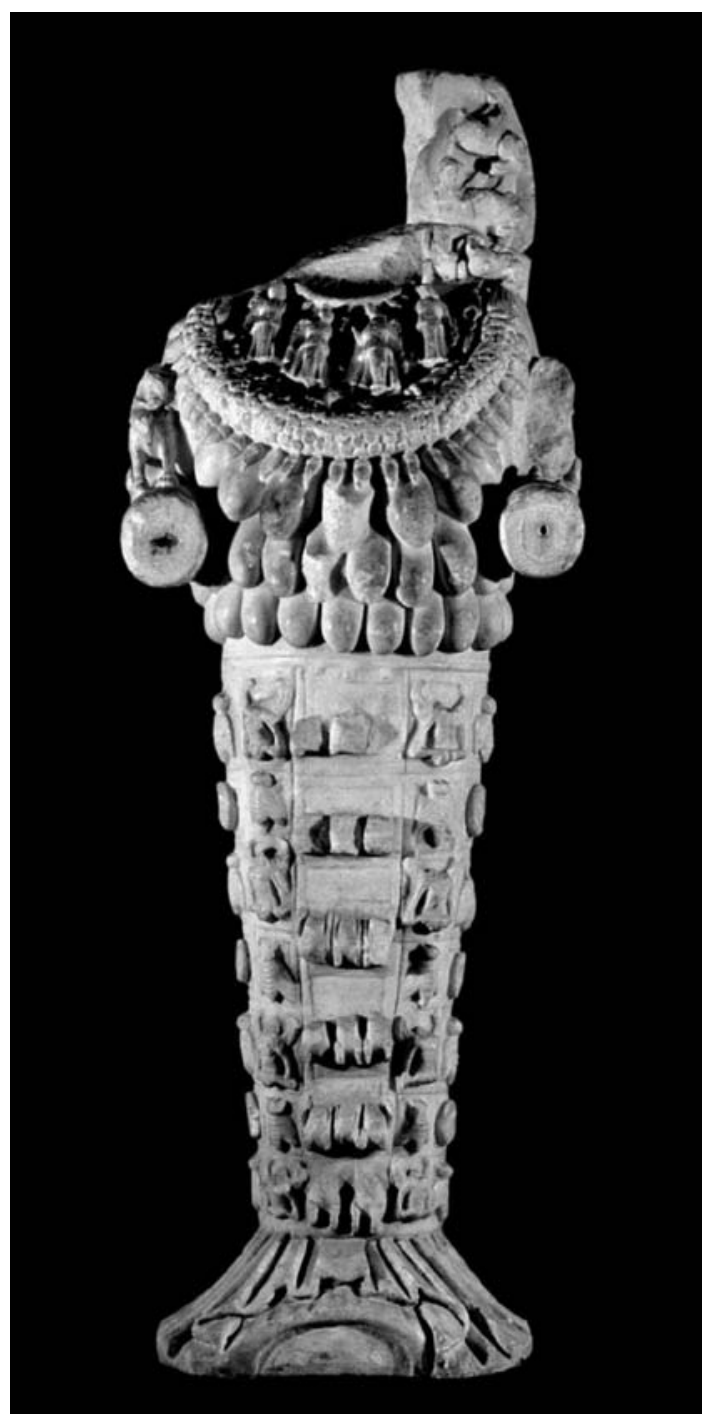

3 ,Kleine Artemis` (EM InvNr. 717) 
Tafel 10

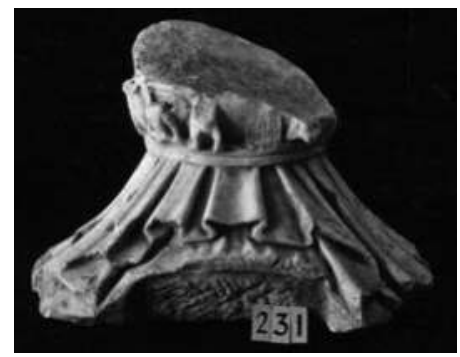

1 Kopie der $>$ Kleinen Artemis (EM 231/56)

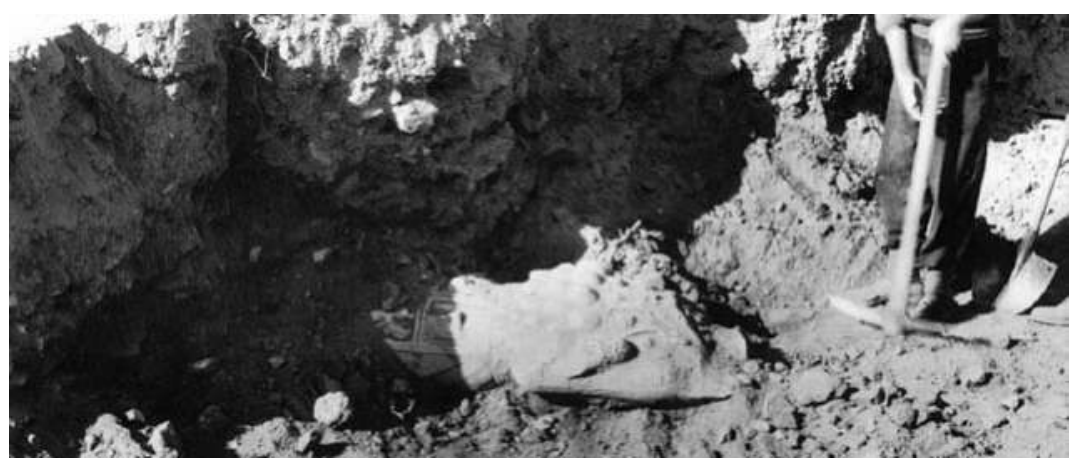

$2>$ Große Artemis $<$ in

Fundlage

(Vorhof)

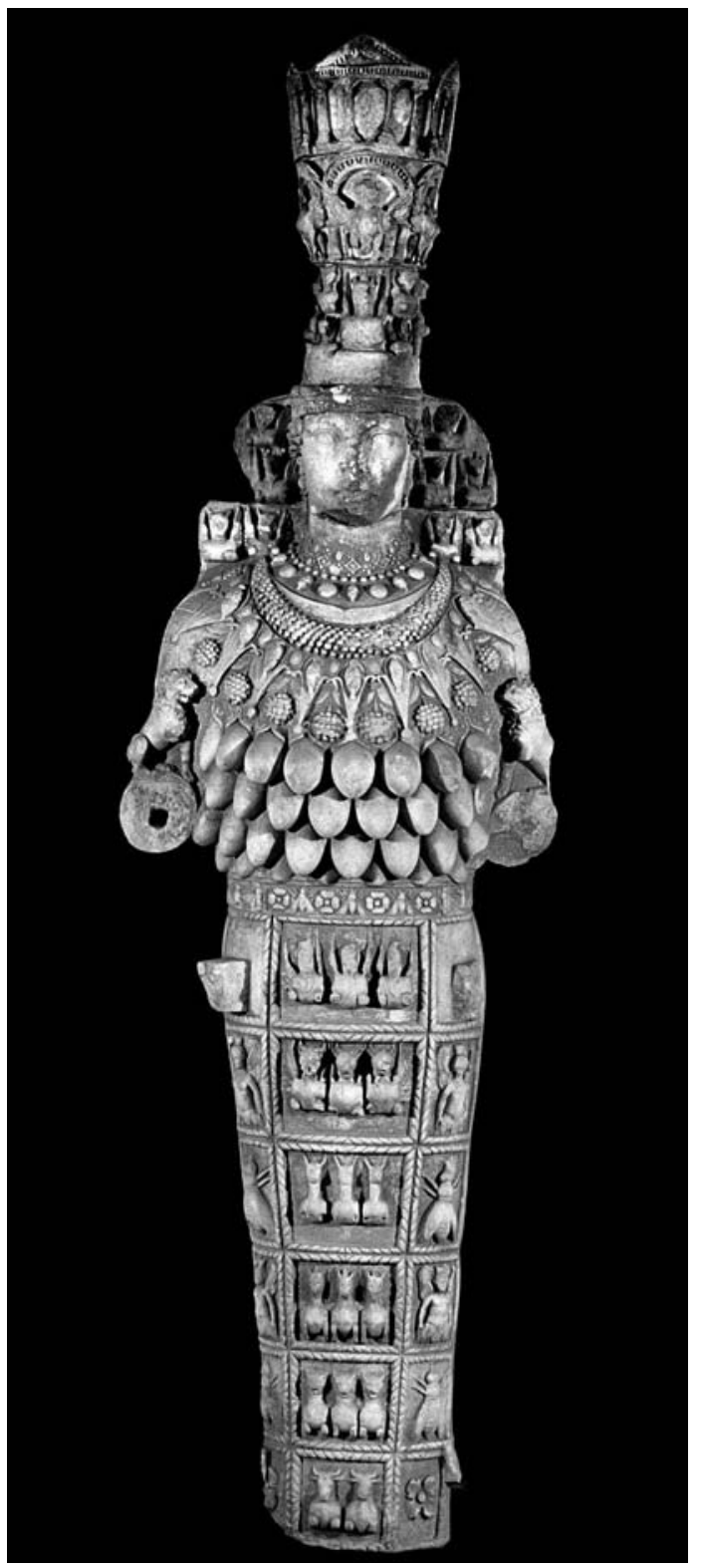

3 , Große Artemis

(EM InvNr. 712) 


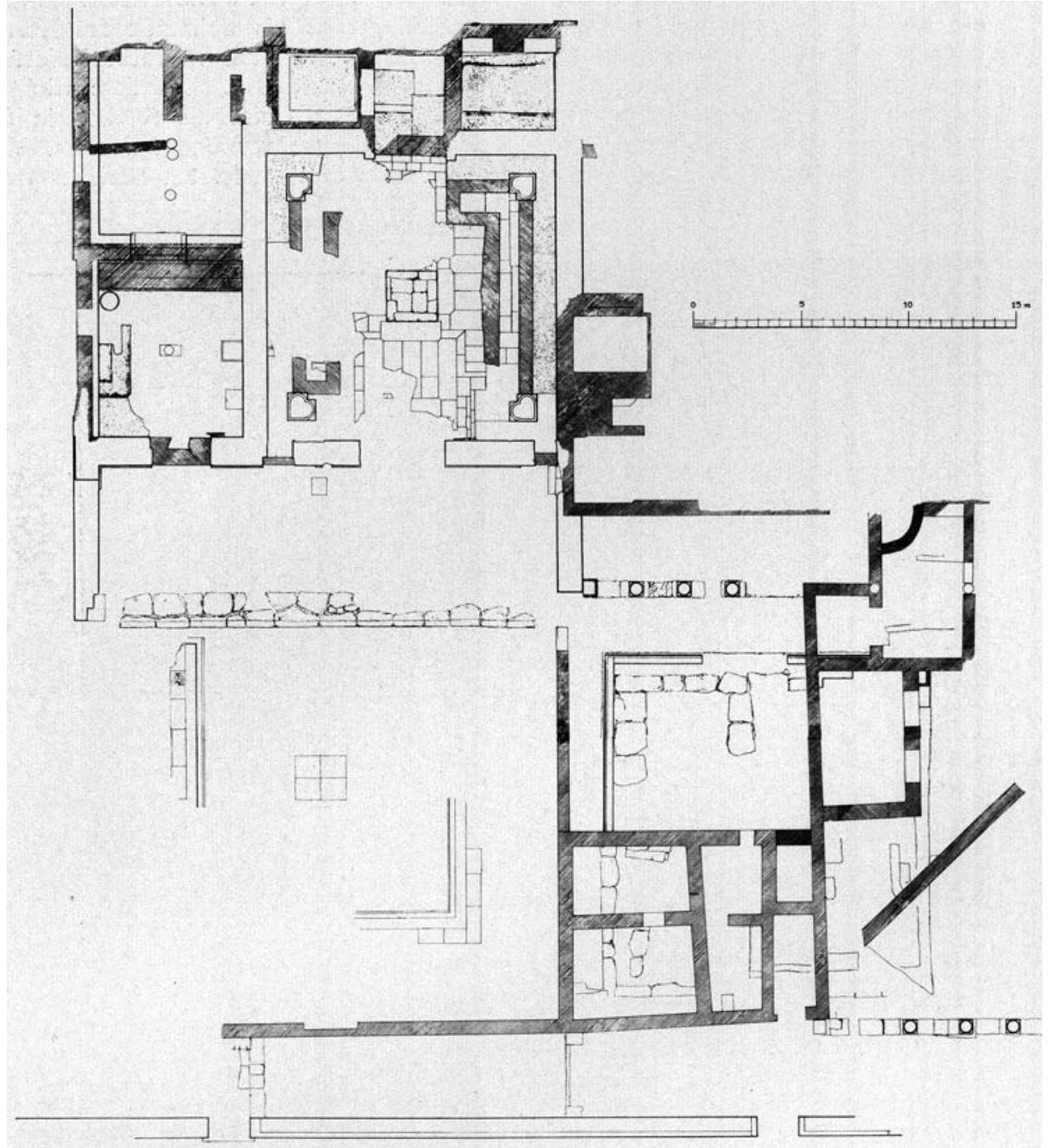

1 Prytaneion 1956. Grundriss

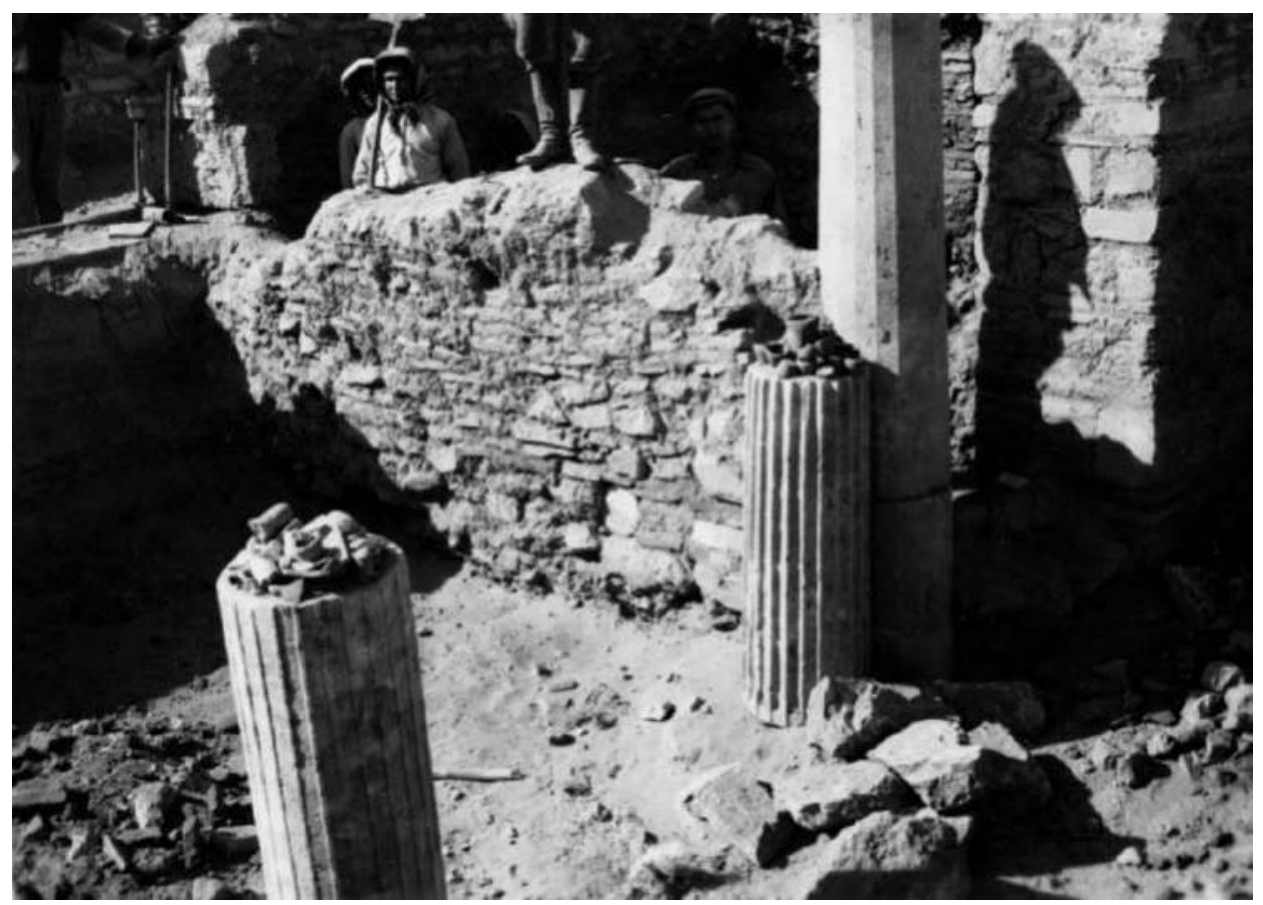

2 Spätantik/byzantinisches Mauerwerk in Raum 5 vor Abtragung 
Tafel 12

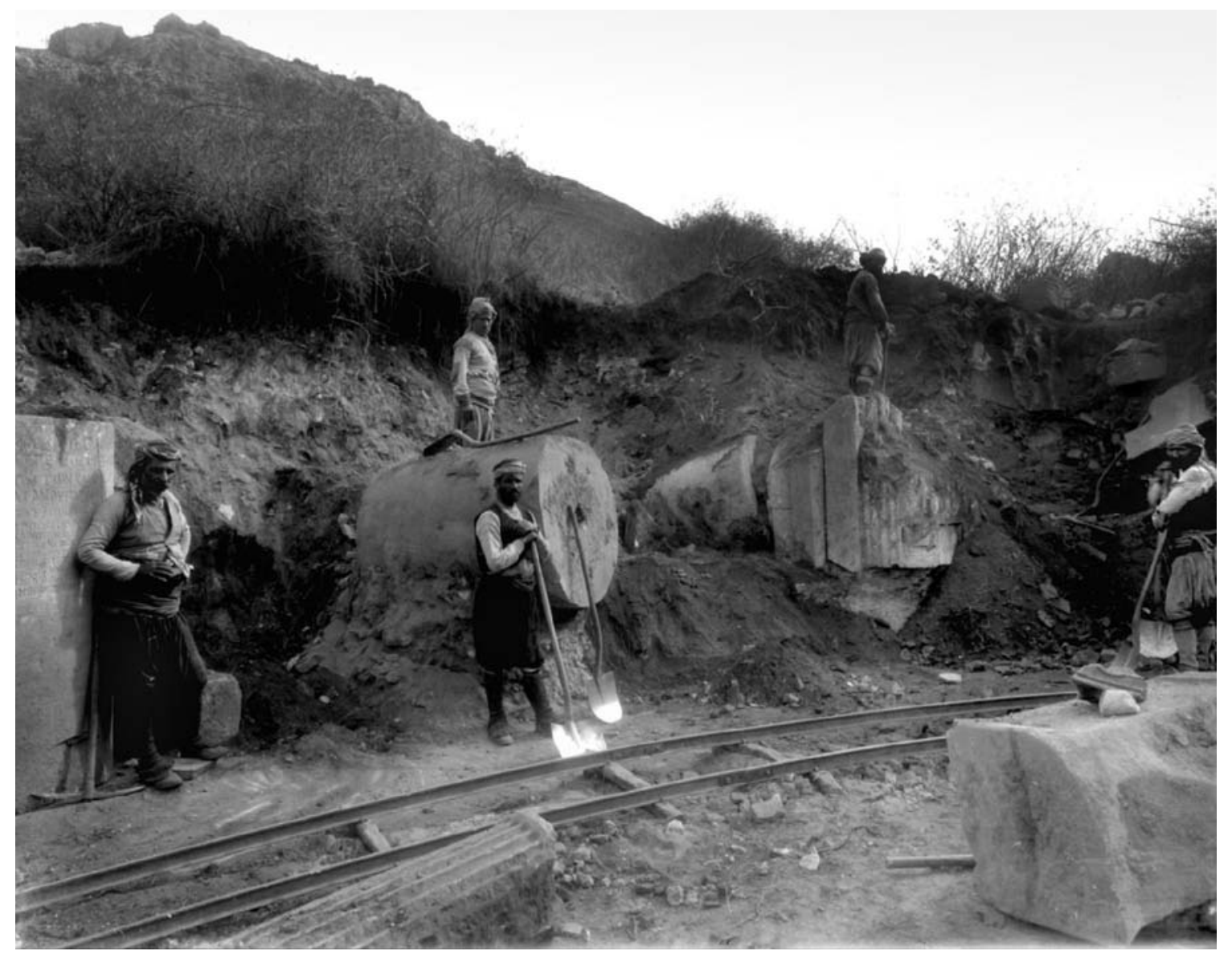

1 Freilegung der $>$ Kuretenhalle $<$ am unteren Embolos

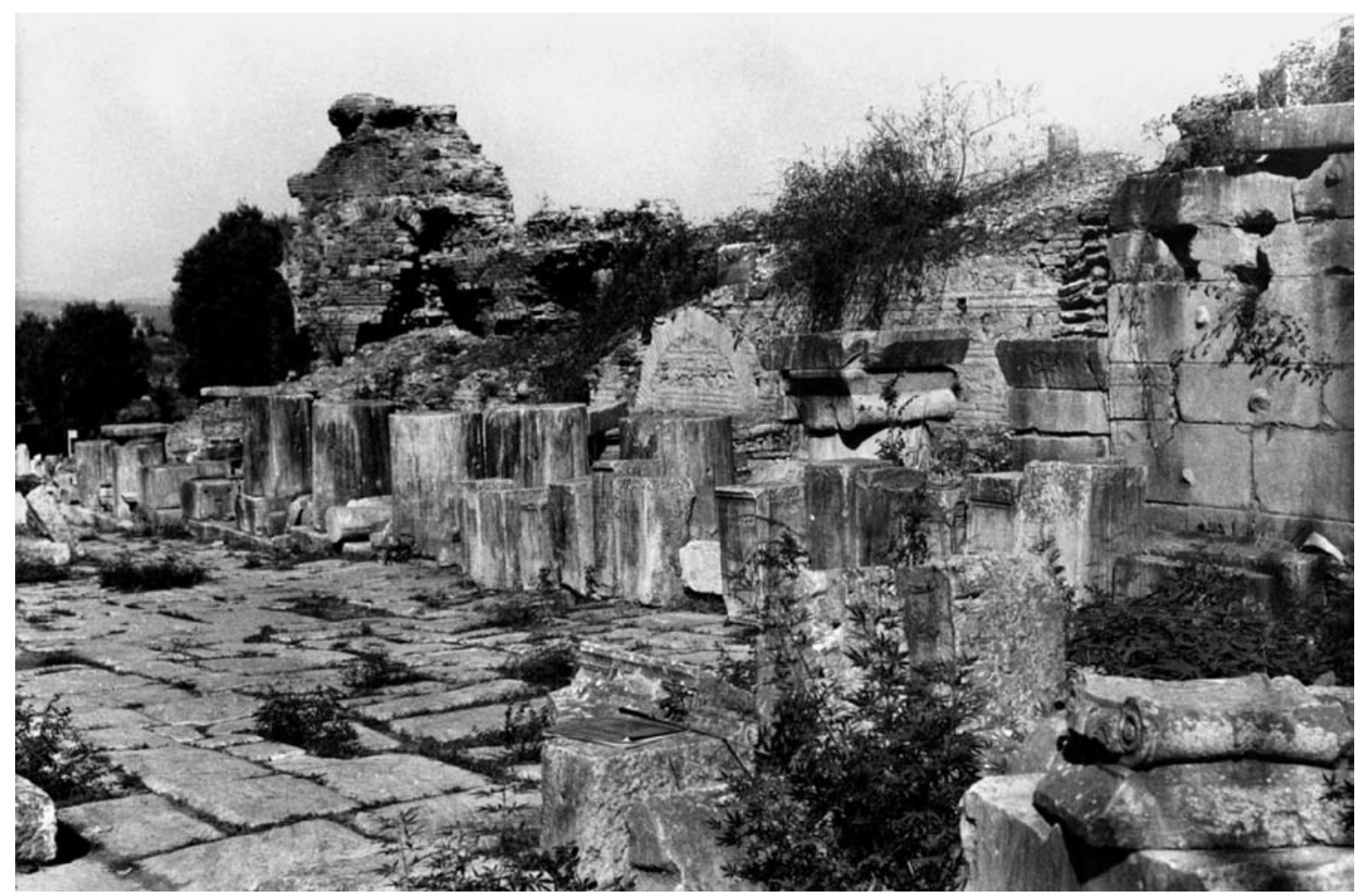

$2>$ Kuretenhalle am unteren Embolos 
Tafel 13

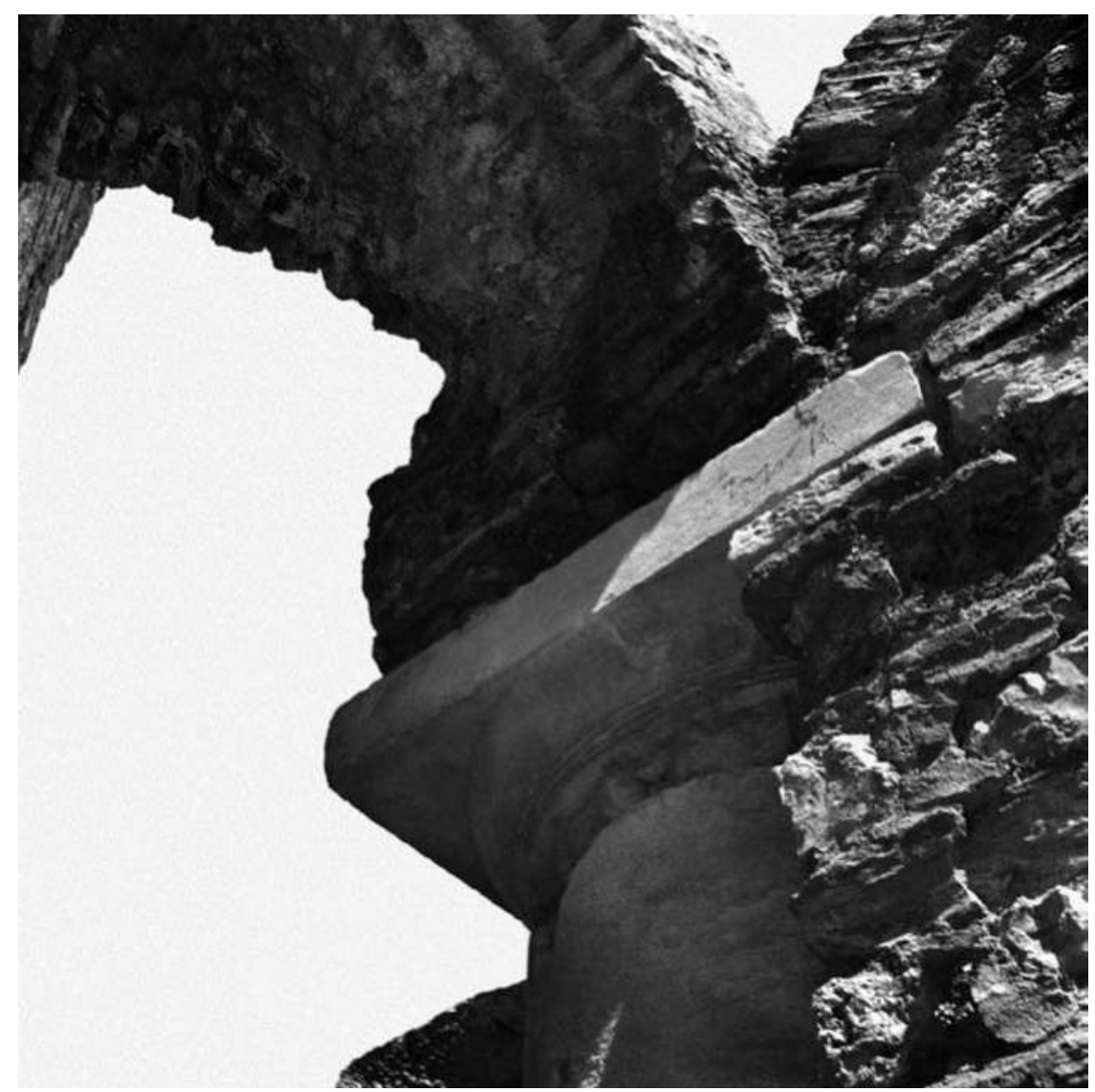

1 Scholastikiatherme. Eingemauerte Säule und Kapitell aus dem Prytaneion

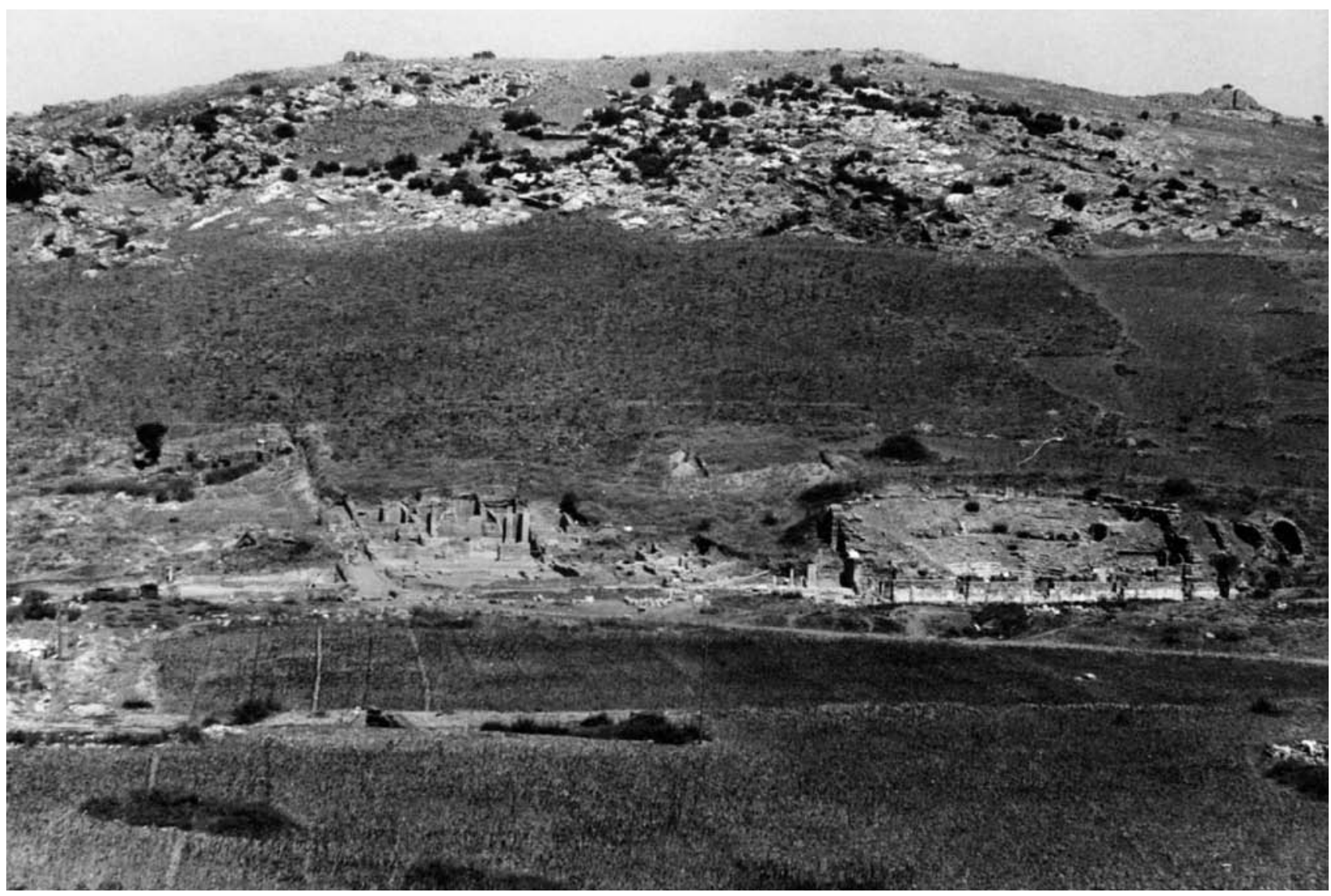

2 Oberer $>$ Staatsmarkt $<1957$ 


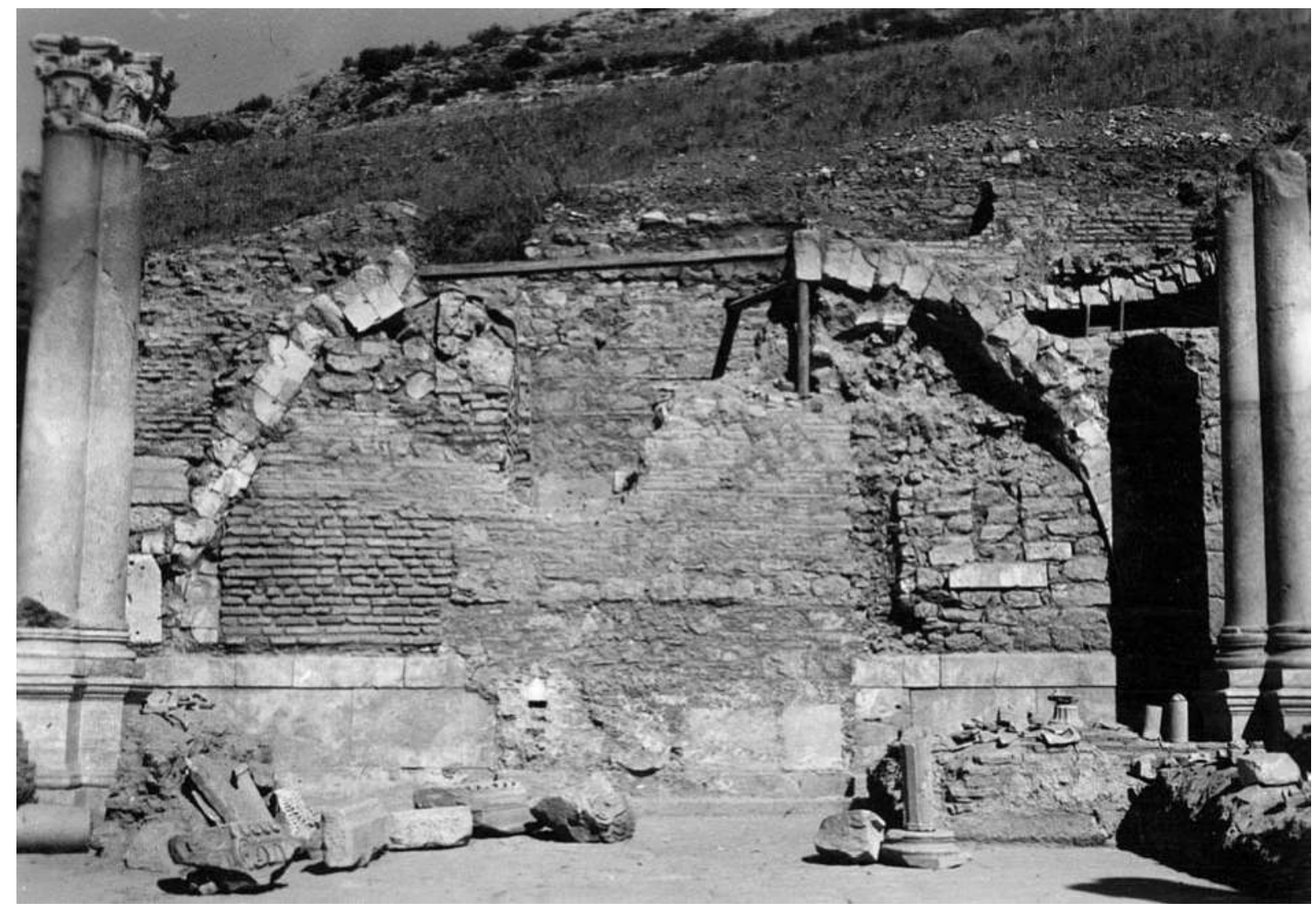

1 Nordwand des $>$ Hestiasaales` vor Entfernung des Statuentorsos

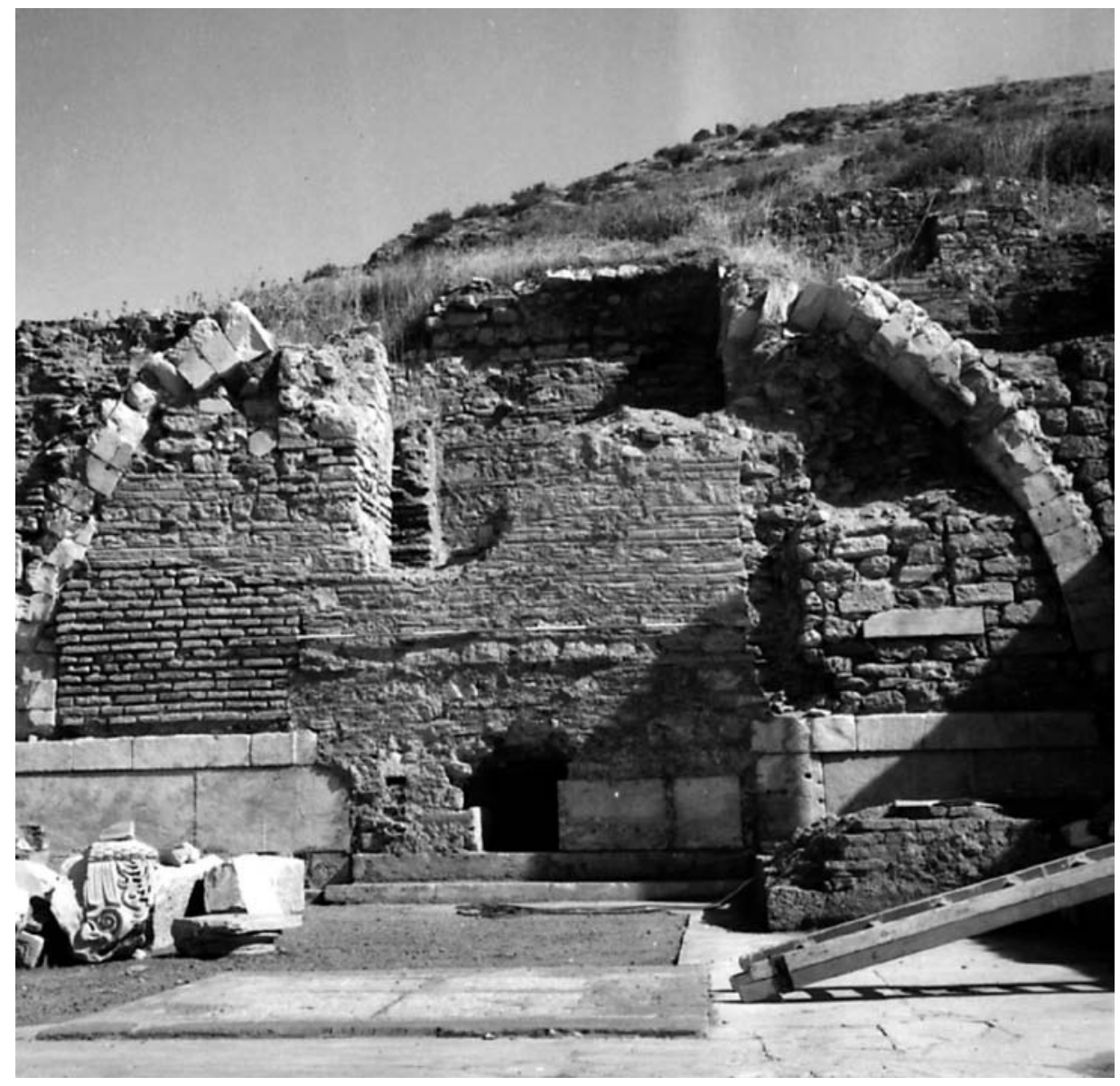

2 Nordwand des $>$ Hestiasaales $«$ nach Entfernung des Statuentorsos 


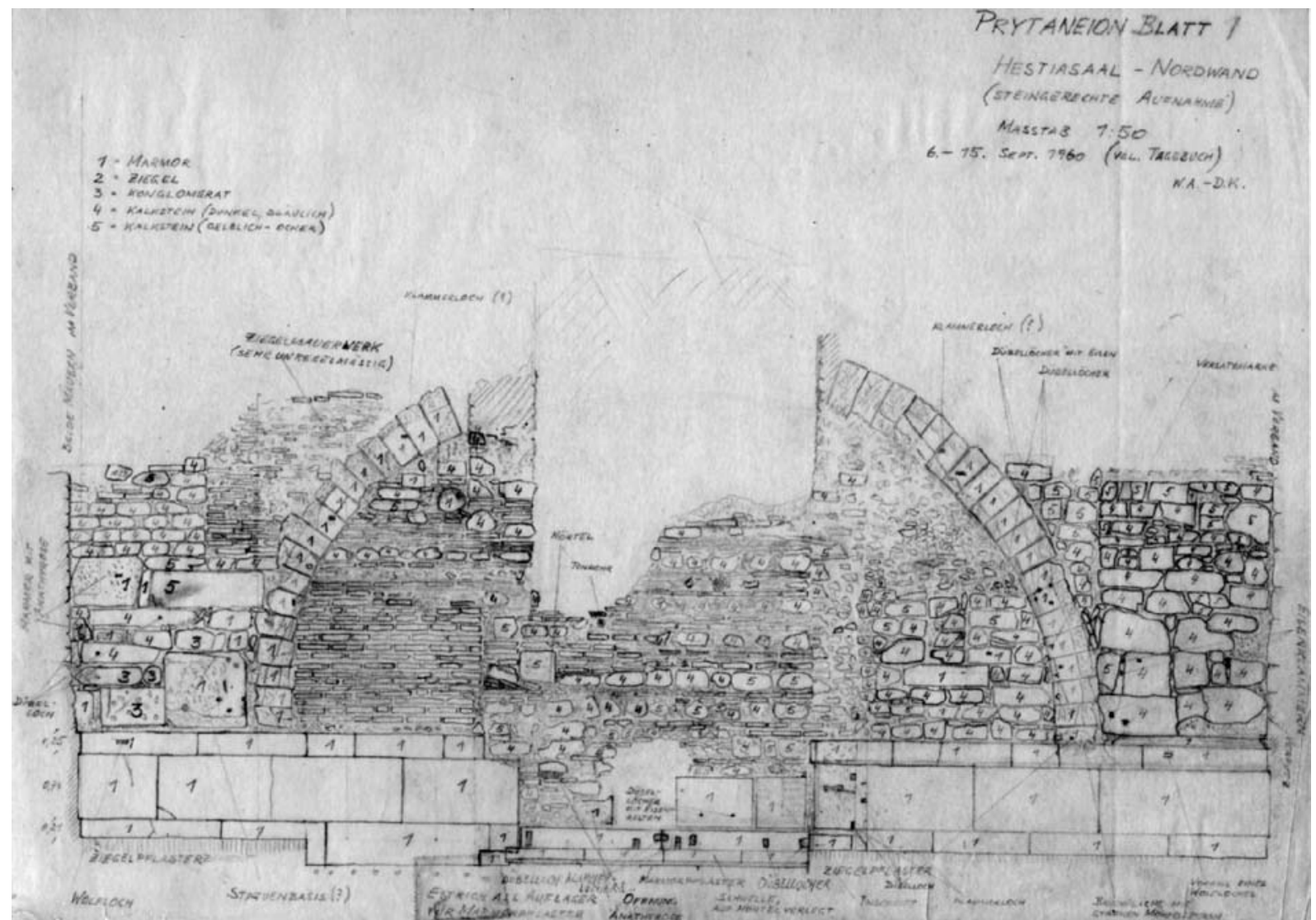

1 Zeichnerische Aufnahme der Nordwand des >Hestiasaales $<1960$

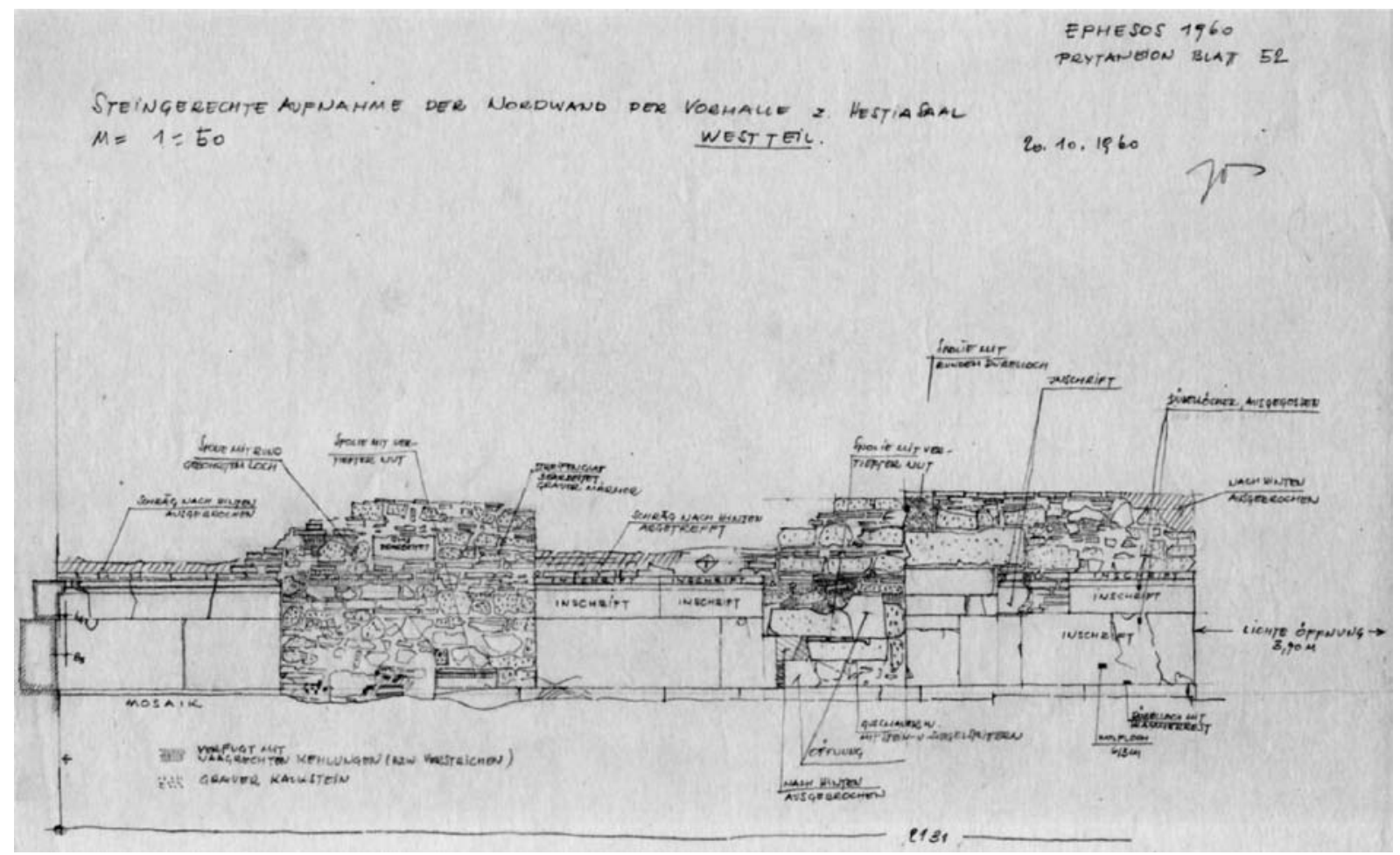

2 Zeichnerische Aufnahme der Nordwand der Vorhalle 1960 
Tafel 16

PRYTANEION

SONDAGEN 1960-1963 unter Bodenniveau

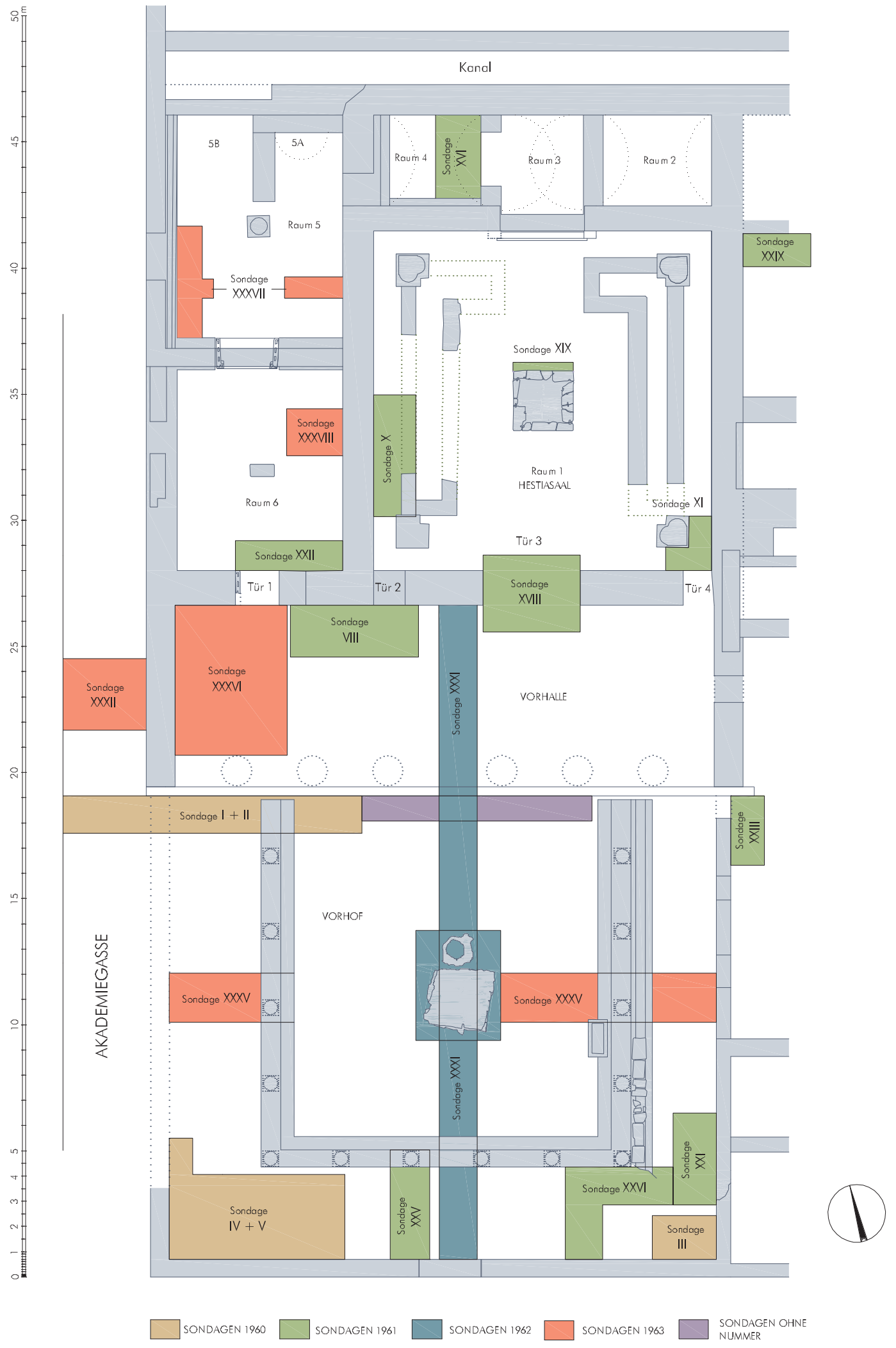

1 Prytaneion. Generalisierter Grundriss mit Sondagenplan 1960-1963 (1:250) 


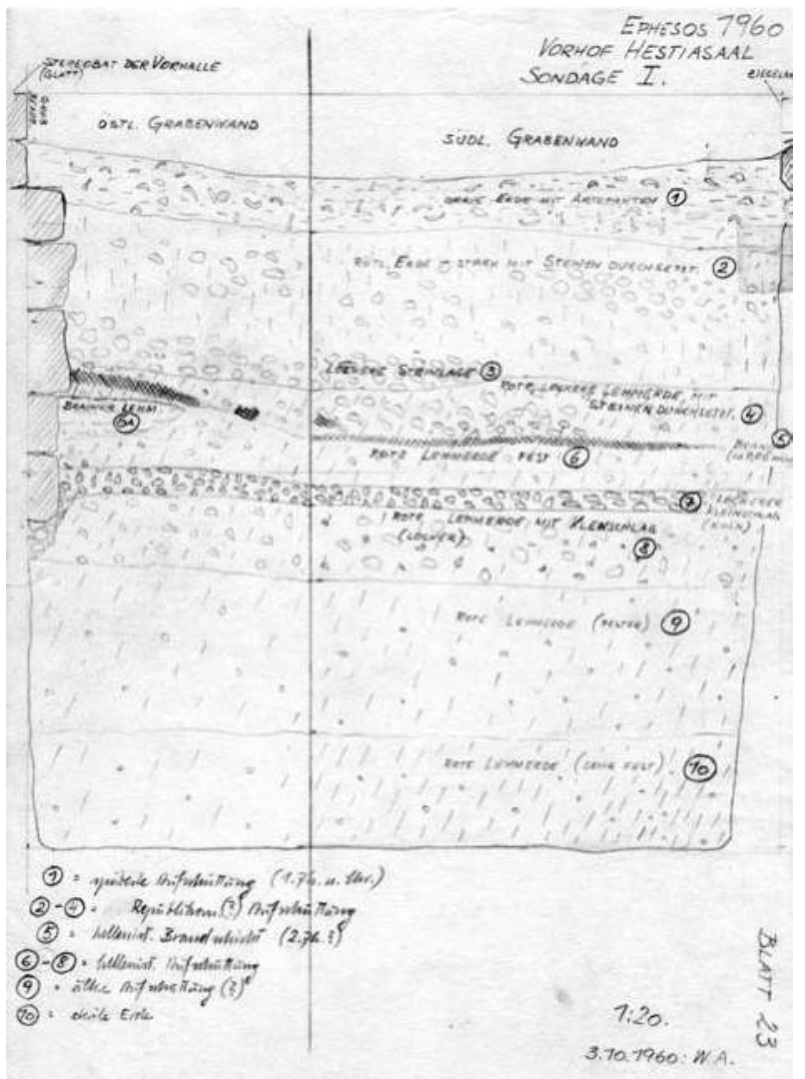

1 Prytaneion. Sondage I (1960). Ost- und Südprofil

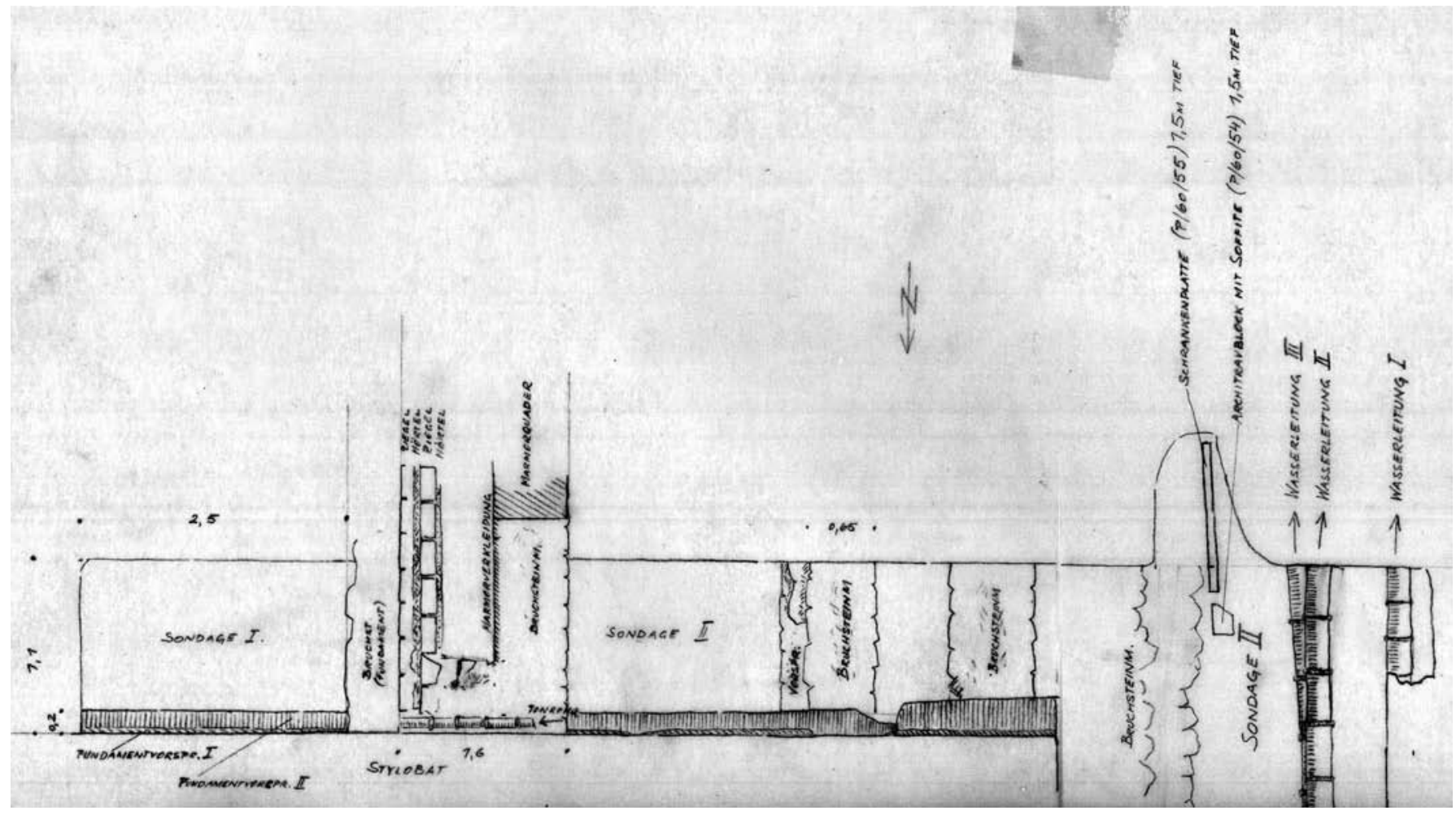

2 Prytaneion. Sondage I und II (1960). Planum 
Tafel 18

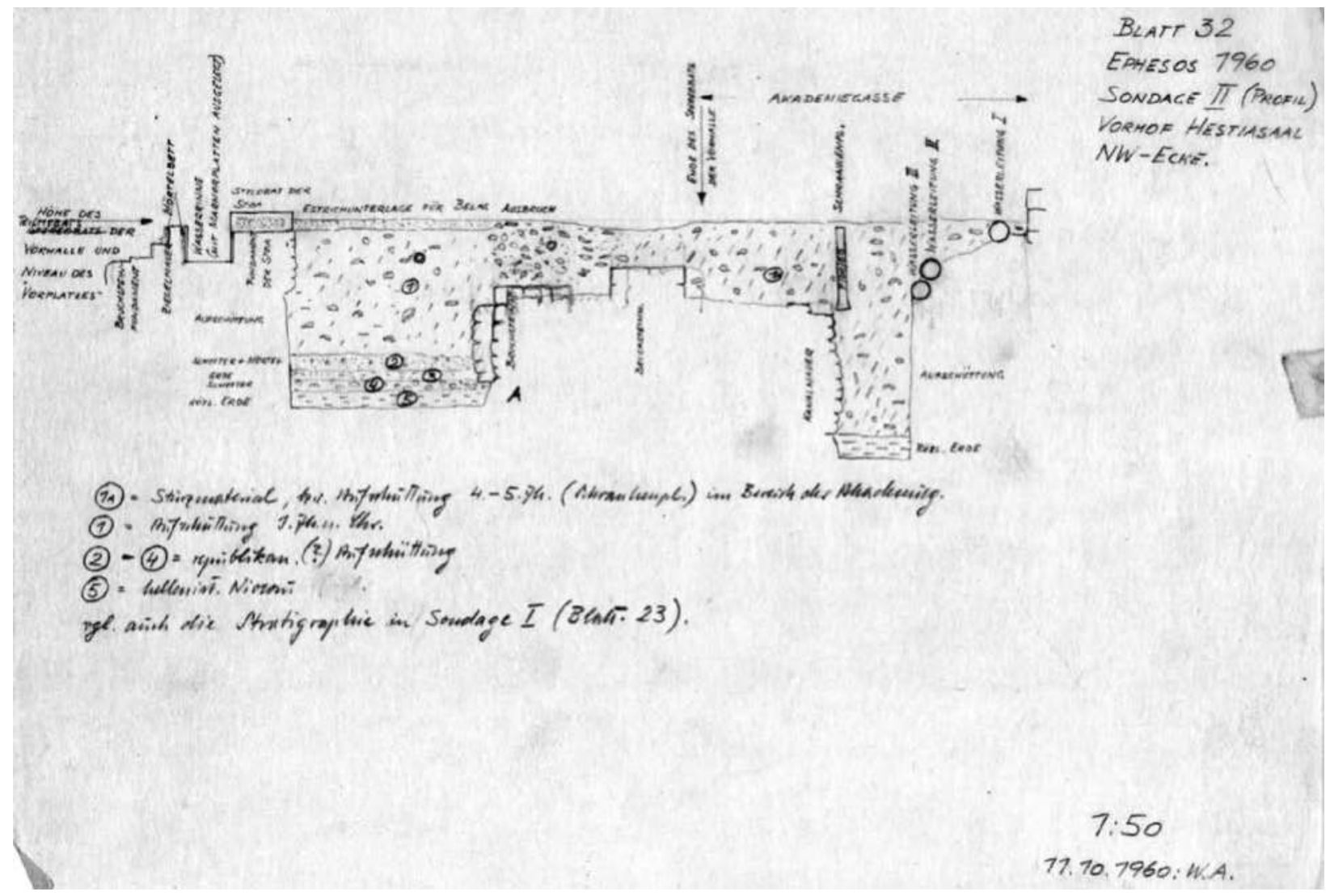

1 Prytaneion. Sondage II (1960). Südprofil

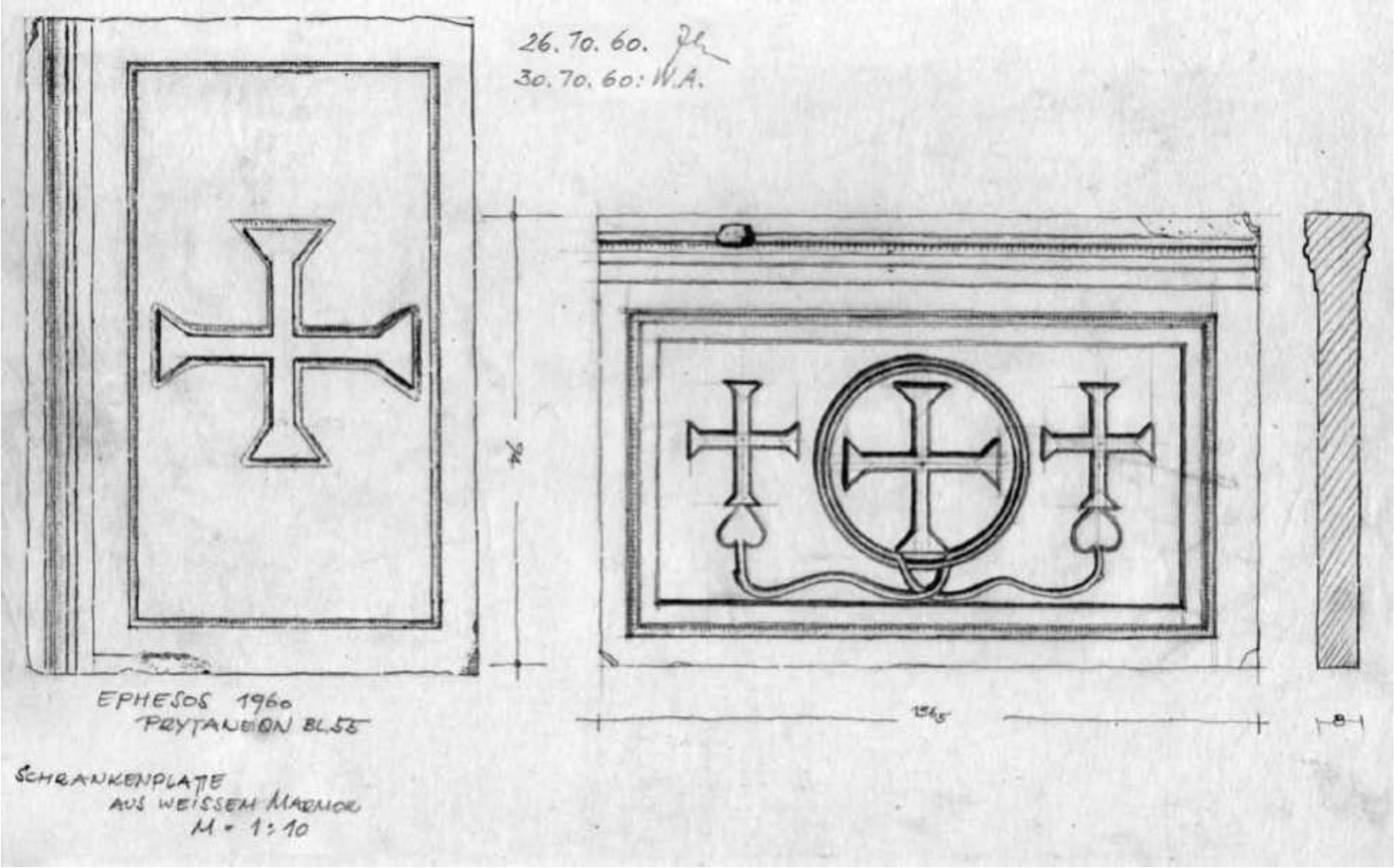

2 Prytaneion - Bereich >Akademiegasse . Schrankenplatte $(\mathrm{P} / 60 / 55)$ aus Sondage II 


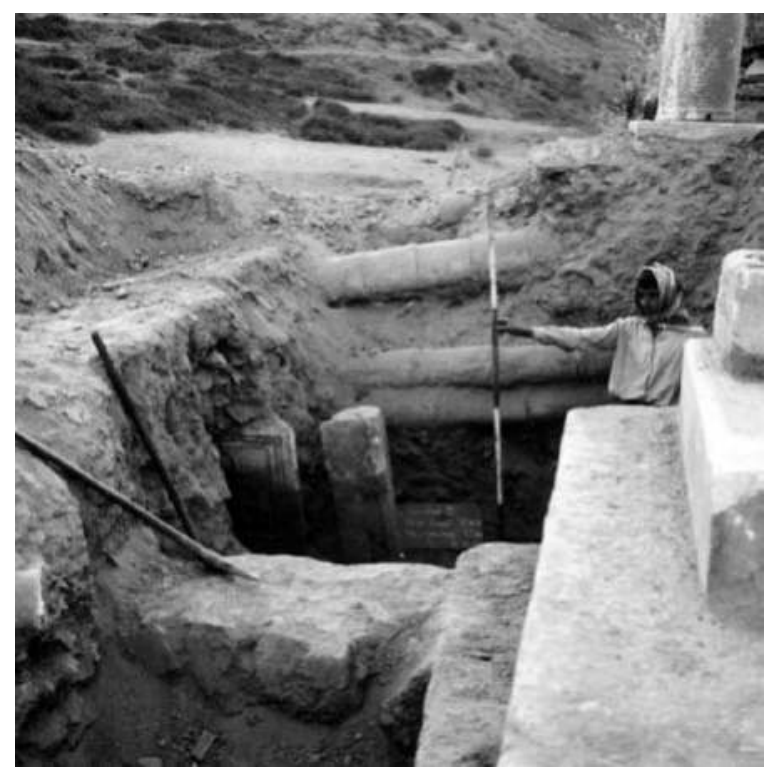

1 Prytaneion - Bereich >Akademiegasse «. Sondage II (1960)

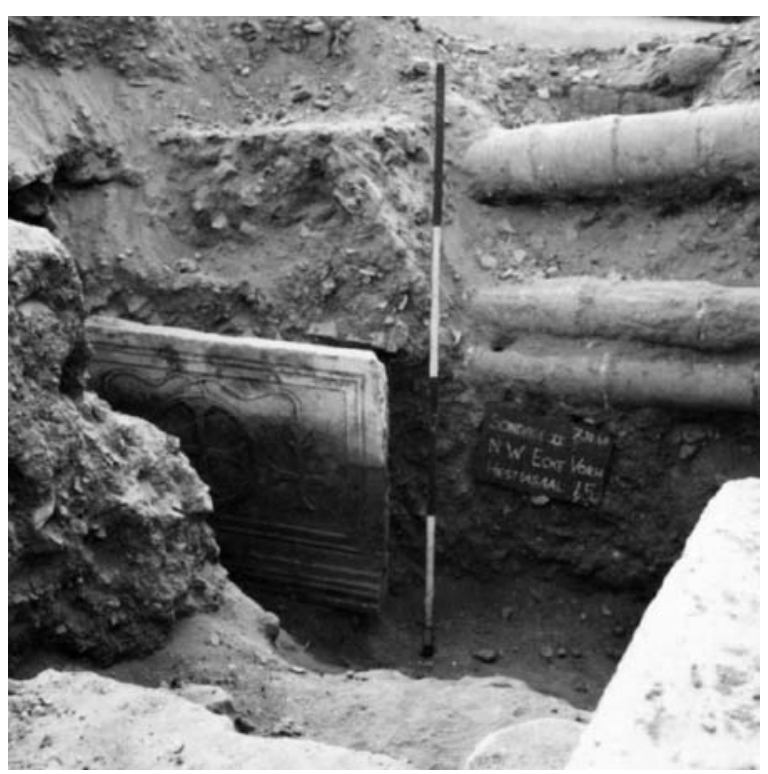

2 Prytaneion - Bereich >Akademiegasse «. Sondage II (1960). Schrankenplatte in Fundlage

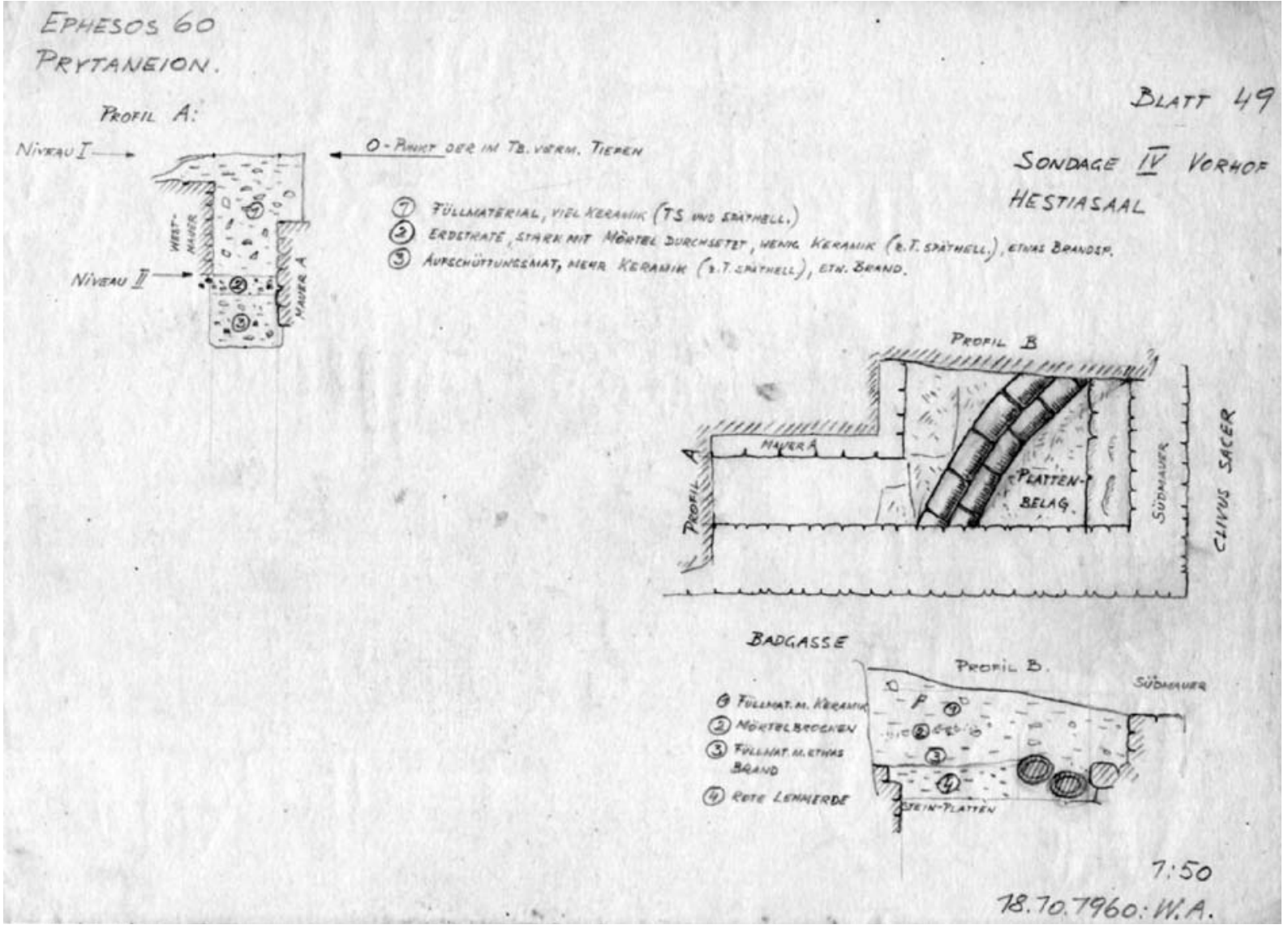

3 Prytaneion. Sondage IV (1960). Planum, Nord- und Ostprofil 
Tafel 20

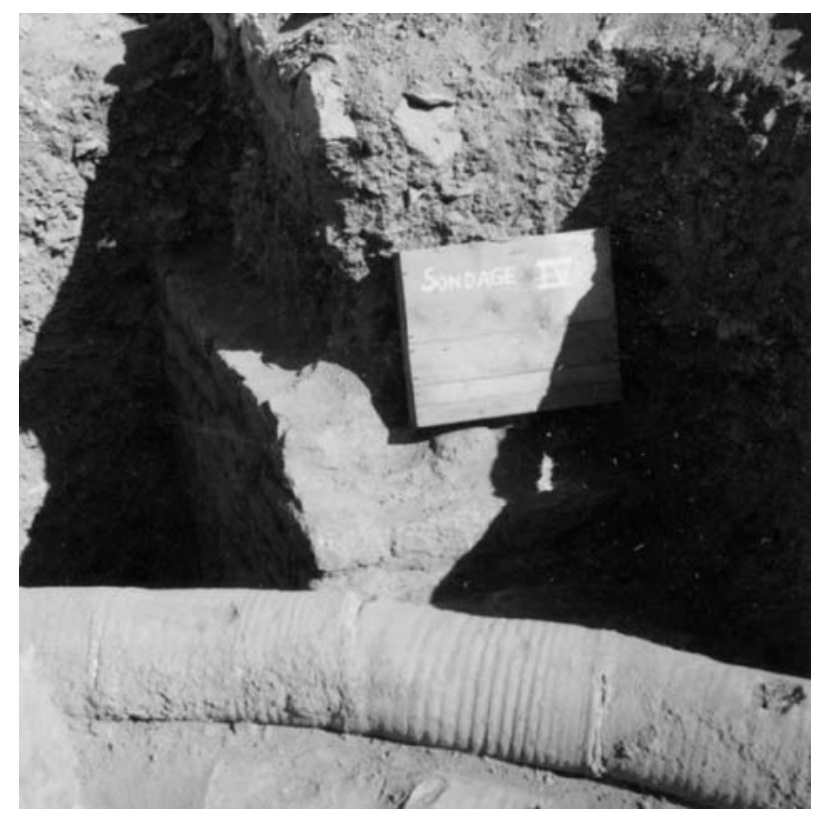

1 Prytaneion. Sondage IV (1960)

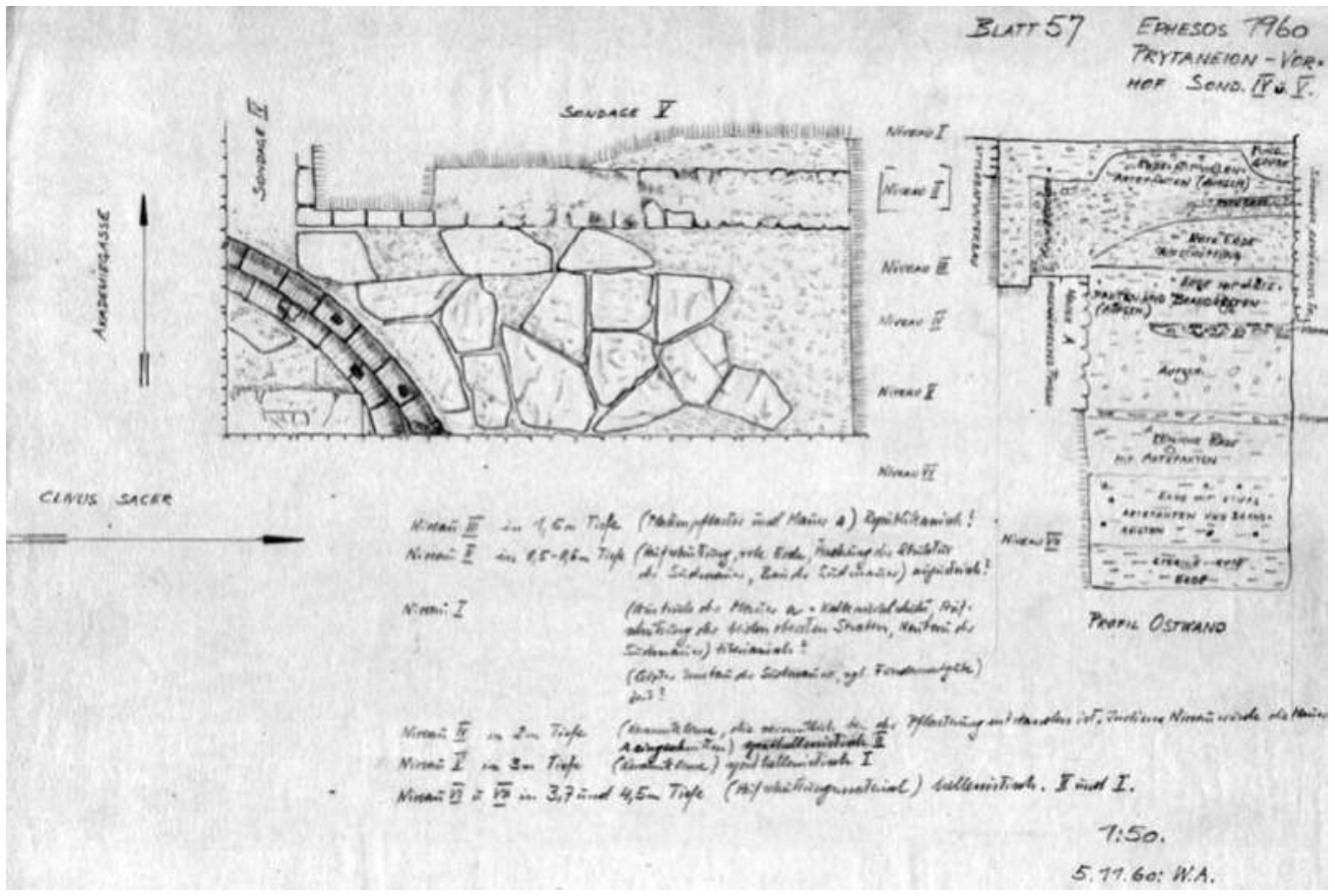

2 Prytaneion. Sondage IV und V (1960). Planum und Ostprofil

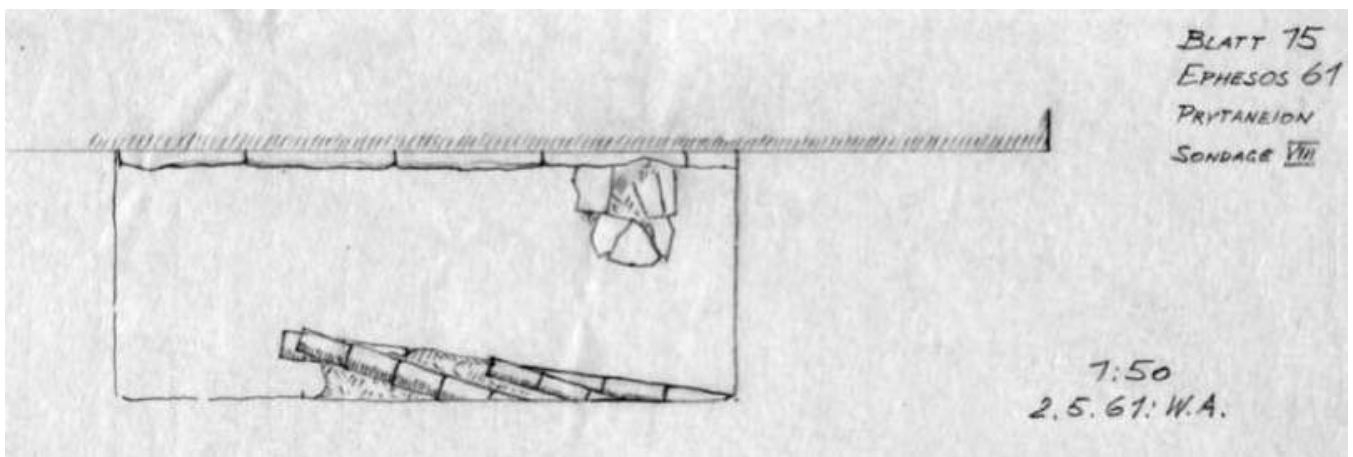

3 Prytaneion. Sondage VIII (1961). Planum 


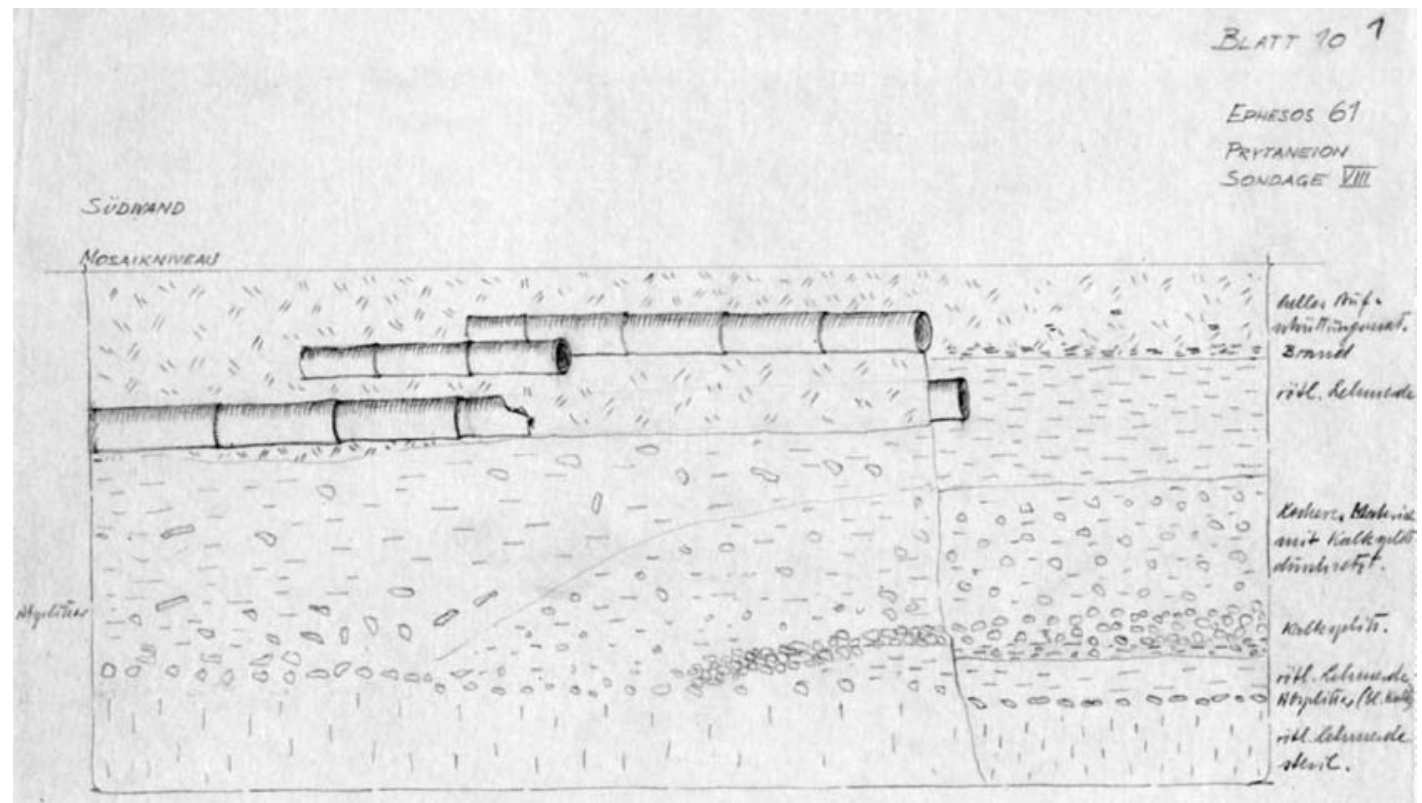

1 Prytaneion. Sondage VIII (1961). Südprofil

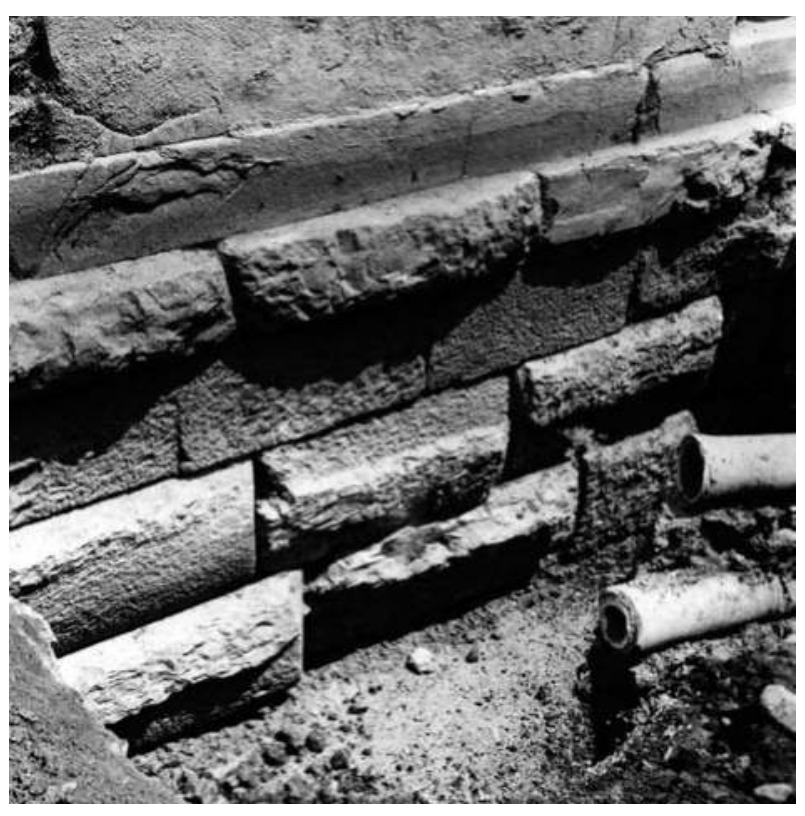

2 Prytaneion. Sondage VIII (1961). Nordwand der Vorhalle

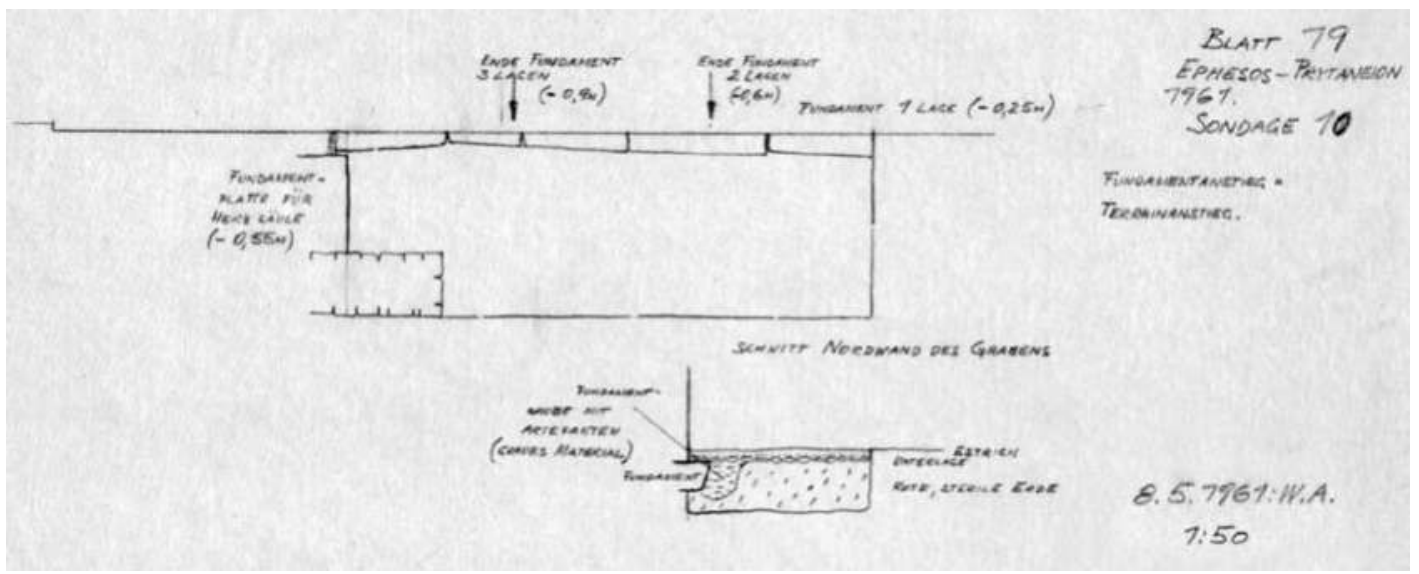

3 Prytaneion. Sondage X (1961). Planum 
Tafel 22

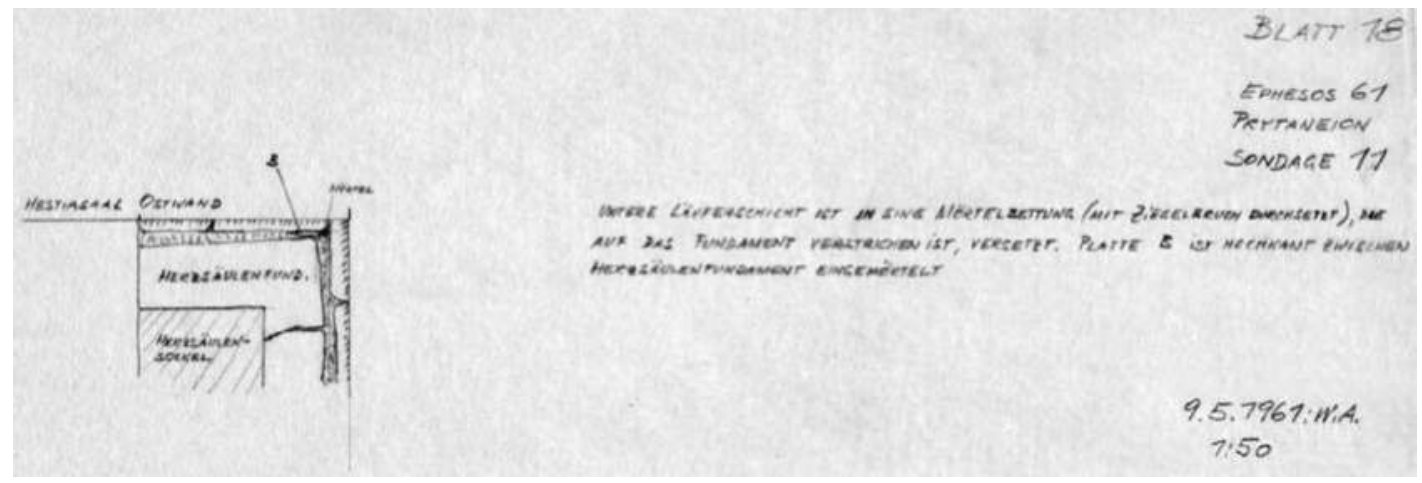

1 Prytaneion. Sondage XI (1961). Planum

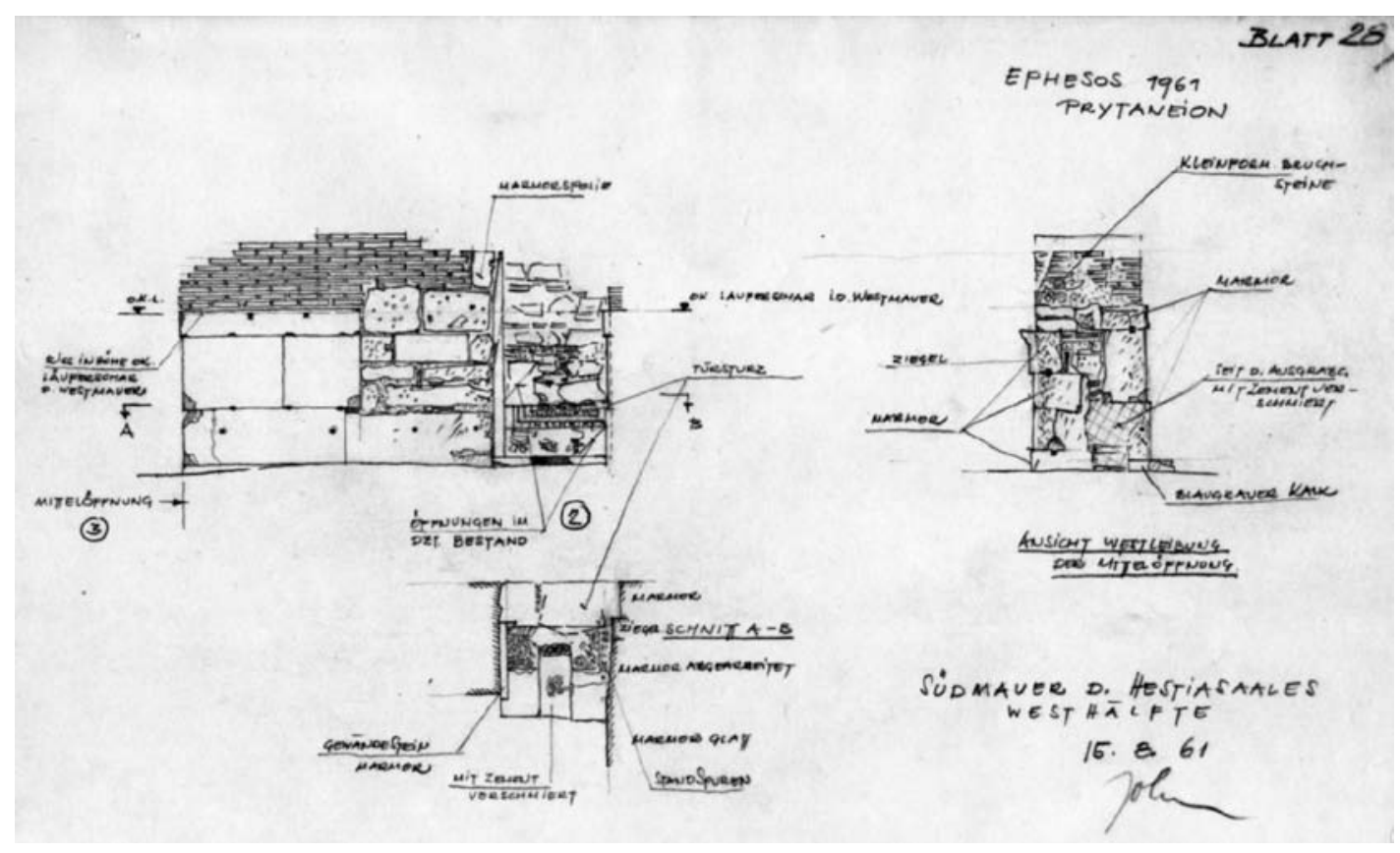

2 Zeichnerische Aufnahme der Südwand des 〉Hestiasaales` 1961 - Westteil

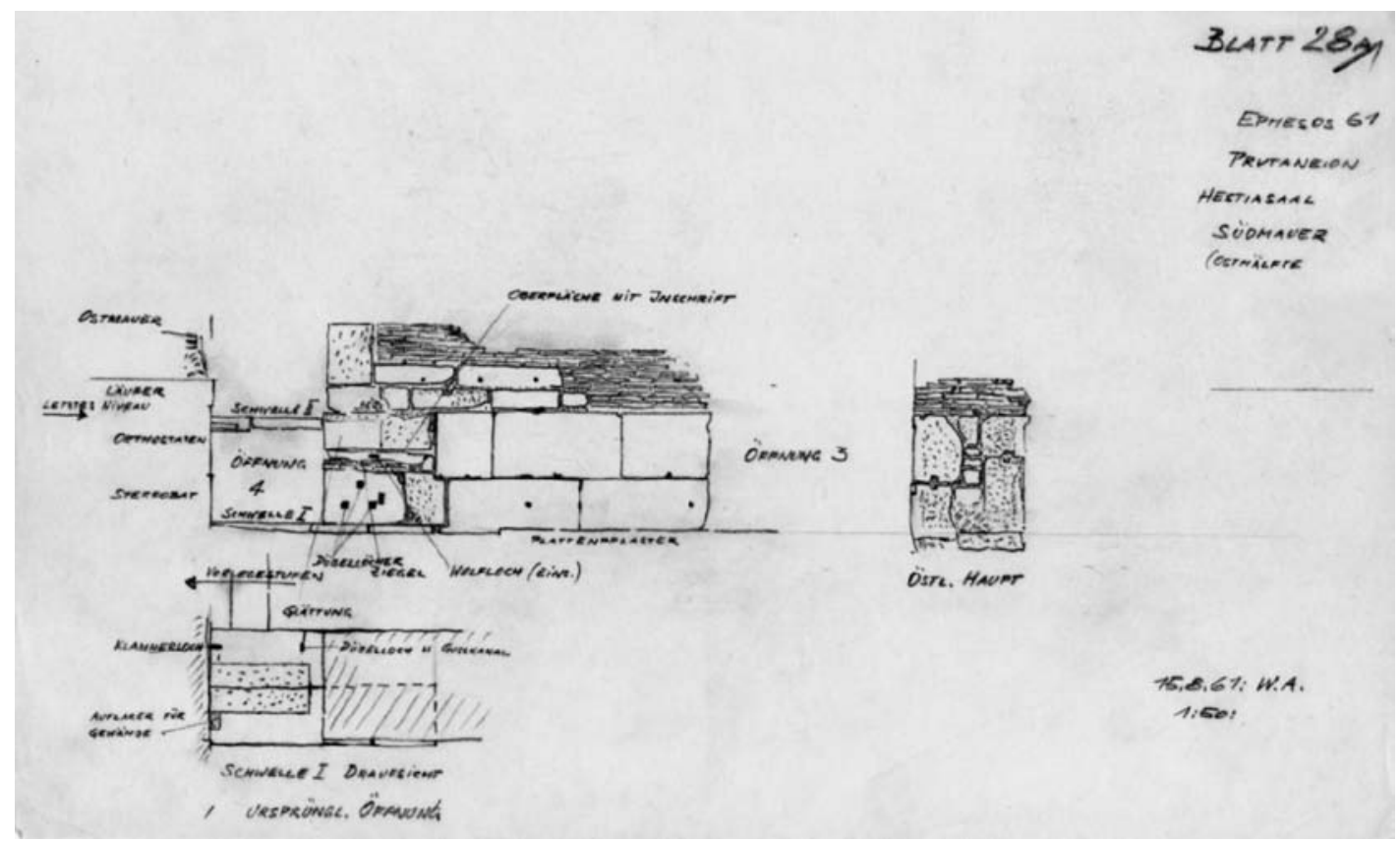

3 Zeichnerische Aufnahme der Südwand des `Hestiasaales` 1961 - Ostteil 
Tafel 23

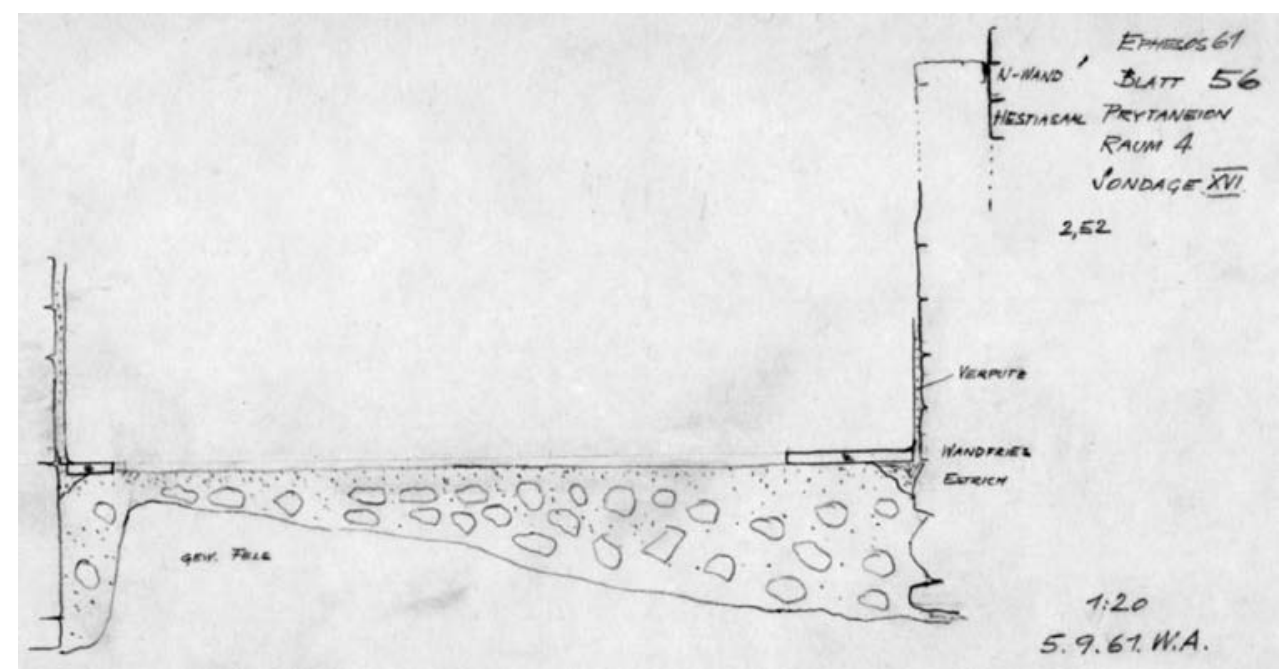

1 Prytaneion. Sondage XVI (1961) Ostprofil

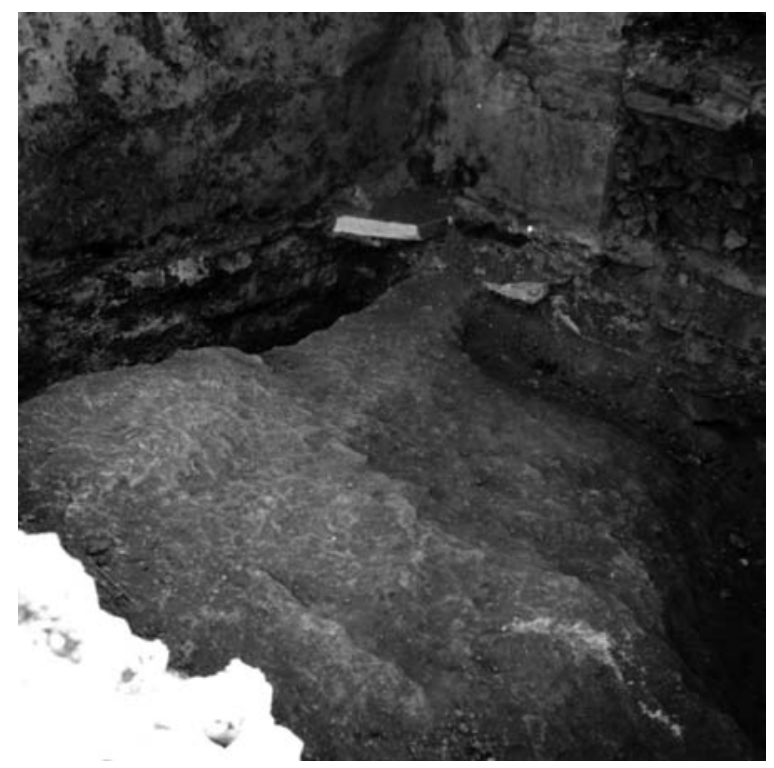

2 Prytaneion. Sondage XVI (1961). Osthälfte Raum 4

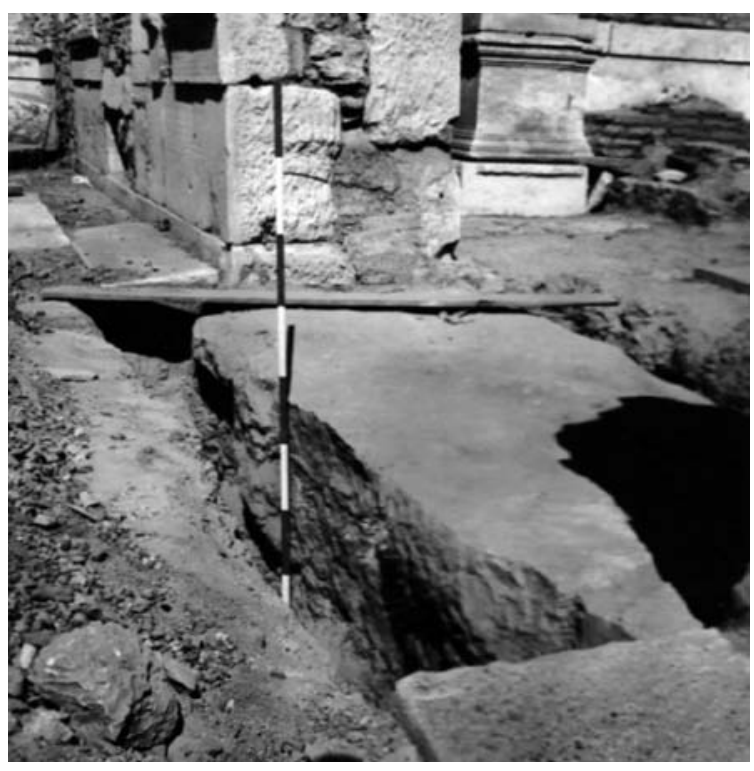

3 Prytaneion. Sondage XVIII (1961). Eingang in >Hestiasaal« (Tür 3)

$$
\begin{aligned}
& \text { EPHESOS } 1967 \\
& \text { PRYTANEION, BLA } 62
\end{aligned}
$$

BRUCHSTUECL EINES LESB KYMATION AUS WEISSLICHEM MARMOR GEFUNDEN IN SONDAGE XXVIII,
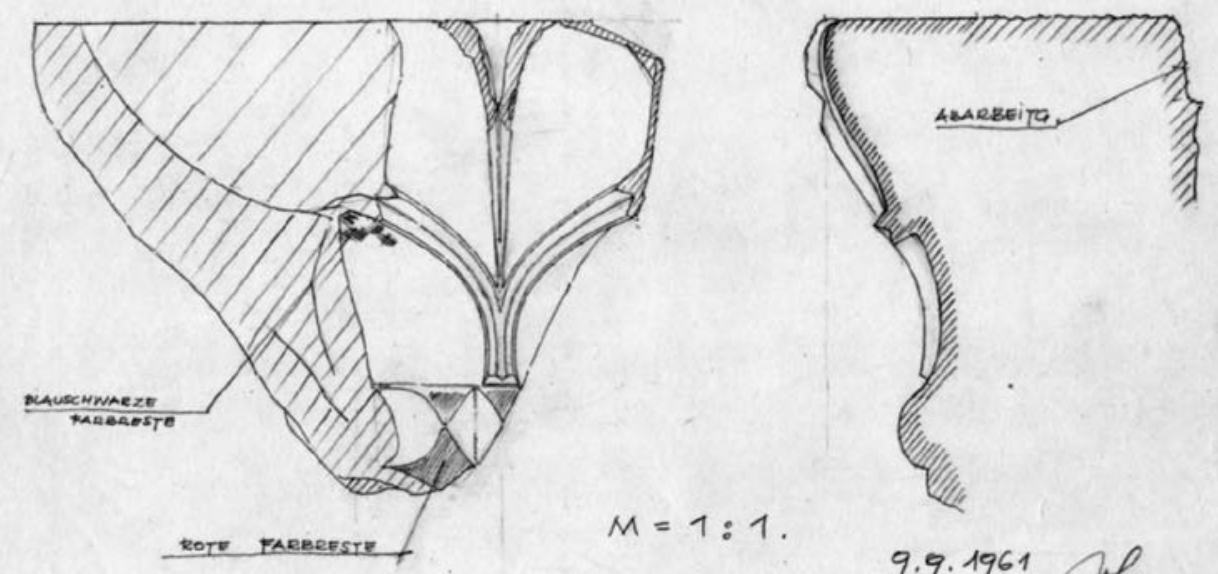

$9 \cdot 9 \cdot 1961$ Lesbisches Kyma-
4 Prytaneion. tion aus Sondage XVIII (?) 
Tafel 24

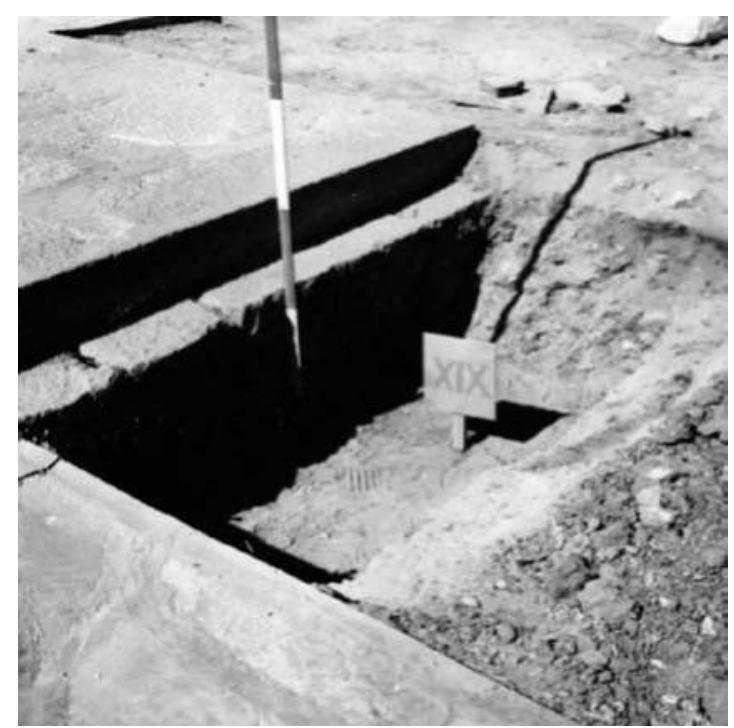

1 Prytaneion. Sondage XIX (1961). Zentrales Fundament im ^Hestiasaal

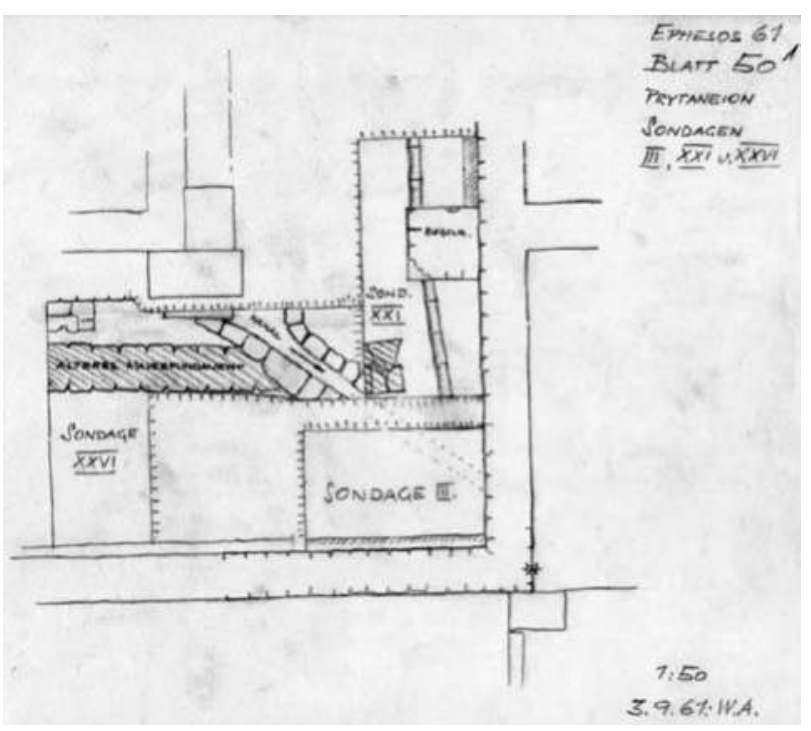

2 Prytaneion. Sondagen XXI und XXVI (1961). Planum

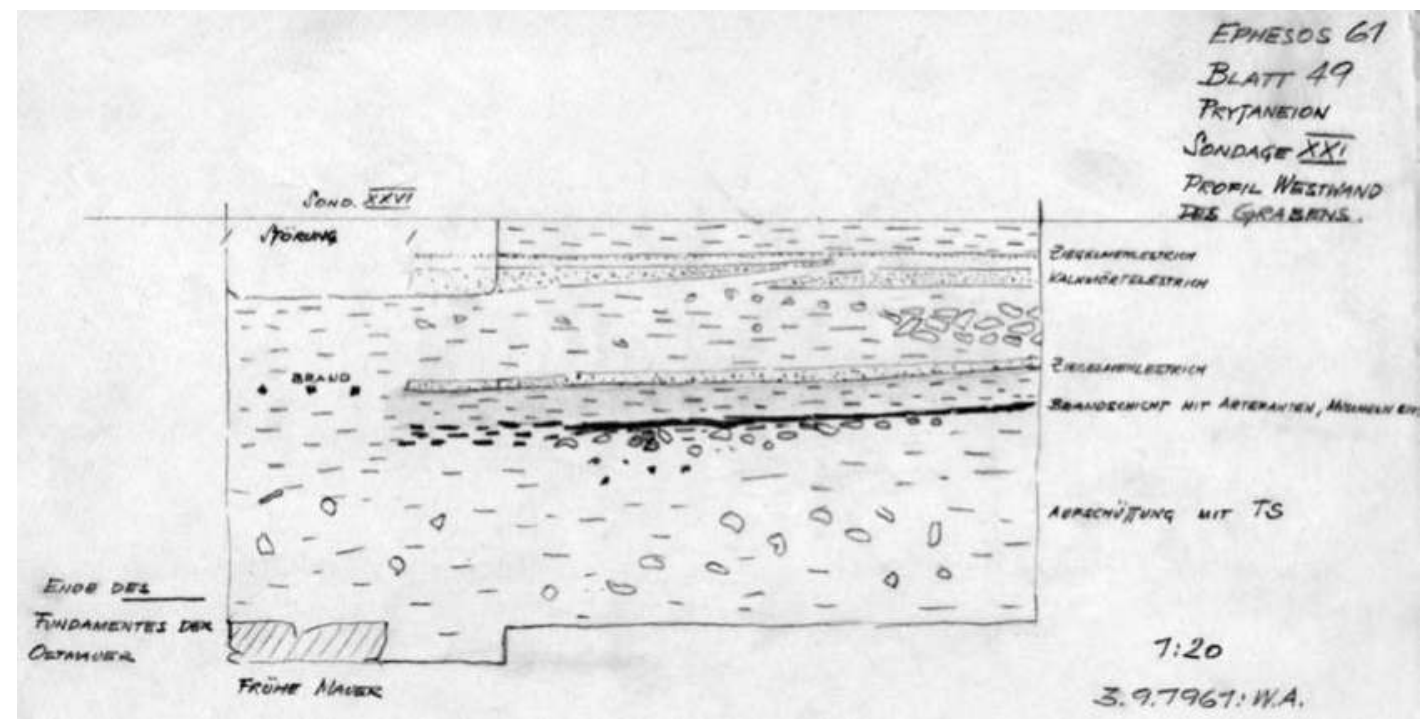

3 Prytaneion. Sondage XXI (1961). Westprofil

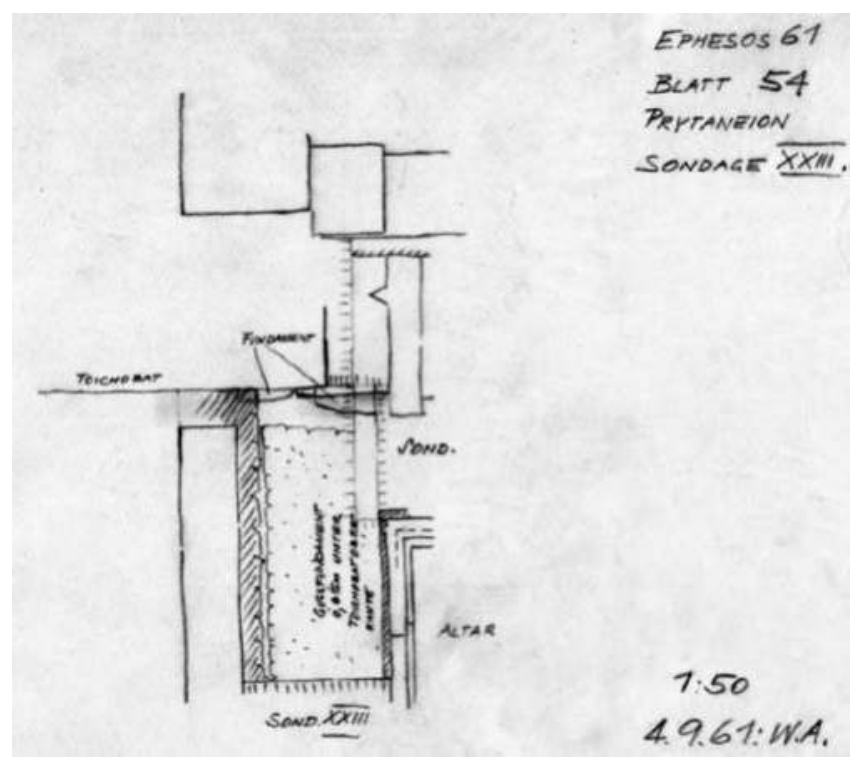

4 Prytaneion. Sondage XXIII (1961). Planum 


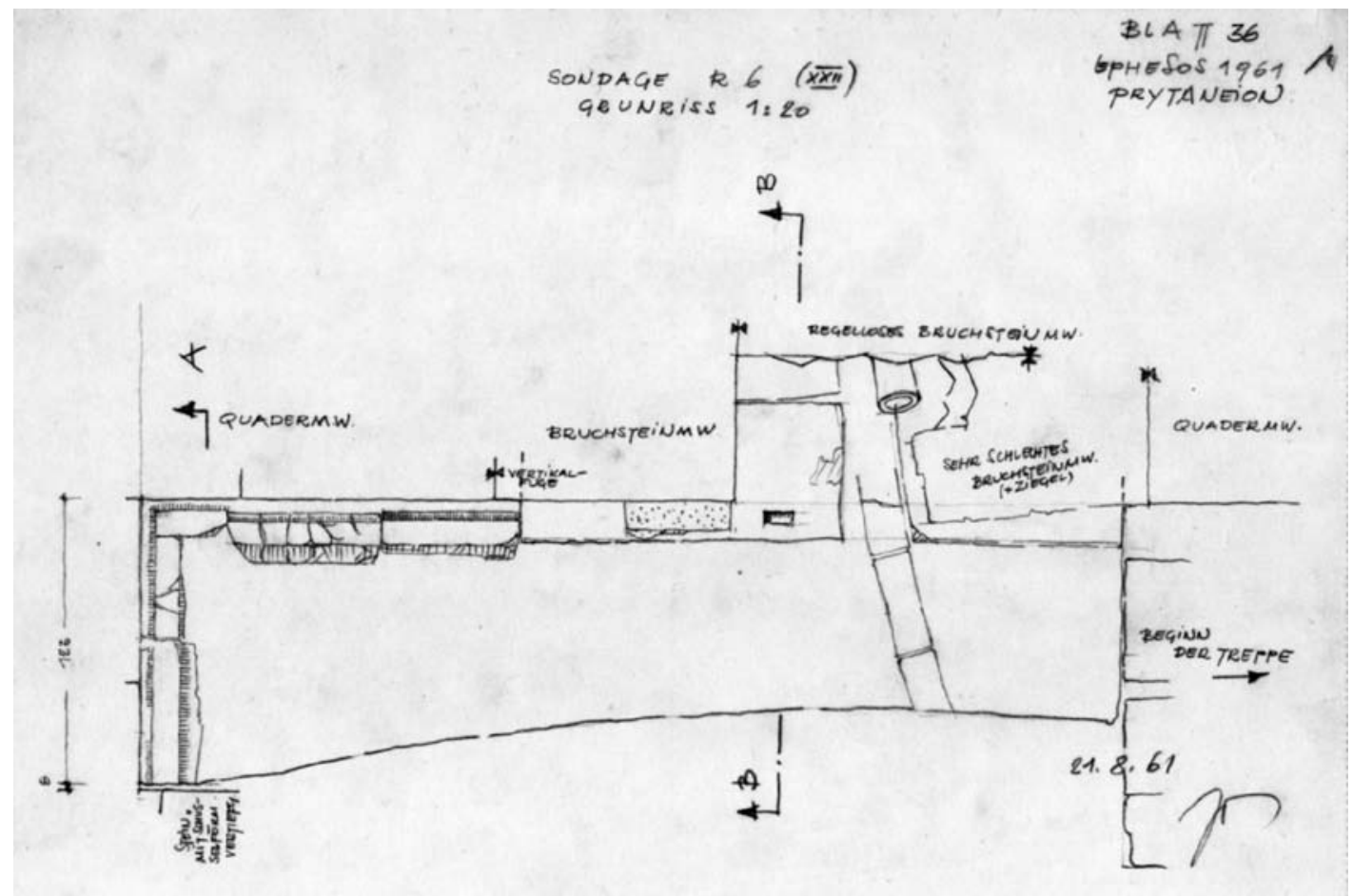

1 Prytaneion. Sondage XXII (1961). Planum
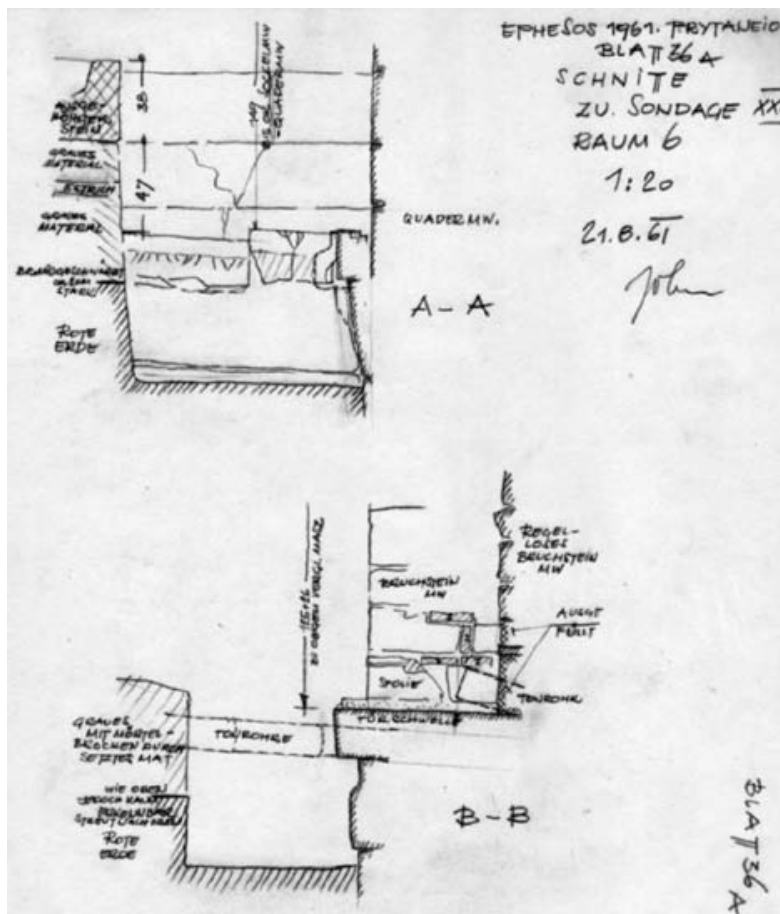

2 Prytaneion. Sondage XXII (1961). Ostprofile

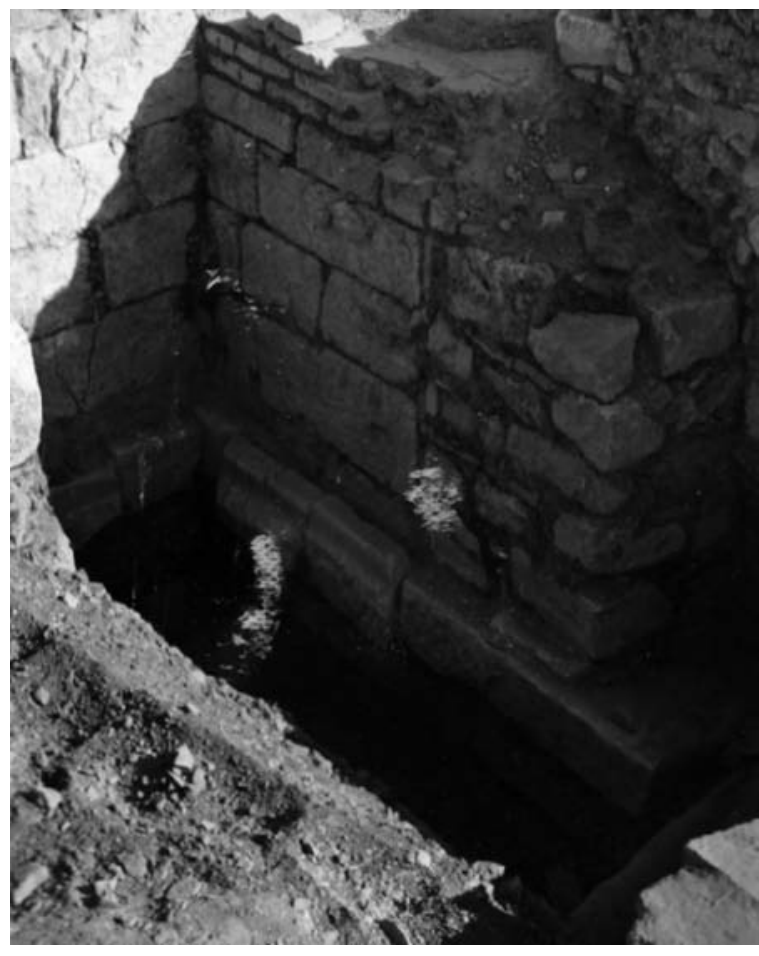

3 Prytaneion. Sondage XXII (1961). Südhälfte Raum 6 
Tafel 26

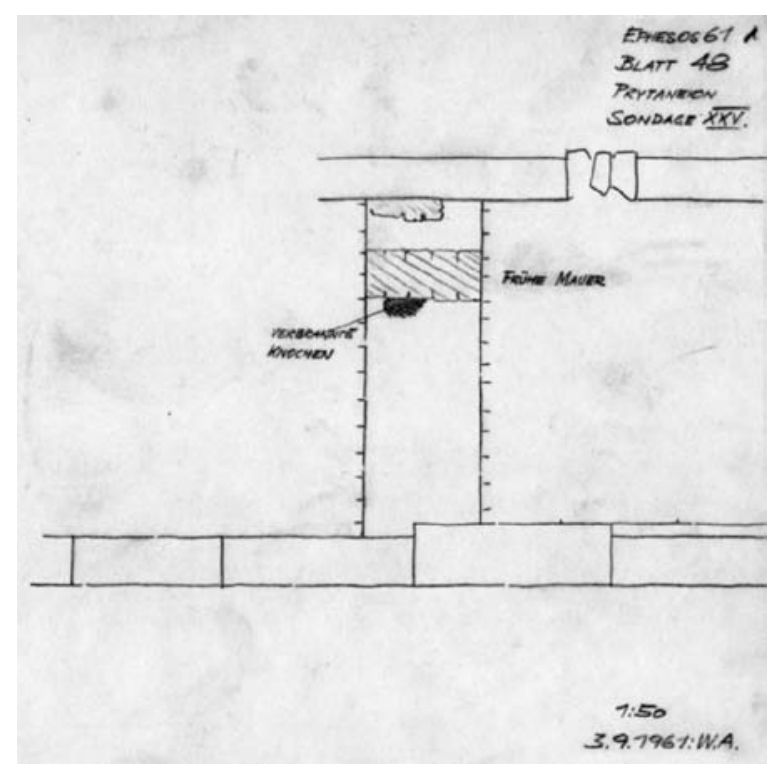

1 Prytaneion. Sondage XXV (1961). Planum

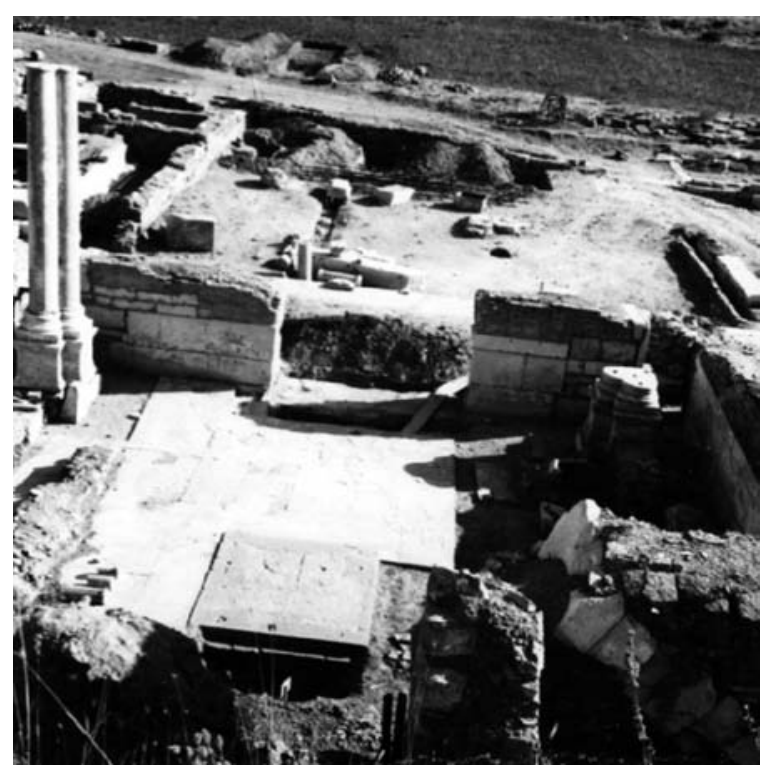

2 Prytaneion von Norden (1961) mit Sondagen XVIII, XIX, XXV, XXVI und XXXI

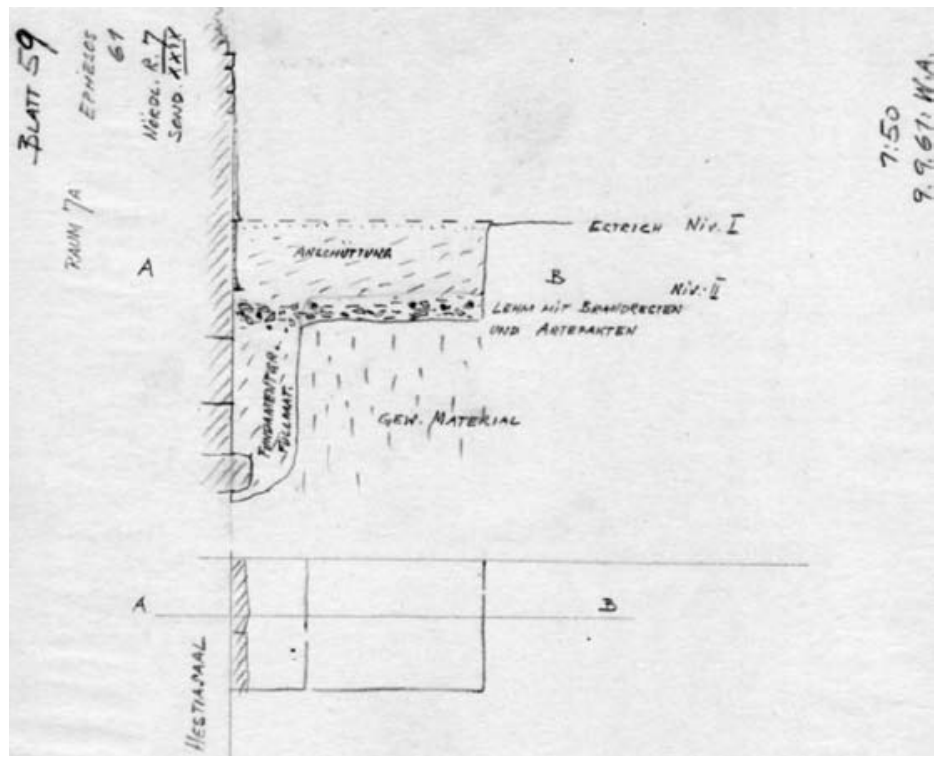

3 Prytaneion. Sondage XXIX (1961). Planum und Südprofil

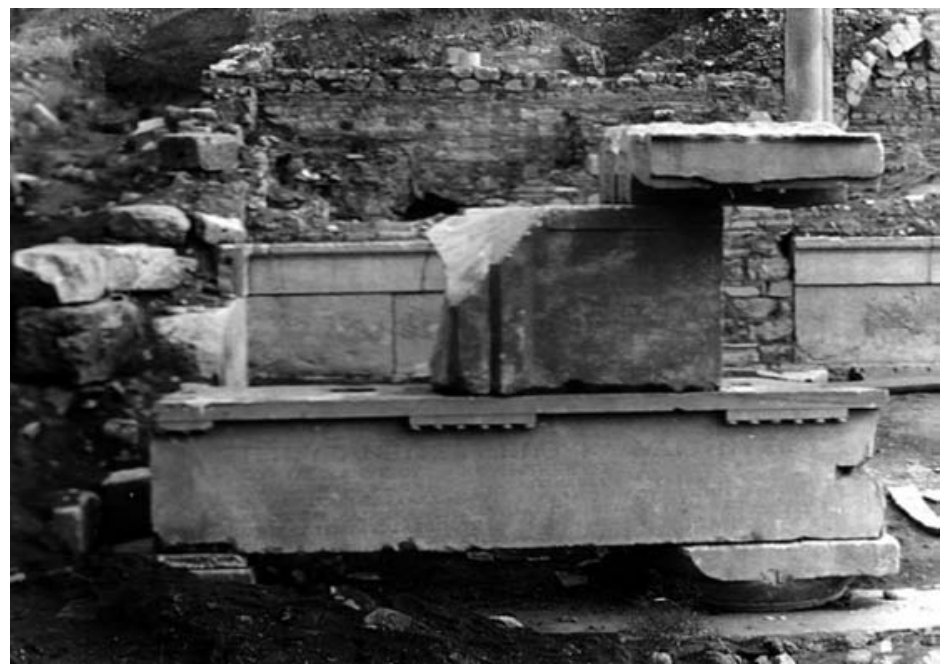

4 Prytaneion. Architekturprobe des dorischen Gebälks der Vorhalle (1961) 


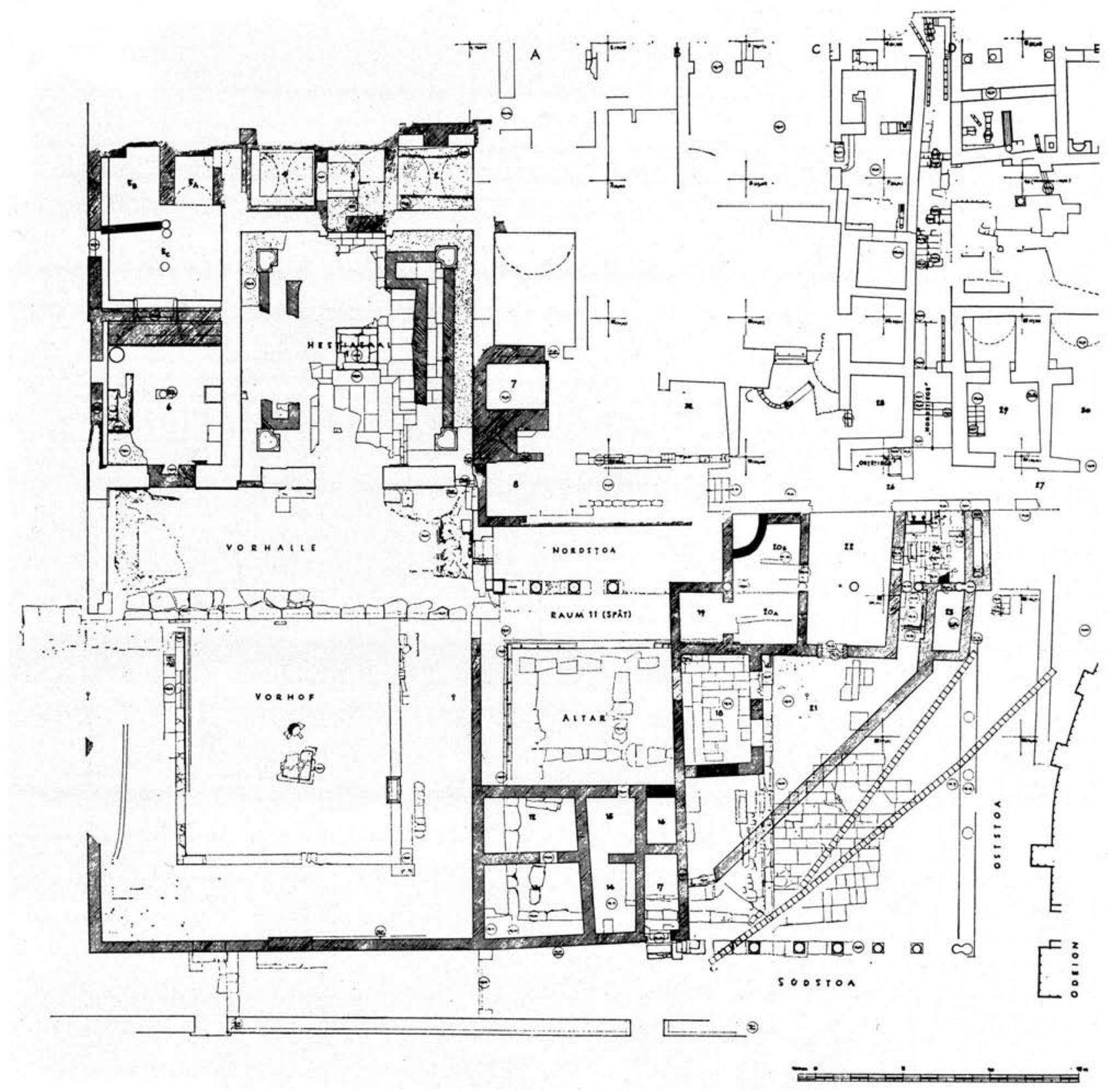

1 Prytaneion 1961. Grundriss 
Tafel 28

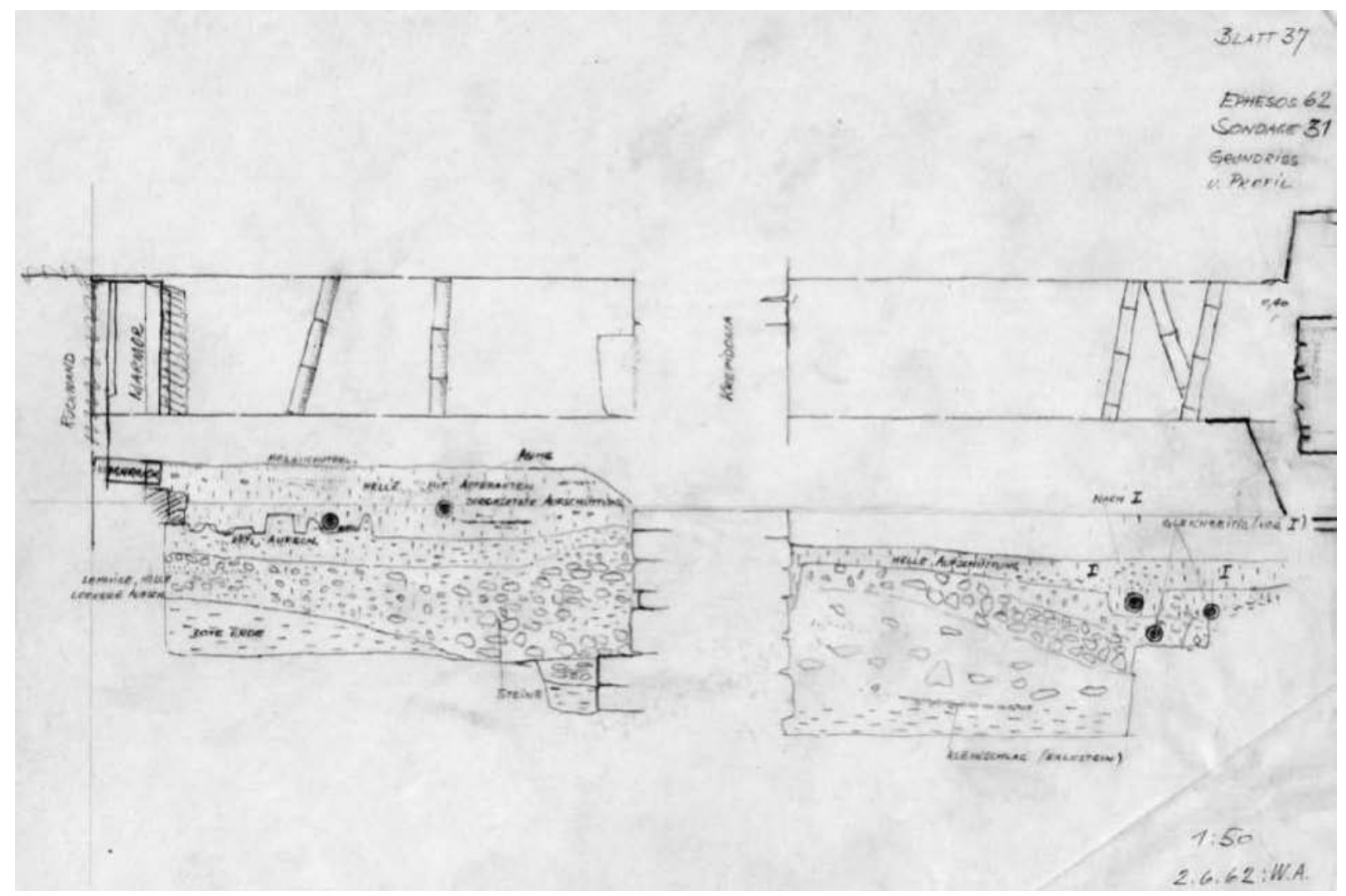

1 Prytaneion. Sondage XXXI Nordhälfte (1962). Planum und Ostprofil

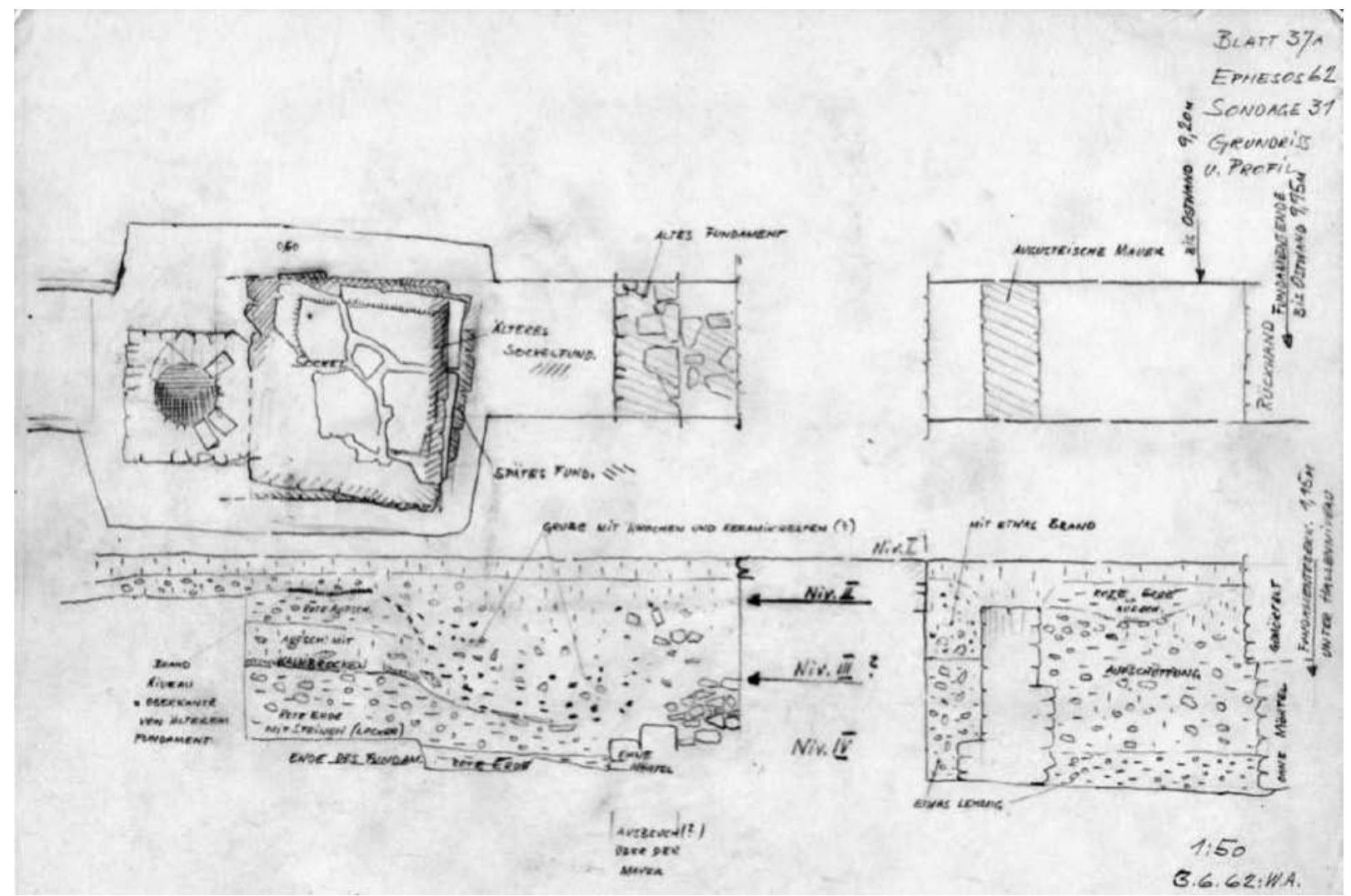

2 Prytaneion. Sondage XXXI Südhälfte (1962). Planum und Ostprofil 


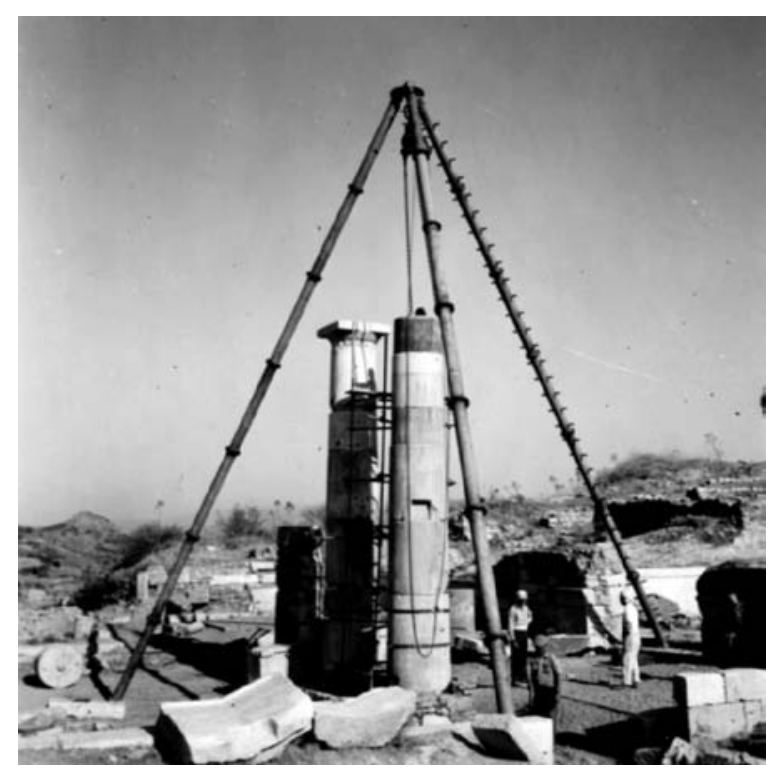

1 Prytaneion. Rekonstruktion der dorischen Ordnung der Vorhalle (1964)

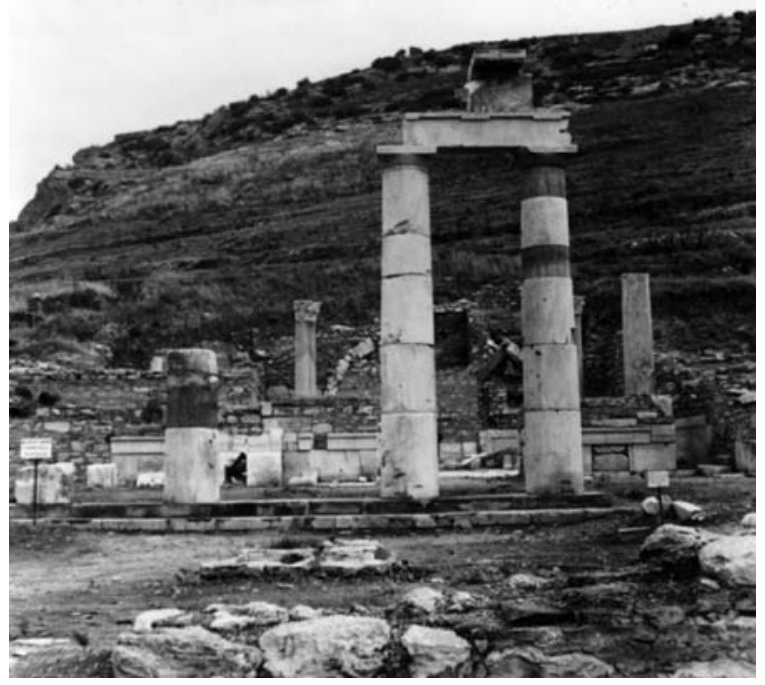

2 Prytaneion. Rekonstruierte dorische Ordnung der Vorhalle (1968)

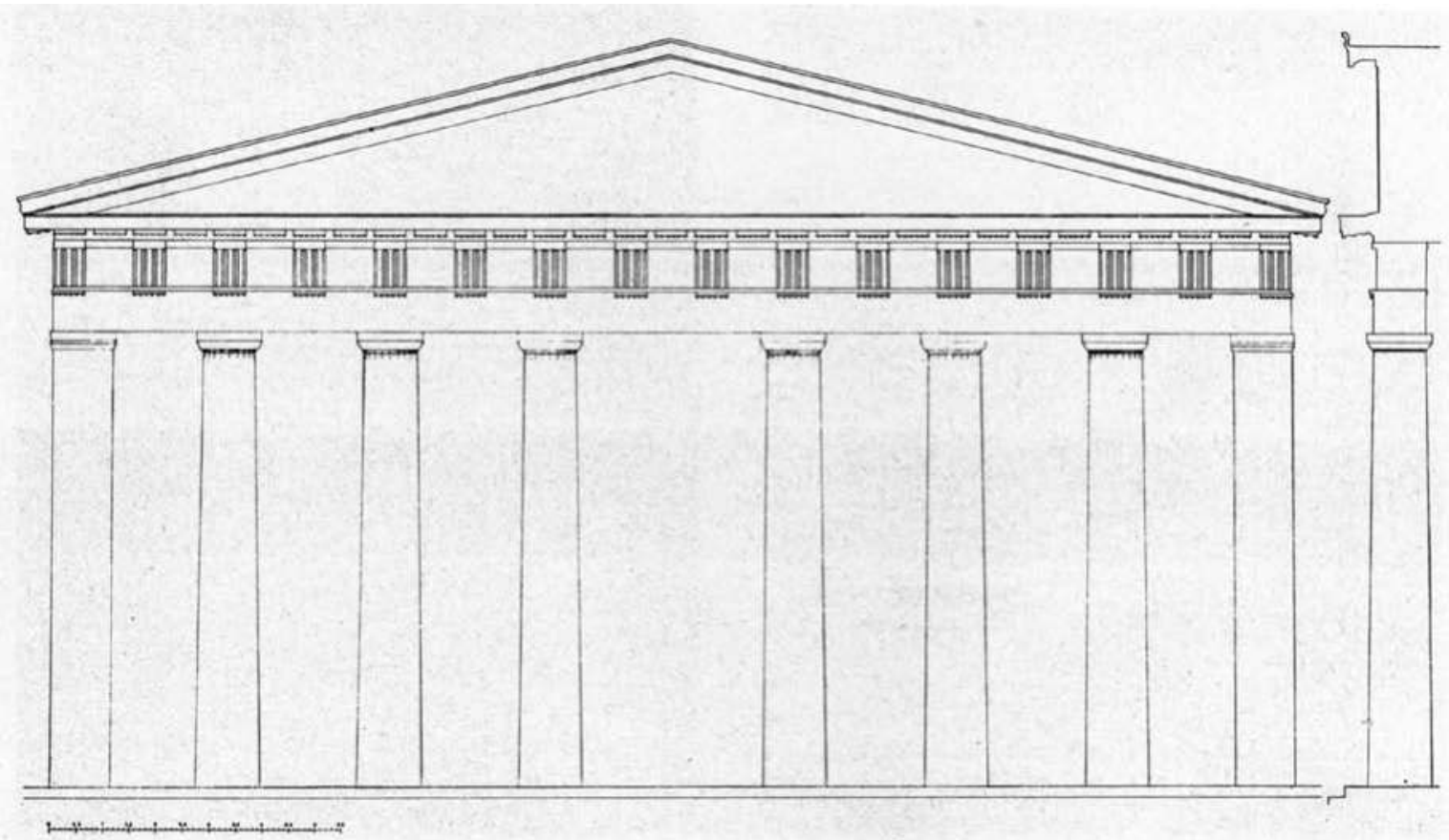

3 Prytaneion. Rekonstruktion der Vorhalle (W. J.) 


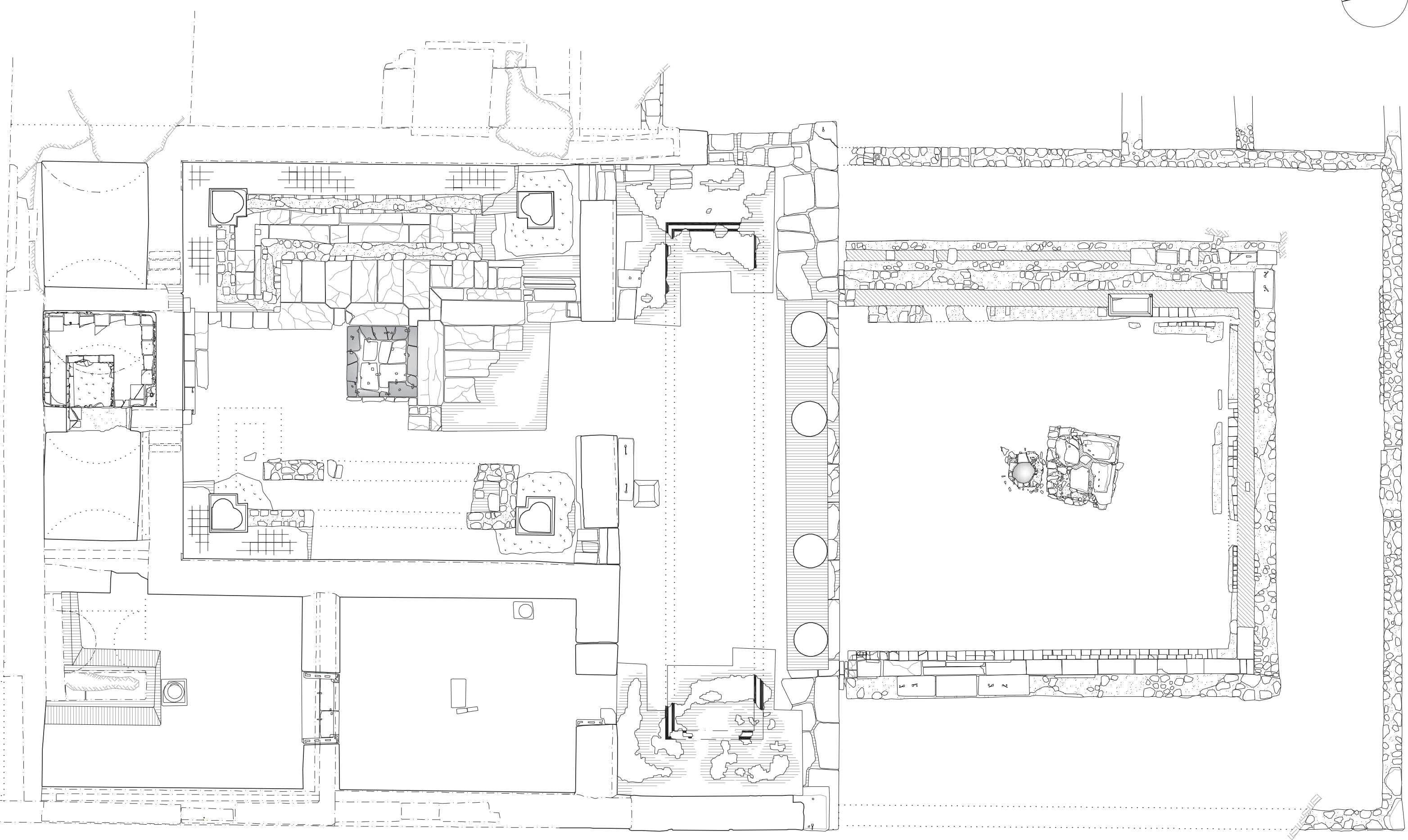


Tafel 31

\section{PRYTANEION}

GRUNDRISS BEMASSUNG

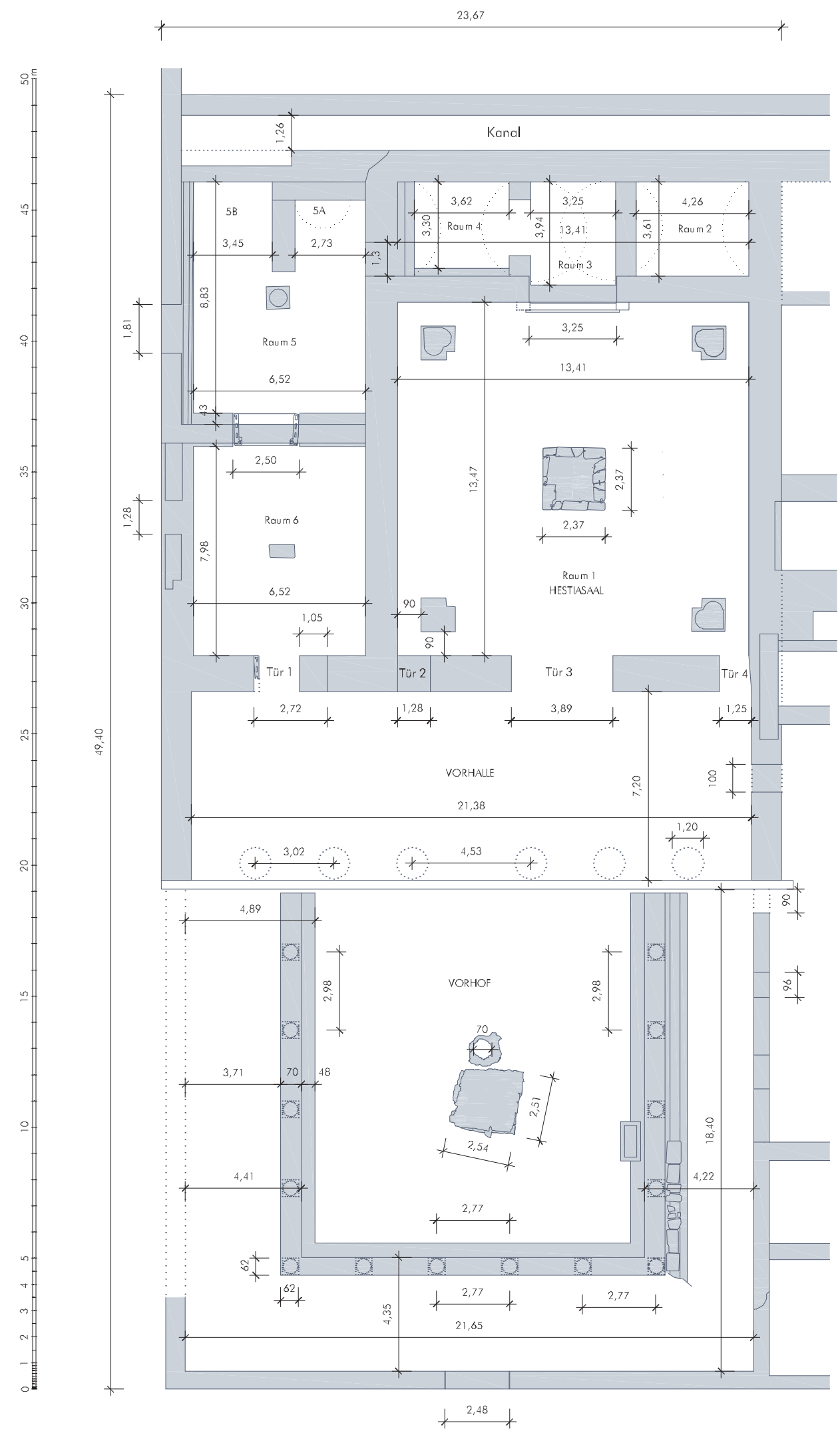


Tafel 32

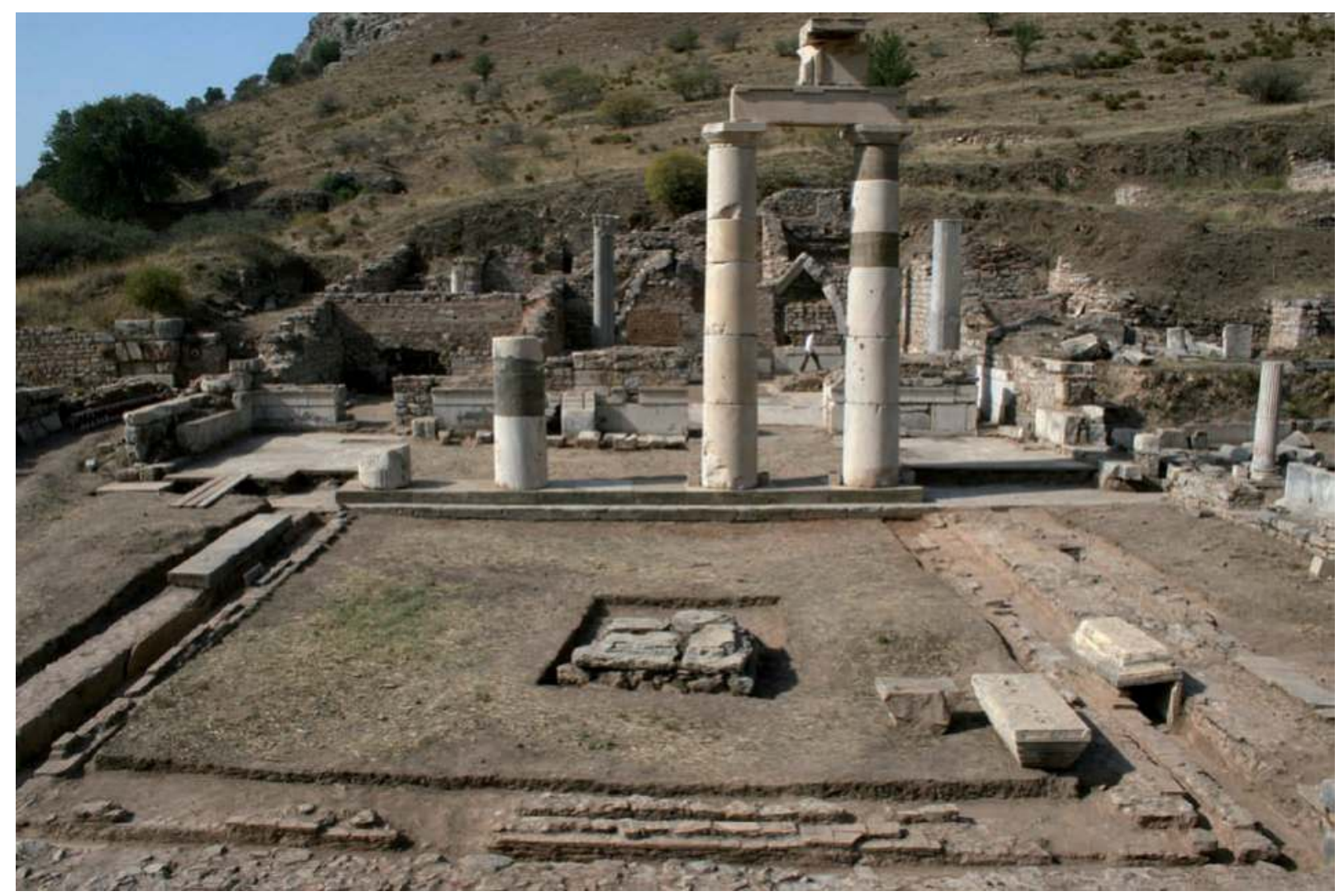

1 Vorhof von Süden

PRYTANEION

Vorhof - Südwand

gezeichnet

P. Moyrhofer

grafische Bearbeitung

L. Zabran

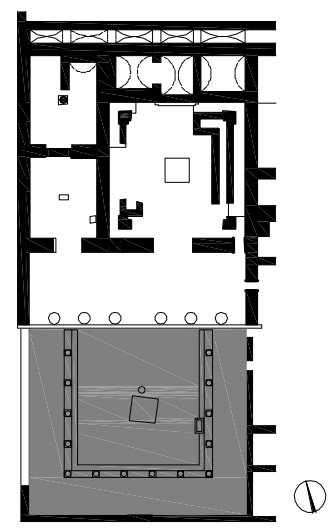

$\left.\begin{array}{c}47,00 \mathrm{~m} \\ 46,00 \mathrm{~m} \\ 45,00 \mathrm{~m}\end{array}\right]$

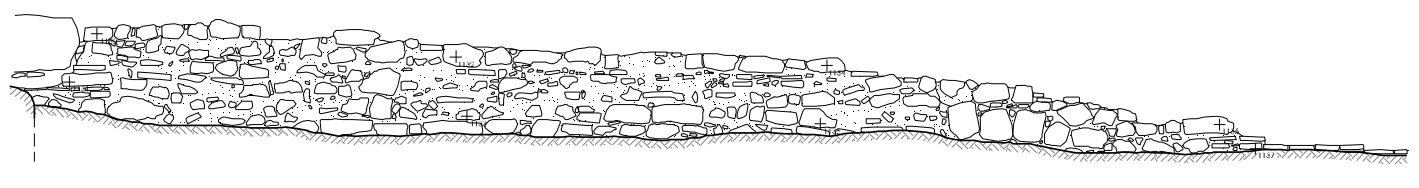

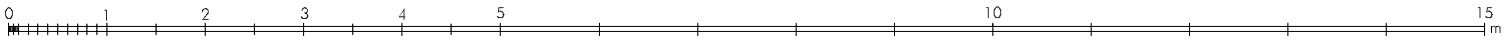

2 Vorhof. Südwand (1:100) 
Tafel 33

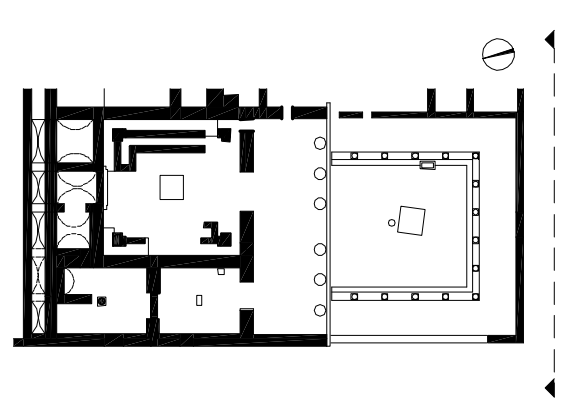

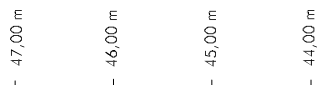

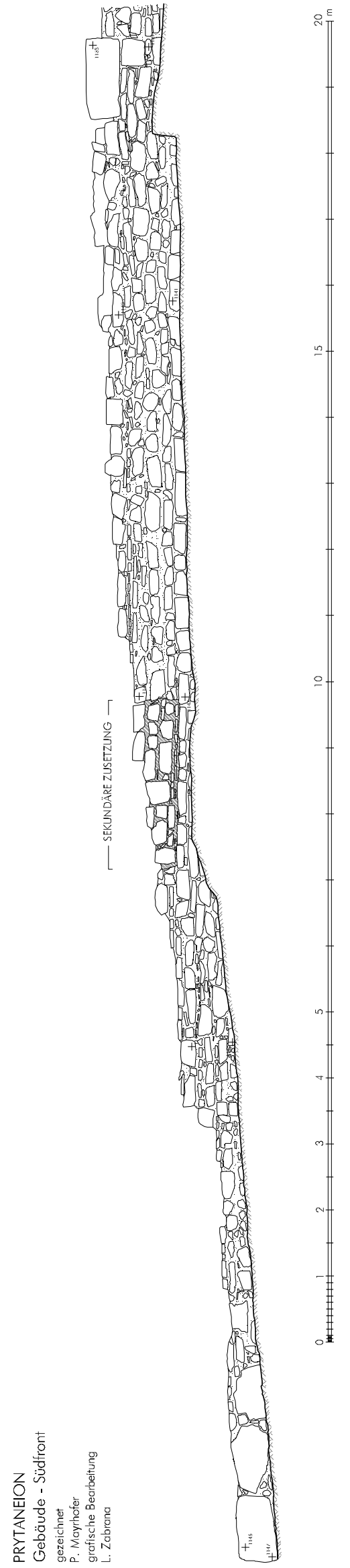

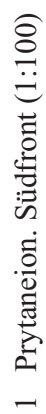


Tafel 34
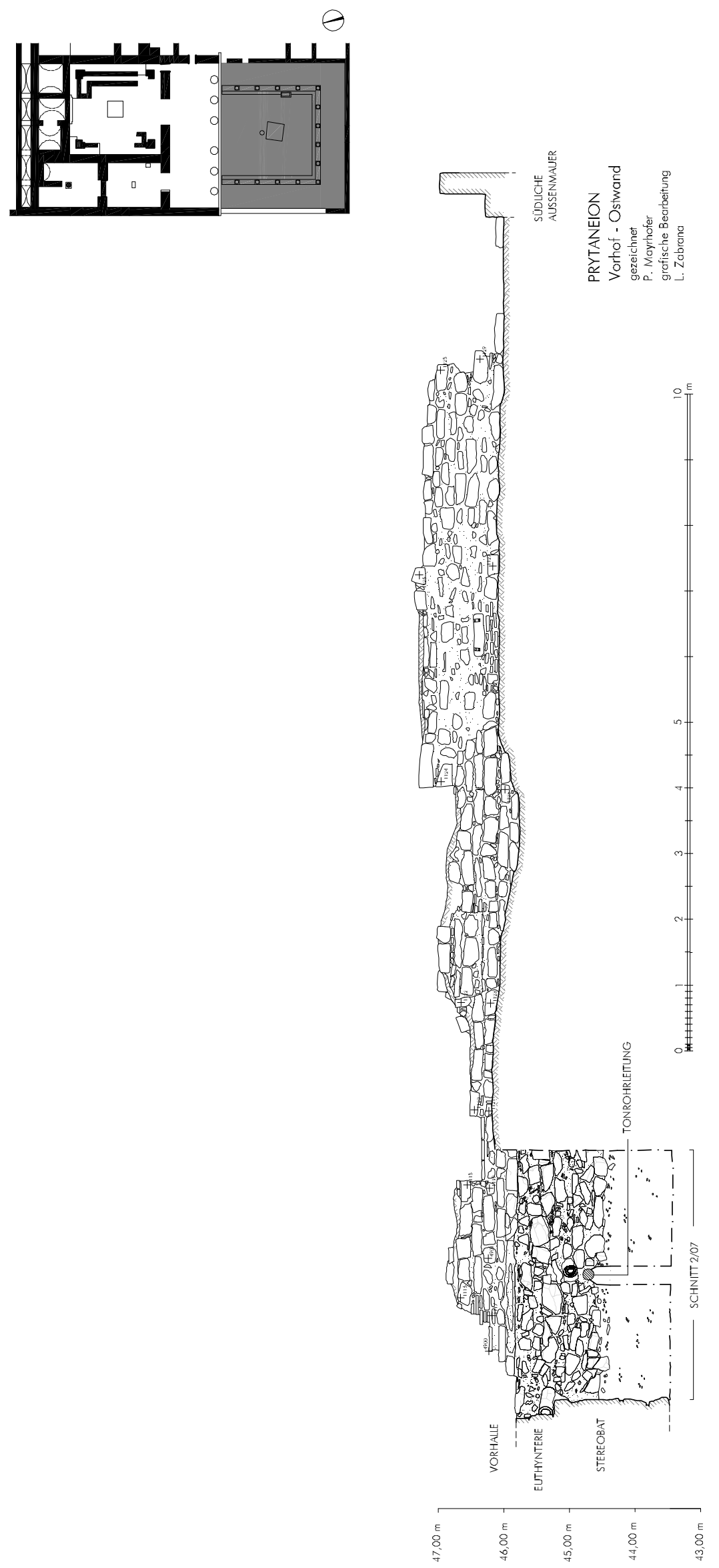
Tafel 35

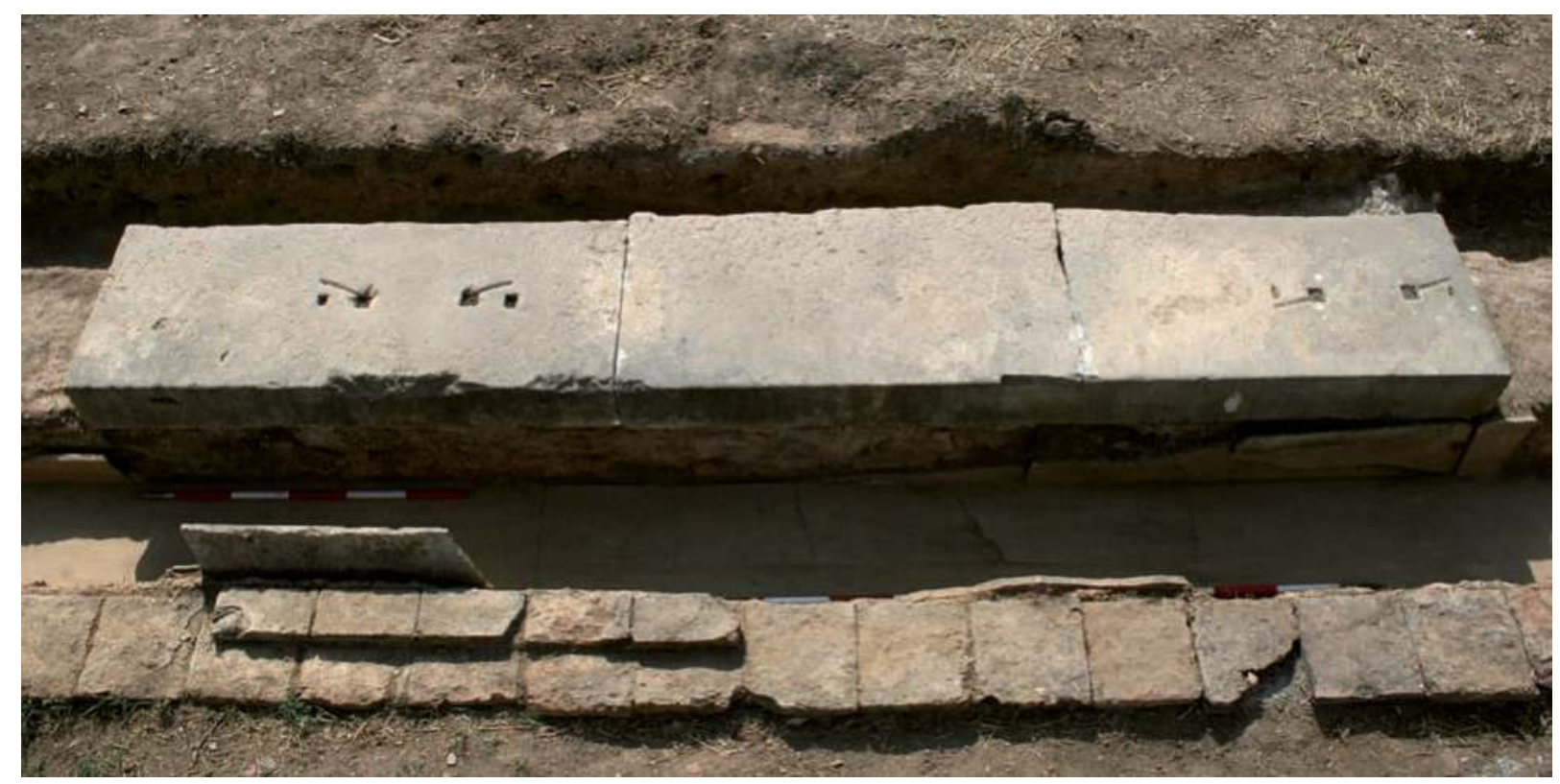

1 Stylobatblöcke der Westseite

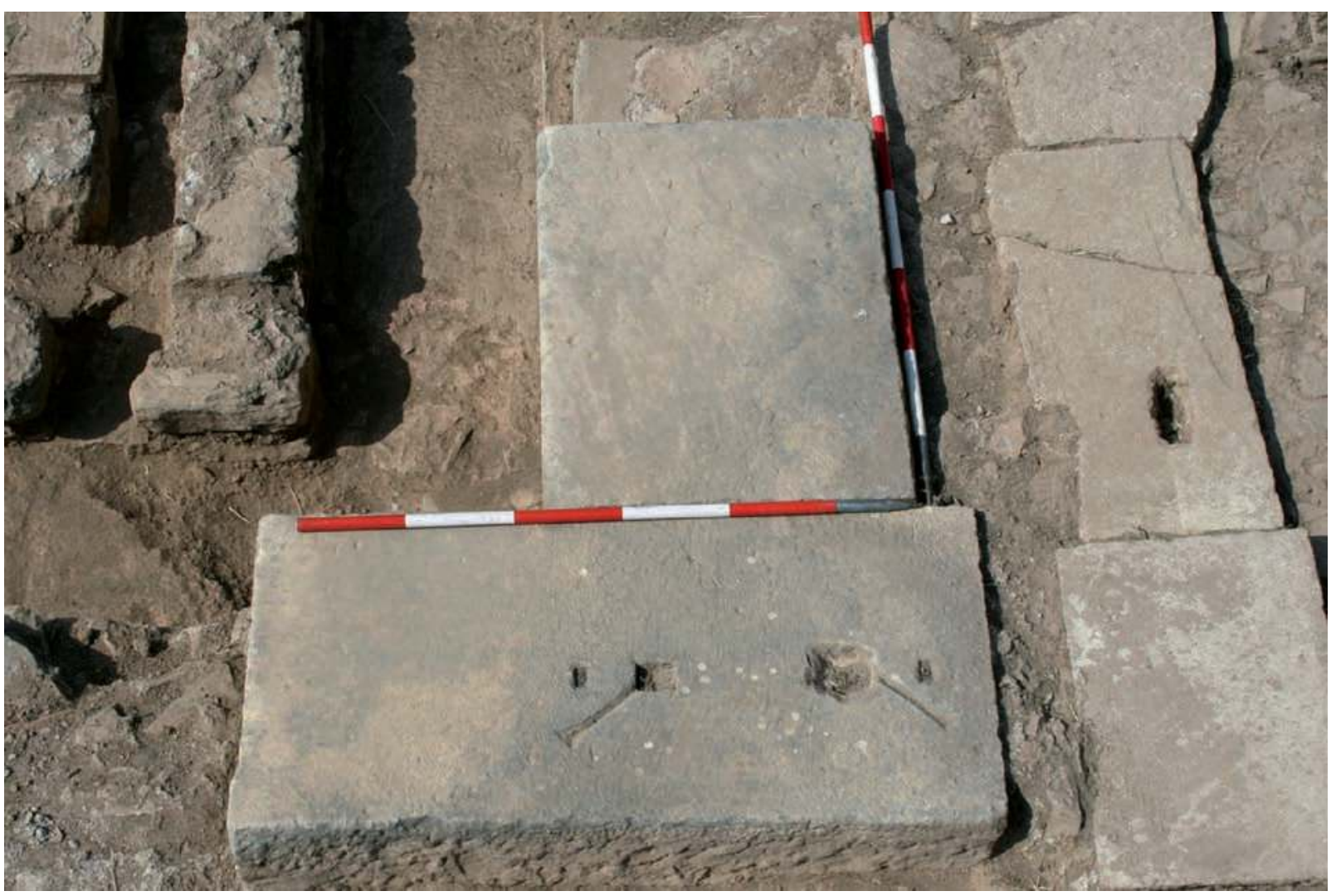

2 Stylobatblöcke der Südostecke 
Tafel 36

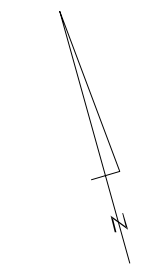

PRYTANEION

Vorhof - Stylobat W-Seite gezeichnet
Josef Eitler graf. Becrbeitung L. Zabrana

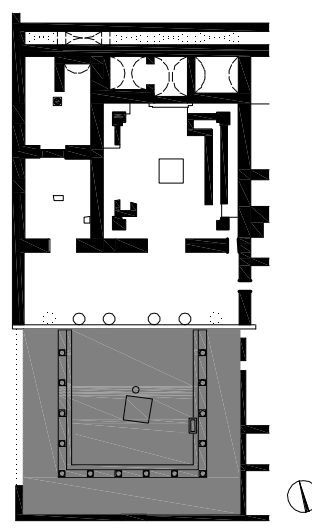

PRYTANEION

Vorhof - Stylobat SO-Ecke gezeichnet

graf. Bearbeitung

L. Zabrana

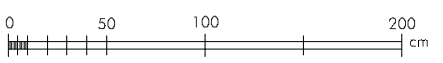

1 Stylobatblöcke der Westseite und der Südostecke (1:50) 
Tafel 37

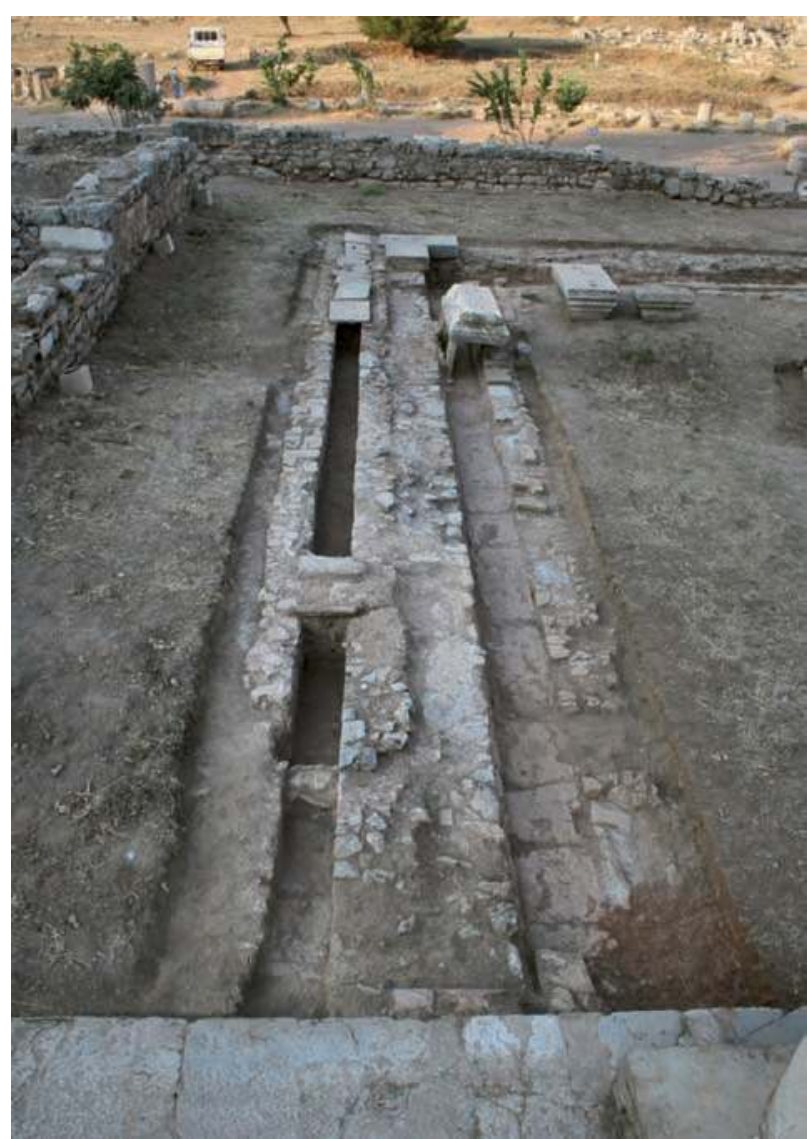

1 Vorhof. Östliche Regenrinne von Norden

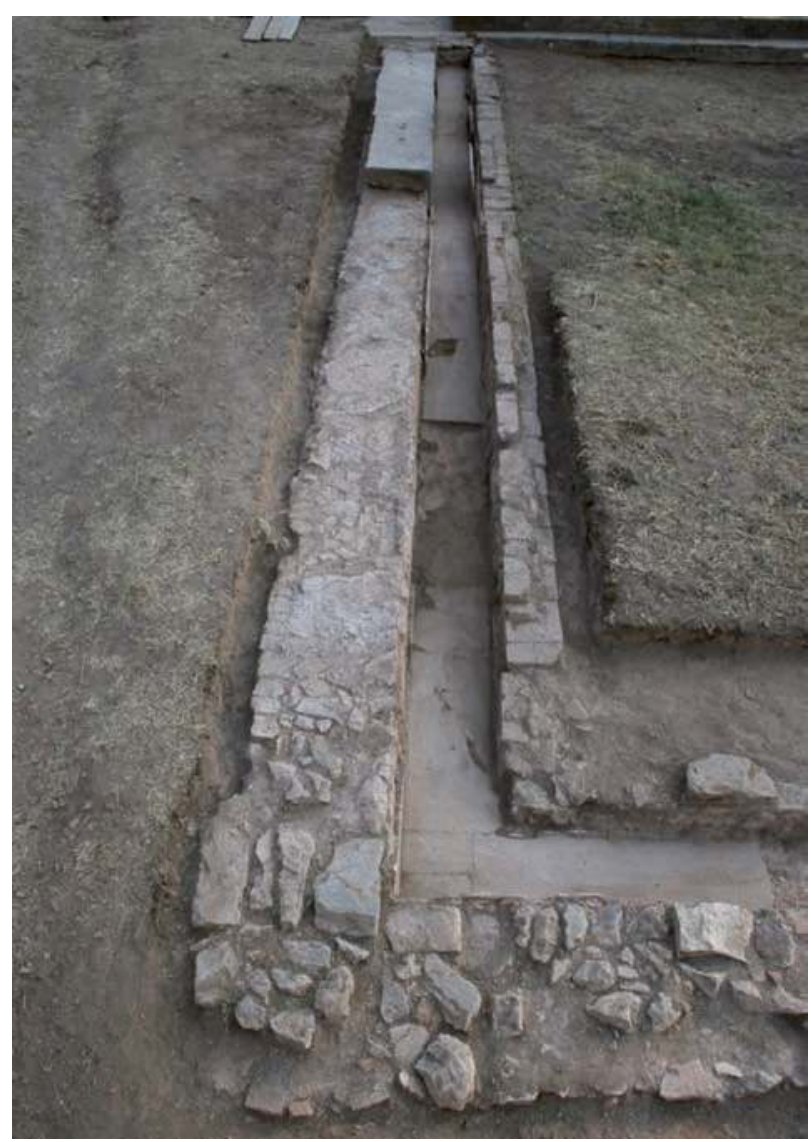

3 Vorhof. Westliche Regenrinne von Süden

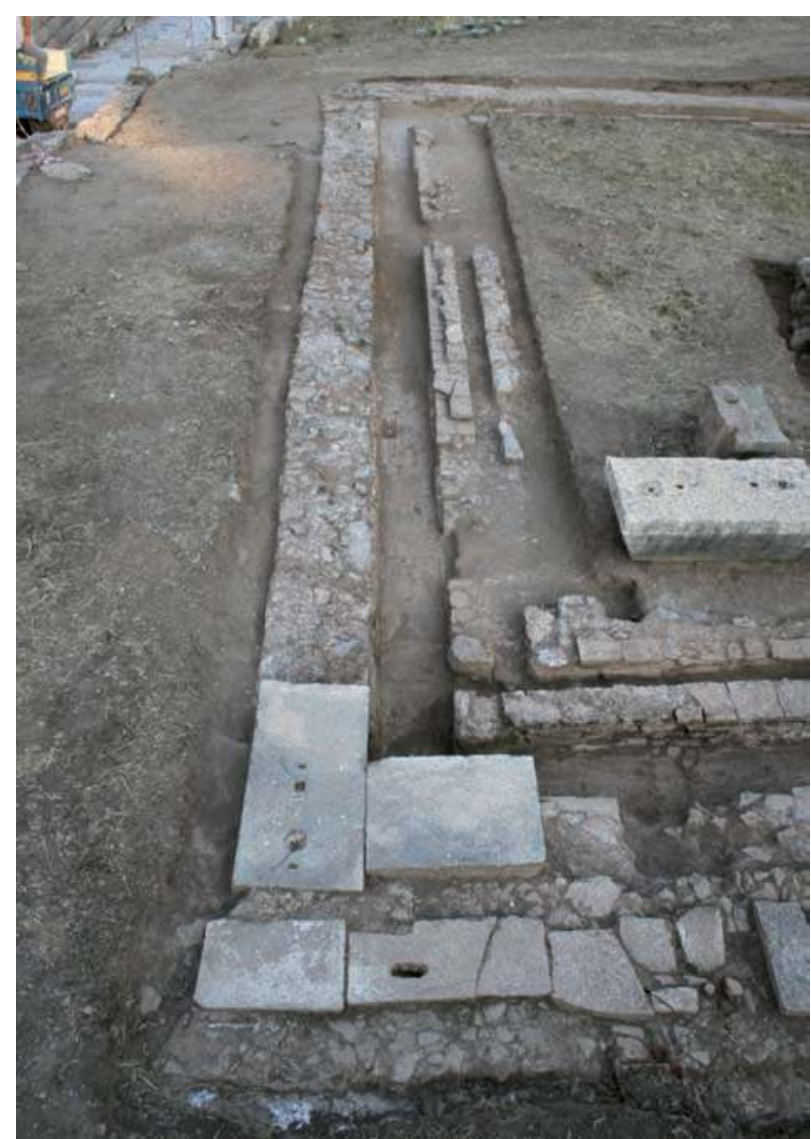

2 Vorhof. Südliche Regenrinne von Osten

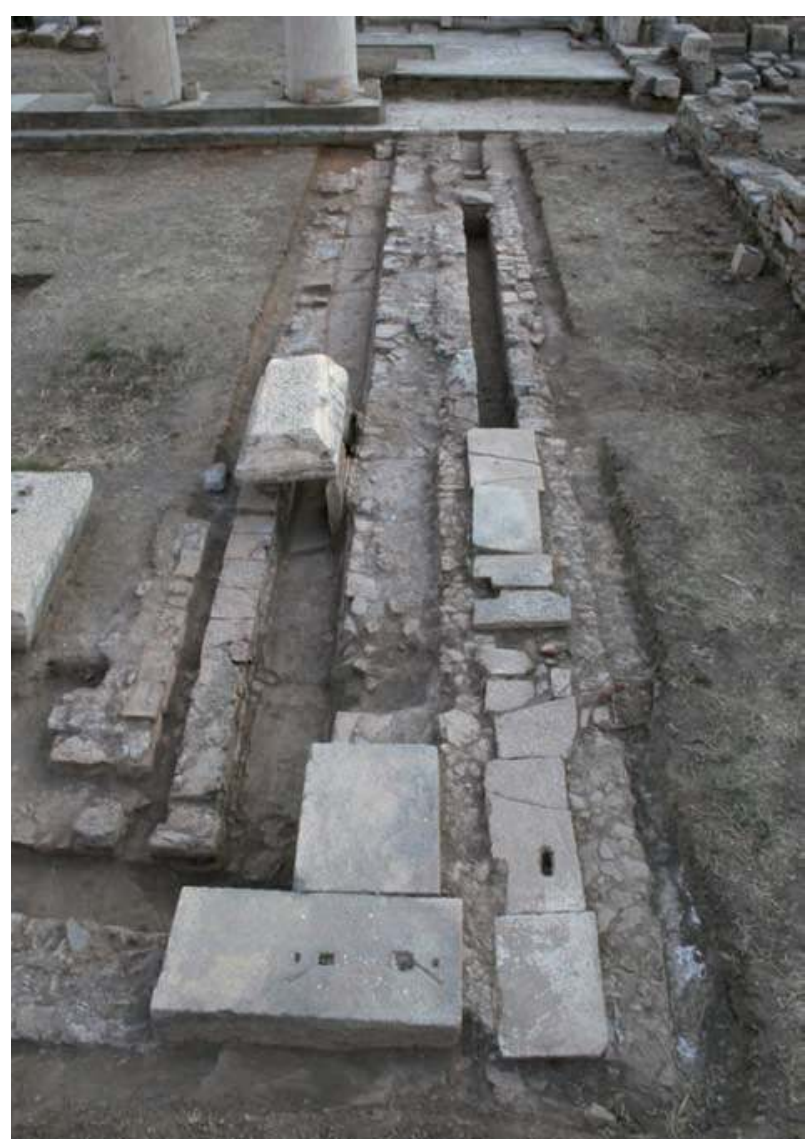

4 Nord-Süd verlaufender Kanal unter östlichem Umgang 
Tafel 38

PRYTANEION

VORHOF - PR 02/07

AUFSATZ EHRENBASIS

gezeichne

grafische Bearbeitung

L. Zabrana

PRYTANEION

VORHOF - PR 01/07

SOCKEL EHRENBASIS

gezeichnet

grafische Bearbeitung

L. Zabrana
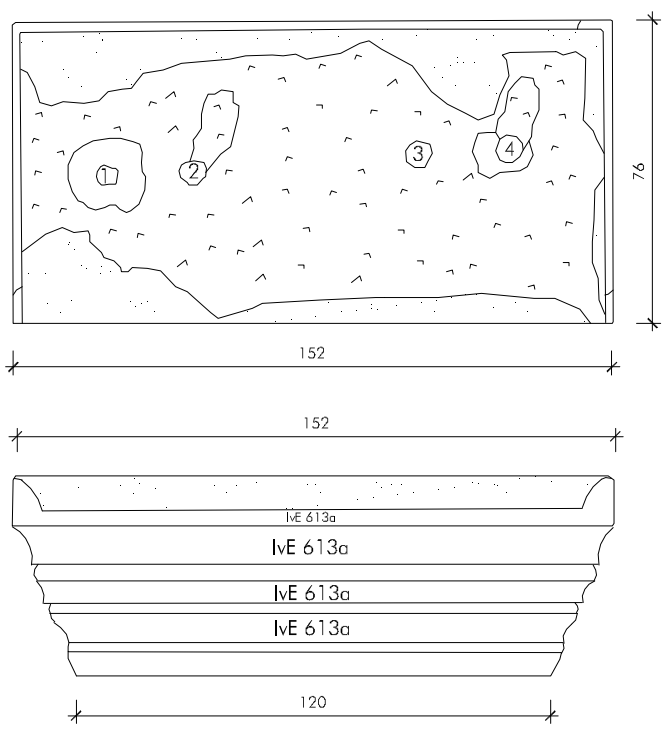

$\stackrel{0}{0}+\underset{+}{+}+100 \quad 200$
1: $T 2,5 \varnothing 5,5$

2: T $4 \varnothing 5,5 \times 6$

3: T5 Ø $5,5 \times 6,5$

4: T4,5 Ø $6,5 \times 7$
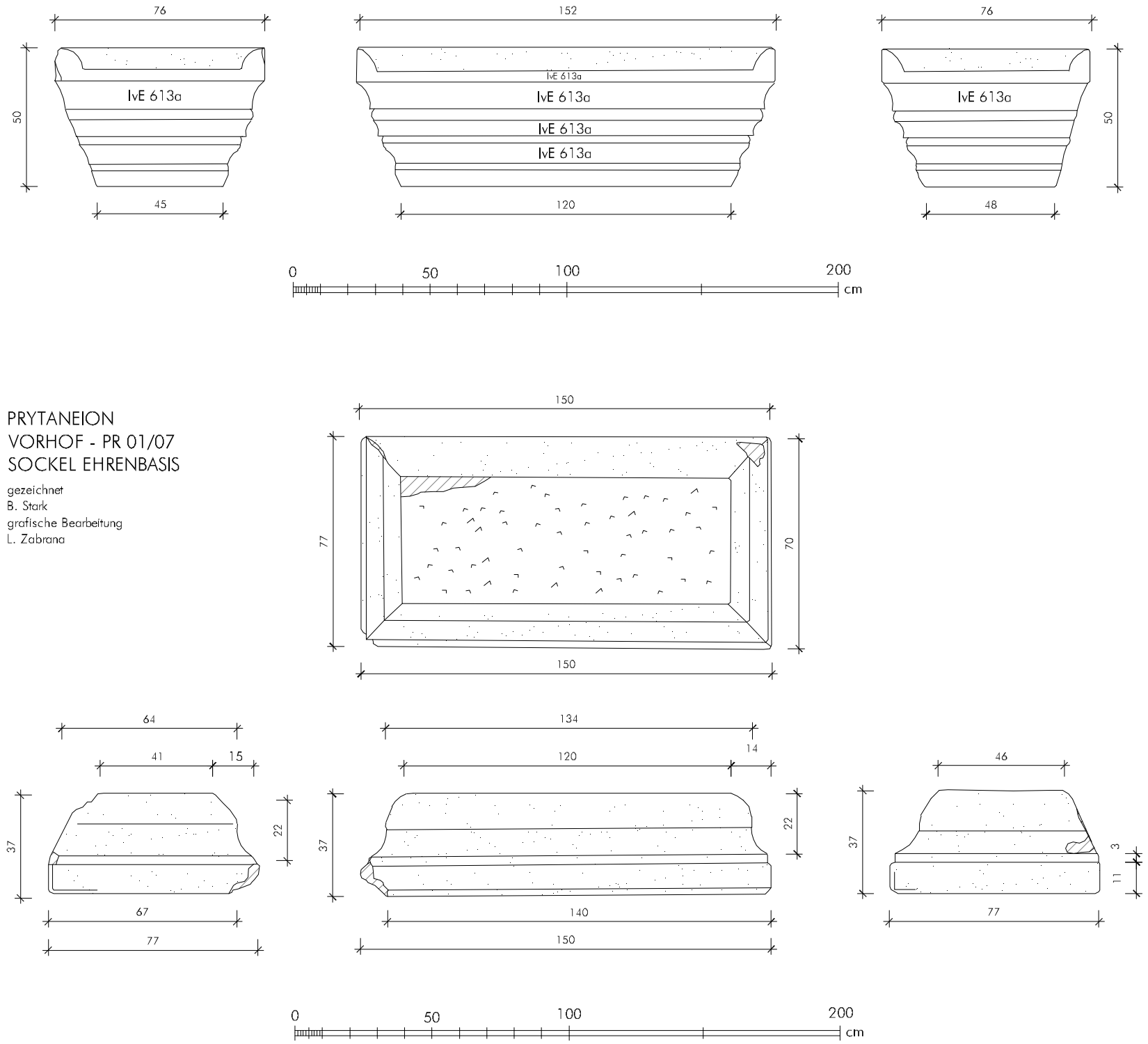

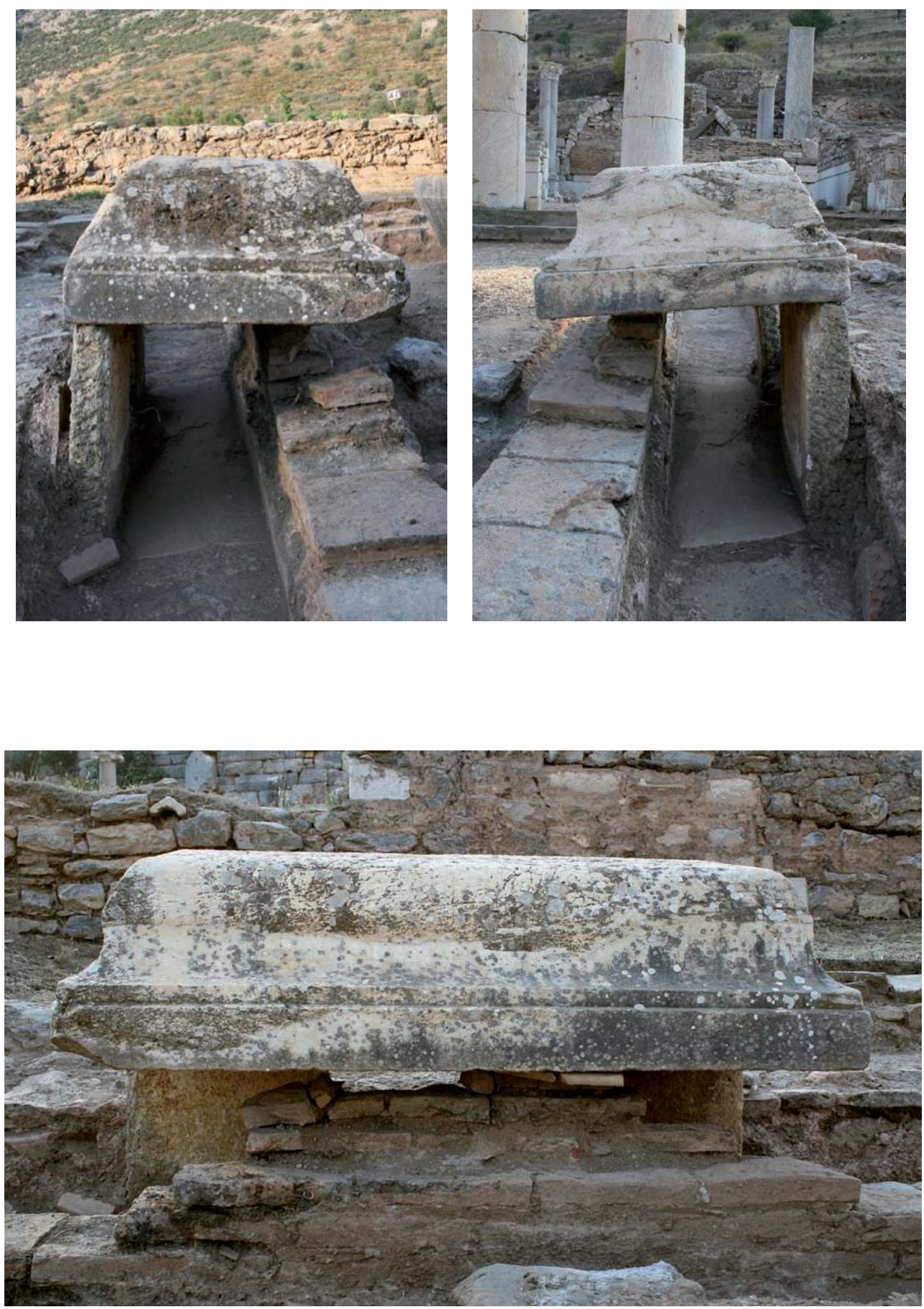

1-3 Sockel Ehrenbasis SK 12 
Tafel 40
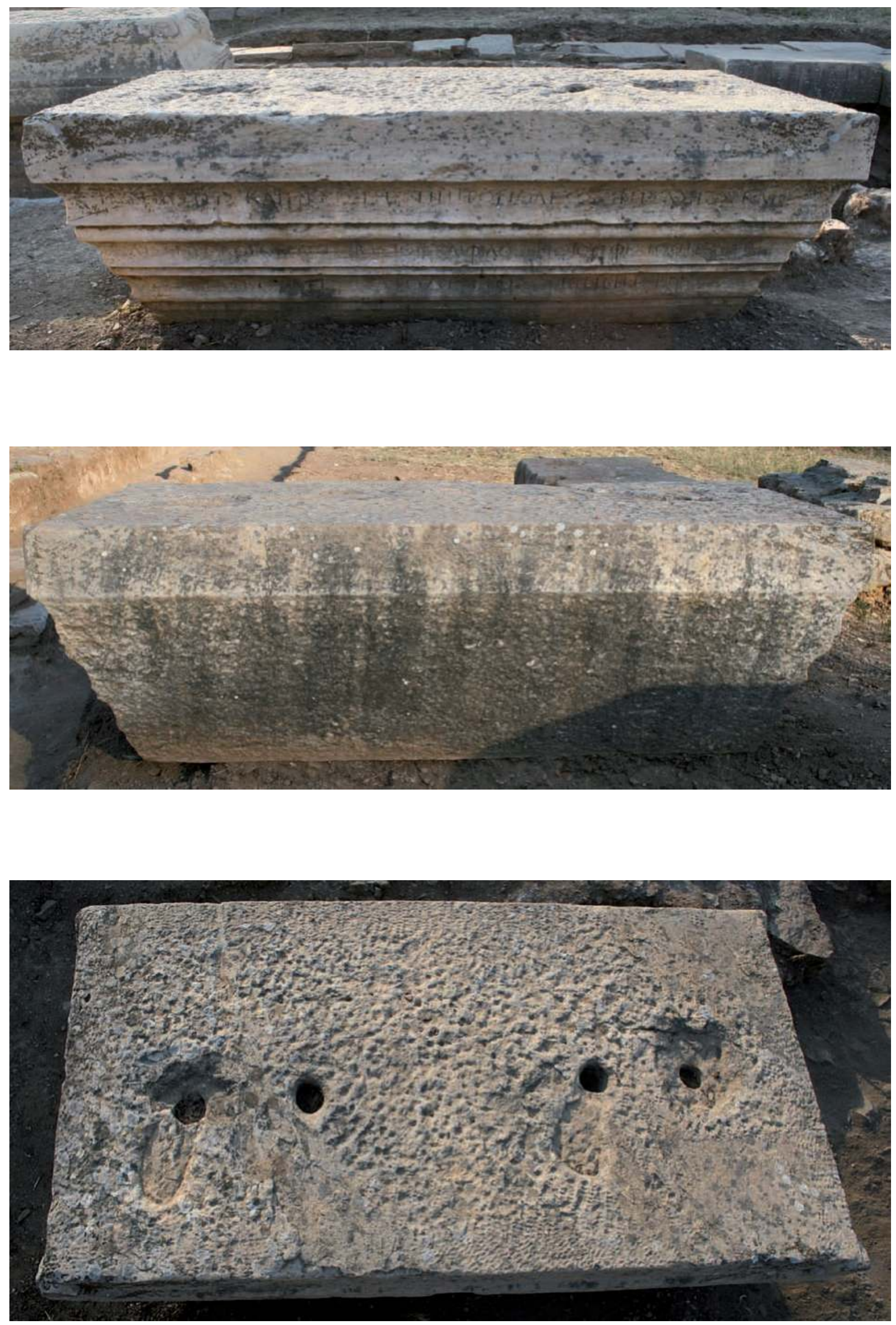

1-3 Aufsatz Ehrenbasis SK 13 
Tafel 41
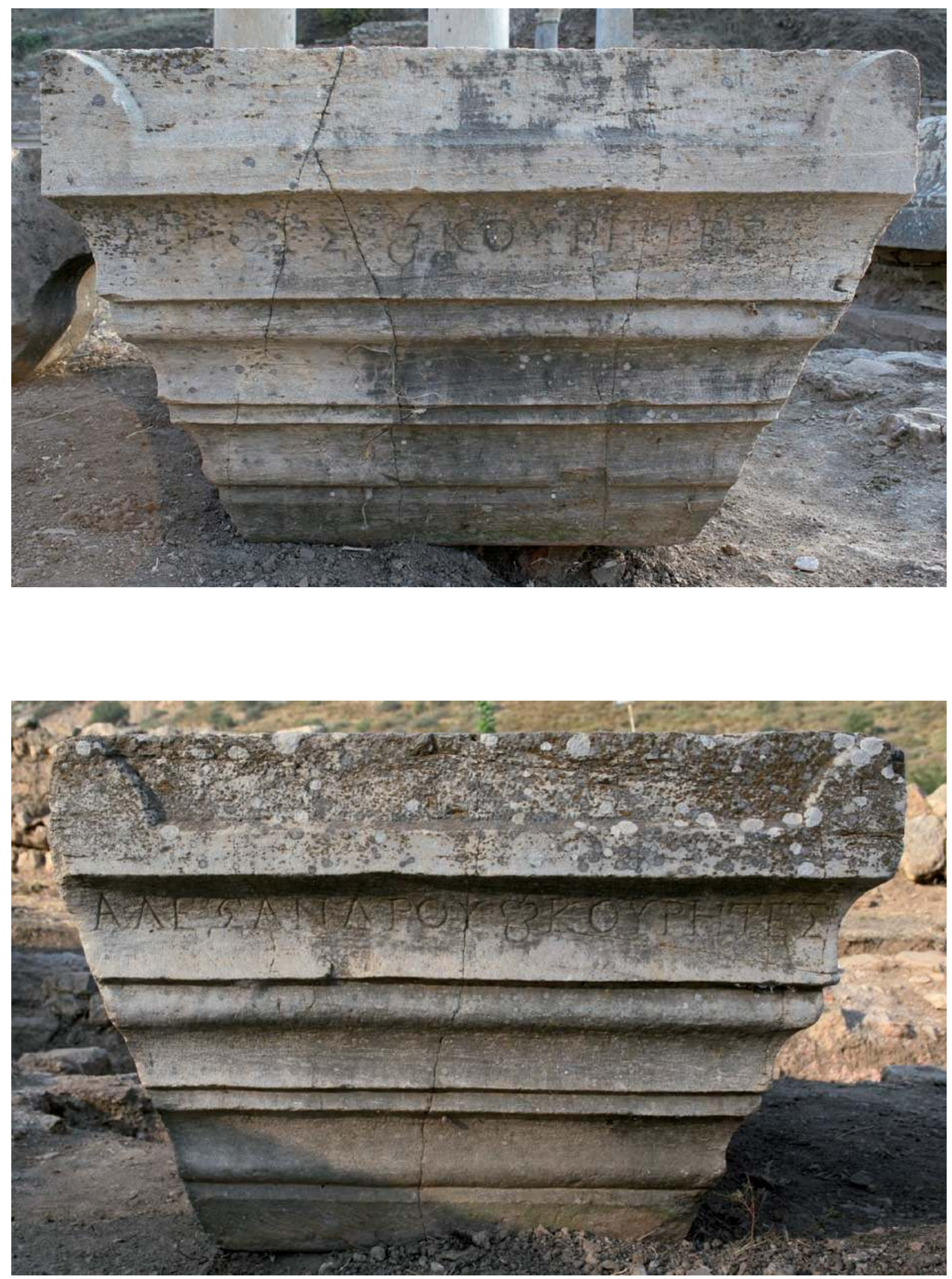

1-2 Aufsatz Ehrenbasis SK 13 
Tafel 42
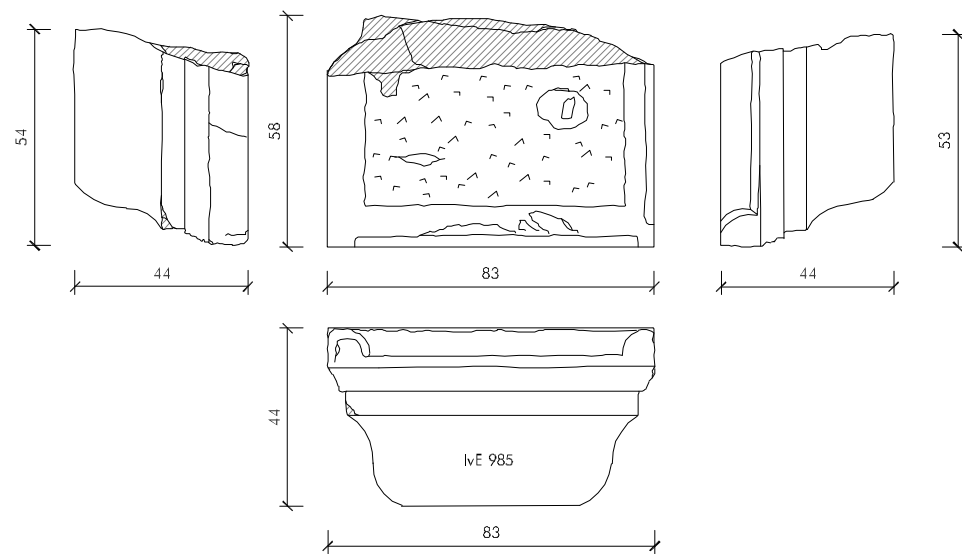

PRYTANEION

VORHOF - PR 03/07

AUFSATZ EHRENBASIS

gezeichnet

grafische Bearbeitung

0

50

100

200

1 Aufsatz Ehrenbasis SK 14 (1:25)
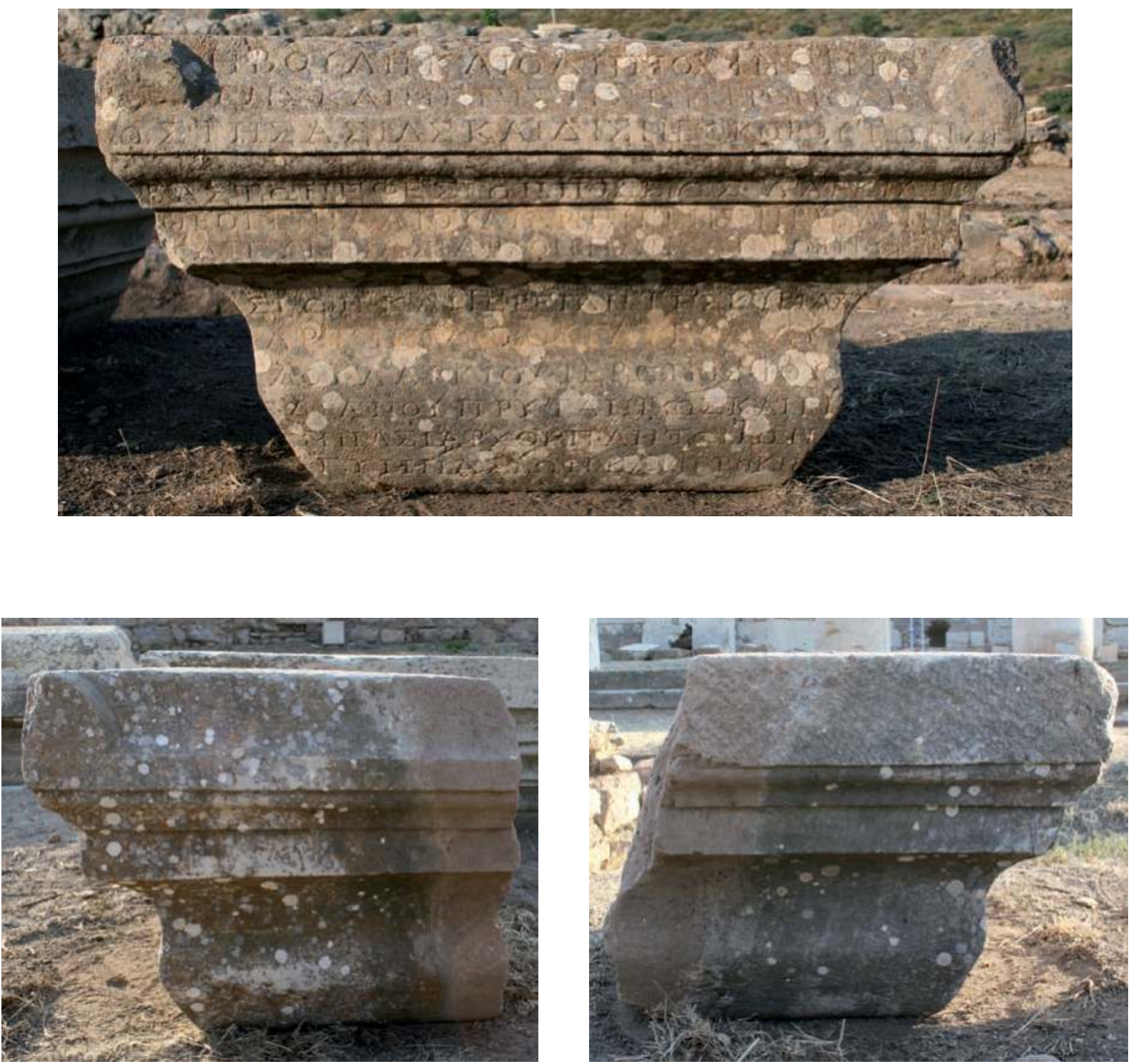

2-4 Aufsatz Ehrenbasis SK 14 
Tafel 43

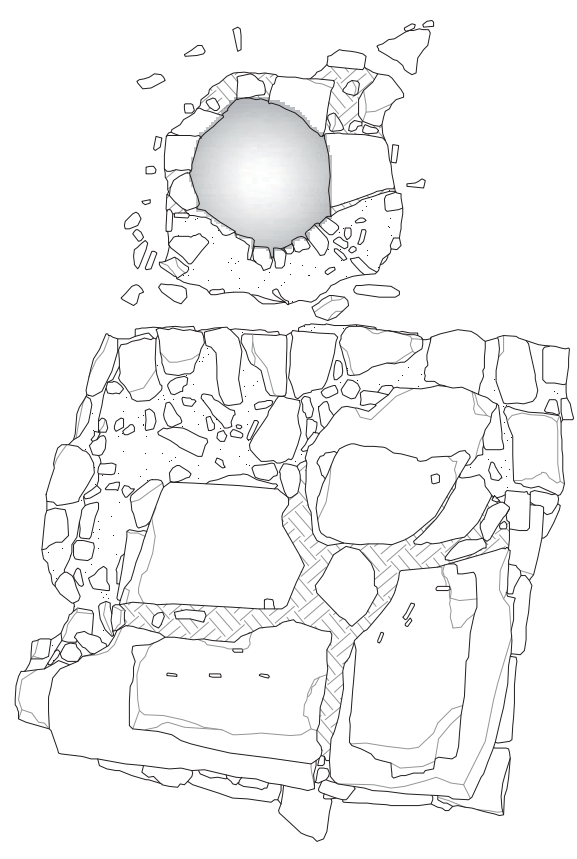

0
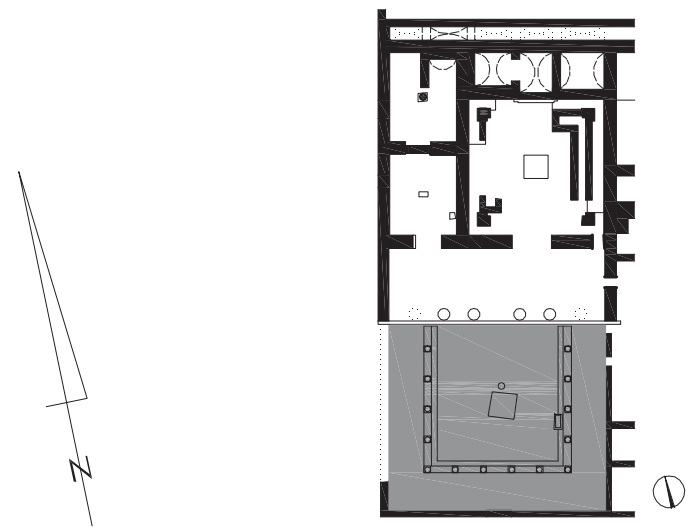

PRYTANEION

Vorhof - Fundament, Bothros

gezeichnet

graf. Bearbeitung

1 Fundament und Bothros im Zentrum des Vorhofes (1:50)

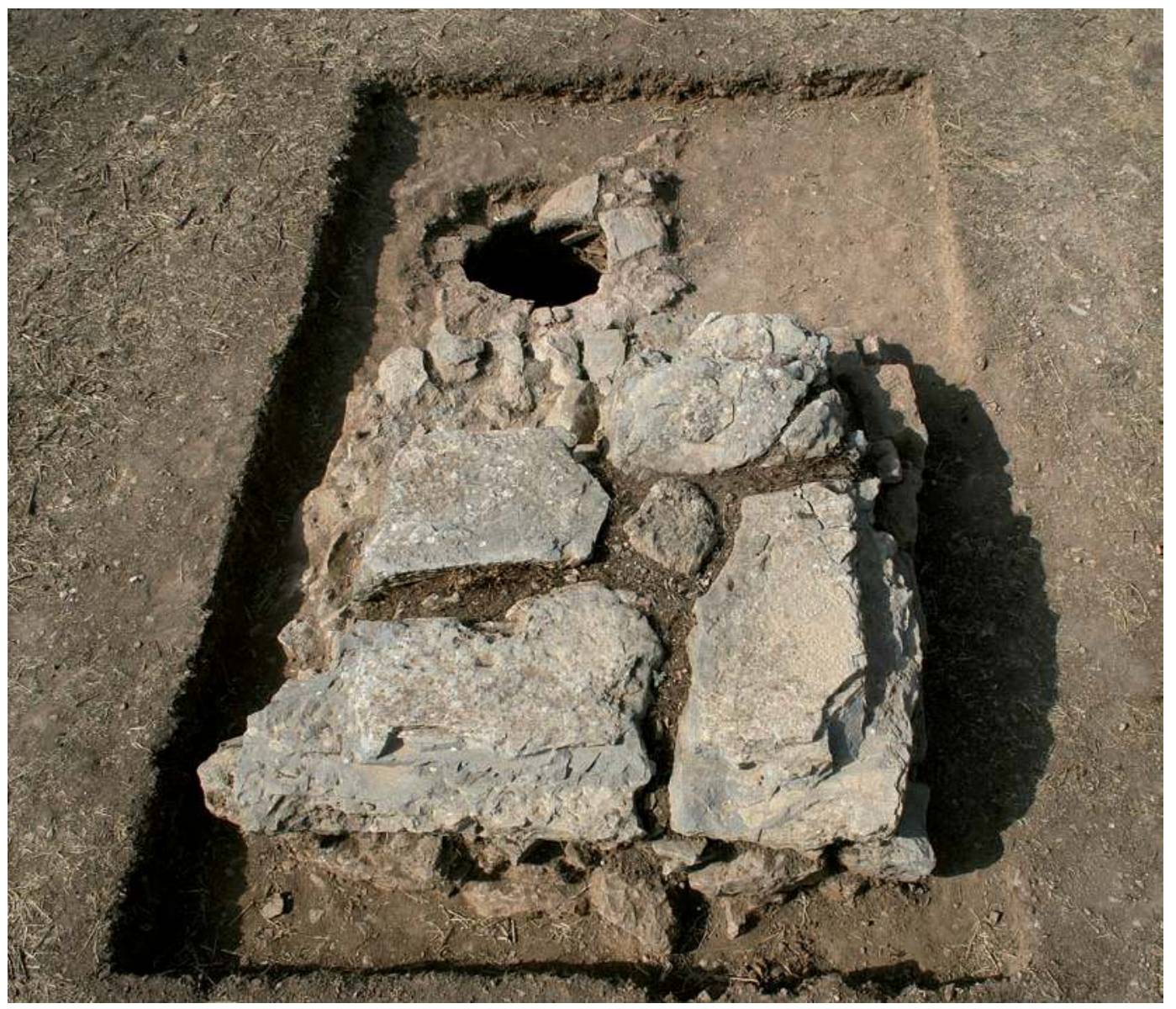

2 Fundament und Bothros von Süden 
Tafel 44

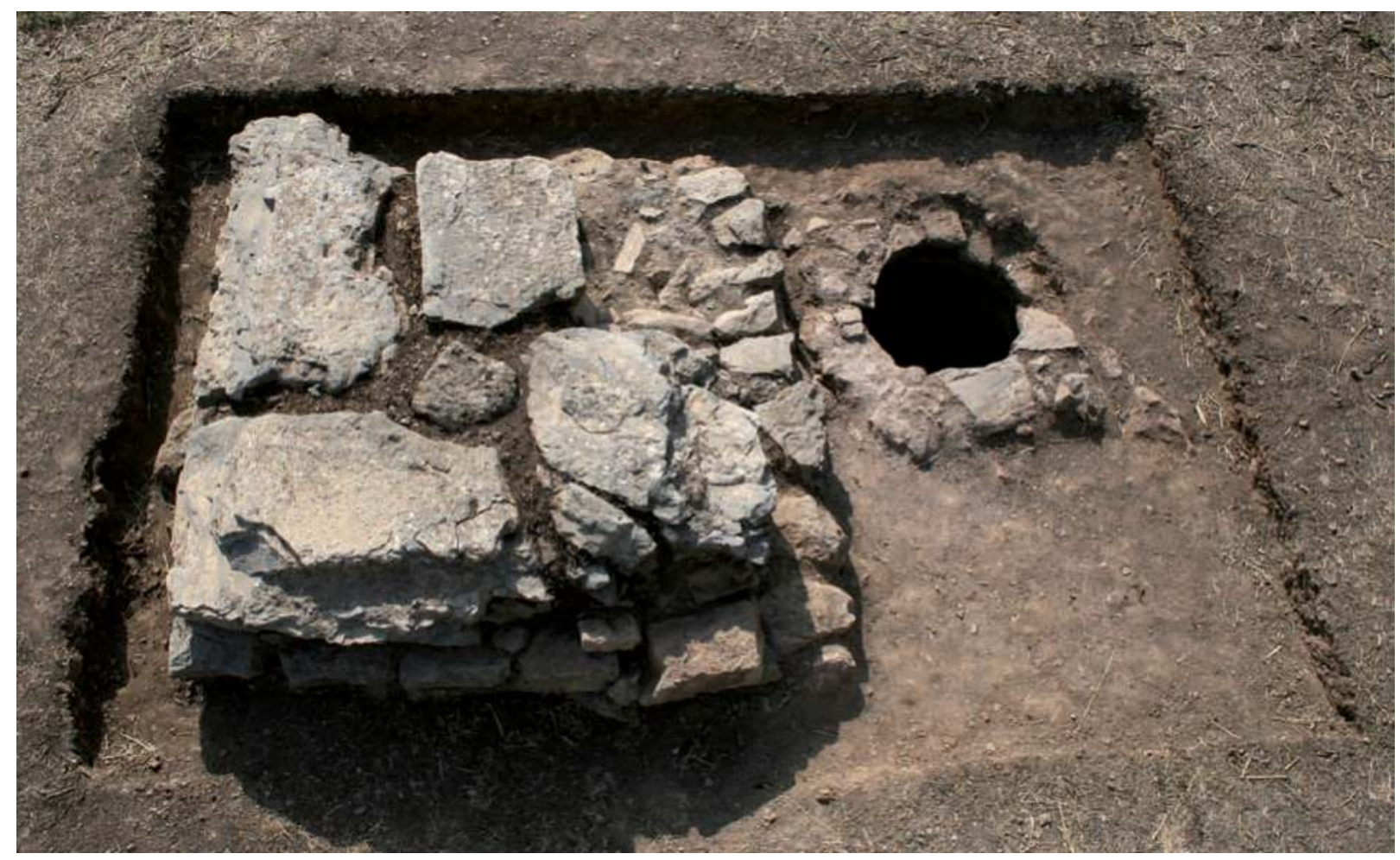

1 Fundament und Bothros von Osten

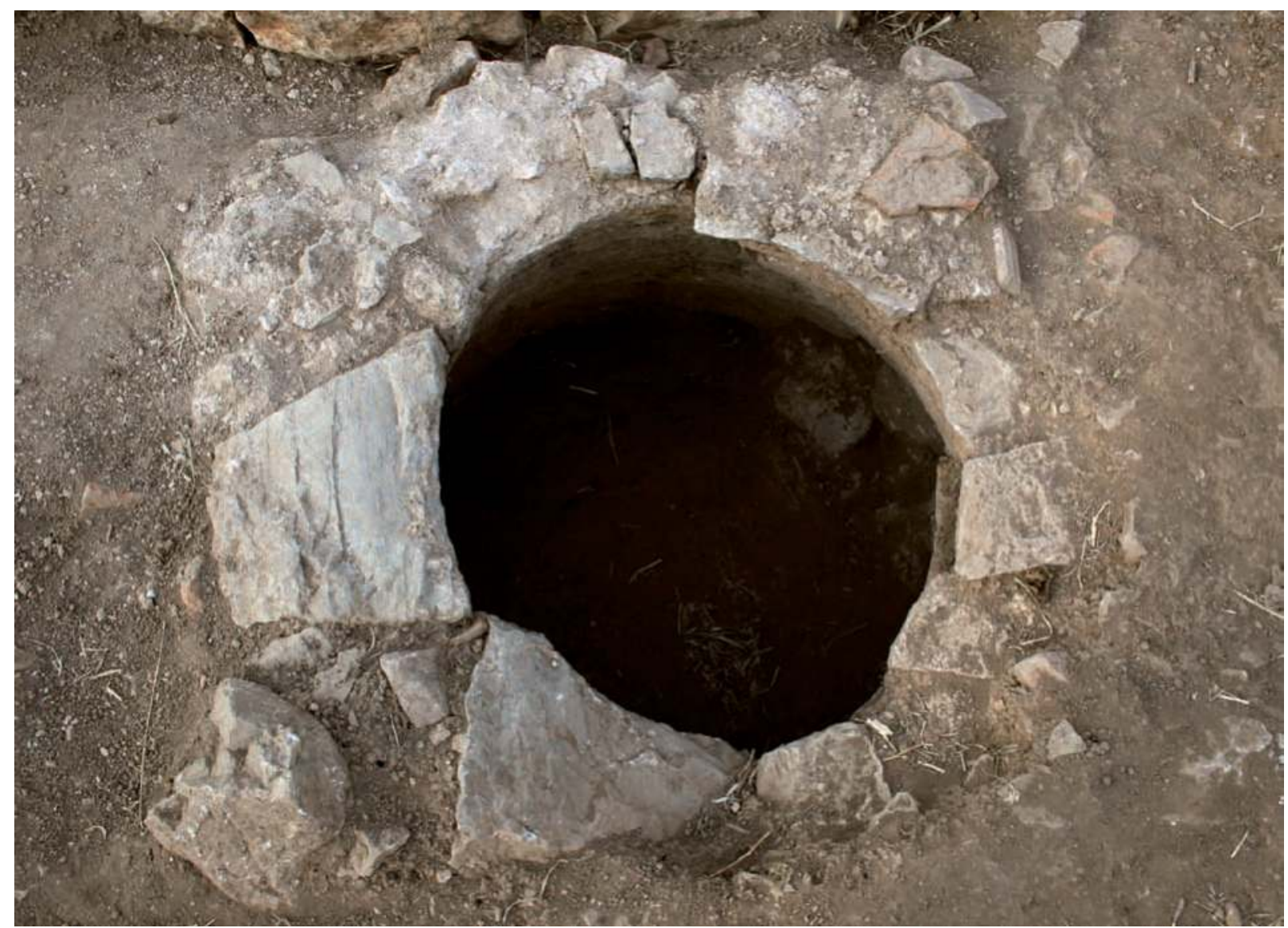

2 Detail Bothros 
Tafel 45

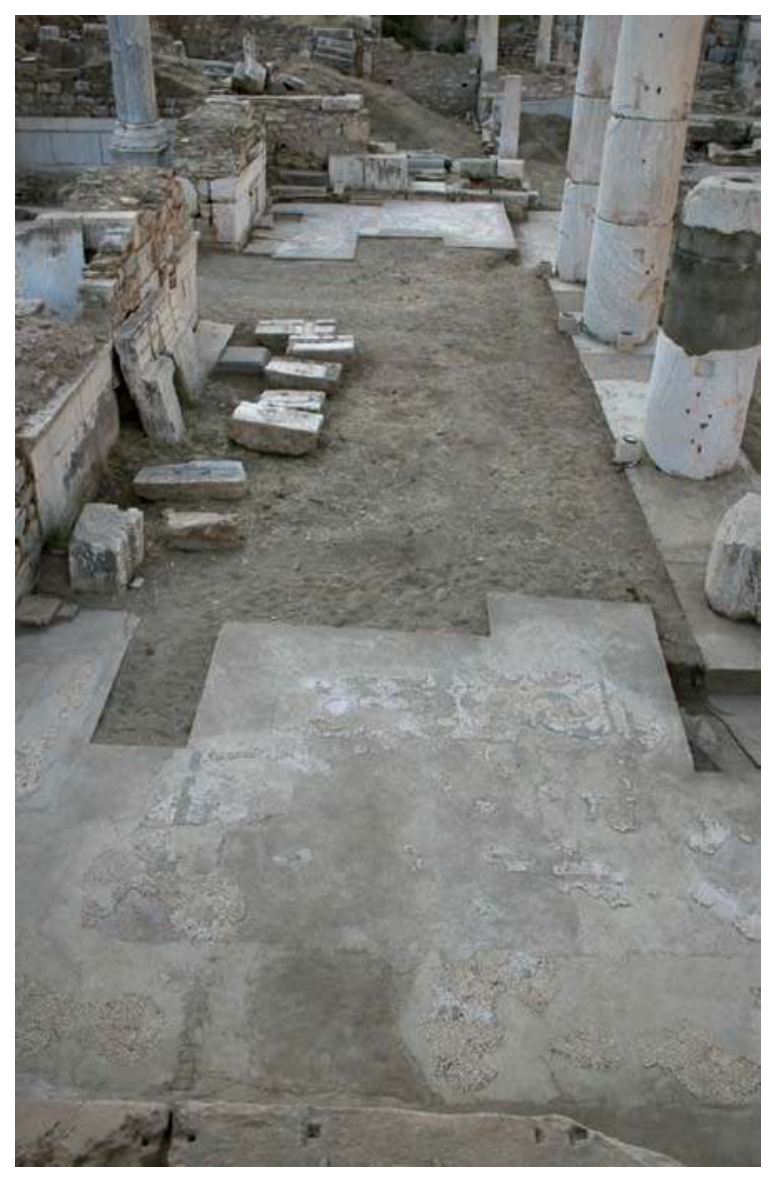

1 Vorhalle von Westen

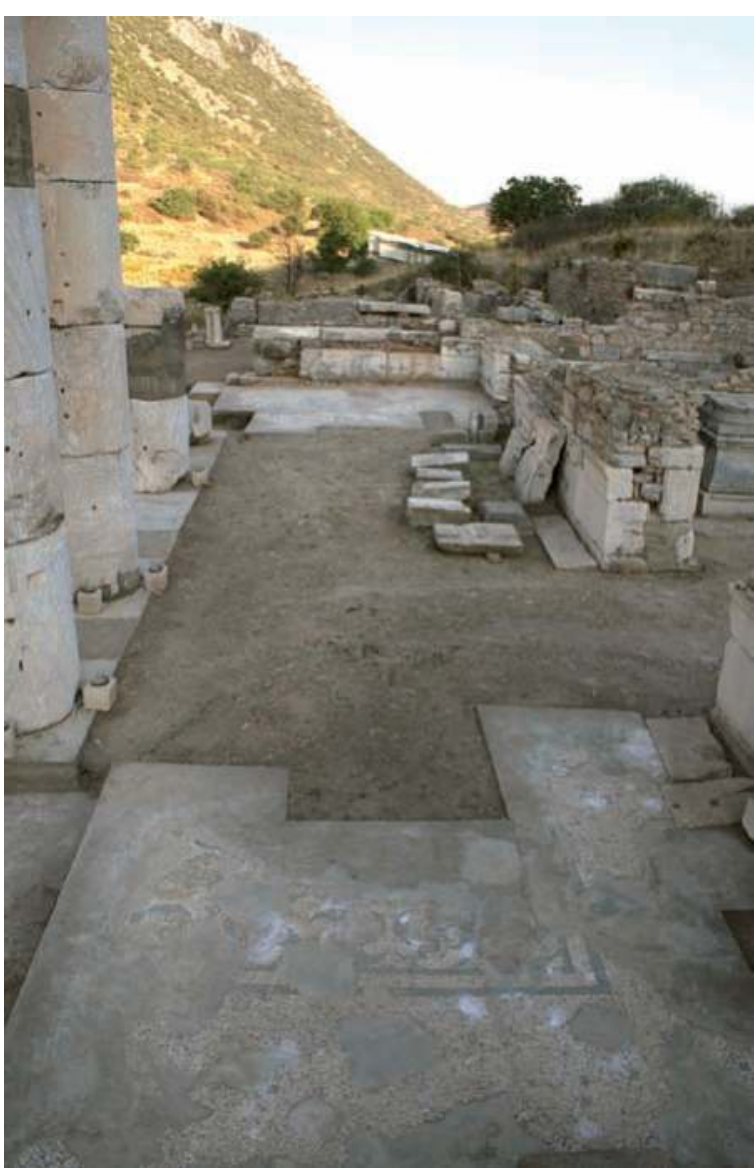

2 Vorhalle von Osten

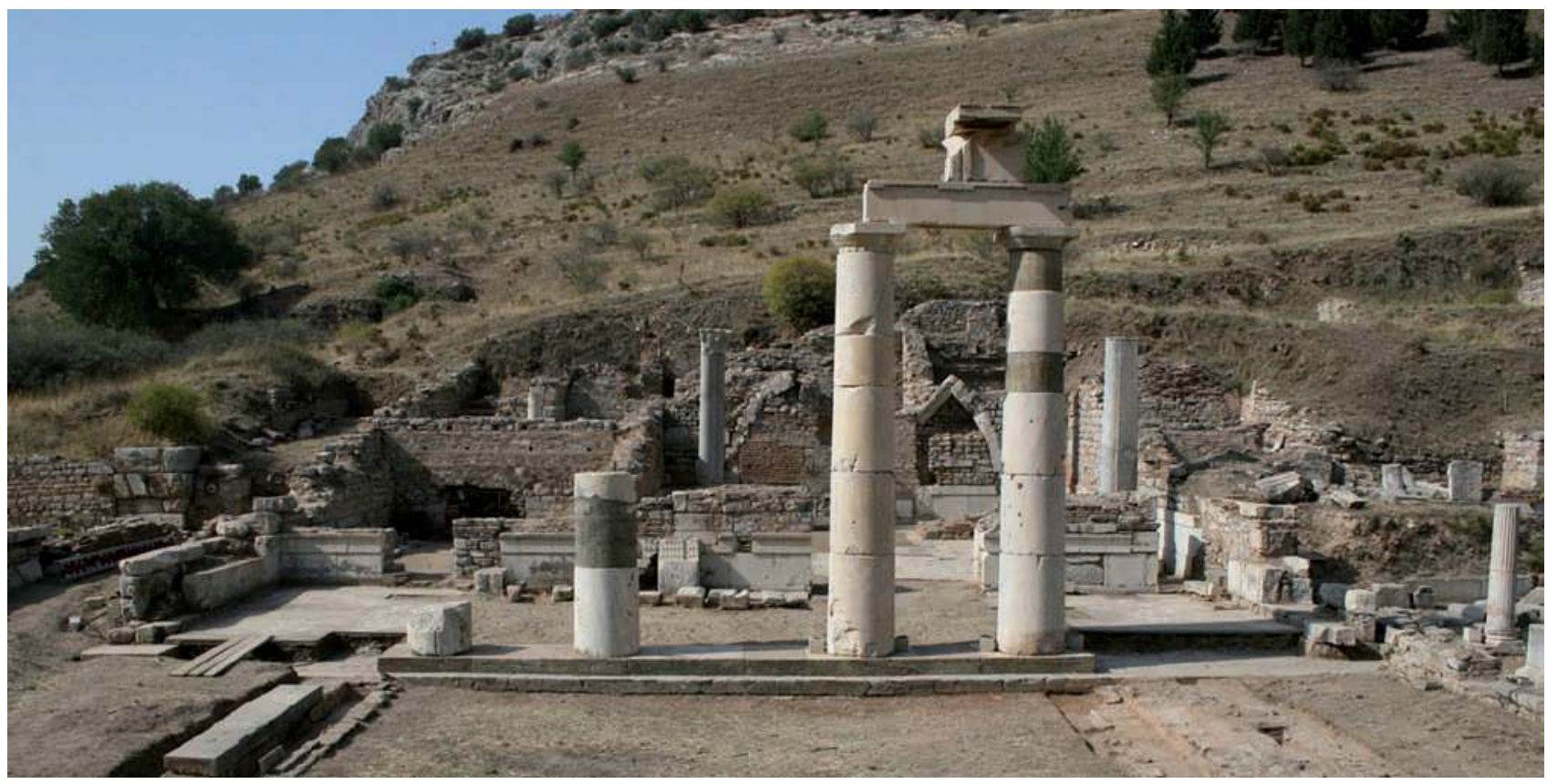

3 Vorhalle von Süden 
Tafel 46

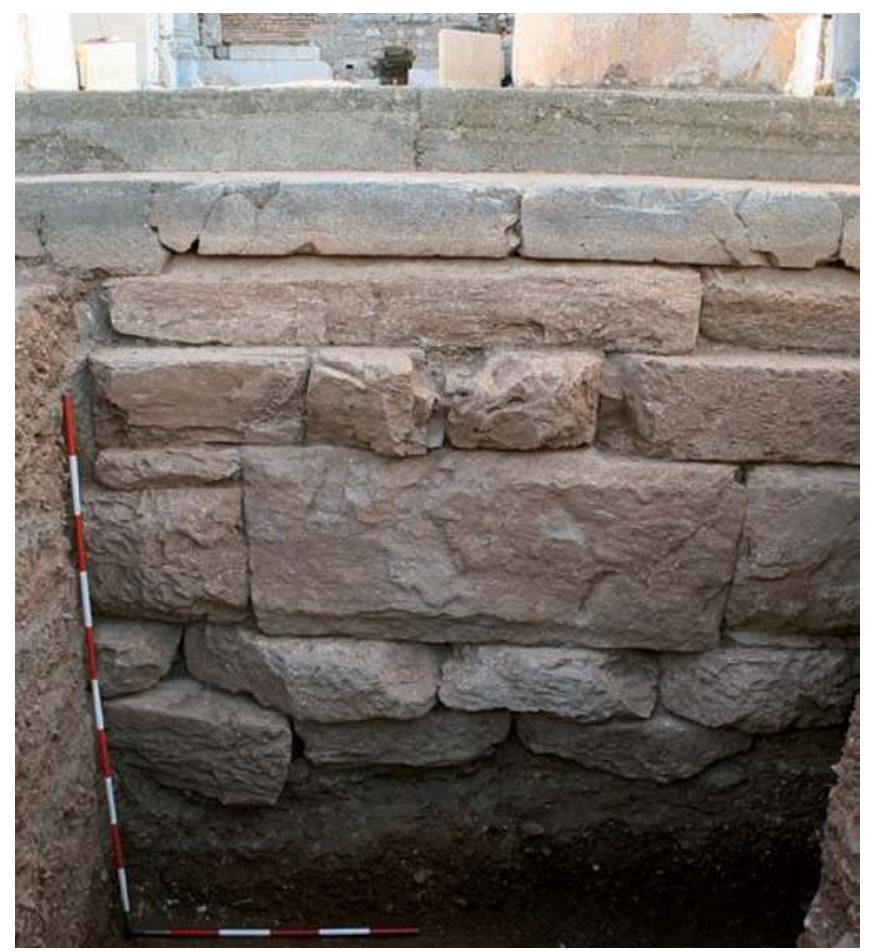

1 Vorhalle. Stereobat der dorischen Ordnung
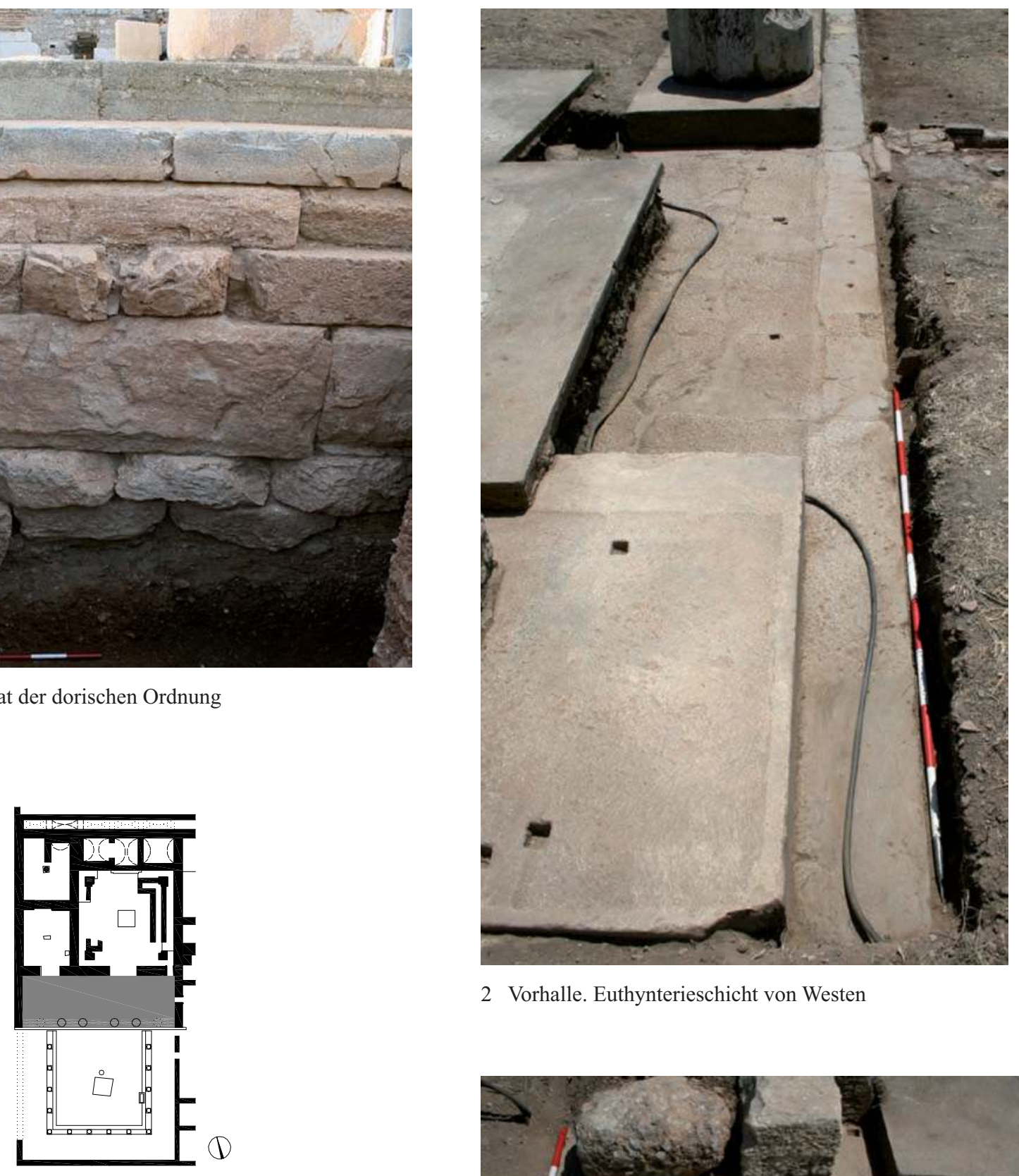

2 Vorhalle. Euthynterieschicht von Westen

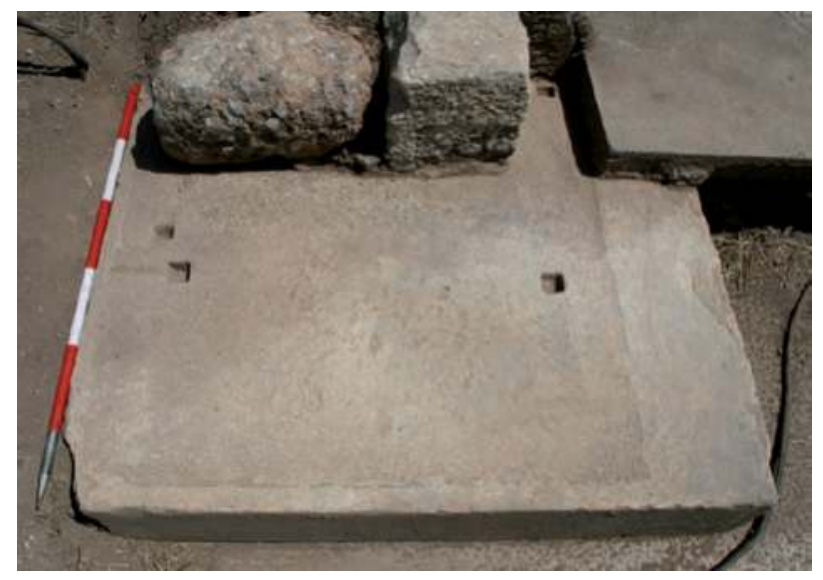

4 Stylobatblock vor der westlichen Antenmauer

PRYTANEION 2007

Vorhalle - westl. Pfeiler

Aufschnürung Stylobatblock

gezeichnet
J. Eitler

J. Eitler
grafische

grafische Bearbeitung
L. Zabrana

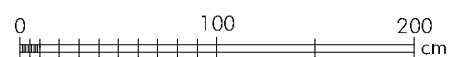

3 Stylobatblock vor der westlichen Antenmauer (1:50) 


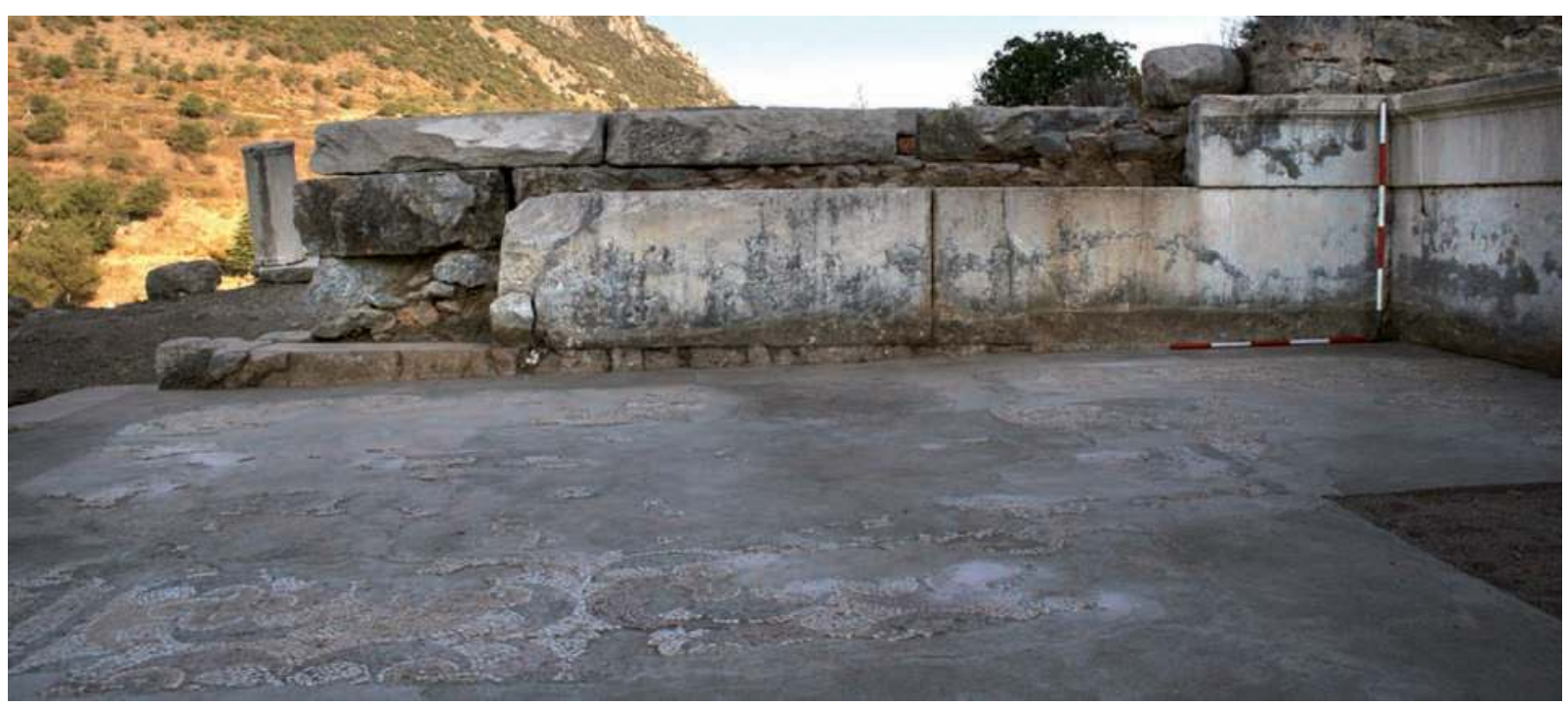

1 Vorhalle. Westliche Antenmauer von Osten

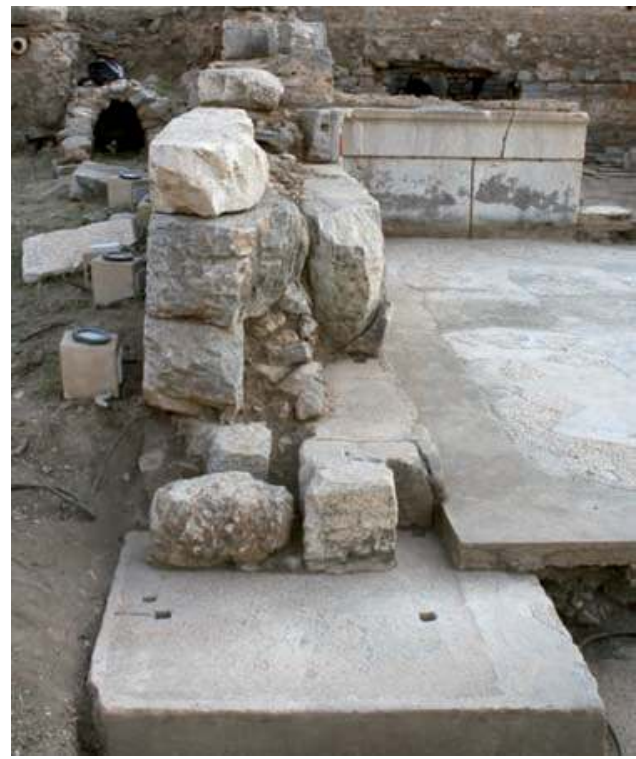

2 Vorhalle. Westliche Antenmauer von Süden

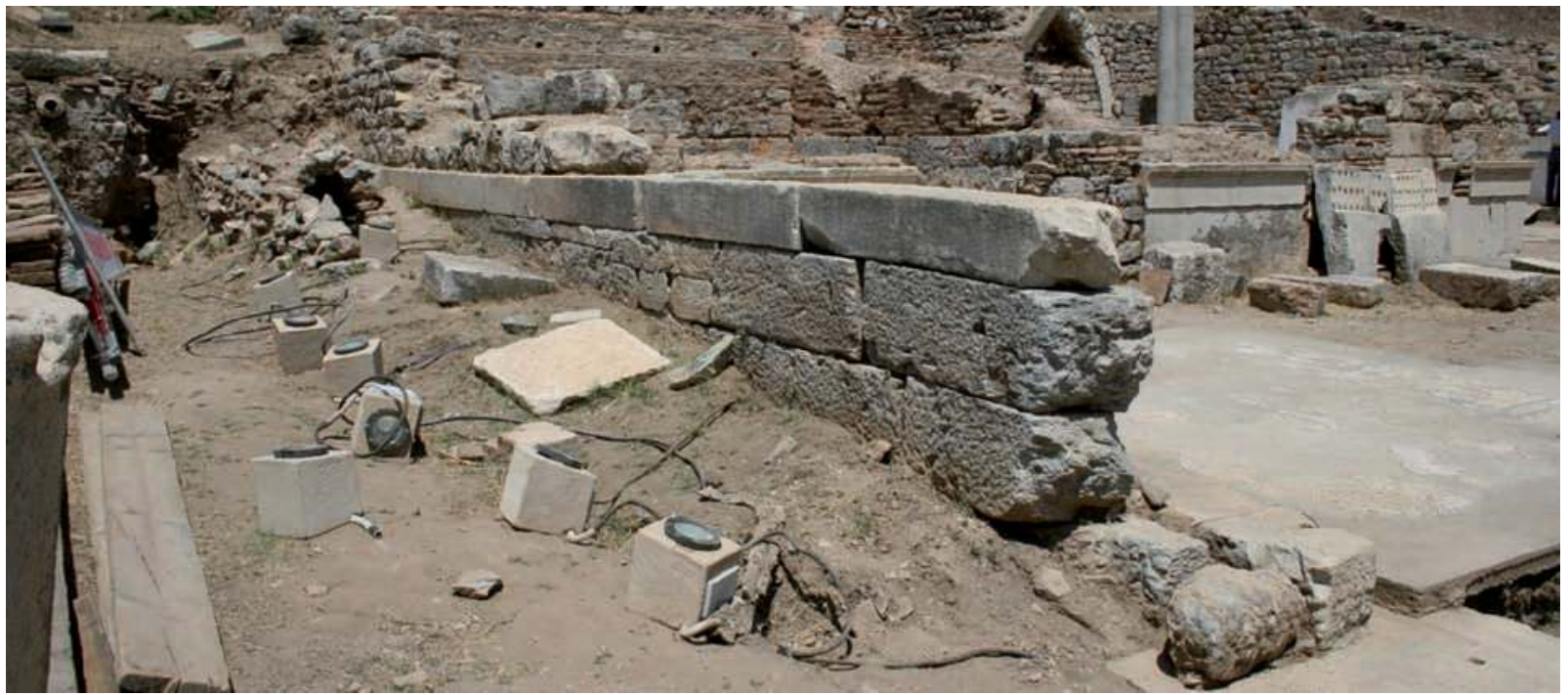

3 Vorhalle. Westliche Antenmauer von Westen 
Tafel 48

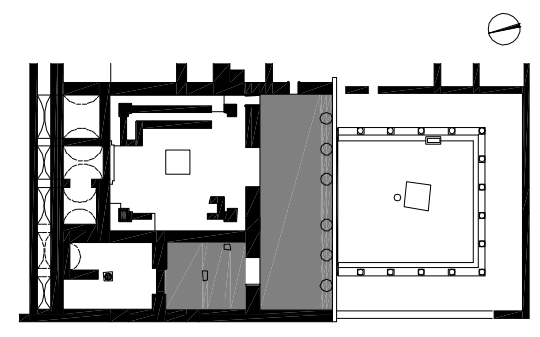

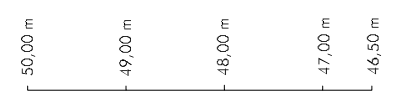
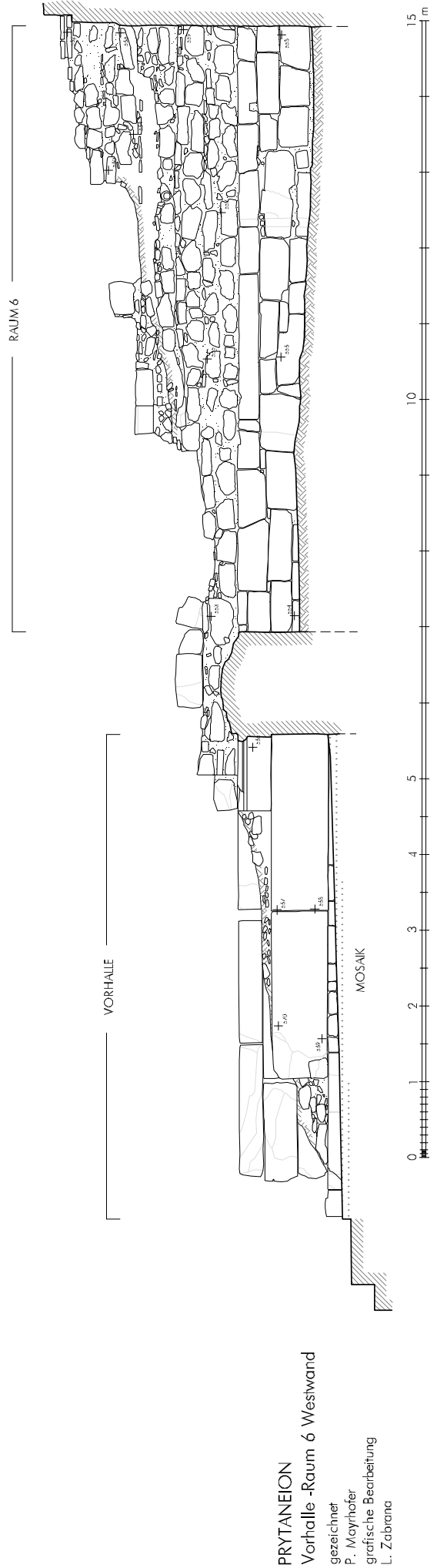
Tafel 49

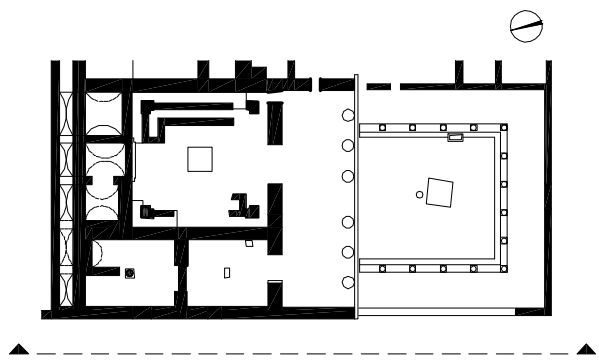


Tafel 50

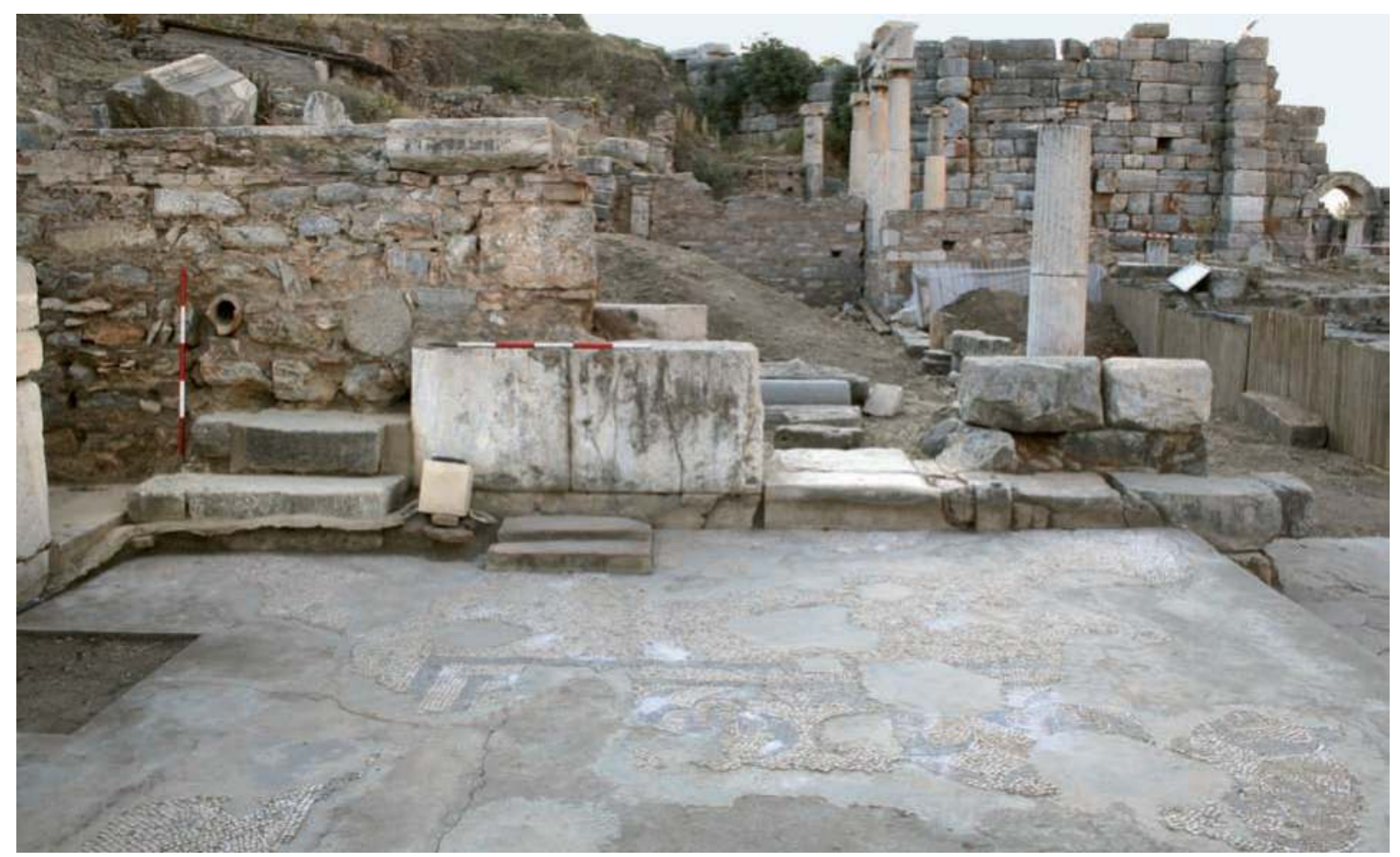

1 Vorhalle. Östliche Antenmauer von Westen

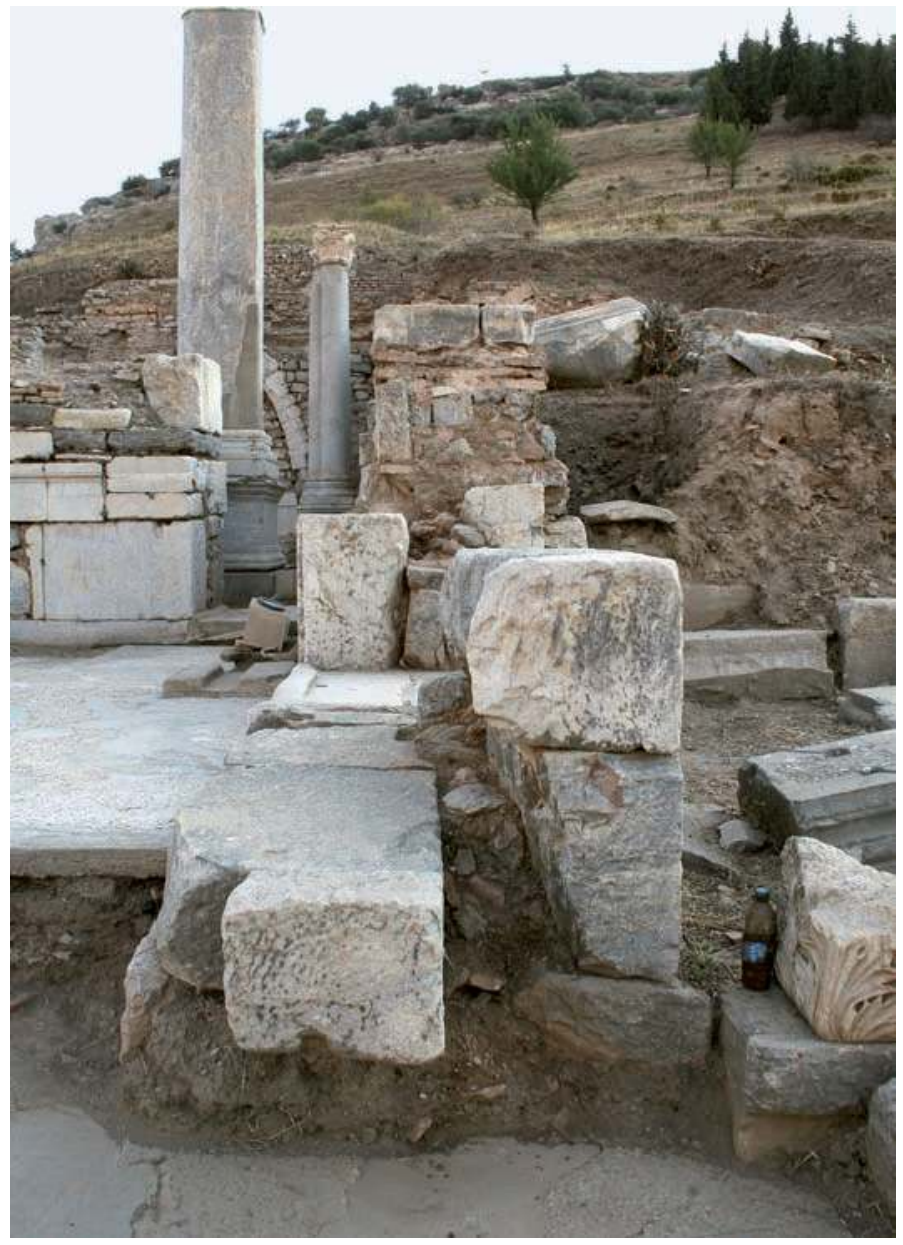

2 Vorhalle. Östliche Antenmauer von Süden 
Tafel 51
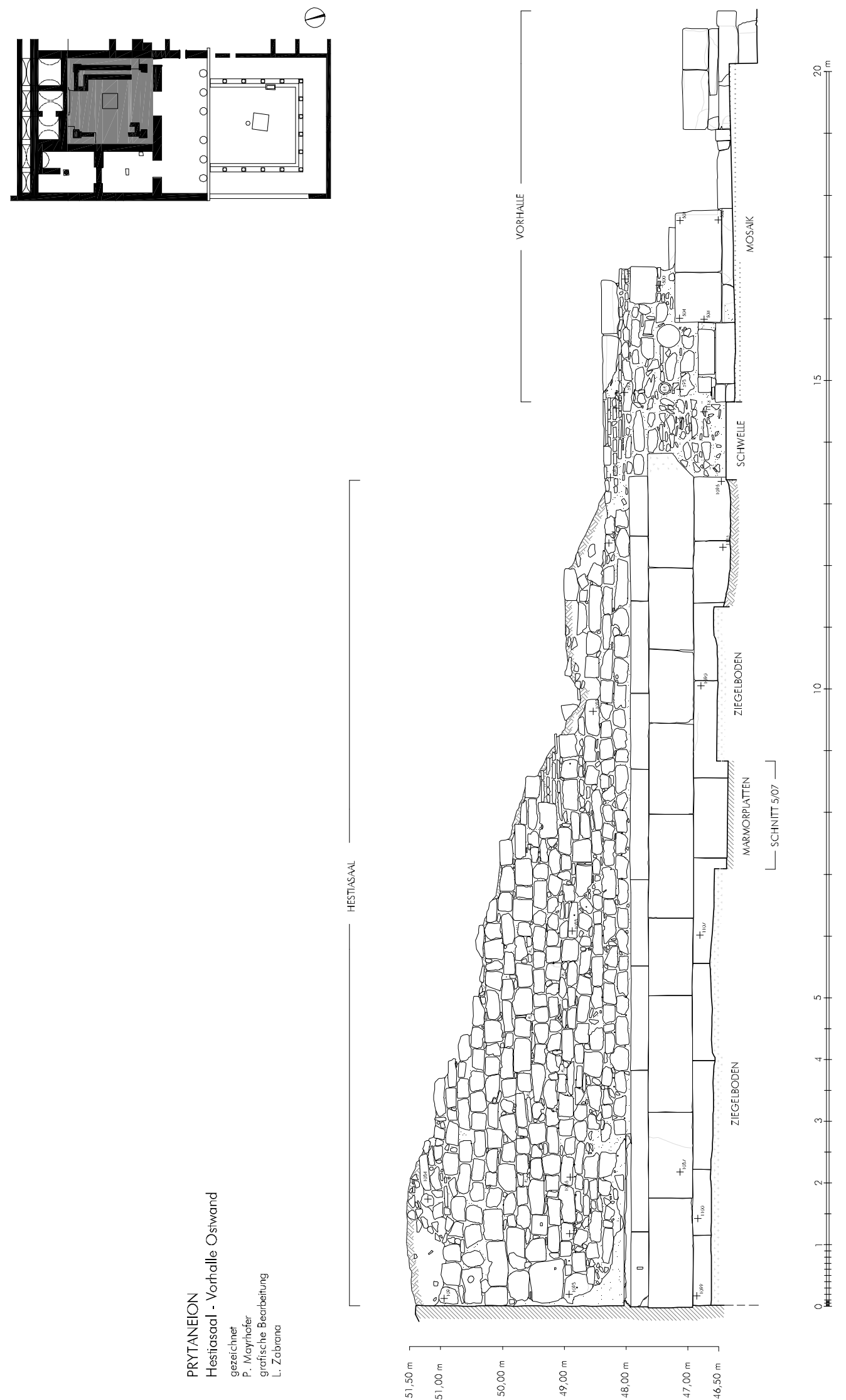

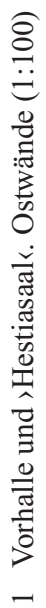


Tafel 52
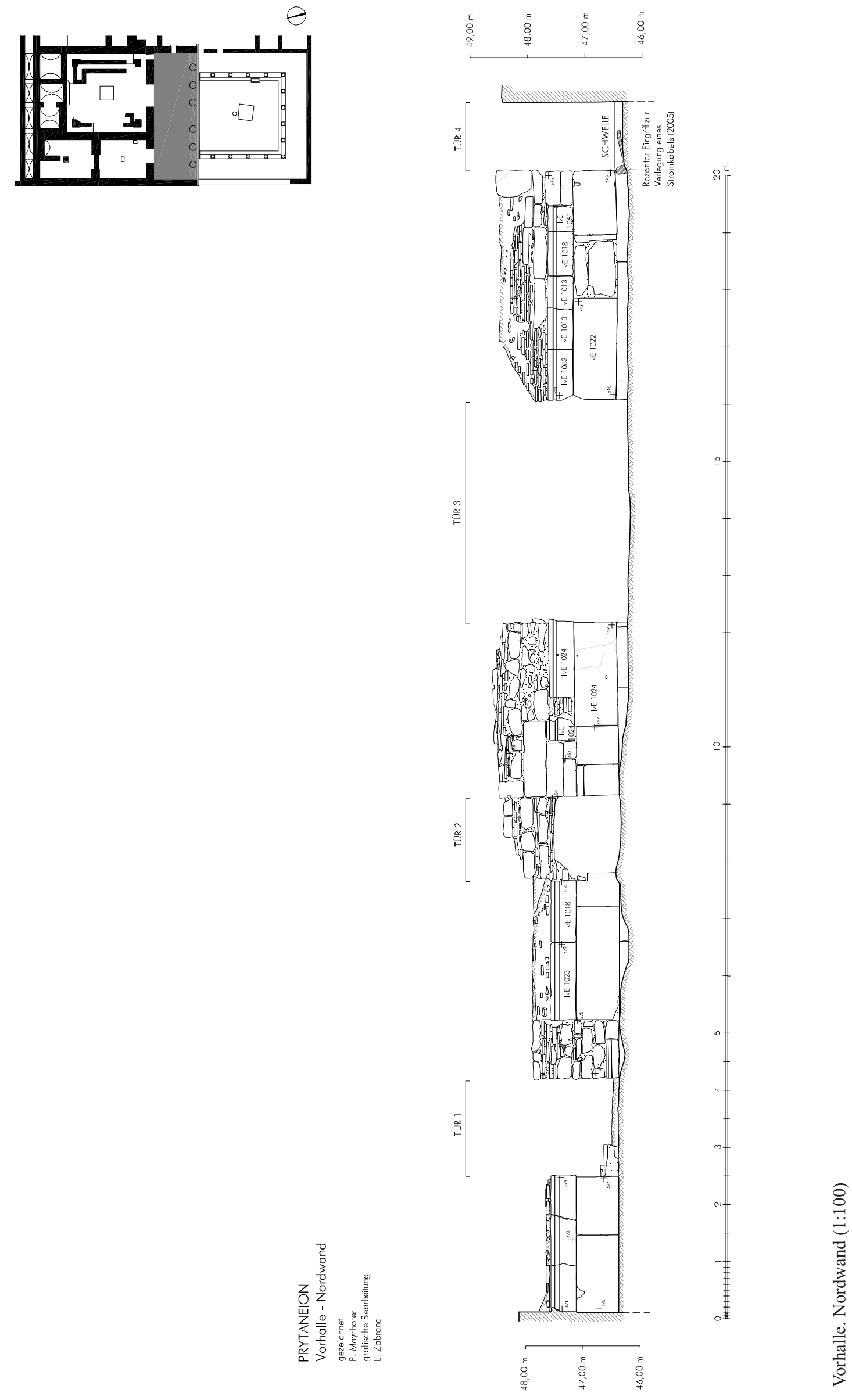
Tafel 53

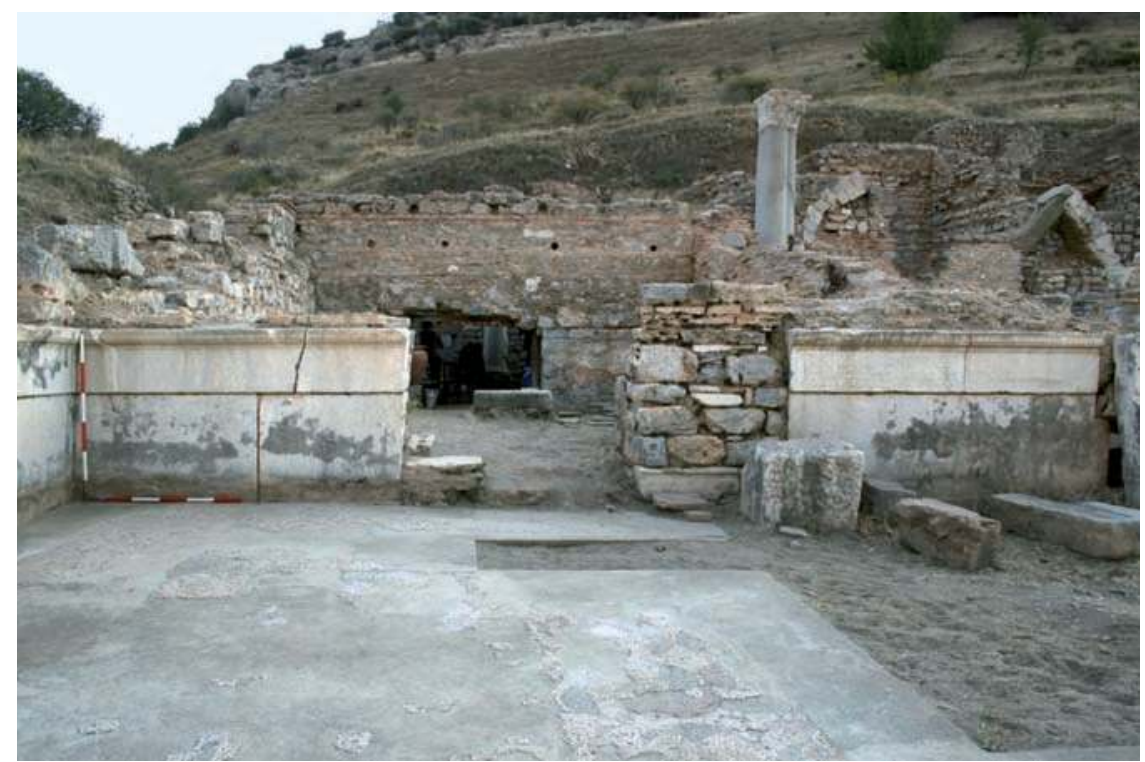

1 Vorhalle.

Nordwand

im Bereich

von Tür 1

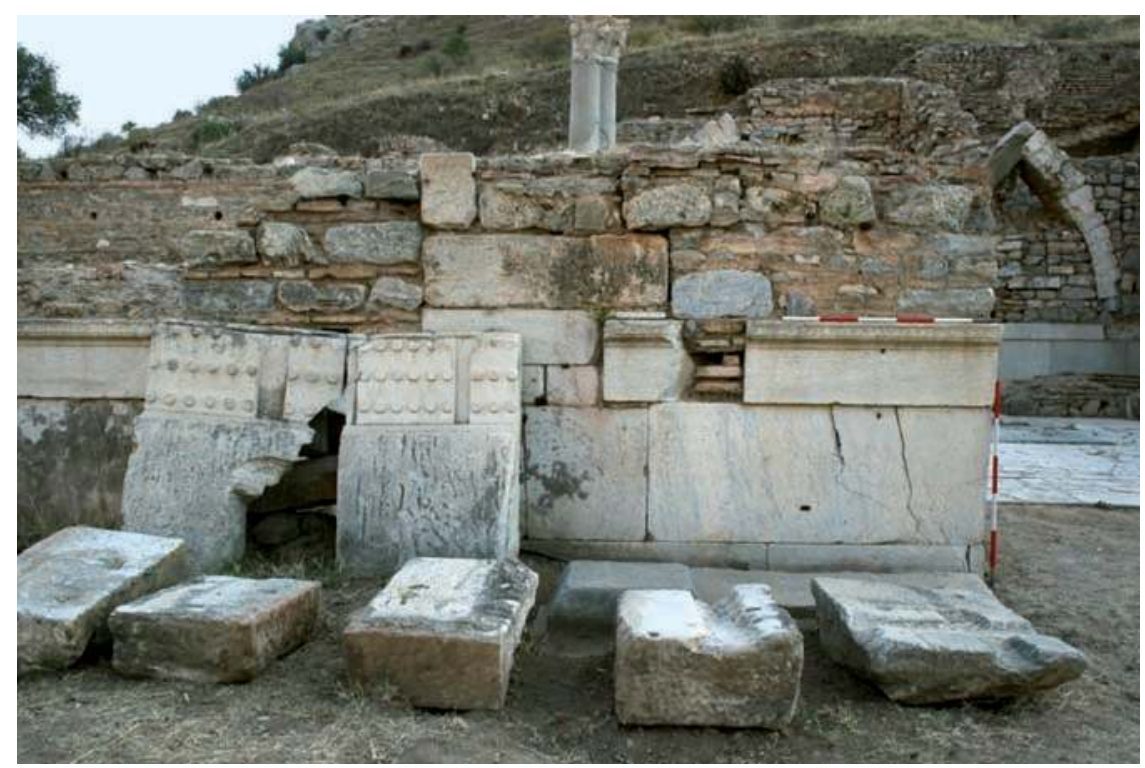

2 Vorhalle.

Nordwand

im Bereich

von Tür 2

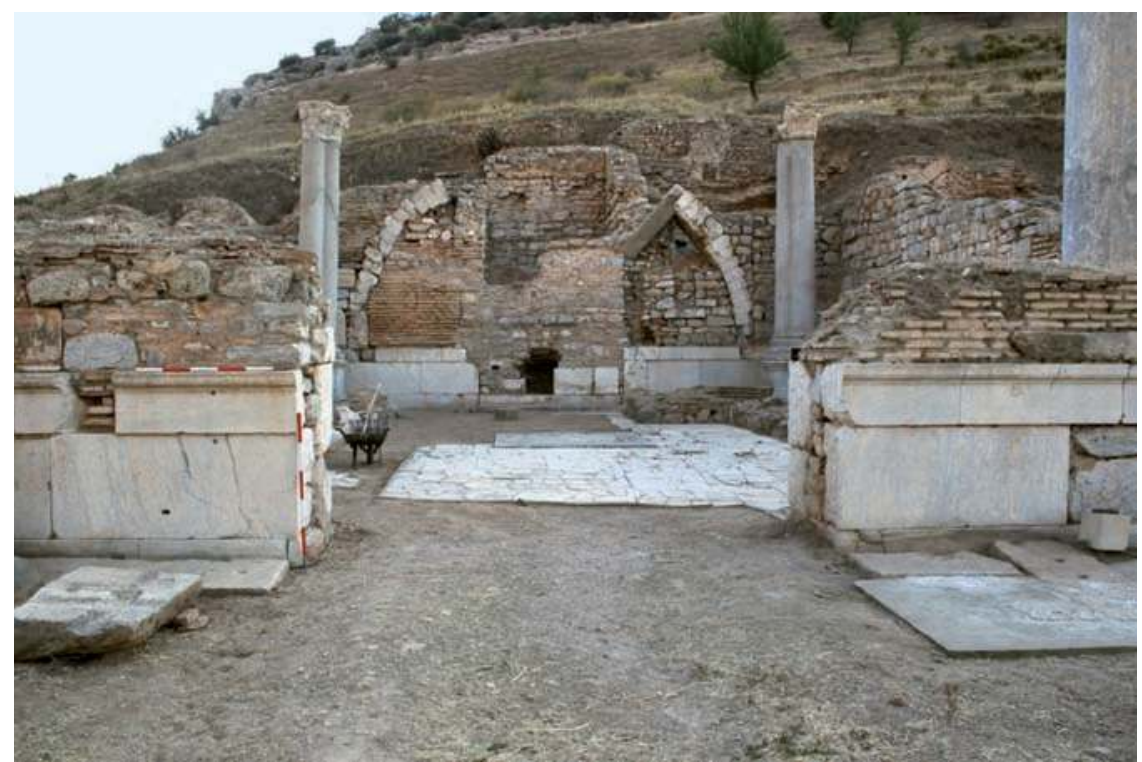

3 Vorhalle.

Nordwand

im Bereich

von Tür 3 
Tafel 54
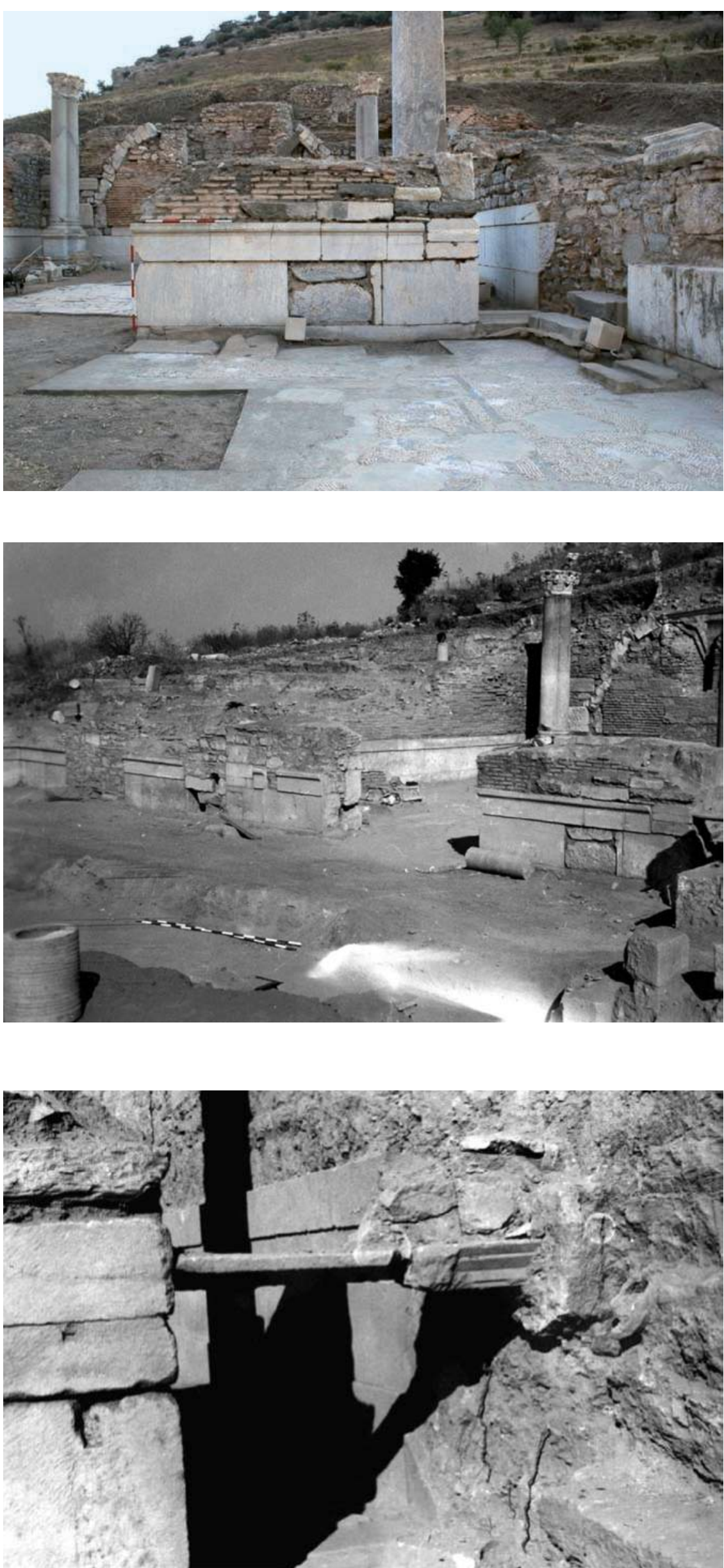

1 Vorhalle. Nordwand im Bereich von Tür 4

2 Vorhalle. Abgemauerte Türen 1 und 2
3 Vorhalle.

Sekundäre Türschwelle in Tür 4 


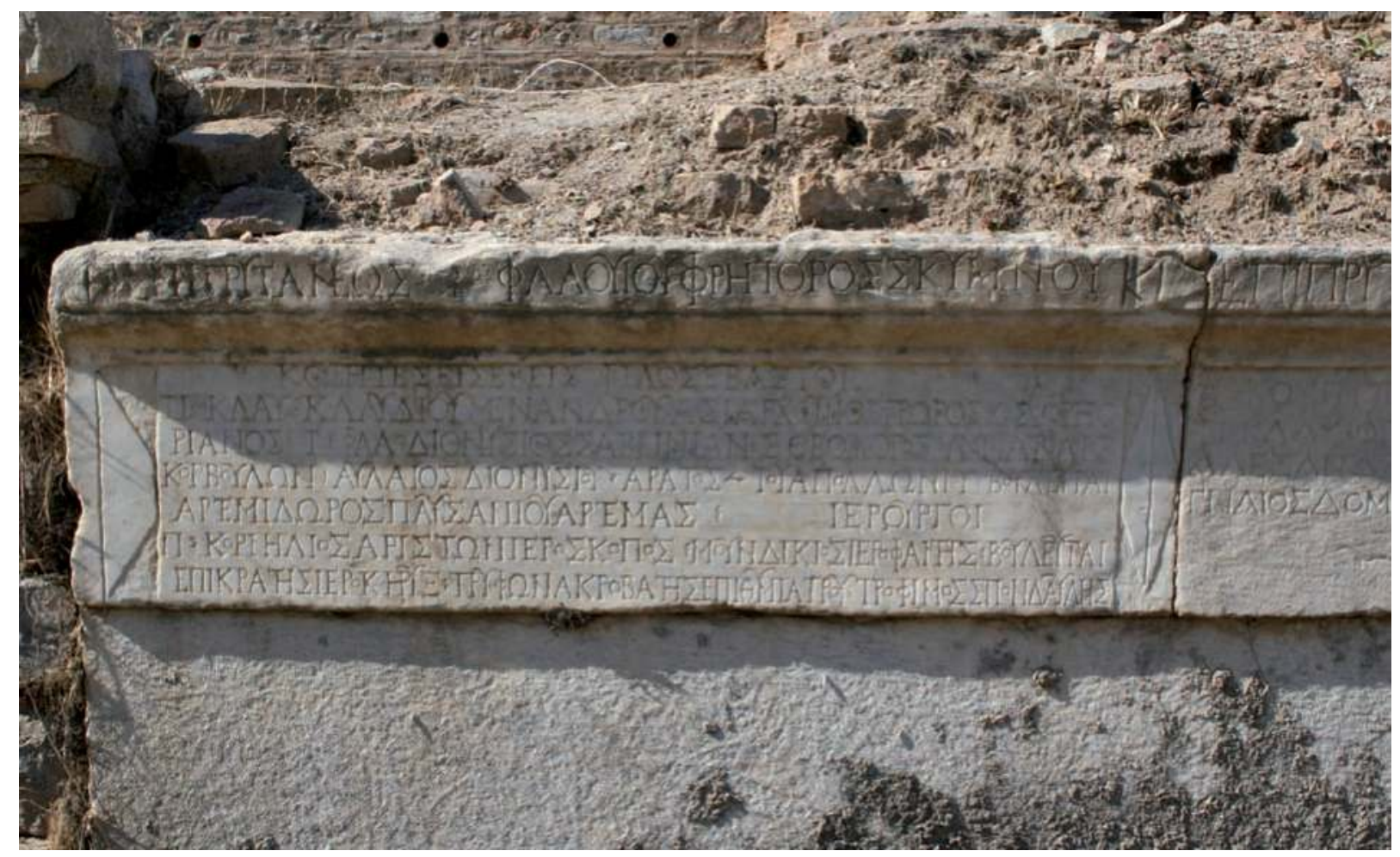

1 Vorhalle. Kureteninschrift auf Nordwand (IvE 1023)

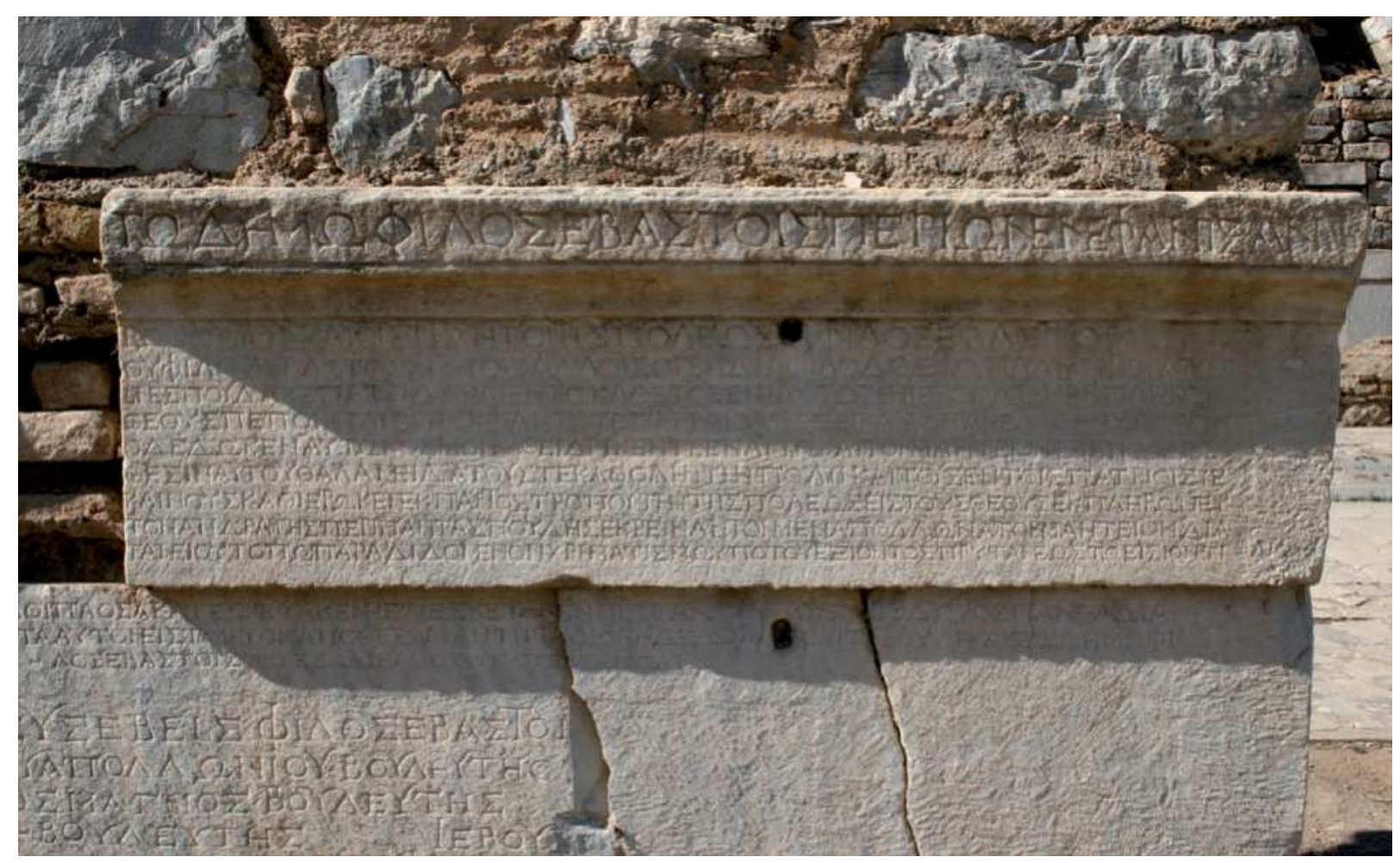

2 Vorhalle. Kureteninschrift auf Nordwand (IvE 1024) 

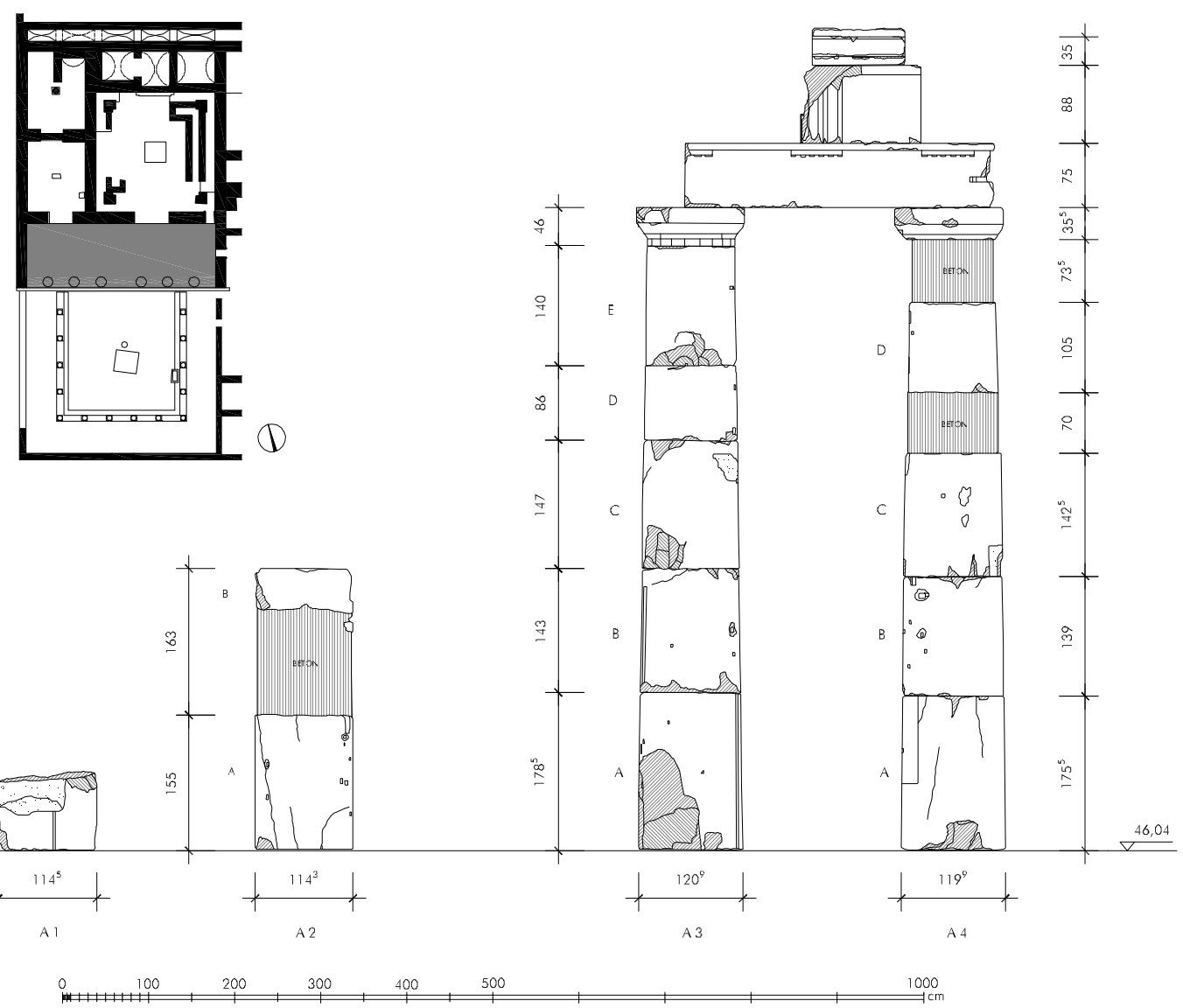

PRYTANEION

VORHALLE - SÄULEN Südansicht gezeichnet

P. Mayrhofer

grafische Bearbeitung

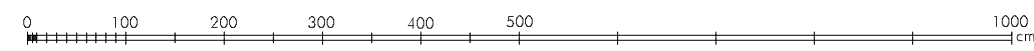

1 Vorhalle. Dorische Ordnung von Süden (1:100)
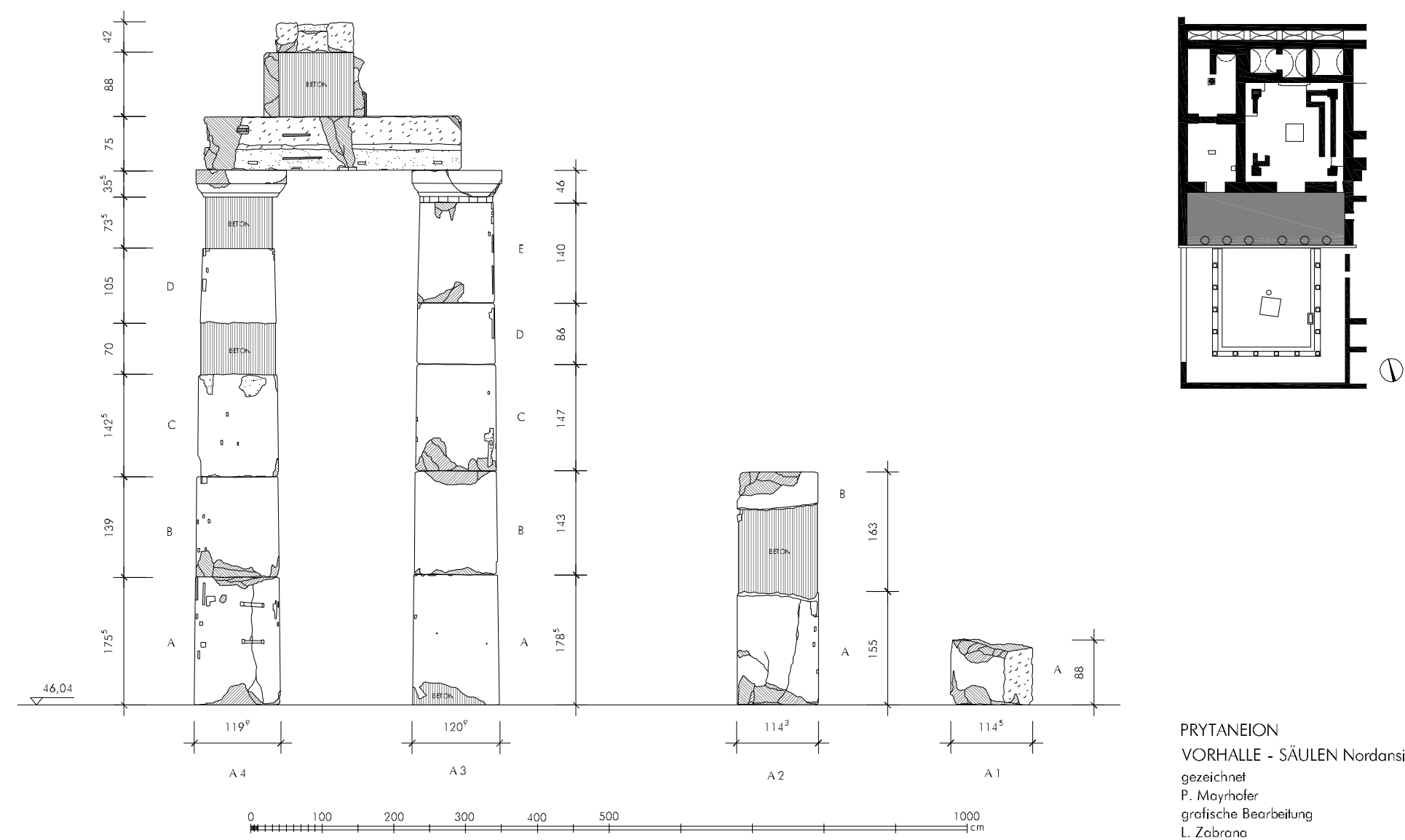

PRYTANEION

VORHALLE - SÄULEN Nordansicht gezeichnet

P. Mayrhofer

grafische Bearbeitung

L. Zabrana

2 Vorhalle. Dorische Ordnung von Norden (1:100) 

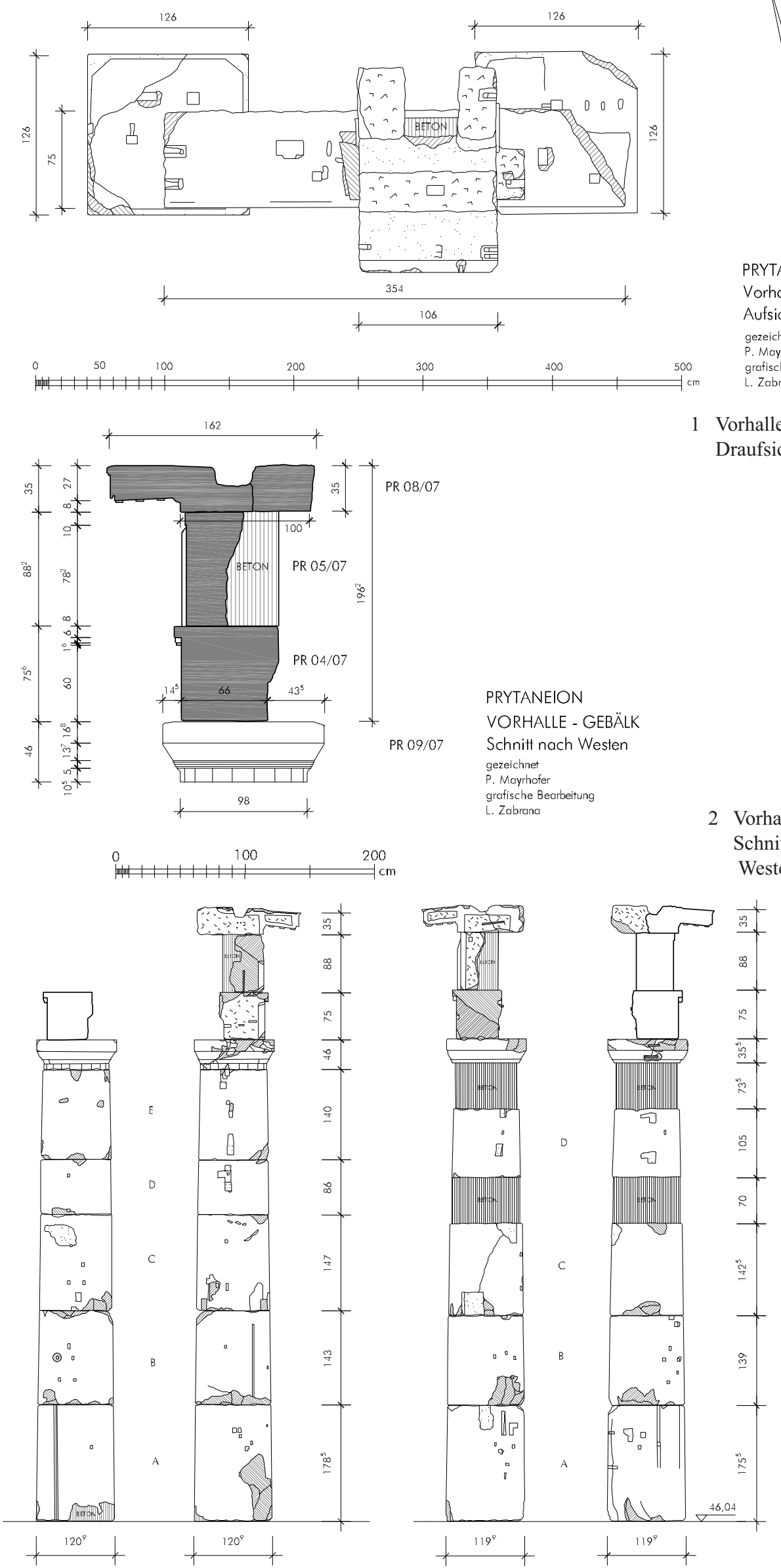

A 3

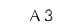

OSTANSICHT

WESTANSICHT

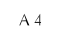

OSTANSICHT

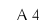

WESTANSICHT

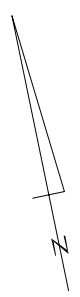

Tafel 57

PRYTANEION

VORHALLE - GEBÄLK

Schnitt nach Westen

gezeichnet

grafische Bearbeitung

PRYTANEION

Vorhalle - Dorische Ordnung

Aufsicht

gezeichnet
P. Mayrhofe

grafische Bearbeitung

L. Zabrana

1 Vorhalle. Dorische Ordnung. Draufsicht (1:50)
2 Vorhalle. Dorische Ordnung. Schnitt durch Gebälk nach Westen (1:50)

PRYTANEION

VORHALLE - SÄULEN A 3, A 4

gezeichnet

grafische Bearbeitung

grafische Beot 
Tafel 58

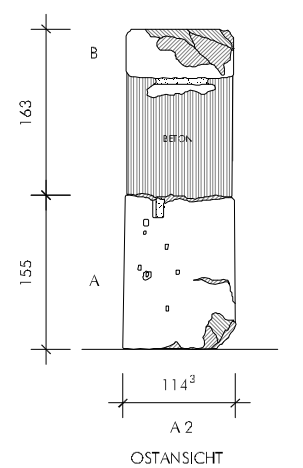

100 $200 \quad 300$
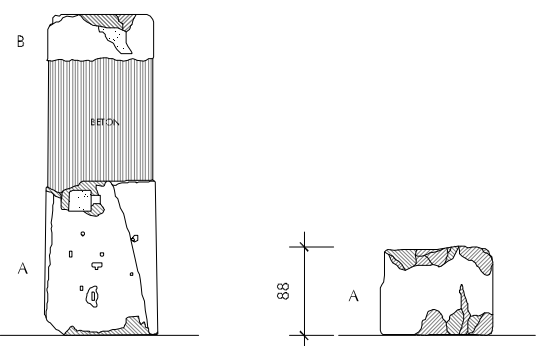

A 1

OSTANSICHT

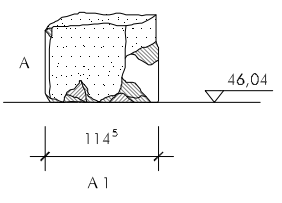

1000
PRYTANEION

VORHALLE - SÄULEN A 1, A 2

gezeichnet

grafische Bearbeitung

L. Zabrana

1 Vorhalle. Dorische Ordnung. Säulen A 1. A 2 (1:100)
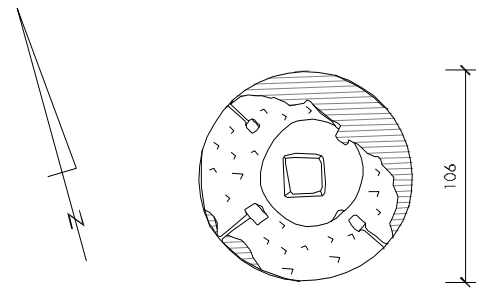

106

100
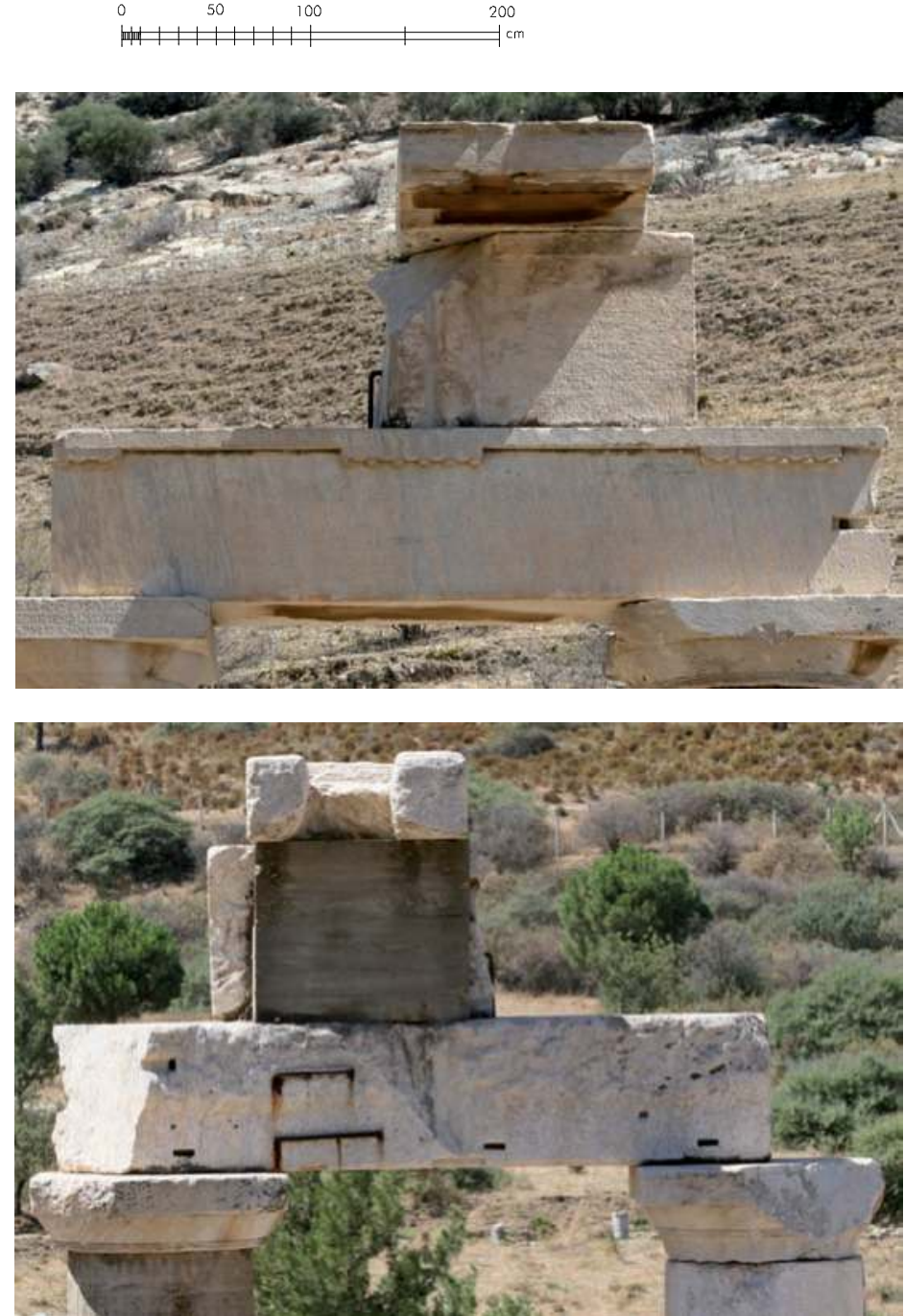

PRYTANEION

Vorhalle - Oberlager Säule A 2

PR 55/07

gezeichnet $N$. High

graf. Bearbeitung L. Zabrono 200

2 Vorhalle. Oberlager der Säule A 2 $(1: 50)$

3 Vorhalle. Dorisches Gebälk von Süden

4 Vorhalle. Dorisches Gebälk von Norden 
Tafel 59

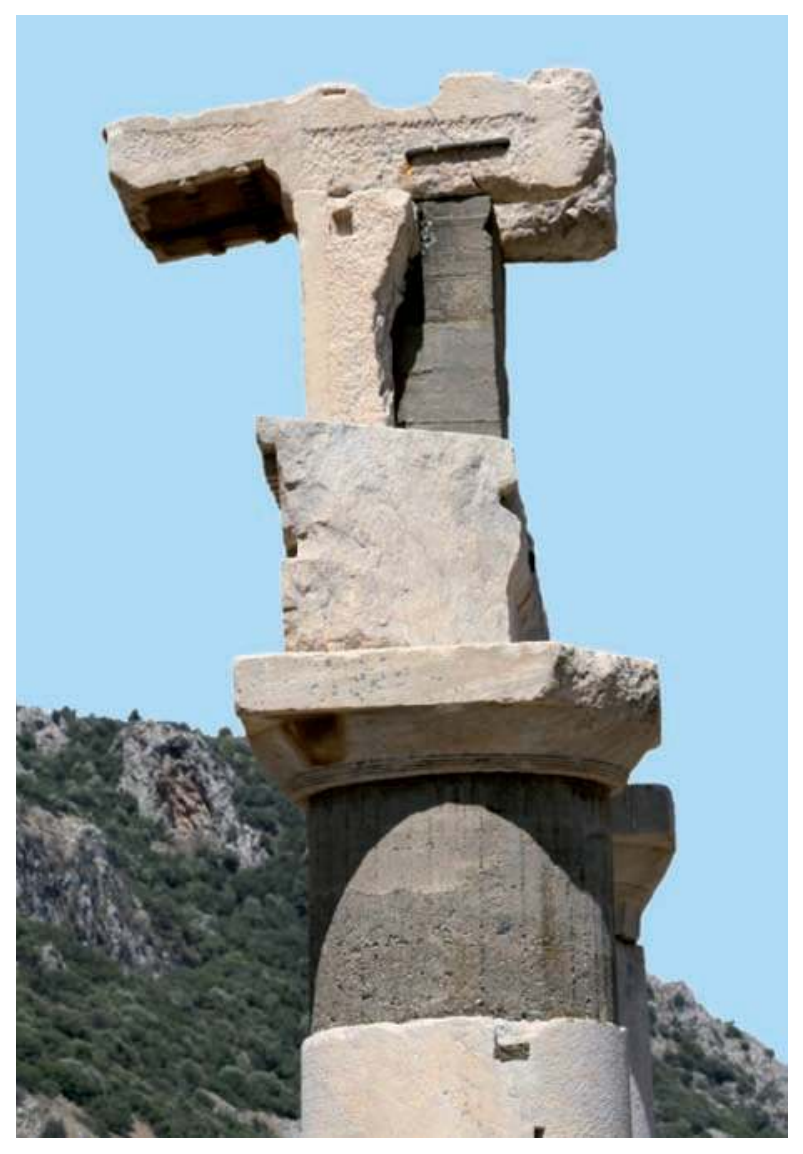

1 Vorhalle. Dorisches Gebälk von Osten

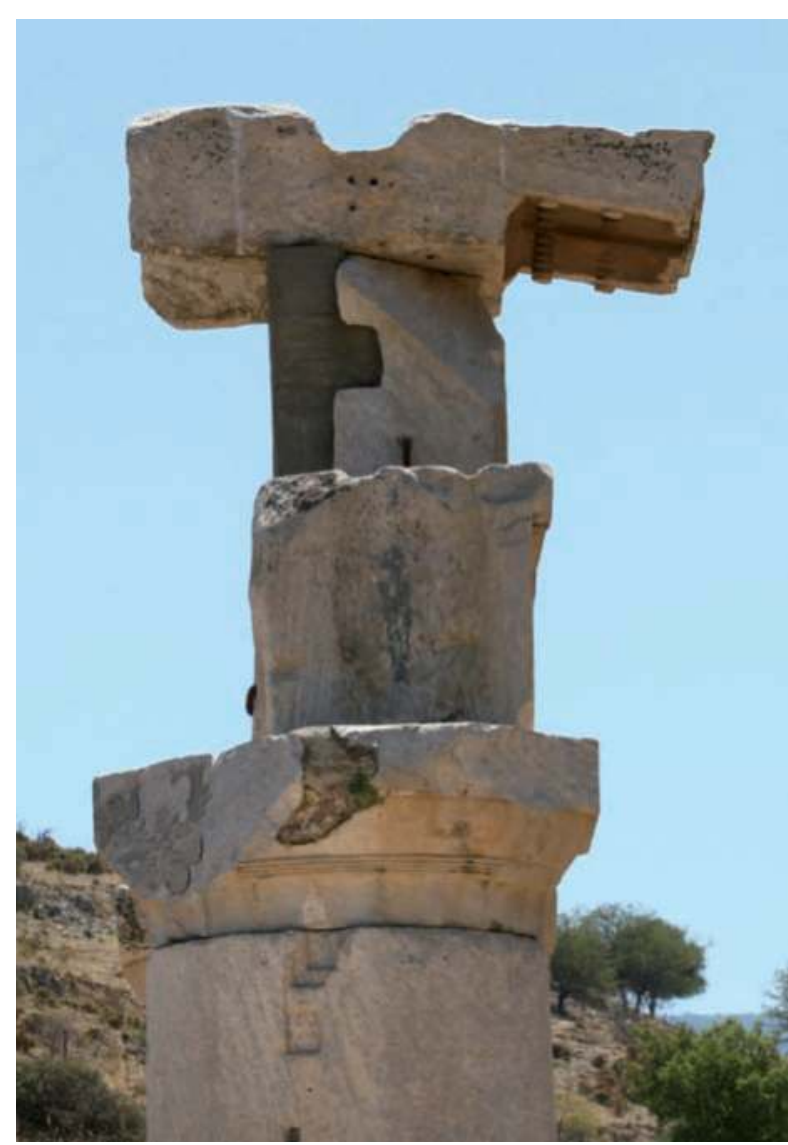

2 Vorhalle. Dorisches Gebälk von Westen

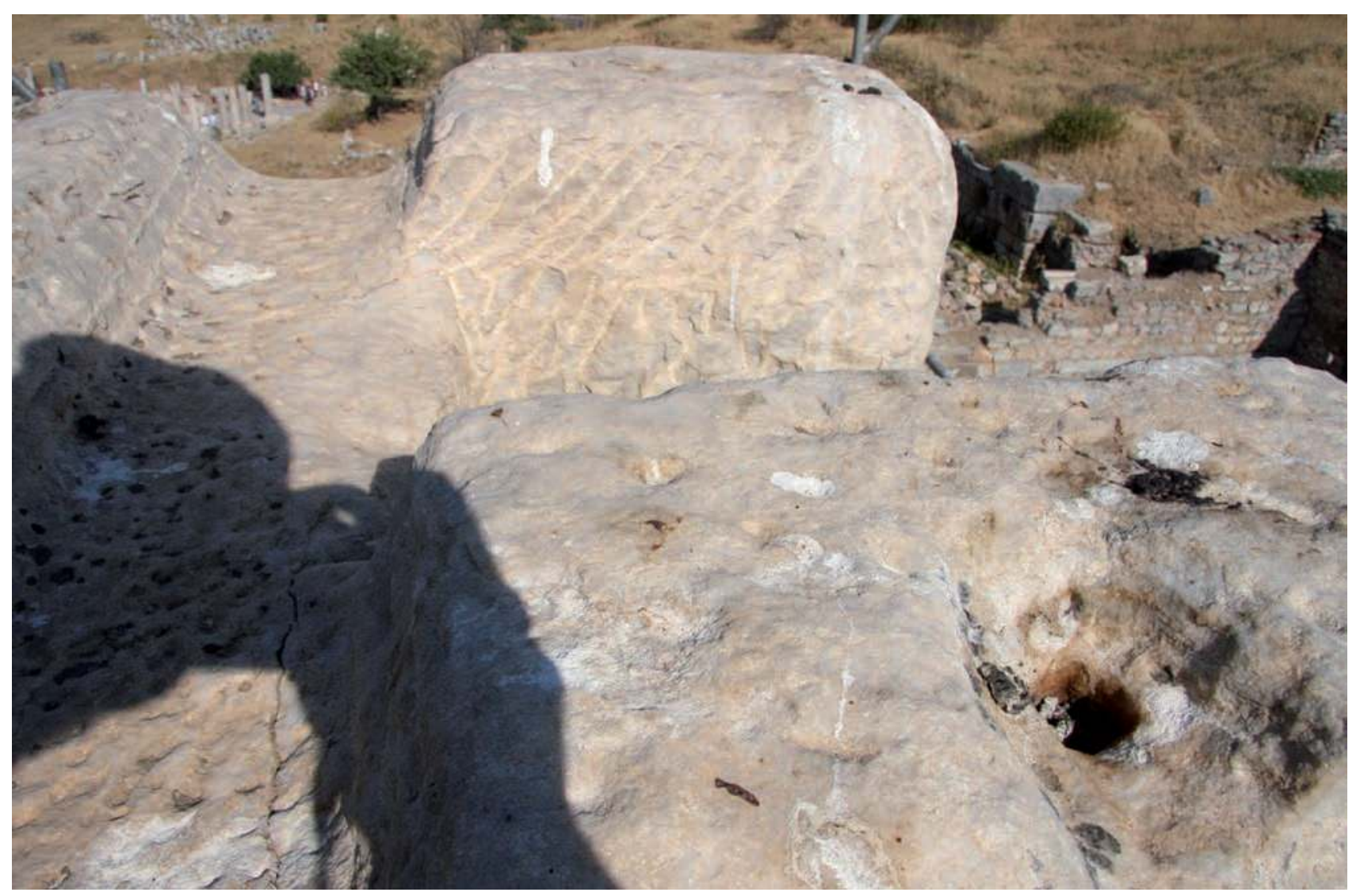

3 Vorhalle. Dorisches Gebälk. Draufsicht 
Tafel 60

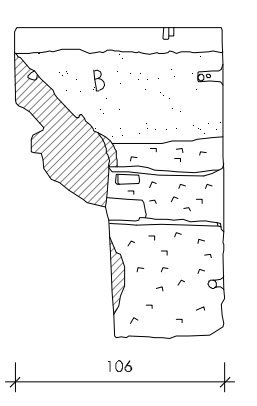

0

O

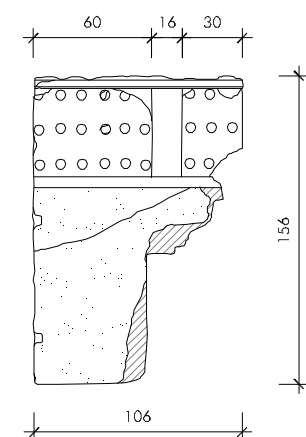

200

PRYTANEION

VORHALLE - PR 06/07

HORIZONTALGEISON

gezeichnet
N. High

grafische Bearbeitung

L. Zabrana

1 Vorhalle. Hori-

zontalgeison A 10

(1:50)

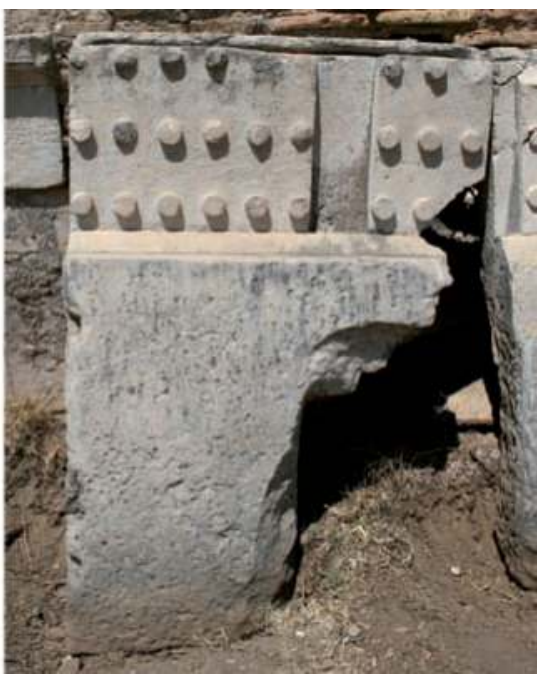

2 Vorhalle. Horizontalgeison A 10

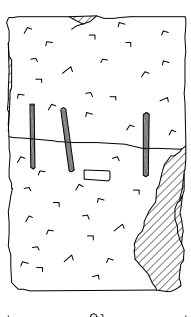

k $91 \quad$,

$$
0
$$$$
100
$$

200

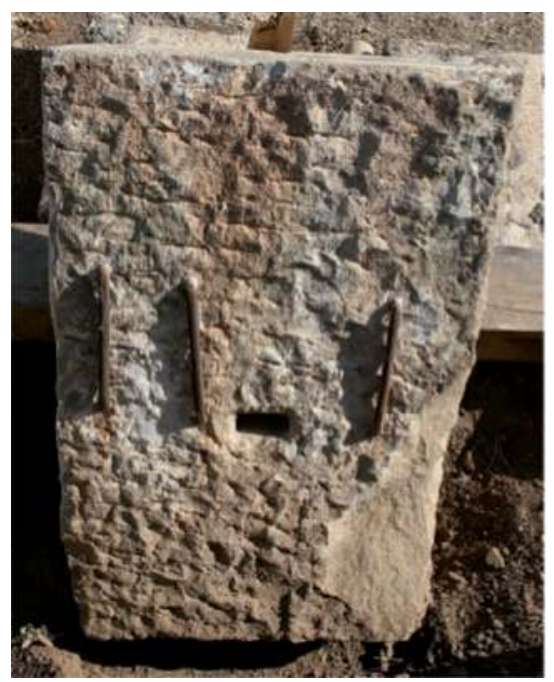

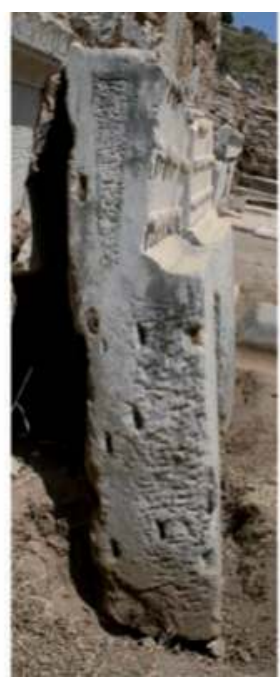

$\left.7\}^{6} \quad 51 \quad x^{8}\right\}^{25} \nmid$
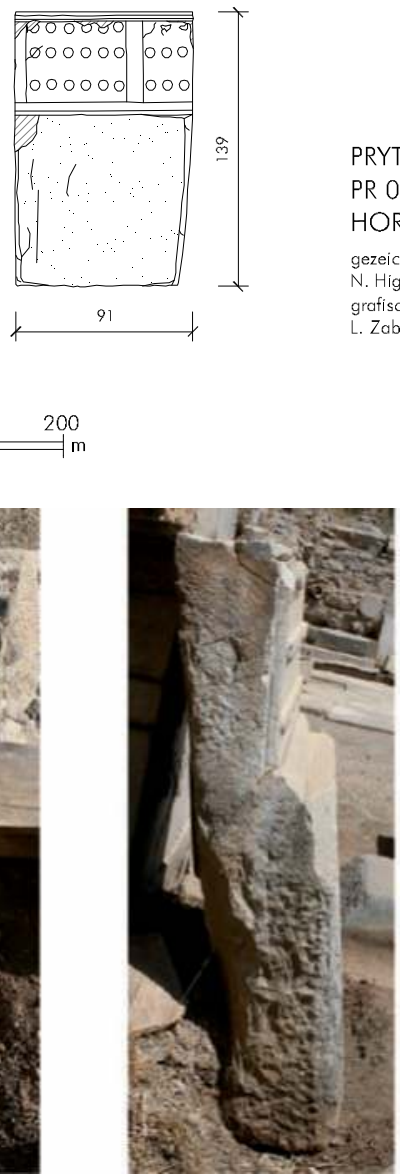

PRYTANEION

PR 07/07

HORIZONTALGEISON

gezeichnet
N. High

grafische Bearbeitung

L. Zabrano

3 Im Prytaneion deponiertes Horizontalgeison A 11 $(1: 50)$

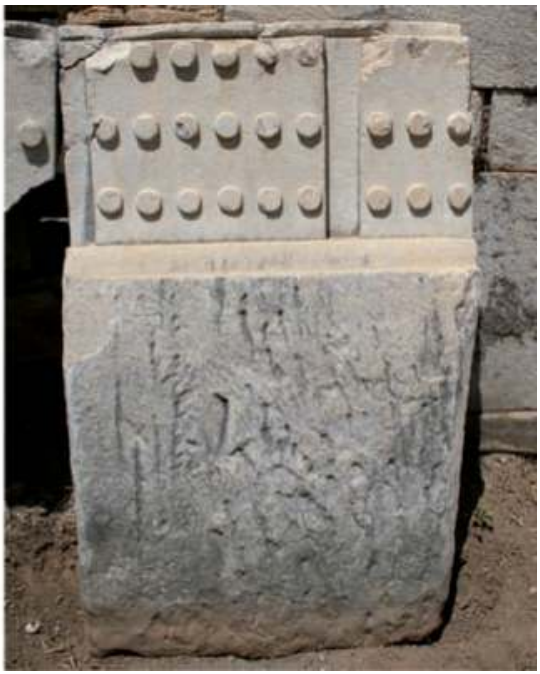

4 Im Prytaneion deponiertes Horizontalgeison A 11 
Tafel 61

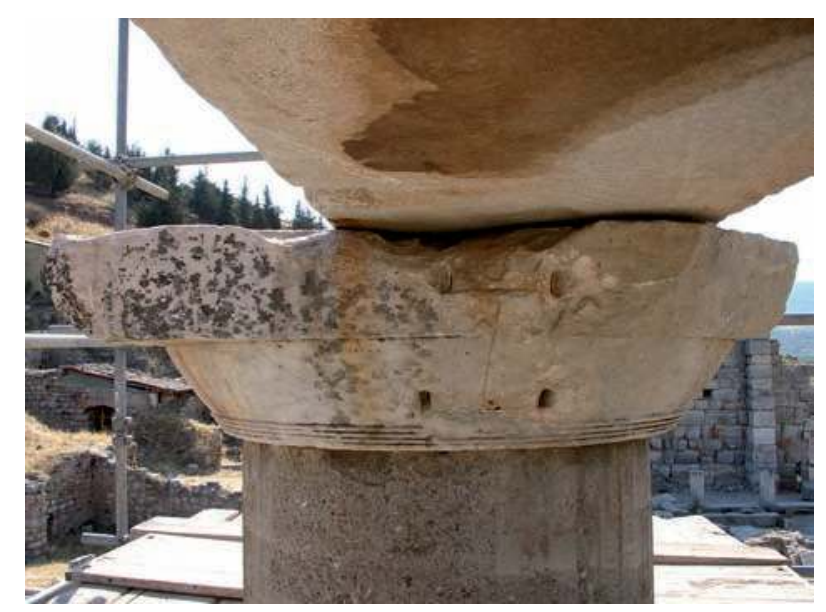

1 Vorhalle. Kapitell A 6

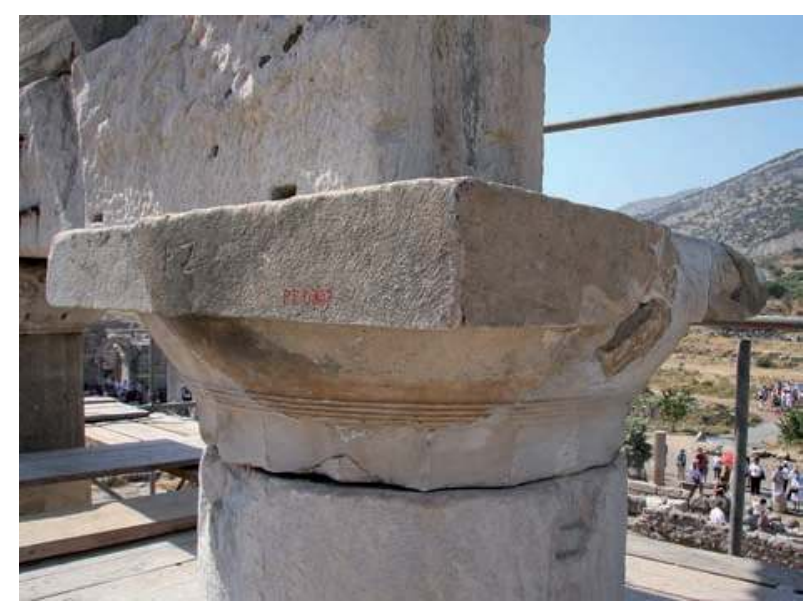

2 Vorhalle. Kapitell A 5

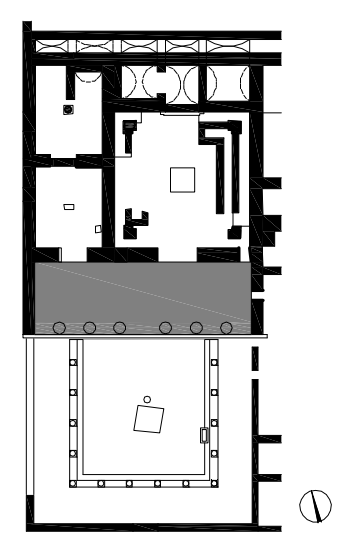

PRYTANEION

VORHALLE - SÄULEN Südansicht gezeichnet

grafische Bearbeitung L. Zabrana

3 Vorhalle. Dorische Ordnung mit Lage der Inschriften (1:100) 
Tafel 62

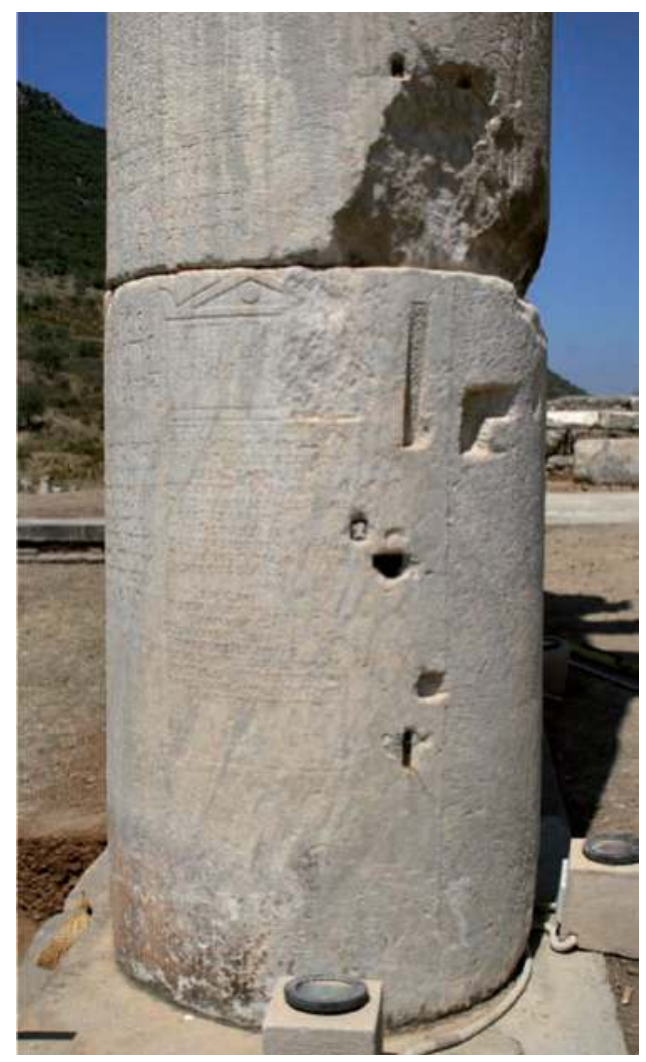

1 Vorhalle.

Detail Inschriften auf

Säule A 3 (IvE 1012

1020. 1021. 1036. 1040. 1042)
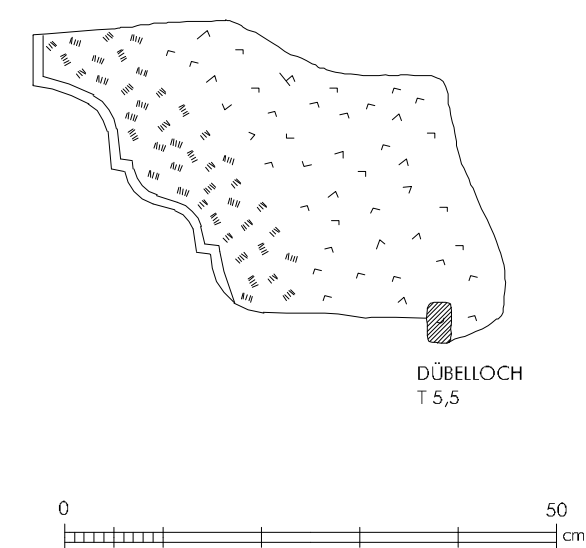

PRYTANEION

SÄULE A3 Trommel C Ostseite Abdruck eines Profils

gezeichnet

grafische Bearbeitung

L. Zabrana
2 Vorhalle. Säule A 3 Trommel C. Einarbeitung für profilierte Brüstung $(1: 10)$

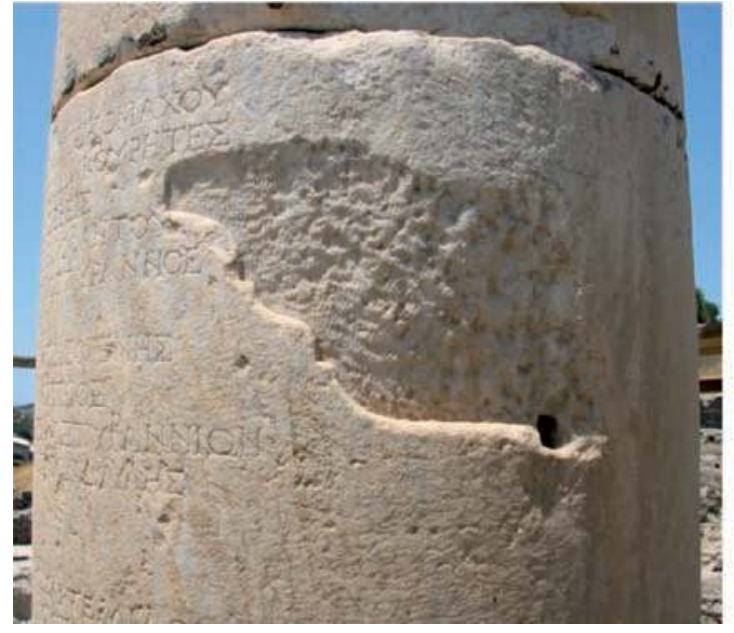

3 Vorhalle. Säule A 3 Trommel C. Einarbeitung für profilierte Brüstung

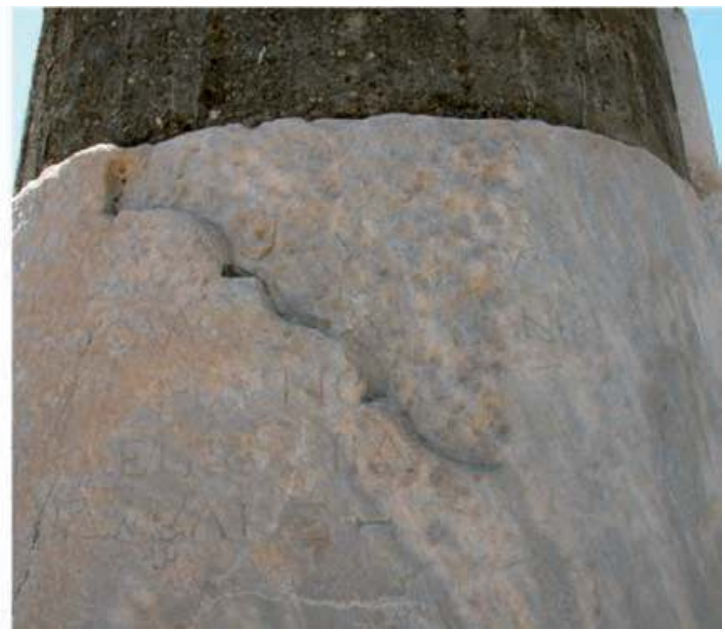

4 Vorhalle. Säule A 4 Trommel C. Einarbeitung für profilierte Brüstung 
Tafel 63

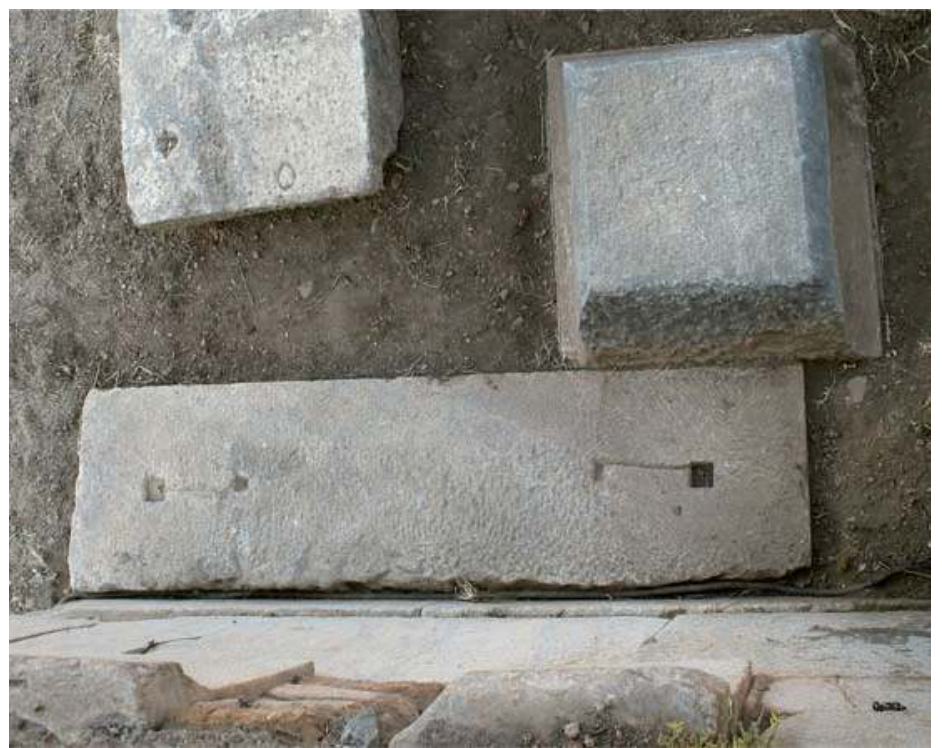

1 Vorhalle. Marmorblock/-platte sowie Sockel der Ehrenbasis SK 15 westlich von Tür 3

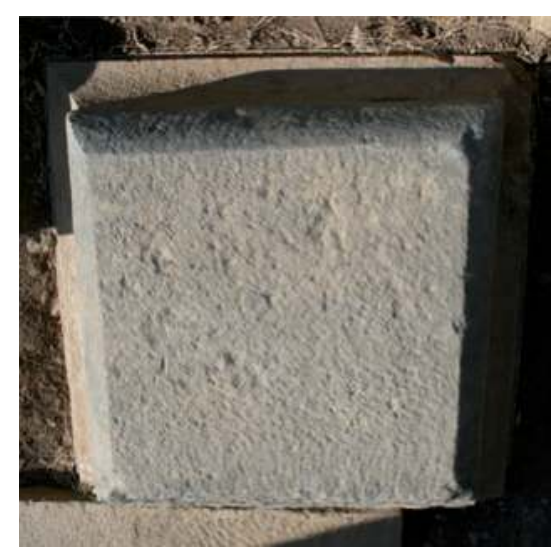

2 Vorhalle. Sockel Ehrenbasis SK 15
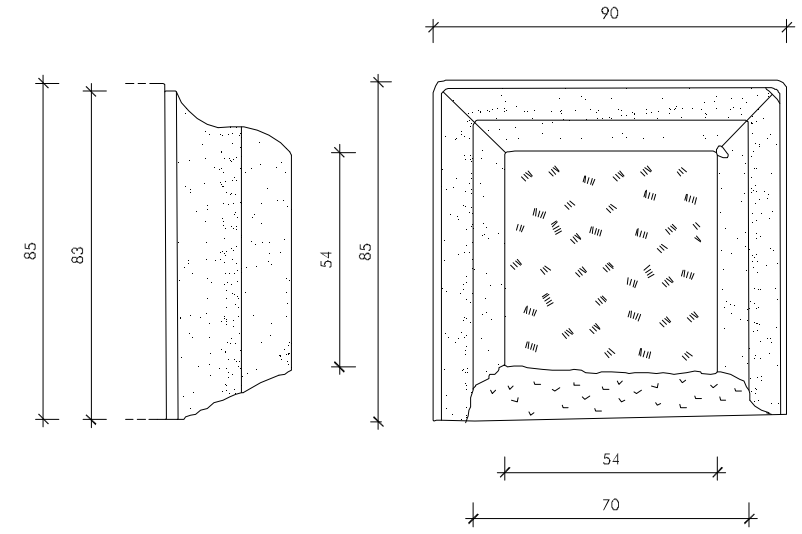
PRYTANEION
VORHALLE - PR 40/07 SOCKEL EHRENBASIS gezeichnet indm 100

3 Vorhalle. Sockel Ehrenbasis SK 15 (1:25)

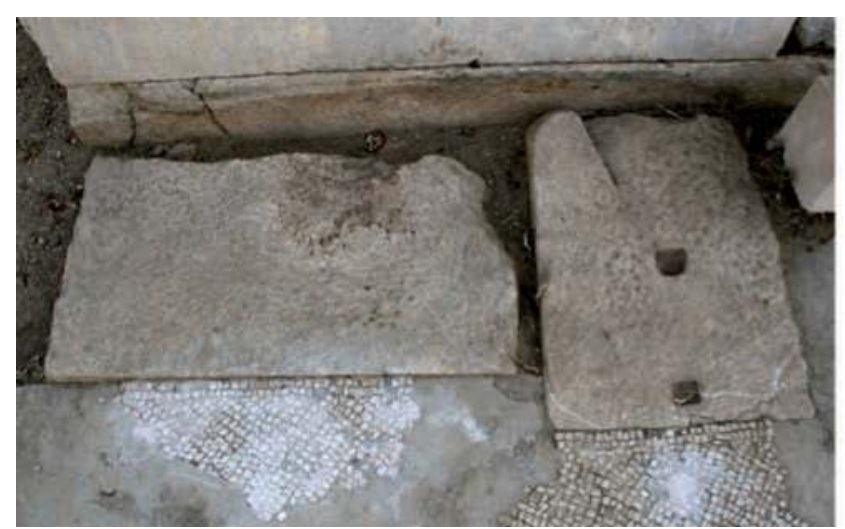

4 Vorhalle. Marmorplatten östlich von Tür 3

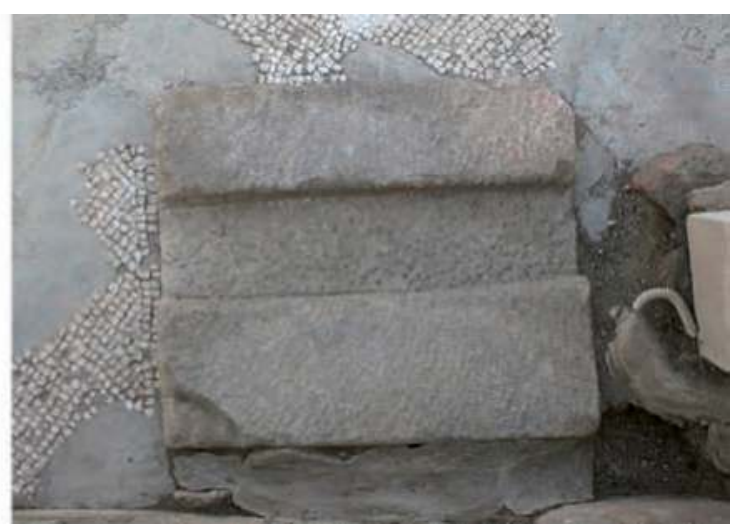

5 Vorhalle. Marmorspolie mit rinnenförmiger Vertiefung 
Tafel 64

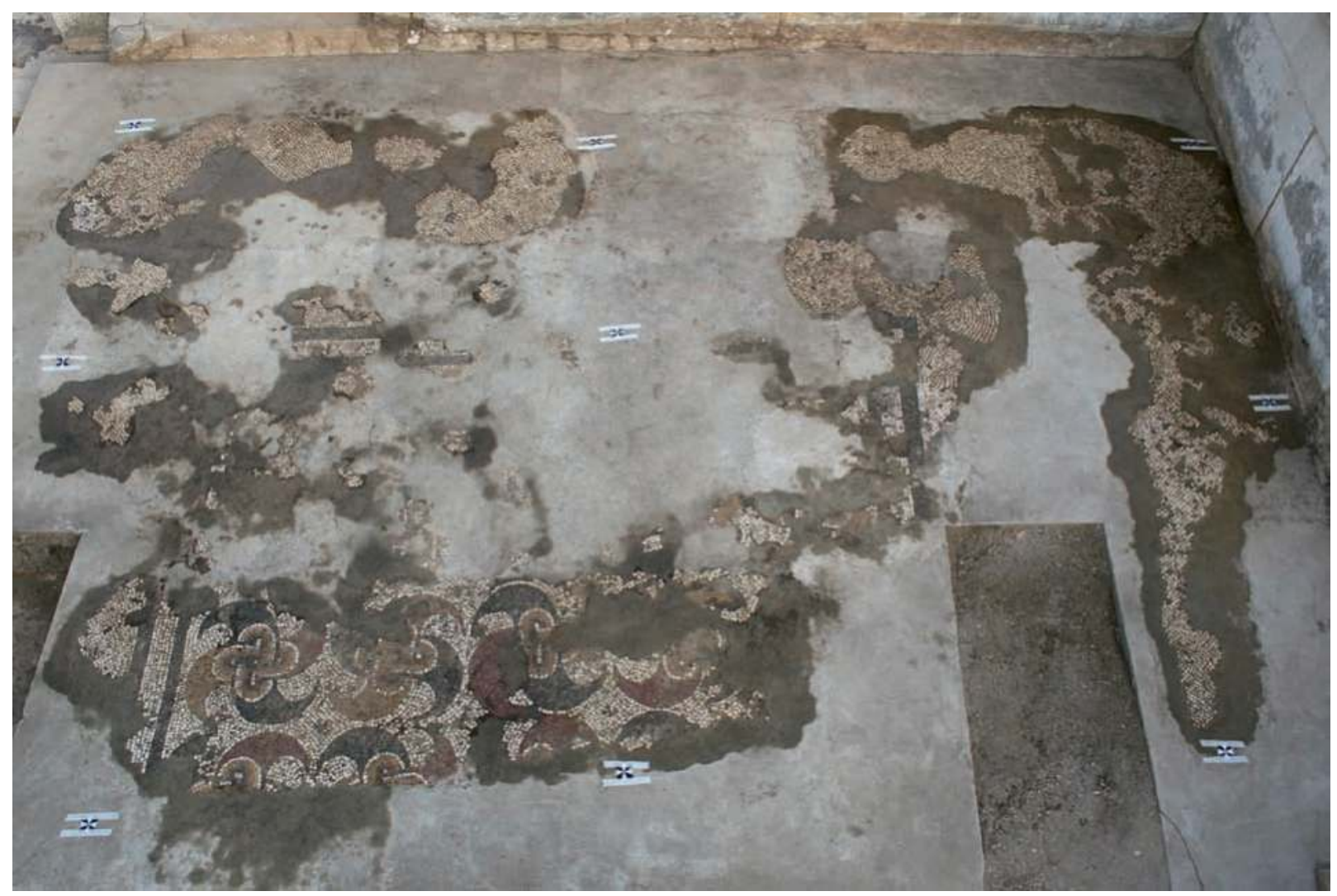

1 Vorhalle. Mosaik. Westseite

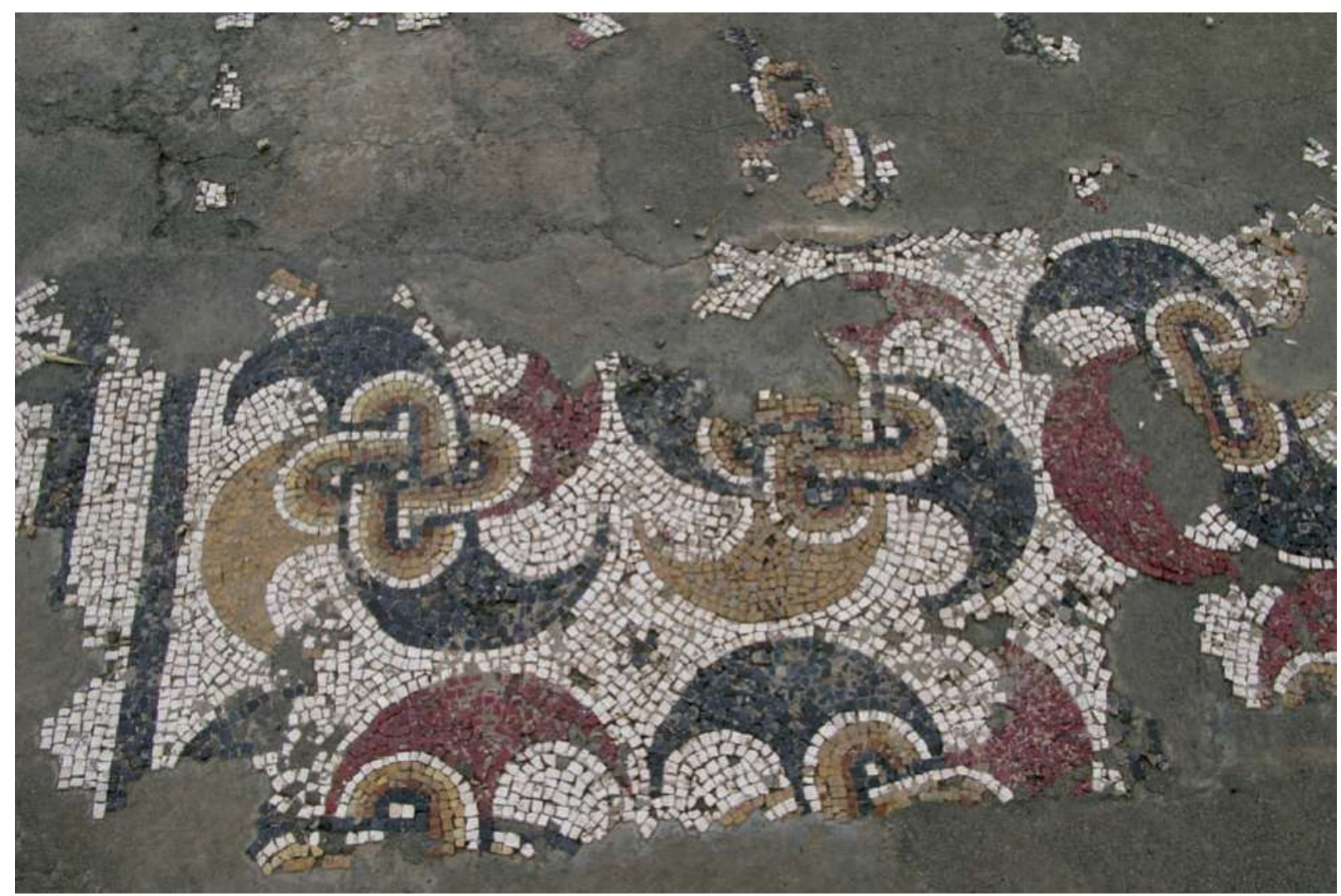

2 Vorhalle. Mosaik. Detail Westseite 
Tafel 65

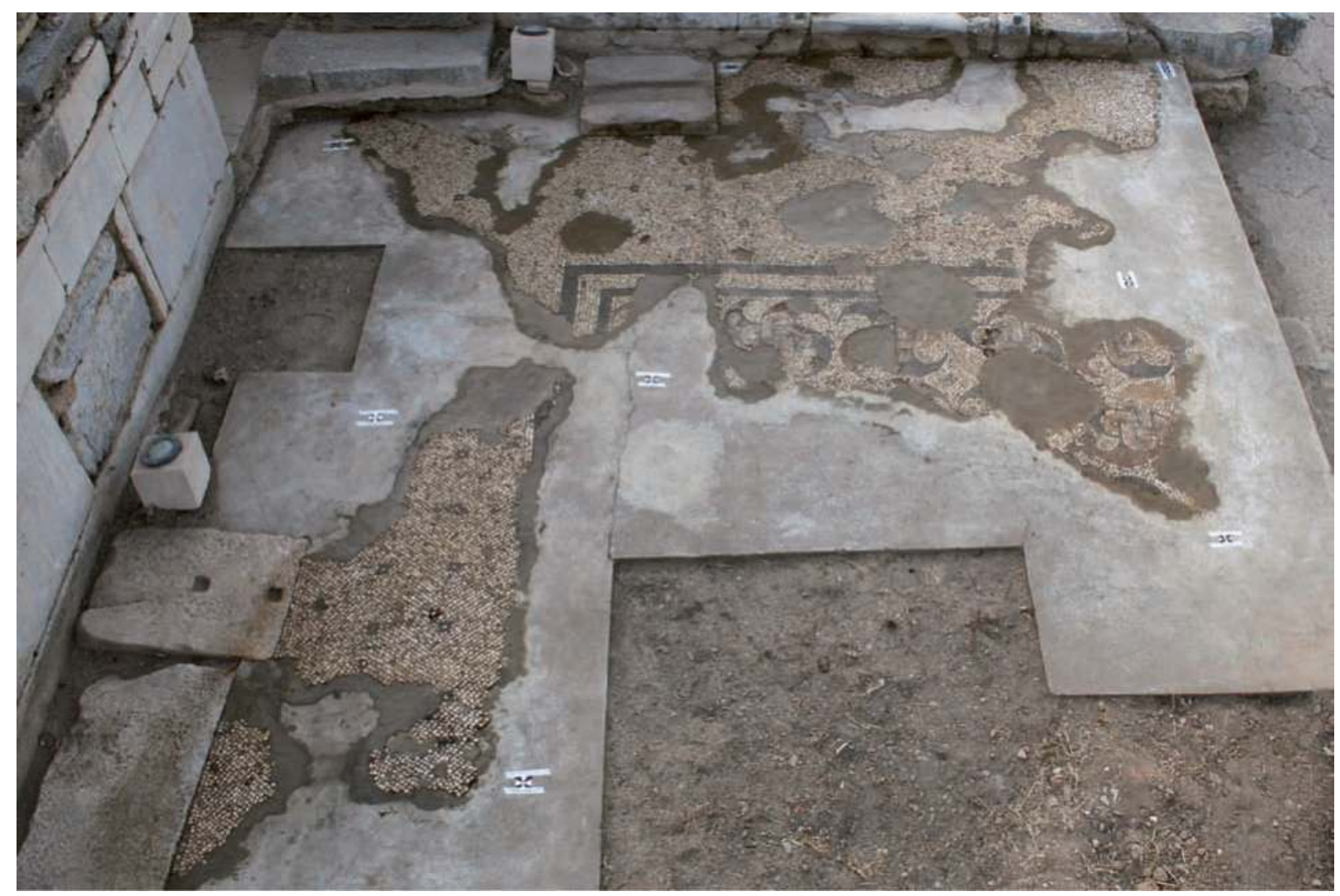

1 Vorhalle. Mosaik. Ostseite

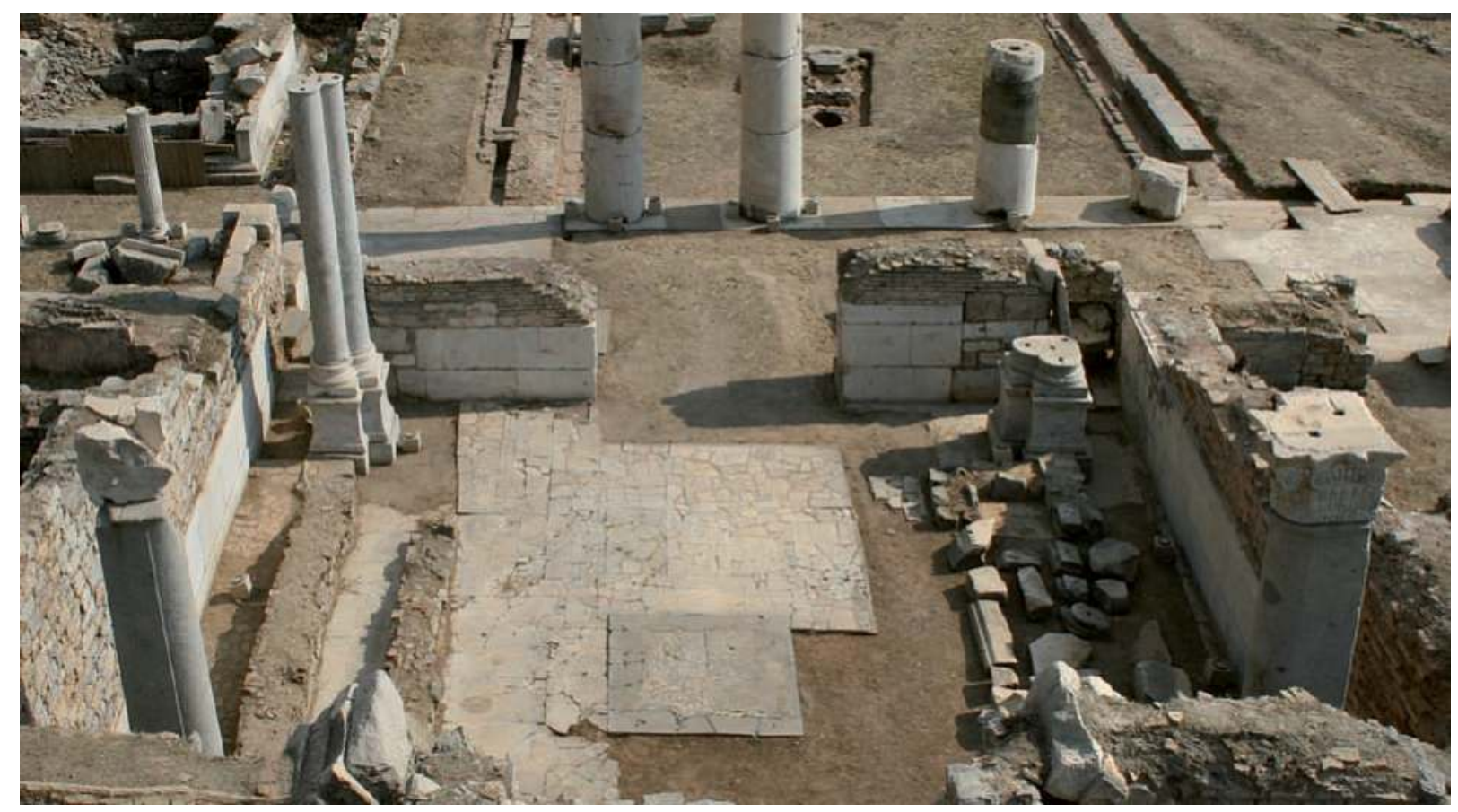

2 \Hestiasaal von Norden 
Tafel 66

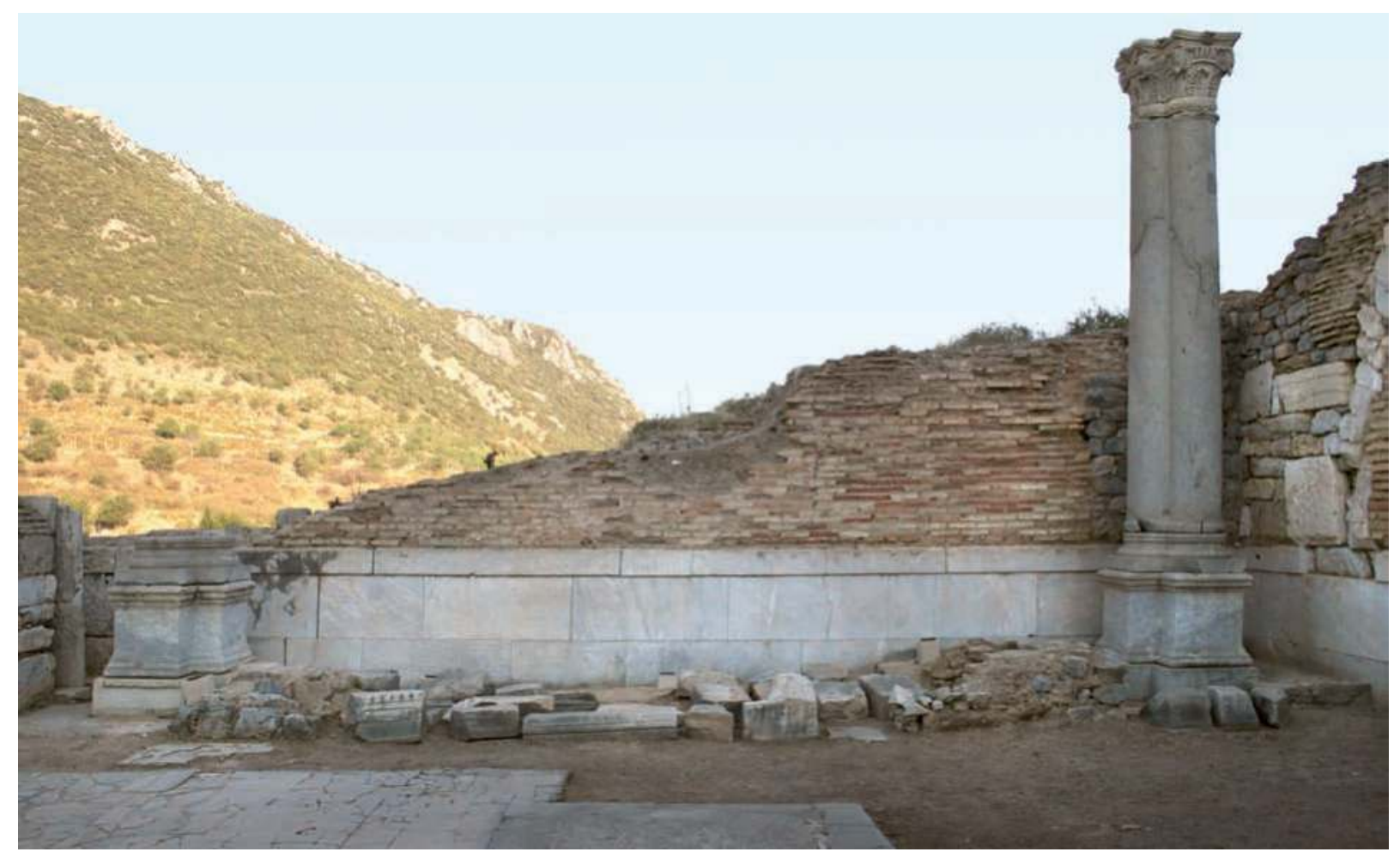

1 〉Hestiasaal<. Westwand

PRYTANEION

Hestiasaal - Nord-Süd Schnitt nach Westen

gezeichnet

hofer, J. Eitler

grafische Bearbeitung
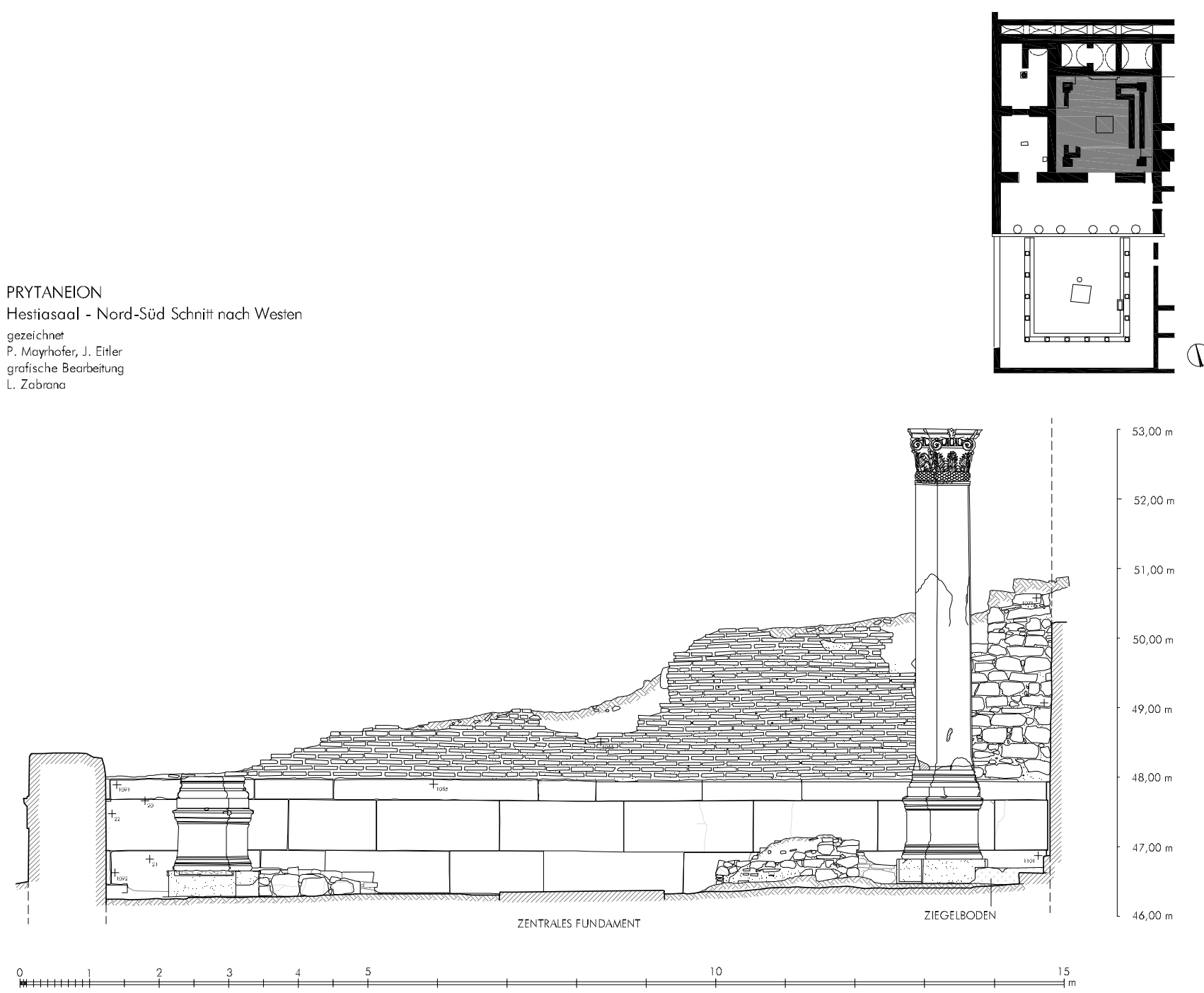

2 >Hestiasaalく. Nord-Süd-Schnitt nach Westen (1:100) 


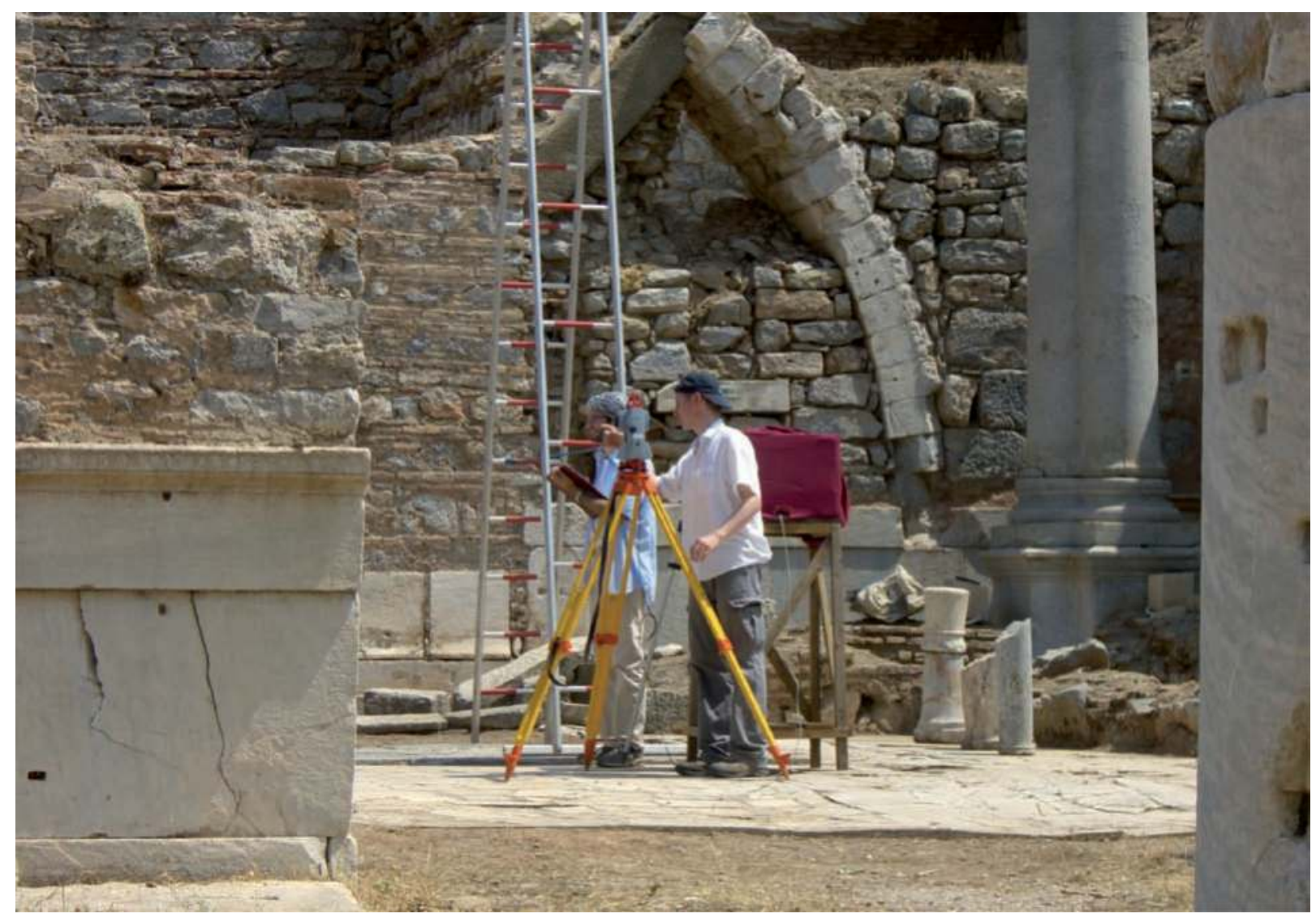

1 >Hestiasaal . Fotogrammetrische Aufnahme der Westwand

PRYTANEION

Hestiasaal - Westwand

gezeichnet

grofische Bearbeitung

grofische Be
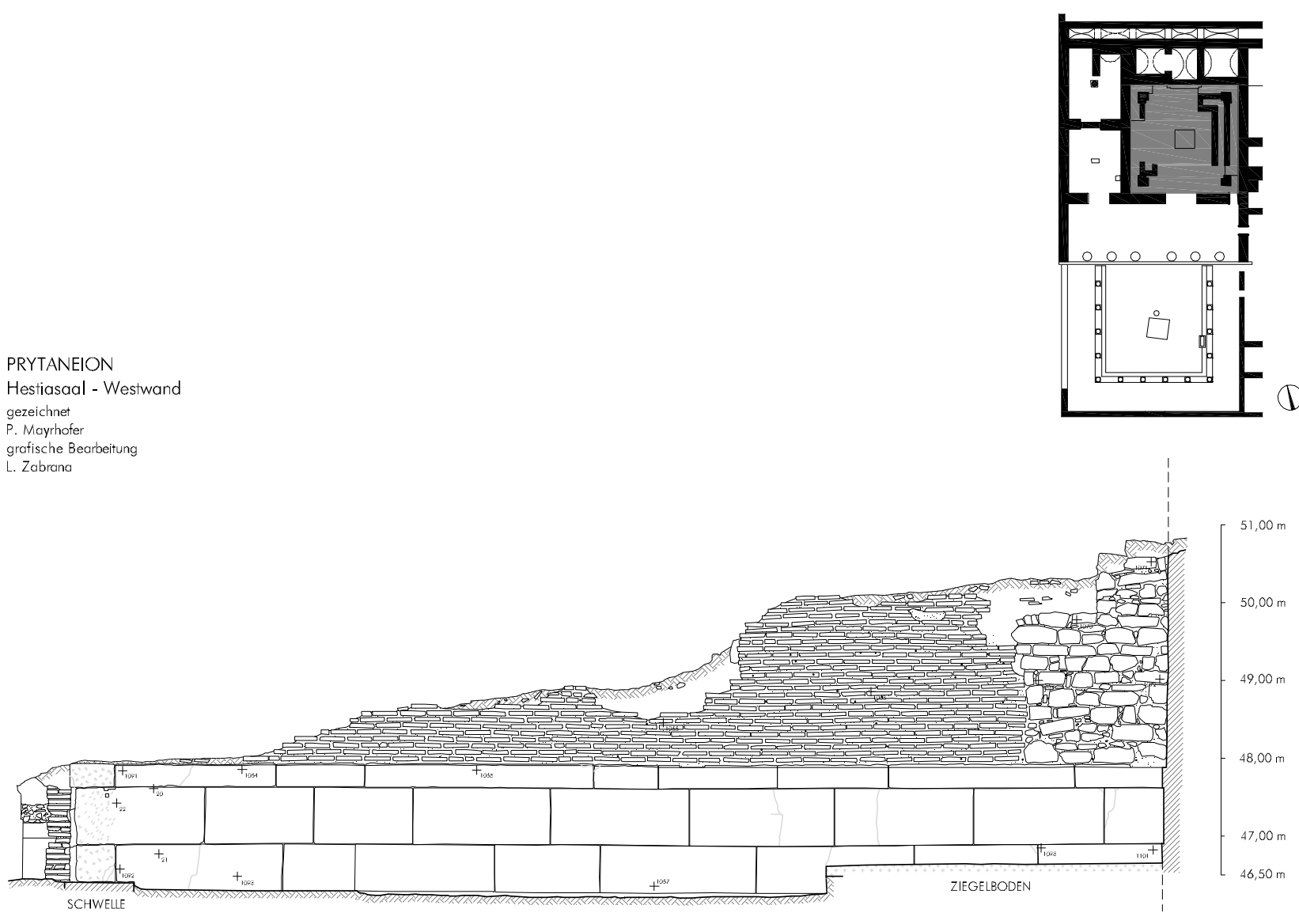
Tafel 68

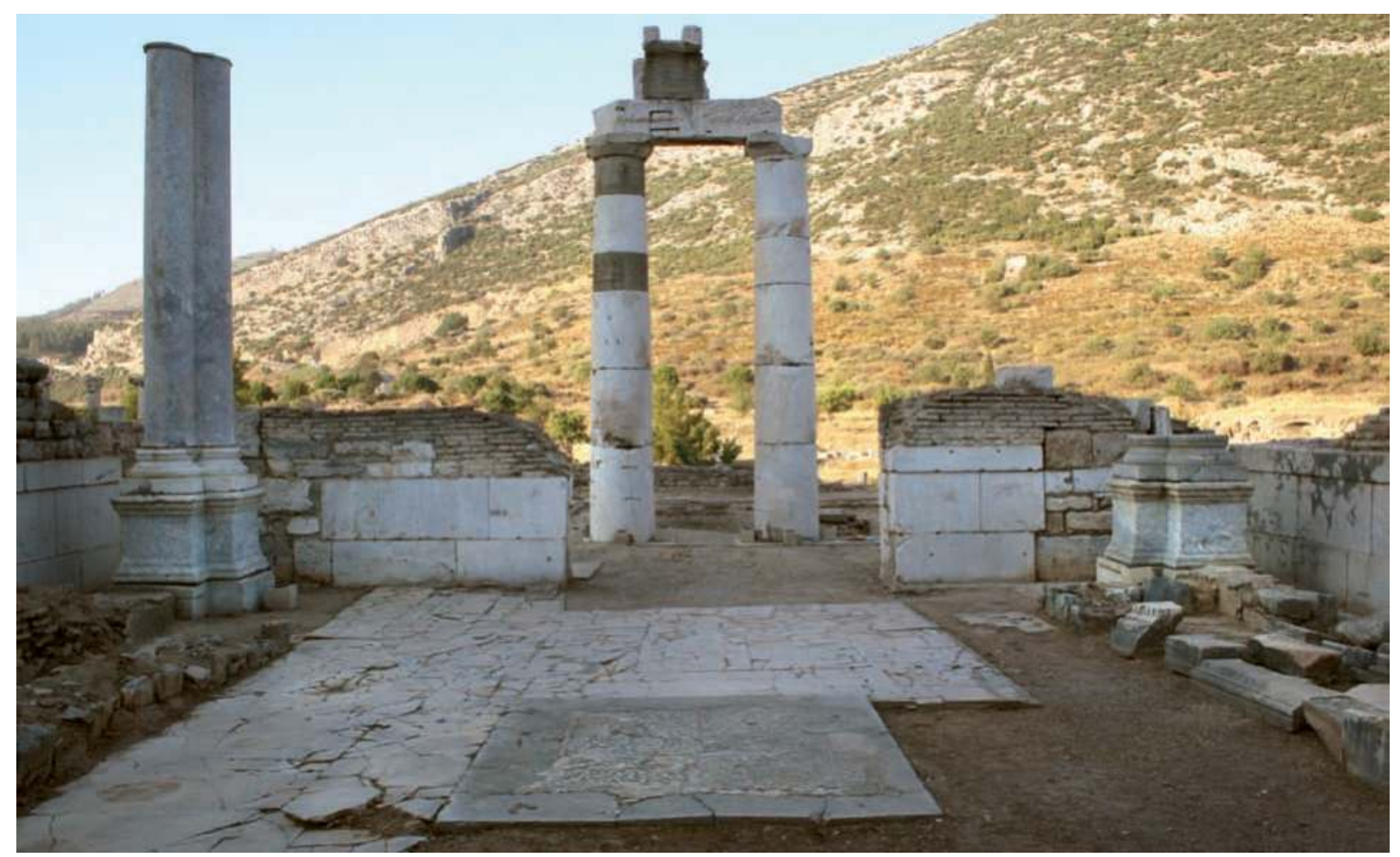

1 >Hestiasaalk. Südwand
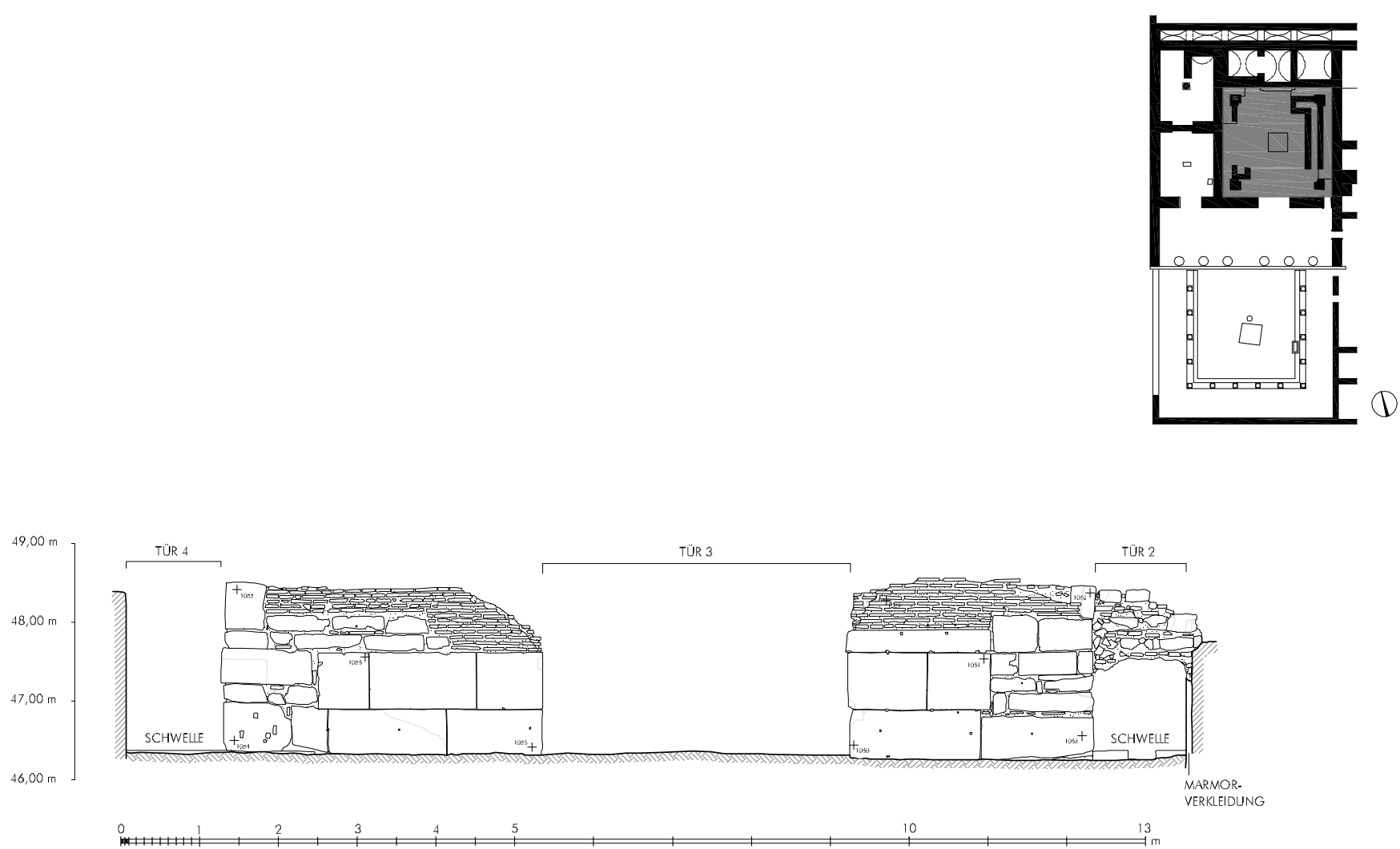

PRYTANEION

Hestiasaal - Südwand

gezeichnet
P. Mayrhofer

P. Mayrholer
grafishe Bearbeitung
L. Zobrana

2 >Hestiasaal<. Südwand (1:100) 


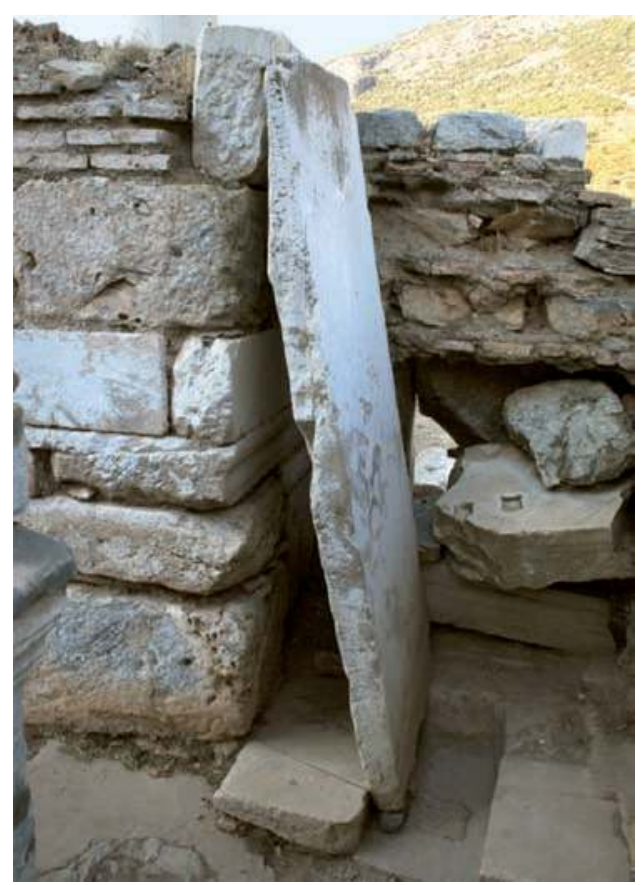

1 `Hestiasaalく. Marmornes Türgewände von Tür 2

3 >Hestiasaal<. Türsturz A 30 in Laibung von Tür 2 verbaut (1:50)

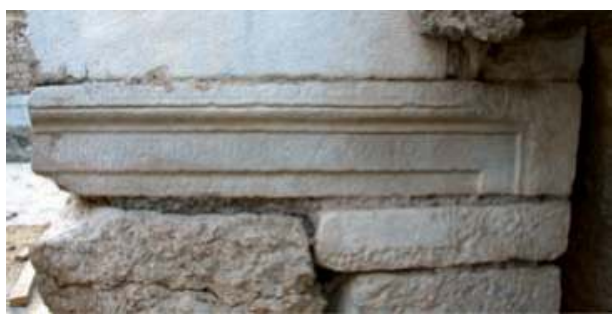

2 >Hestiasaak. Türsturz A 30 in Laibung von Tür 2 verbaut

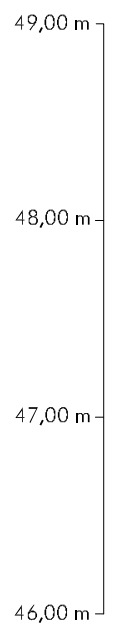

$46,00 \mathrm{~m}-$

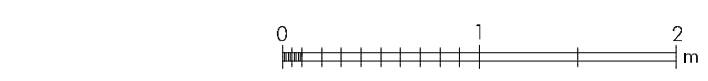

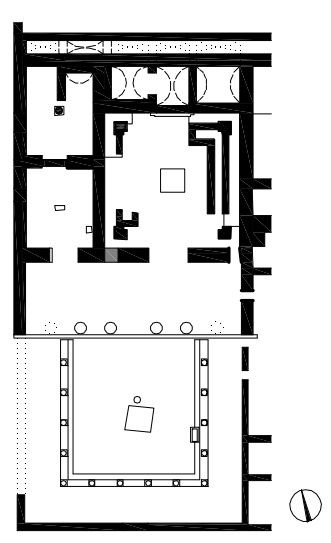

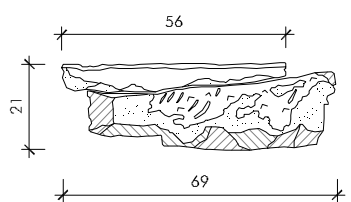

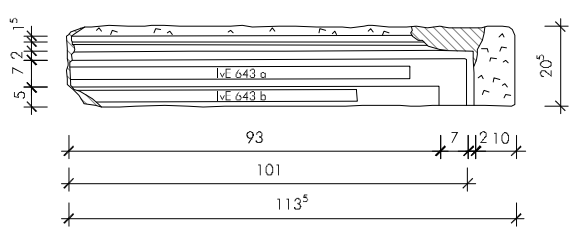

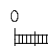

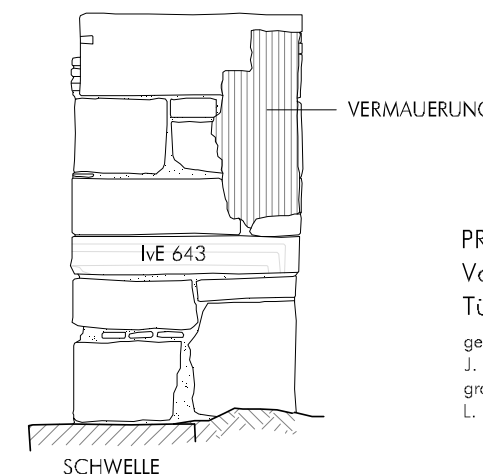

PRYTANEION

Vorhalle - Hestiasaal,

Tür 2, östl. Türlaibung

gezeichnet
J. Eitler

grofische Beorbeitung

L. Zabrana
IVE 643 a: $H: 3 \mathrm{~cm}, \mathrm{~L}: 86 \mathrm{~cm}$ IvE $643 \mathrm{~b}$ : $\mathrm{H:}: 3 \mathrm{~cm}, \mathrm{L:}: 70 \mathrm{~cm}$

PRYTANEION

HESTIASAAL PR 58/07

TÜRSTURZ

gezeichnet
B. Stark
grafische Bearbeitung
L. Zabrana

grafische Bearbeitung
L. Zabrana

4 >Hestiasaal Türsturz A 30

$(1: 25)$

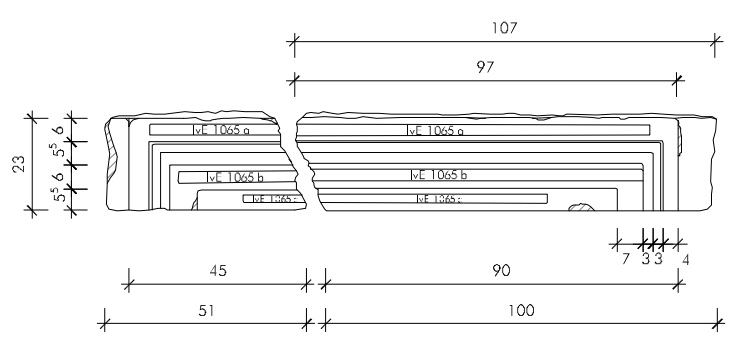
O 200

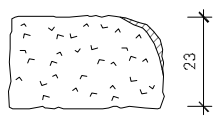

IVE 1065 a: H: $3 \mathrm{~cm}$, L: $89 \mathrm{~cm}$ IVE 1065 b: H: $3 \mathrm{~cm}, \mathrm{~L}: 84 \mathrm{~cm}$ IvE 1065 c: H: $2 \mathrm{~cm}, \mathrm{~L}: 54 \mathrm{~cm}$

PRYTANEION

HESTIASAAL PR 59/07, PR 60/07

TÜRSTURZ

gezeichnet

grafische Bearbeitung

L. Zabrana
5 >Hestiasaal<. Türsturz A 31 $(1: 25)$

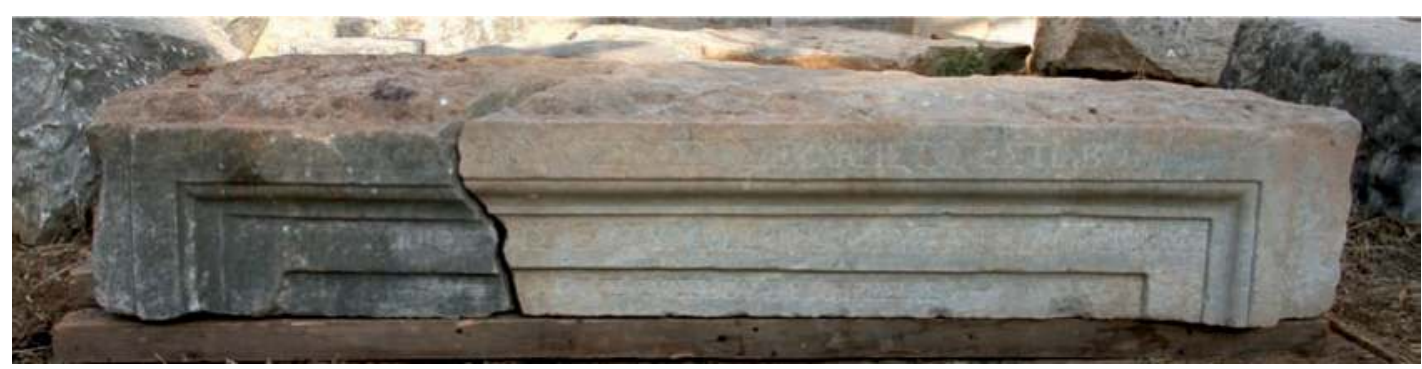

6 >Hestiasaalく. Türsturz A 31 nach Bergung 
Tafel 70

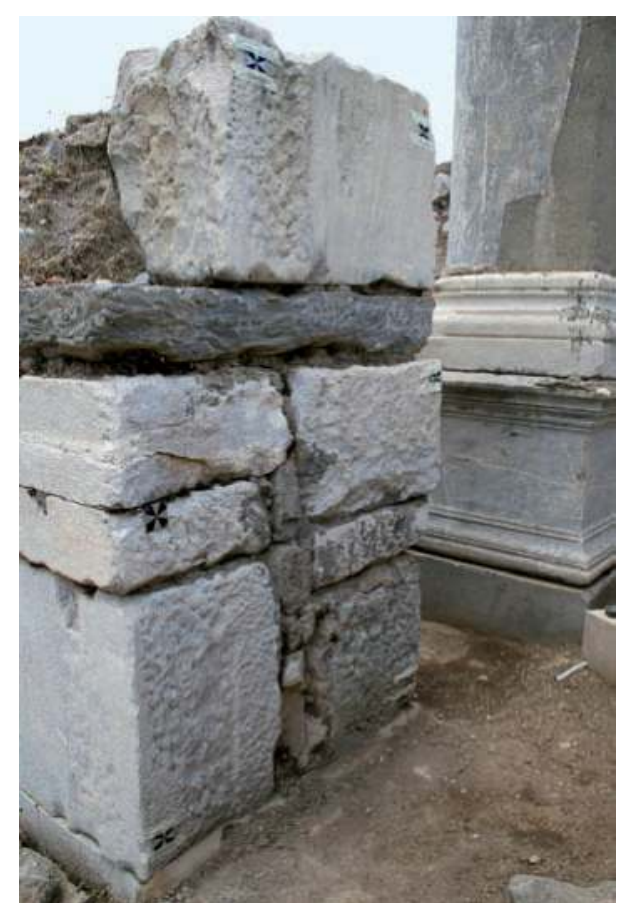

1 >Hestiasaalく. Westliche Türlaibung von Tür 4
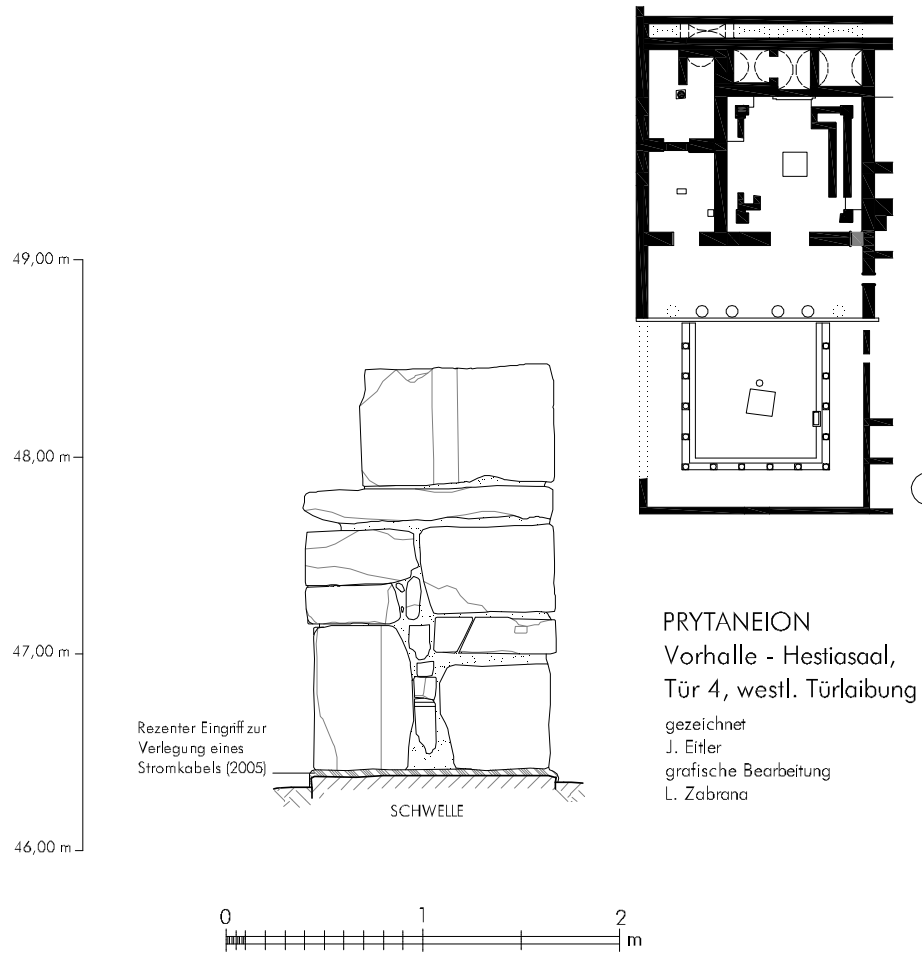

PRYTANEION

Vorhalle - Hestiasaal,

Tür 4, westl. Türlaibung

gezeichnet

grafische Bearbeitung

L. Zabrana

2 >Hestiasaak. Westliche Türlaibung von Tür 4 (1:50)

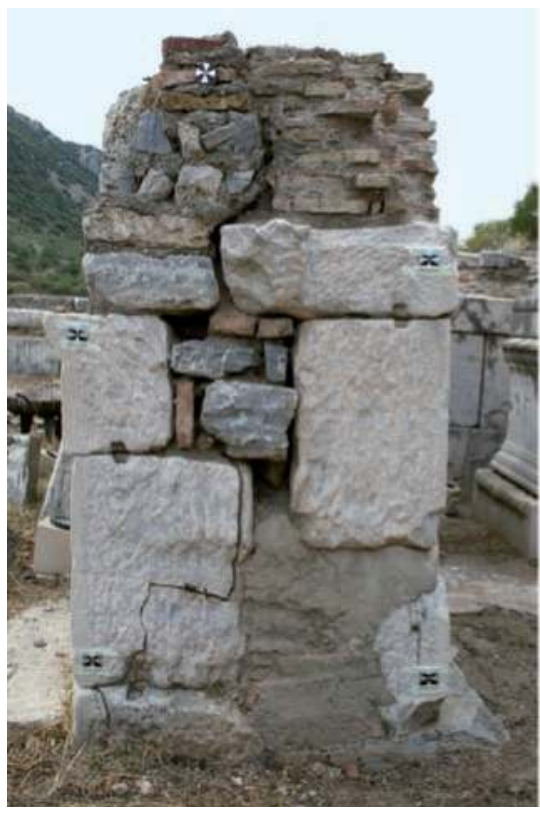

WESTLICHE TÜRLAIBUNG
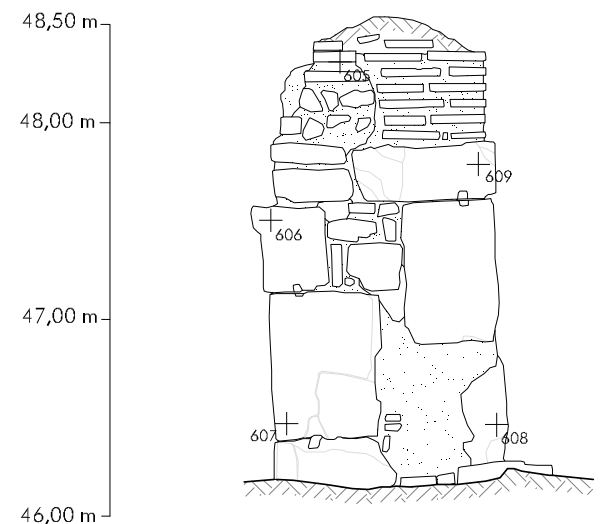

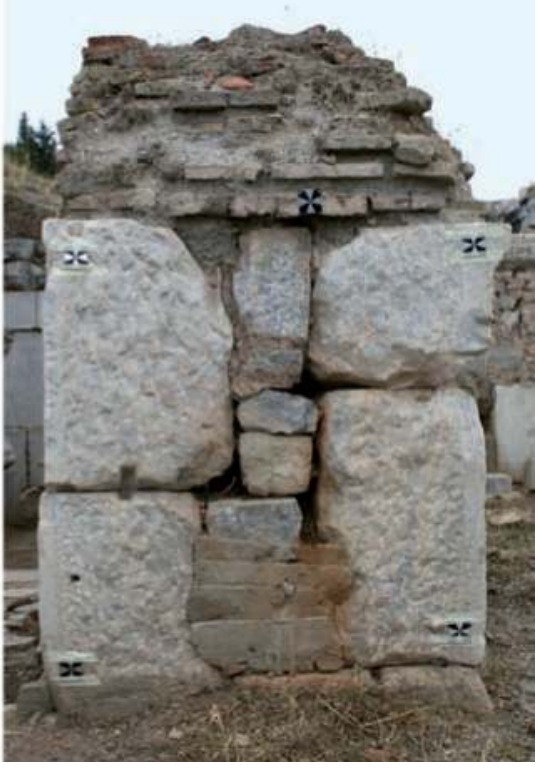

ÖSTLICHE TÜRLAIBUNG

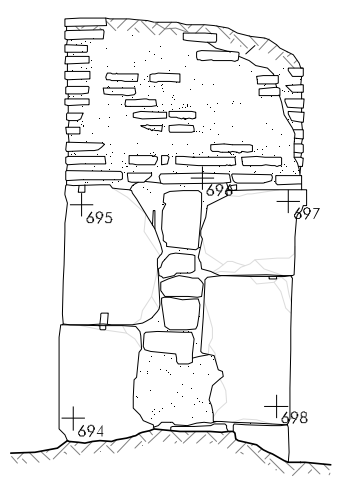

3 >Hestiasaal<. Westliche und östliche Türlaibung von Tür 3

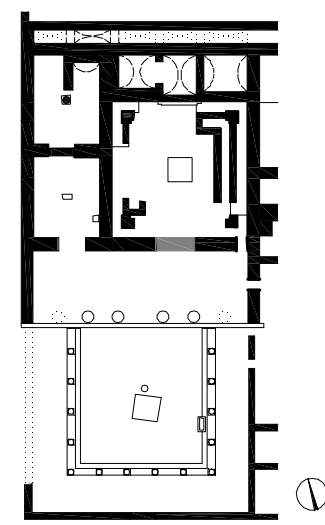

PRYTANEION

Vorhalle - Hestiasaal,

Tür 3, westl. und östl. Türlaibung gezeichnet

grafische Bearbeitung

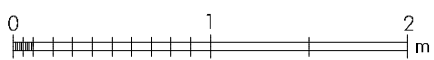

4 >Hestiasaalく. Westliche und östliche Türlaibung von Tür 3 (1:50) 


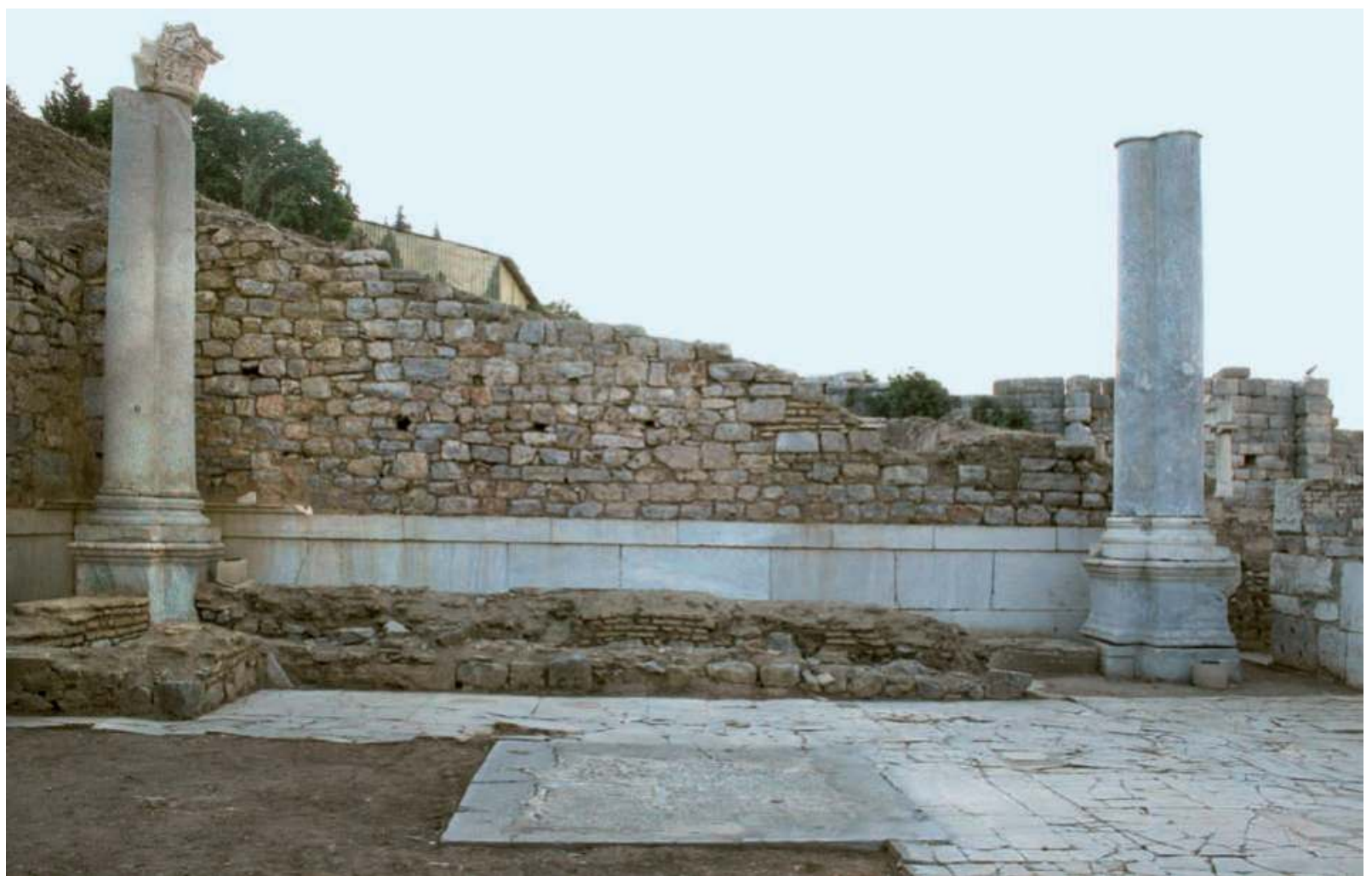

1 〉Hestiasaalく. Ostwand

PRYTANEION

Hestiasaal - Nord-Süd Schnitt nach Osten

gezeichnet

P. Mayrhofer, J. Eitle

L. Zabrana
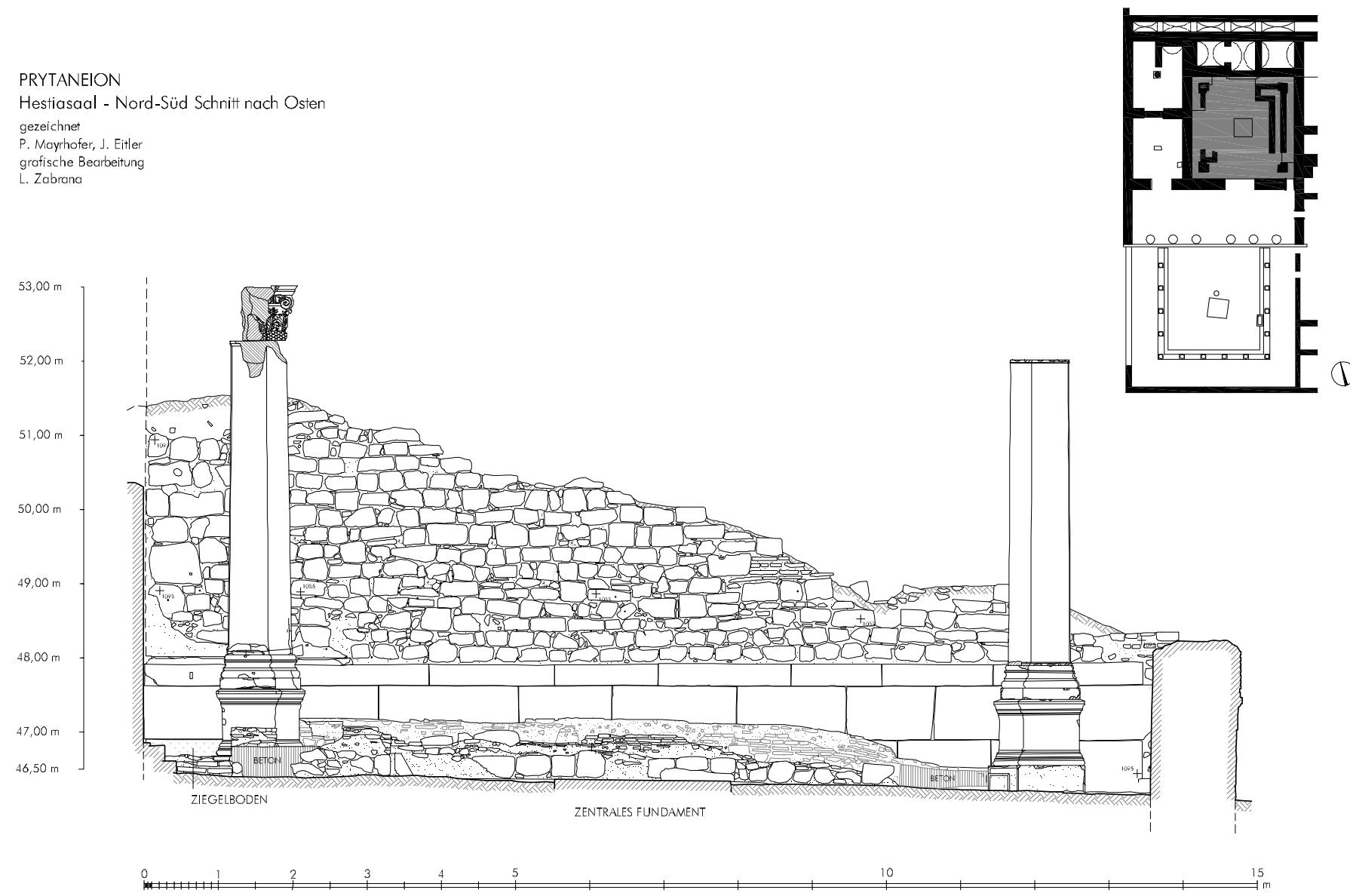
Tafel 72

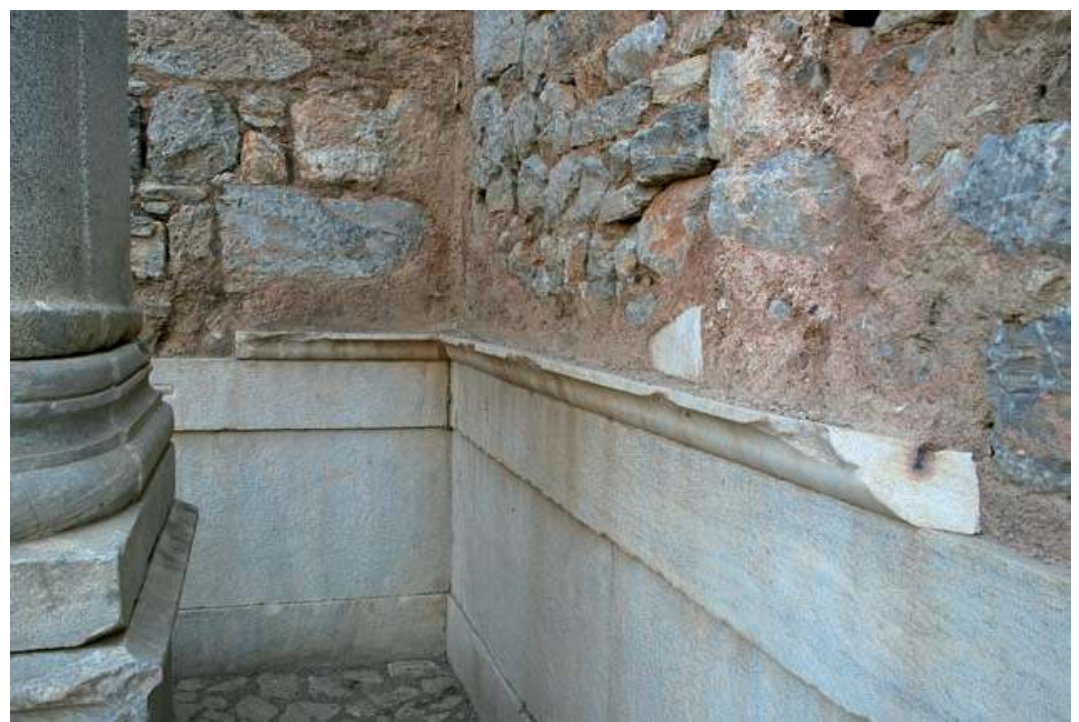

1 >Hestiasaalく. Nordostecke. Detail Gesims sowie Rest der Marmorverkleidung

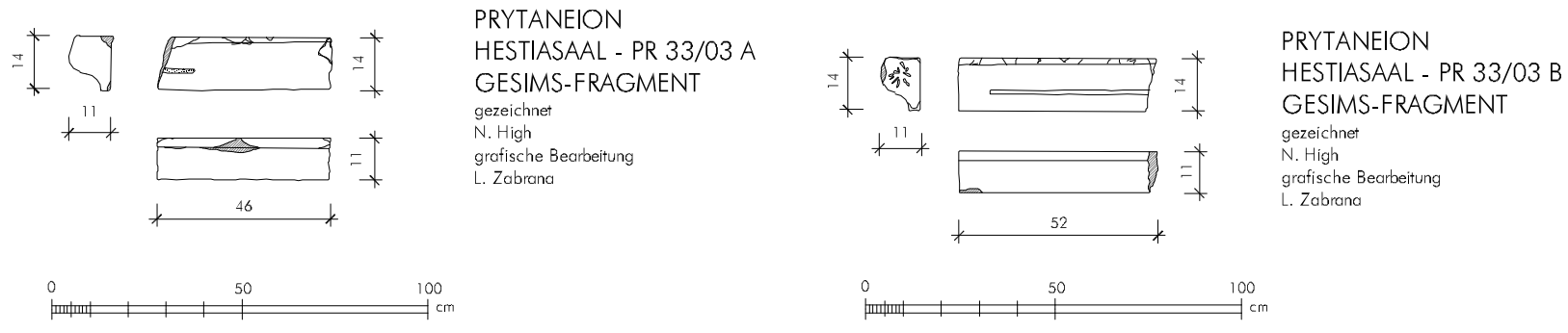

2 >Hestiasaalk. Fragmente des Gesimses A 26 (1:25)
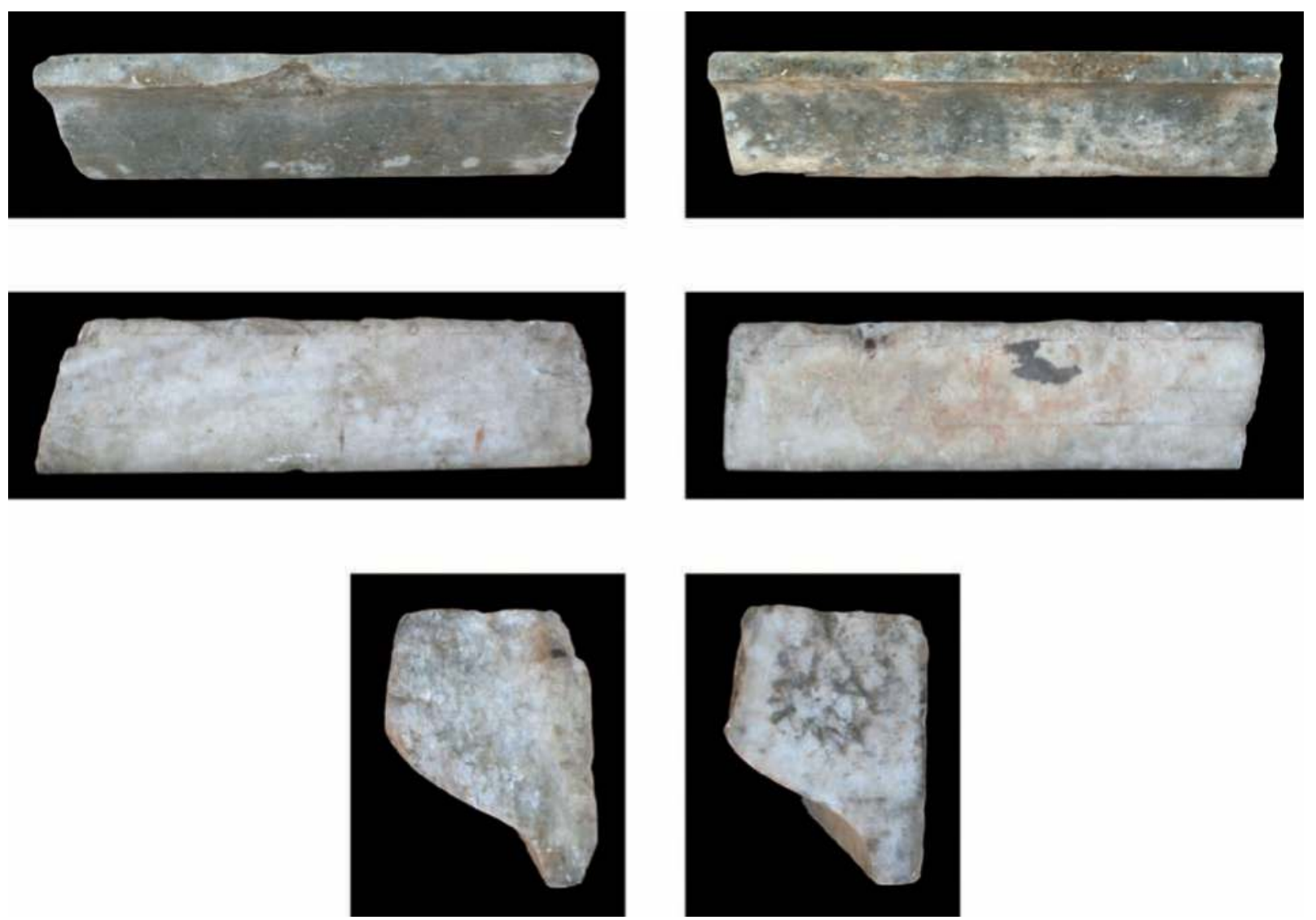

3 >Hestiasaal . Fragmente des Gesimses A 26 


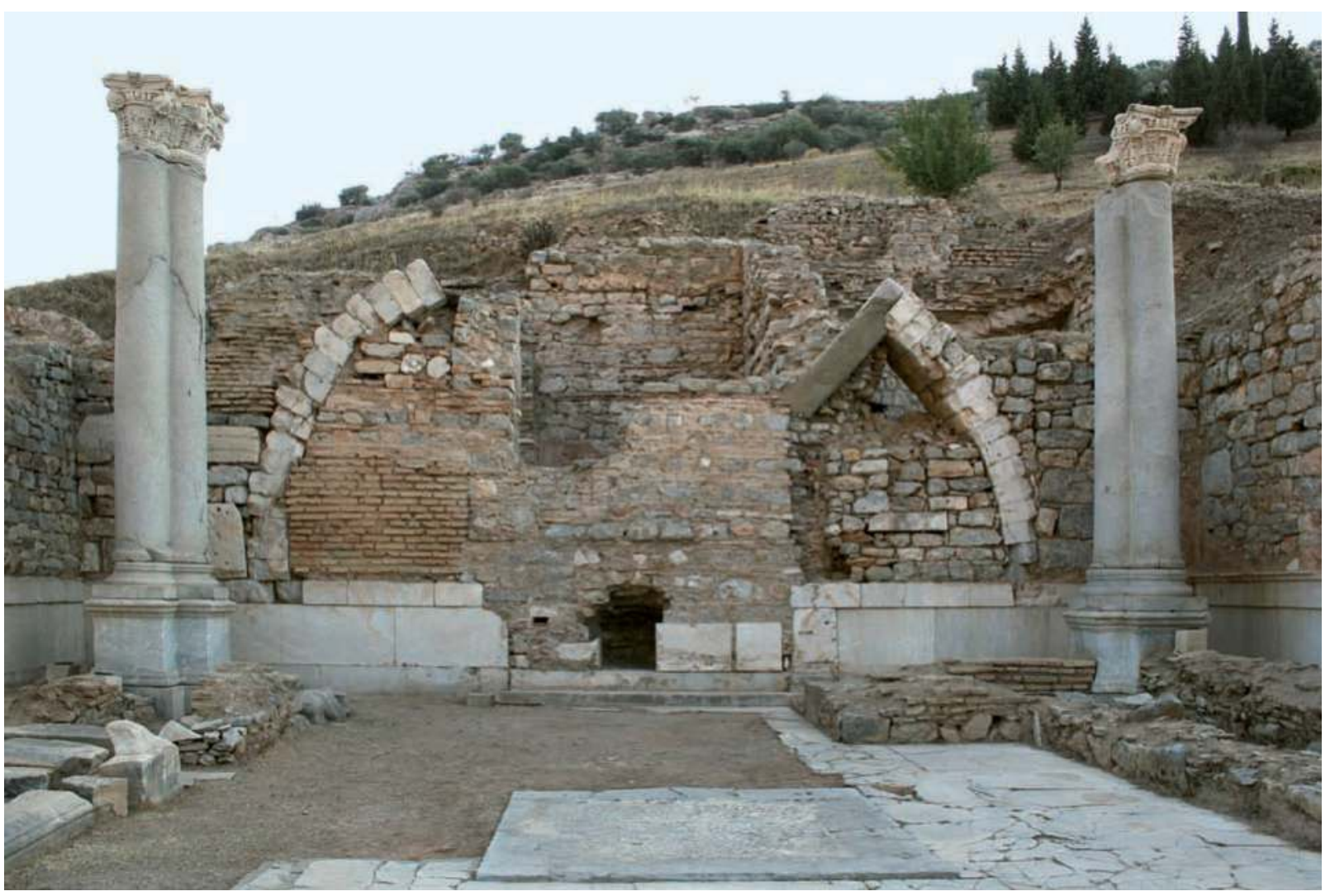

1 >Hestiasaalく. Nordwand

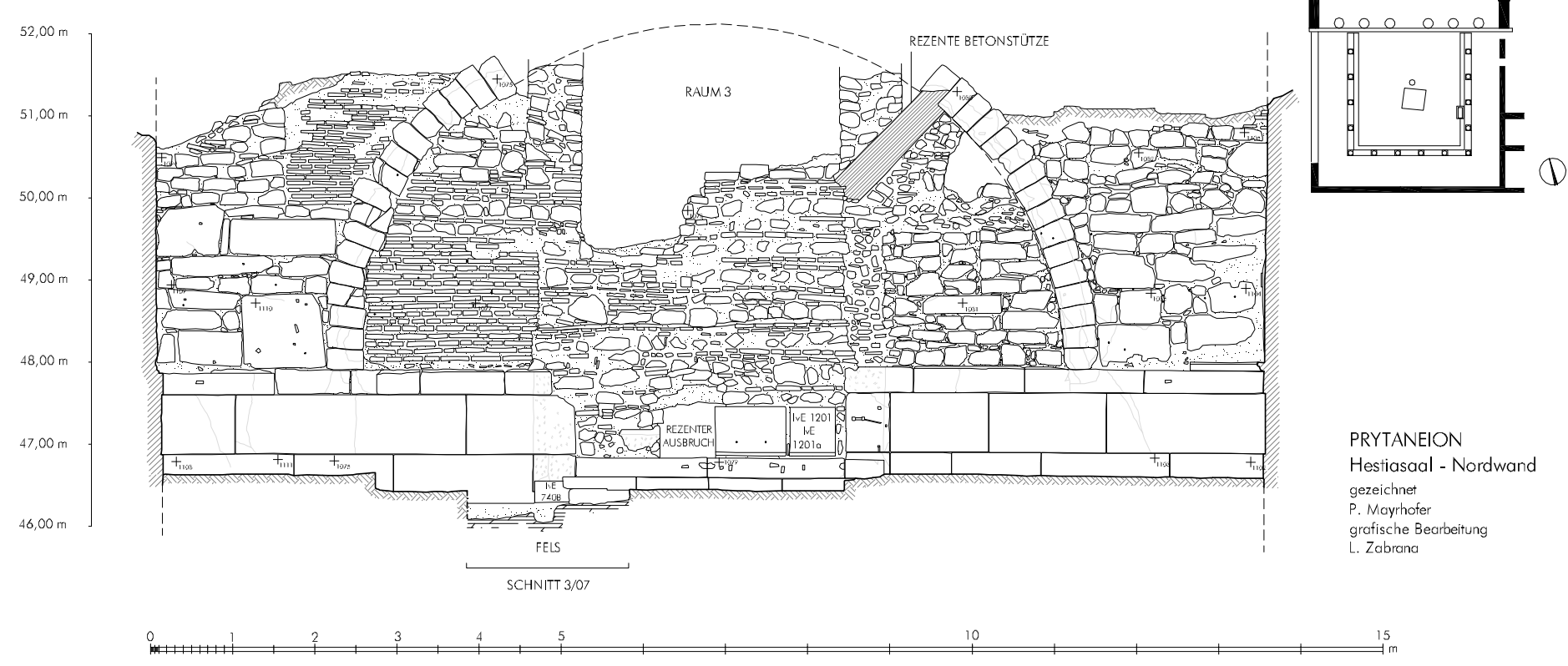

$2>$ Hestiasaal . Nordwand (1:100) 
Tafel 74

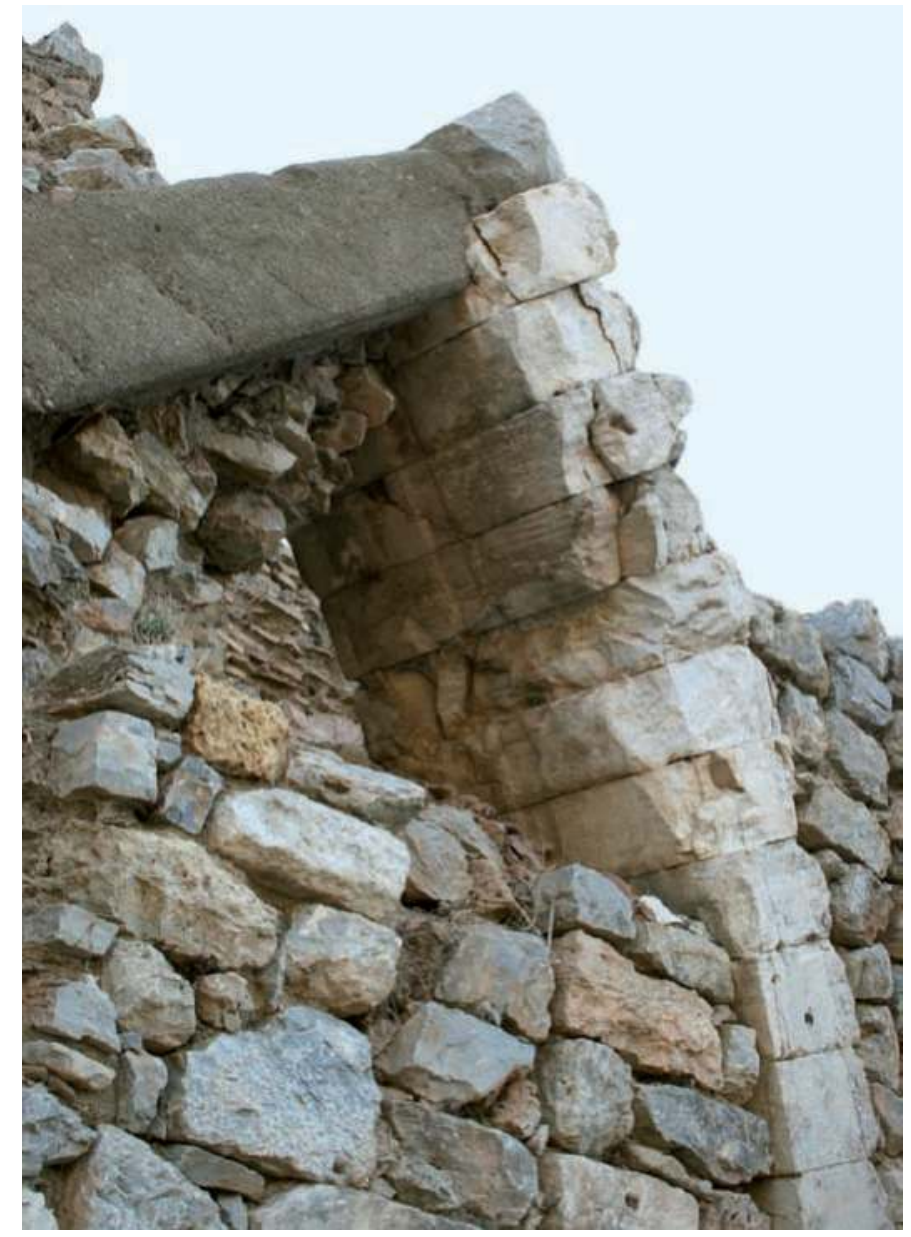

1 〉Hestiasaal . Nordwand. Keilsteinbogen Innenansicht

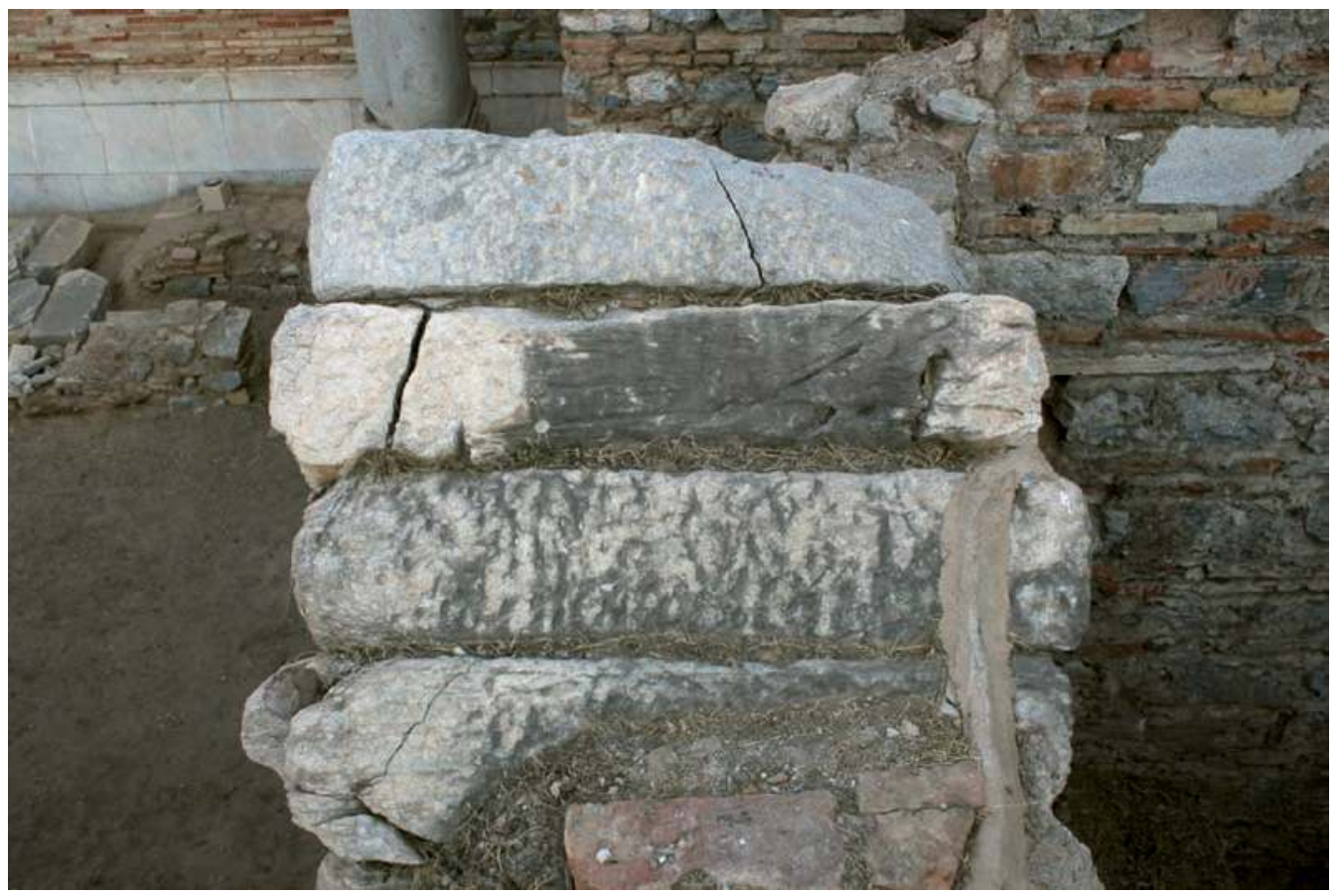

2 >Hestiasaal . Nordwand. Keilsteinbogen Draufsicht 
Tafel 75
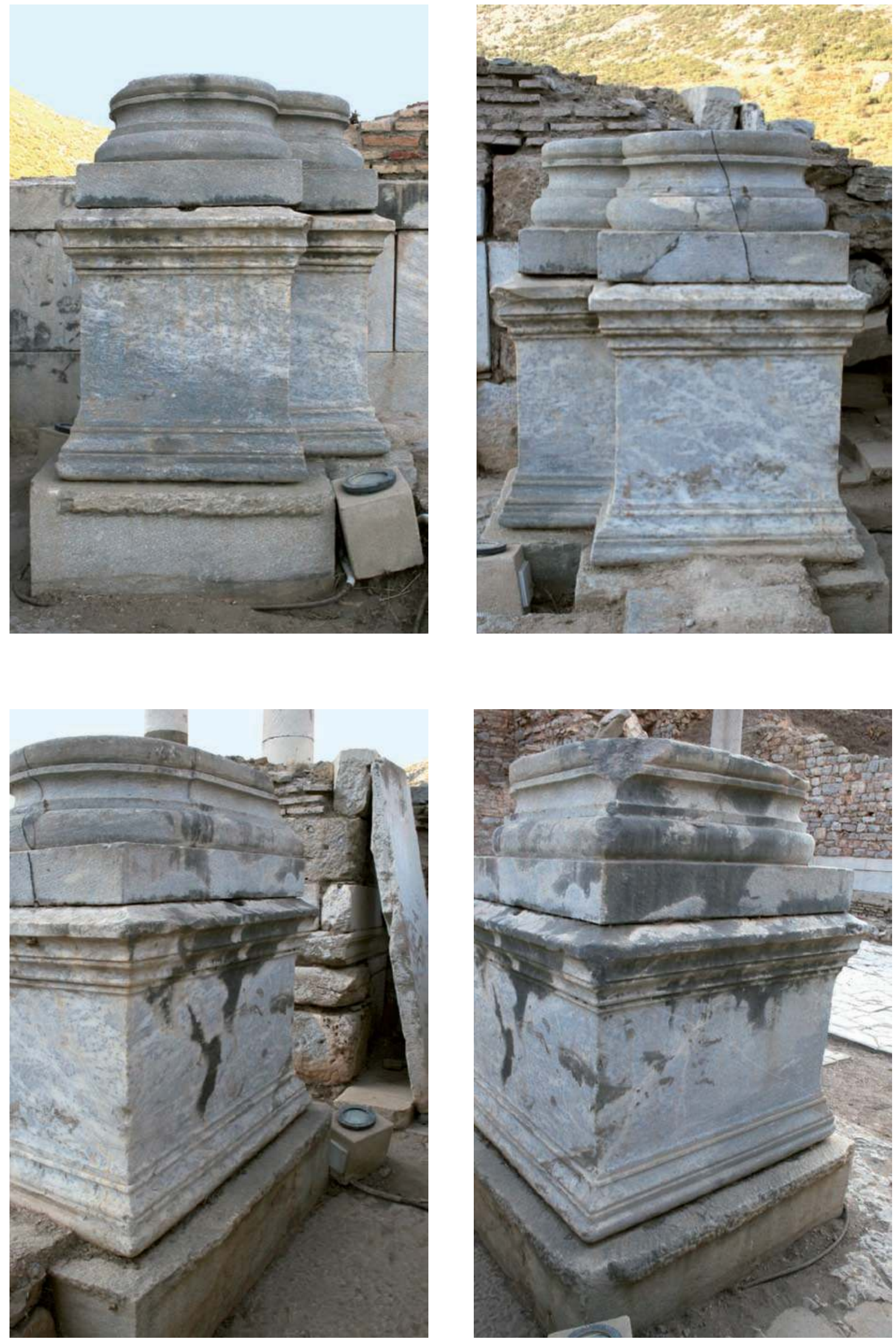

1 >Hestiasaalく. Südwestlicher Säulenstuhl mit Basis A 12. 13 
Tafel 76

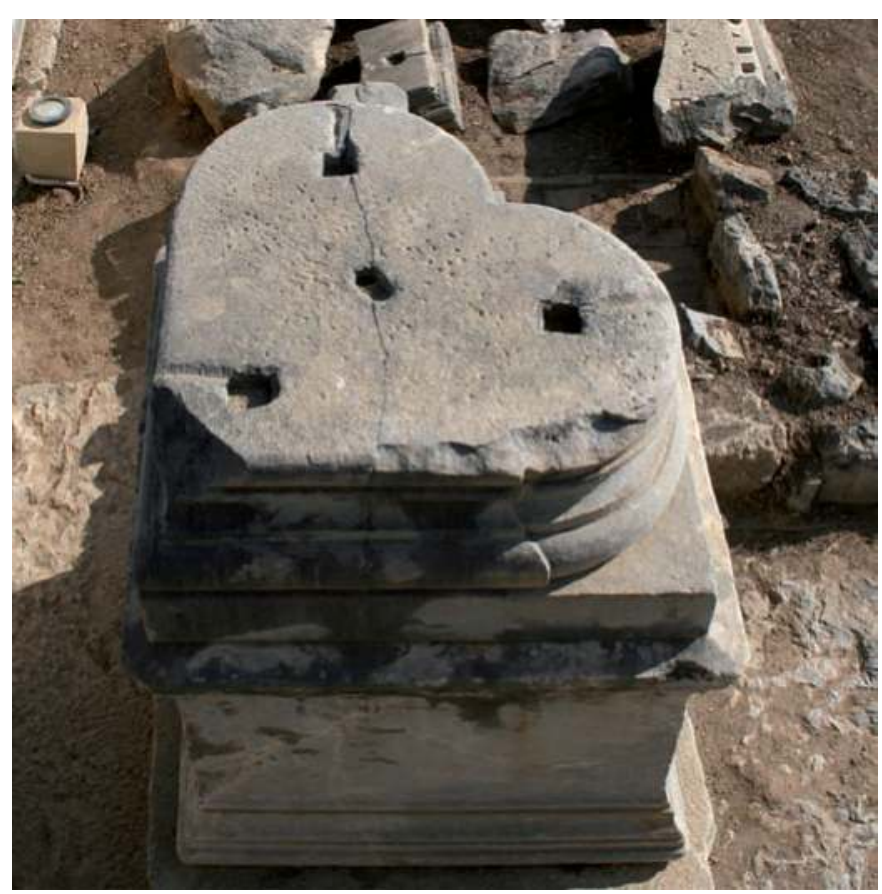

$1>$ Hestiasaal

Südwestlicher Säulenstuhl mit Basis

A 12.13

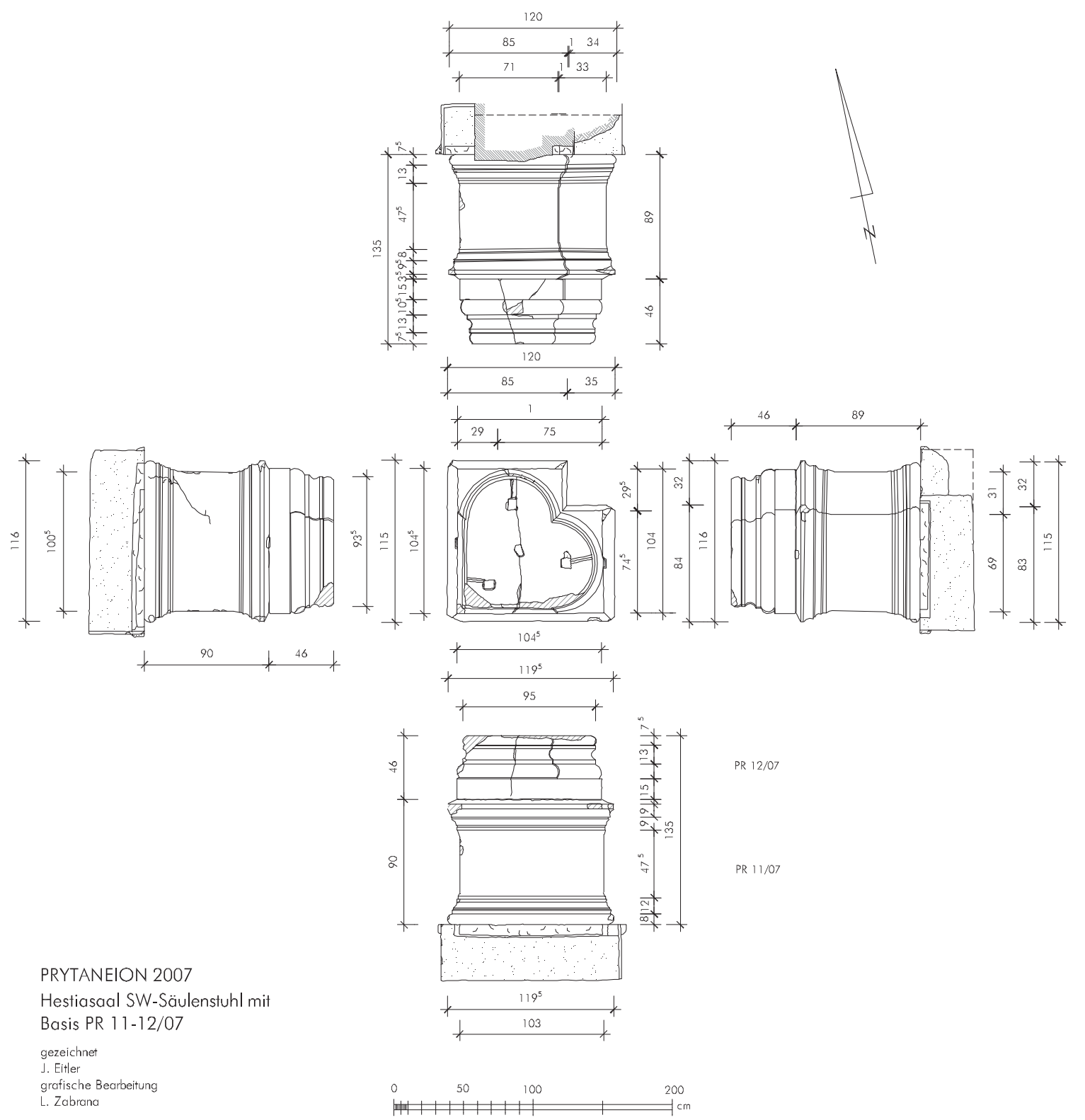

2 >Hestiasaalk. Südwestlicher Säulenstuhl mit Basis A 12.13 (1:50) 
Tafel 77
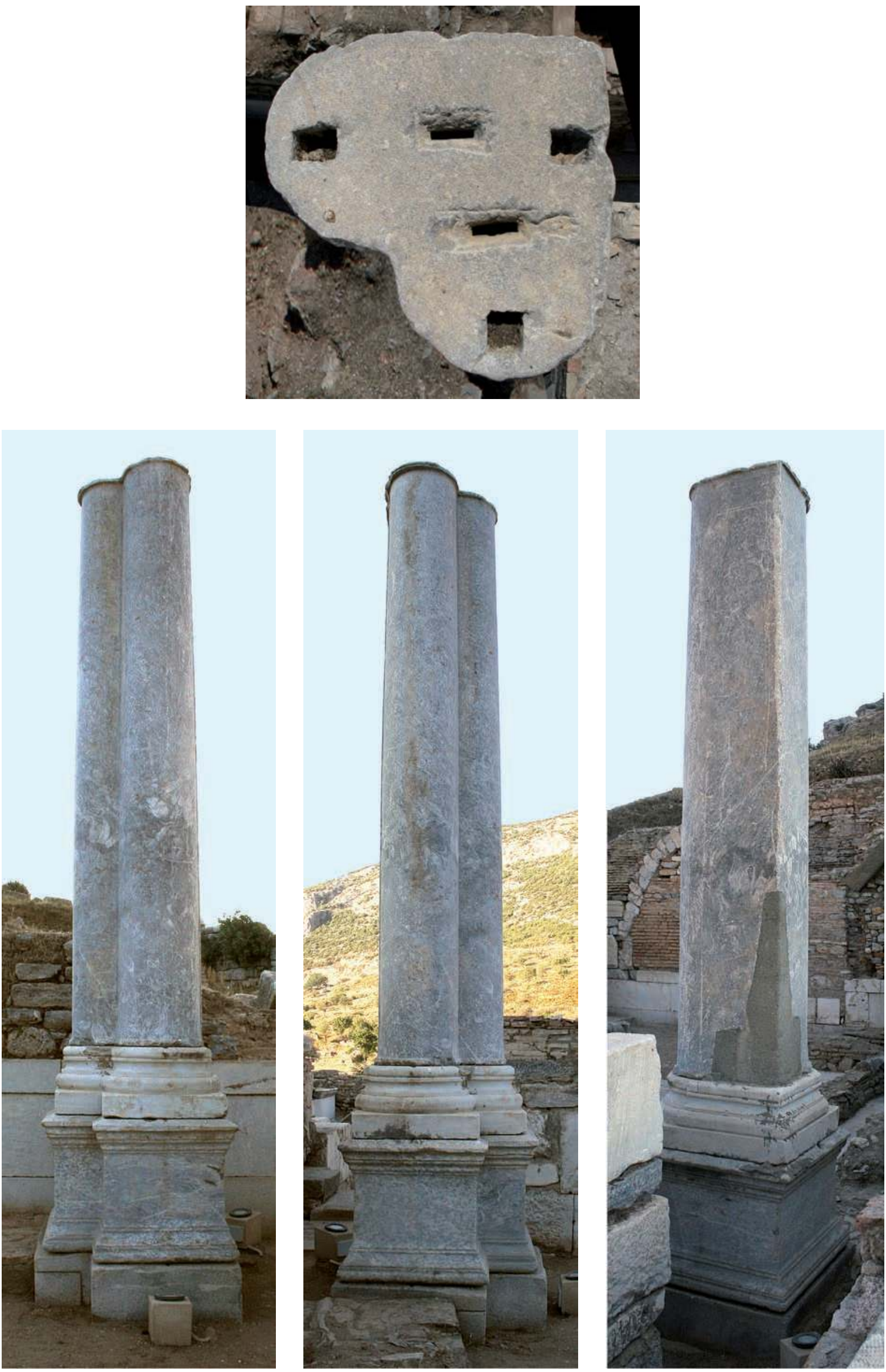

1 〉Hestiasaak. Südöstlicher Säulenstuhl mit Eck-Doppelhalbsäulen A 14-16 
Tafel 78

PRYTANEION

Hestiasaal SO- Säule PR 13-15/07

gezeichnet $\rfloor$. Eitler

graf. Bearbeitung L. Zobrano
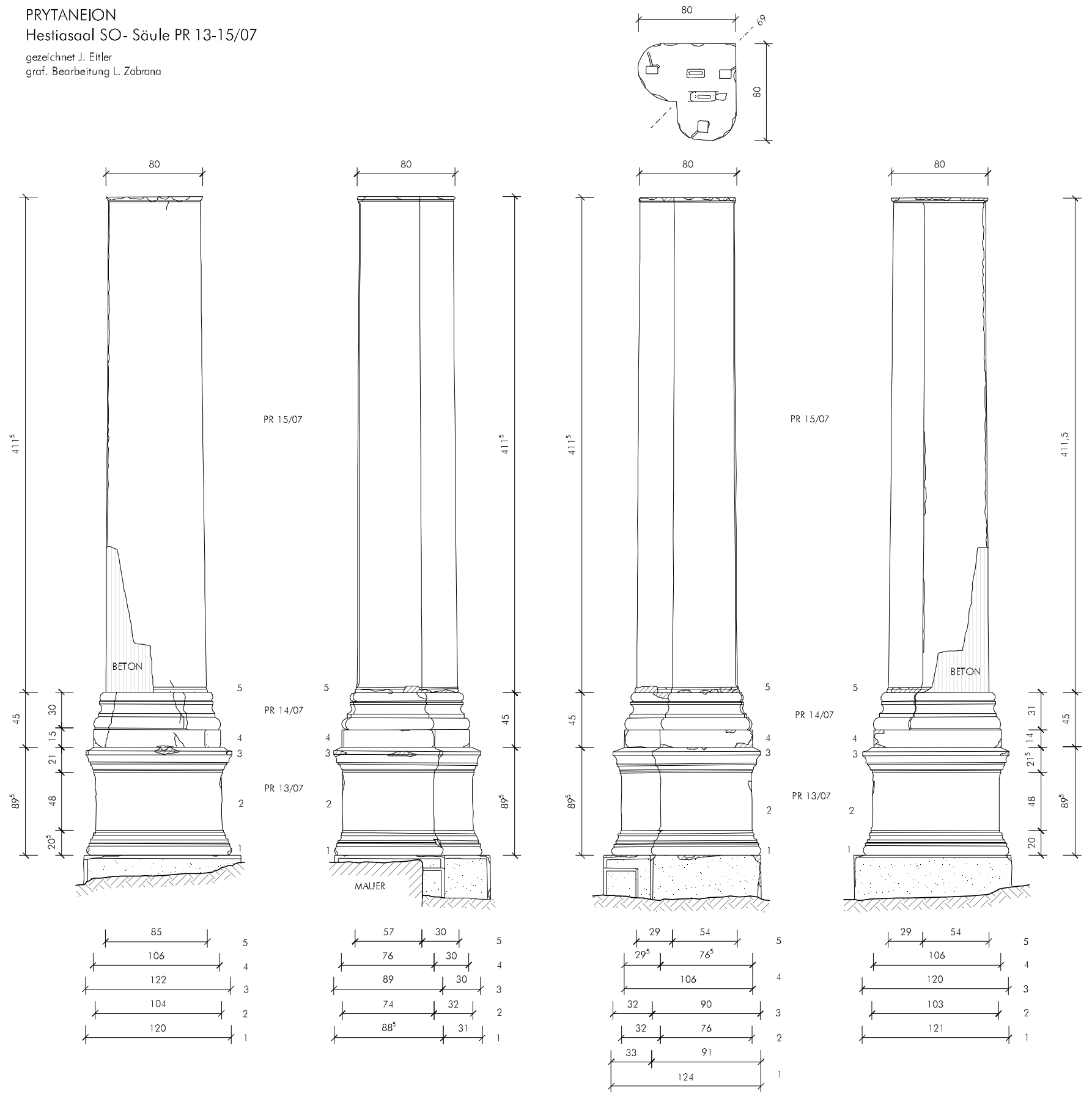

OSTSEITE

NORDSEITE

WESTSEITE

SÜDSEITE

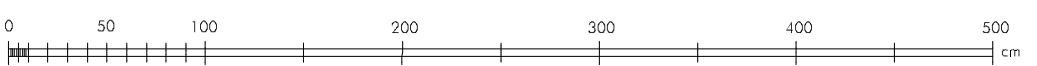

1 >Hestiasaalく. Südöstlicher Säulenstuhl mit Eck-Doppelhalbsäulen A 14-16 (1:50) 
Tafel 79
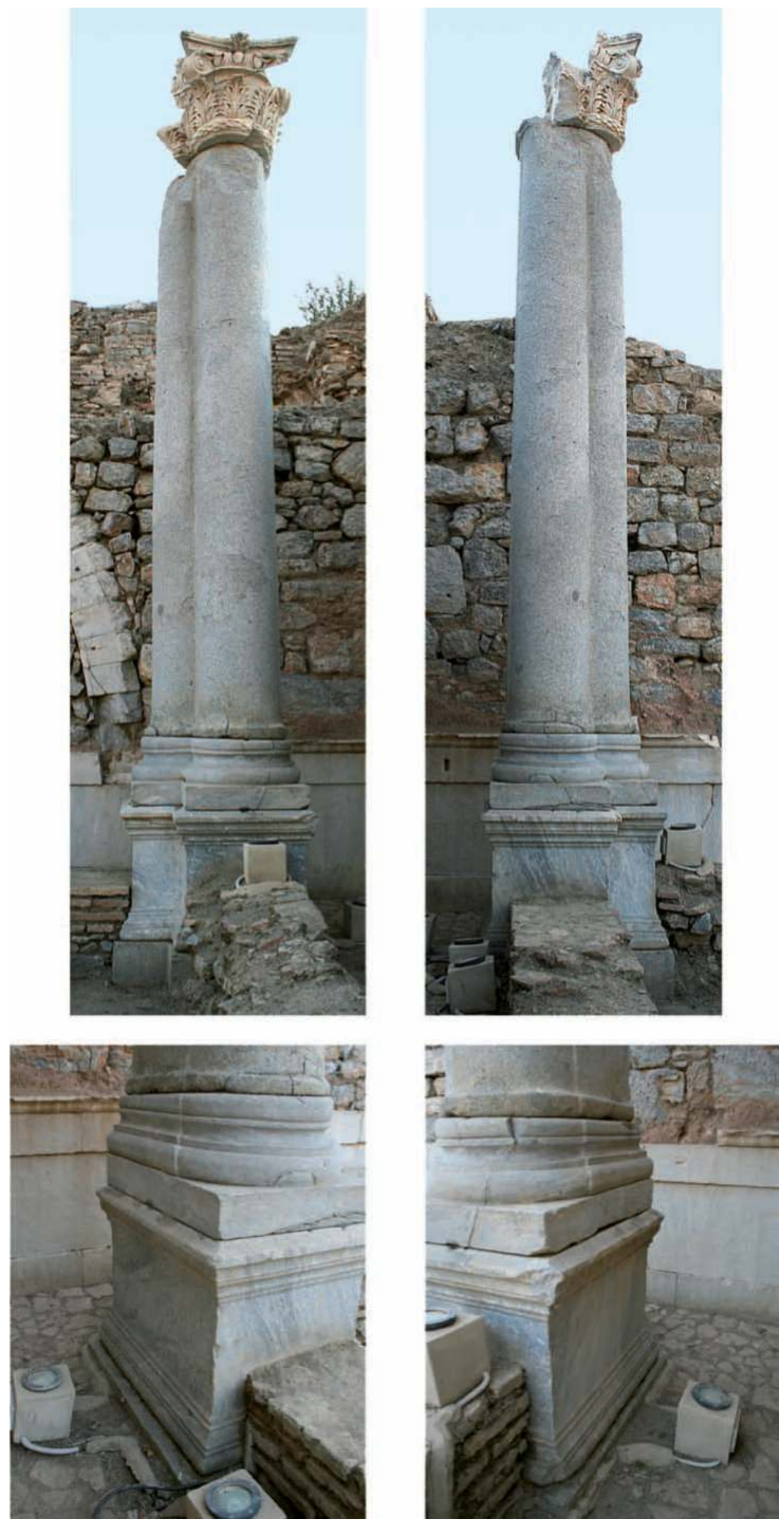

1 >Hestiasaak. Nordöstlicher Säulenstuhl mit Eck-Doppelhalbsäulen A 17-20 
Tafel 80

PRYTANEION

Hestiasaal NO- Säule PR 16-19/07

gezeichnet J. Eitler, P. Micyrhofer

graf. Bearbeitung L. Zabrana

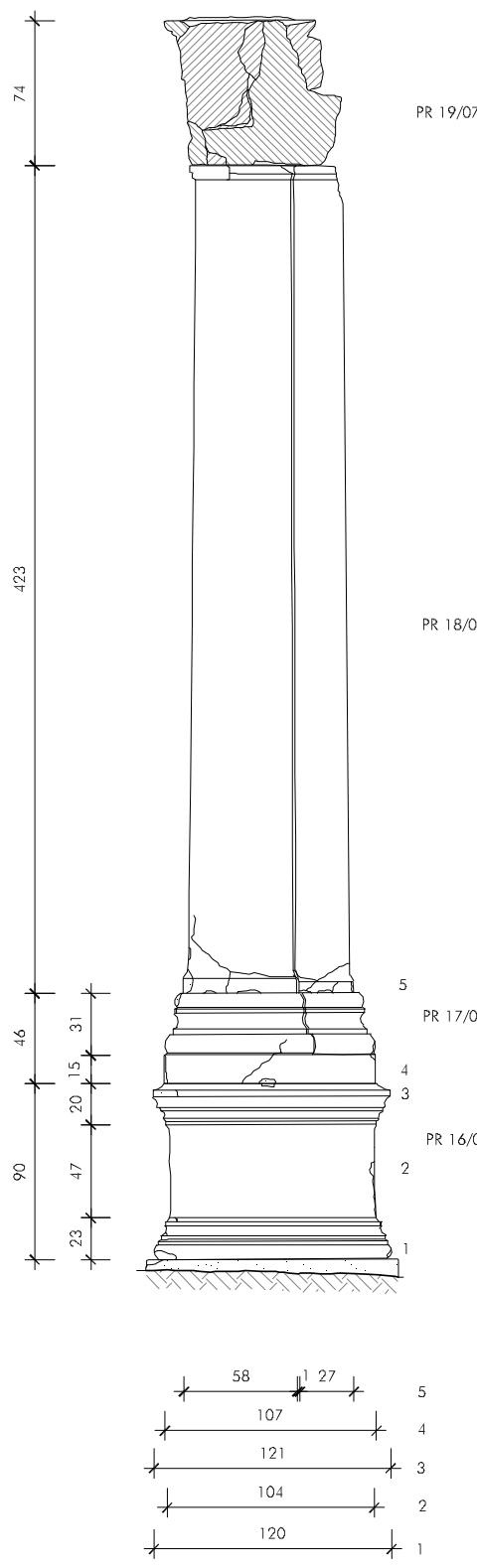

NORDSEITE
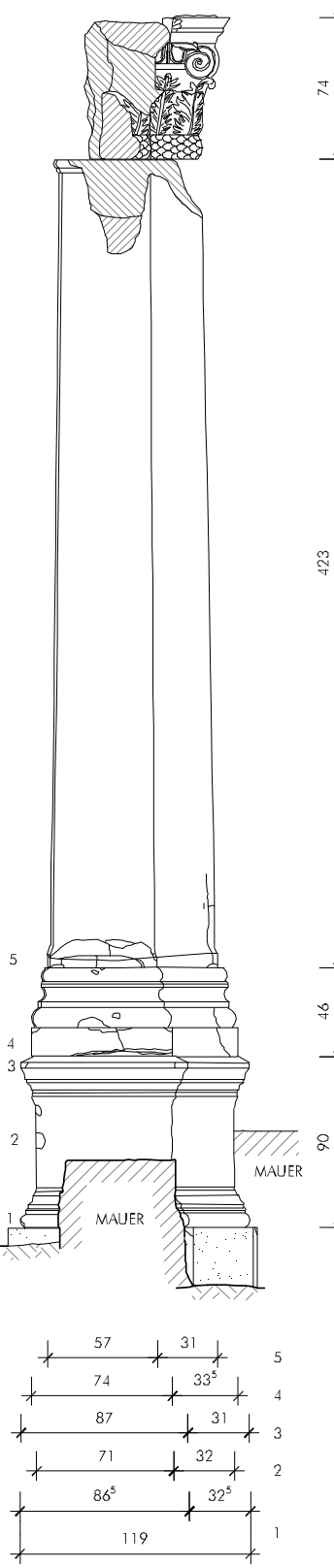

WESTSEITE

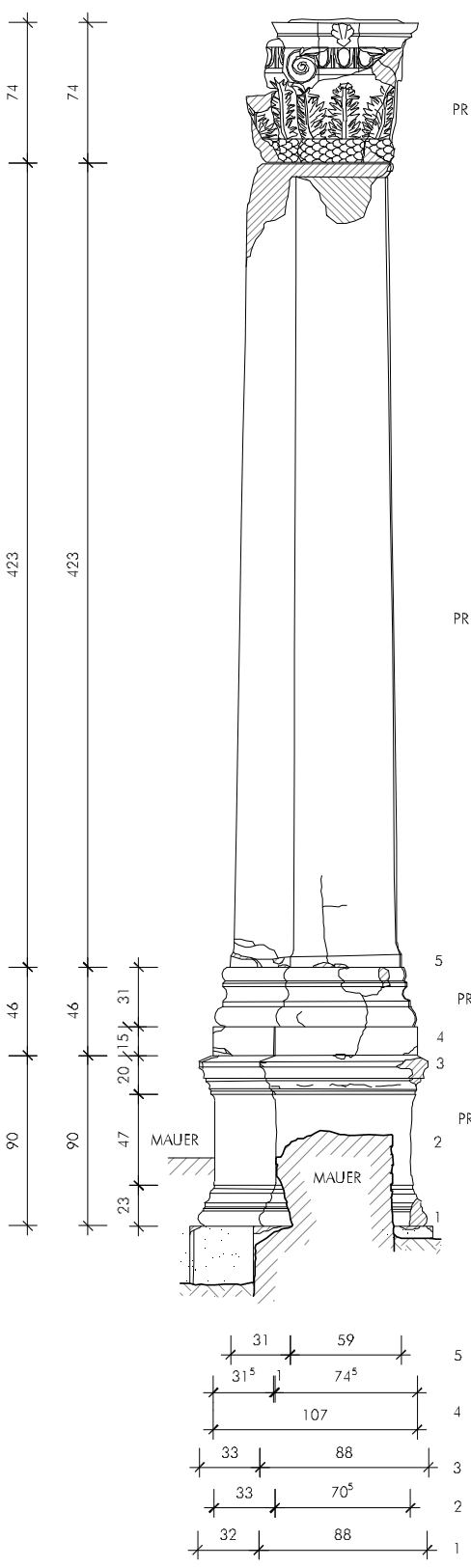

SÜDSEITE
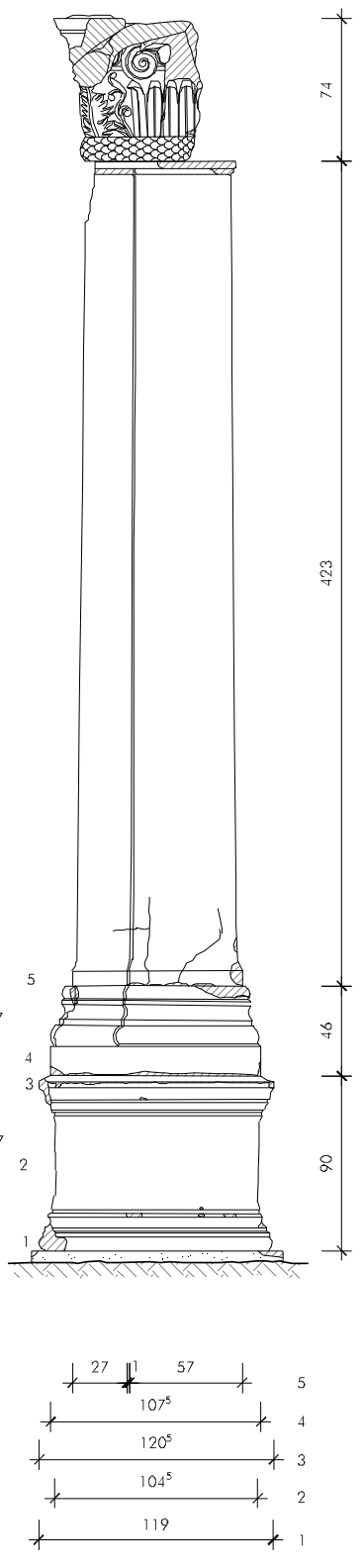

OSTSEITE

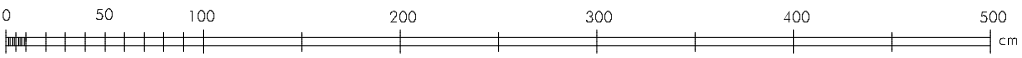

1 >Hestiasaak. Nordöstlicher Säulenstuhl mit Eck-Doppelhalbsäulen A 17-20 (1:50) 
Tafel 81
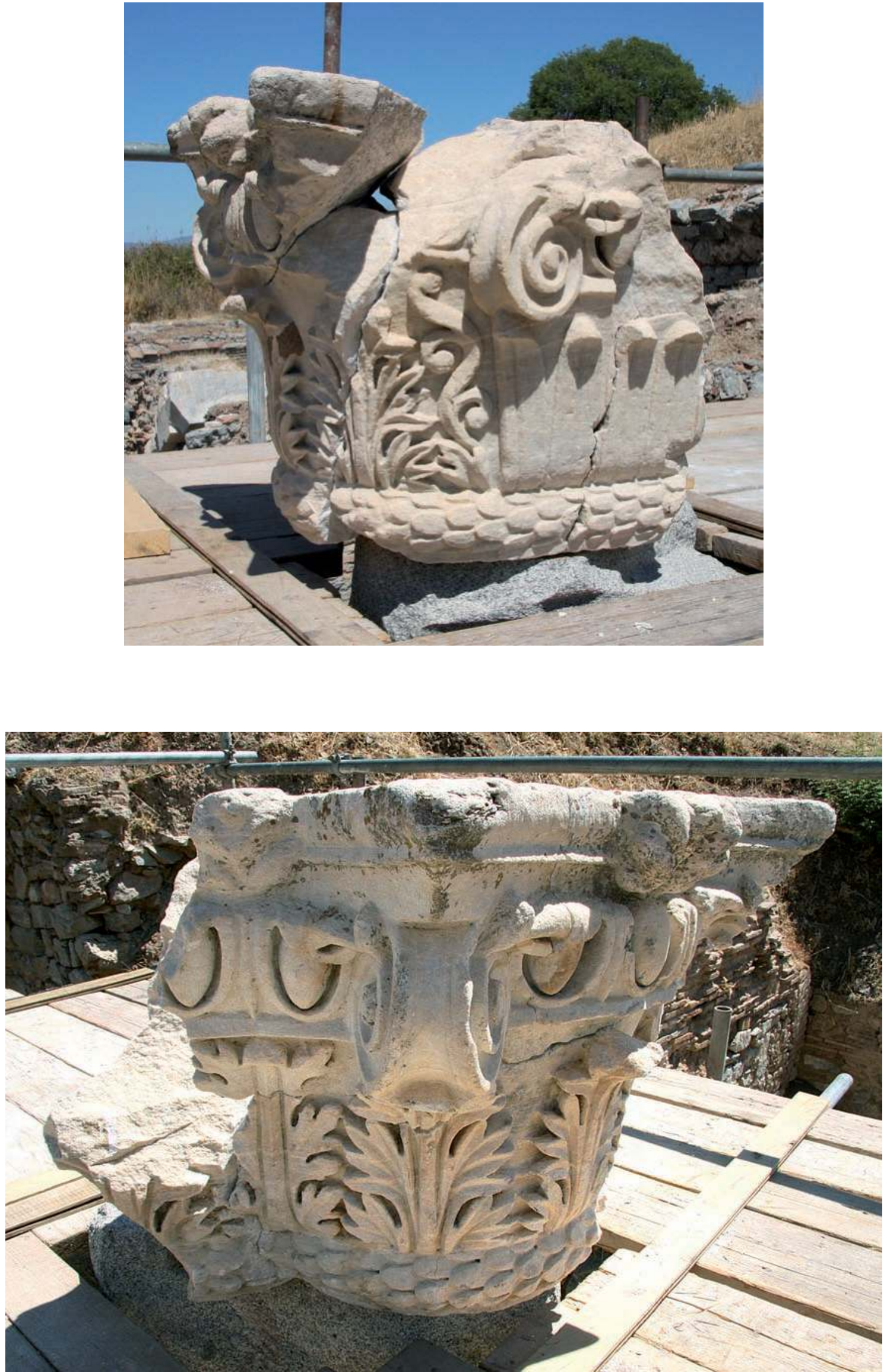

1 〉Hestiasaal<. Detail Kompositkapitell A 20 
Tafel 82
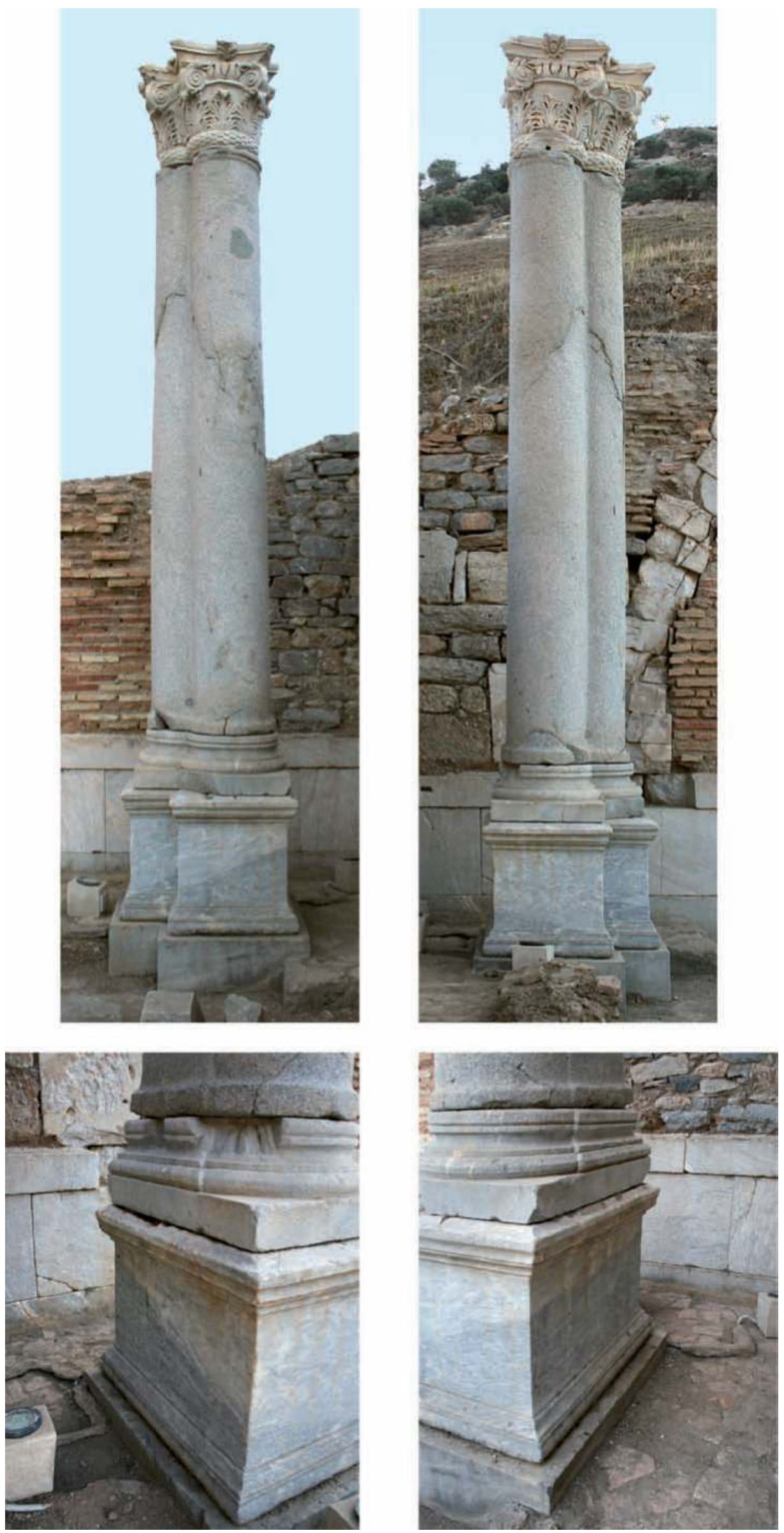

1 >Hestiasaalく. Nordwestlicher Säulenstuhl mit Eck-Doppelhalbsäulen A 21-24 
PRYTANEION

Hestiasaal NW- Säule PR 20-23/07

gezeichnet J. Eitler, P. Mayrhofer

grof. Bearbeitung L. Zabrana
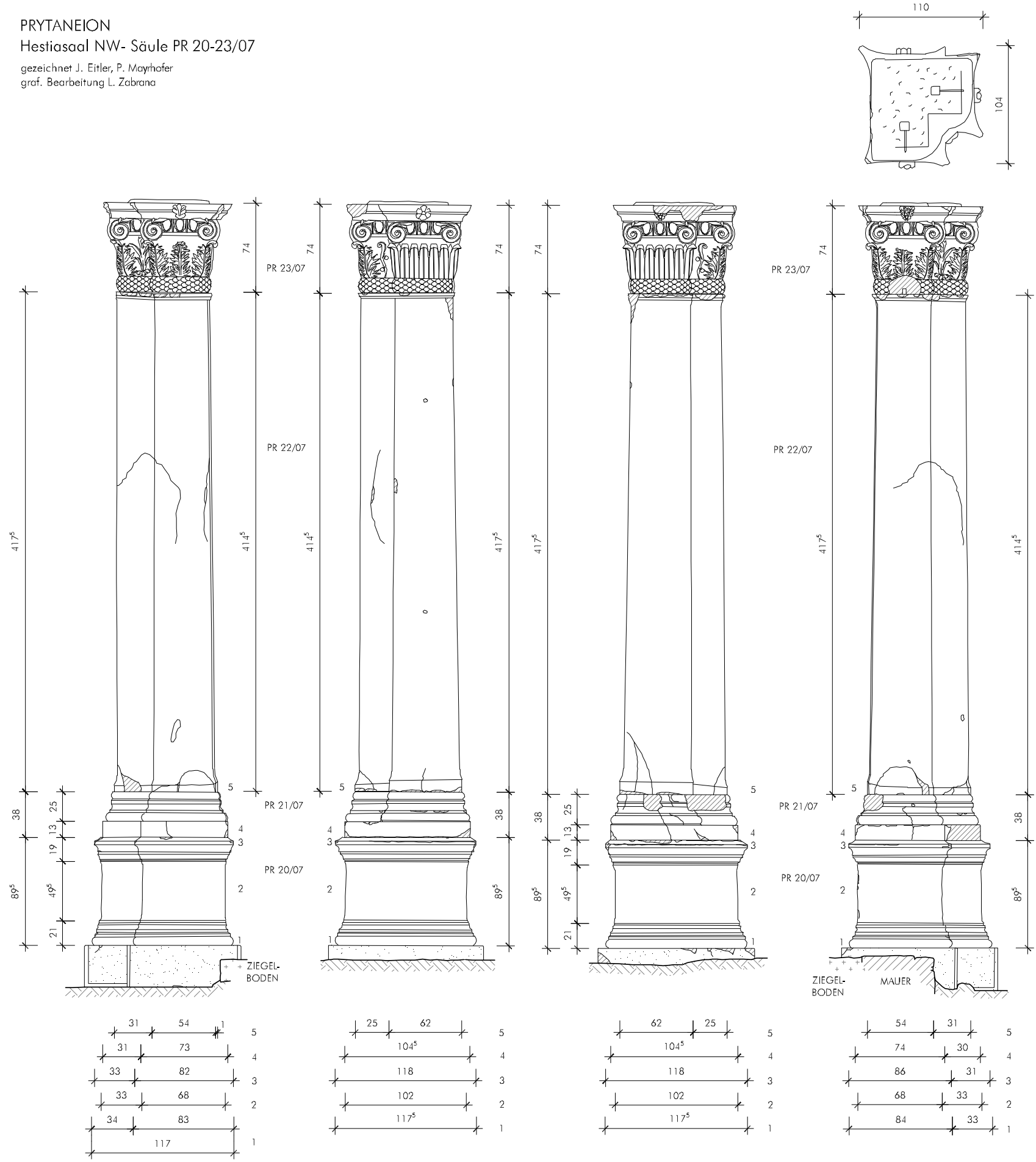

OSTSETE

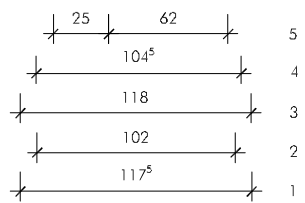

NORDSEITE

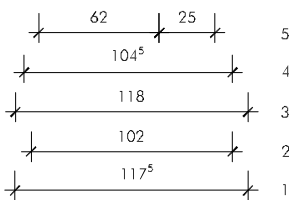

WESTSEITE

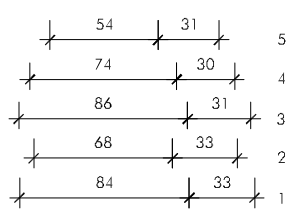

SÜDSEITE

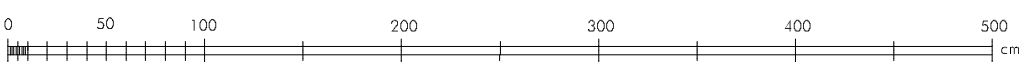

1 〉Hestiasaalく. Nordwestlicher Säulenstuhl mit Eck-Doppelhalbsäulen A 21-24 (1:50) 
Tafel 84
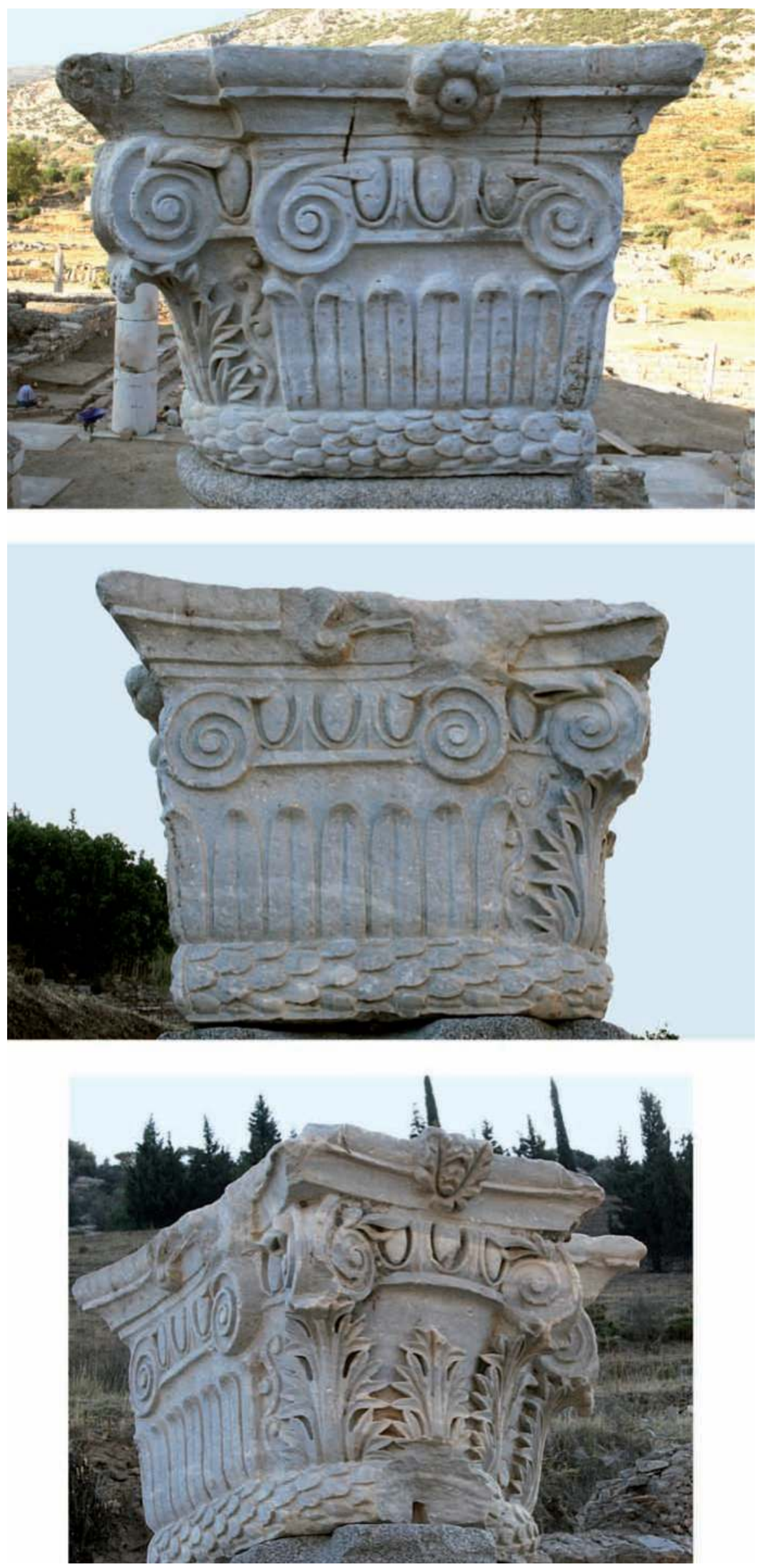

1 >Hestiasaalく. Detail Kompositkapitell A 24 
Tafel 85
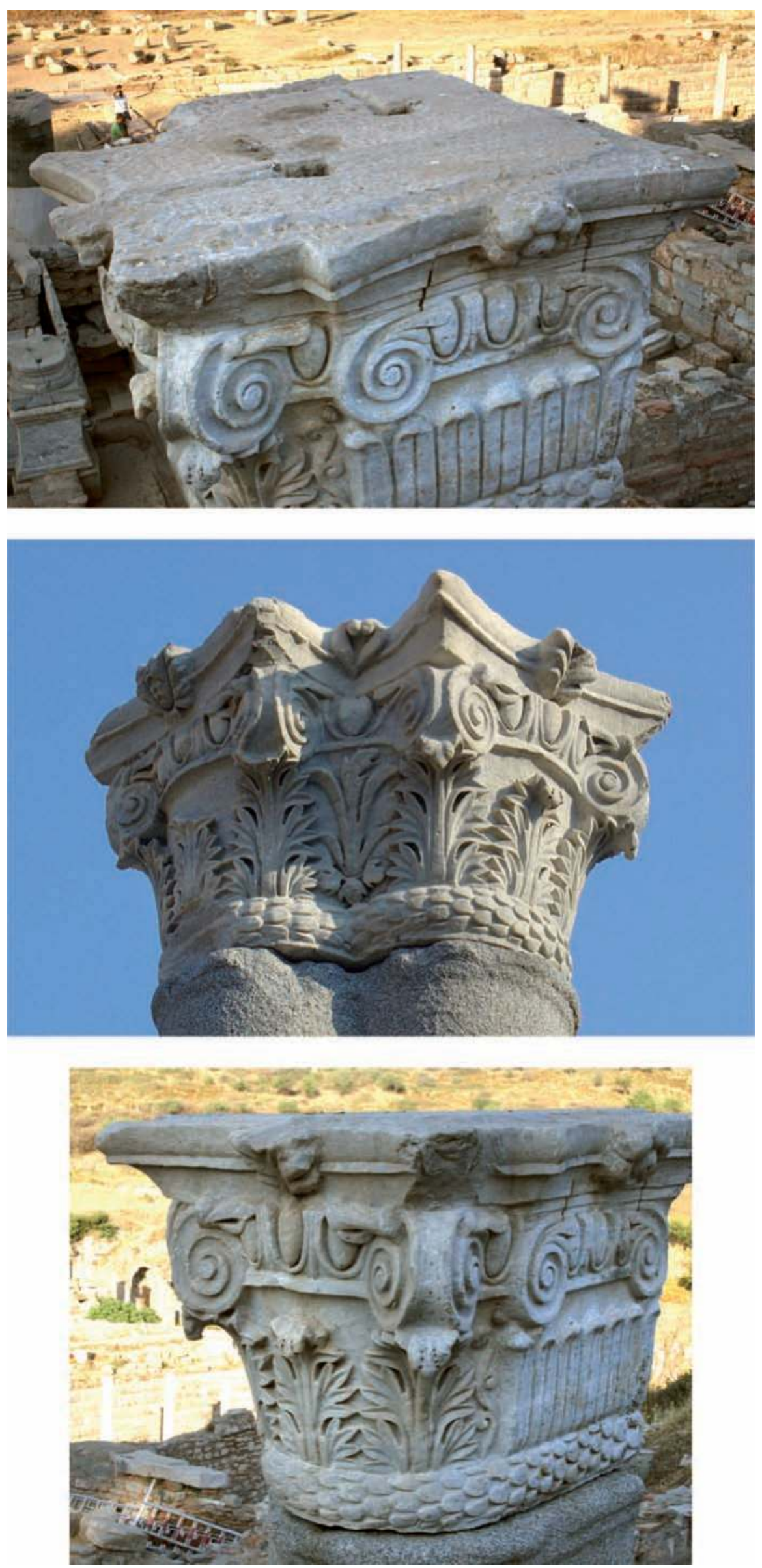

1 ’Hestiasaalく. Detail Kompositkapitell A 24 
Tafel 86
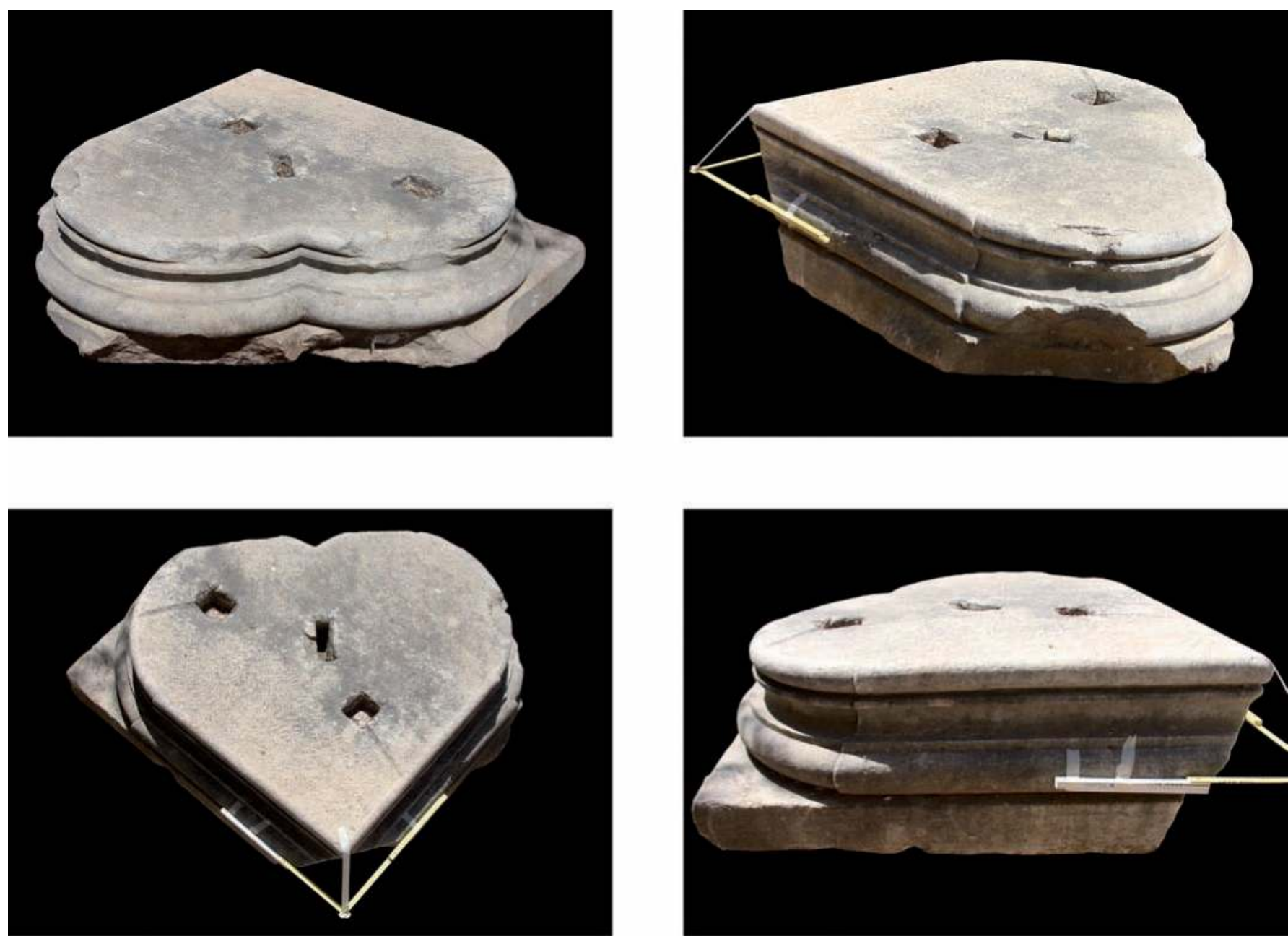

1 〉Hestiasaalく. Originale attische Basis A 47

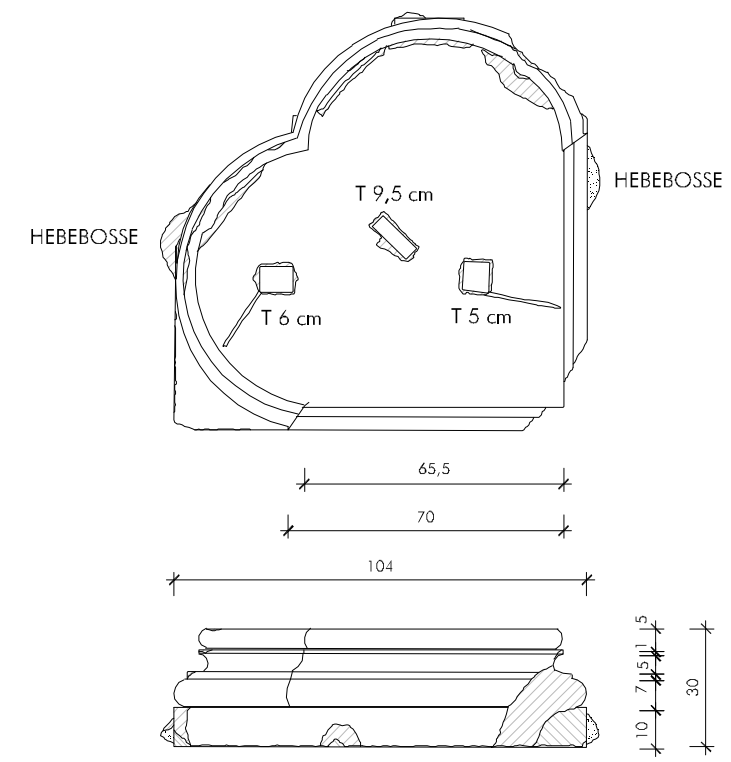

PRYTANEION

PR 01/08

ATTISCHE BASIS

gezeichnet

grafische Bearbeitung

o

$2 \quad$ grafische

2 >Hestiasaalく. Originale attische Basis A 47 (1:25) 

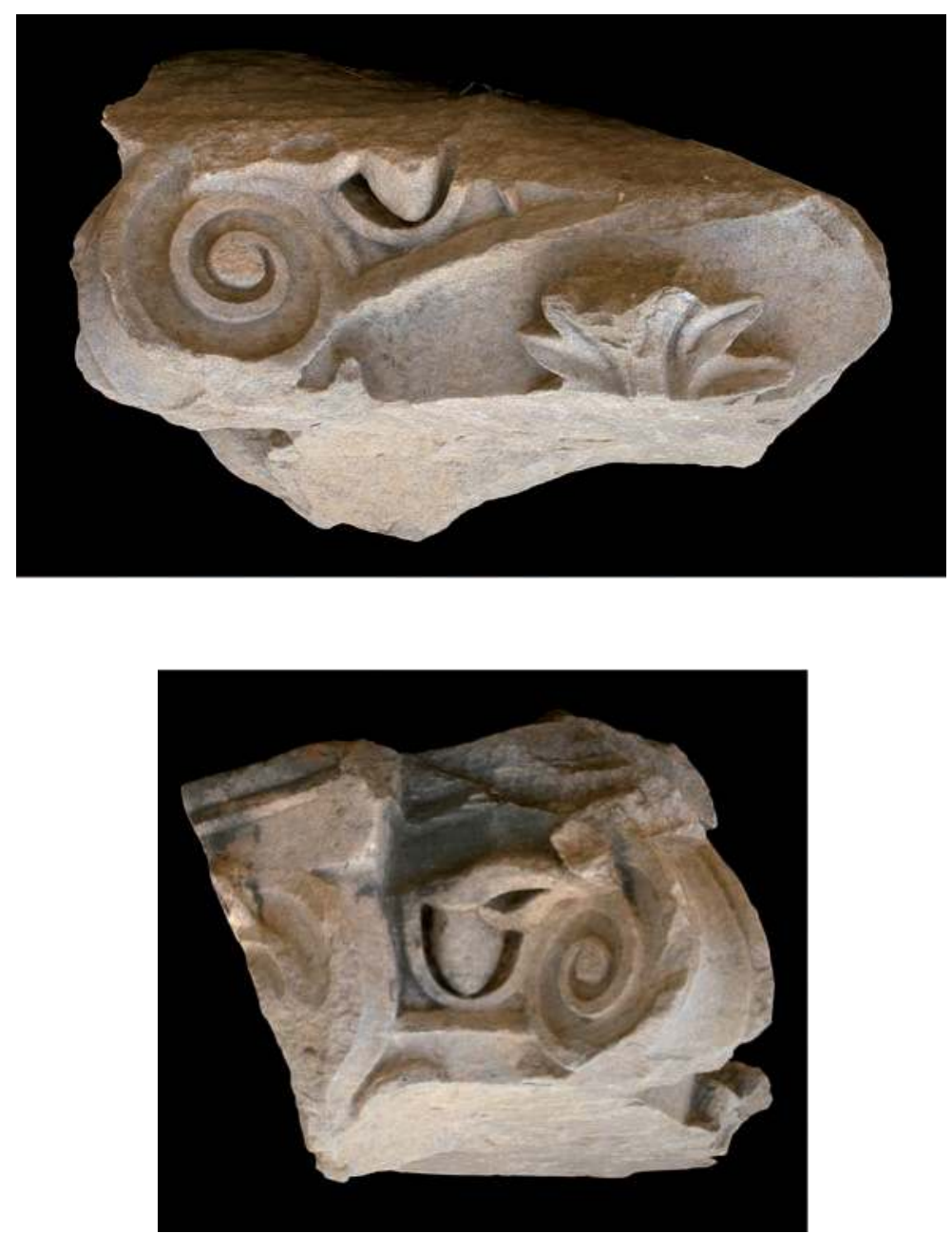

1 >Hestiasaalく. Kompositkapitell A 25

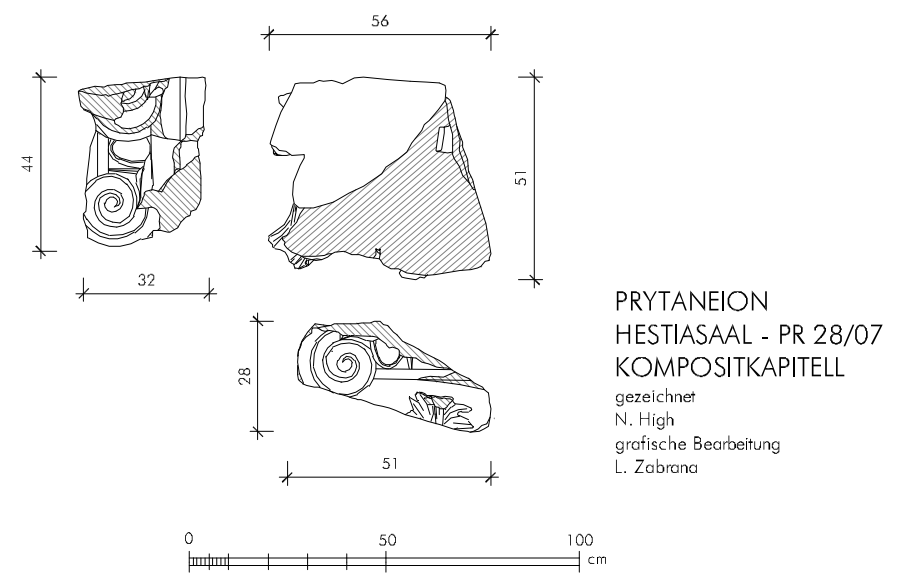

2 >Hestiasaal<. Kompositkapitell A 25 (1:25) 
Tafel 88

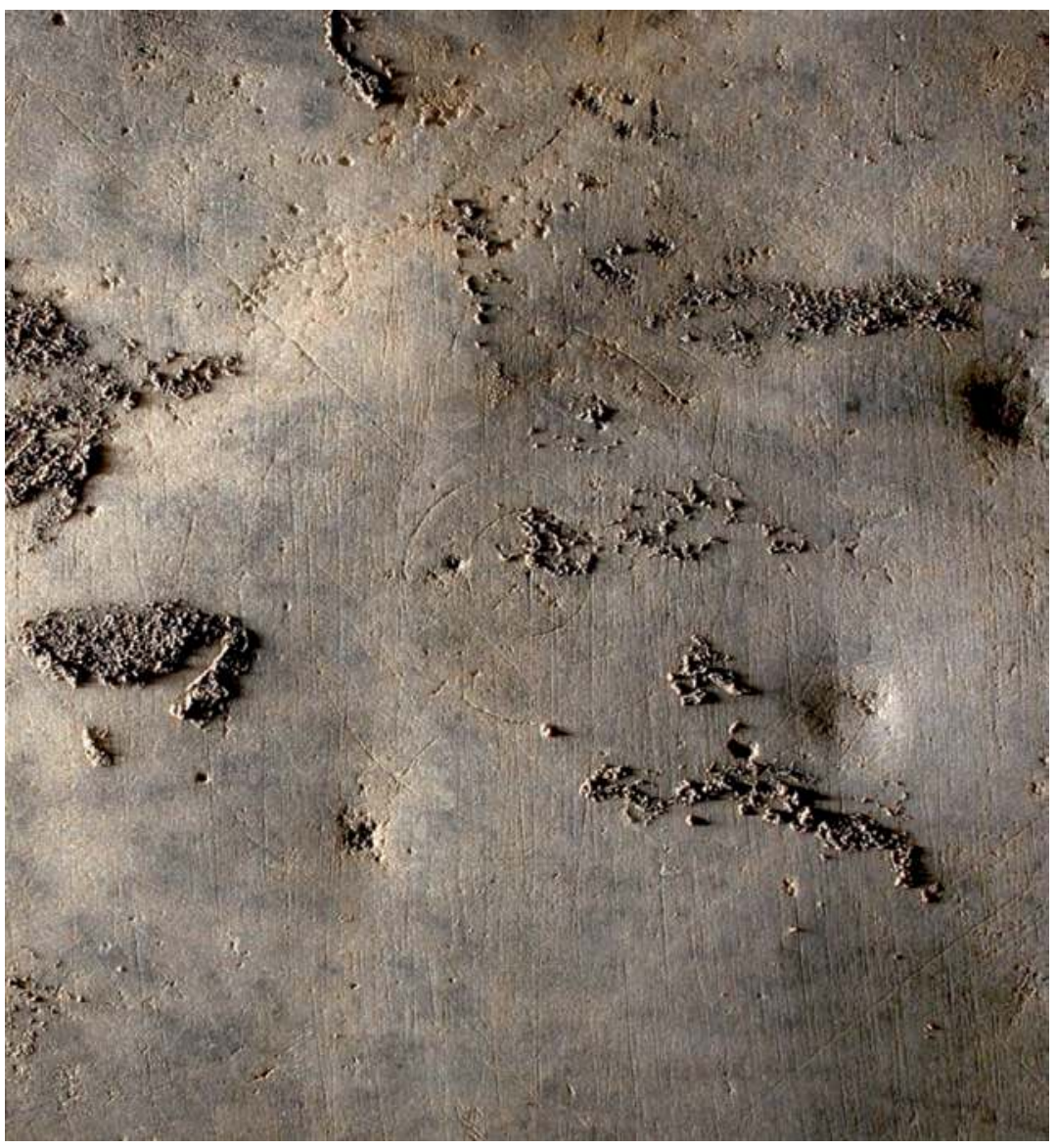

1 >Hestiasaalく. Werkriss auf südwestlichem Säulenstuhl A 12 (Volute 1)

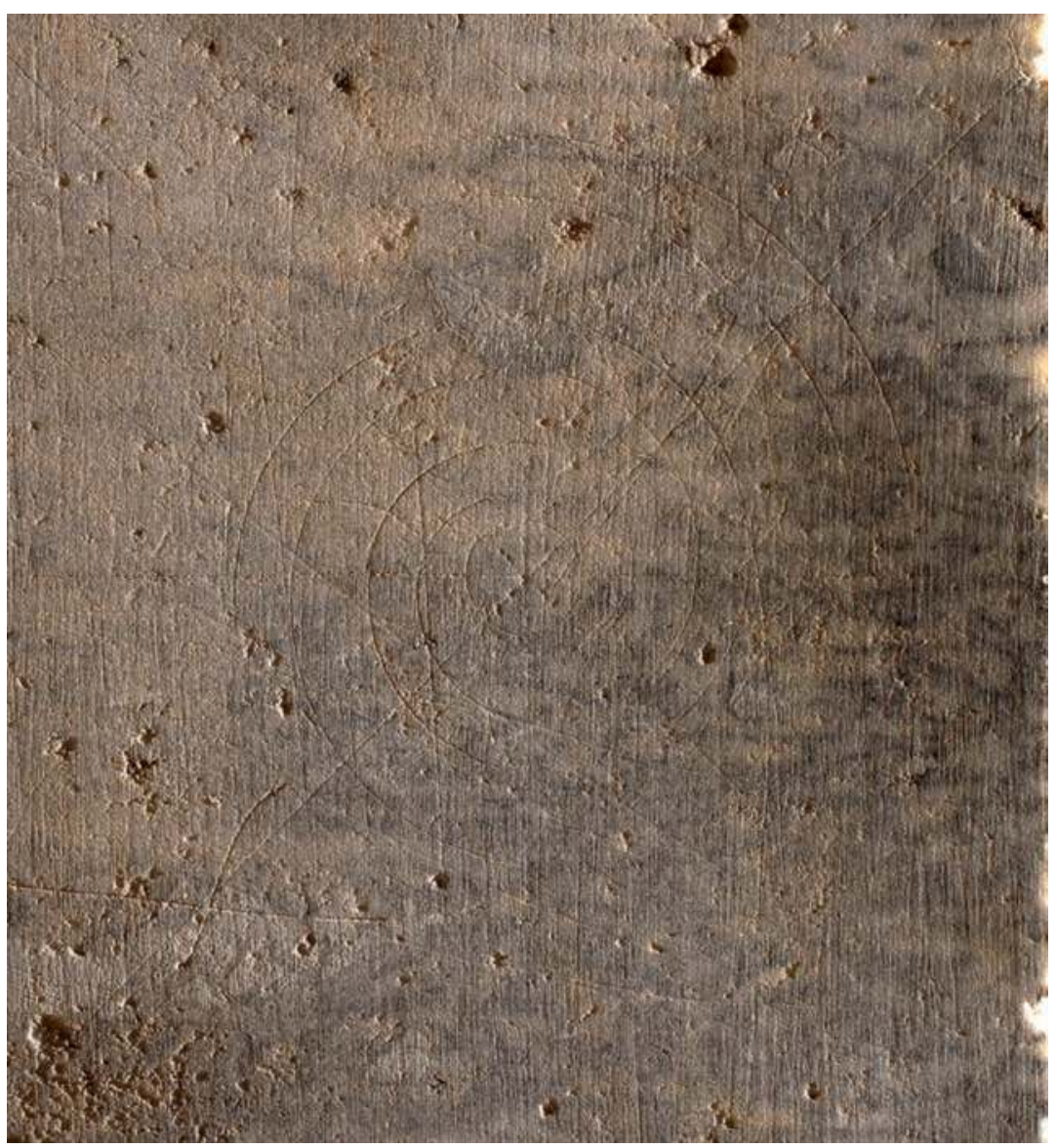

2 >Hestiasaalく. Werkriss auf südwestlichem Säulenstuhl A 12 (Volute 2) 
Tafel 89
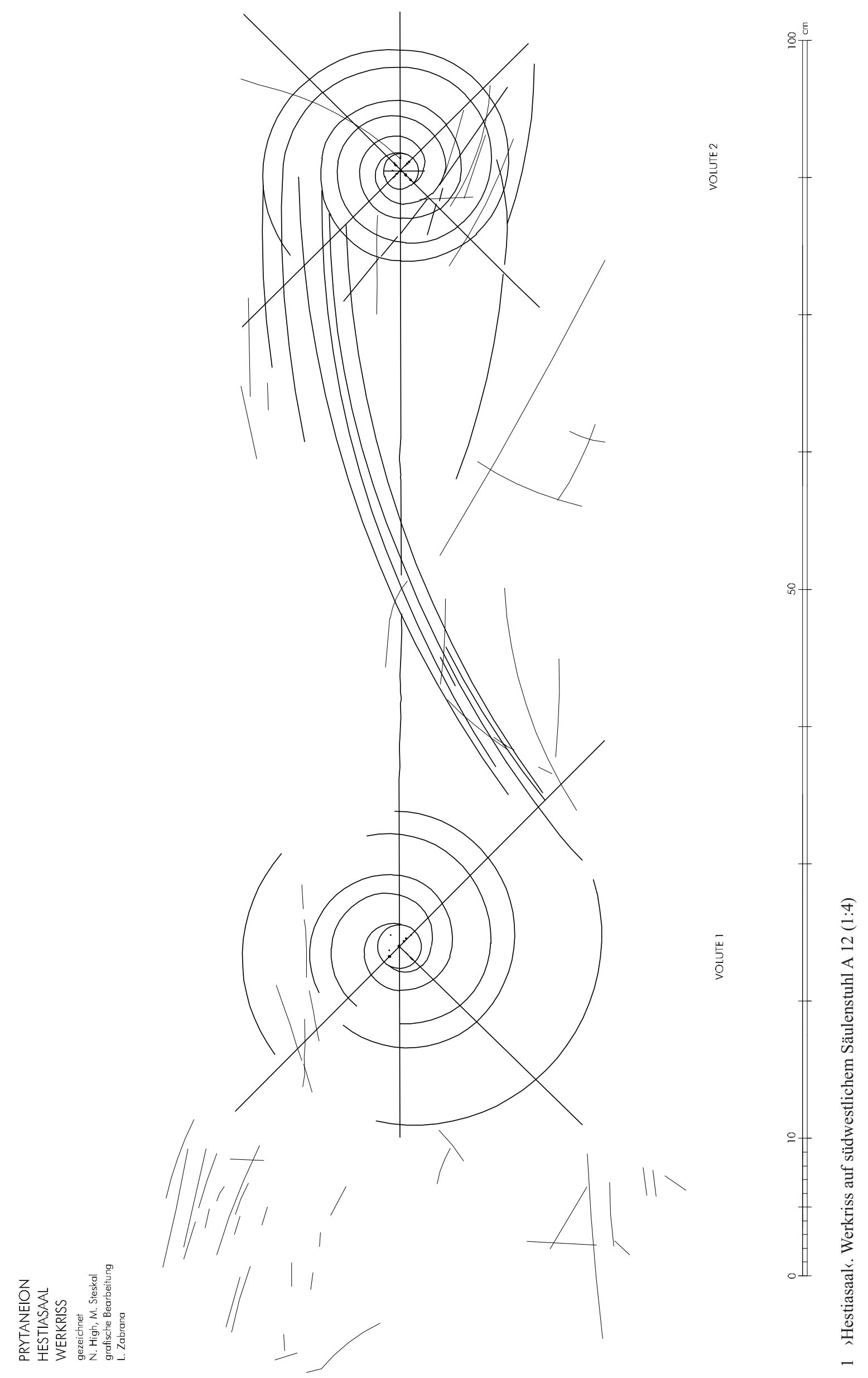
Tafel 90

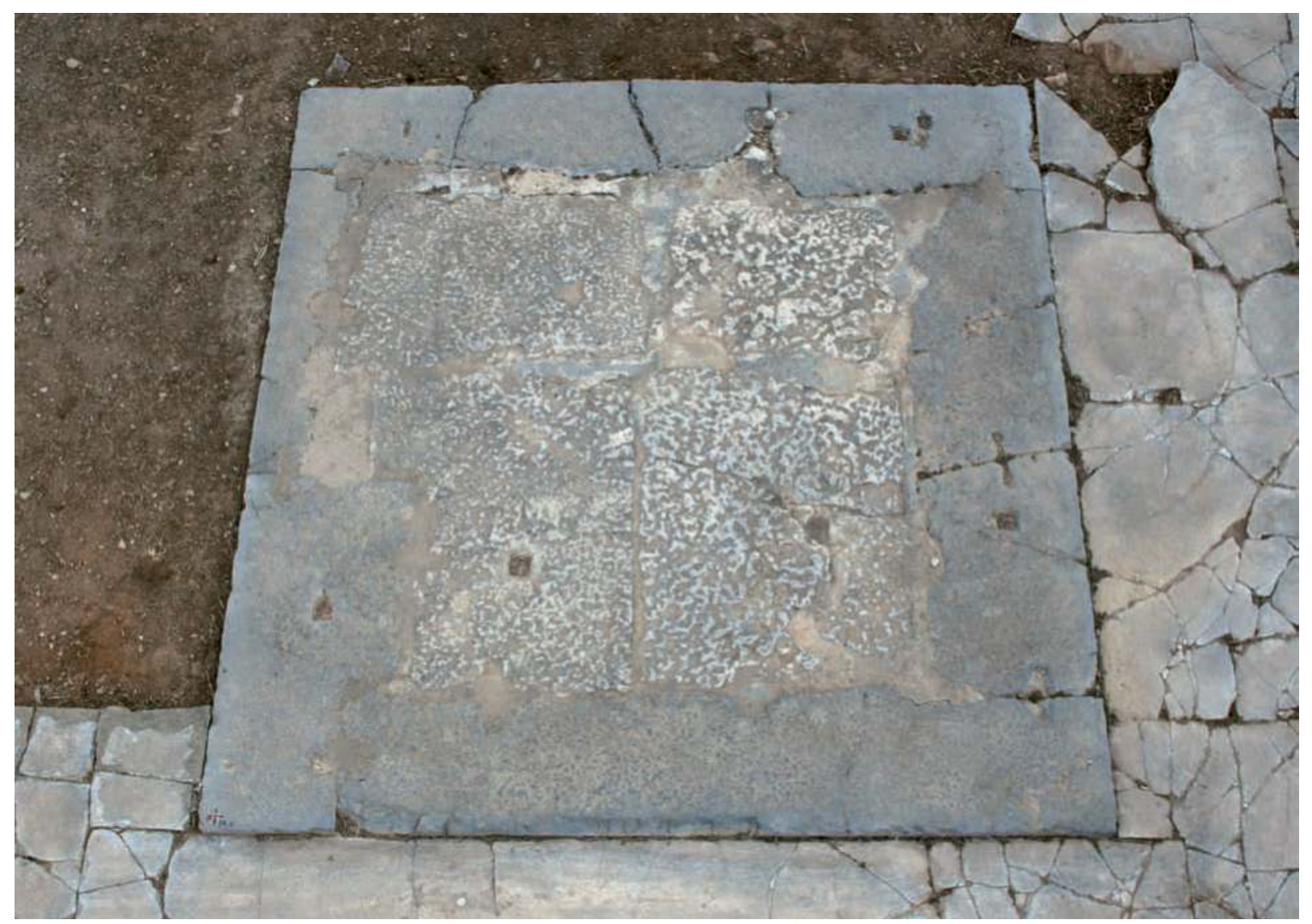

1 >Hestiasaal . Zentrales Fundament für Anrichte

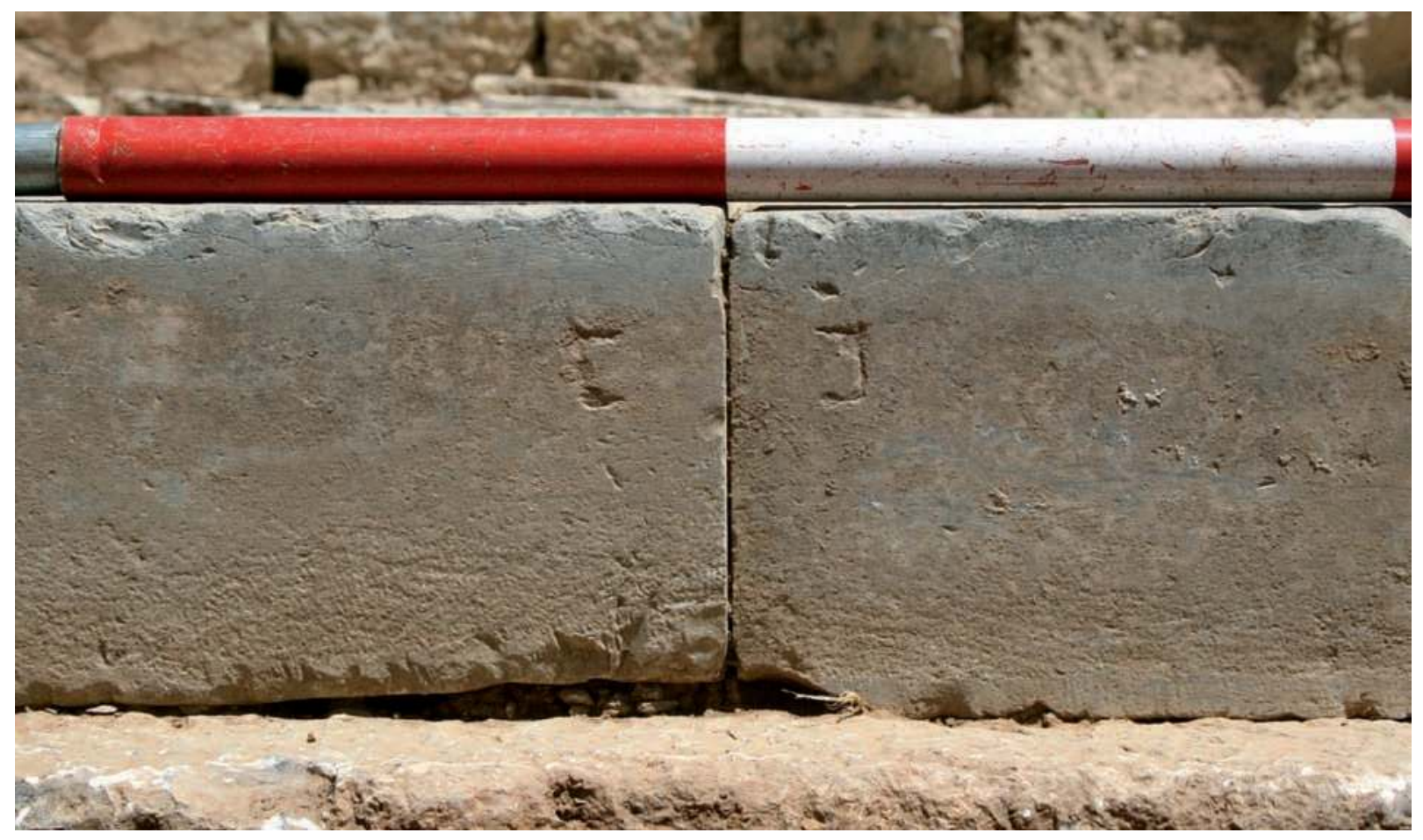

$2>$ Hestiasaal . Zentrales Fundament für Anrichte. Freigelegte Westseite mit Versatzmarken zur Verlegung der Blöcke 
Tafel 91
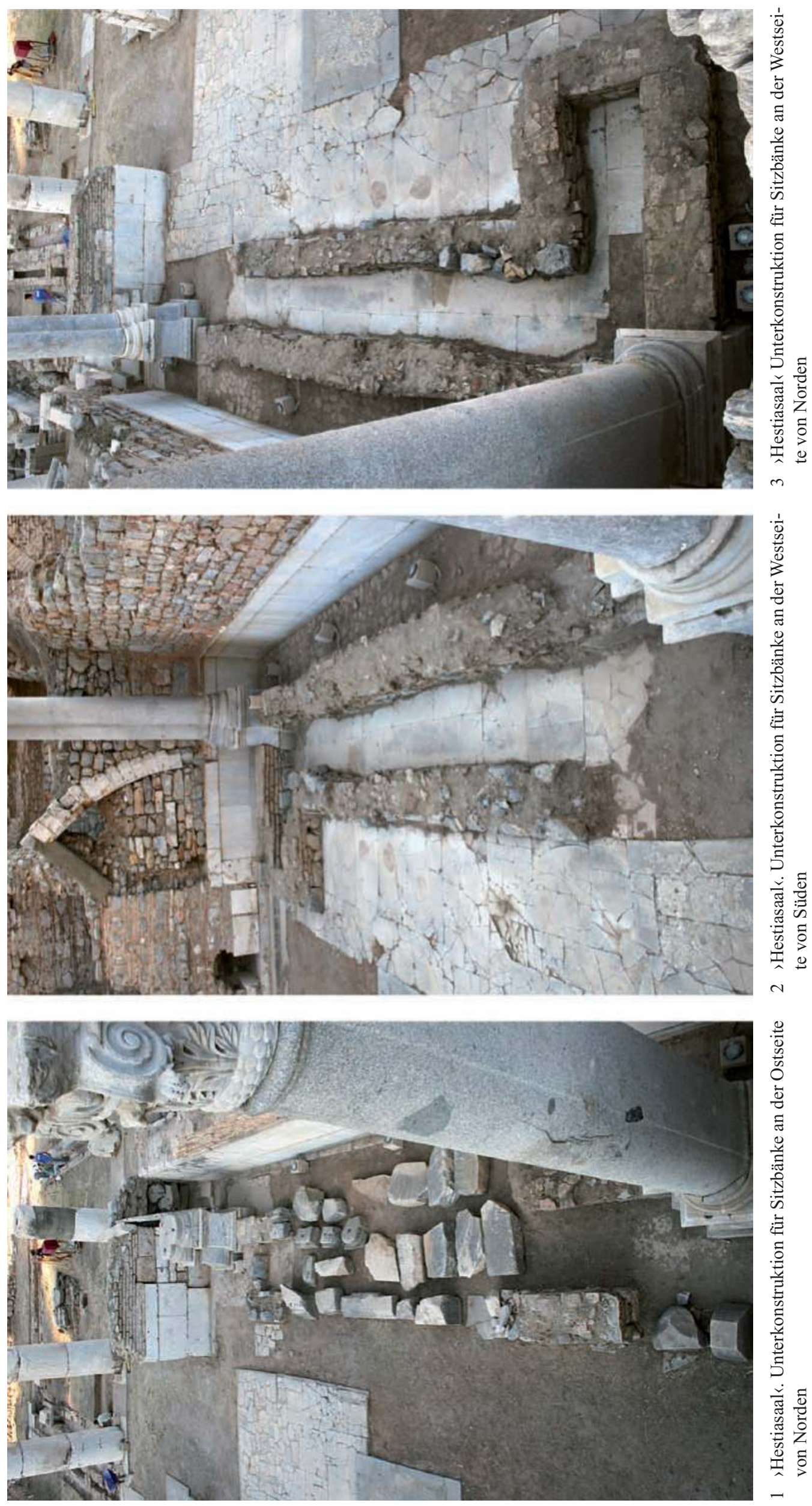
Tafel 92

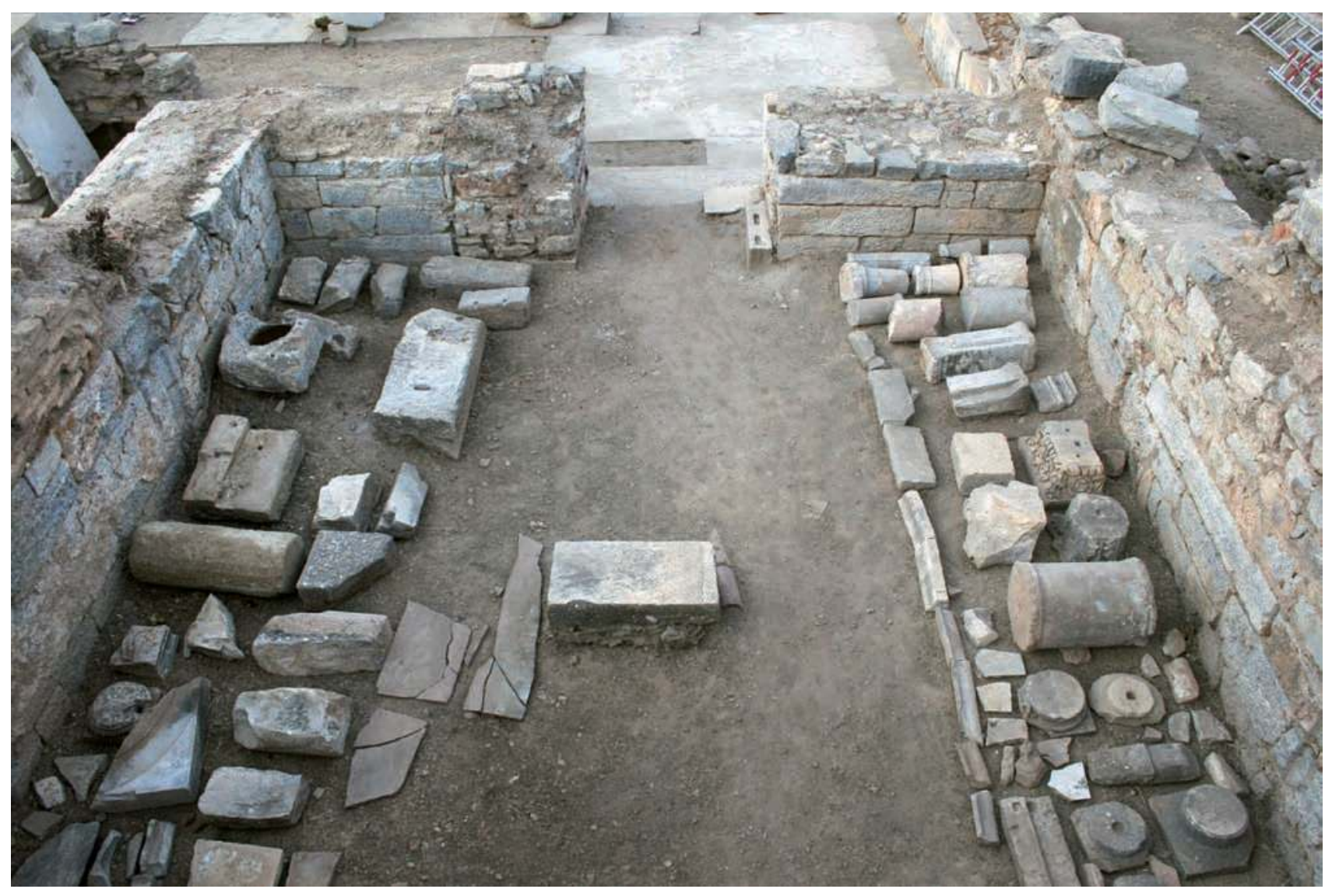

1 Raum 6 von Norden
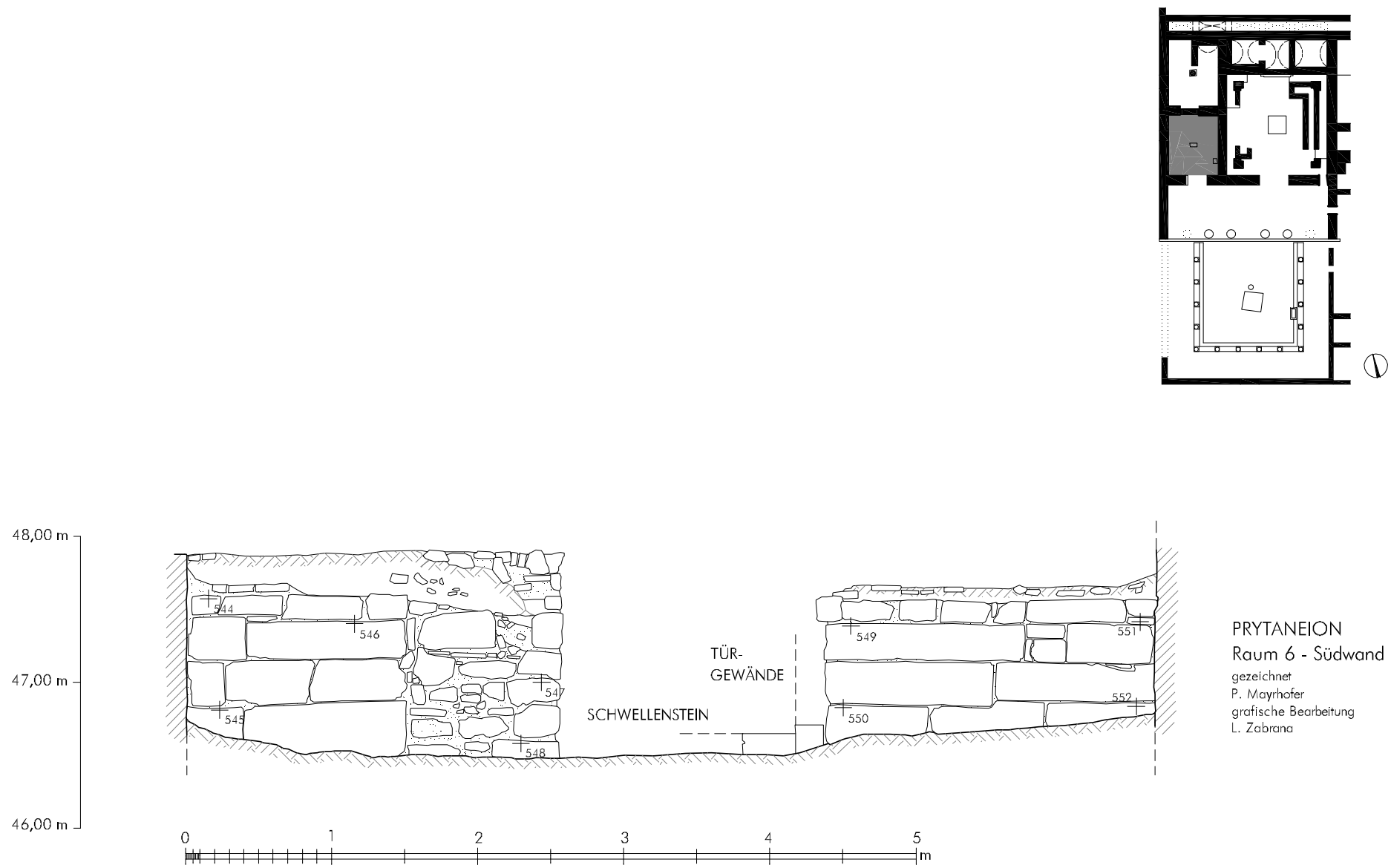

2 Raum 6. Südwand (1:50) 
Tafel 93

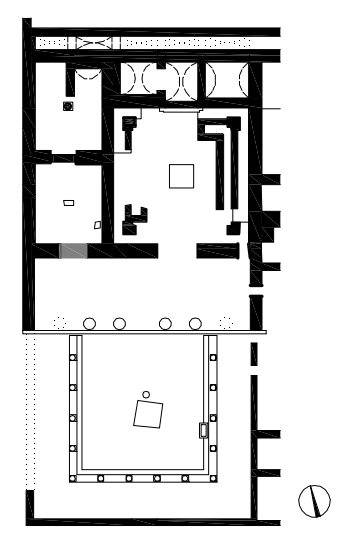

WESTLICHE TÜRLAIBUNG

ÖSTLICHE ZUSETZUNG
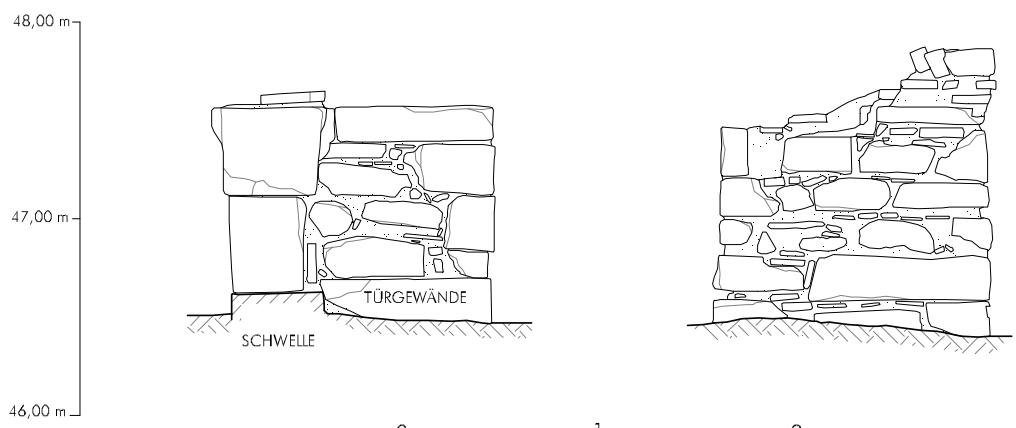

PRYTANEION

Raum 6 - Vorhalle

Tür 1, westl. Türlaibung

und östl. Zusetzung

gezeichne

J. Eitler

grafische Bearbeitung

L. Zabrano

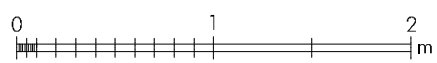

1 Raum 6/Vorhalle. Tür 1. Westliche Türlaibung und östliche Zusetzung (1:50)

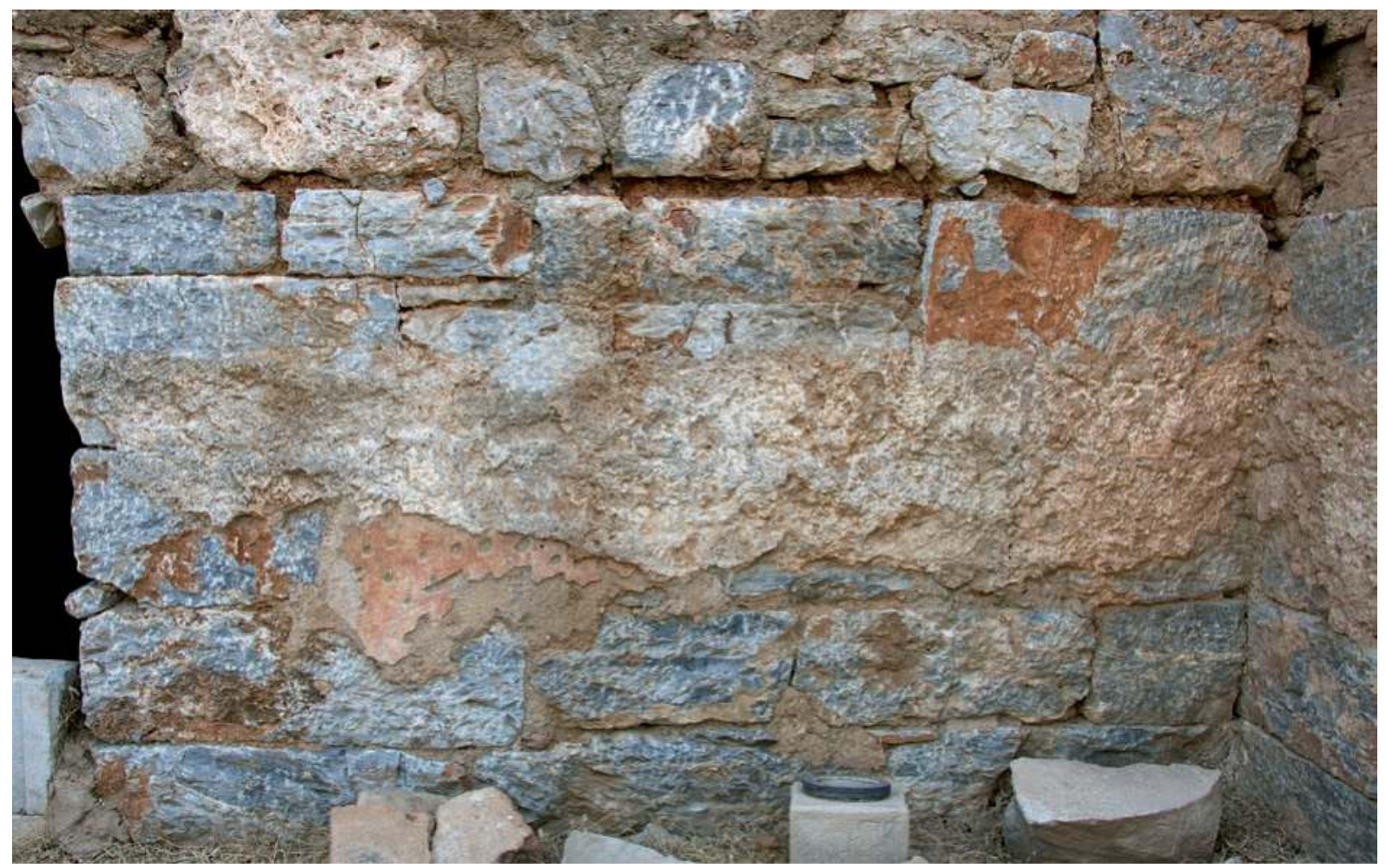

2 Raum 6. Nordwand. Detail Wandmalerei 
Tafel 94

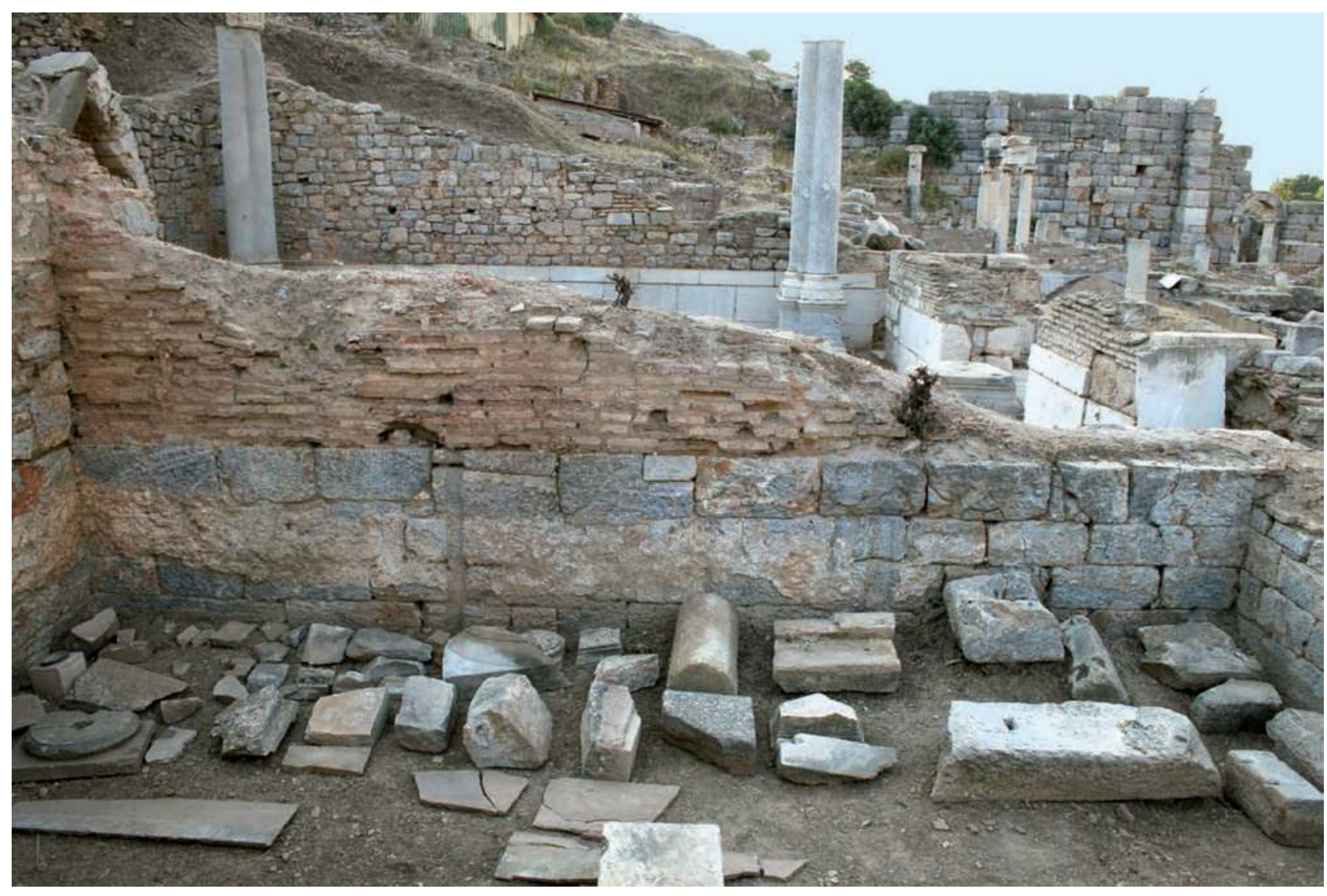

1 Raum 6. Ostwand

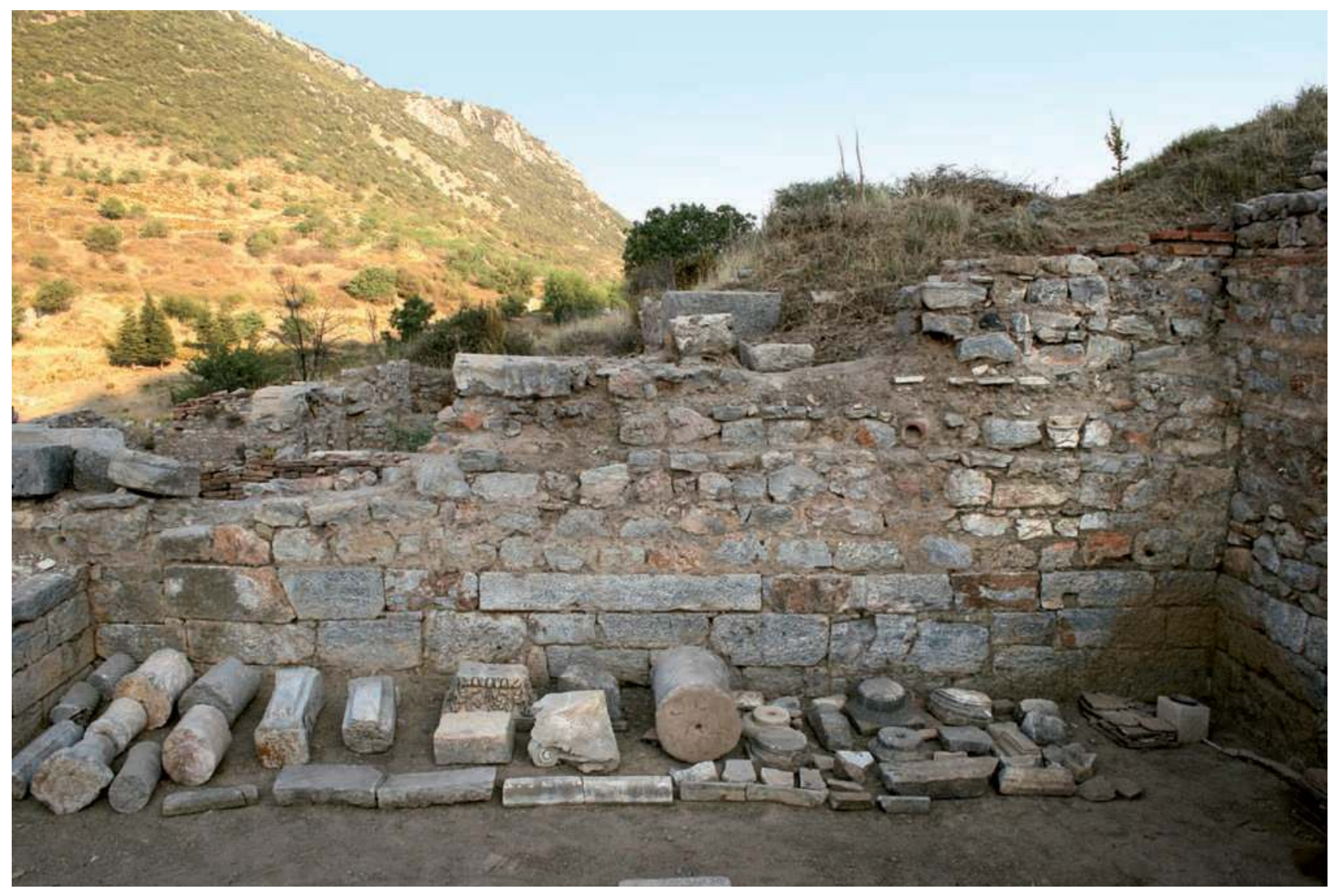

2 Raum 6. Westwand 
Tafel 95

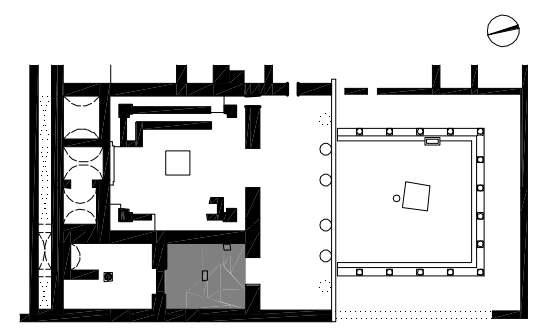

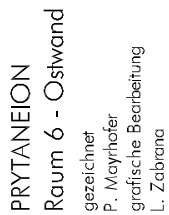
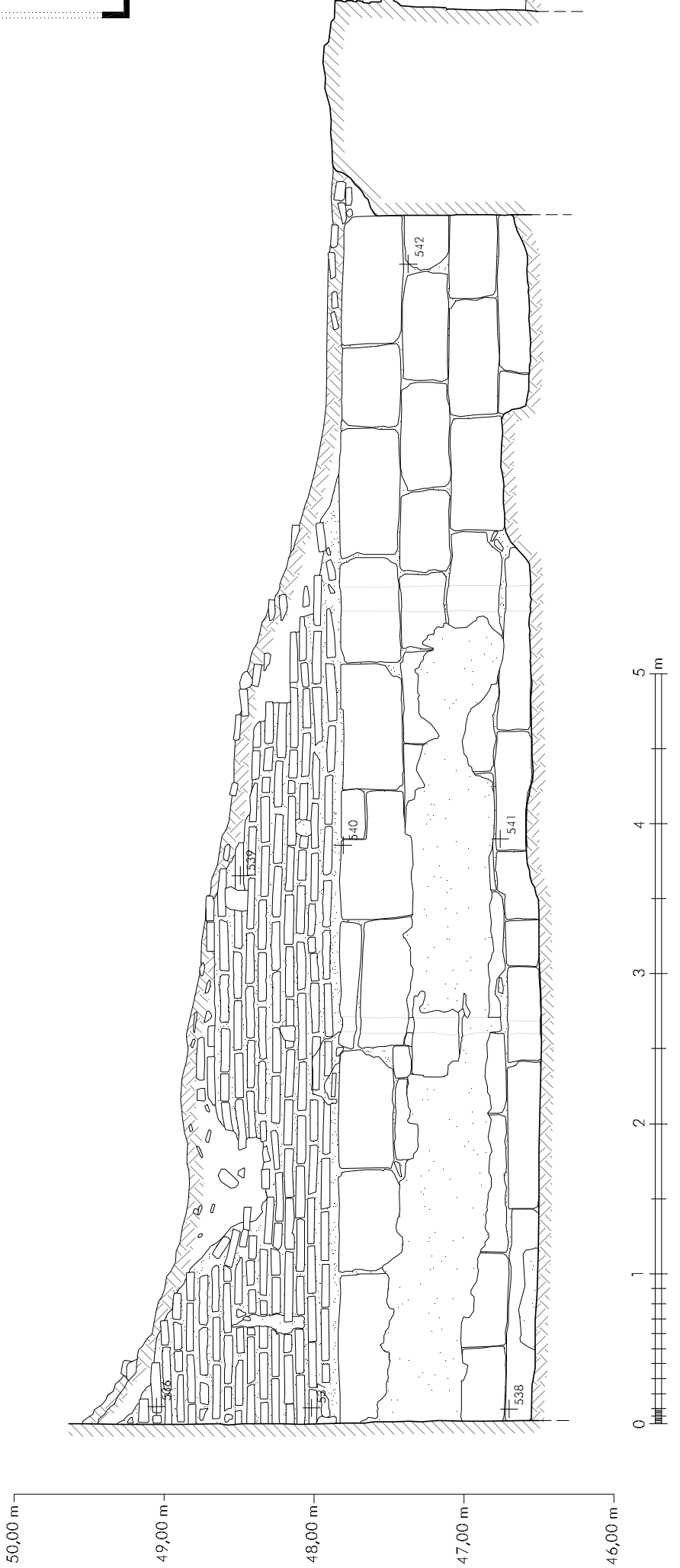

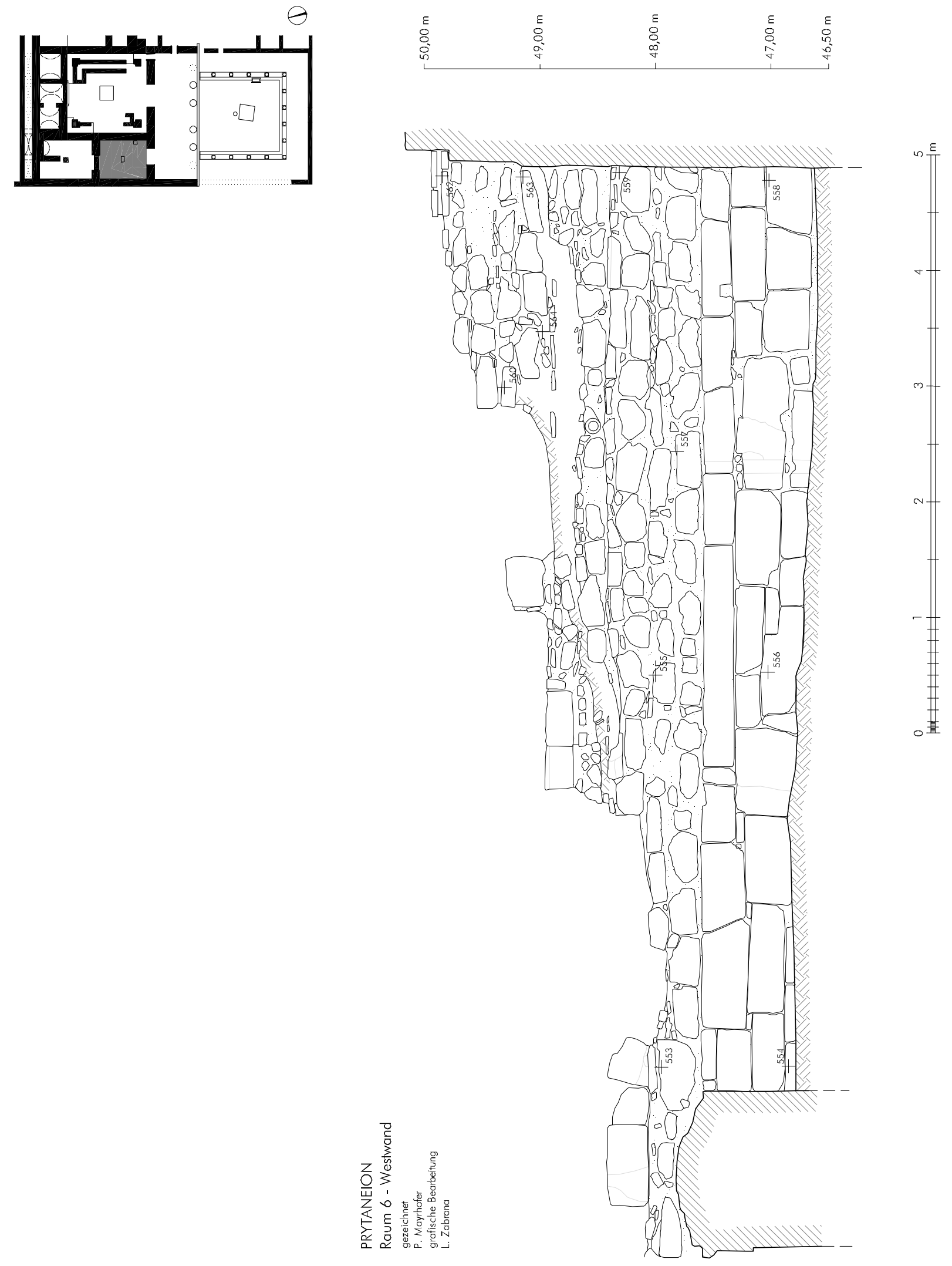

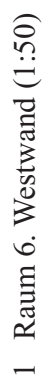




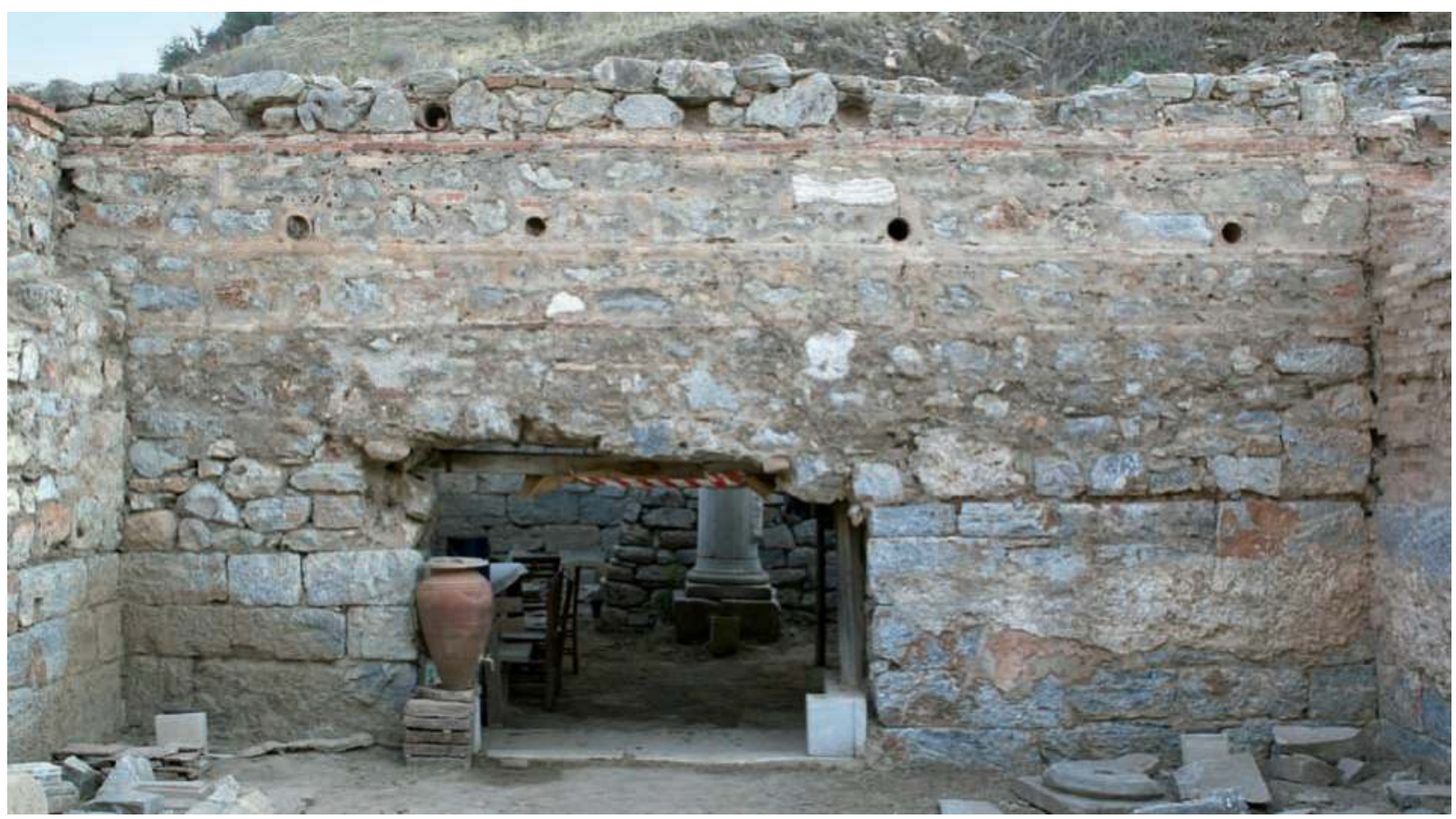

1 Raum 6. Nordwand
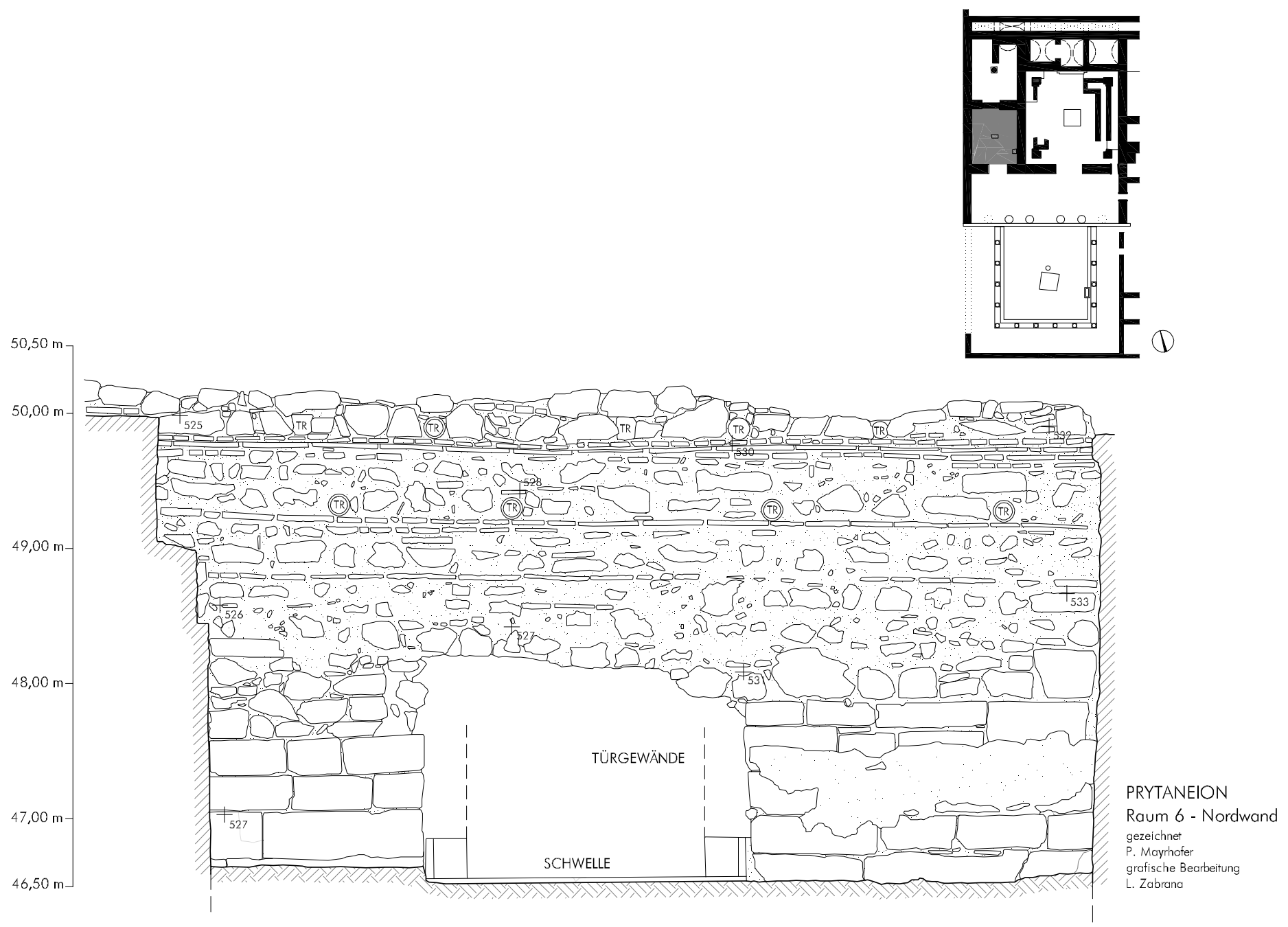

Raum 6 - Nordwand

gezeichnet
P. Moyrhofer

afische Bearbeitung

0

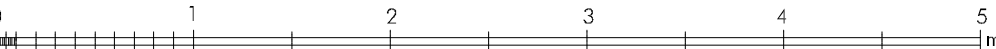

2 Raum 6. Nordwand (1:50) 
Tafel 98

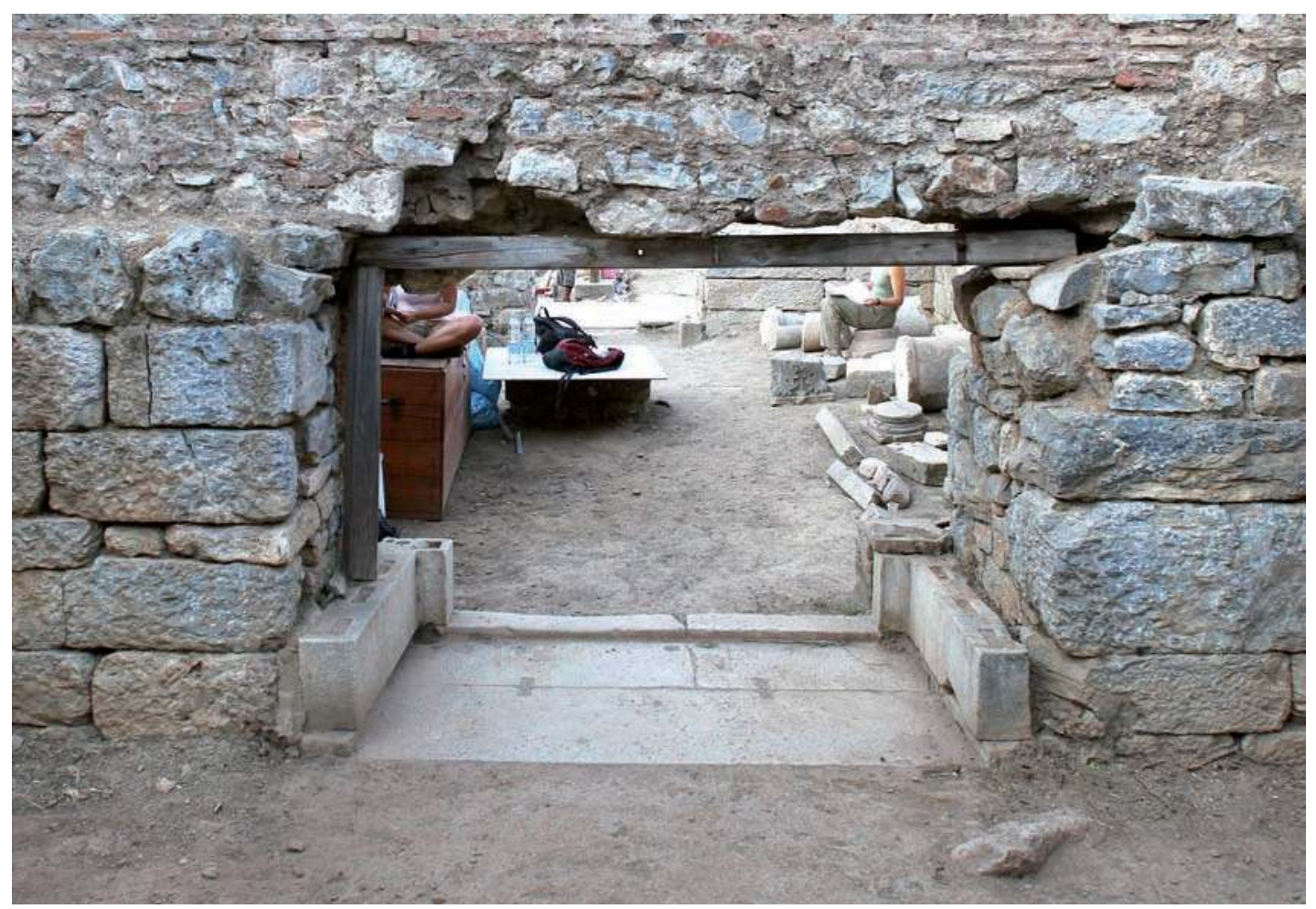

1 Raum 6/Raum 5. Tür von Norden

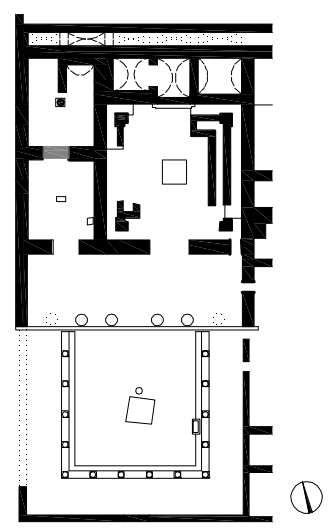

WESTLICHE TÜRLAIBUNG

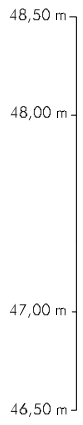

ÖSTLCHE TÜRLAIBUNG

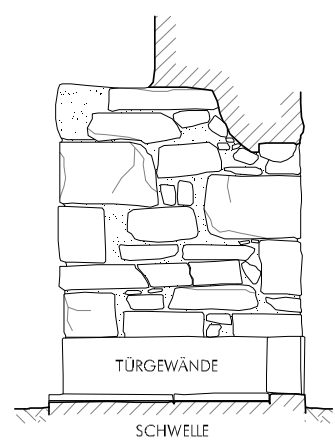

PRYTANEION

Raum 5 - Raum 6

Tür, westl. und östl. Türlaibung

gezeichnet
J. Eitler

grafische Bearbeitung

L. Zabrana

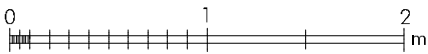

2 Raum 6/Raum 5. Westliche und östliche Türlaibung (1:50) 
Tafel 99
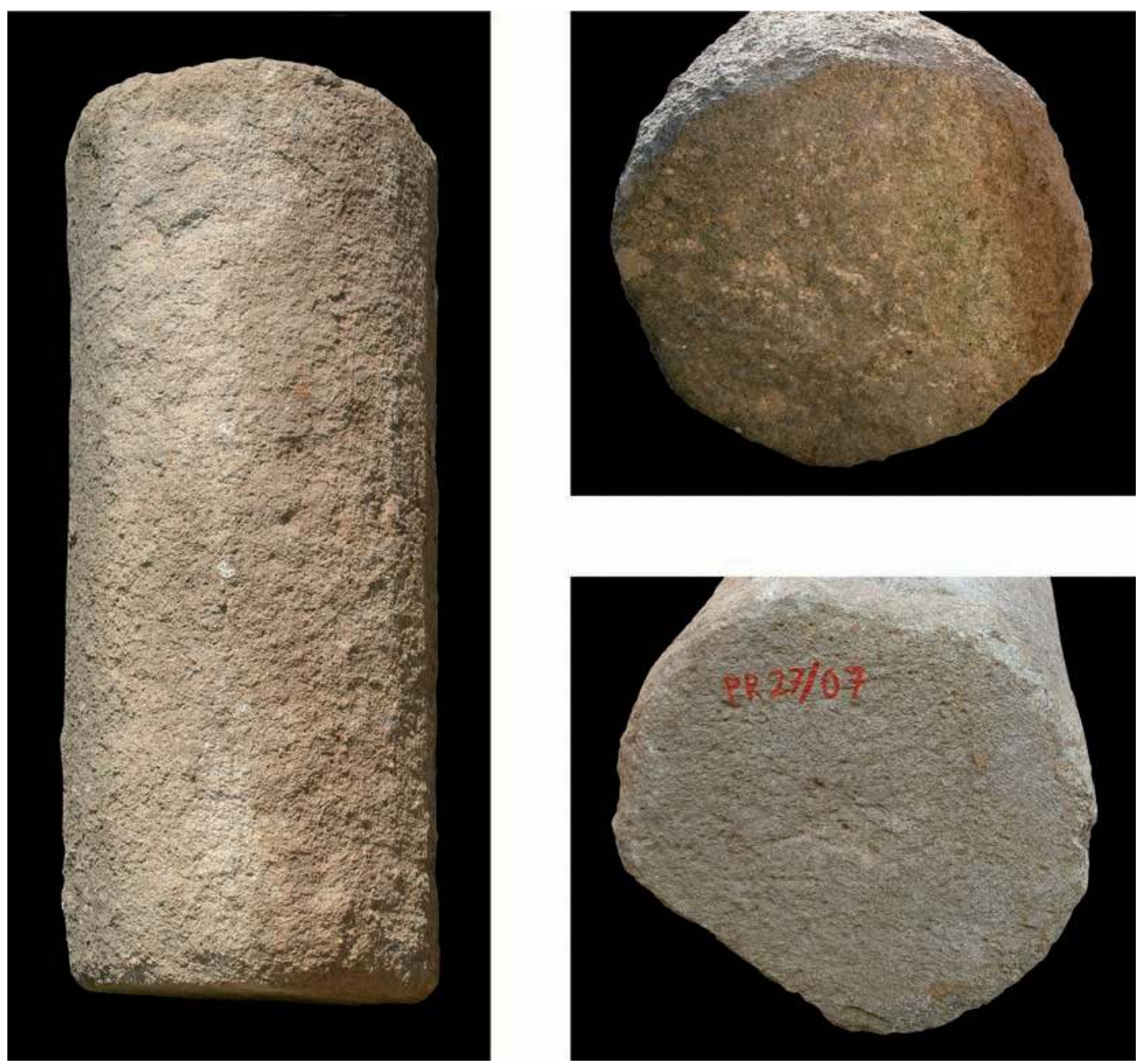

1 Raum 6. Säulentrommel A 29
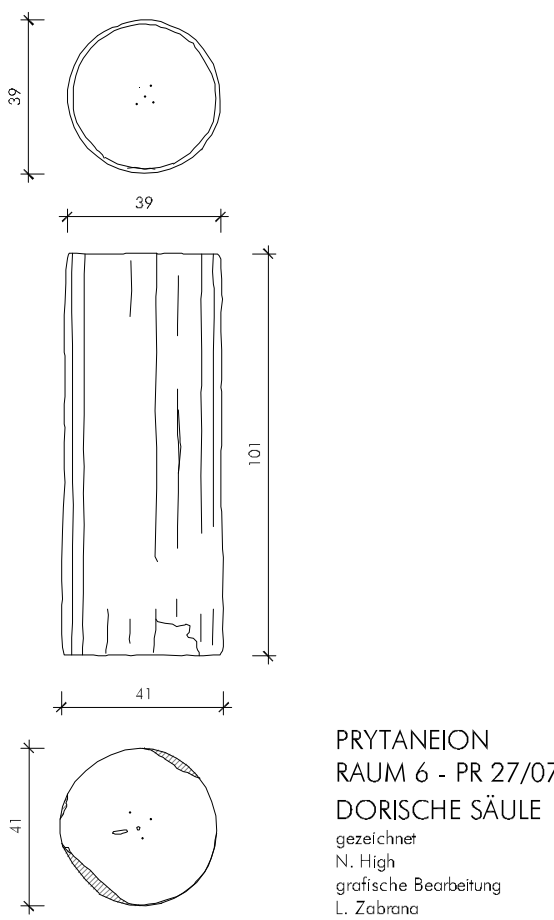

0 ${ }_{100}^{100} \mathrm{~cm}$

2 Raum 6. Säulentrommel A 29 (1:25) 
Tafel 100

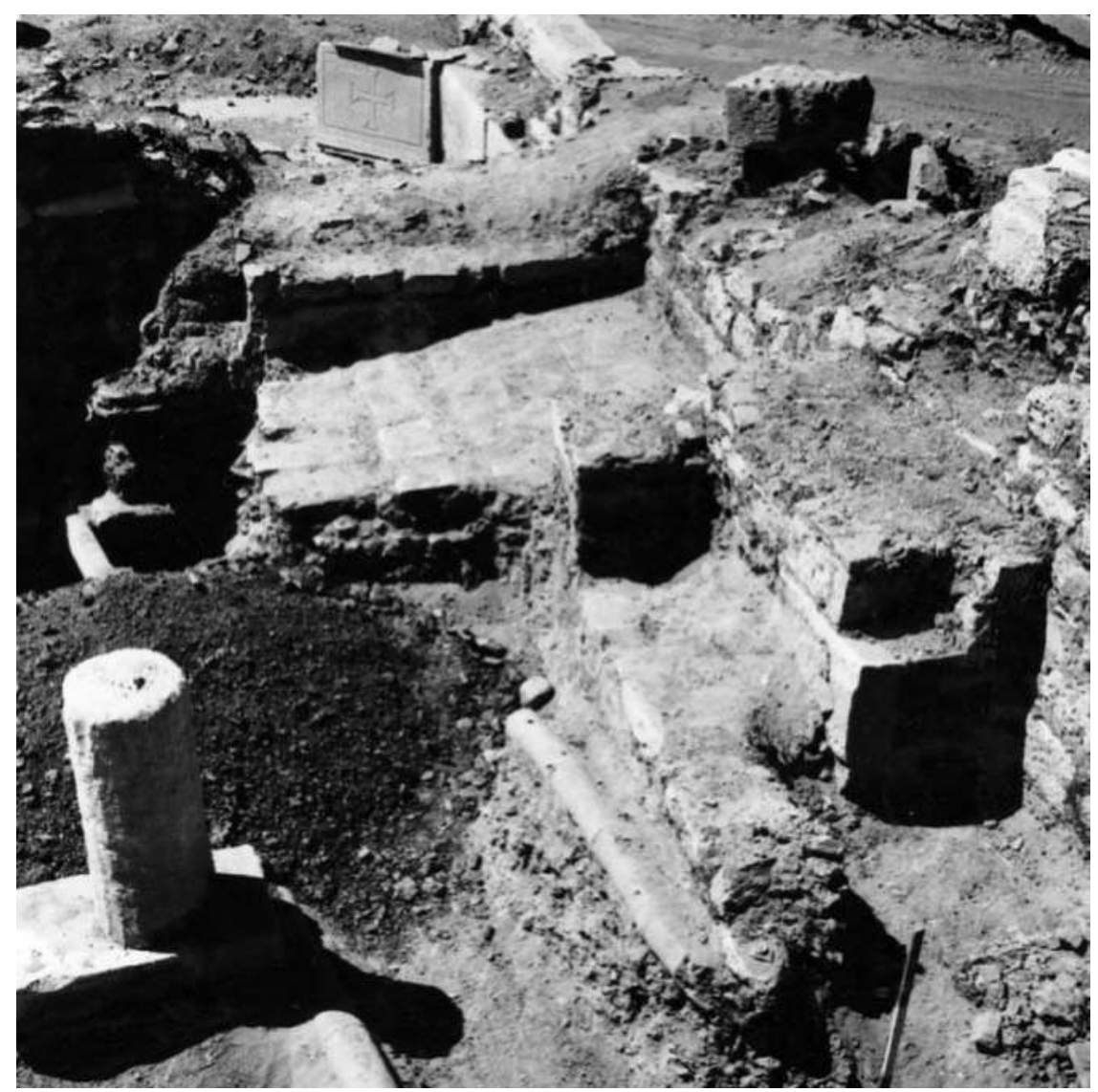

1 Raum 6. Rampenartige Treppe an der Südwand

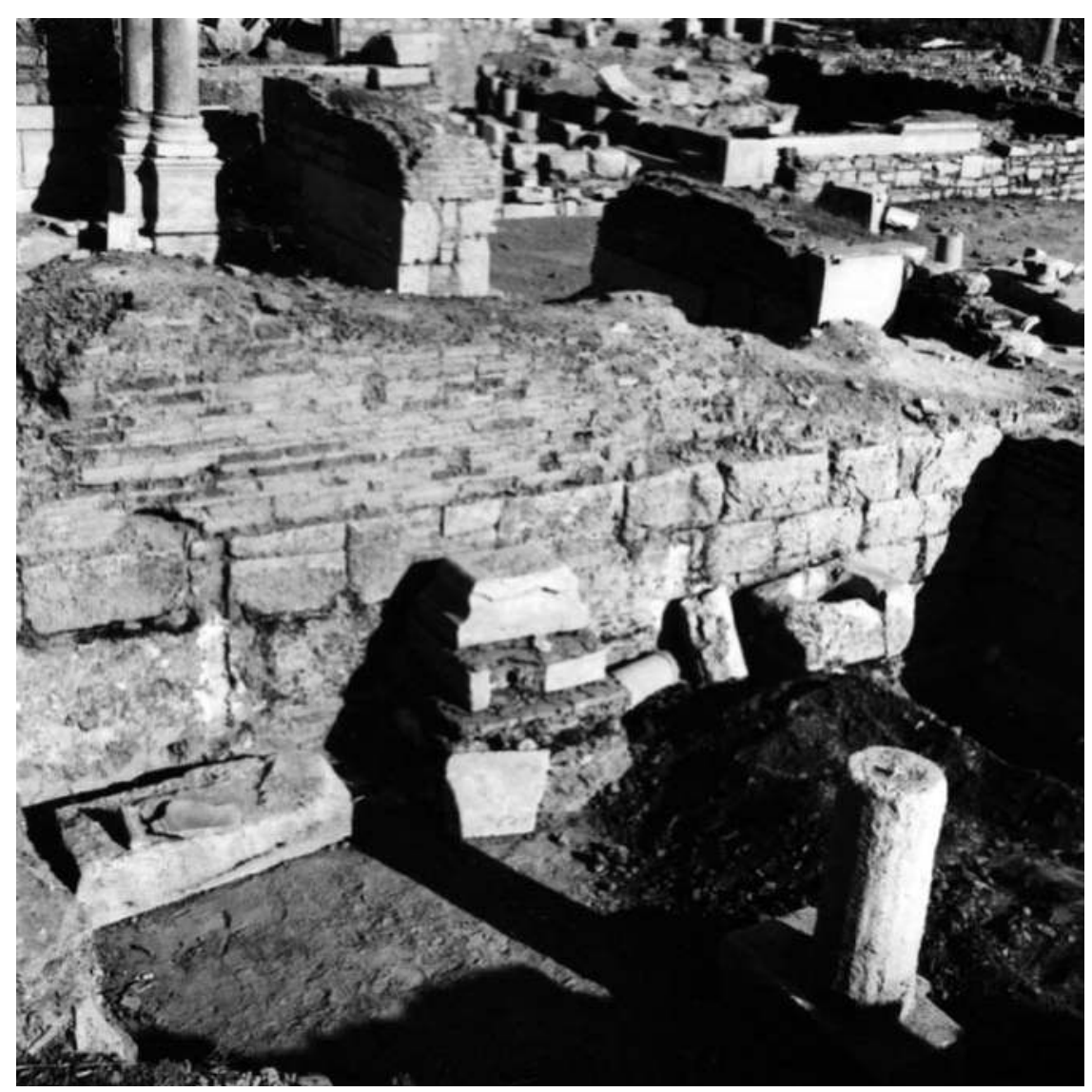

2 Raum 6. Marmorbasis vor der Ostwand 
Tafel 101

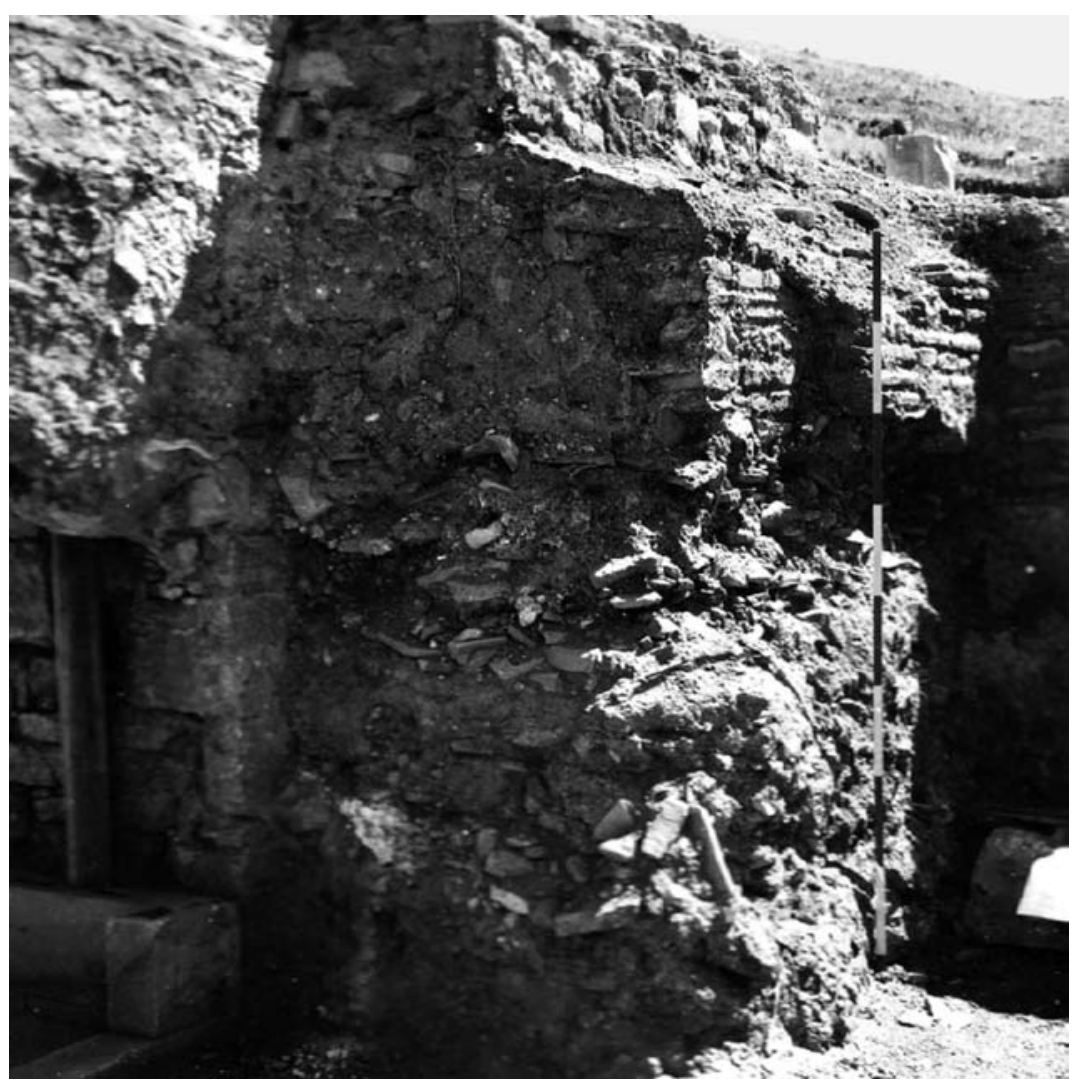

1 Raum 6. An die Nordwand angesetzte sekundäre Mauer

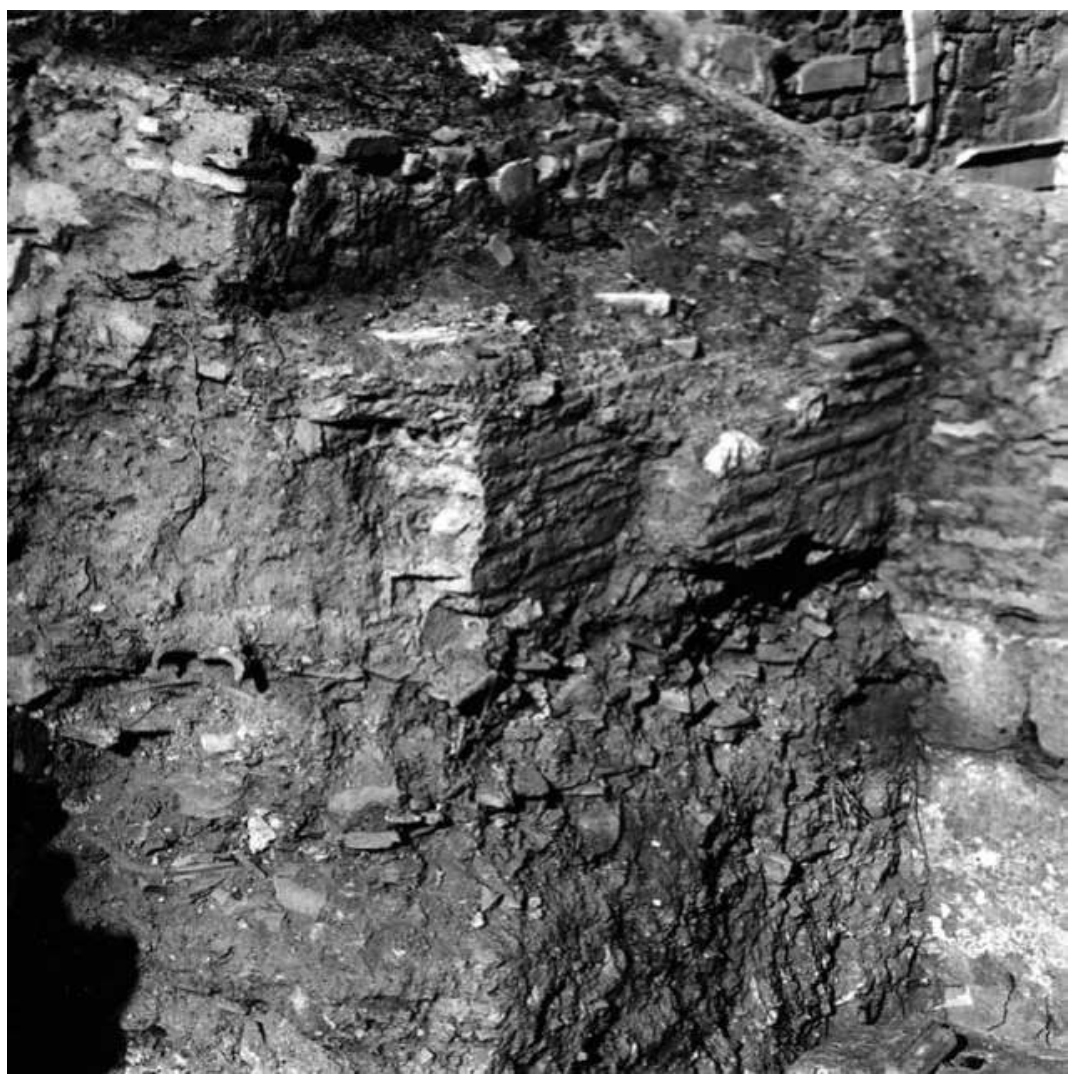

2 Raum 6. Detail der an die Nordwand angesetzten sekundären Mauer 


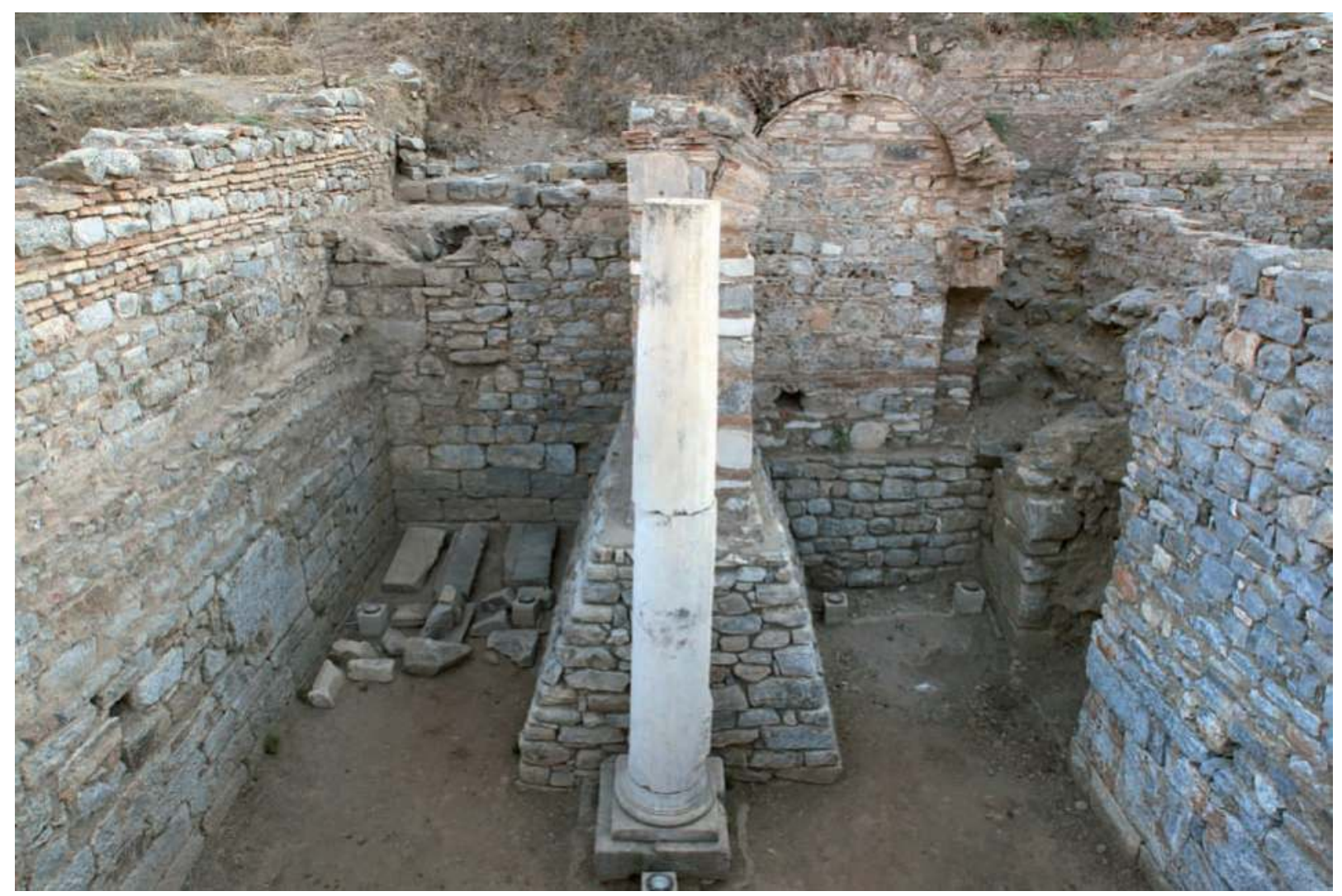

1 Raum 5 von Süden

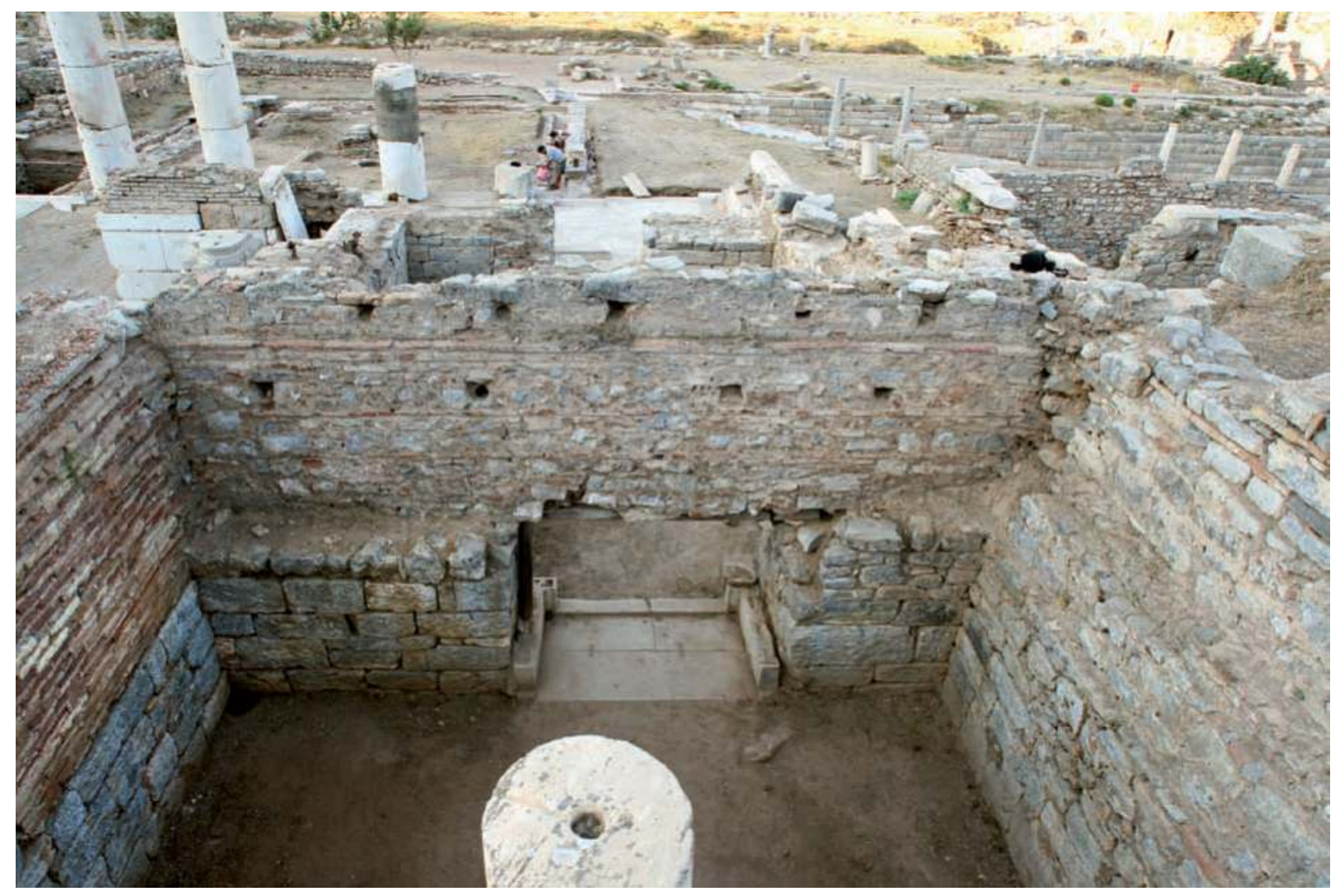

2 Raum 5 von Norden 
Tafel 103

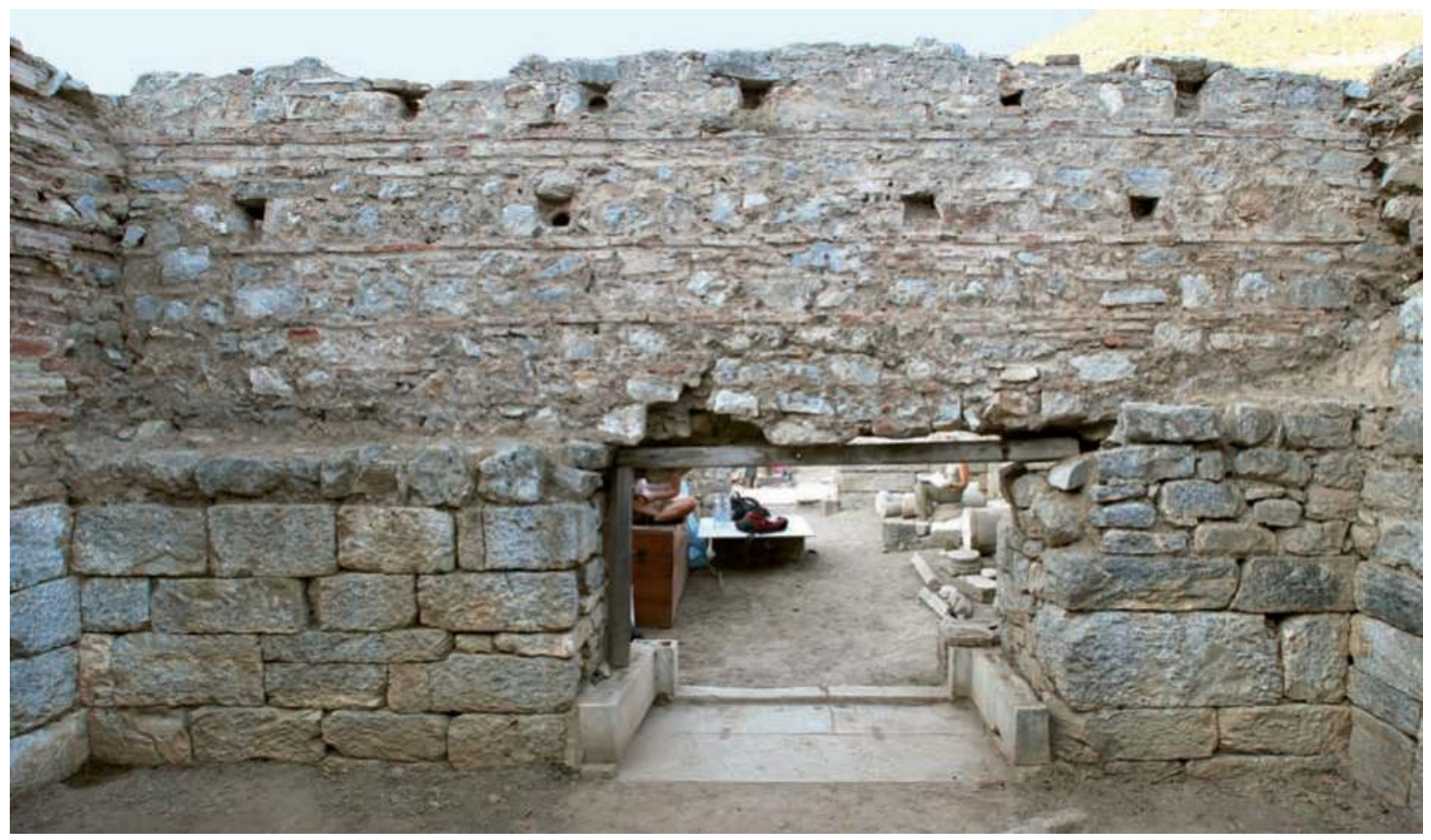

1 Raum 5. Südwand
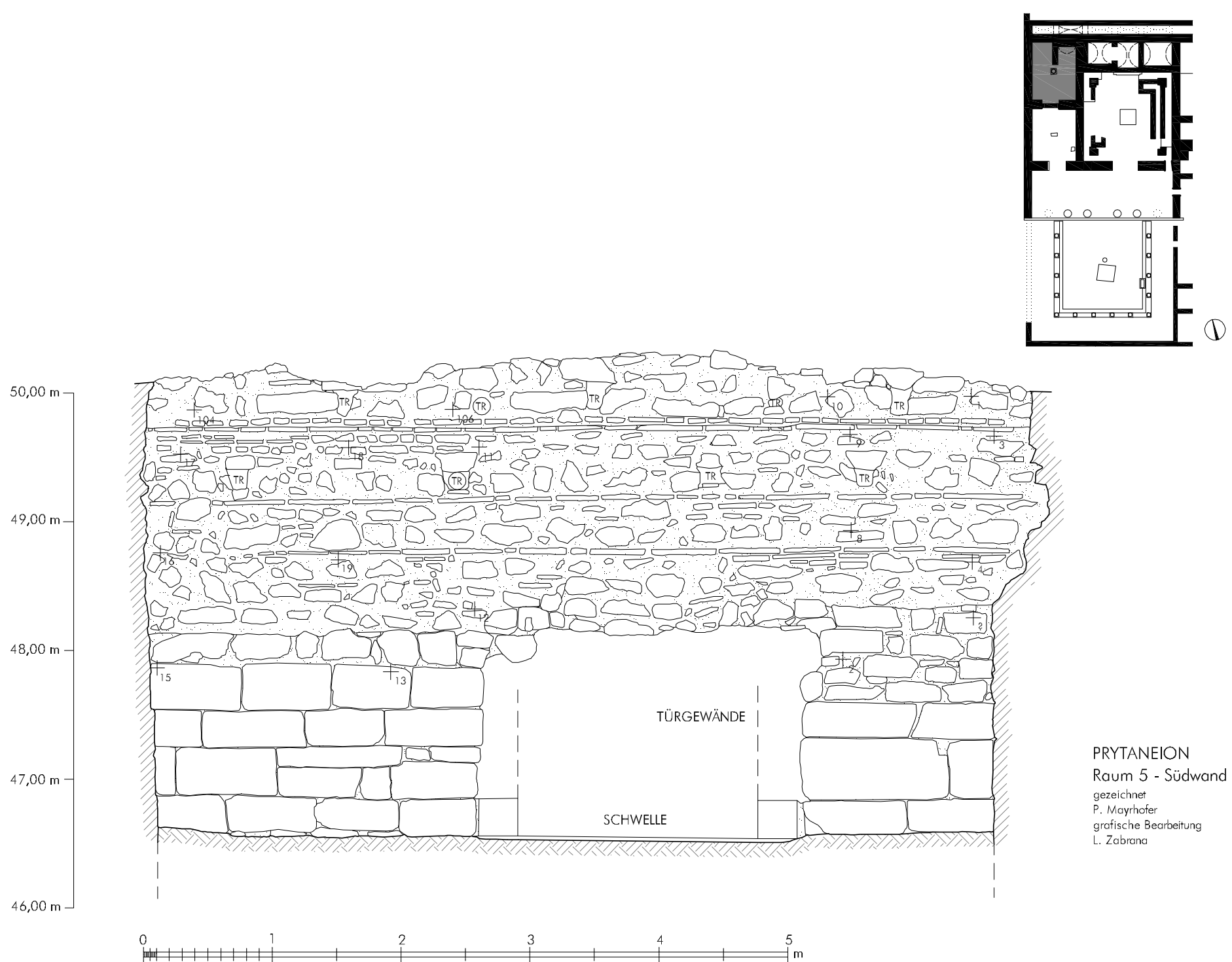

PRYTANEION

Raum 5 - Südwand

gezeichnet
P. Mayrhofer

grafische Bearbeitung

Zabrana 


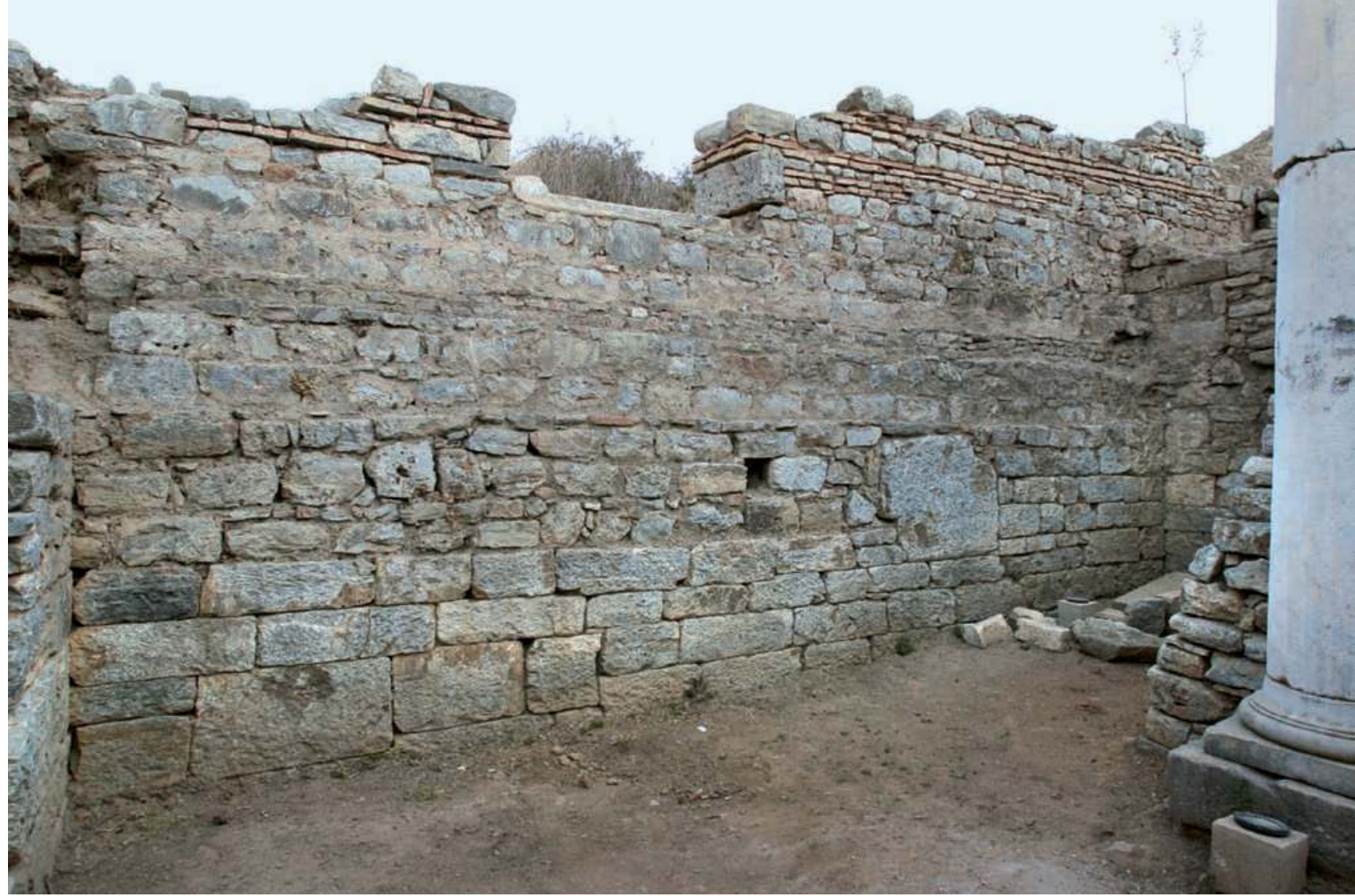

1 Raum 5. Westwand

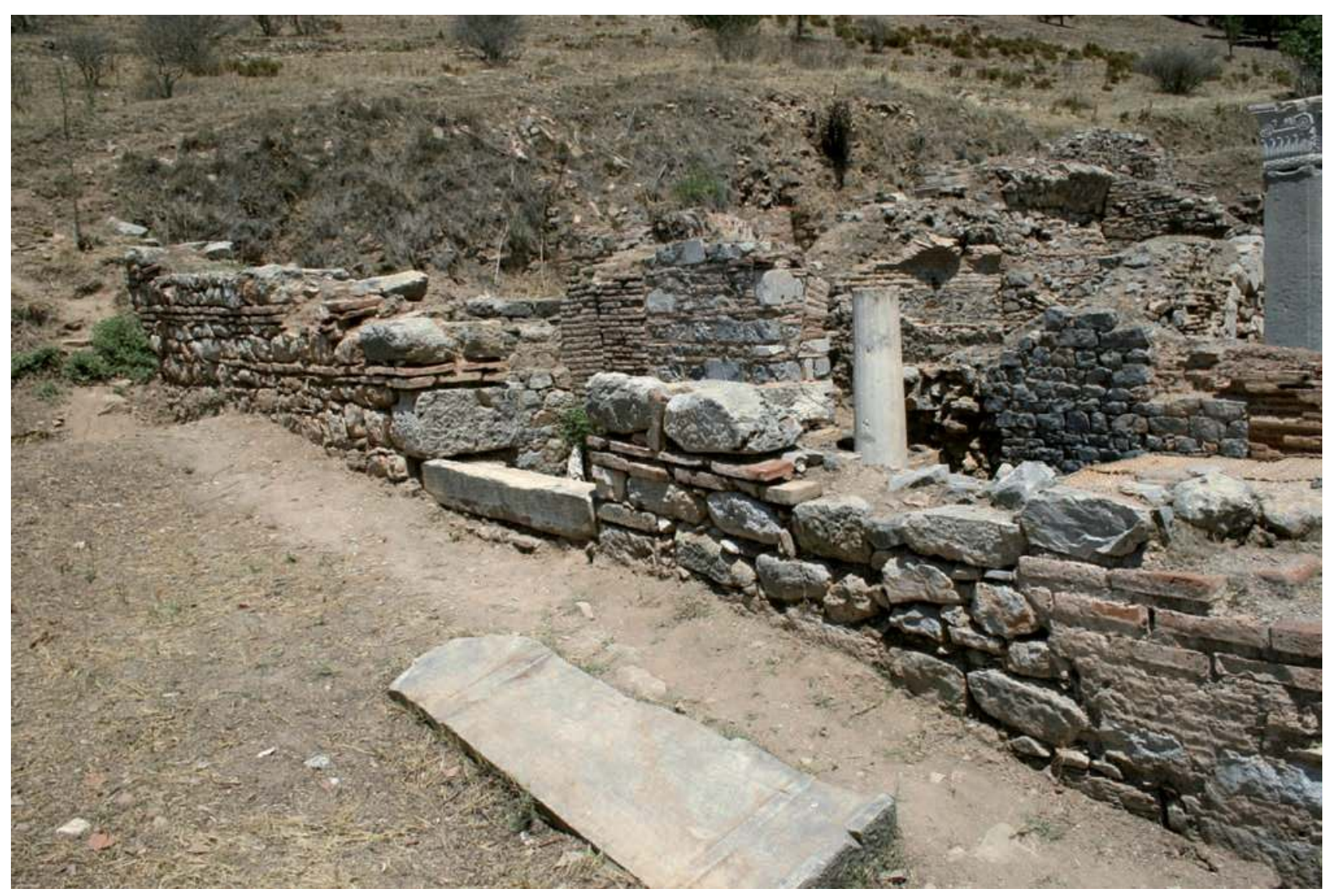

2 Raum 5/>Akademiegasseく. Marmorschwelle der sekundären Tür 
Tafel 105

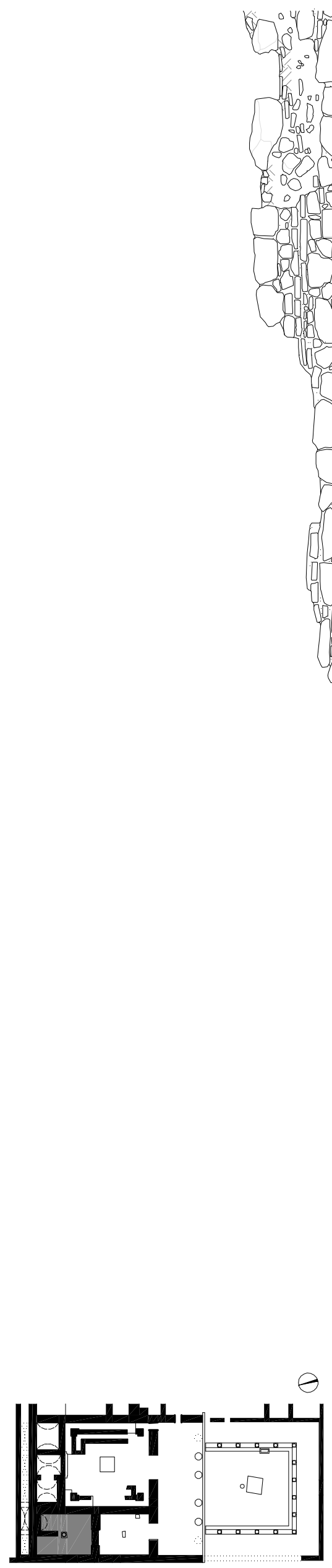




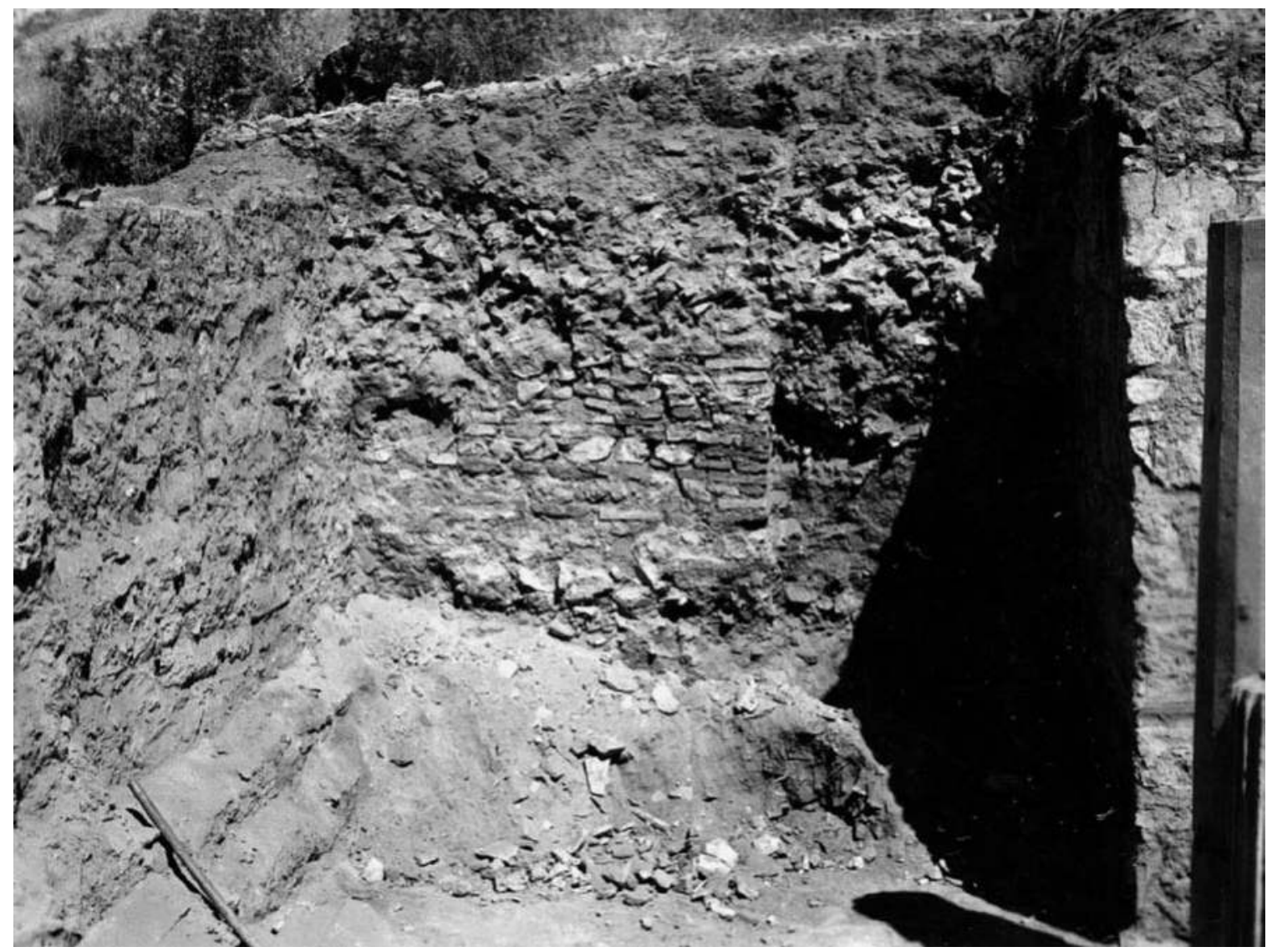

1 Raum 5. An die Nordwand angesetzte sekundäre Mauer

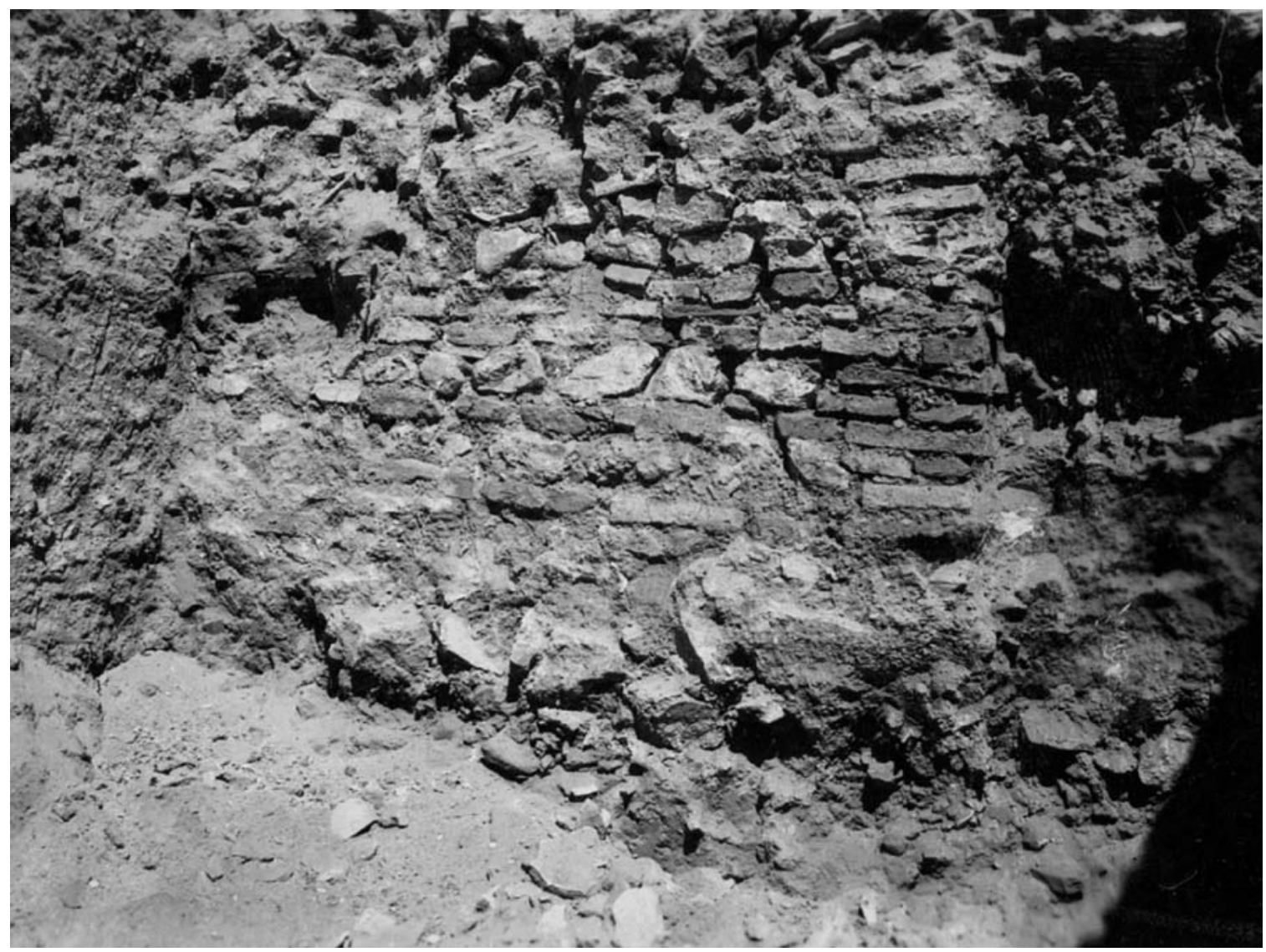

2 Raum 5. Detail der an die Nordwand angesetzten sekundären Mauer 
Tafel 107

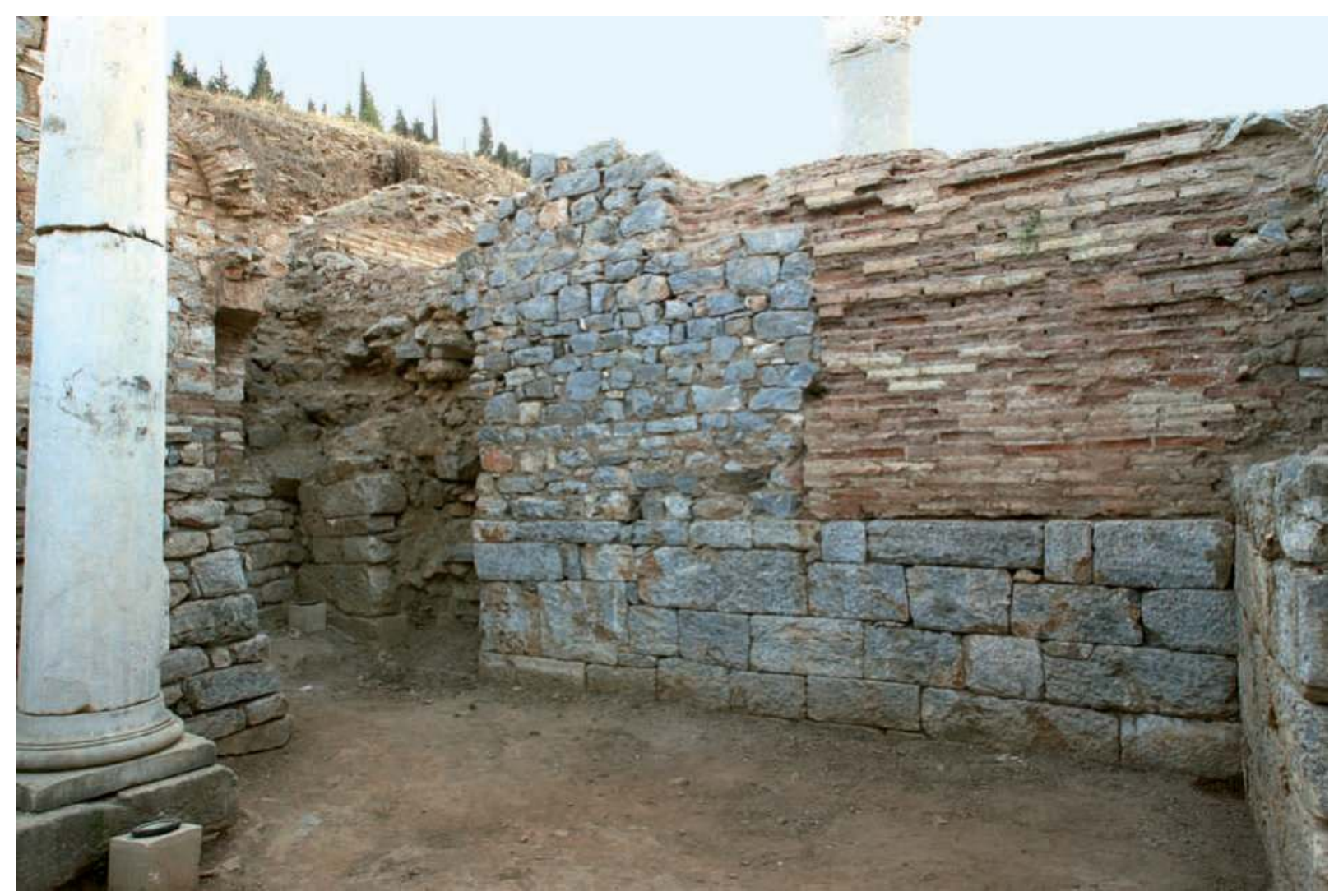

1 Raum 5. Ostwand

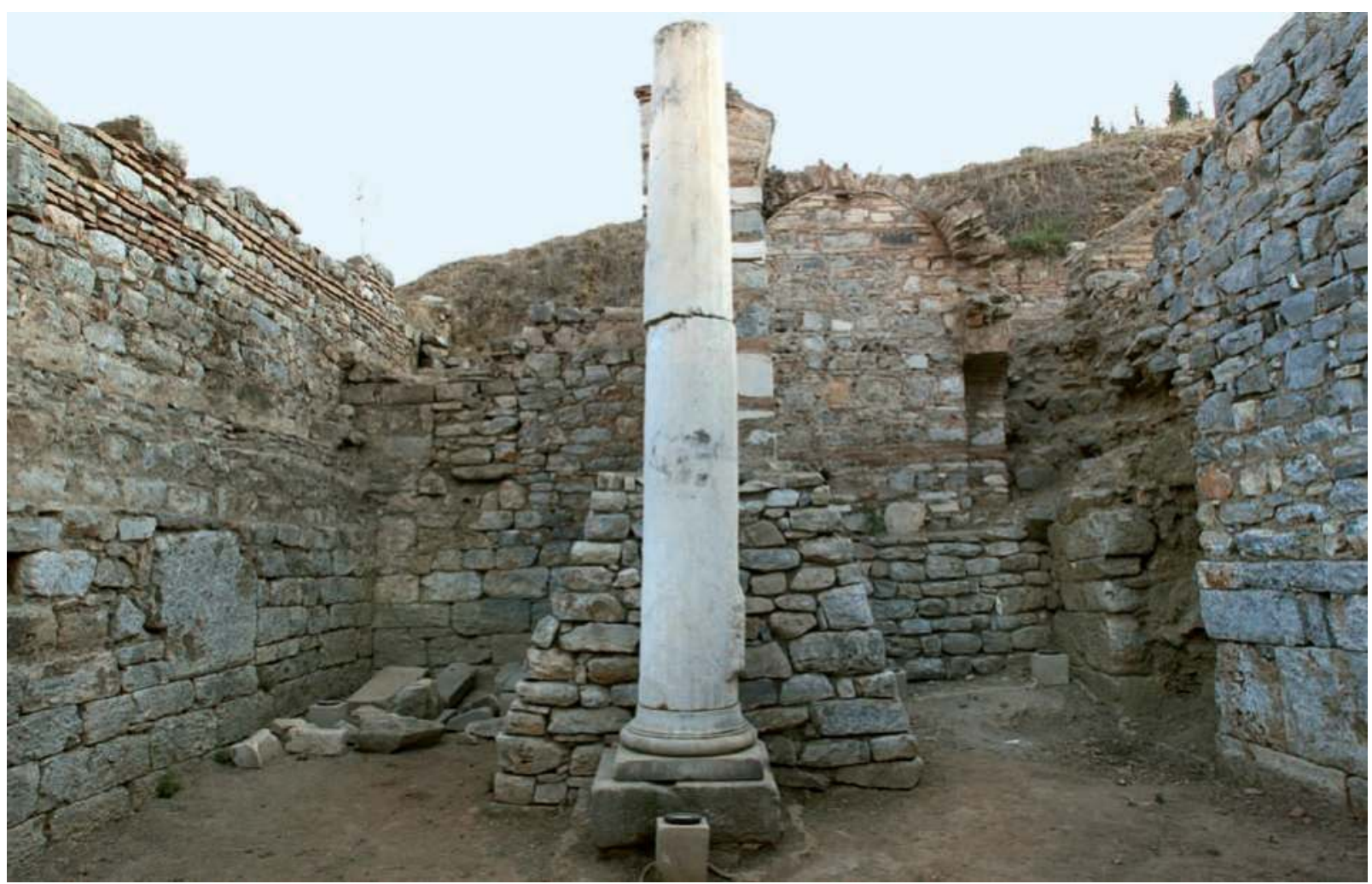

2 Raum 5. Nordwand 

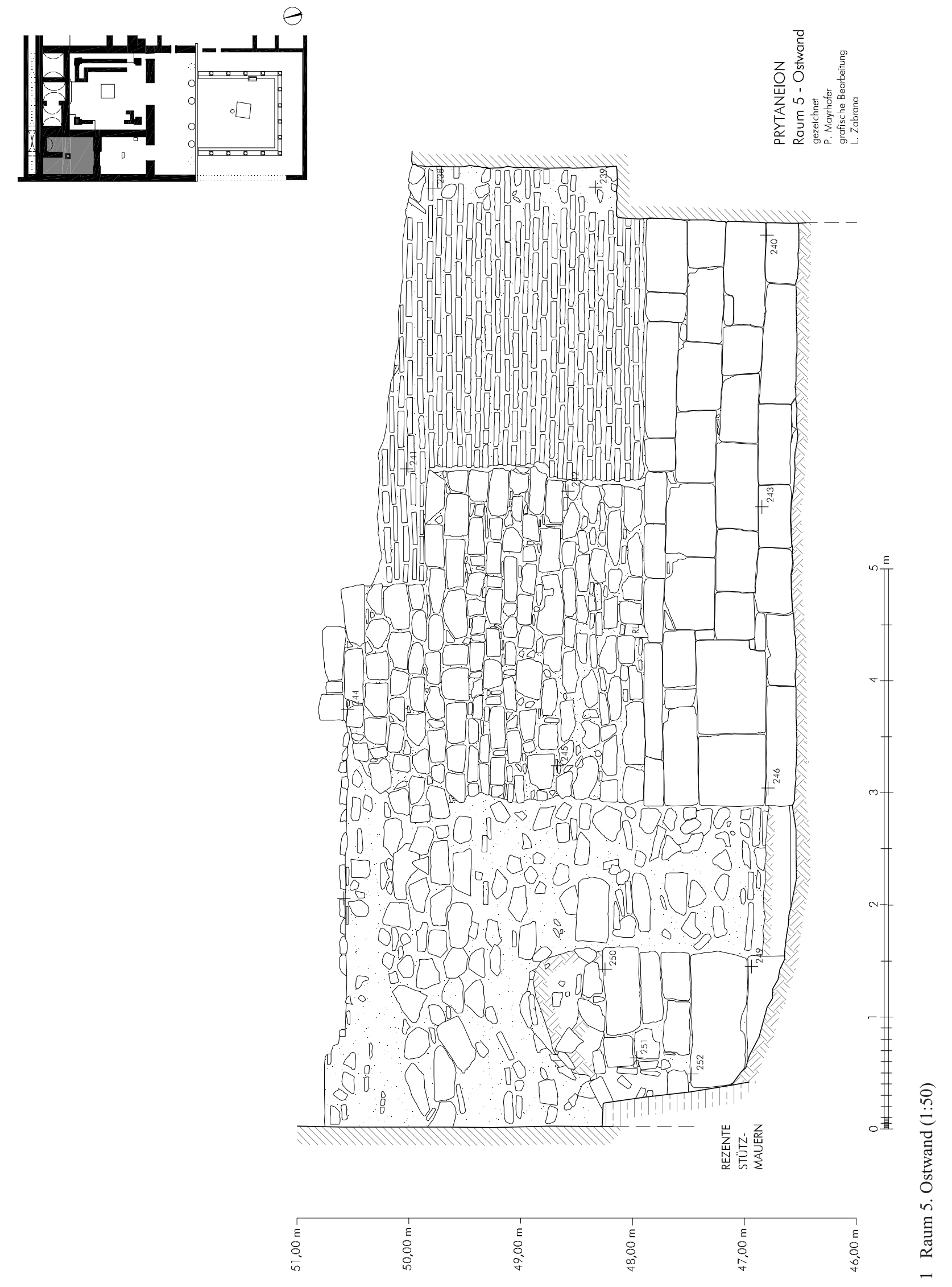

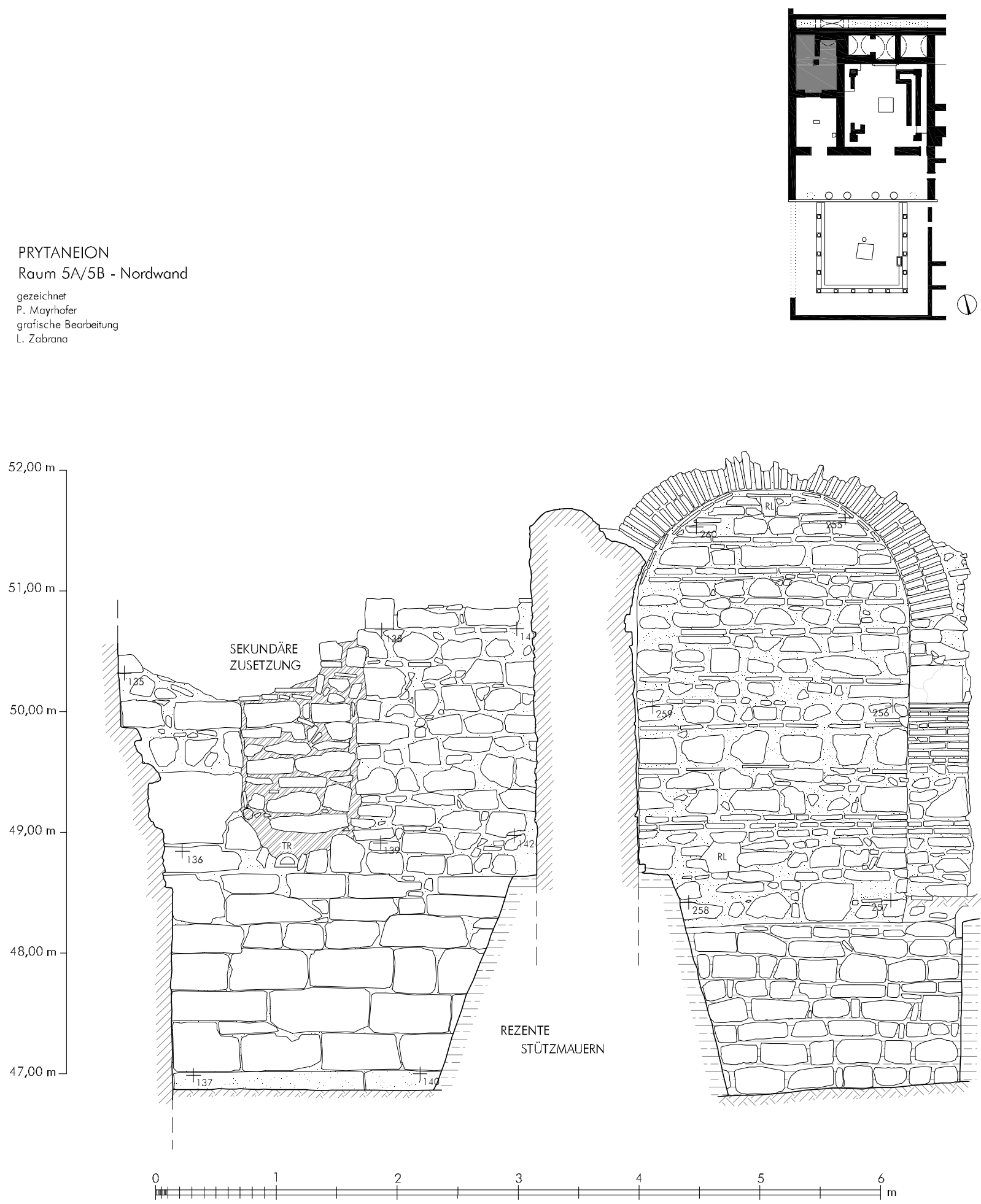

1 Raum 5. Nordwand (1:50) 
Tafel 110

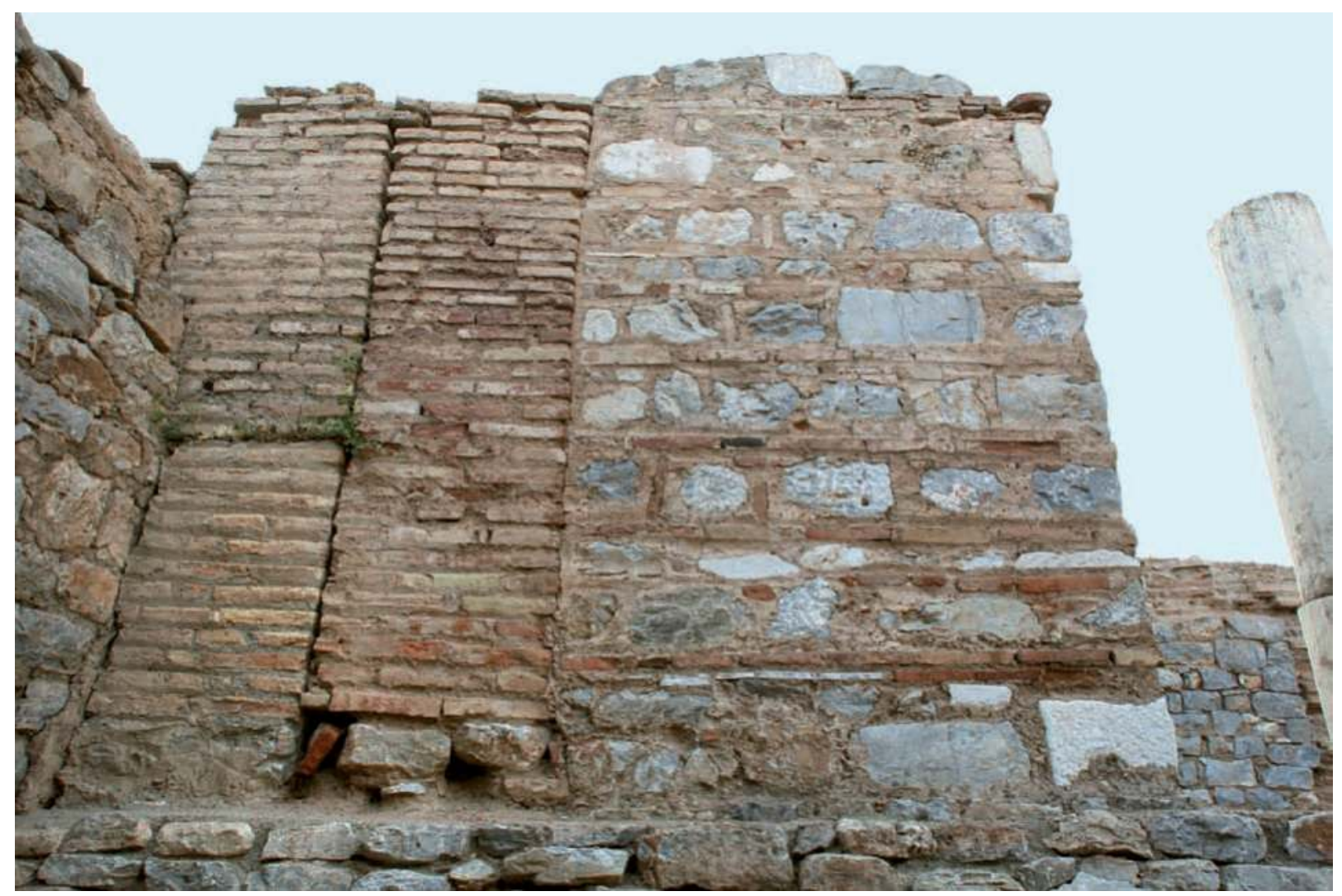

1 Raum 5. Sekundäre Nord-Süd-Mauer von Westen

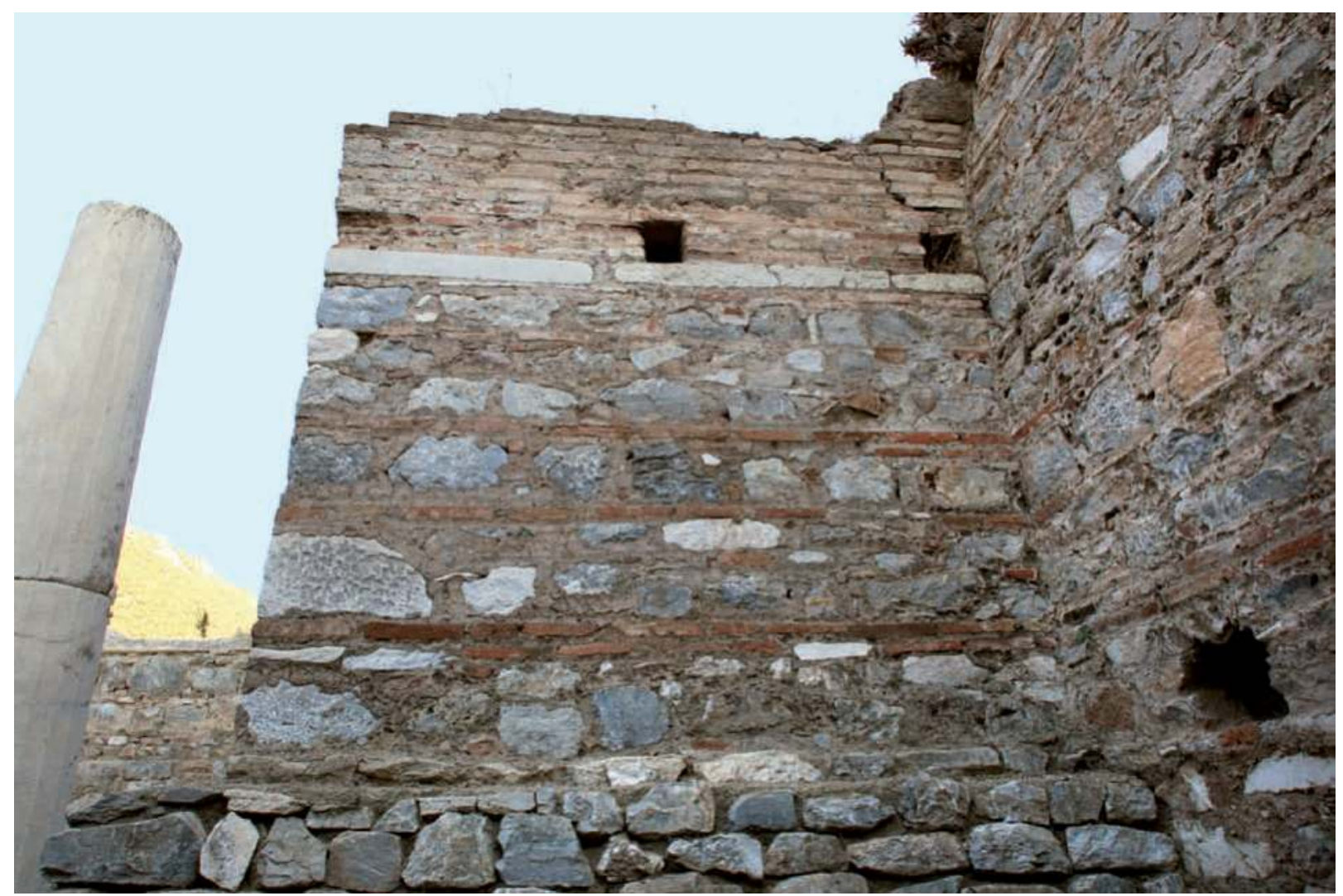

2 Raum 5. Sekundäre Nord-Süd-Mauer von Osten 
Tafel 111
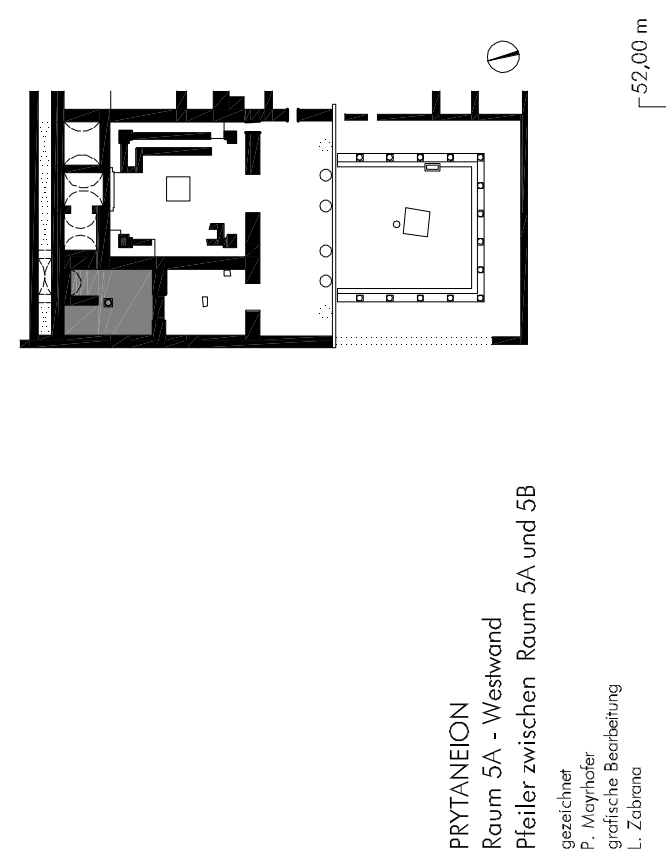

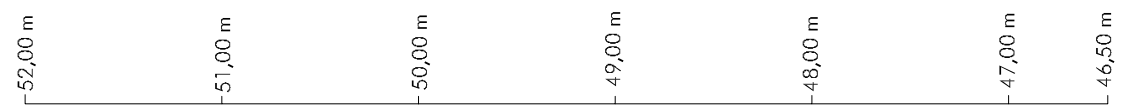
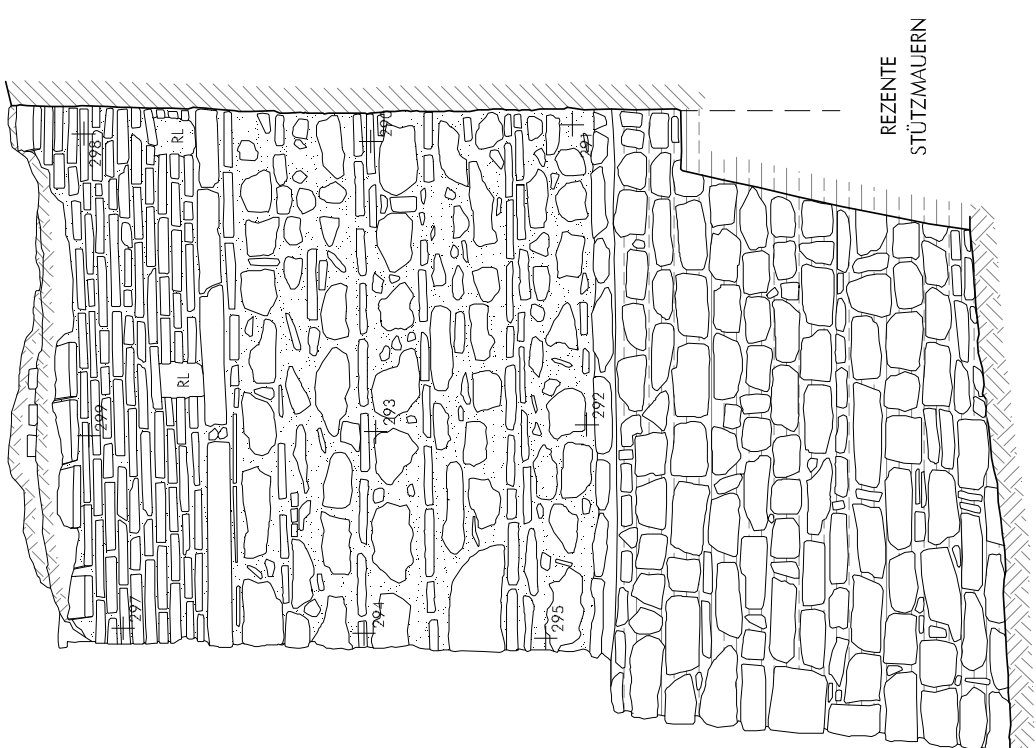

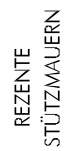
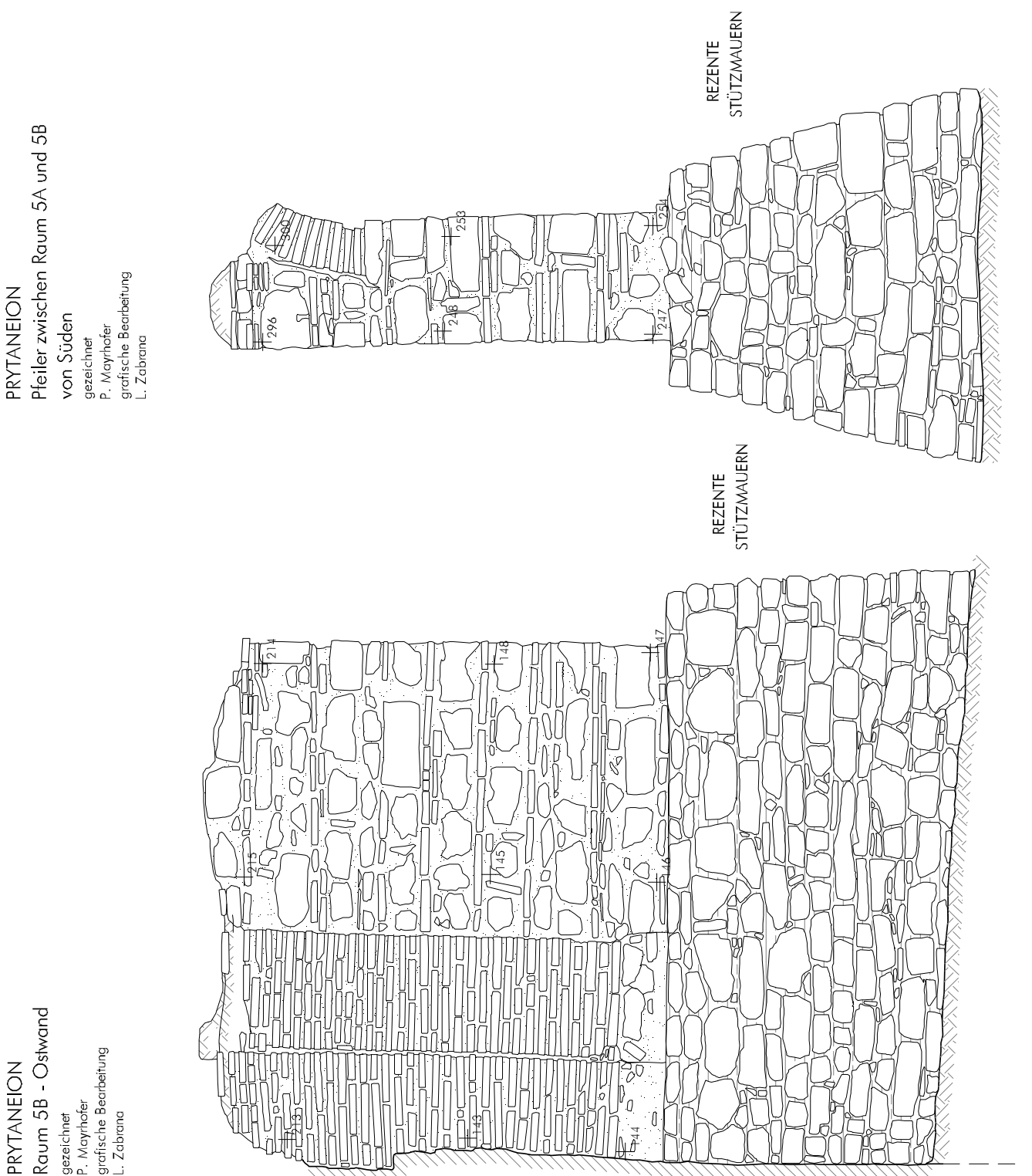

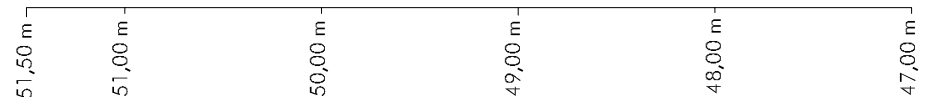



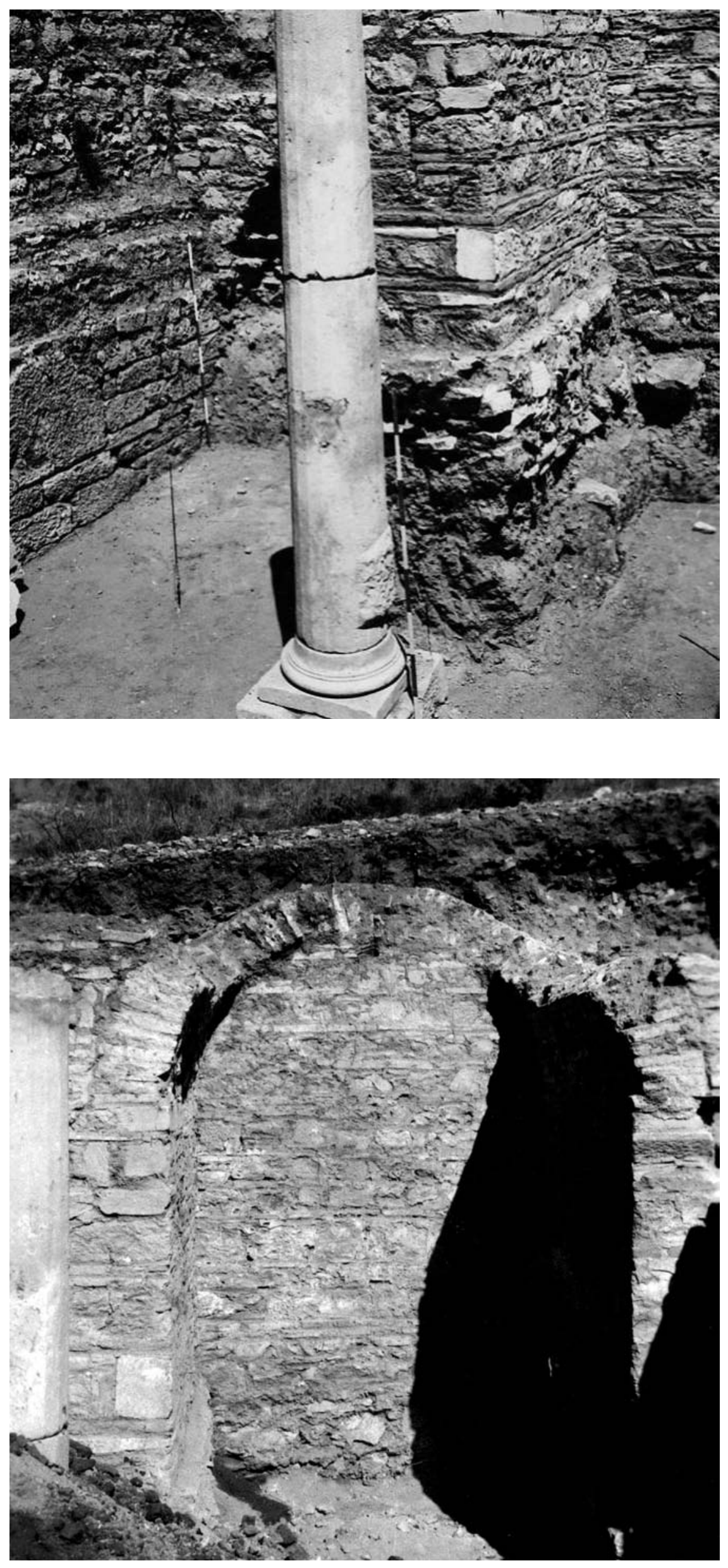

1 Raum 5.

Sekundäre Nord-SüdMauer vor Sicherung
2 Raum 5. Gewölbe vor Absturz der Ostwand 
Tafel 113

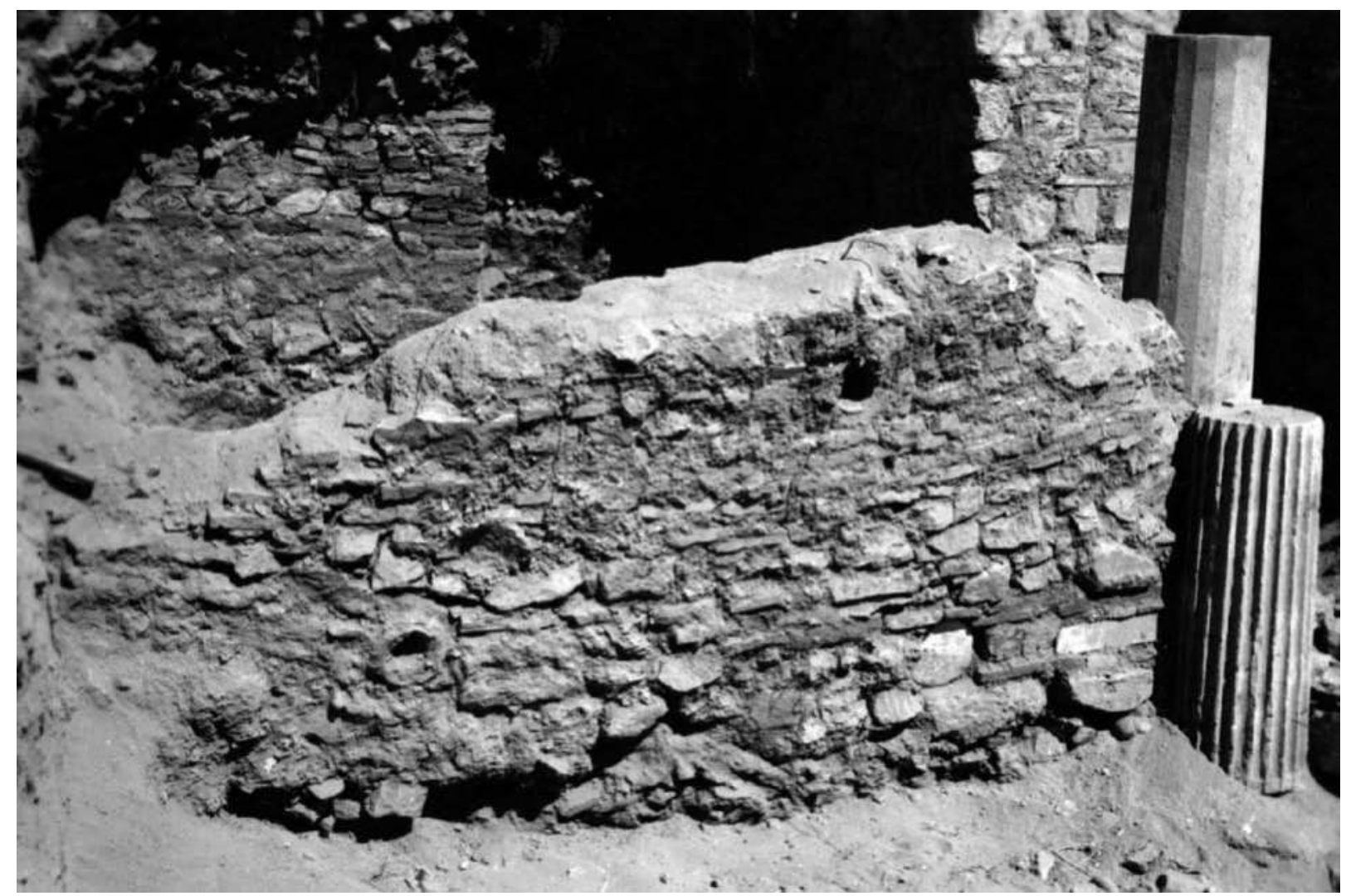

1 Raum 5. Sekundäre Mauer zwischen Säule und Westwand
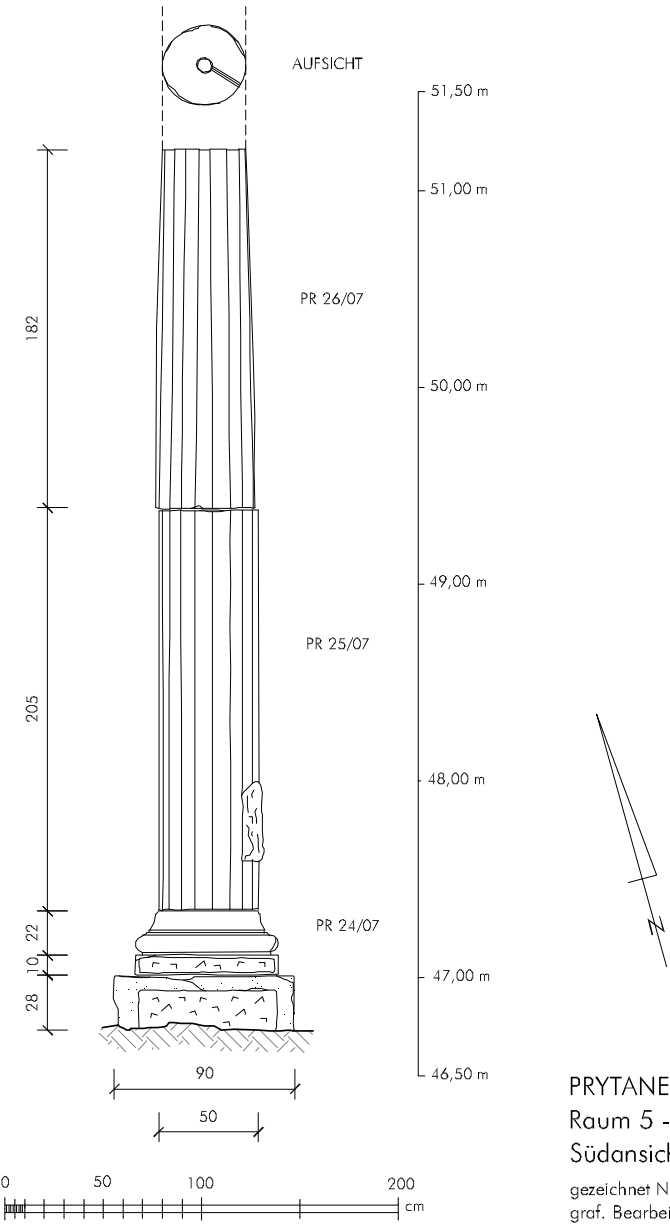

PRYTANEION

Raum 5 - Säule PR 24-26/07

Südansicht

gezeichnet N. High

grof. Becrbeitung L Zabrona

2 Raum 5. Säule A 27. 28 (1:50) 


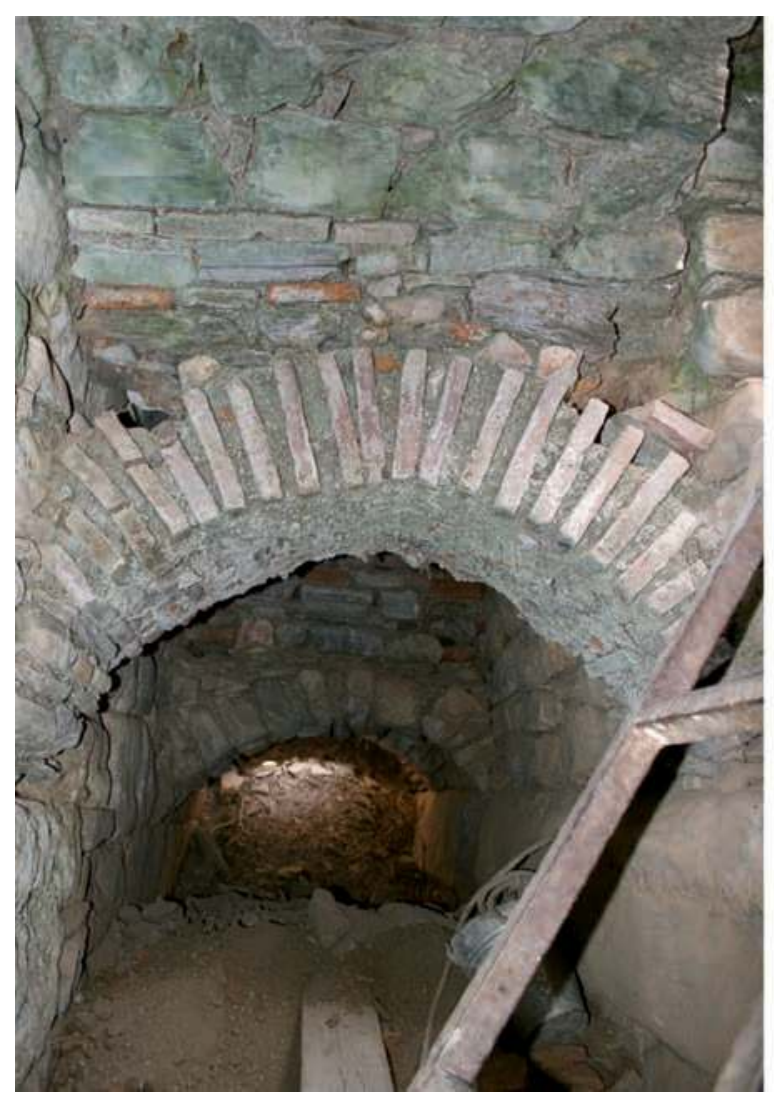

1 Kanal nördlich der Räume 5, 4, 3, 2

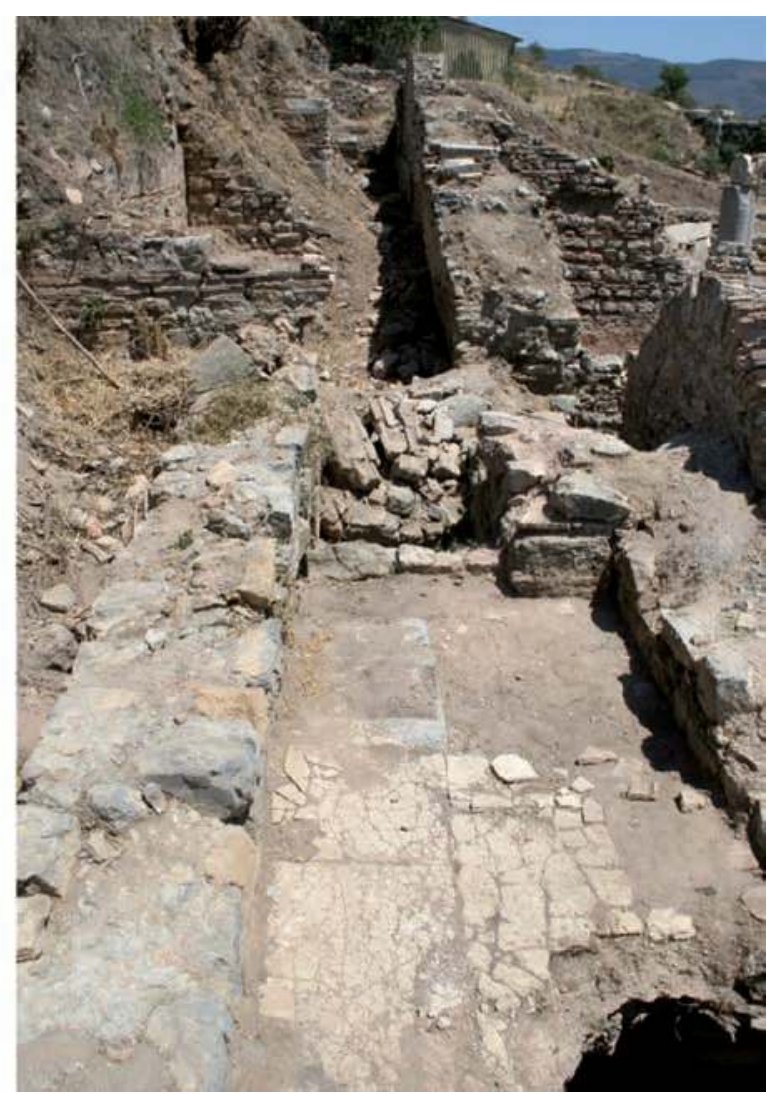

2 Bauwich nördlich der Räume 5, 4, 3, 2
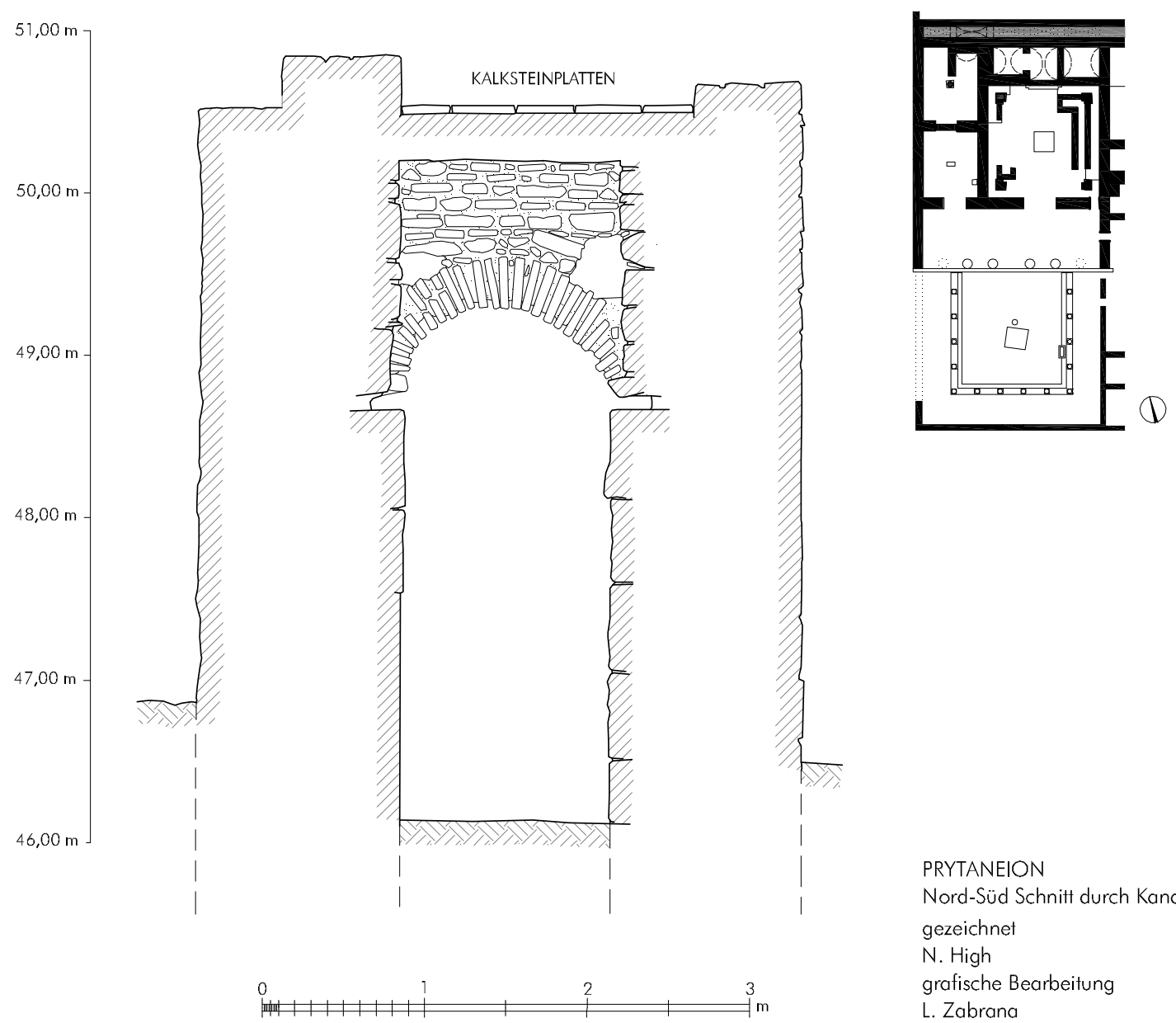

PRYTANEION

Nord-Süd Schnitt durch Kanal nach Osten gezeichnet

N. High

grafische Bearbeitung

L. Zabrana 
Tafel 115

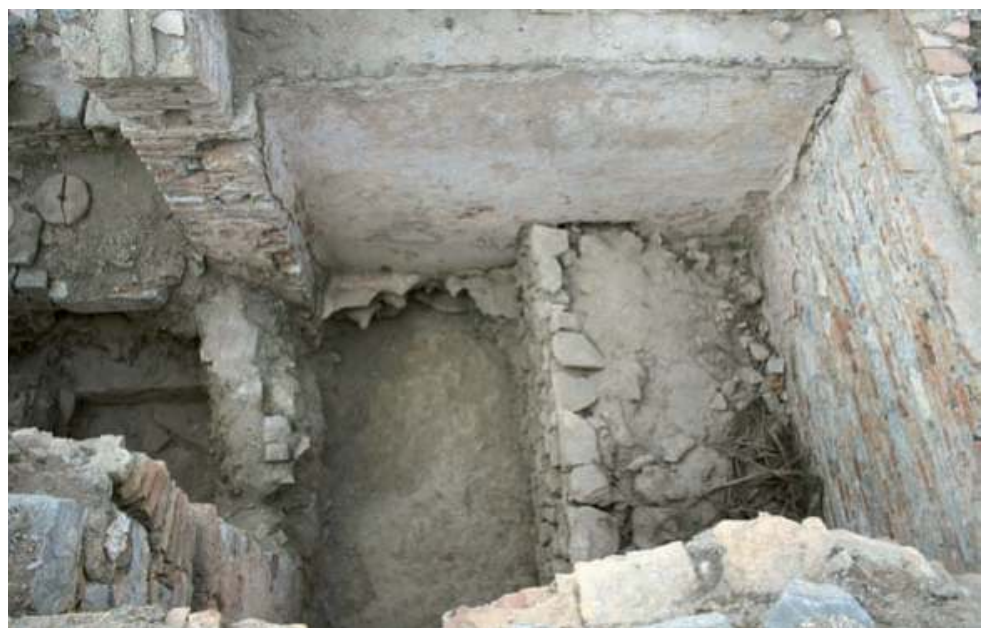

1 Raum 4 von Norden

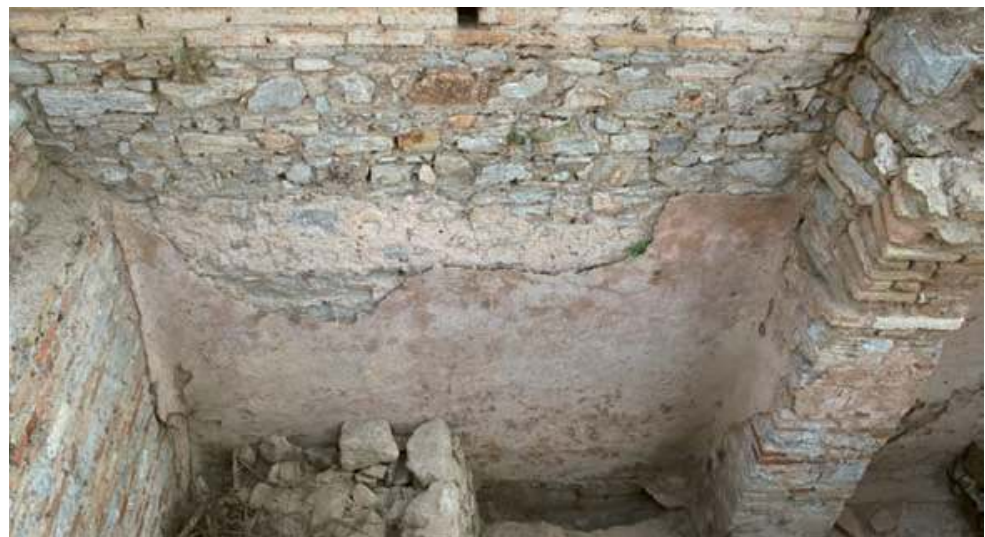

2 Raum 4. Nordwand
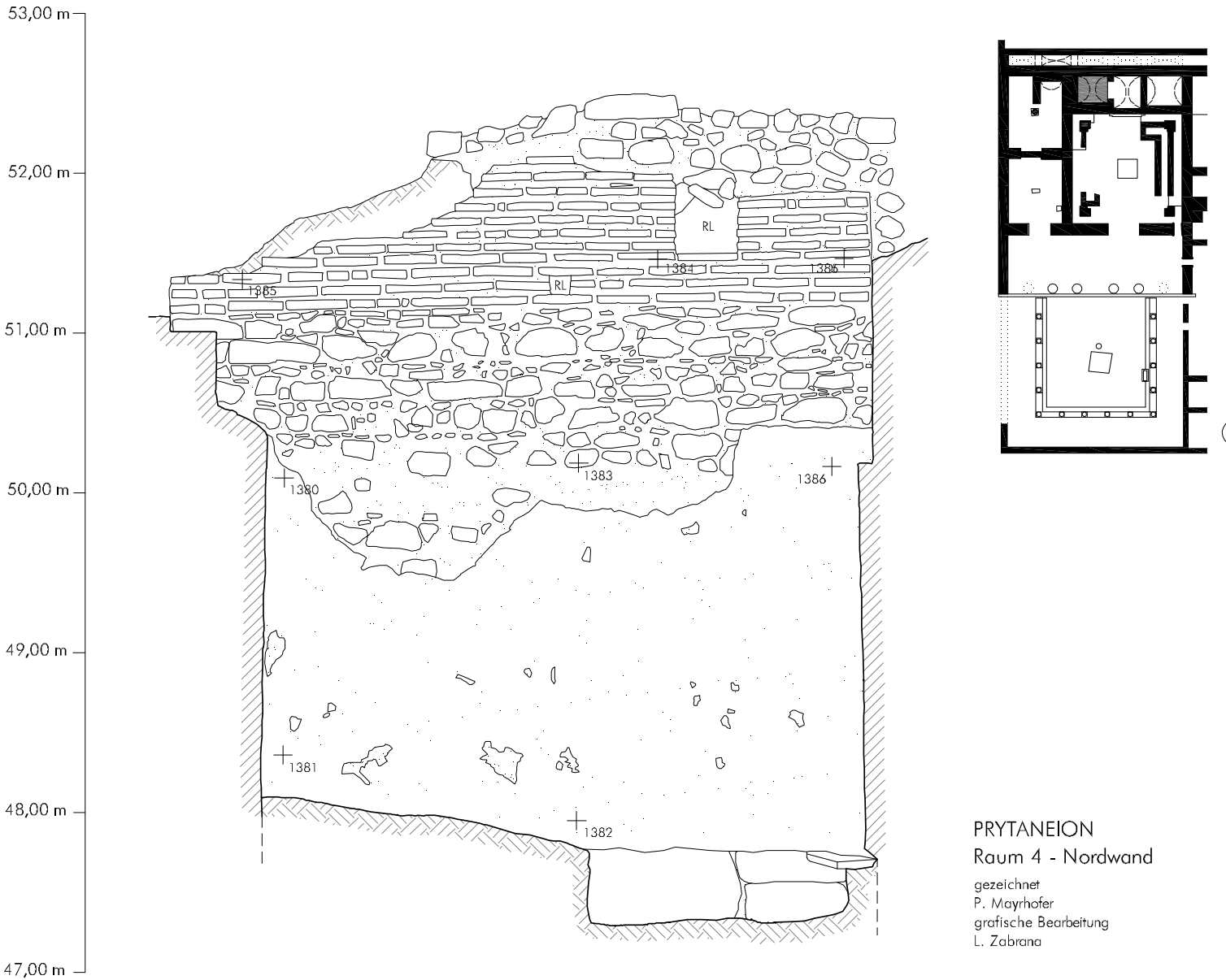
(1)

PRYTANEION

Raum 4 - Nordwand

gezeichnet
P. Nayrhofer

grafische Bearbeitung

L. Zabrana

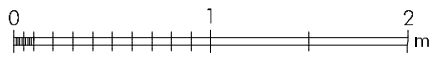

3 Raum 4. Nordwand (1:50) 
Tafel 116

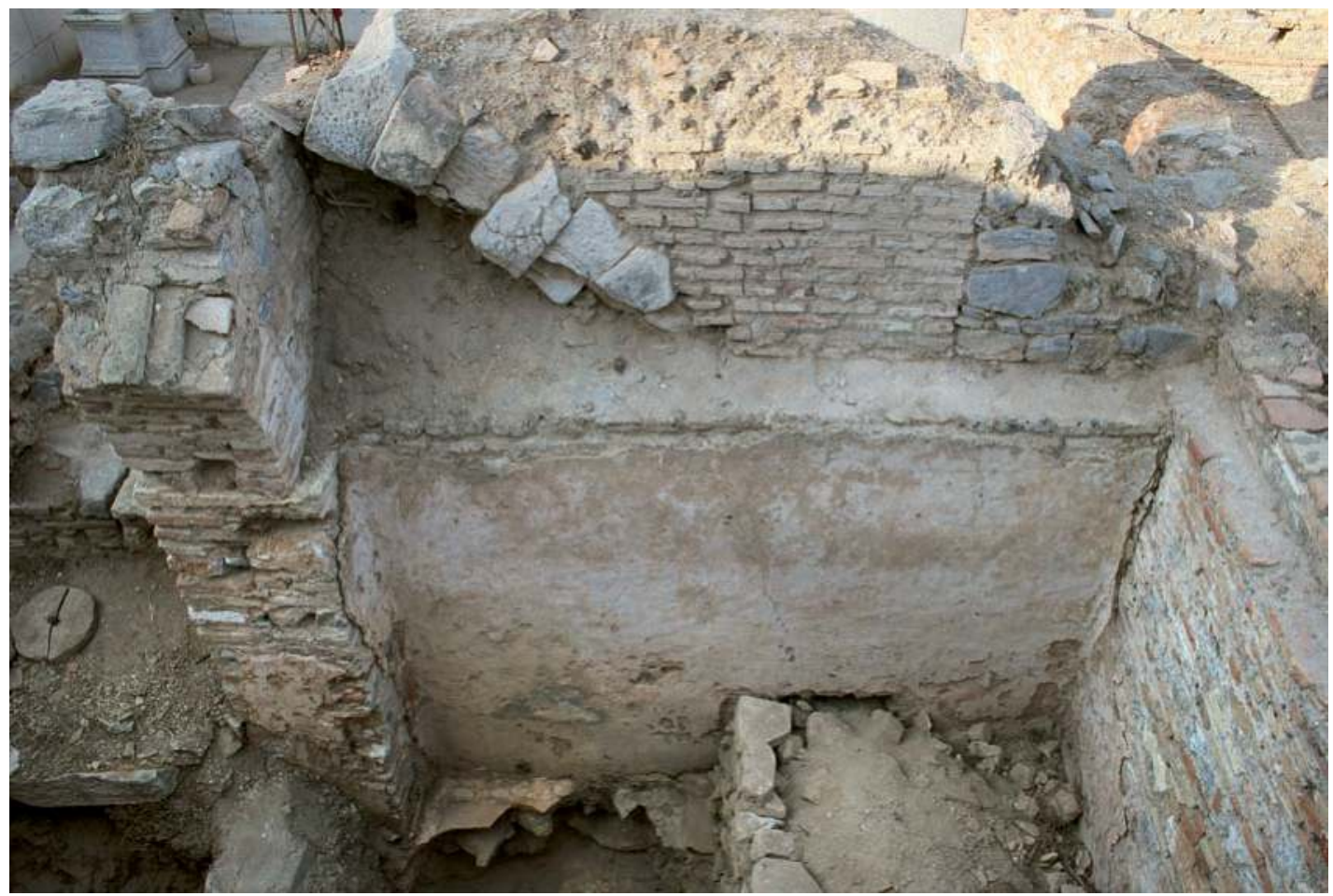

1 Raum 4. Südwand
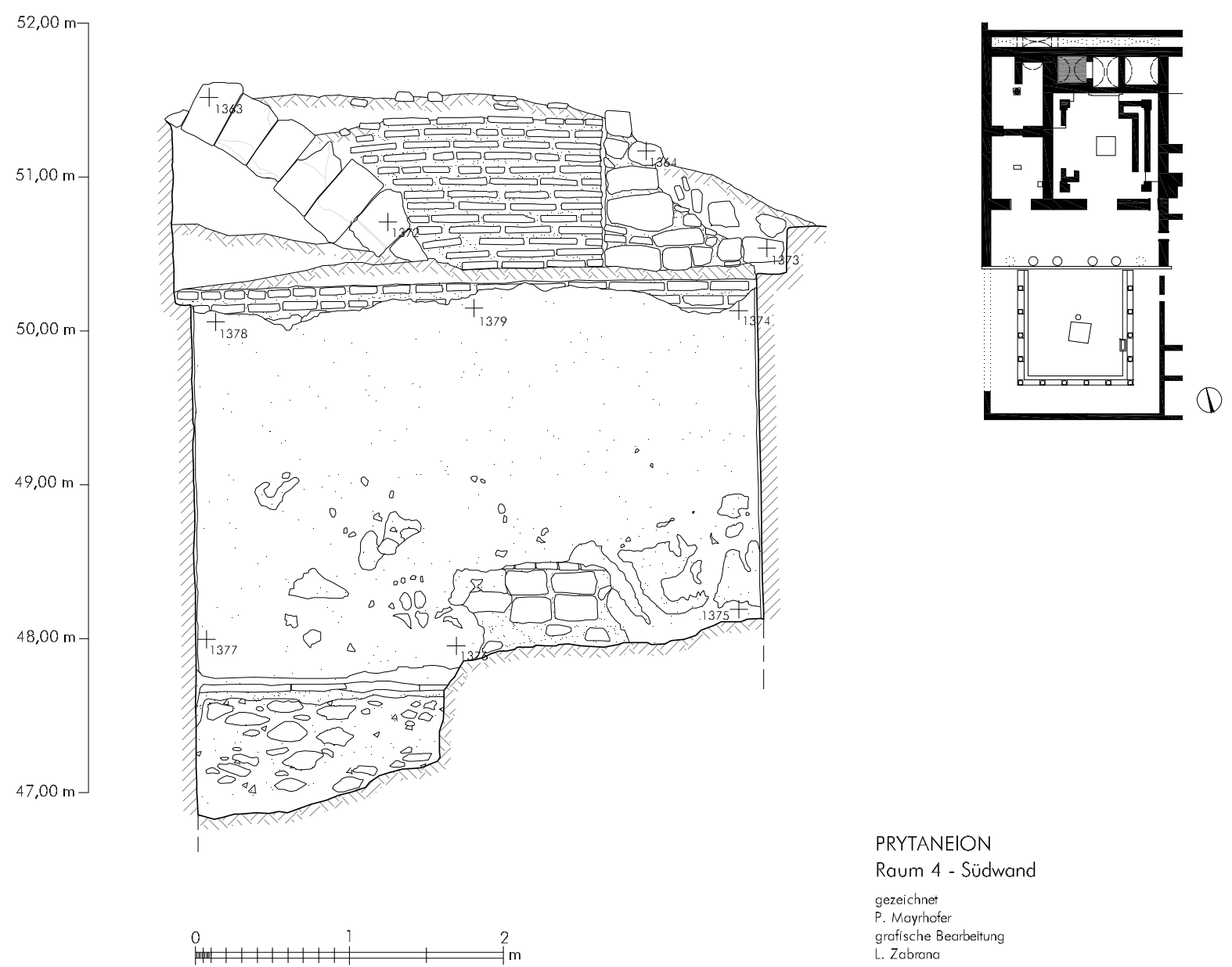

PRYTANEION

Raum 4 - Südwand

gezeichnet

grafische Bearbeitung

L. Zabrana

2 Raum 4. Südwand (1:50) 
Tafel 117

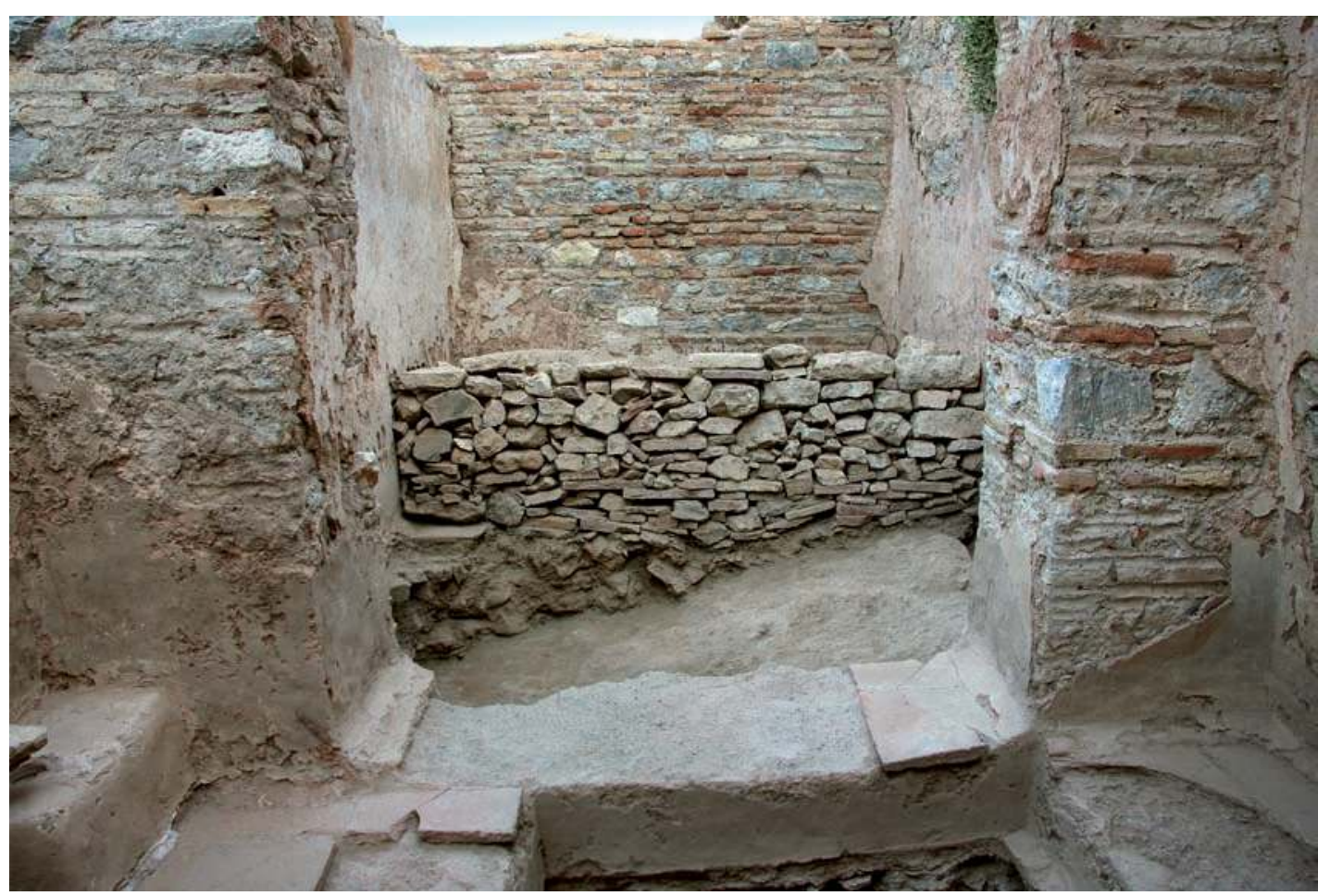

1 Raum 4. Westwand
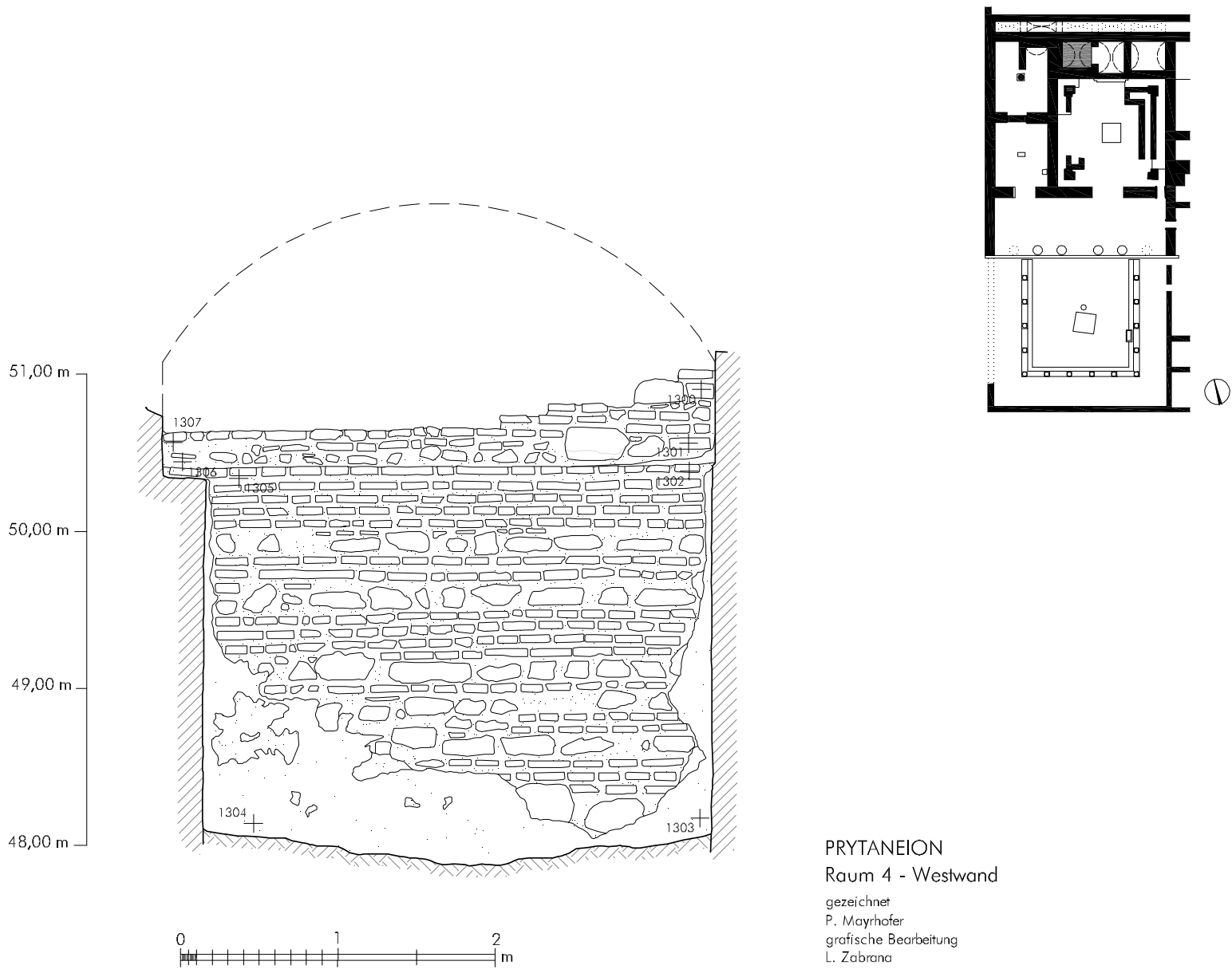

PRYTANEION

Raum 4 - Westwand

gezeichnet

grafische Bearbeitung

L. Zabrana

2 Raum 4. Westwand (1:50) 
Tafel 118

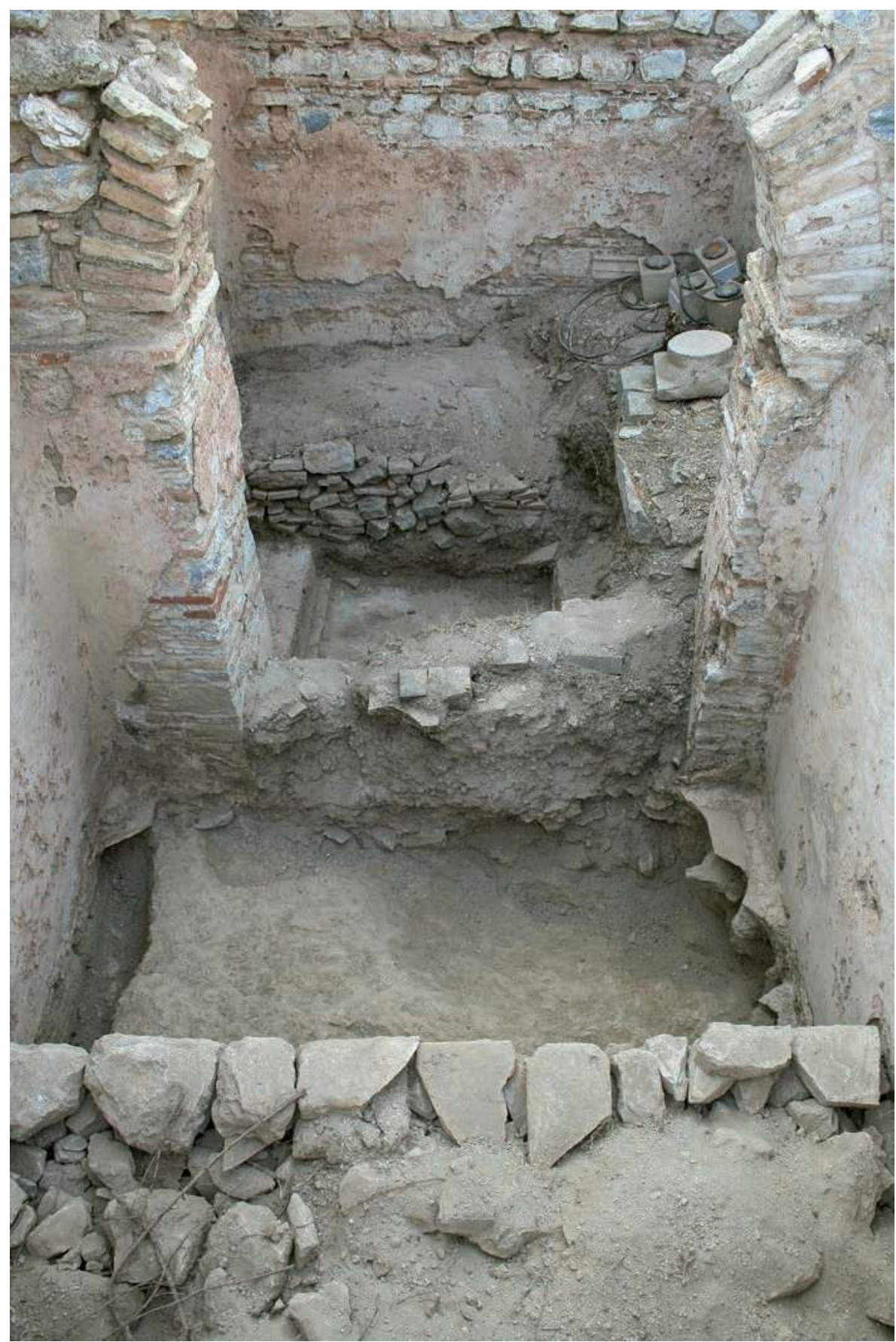

1 Raum 4. Pfeiler der Ostwand 
Tafel 119
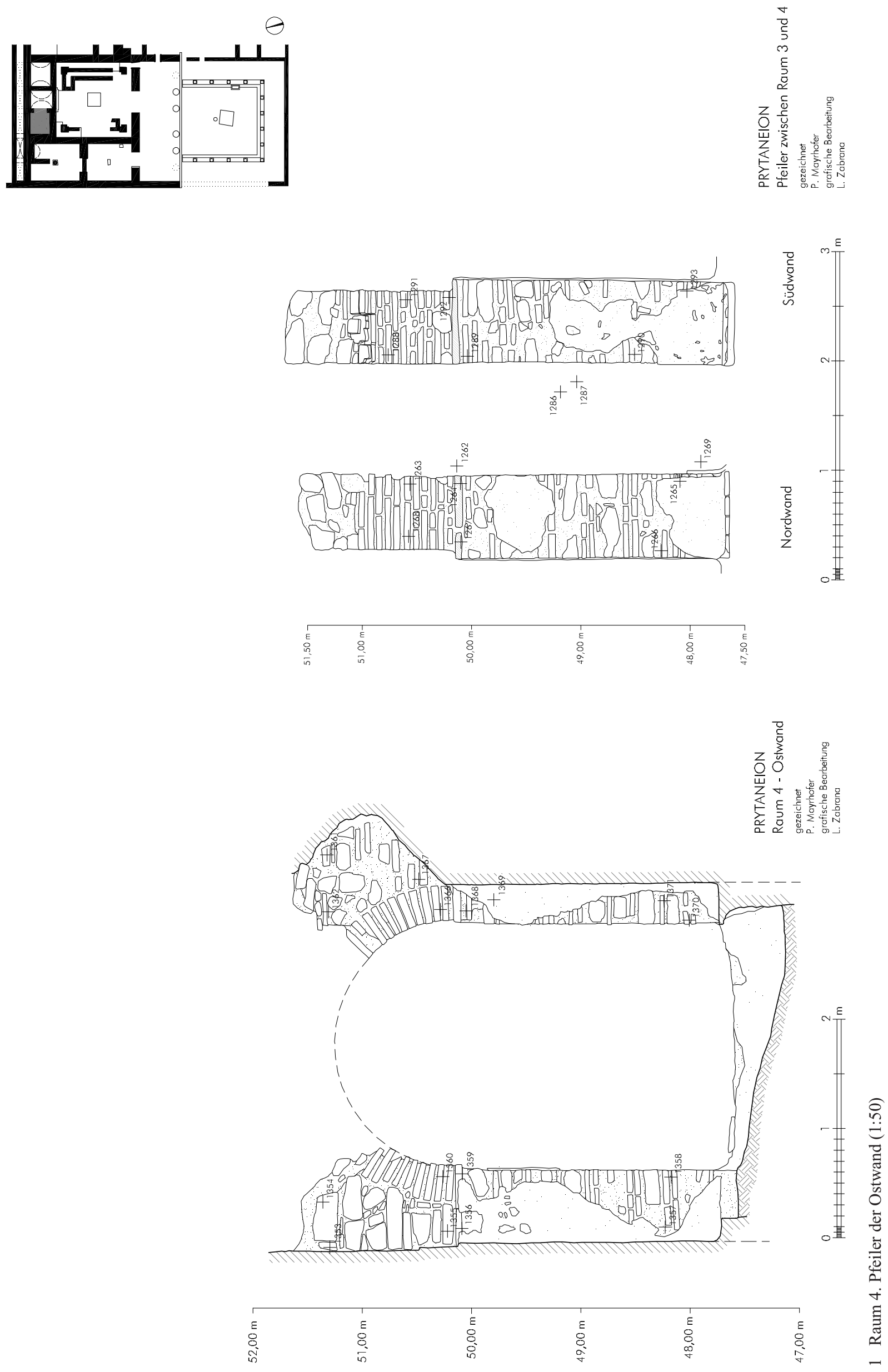
Tafel 120

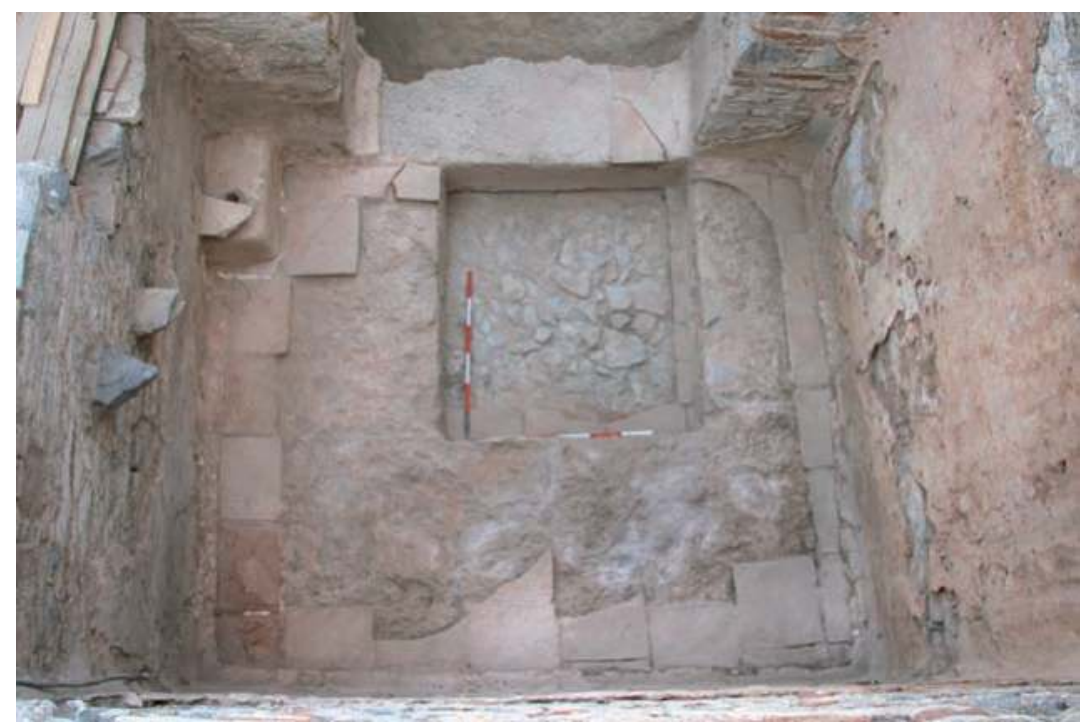

1 Raum 3 von Osten

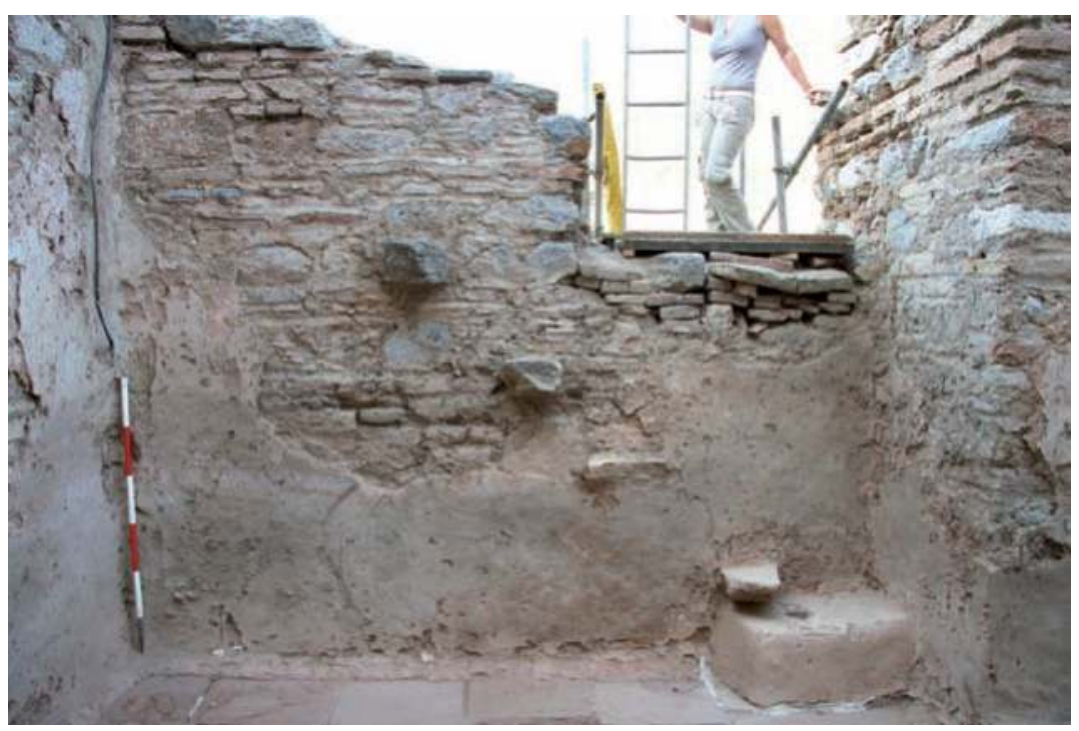

2 Raum 3. Südwand
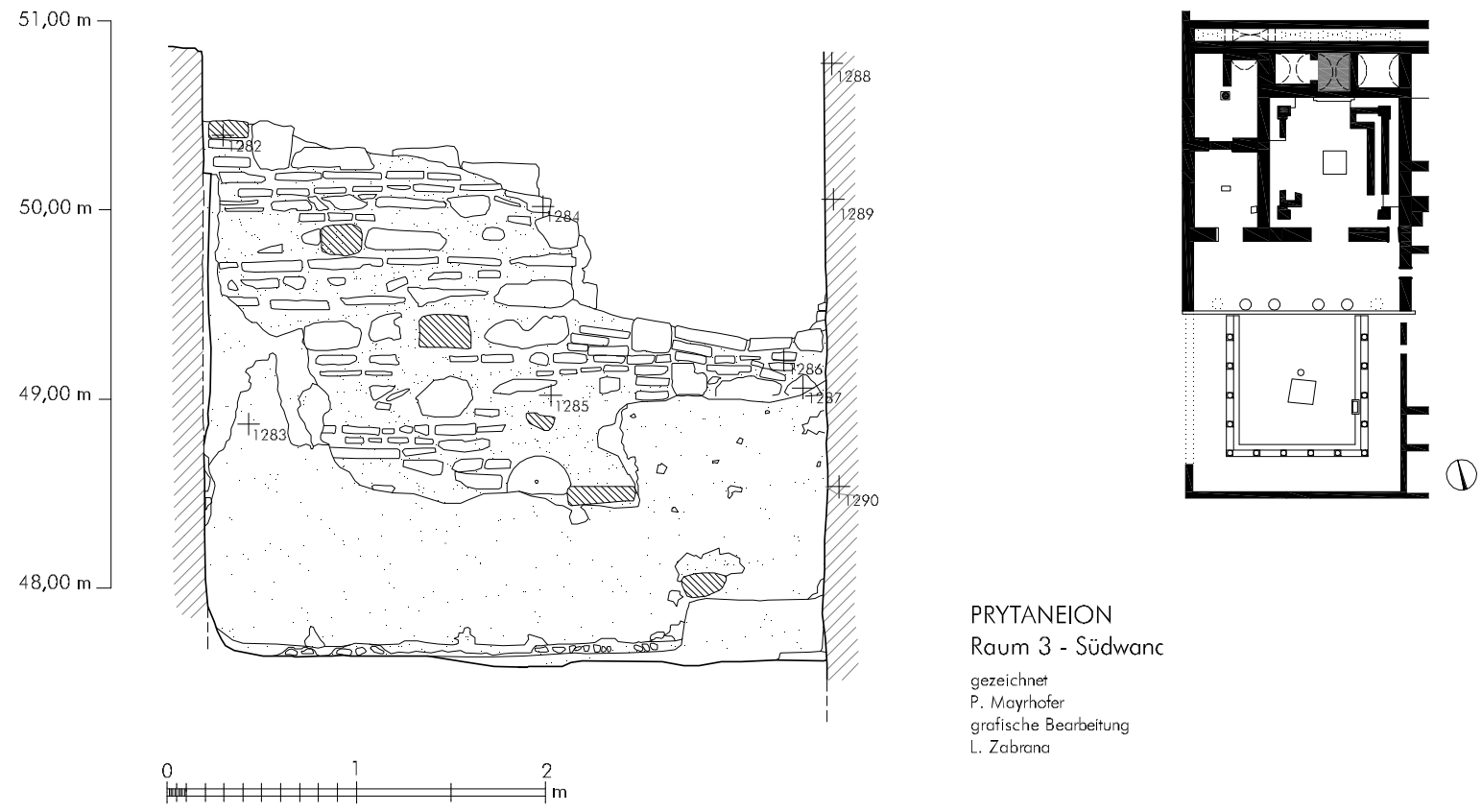

PRYTANEION

Raum 3 - Südwanc

gezeichnet

P. Mayrhofer

grafische Bearbeitung

L. Zobrano

3 Raum 3. Südwand (1:50) 
Tafel 121

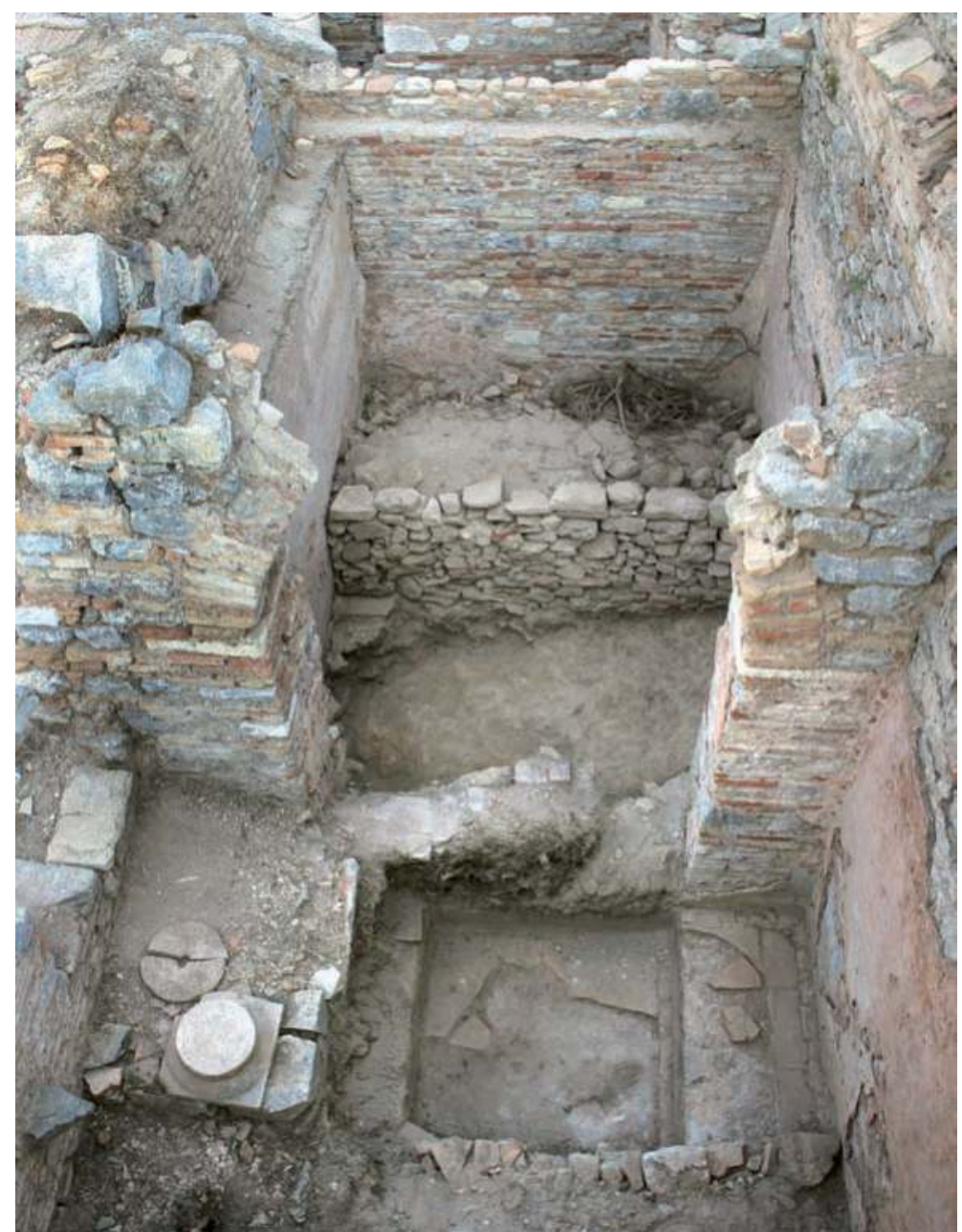

1 Raum 3. Pfeiler der Westwand
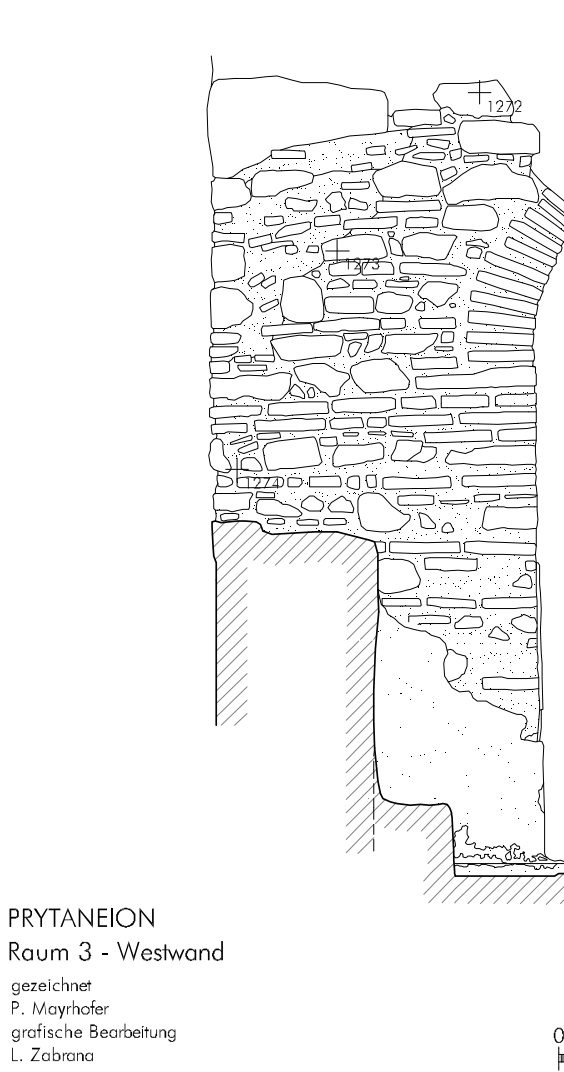

$-52,00 \mathrm{~m}$

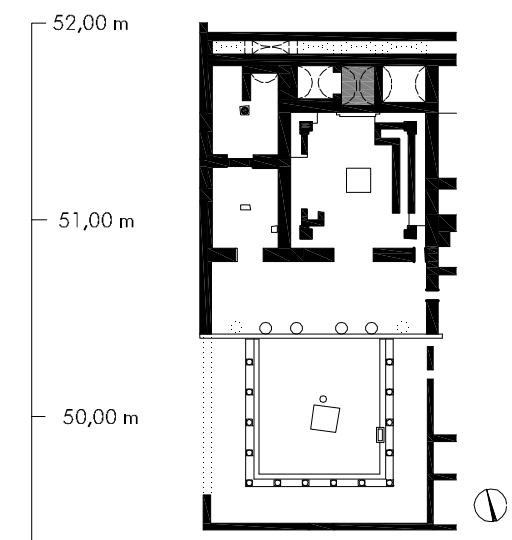

Raum 3. Pfeiler der Westwand (1:50)

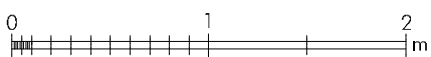

(1) 


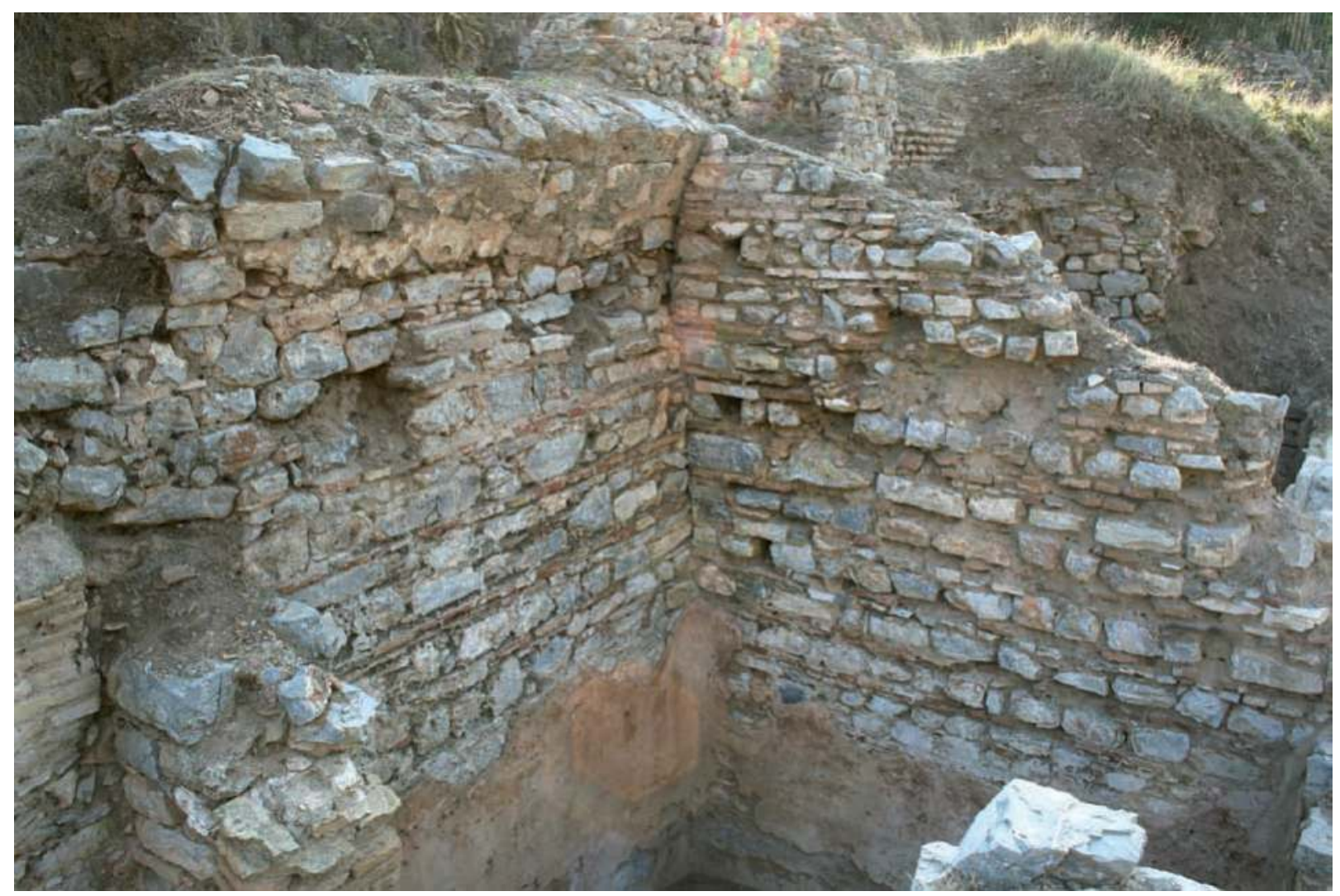

1 Raum 3. Nordwand oberer Teil

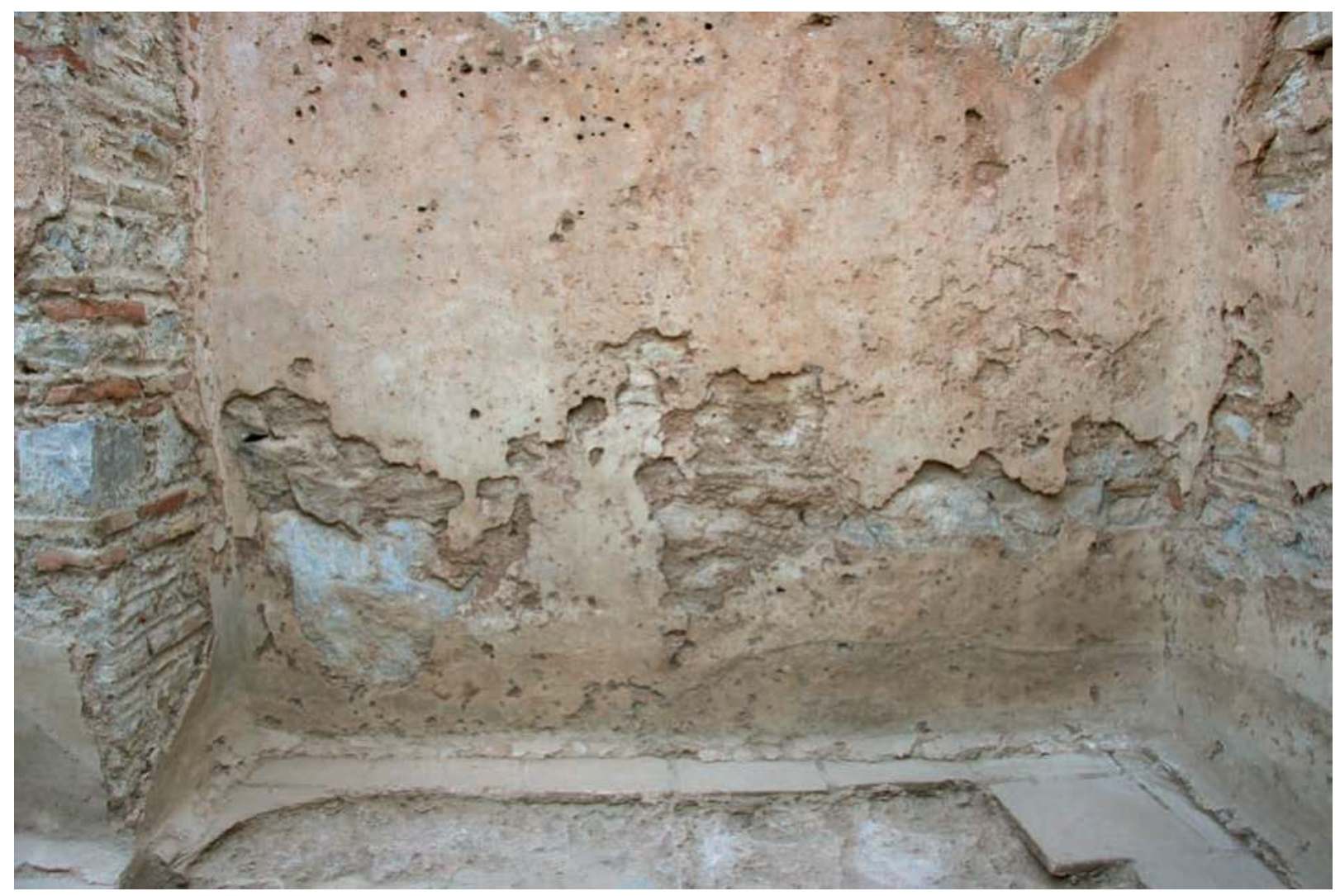

2 Raum 3. Nordwand unterer Teil 
Tafel 123
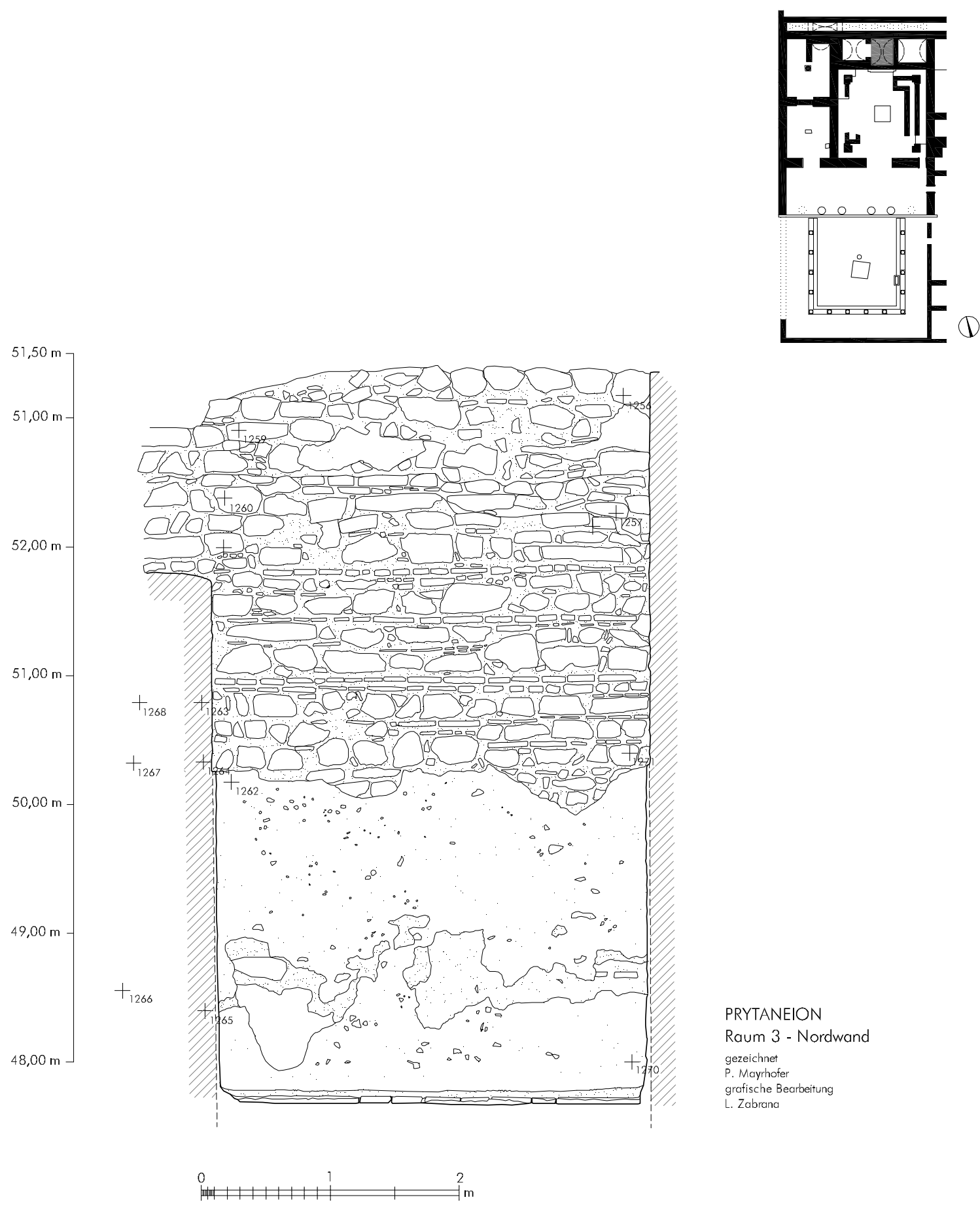

PRYTANEION

Raum 3 - Nordwand

gezeichnet

P. Mayrhofer
grafische Bearbeitung

grafische Be
L. Zabrana

1 Raum 3. Nordwand (1:50) 
Tafel 124

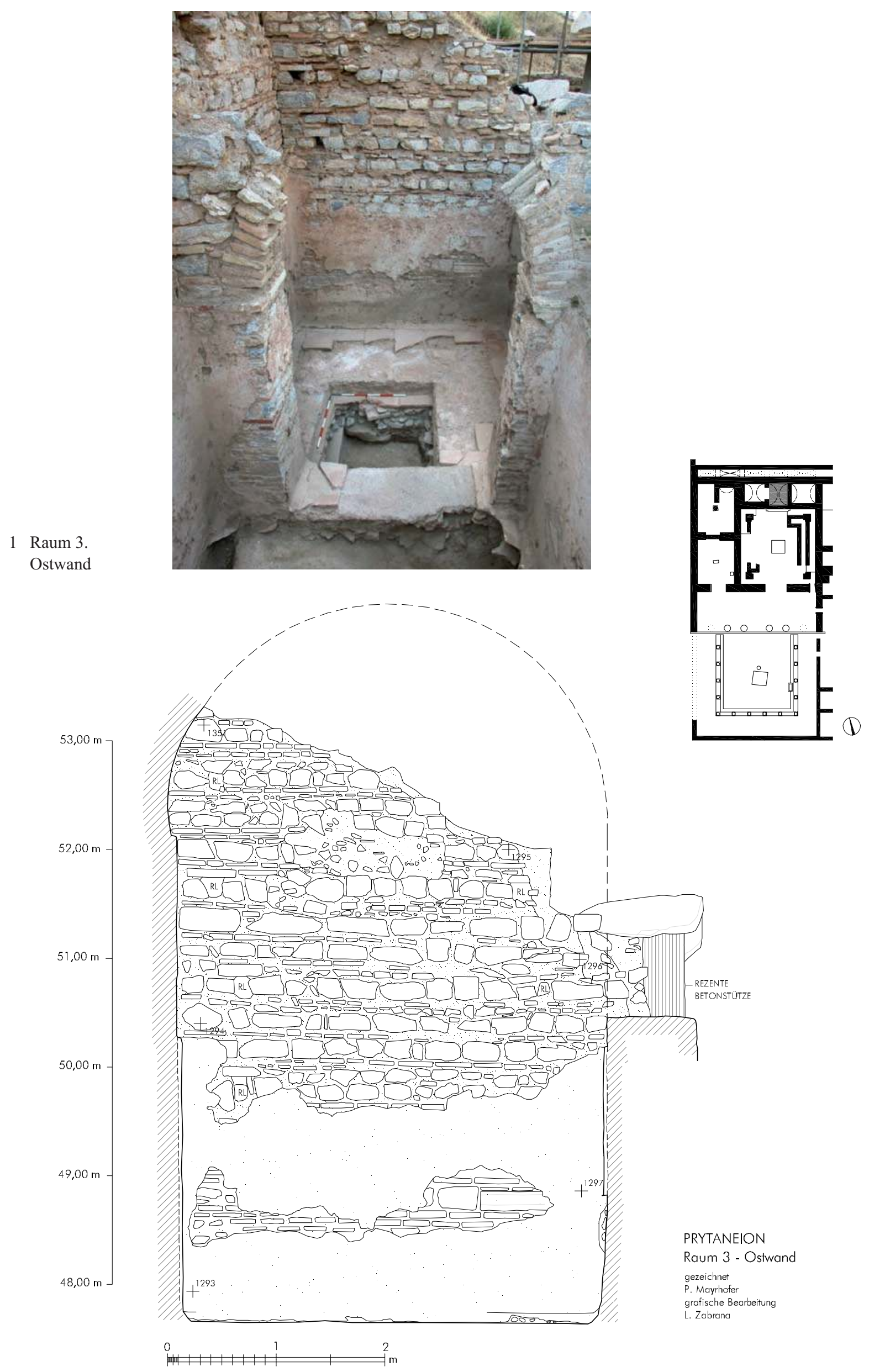

2 Raum 3. Ostwand (1:50) 
Tafel 125

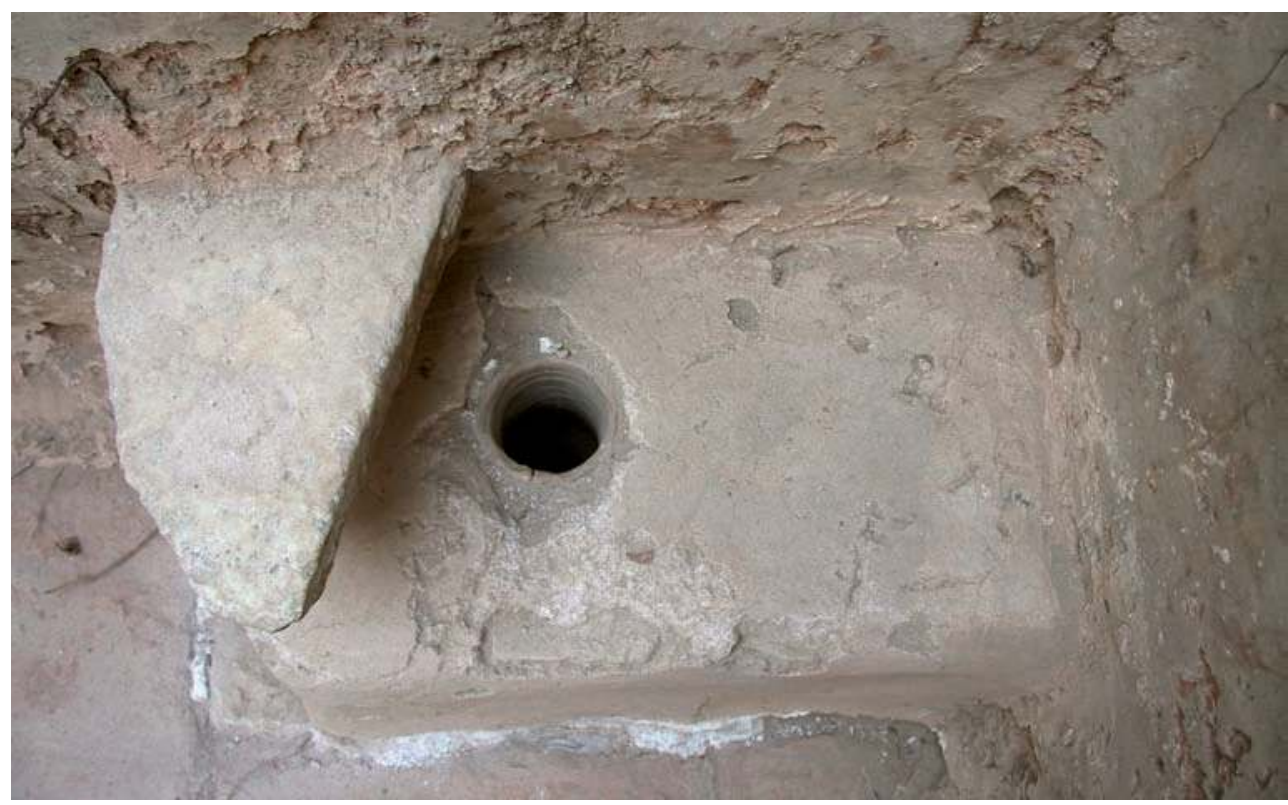

1 Raum 3. Ausfluss des Wasserreservoirs

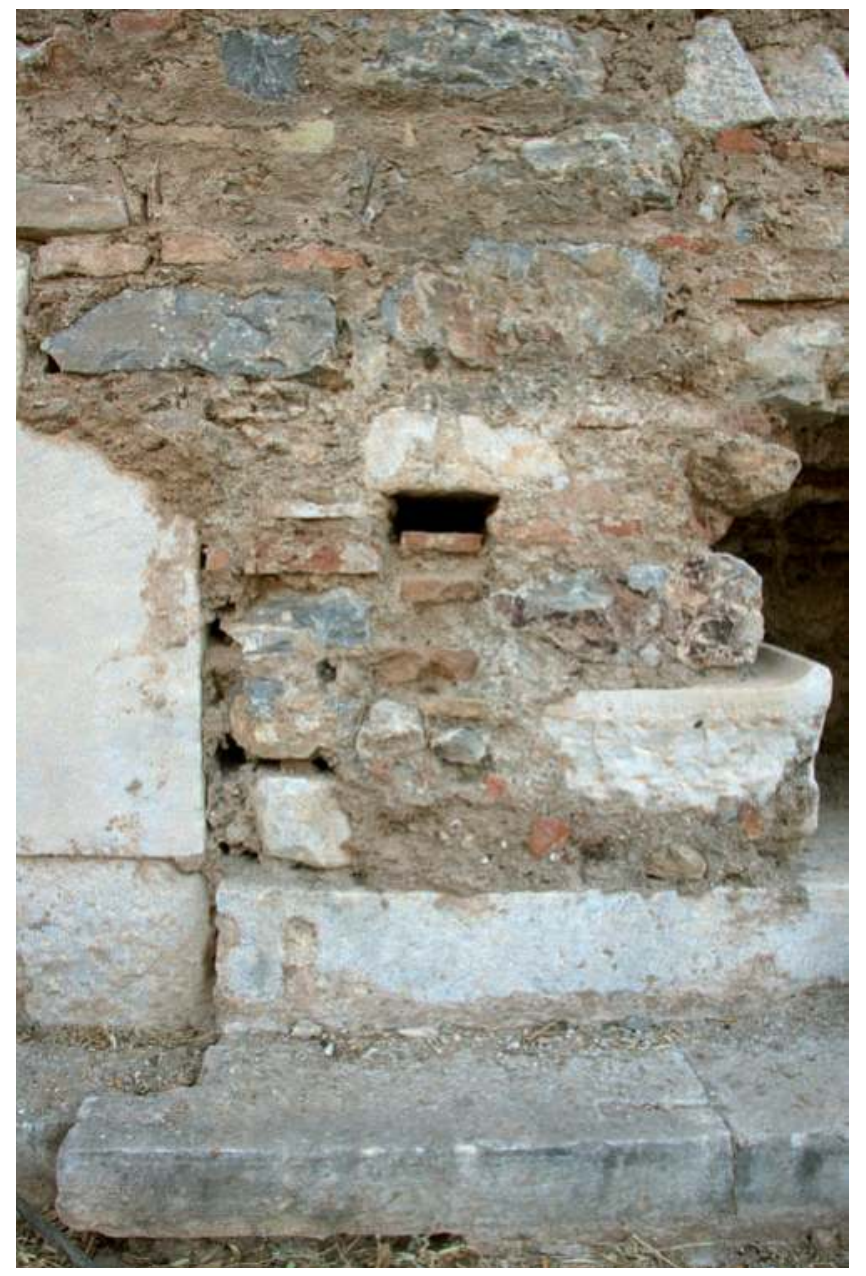

2 >Hestiasaal . Sekundäre Öffnung in Nordwand zur Wasserentnahme

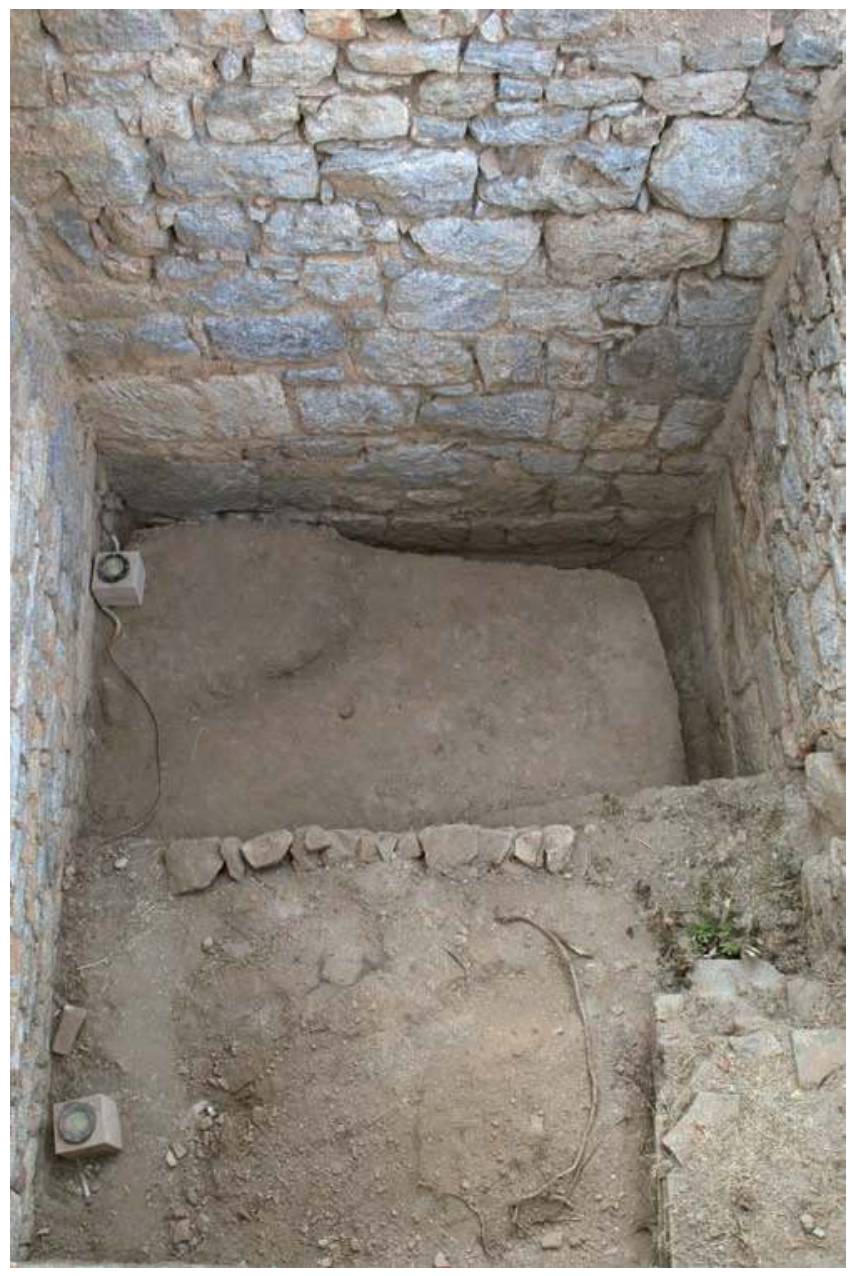

3 Raum 2 von Westen 
Tafel 126

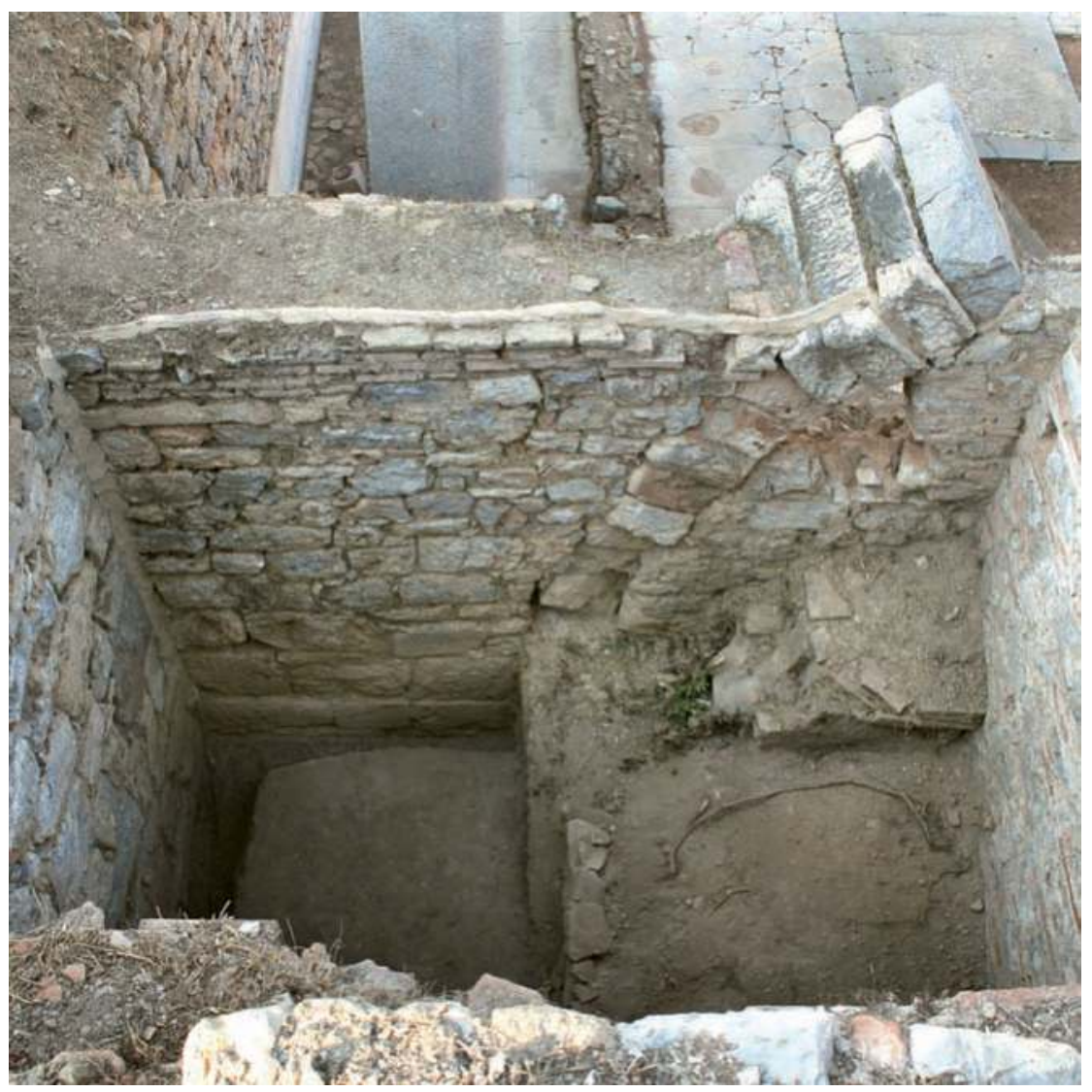

1 Raum 2.

Südwand
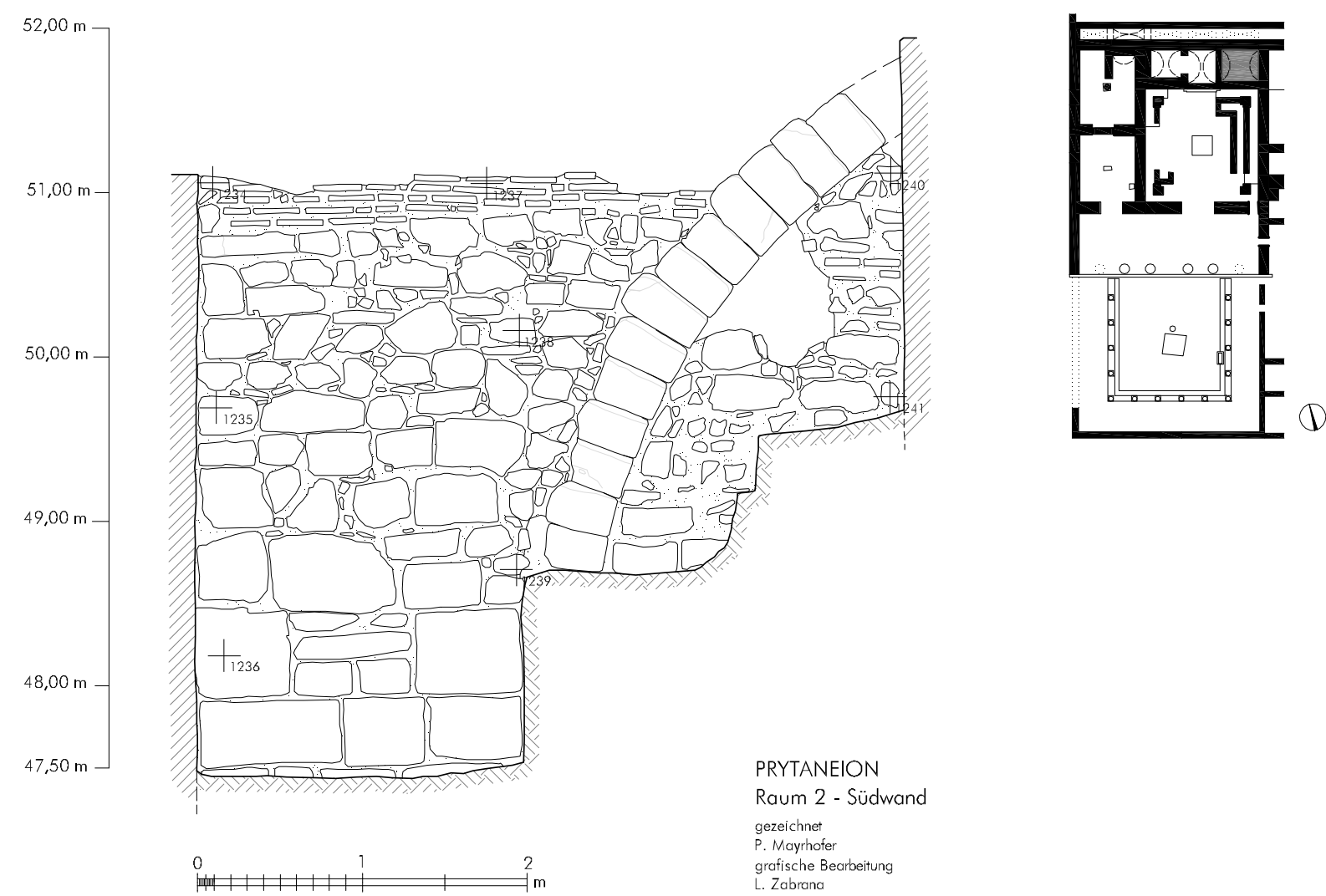

2 Raum 2. Südwand (1:50) 

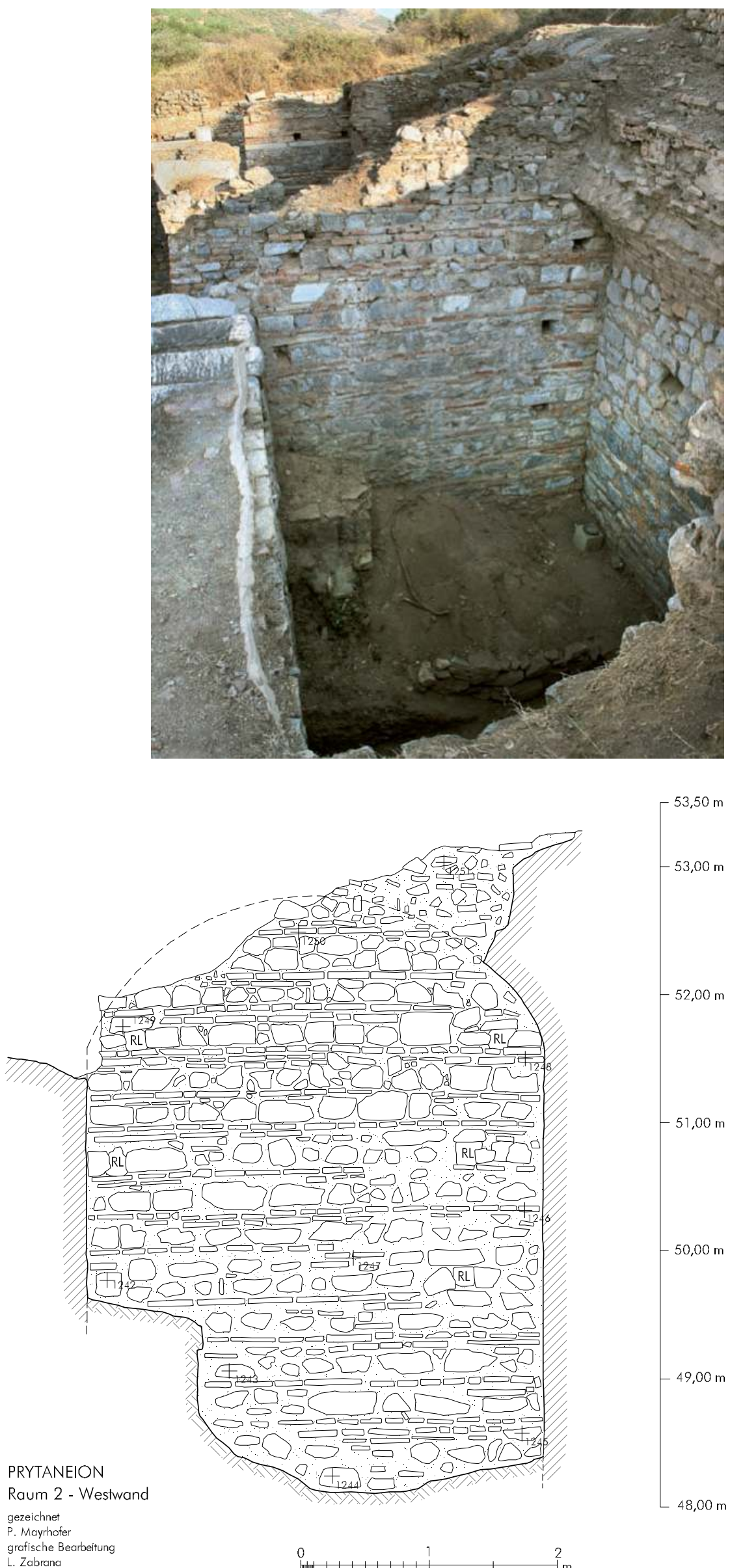

grafische Babrana $\stackrel{0}{m}+1+1+1+1$

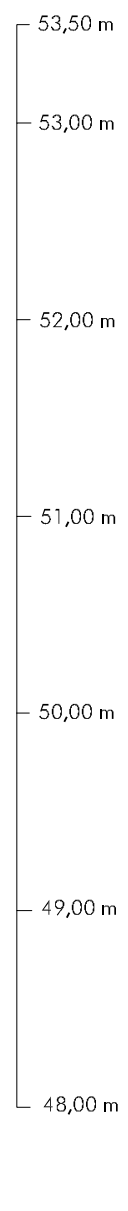

1 Raum 2.

Westwand

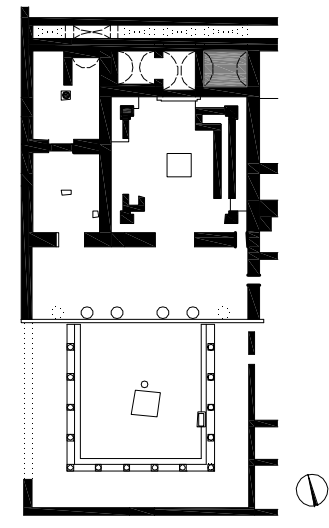

2 Raum 2. Westwand (1:50) 


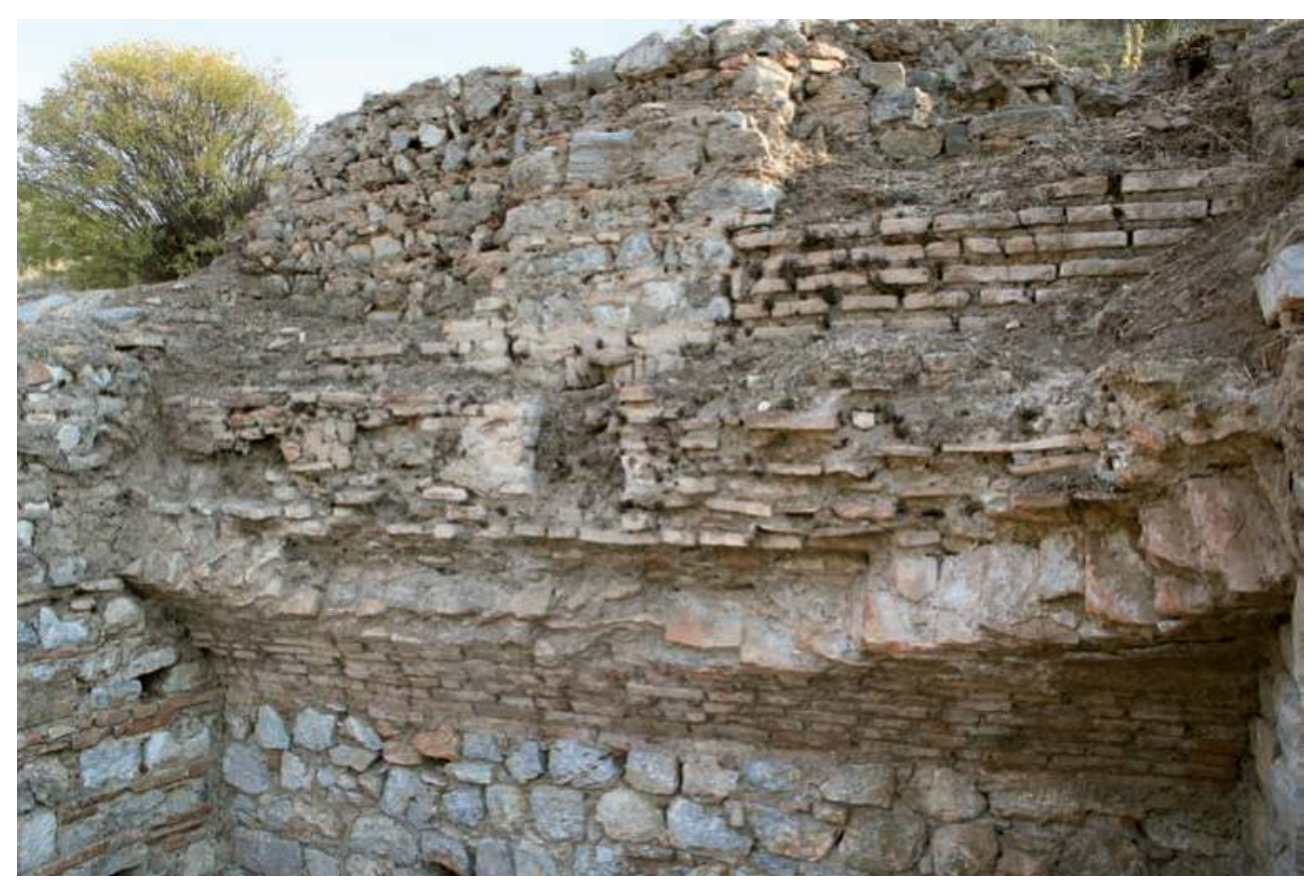

1 Raum 2. Nordwand oberer

Teil
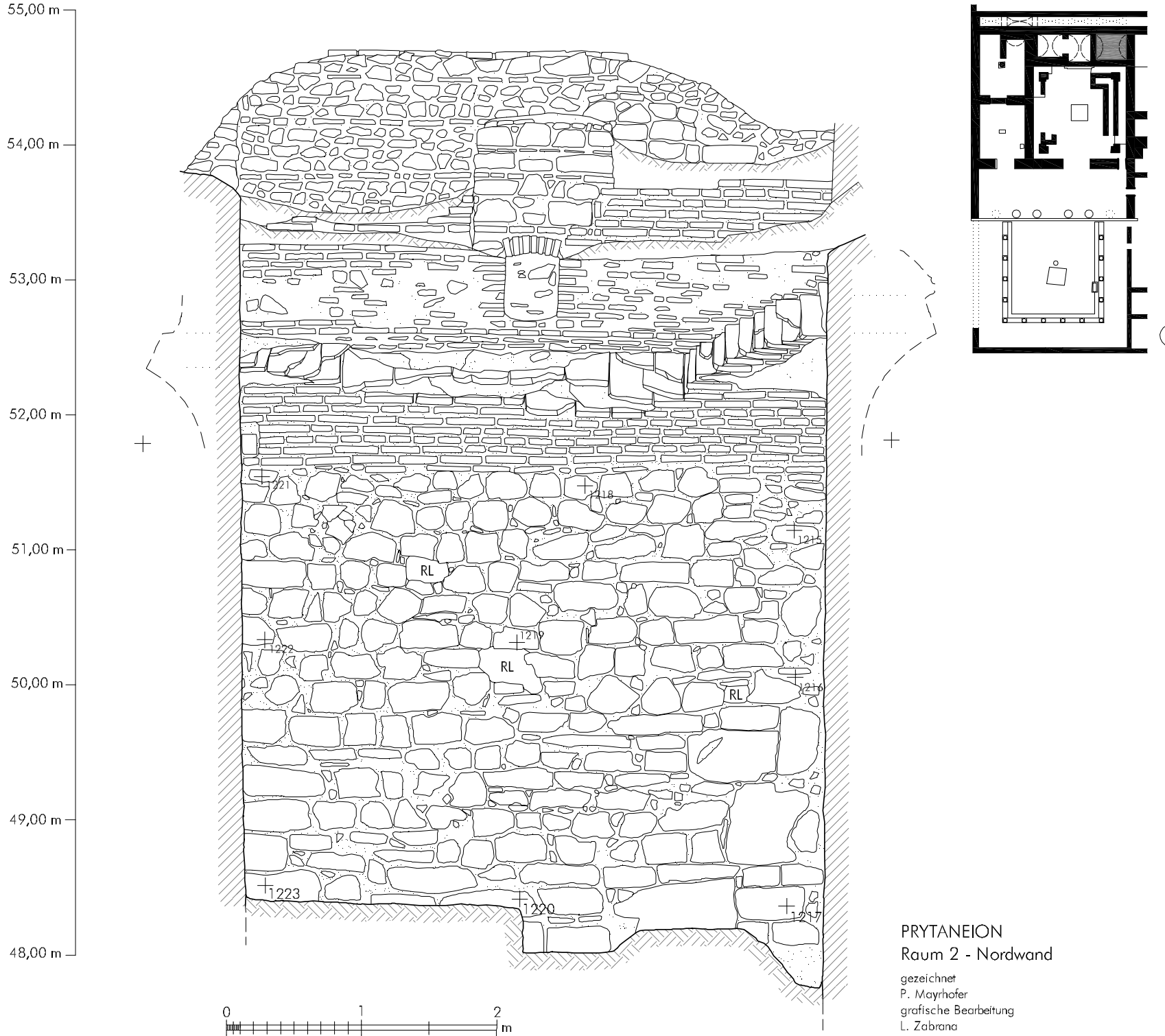

PRYTANEION

Raum 2 - Nordwand

gezeichnet

P. Mayrhofe

grafische Bearbeitung

Zabrana

2 Raum 2. Nordwand (1:50) 


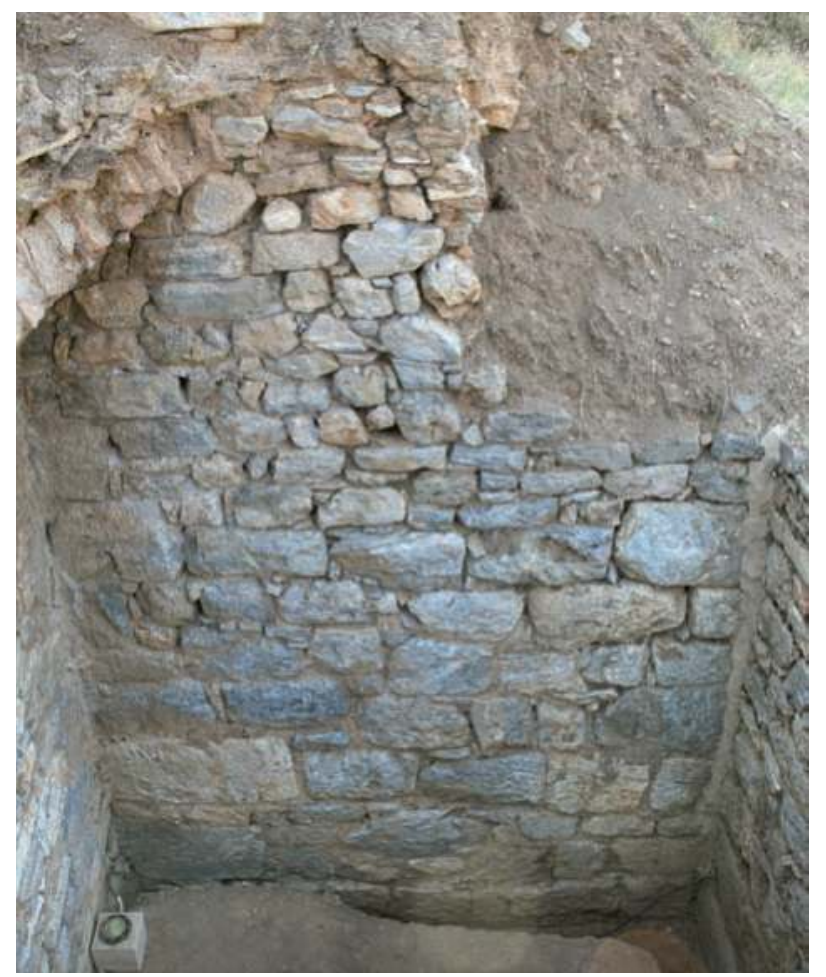

1 Raum 2. Ostwand
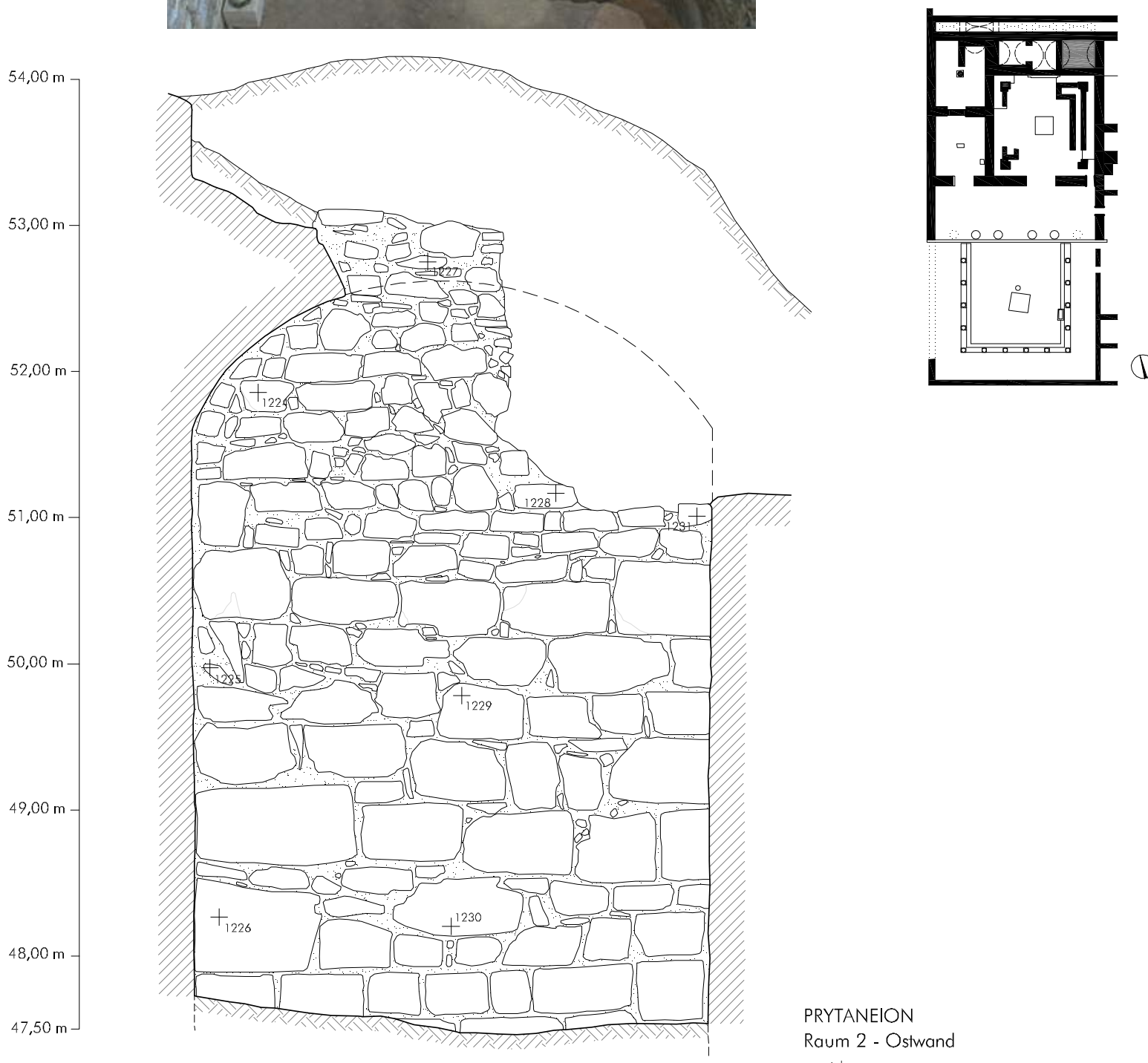

PRYTANEION

Raum 2 - Ostwand gezeichnet

P. Mayrhofer

grafische Bearbeitung

0 2 
Tafel 130

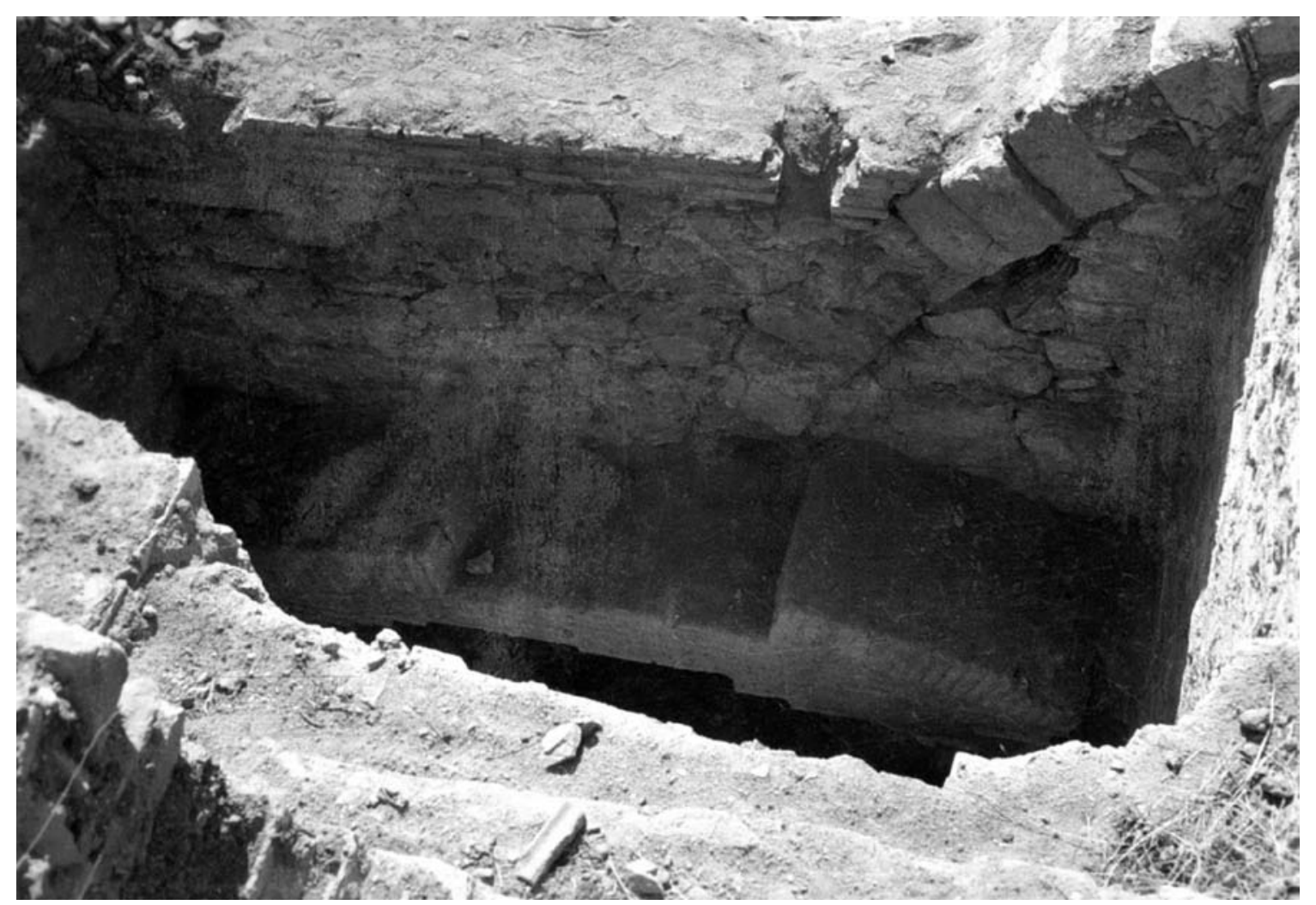

1 Raum 2. Ziegelbogen in Sturzlage

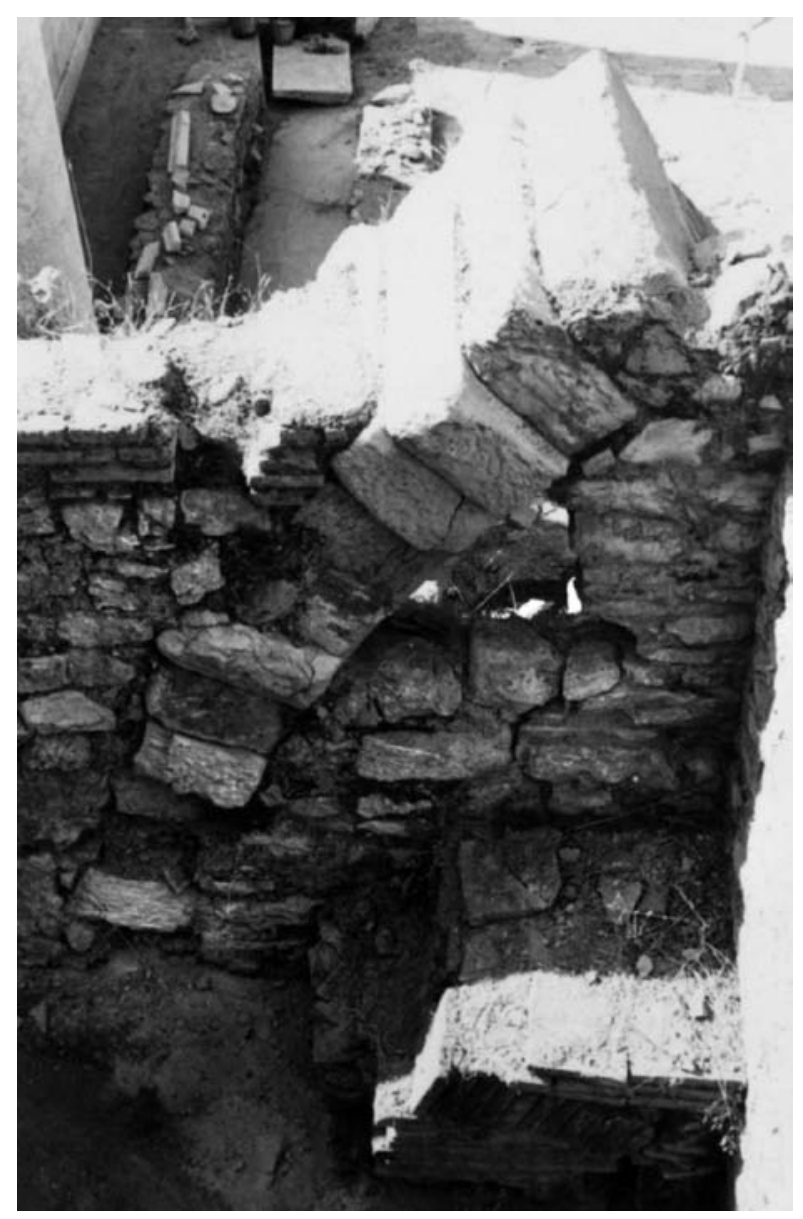

2 Raum 2. Ende der 1960er Jahre bereits weitgehend zerstörter Ziegelbogen 
Tafel 131

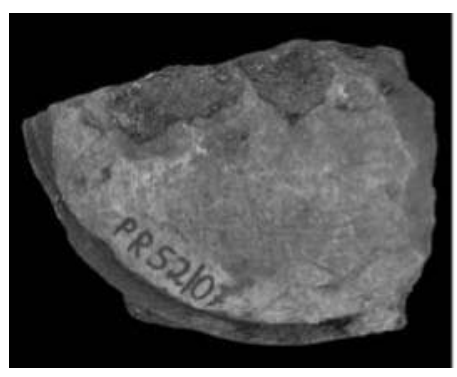

1 Attische Basis A 32

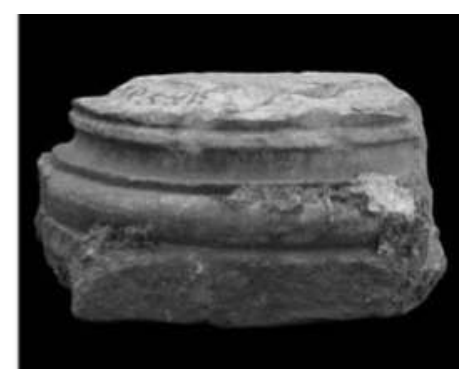

$$
\text { ○ }
$$

2 Attische Basis A 32 (1:25)
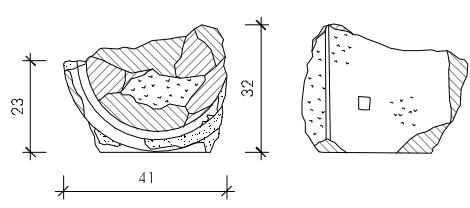

+

PRYTANEION

PR 52/07

ATTISCHE BASIS

gezeichner

grofische Bearbeitung

grotische Be

${ }_{100}^{100} \mathrm{~cm}$
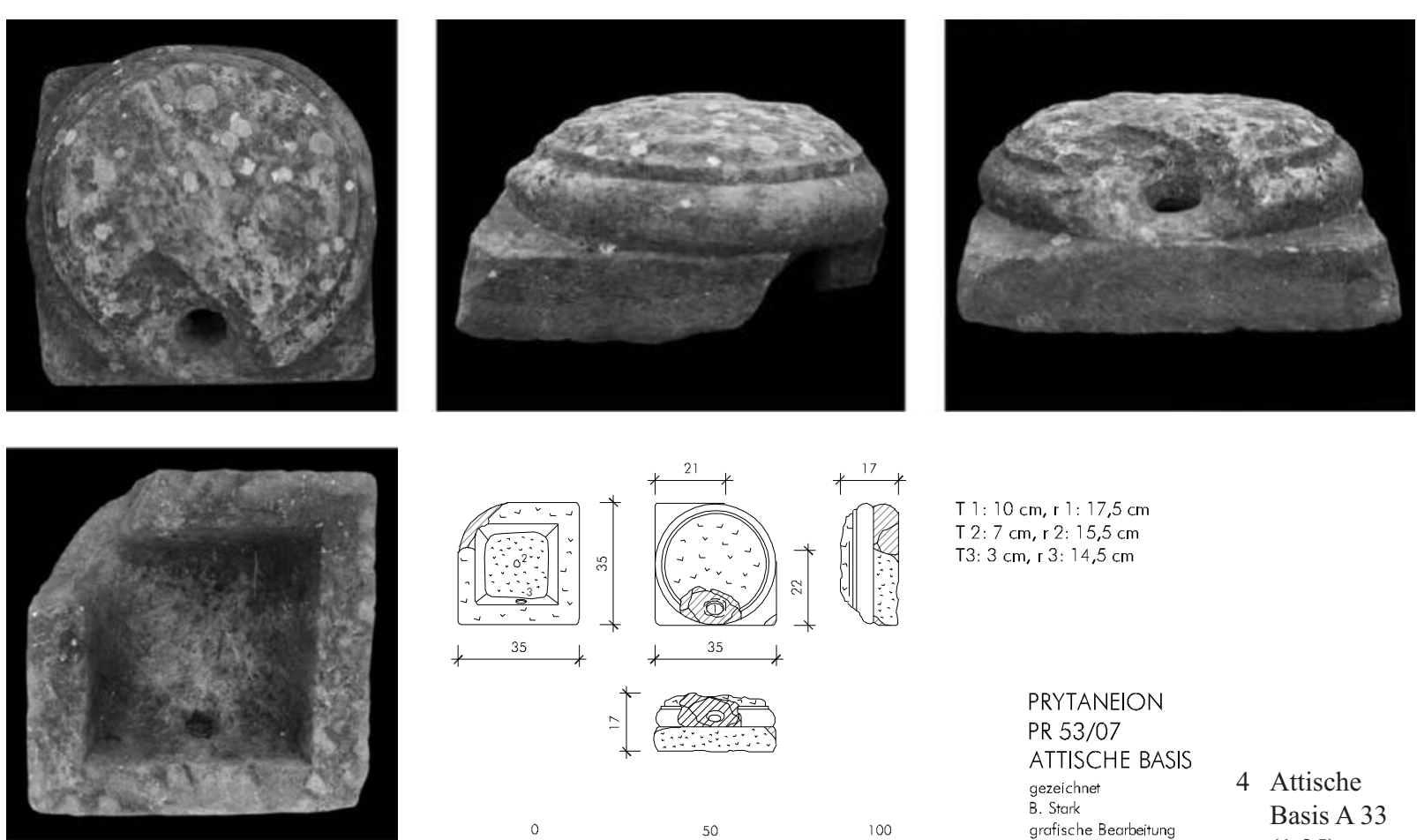

T 1: $10 \mathrm{~cm}, \mathrm{r} 1: 17,5 \mathrm{~cm}$

T 2: $7 \mathrm{~cm}, \mathrm{r} 2: 15,5 \mathrm{~cm}$

T3: $3 \mathrm{~cm}, \mathrm{r} 3: 14,5 \mathrm{~cm}$

PRYTANEION

PR 53/07

ATTISCHE BASIS

gezeichnet

B. Stark
grafische

4 Attische

grafische Bearbeitung

Basis A 33

3 Attische Basis A 33
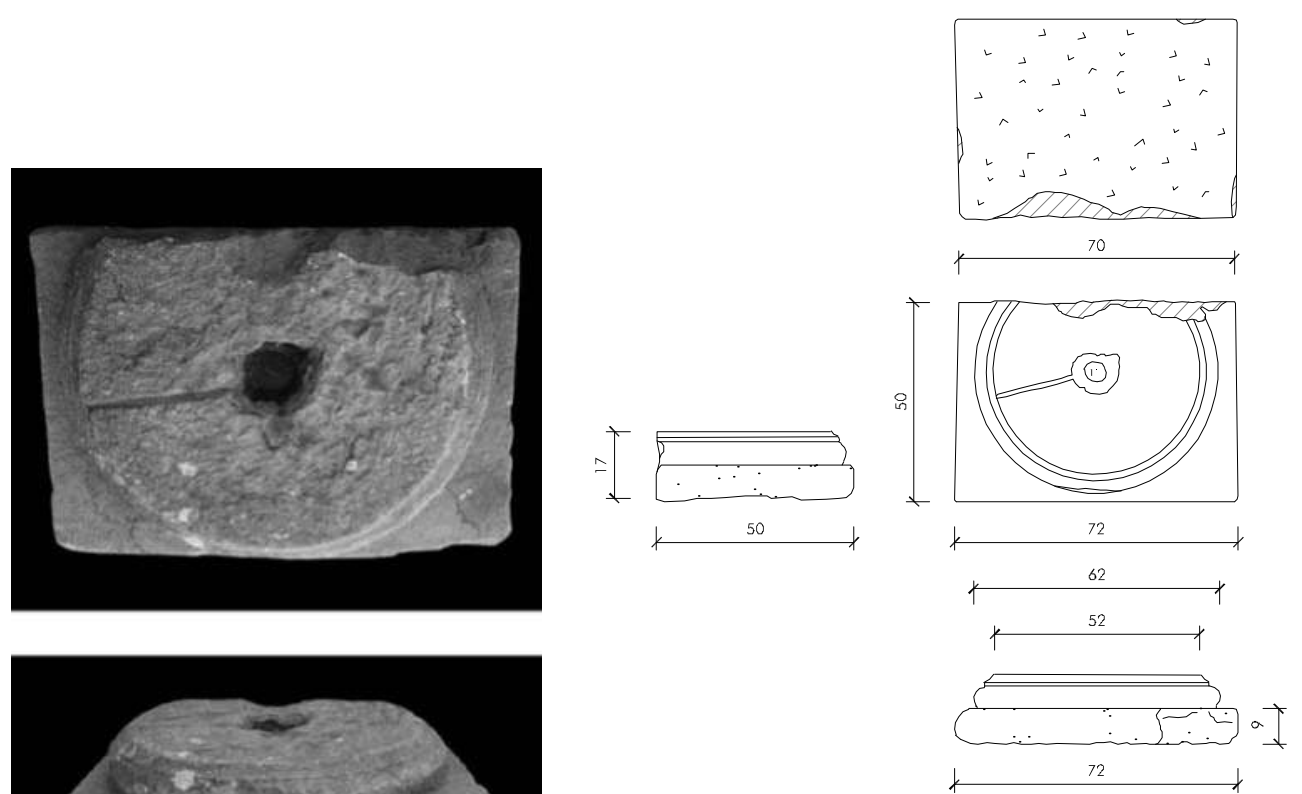

$r 1: 26$

12. 28

$r$ 3: 31
1: $T 6$

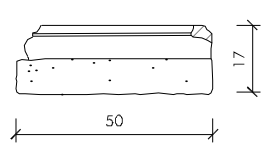

PRYTANEION

PR 31/07

ATTISCHE BASIS

gezeichnet

B. Stork
grafische Bearbeitung

grafische Beara 
Tafel 132
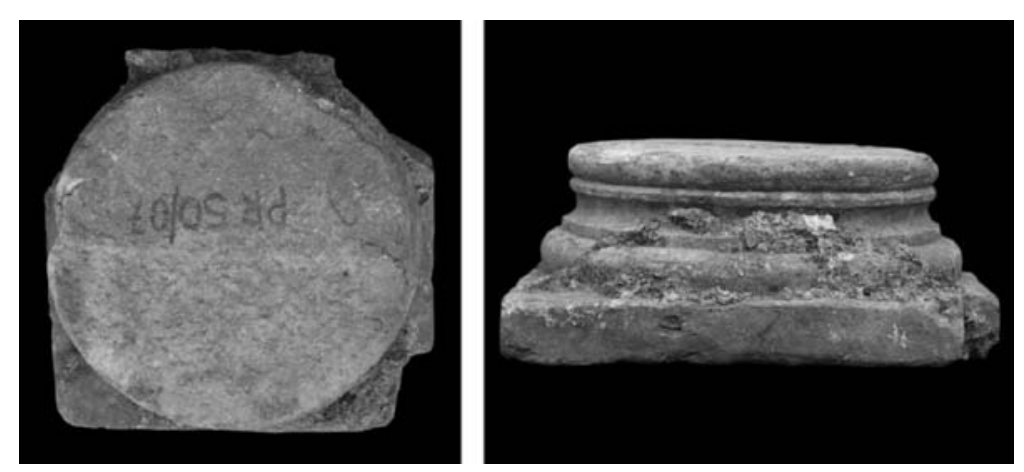

1 Attische Basis A 35
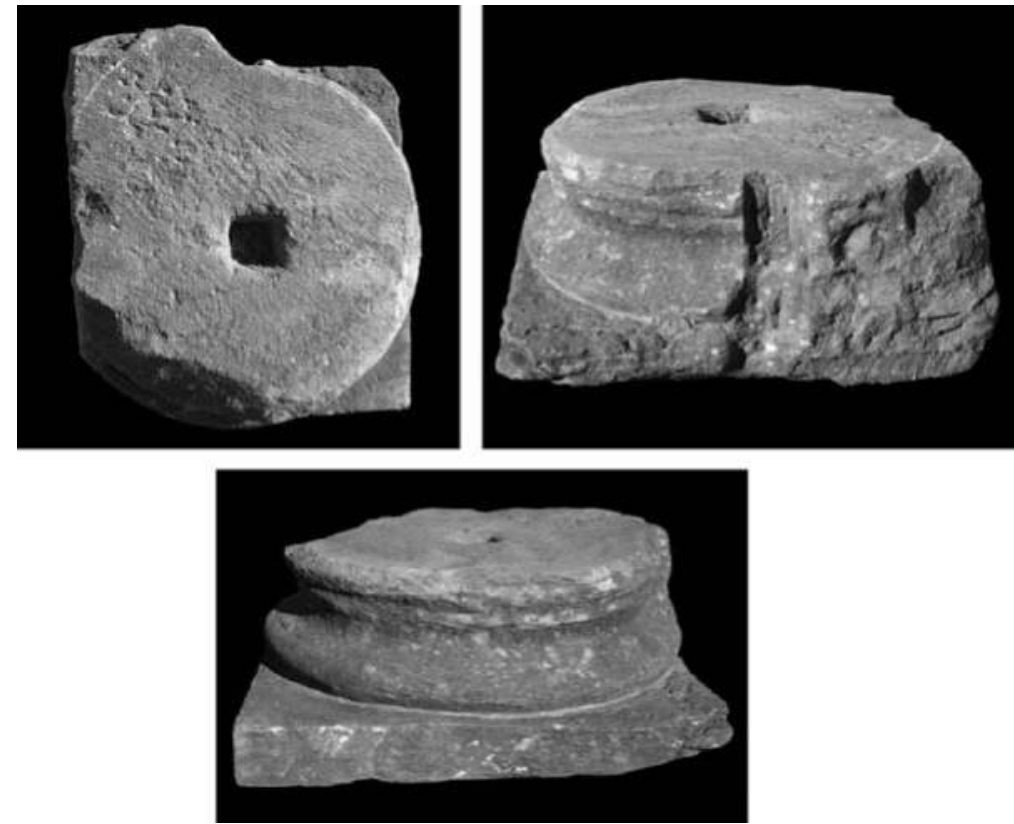

3 Attische Basis einer Dreiviertelsäule A 36
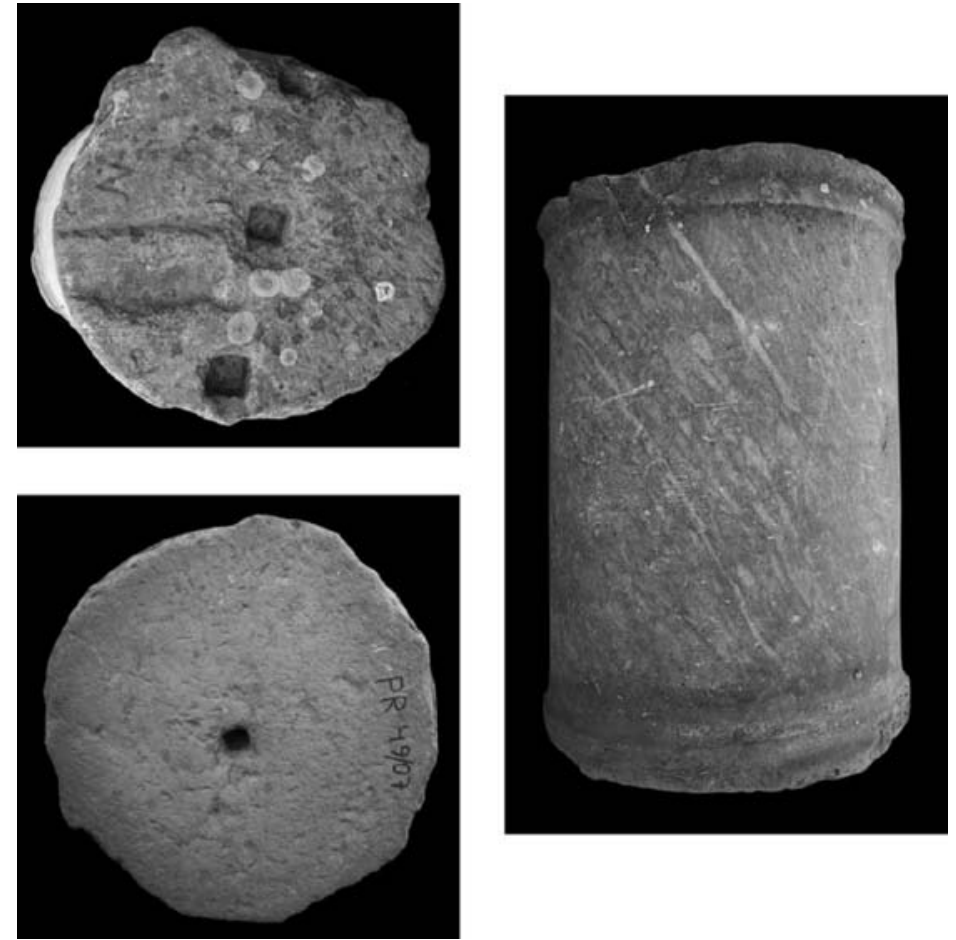

5 Rundbasis A 37

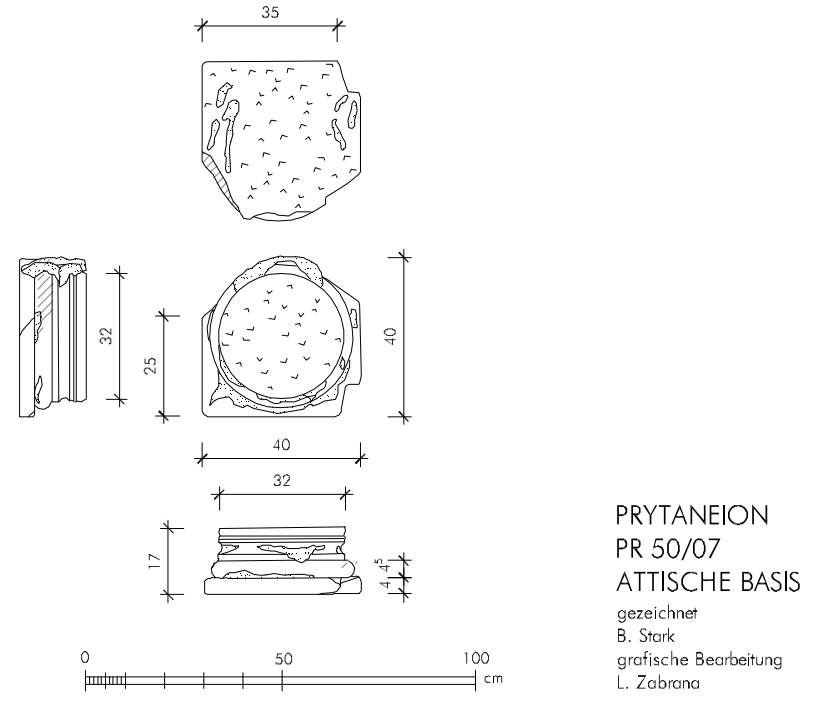

2 Attische Basis A 35 (1:25)
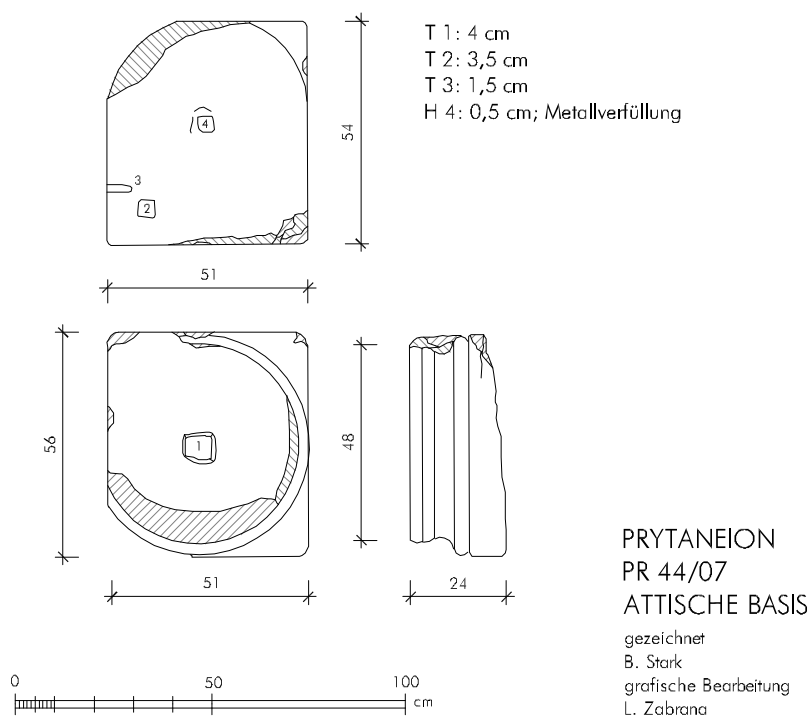

4 Attische Basis einer Dreiviertelsäule A 36 (1:25)
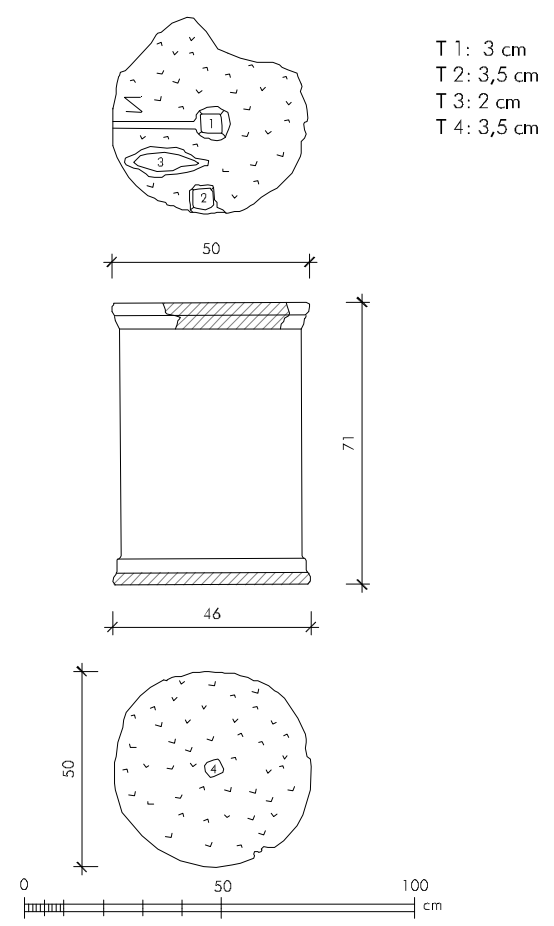

PRYTANEION PR 49/07 RUNDBASIS $\underset{\substack{\text { gezeichnet } \\ B \text { S Stark }}}{ }$ B. Stark grafische Bearbeitung L. Zabrand

6 Rundbasis A 37 (1:25) 
Tafel 133
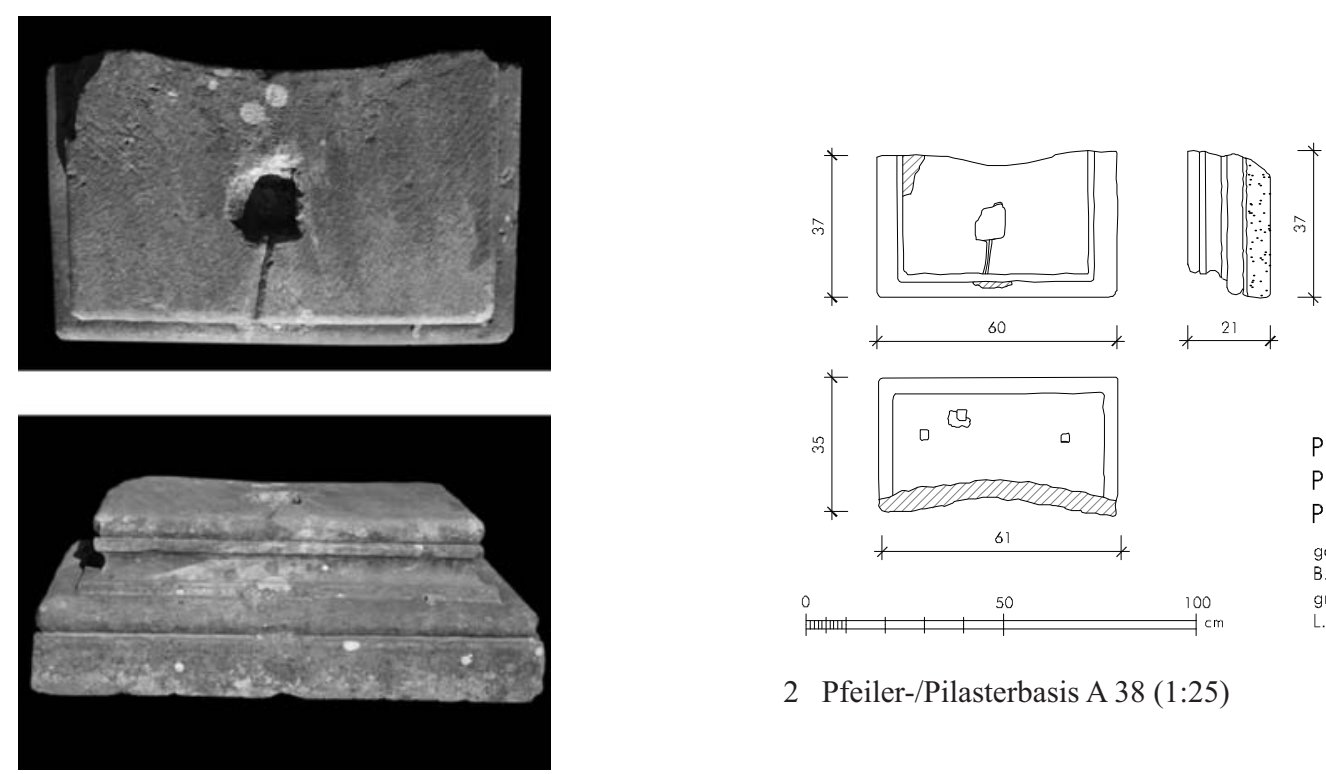

PRYTANEION

PR 30/07

PFEILER-/PILASTERBASIS

gezeichnet
B. Stark

grafische Bearbeitung

2 Pfeiler-/Pilasterbasis A 38 (1:25)

1 Pfeiler-/Pilasterbasis A 38

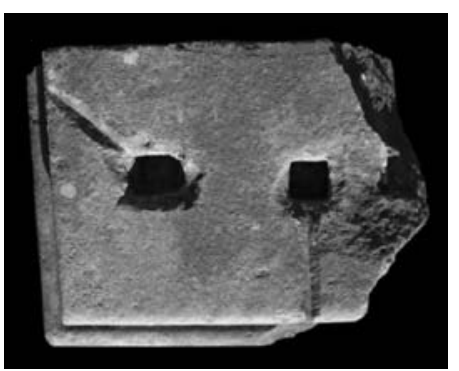

3 Pfeiler-/Pilasterbasis A 39

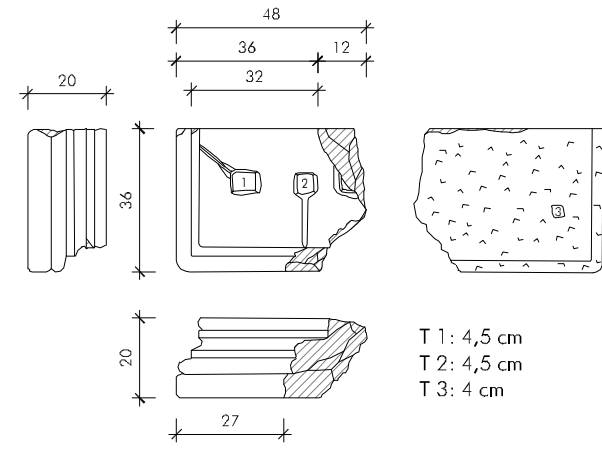

0

4 Pfeiler-/Pilasterbasis A 39 (1:25)

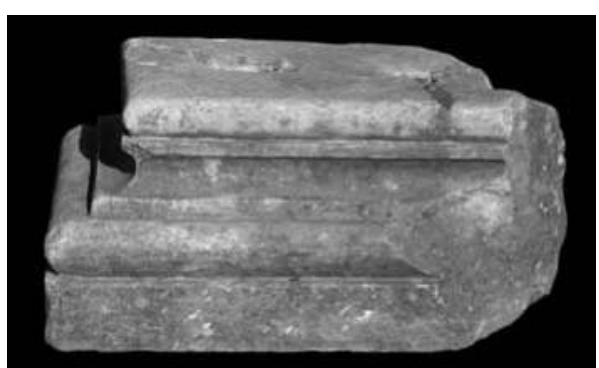

PRYTANEION

PR 43/07

PFEILER-/PILASTERBASIS gezeichnet
B. Stark

grafische Bearbeitung

L. Zabrano

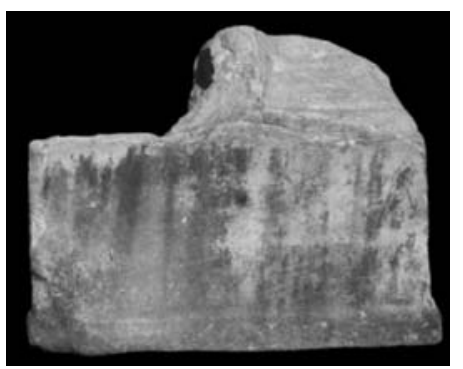

5 Pfeiler A 40
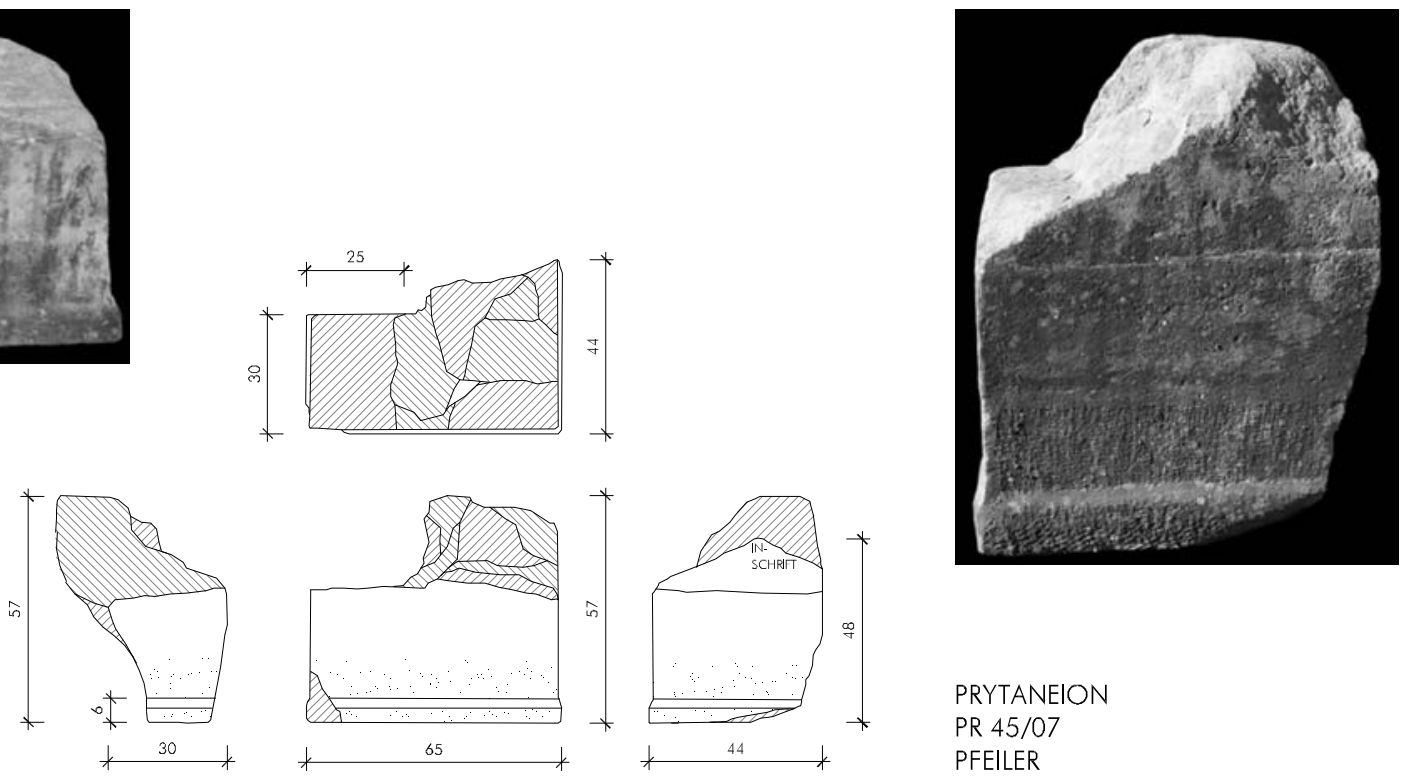

PRYTANEION

PR 45/07

PFEILER

gezeichnet

B. Stark

grafische Bearbeitung 
Tafel 134
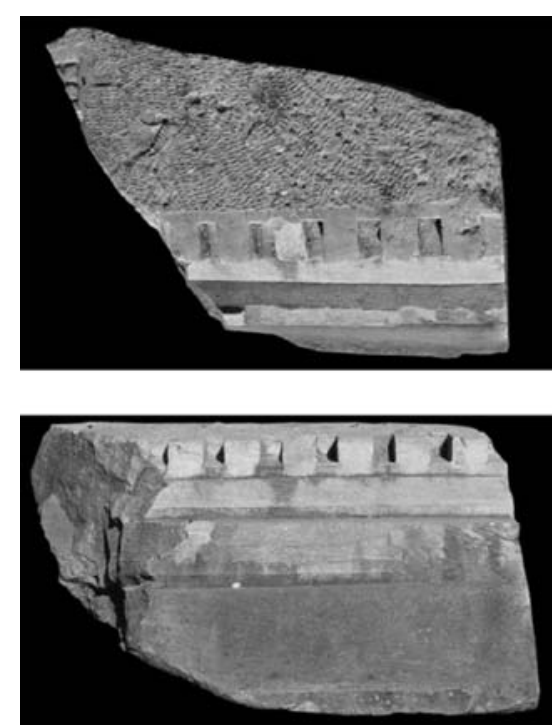

1 Zahnschnittgeison mit Sima A 41
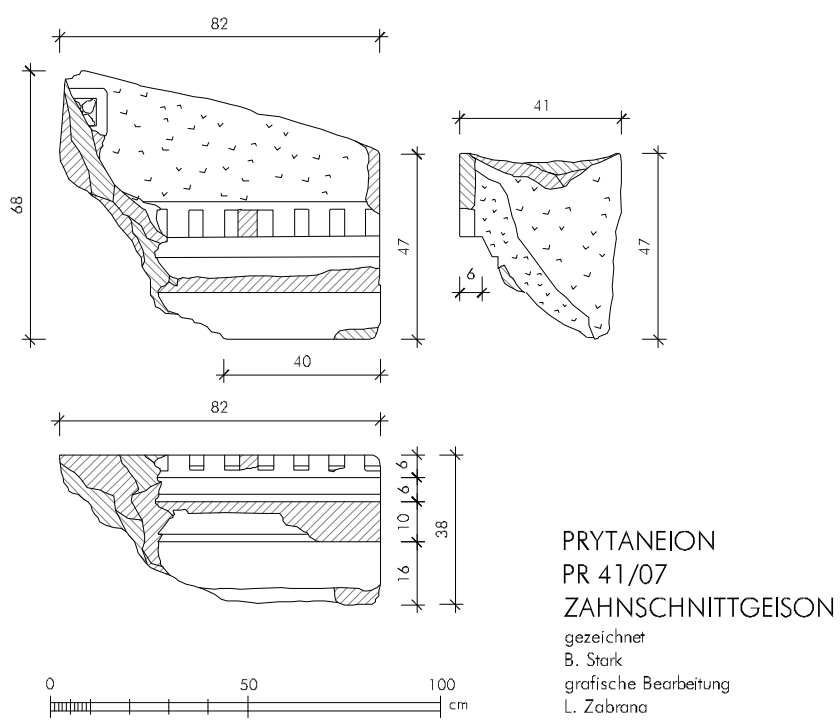

2 Zahnschnittgeison mit Sima A 41 (1:25)

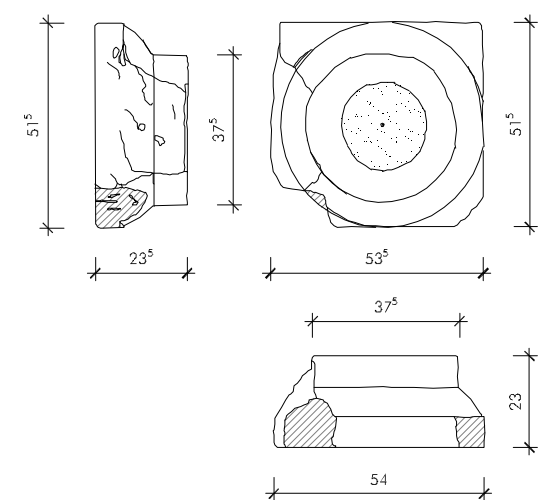

0

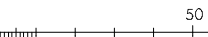

50

4 Dorisches Kapitell A 42 (1:25)

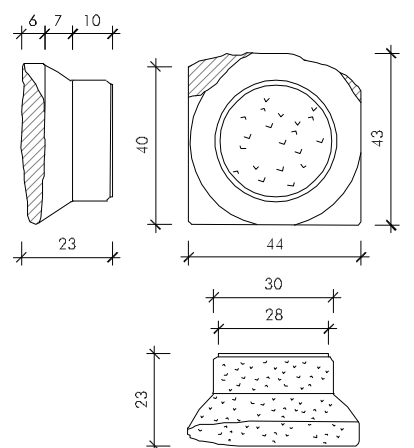

$$
\text { ind }
$$

NEION

PR 51/07

TUSKANISCHES KAPITELL gezeichnet Stark

grafische Bearbeitung
TANEION gezeichne N. High grafische Bearbeitung 100

5 Tuskanisches Kapitell A 43

6 Tuskanisches Kapitell A 43 (1:25) 
Tafel 135
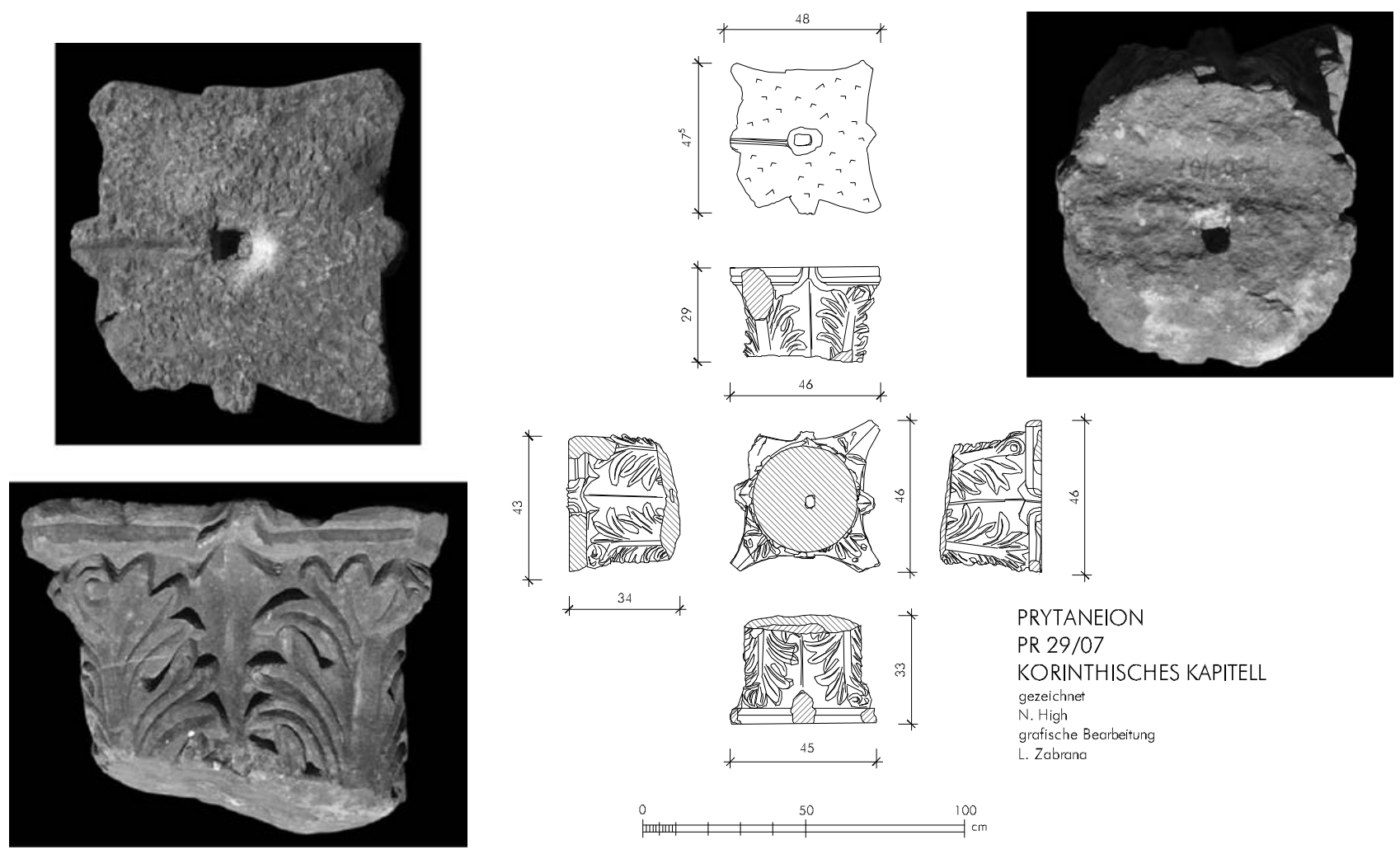

PRYTANEION

PR 29/07

KORINTHISCHES KAPITELL

gezeichnet
N. High

grafische Bearbeitung

인

1 Korinthisches Kapitell A 44

2 Korinthisches Kapitell A 44 (1:25)
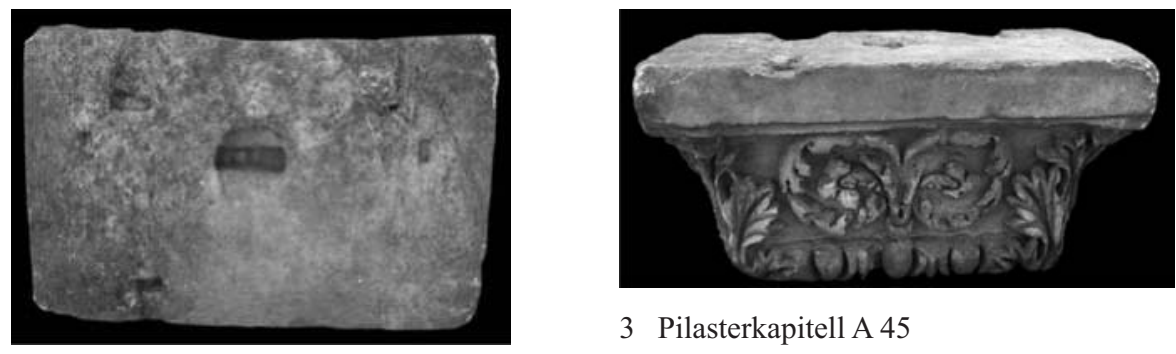

3 Pilasterkapitell A 45

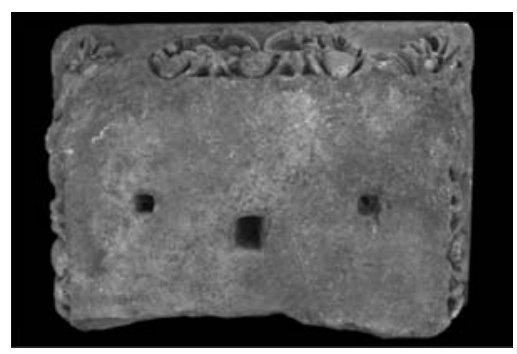

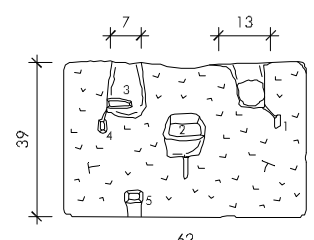
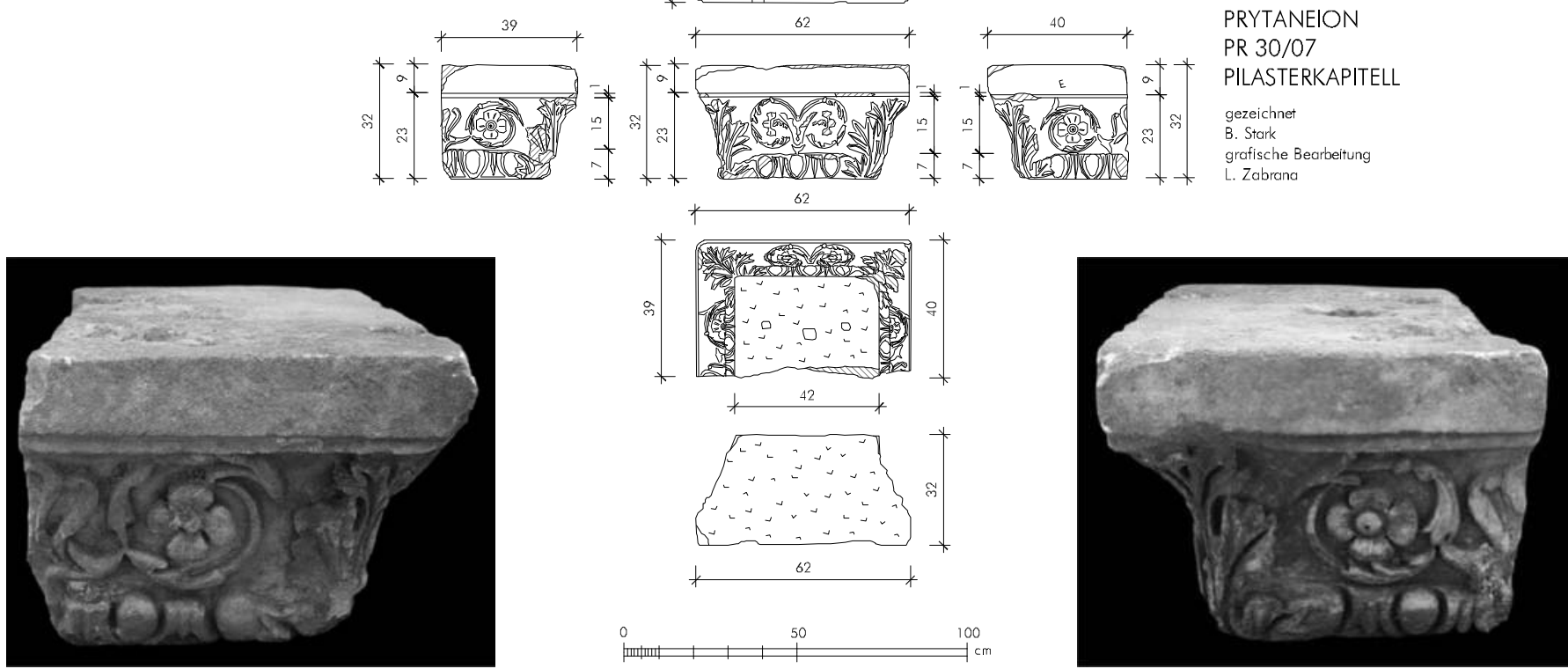

4 Pilasterkapitell A 45 (1:25) 
Tafel 136
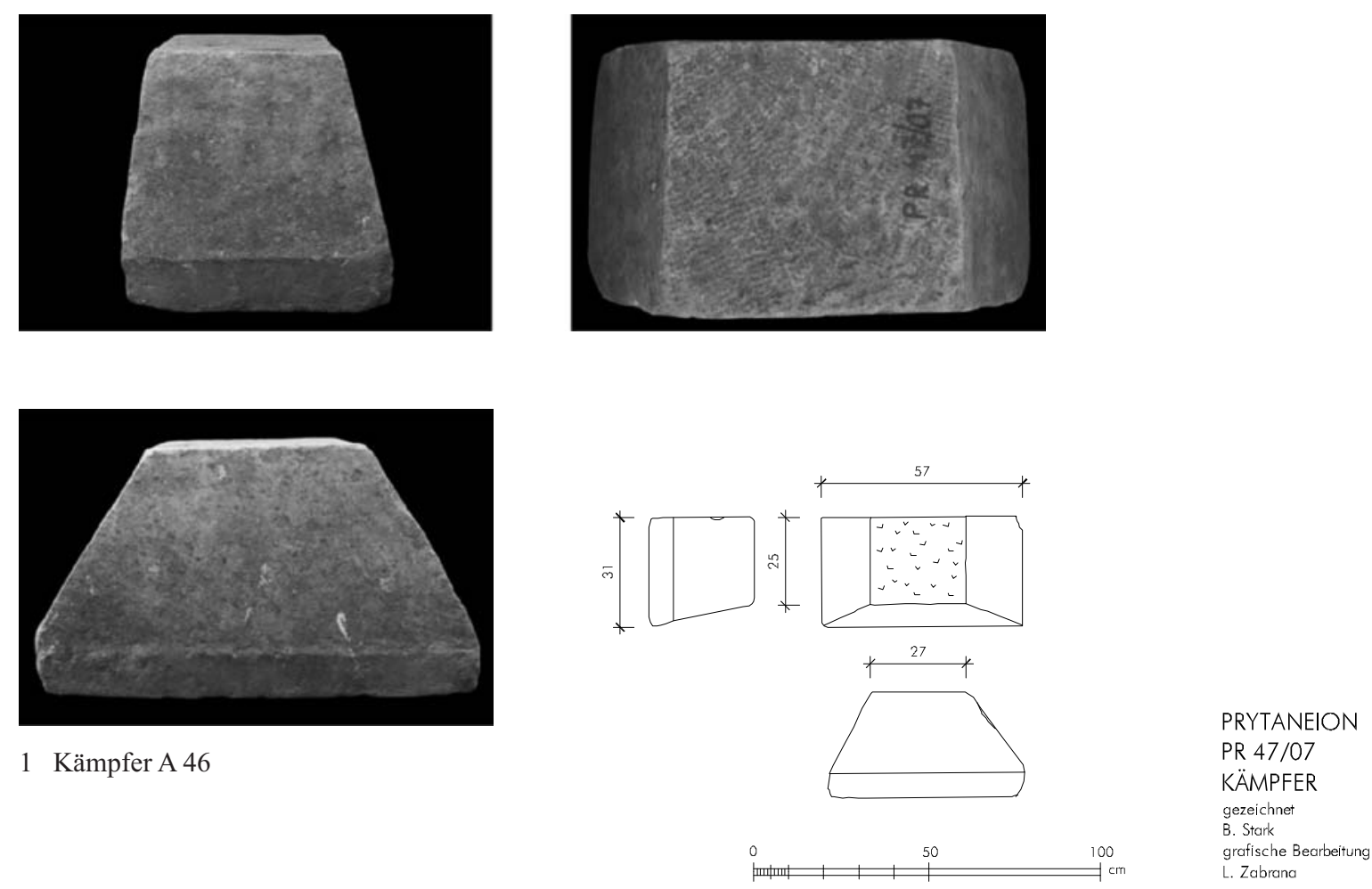

2 Kämpfer A 46 (1:25)
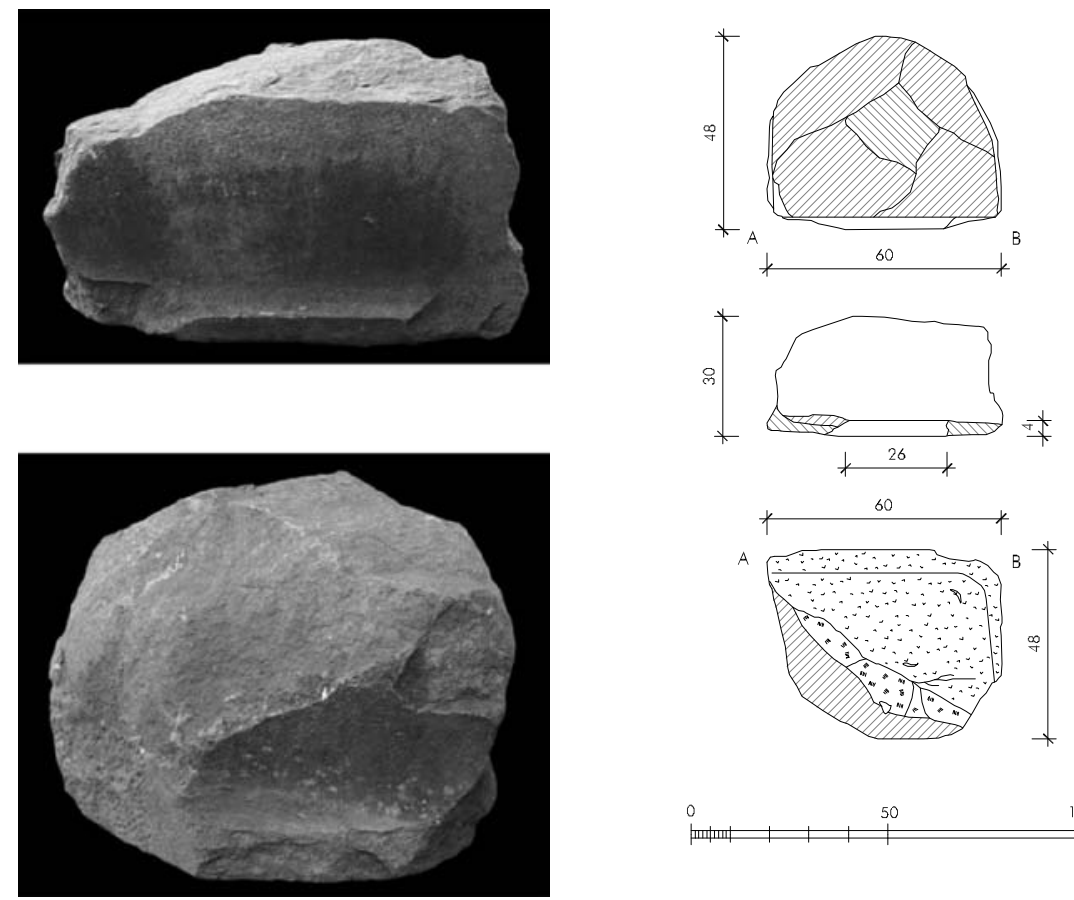

PRYTANEION

PR 46/07

SOCKEL EHRENBASIS

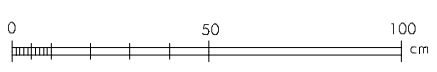

gezeichnet
B. Stork
grofische Bearbeitung
L. Zobranc

3 Sockel Ehrenbasis? SK 16

4 Sockel Ehrenbasis? SK 16 (1:25) 
Tafel 137

\section{PRYTANEION}

SONDAGEN 2007-2008

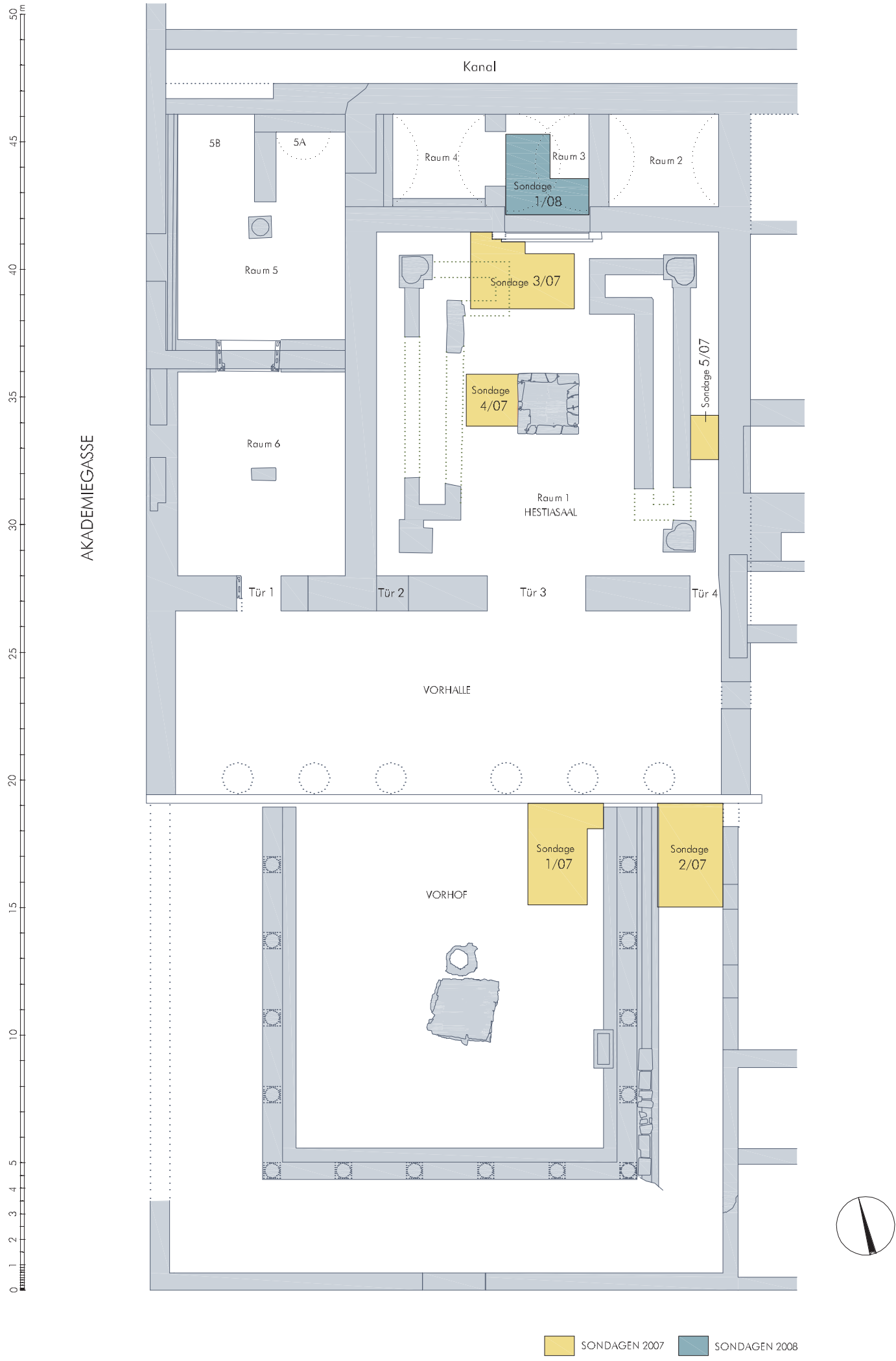

1 Prytaneion. Generalisierter Grundriss mit Sondagenplan 2007-2008 (1:250) 
Tafel 138

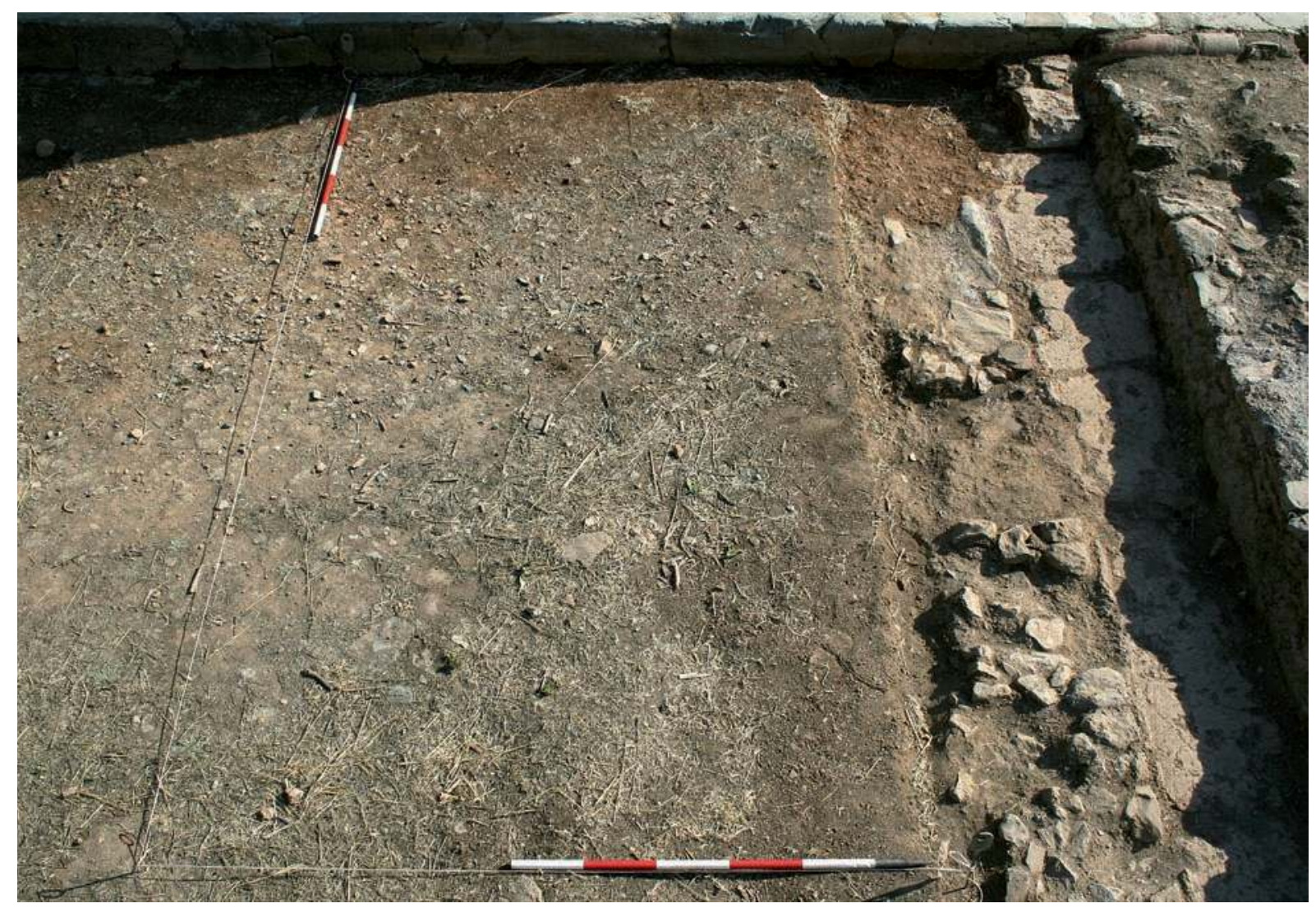

1 Schnitt 1/07. Ausgangssituation von Süden

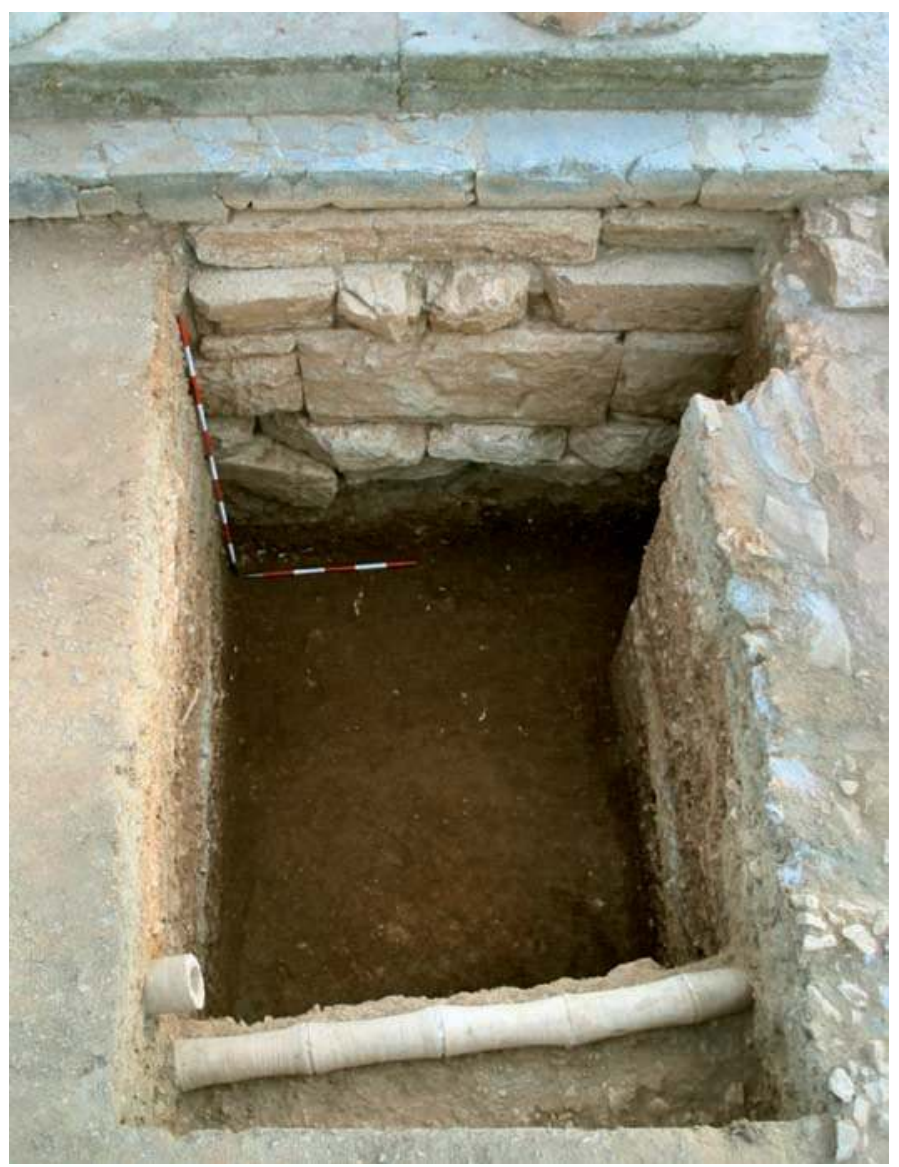

2 Schnitt 1/07. Endsituation von Süden 
Tafel 139

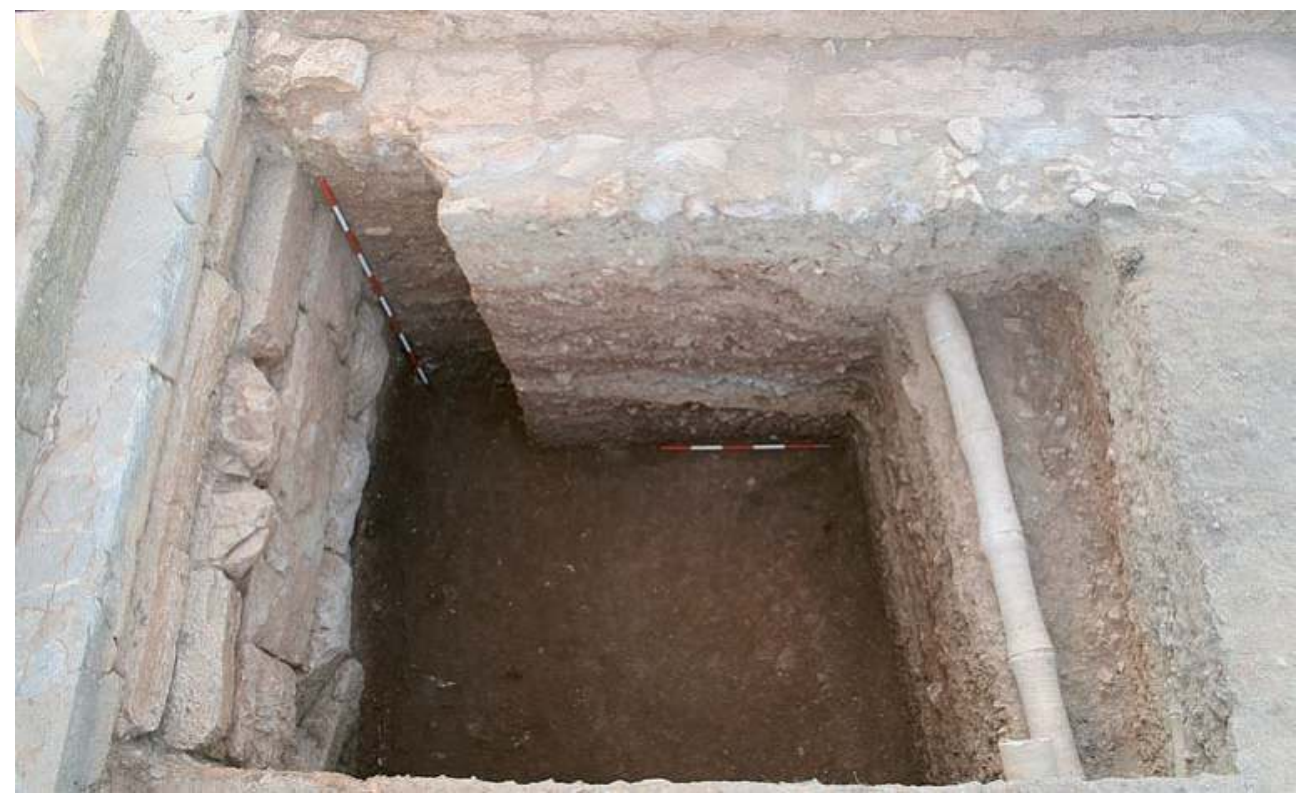

1 Schnitt 1/07.

Endsituation

von Westen

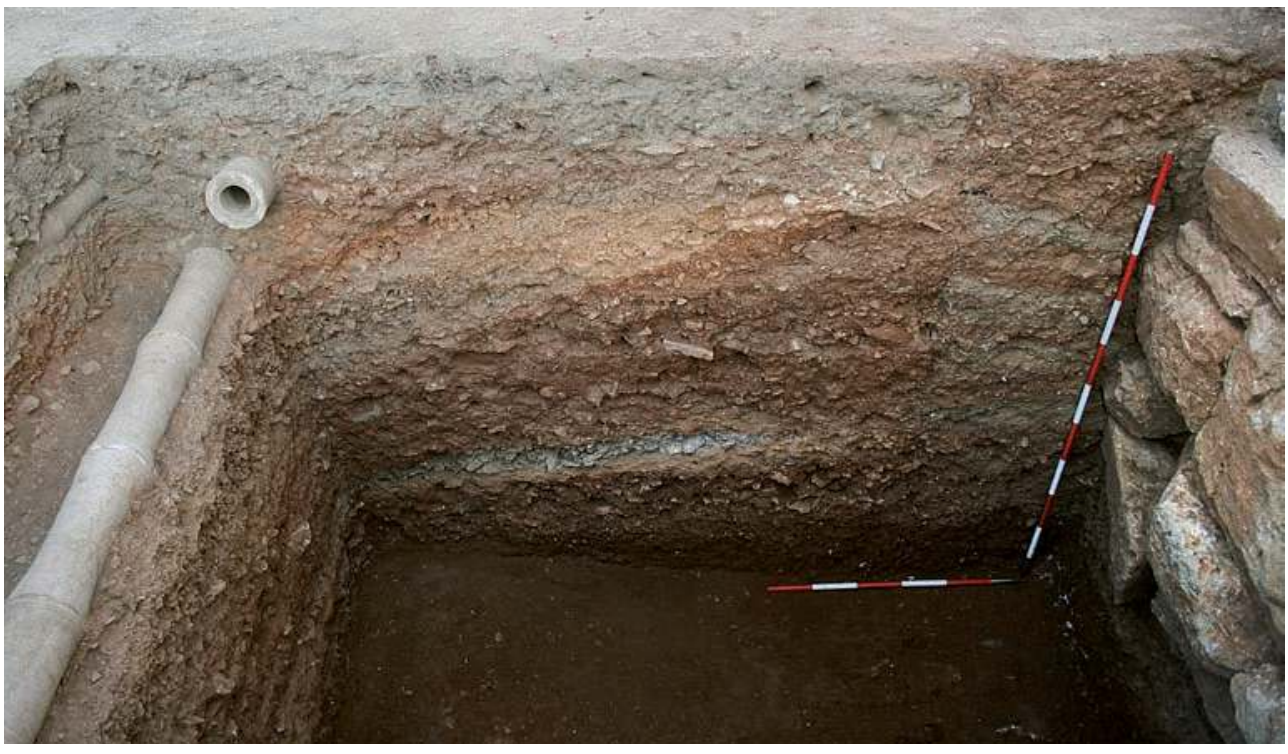

2 Schnitt 1/07.

Westprofil

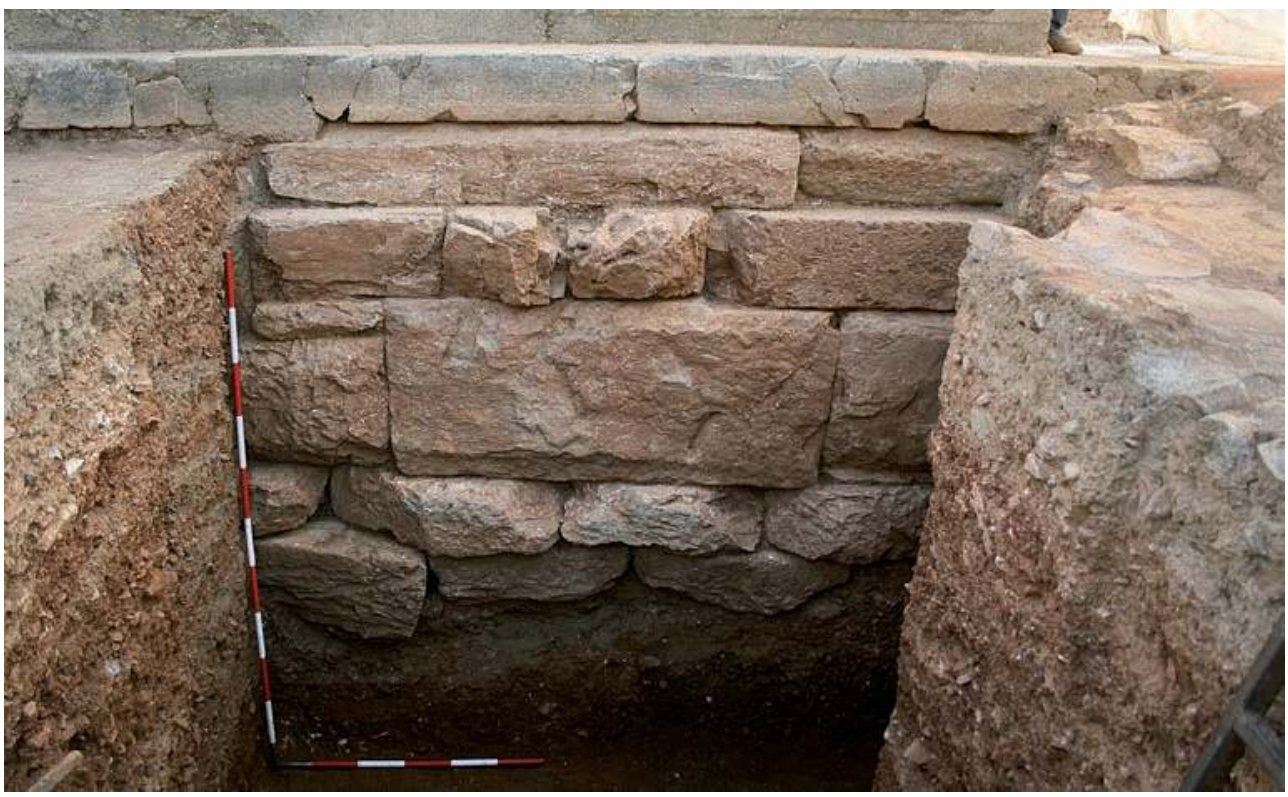

3 Schnitt 1/07. Nordprofil 
Tafel 140
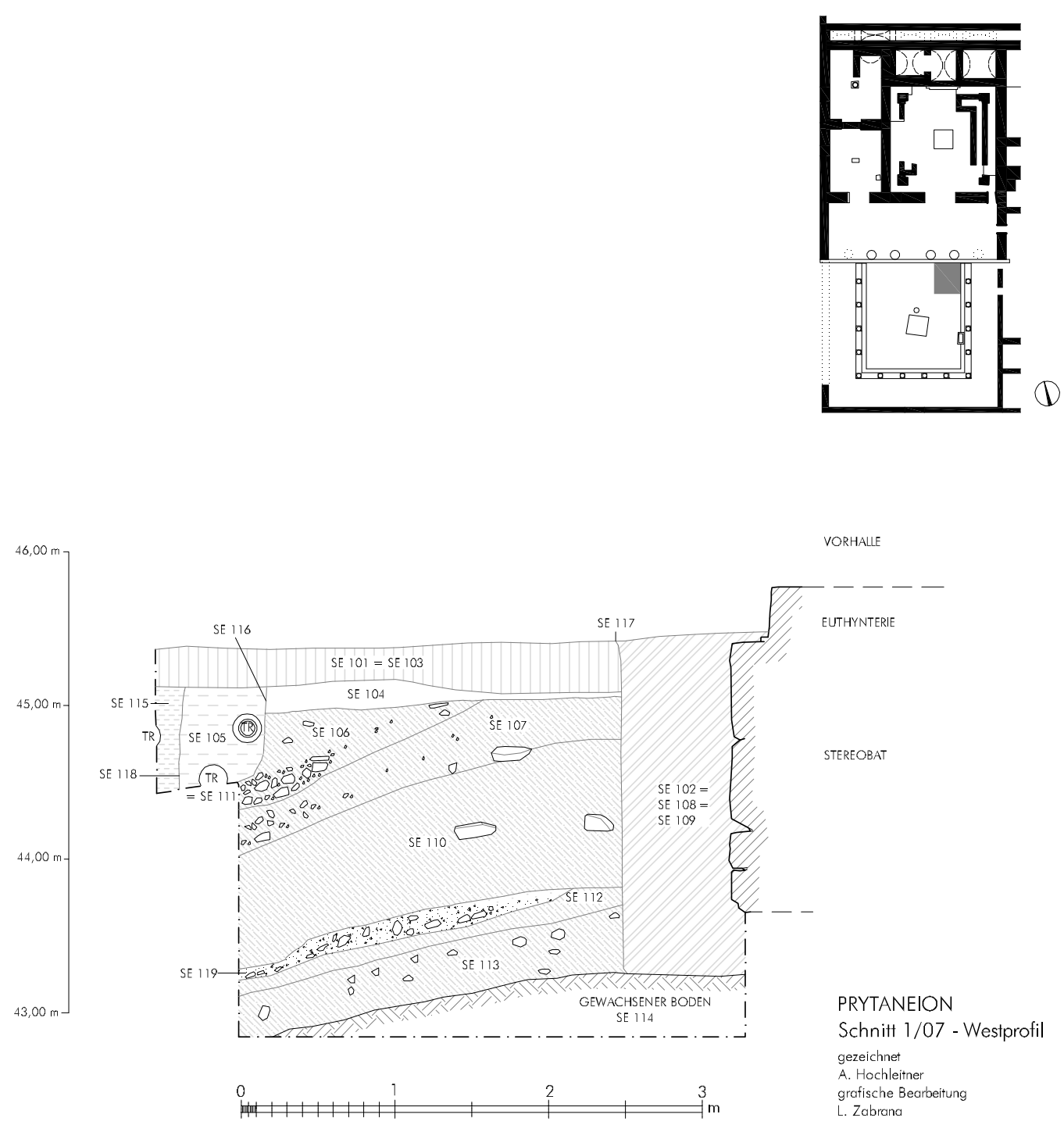

1 Schnitt 1/07. Westprofil (1:50)

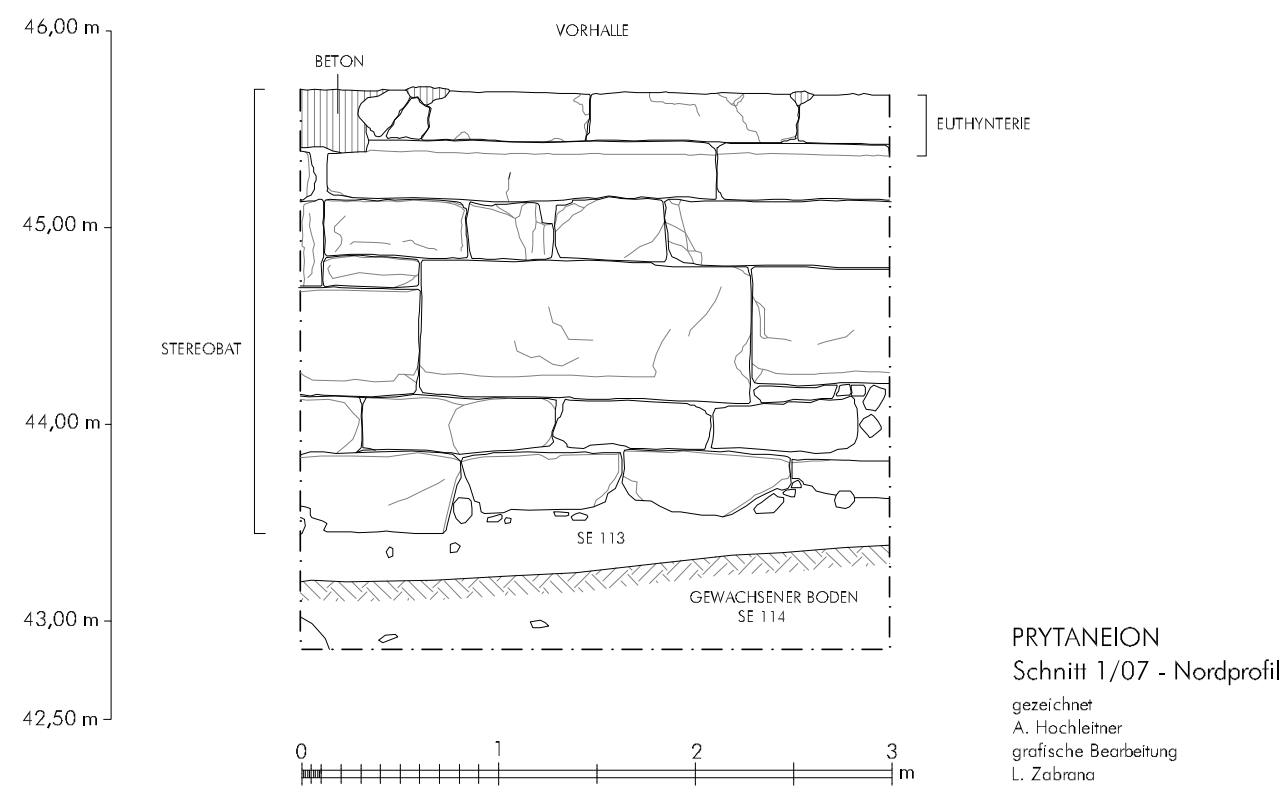

2 Schnitt 1/07. Nordprofil (1:50) 
Tafel 141

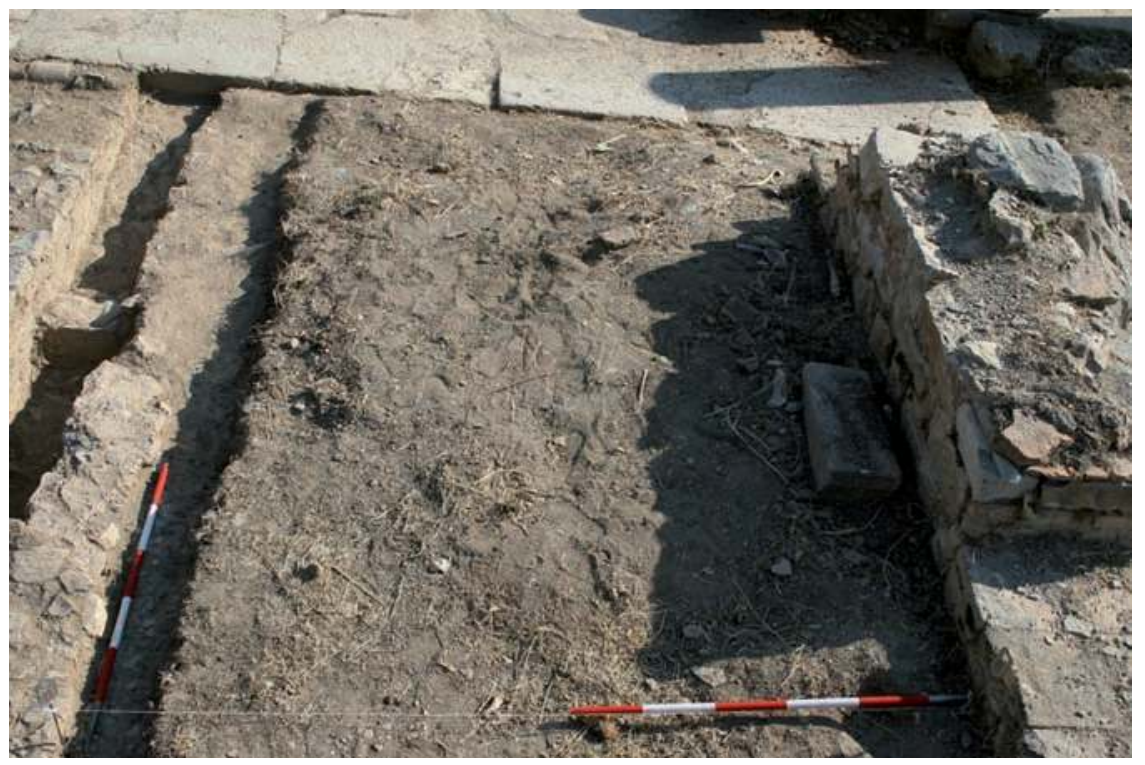

1 Schnitt 2/07.

Ausgangs-

situation von

Süden

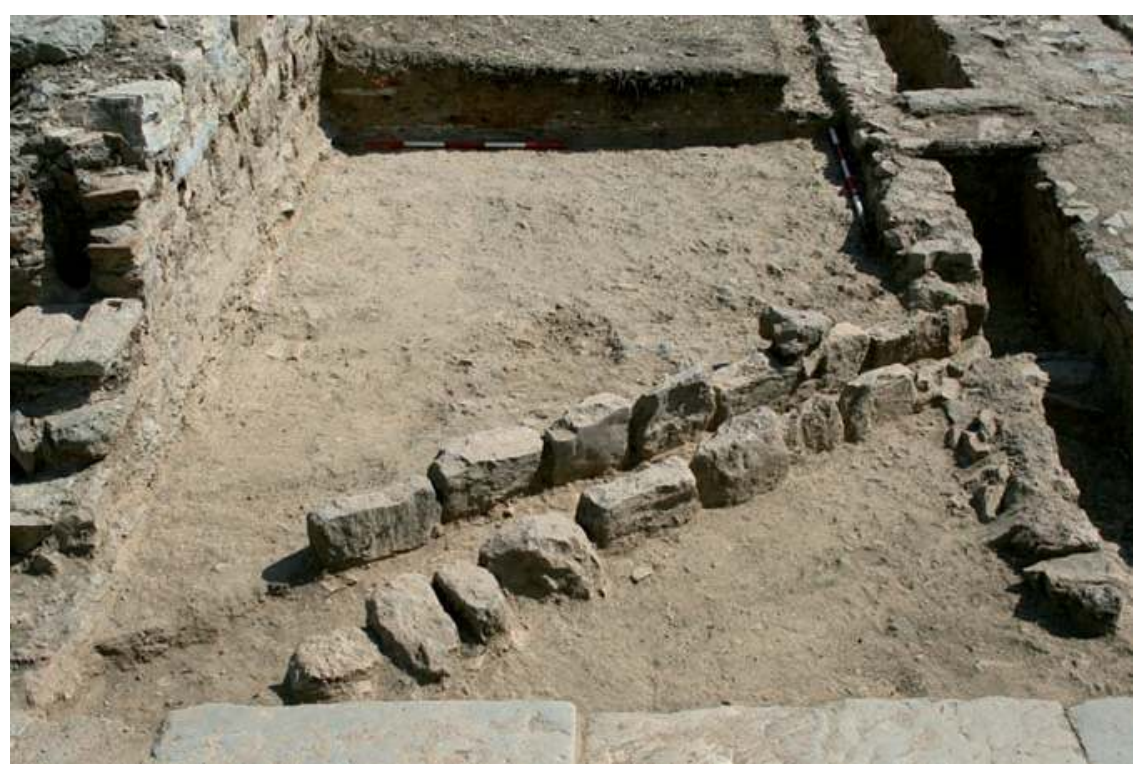

2 Schnitt 2/07.

Kanal SE

204

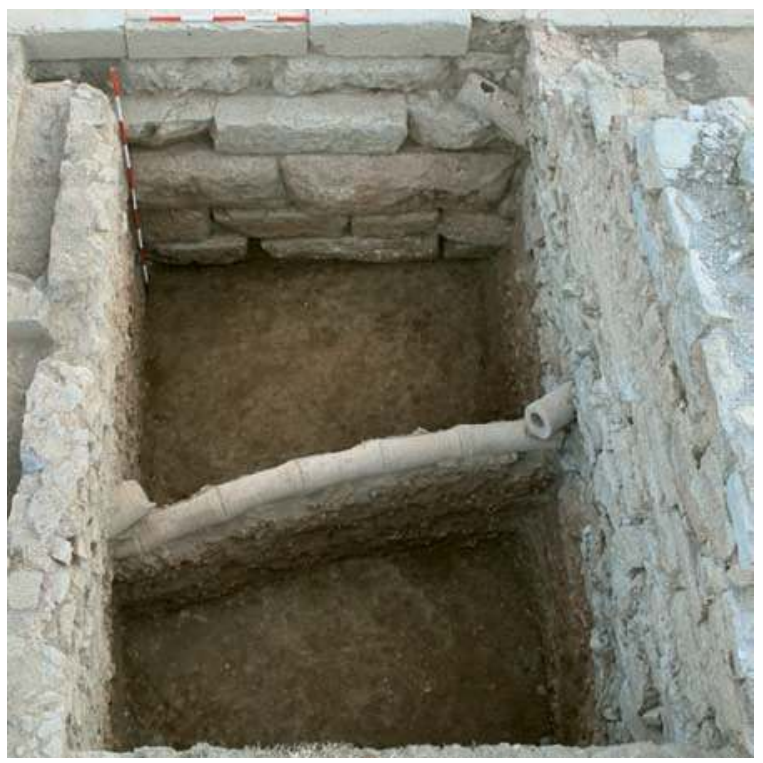

3 Schnitt 2/07. Endsituation von Süden 
Tafel 142
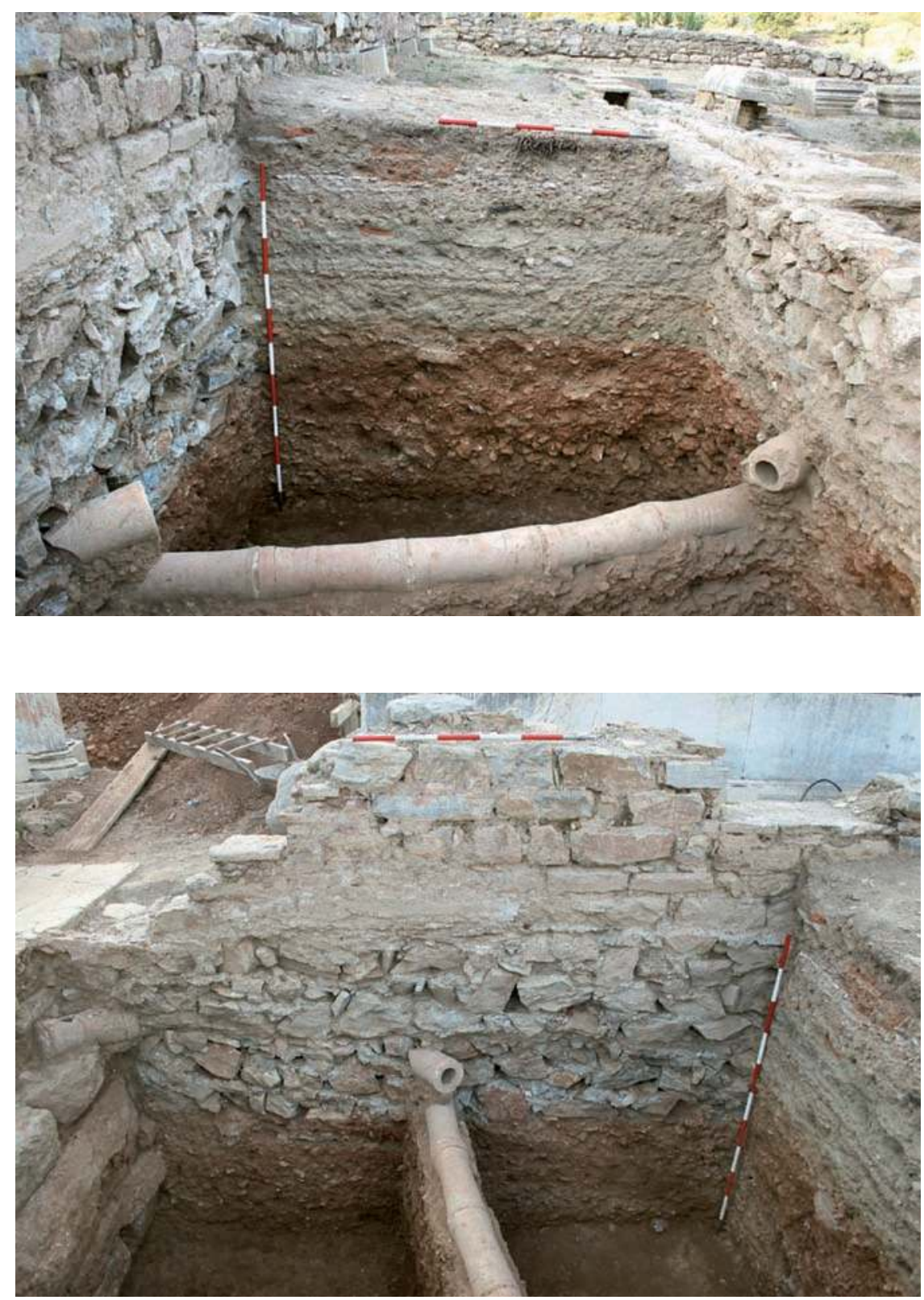

1 Schnitt 2/07. Südprofil

2 Schnitt 2/07. Ostprofil 
Tafel 143

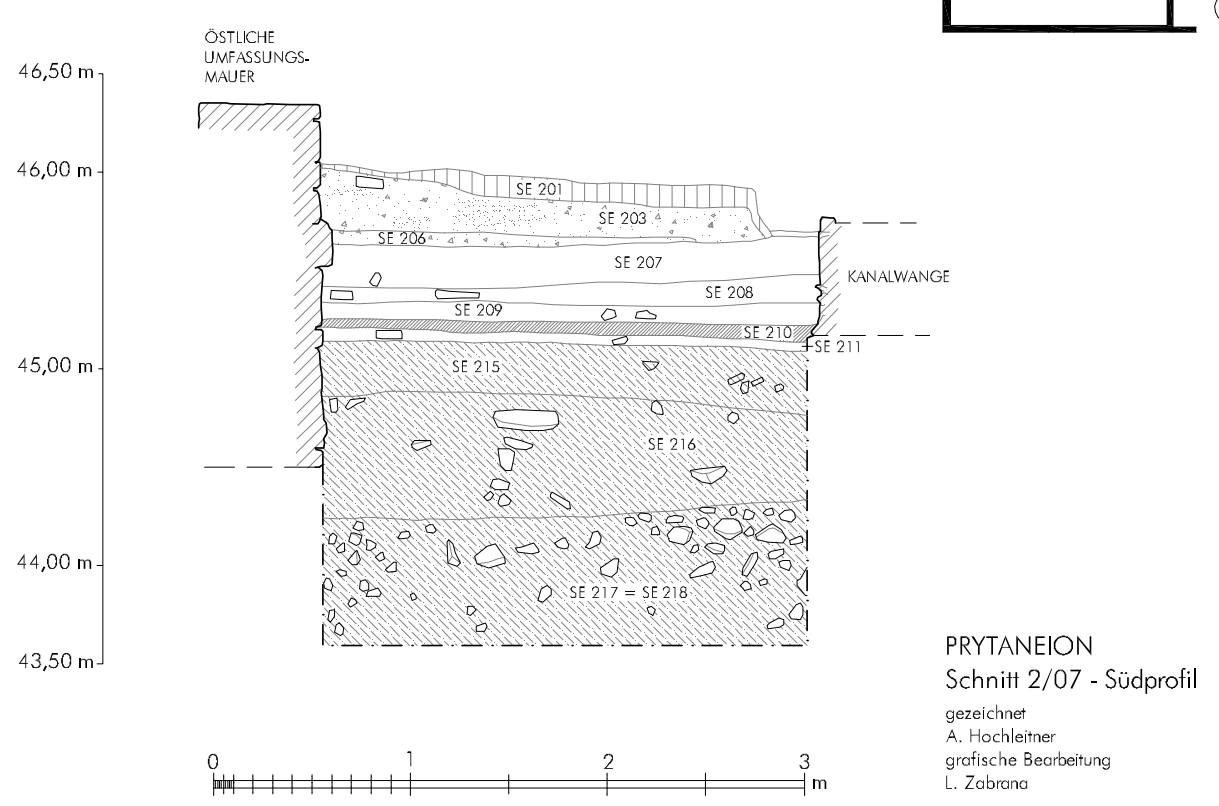

1 Schnitt 2/07. Südprofil (1:50)

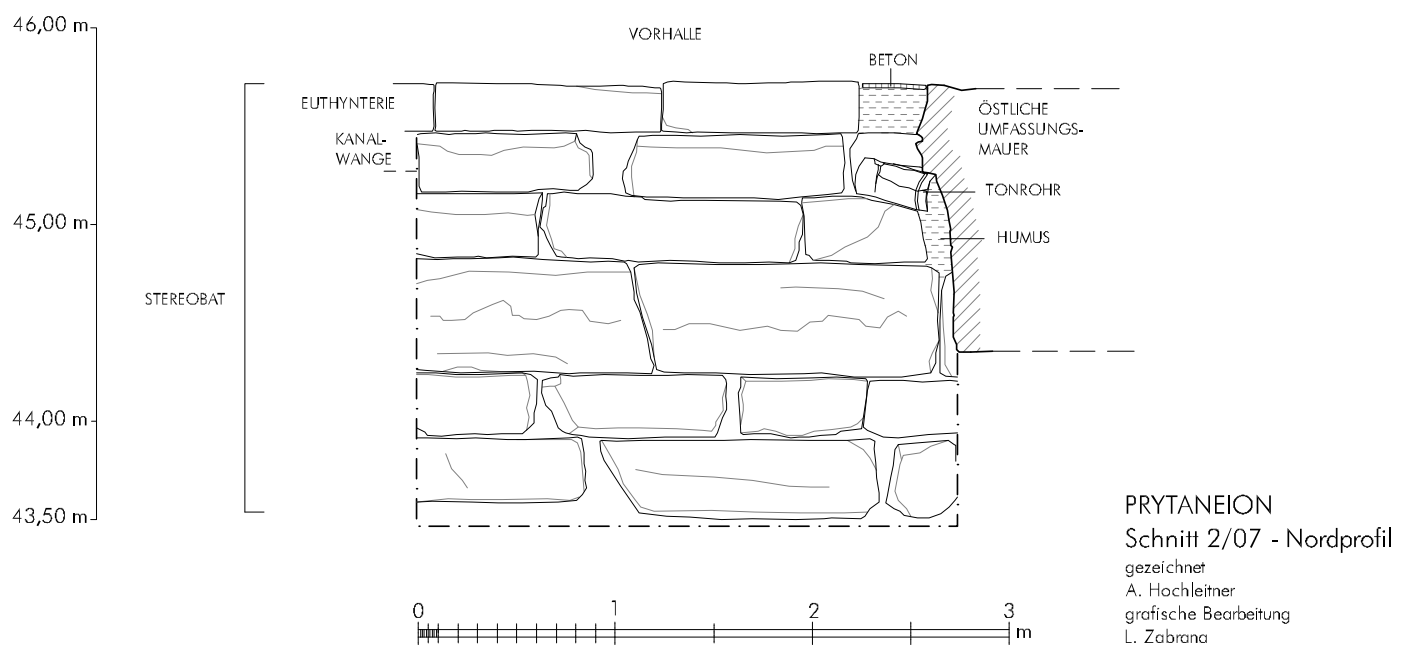

2 Schnitt 2/07. Nordprofil (1:50) 
Tafel 144

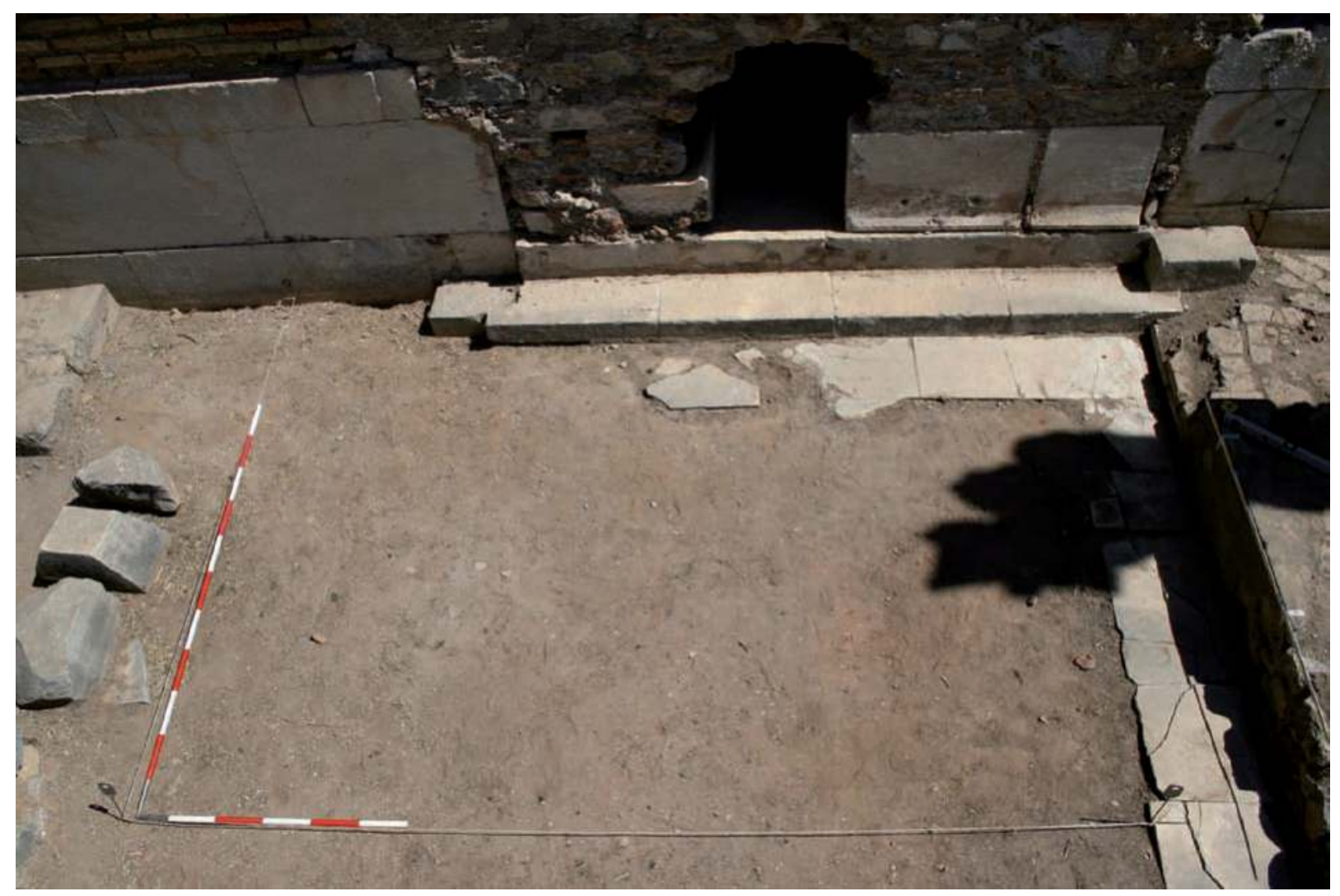

1 Schnitt 3/07. Ausgangssituation von Süden

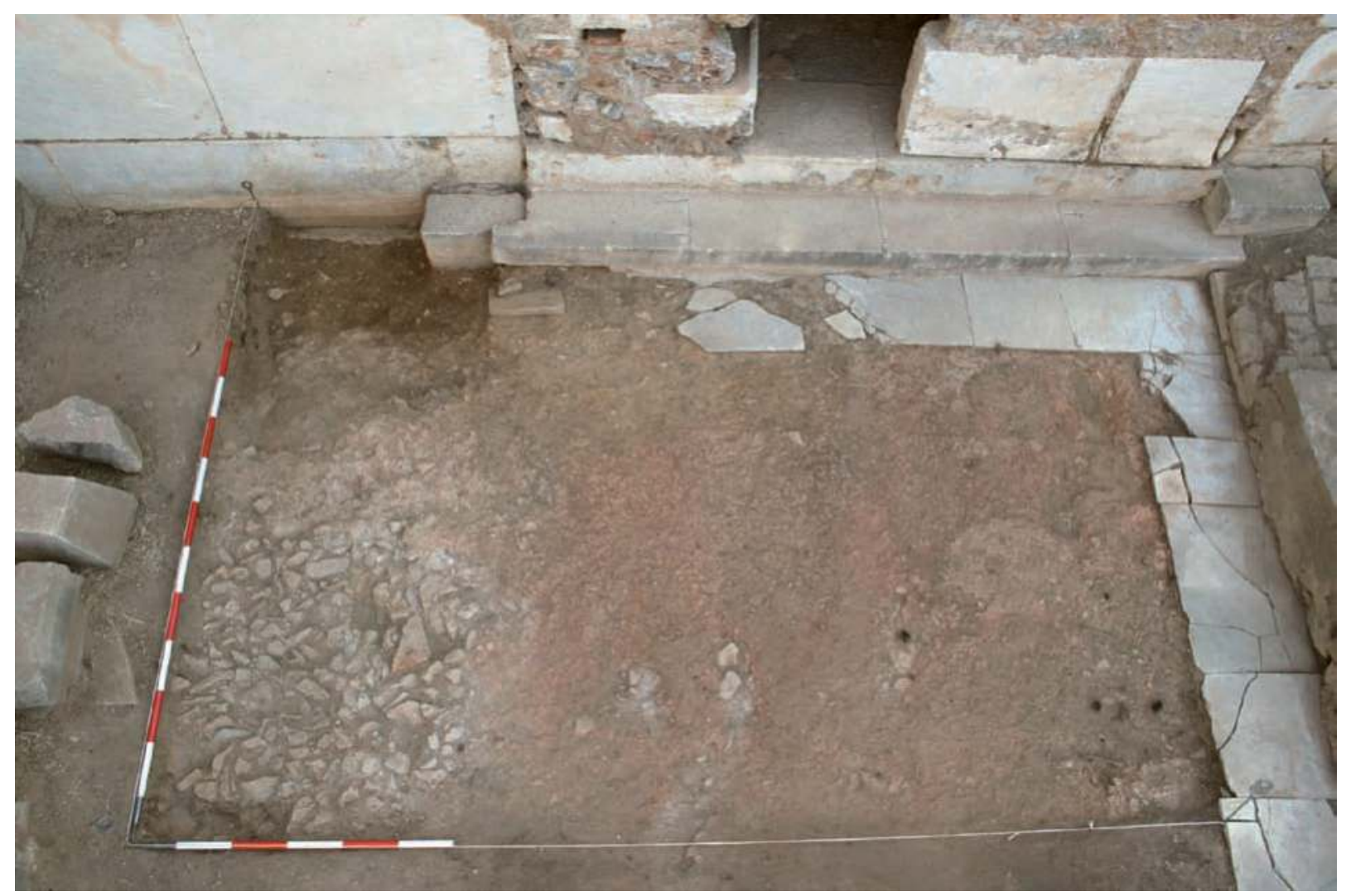

2 Schnitt 3/07. Fundament und Estrich (SE 303, SE 304) des Marmorplattenbodens 


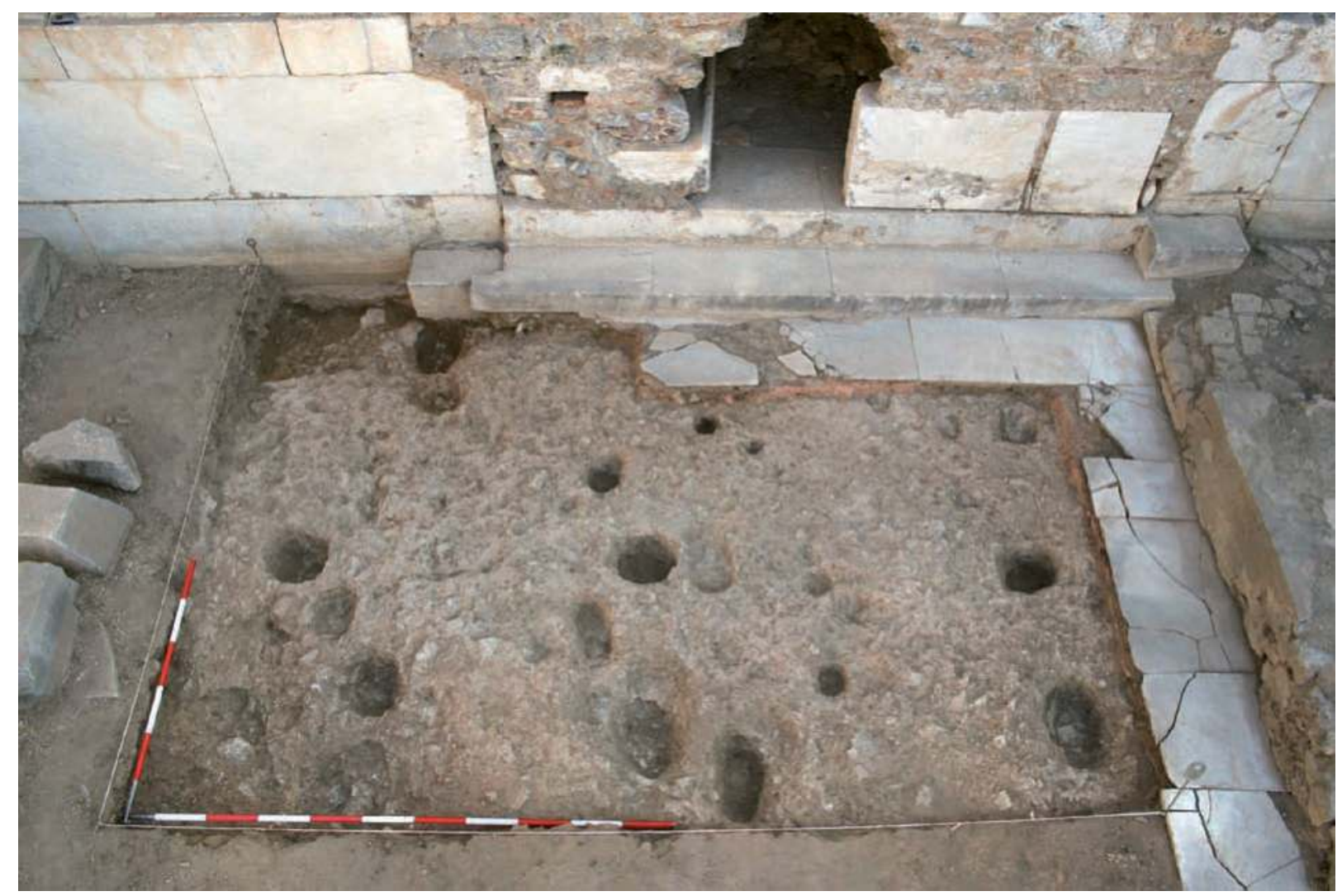

1 Schnitt 3/07. Endsituation von Süden
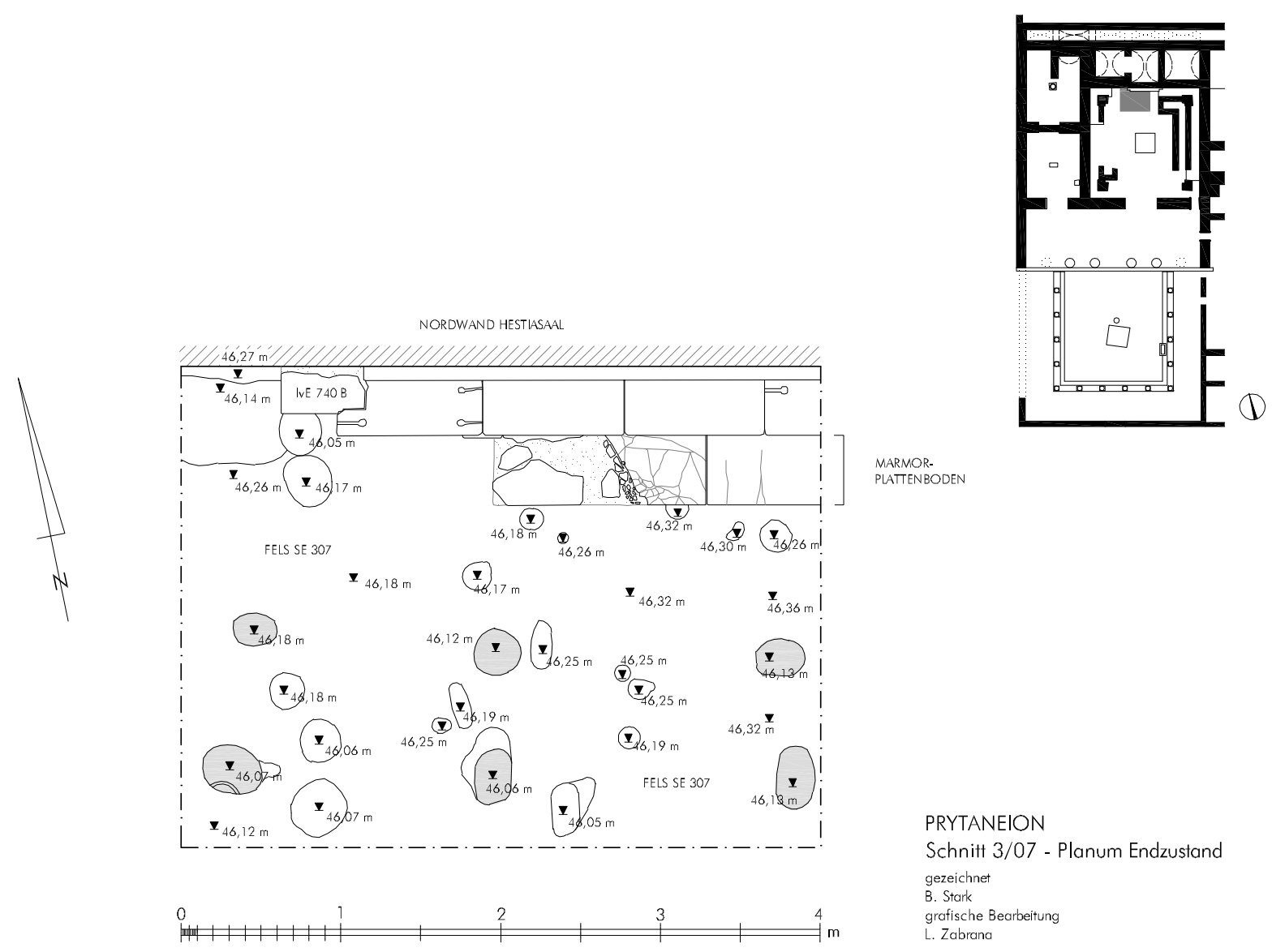

MARMOR-

PLATTENBODEN

PRYTANEION

Schnitt 3/07 - Planum Endzustand

gezeichnet

B. Stark

grafische Bearbeitung

2 Schnitt 3/07. Planum Endzustand (1:50) 
Tafel 146

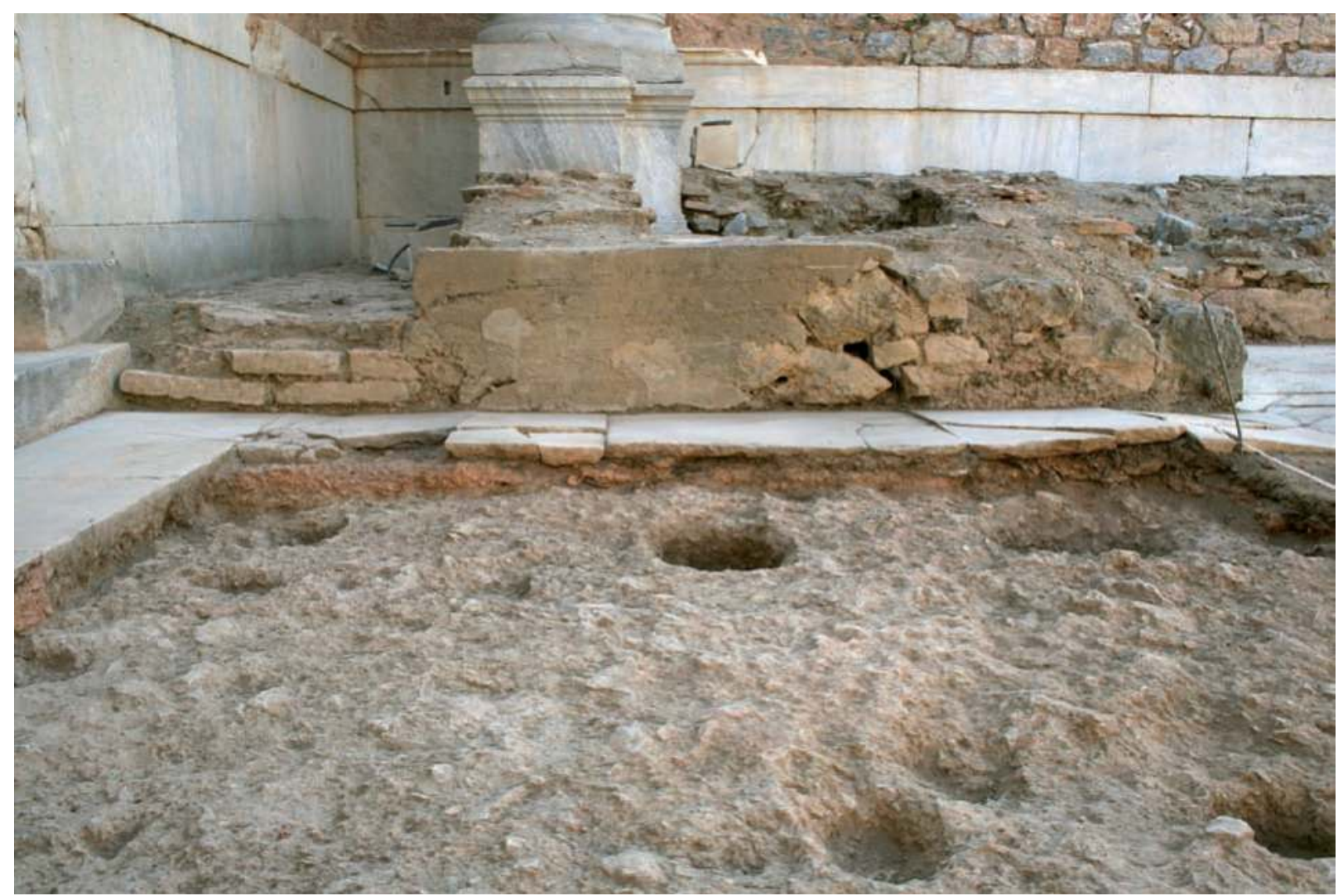

1 Schnitt 3/07. Ostprofil
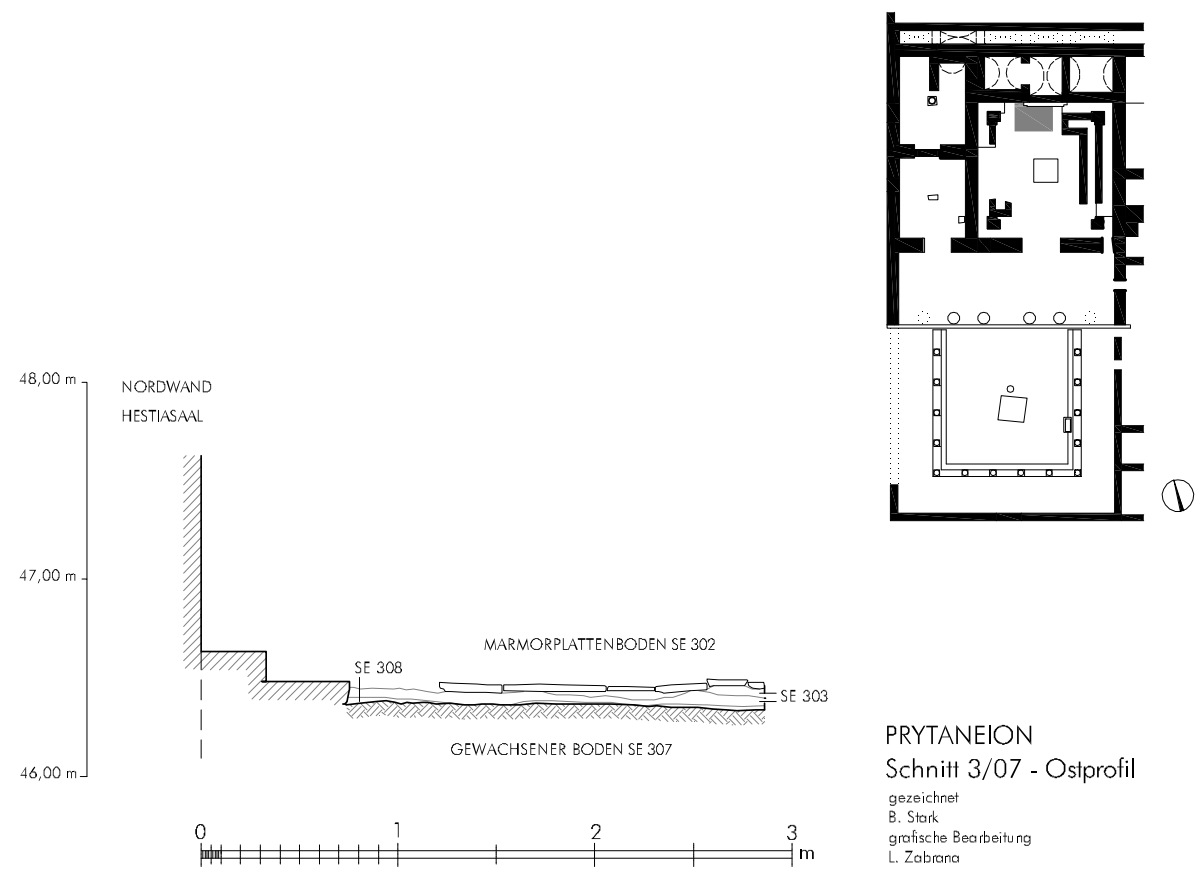

2 Schnitt 3/07. Ostprofil (1:50)

PRYTANEION

Schnitt 3/07 - Ostprofil

gezeichnet
B. Statk

grotische Bearbeitung
Labbrona 
Tafel 147

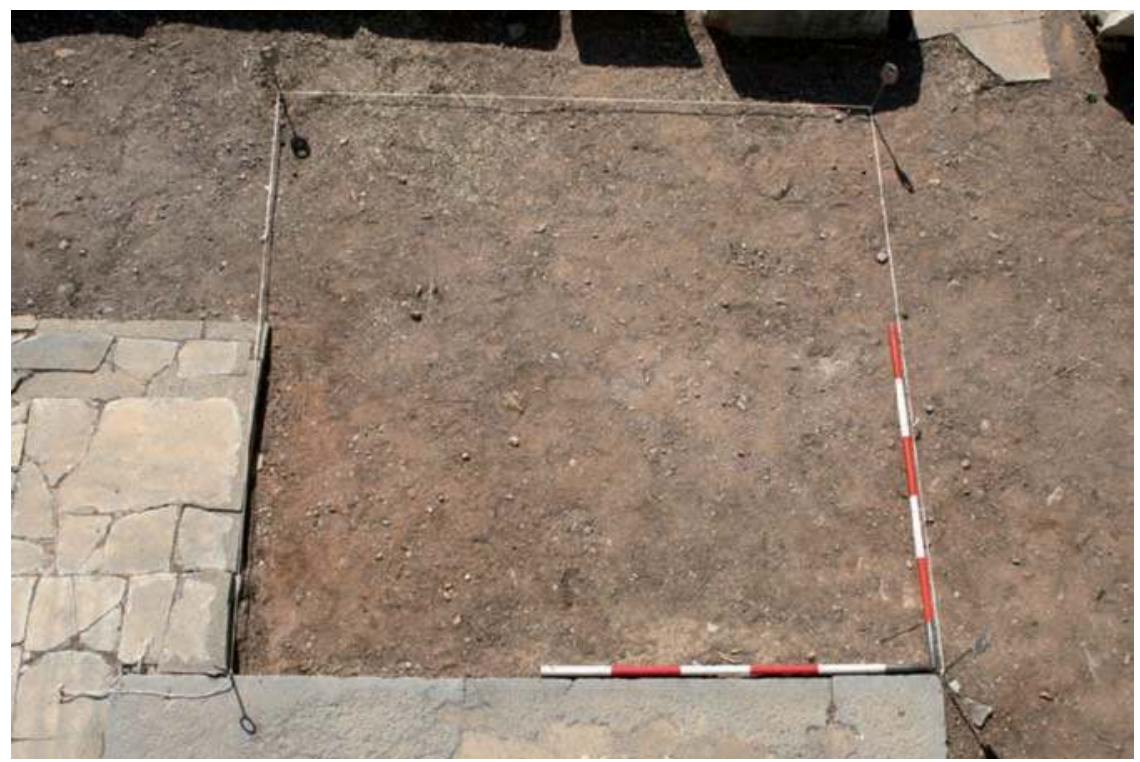

1 Schnitt 4/07. Ausgangssituation von Osten

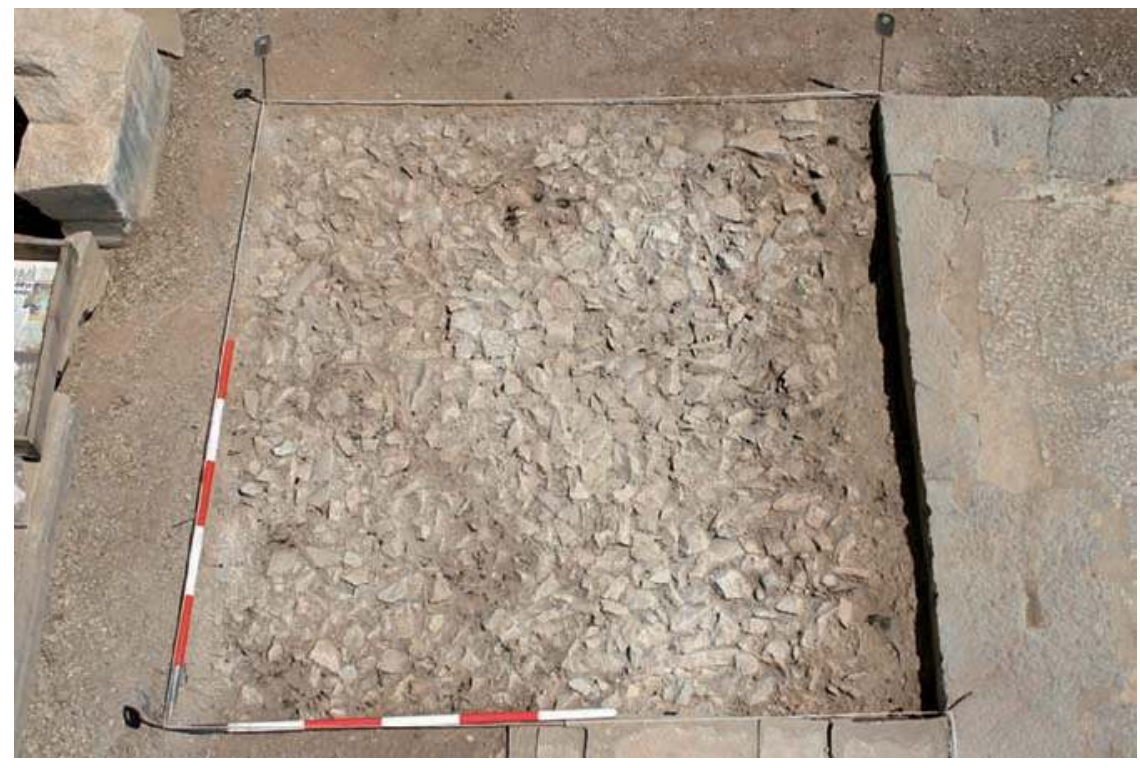

2 Schnitt 4/07. Fundament und Estrich (SE 402, SE 403) des Marmorplattenbodens

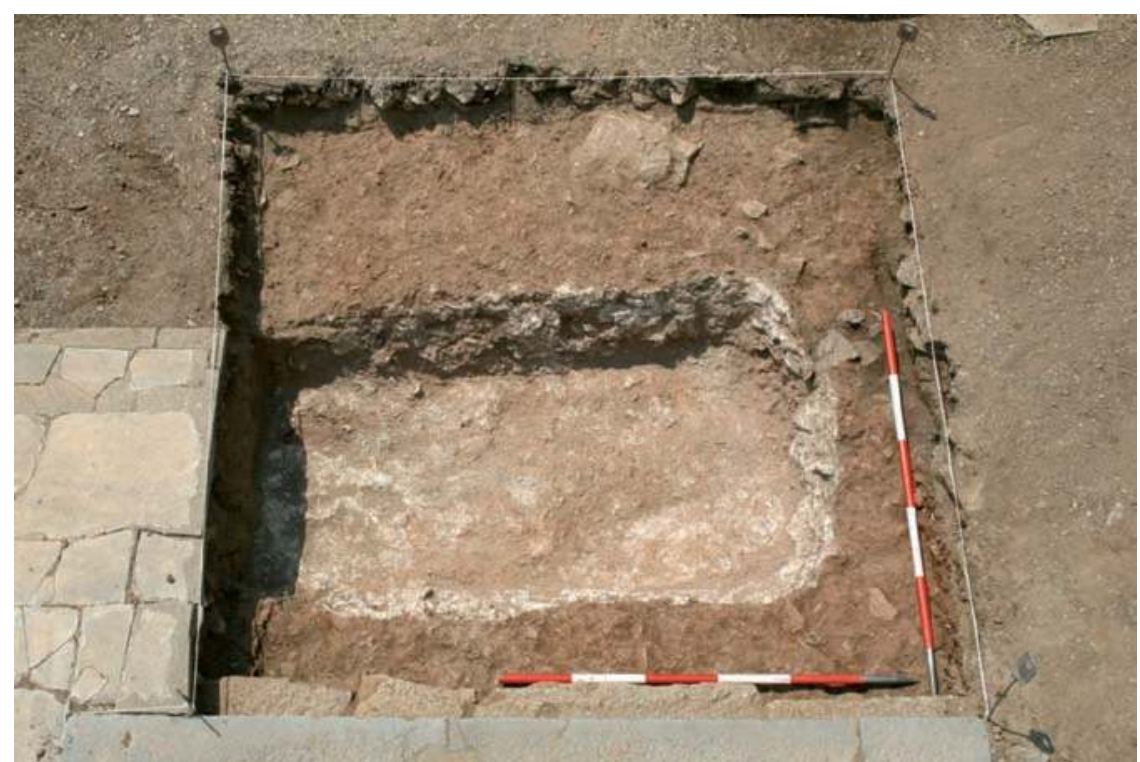

3 Schnitt 4/07. Kalkgrube SE 407 
Tafel 148

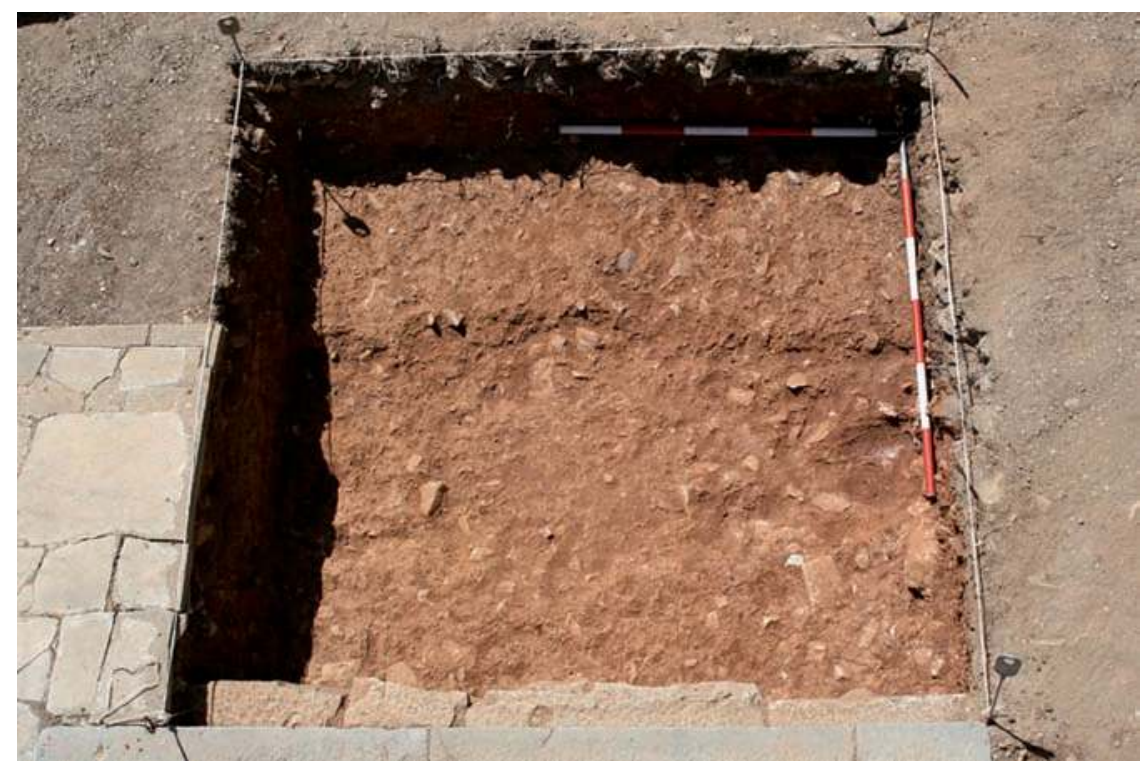

1 Schnitt 4/07. Endsituation von Osten

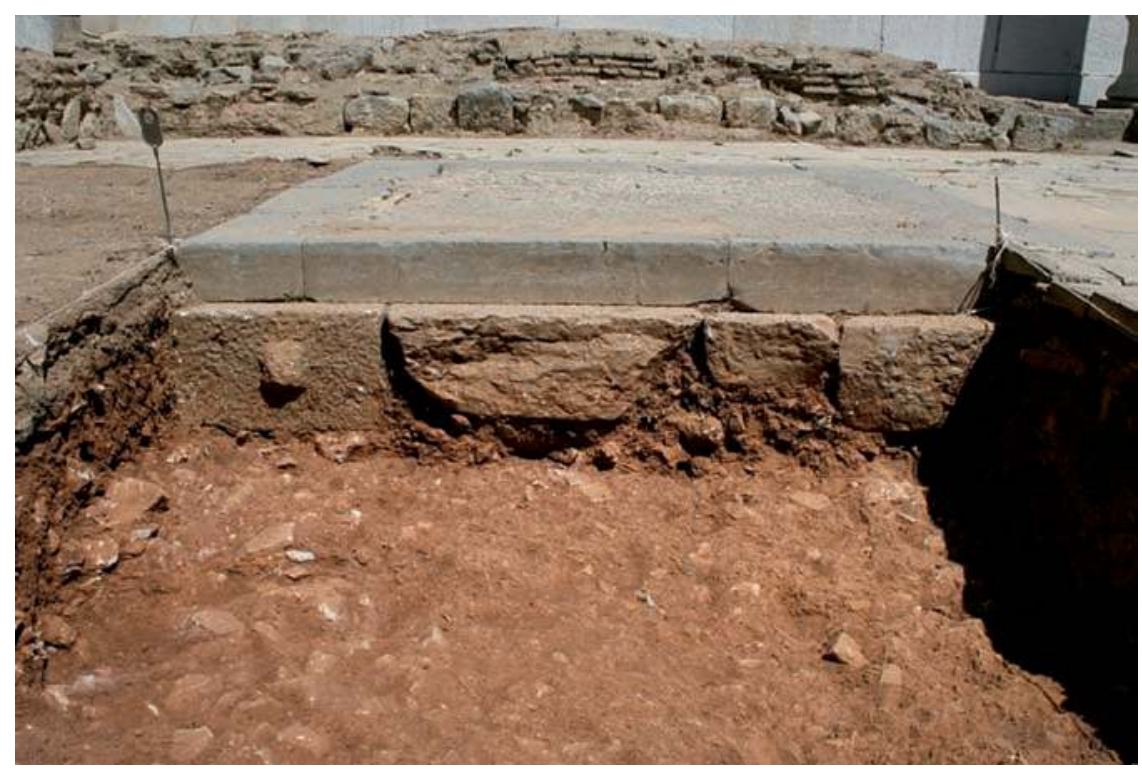

2 Schnitt 4/07. Ostprofil

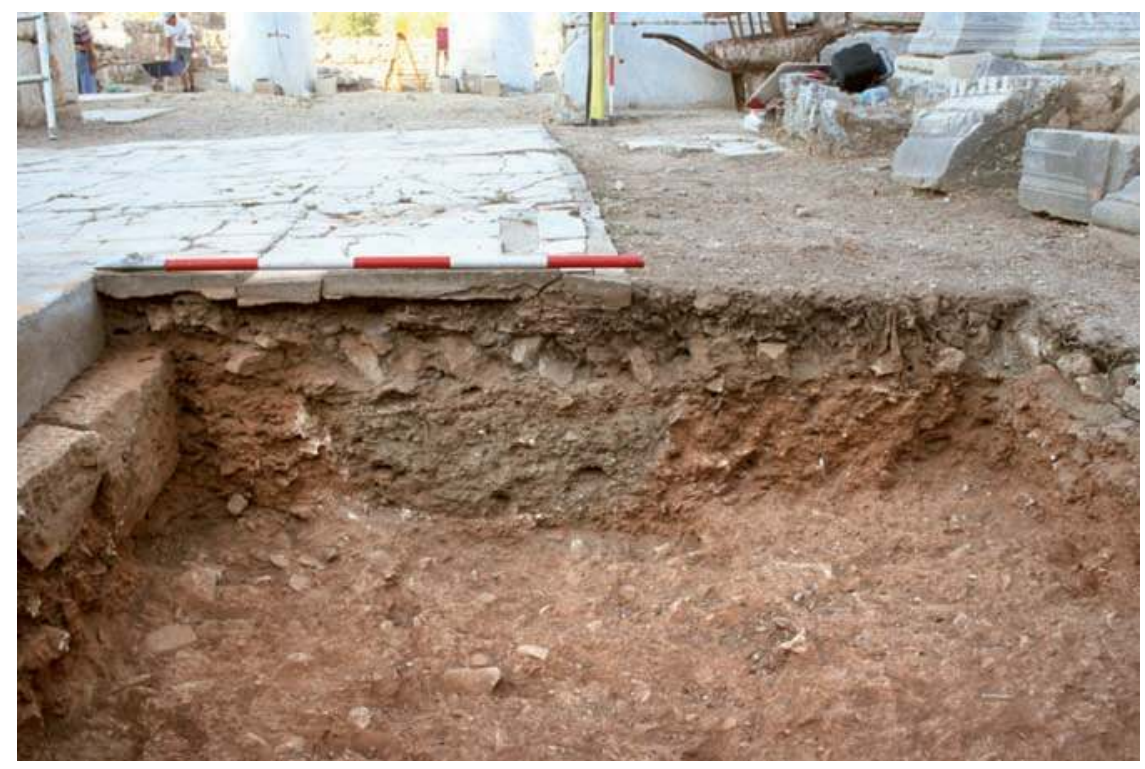

3 Schnitt 4/07. Südprofil 
Tafel 149

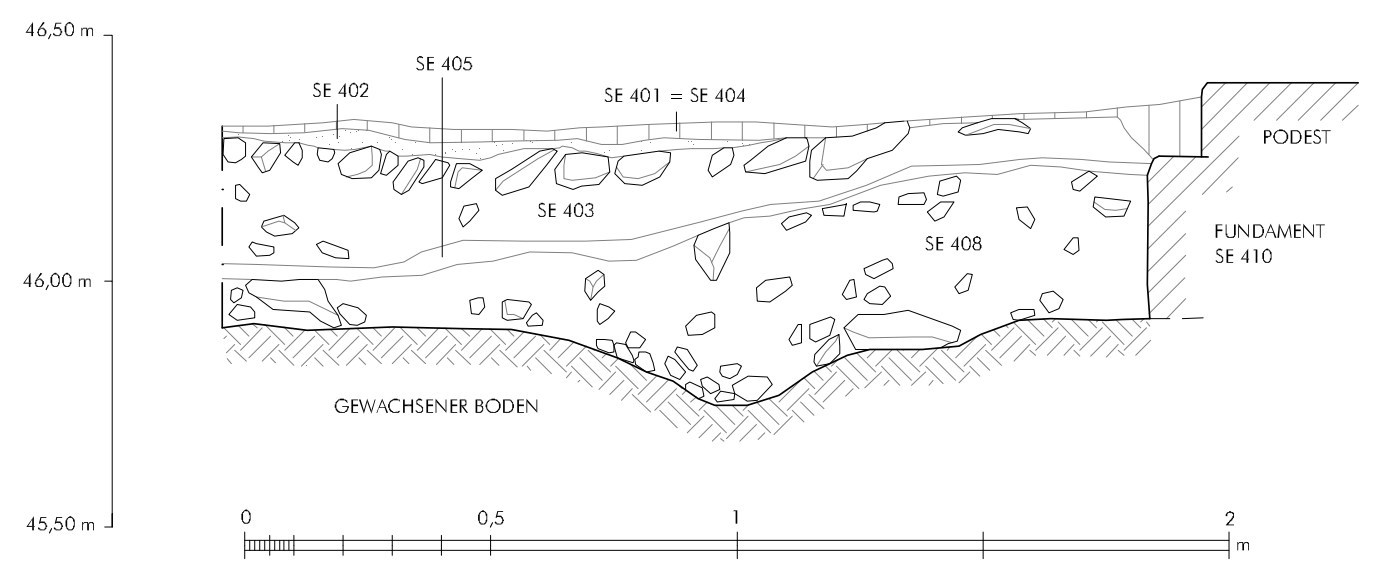

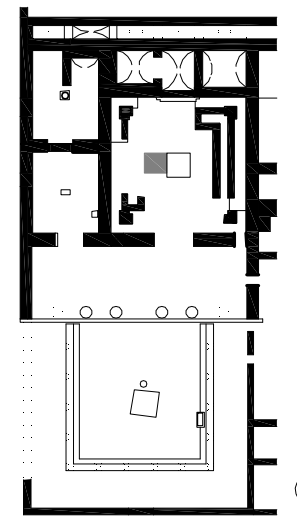

PRYTANEION

Schnitt 4/07 - Nordprofil gezeichnet

grafische Bearbeitung

L. Zabrana

1 Schnitt 4/07. Nordprofil (1:20)

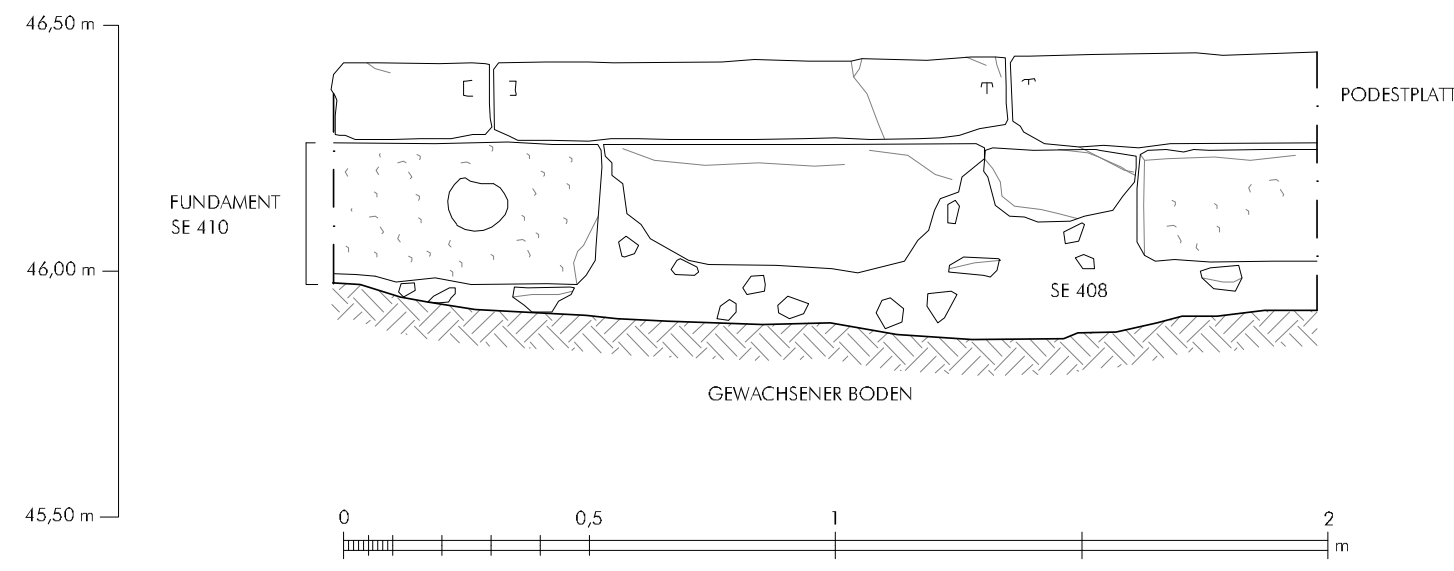

PRYTANEION

Schnitt 4/07 - Ostprofil gezeichnet
B. Stark

grafische Bearbeitung

L. Zabrana

2 Schnitt 4/07. Ostprofil (1:20)

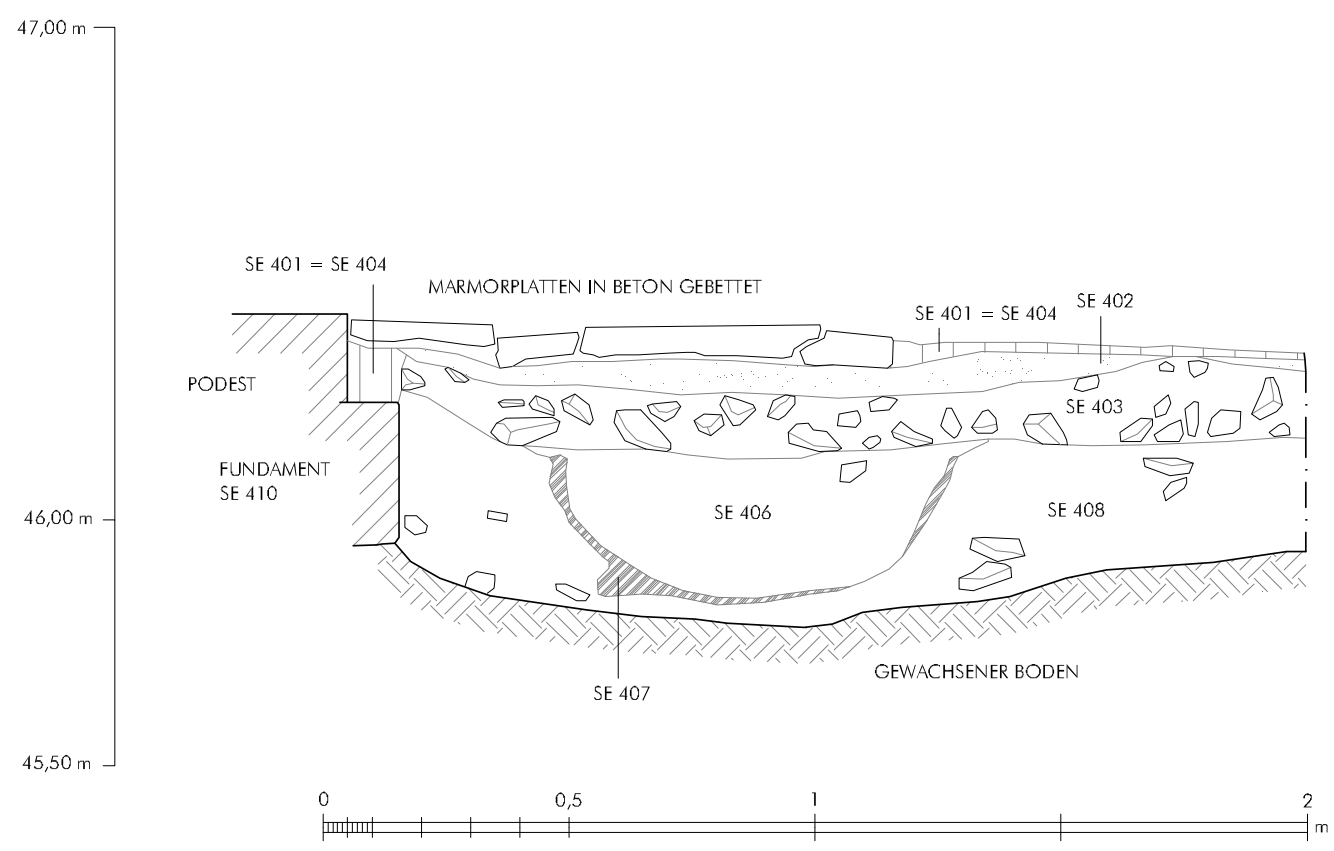

PRYTANEION

Schnitt 4/07 - Südprofil gezeichnet

grafische Bearbeitung

3 Schnitt 4/07. Südprofil (1:20) 
Tafel 150

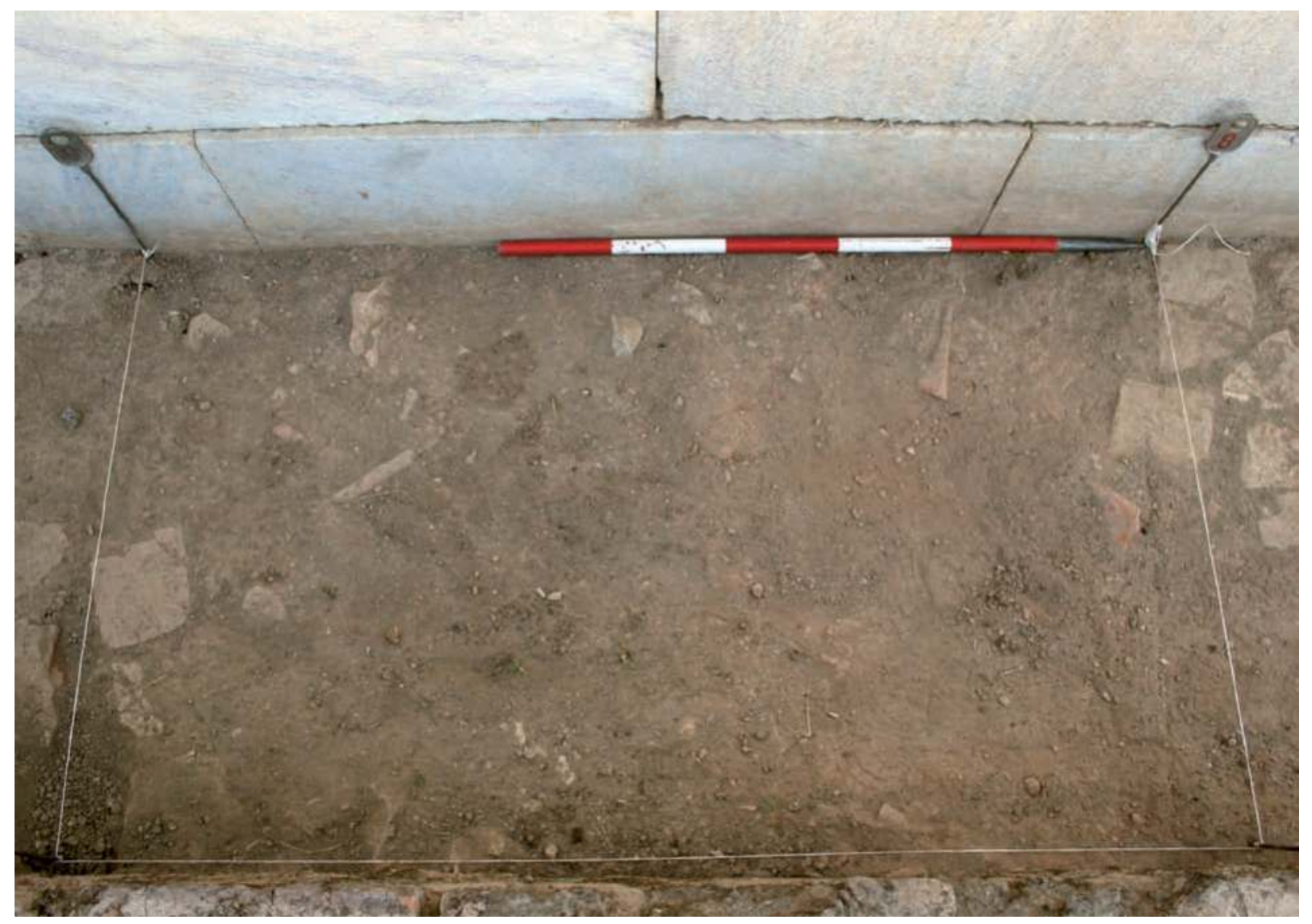

1 Schnitt 5/07. Ausgangssituation von Westen

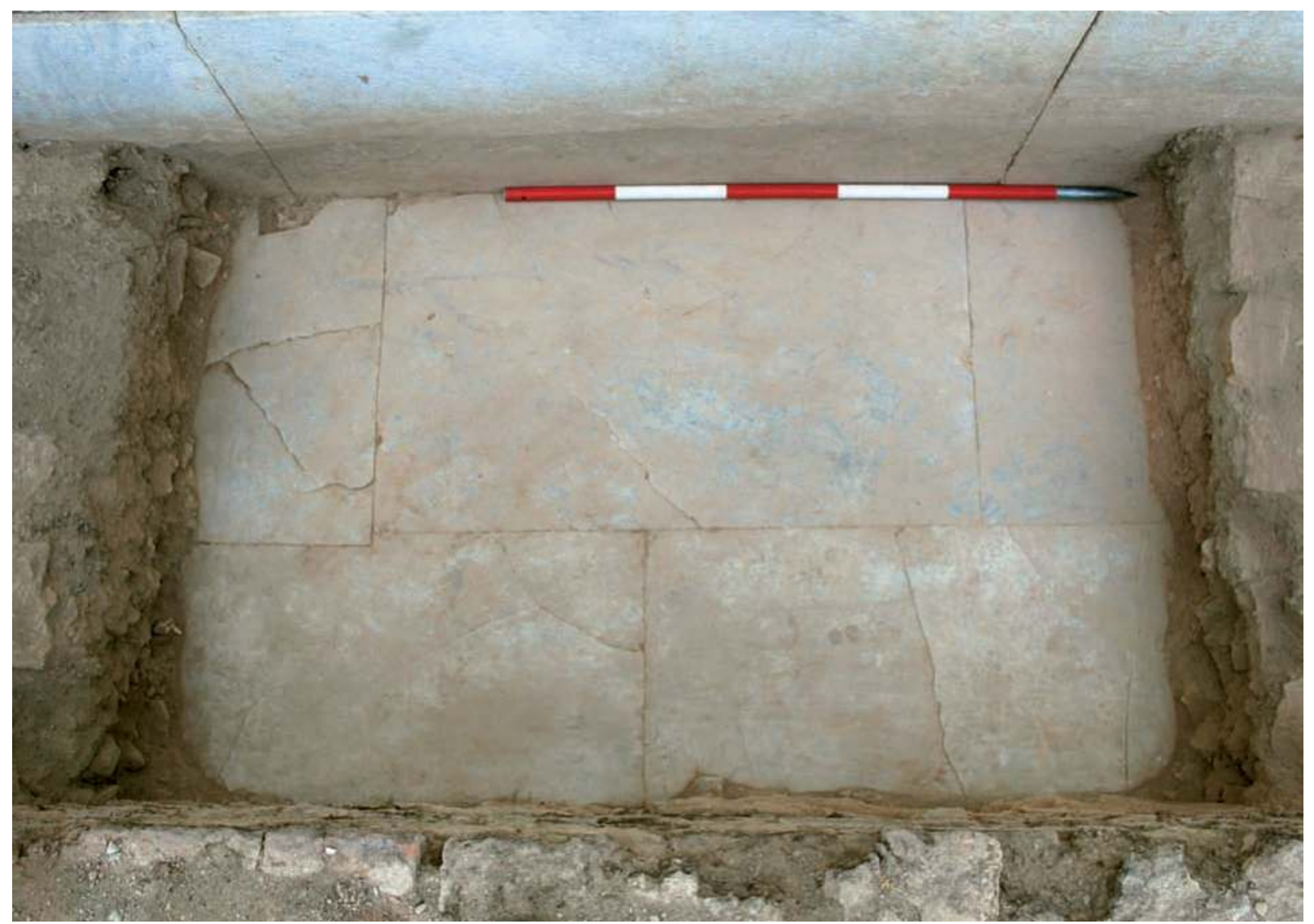

2 Schnitt 5/07. Endsituation von Westen 
Tafel 151

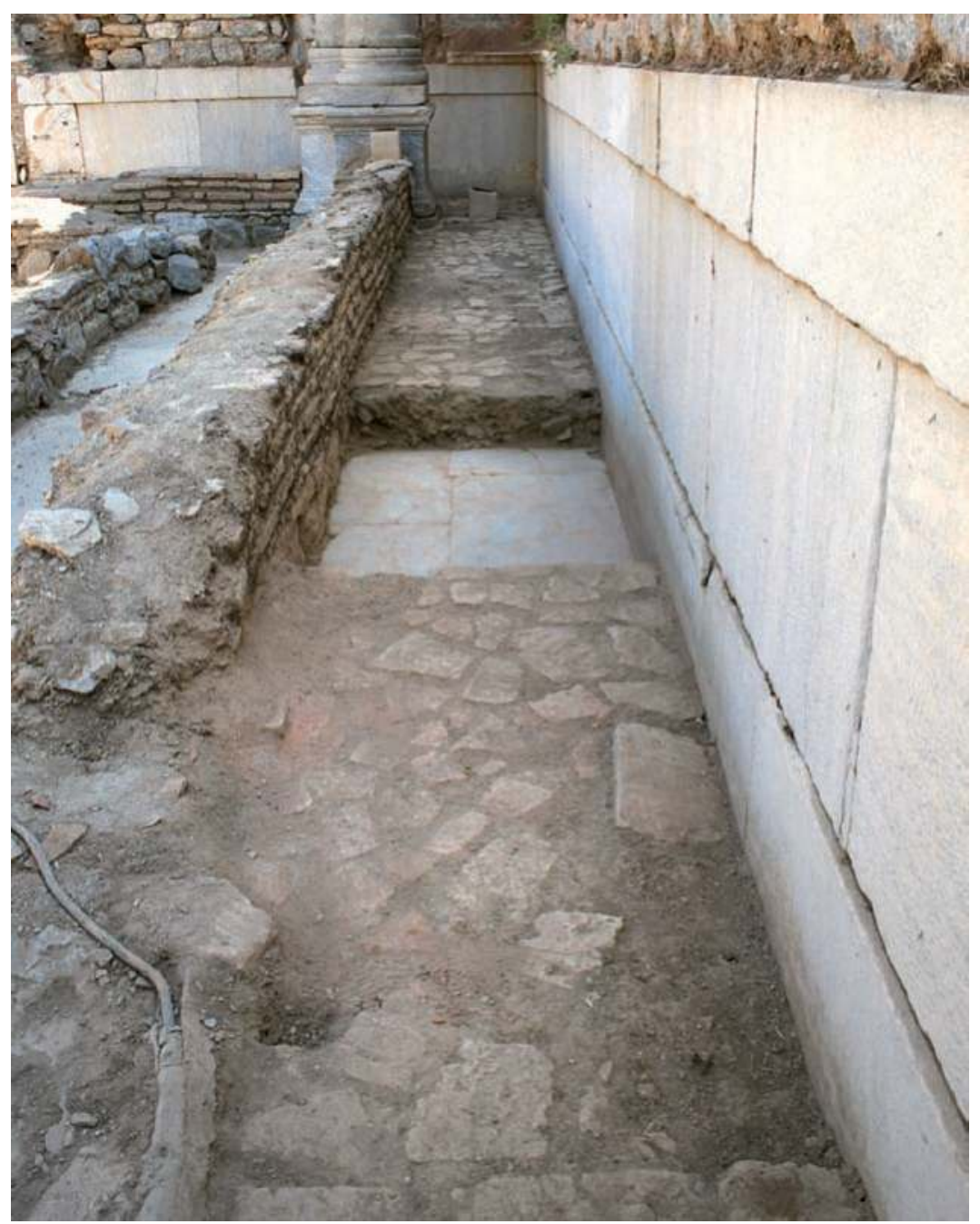

1 Schnitt 5/07. Endsituation von Süden

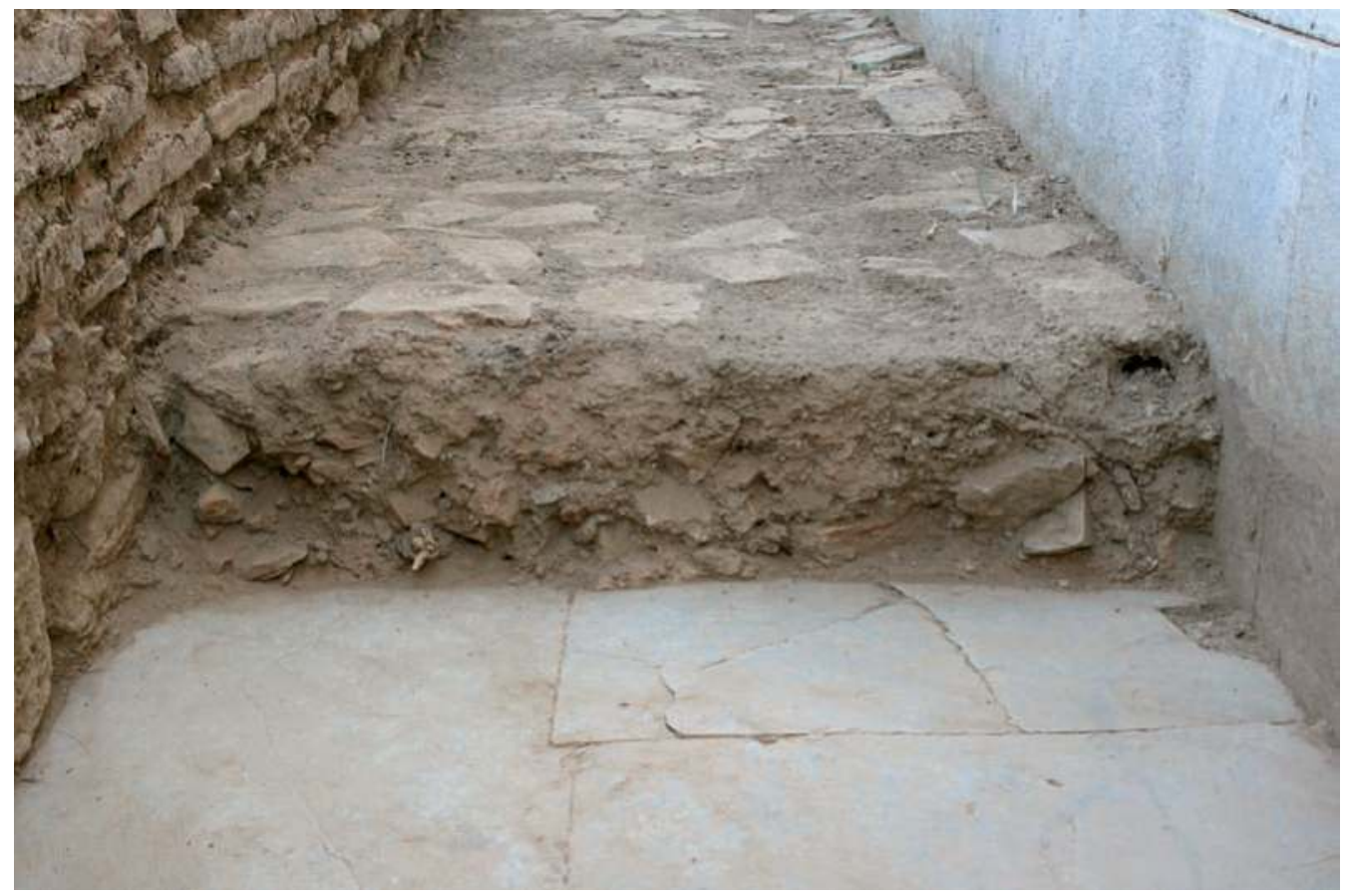

2 Schnitt 5/07. Nordprofil 
Tafel 152
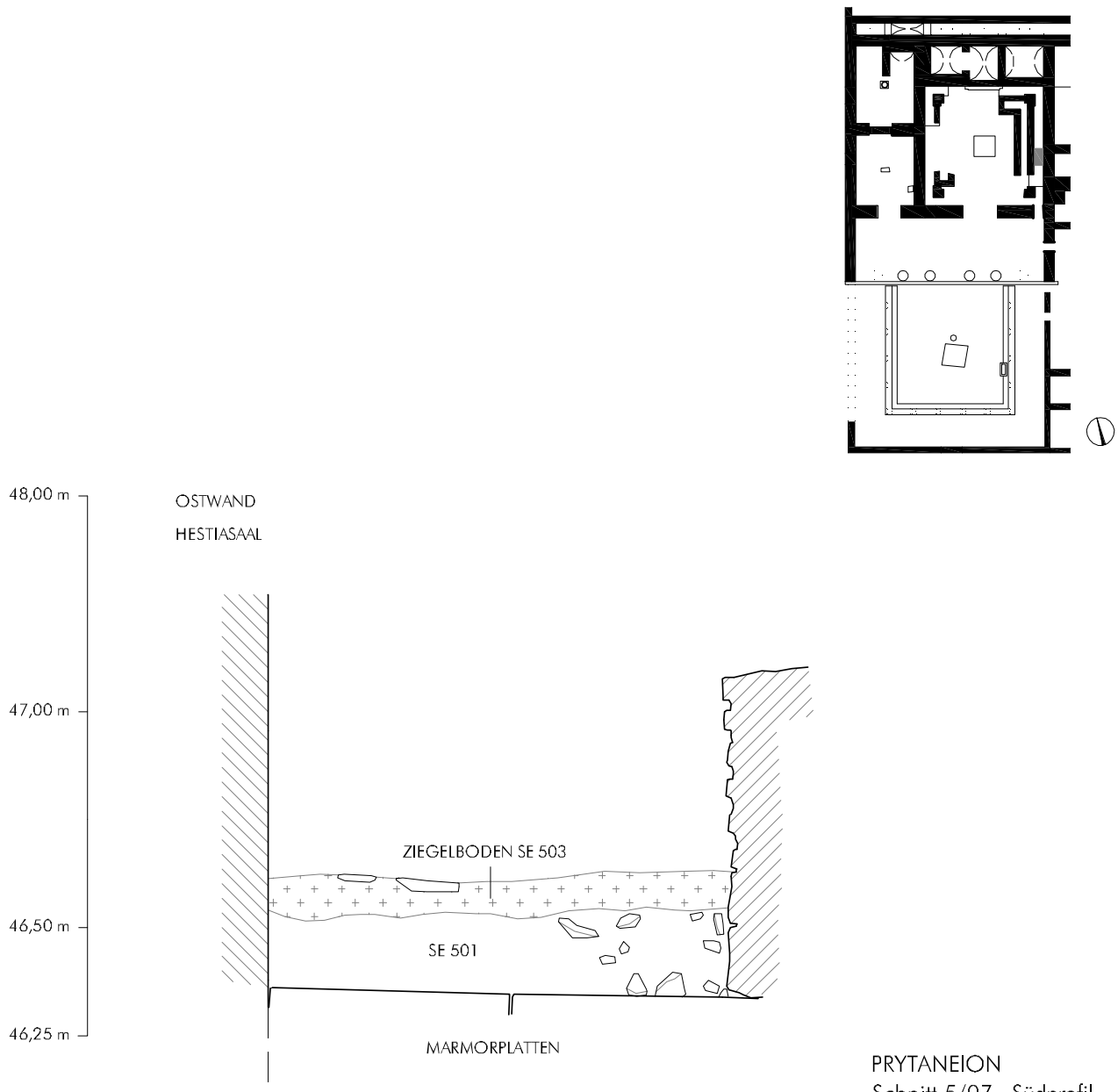

PRYTANEION

Schnitt 5/07 - Südprofil gezeichne

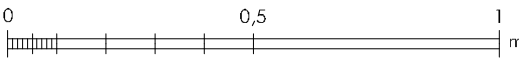

grafische Bearbeitung

L. Zabrana
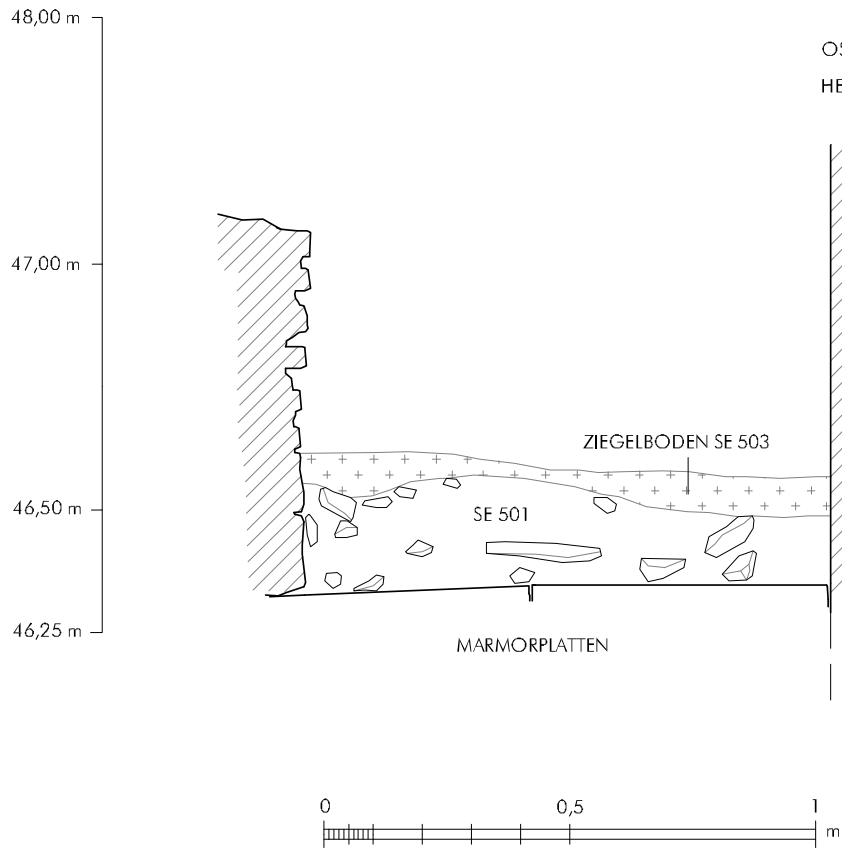

PRYTANEION

Schnitt 5/07 - Nordprofil

gezeichnet

B. Stark

grafische Bearbeitung

L. Zabrana

1 Schnitt 5/07. Süd- und Nordprofil (1:20) 
Tafel 153

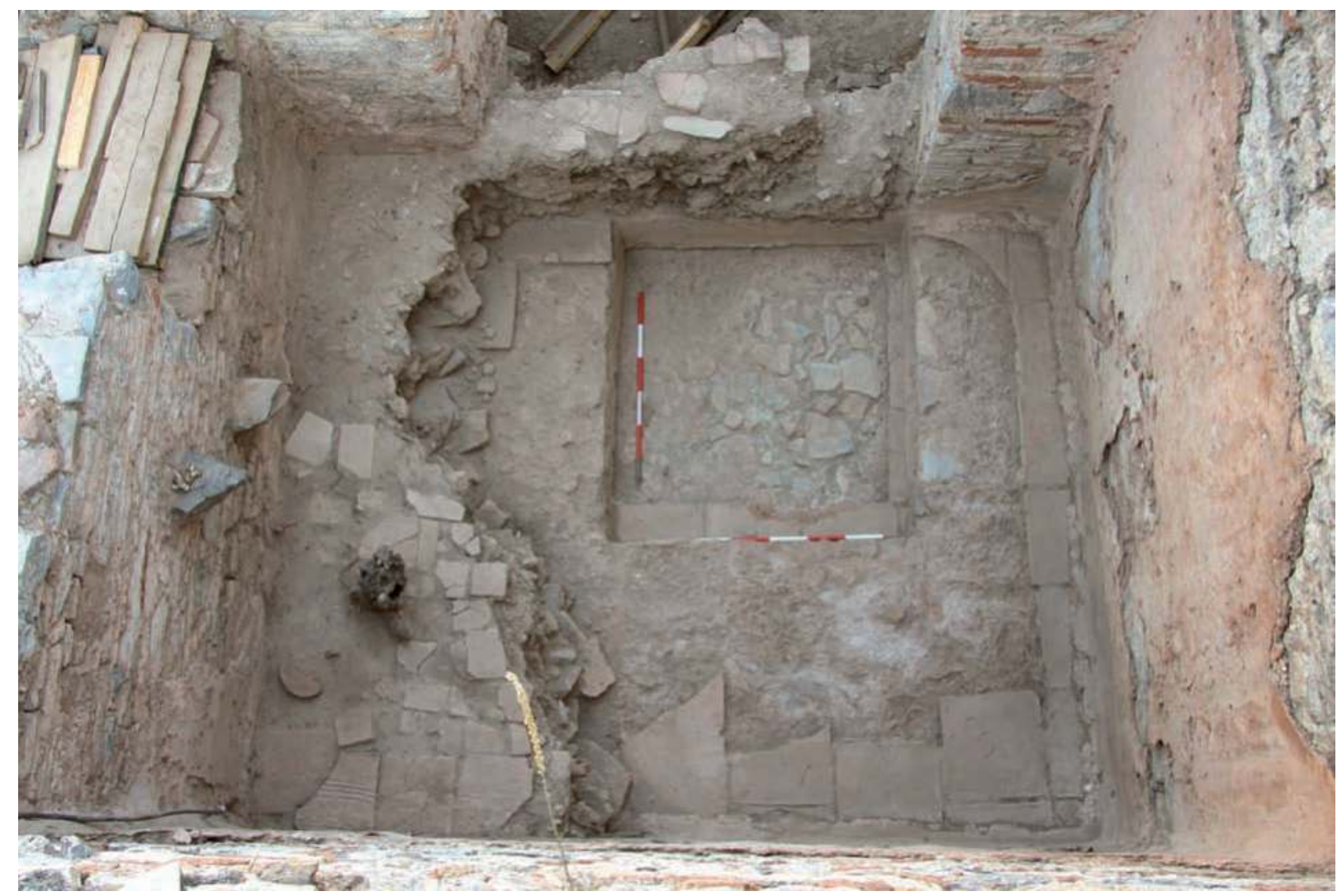

1 Schnitt 1/08. Ausgangssituation von Westen

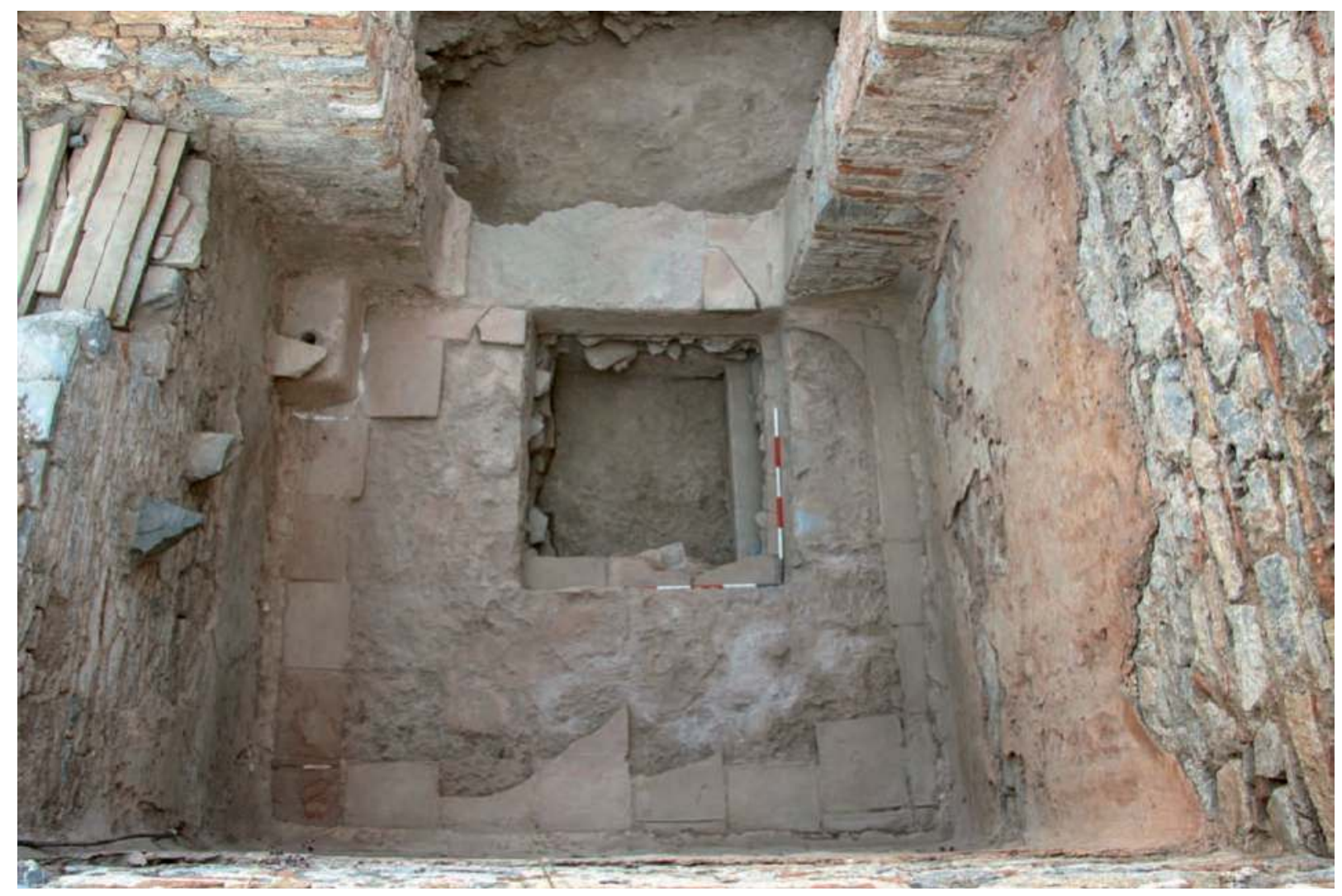

2 Schnitt 1/08. Endsituation von Westen 
Tafel 154
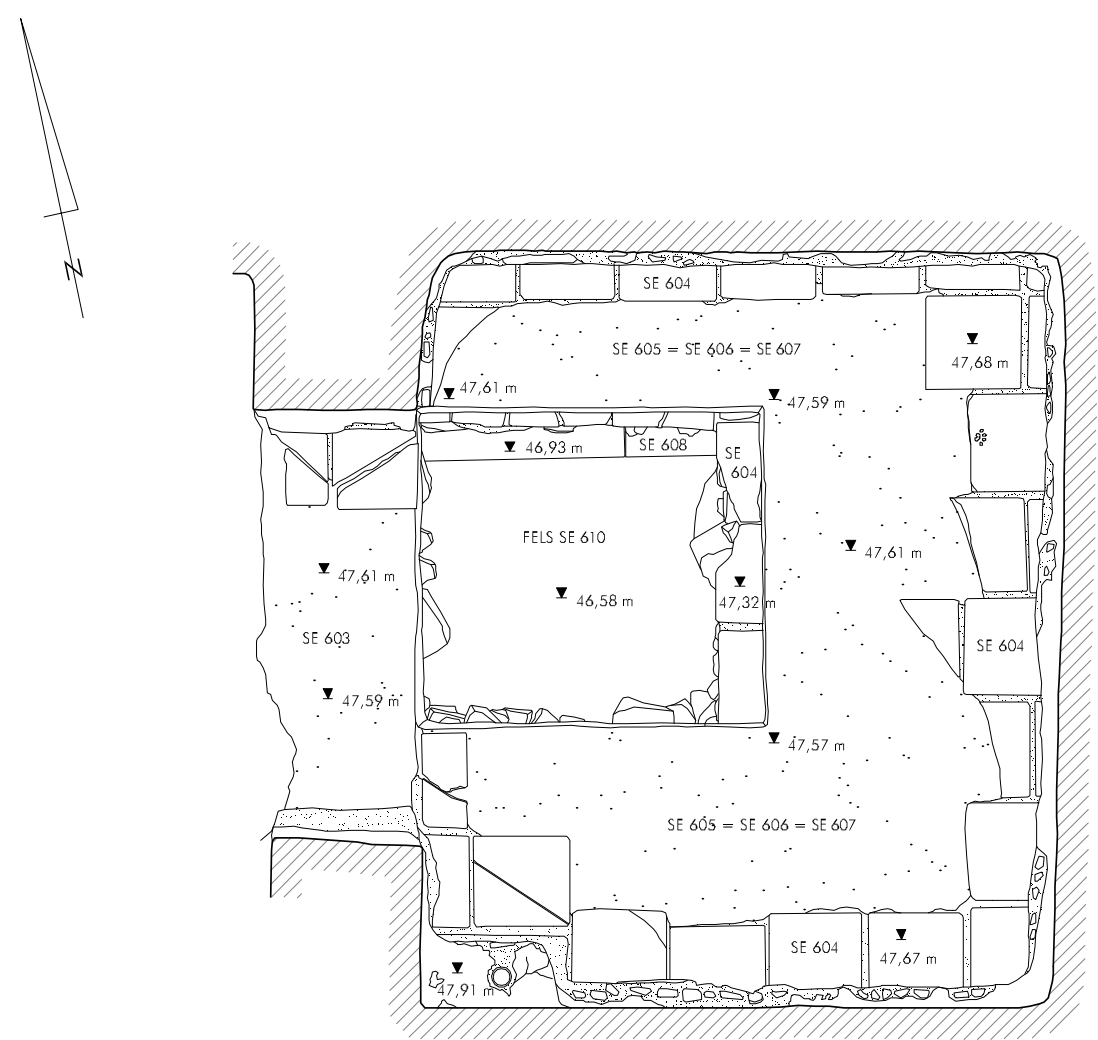

NORDWAND HESTAASAAL
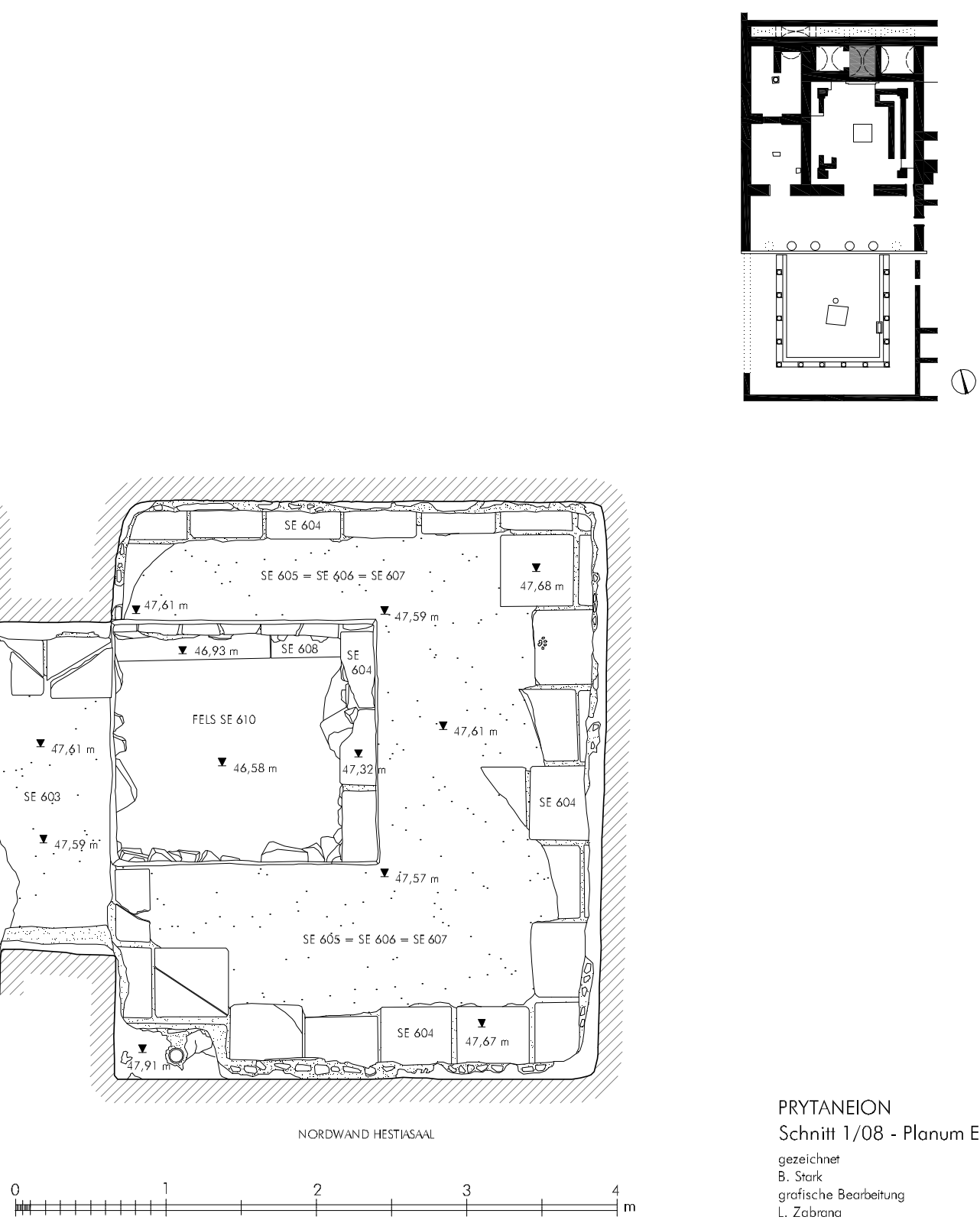

PRYTANEION

Schnitt 1/08 - Planum Endzustand gezeichnet
B. Stark

grafische Bearbeitung

L. Zabrana

1 Schnitt 1/08. Planum Endzustand (1:50) 
Tafel 155

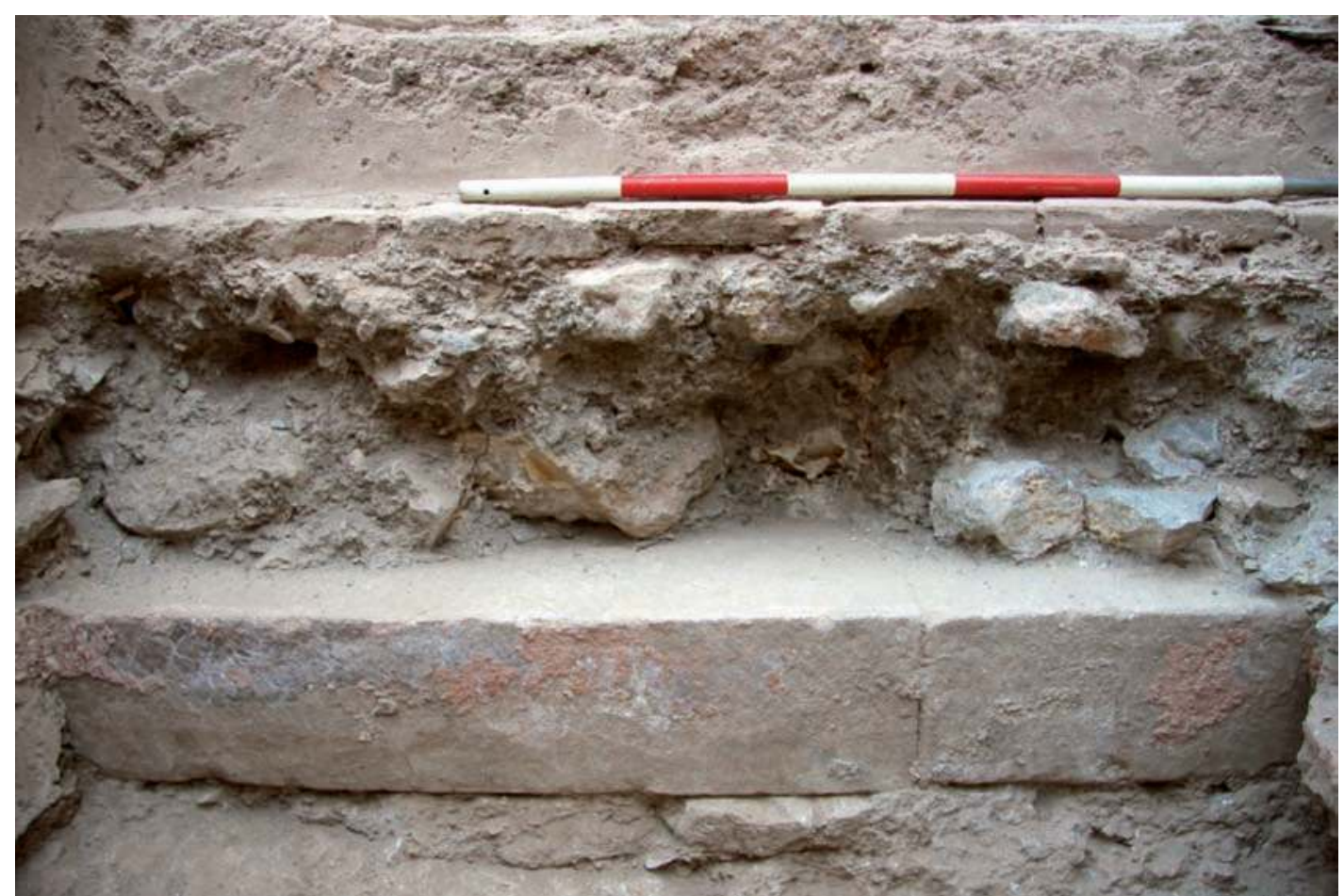

1 Schnitt 1/08. Nordprofil
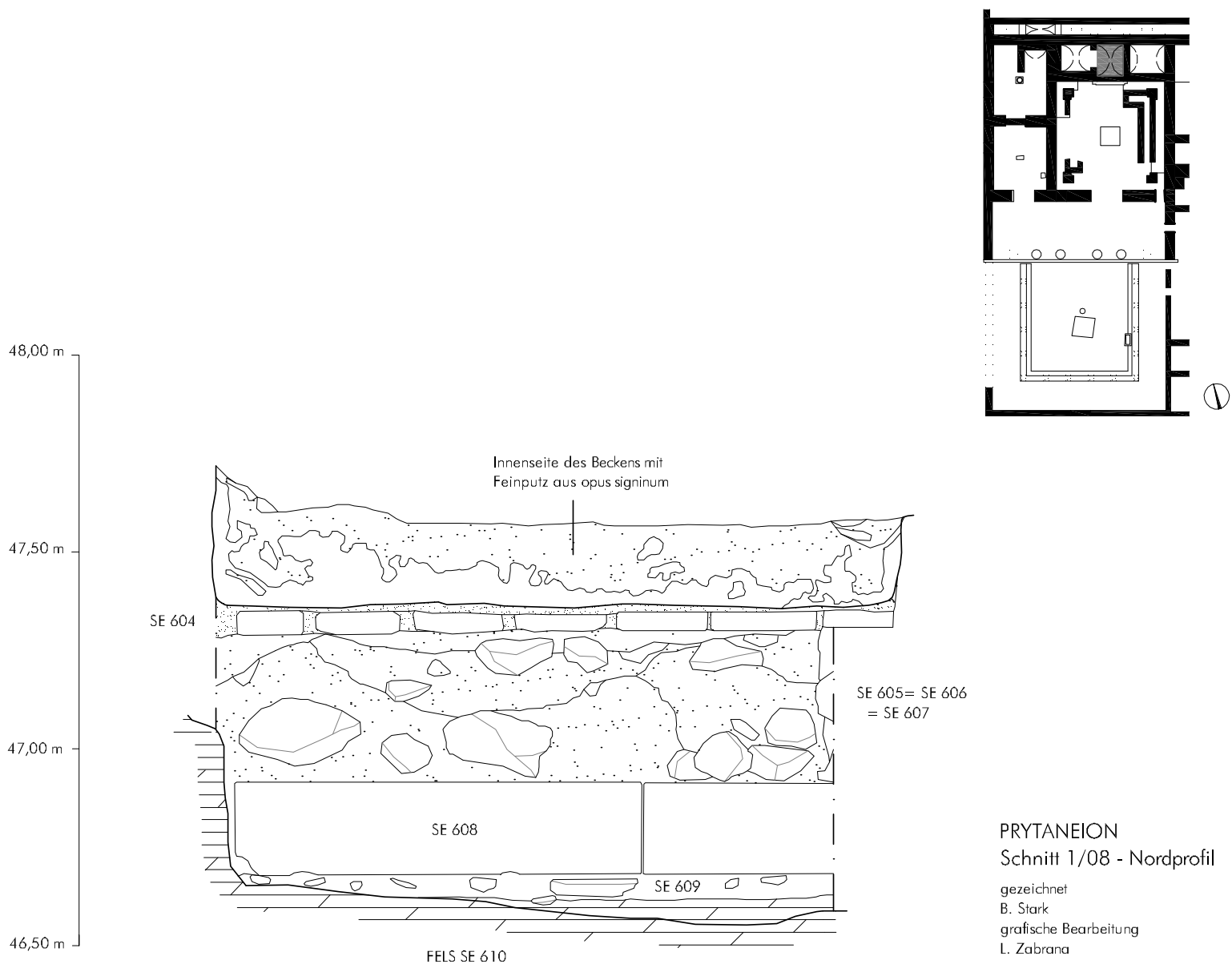

PRYTANEION

Schnitt 1/08 - Nordprofil

gezeichn

B. Stark

grafische Bearbeitung

FELS SE 610

Zabrana

0

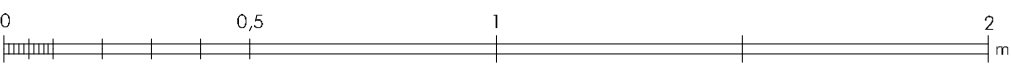

2 Schnitt 1/08. Nordprofil (1:20) 
Tafel 156

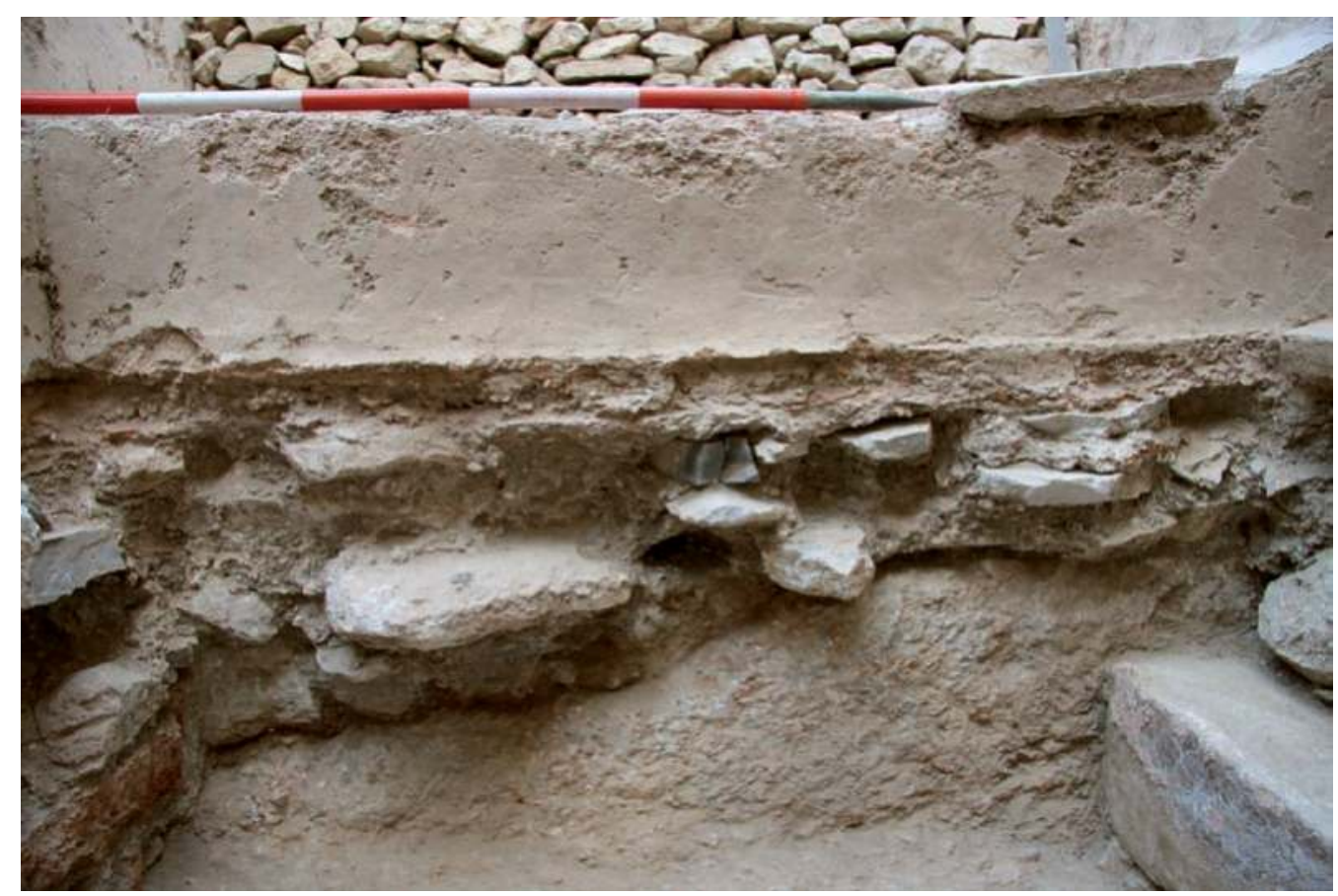

1 Schnitt 1/08. Ostprofil

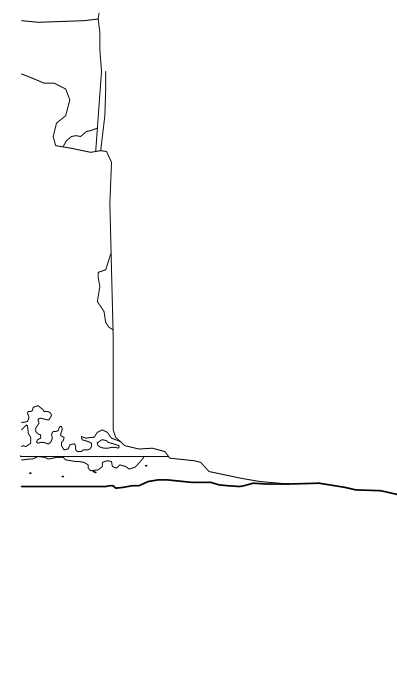

PRYTANEION

Schnitt 1/08 - Westprofil

gezeichnet

grafische Bearbeitung

Lrabischana
Innenseite des Beckens mit Feinputz aus opus

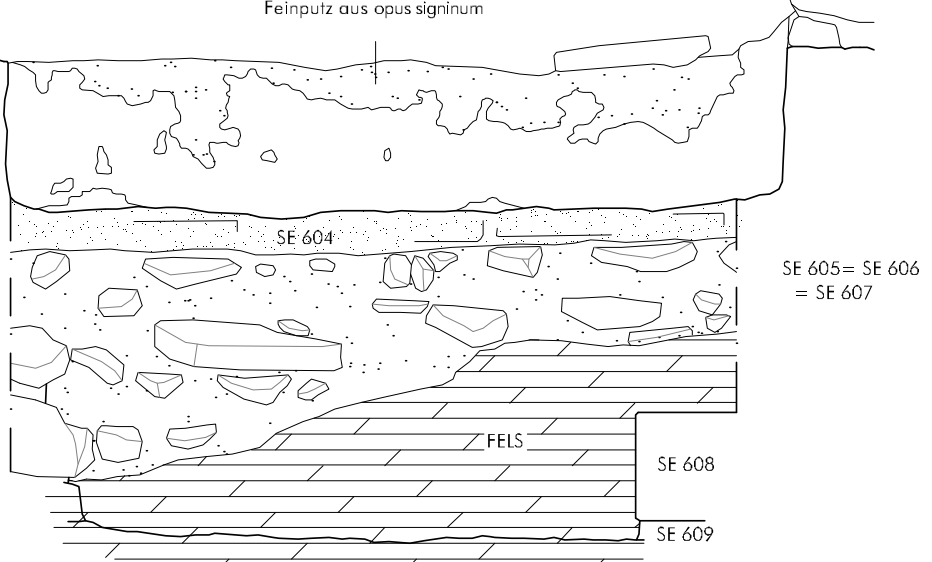

FELS SE 610

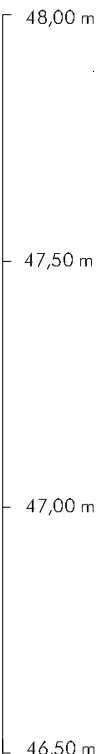

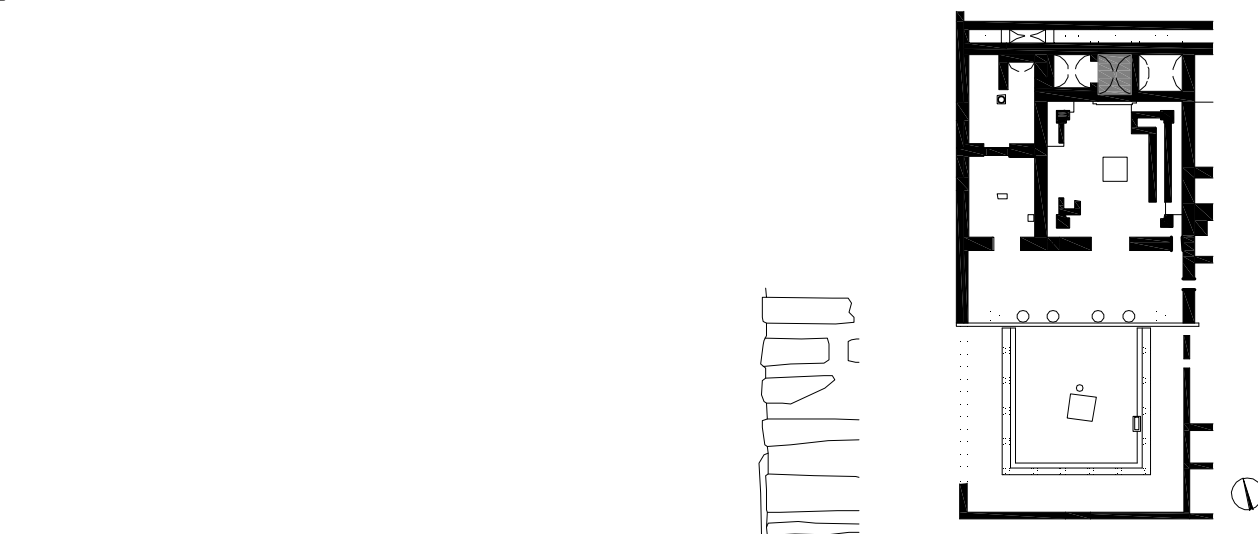

0 0,5 1 2

2 Schnitt 1/08. Ostprofil (1:20) 
Tafel 157

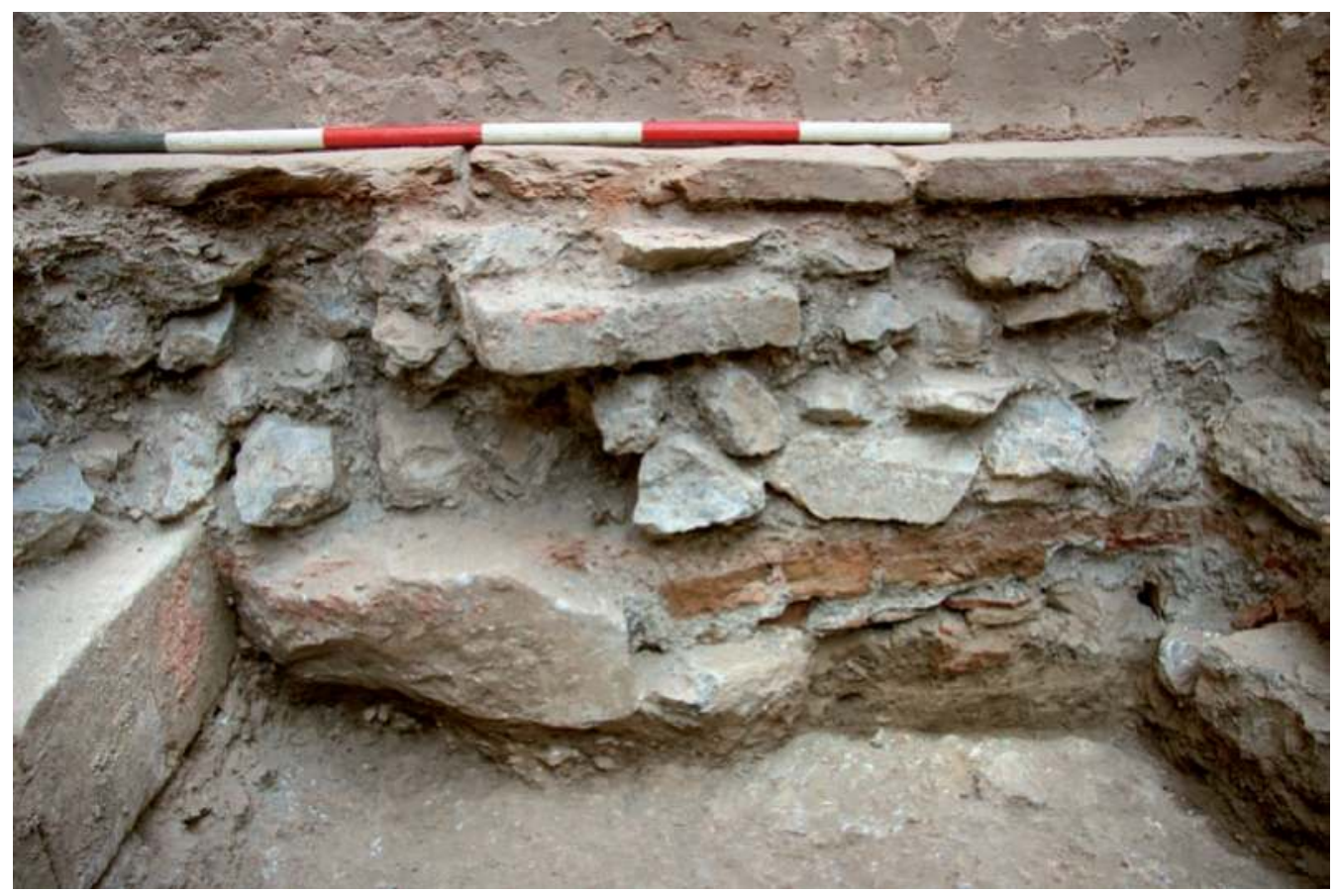

1 Schnitt 1/08. Westprofil

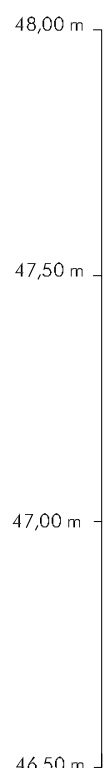

$46,50 \mathrm{~m}$

Innenseite des Beckens mit Feinputz aus opus signinum

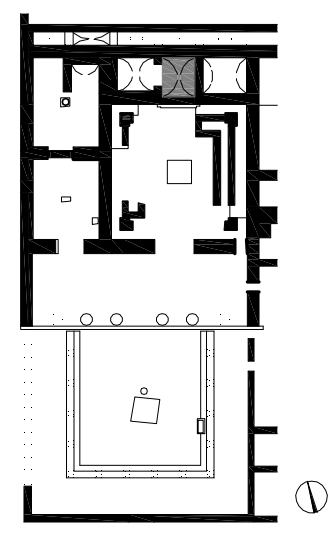

PRYTANEION

Schnitt 1/08 - Ostprofil

gezeichnet
B. Stark

grafische Bearbeitung

L. Zabrana

SE $605=$ SE 606

$=$ SE 607

SE 608

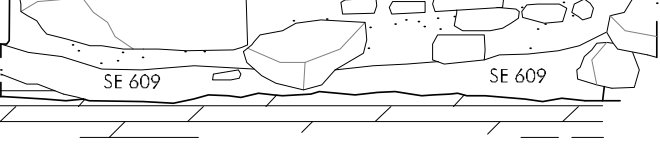

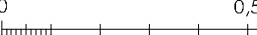

1

2 Schnitt 1/08. Westprofil (1:20) 


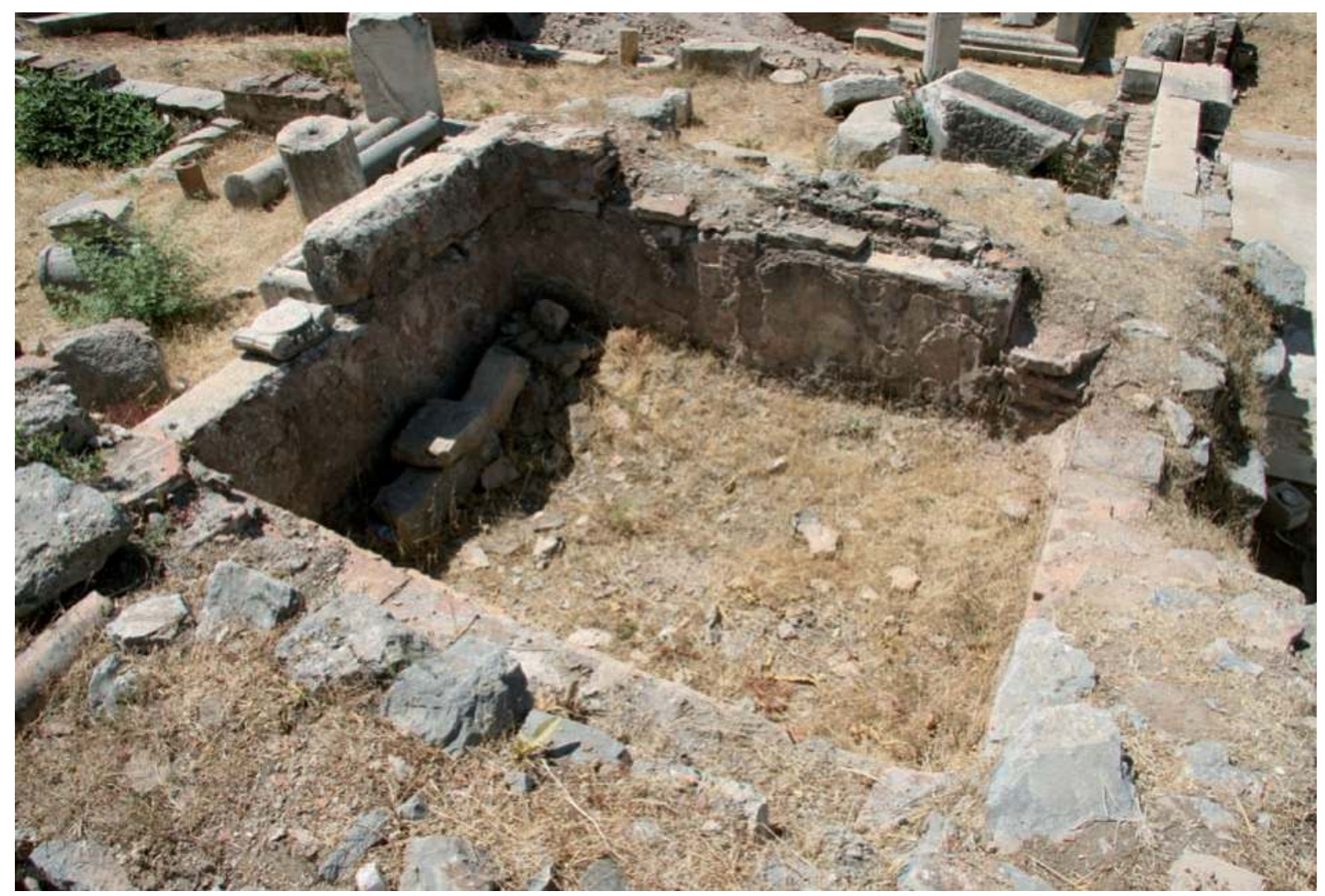

1 Sekundäres Wasserreservoir in Raum 7 östlich des Prytaneions

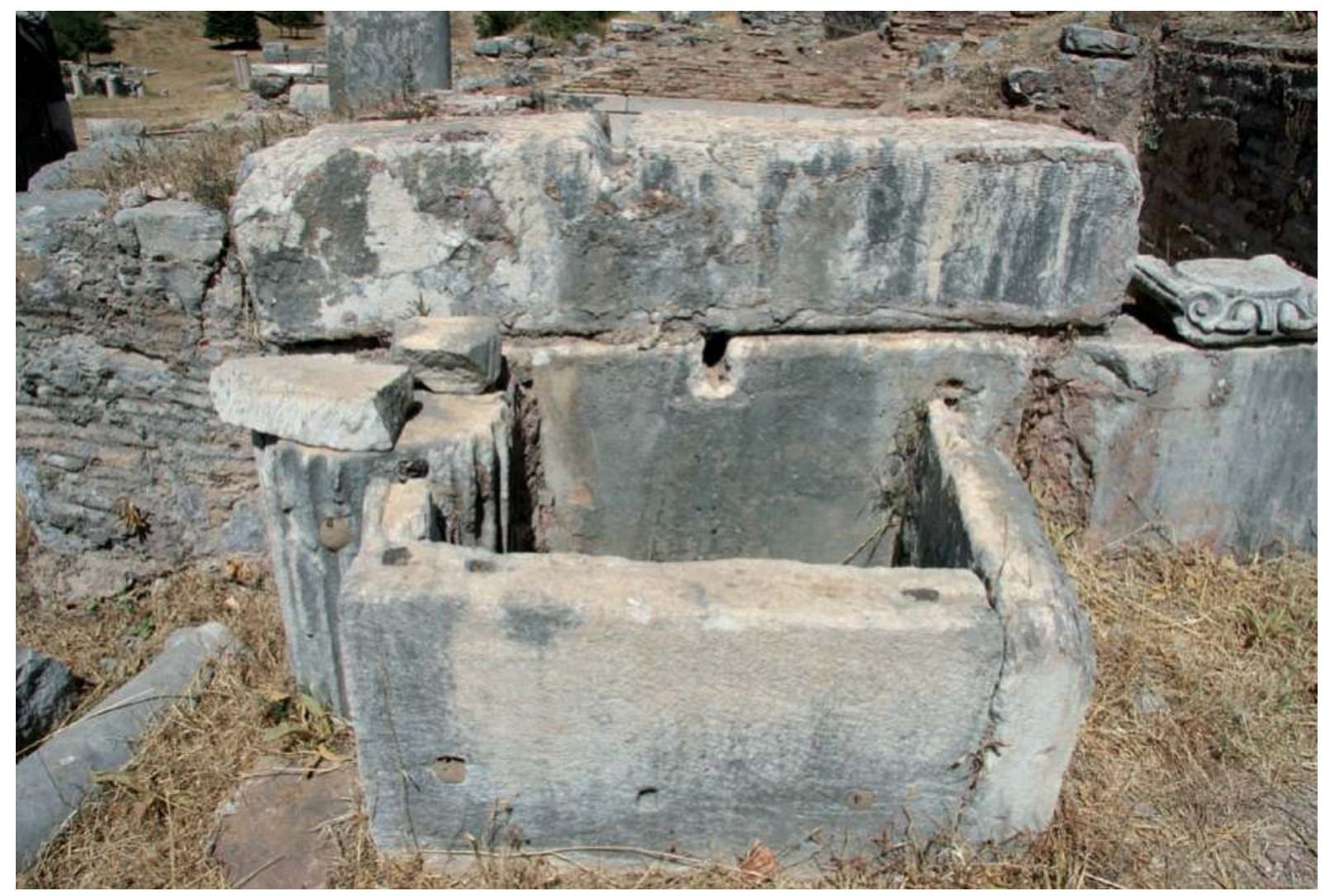

2 Sekundäre Wasserentnahmestelle östlich von Raum 7 
Tafel 159

\section{PRYTANEION}

BAUPHASE 1 Rekonstruktion
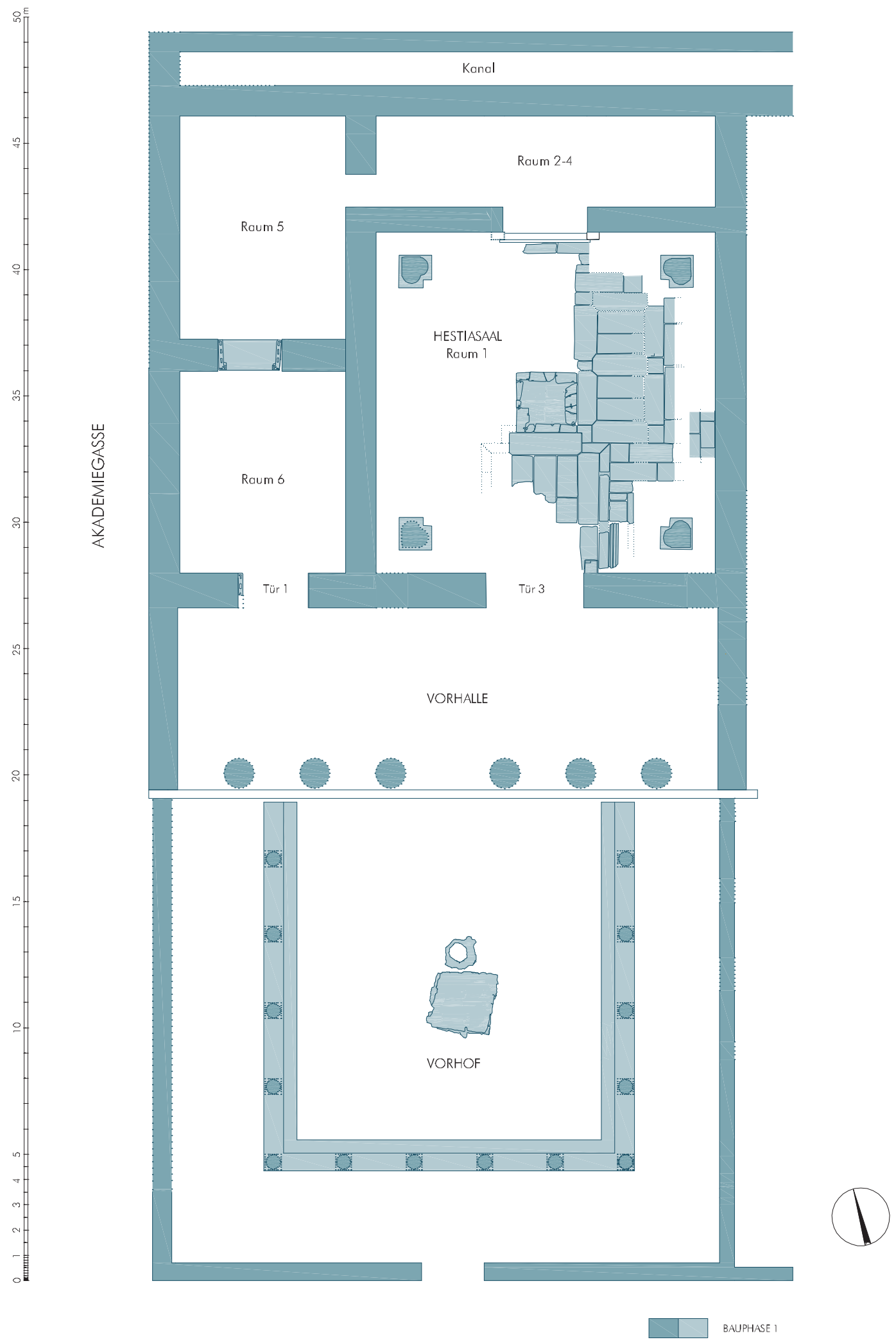

1 Prytaneion. Rekonstruierter Grundriss - Bauphase 1 (1:250). - Geschnittene Bauteile dunkel, aufsichtige Bauteile hell 
Tafel 160

PRYTANEION

BAUPHASE 2 Rekonstruktion

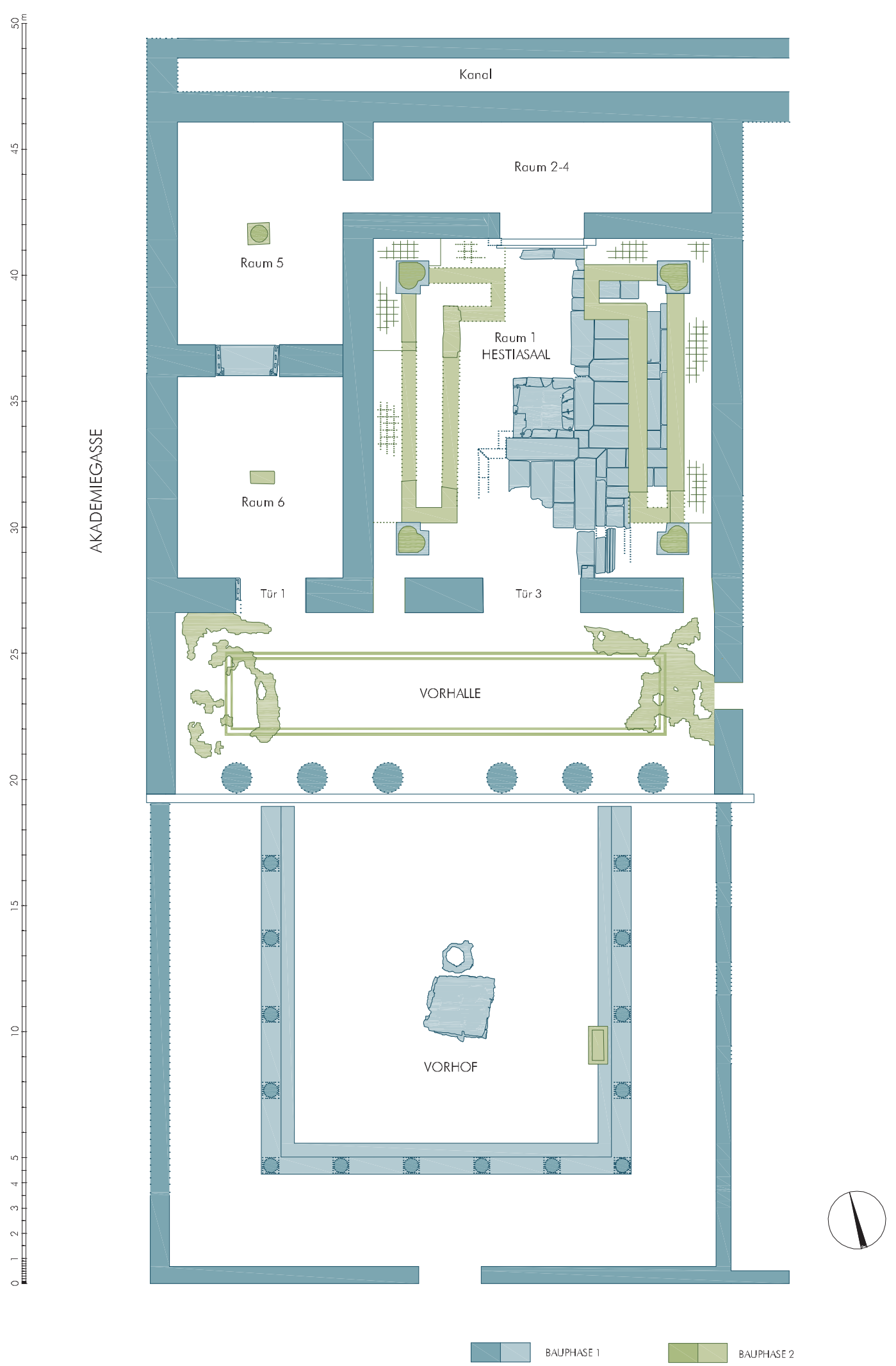

1 Prytaneion. Rekonstruierter Grundriss - Bauphase 2 (1:250). - Geschnittene Bauteile dunkel, aufsichtige Bauteile hell 
Tafel 161

PRYTANEION

BAUPHASE 3 Rekonstruktion

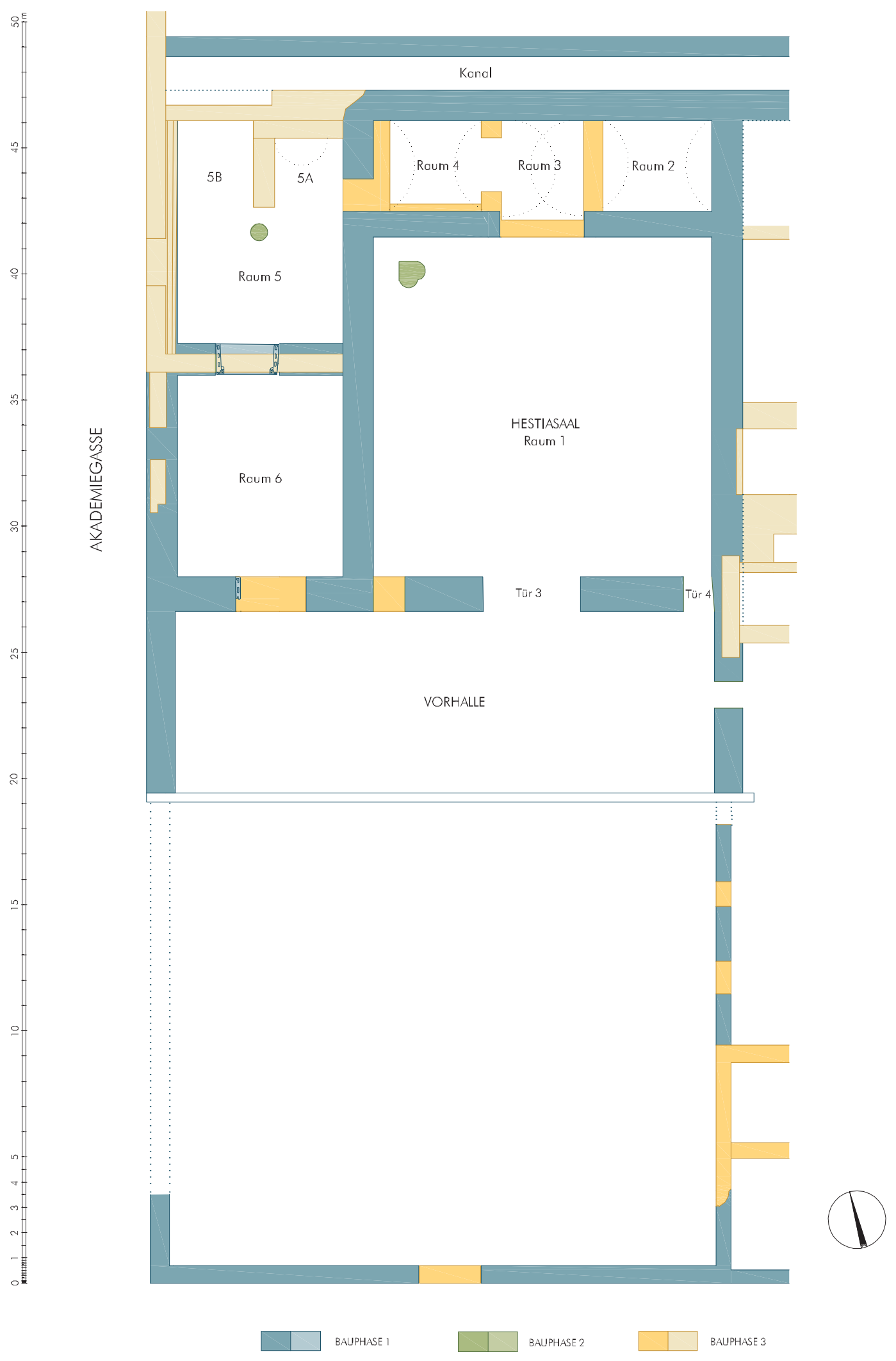

1 Prytaneion. Rekonstruierter Grundriss - Bauphase 3 (1:250). - Geschnittene Bauteile dunkel, aufsichtige Bauteile hell 
Tafel 162
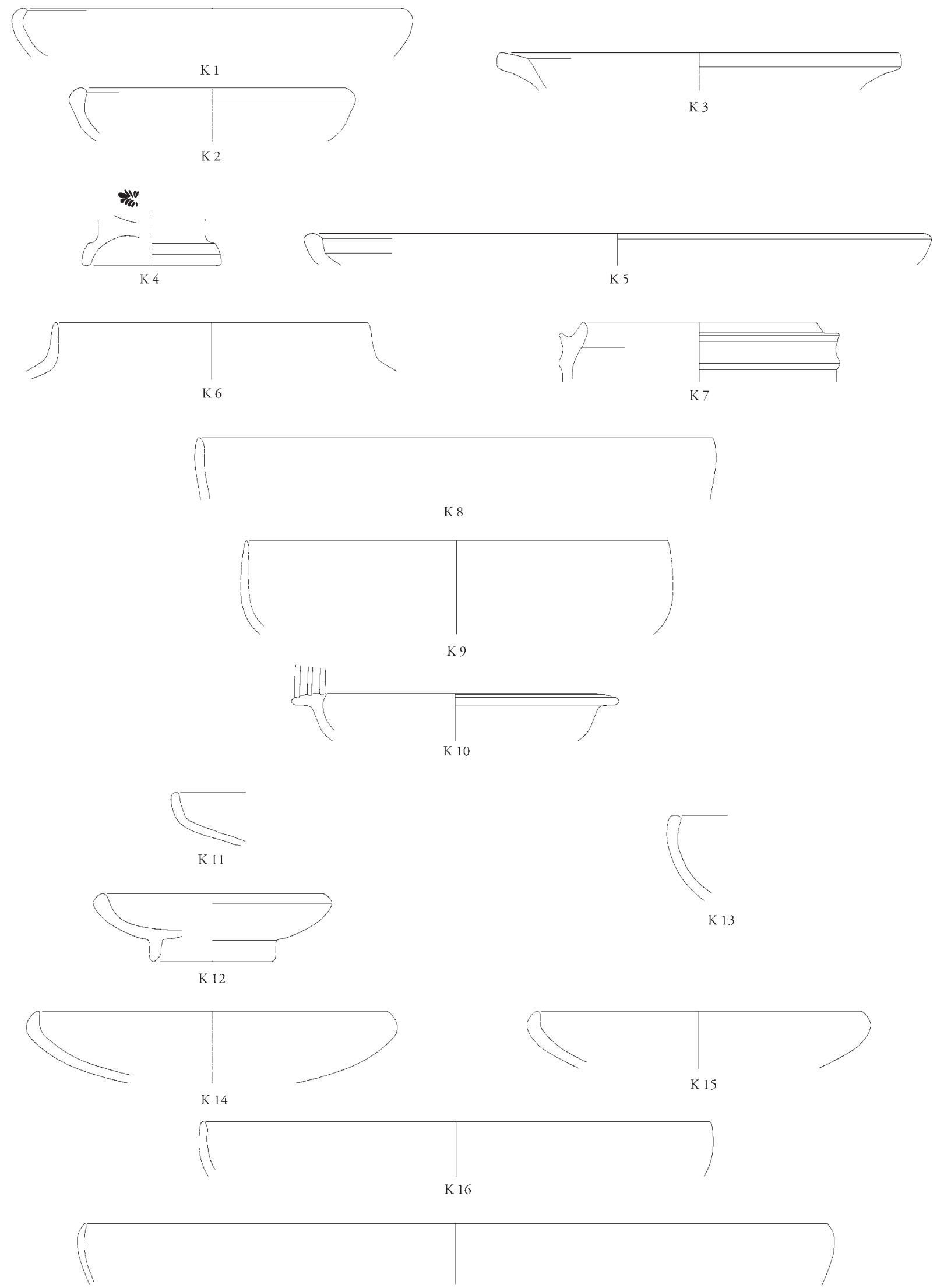

K 17

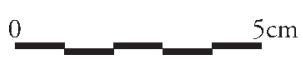

K 1-17 


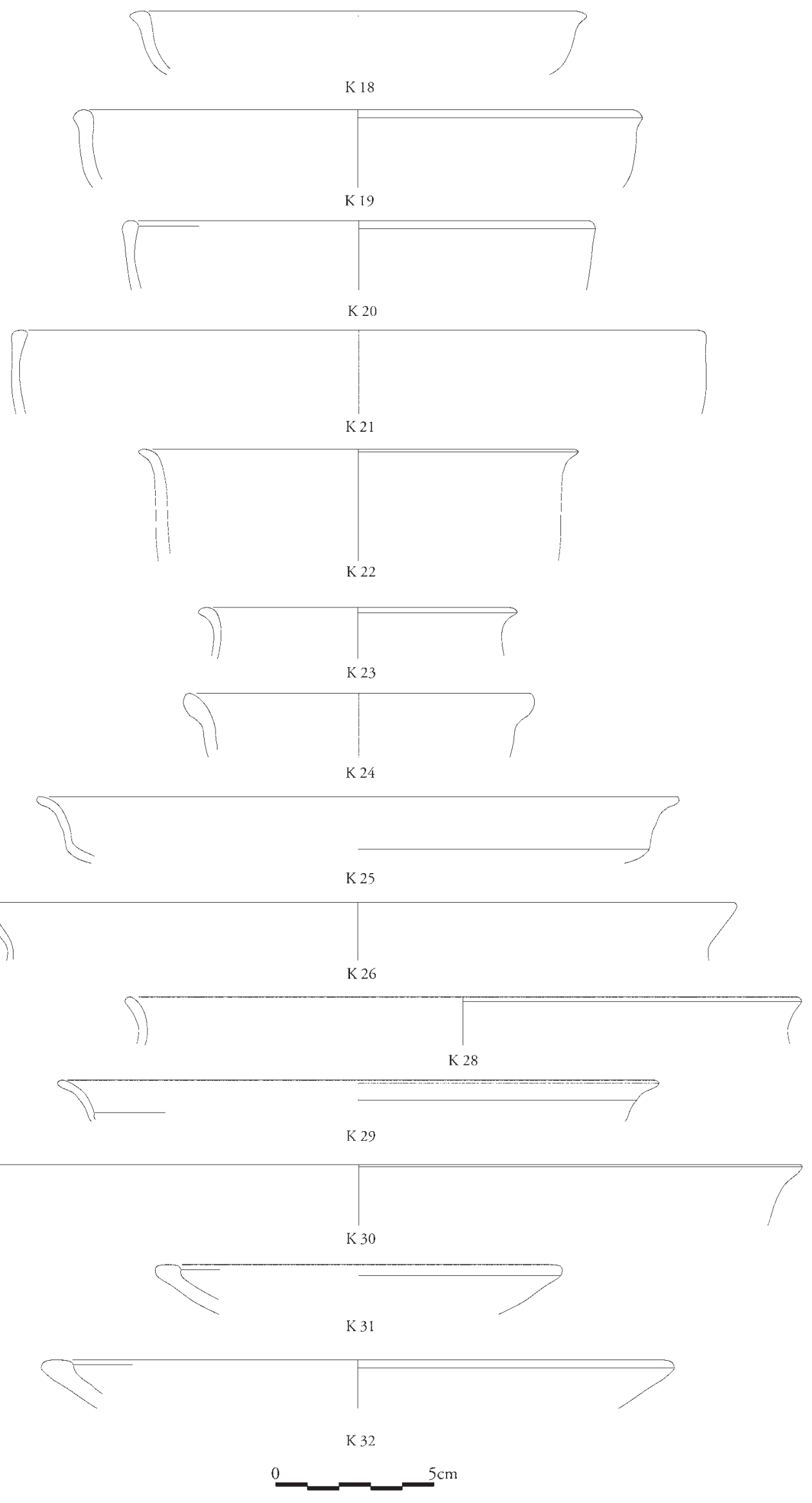

K 18-32 
Tafel 164

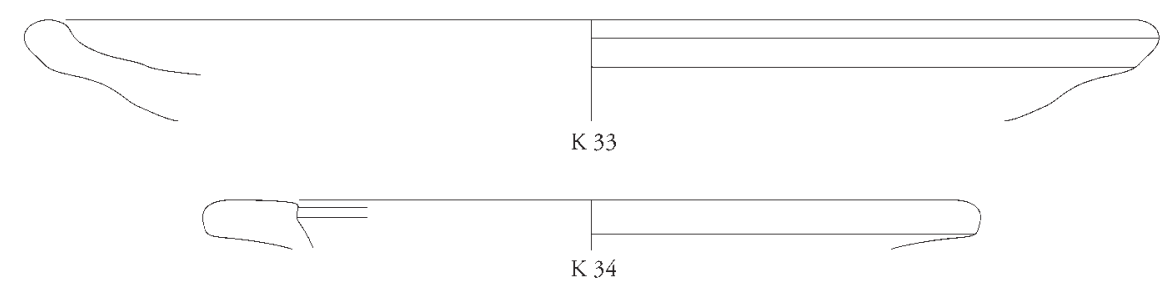

$\varnothing 33,4 \mathrm{~cm}$

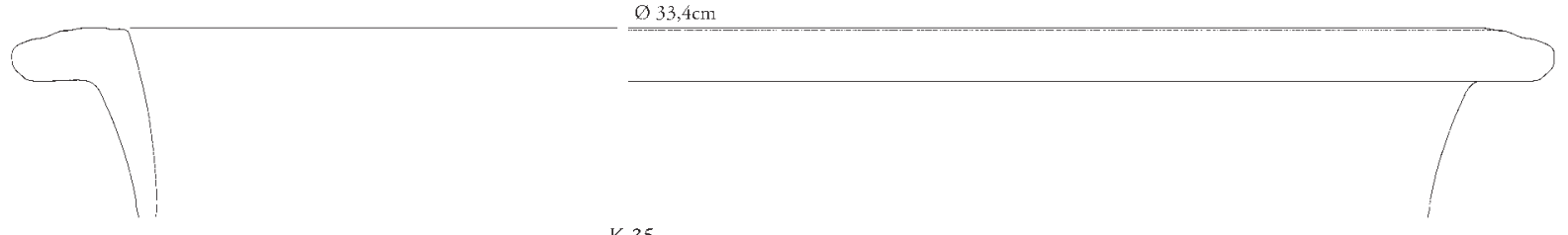

K 35
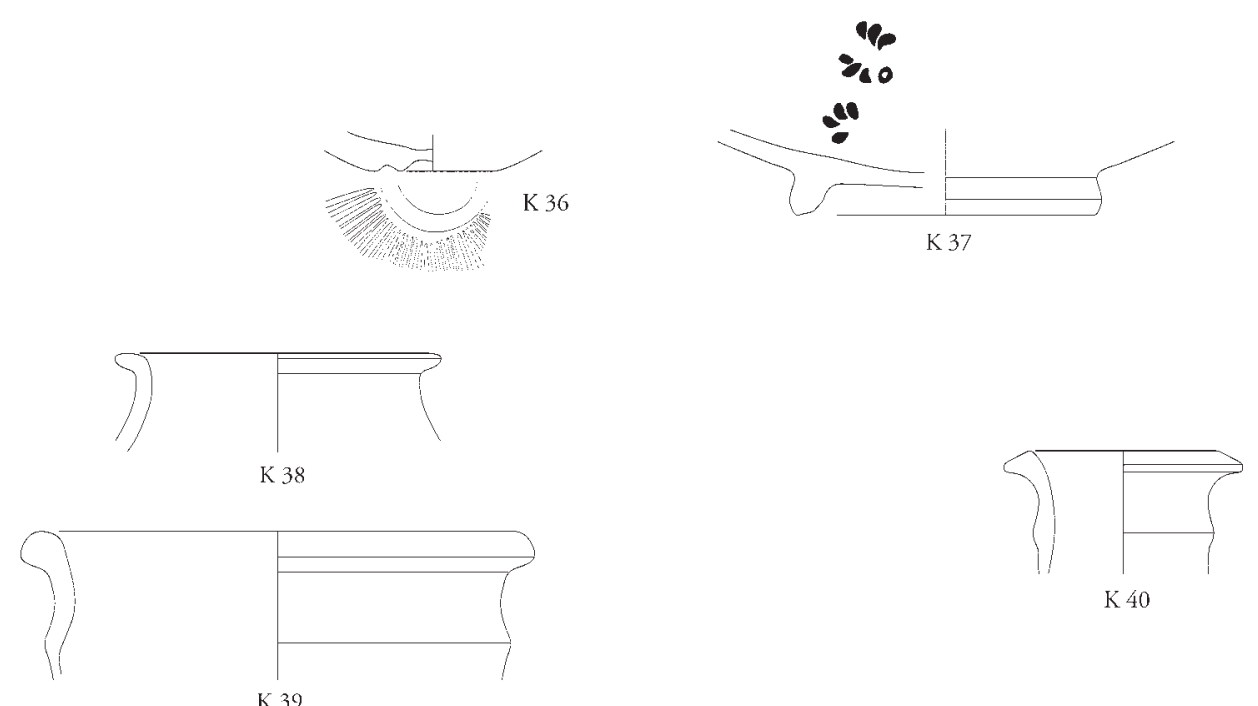

K 40

K39

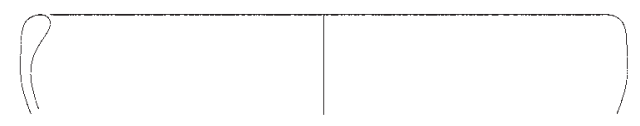

K 41
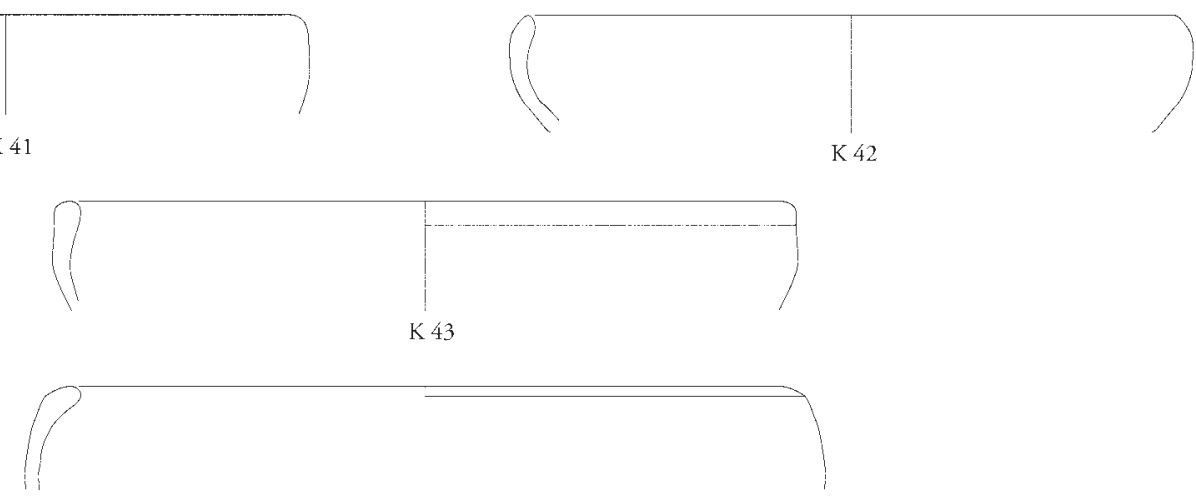

K 44

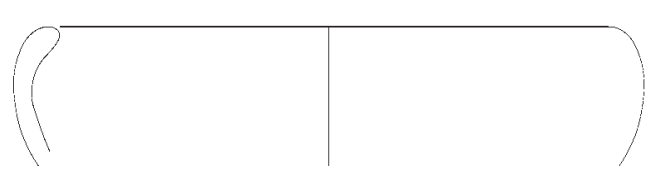

K 45

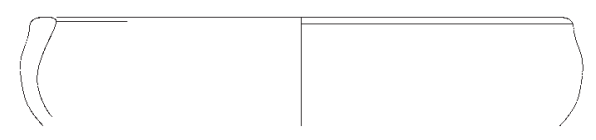

K 46

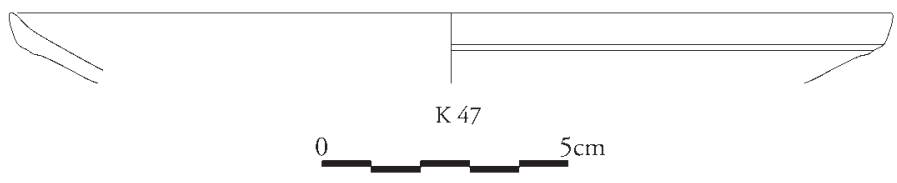

K 33-47 
Tafel 165
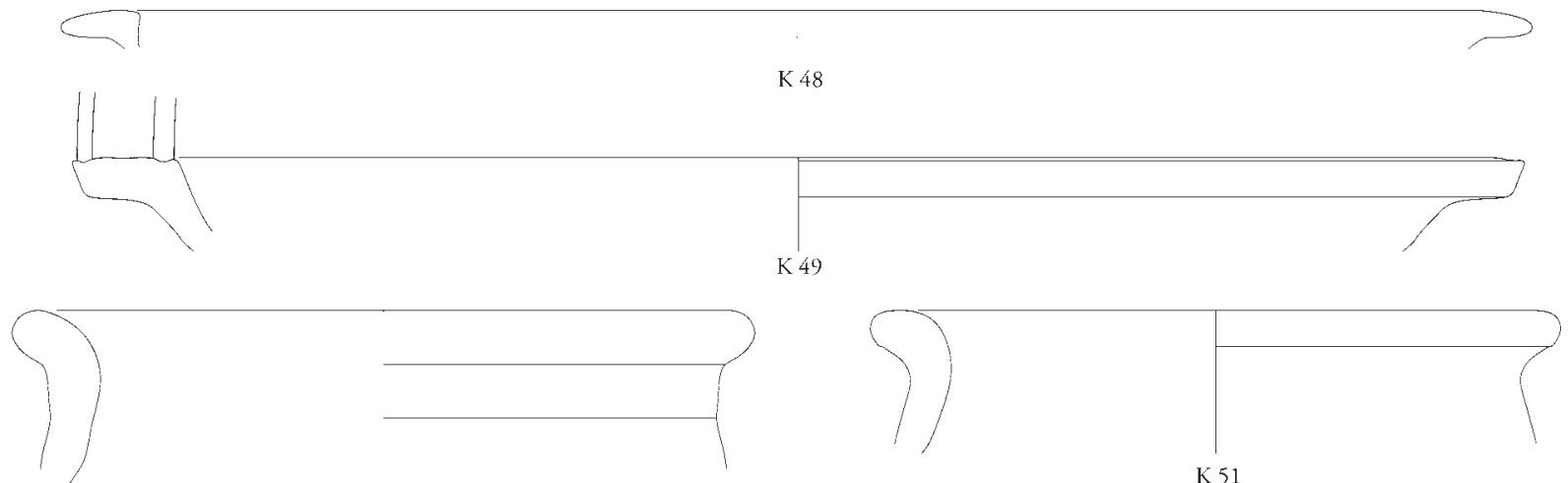

K 50
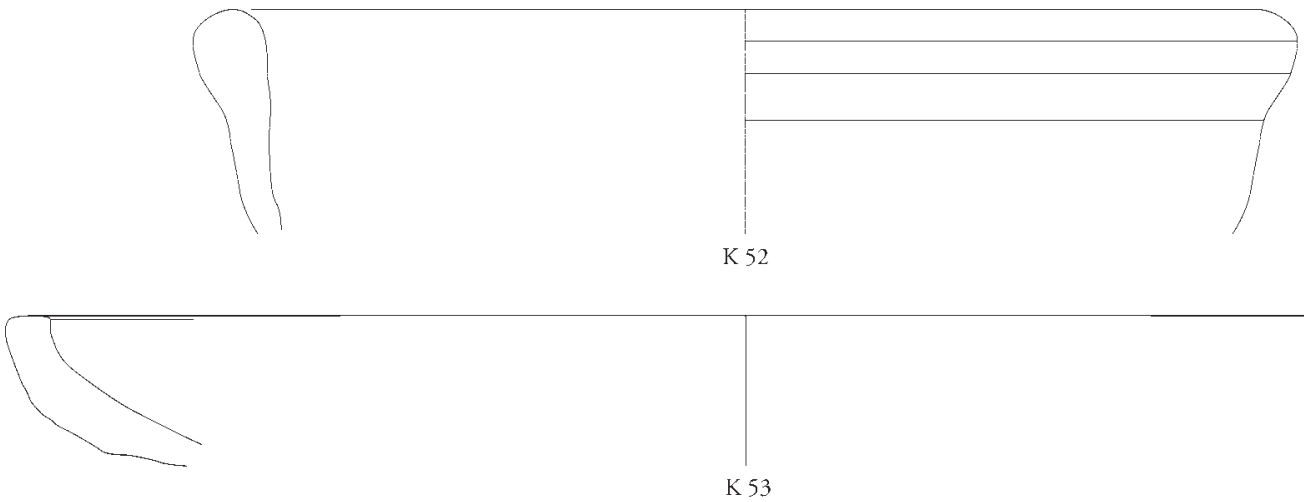

K 53
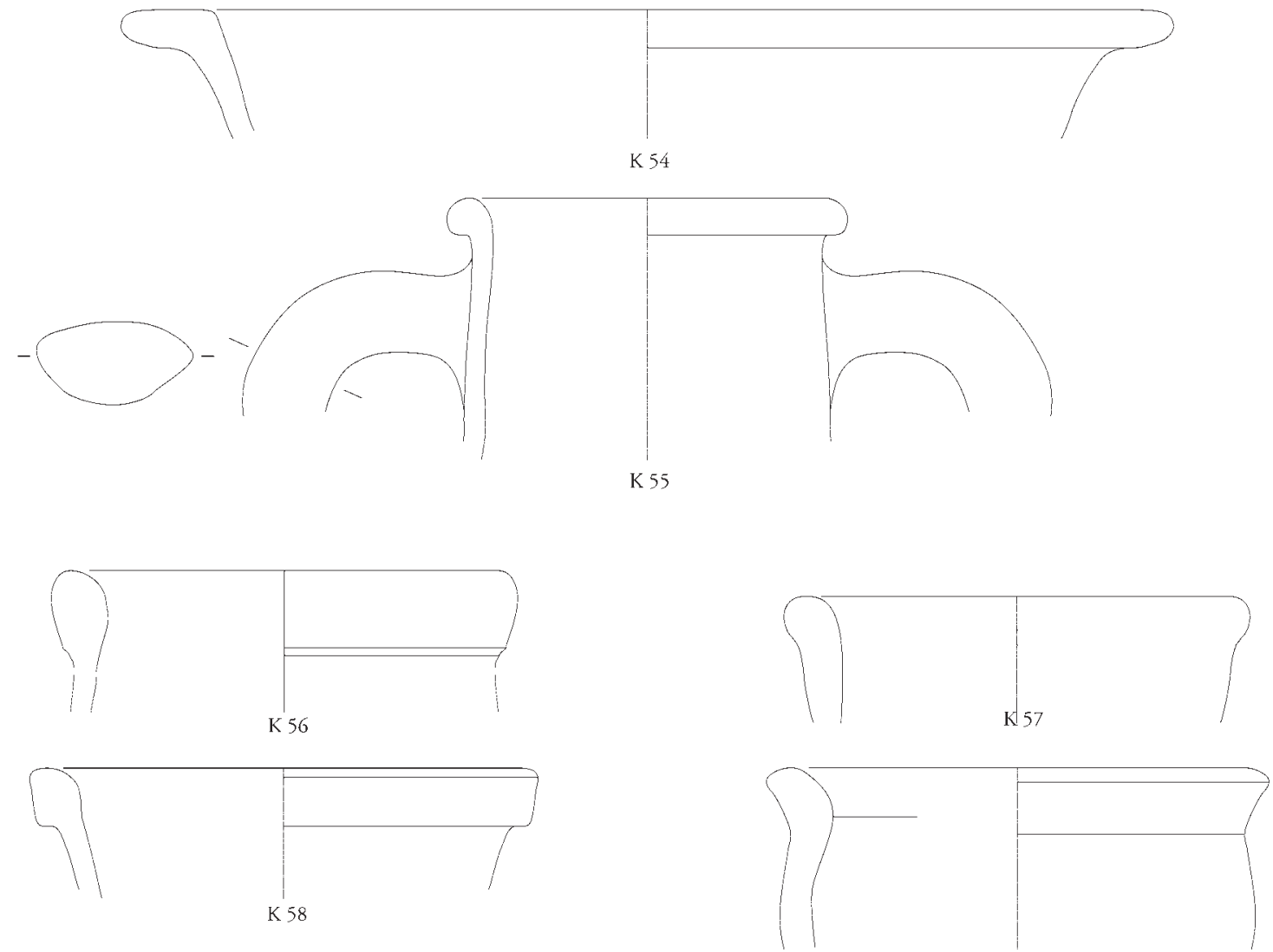

K 59

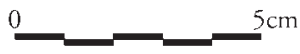

K 48-59 
Tafel 166

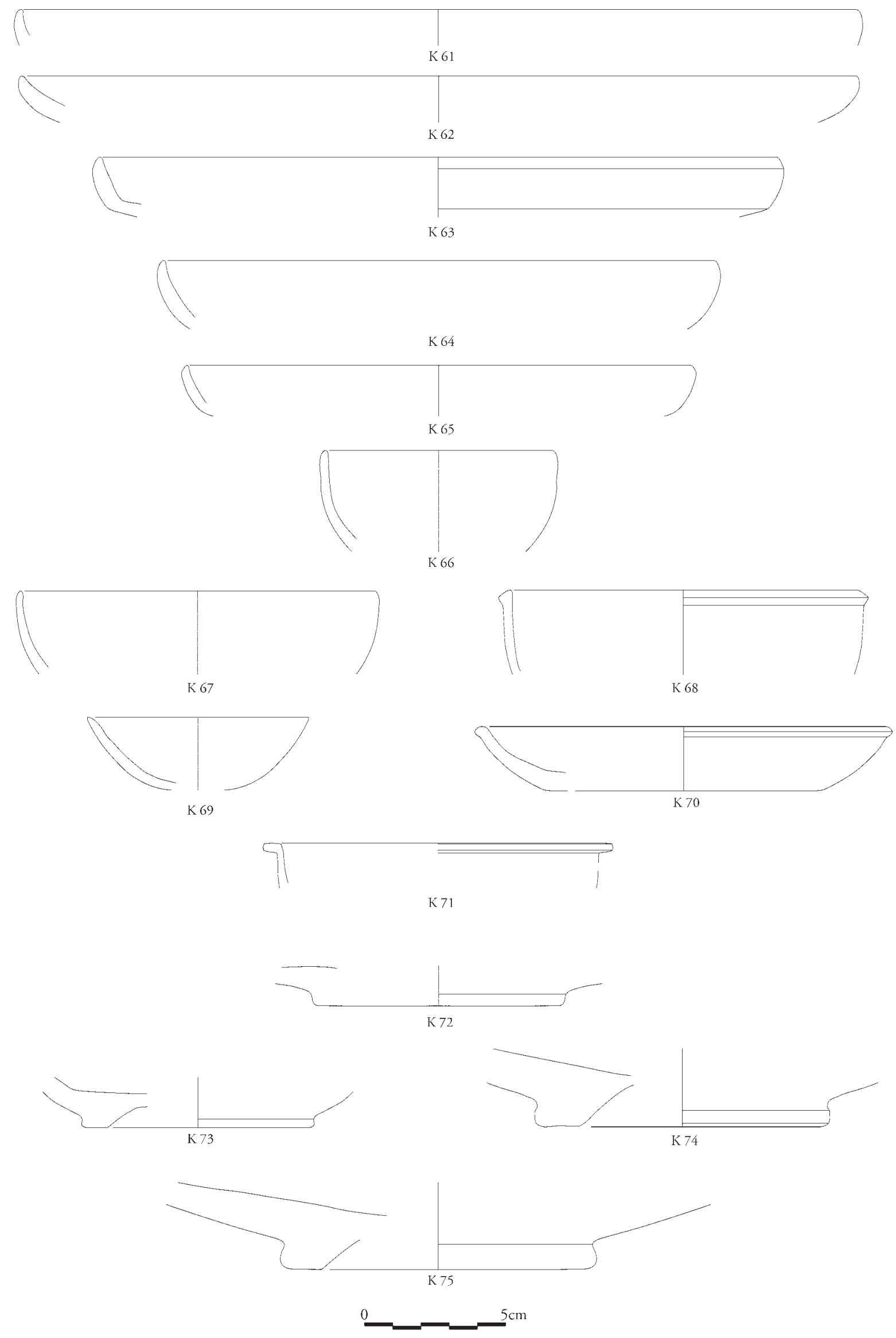

K 61-75 
Tafel 167
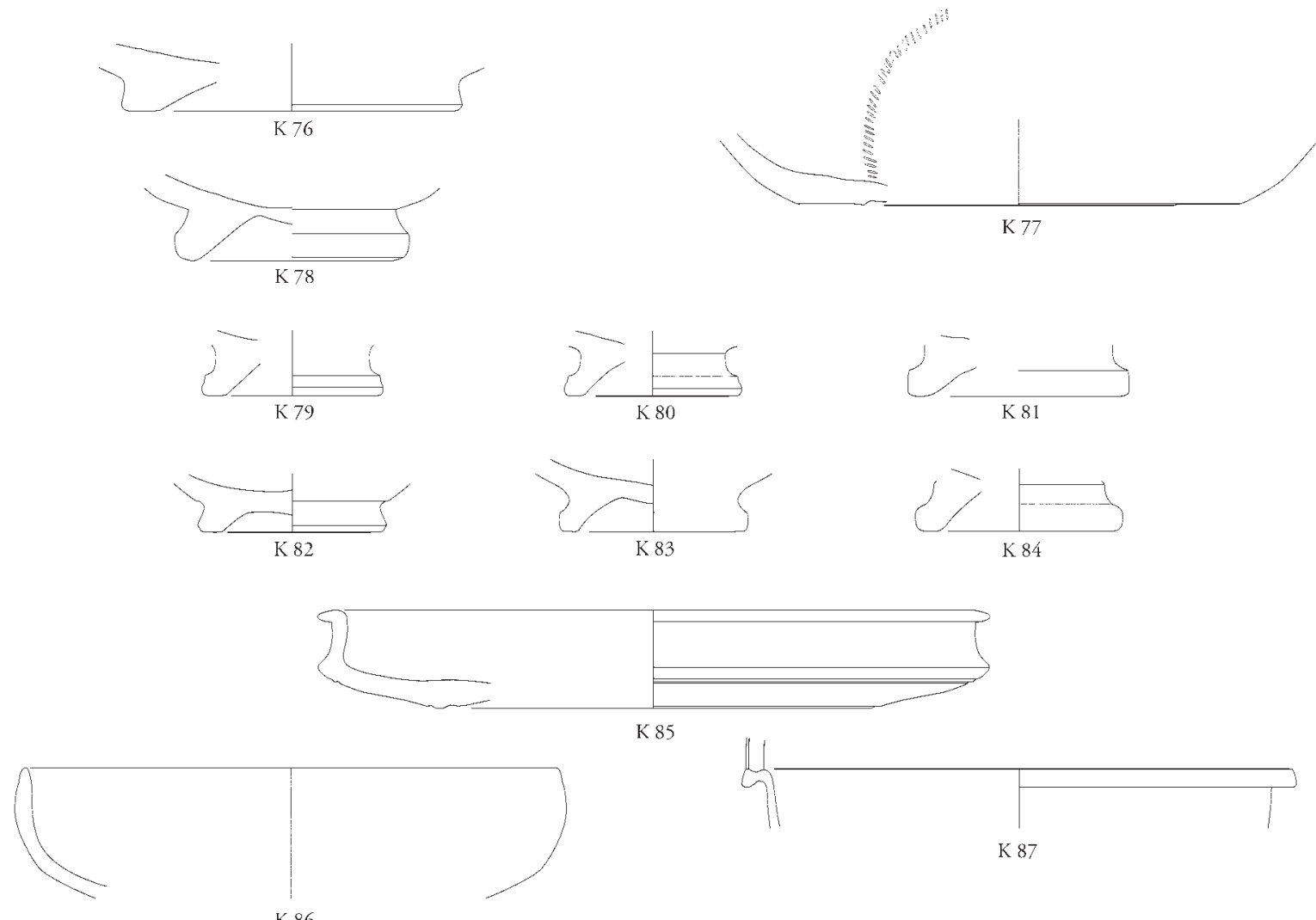

K 86
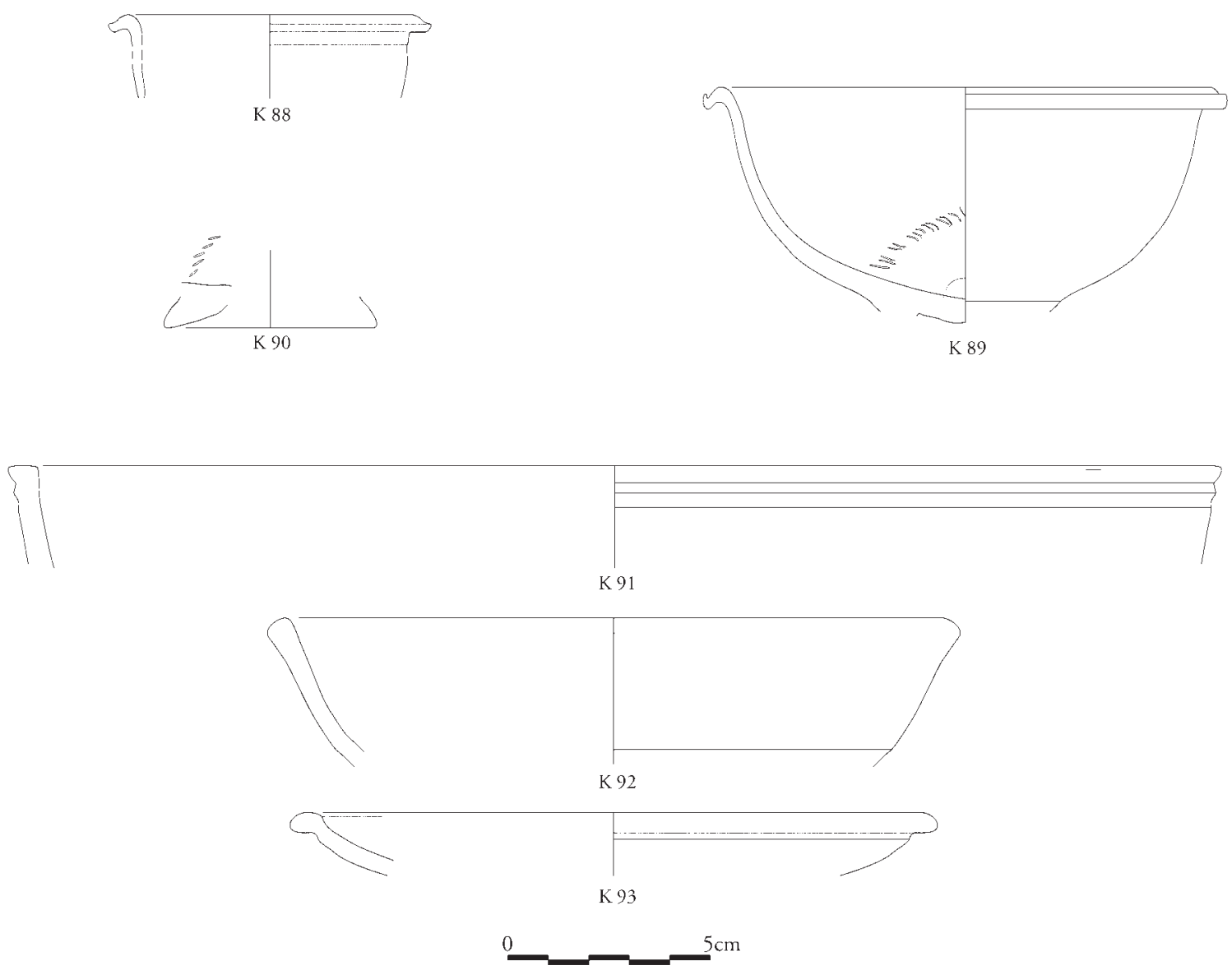

K 76-93 
Tafel 168
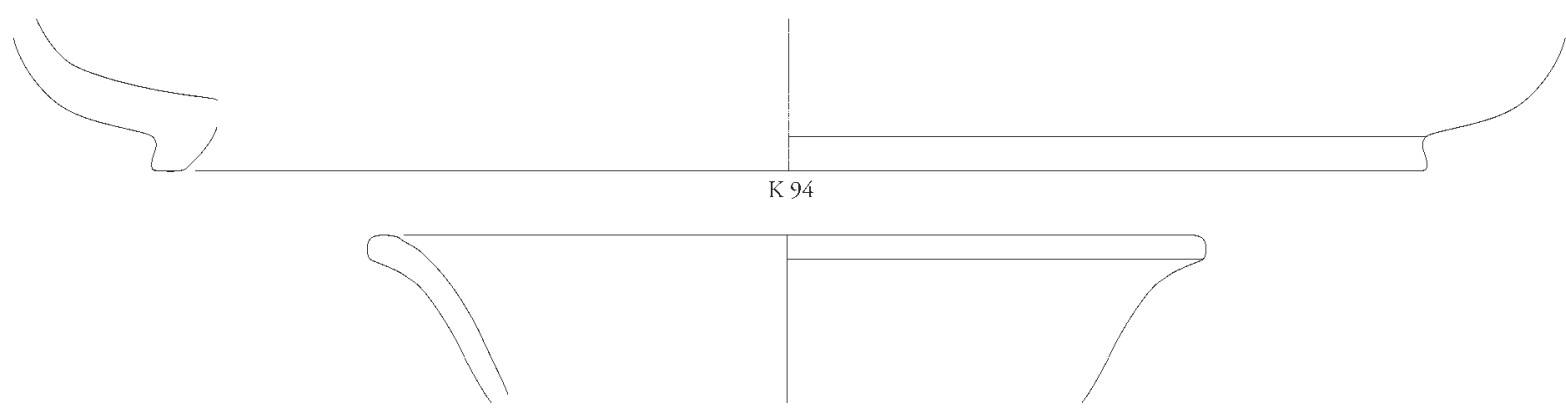

K 95
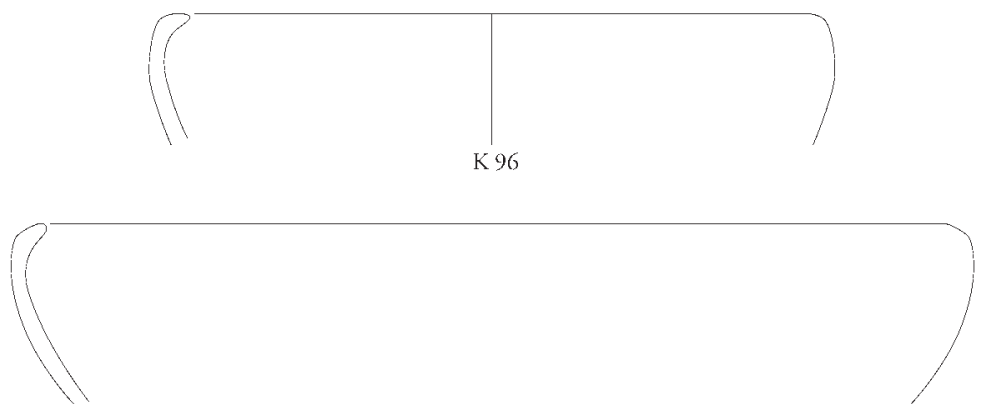

K 97

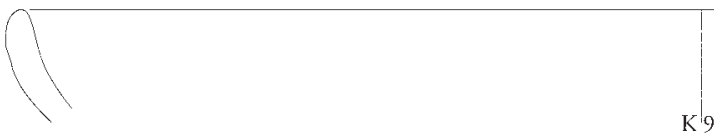

K 99
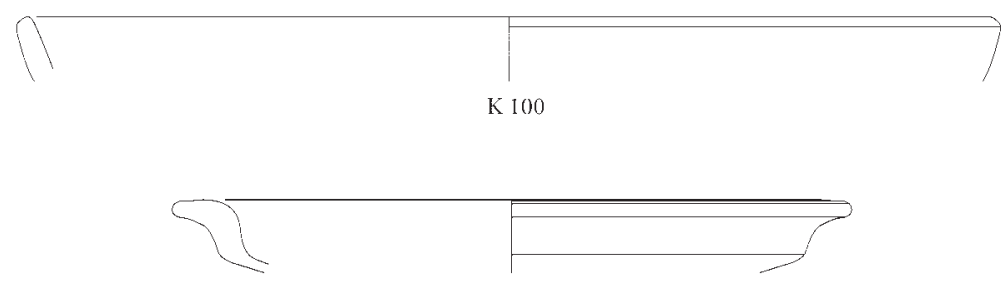

K 101
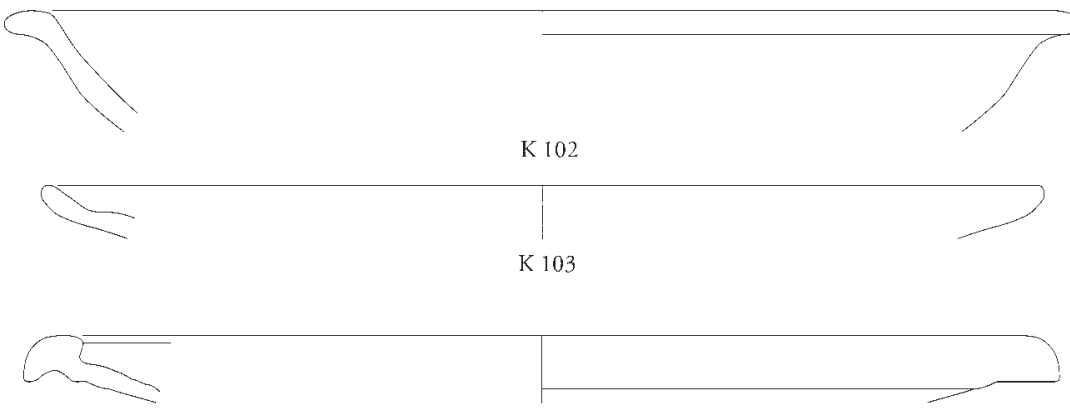

K 104

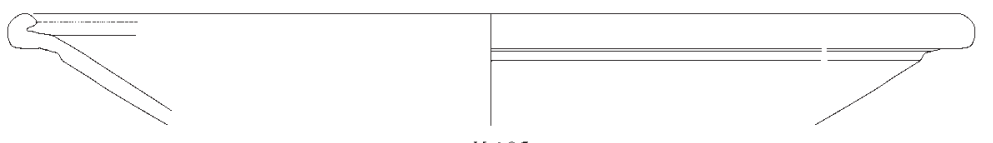

K 105

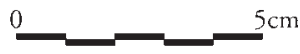

K 94-105 

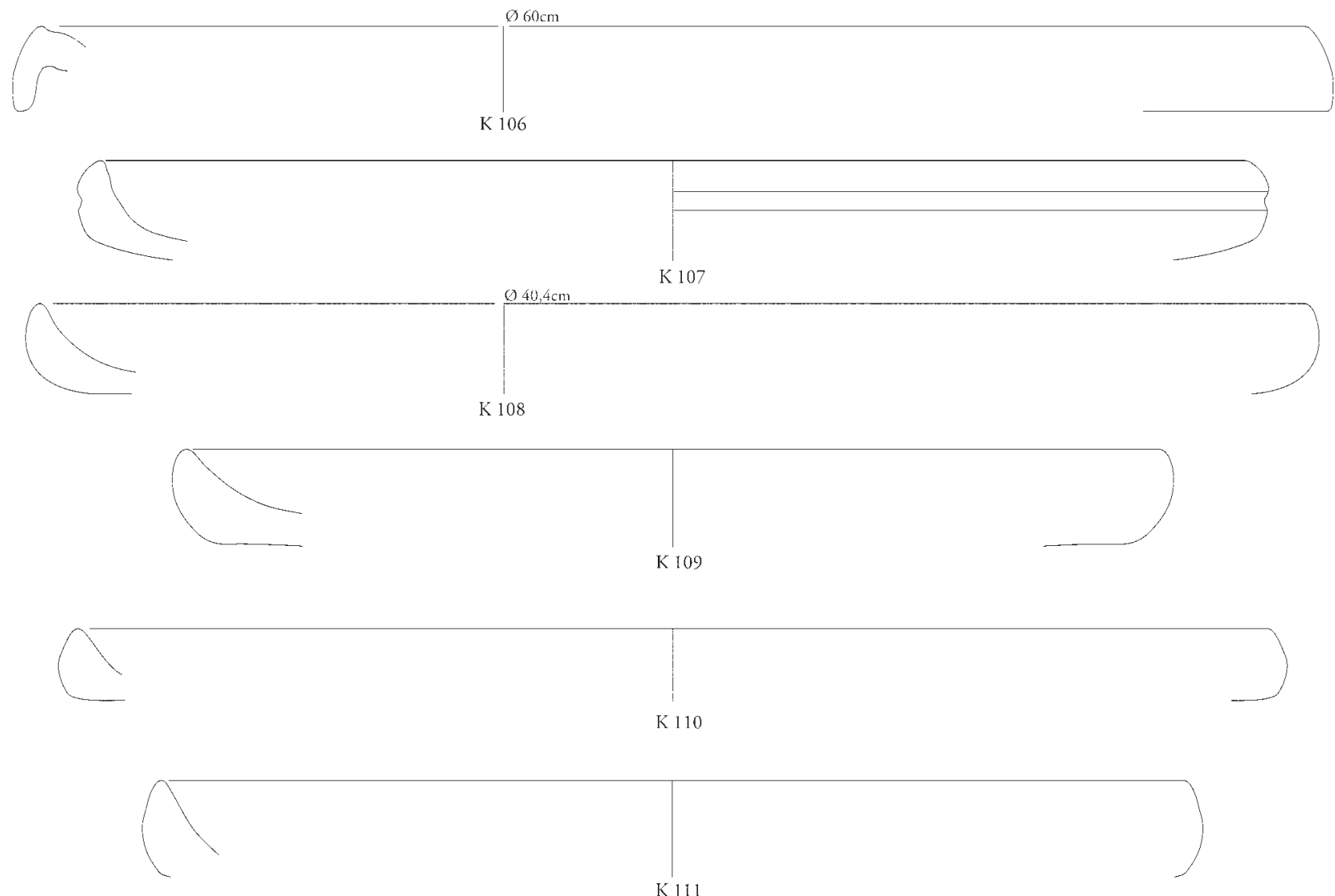

$064 \mathrm{~cm}$

$\mathrm{K} 112$
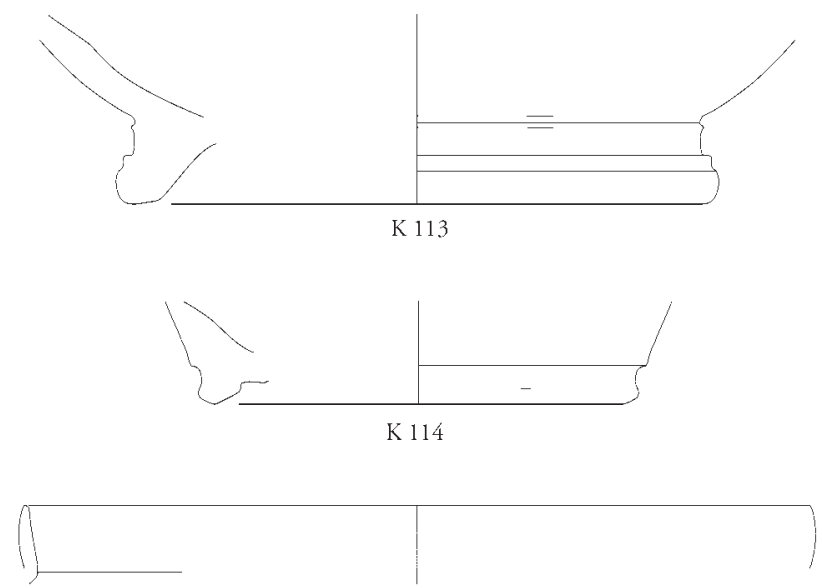

K 117
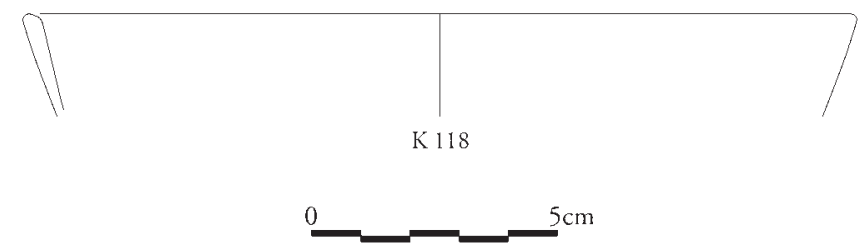

K 106-114. 117-118 
Tafel 170

Q) $35,4 \mathrm{~cm}$

K 119
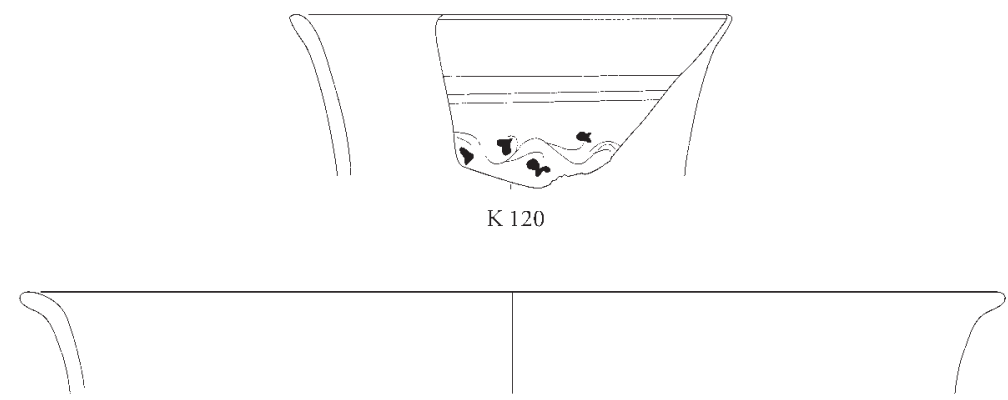

K 122

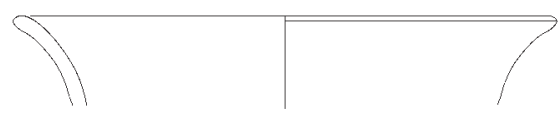

K 123

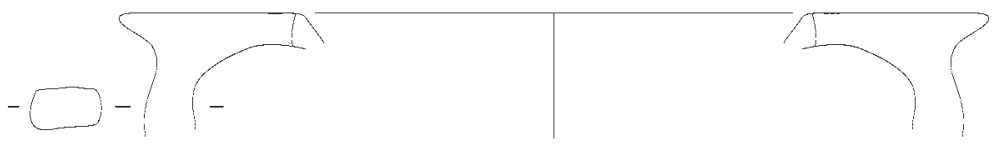

K 124
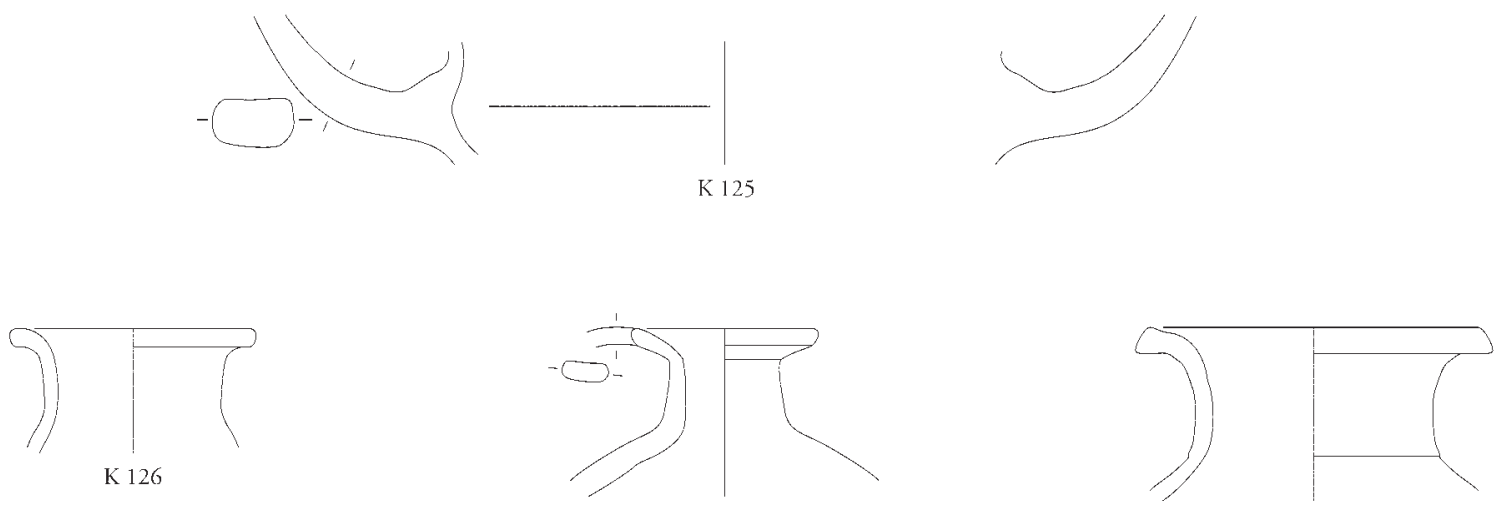

K 127
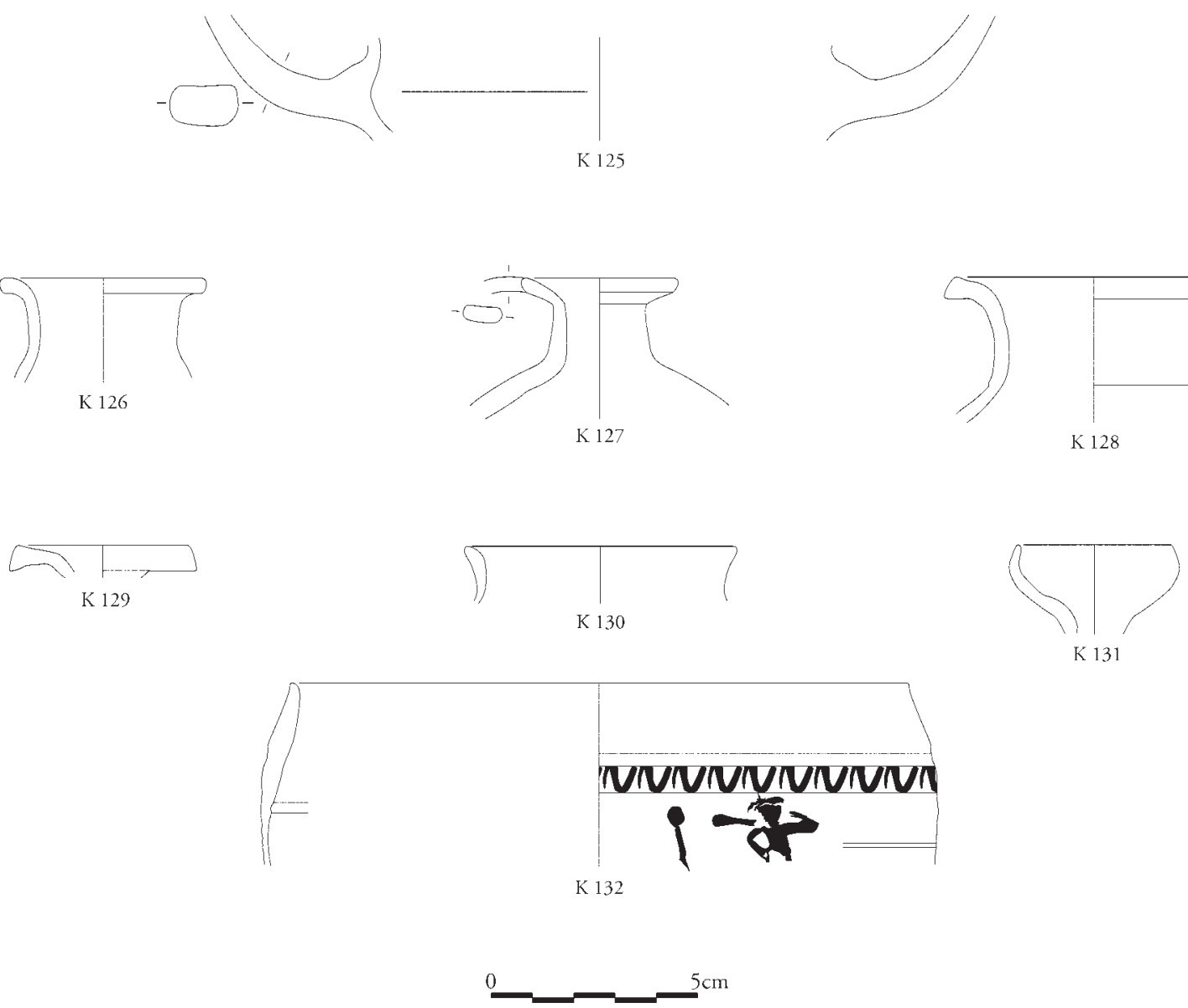

K 119-120. 122-132 
Tafel 171

\section{IVIVIVIVIVIV \\ K 133}

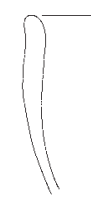

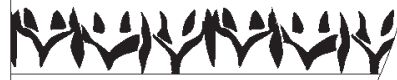

K I34
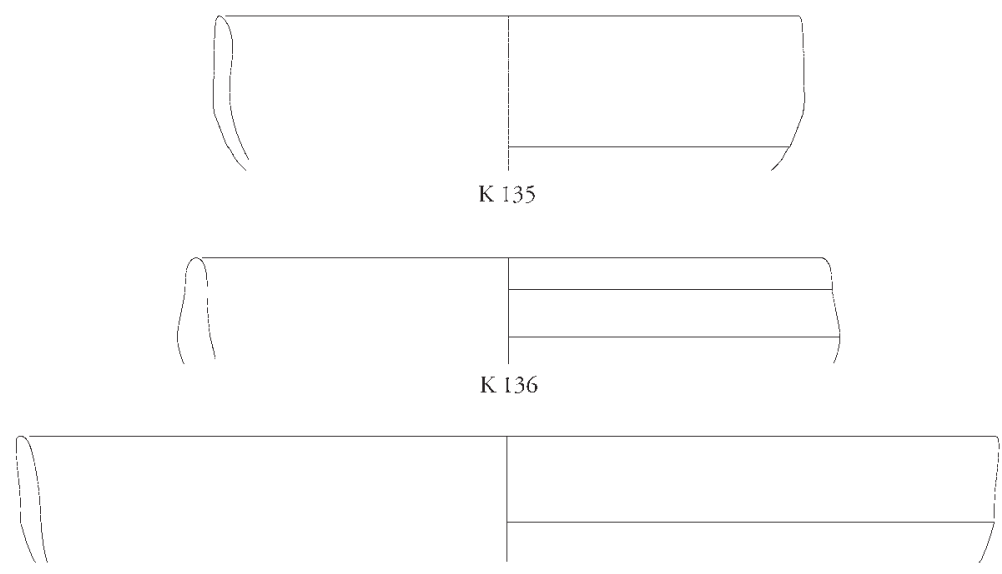

K 137
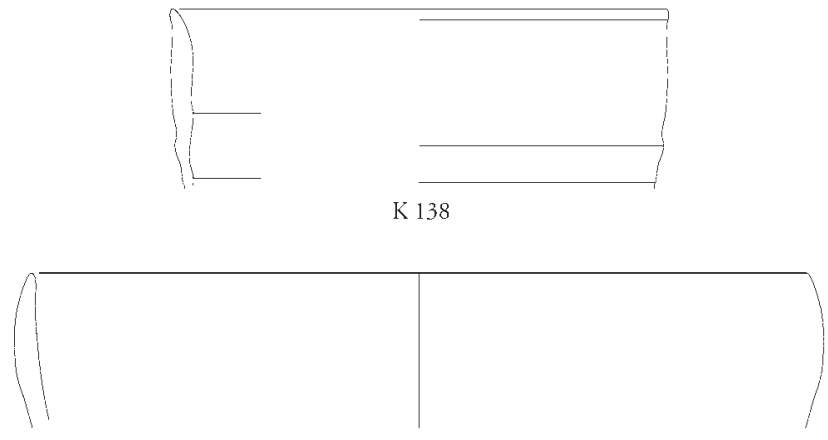

K 151
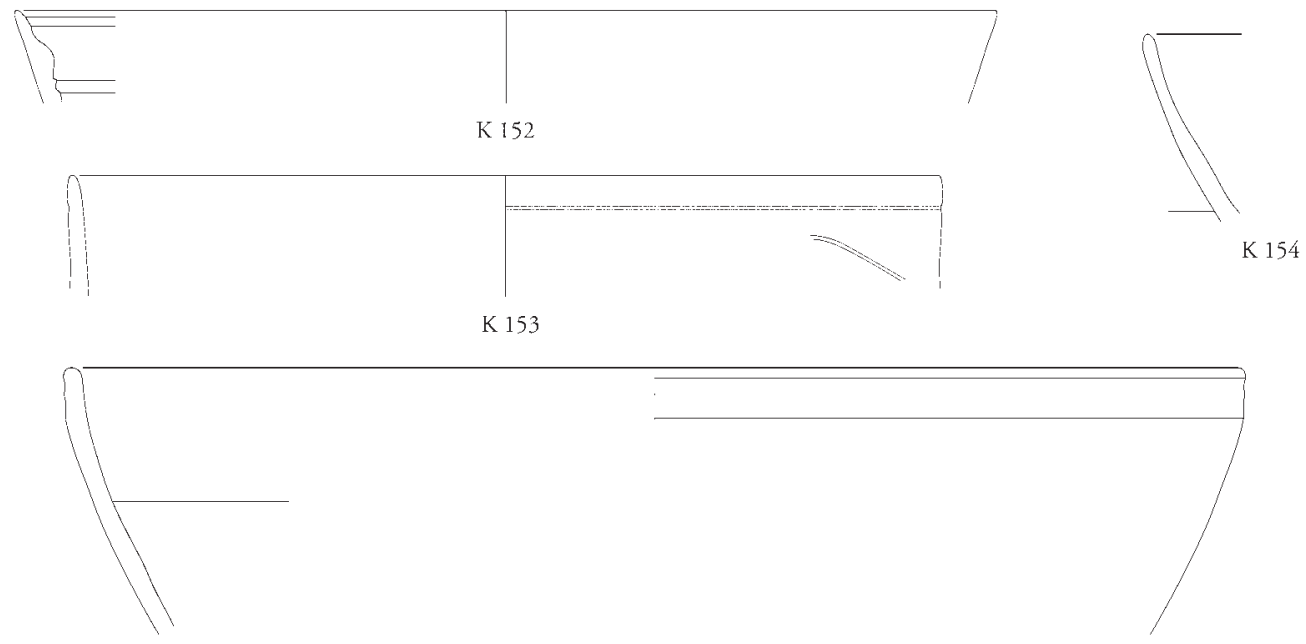

K 155

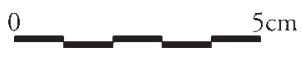

K 133-138. 151-155 
Tafel 172
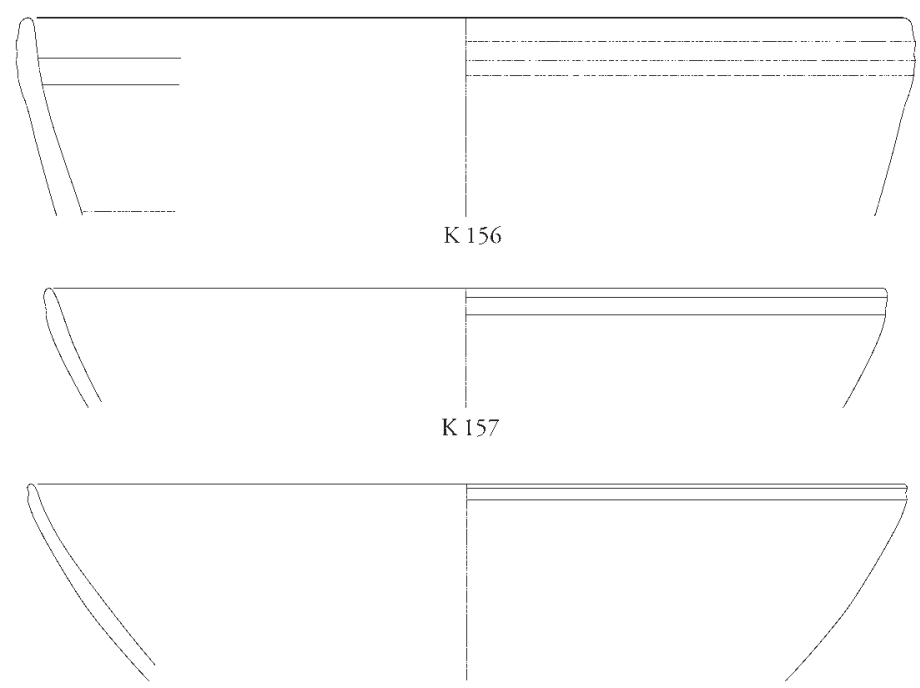

K 158

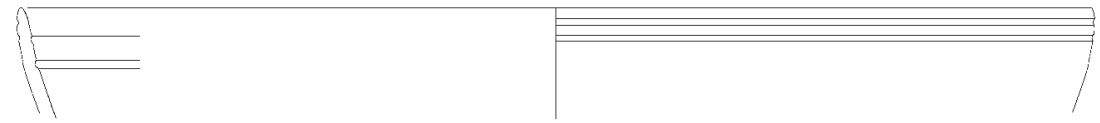

K 159

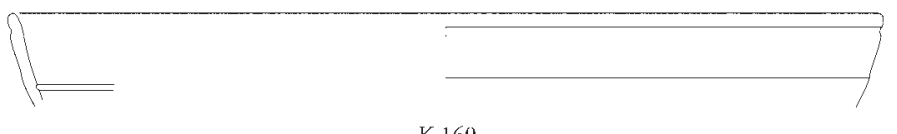

K 160
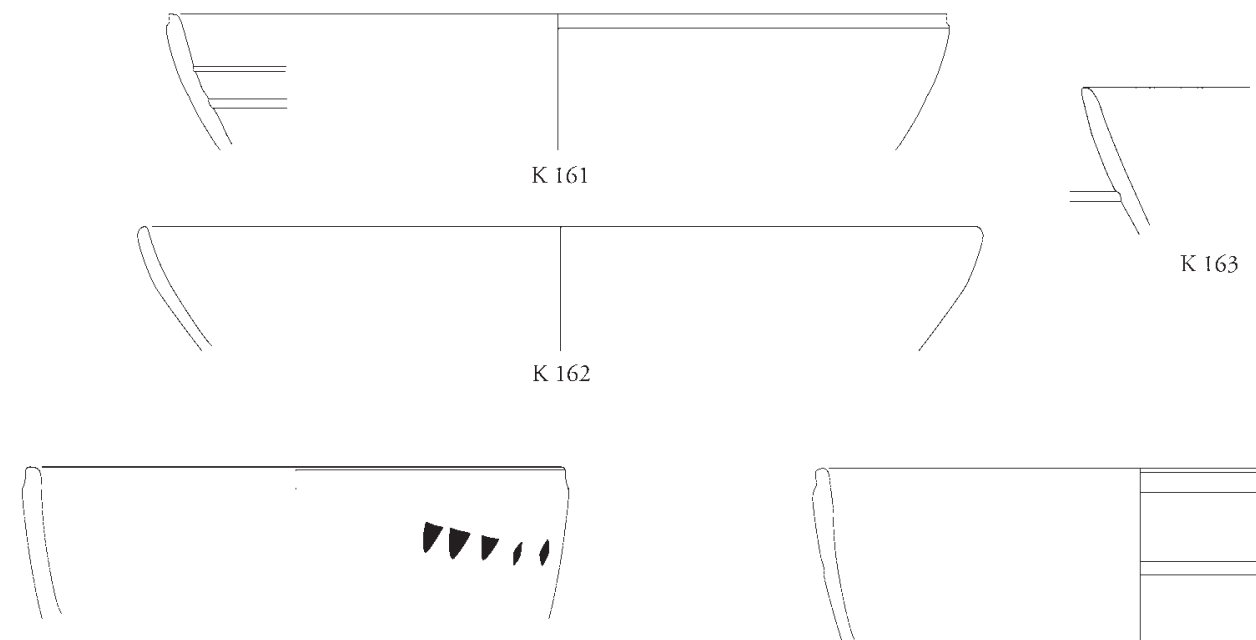

K 167

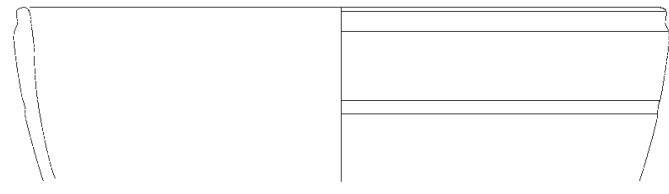

K 168

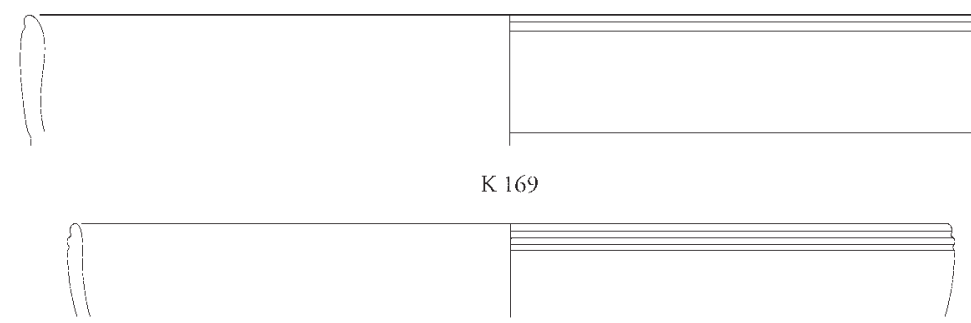

K 170

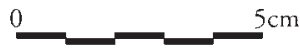

K 156-163. 167-170 
Tafel 173

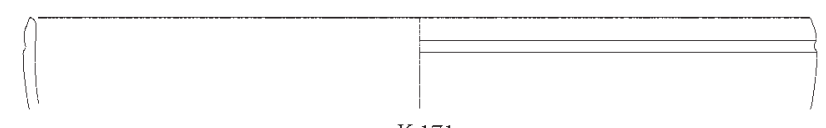

K 171
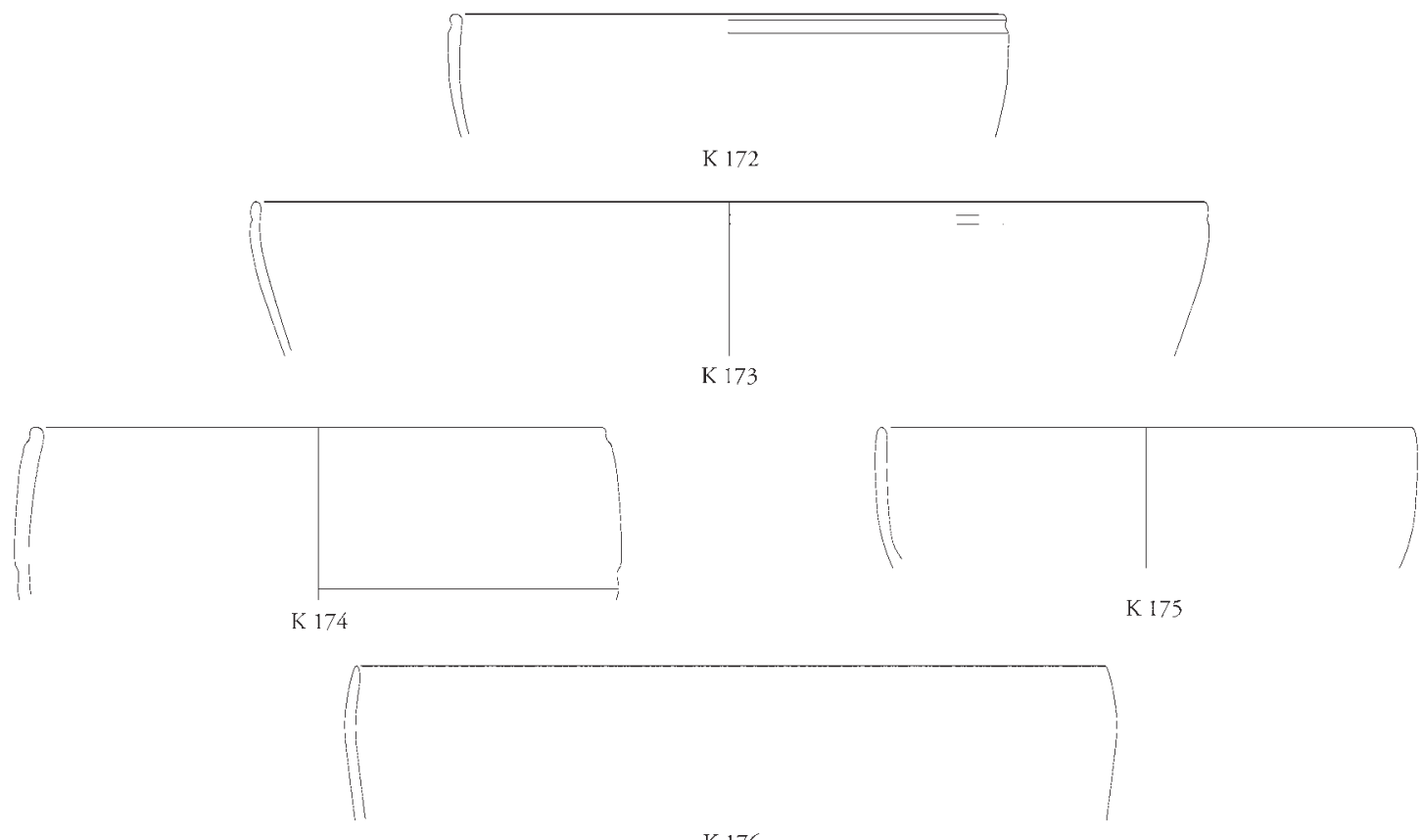

K 176
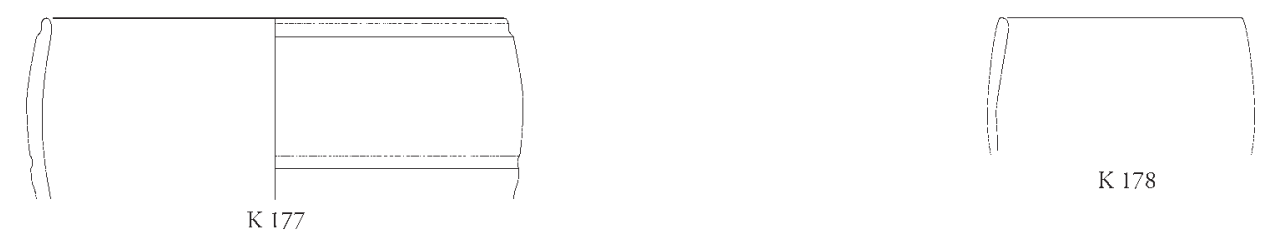

K 178
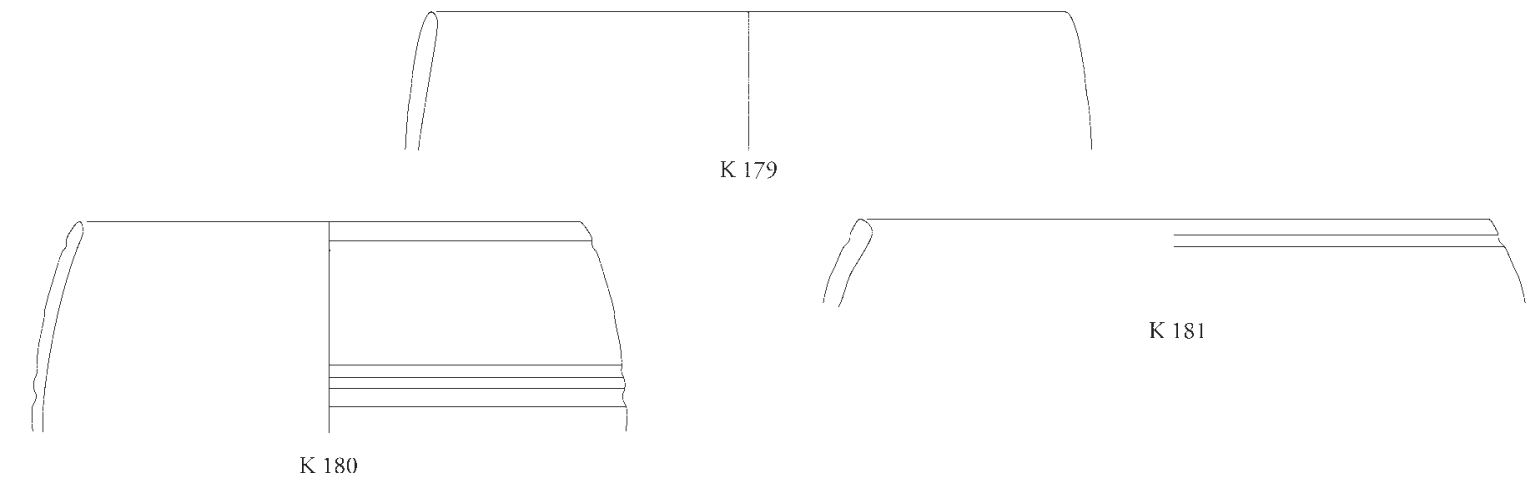

K 181
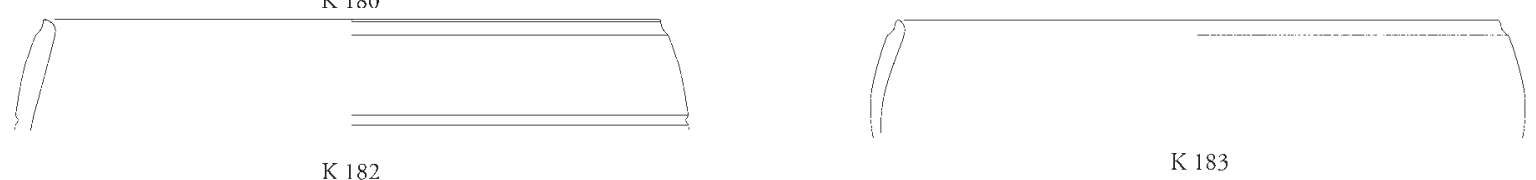

K 183
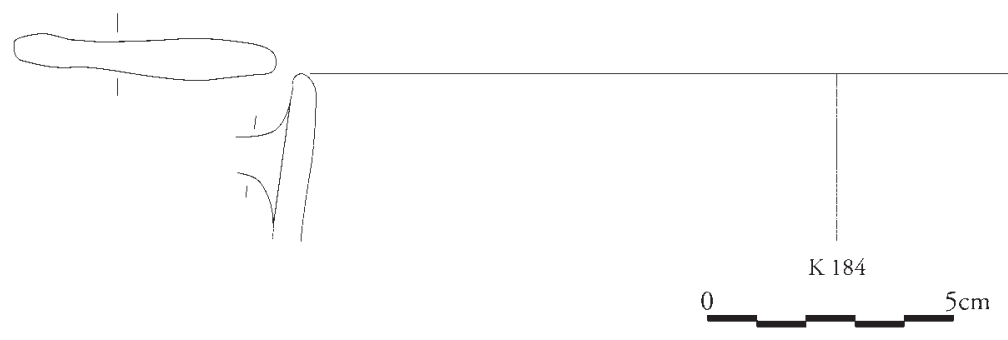

K 171-184 
Tafel 174

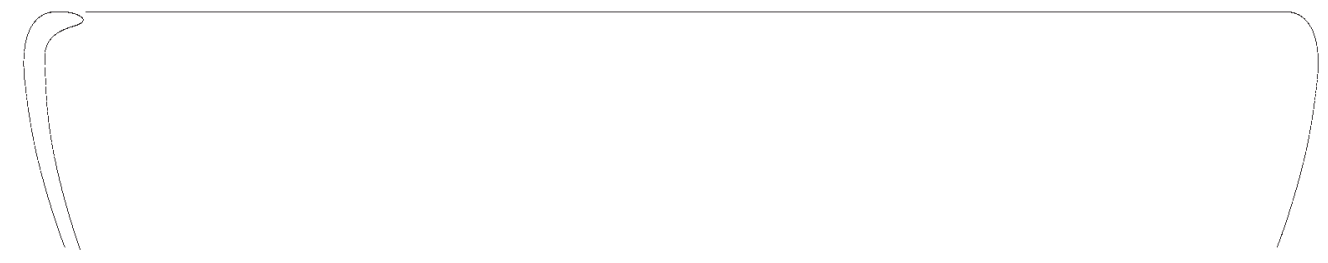

K 185

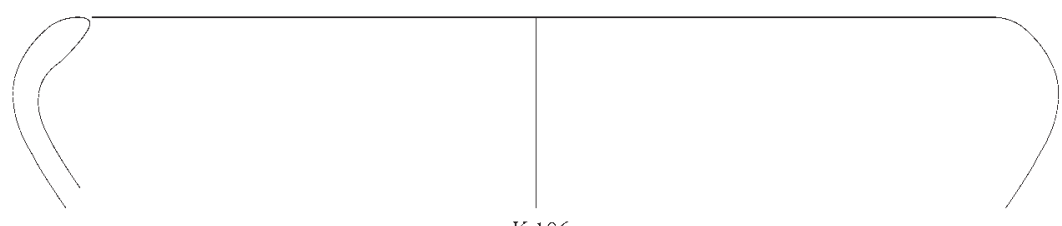

K 186
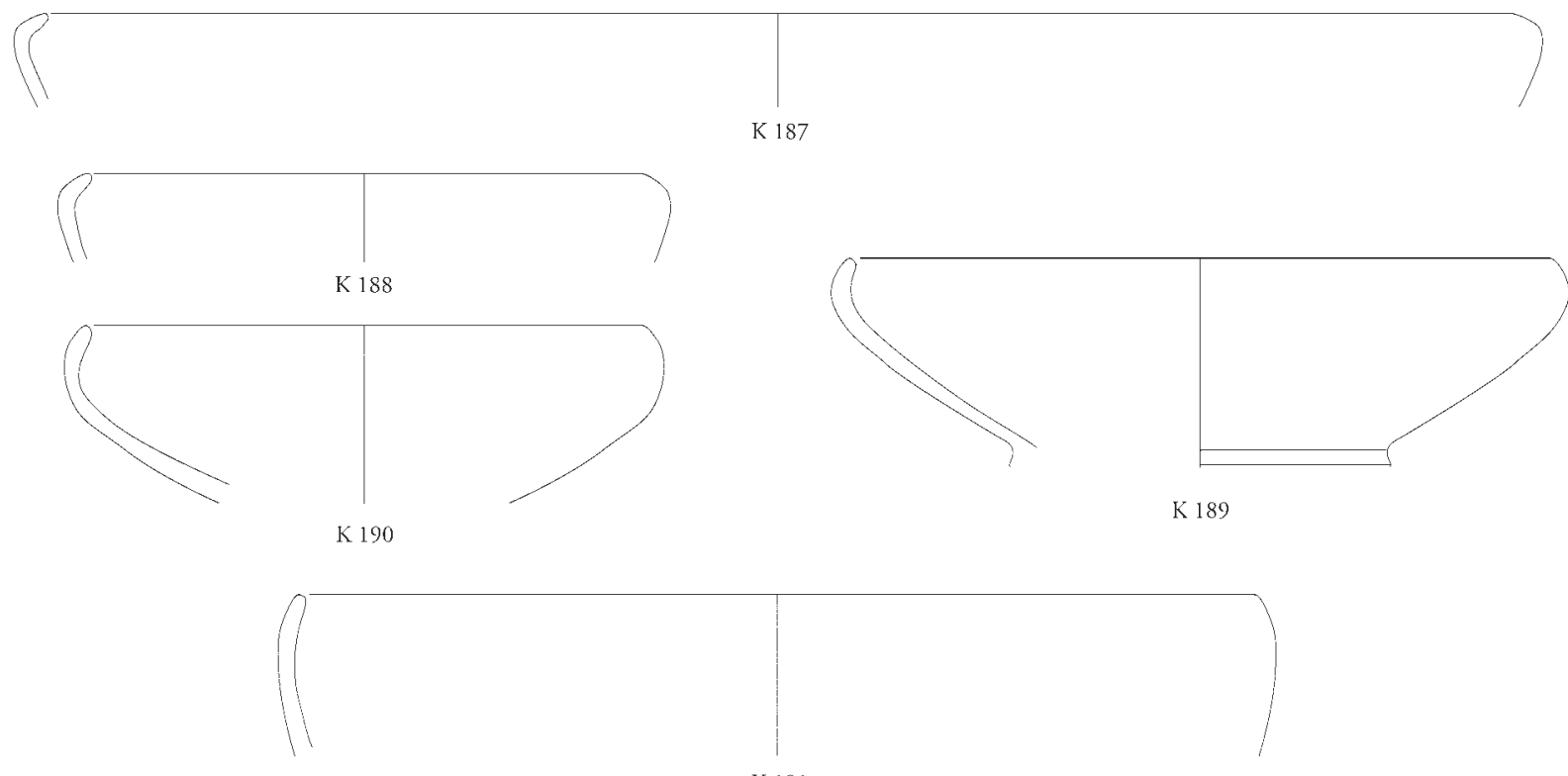

K 191
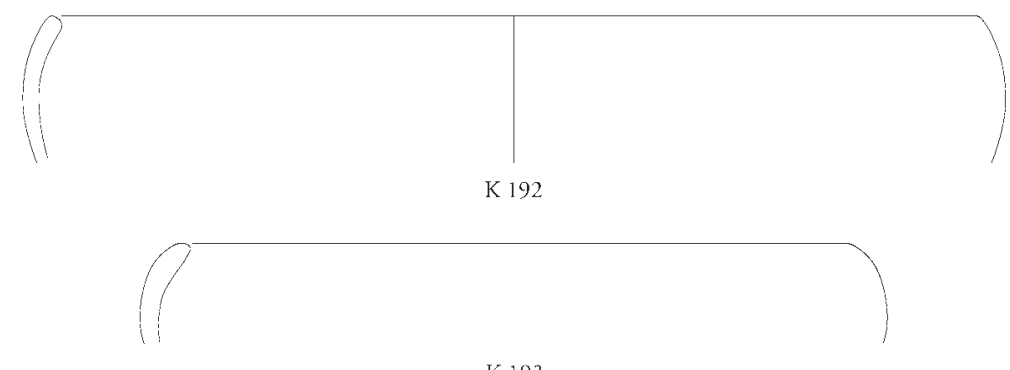

K 193
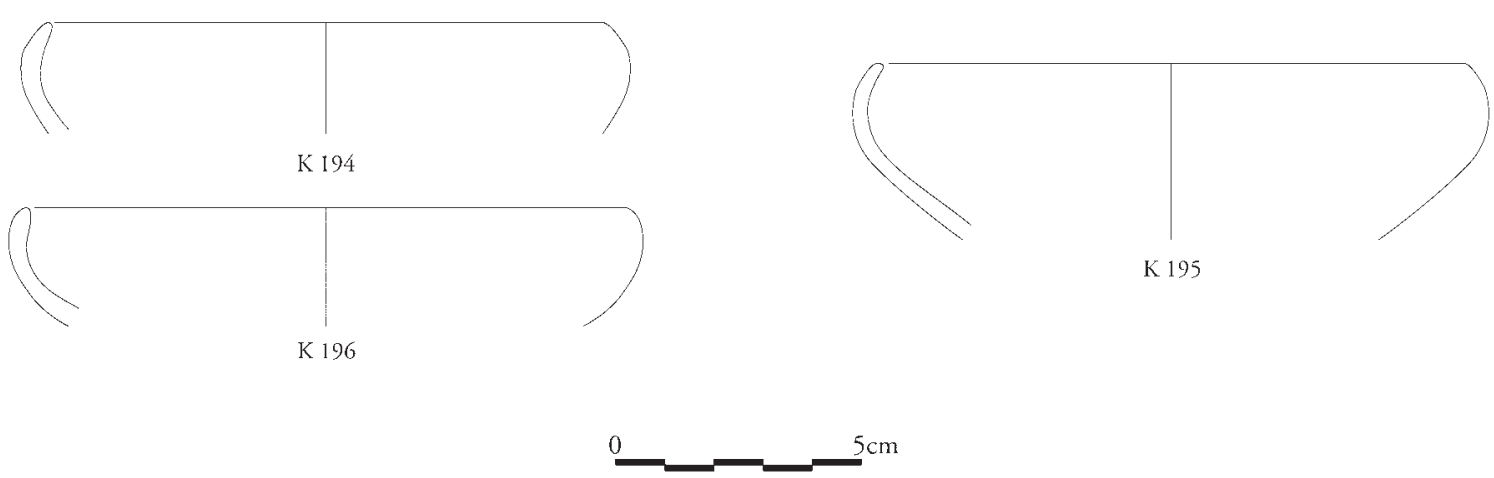

K 185-196 
Tafel 175
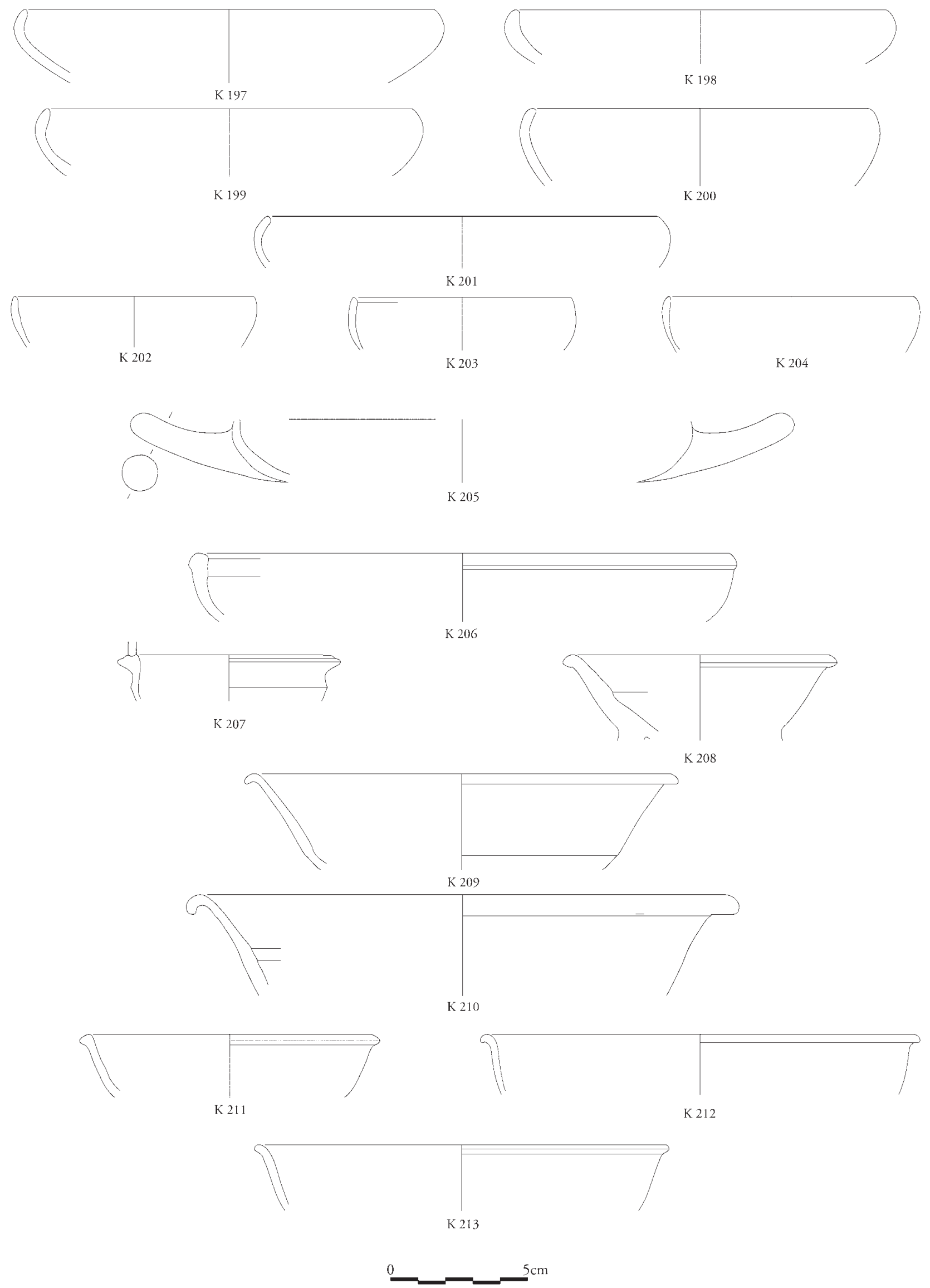

K 197-213 
Tafel 176
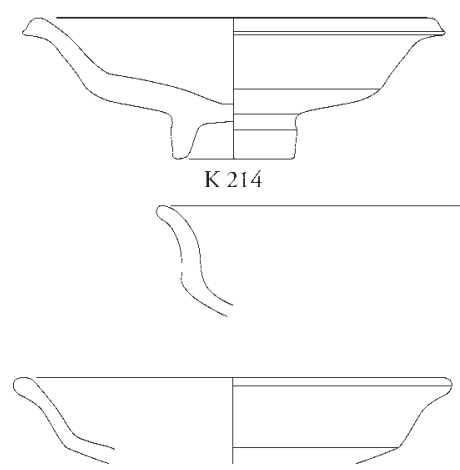

K 217
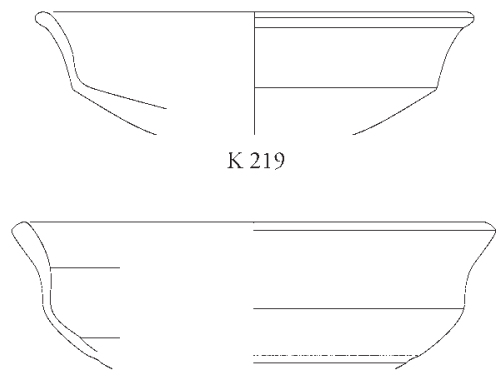

K 221
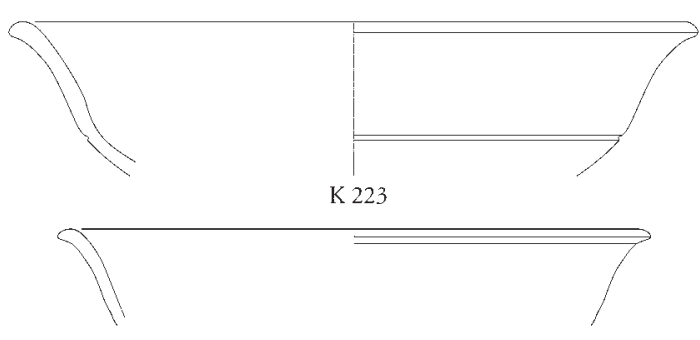

K 225

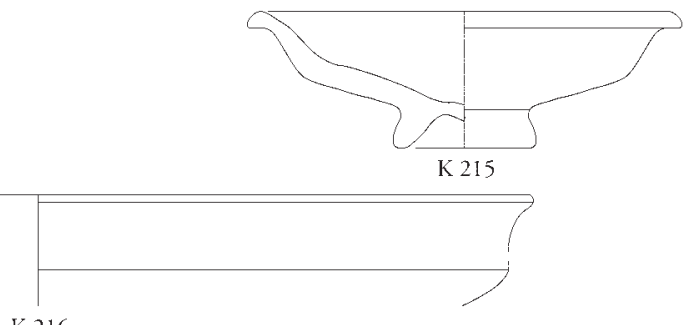

K 216
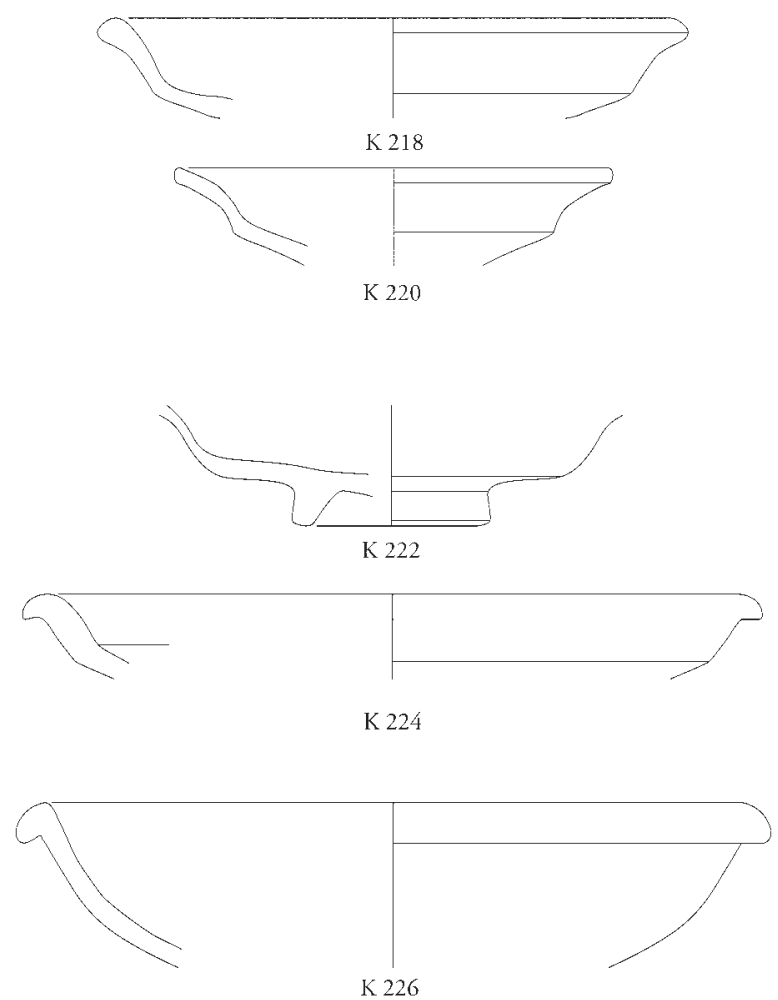

K 226

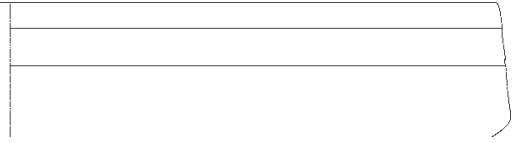

K 227

K 228

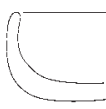

K 229

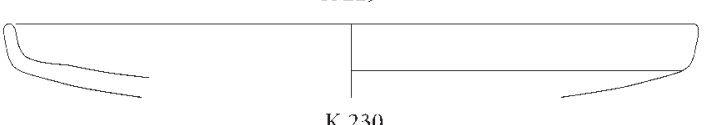

K 231

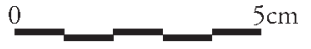

K 214-231 
Tafel 177
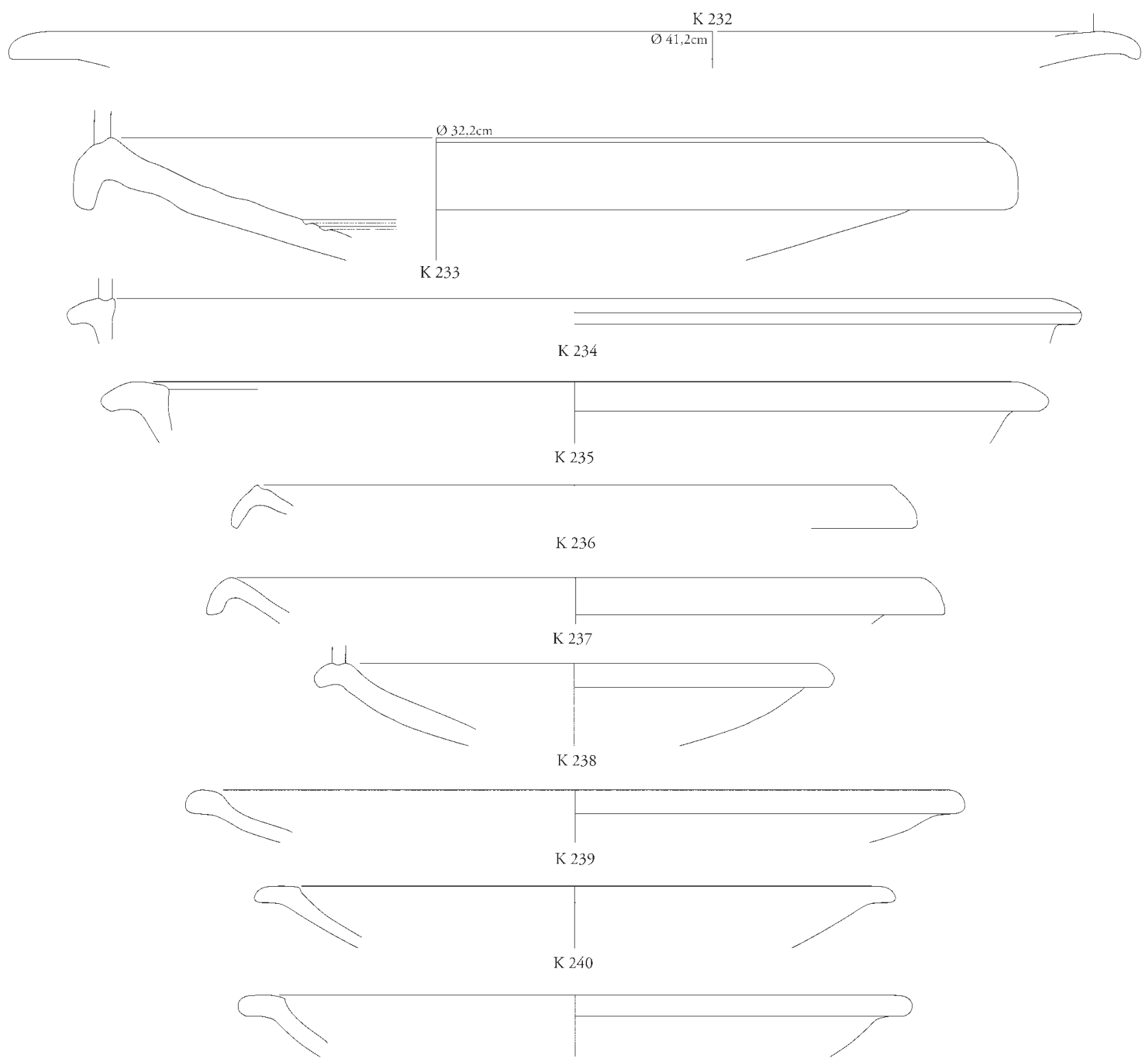

K 241
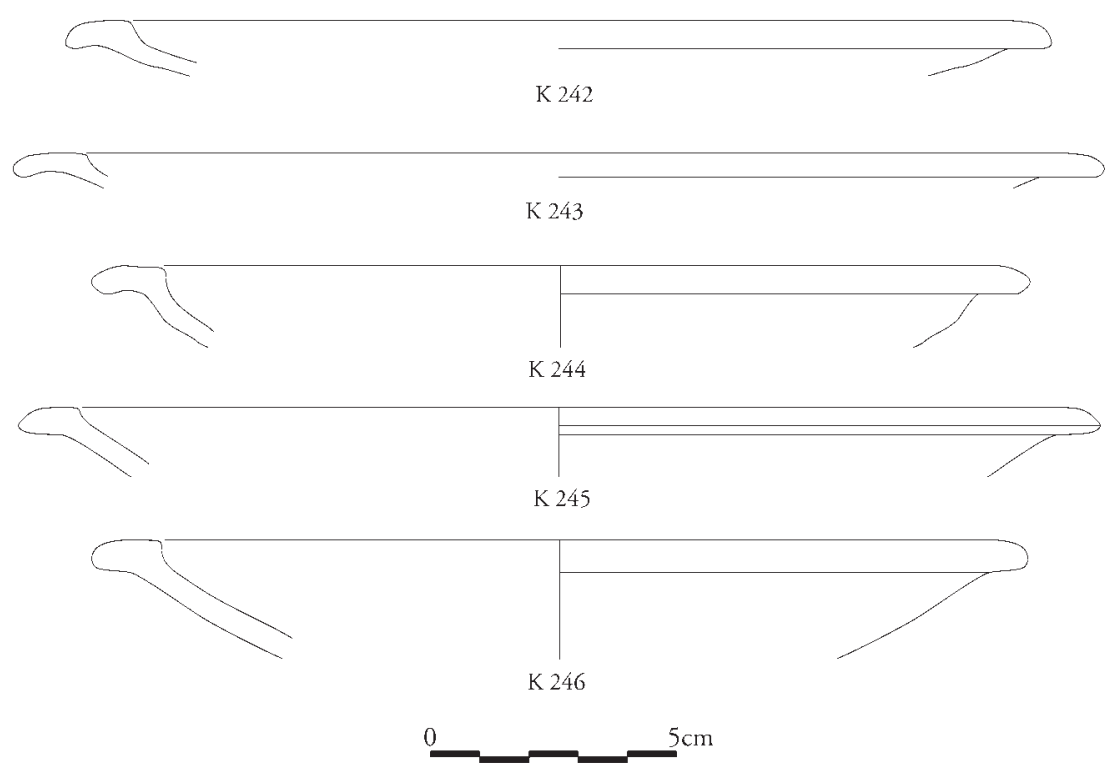

K 232-246 
Tafel 178
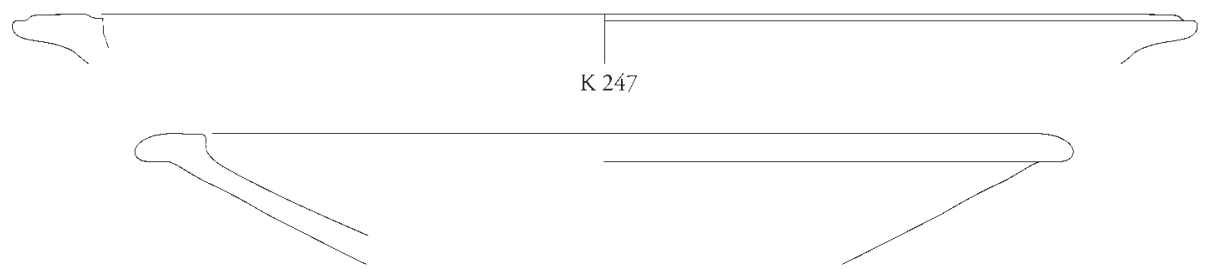

K 248
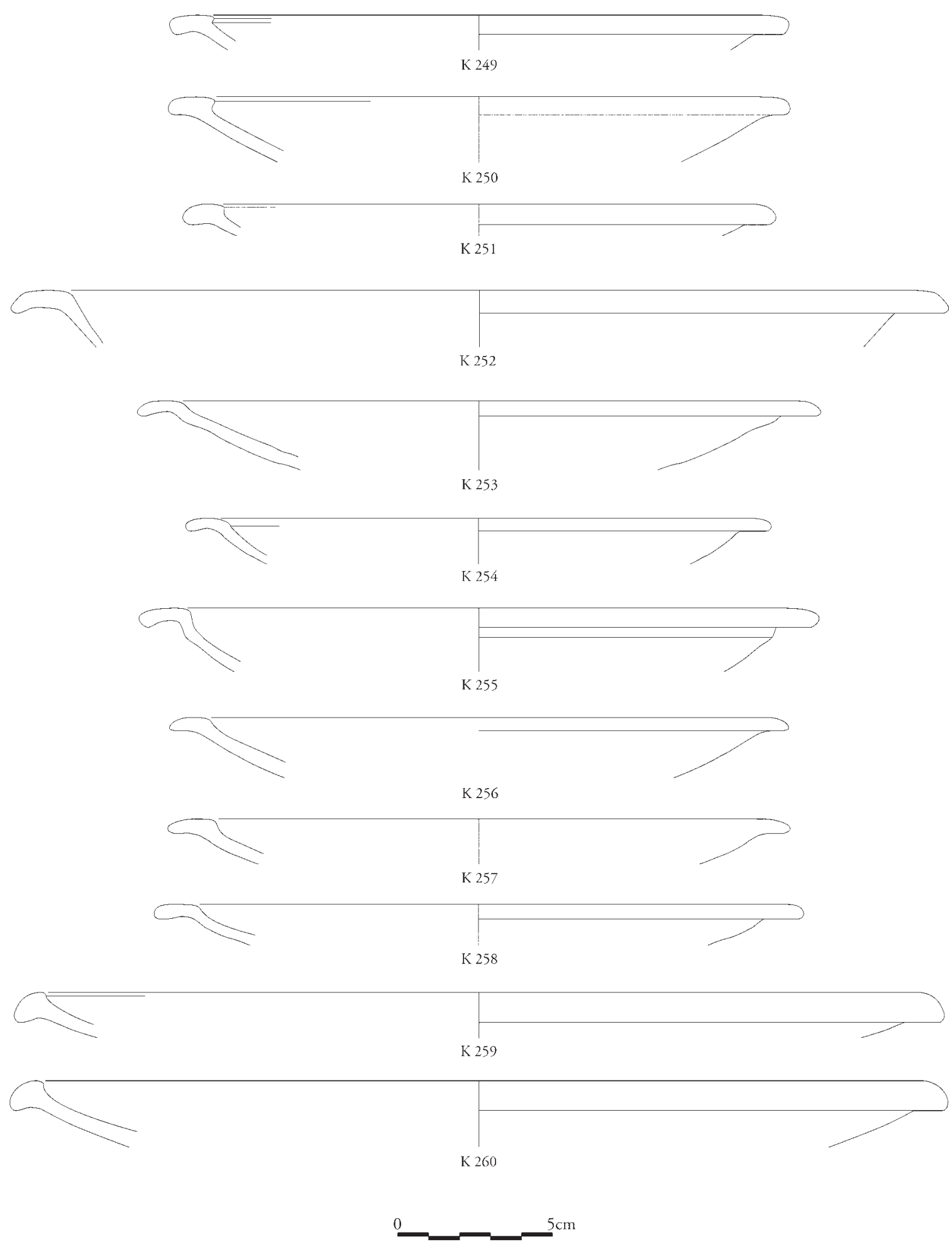

K 247-260 

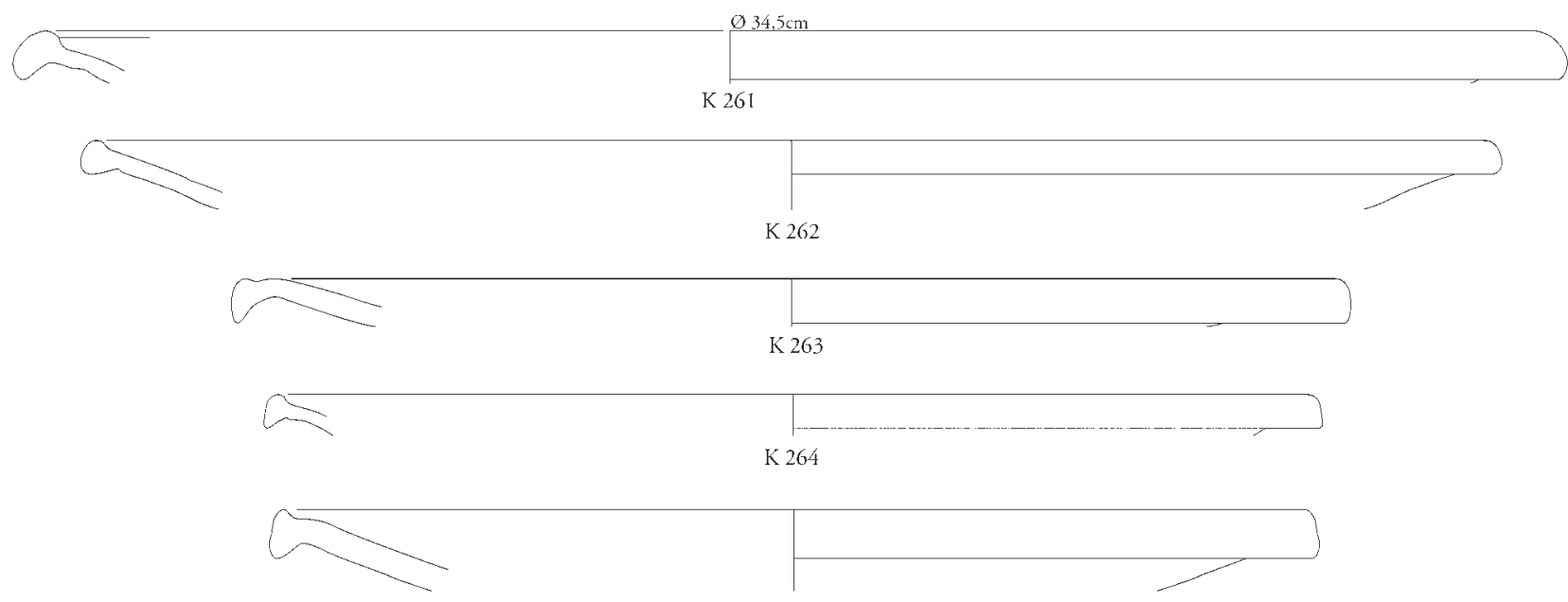

K 265
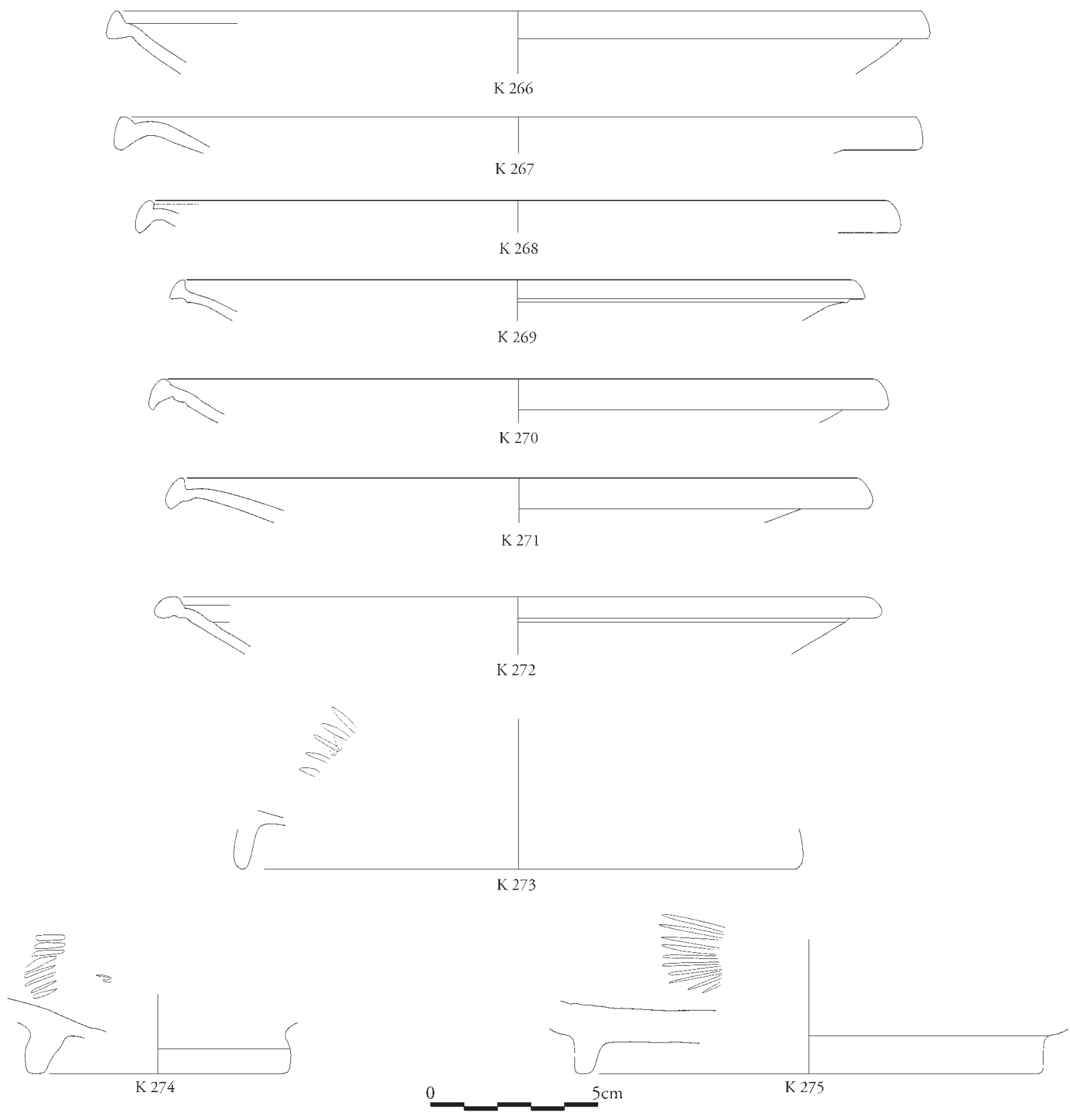

K 261-275 
Tafel 180
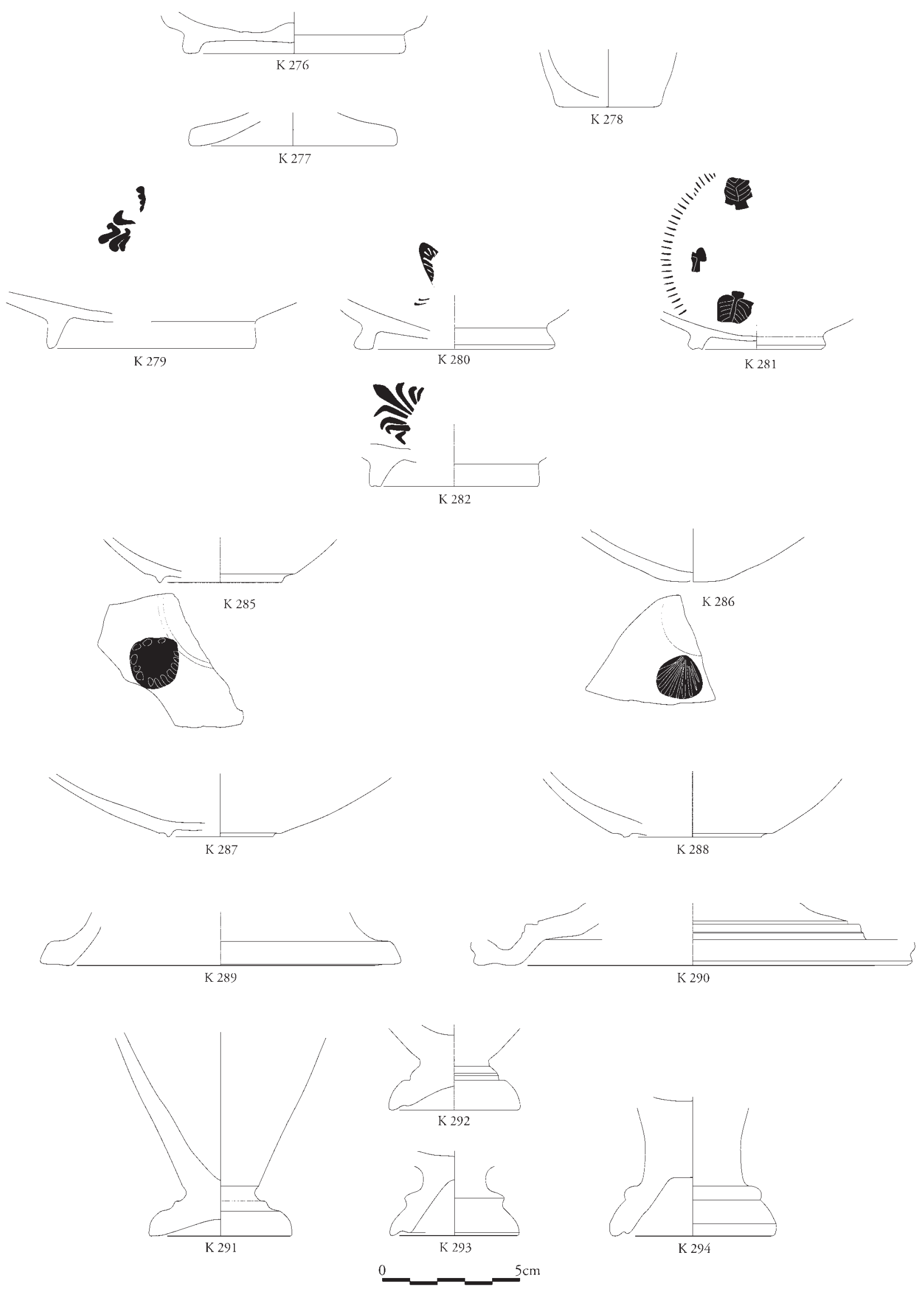

K 276-282. 285-294 
Tafel 181
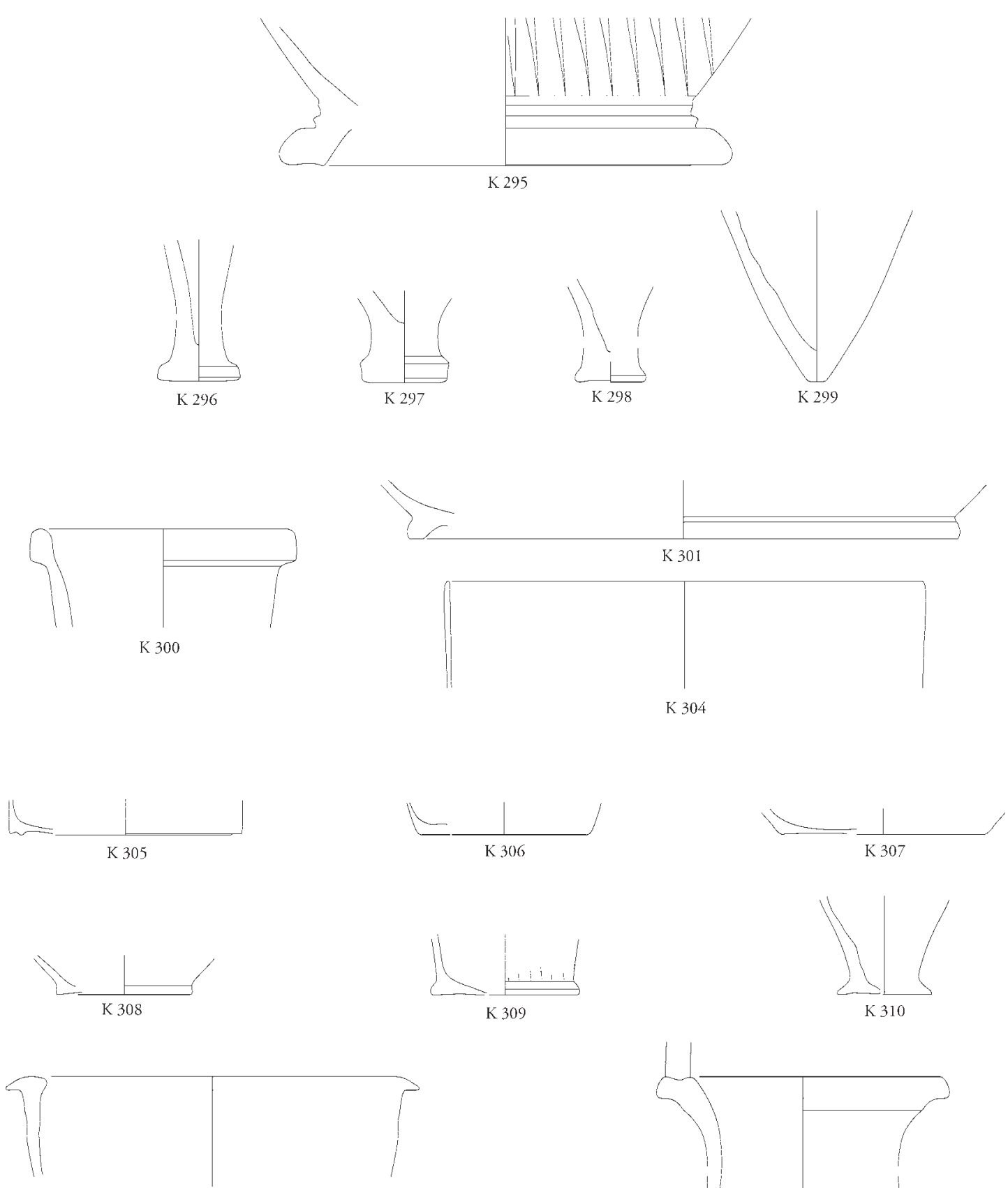

K 313
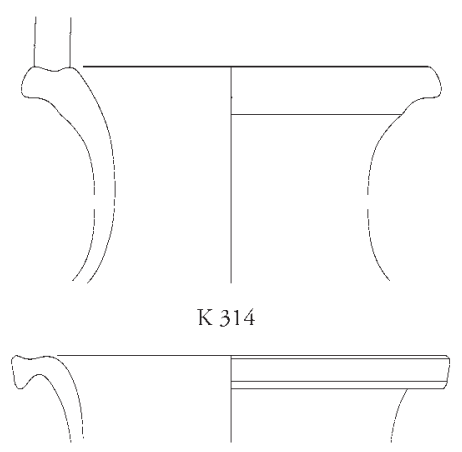

K 316

K 315

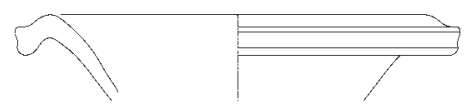

K 317

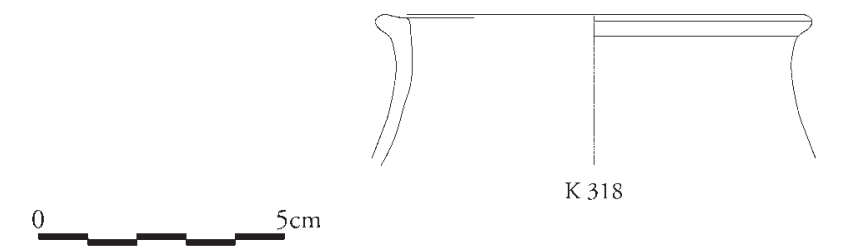

K 295-301. 304-310. 313-318 
Tafel 182
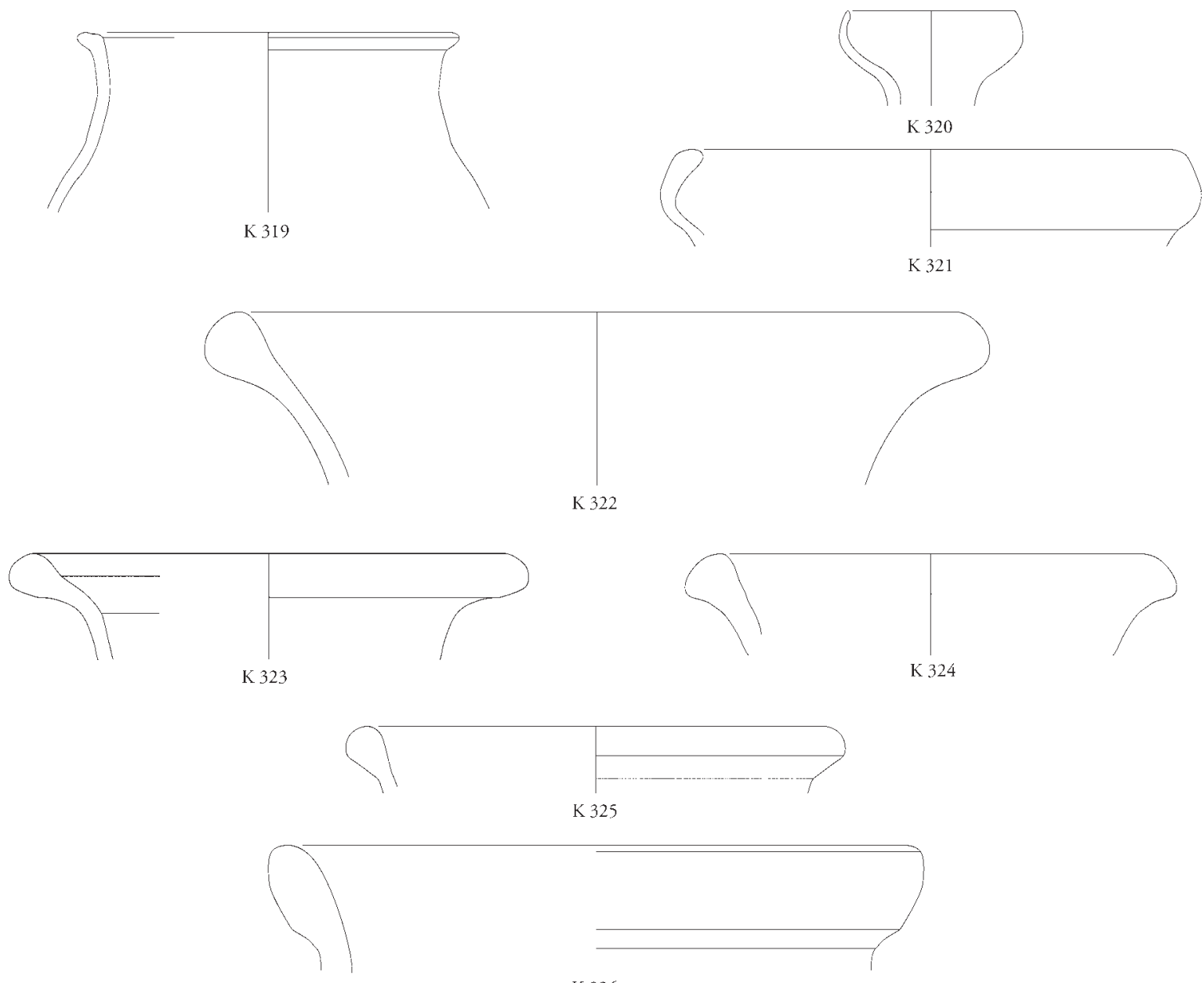

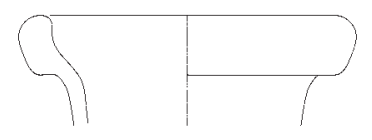

K 327
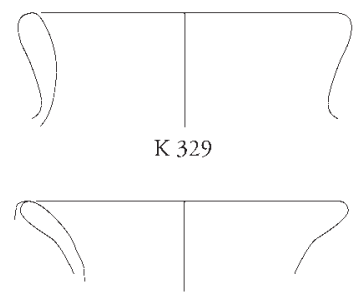

K 331
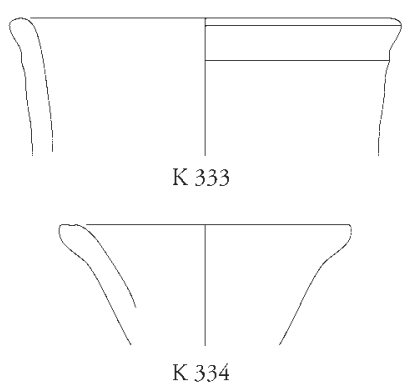
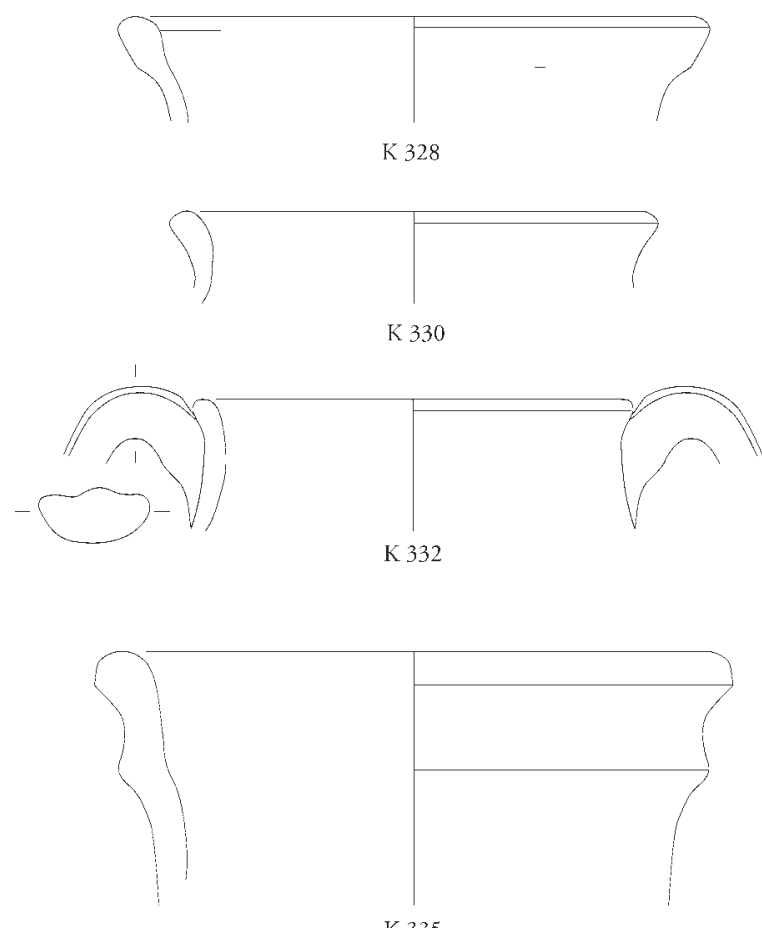

K 335

K 319-335 
Tafel 183
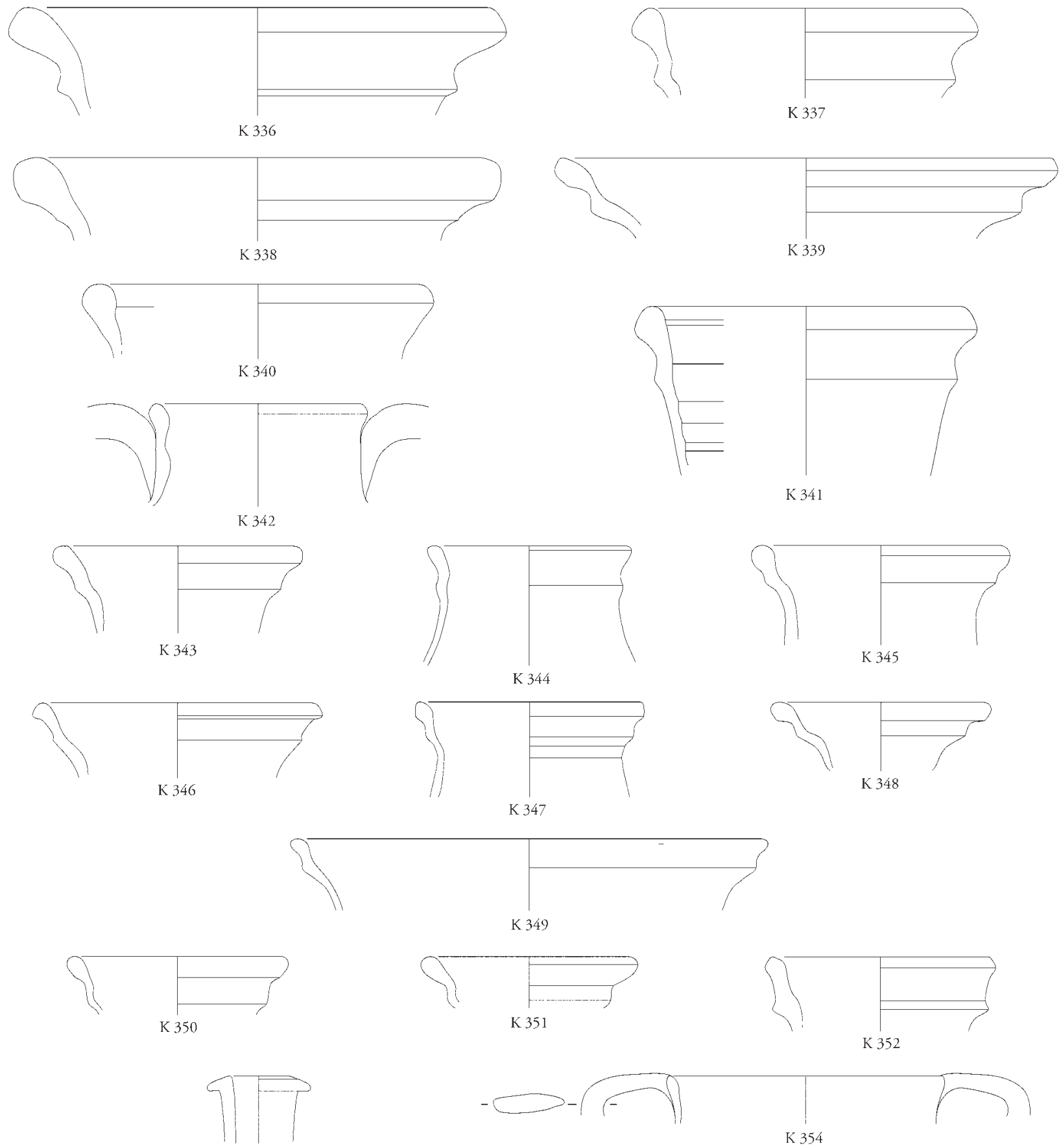

K 353
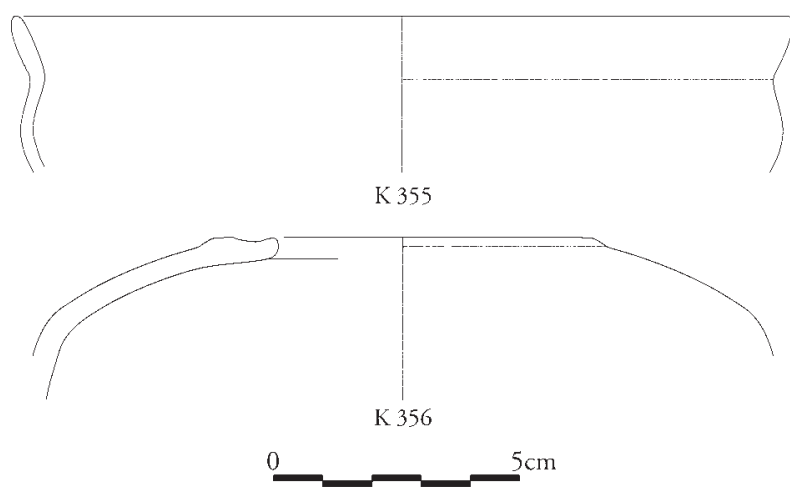

K 336-356 
Tafel 184

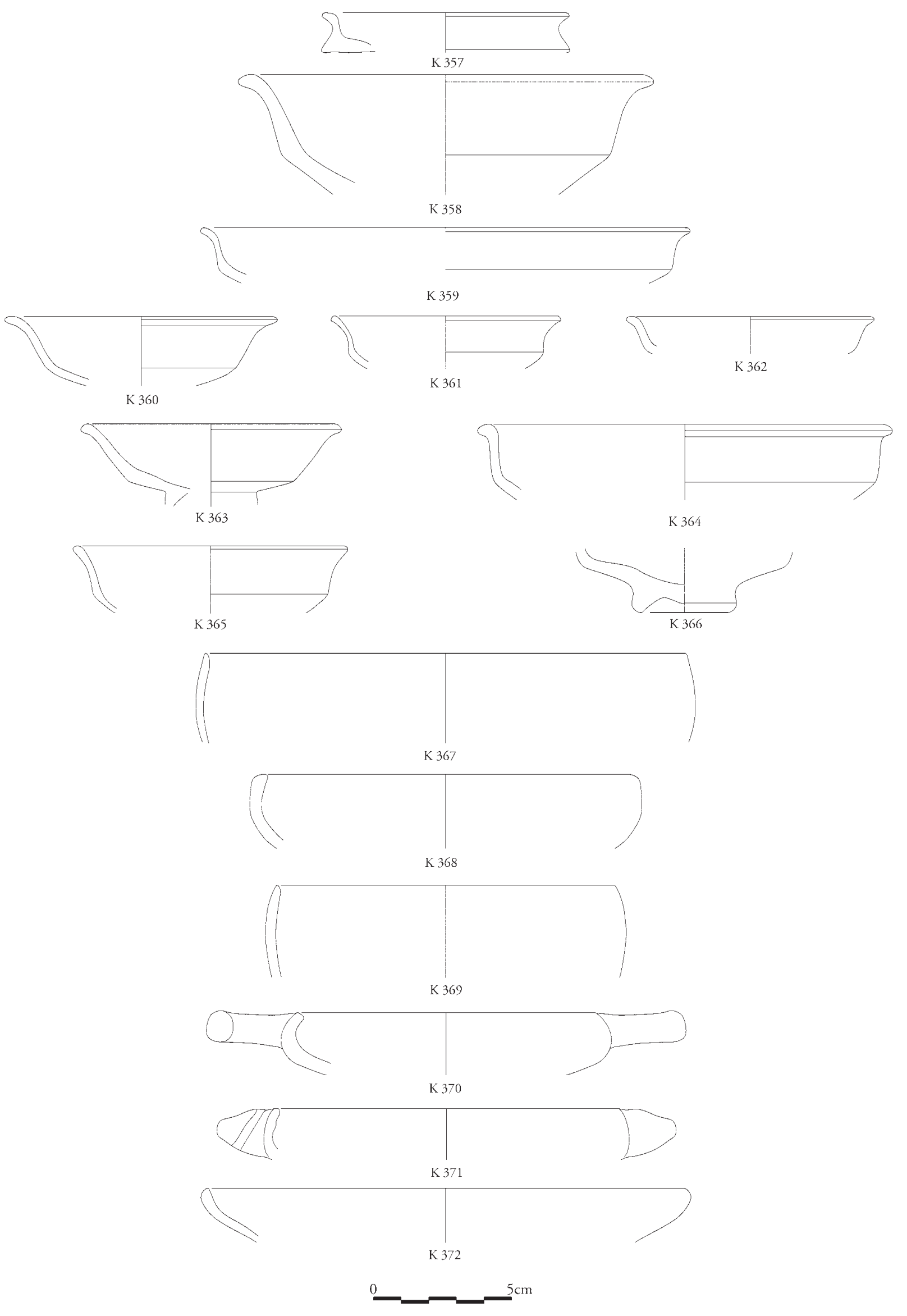

K 357-372 
Tafel 185

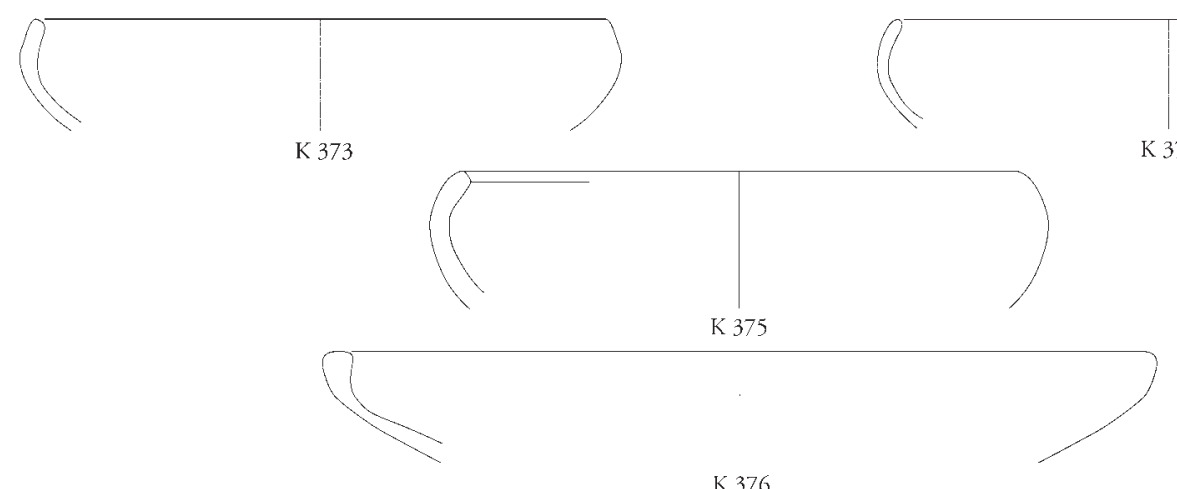

K 376

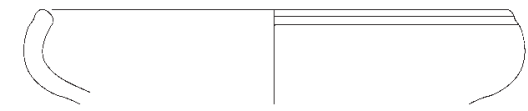

K 377
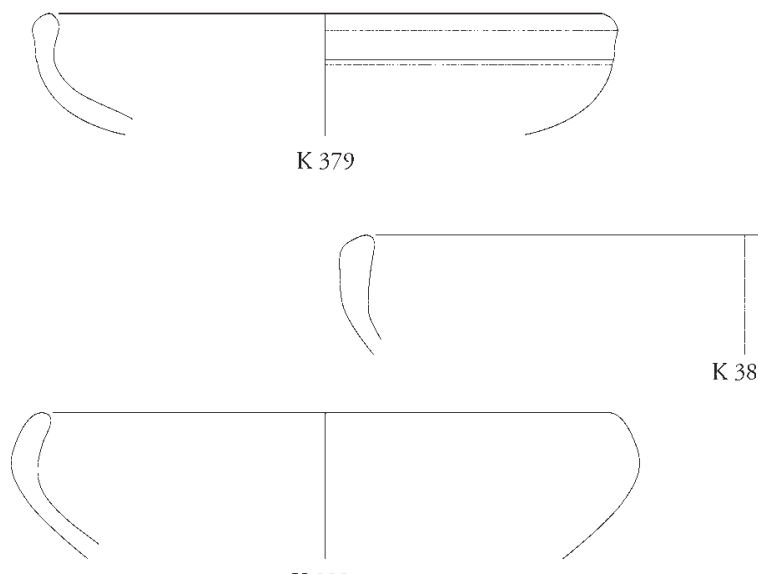

K 382

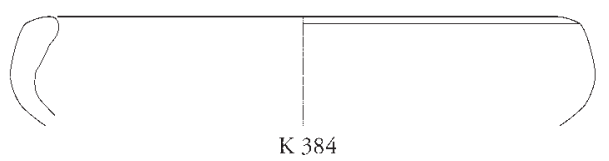

K 384
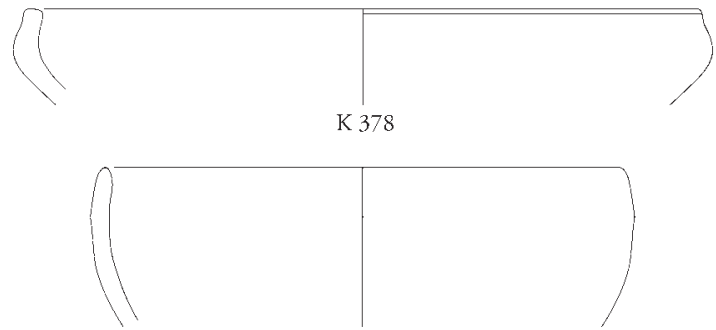

K 380
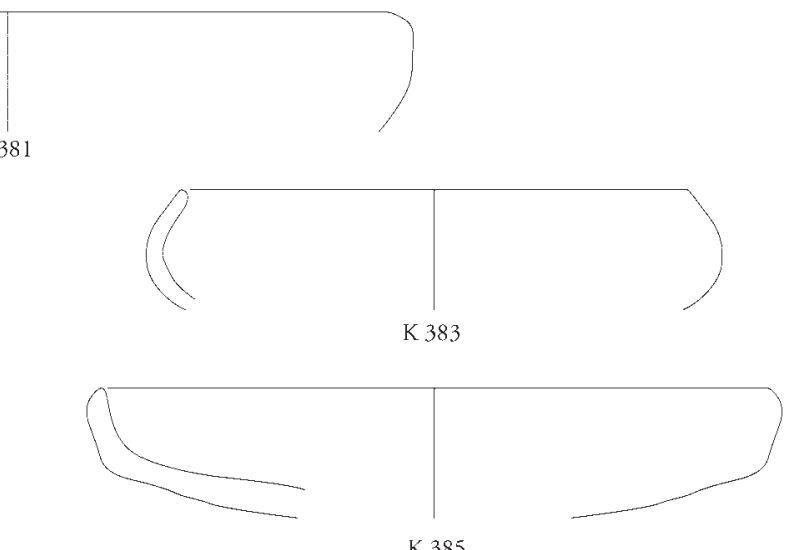
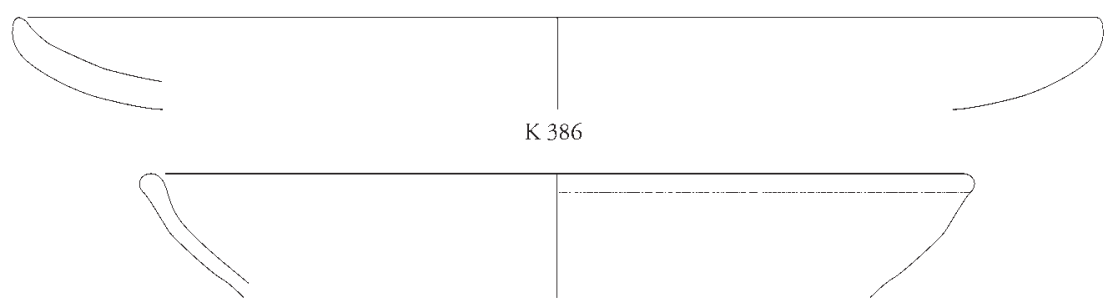

K 387

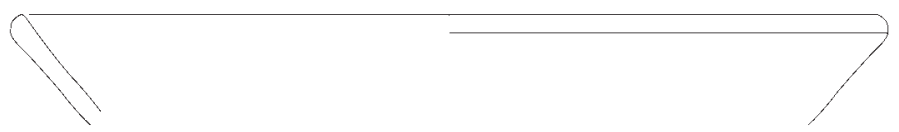

K 388

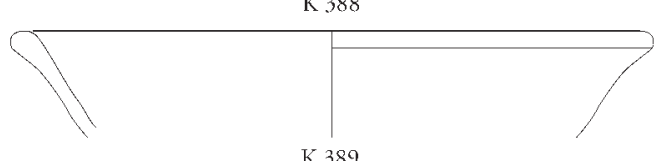

K 389

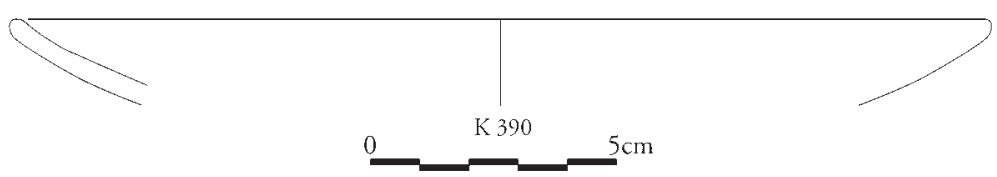

K 373-390 
Tafel 186
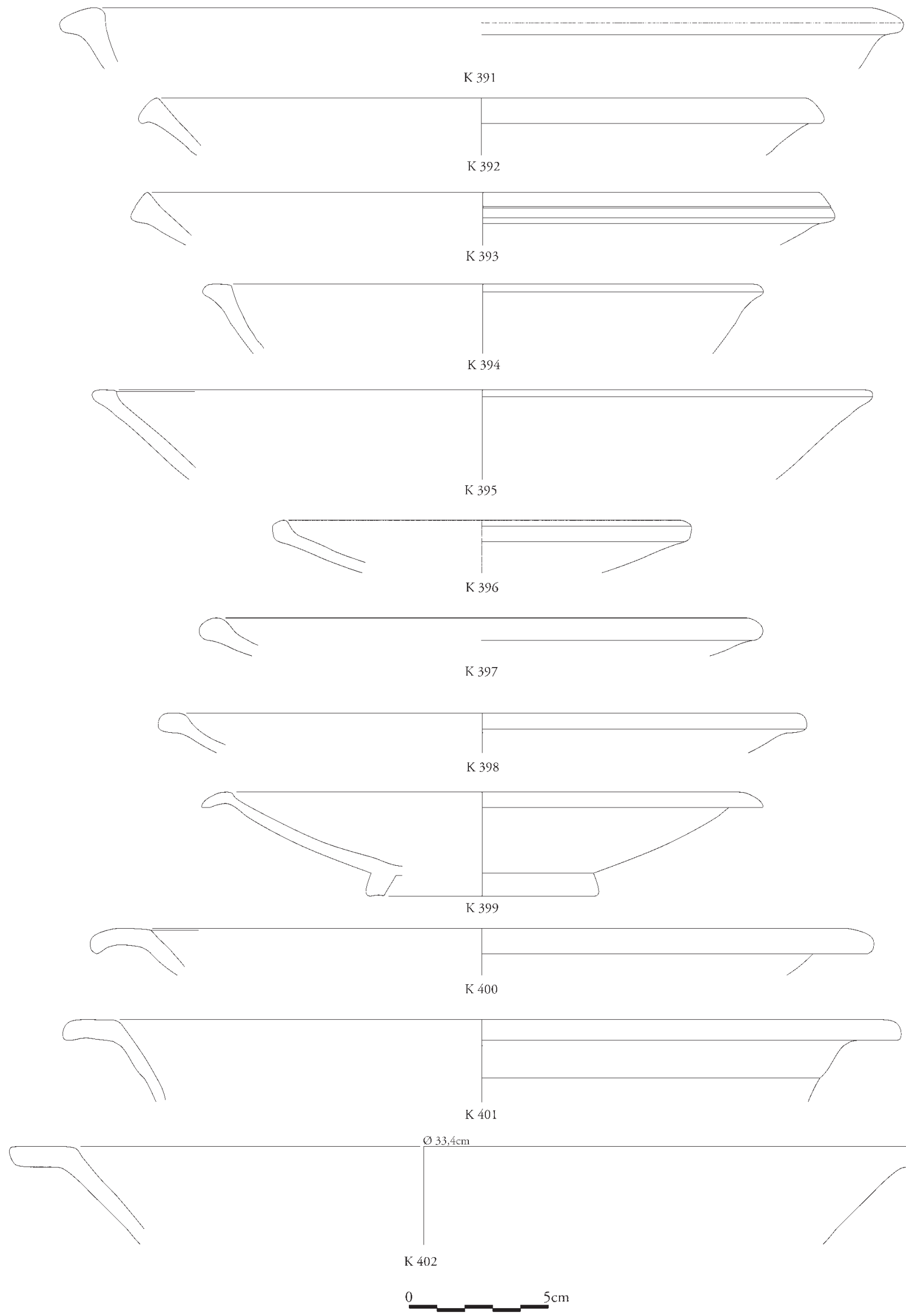

K 391-402 

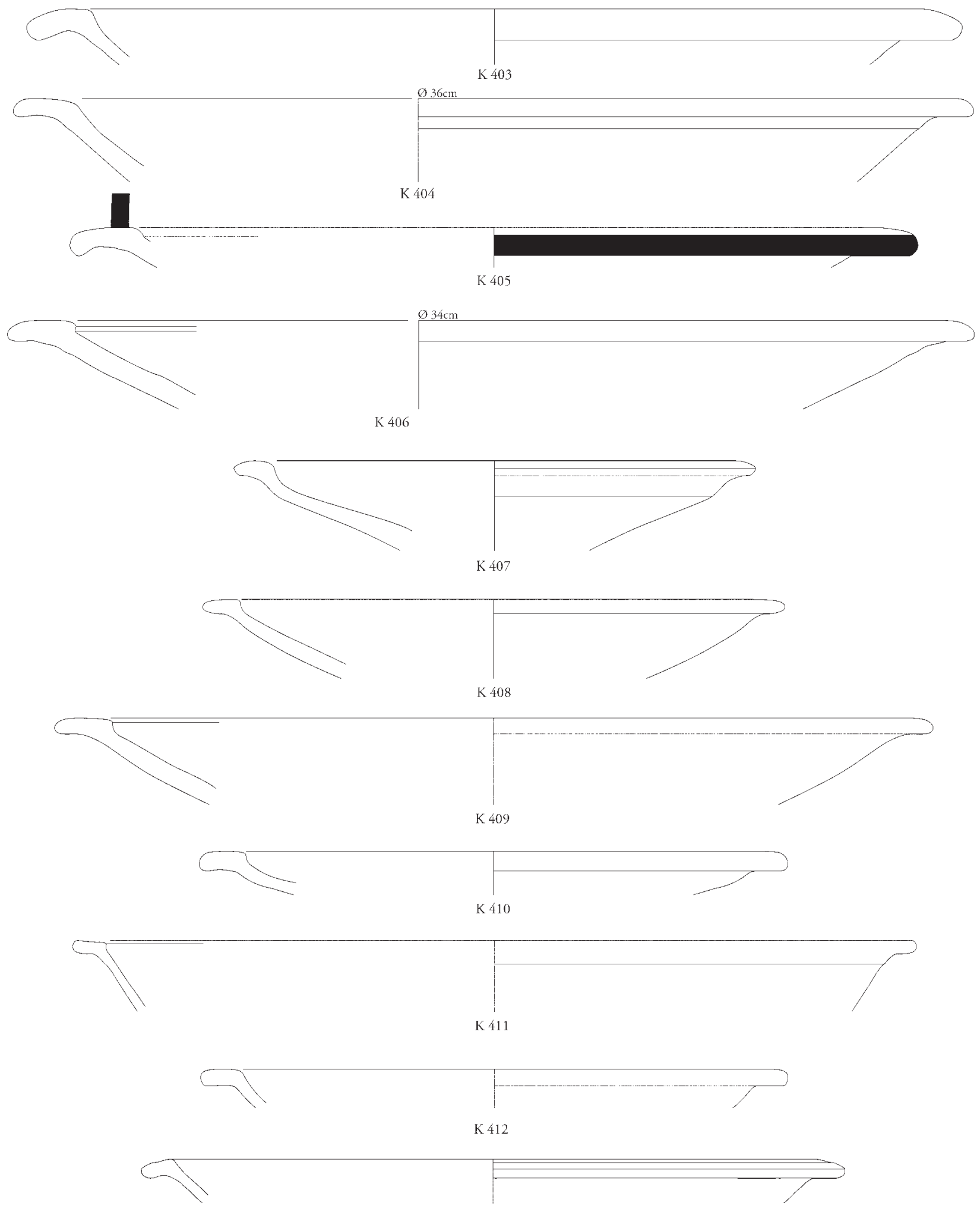

K 413

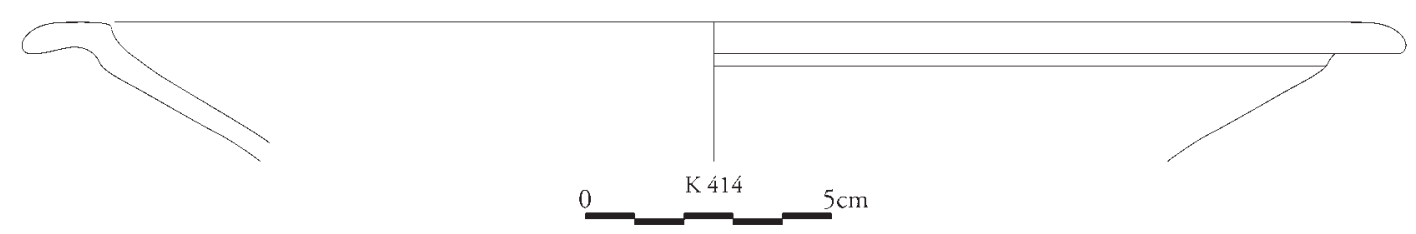

K 403-414 
Tafel 188
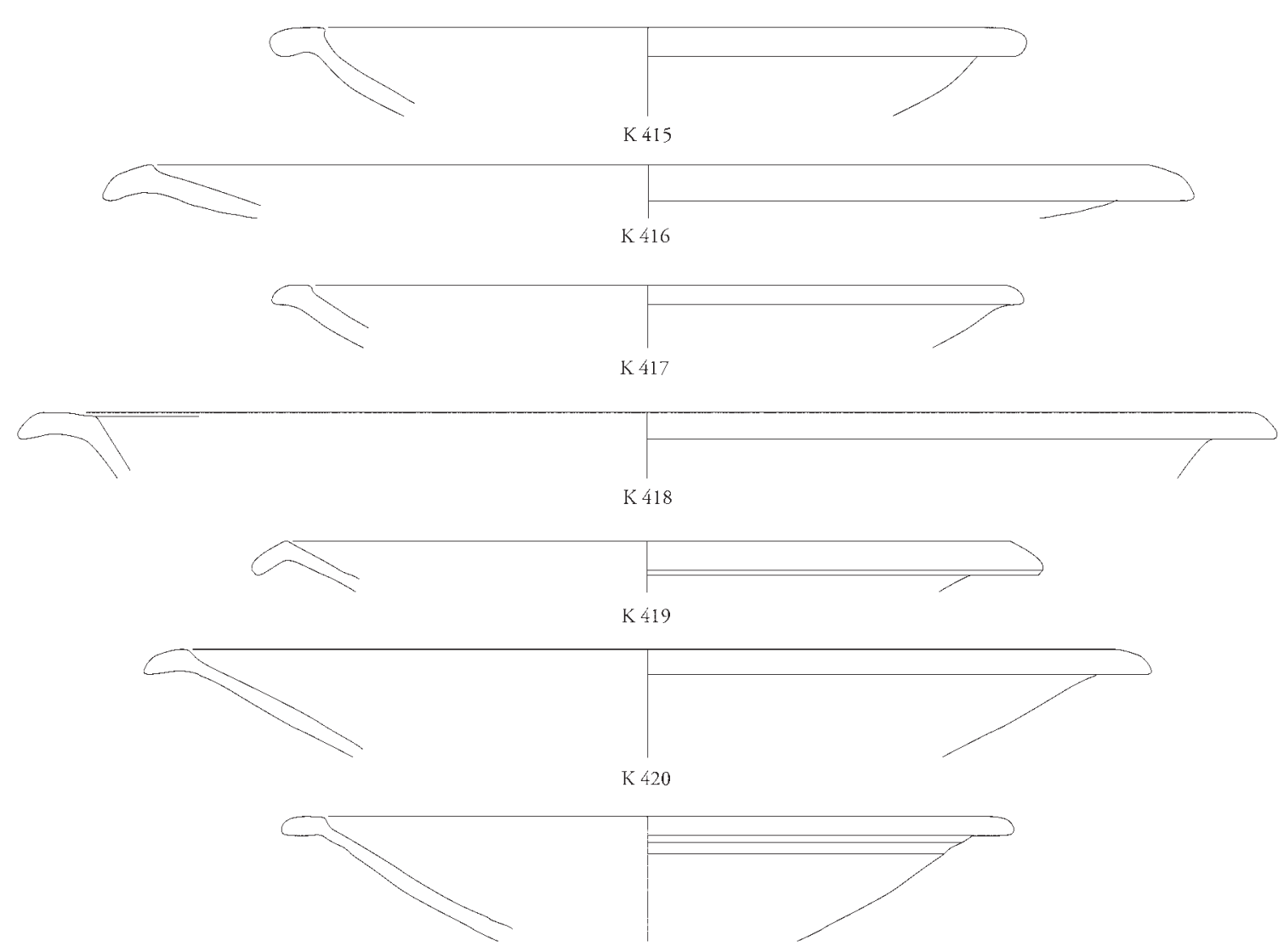

K 421

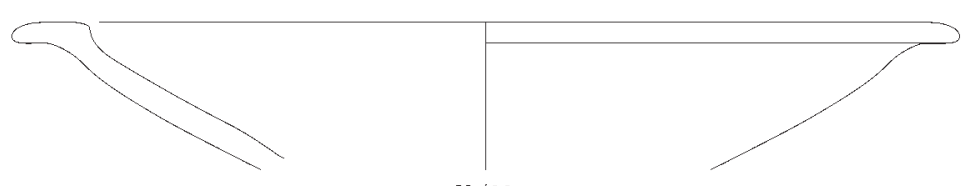

K 422
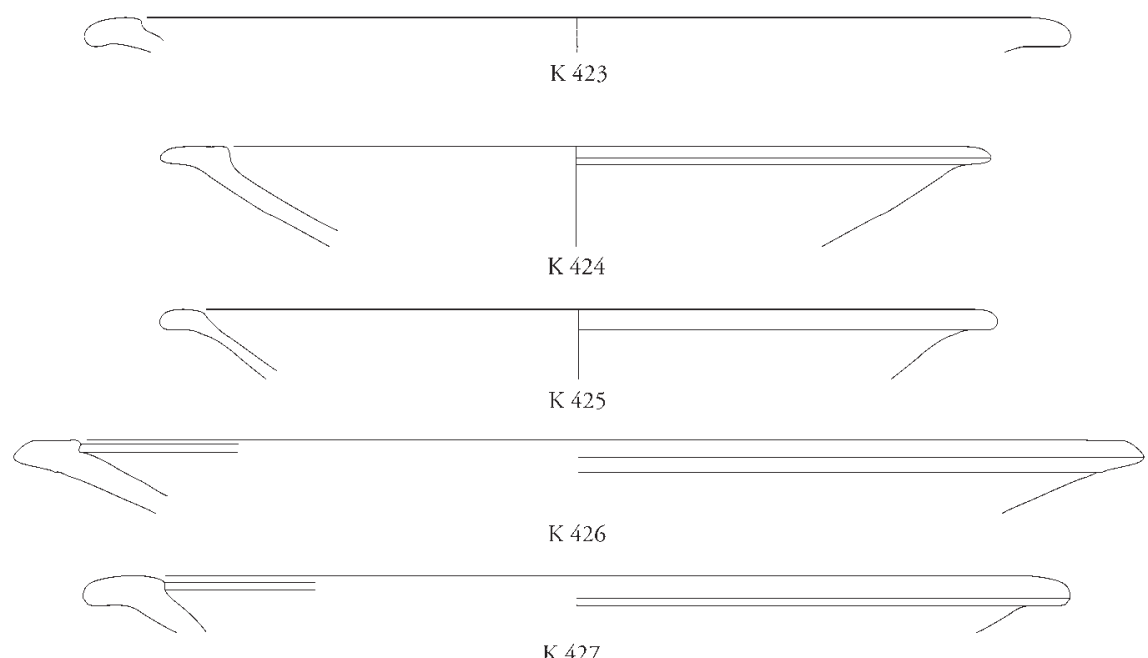

\section{0.}
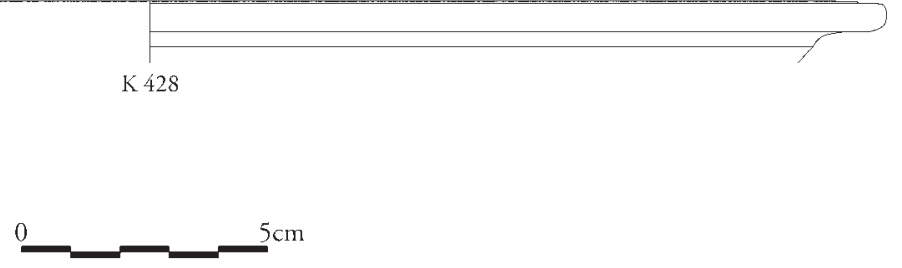

K 415-428 

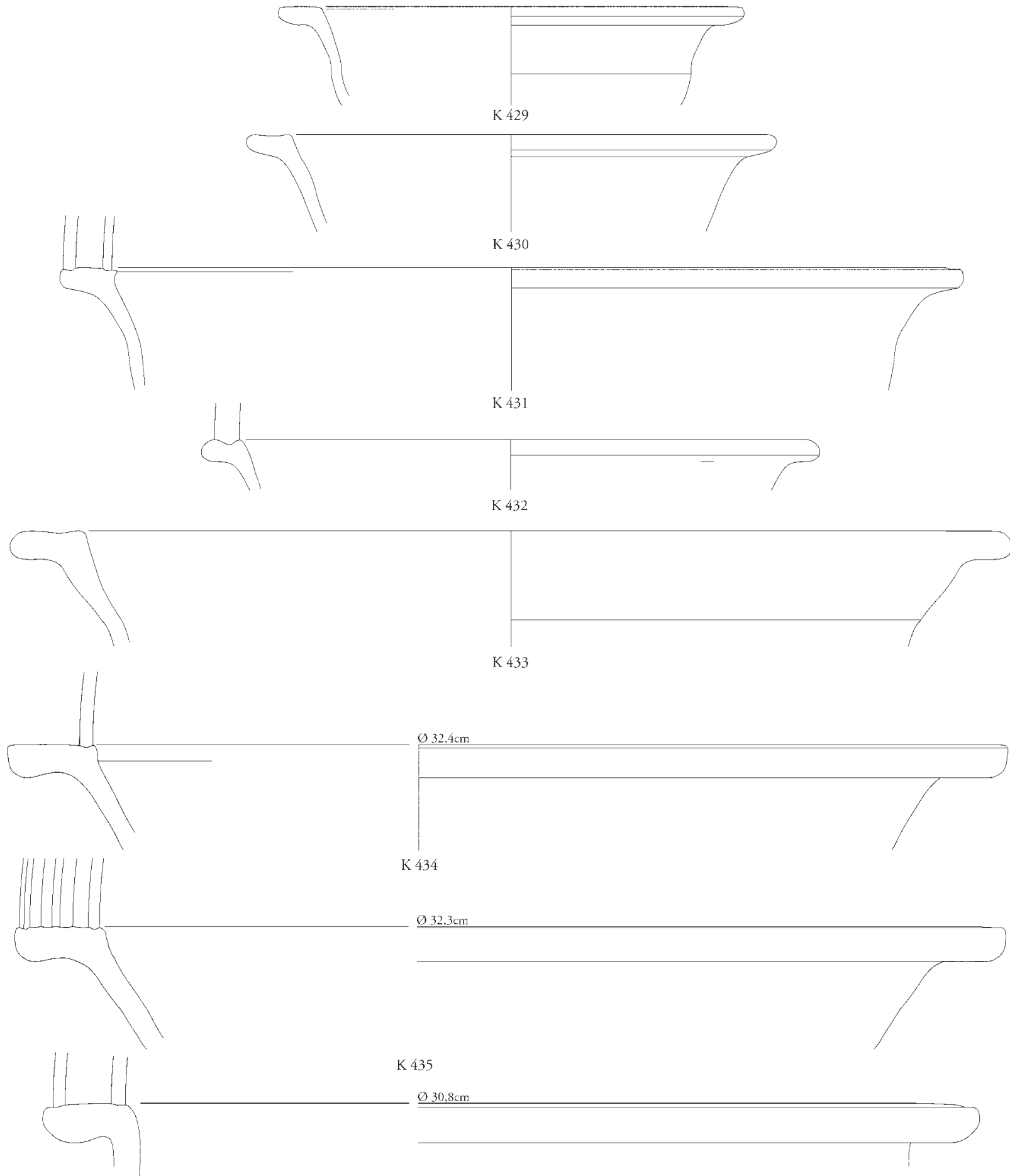

K 436

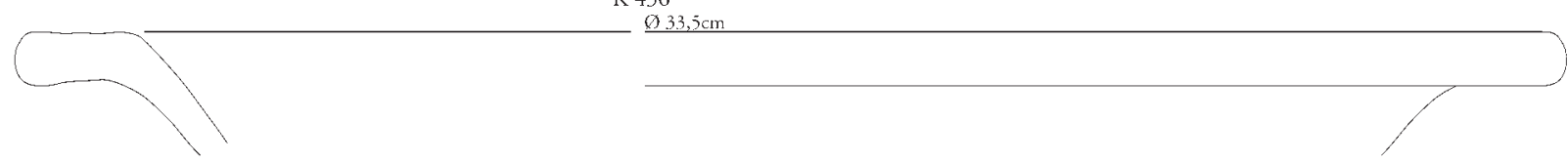

K 437

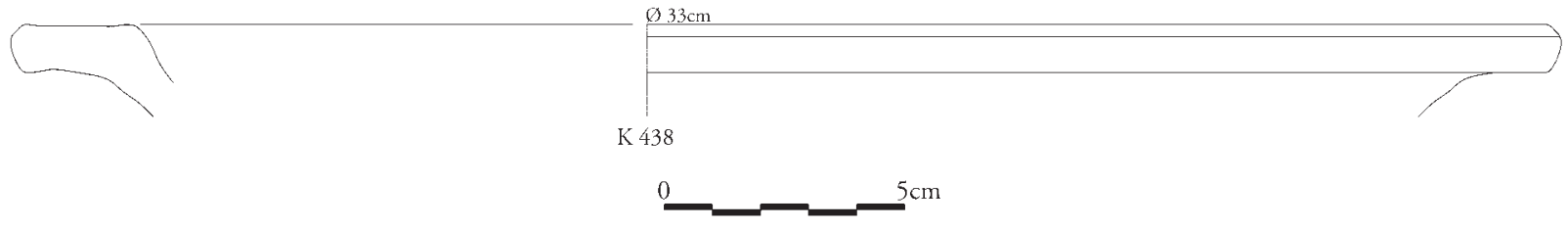

K 429-438 
Tafel 190
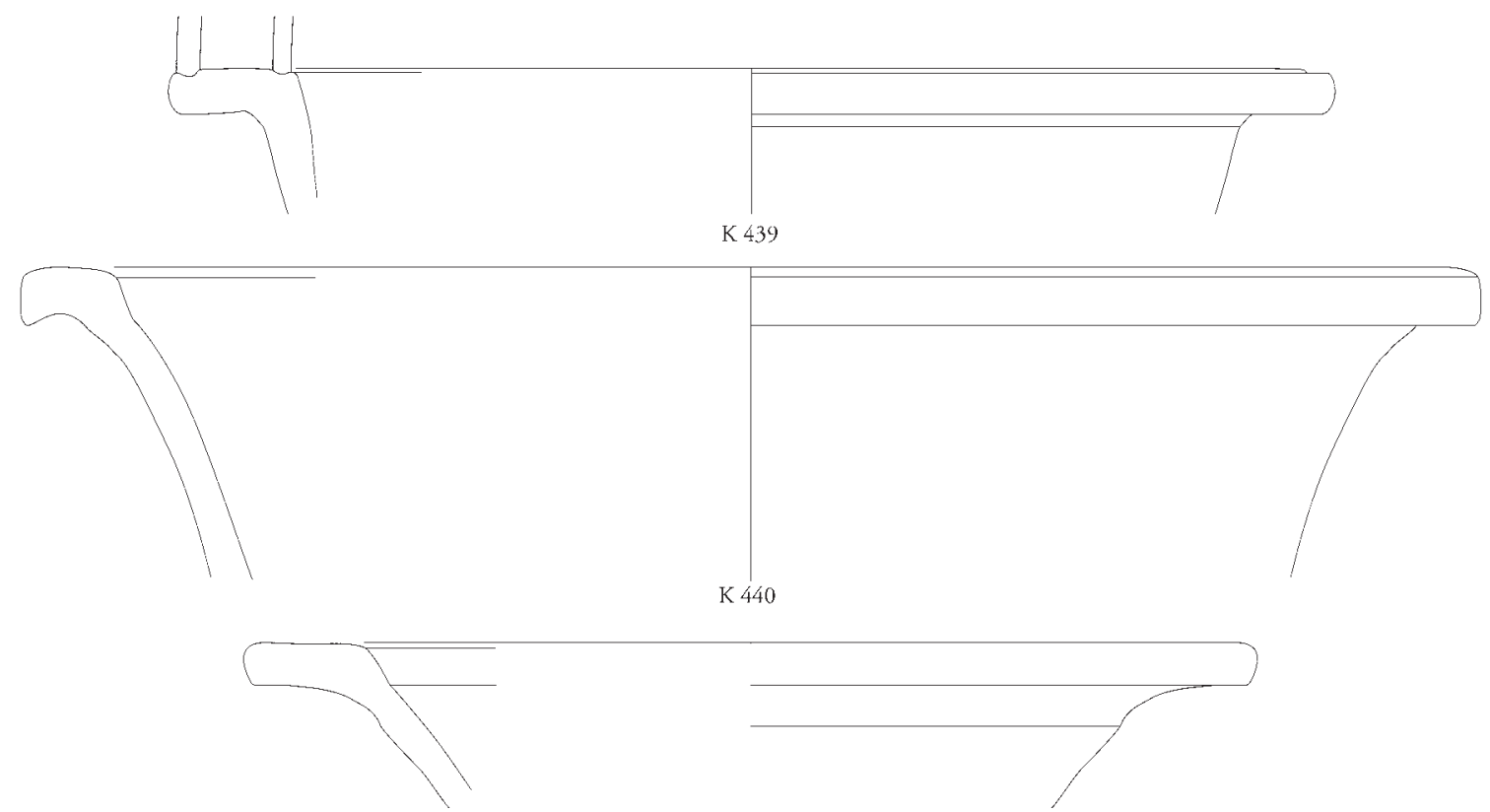

K 441
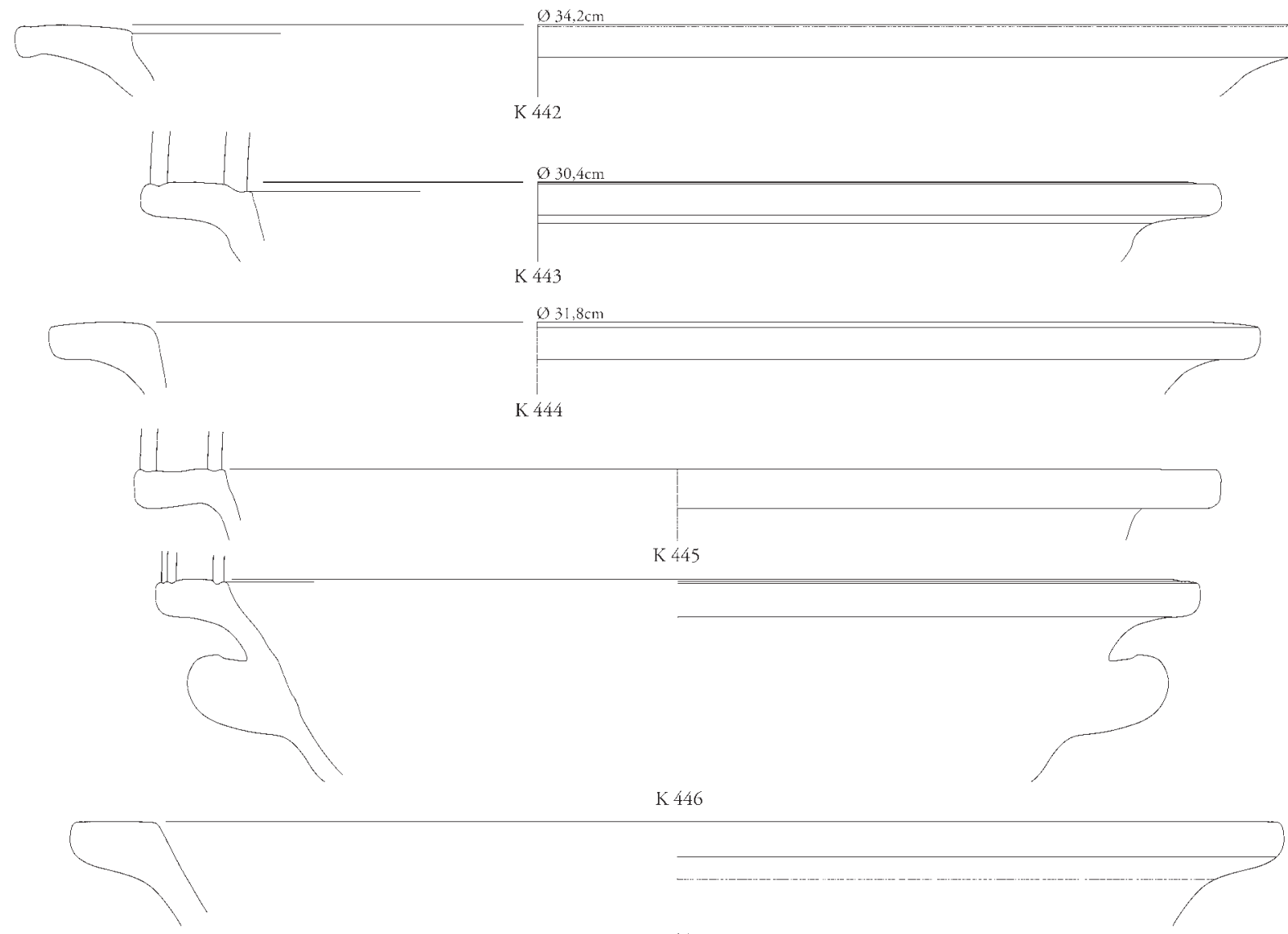

K 447
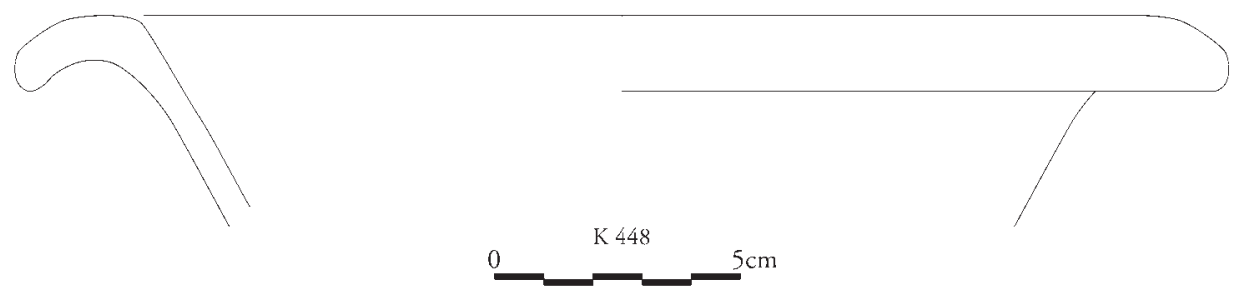

K 439-448 
Tafel 191
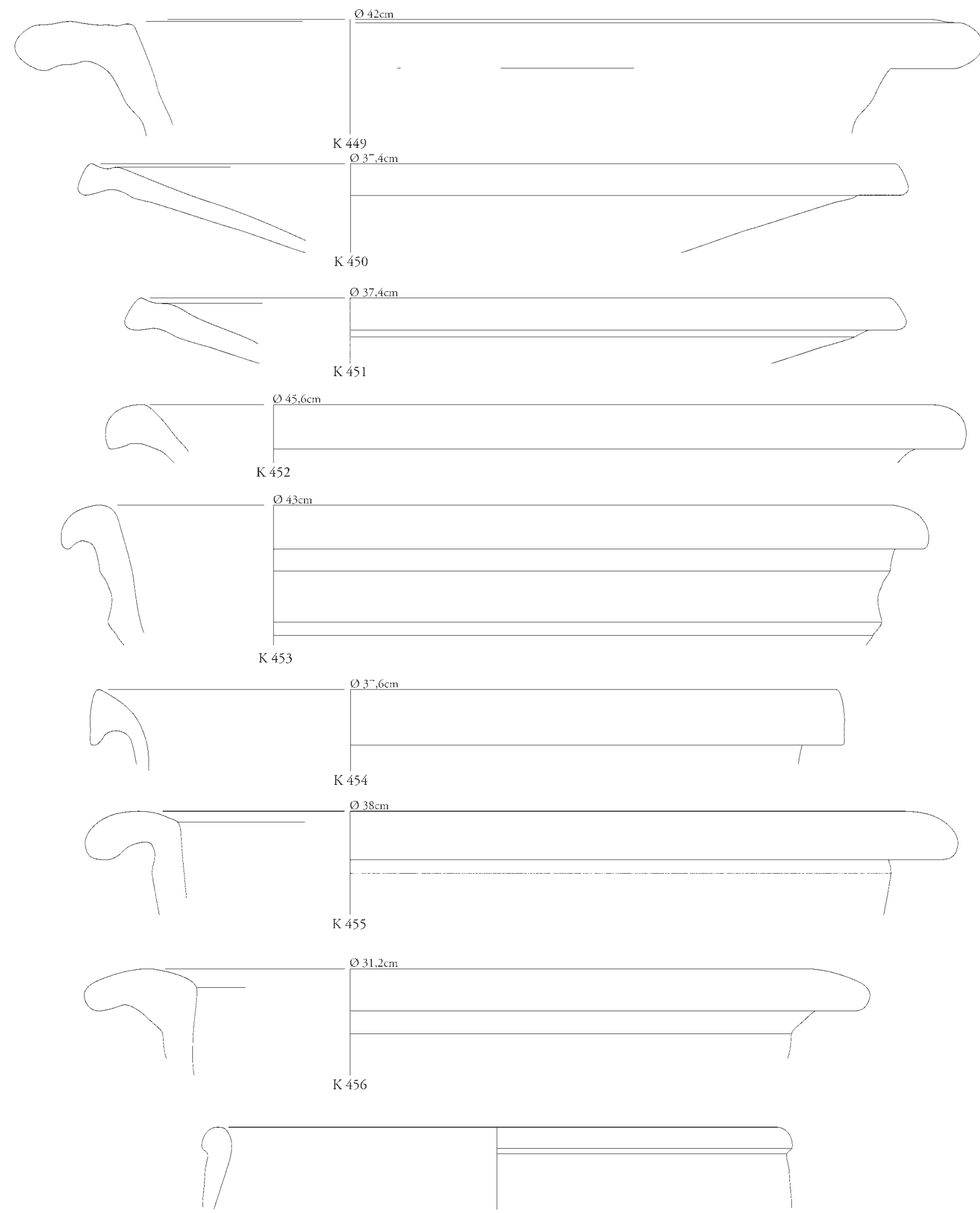

K 457

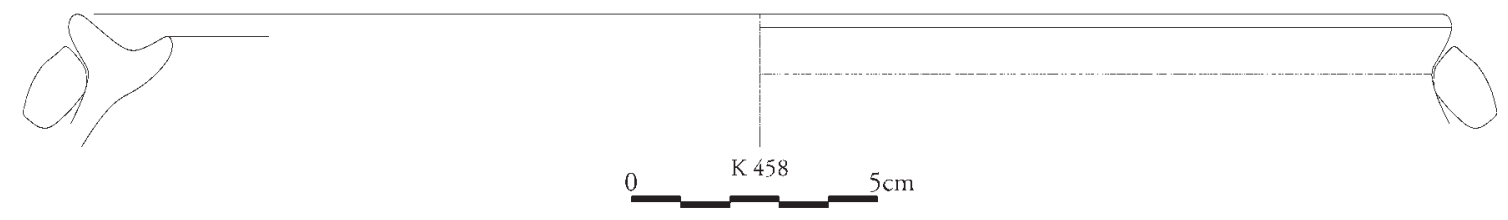

K 449-458 
Tafel 192
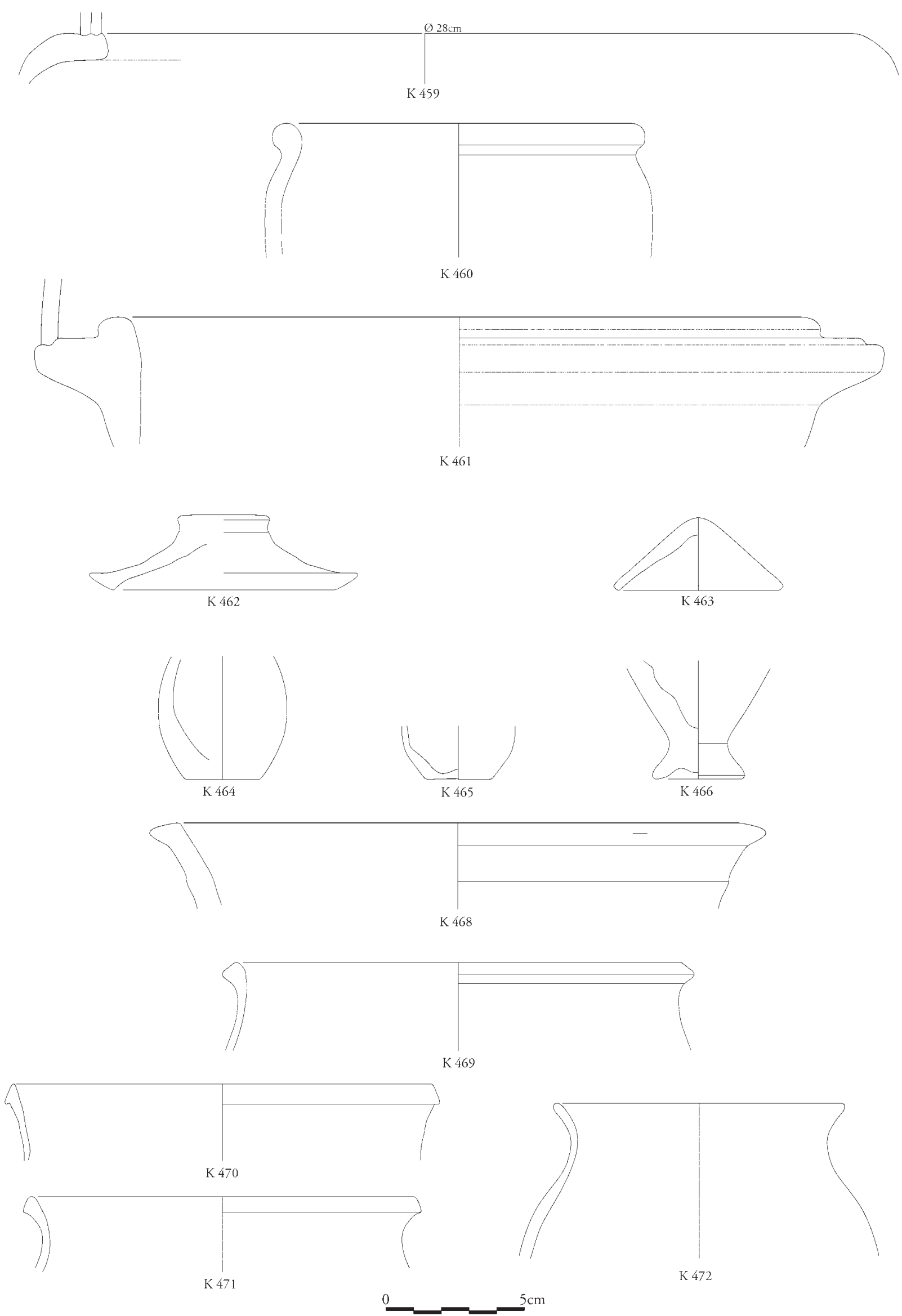

K 459-466. 468-472 
Tafel 193

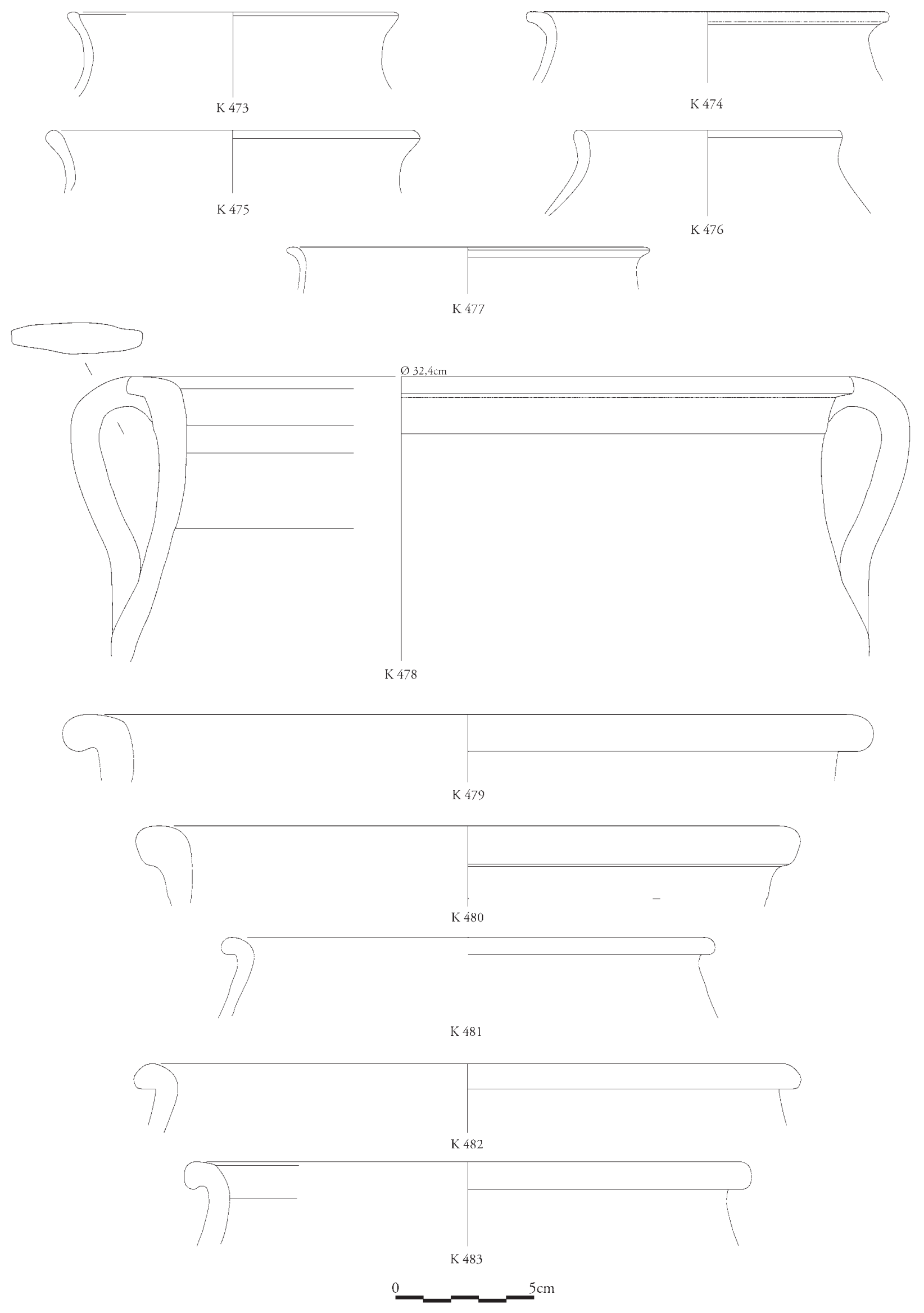

K 473-483 
Tafel 194

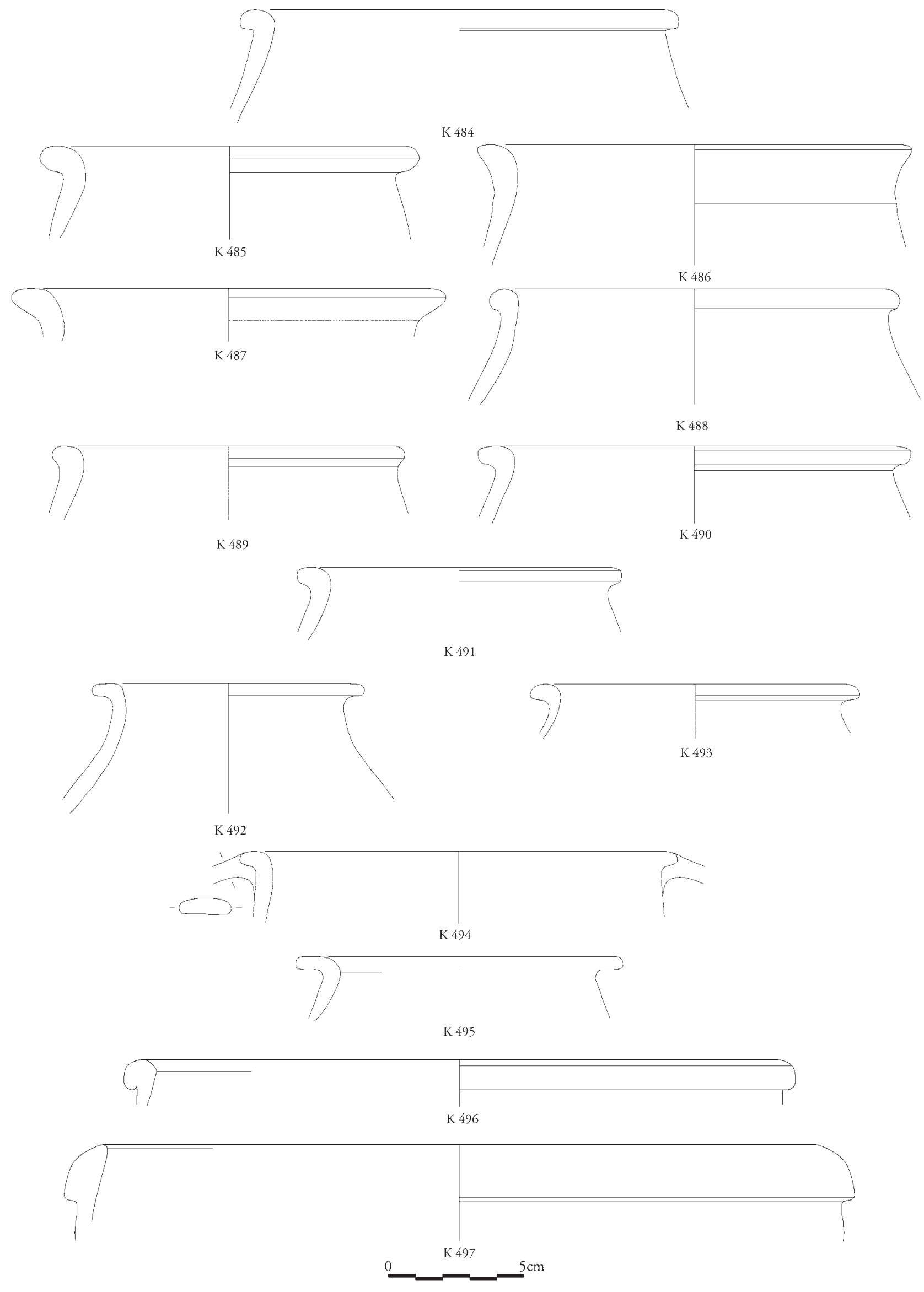

K 484-497 
Tafel 195
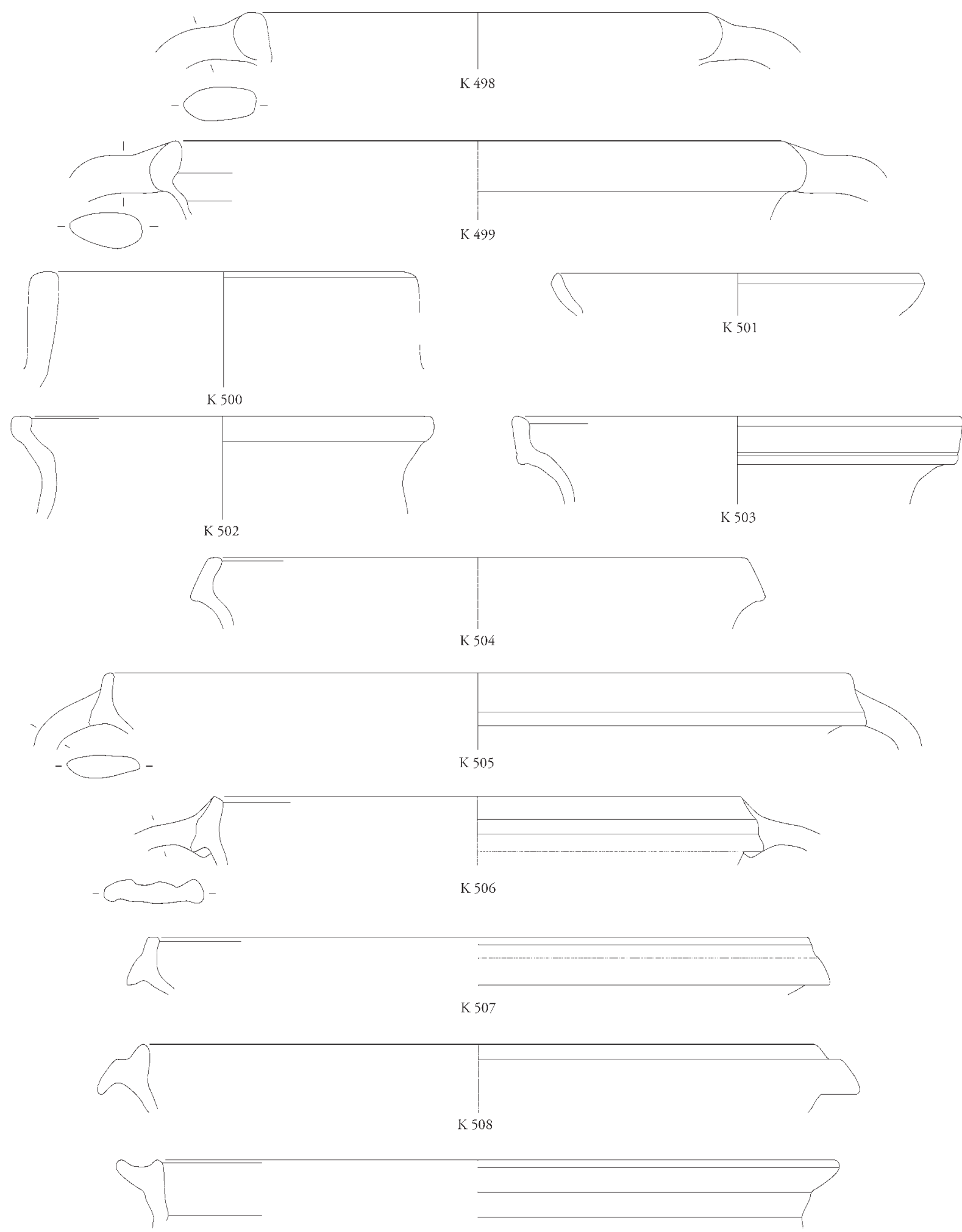

K 509
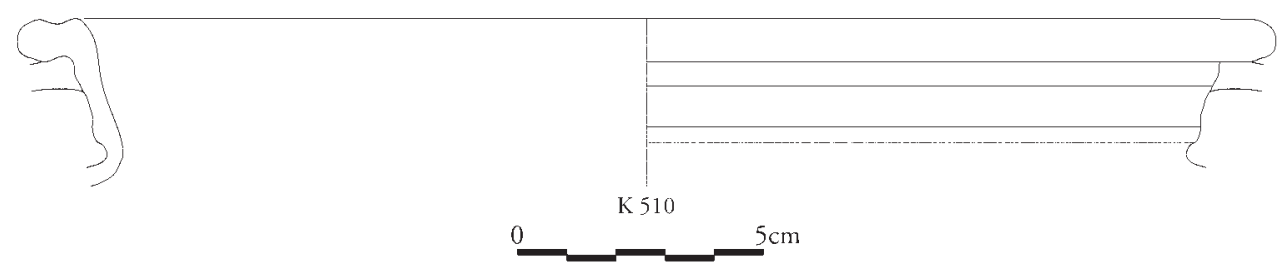

K 498-510 
Tafel 196
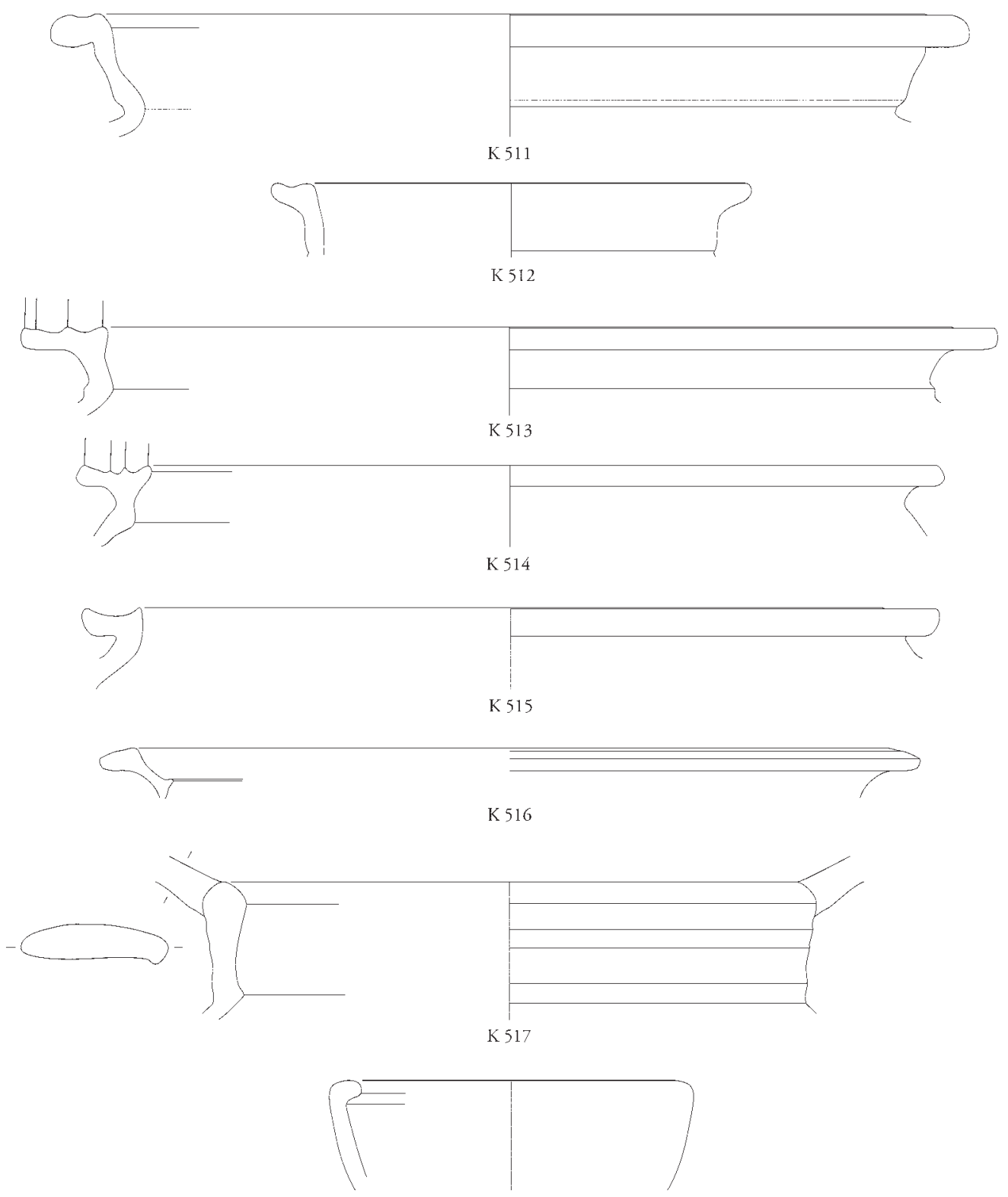

K 518
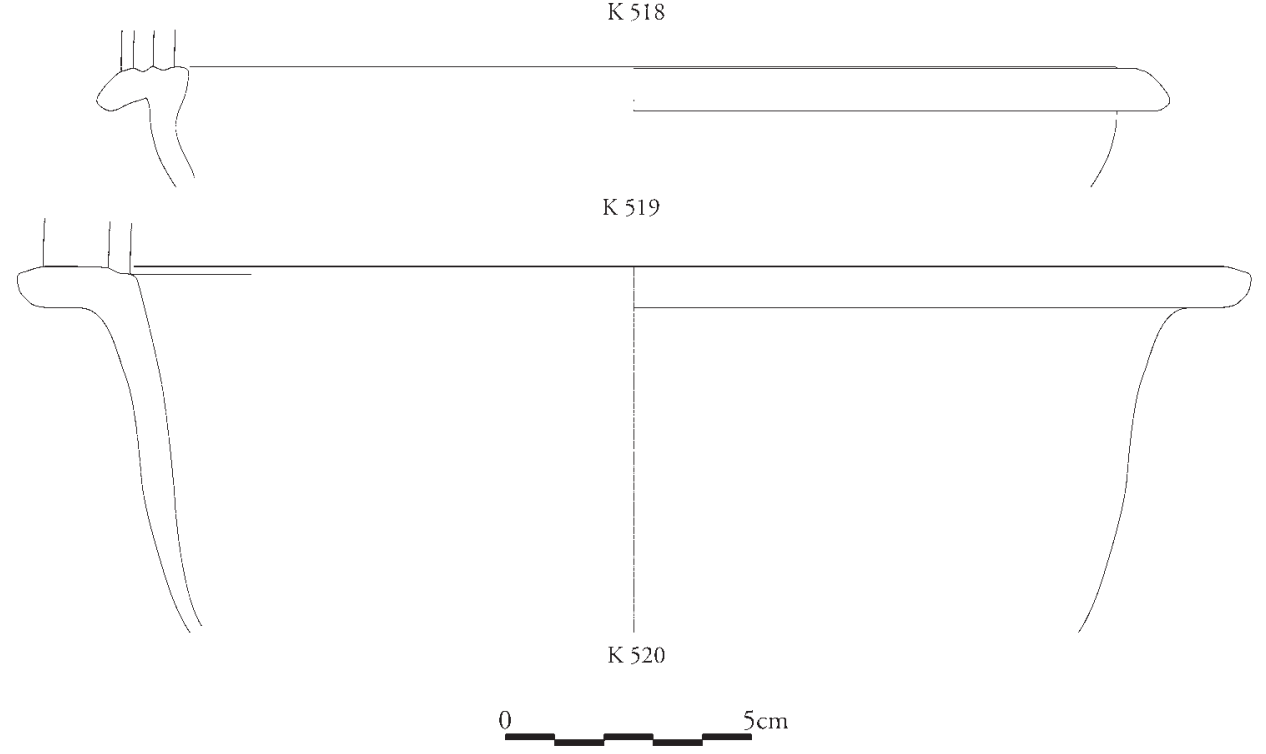

K 511-520 

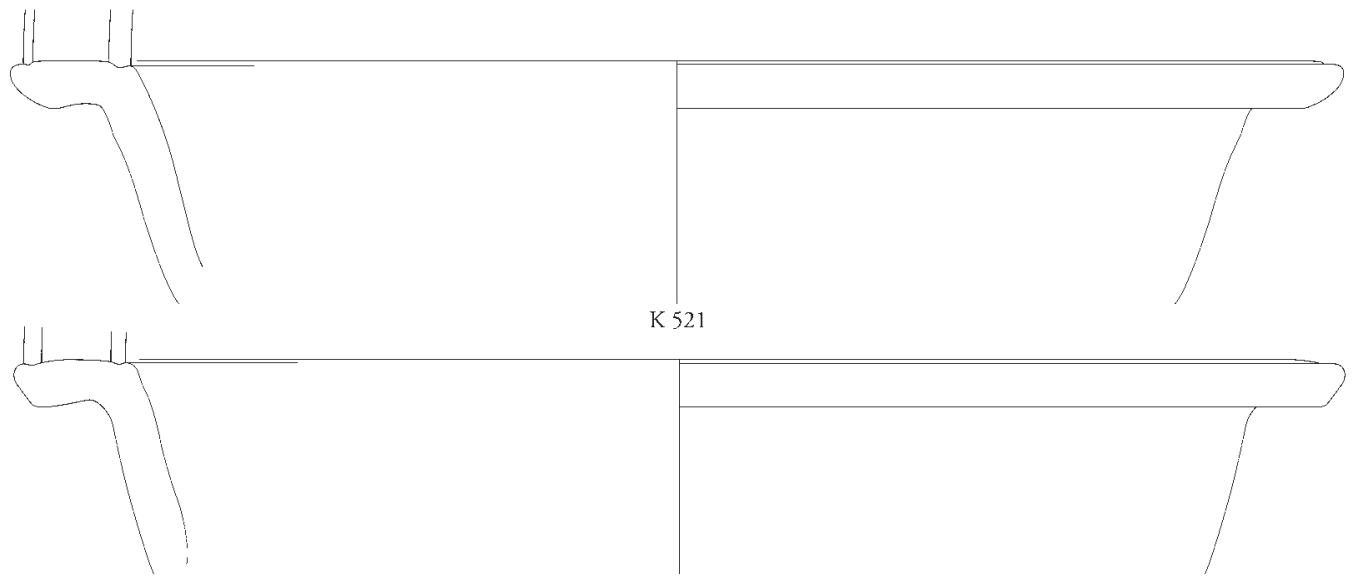

K 522

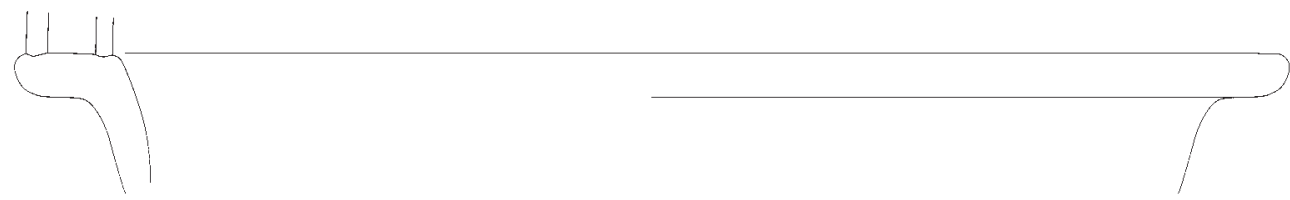

K 523
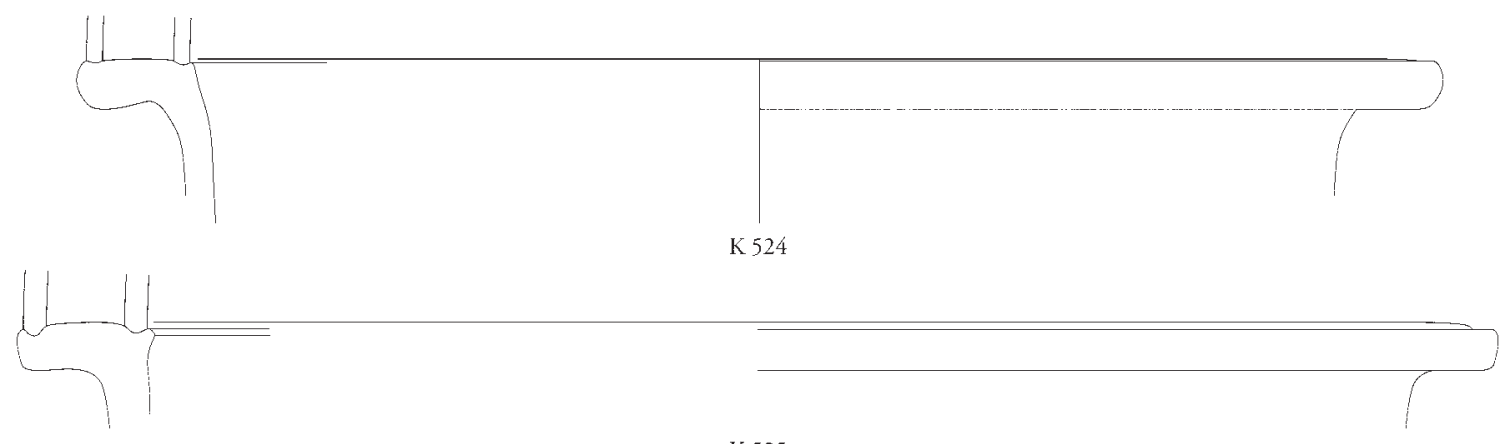

K 525
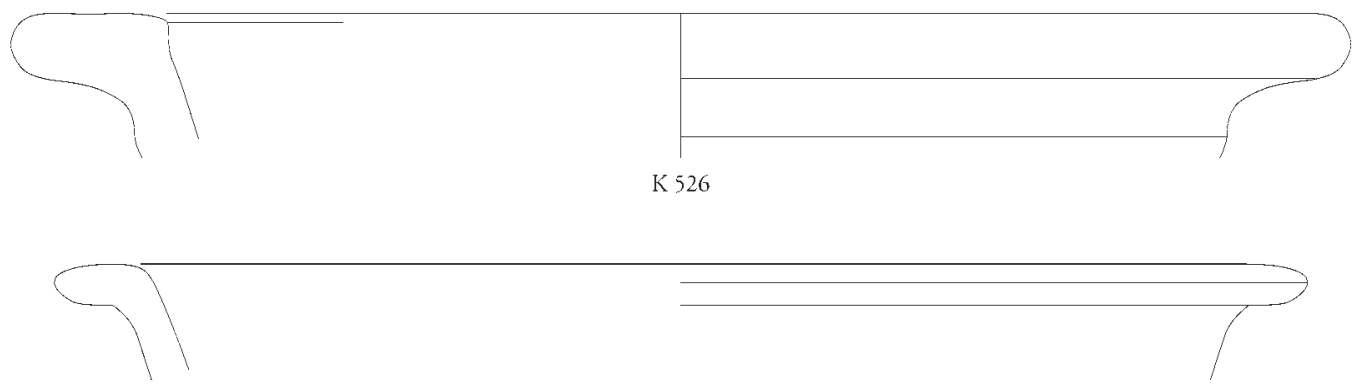

K 527
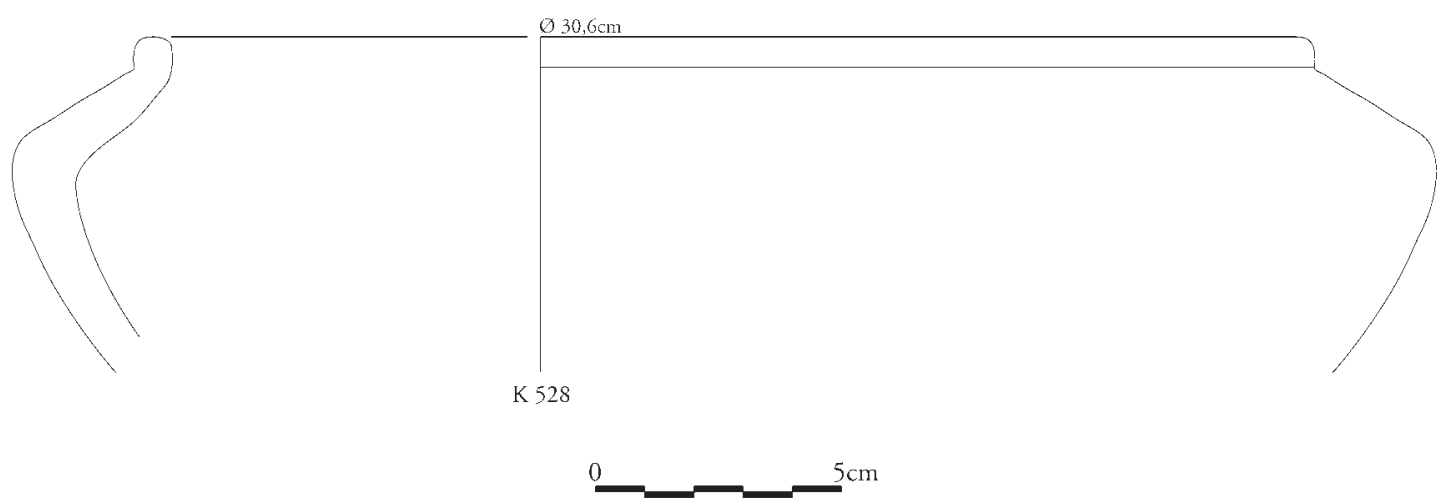

K 521-528 
Tafel 198
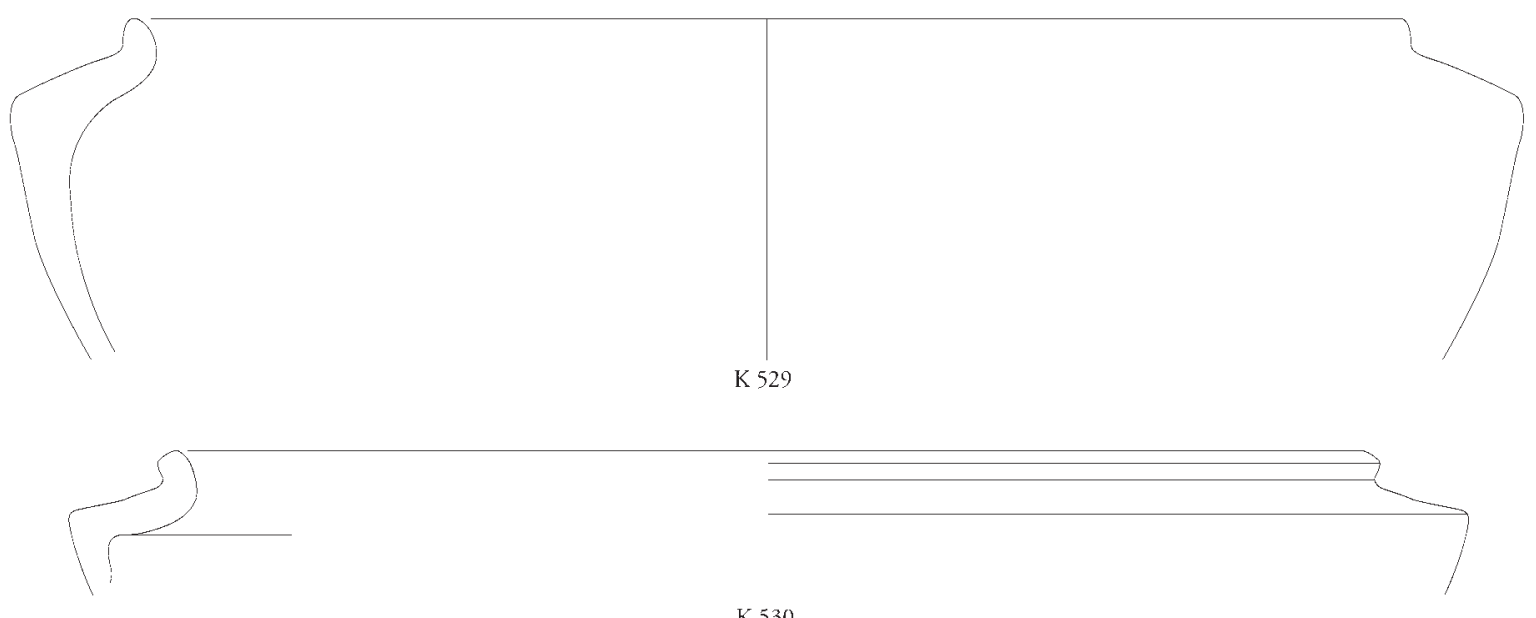

K530
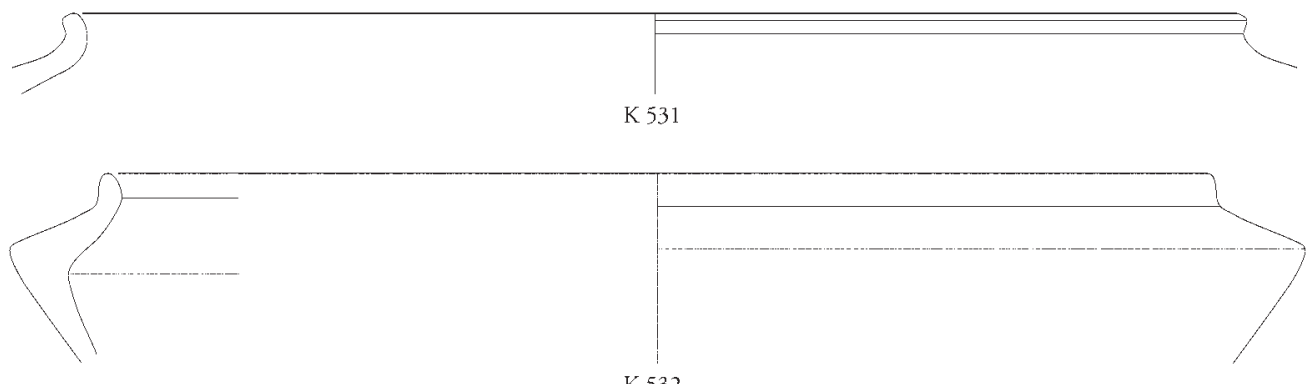

K 532

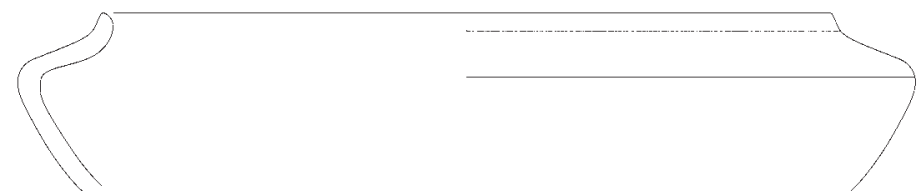

K 533
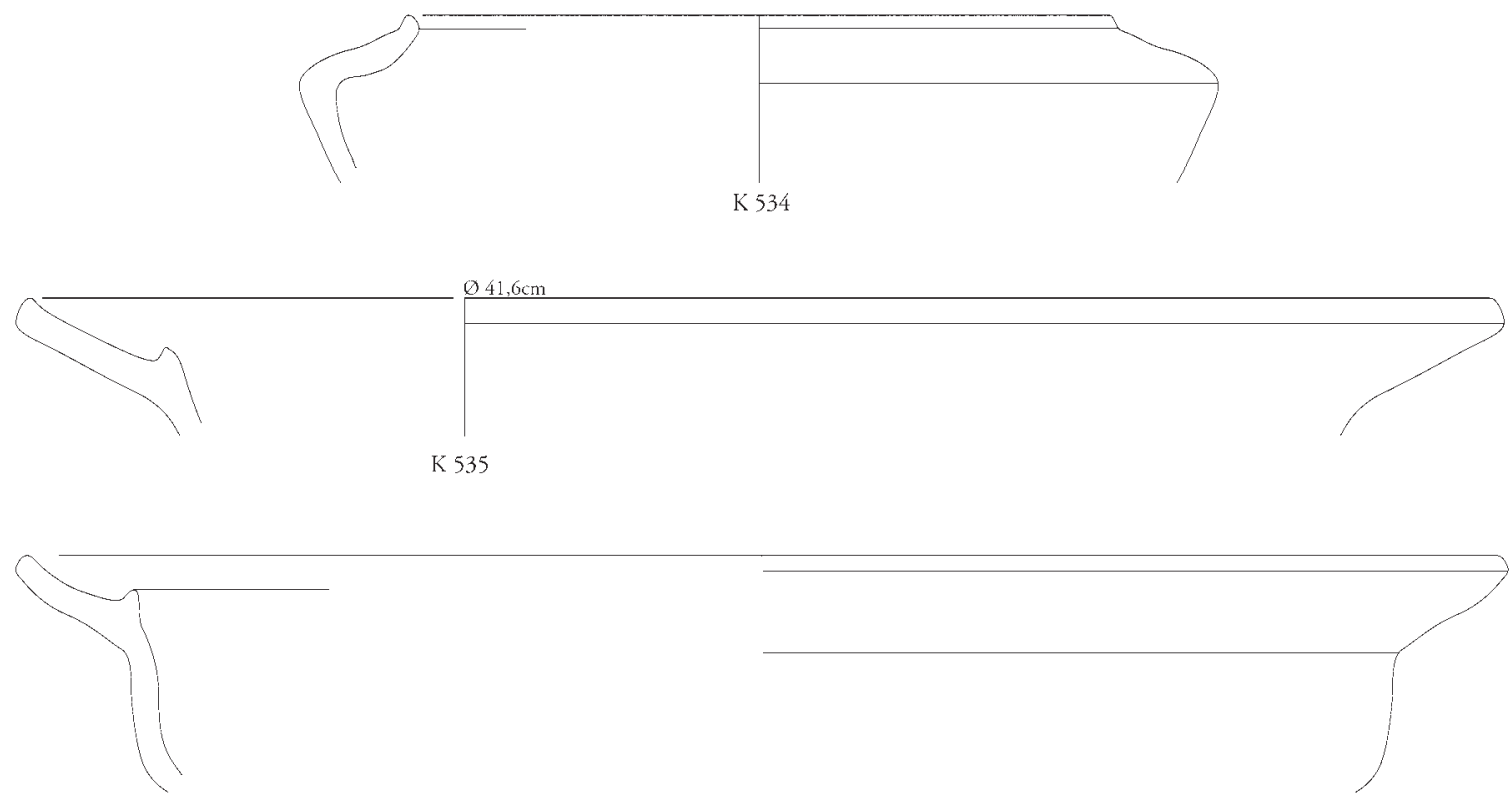

K 536

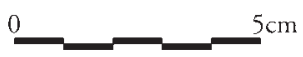

K 529-536 

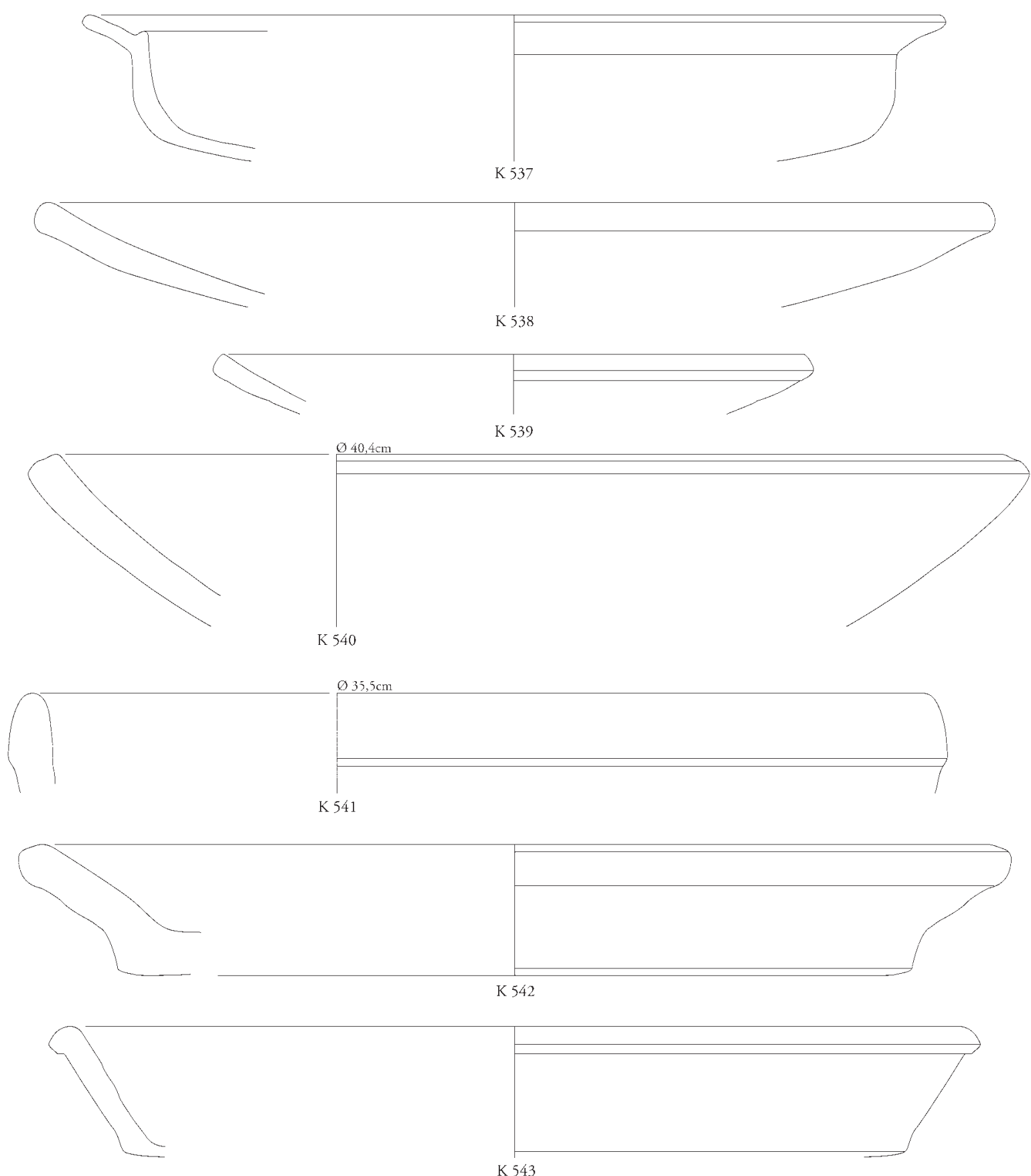

$042,2 \mathrm{~cm}$

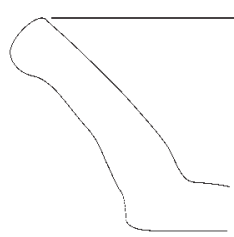

K 544
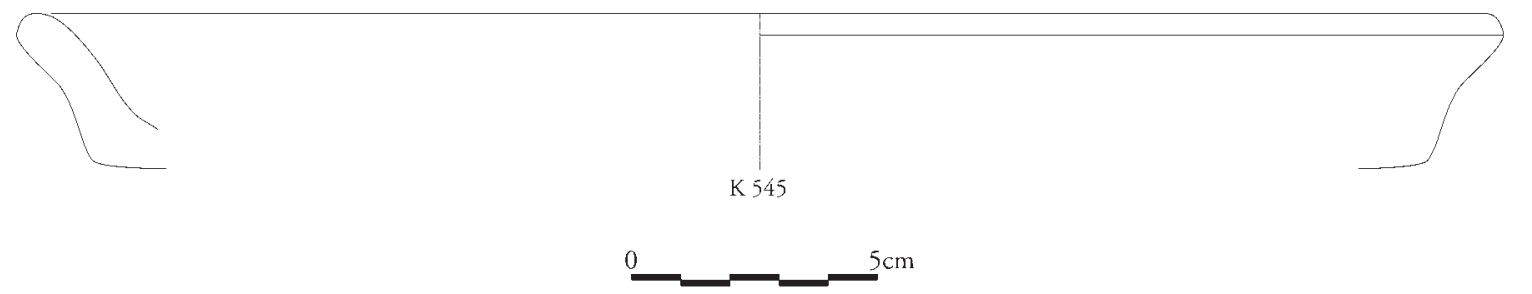

K 537-545 
Tafel 200
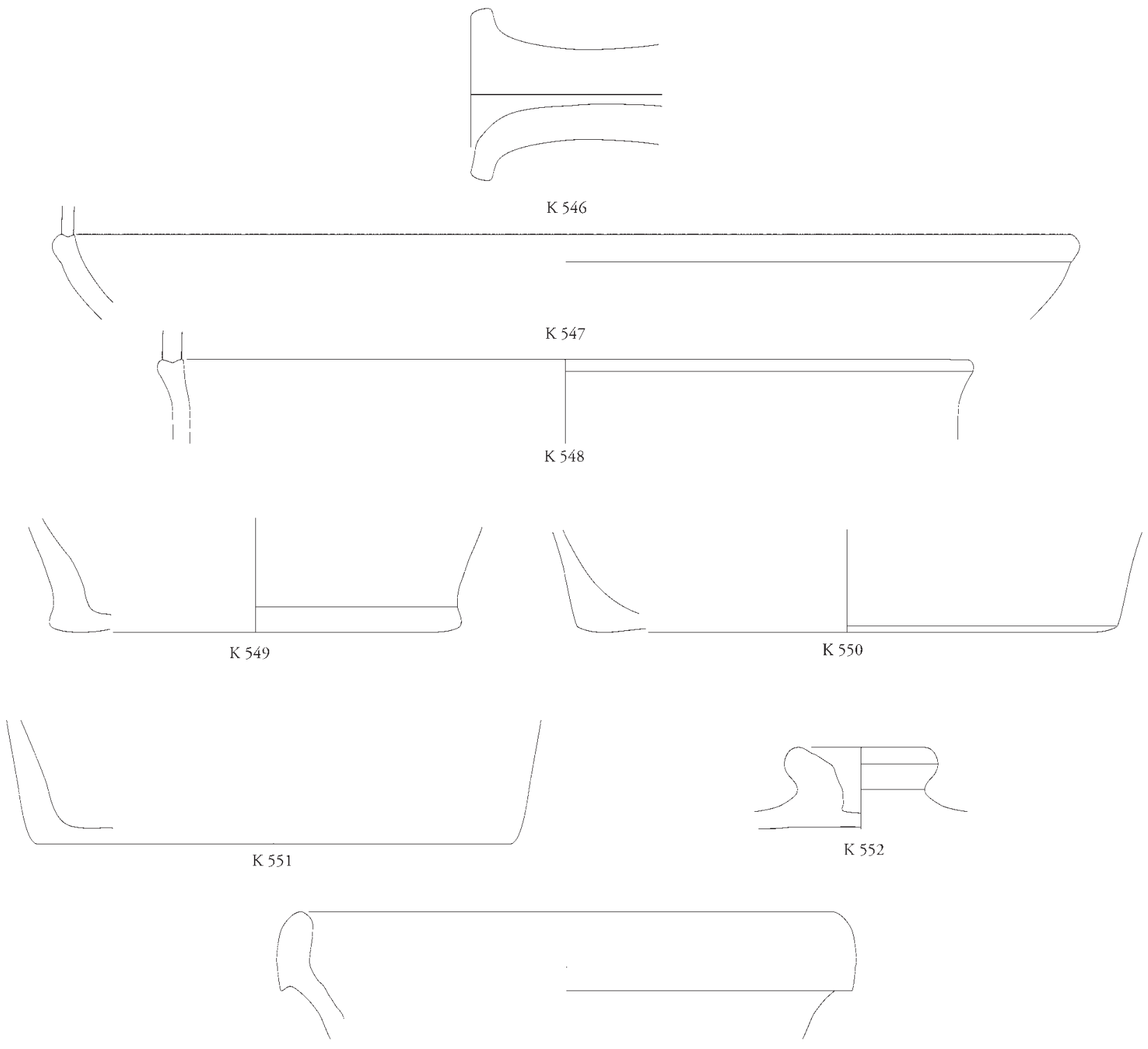

K 553
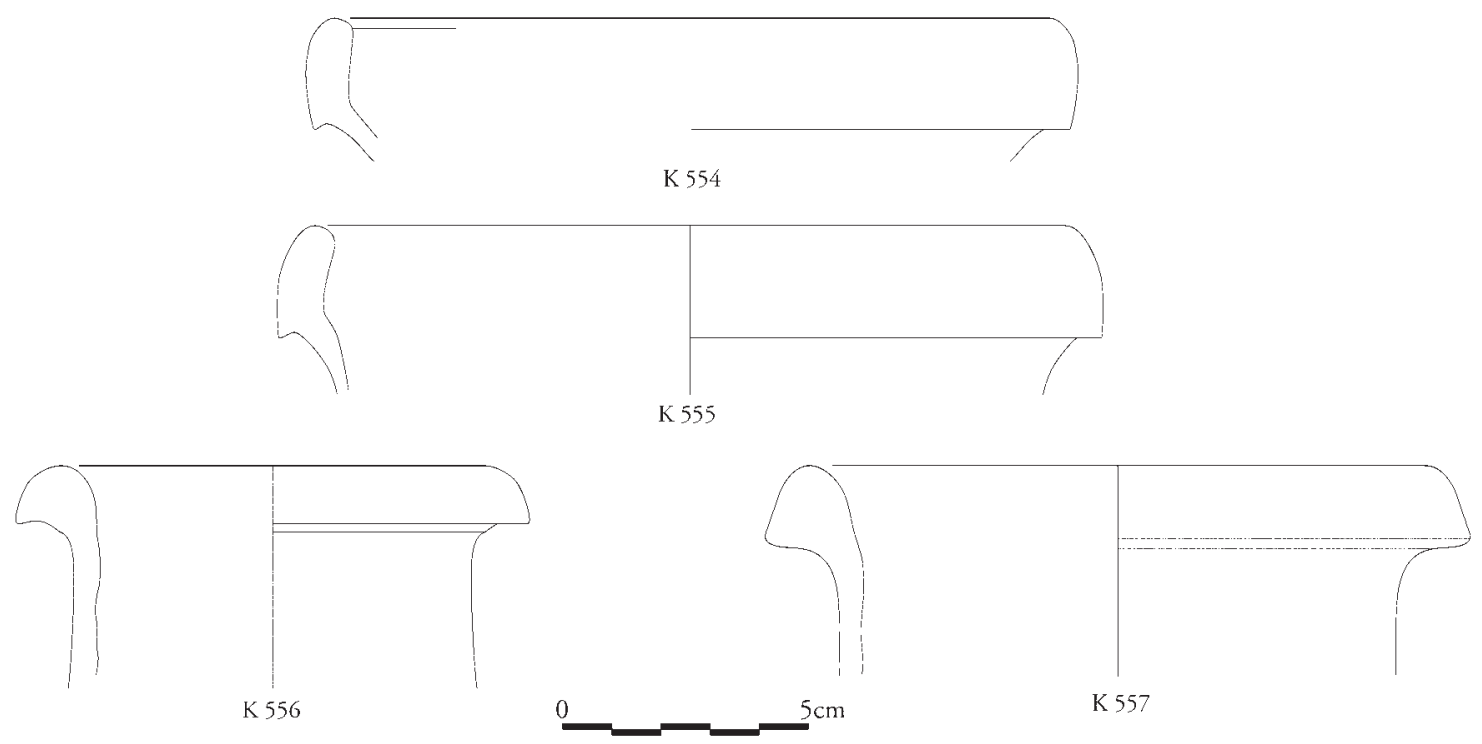

K 546-557 
Tafel 201
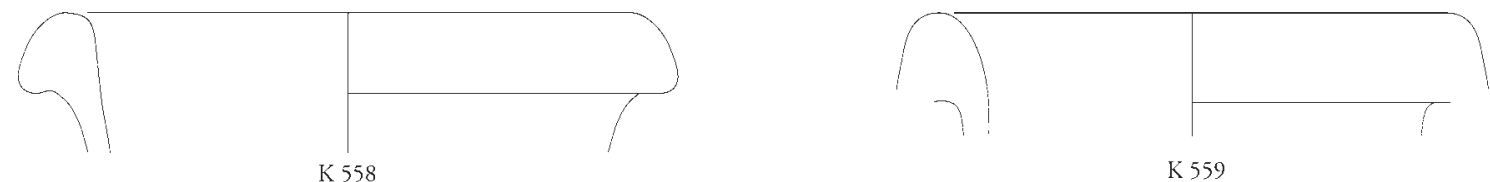

K 559
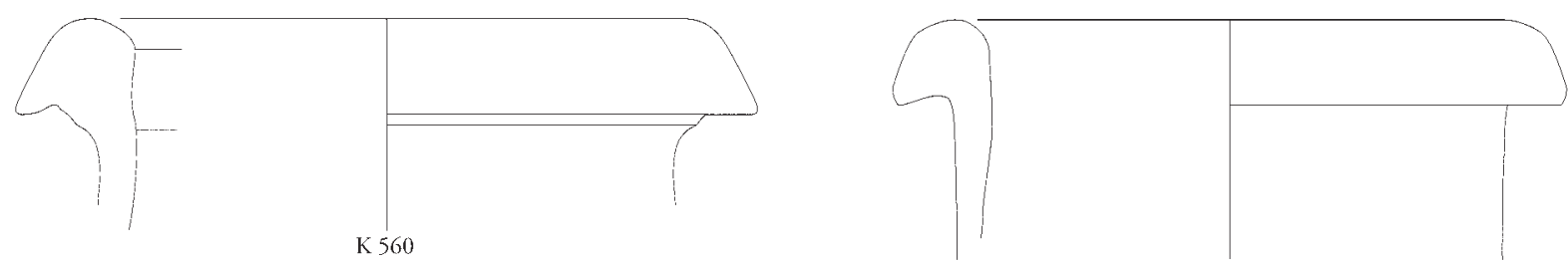

K 561

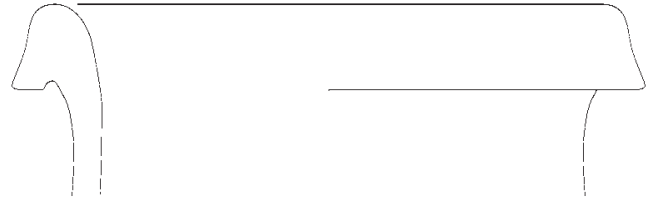

K 562

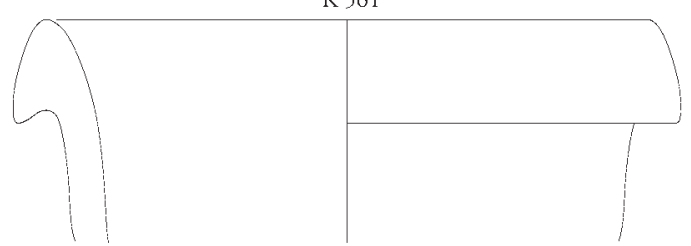

K 563

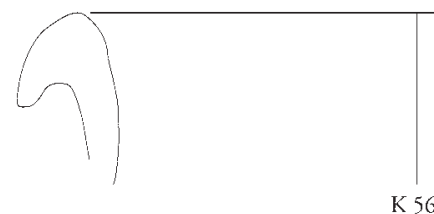

K 564
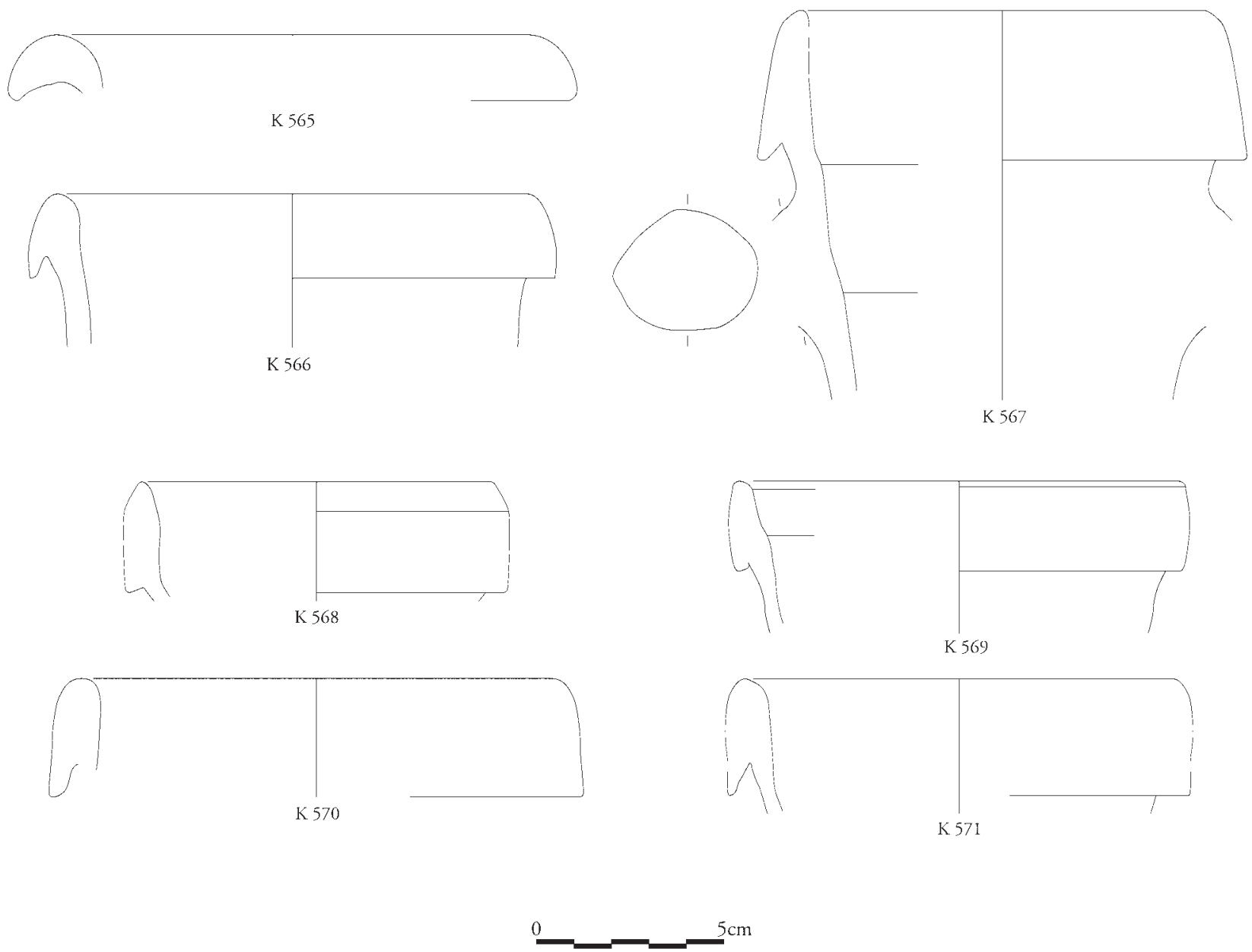

K 558-571 
Tafel 202
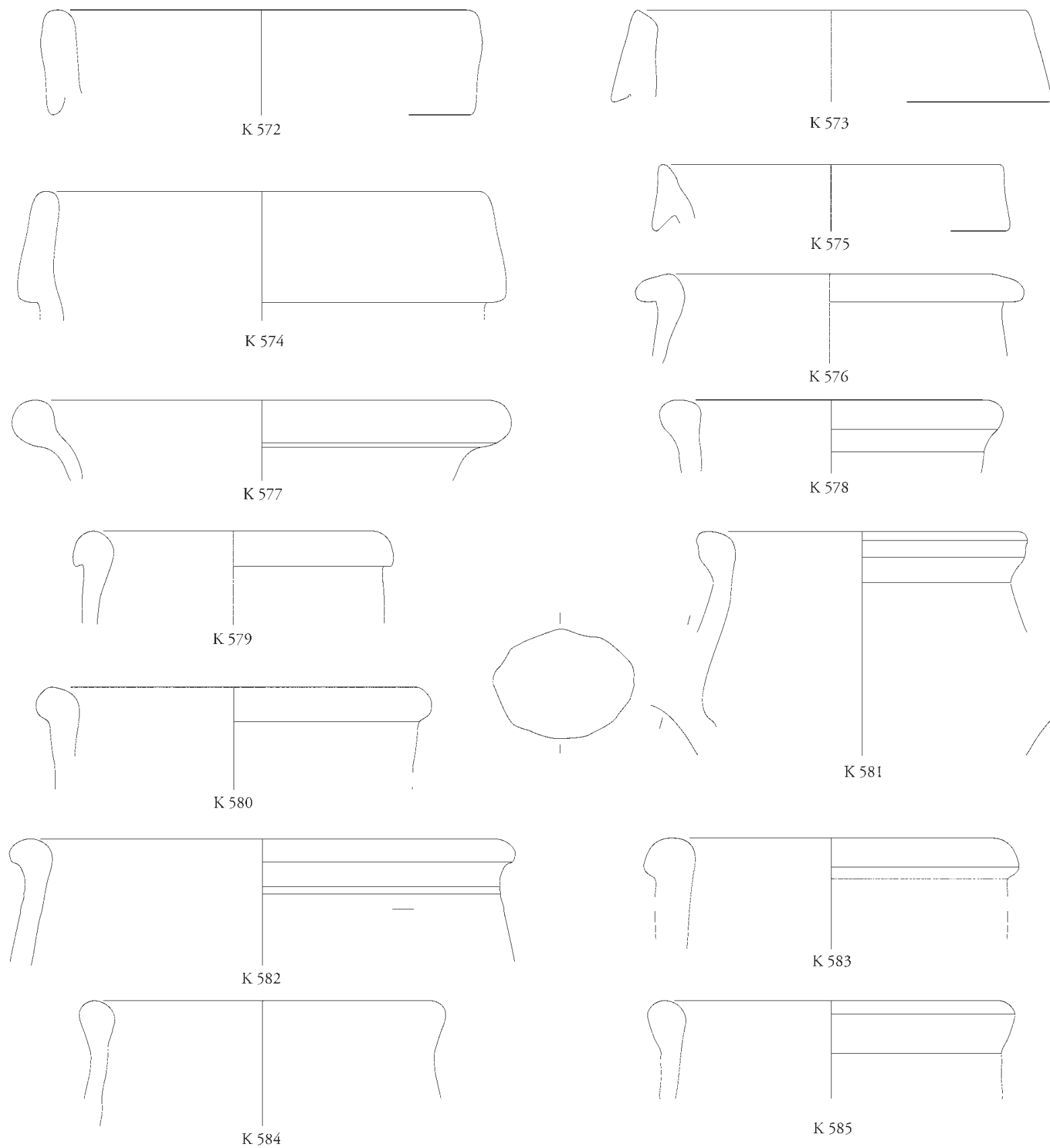

K 585

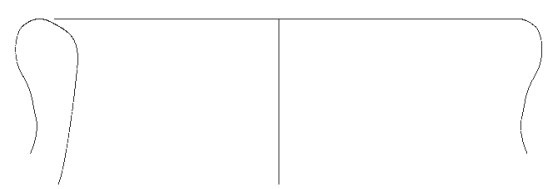

K 586
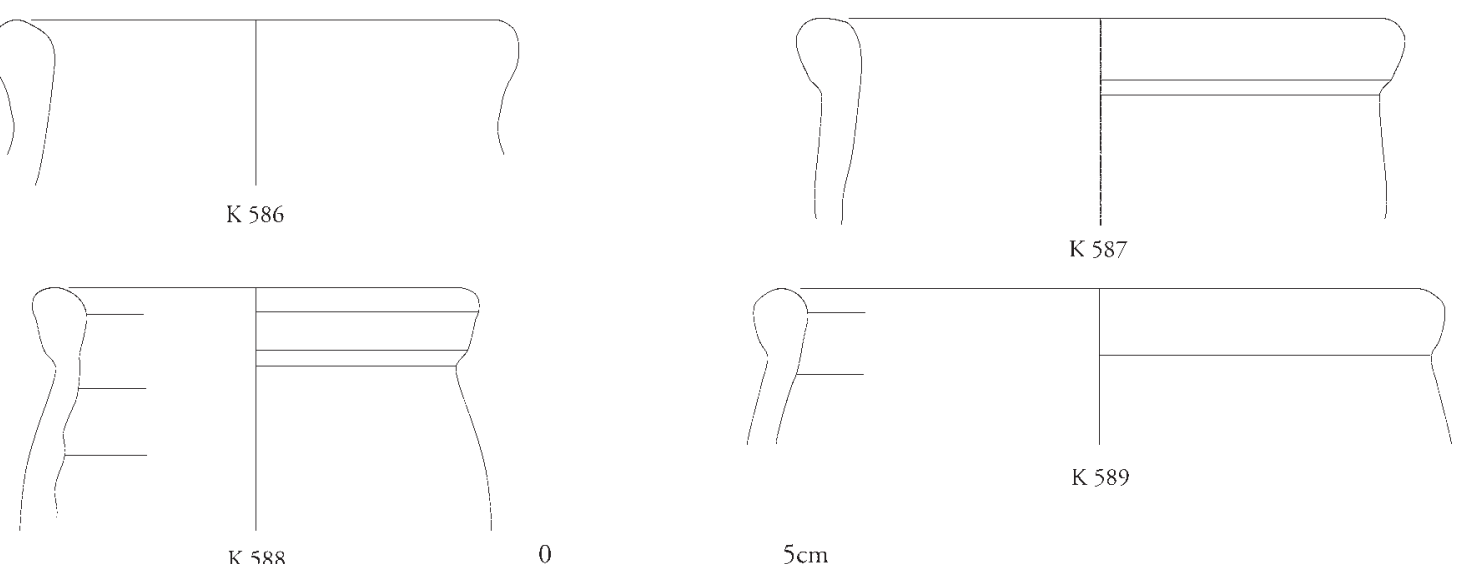

K 588

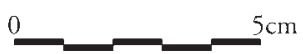

K 572-589 
Tafel 203
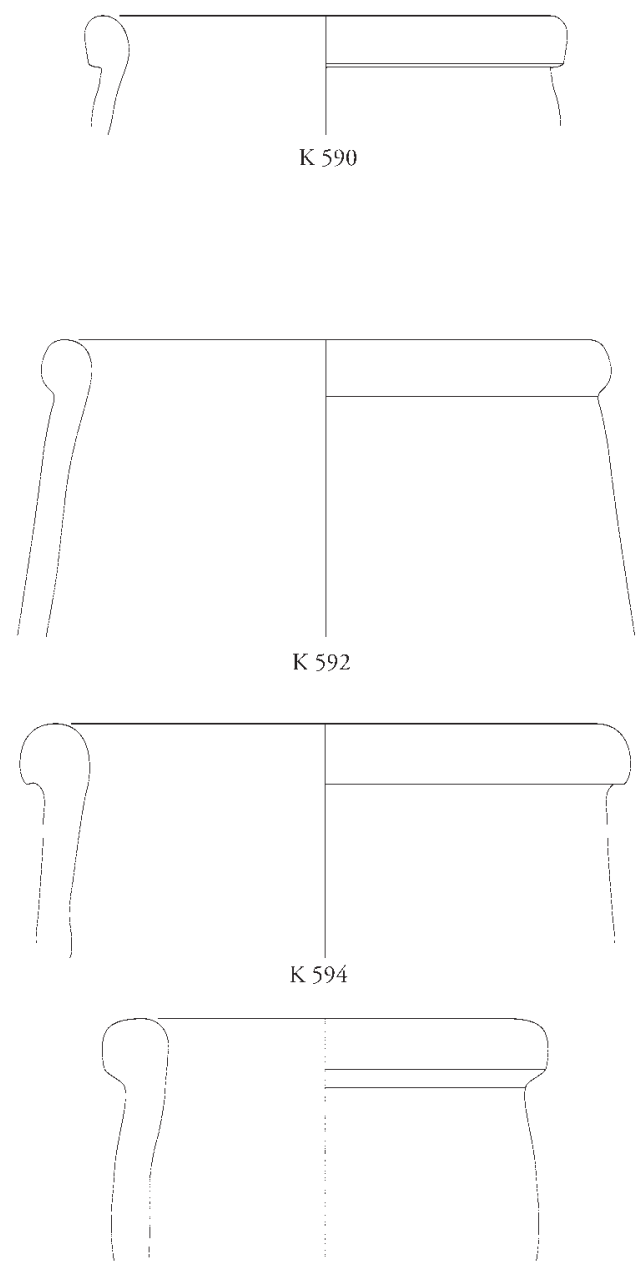

K 596

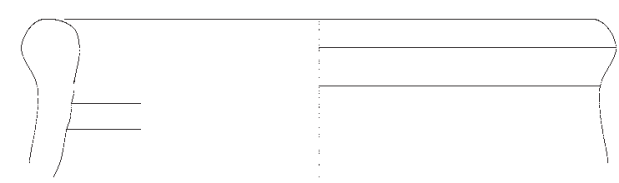

K 598

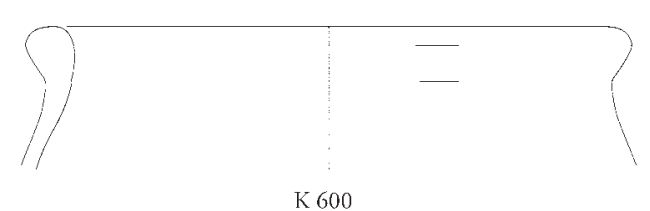

K 600

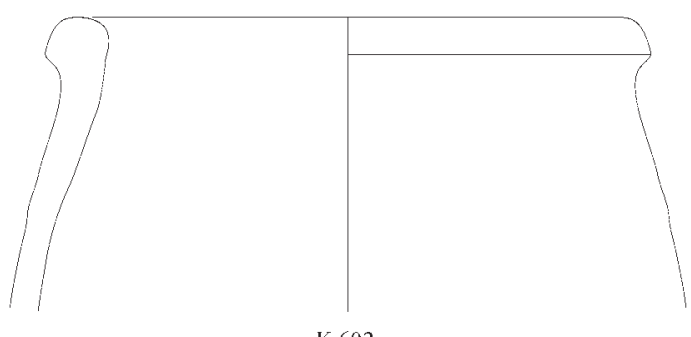

K 602
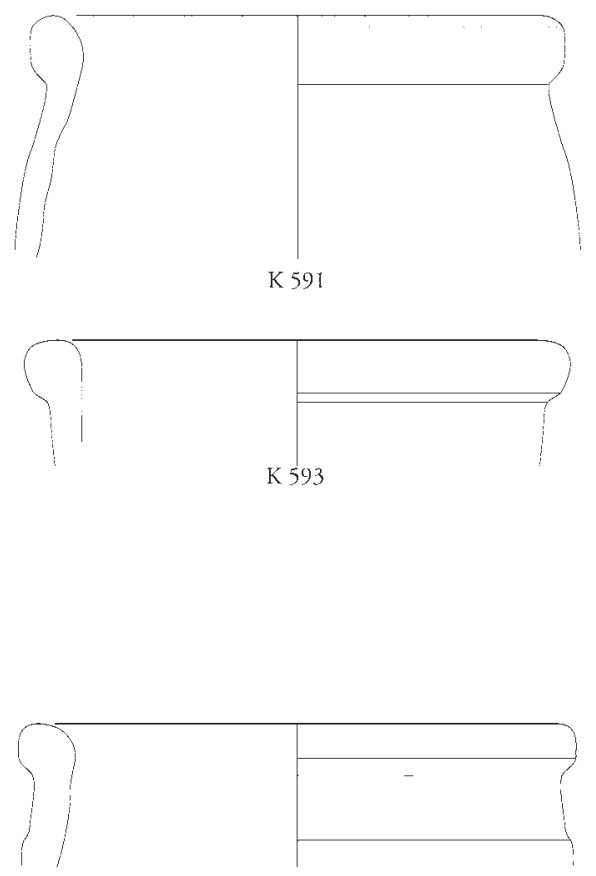

K 595

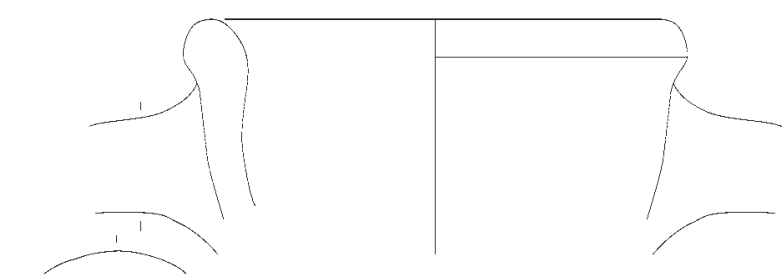

K 597

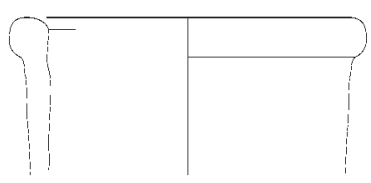

K 599

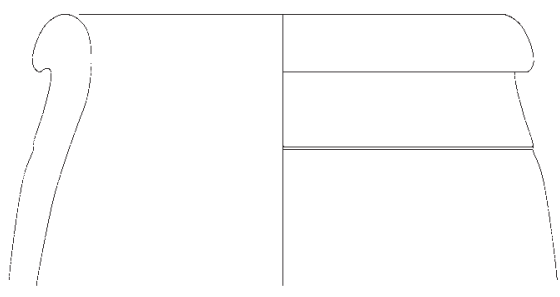

K 601

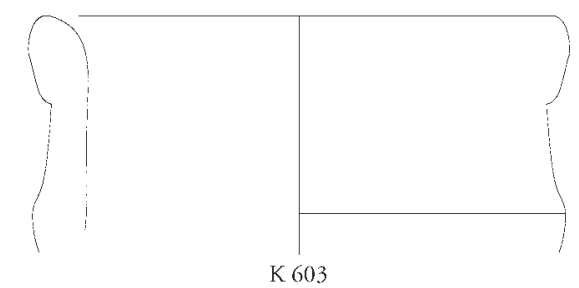

K 590-603 
Tafel 204
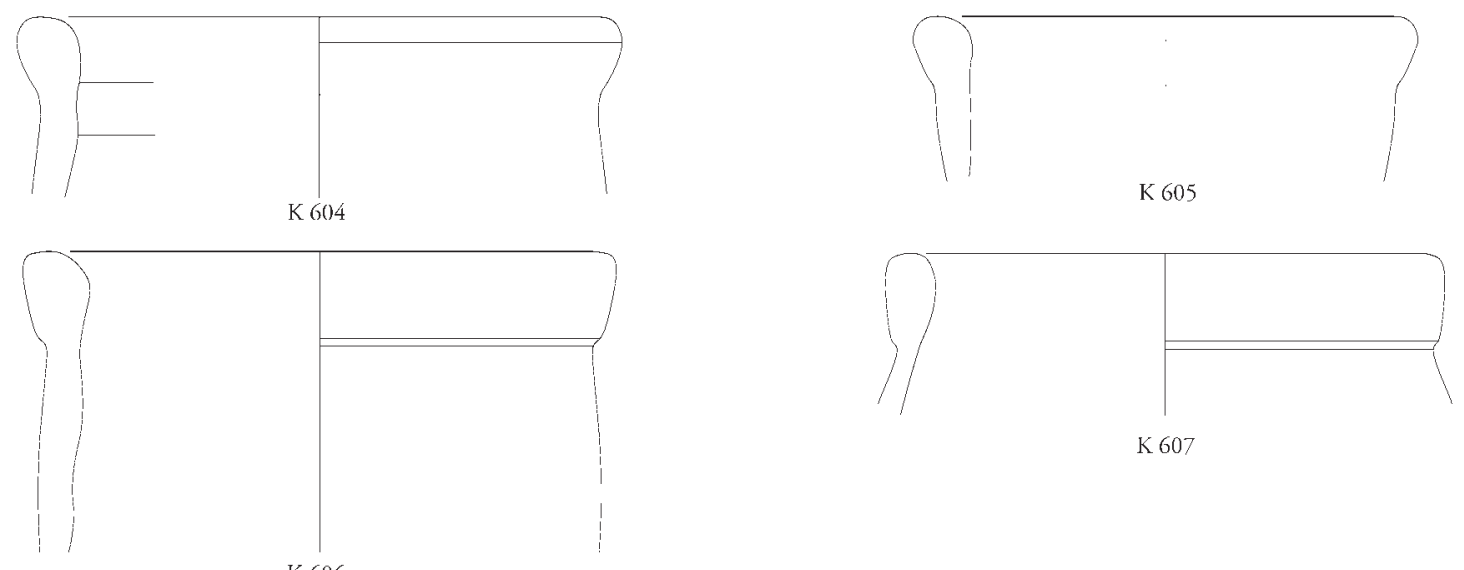

K 607
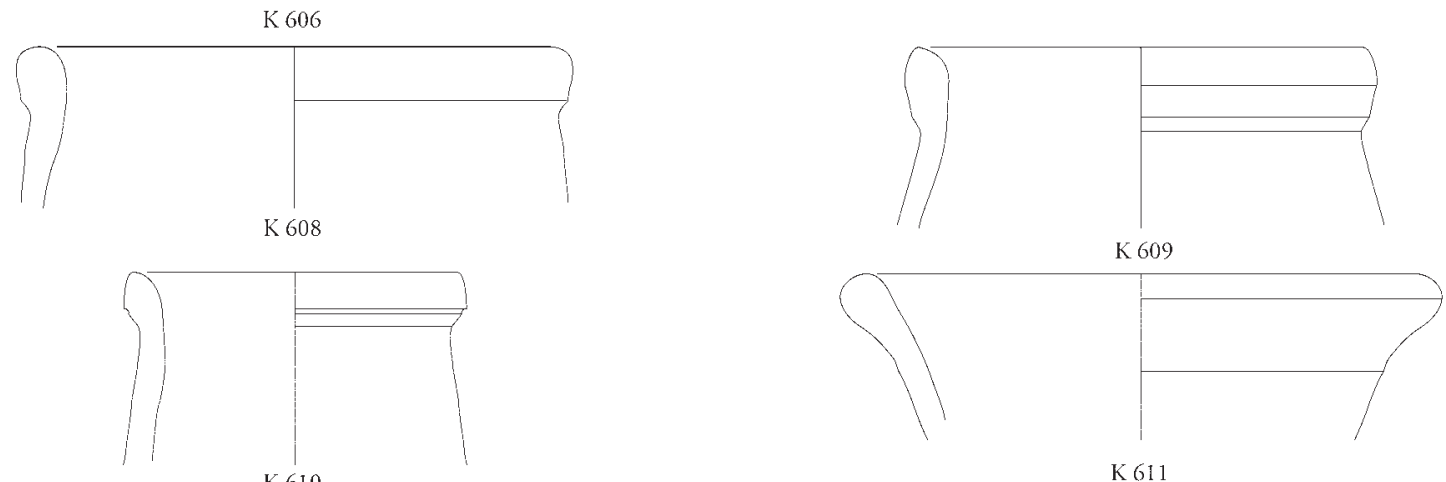

K 611

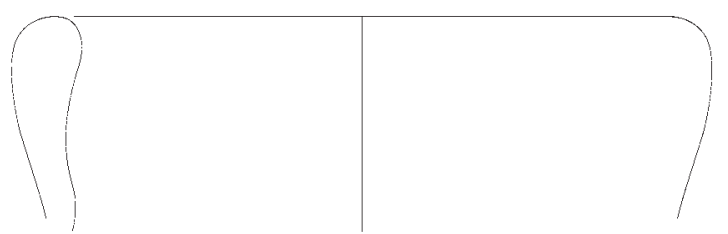

K 612

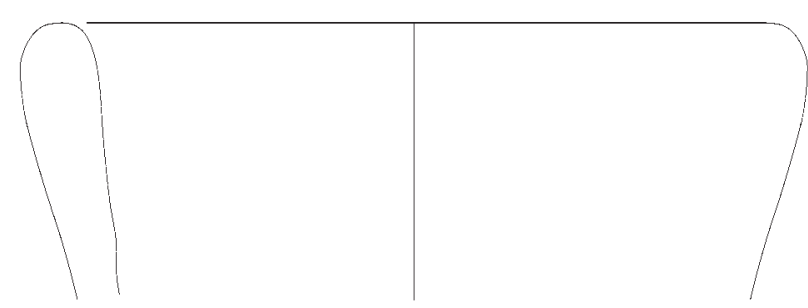

K 613
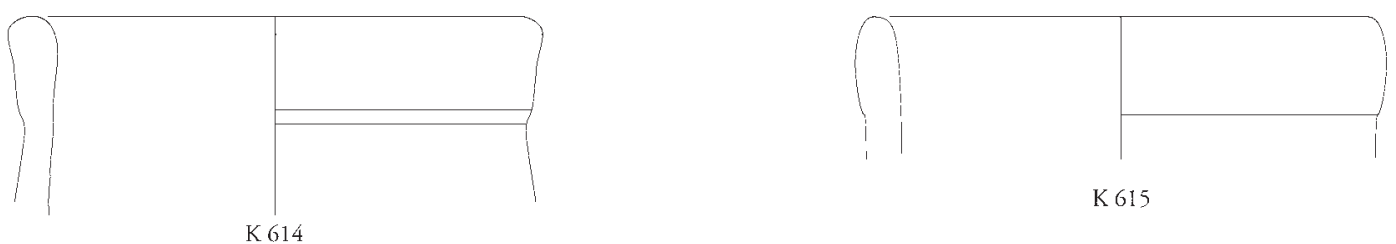

K 615
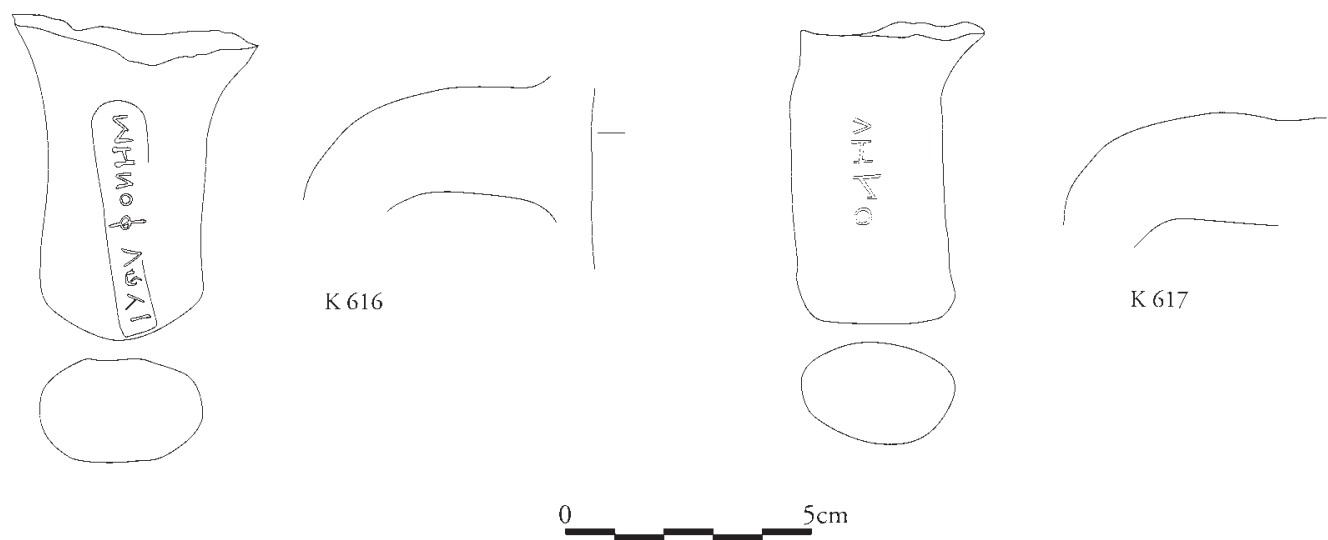

K 604-617 
Tafel 205
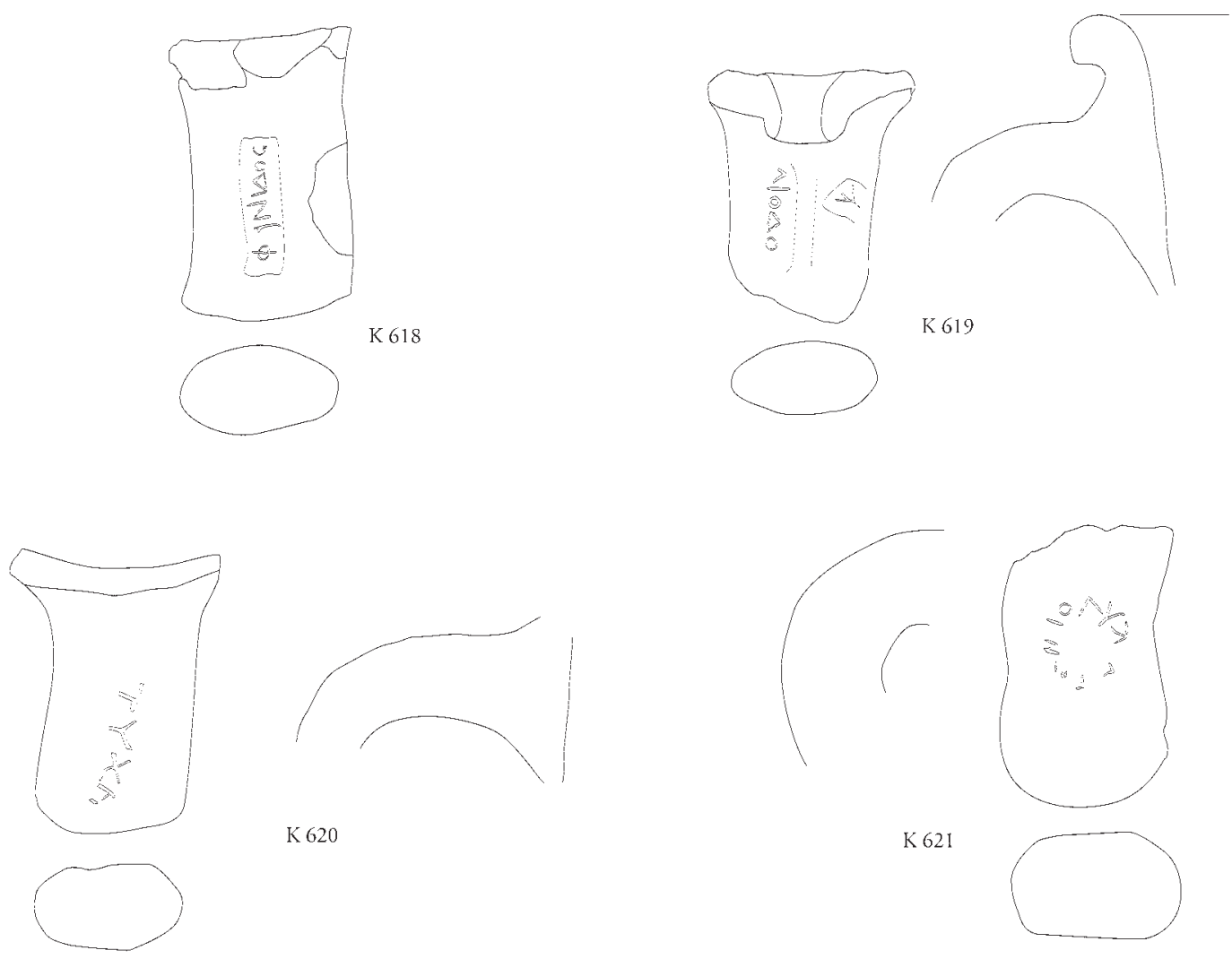

K 621
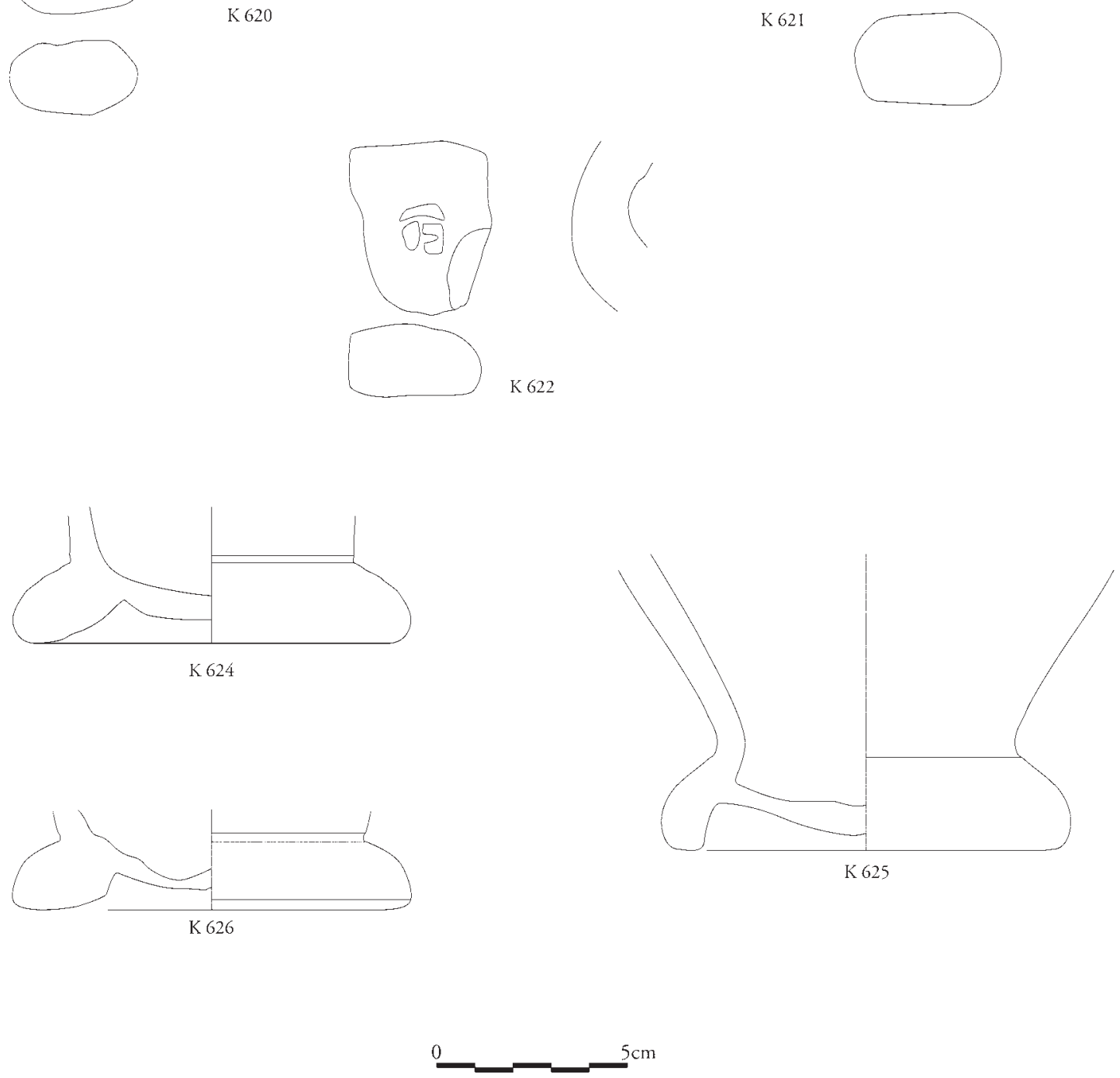

K 618-622. 624-626 
Tafel 206
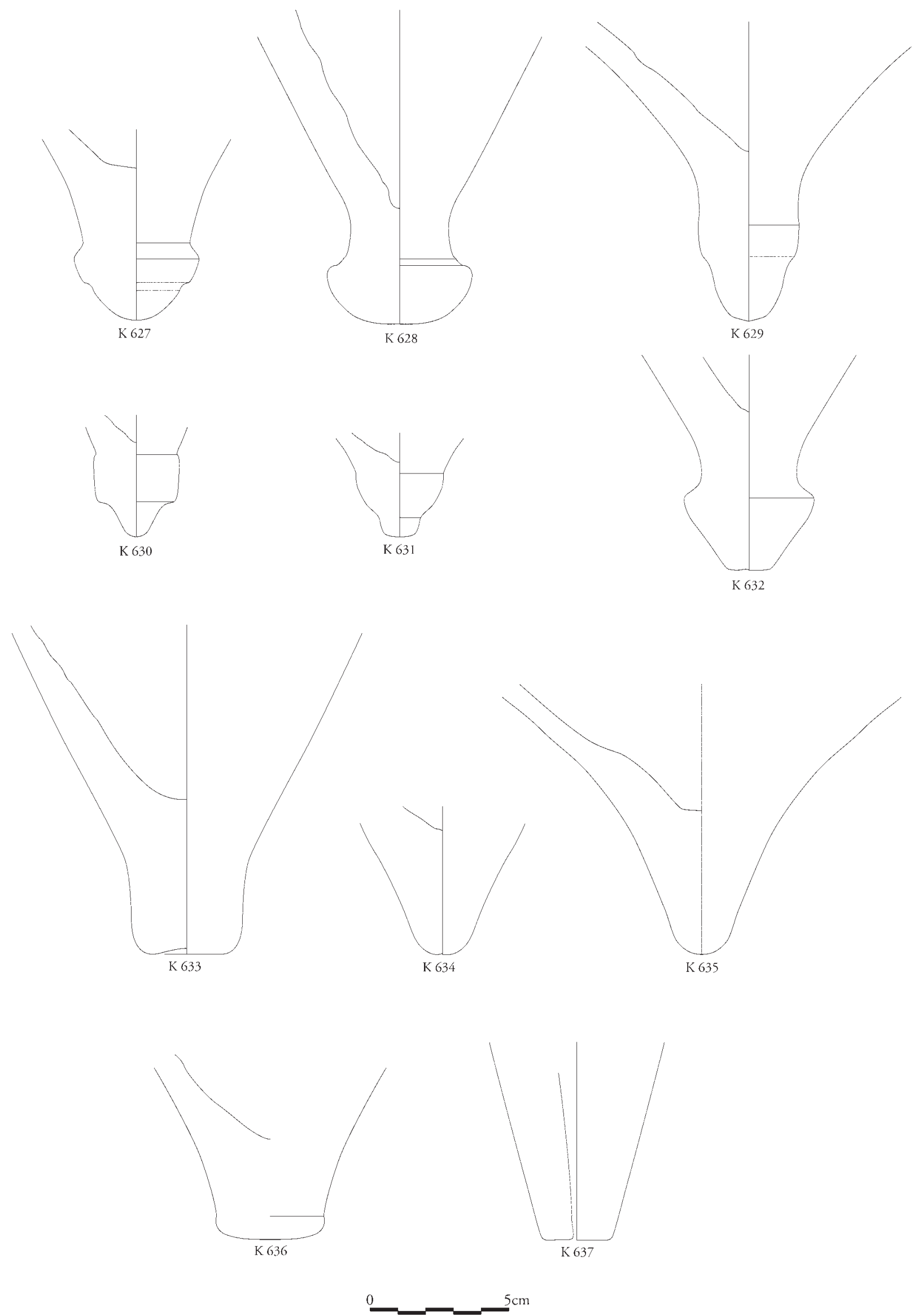

K 627-637 
Tafel 207
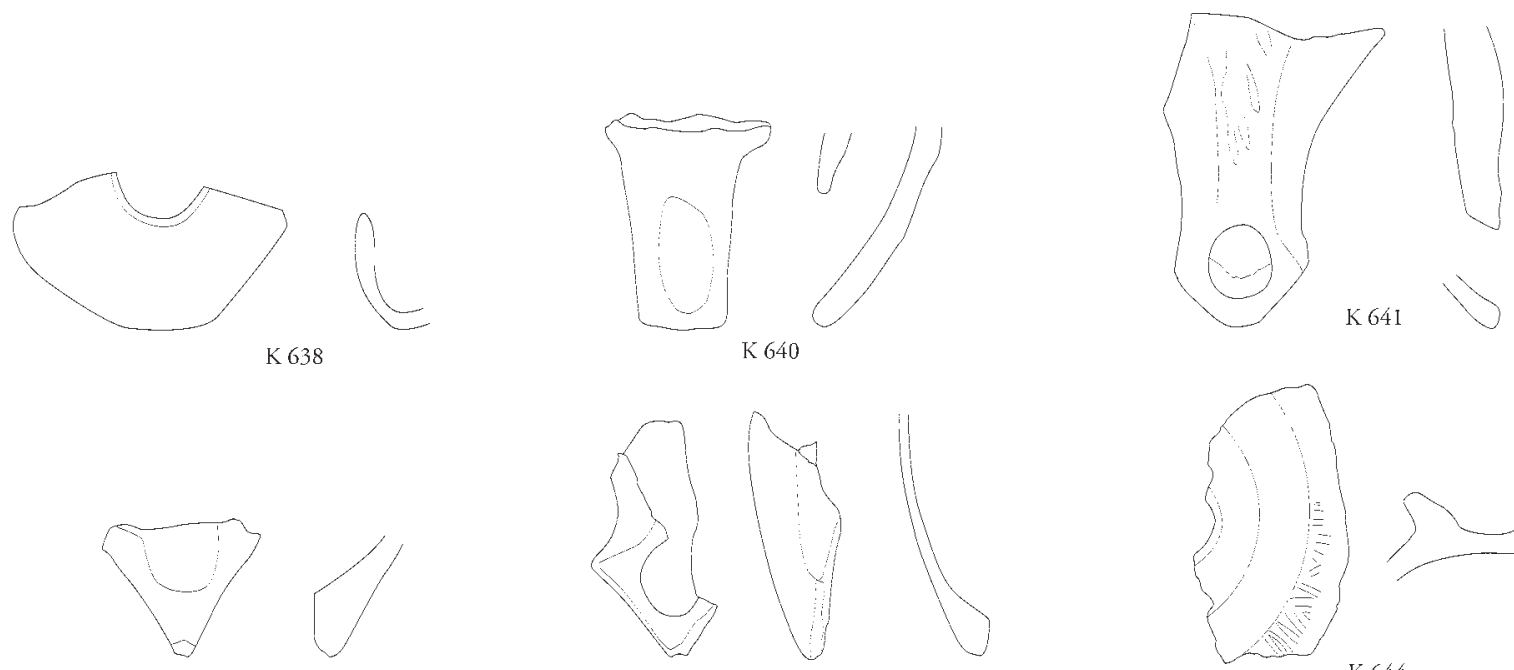

K 642
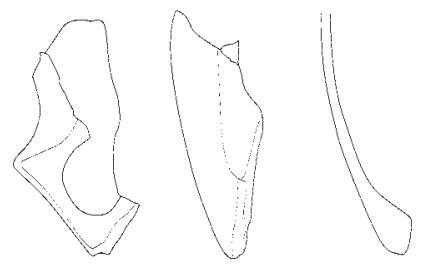

K 643
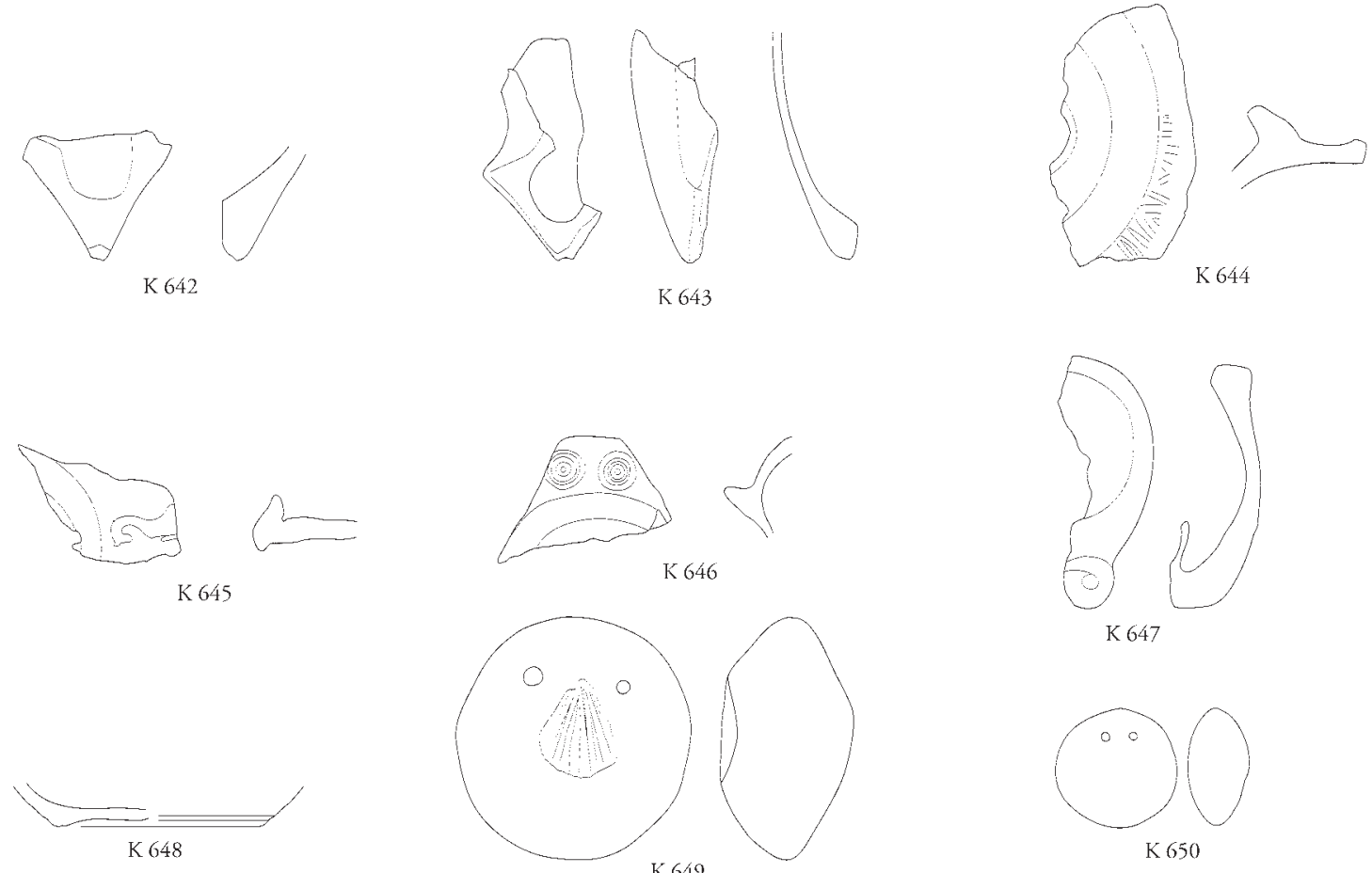

649
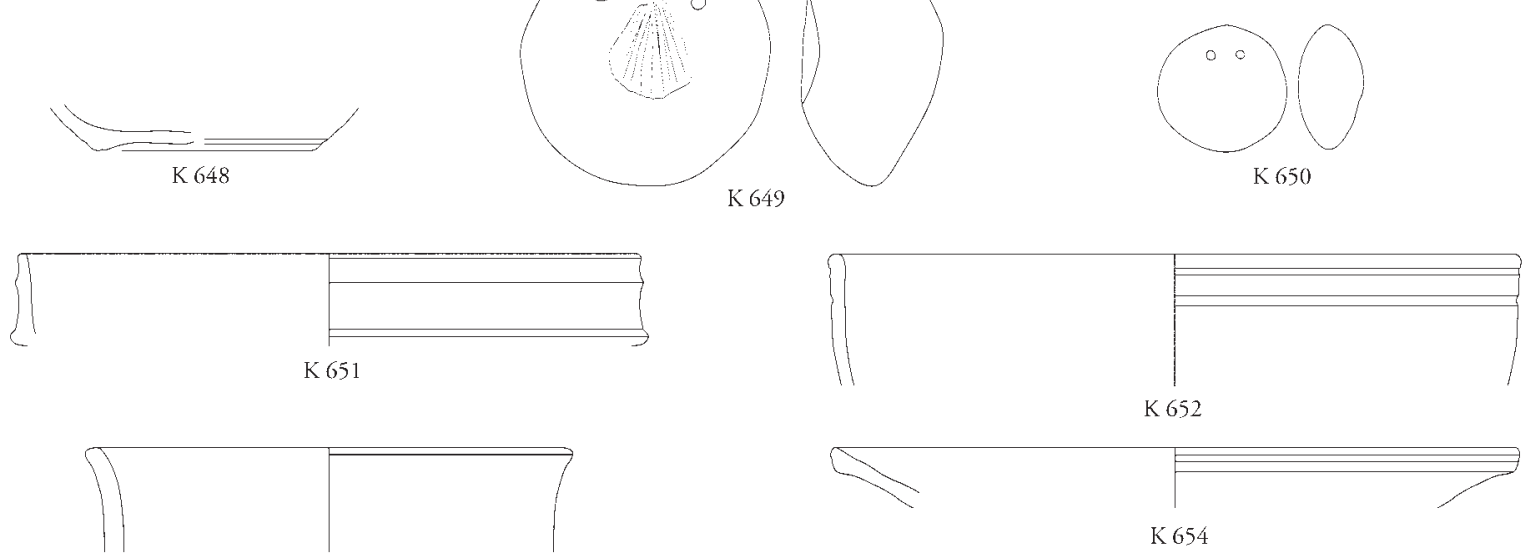

K 653

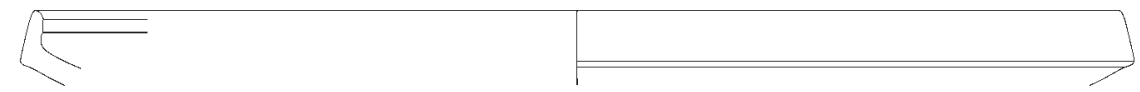

K 655
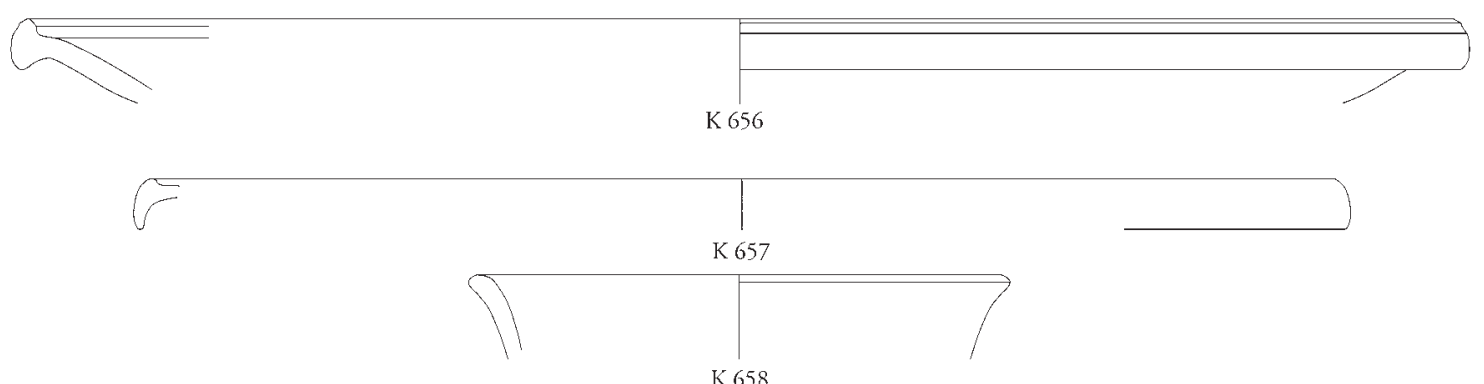

K 658

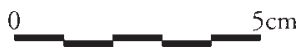

K 638. 640-658 
Tafel 208
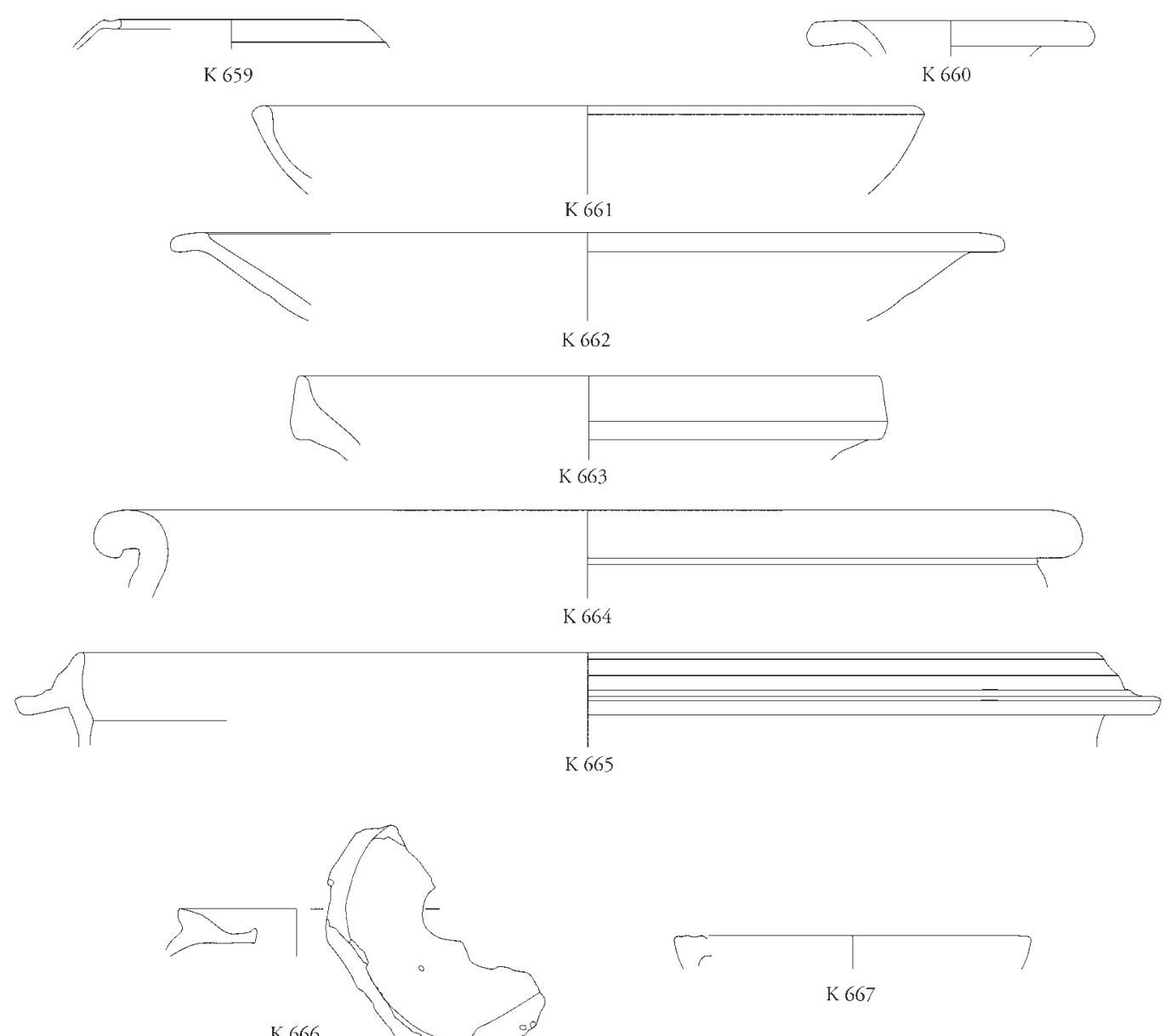

K 668
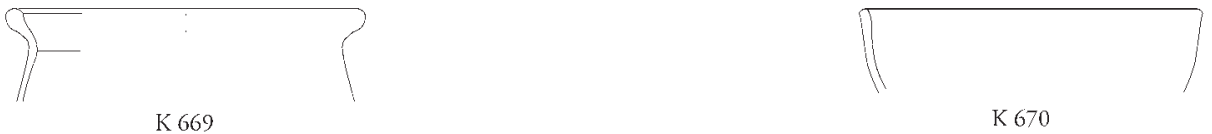

K 670

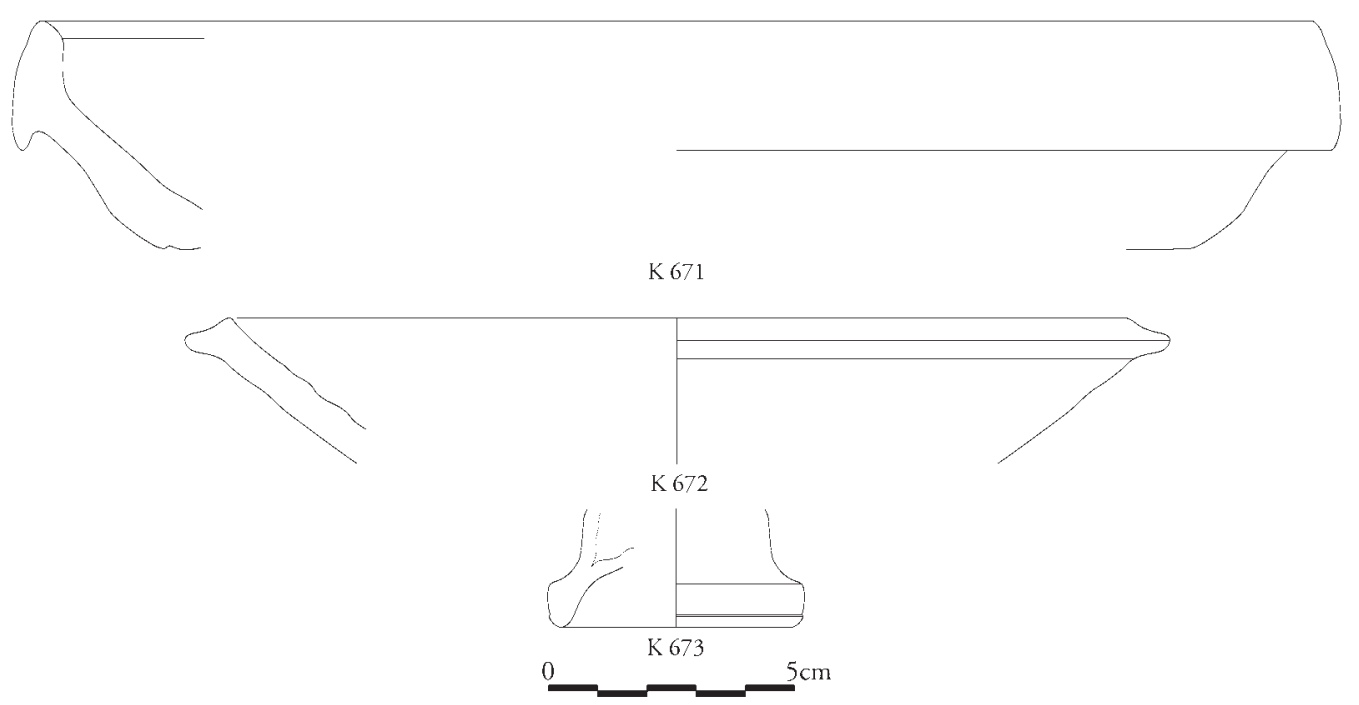

K 659-673 
Tafel 209
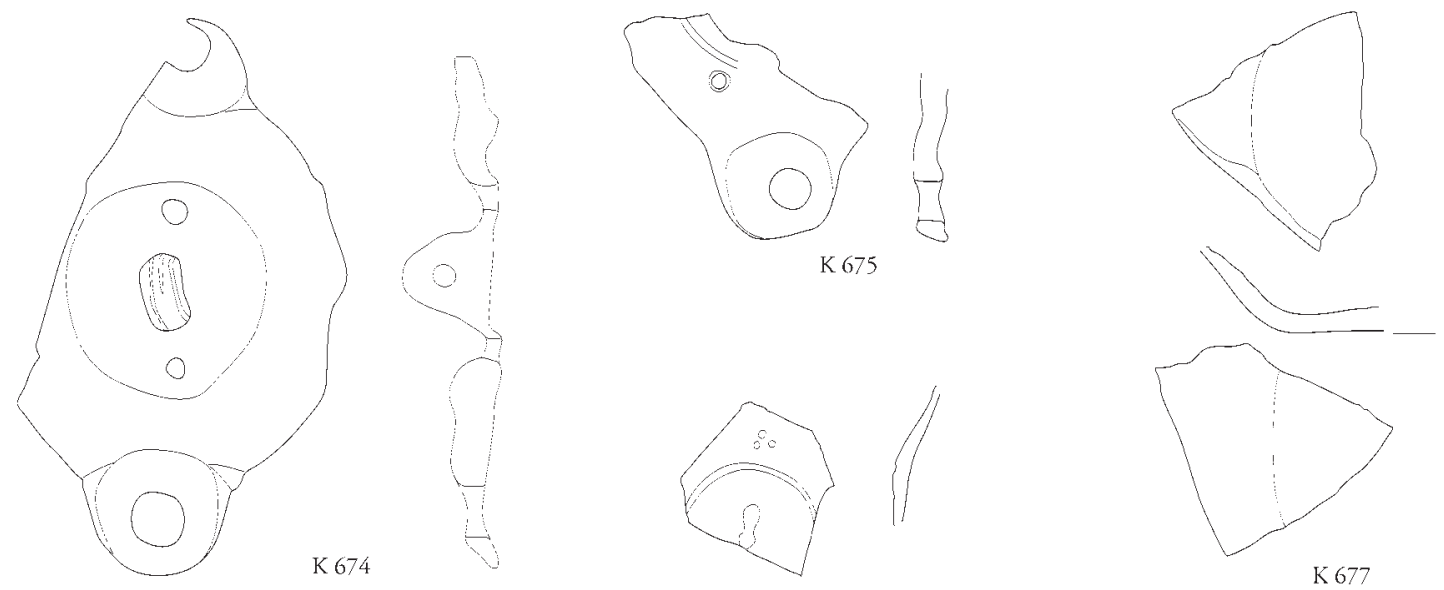

K 676
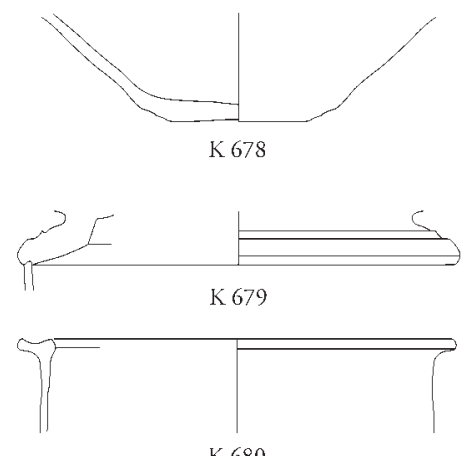

Ø $43 \mathrm{~cm} \mathrm{~K} 680$
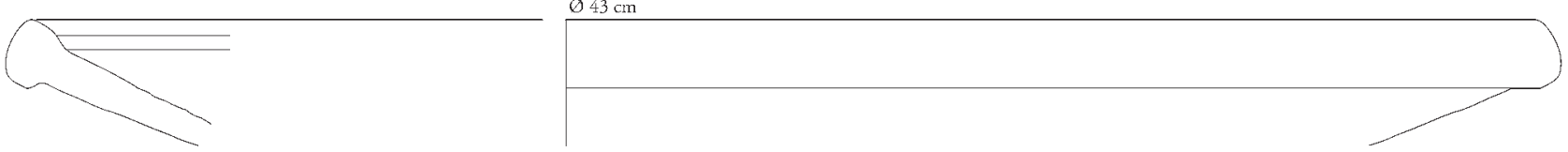

K 681
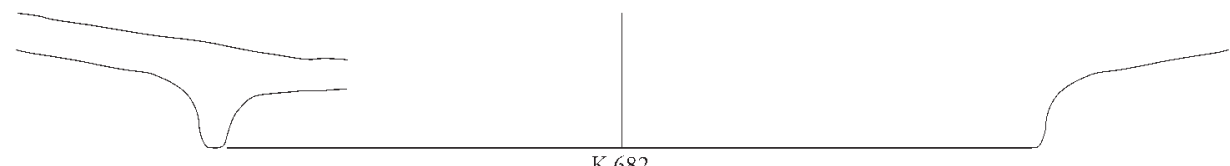

K 682

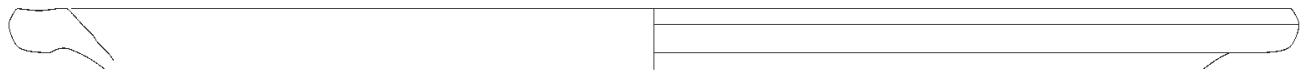

K 683
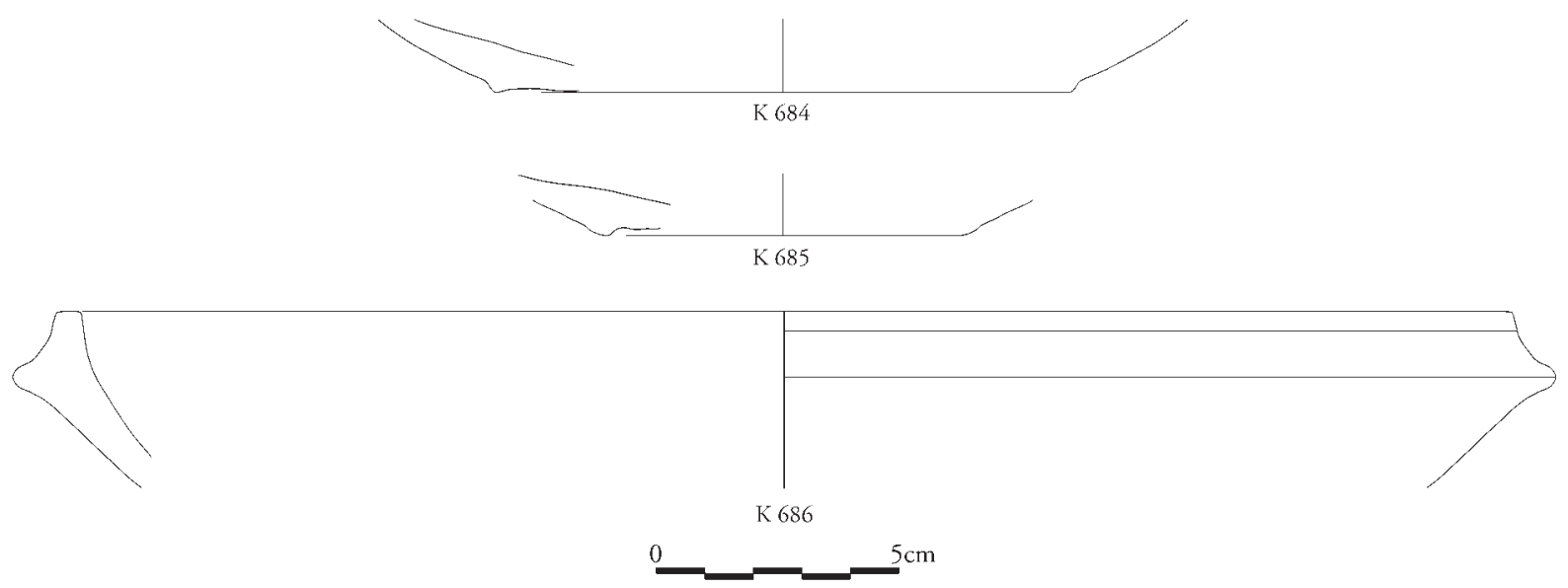

K 674-686 
Tafel 210
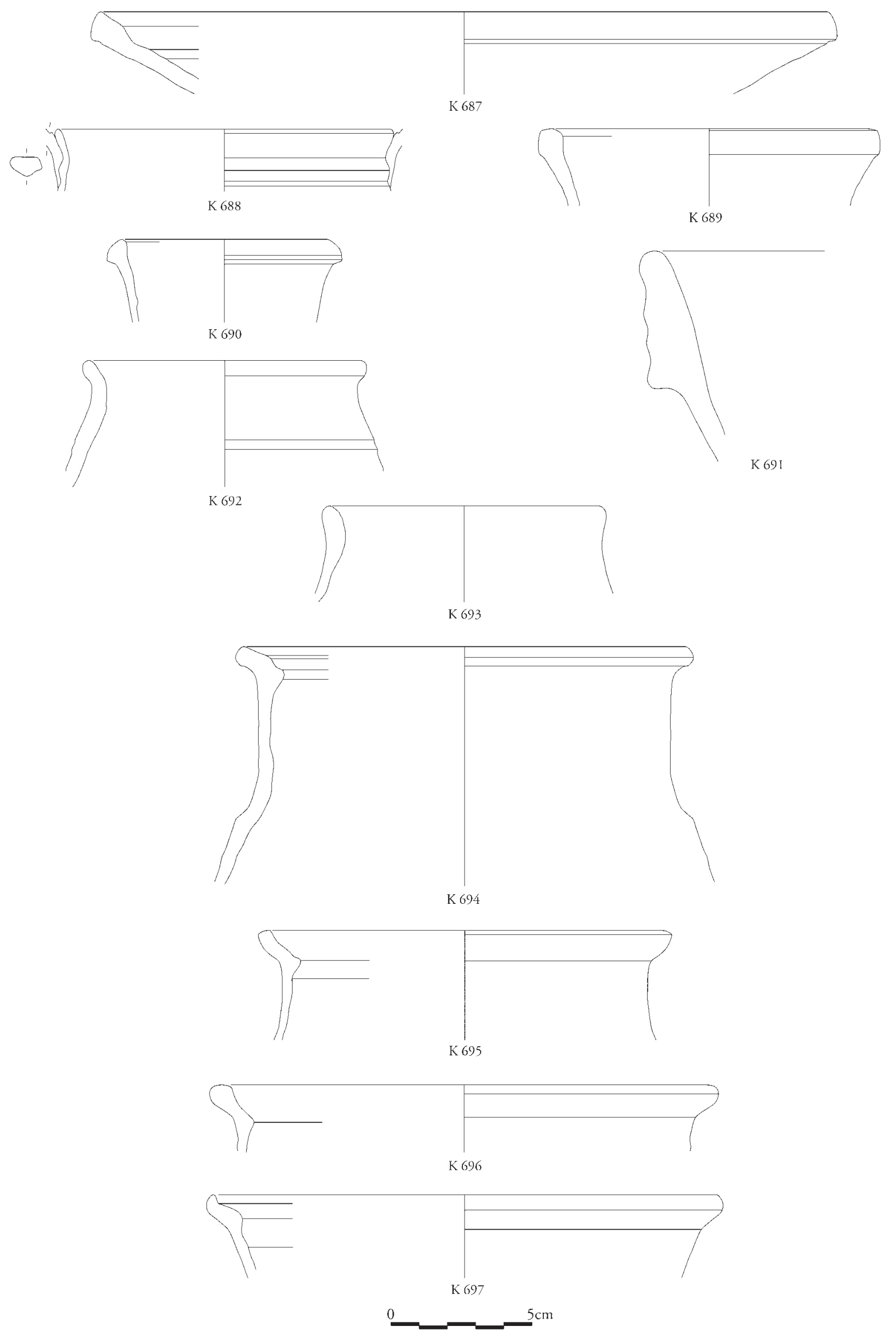

K 687-697 
Tafel 211
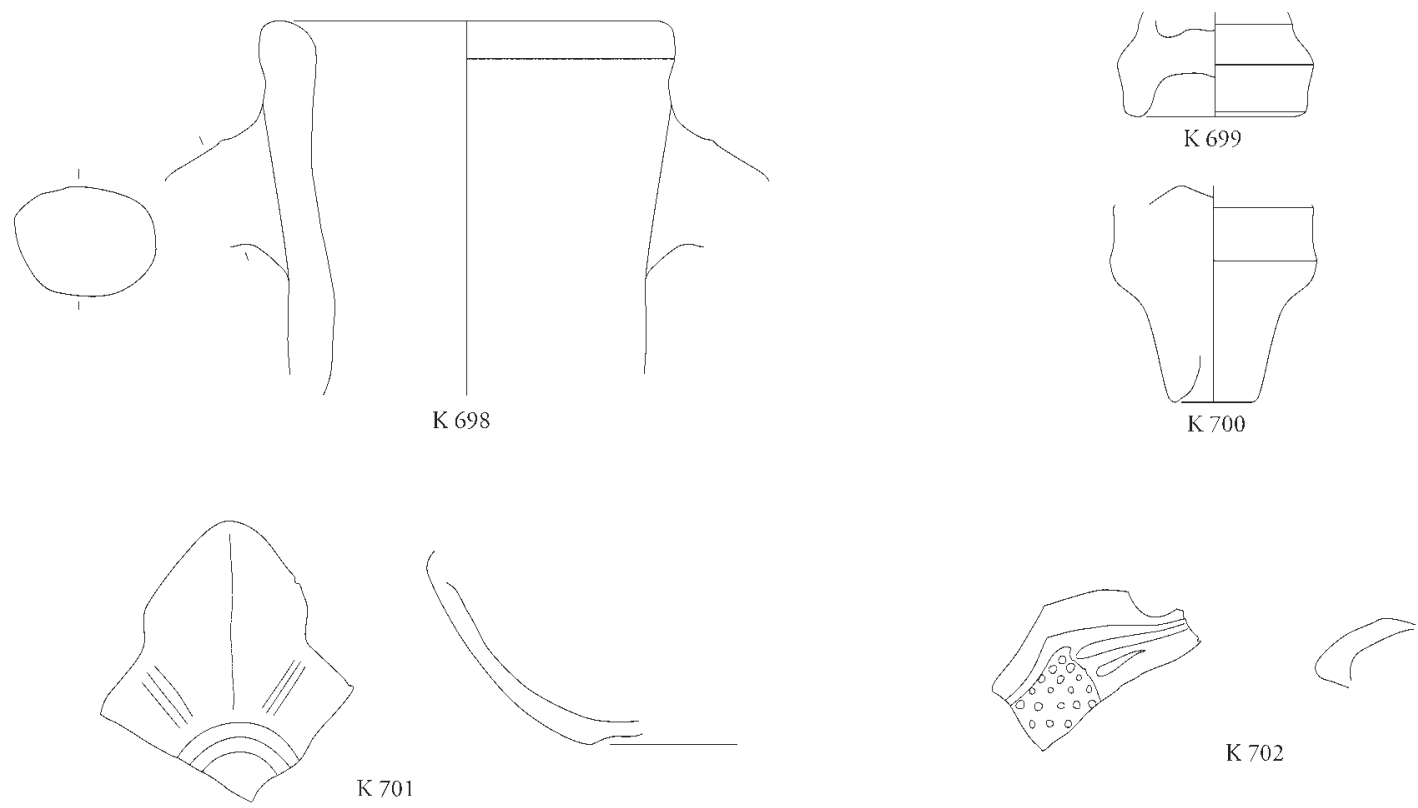

K 702

K 701

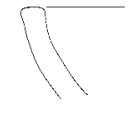

K 703

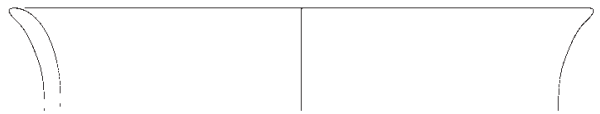

K 704

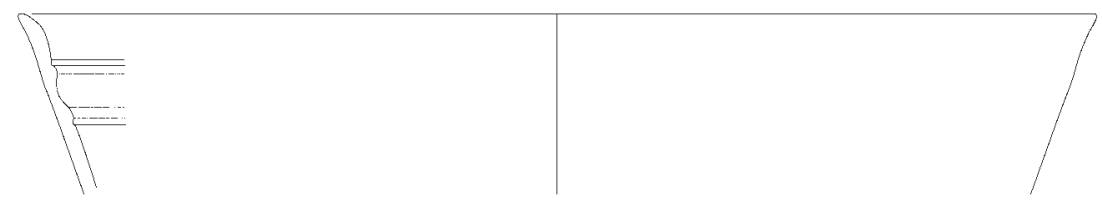

K 706

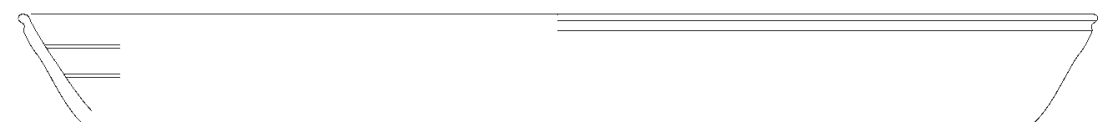

K 707
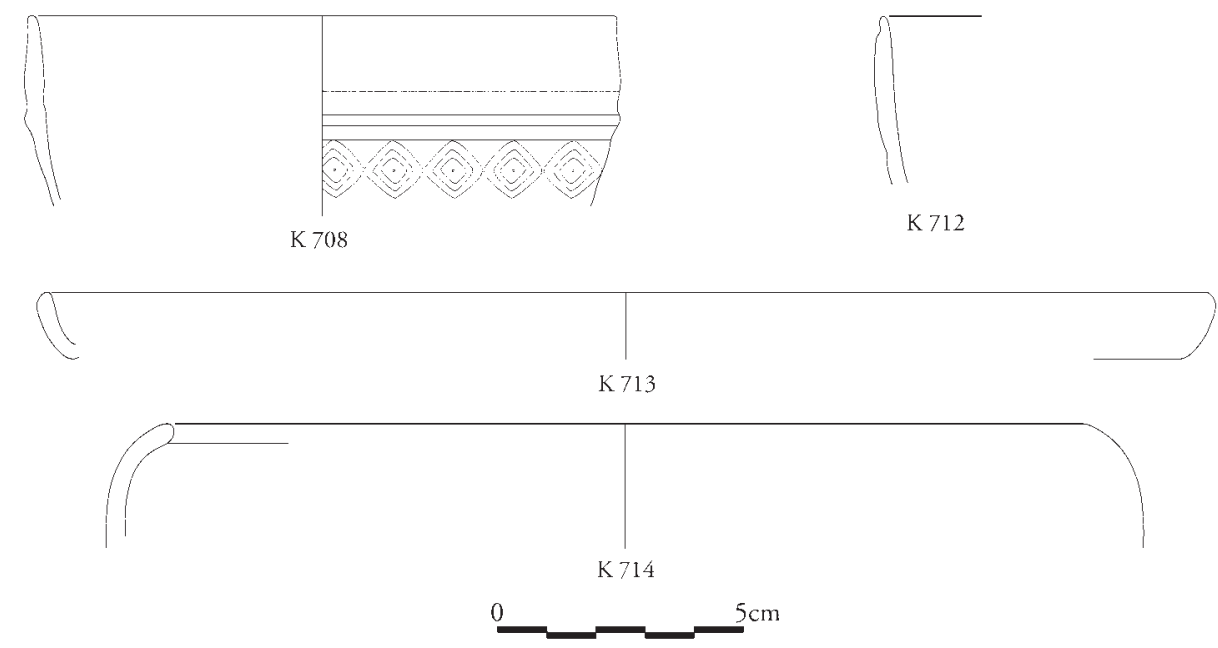

K 698-704. 706-708. 712-714 
Tafel 212
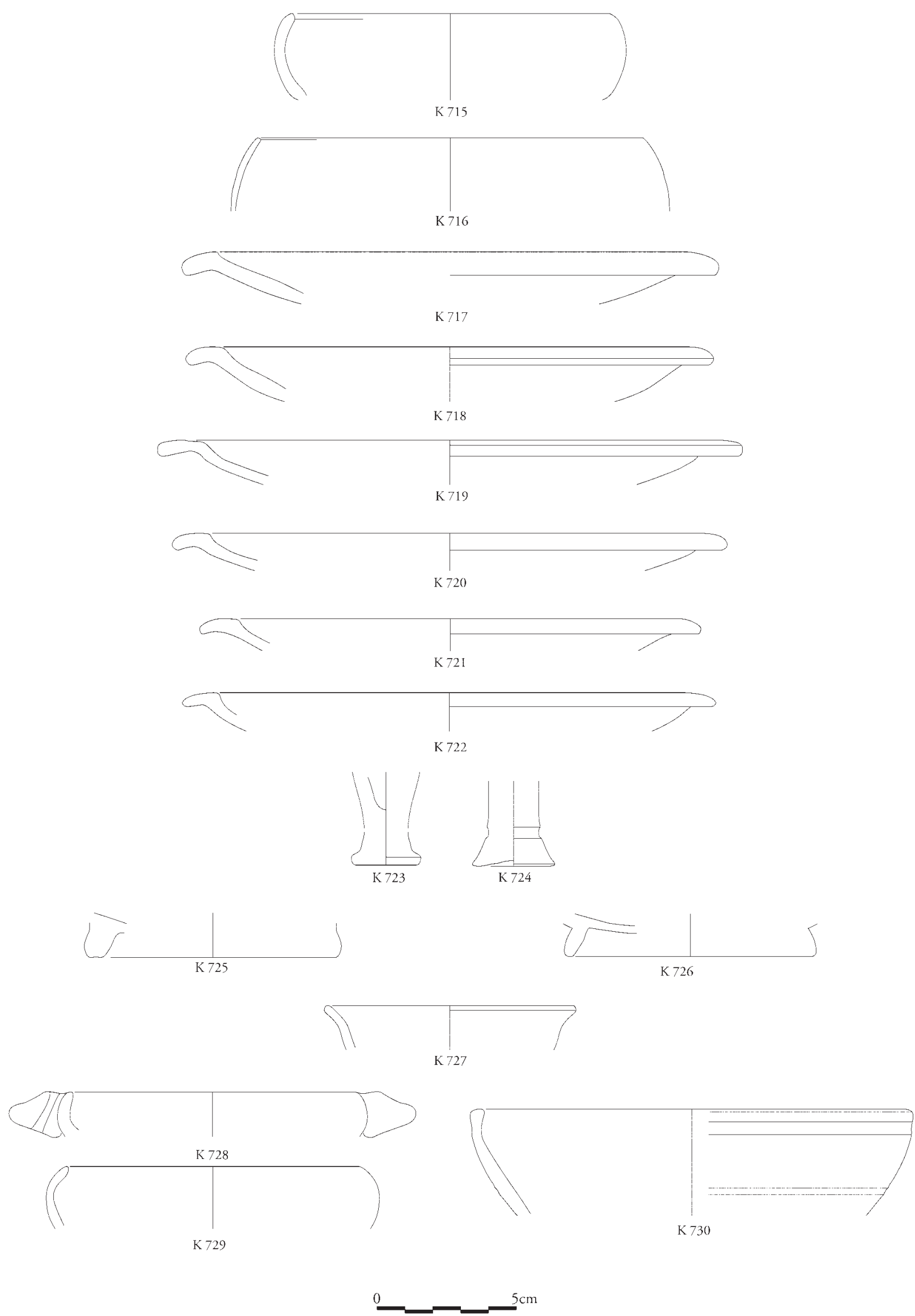

K 715-730 
Tafel 213
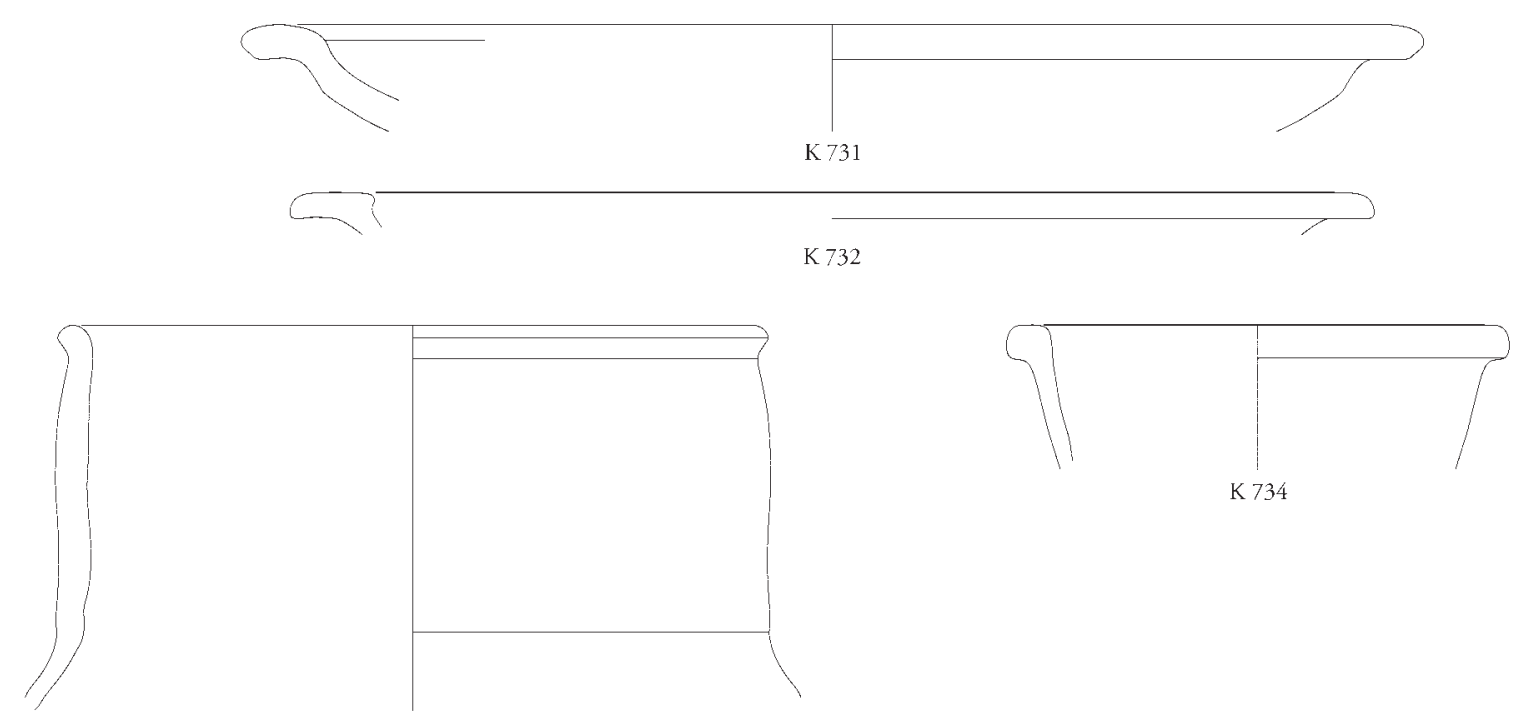

K 733
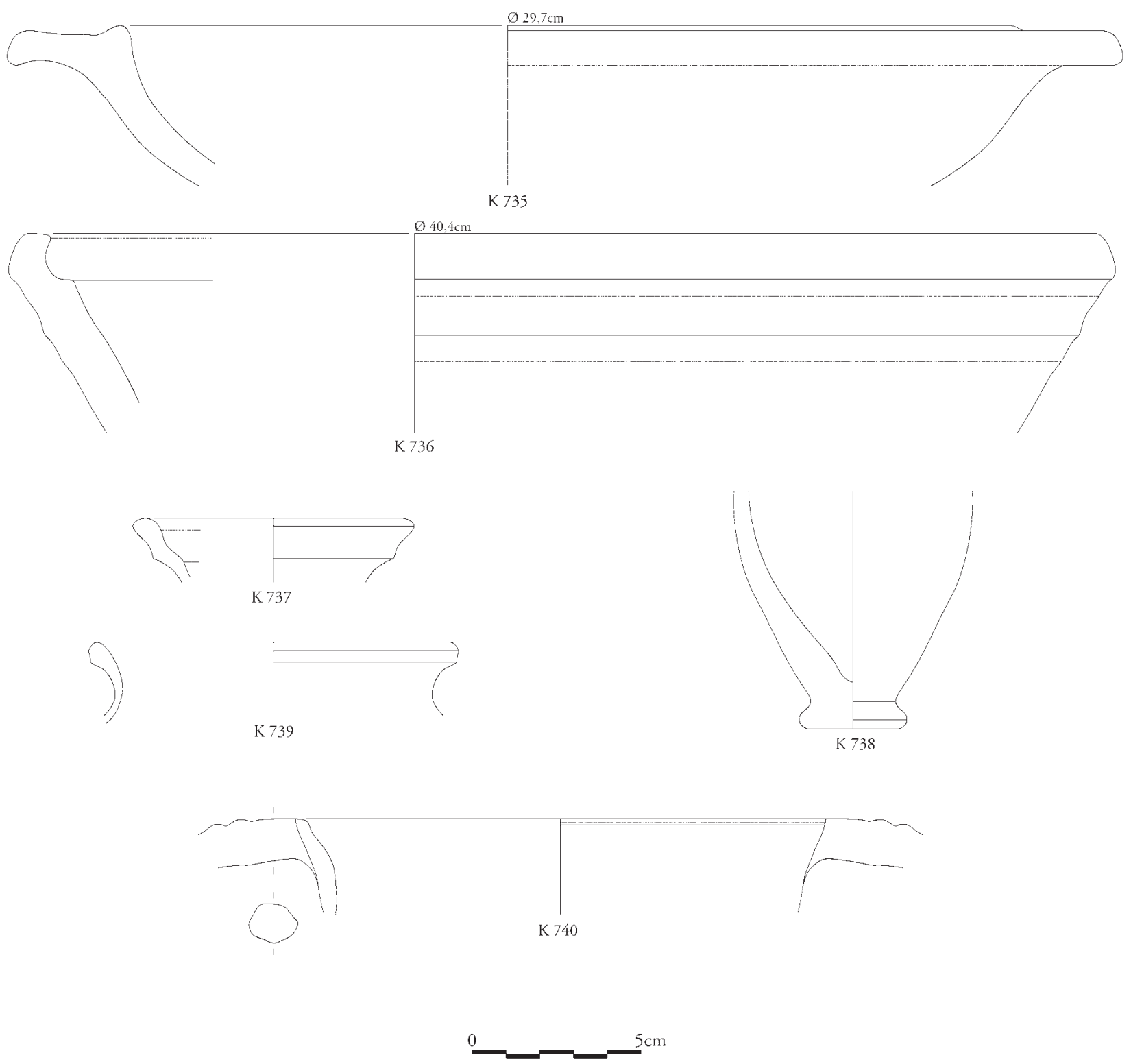

K 731-740 
Tafel 214
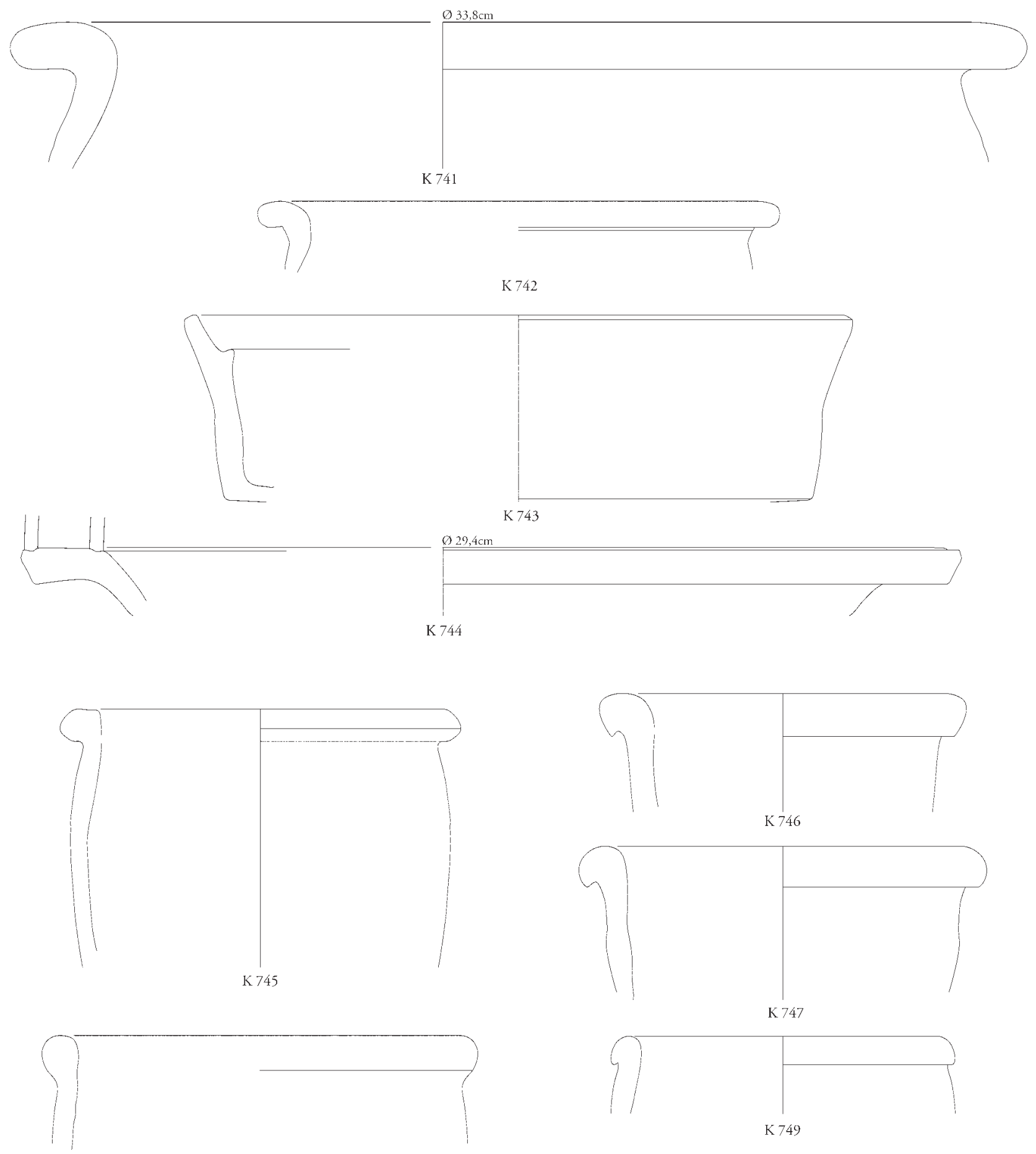

K 748
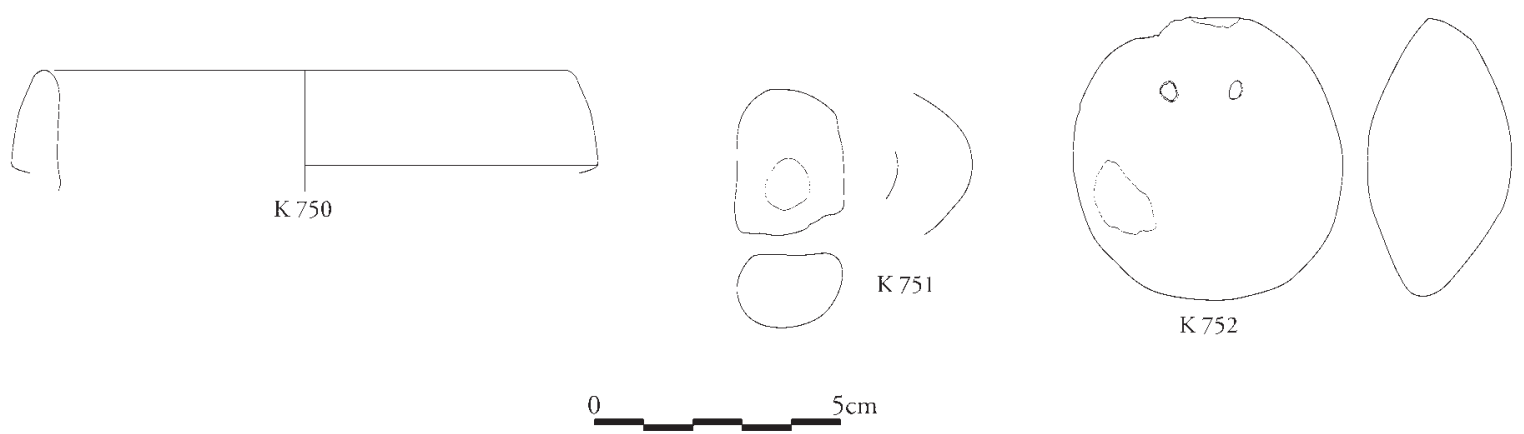

K 741-752 
Tafel 215
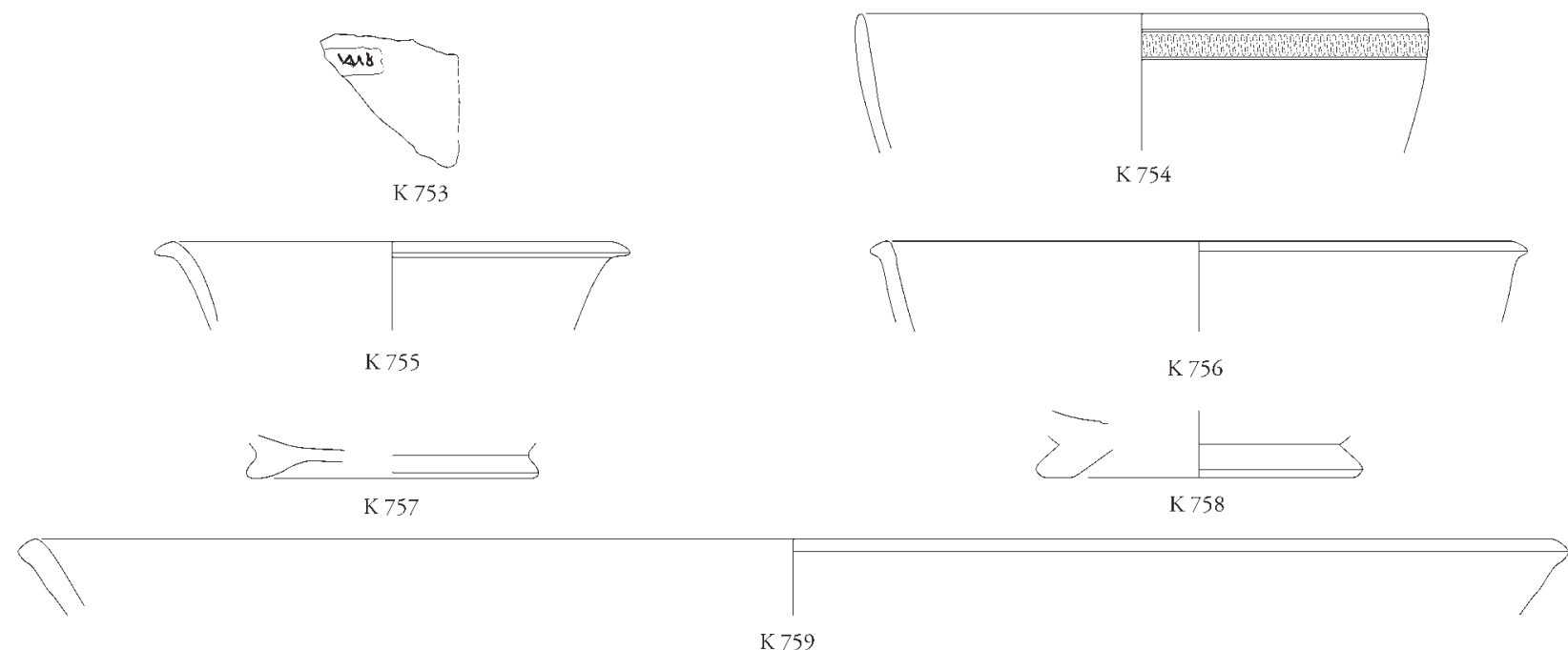

K 75
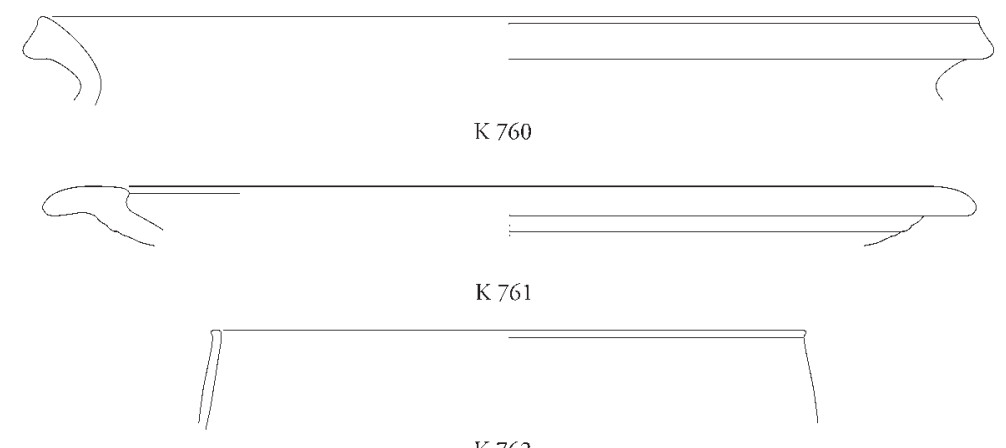

K 762
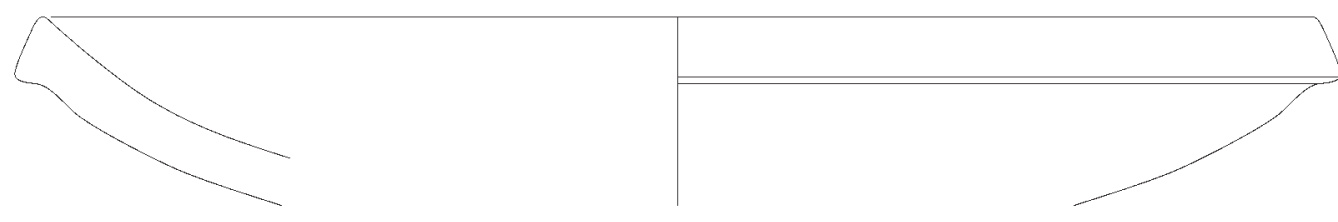

K 763

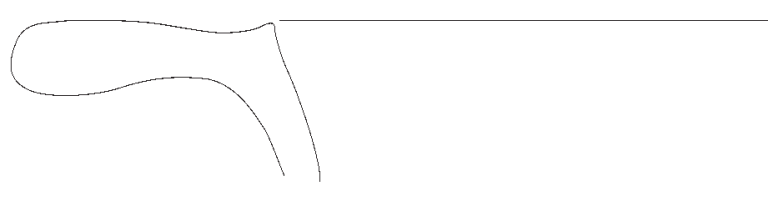

K 764
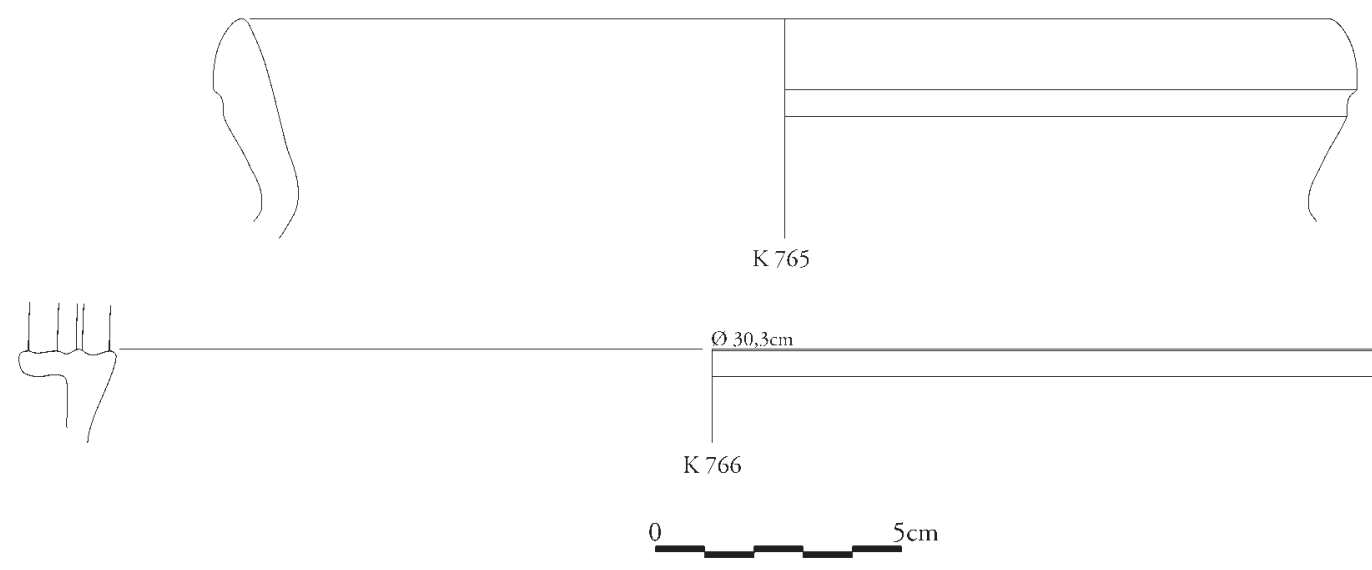

K 753-766 
Tafel 216

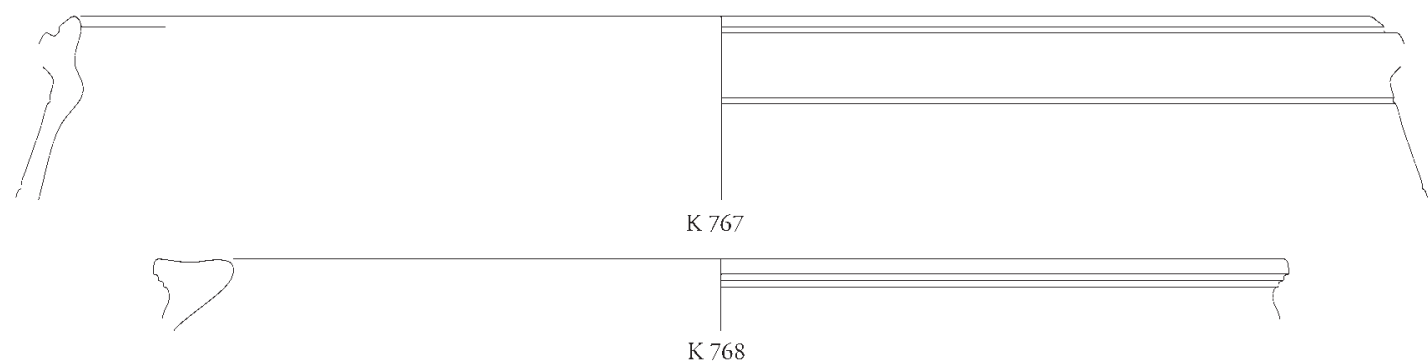

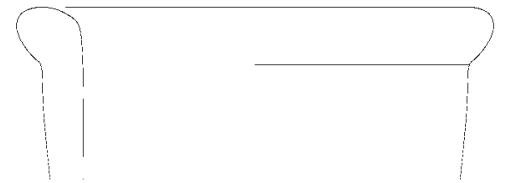

K 769
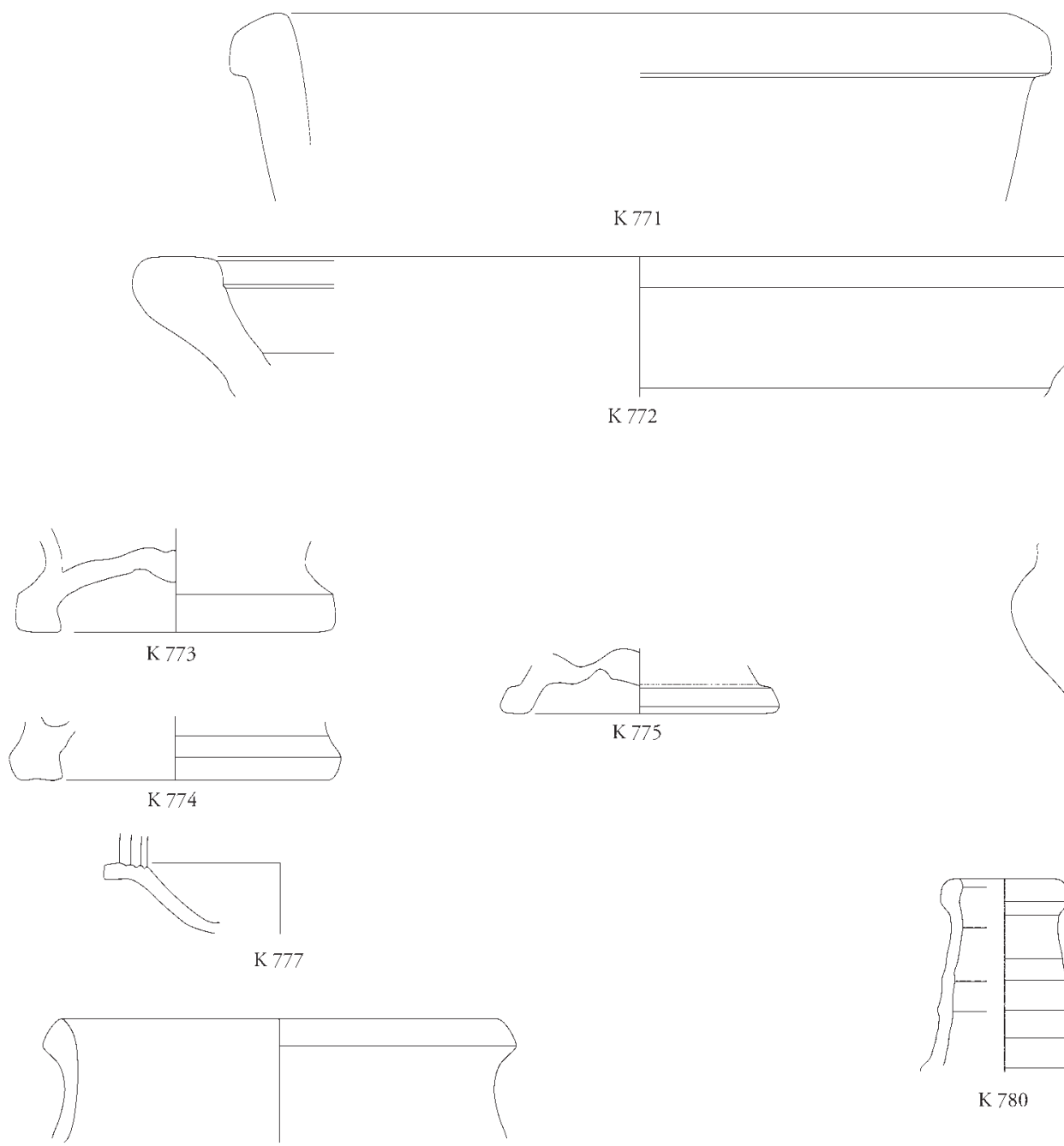

K 778

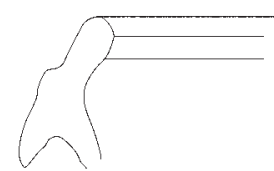

K 771

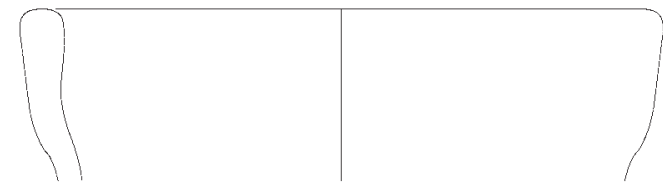

K 770
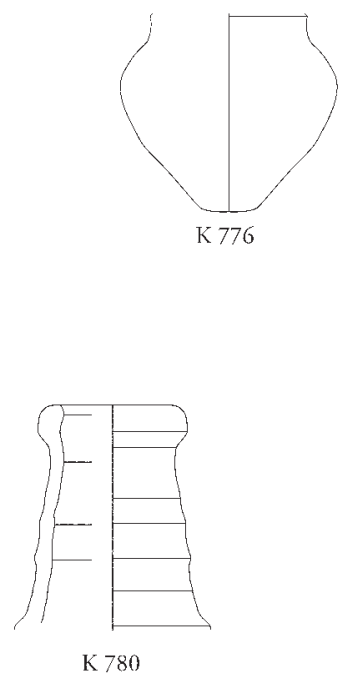

K 779
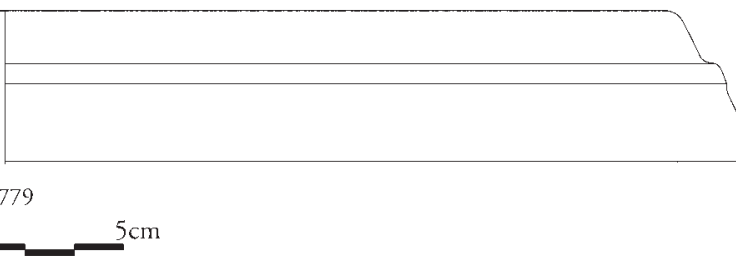

K 767-779 
Tafel 217
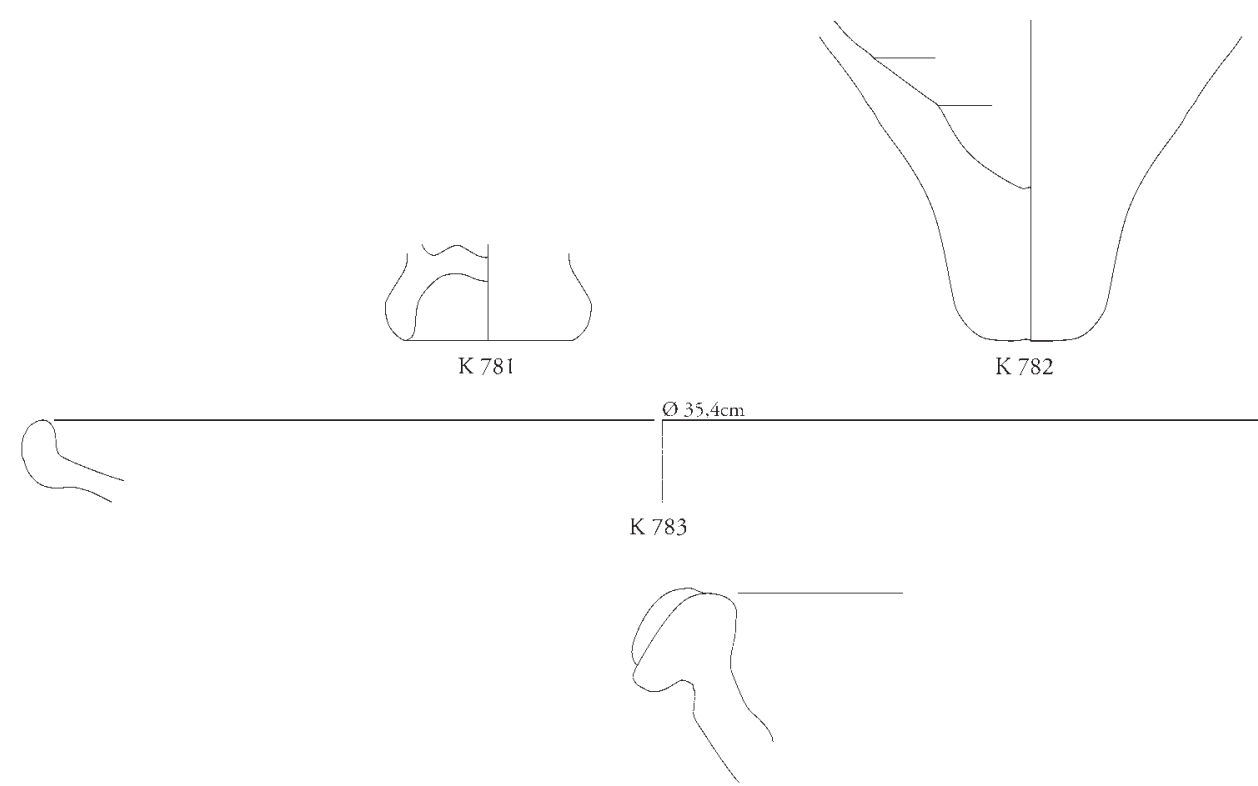

K 784

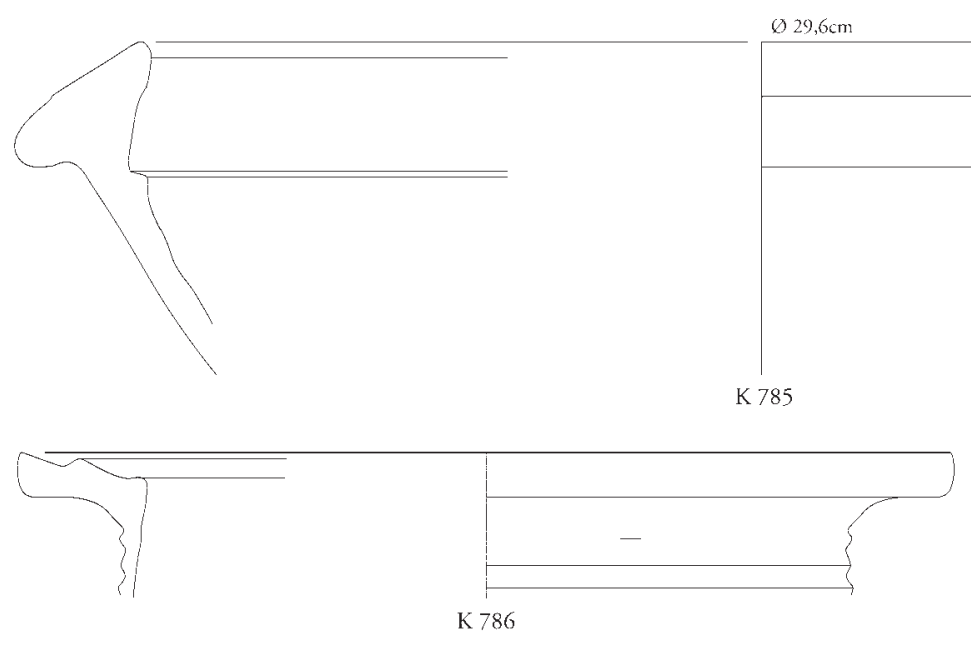

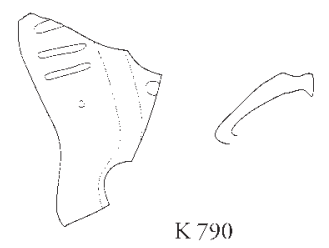

K 790
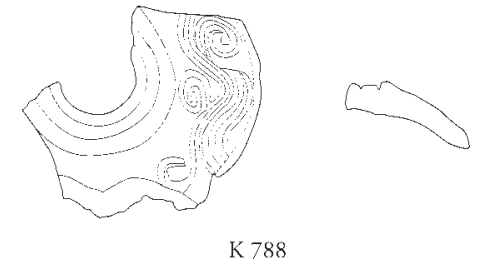

K 788

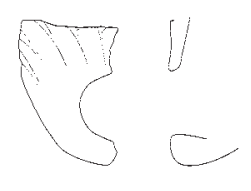

K 791

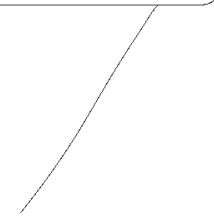

K 789

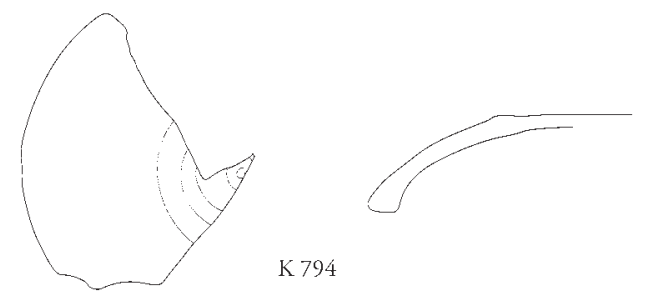

K 792

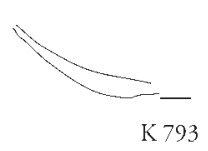

K 794

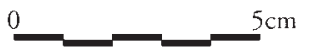

K 781-786. 788-794 
Tafel 218

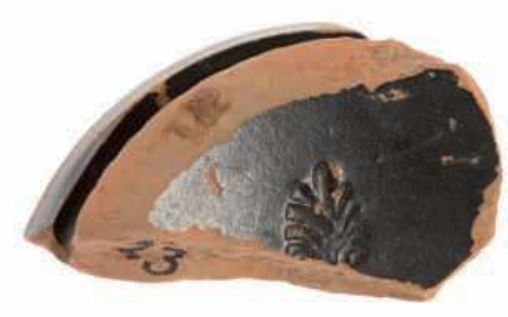

K 4

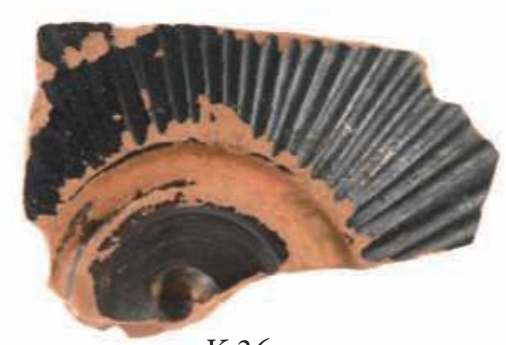

K 36

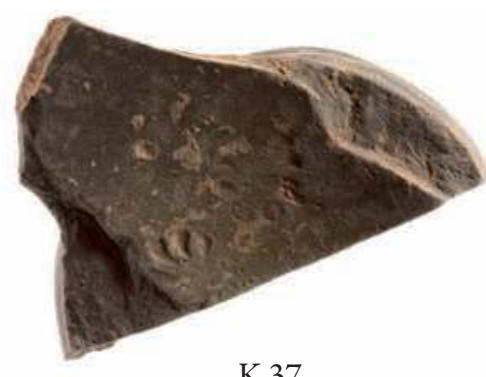

K 37

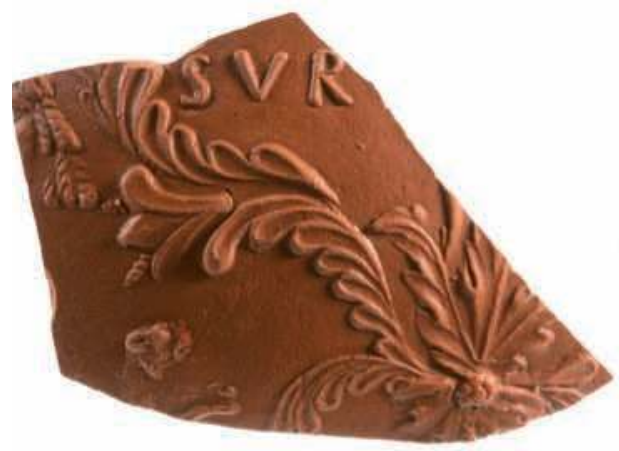

K 60

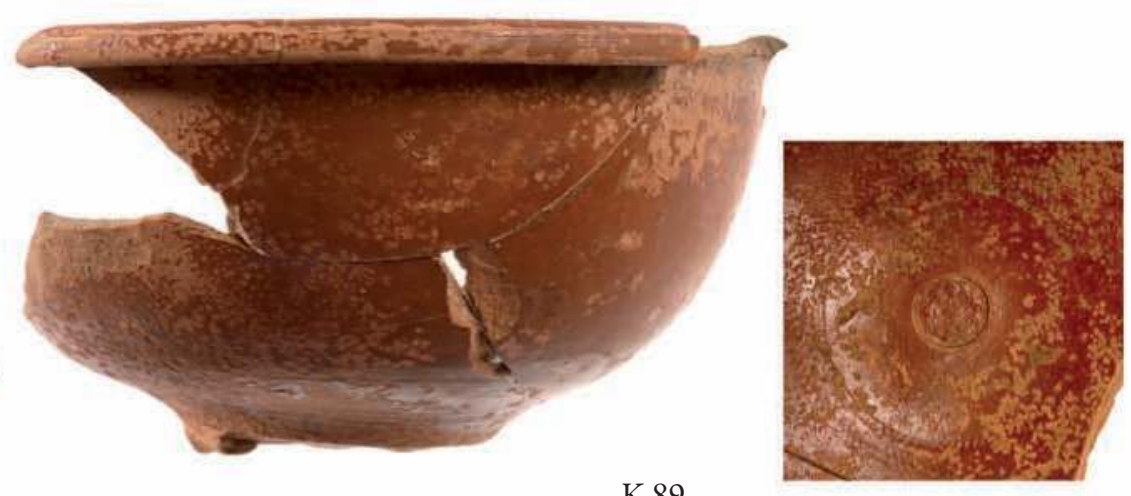

K 89

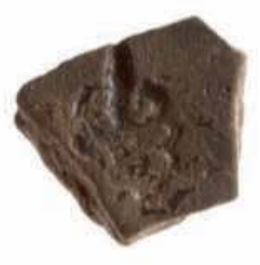

K 116
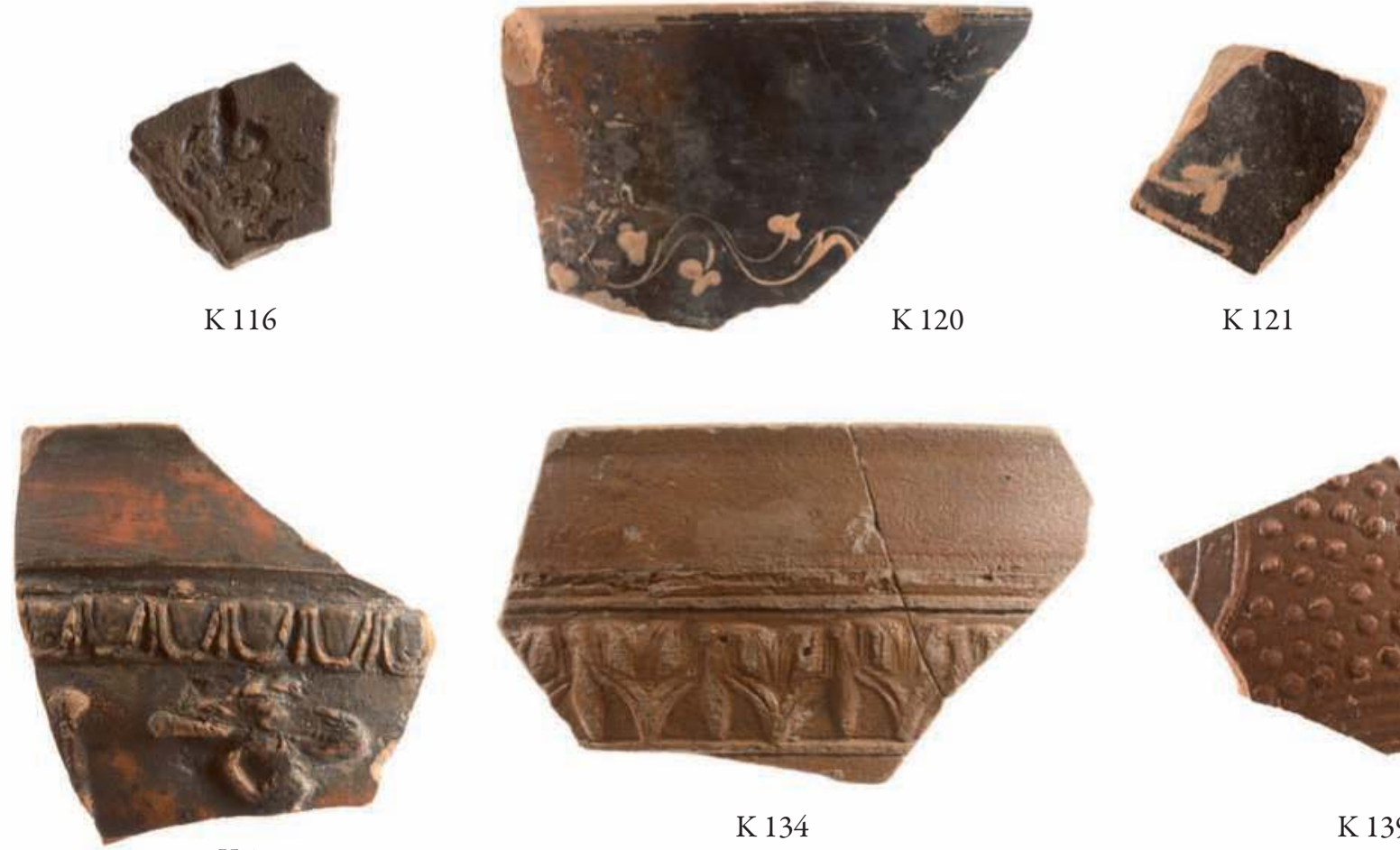

K 134

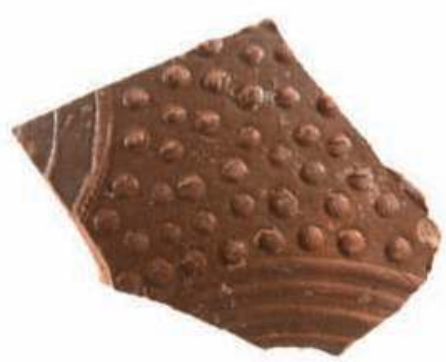

K 139

K 132

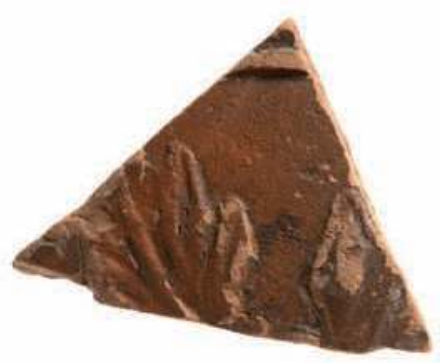

K 140

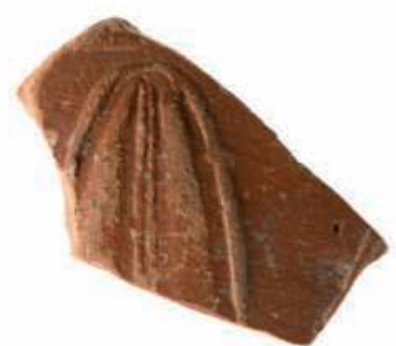

K 141

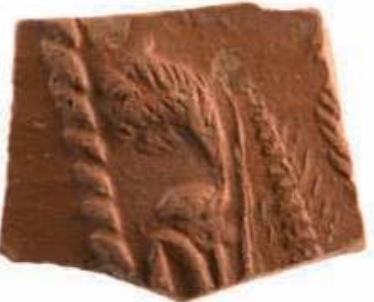

K 142

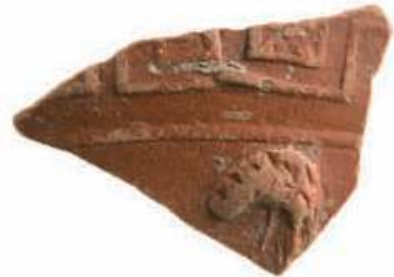

K 143

K 4. 36. 37. 60. 89. 116. 120. 121. 132. 134. 139-143 
Tafel 219

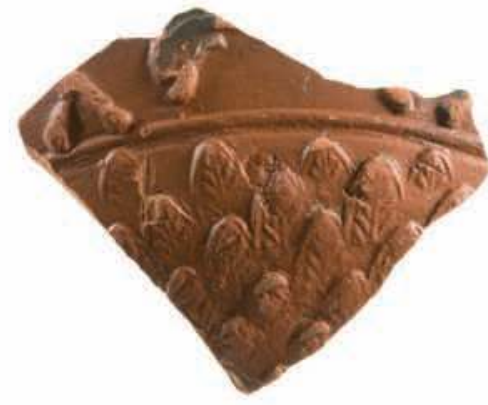

K 144

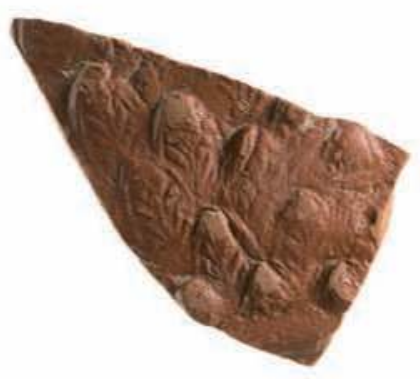

K 145

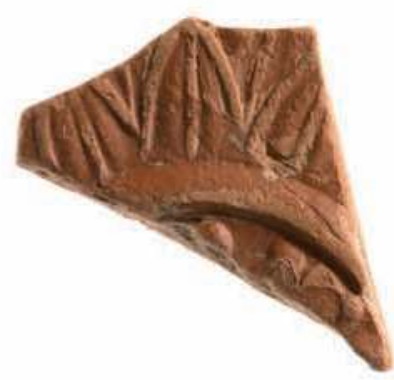

K 146

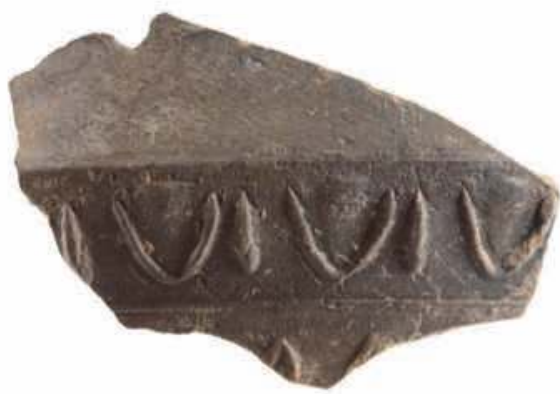

K 147

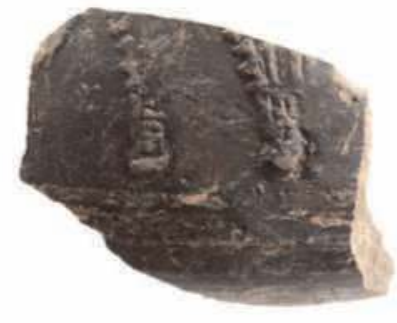

K 148

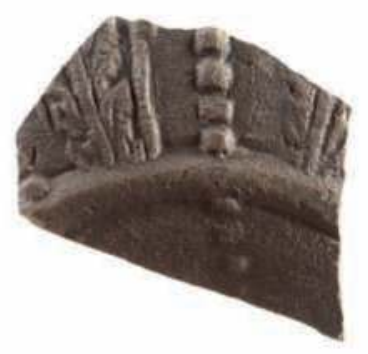

K 149

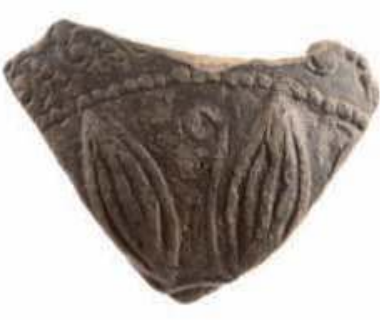

K 150
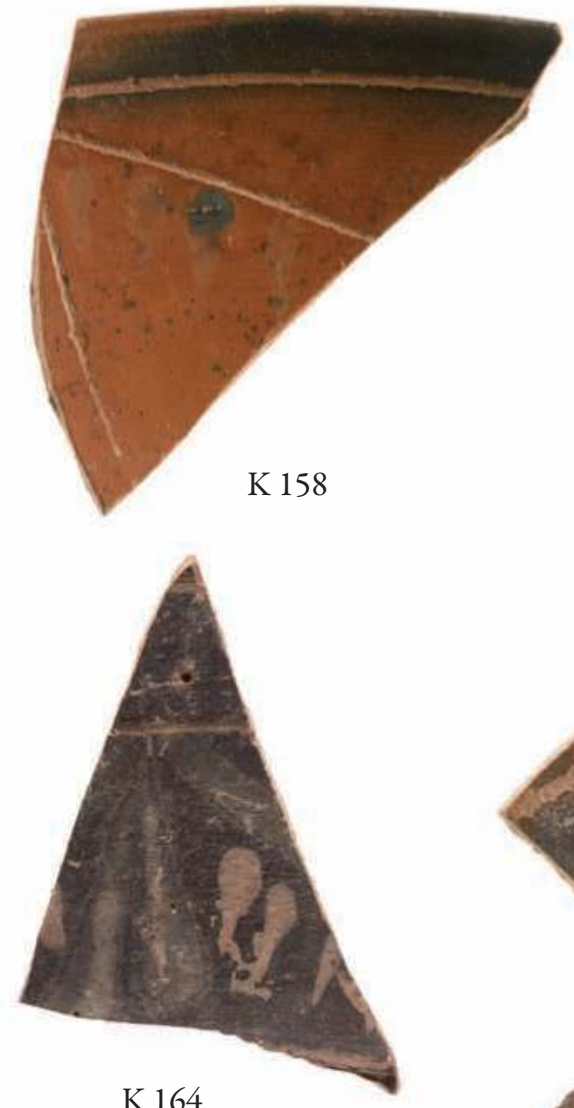

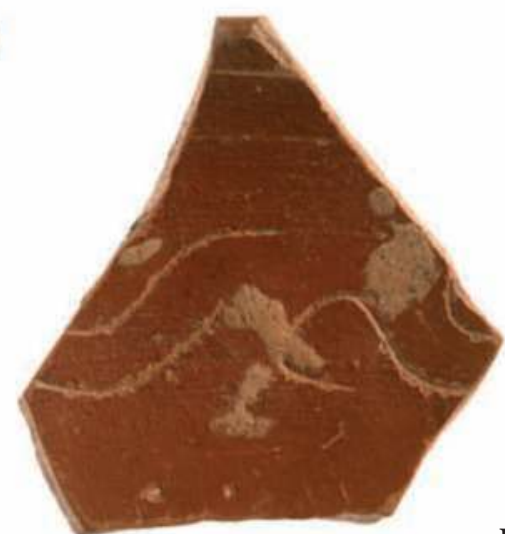

K 162
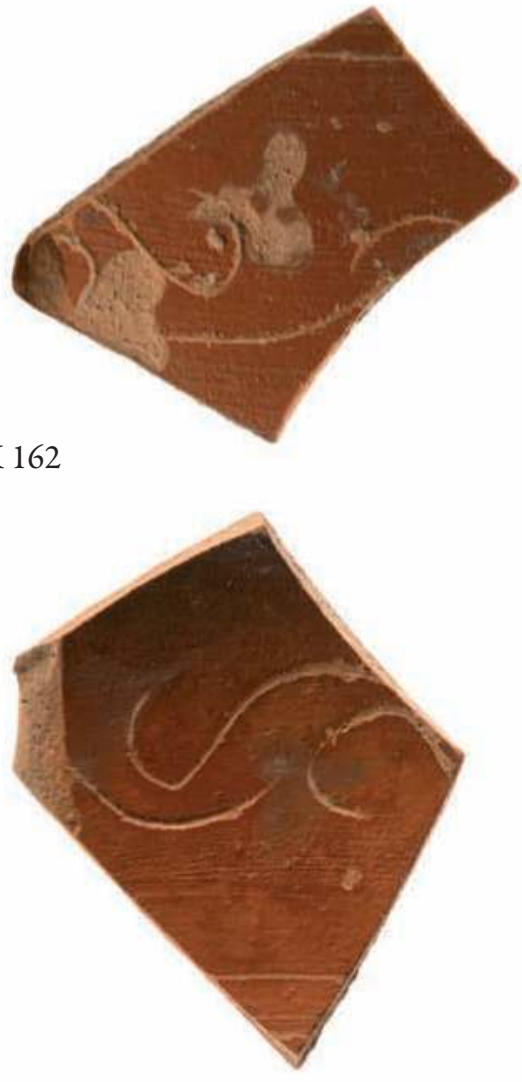

K 166

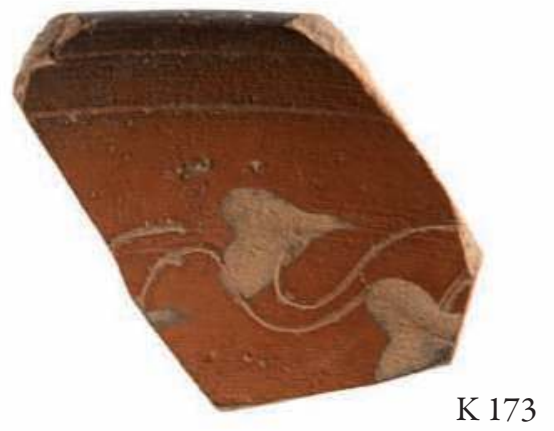

K 144-150. 158. 162. 164-166. 173 
Tafel 220
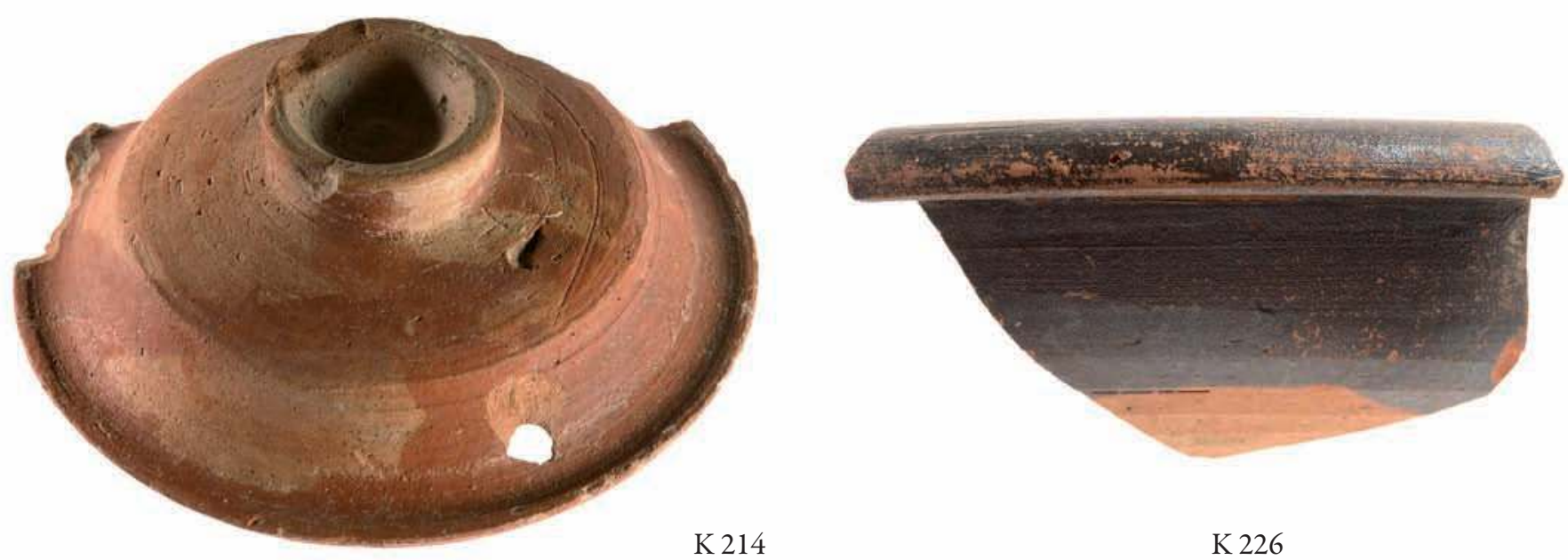

K 214

K 226
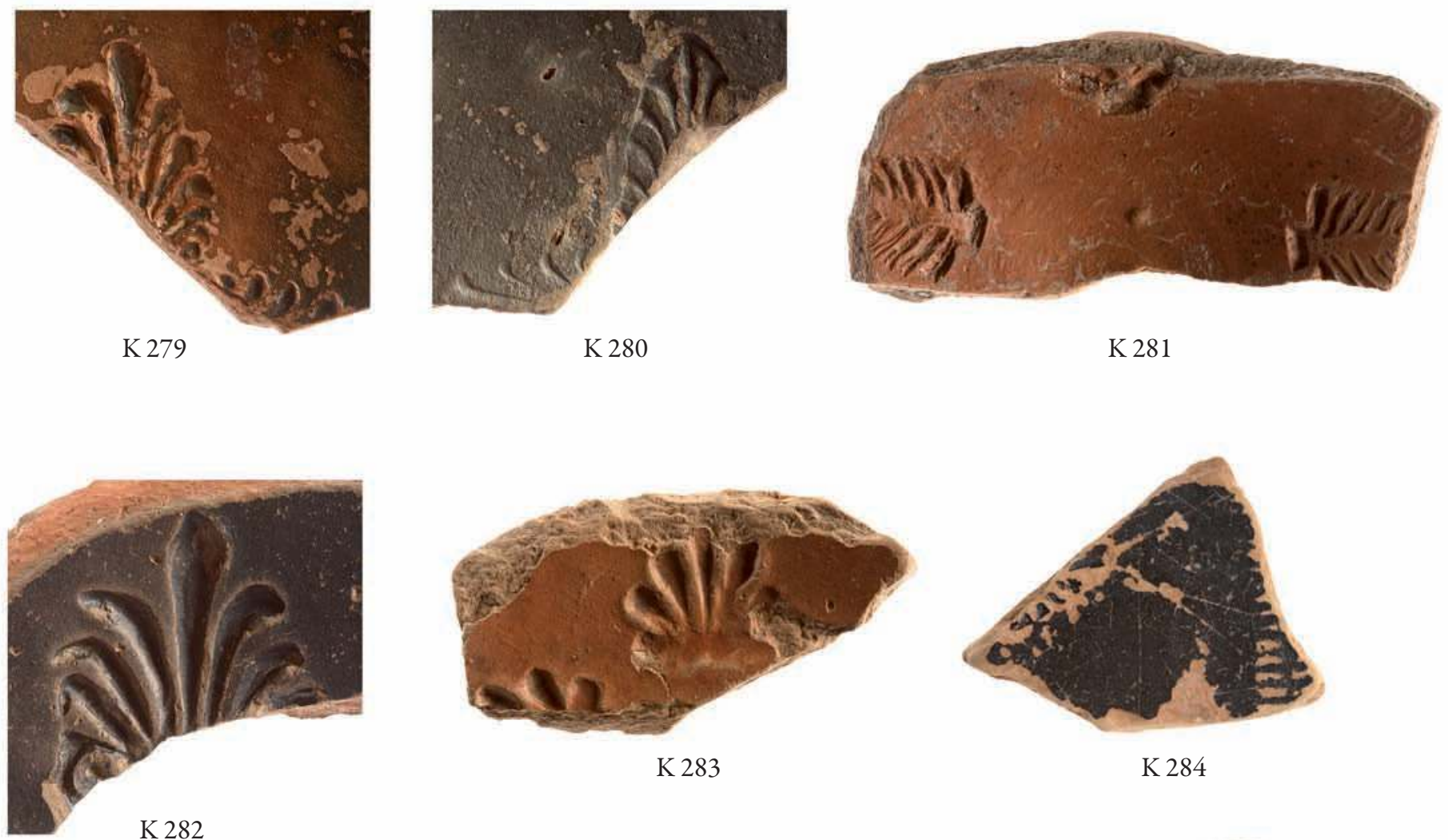

K 282
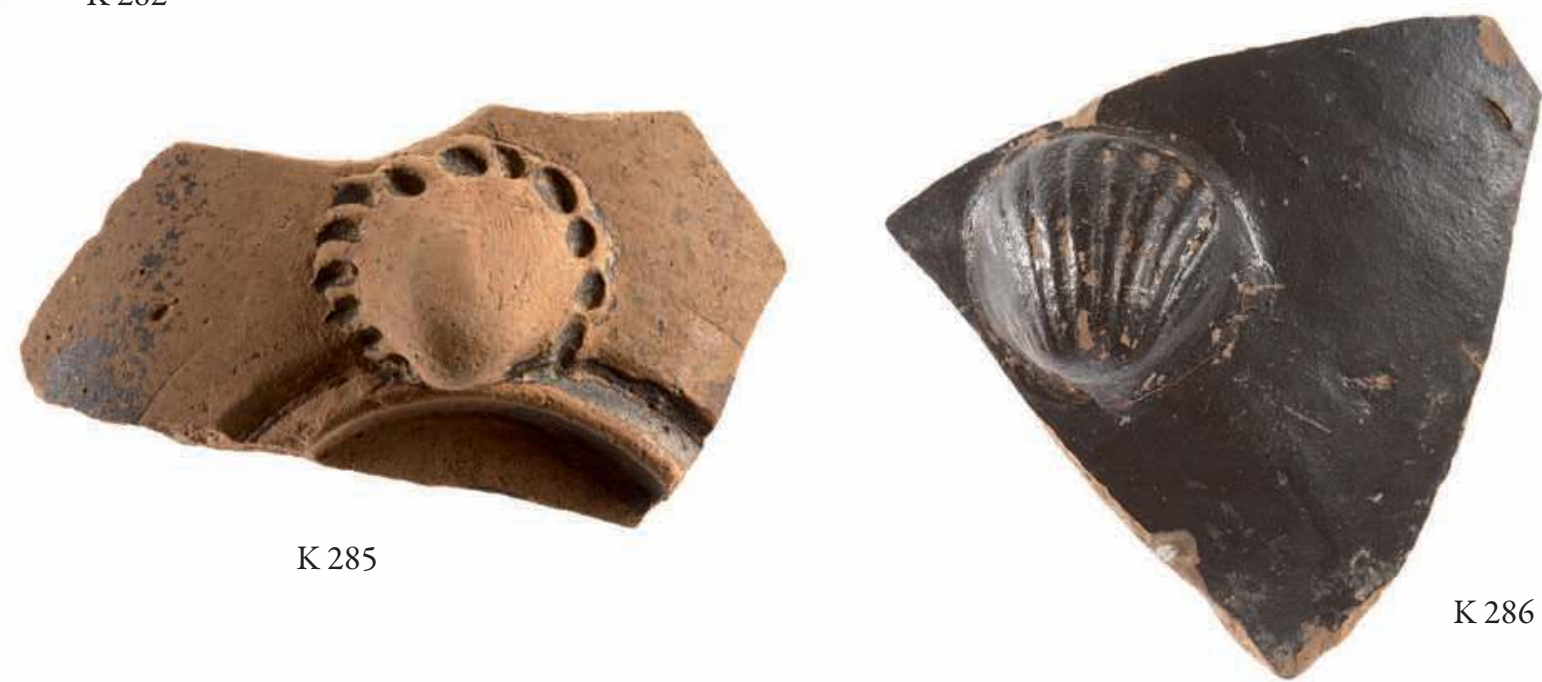
Tafel 221

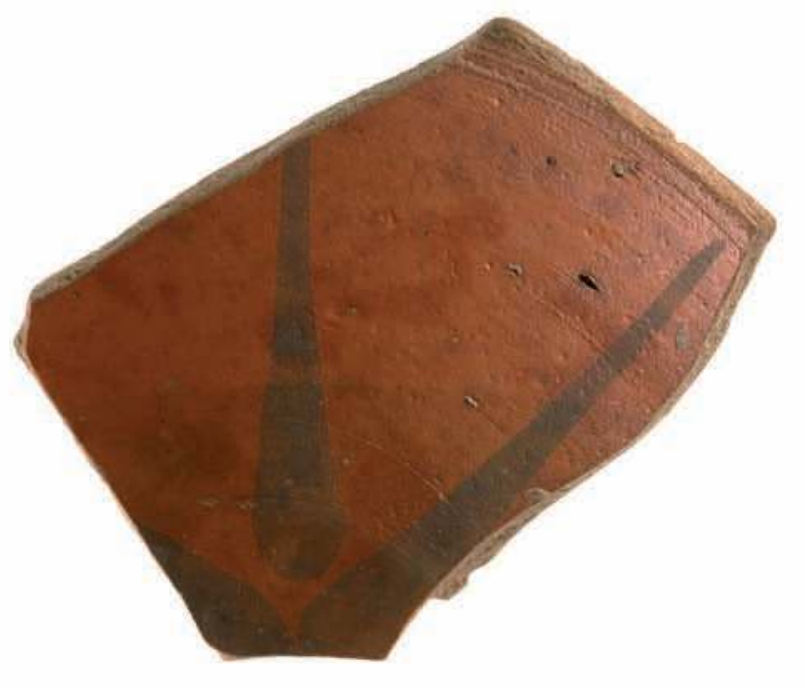

K 287

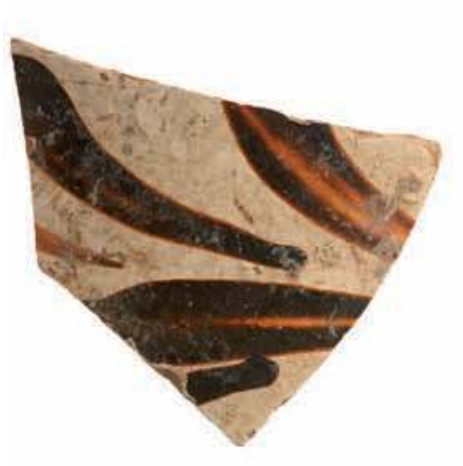

K 291

K 302
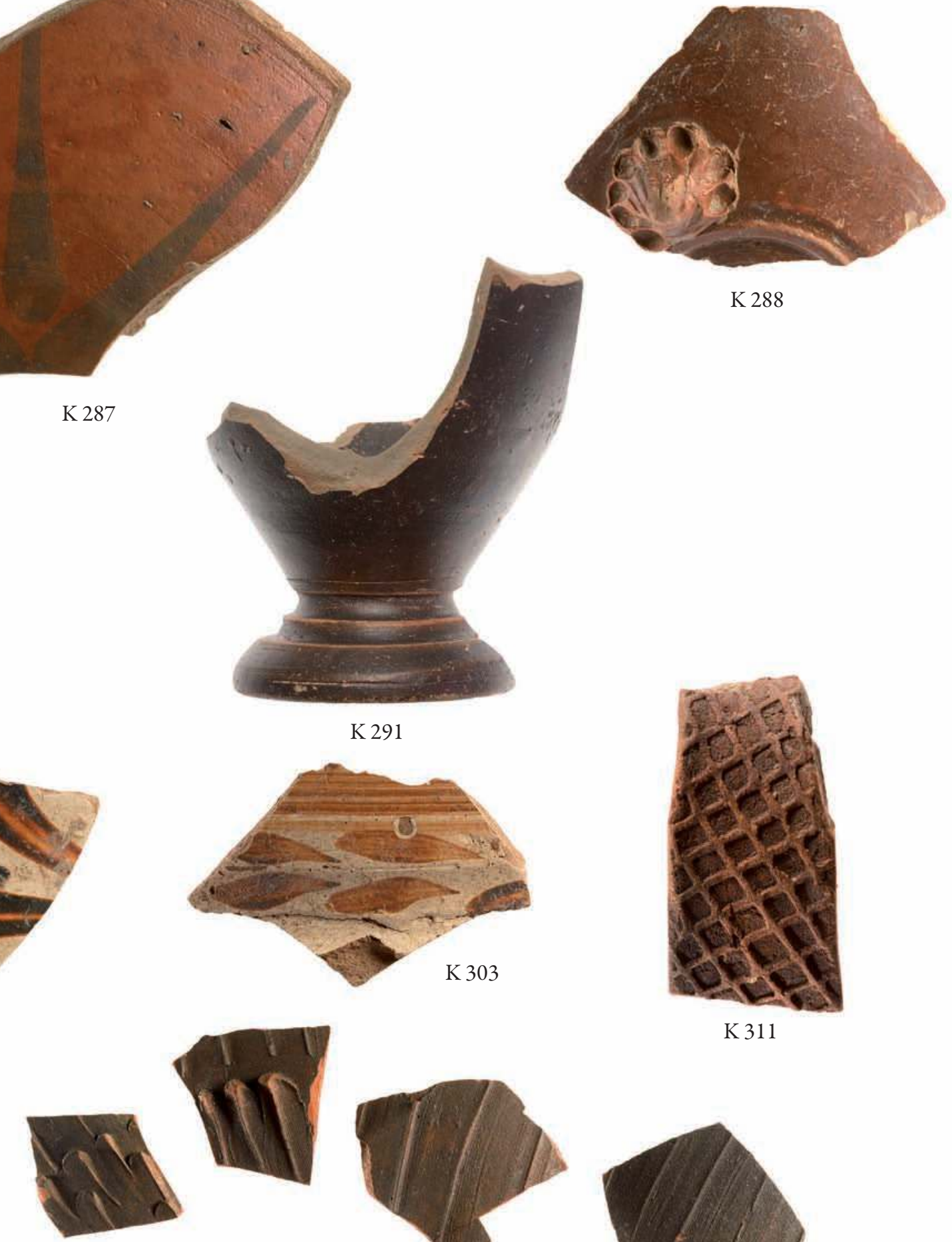

K 288

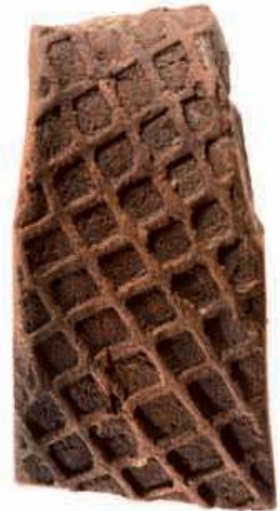

K 311

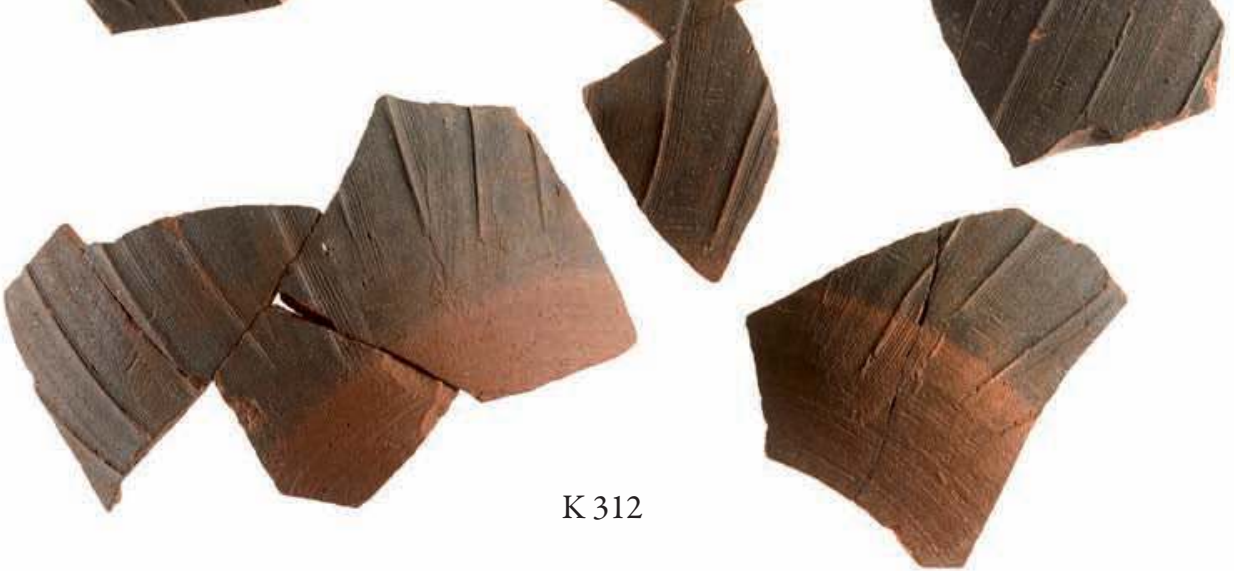

K 287. 288. 291. 302. 303.311. 312 

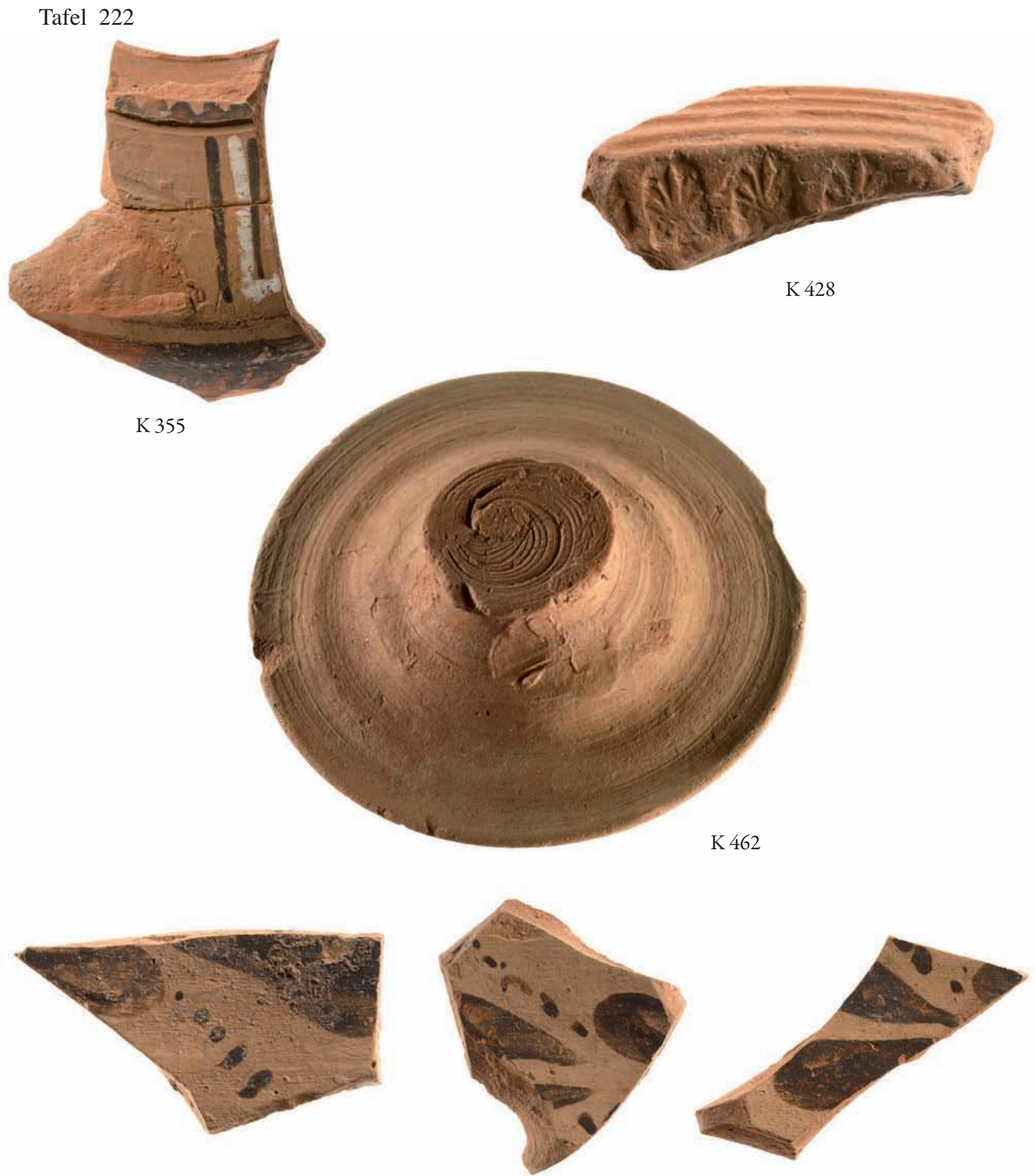

K 467
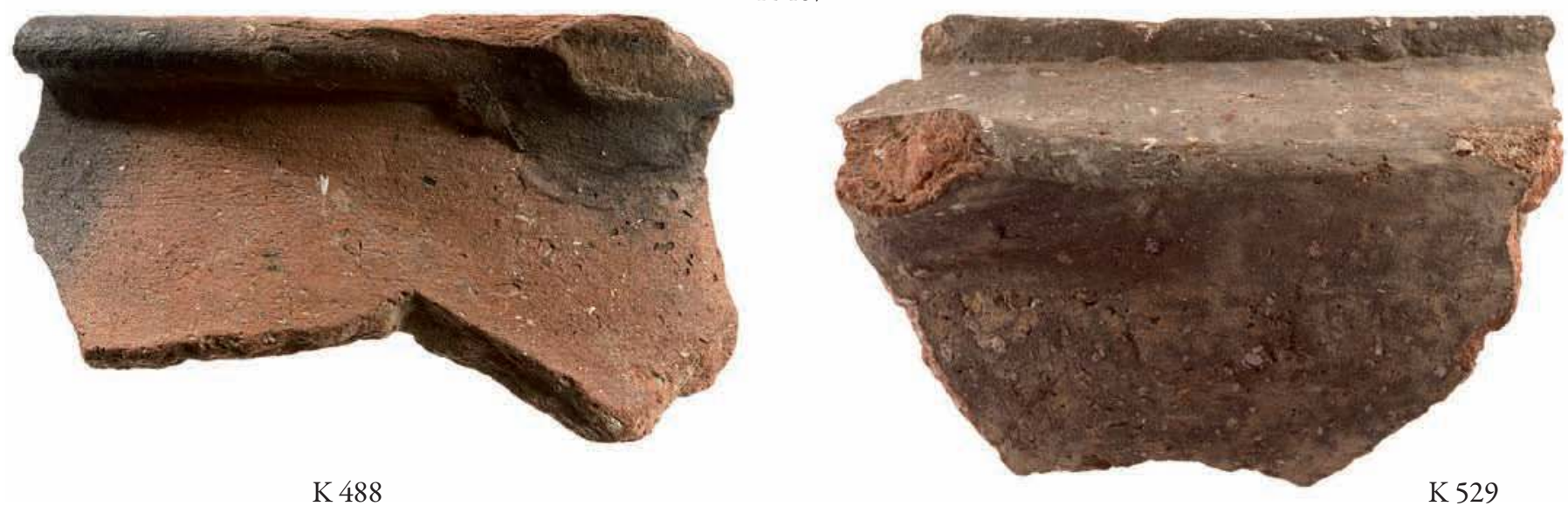

K 488

K 321. 355. 428. 462. 467. 488. 529 
Tafel 223

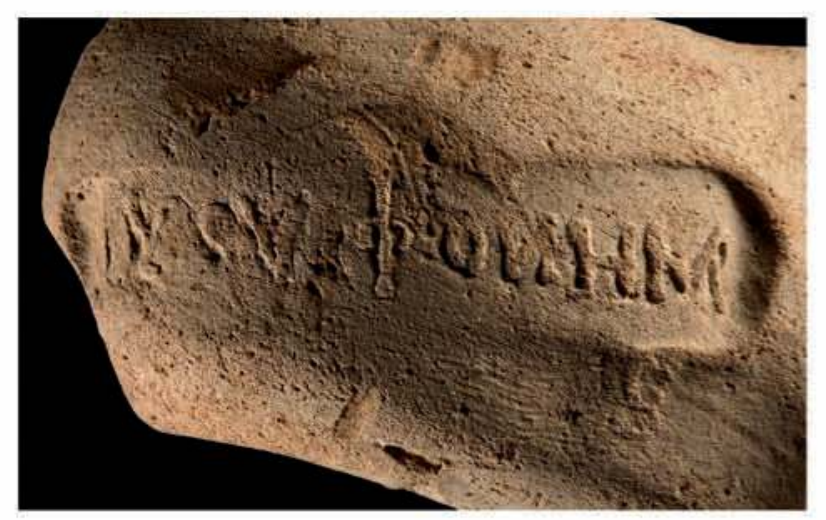

K 616

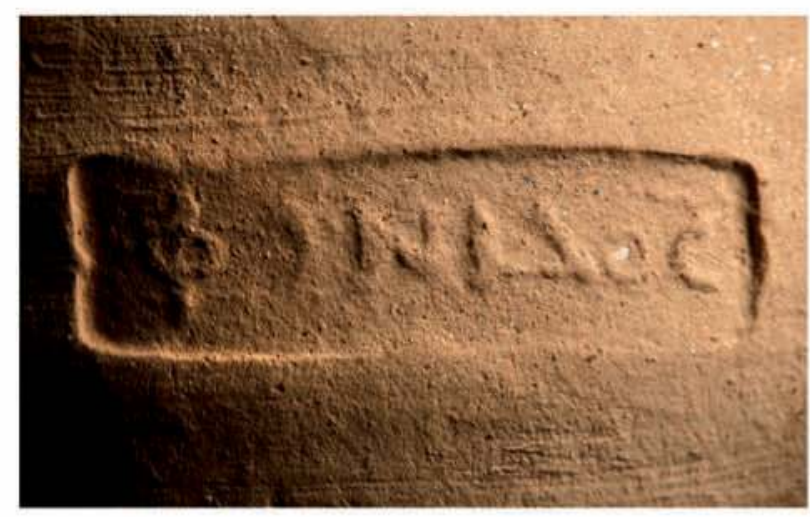

K 618

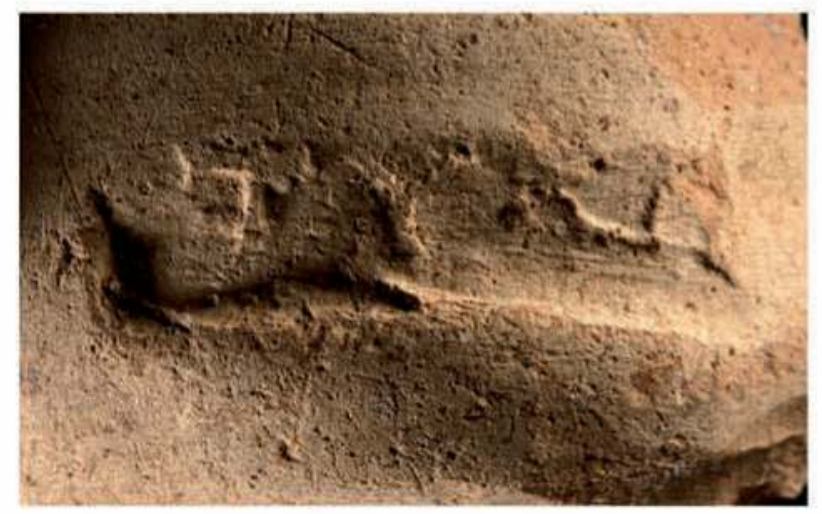

K 620

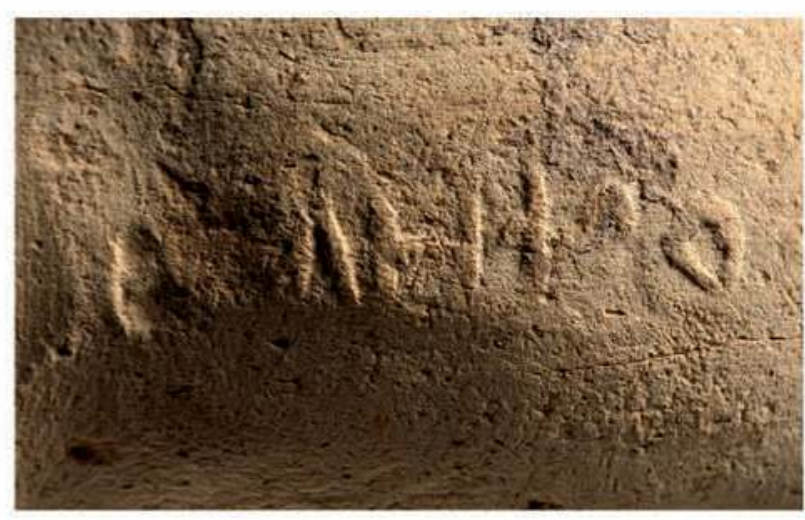

K 617

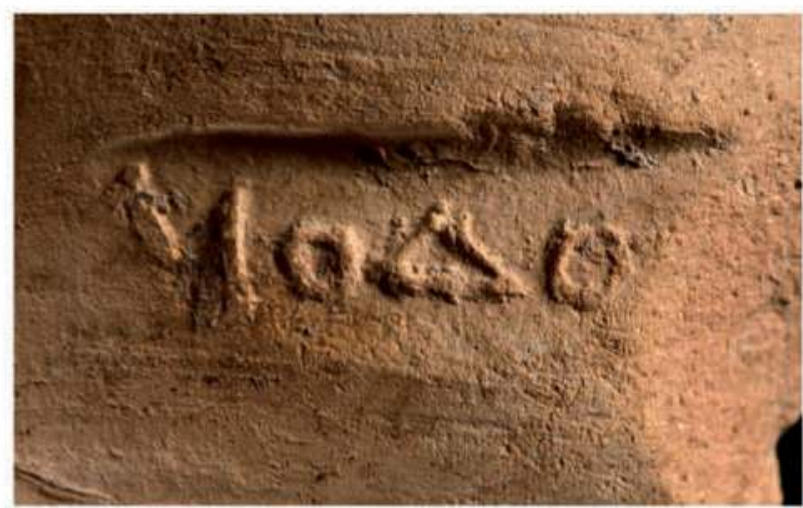

K 619

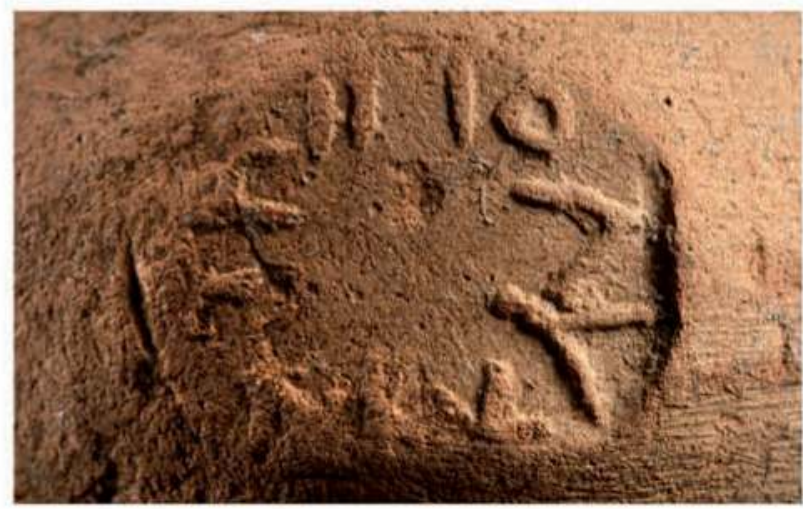

K 621

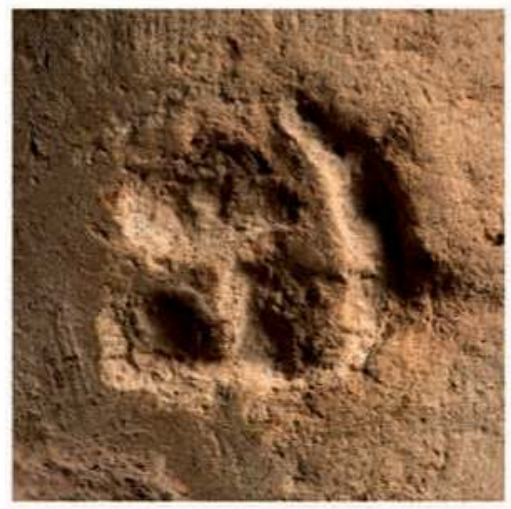

K 622 
Tafel 224

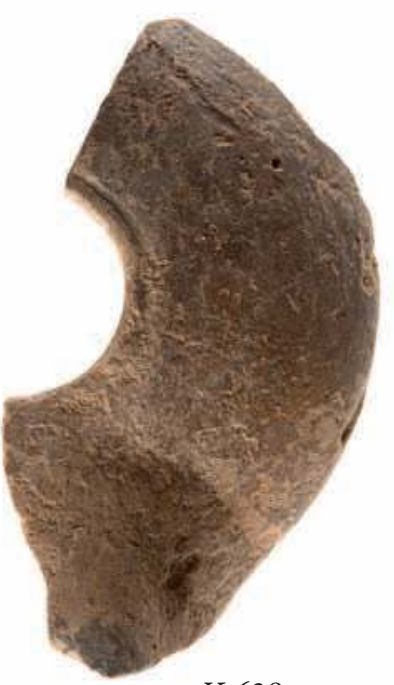

K 638

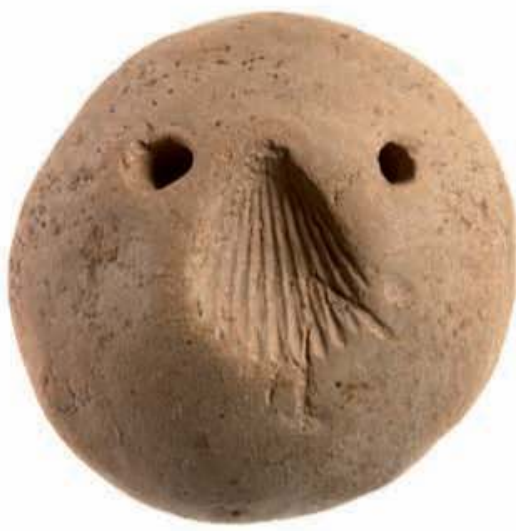

K 649
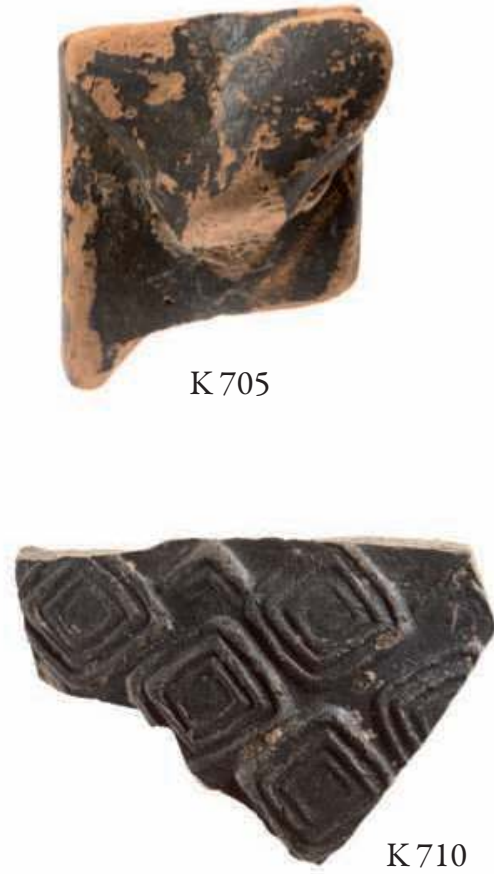

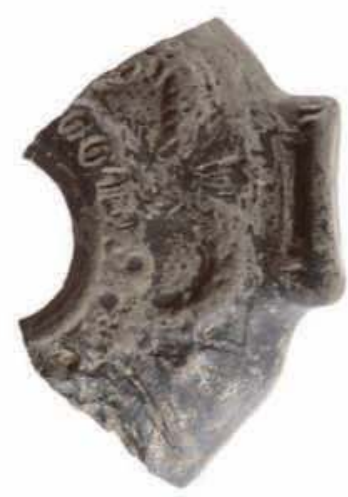

K 639

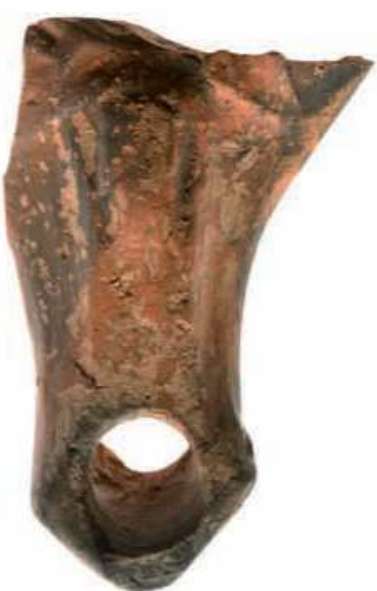

K 641

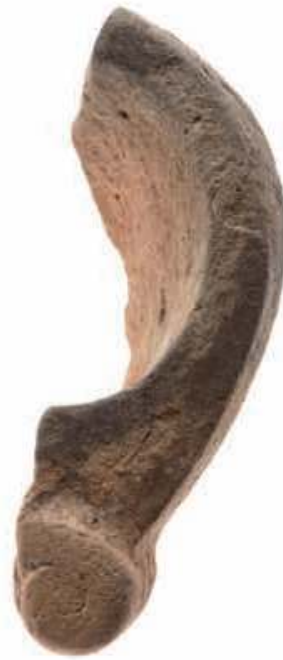

K 647

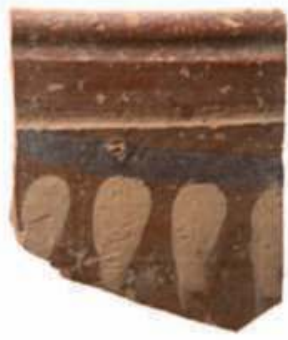

K 652

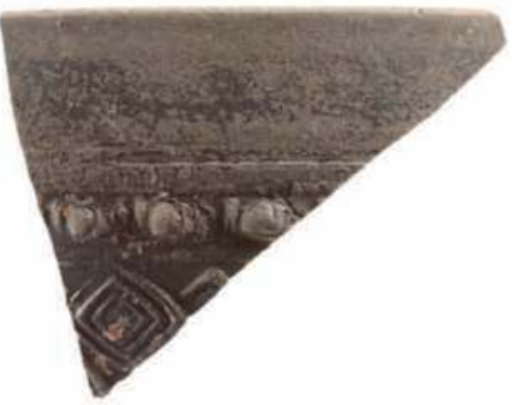

K 708

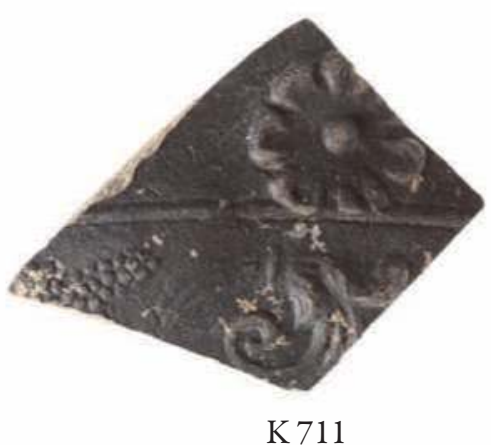

K 711

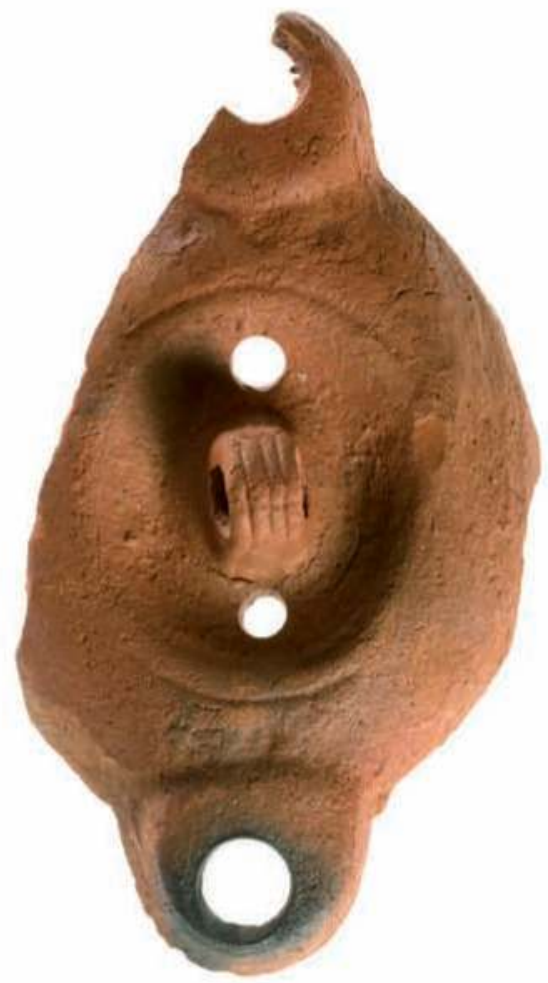

K 674

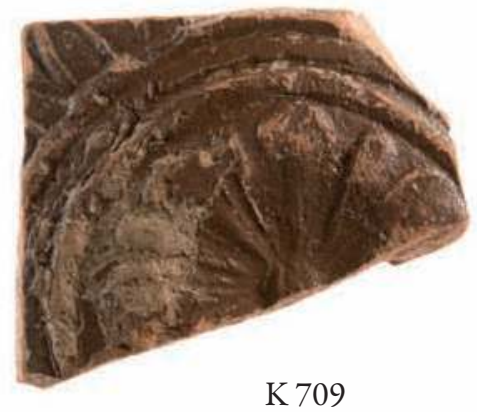

K 638. 639. 641. 647. 649. 652. 674. 705.708-711 
Tafel 225

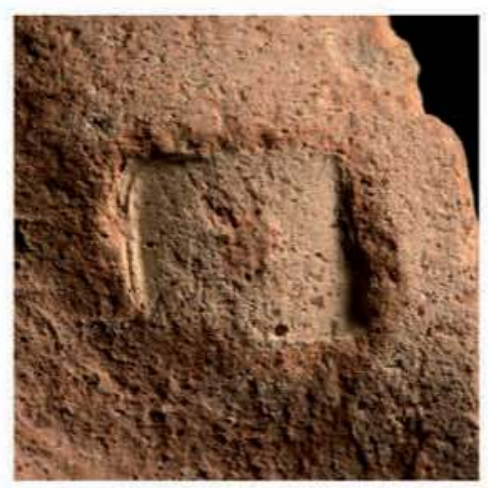

K 751
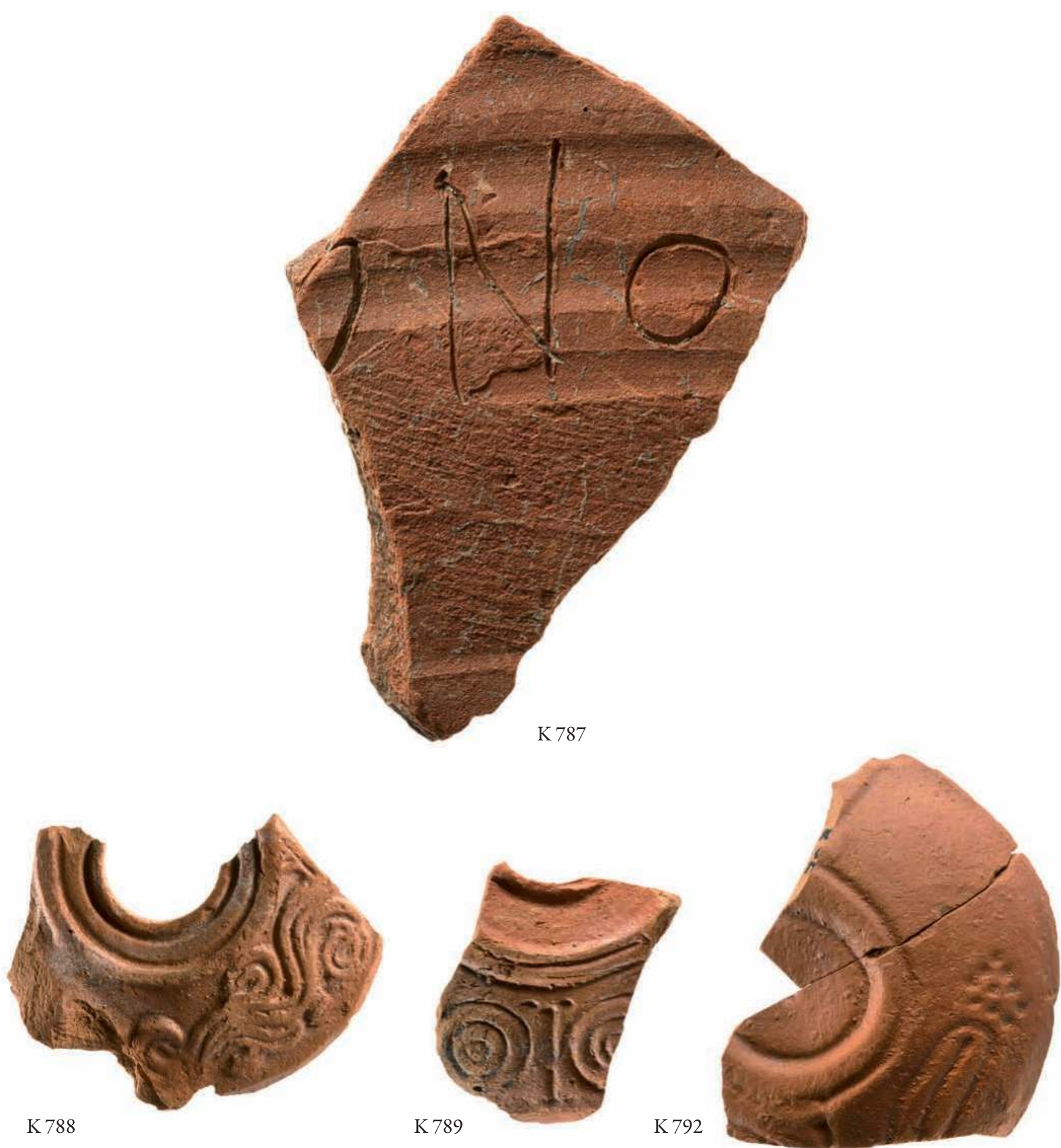

K 751. 787-789. 792 


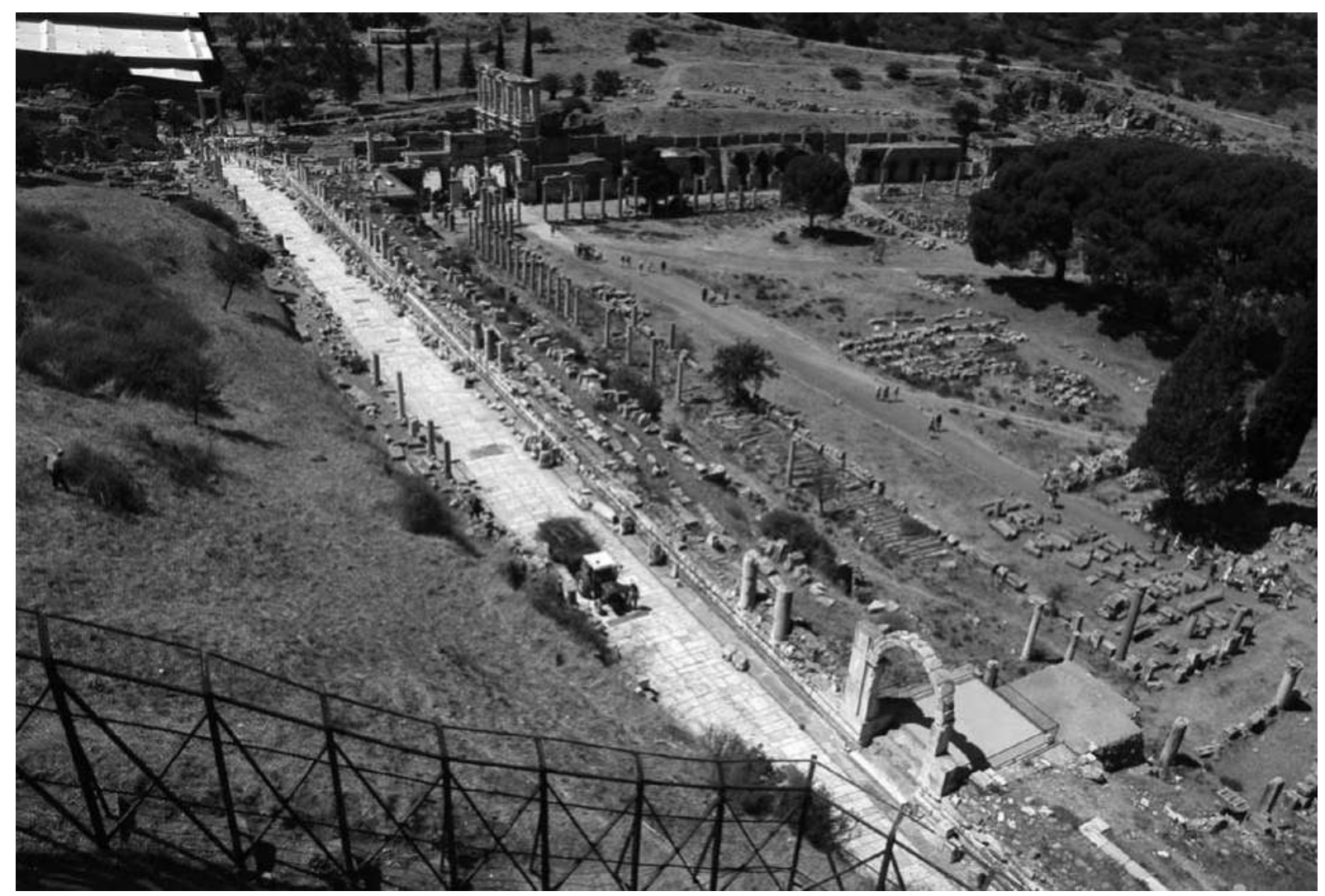

1 `Neronische Halle $\prec$. Blick von Norden

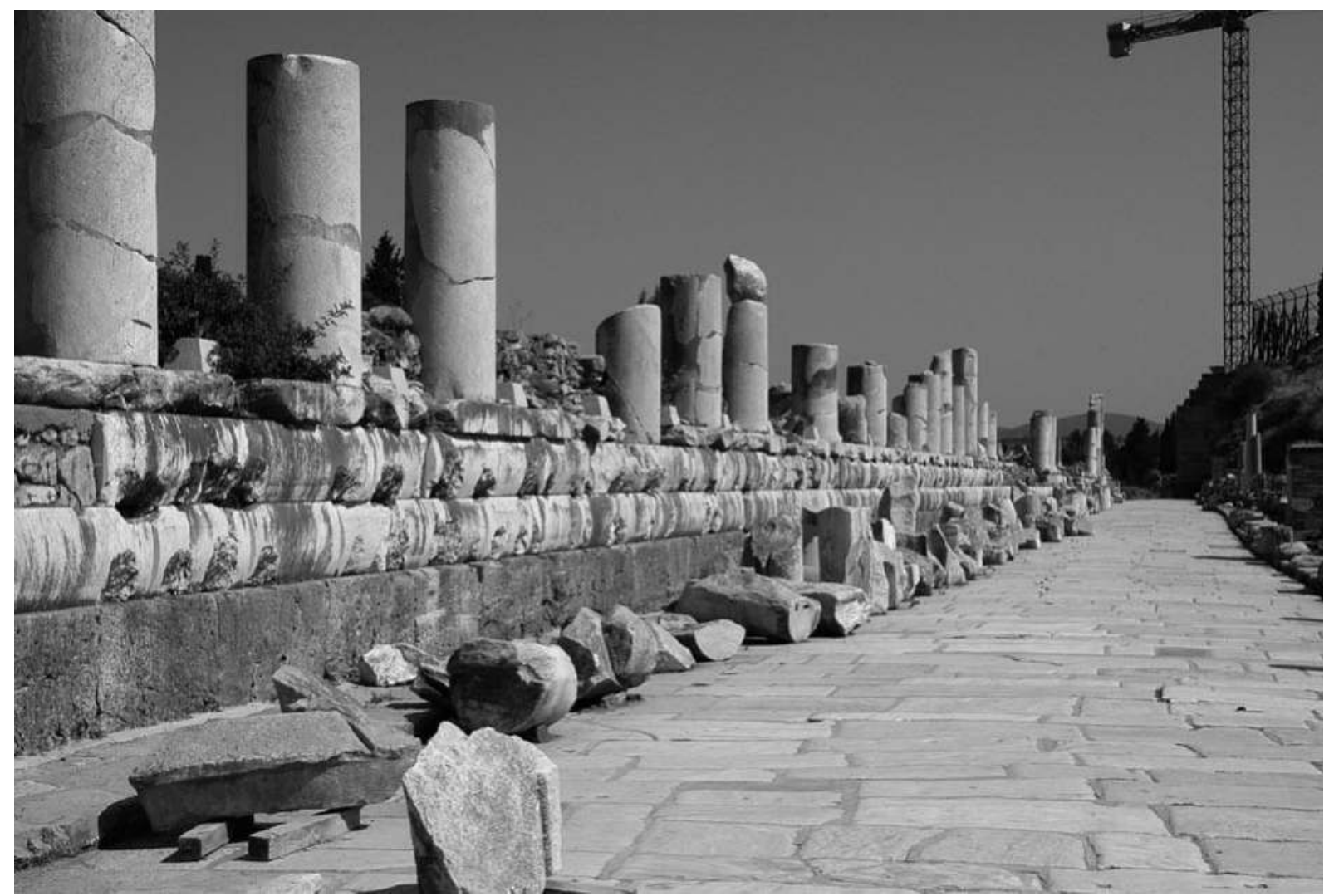

2 >Neronische Halle $\prec$. Sockelzone an der $>$ Marmorstraße 
Tafel 227

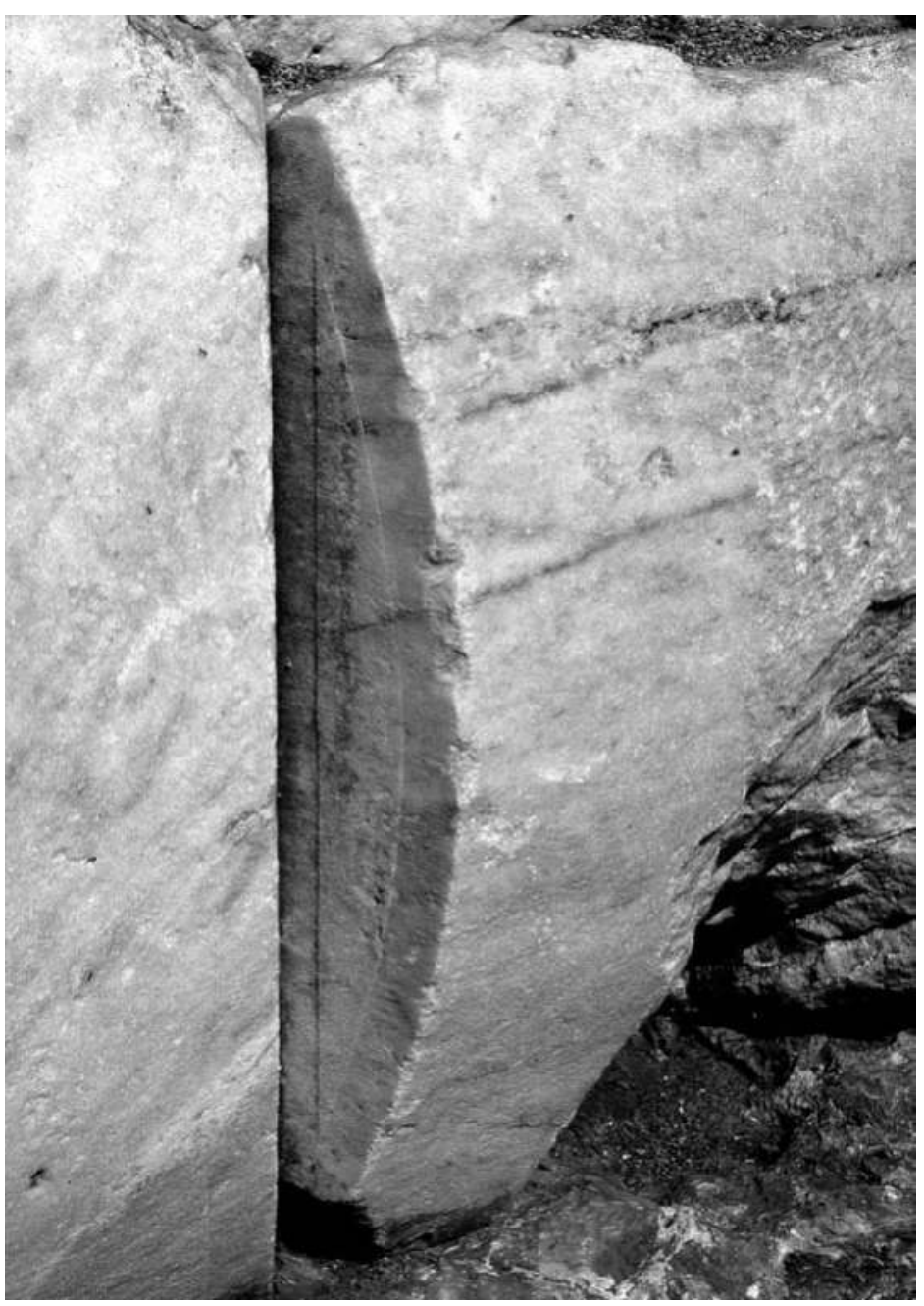

1 >Neronische Halleく. Polsterquader der Sockelzone: Saum an den Stoßflächen

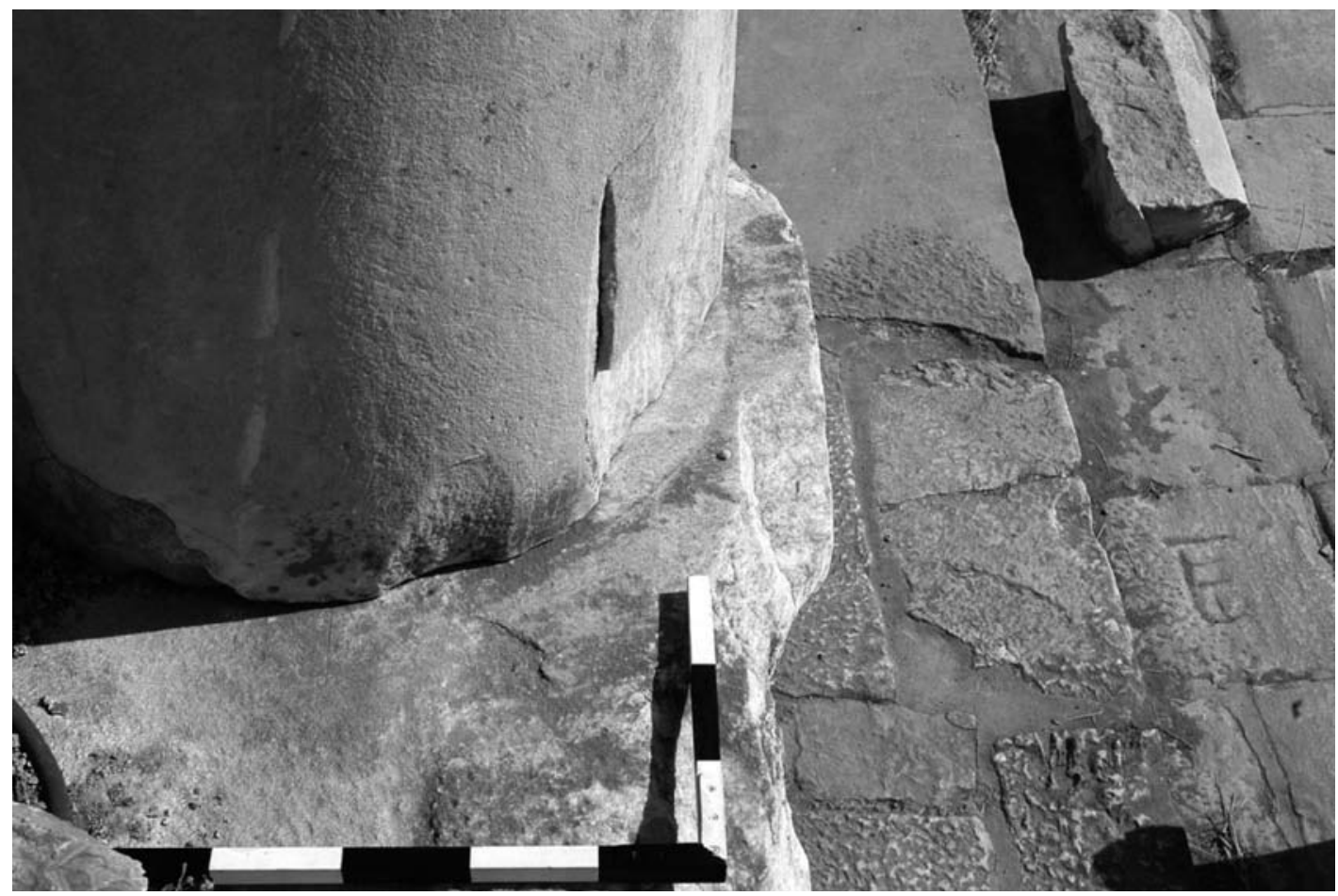

2 >Neronische Halle`. Stylobat mit Risslinien zur Markierung der Säulenachse 
Tafel 228
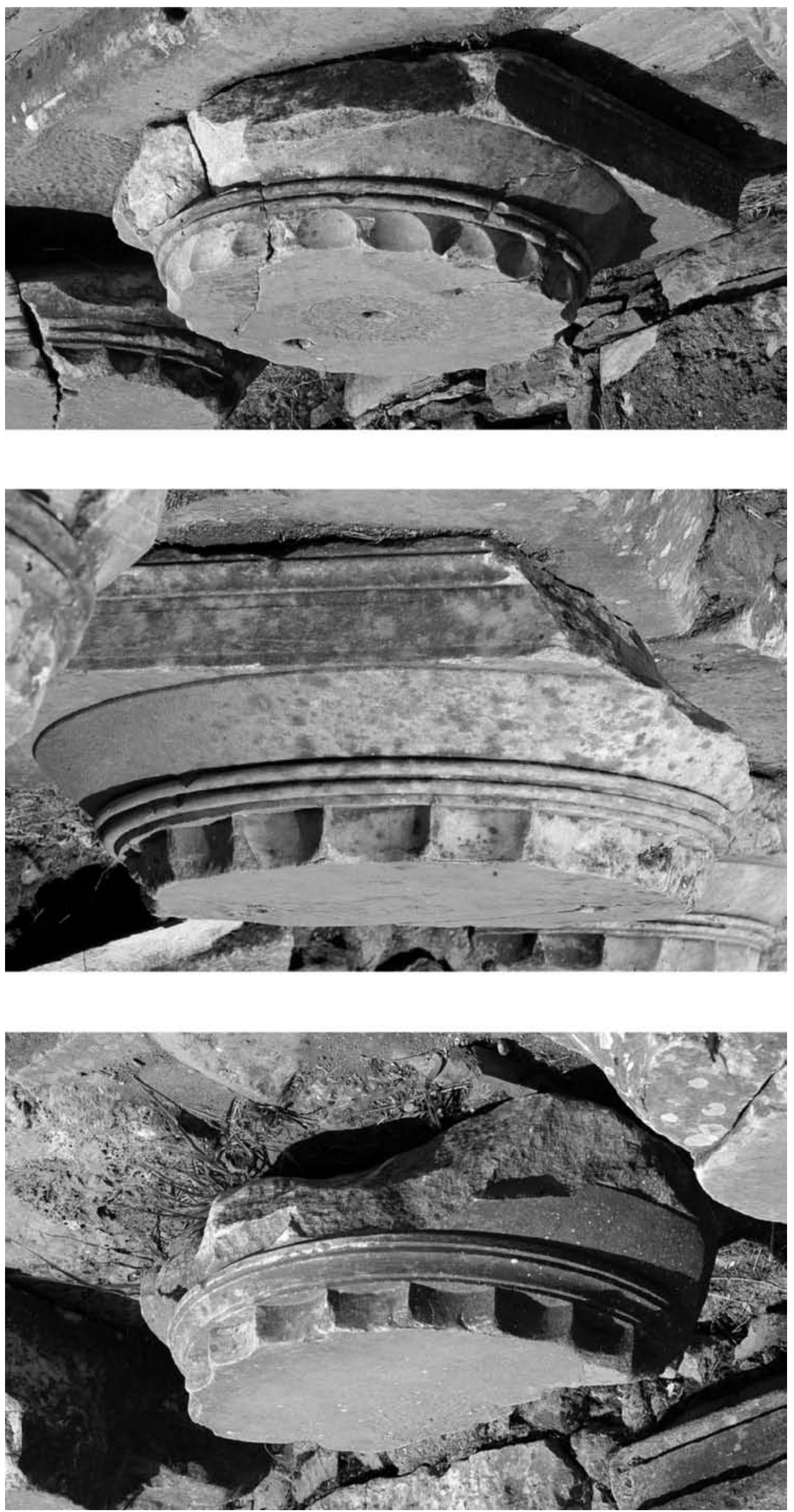

1-3 >Neronische Halleく. Dorische Kapitelle 
Tafel 229

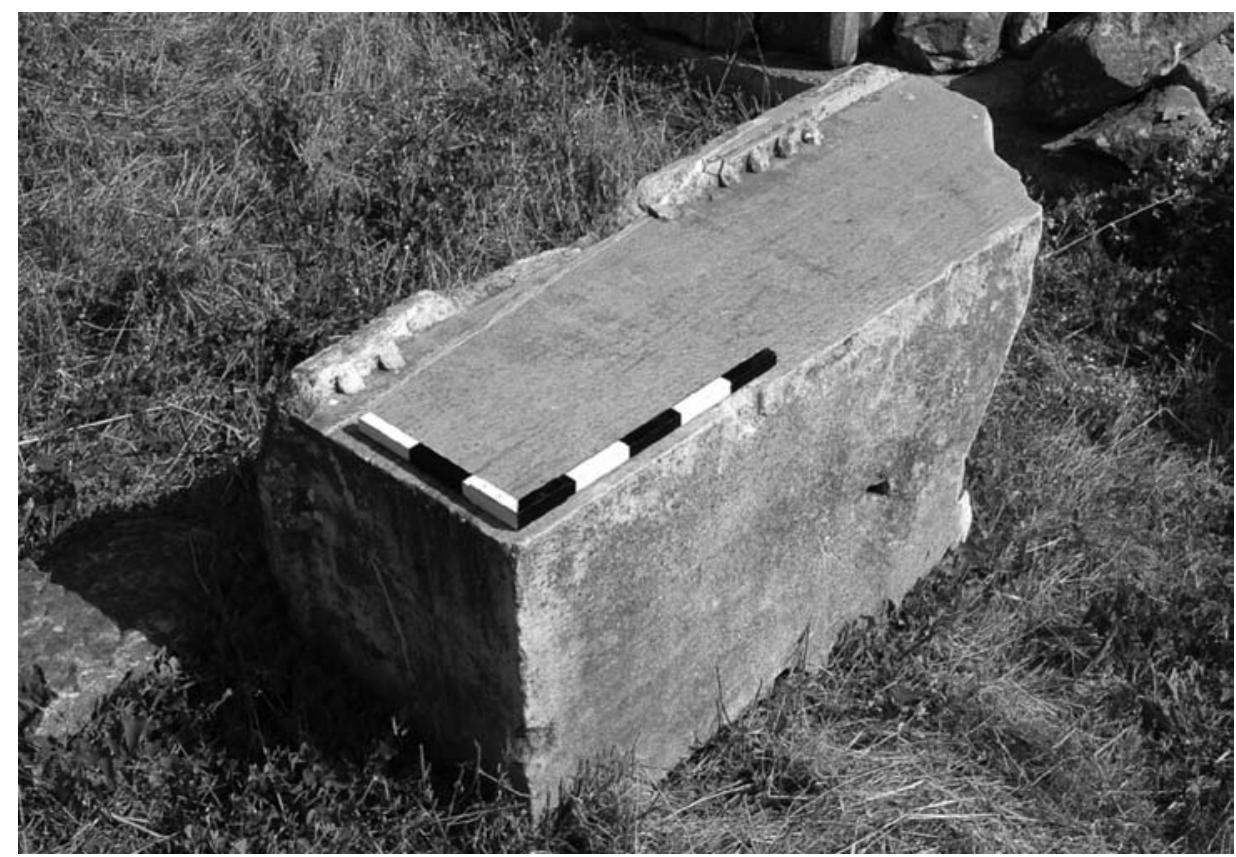

1 >Neronische Halle`. Eckarchitrav

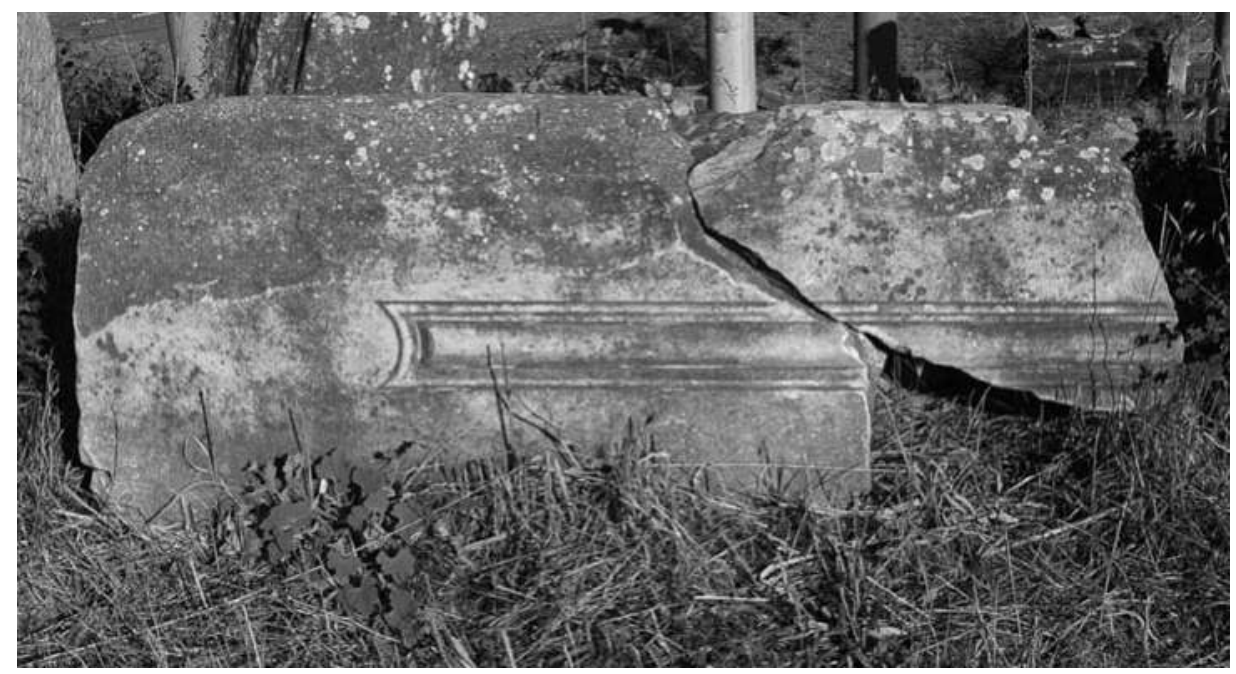

2 >Neronische Halle`. Architrav: Soffitte

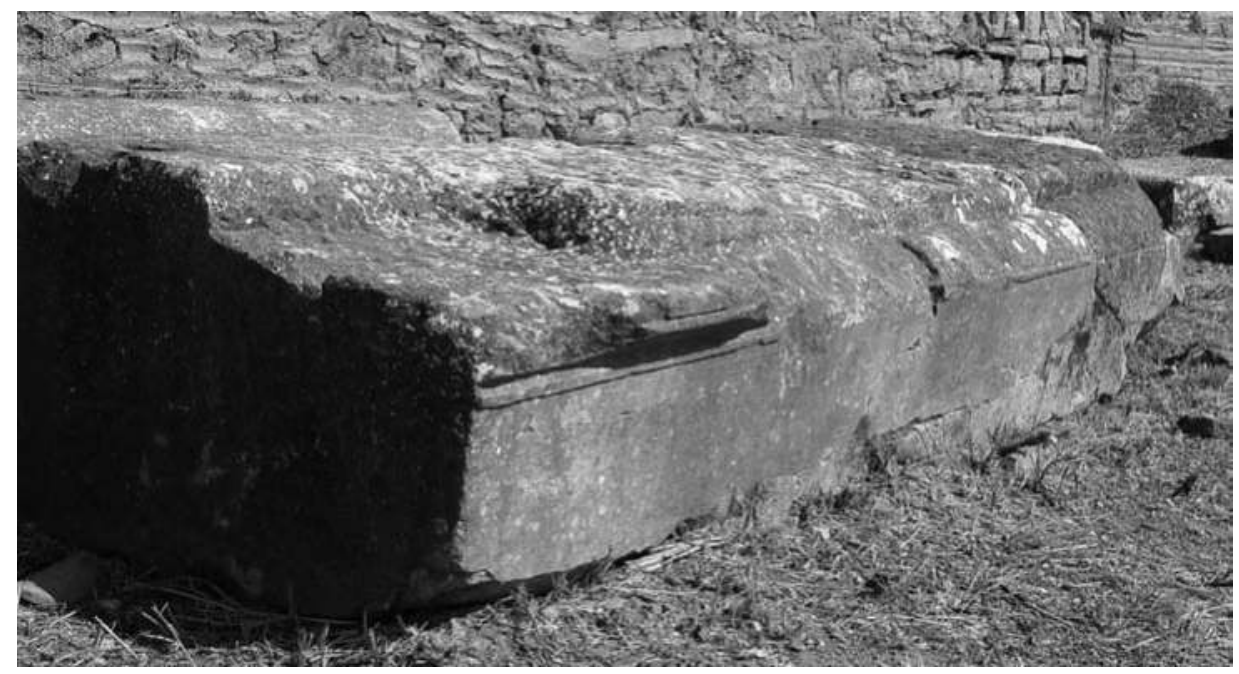

3 >Neronische Halleく. Architrav: Rückseite 
Tafel 230
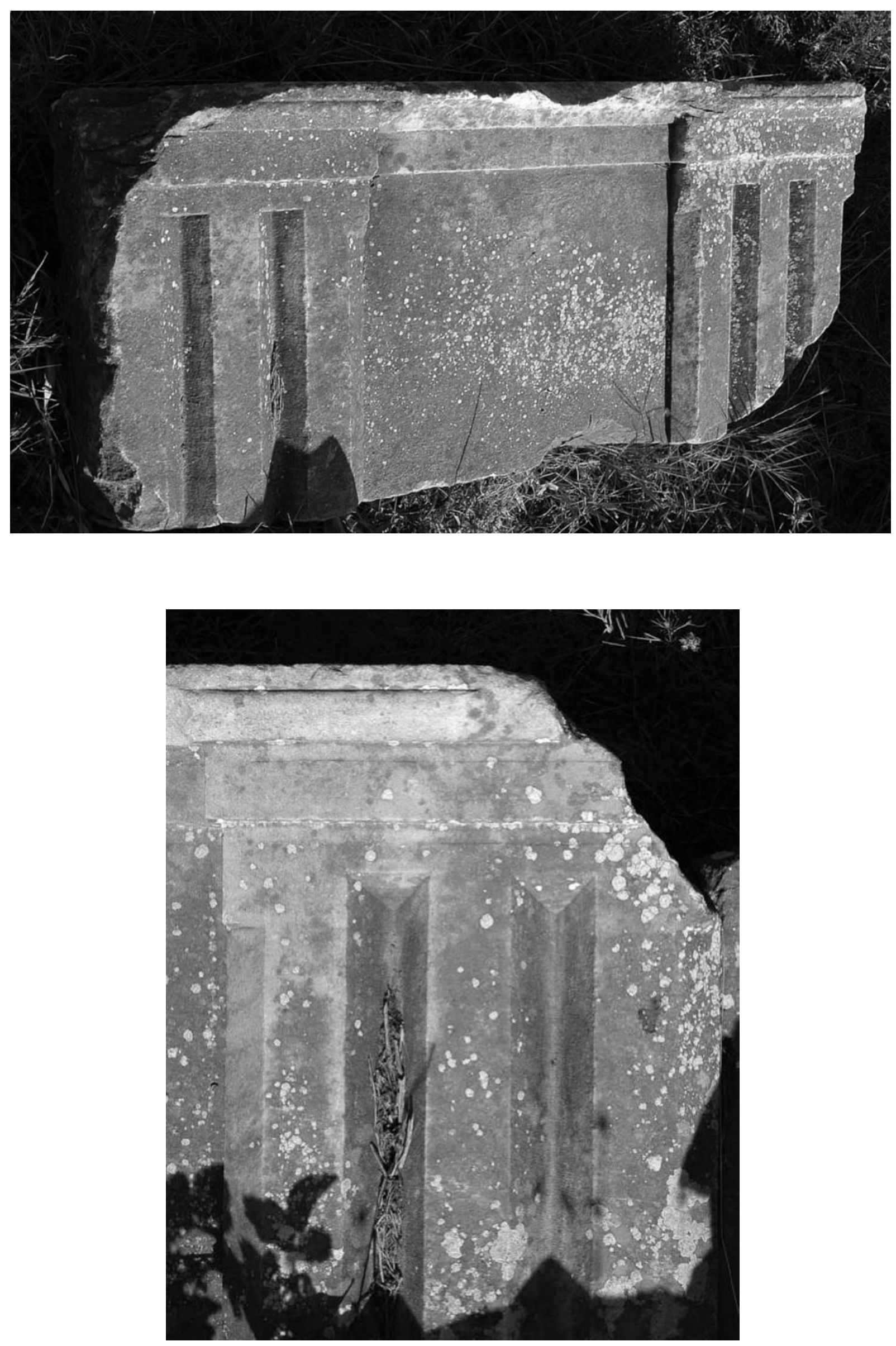

$1.2>$ Neronische Halleく. Metopen-Triglyphen-Fries 
Tafel 231

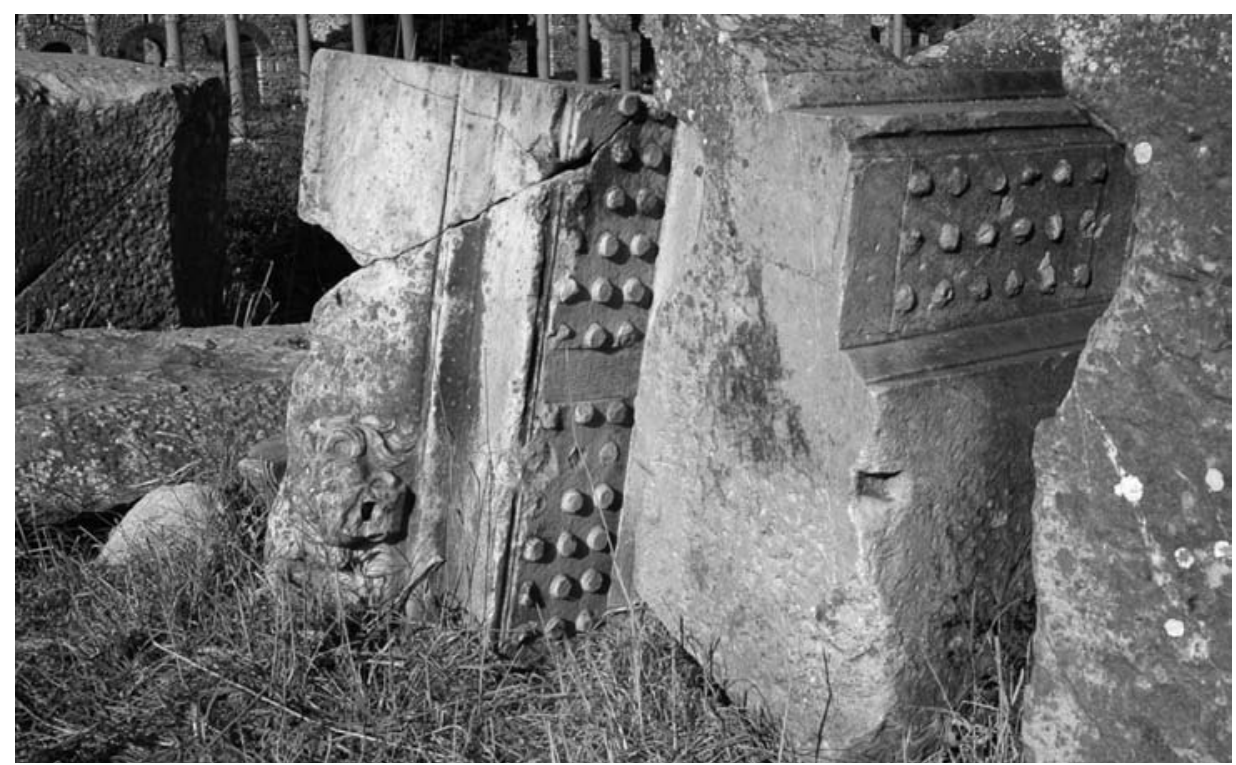

1 `Neronische Halle‘. Geison

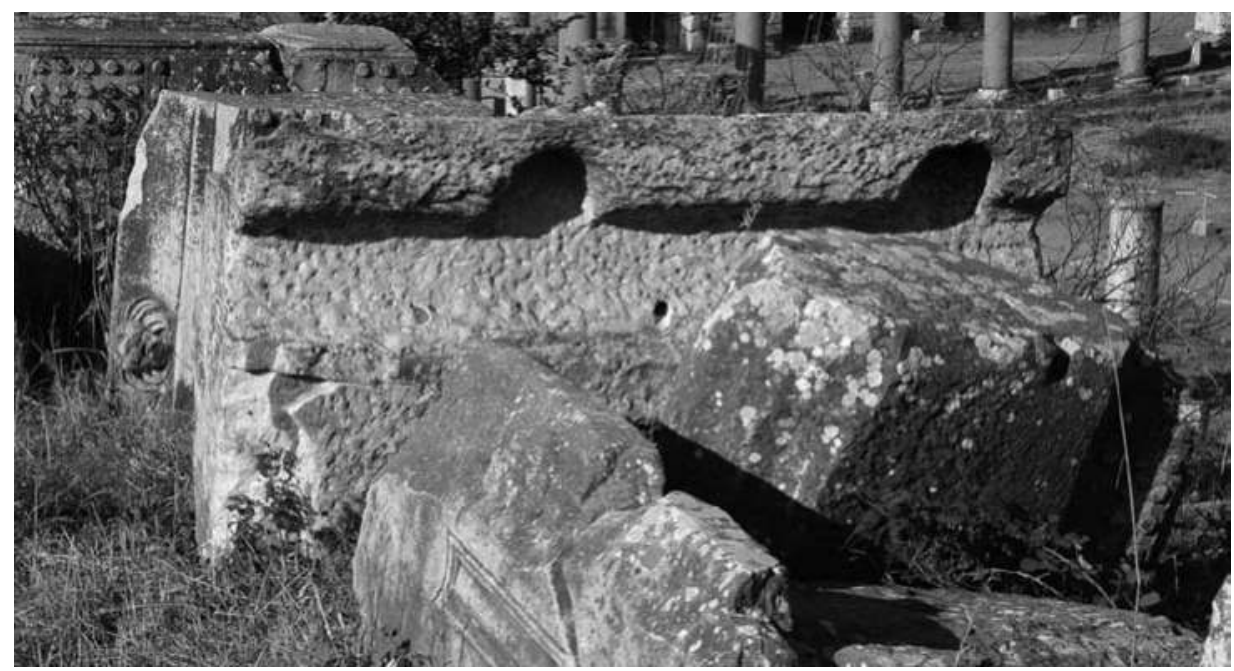

2 >Neronische Halle^. Geison: Wasserrinne an der Oberseite

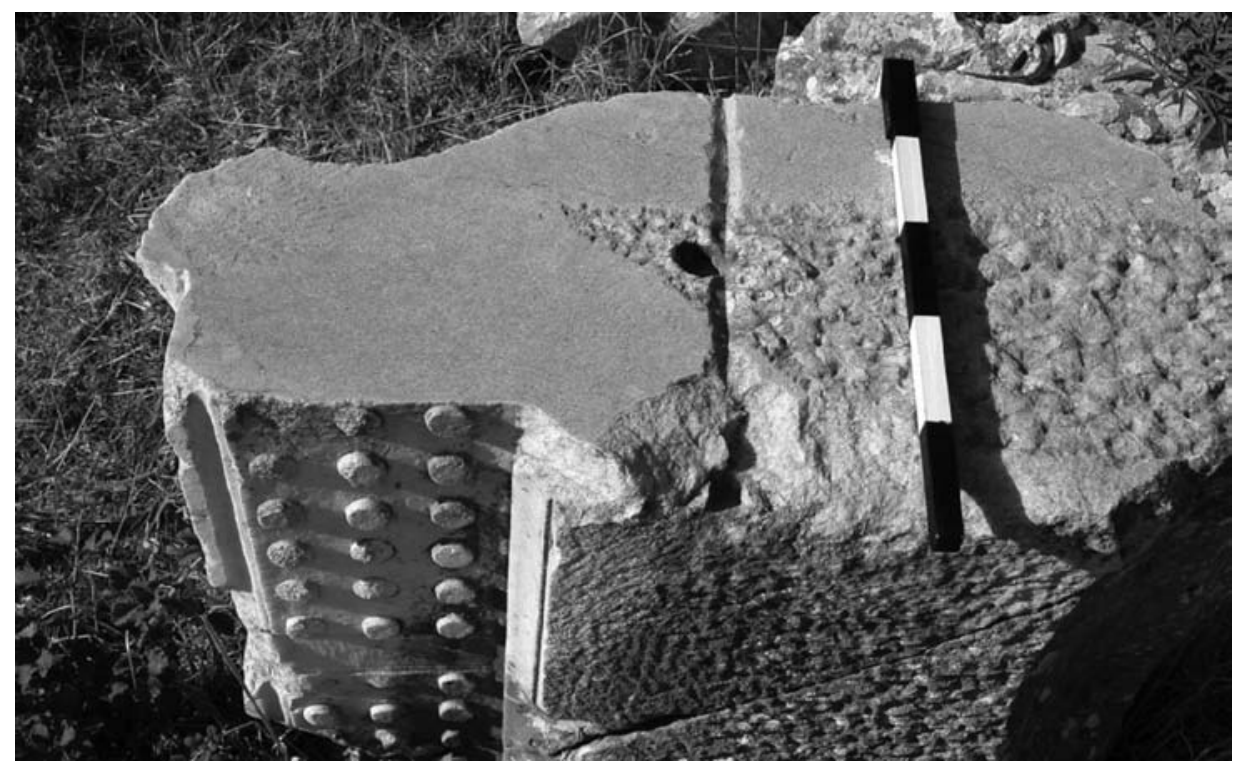

3 >Neronische Halle`. Geison: vertikaler Gusskanal an der Stoßfuge 
Tafel 232

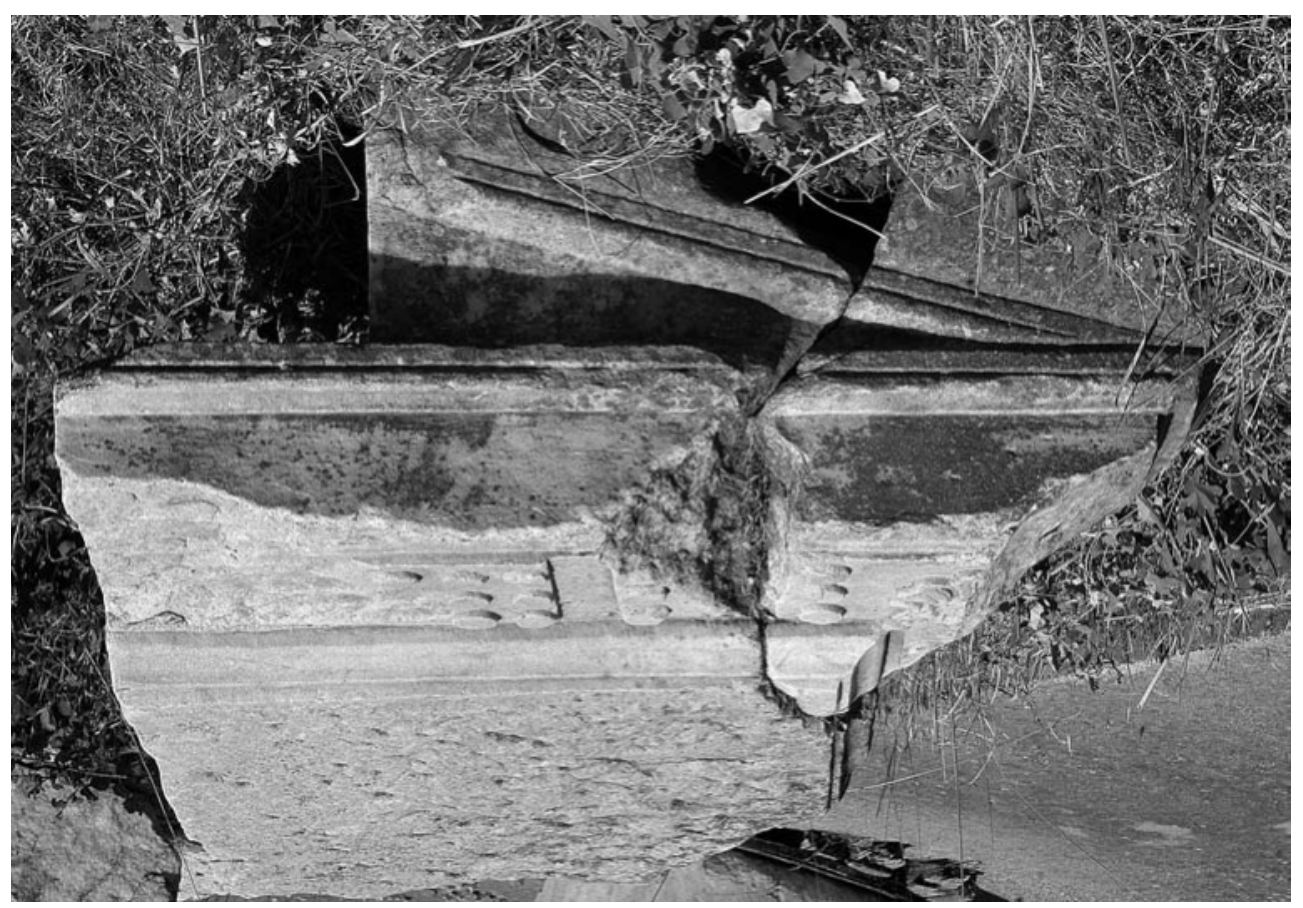

1 `Neronische Halle^. Geison: Südostecke mit Ansatz des Schräggeisons

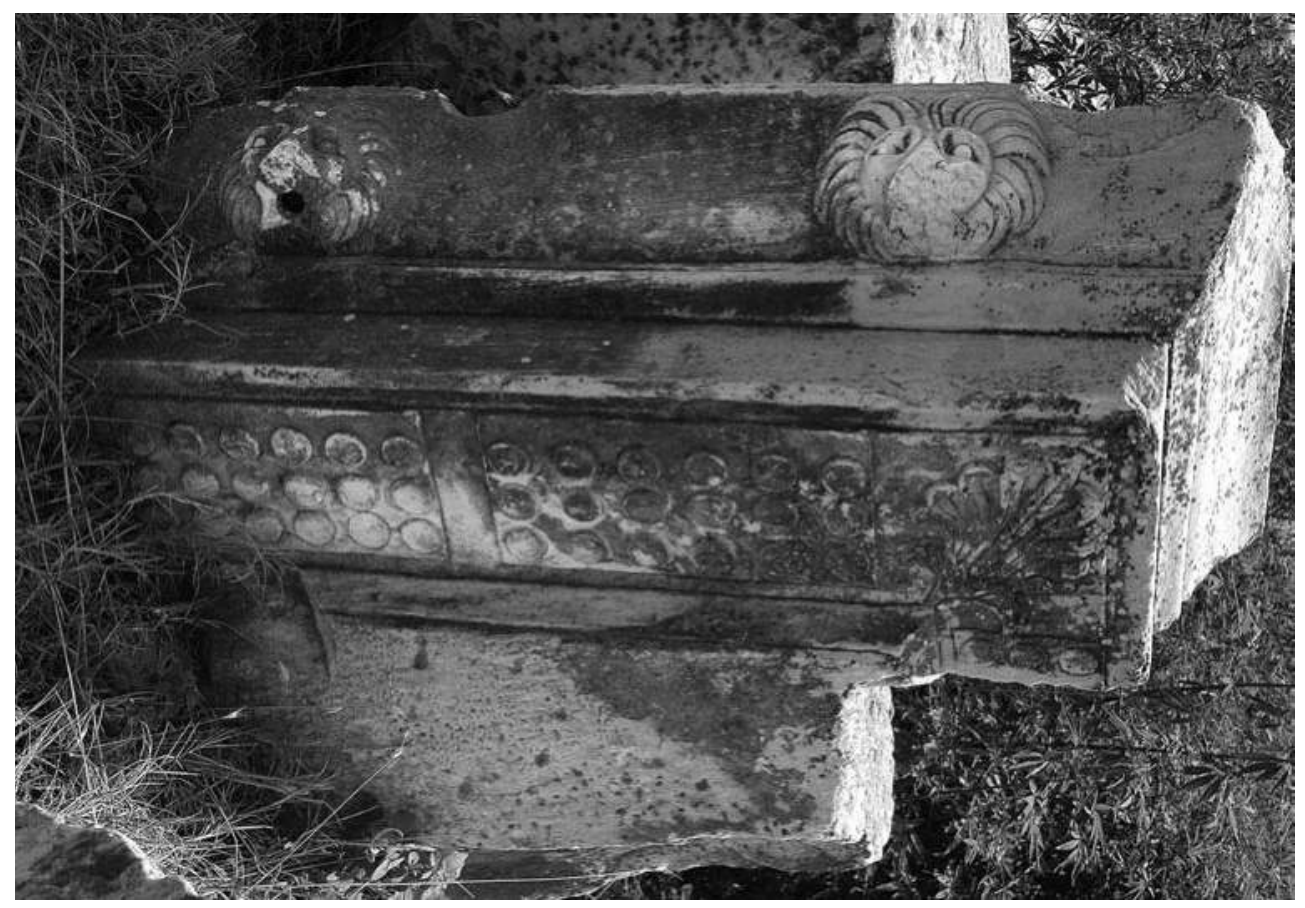

2 >Neronische Halle‘. Eckgeison von der Nordseite 
Tafel 233

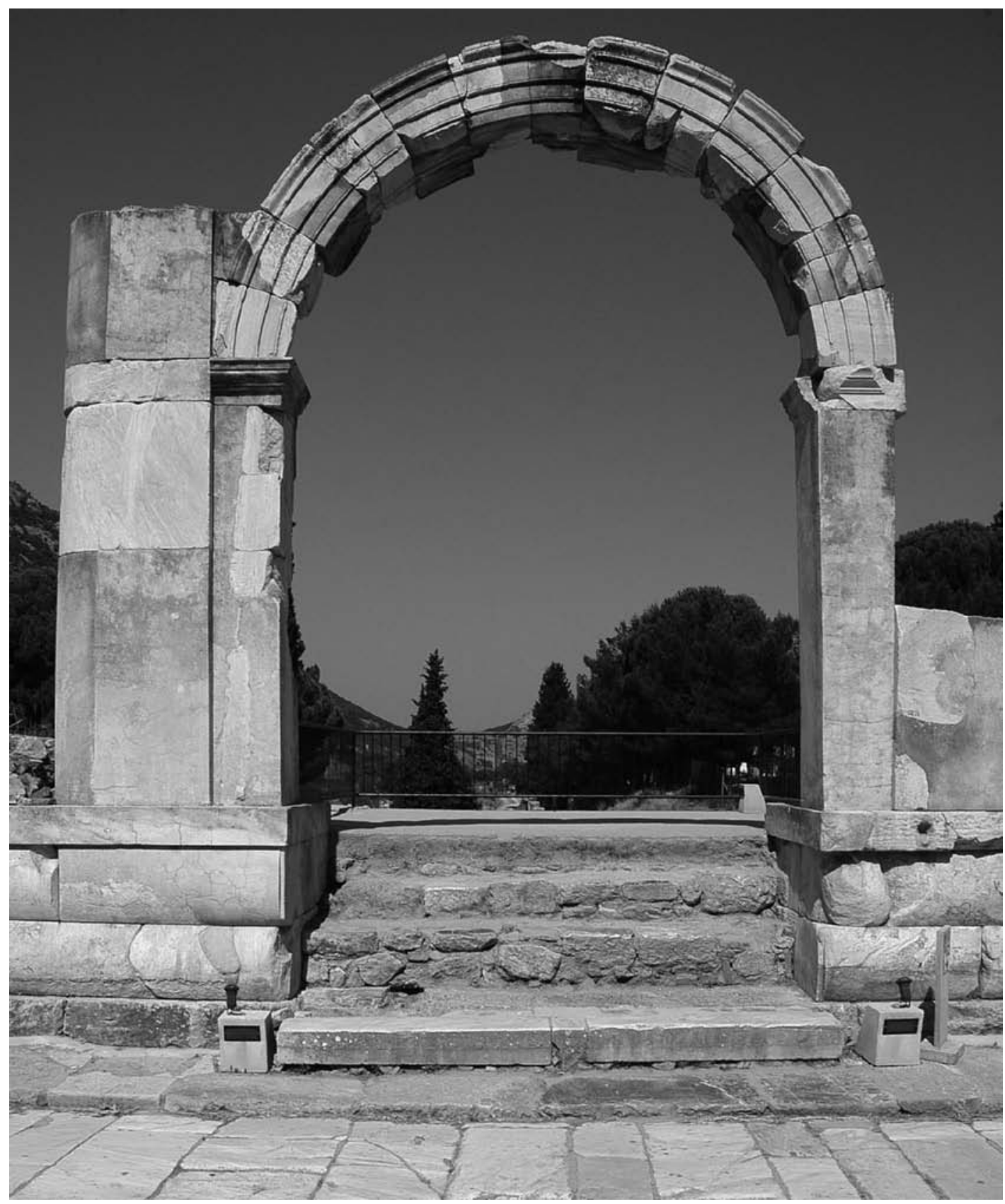

1 >Neronische Halle . Zugang an der östlichen Langseite

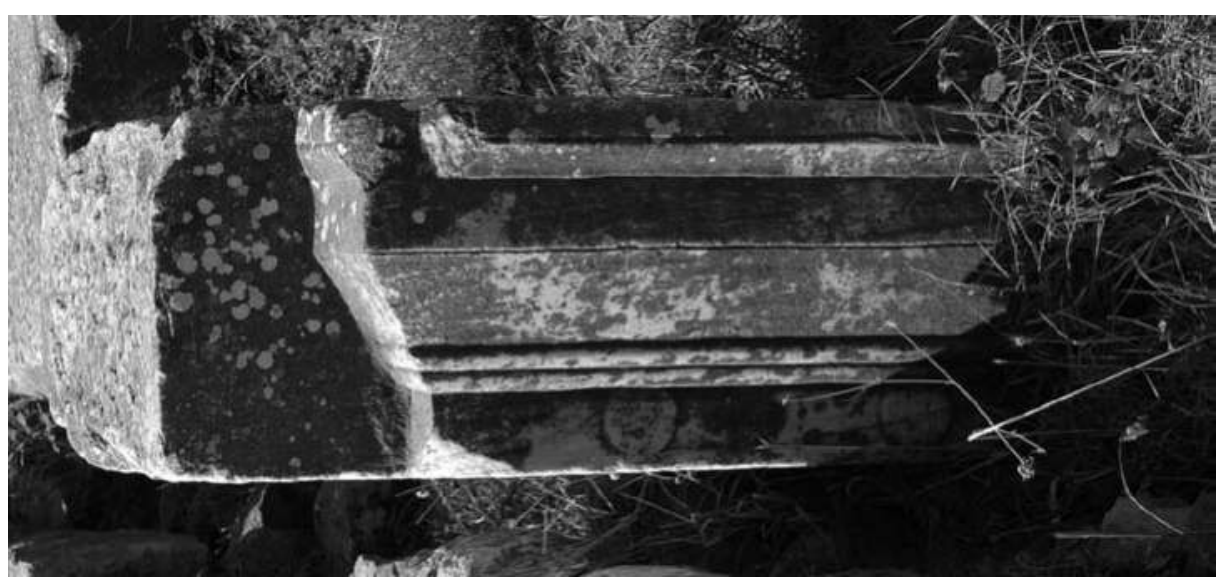

2 >Neronische Halleく. Dorisches `Antenkapitell am Zugang in der östlichen Langseite 


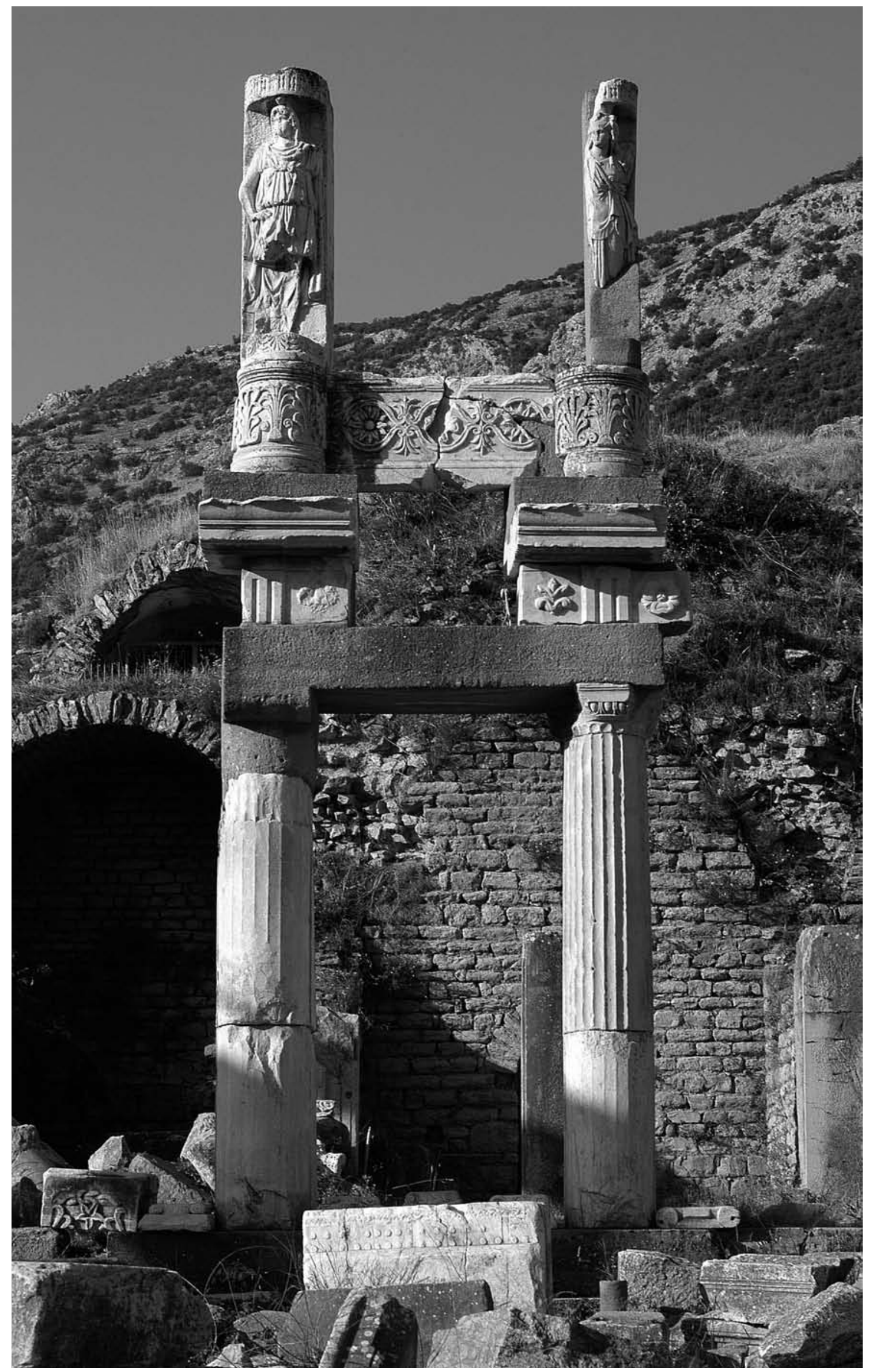

1 Domitiansterrasse. Architekturprobe der Fassade 
Tafel 235

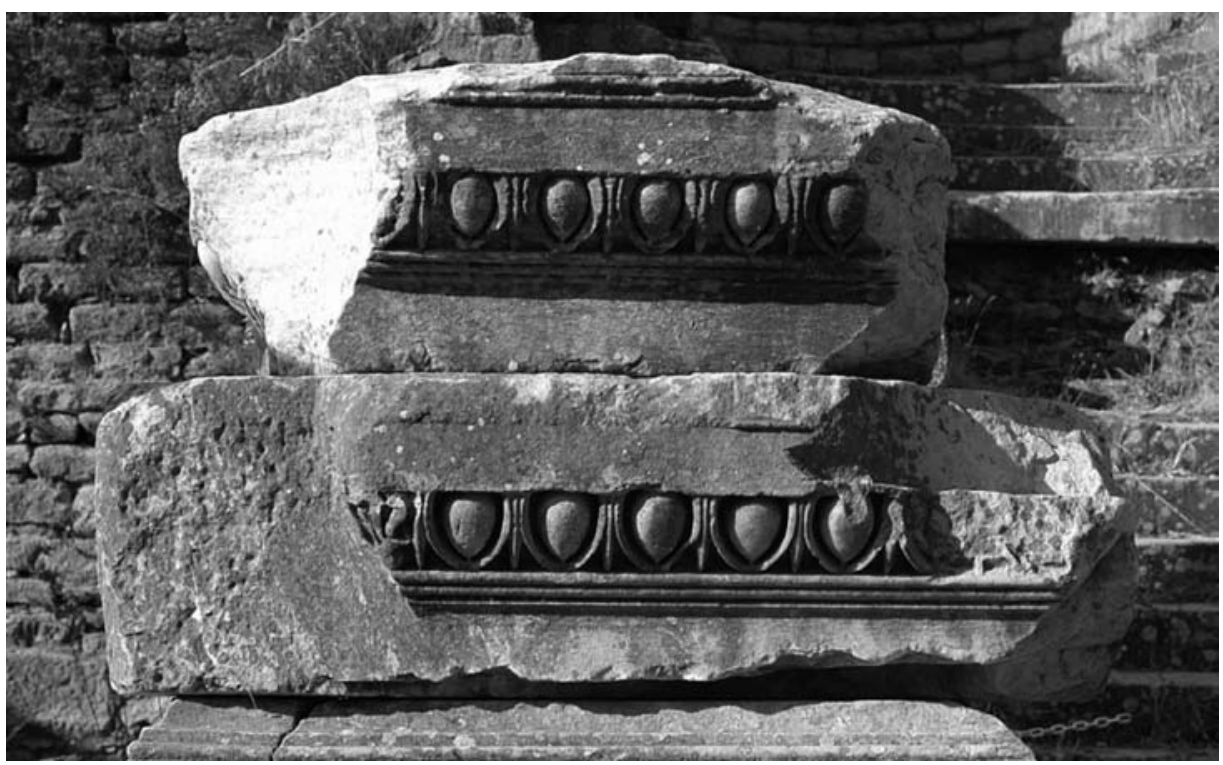

1 Domitiansterrasse. Dorisierende Kapitelle vom Untergeschoss der Fassade

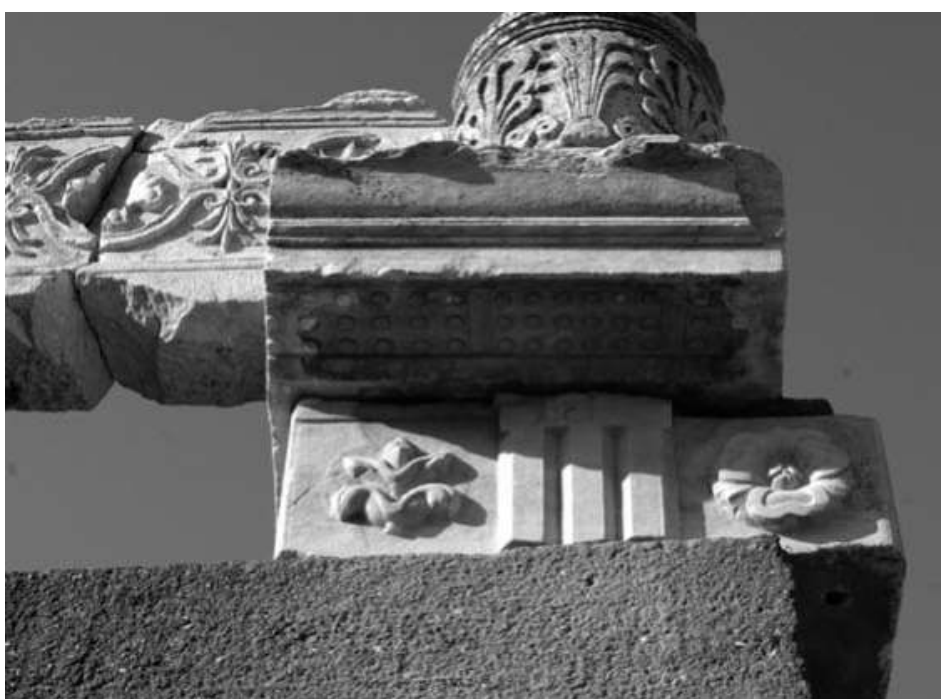

2 Domitiansterrasse. Dorisches Gebälk des Untergeschosses der Fassade

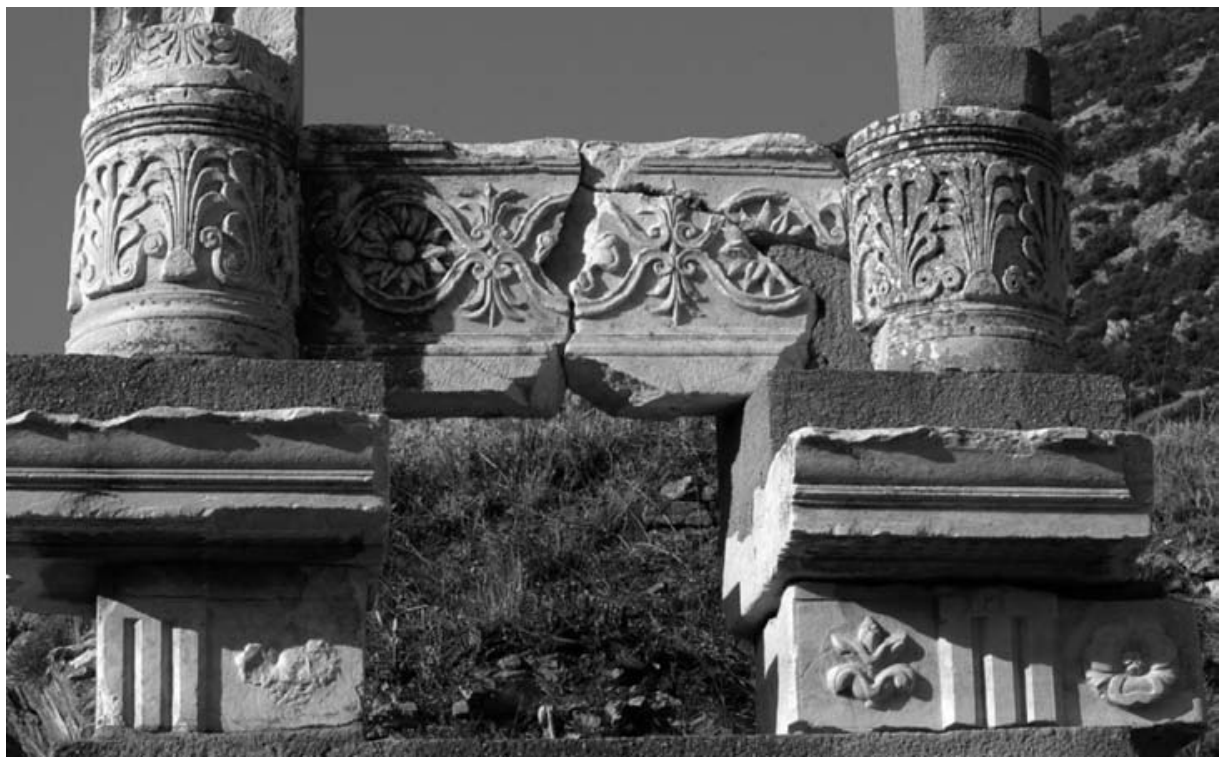

3 Domitiansterrasse. Sockelzone des mittleren Fassadengeschosses 


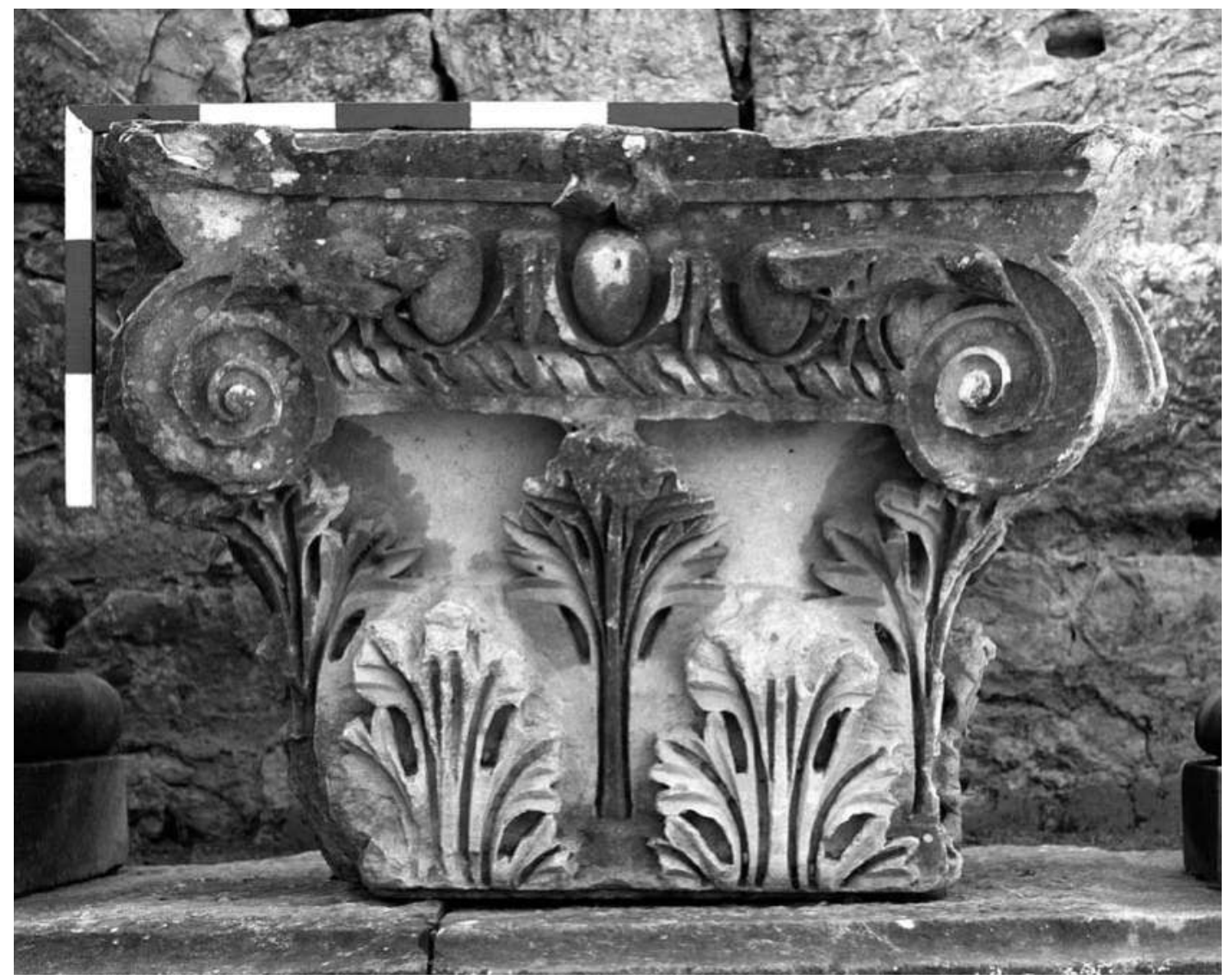

1 Vediusgymnasium. Pfeilerkapitell aus dem `Marmorsaal

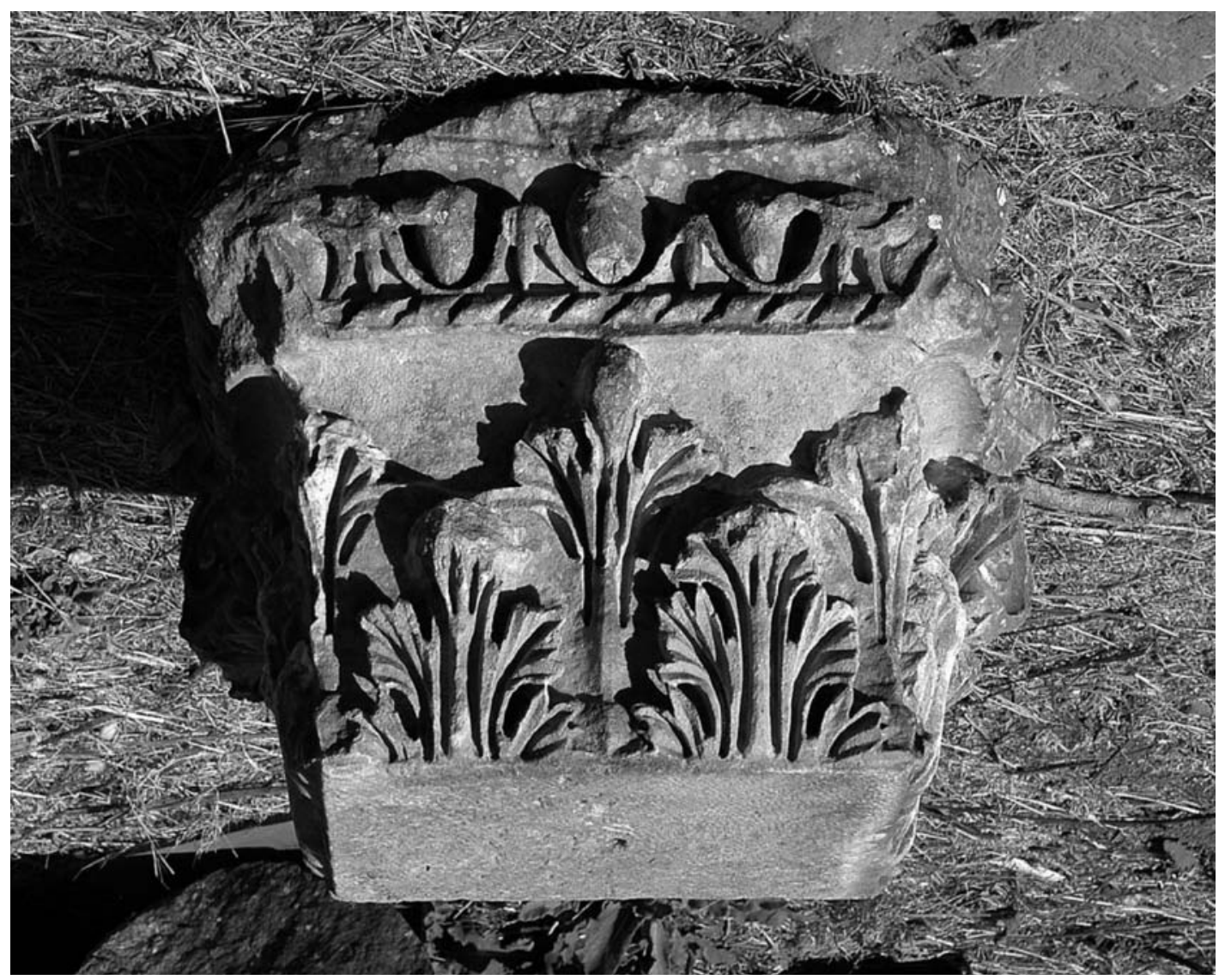

2 Ostgymnasium. Pfeilerkapitell aus dem ^Marmorsaak 

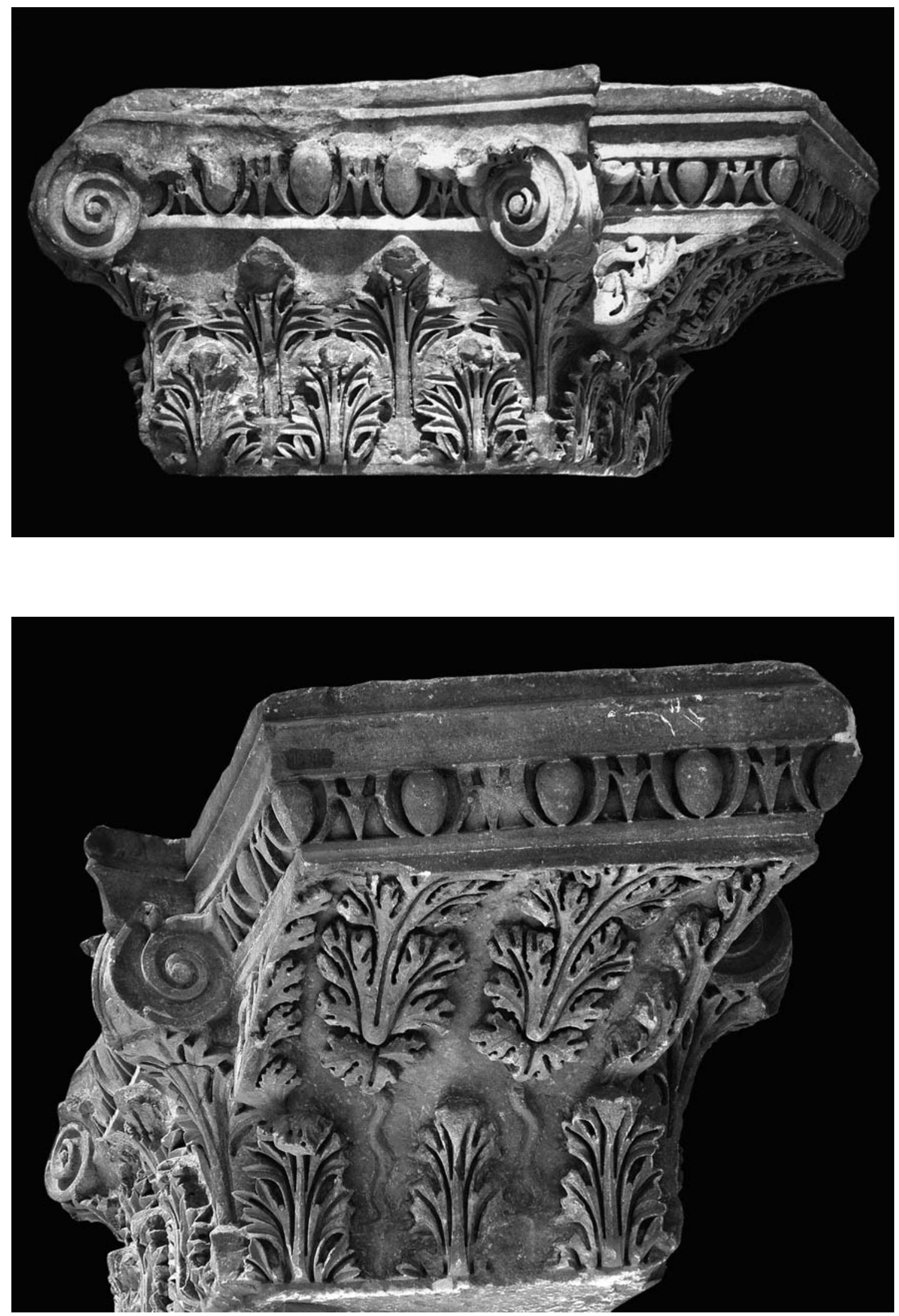

1. 2 >Südliches Hafentor`. Pfeilerkapitell 


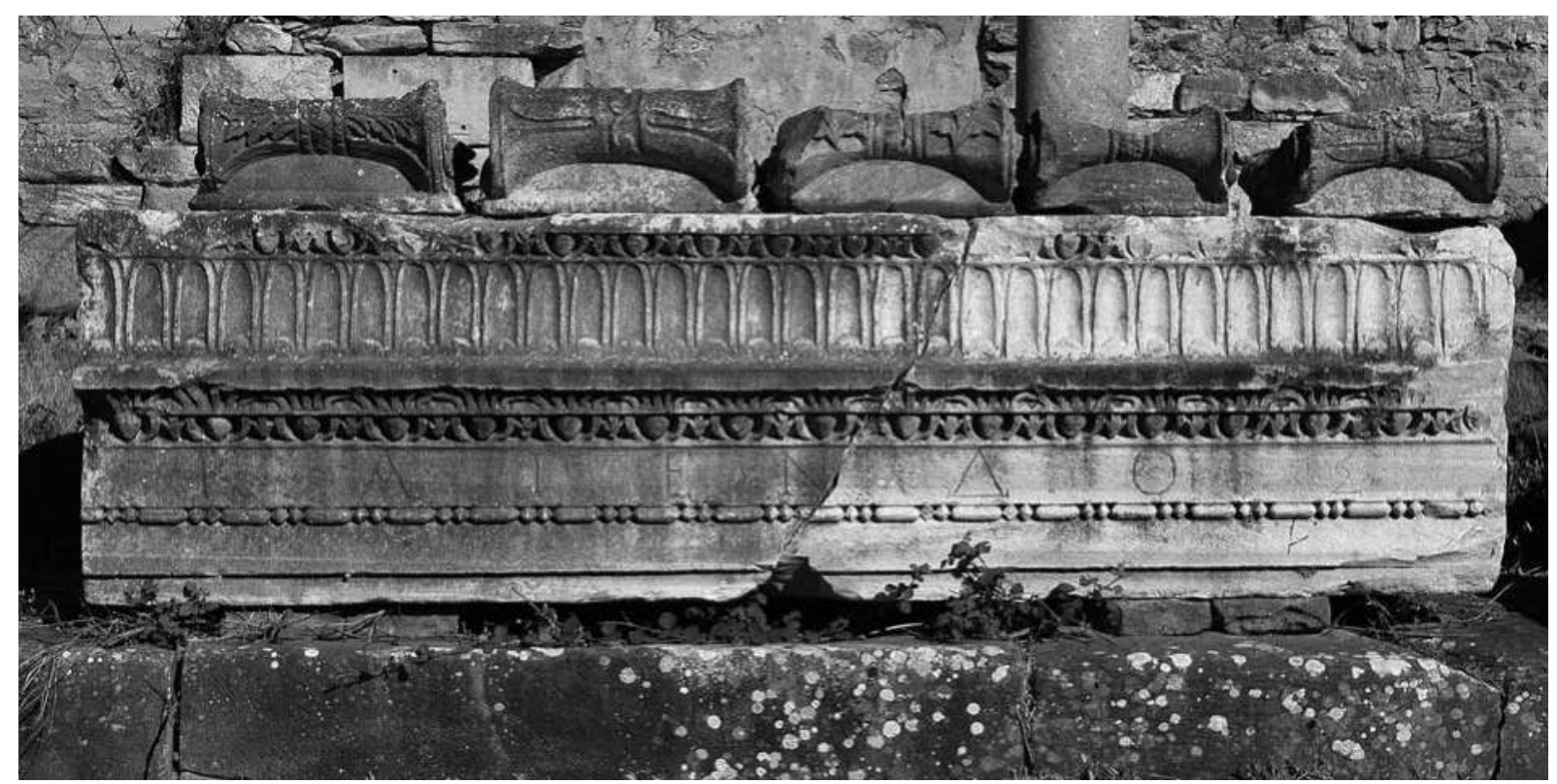

1 Tetragonos Agora. Architrav

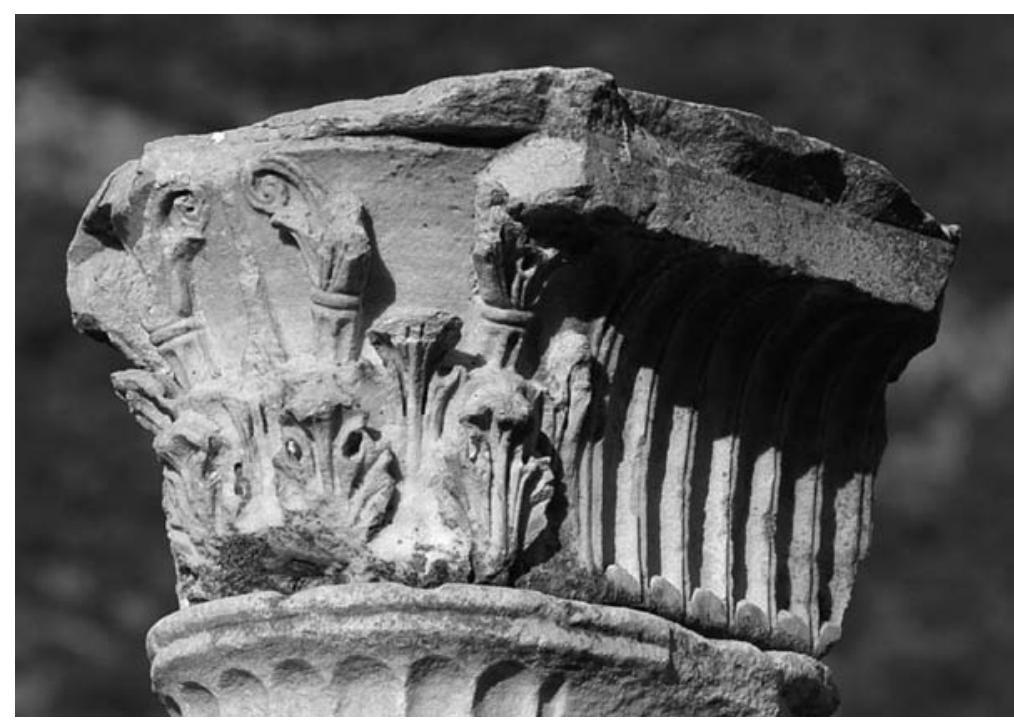

2 Basilike Stoa auf dem `Staatsmarkt $`$. Halbsäulen-Pfeilerkapitell vom Obergeschoss

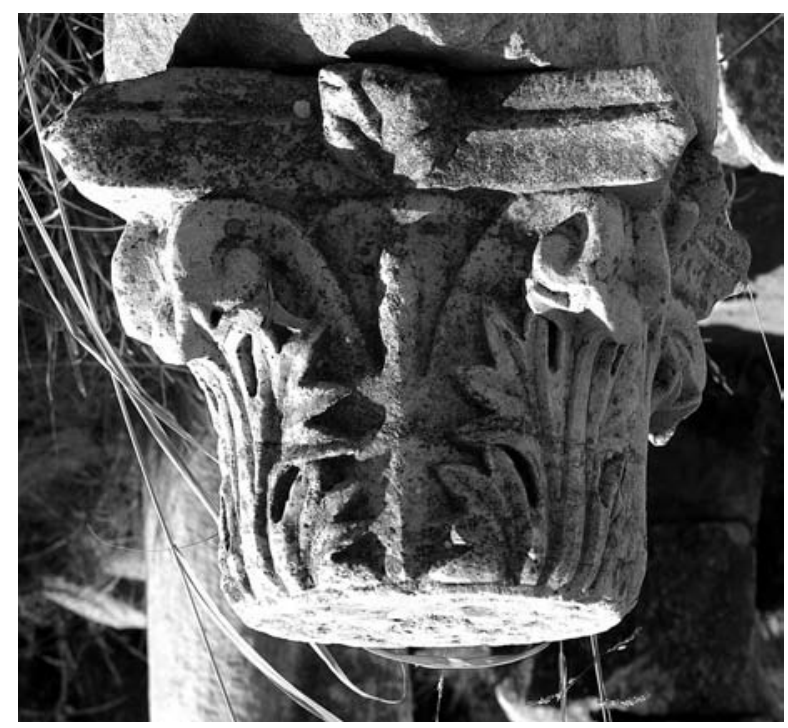

3 Domitiansplatz. Kapitell 
Tafel 239

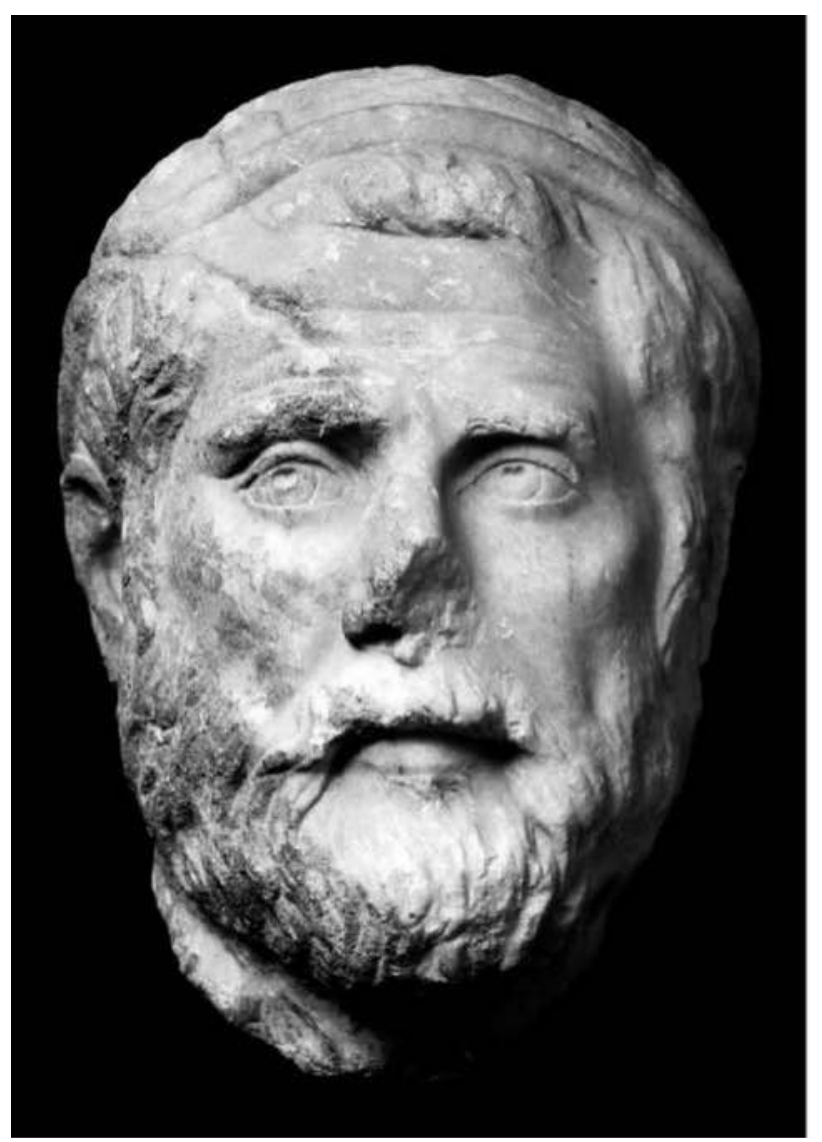

1 Männlicher Porträtkopf SK 5

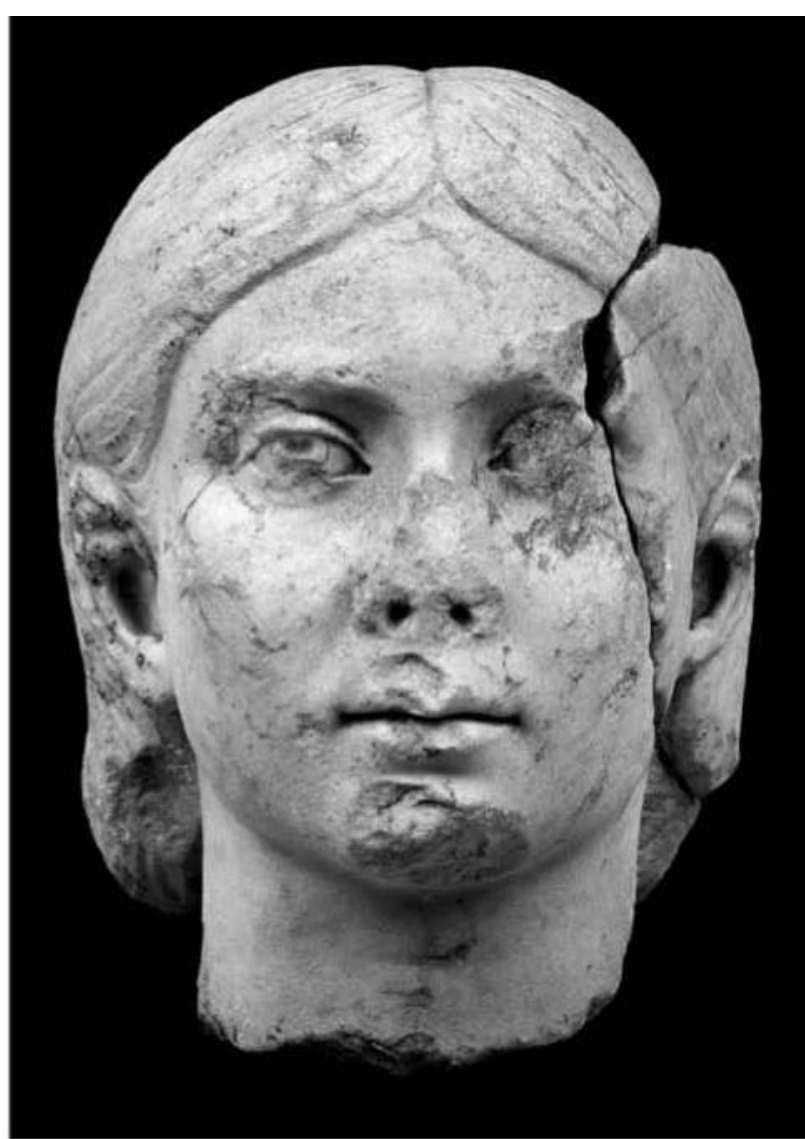

2 Porträt einer jungen Frau SK 6

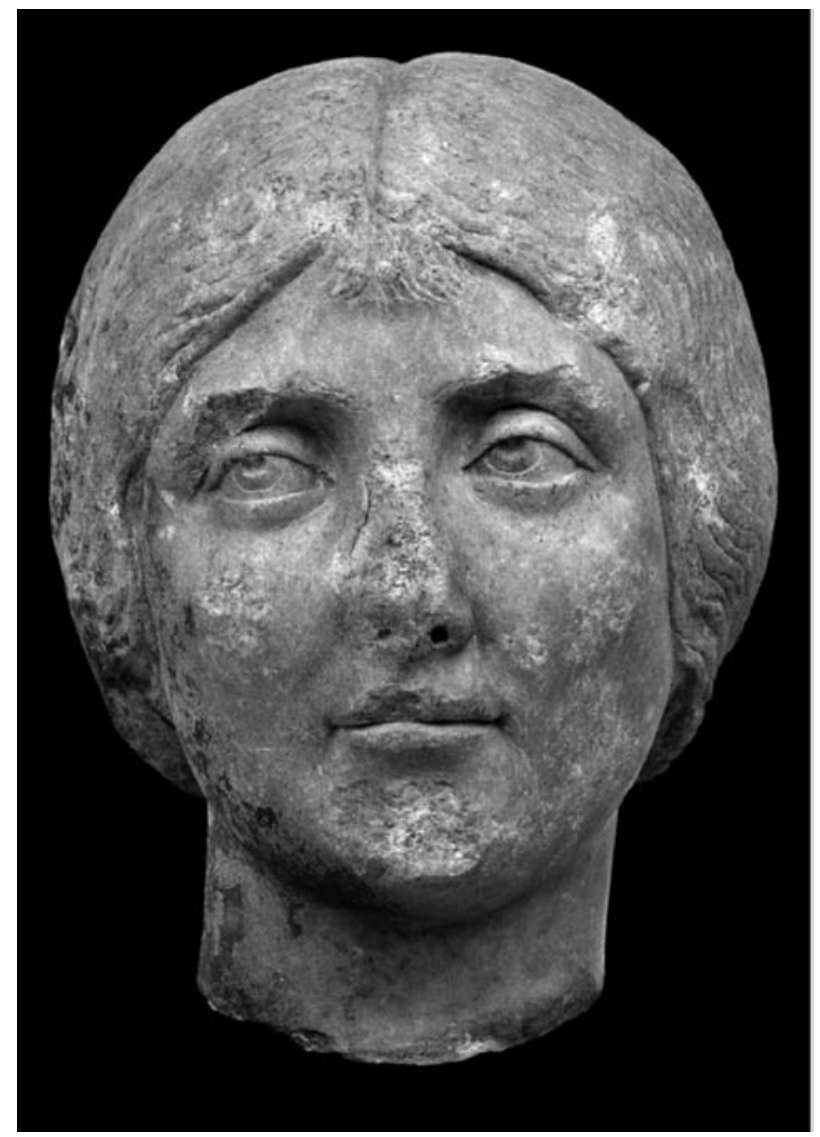

3 Porträt einer Frau SK 7 


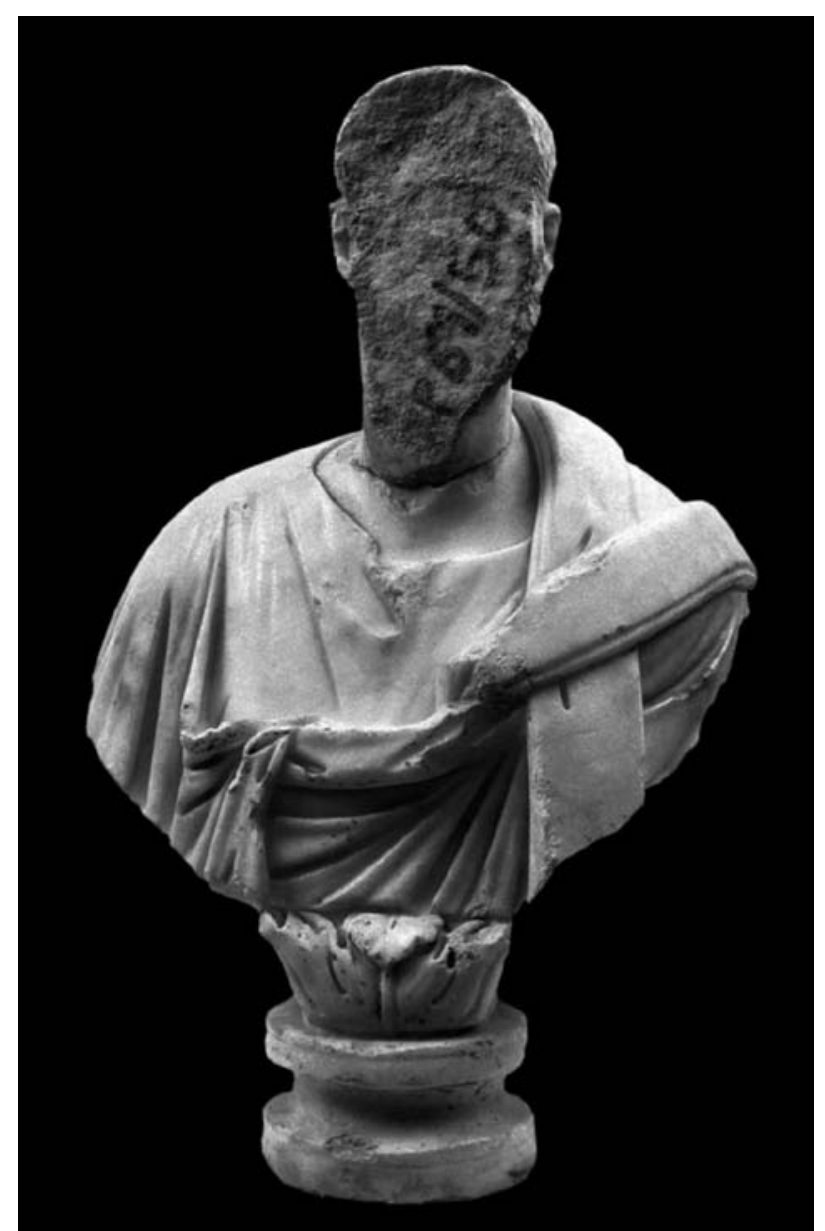

1 Männliche Porträtbüste SK 8

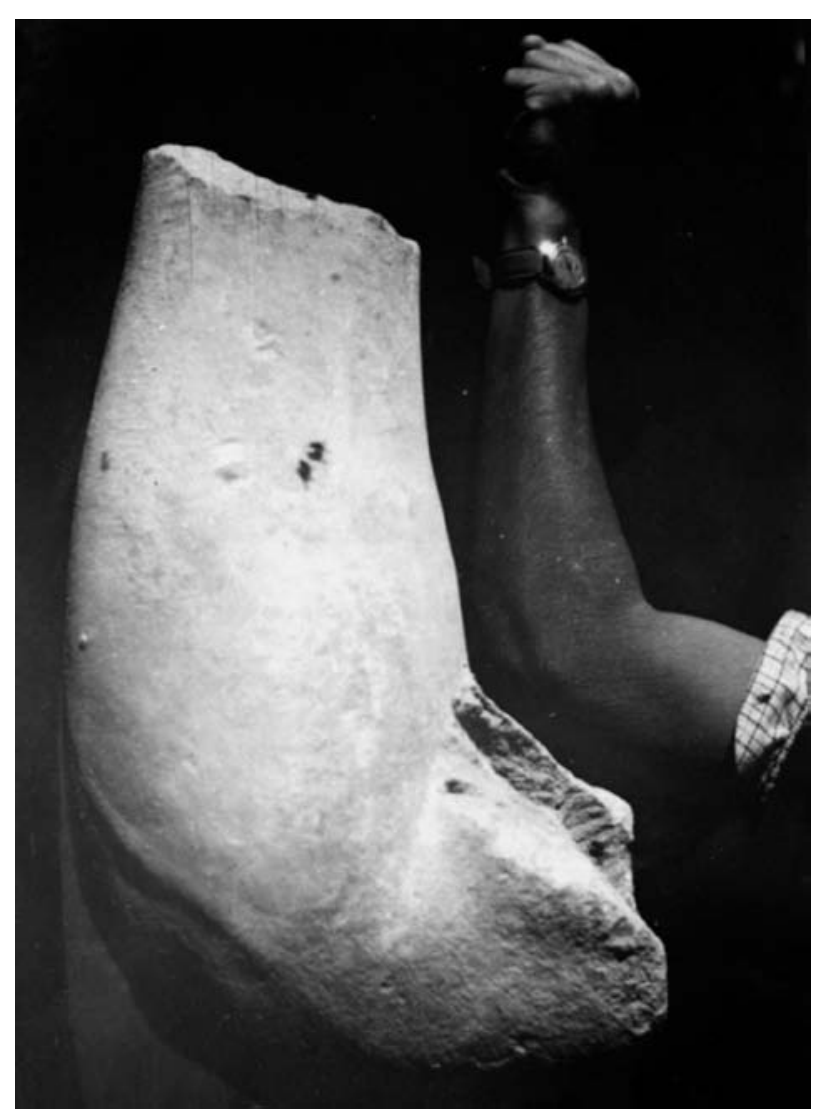

3 Linker Unterarm einer männlichen Kolossalstatue SK 11

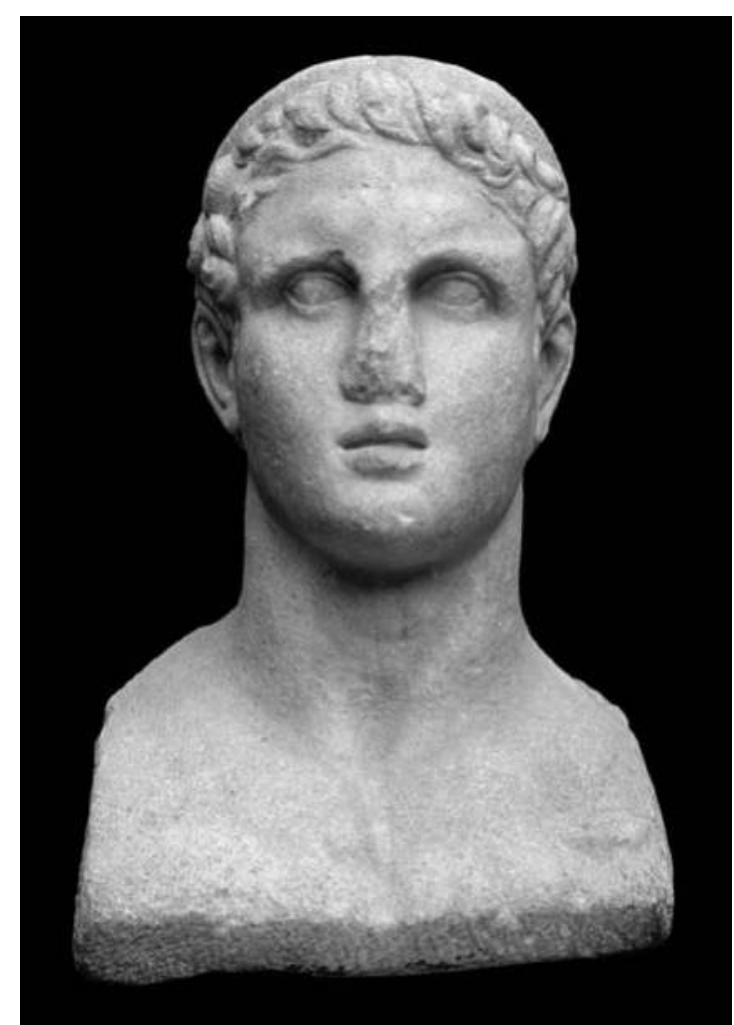

2 Männliche, hermenförmige Büste SK 9

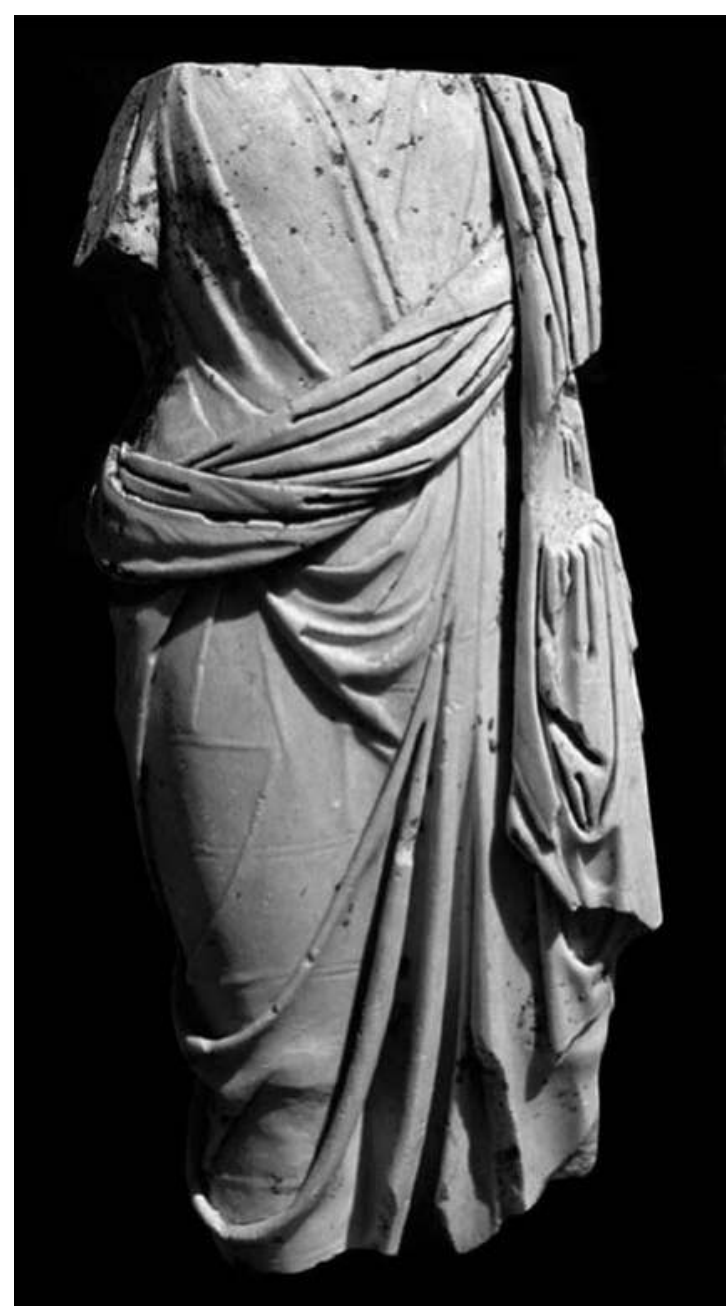

4 Torso einer männlichen Ehrenstatue SK 10 


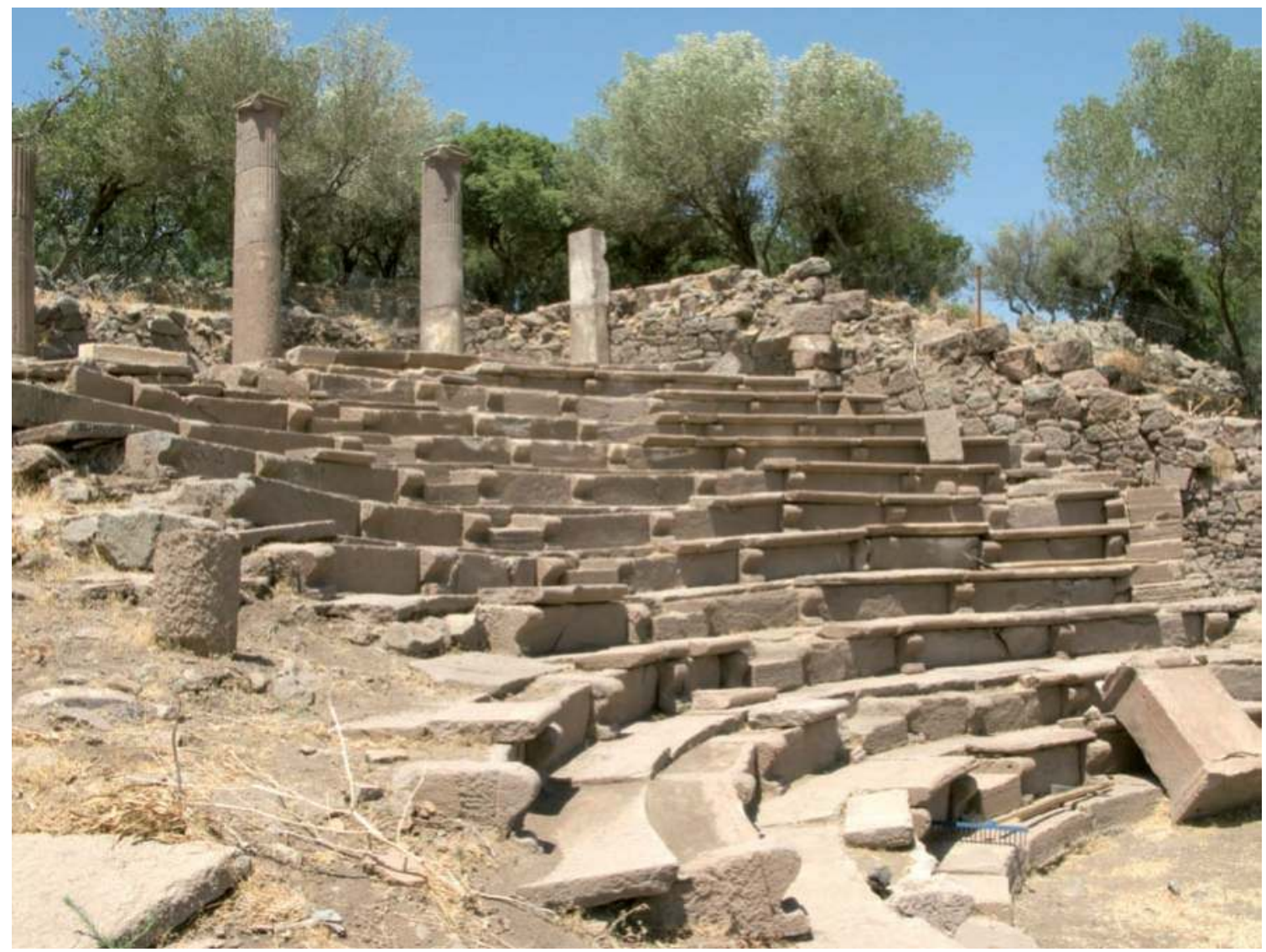

1 Bouleuterion von Aigai

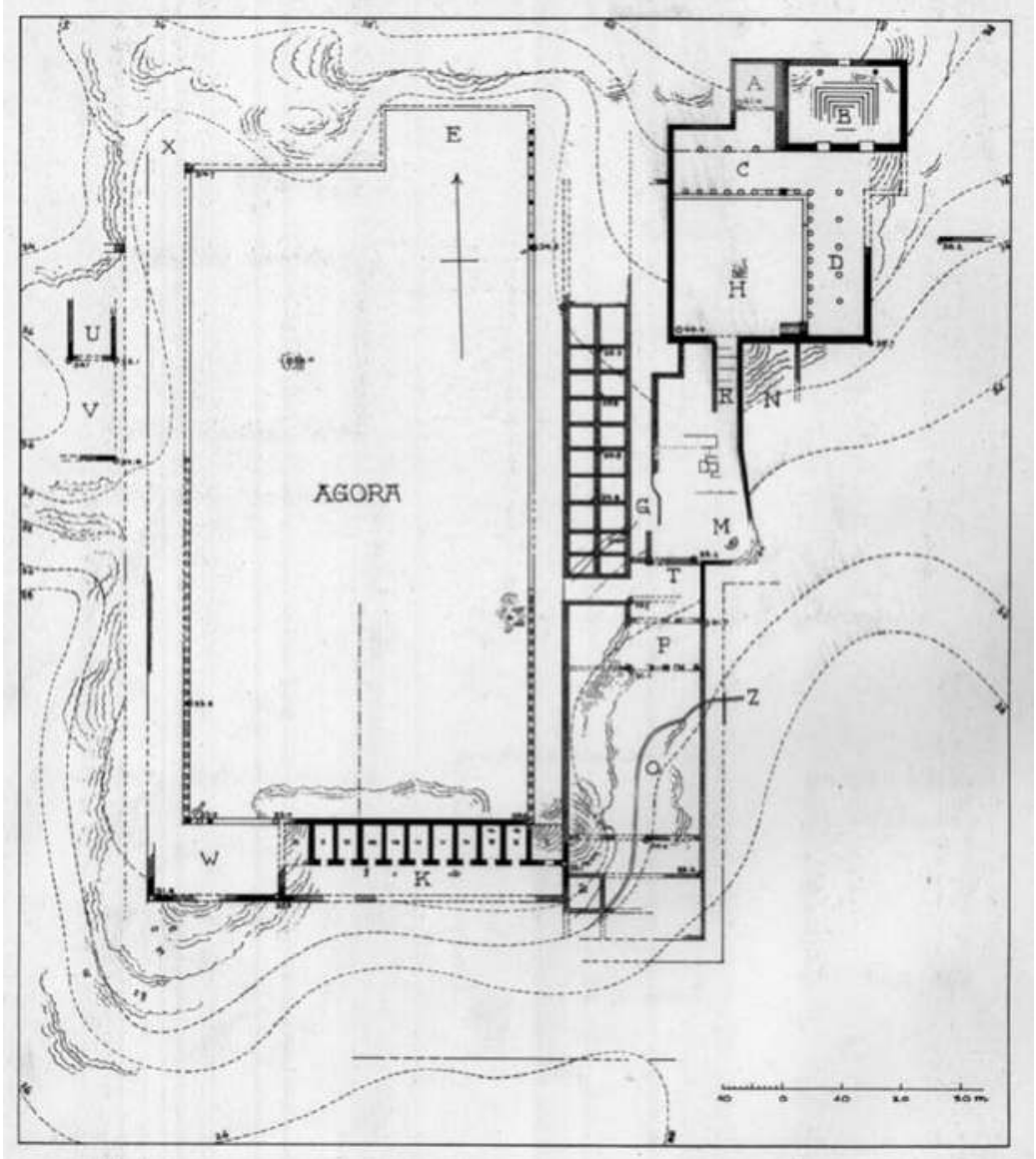

2 Übersichtsplan der Agora von Herakleia am Latmos 
Tafel 242
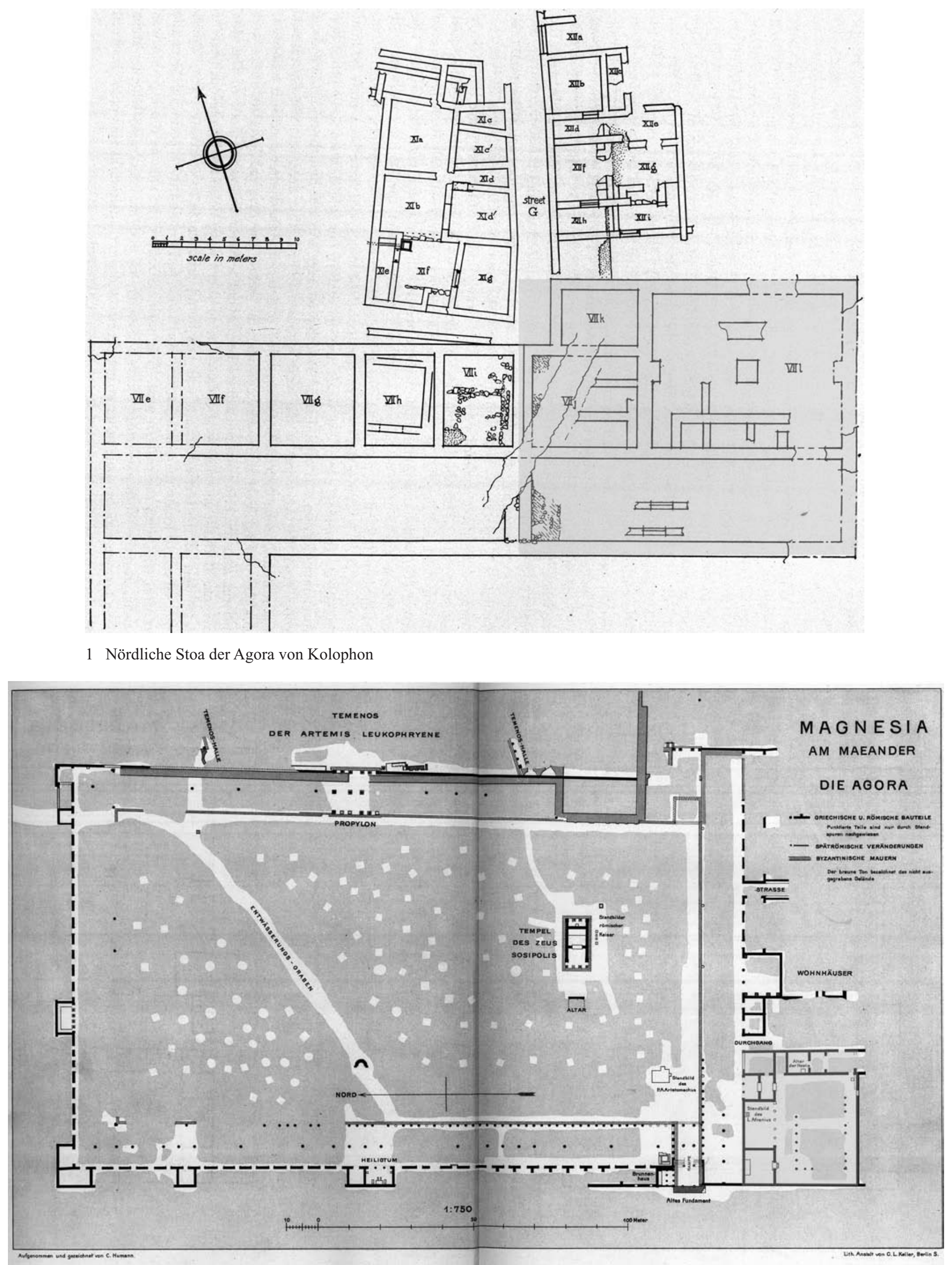

2 Übersichtsplan der Agora von Magnesia am Mäander 
Tafel 243

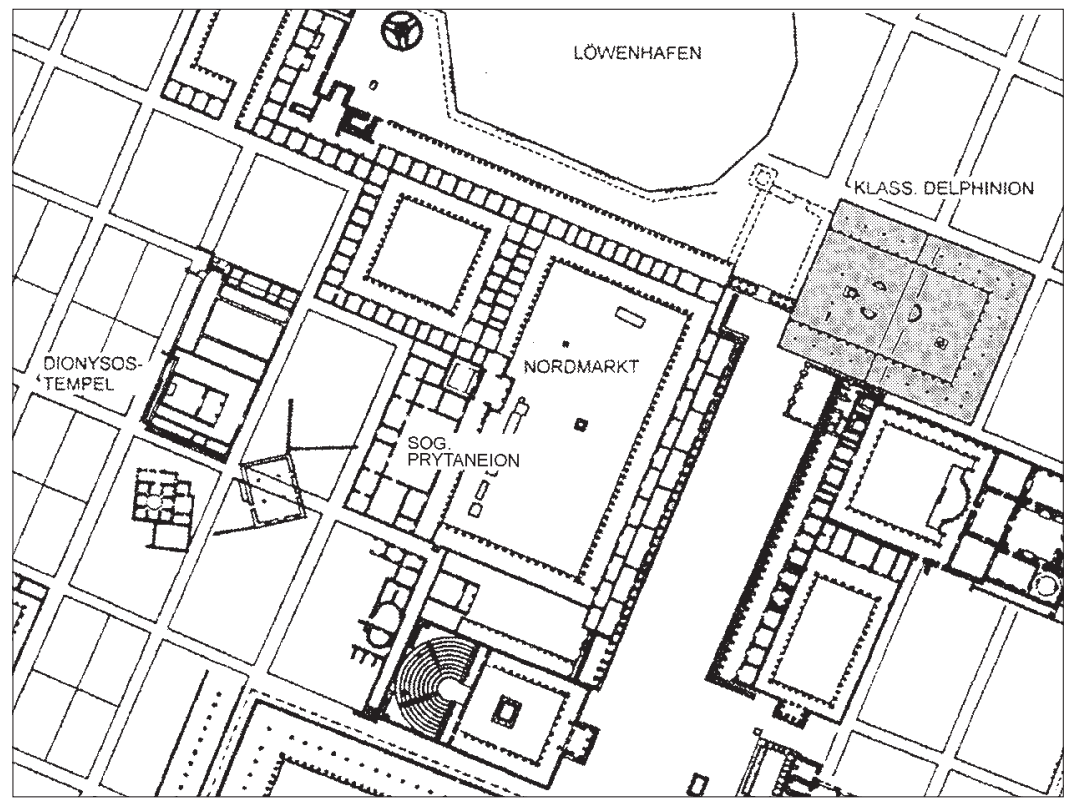

1 Stadtplan von Milet

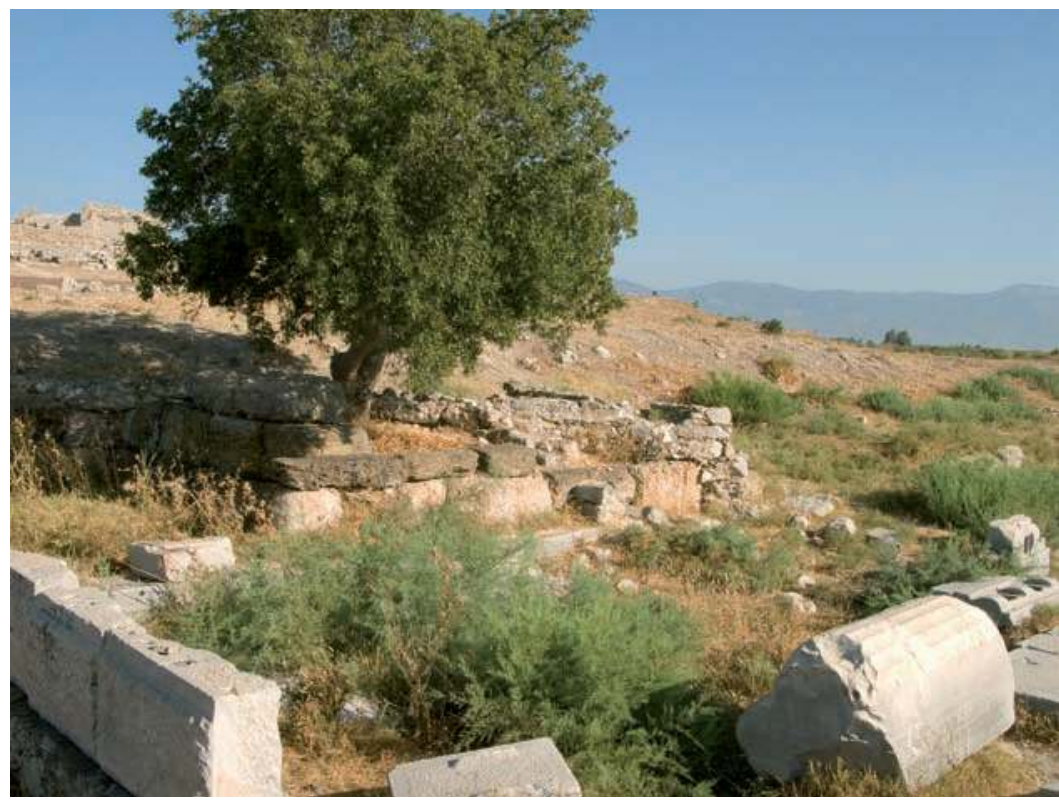

2 Sog. Prytaneion von Milet in der Südwestecke des Nordmarktes von Süden

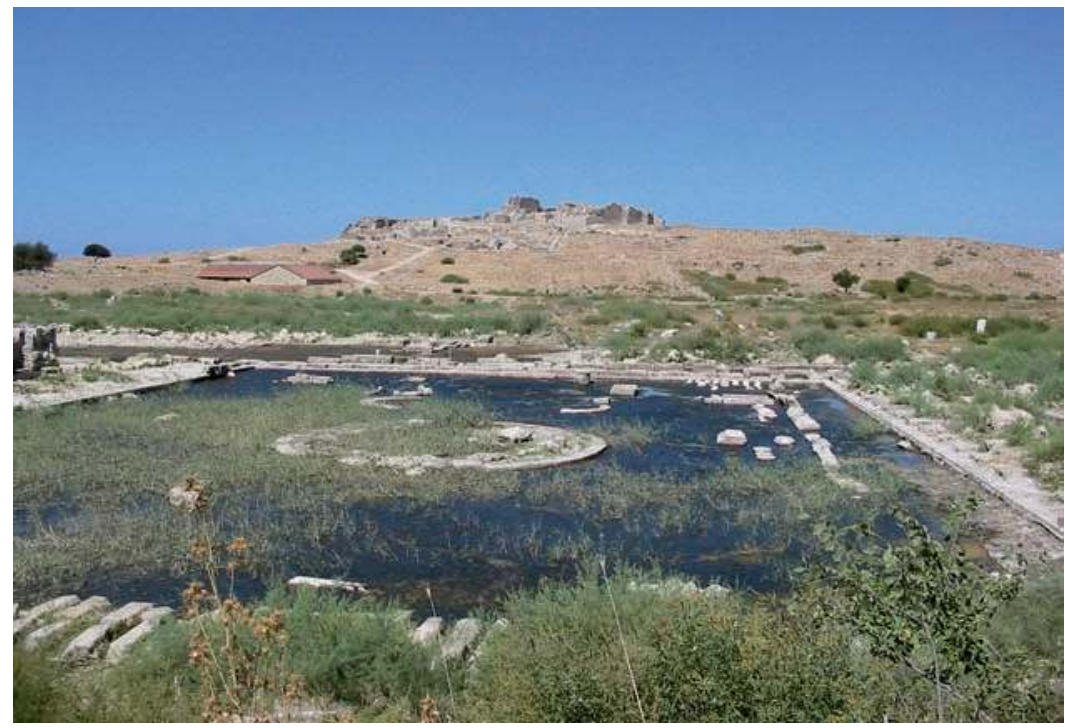


Tafel 244

1 Bau $\mathrm{H}$ von

Pergamon

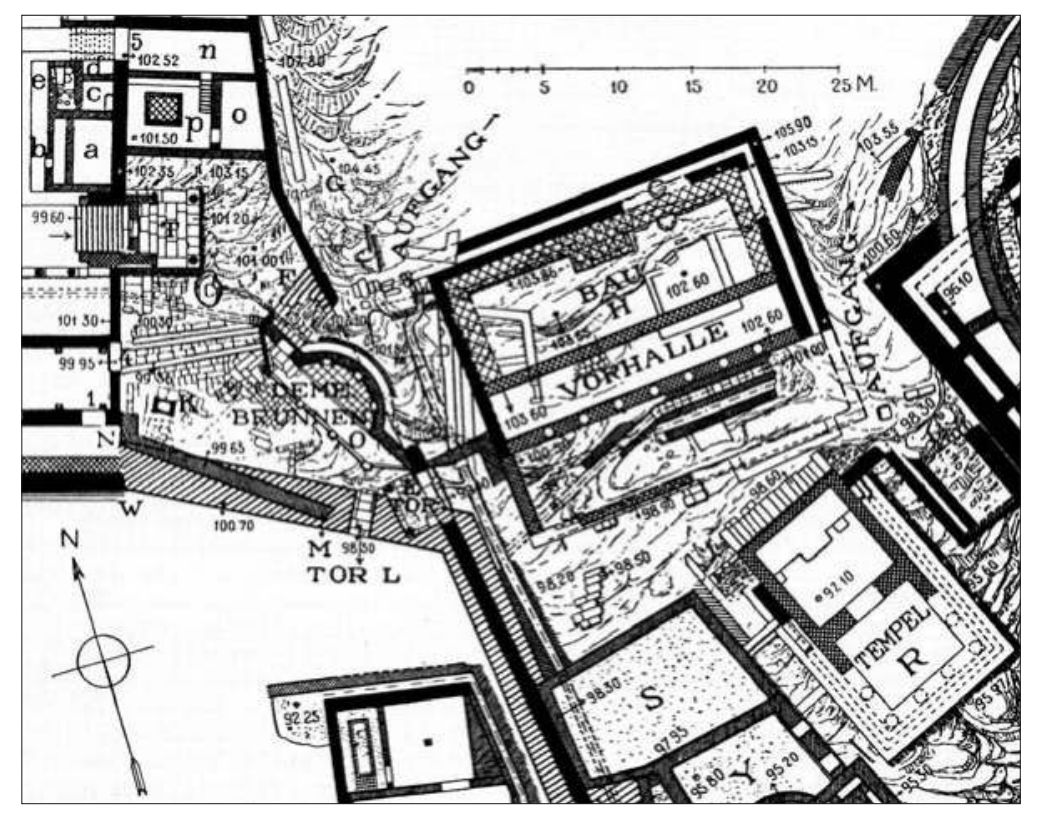

$2 \mathrm{Bau} \mathrm{H}$ von

Pergamon von

Westen

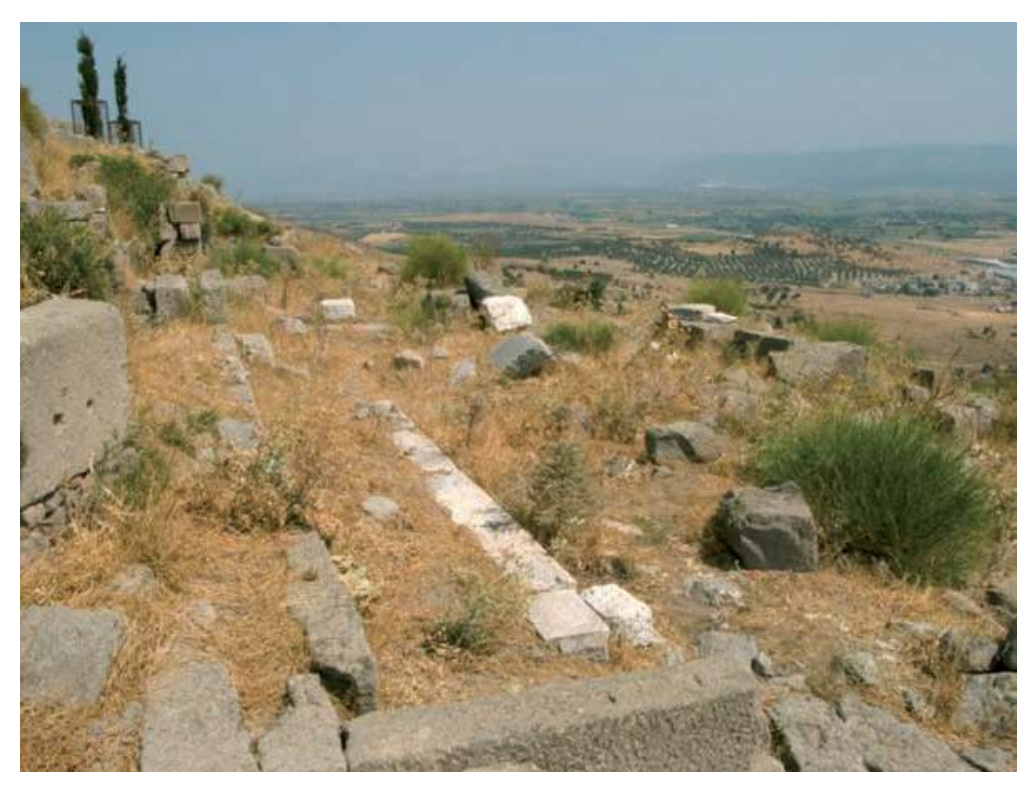

3 Bau $\mathrm{H}$ von

Pergamon von

Nordosten

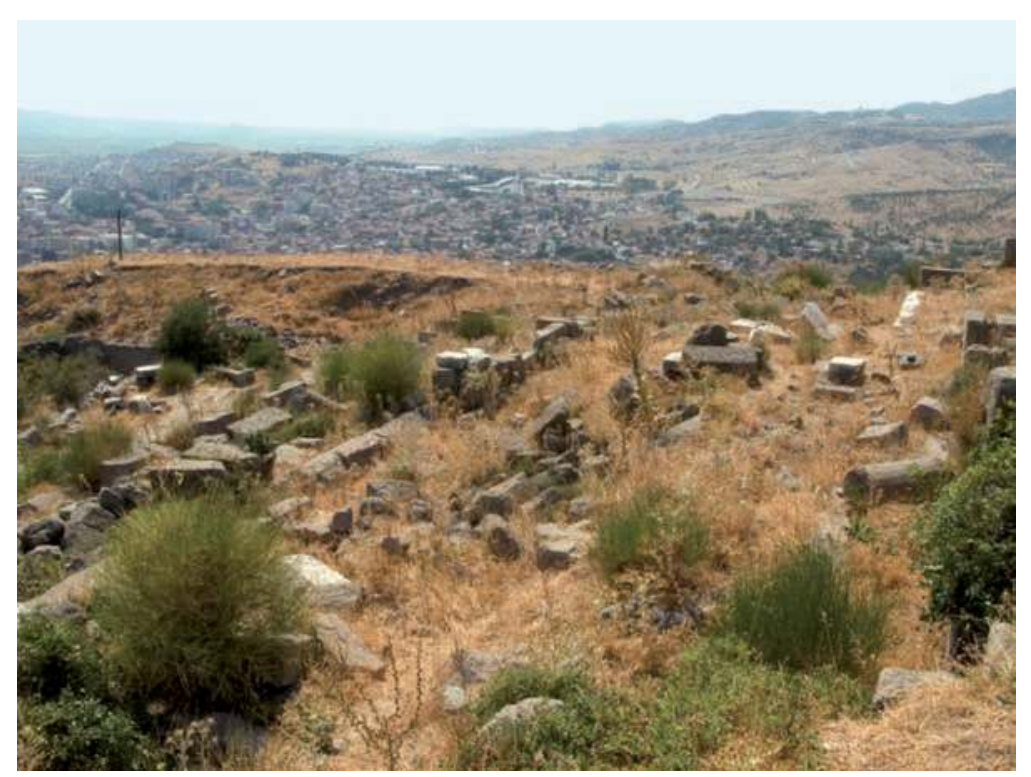


Tafel 245

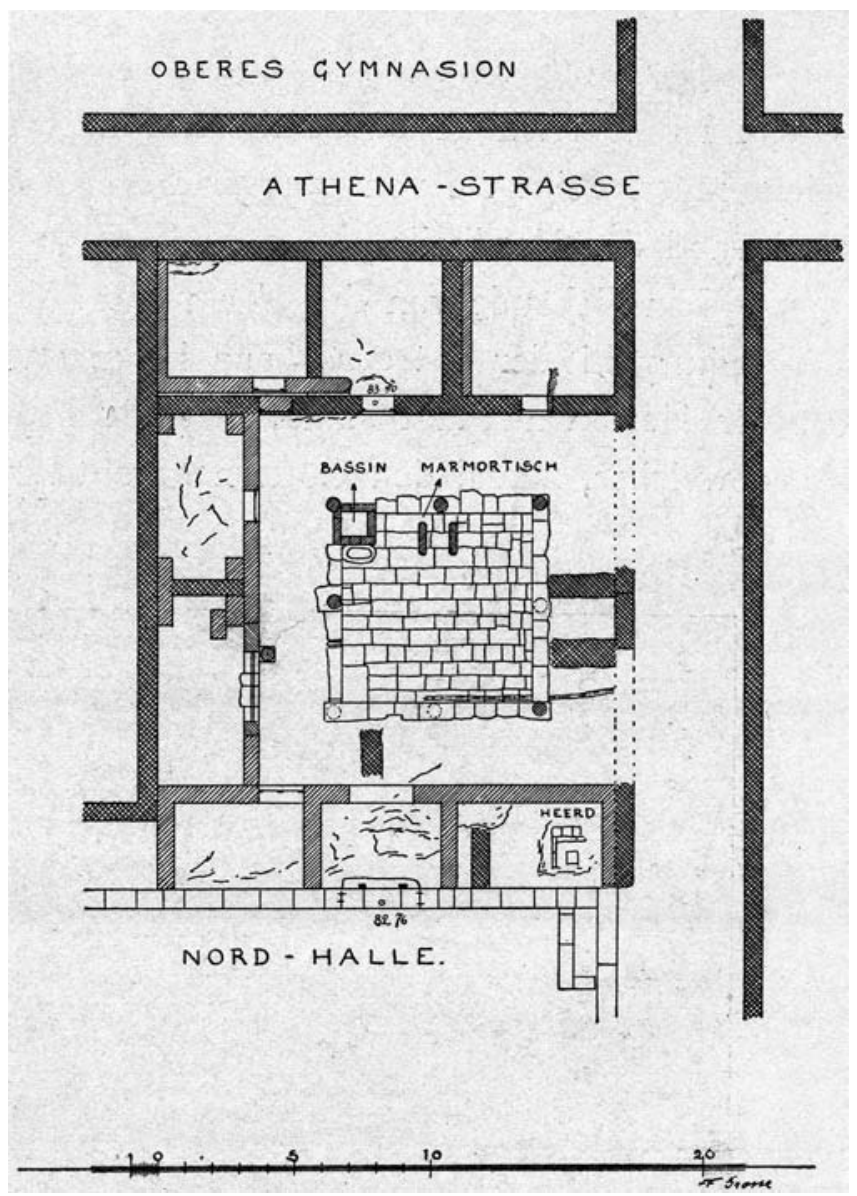

1 Grundriss des

Prytaneions von Priene

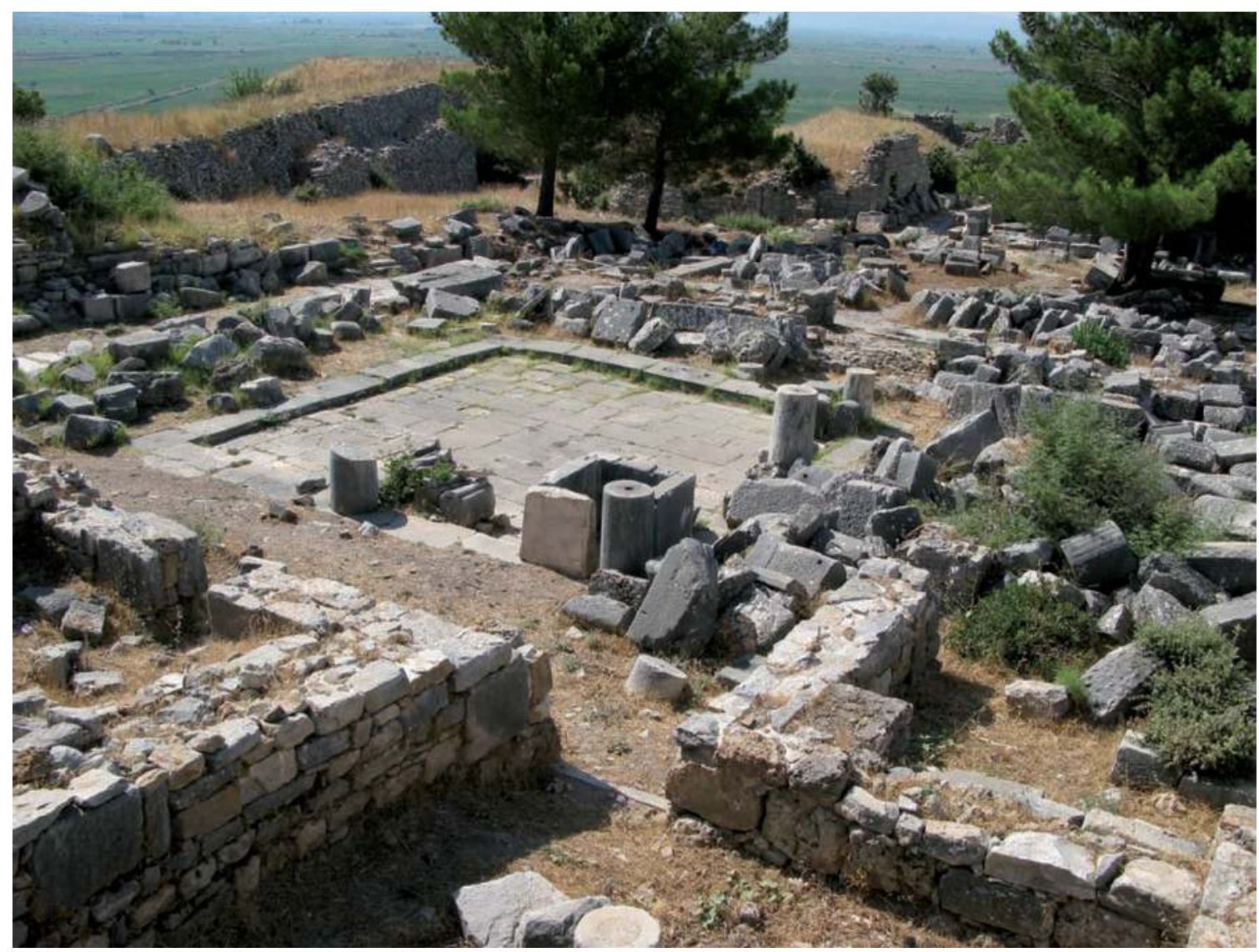

2 Prytaneion von Priene von Nordwesten 
Tafel 246

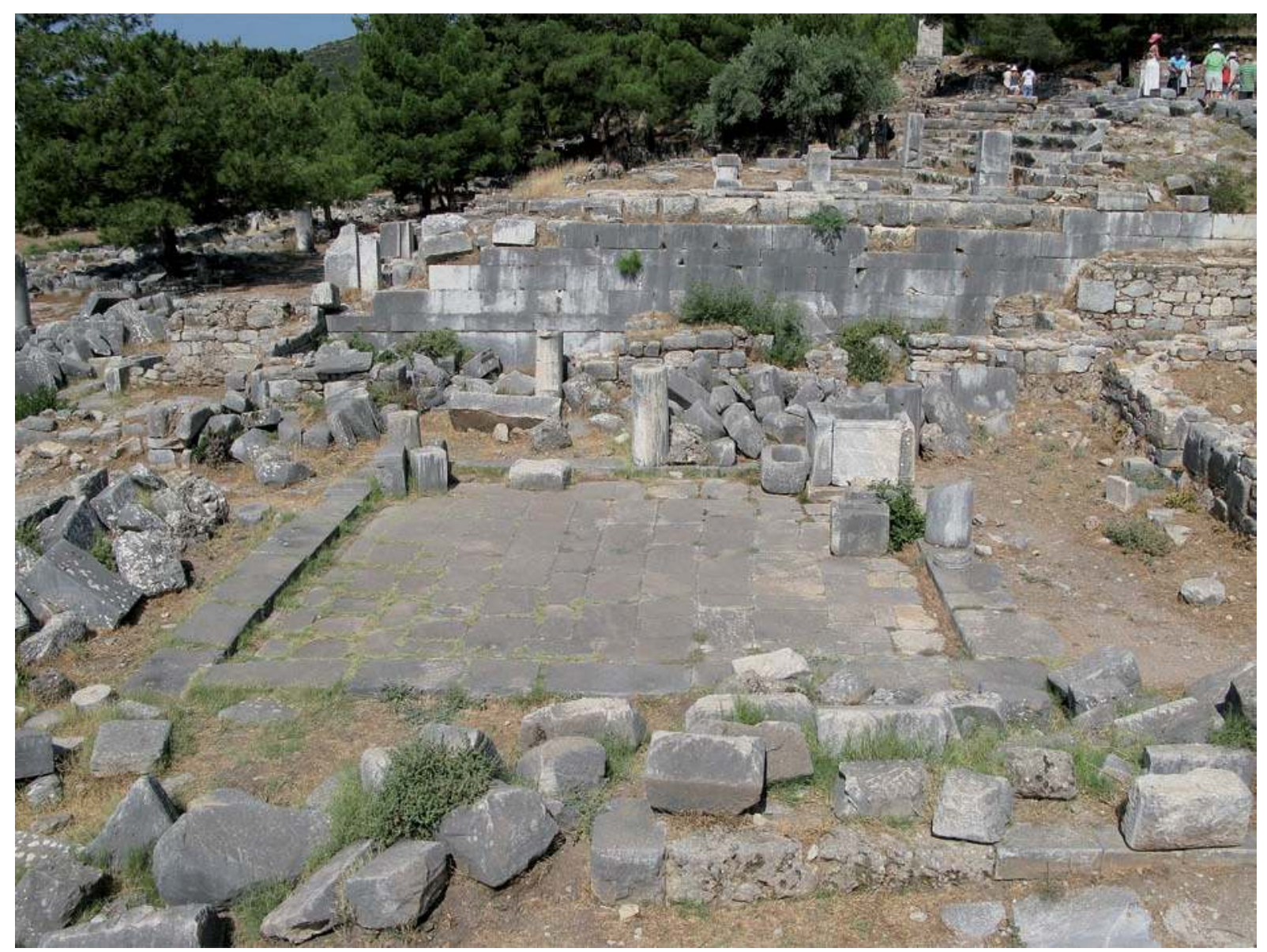

1 Prytaneion von Priene von Osten

2 Prytaneion von Priene. Ehreninschrift für M. Aurelius Tatianus

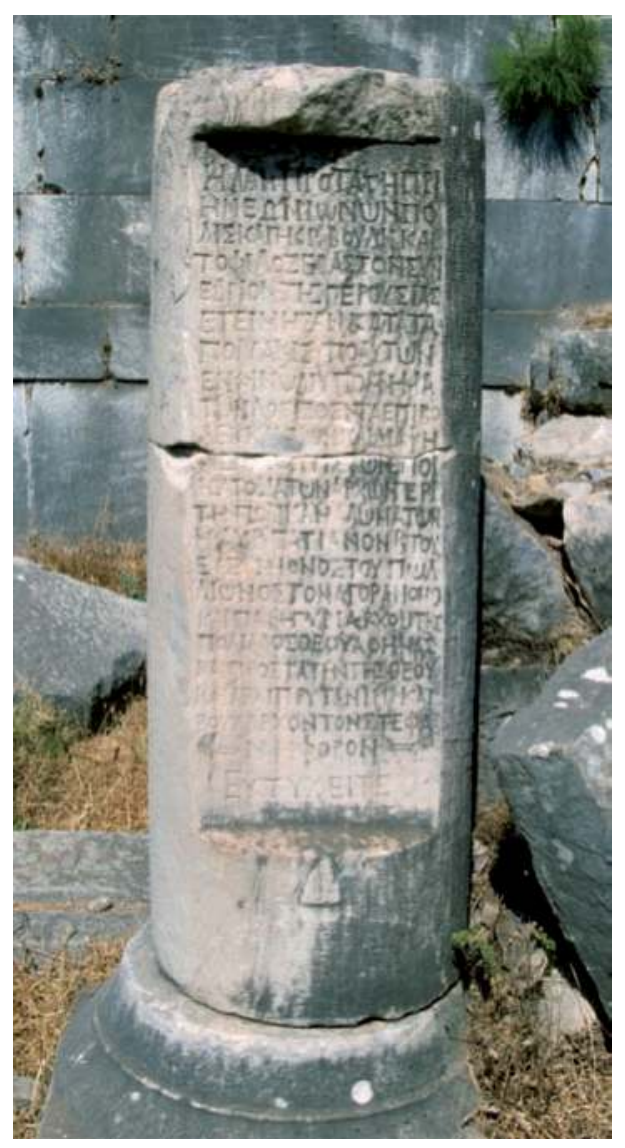


Tafel 247

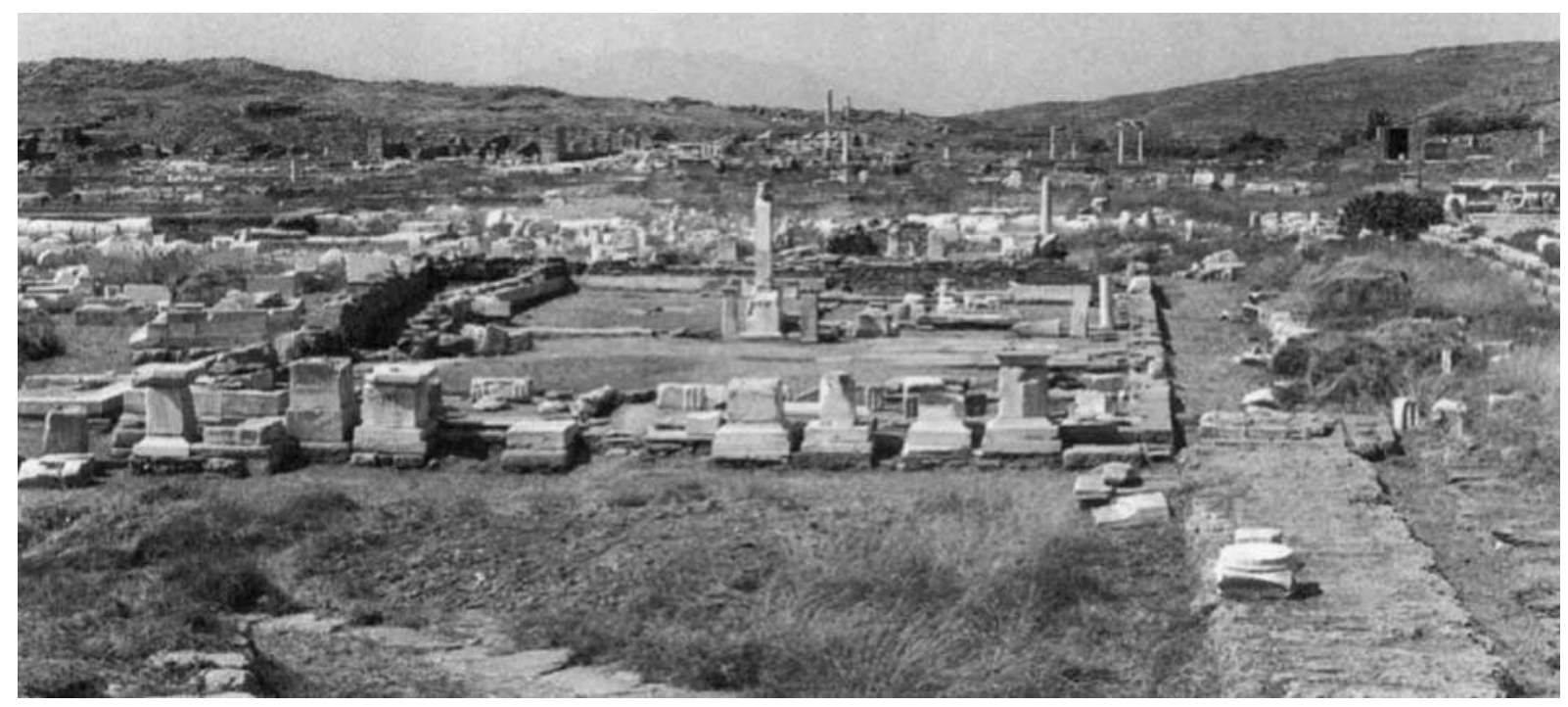

1 Prytaneion von Delos von Süden

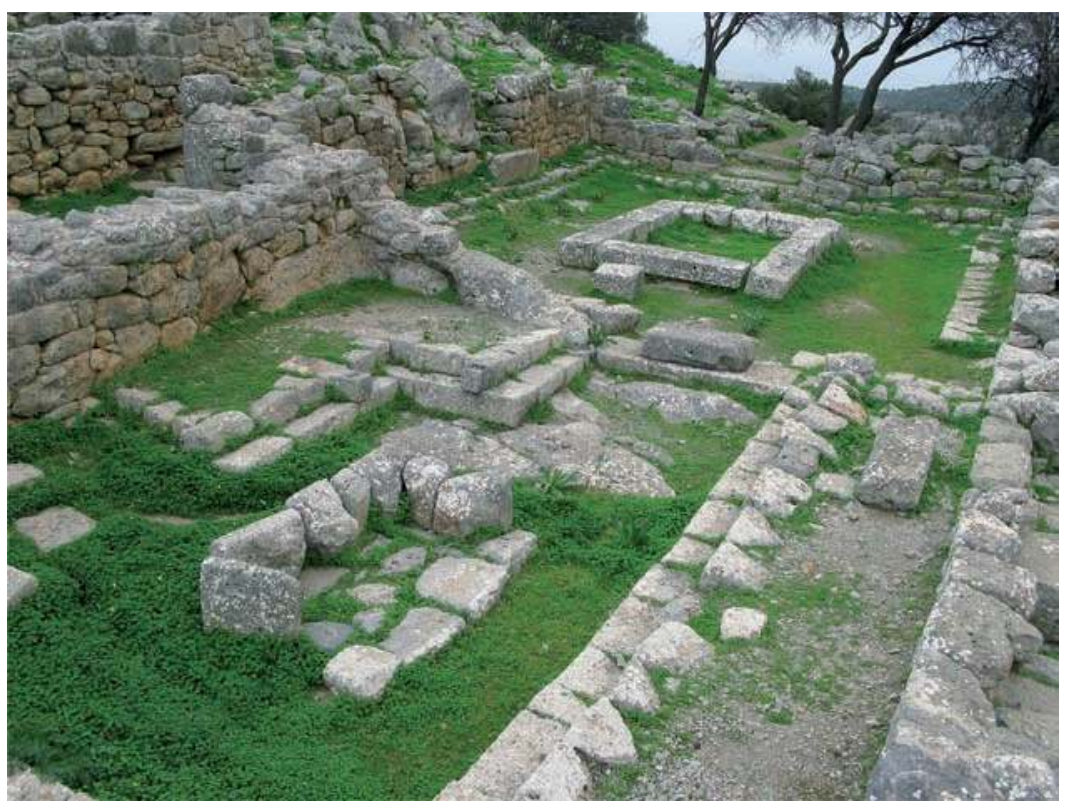

2 Prytaneion von Lato auf

Kreta von

Südwesten

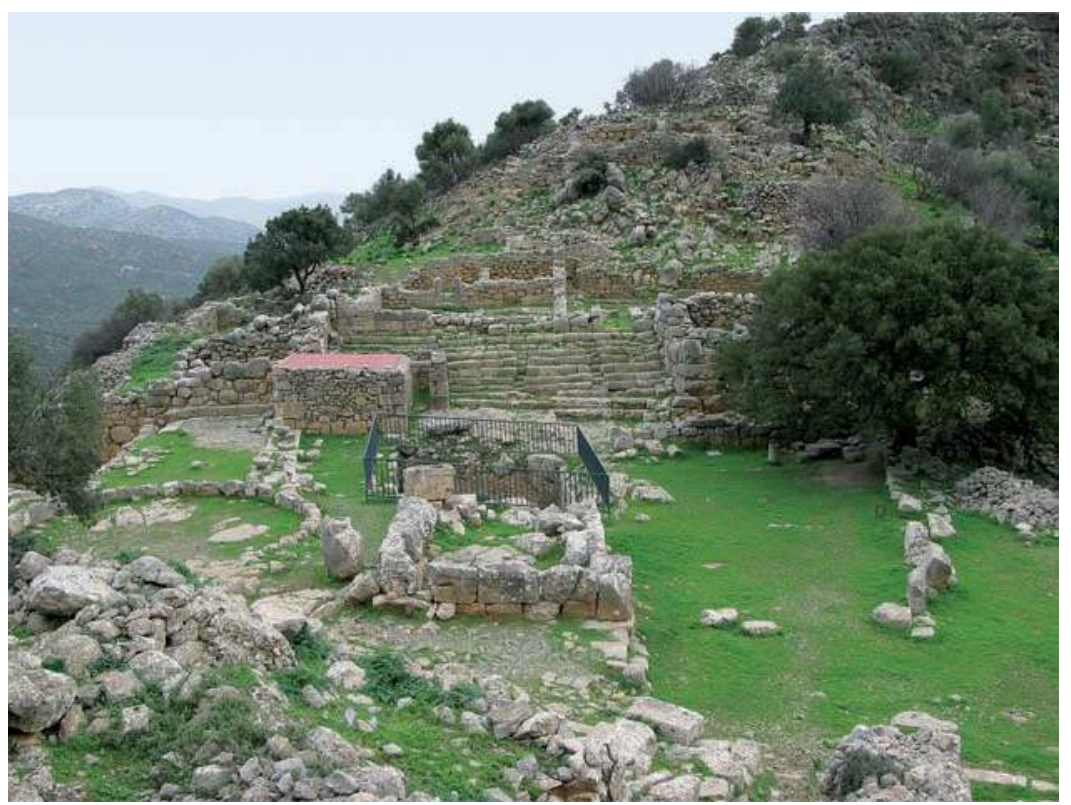

3 Aufgang zum Prytaneion

von Lato von

Süden 
Tafel 248

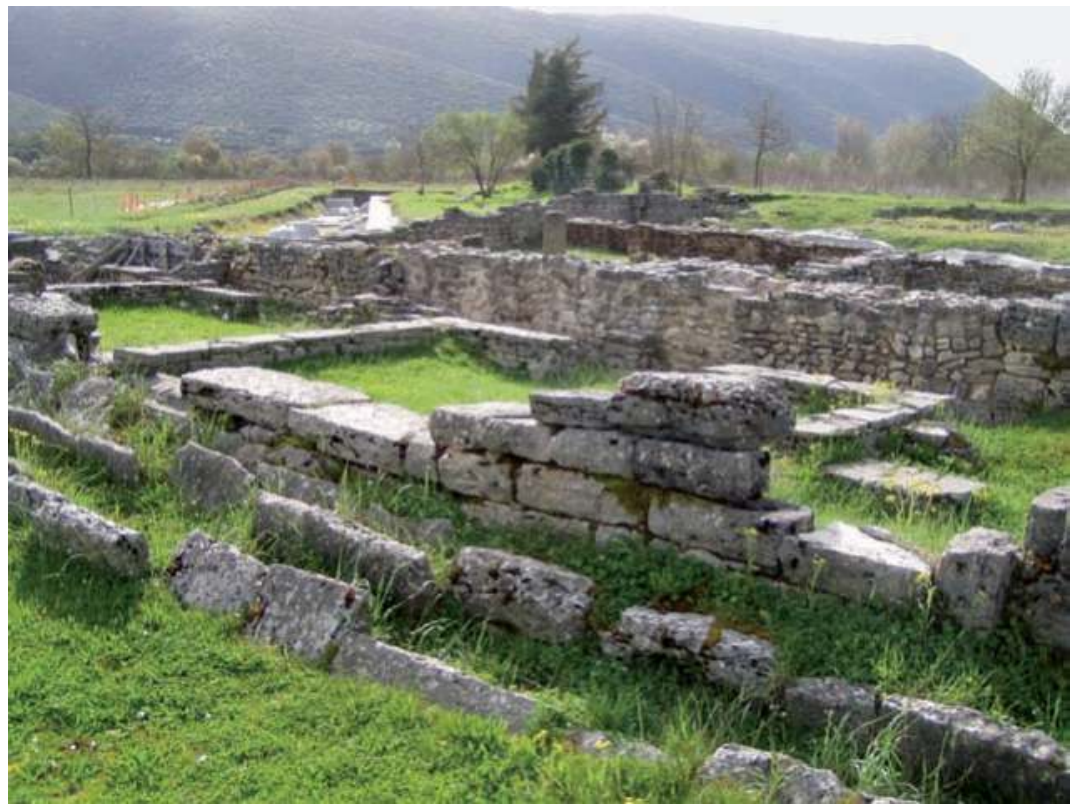

1 Prytaneion von Dodona von Nordwesten

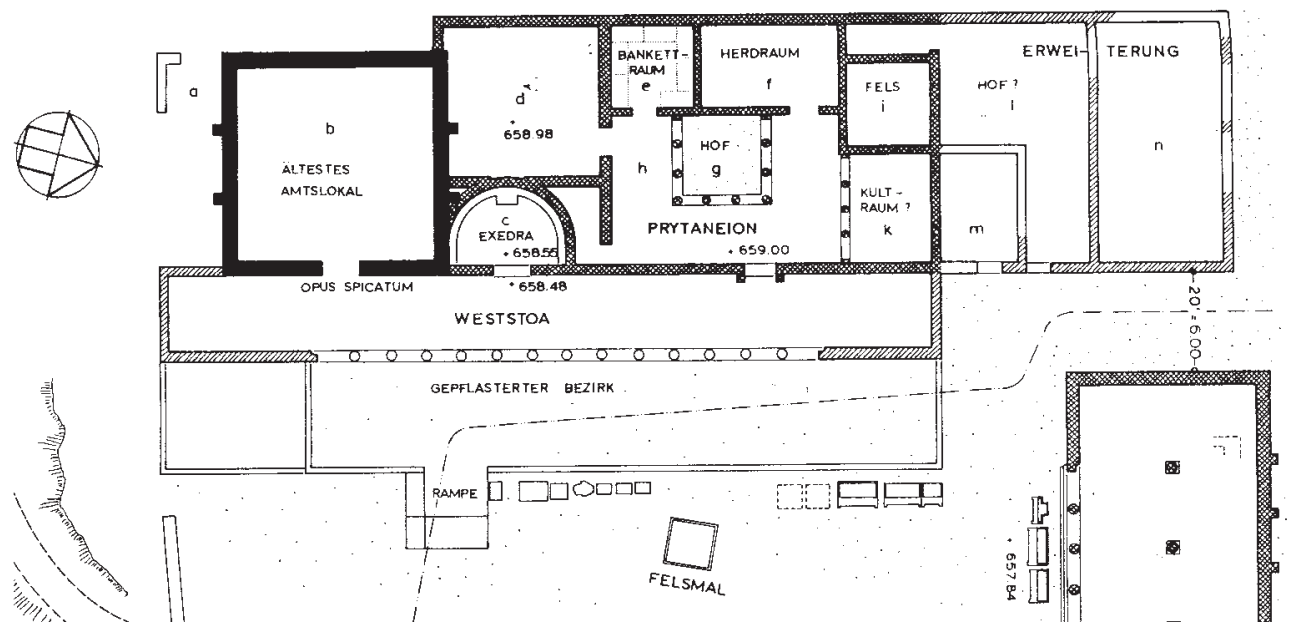

2 Grundriss des Prytaneions von Kassope

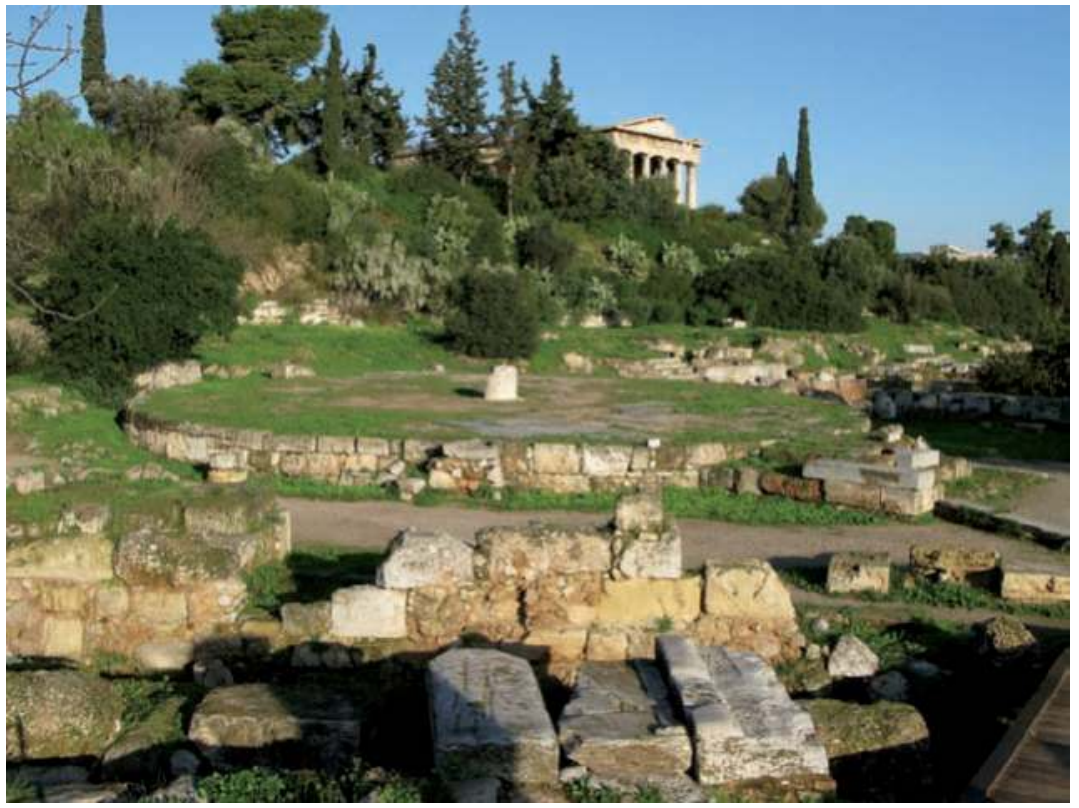

3 Tholos der Athener Agora von Südosten 
Tafel 249

\section{PRYTANEION}

SCHNITTLINIEN BAUAUFNAHME

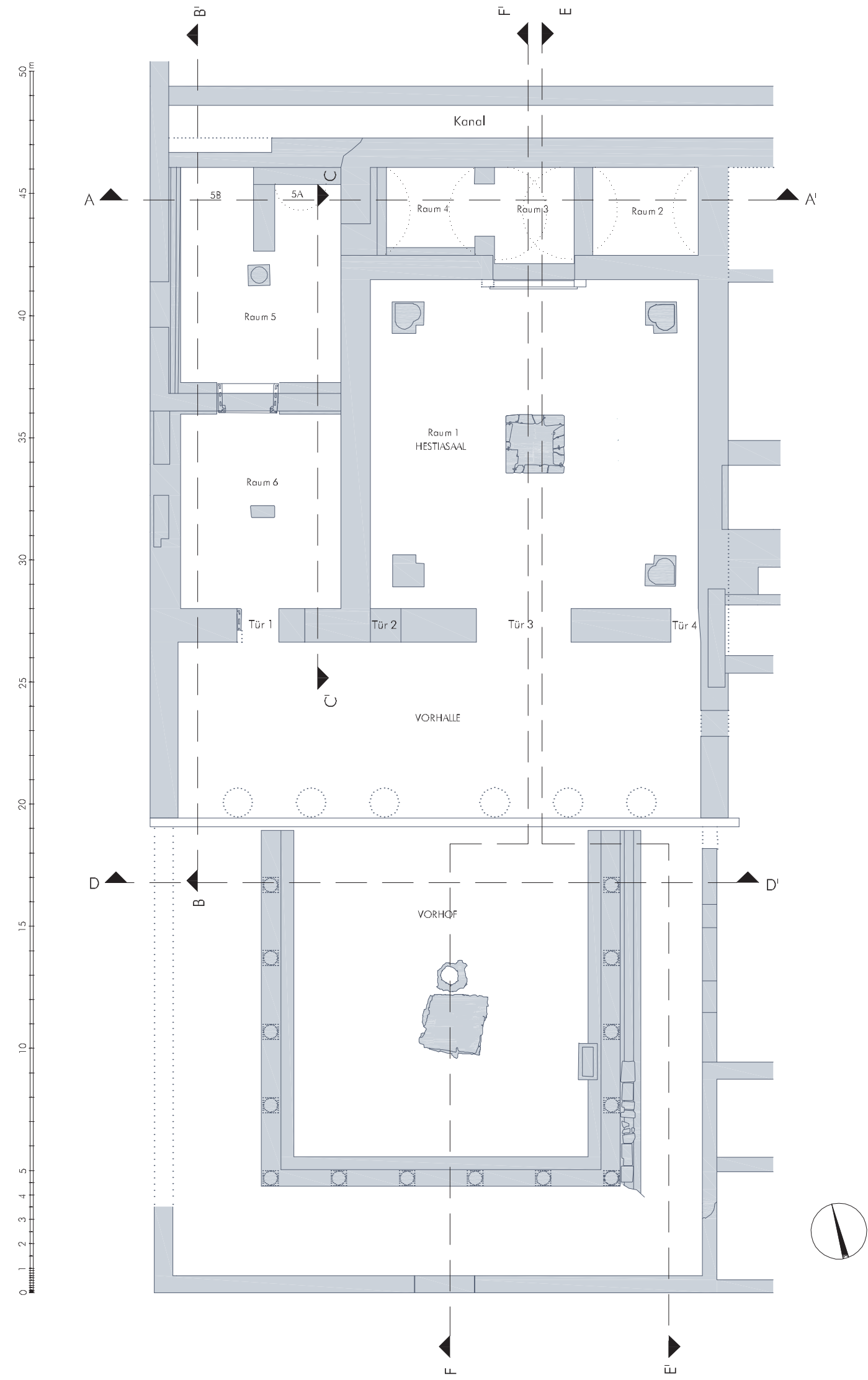

1 Prytaneion. Übersicht Schnitte durch Bauaufnahme (1:250) 
Tafel 250

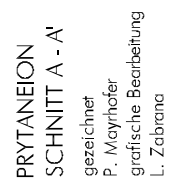

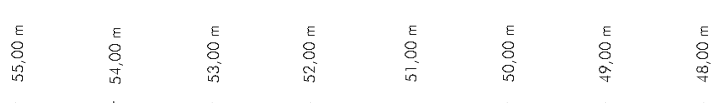
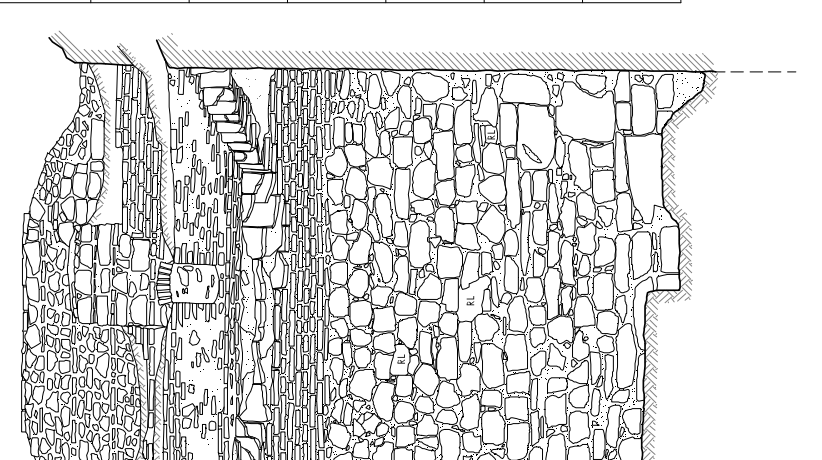
Tafel 251

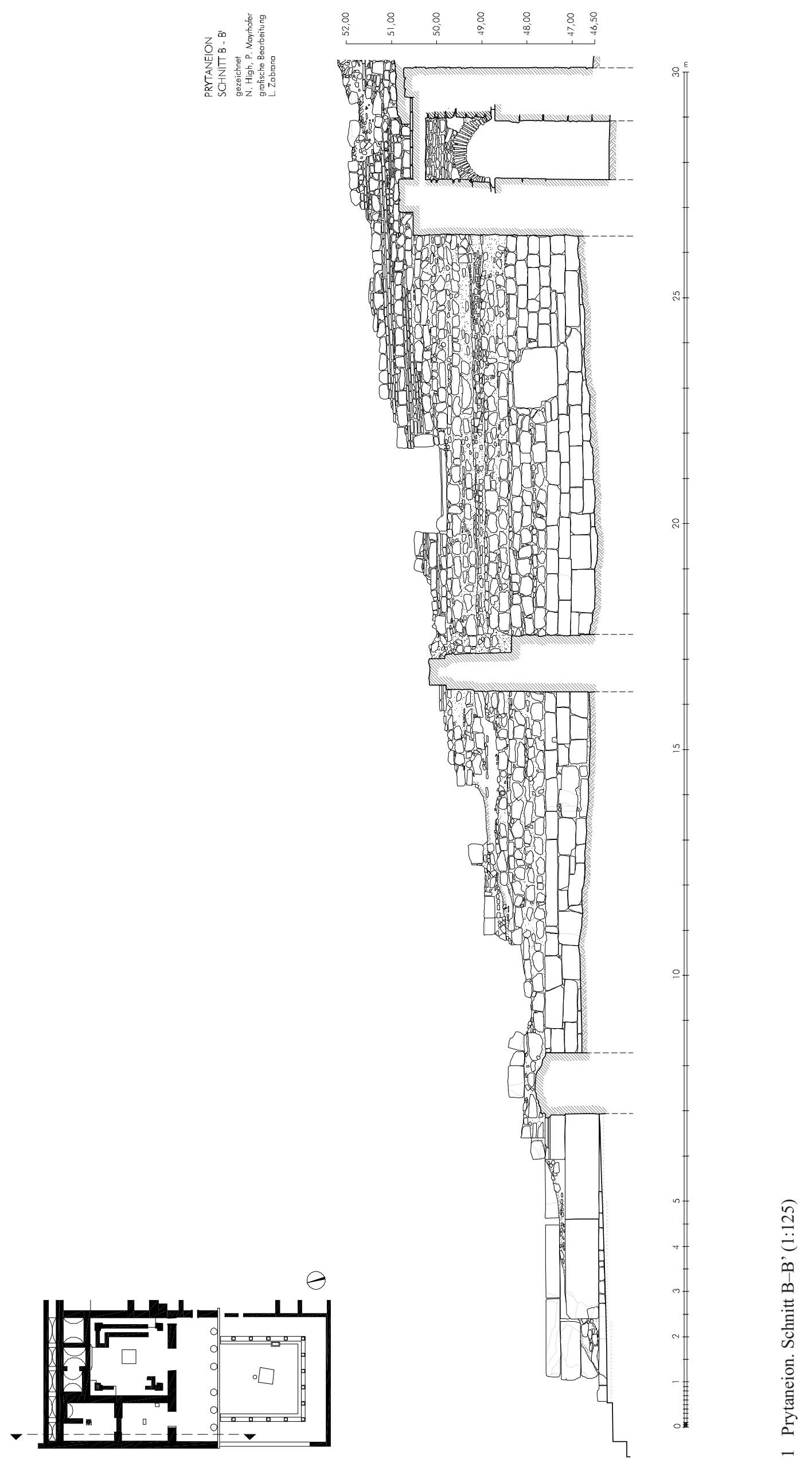


Tafel 252
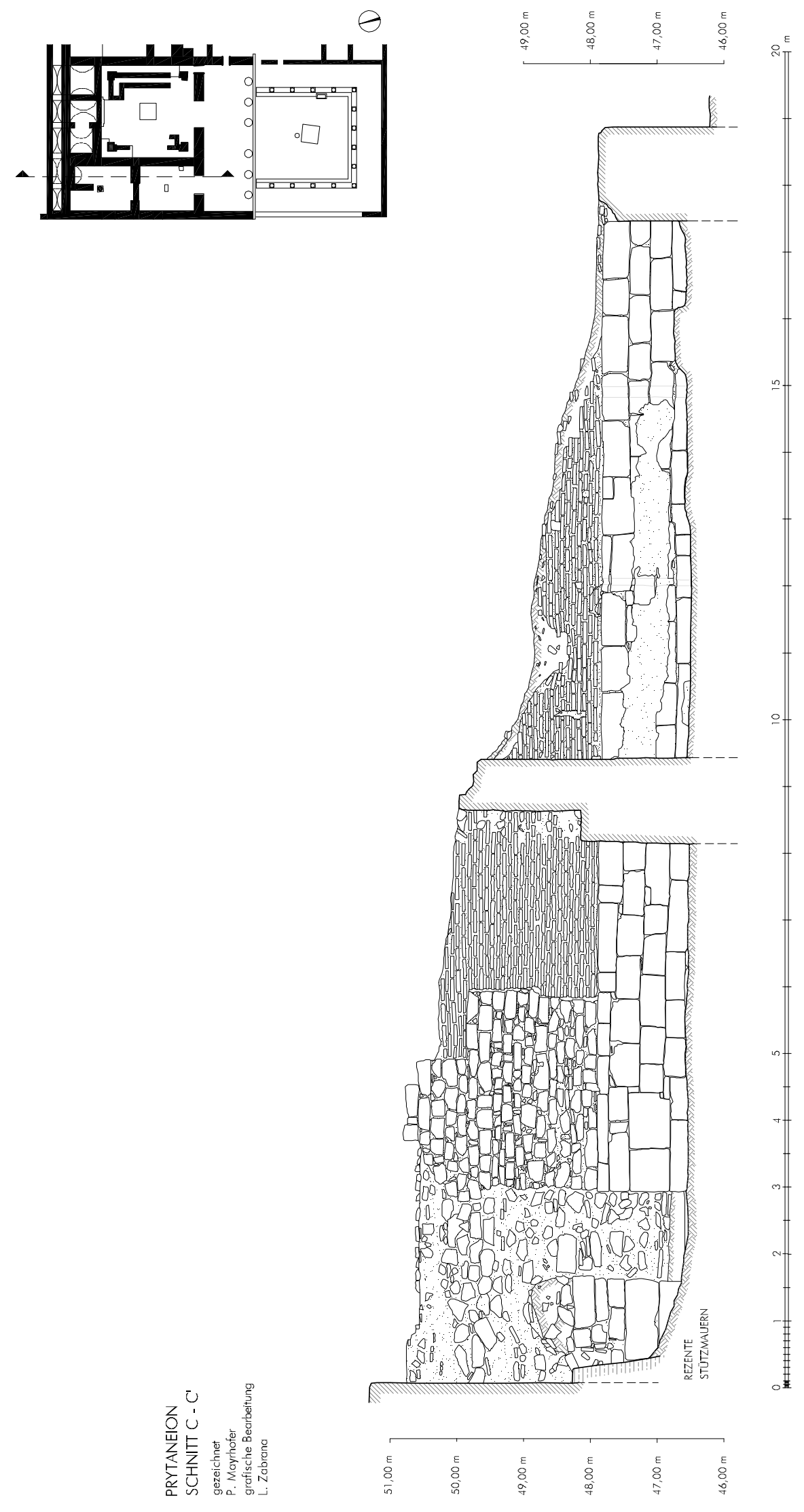
Tafel 253

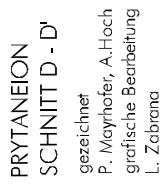

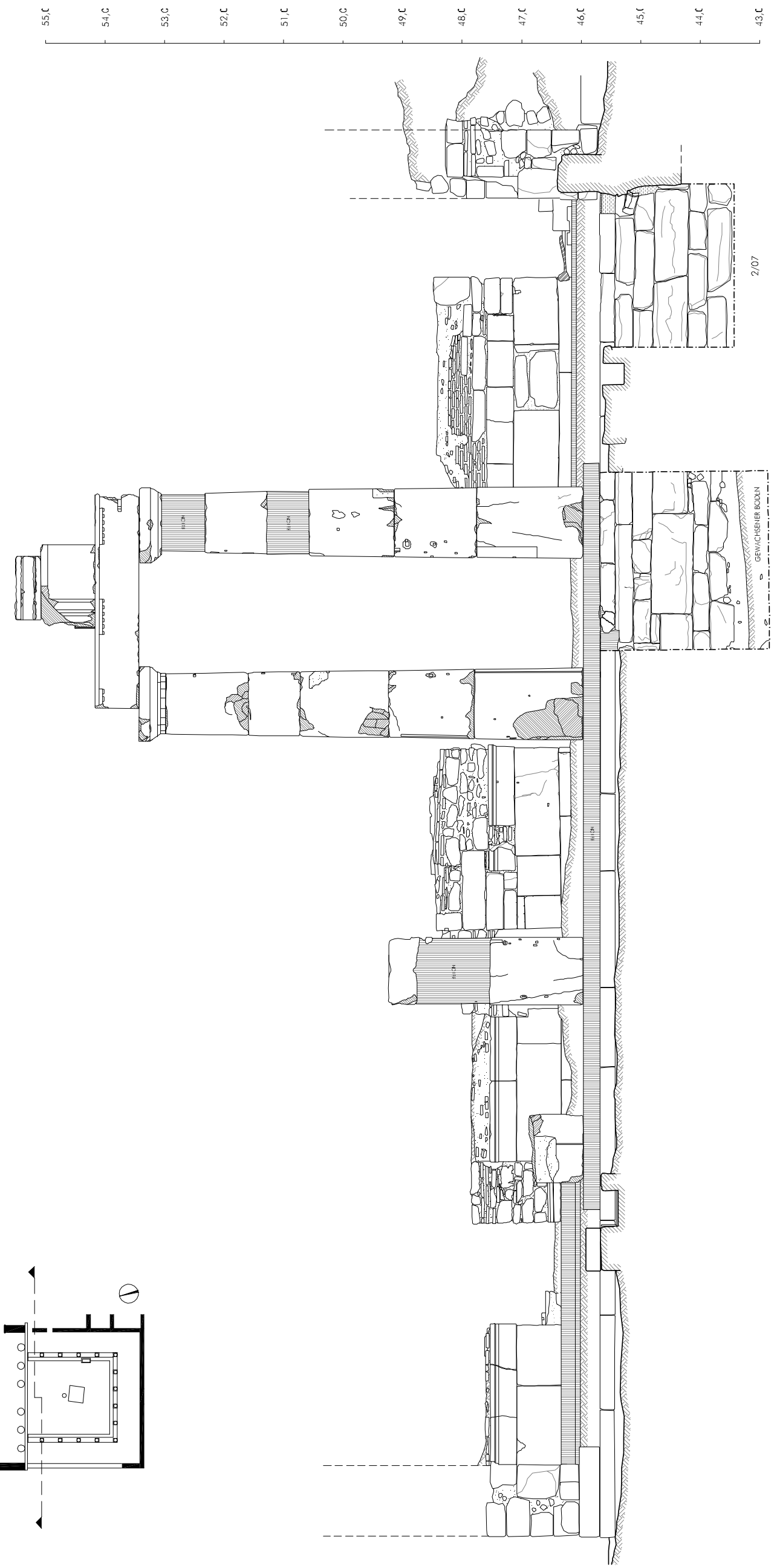

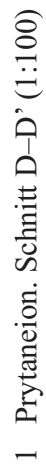




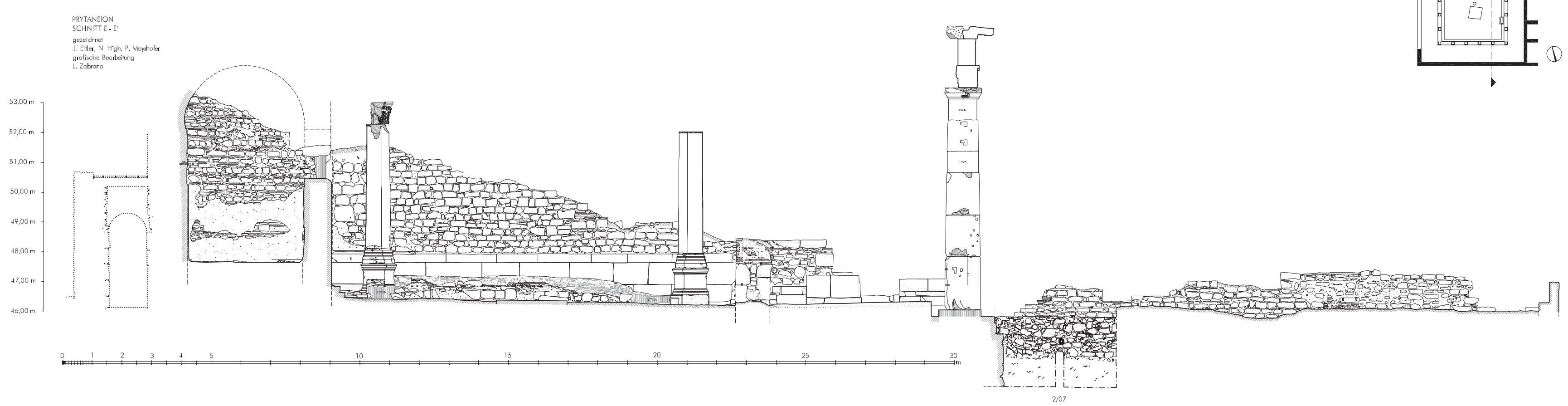

1 Prytaneion. Schnitt E-E’ (1:150)

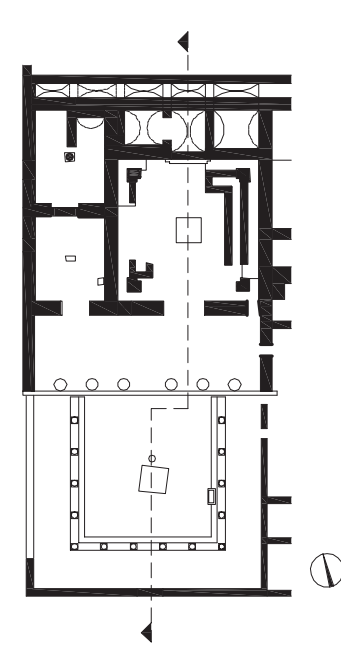


Tafel 255

\section{PRYTANEION}

SCHNITTLINIEN REKONSTRUKTION

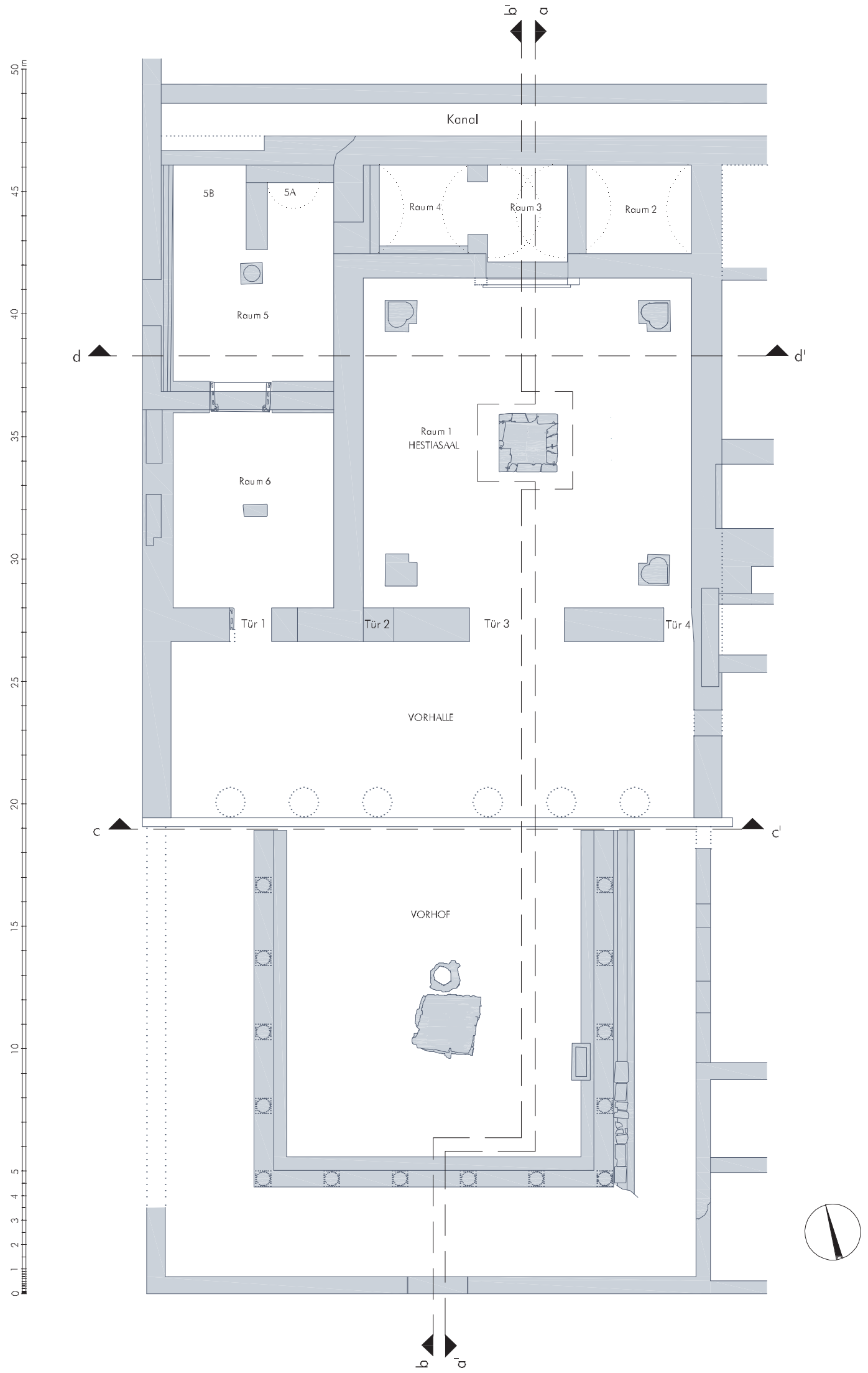

1 Prytaneion. Übersicht Rekonstruktionsschnitte (1:250) 


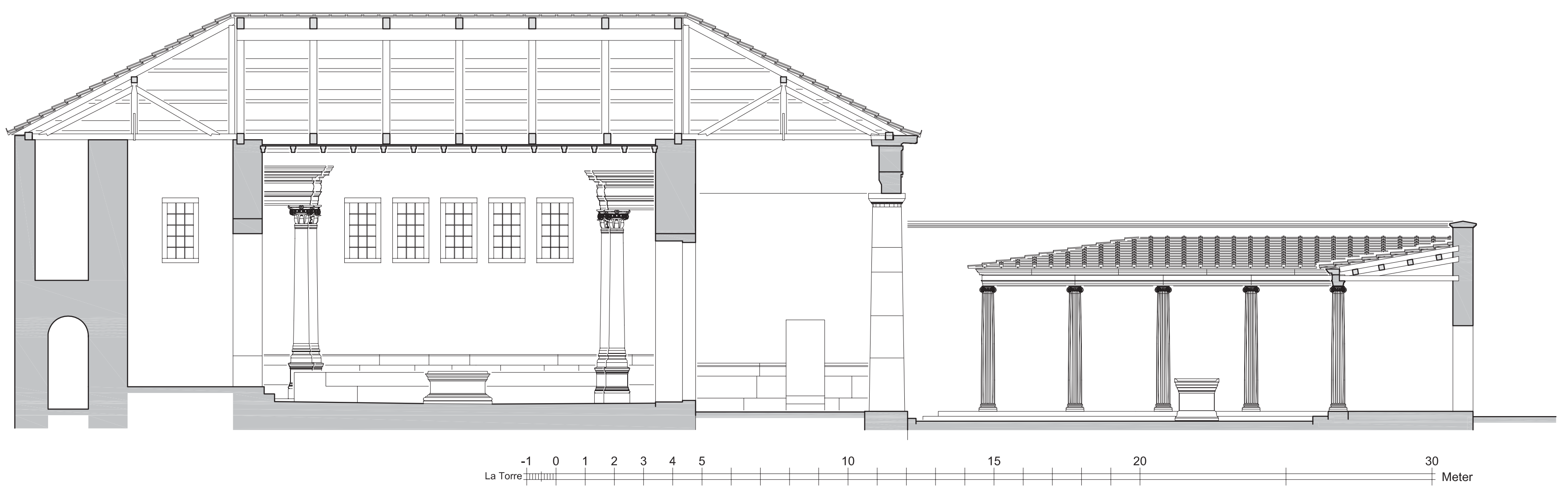

1 Prytaneion. Schnitt a-a' $(1: 150)$

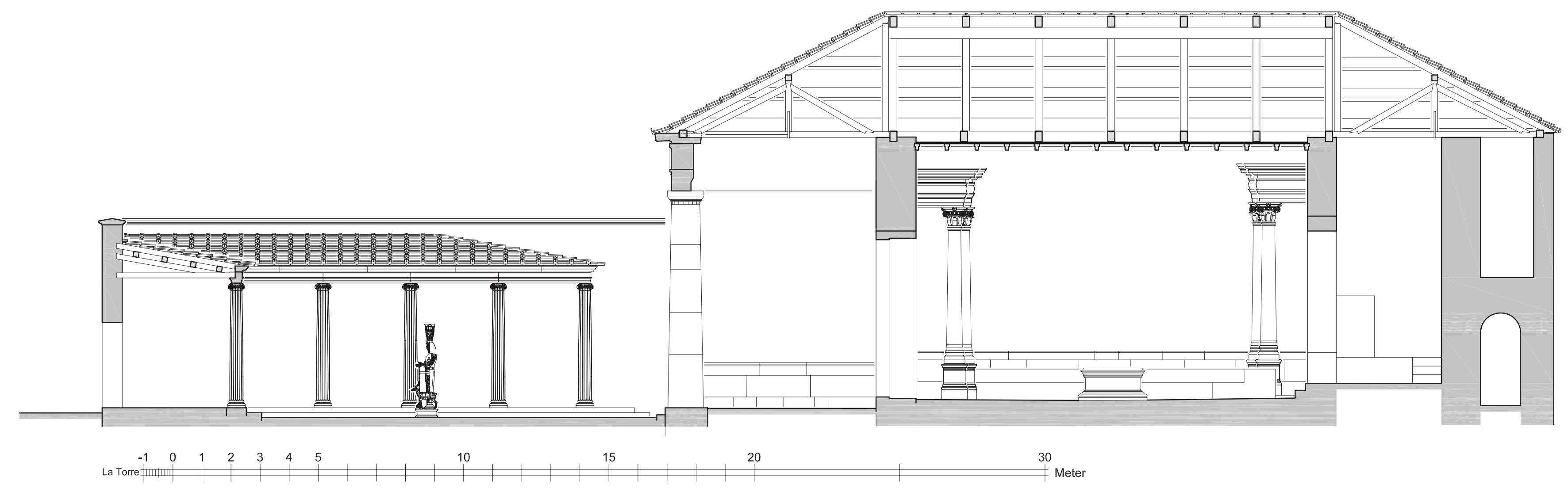


Tafel 257

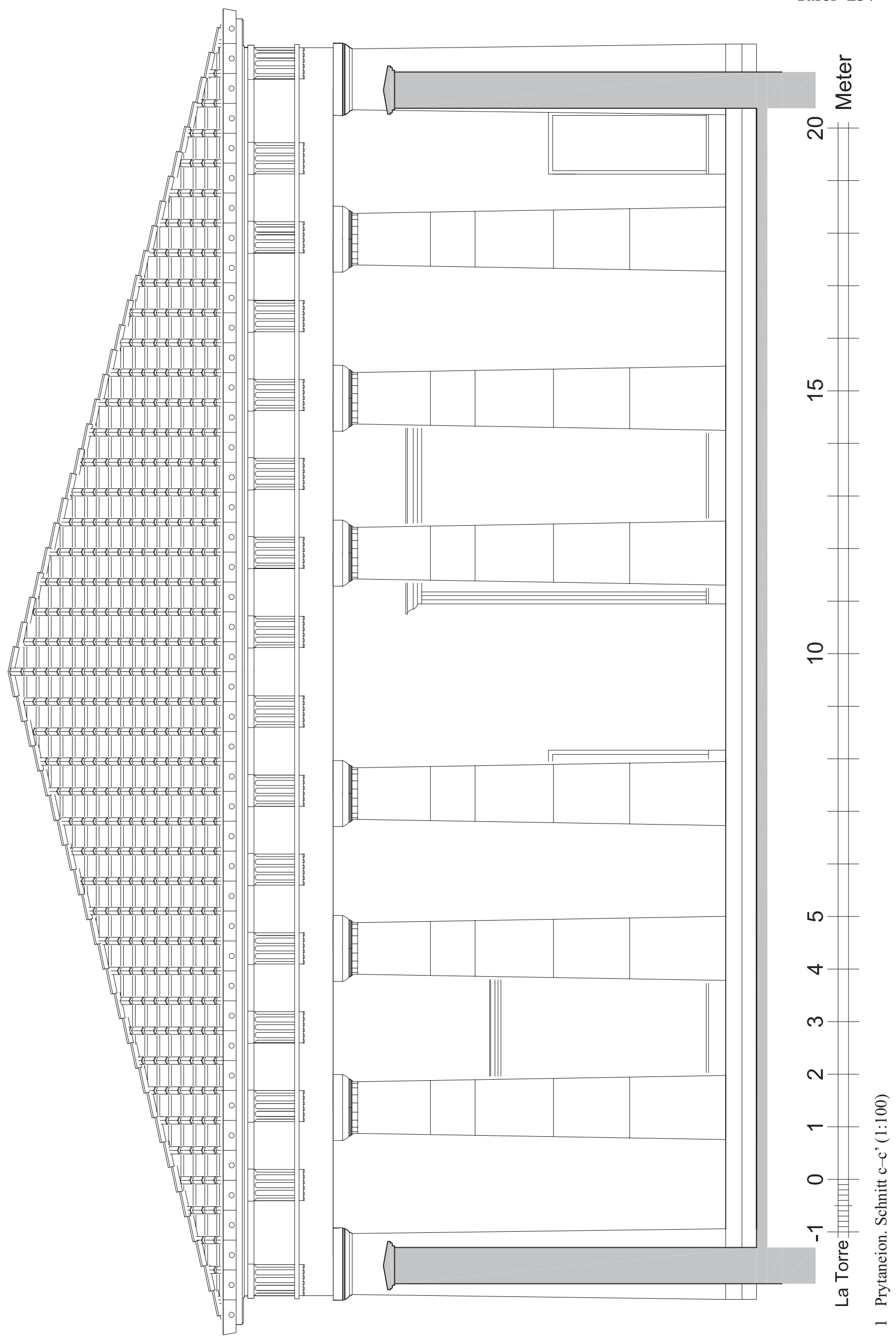


Tafel 258
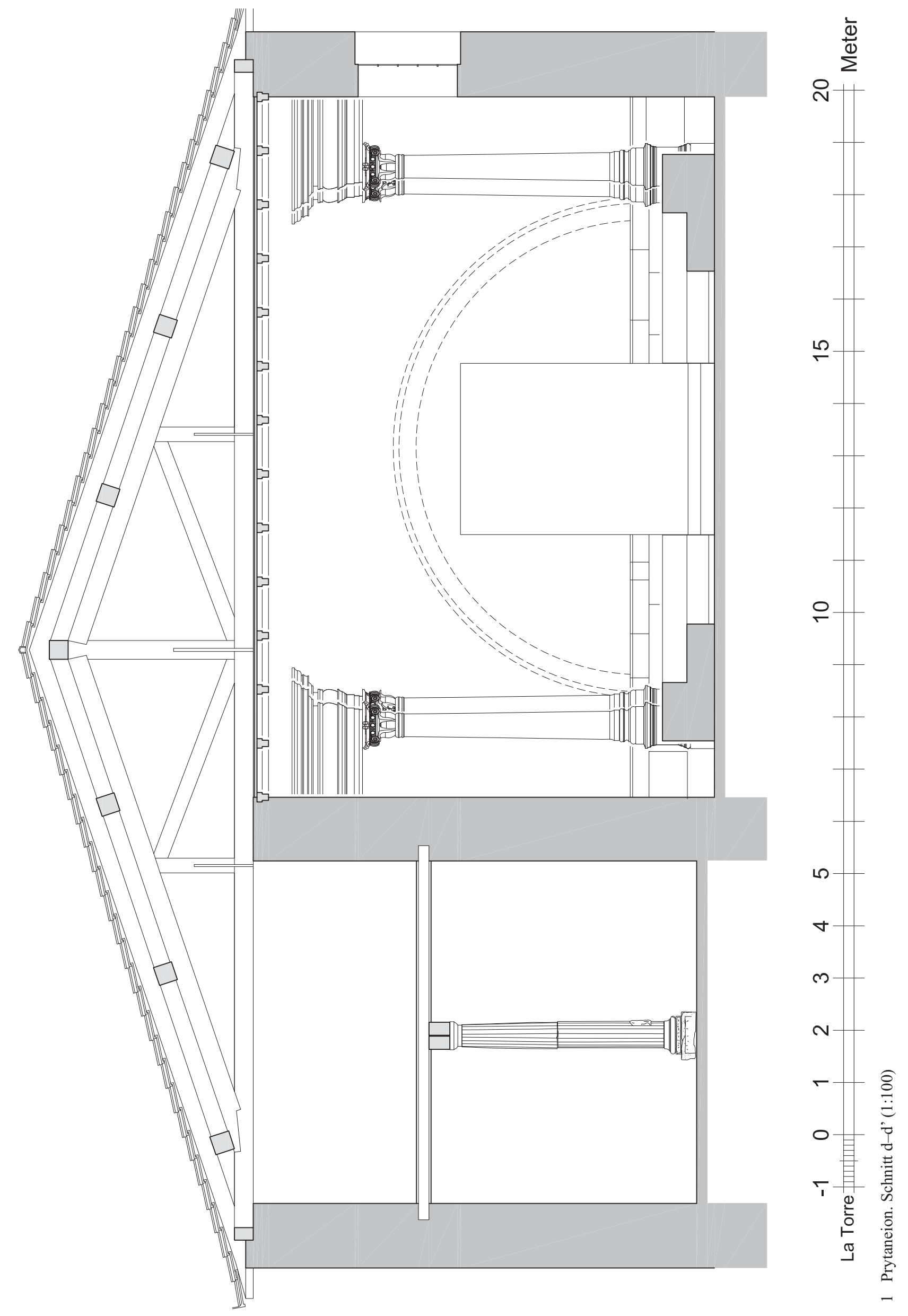


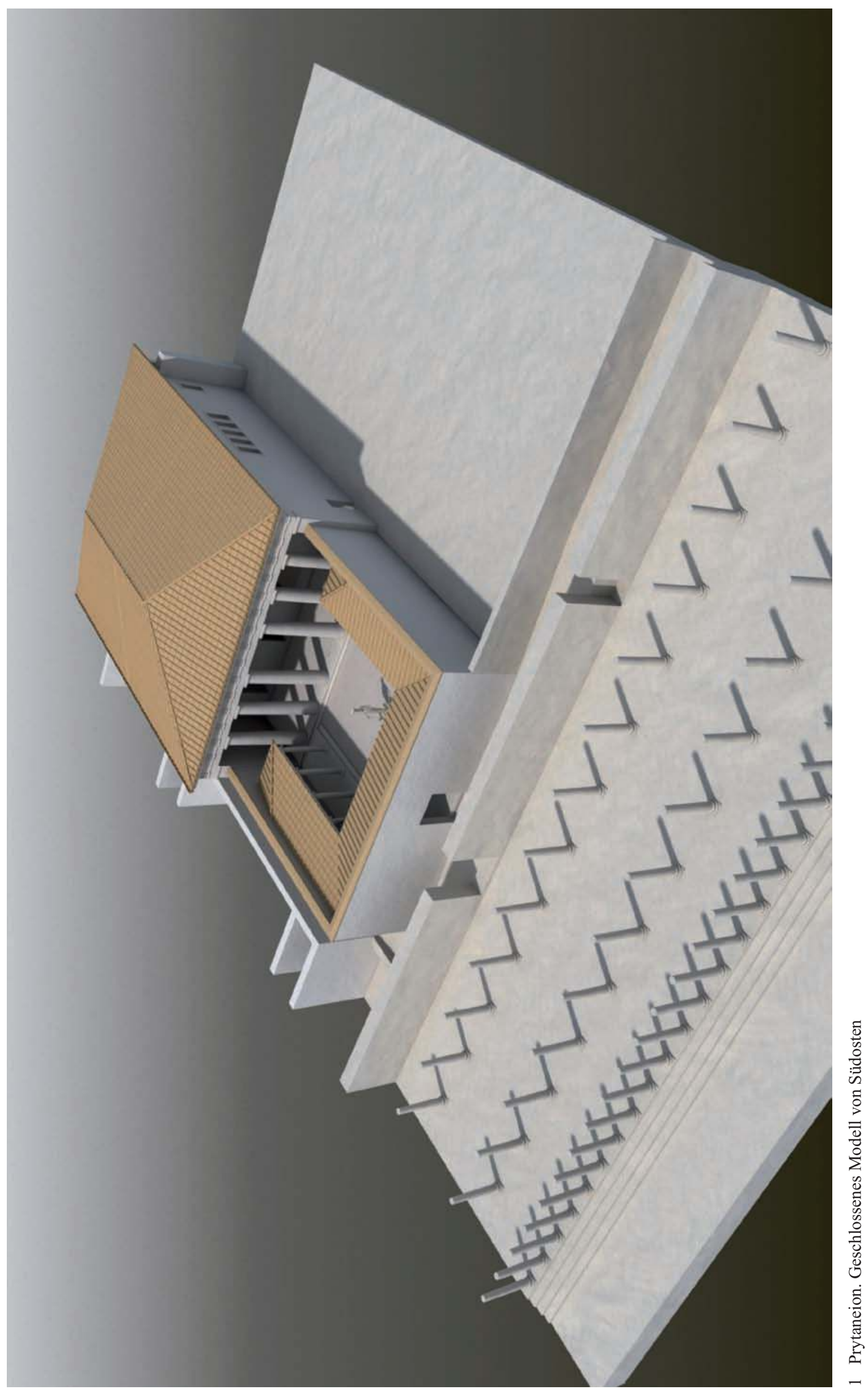




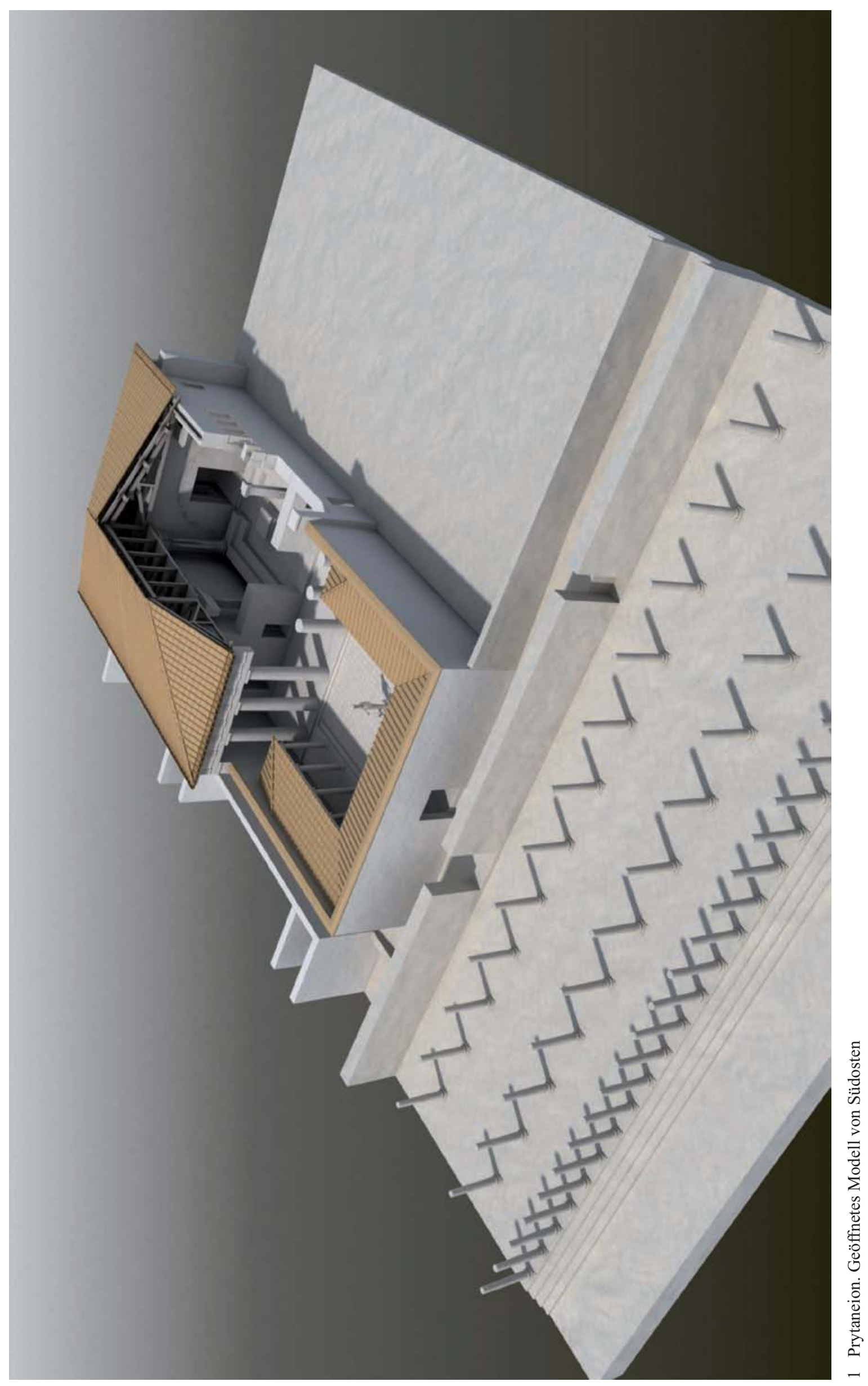




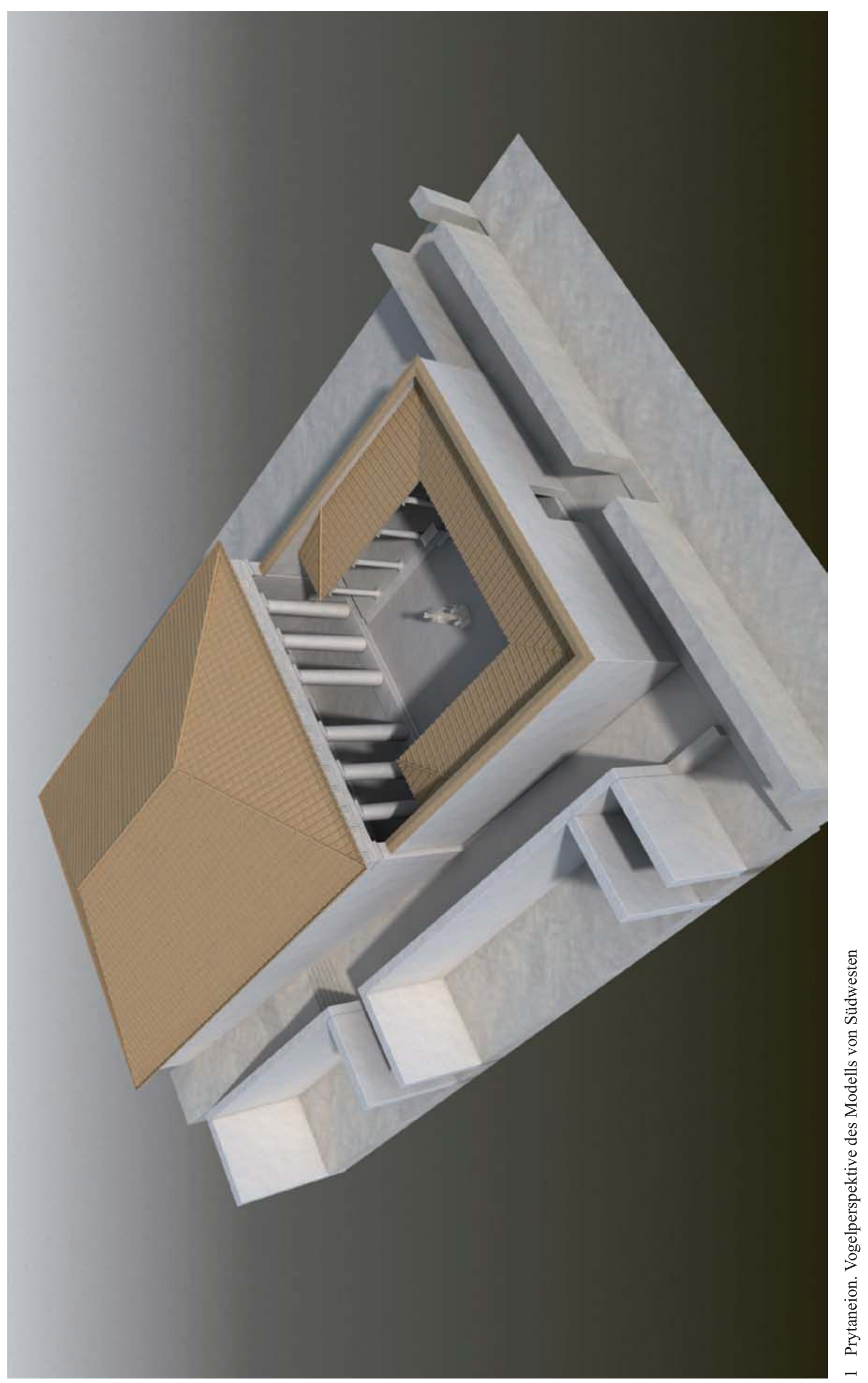


Tafel 262

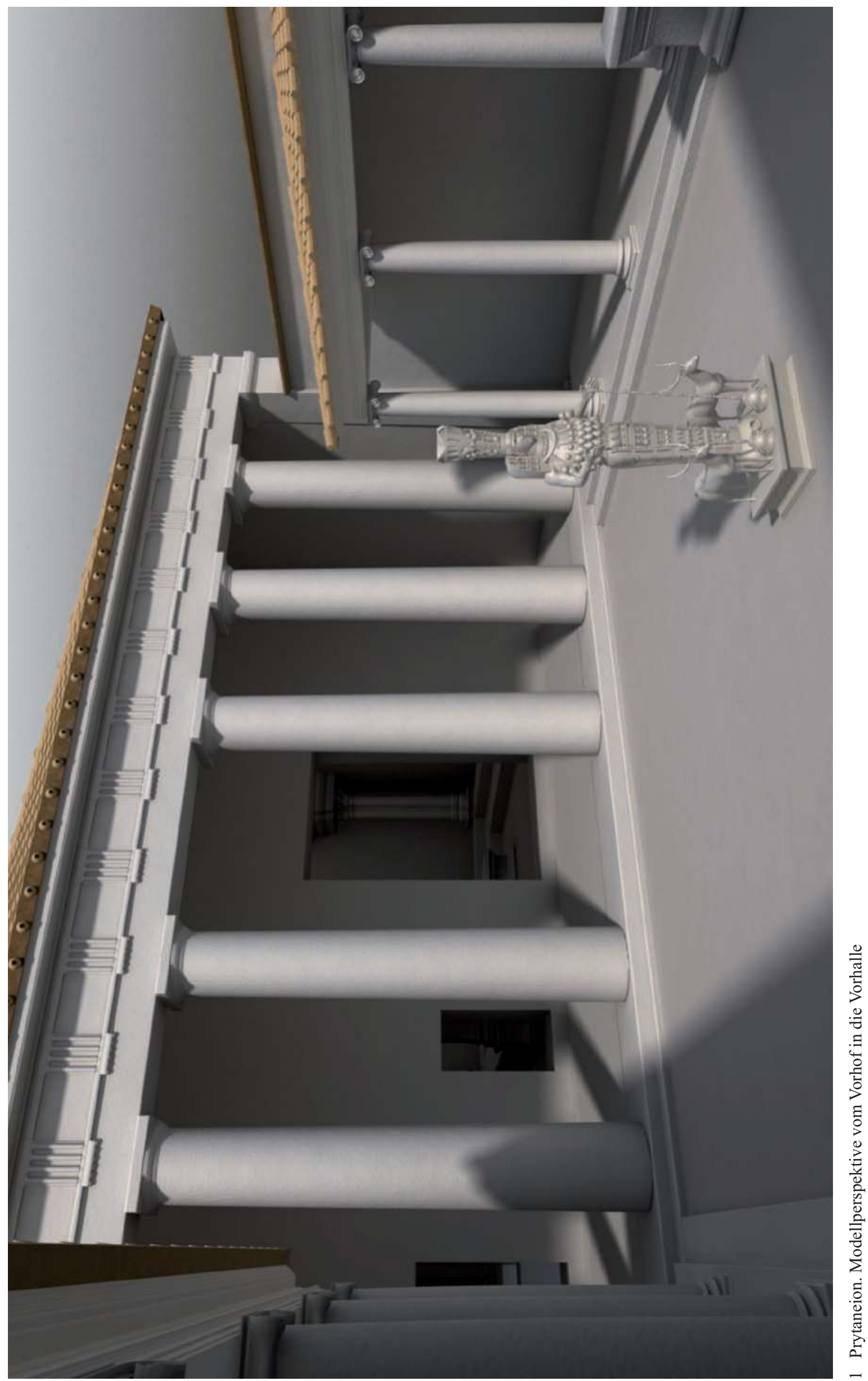




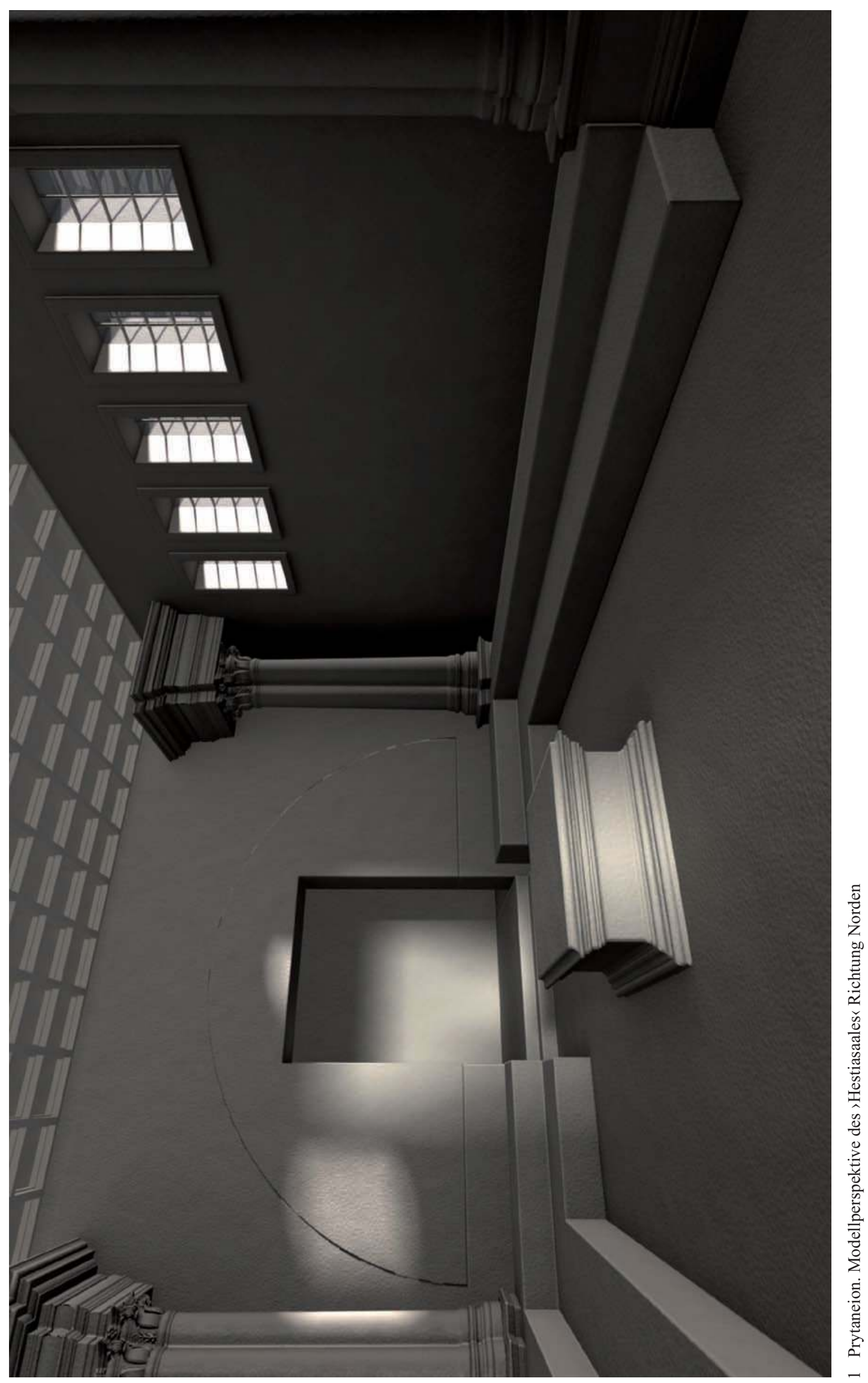

